\title{
Karen Schoch
}

\section{Die doppelte Aphrodite - alt und neu bei griechischen Kultbildern}

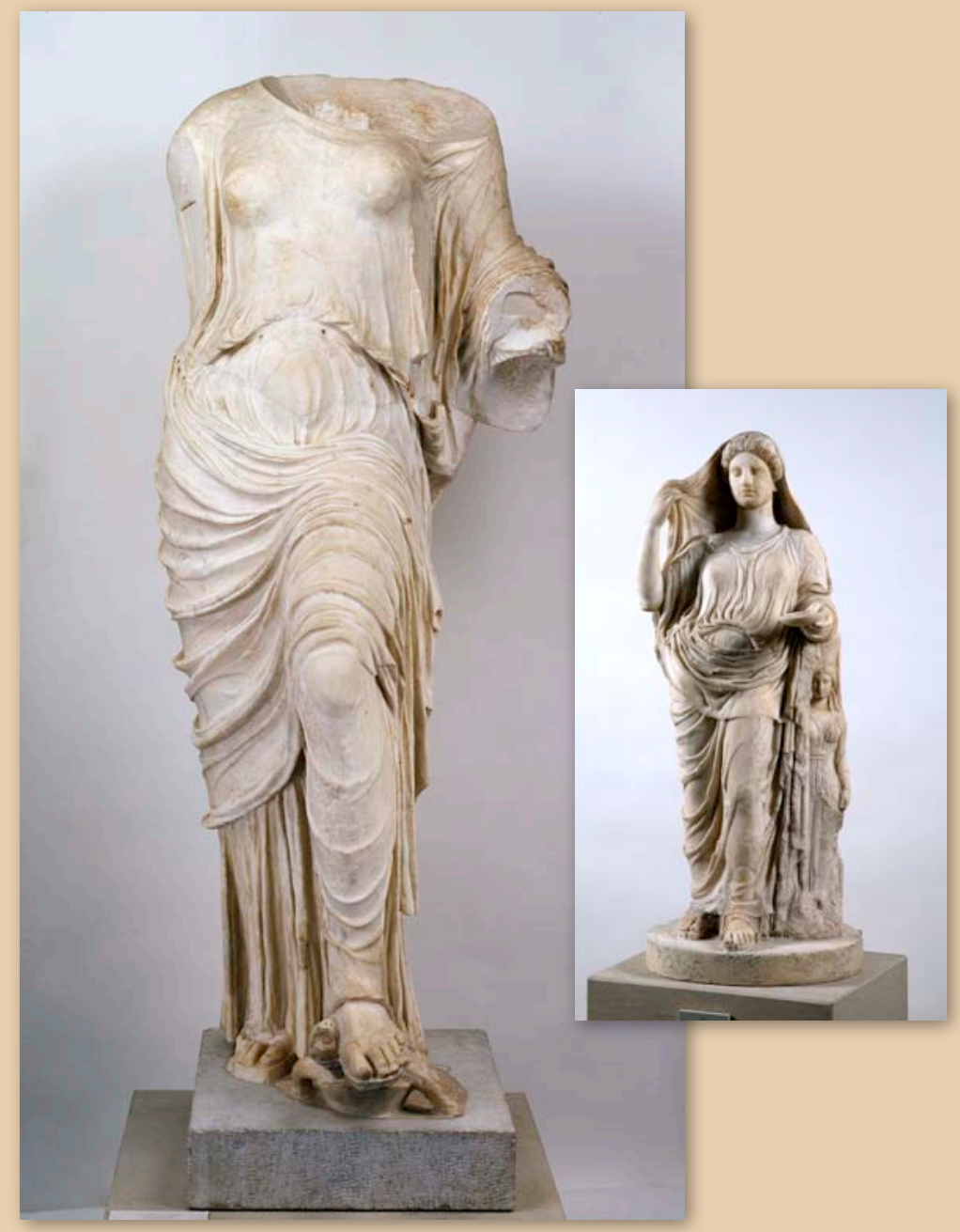

Universitätsdrucke Göttingen 

Die doppelte Aphrodite - alt und neu bei griechischen Kultbildern

This work is licensed under the Creative Commons License 2.0 "by-nd", allowing you to download, distribute and print the document in a few copies for private or educational use, given that the document stays unchanged and the creator is mentioned. You are not allowed to sell copies of the free version. 
erschienen in der Reihe der Universitätsdrucke im Universitätsverlag Göttingen 2009 
Karen Schoch

Die doppelte Aphrodite alt und neu bei griechischen Kultbildern

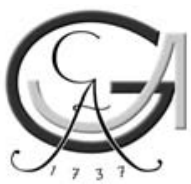

Universitätsverlag Göttingen 2009 


\section{Bibliographische Information der Deutschen Nationalbibliothek}

Die Deutsche Nationalbibliothek verzeichnet diese Publikation in der Deutschen Nationalbibliographie; detaillierte bibliographische Daten sind im Internet über $<$ http://dnb.ddb.de $>$ abrufbar.

Anschrift des Autors

Karen Schoch

e-mail: Karen.Schoch@daad-alumni.de

Dieses Buch ist auch als freie Onlineversion über die Homepage des Verlags sowie über den OPAC der Niedersächsischen Staats- und Universitätsbibliothek (http://www.sub.uni-goettingen.de) erreichbar und darf gelesen, heruntergeladen sowie als Privatkopie ausgedruckt werden. Es gelten die Lizenzbestimmungen der Onlineversion. Es ist nicht gestattet, Kopien oder gedruckte Fassungen der freien Onlineversion zu veräußern.

Satz und Layout: Karen Schoch Umschlaggestaltung: Jutta Pabst

Titelabbildung: Staatliche Museen zu Berlin, Antikensammlung

Foto: Gisela Geng/Johannes Laurentius

(C) 2009 Universitätsverlag Göttingen

http://univerlag.uni-goettingen.de

ISBN: 978-3-941875-19-7 
Meinen Eltern 



\section{Inhaltsverzeichnis}

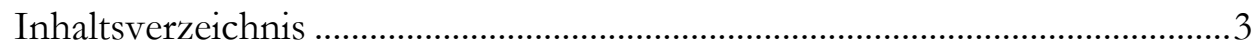

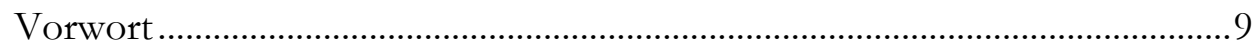

Abkürzungsverzeichnis .....................................................................................11

1. Einleitung - Fragestellung und Materialauswahl..........................................25

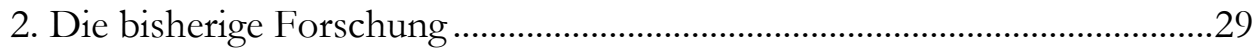

3. Aphroditebilder mit weiblichen Idolen und Hermen als Stütze ..................33

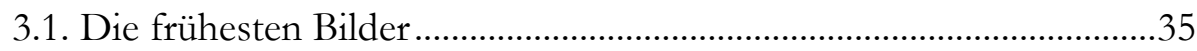

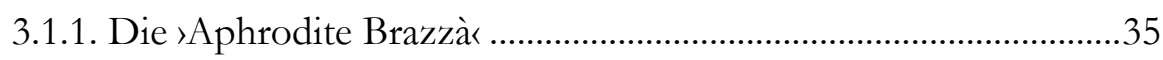

3.1.2. Eine Aphroditestatuette aus Tarquinia .............................................39

3.1.3. Ein Relief im Vatikan........................................................................ 40

3.2. Nachfolger der >Aphrodite Brazzà ........................................................41

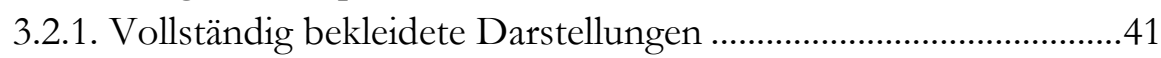

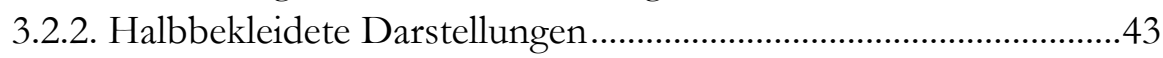

3.2.3. Variante mit übergeschlagenem Bein ...............................................4 44

3.2.4. Weitere Veränderungen und andere Körpertypen .........................45

3.3. Nicht sicher zuzuordnende Idole...........................................................

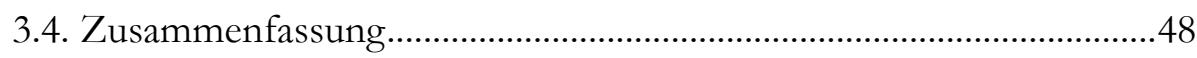

4. Aphroditebilder mit männlichen Stützfiguren ................................................51

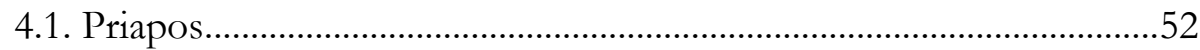

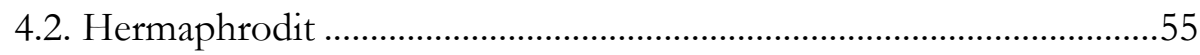

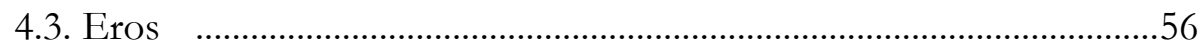

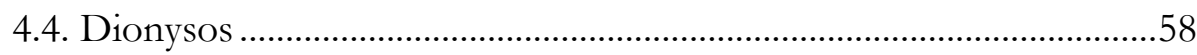

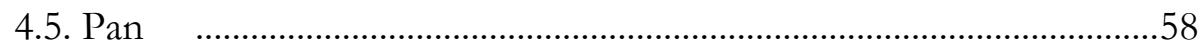

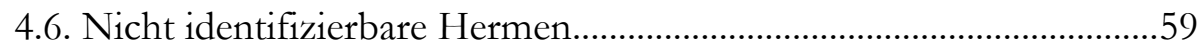

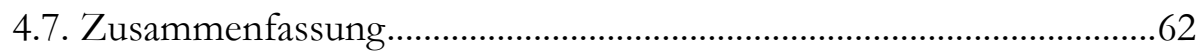


5. Die Aphrodite Urania in Elis, in Athen und die >Aphrodite Brazzà - die ersten Bilder mit ikonischer Stütze? ........................................................6 65

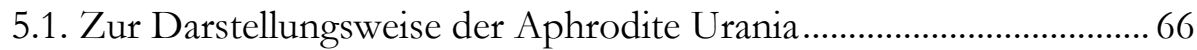

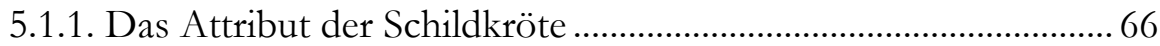

5.1.2. Ein Terrakottafragment aus Elis..................................................... 69

5.1.3. Die Verbindung mit dem Orient und die Darstellung als

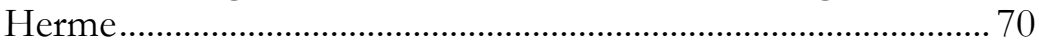

5.2. Die Verbindung des Typus mit den Statuen in Elis und Athen und die Frage nach den Stützen dieser Statuen ......................... 74

5.2.1. Die Meinung der Forschung .......................................................... 74

5.2.2. Rekonstruktion der Aphrodite Urania-Statuen durch das

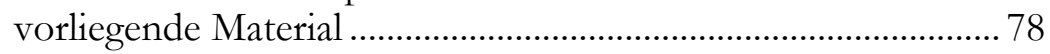

5.2.3. Andere Aphroditebilder mit der Schildkröte .................................. 81

5.2.4. Zusammenfassung ........................................................................... 83

5.3. Die `Aphrodite Brazzà - ein `Kultbild aus Athen? .............................. 85

5.3.1. Wiederholungen bekannter Werke im 5. Jahrhundert v. Chr..... 85

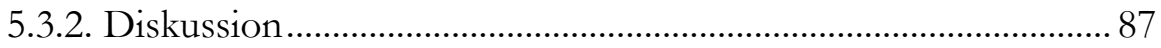

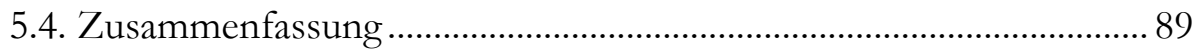

6. Weitere Aphroditetypen und andere Götter in aufgelehnter Haltung....... 91

6.1. Weitere aufgelehnte Aphroditebilder ....................................................... 92

6.2. Weitere Götter........................................................................................ 97

6.3. Ikonische Stützen bei anderen Göttern............................................100

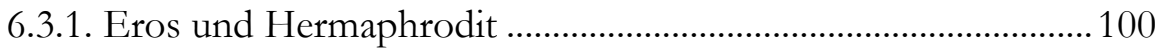

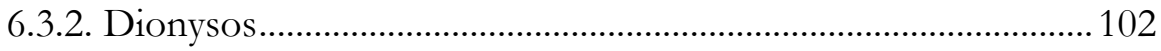

6.3.3. Weitere Götter und mythologische Gestalten .............................. 105

6.4. Zusammenfassung .............................................................................. 107

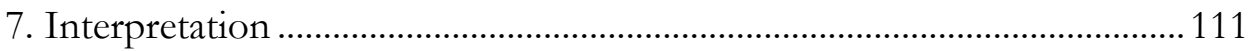

7.1. Diskussion der Deutungen der figürlichen Stütze der Aphrodite .. 111

7.1.1. Die Deutung des weiblichen Idols in der Forschung ................. 111

7.1.1.1. Die Deutung als altes Aphroditebild ...........................112

7.1.1.2. Die Deutung als chthonische Aphrodite ................... 113

7.1.1.3. Die Deutung als andere Göttin..................................... 114

7.1.1.4. Die Deutung als >Votivbild ........................................... 116 
7.1.1.5. Die Deutung als Sterbliche........................................... 118

7.1.1.6. Die Deutung als $>$ Kore oder $>$ Karyatide .................... 120

7.1.2. Die Deutung der weiblichen Herme............................................. 122

7.1.3. Zur Bedeutung des Polos ........................................................... 124

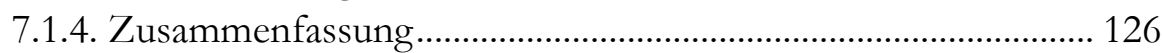

7.2. Deutung der Aphroditebilder im Rahmen der klassischen

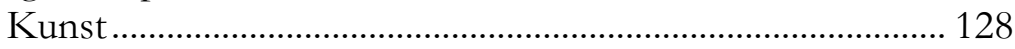

7.2.1. Das Stützidol als Element des Archaismus.................................. 128

7.2.2. Die aufgelehnte Aphrodite im Rahmen des klassischen

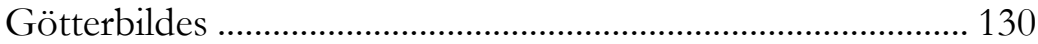

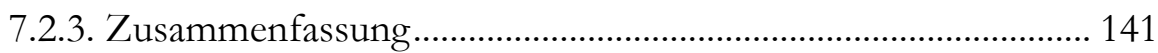

7.3. Zur Bedeutung der männlichen Stützfiguren..................................... 142

7.4. Deutung der anderen Götterbilder und ihrer Stützfiguren .............. 144

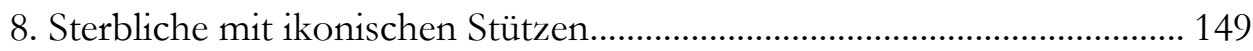

8.1. Männer und Jünglinge............................................................................ 149

8.2. Sisyphos II. aus der Daochos-Weihung in Delphi ............................ 150

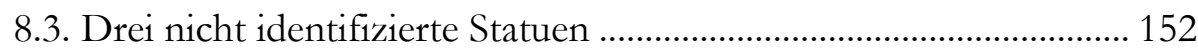

8.4. Frauen und Mädchen ............................................................................ 155

8.5. Zusammenfassung................................................................................ 157

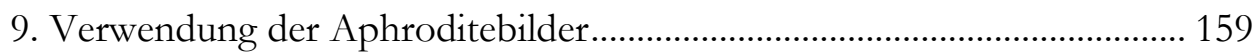

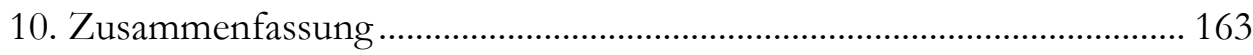

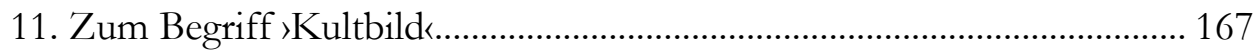

11.1. Die heutige Verwendung des $\gg$ Kultbild-८ Begriffes .......................... 169

11.2. \Kultbilder in der griechischen Antike.............................................. 181

11.2.1. Antike Terminologie ................................................................... 181

11.2.2. Anwendung des Kultbildbegriffes auf die griechische

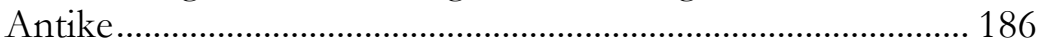

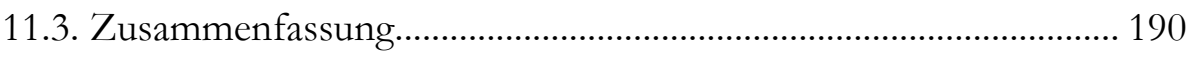


12. Heiligtümer mit mehr als einem möglichen $\gg$ Kultbildk.............................. 193

12.1. Athena auf der Athener Akropolis..................................................... 194

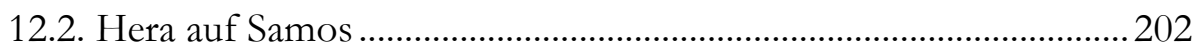

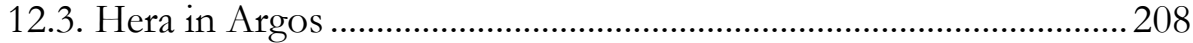

12.4. Zeus in Olympia........................................................................... 212

12.5. Dionysos Eleuthereus in Athen..........................................................217

12.6. Dionysos Kadmeios in Theben ........................................................ 220

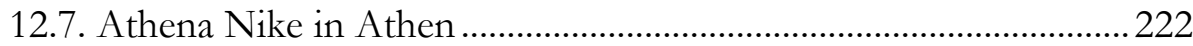

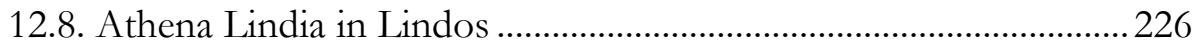

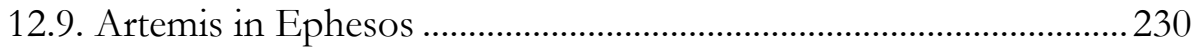

12.10. Artemis Brauronia in Brauron und Athen ..................................... 235

12.11. Artemis Orthia in Messene...............................................................242

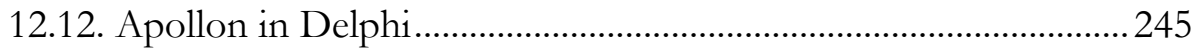

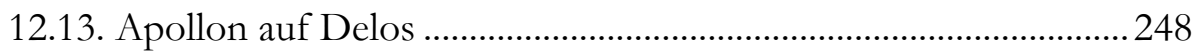

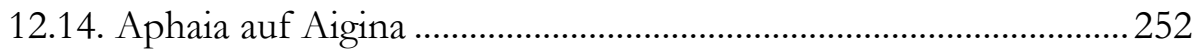

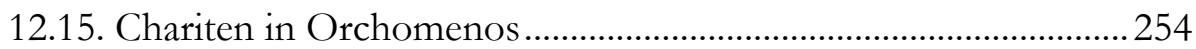

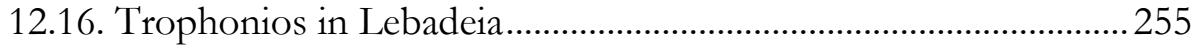

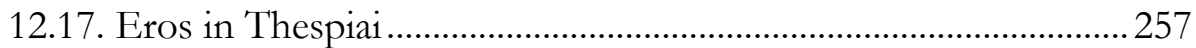

12.18. Weitere, nicht gesicherte Beispiele unterschiedlich alter

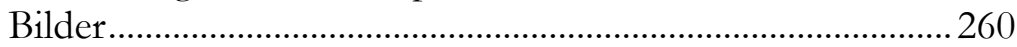

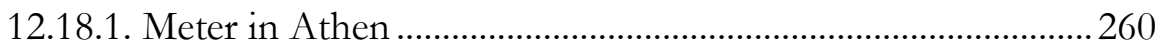

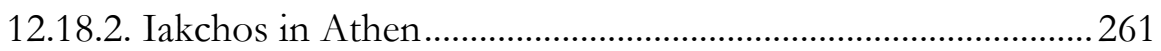

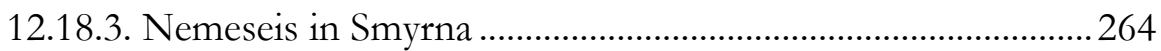

12.18.4. Artemis Laphria in Kalydon...................................................... 265

12.19. Weitere Belege für die Aufstellung neuer Bilder neben den

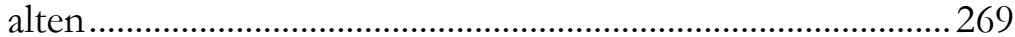

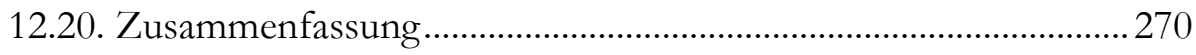

13. Weitere Doppel- oder Mehrfachbilder....................................................275

14. Weitere Belege für verschiedene Kulte ...................................................... 281 


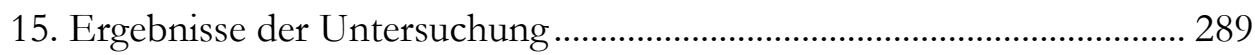

15.1. Alter, Material und Standort der Bilder........................................... 289

15.2. Gründe für die Existenz mehrerer \Kultbilder` und ihre Einbindung in die Kultpraxis................................................... 296

15.2.1. Zur Funktion der Bilder im Kult ............................................... 297

15.2.2. Zweitkultbilder für bestimmte Riten .......................................... 303

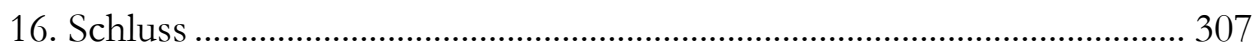

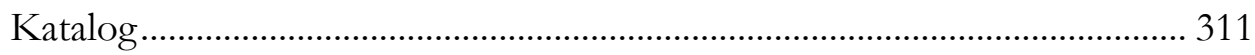

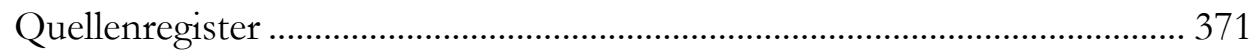

Verzeichnis der verwendeten Übersetzungen ................................................ 375

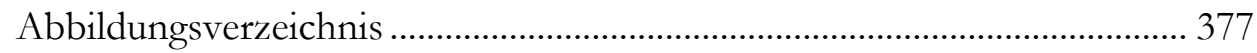

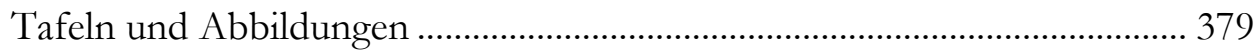





\section{Vorwort}

Die vorliegende Arbeit ist die leicht überarbeitete Fassung meiner Dissertation „Die doppelte Aphrodite - alt und neu bei griechischen Kultbildern“, die im September 2008 von der Philosophischen Fakultät der Georg-August-Universität Göttingen angenommen wurde.

Die Anregung zu diesem Thema verdanke ich Frau Professor Dr. Marianne Bergmann (Göttingen), die die Arbeit betreut und mir während der gesamten Entstehungszeit mit wertvollen Ratschlägen und wohlwollender Kritik zur Seite gestanden und damit entschieden zum Gelingen der Untersuchung beigetragen hat. Frau Professor Dr. Johanna Fabricius (Berlin) danke ich herzlich für die Übernahme des Korreferats und das Ermöglichen des zügigen Abschlusses meiner Promotion.

Mein Dank gilt ebenso Herrn Professor Dr. Andreas Scholl (Berlin) und Herrn Johannes Laurentius (Berlin), die mir hervorragende Aufnahmen der Berliner `Aphrodite mit der Schildkröte` zur Verfügung gestellt und deren Publikation gestattet haben.

Stephan Eckardt (Göttingen) danke ich für die ständige Hilfsbereitschaft bei technischen Problemen und die Unterstützung bei der Bildbearbeitung. Nicht vergessen seien auch die wertvollen Gespräche mit meinen Kommilitonen des Archäologischen Instituts der Universität Göttingen, besonderer Dank gilt B. Rabe, M. Kovacs und A. Görlich für das detaillierte Korrekturlesen.

Von Herzen möchte ich mich auch bei meinen Eltern bedanken, ohne deren unermüdliche Unterstützung das Zustandekommen dieser Arbeit unmöglich gewesen wäre.

Göttingen, im September 2009 



\section{Abkürzungsverzeichnis}

Außer den vom Deutschen Archäologischen Institut vorgeschlagenen Richtlinien, zuletzt aktualisiert am 04.12.2007, <http://www.dainst.org/index_141_de.html> (30.09.09) werden folgende Abkürzungen verwendet:

ANTI 1916

ANTI 1927

ARACHNE

ASMUSSEN - LCESSØE $1971 / 1972$

EA

BALD ROMANO 1980

BAMMER 1968

BAMMER 1991

BAMMER 1993

BAMMER - MUSS 1996

BANKEL 1993

BECAT'TI 1951

BELTING 1993

BERGMANN 2007

BERLEJUNG 1998

BERLEJUNG u. a. 1999a

BERLEJUNG 1999b
C. Anti, L'Artemis Laphria di Patrai, ASAtene 2, 1916, 181-199.

C. Anti, Afrodite Urania, Africa Italiana 1, 1927, 41-52. Arachne. Objektdatenbank und kulturelle Archive des Forschungsarchivs für Antike Plastik Köln und des DAI, zuletzt aktualisiert am (30.09.09), <http://www.arachne.uni-koeln.de/> (30.09.09). J. P. Asmussen - J. Lœssøe (Hrsg.), Handbuch der Religionsgeschichte I/II (1971/1972).

P. Arndt - W. Amelung (Hrsg.), Photographische Einzelaufnahmen antiker Sculpturen (München 1893 1947).

I. Bald Romano, Early Greek Cult Images (Diss. University of Pennsylvania Philadelphia 1980).

A. Bammer, Der Altar des jüngeren Artemisions von Ephesos, AA 1968, 400-423.

A. Bammer, Les sanctuaires des VIII' et VII e siècles à l'Artémision d'Ephèse, RA 1991, 63-84.

A. Bammer, Die Geschichte des Sekos im Artemision von Ephesos, ÖJh 62, 1993, Beibl. 137-167.

Bammer - U. Muss, Das Artemision von Ephesos.

Das Weltwunder Ioniens in archaischer und klassischer Zeit (Mainz 1996).

H. Bankel, Der spätarchaische Tempel der Aphaia auf Aegina (Berlin 1993).

G. Becatti, Problemi fidaci (Mailand 1951).

H. Belting, Bild und Kult. Eine Geschichte des Bildes vor dem Zeitalter der Kunst ${ }^{2}$ (München 1993).

M. Bergmann, The Philosophers and Poets in the Sarapieion at Memphis, in: Schultz - von den Hoff 2007, 246-263.

A. Berlejung, Die Theologie der Bilder. Herstellung und Einweihung von Kultbildern in Mesopotamien und die alttestamentliche Bilderpolemik (Freiburg/Schweiz 1998).

DNP VI (1999) 901-908 s. v. Kultbild (A. Berlejung - H. G. Niemeyer - Chr. Frateantonio - R.

Neudecker - M. Heimgartner - F. Prescendi - W. Sallaberger - H. Felber - H. Heckel).

A. Berlejung, Geheimnis und Ereignis. Zur Funktion und Aufgabe der Kultbilder in Mesopotamien, in: I. 
Abkürzungsverzeichnis

BERNOULLI 1873

BETTINETTTI 2001

BIEBER 1955

BIEBER 1977

BLÜMEL 1966

BOARDMAN 1981

BOARDMAN 1987

BOARDMAN 1995

BOL 2002

BOL 2004

BORBEIN 1995

BRAHMS 1994

BROMMER 1950

BRUNEAU - DUCAT 1983

BRUNEAU 1970

BURN - HIGGINS 2001

BURR THOMPSON 1959

BUSCHOR 1930

CAIN 1997

CAMP 1986
Baldermann - E. Dassmann - O. Fuchs u. a. (Hrsg.), Die Macht der Bilder. Jahrbuch für Biblische Theologie 13 (Neukirchen-Vluyn 1999) 109-143. J. J. Bernoulli, Aphrodite. Ein Baustein zur griechischen Kunstmythologie (Leipzig 1873).

S. Bettinetti, La statua di culto nella pratica rituale greca (Bari 2001).

M. Bieber, The Sculpture of the Hellenistic Age (New York 1955).

M. Bieber, Ancient Copies. Contributions to the History of Greek and Roman Art (New York 1977).

C. Blümel, Die klassischen griechischen Skulpturen der Staatlichen Museen zu Berlin (Berlin 1966).

J. Boardman, Griechische Plastik. Die archaische Zeit (Mainz 1981).

H. Boardman, Griechische Plastik. Die klassische Zeit (Mainz 1987).

J. Boardman, Griechische Plastik. Die spätklassische Zeit und die Plastik in Kolonien und Sammlungen (Mainz 1995).

P. C. Bol (Hrsg.), Die Geschichte der antiken Bildhauerkunst I. Frühgriechische Plastik (Mainz 2002). P. C. Bol (Hrsg.), Die Geschichte der antiken Bildhauerkunst II. Klassische Plastik (Mainz 2004).

A. H. Borbein, Die bildende Kunst Athens im 5. und 4. Jahrhundert v. Chr., in: Eder 1995, 429-473.

T. Brahms, Archaismus. Untersuchungen zu Funktion und Bedeutung archaistischer Kunst in der Klassik und im Hellenismus, Europäische Hochschulschriften. Reihe 38, Archäologie 53 (Frankfurt a. M. 1994). F. Brommer, Beiträge zur griechischen Bildhauergeschichte, MdI 3, 1950, 80-98.

Ph. Bruneau - J. Ducat, Guide de Délos ${ }^{3}$ (Paris 1983). $\mathrm{Ph}$. Bruneau, Recherches sur les cultes de Délos a l'époque hellénistique et a l'époque impériale (Paris 1970).

L. Burn - R. Higgins, Catalogue of Greek Terracottas in the British Museum II (London 2001).

D. Burr Thompson, Three Centuries of Hellenistic Terracottas, Hesperia 28, 1959, 133-138.

E. Buschor, Heraion von Samos: Frühe Bauten, AM 55, 1930, 1-99.

H.-U. Cain, Dionysos - „Die Locken lang, ein halbes Weib?..." Ausstellungskatalog München (München 1997).

J. M. Camp, The Athenian Agora. Excavations in the Heart of Classical Athens (London 1986). 
CAMPENHAUSEN 1957

COUILLOUD 1974

COURBY 1931

DALLY 1997

DAMASKOS 1999

DE CESARE 1997

DEONNA 1950

DE RIDDER 1904

DELIVORRIAS 1968

DELIVORRIAS 1984

DESPINIA 1997

DESPINIS 2004

DONOHUE 1988

DONOHUE 1997

DORN 1968

DÖRPFELD 1935

DUMOULIN 1994

DYGGVE - POULSEN 1948

EDER 1995

EKSCHMITTT 1984
H. Freiherr von Campenhausen, Die Bilderfrage als theologisches Problem der alten Kirchen, in: Schöne 1957, 77-108.

M.-F. Couilloud, Les monuments funéraires de Rhénée, Délos 30 (Paris 1974).

F. Courby, Les temples d'Apollon, Délos 12 (Paris 1931).

O. Dally, Kulte und Kultbilder der Aphrodite in Attika im späteren 5. Jahrhundert v. Chr., JdI 112, 1997, 1-20.

D. Damaskos, Untersuchungen zu hellenistischen Kultbildern (Stuttgart 1999).

M. de Cesare, Le statue in immagine. Studi sulle raffigurazioni di statue nella pittura vascolare greca (Rom 1997).

W. Deonna, Aphrodite accoudée, AntCl 19, 1950, 45-64.

A. H. P. de Ridder, Collection de Clerqc. Catalogue méthodique et raisonné III. Les bronzes (Paris 1904).

A. Delivorrias, Die Kultstatue der Aphrodite von Daphni, AntPl 8 (Berlin 1968) 19-31.

LIMC II (1984) 3-151 s. v. Aphrodite (A.

Delivorrias).

G. Despinis, Zum Athener Brauronion, in: Hoepfner 1997, 209-217.

G. I. Despinis, Die Kultstatuen der Artemis in Brauron, AM 119, 2004, 261-315.

A. Donohue, Xoana and the Origins of Greek Sculpture (Atlanta 1988).

A. Donohue, The Greek Images of Gods: Considerations on Terminology and Methodology, Hephaistos 15, 1997, 31-45.

Th. Dorn, Die Marmor-Standbilder des DaochosWeihgeschenks in Delphi, AntPl 8 (Berlin 1968) 33-53. W. Dörpfeld, Alt-Olympia. Untersuchungen und Ausgrabungen zur Geschichte des ältesten Heiligtums von Olympia und der älteren griechischen Kunst I (Berlin 1935).

D. Dumoulin, Antike Schildkröten (Würzburg 1994). E. Dyggve - F. Poulson, Das Laphrion. Der Tempelbezirk von Kalydon (Kopenhagen 1948).

W. Eder (Hrsg.), Die athenische Demokratie im 4. Jahrhundert v. Chr. Vollendung oder Verfall einer Verfassungsform? Akten eines Symposiums 3. - 7. August 1992, Bellagio (Stuttgart 1995).

W. Ekschmitt, Die Sieben Weltwunder. Ihre Erbauung, Zerstörung und Wiederentdeckung (Mainz 1984). 
ELLIGER 1985

FAULSTICH 1997

FEHR 1979

FERRI 1927

FLEISCHER 1973

FLEISCHER 1999

FRICKENHAUS 1908

FRICKENHAUS 1913

FRIESINGER - KRINZINGER 1999

FRONING 1992

FRONING 2005

FUCHS 1969

FURTWÄNGLER 1900

FUCHS - FLOREN 1987

FURTWÄNGLER 1906

GALLET 1958

GARHAMMER 2007

GARLAND 1992

GASPARRI 1986

GEOMINY 1998

GERHARD 1826
W. Elliger, Ephesos. Geschichte einer antiken Weltstadt (Stuttgart 1985).

E. I. Faulstich, Hellenistische Kultstatuen und ihre Vorbilder (Frankfurt a. M. 1997).

B. Fehr, Bewegungsweisen und Verhaltensideale. Physiognomische Deutungsmöglichkeiten der Bewegungsdarstellung an griechischen Statuen des 5. und 4. Jhs. v. Chr. (Bad Brahmstedt 1979).

S. Ferri, Statuetta di Afrodite Urania del Museo di Bengasi, Libya 3, 1, 1927, 117-123.

R. Fleischer, Artemis von Ephesos und verwandte Kultstatuen aus Anatolien und Syrien (Leiden 1973).

R. Fleischer, Neues zum Kultbild der Artemis von Ephesos, in: Friesinger - Krinzinger 1999, 605-609. A. Frickenhaus, Das Athenabild des Alten Athenatempels in Athen, AM 33, 1908, 17-32. A. Frickenhaus, Phidias und Kolotes, JdI 28, 1913, 341-369.

H. Friesinger - F. Krinzinger (Hrsg.), 100 Jahre österreichische Forschungen in Ephesos. Akten des Symposions Wien 1995 (Wien 1999). H. Froning - T. Hölscher - H. Mielsch (Hrsg.), Kotinos. Festschrift für Erika Simon (Mainz 1992). H. Froning, Überlegungen zur Aphrodite Urania des Phidias in Elis, AM 120, 2005, 285-294.

W. Fuchs, Die Skulptur der Griechen (München 1969).

A. Furtwängler, Die antiken Gemmen. Geschichte der Steinschneidekunst im klassischen Altertum I (Leipzig 1900).

W. Fuchs - J. Floren, Die griechische Plastik I. Die geometrische und archaische Plastik, HdArch (München 1987).

A. Furtwängler, Aegina. Das Heiligtum der Aphaia (München 1906).

H. Gallet de Santerre, Délos primitive et archaïque (Paris 1958).

E. Garhammer (Hrsg.), BilderStreit. Theologie auf Augenhöhe (Würzburg 2007).

R. Garland, Introducing New Gods. The Politics of Athenian Religion (Ithaca 1992).

LIMC III (1986) 414-514 s. v. Dionysos (C.

Gasparri).

W. Geominy, Zum Daochos-Weihgeschenk, Klio 80, 1998, 369-401.

E. Gerhard, Venere Proserpina Illustrata (Florenz 1826). 
GERHARD 1866

GLADIGOW u. a. 1998

GOLDAMMER 1985

GRAEPLER 1994

GRAEPLER 1997

GRUBEN 1997

GRUBEN 2001

HÄGG - MARINATOS 1981

HARENBERG 2002

HARRISON 1965

HARRISON 1984

HARWARD 1982

HEDRICK 1988

HERINGTON 1955

HELD 1995

HERMARY 1986

HIGBIE 2003

HIGGINS 1967

HILLER 1976

HIMMELMANNWILDSCHÜTZ 1959
E. Gerhard, Gesammelte Akademische Abhandlungen und kleine Schriften I (Berlin 1866). H. Cancik - B. Gladigow - K.-H. Kohl (Hrsg.), Handbuch religionswissenschaftlicher Grundbegriffe IV (1998) 9-14 s. v. Kultbild (B. Gladigow).

K. Goldammer (Hrsg.), Wörterbuch der Religionen ${ }^{4}(1985)$.

D. Graepler, Kunstgenuß im Jenseits? Zur Funktion und Bedeutung hellenistischer Terrakotten als Grabbeigabe, in: Bürgerwelten. Hellenistische Tonfiguren und Nachschöpfungen im 19. Jh. Ausstellungskatalog Berlin (Mainz 1994) 43-58.

D. Graepler, Tonfiguren im Grab. Fundkontexte hellenistischer Terrakotten aus der Nekropole von Tarent (München 1997).

G. Gruben, Naxos und Delos. Studien zur archaischen Architektur der Kykladen, JdI 112, 1997, 261- 416.

G. Gruben, Griechische Tempel und Heiligtümer 5 (München 2001).

R. Hägg - S. Marinatos (Hrsg.), Sanctuaries and Cults in the Aegean Bronze Age. Proceedings of the First International Symposium at the Swedish Institute in Athens, 12-13 May, 1980 (Stockholm 1981). Harenberg Lexikon der Religionen. Die Religionen und Glaubensgemeinschaften der Welt, Ihre Bedeutung in Alltag, Geschichte und Gesellschaft (2002). E. B. Harrison, Archaic and Archaistic Sculpture, Agora 11 (Princeton 1965).

E. B. Harrison, A Pheidian Head of Aphrodite Ourania, Hesperia 53, 1984, 379-388.

V. Judson Harward, Greek Domestic Sculpture and the Origins of Private Art Patronage (Diss. Harvard University 1982).

Ch. W. Hedrick, The Temple and Cult of Apollo Patroos in Athens, AJA 92, 1988, 185-210.

C. J. Herington, Athena Parthenos und Athena Polias (Manchester 1955).

W. Held, Wo stand die Hera von Samos?, IstMitt 45, 1995, 13-23.

LIMC III (1986) 850-942 s. v. Eros (A. Hermary).

C. Higbie, The Lindian Chronicle and the Greek Creation of their Past (Oxford 2003).

R. A. Higgins, Greek Terracottas (London 1967).

St. Hiller, Statuenstützen im fünften Jahrhundert v. Chr., AntK 19, 1976, 30-40.

N. Himmelmann-Wildschütz, Zur Eigenart des klassischen Götterbildes (München 1959). 
HIMMELMANN 2003

HÖLSCHER 1974

HÖLSCHER 1989

HOEPFNER 1997

HOEPS 2007

HORNBOSTEL 1973

HUEBER 1997

HURWITT 1999

IMHOOF-BLUMER GARDNER 1964

JOHNSTON 2004

JUDEICH 1931

KÄHLER 1971a

KÄHLER 1971b

KAHIL 1984

KARAKASI 2001

KARWIESE 1995

KEKULÉ 1894

KLASSIK 2002

KLIMKEIT

KNELL 1995
N. Himmelmann, Alltag der Götter, Nordrhein-

Westfälische Akademie der Wissenschaften. Vorträge G 385 (Paderborn 2003).

T. Hölscher, Die Nike der Messenier und Naupaktier in Olympia. Kunst und Geschichte im späten 5. Jahrhundert v. Chr., JdI 89, 1974, 70-111.

T. Hölscher, Die unheimliche Klassik der Griechen (Bamberg 1989).

W. Hoepfner (Hrsg.), Kult und Kultbauten auf der Akropolis. Internationales Symposion vom 7. bis 9. Juli 1995 in Berlin (Berlin 1997).

R. Hoeps (Hrsg.), Handbuch der Bildtheologie I.

Bild-Konflikte (Paderborn 2007).

W. Hornbostel, Sarapis. Studien zur Überlieferungsgeschichte, den Erscheinungsformen und Wandlungen der Gestalt eines Gottes (Leiden 1973).

F. Hueber, Ephesos. Gebaute Geschichte (Mainz 1997).

J. M. Hurwitt, The Athenian Acropolis. History, Mythology, and Archaeology from the Neolithic Era to the Present (Cambridge 1999).

F. W. Imhoof-Blumer - P. Gardner, Ancient Coins illustrating Lost Masterpieces of Greek Art (Chicago 1964).

S. Iles Johnston (Hrsg.), Religions of the Ancient World. A Guide (Cambridge 2004).

W. Judeich, Topographie von Athen, HAW III 2, 2 (München 1931).

H. Kähler, Lindos (Zürich 1971).

H. Kähler, Die Akropolis von Lindos, AW 2, 2, 1971 , 3-12.

LIMC II (1984) 618-753 s. v. Artemis (L. Kahil).

K. Karakasi, Archaische Koren (München 2001).

St. Karwiese, Groß ist die Artemis von Ephesos. Die Geschichte einer der großen Städte der Antike (Wien 1995).

R. Kekulé, Ueber eine weibliche Gewandstatue aus der Werkstatt der Parthenongiebelfiguren (Berlin 1894).

Die griechische Klassik. Idee oder Wirklichkeit. Ausstellungskatalog Berlin (Mainz 2002).

H.-J. Klimkeit (Hrsg.), Götterbild in Kunst und Schrift (Bonn 1984).

H. Knell, Überlegungen zur öffentlichen Architektur des IV. Jahrhunderts in Athen, in: Eder 1995, 475-514. 
KOLLWITZ 1957a

KOLLWITZ 1957b

KORRES 1997

KOSSATZ-DEISSMANN 1994

KRATZ -

SPIECKERMANN 2006a

KRATZ -

SPIECKERMANN 2006b

KREEB 1988

KREIKENBOM 2004

KÜNZL 1970

KUNZE 1992

KYRIELEIS 1981

KYRIELEIS 2006

LACROIX 1949

LANGLOTZ 1947

LANGLOTZ 1954

LAPATIN 2001

LAUER - PICARD 1955

LEHNSTEDT 1970
J. Kollwitz, Zur Frühgeschichte der Bilderverehrung, in: Schöne 1957, 57-76.

J. Kollwitz, Bild und Bildertheologie im Mittelalter, in: Schöne 1957, 109-138.

M. Korres, Die Athena-Tempel auf der Akropolis, in: Hoepfner 1997, 218-243.

LIMC VII (1994) 176-188 s. v. Paridis Iudicium (A.

Kossatz-Deissmann).

R. G. Kratz - H. Spieckermann (Hrsg.), Götterbilder, Gottesbilder, Weltbilder. Polytheismus und Monotheismus in der Welt der Antike I. Ägypten, Mesopotamien, Persien, Kleinasien, Syrien, Palästina (Tübingen 2006).

R. G. Kratz - H. Spieckermann (Hrsg.), Götterbilder, Gottesbilder, Weltbilder. Polytheismus und Monotheismus in der Welt der Antike II. Griechenland und Rom, Judentum, Christentum und Islam (Tübingen 2006).

M. Kreeb, Untersuchungen zur figürlichen Ausstattung delischer Privathäuser (Chicago 1988 ).

D. Kreikenbom, Der reiche Stil, in: Bol 2004, 185258.

E. Künzl, Venus vor dem Bade - Ein Neufund aus der Colonia Ulpia Traiana und Bemerkungen zum Typus der 'sandalenlösenden Aphrodite', BJb 170, 1970, 102-162.

M. Kunze, Staatliche Museen zu Berlin. Die Antikensammlung im Pergamonmuseum und in Charlottenburg (Mainz 1992).

H. Kyrieleis, Führer durch das Heraion von Samos (Athen 1981).

H. Kyrieleis, Anfänge und Frühzeit des Heiligtums von Olympia. Die Ausgrabungen am Pelopion 1987 1996 (Berlin 2006).

L. Lacroix, Les reproductions de statues sur les monnaies grecques (Liège 1949).

E. Langlotz, Phidiasprobleme (Frankfurt a. M. 1947).

E. Langlotz, Aphrodite in den Gärten (Heidelberg 1954).

K. D. S. Lapatin, Chryselephantine Statuary in the Ancient Mediterranean World (Oxford 2001). J.-Ph. Lauer - Chr. Picard, Les statues ptolémaïques du Sarapieion de Memphis (Paris 1955).

K. Lehnstaedt, Prozessionsdarstellungen auf attischen Vasen (Diss. Ludwig-Maximilians-Universität München 1970). 
LINANT DE BELLEFONDS u. a. 2004

LIPPOLD 1950

LIPPOLIS 1988/89

MAASS 1993

MADERNA 2004

MALLWITZ 1966

MALLWITZ 1972

MARCADÉ 1969

MARK 1993

MATZ - VON DUHN 1881

MATZ - VON DUHN 1882

MILLER AMMERMANN 1990

MOLLARD-BESQUES 1954

MOLLARD-BESQUES 1963

MOLLARD-BESQUES 1972

MOLLARD-BESQUES 1986
ThesCRA II (2004) 417-507 s. v. Rites et activités relatifs aux images de culte (P. Linant de Bellefonds A. Kauffmann-Samaras - A.-V. Szabados - A. Nercessian - N. Blanc - C. Lochin - N. IcardGianolio).

G. Lippold, Die Griechische Plastik, HdArch V (München 1950).

E. Lippolis, Il santuario di Athana a Lindo, ASAtene 66/67 (NS 48/49), 1988/89, 97-157.

M. Maass, Das antike Delphi. Orakel, Schätze und Monumente (Darmstadt 1993).

C. Maderna, Die letzten Jahrzehnte der spätklassischen Plastik. Die Gleichzeitigkeit des Andersartigen, in: Bol 2004, 316-356.

A. Mallwitz, Das Heraion von Olympia und seine Vorgänger, JdI 81, 1966, 310-376.

A. Mallwitz, Olympia und seine Bauten (München 1972).

J. Marcadé, Au musée de Délos. Étude sur la sculpture hellénistique en ronde bosse découverte dans l'île (Paris 1969).

I. S. Mark, The Sanctuary of Athena Nike in Athens. Architectural Stages and Chronology (Princeton 1993). F. Matz - F. von Duhn, Antike Bildwerke in Rom mit Ausschluss der grösseren Sammlungen I (Leipzig 1881).

F. Matz - F. von Duhn, Antike Bildwerke in Rom mit Ausschluss der grösseren Sammlungen III (Leipzig 1882).

R. Miller Ammerman, The Religious Context of Hellenistic Terracotta Figurines, in: Uhlenbrock 1990, 37-46.

S. Mollard-Besques, Musée National du Louvre. Catalogue raisonné des figurines et reliefs en terrecuite grecs et romains I. Époques préhellénique, géométrique, archaïque et classique (Paris 1954). S. Mollard-Besques, Catalogue raisonné des figurines et reliefs en terre-cuite grecs et romains II. Myrina. Musée du Louvre et Collections des Universités de France (Paris 1963).

S. Mollard-Besques, Musée National du Louvre, Catalogue raisonné des figurines et reliefs en terrecuite grecs, étrusques et romains III. Époques hellénistique et romaine. Grèce et Asie Mineure (Paris 1972).

S. Mollard-Besques, Musée du Louvre. Catalogue raisonné des figurines et reliefs en terre-cuite grecs, 
MOLLARD-BESQUES 1992

VON MOOCK 1998

MOUSTAKA 2002

MÜLLER 1915

MÜLLER 1931

MÜTH 2007

MUSS - SCHUBERT 1988

MUTHMANN 1951

MYLONAS 1961

MYLONAS SHEAR 1963

NICK 2002

OEHMKE 2004

OENBRINK 1997

OHLY 1953 étrusques et romains IV 1. Époques hellénistique et romaine. Italie méridionale - Sicile - Sardaigne (Paris 1986).

S. Mollard-Besques, Musée du Louvre. Catalogue raisonné des figurines et reliefs en terre-cuite grecs, étrusques et romains IV 2. Époques hellénistique et romaine. Cyrénaïque, Egypte ptolémaïque et romaine, Afrique du nord et Proche-Orient (Paris 1992).

D. W. von Moock, Die figürlichen Grabstelen Attikas in der Kaiserzeit, Studien zur Verbreitung, Chronologie, Typologie und Ikonographie, BeitrESkAr 19 (Mainz 1998).

A. Moustaka, Zeus und Hera im Heiligtum von Olympia und die Kulttopographie von Elis und Triphylien, in: H. Kyrieleis (Hrsg.), Olympia 18752000. 125 Jahre deutsche Ausgrabungen.

Internationales Symposion, Berlin 9. - 11. November 2000 (Mainz 2002) 301-315.

V. K. Müller, Der Polos, die griechische Götterkrone (Diss. Friedrich-Wilhelms-Universität Berlin 1915). RE Suppl. V (Stuttgart 1931) 472-511 s. v. Kultbild (V. Müller).

S. Müth, Eigene Wege. Topographie und Stadtplan von Messene in spätklassisch-hellenistischer Zeit, Internationale Archäologie 99 (Rahden 2007). U. Muss - Chr. Schubert, Die Akropolis von Athen (Graz 1988).

F. Muthmann, Statuenstützen und dekoratives Beiwerk an griechischen und römischen Bildwerken.

Ein Beitrag zur Geschichte der römischen

Kopistentätigkeit (Heidelberg 1951).

G. E. Mylonas, Eleusis and the Eleusinian Mysteries (Princeton 1961).

I. Mylonas Shear, Kallikrates, Hesperia 32, 1963, 375424.

G. Nick, Die Athena Parthenos. Studien zum griechischen Kultbild und seiner Rezeption, AM Beih. 19 (Mainz 2002).

St. Oehmke, Das Weib im Manne. Hermaphroditos in der griechisch-römischen Antike (Berlin 2004).

W. Oenbrink, Das Bild im Bilde. Zur Darstellung von Götterstatuen und Kultbildern auf griechischen Vasen, Europäische Hochschulschriften. Reihe 38, Archäologie 64 (Frankfurt a. M. 1997).

D. Ohly, Die Göttin und ihre Basis, AM 68, 1953, 25-50. 
OHLY 1977

ORLANDOS 1962

OSANNA 1988/89

PARIBENI 1959

PARKE 1977

PFUHL - MÖBIUS 1977

PHILIPP 1968

PIRENNE-DELFORGE 1994

POCHMARSKI 1974

PÖHLMANN - GAUER 1994

POLLITT 1990

RAAB 1972

POZZI 1989

REINACH - POTTIER 1887

REINACH 1882

REINACH 1897a

REINACH 1897b

REINACH 1904

REINACH 1910

REINACH 1924

REINACH 1930
D. Ohly, Tempel und Heiligtum der Aphaia auf Ägina (München 1977).

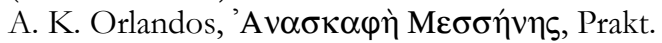
1962, 99-1121.

M. Osanna, Il problema topographico del santuario di Afrodite Urania ad Atene, ASAtene 66/67 (NS 48/49), 1988/89, 73-95.

E. Paribeni, Catalogo delle sculture di Cirene. Statue e rilievi di carattere religioso (Rom 1959).

H. W. Parke, Festivals of the Athenians (London 1977).

E. Pfuhl - H. Möbius, Die Ostgriechischen Grabreliefs I (Mainz 1977).

H. Philipp, Tektonon Daidala. Der bildende Künstler und sein Werk im vorplatonischen Schrifttum (Berlin 1968).

V. Pirenne-Delforge, L`Aphrodite grecque. Contribution à l'étude de ses cultes et de sa personnalité dans le panthéon archaïque et classique (Athen 1994).

E. Pochmarski, Das Bild des Dionysos in der Rundplastik der klassischen Zeit Griechenlands (Wien 1974).

E. Pöhlmann - W. Gauer, Griechische Klassik. Vorträge bei der interdisziplinären Tagung des Deutschen Archäologenverbandes und der Mommsengesellschaft vom 24. - 27. 10. 1991 in Blaubeuren (Nürnberg 1994). J. J. Pollitt, The Art of Ancient Greece: Sources and Documents ${ }^{2}$ (Cambridge 1990).

I. Raab, Zu den Darstellungen des Parisurteils in der griechischen Kunst (Frankfurt 1972).

E. Pozzi, Le Collezioni del Museo Nazionale di Napoli II (Neapel 1989).

S. Reinach - E. Pottier, La Nécropole de Myrina (Paris ca. 1887).

S. Reinach, Antiquités du Bosphore cimmérien ${ }^{2}$ (Paris 1892).

S. Reinach, Répertoire de la statuaire grecque et romaine I (Paris 1897).

$\mathrm{S}$. Reinach, Répertoire de la statuaire grecque et romaine II 1 (Paris 1897).

S. Reinach, Répertoire de la statuaire grecque et romaine III (Paris 1904).

S. Reinach, Répertoire de la statuaire grecque et romaine IV (Paris 1910).

S. Reinach, Répertoire de la statuaire grecque et romaine V (Paris 1924).

S. Reinach, Répertoire de la statuaire grecque et romaine VI (Paris 1930). 
RIDGWAY 1981

RIDGWAY 1992

RIDGWAY 1997

RIZZO 1932

ROMEO 1993

ROUX 1971

ROUX 1979

RÜCKERT 1998

RUMSCHEID 2006

SCHEER 2000

SCHERRER 1995

SCHLEIF 1933

SCHLÖRB 1964

SCHMIDT 1922

SCHMIDT 1997

SCHNEIDER - HÖCKER 1993

SCHNEIDER - HÖCKER 2001

SCHÖNE 1957

SCHOLL 2001

SCHRADER 1924
B. Sismondo Ridgway, Fifth Century Styles in Greek Sculpture (Princeton 1981).

B. Sismondo Ridgway, Images of Athena on the Acropolis, in: J. Neils (Hrsg.), Goddess and Polis. The Panathenaic Festival in Ancient Athens. Ausstellungskatalog Hanover (Princeton 1992) 119-142.

B. Sismondo Ridgway, Fourth-Century Styles in Greek Sculpture (London 1997).

G. E. Rizzo, Prassitele (Mailand 1932).

I. Romeo, Sull' «Afrodite nei giardini» di Alcamene, Xenia Antiqua 1993, 2, 31-44.

G. Roux, Delphi. Orakel und Kultstätten (München 1971).

G. Roux, Le vrai temple d'Apollon à Délos, BCH 103, 1, 1979, 109-135.

B. Rückert, Die Herme im öffentlichen und privaten Leben der Griechen. Untersuchungen zur Funktion der griechischen Herme als Grenzmal, Inschriftenträger und Kultbild des Hermes (Regensburg 1998).

F. Rumscheid, Die figürlichen Terrakotten von Priene. Fundkontexte, Ikonographie und Funktion in Wohnhäusern und Heiligtümern im Licht antiker Parallelbefunde, AF 22 (Wiesbaden 2006).

T. S. Scheer, Die Gottheit und ihr Bild. Untersuchungen zur Funktion griechischer Kultbilder in Religion und Politik, Zetemata 105 (München 2000). P. Scherrer, Ephesos. Der neue Führer. 100 Jahre österreichische Ausgrabungen 1895-1995 (Wien 1995).

H. Schleif, Heraion von Samos: Das Vorgelände des Tempels, AM 58, 1933, 211-247.

B. Schlörb, Untersuchungen zur Bildhauergeneration nach Phidias (Waldsassen 1964).

E. Schmidt, Archaistische Kunst in Griechenland und Rom (München 1922).

LIMC VIII (1997) 192-230 s. v. Venus (Ev. Schmidt). L. Schneider - Chr. Höcker, Phidias (Reinbek 1993).

L. Schneider - Chr. Höcker, Die Akropolis von Athen. Eine Kunst- und Kulturgeschichte ${ }^{2}$ (Darmstadt 2001). W. Schöne - J. Kollwitz - H. Freiherr von Campenhausen, Das Gottesbild im Abendland (Witten 1957). A. Scholl, Bürgerbeteiligung am Weltkulturerbe. Die Restaurierung der Berliner Aphrodite, Jahrbuch Preußischer Kulturbesitz 38, 2001, 279-285. H. Schrader, Phidias (Frankfurt a. M. 1924). 
SCHRÖDER 1993

SCHRÖDER 2004

SCHULTZ - VON DEN HOFF 2007

SEITERLE 1979

SETTIS 1966

SINN 2004

STEMMER 1995

STEMMER 2001

STEPHANI 1876

STEWART 1990

STEINER 2001

THEMELIS 1994

THEMELIS 2003

THOMPSON 1937

THOMPSON 1976

TRAVLOS 1971

UHLENBROCK 1990
St. F. Schröder, Katalog der antiken Skulpturen des Museo del Prado in Madrid I. Die Portraits (Mainz 1993).

St. F. Schröder, Katalog der antiken Skulpturen des Museo del Prado in Madrid II. Idealplastik (Mainz 2004).

P. Schultz - R. von den Hoff (Hrsg.), Early

Hellenistic Portraiture. Image, Style, Context

(Cambridge 2007).

G. Seiterle, Artemis - Die Grosse Göttin von

Ephesos, AW 10, 3, 1979, 3-16.

S. Settis, XE $\Lambda \Omega N H$. Saggio sull'Afrodite Urania di Fidia (Pisa 1966).

U. Sinn, Das antike Olympia. Götter, Spiel und Kunst (München 2004).

K. Stemmer (Hrsg.), Standorte. Kontext und Funktion antiker Skulptur. Ausstellungskatalog Berlin (Berlin 1995).

K. Stemmer (Hrsg.), In den Gärten der Aphrodite. Ausstellungskatalog Berlin (Berlin 2001).

L. Stephani, Erklärung einiger im Jahre 1872 im südlichen Russland gefundener Kunstwerke, CRPétersbourg 1873, 1876, 5-69.

A. Stewart, Greek Sculpture. An Exploration (New Haven 1990).

D. Tarn Steiner, Images in Mind. Statues in Archaic and Classical Greek Literature and Thought

(Princeton 2001).

P. Themelis, Artemis Ortheia at Messene. The Epigraphical and Archaeological Evidence, in: R. Hägg (Hrsg.), Ancient Greek Cult Practice from the Epigraphical Evidence. Proceedings of the Second International Seminar on Ancient Greek Cult, organized by the Swedish Institute at Athens, 22-24 November 1991 (Jonsered 1994) 101-122.

P. Themelis, Das antike Messene (Athen 2003). H. A. Thompson, Buildings on the West Side of the Agora, Hesperia 6, 1, 1937, 1-226.

H. A. Thompson (Hrsg.), The Athenian Agora. A Guide to the Excavation and Museum ${ }^{3}$ (Athen 1976). J. Travlos, Bildlexikon zur Topographie des antiken Athen (Tübingen 1971). J. P. Uhlenbrock (Hrsg.), The Coroplast's Art. Greek Terracottas of the Hellenistic World. Ausstellungskatalog Princeton (New York 1990). 
VIVIERS 1992

WALDENFELS 1999

WALDSTEIN 1902

WALTER - CLEMENTE 1986

WALTER 1990

WATZINGER 1901

WHITLEY 2001

WILLERS 1975

WILLIAMS 1982

WINTER 1903

WÖRRLE - ZANKER 1995

WREDE 1985

ZAGDOUN 1989

ZANKER 1998

ZIMMER 1994
D. Viviers, Recherches sur les ateliers de sculpteurs et la Cité d'Athènes à l'époque archaïque. Endoios, Philergos, Aristoklès (Gembloux 1992).

H. Waldenfels (Hrsg.), Lexikon der Religionen. Phänomene - Geschichte - Ideen ${ }^{4}(1999)$.

C. Waldstein, The Argive Heraeum I (Boston 1902).

H. Walter - A. Clemente, Zum Monopteros im Heraion von Samos, AM 101, 1986, 137-147.

H. Walter, Das griechische Heiligtum. Dargestellt am Heraion von Samos (Stuttgart 1990).

C. Watzinger, Vasenfunde aus Athen, AM 26, 1901, 50-102.

J. Whitley, The Archaeology of Ancient Greece (Cambridge 2001).

D. Willers, Zu den Anfängen der archaistischen Plastik in Griechenland, AM Beih. 4 (Berlin 1975).

D. Williams, Aegina, Aphaia-Tempel IV. The Inscription Commemorating the Construction of the First Limestone Temple and Other Features of the Sixth Century Temenos, AA 1982, 55-68.

F. Winter, Die Typen der figürlichen Terrakotten II, Die antiken Terrakotten 3, 2 (Stuttgart 1903).

M. Wörrle - P. Zanker (Hrsg.), Stadtbild und Bürgerbild im Hellenismus. Kolloquium München, 24. bis 26. Juni 1993 (München 1995).

H. Wrede, Die antike Herme (Mainz 1985).

M.-A. Zagdoun, La Sculpture archaïsante dans l'art hellénistique et dans l'art romain du haut-empire (Paris 1989).

P. Zanker, Eine Kunst für die Sinne. Zur hellenistischen Bilderwelt des Dionysos und der Aphrodite (Berlin 1998).

G. Zimmer, Frauen aus Tanagra, in: Bürgerwelten. Hellenistische Tonfiguren und Nachschöpfungen im 19. Jh. Ausstellungskatalog Berlin (Mainz 1994) 19-28. 



\section{Einleitung - Fragestellung und Materialauswahl}

Ein altes Rätsel in den Diskussionen um die Gestaltungsmöglichkeiten klassischer Götterbilder ist die Frage nach dem Sinn der archaistischen Figuren ${ }^{1}$, auf die seit dem späteren 5. Jahrhundert v. Chr. Aphrodite und andere Götter gelehnt dargestellt wurden sowie die Frage nach der Deutung des Bildmotivs insgesamt. So gibt es gerade für das möglicherweise früheste Beispiel dieser Art, die sog. Aphrodite Brazzà in Berlin viele Kontroversen: Ist sie ein Original des 5. Jahrhunderts v. Chr., vielleicht von der Hand des Phidias oder eine kaiserzeitliche Kopie? Ist sie oder repräsentiert sie die Aphrodite Urania von Elis oder dieselbe Göttin aus dem Heiligtum in der Nähe der Athener Agora? Hatte sie eine archaistische korenförmige Figur als Stütze, wie viele spätere Aphroditebilder desselben Typus? Oder hatte ihre Stütze, deren Reste in der Neuzeit völlig entfernt worden sind, die Form einer weiblichen Herme, wie sie offenbar mit dem Konzept der Aphrodite Urania verknüpft war? Wie in den letzten Jahren mehrfach gezeigt wurde, sind die archaistischen Stützen im weiteren Rahmen des im frühen 5. Jahrhundert v. Chr. aufkommenden Archaismus zu diskutieren, jener Ikonographie, die das Bewusstsein der besonderen Verehrungswürdigkeit alter Götterbilder bezeugt ${ }^{2}$. Aber wie steht es mit der Funktion der archaistischen Statuen als Stützfiguren ${ }^{3}$ ? Sind sie

\footnotetext{
${ }^{1}$ Der Begriff >Archaismus bezeichnet die Verwendung altertümlicher, vor allem archaischer Formen und Stilmittel seit der Zeit der Klassik als bewusste Rückwendung auf die vergangenen Epochen, vgl. Brahms 1994, $17 \mathrm{f}$.

2 Vgl. Kap. 7.2.1.

3 Der Begriff `Stützfigur` ist von Muthmann 1951, 18-20 zur Bezeichnung archaistischer Idole, auf die sich größere Figuren auflehnen, eingeführt worden. Er soll hier zur Bezeichnung aller ikonisch gebildeten Stützen, auf die sich Götter und Menschen auflehnen, benutzt werden, um einen festen Begriff zur Verfügung zu haben. Der ebenfalls von F. Muthmann verwendete Begriff ıStatuenstütze ist zu unpräzise, außerdem sind nur die wenigsten hier untersuchten Beispiele Statuen. Die Bezeichnung sStützfigur ist von E. Pochmarski, Dionysische Gruppen. Eine typologische Untersuchung zur Geschichte des Stützmotivs (Wien 1990) in ähnlichem Sinne zur Benennung von Figuren, die den trunkenen Dionysos stützen, verwendet worden.
} 
Götterbilder, so dass sich die Götter auf ihre eigene Kultstatue lehnen, sind sie als Weihgeschenke zu verstehen, die das Heiligtum, in dem die Gottheit erscheint, anzeigen? Oder handelt es sich bei der Stützfigur um die Verkörperung eines bestimmten Aspektes der aufgelehnten Gottheit oder um eine andere Gottheit oder eine Sterbliche? Und wie fügt sich die aufgelehnte Aphrodite in die von der archaischen zur klassischen Zeit gewandelte Darstellungsweise der Götter ein? Aphrodite wird bei diesen Bildern als möglichst lässig und sinnlich mit betont weiblichen Körperformen neben den altertümlichen Bildern gezeigt. Offensichtlich ist eine genauere Deutung dieses Statuenschemas für die Göttervorstellung und das Götterbild seit der klassischen Zeit von nachhaltiger Bedeutung. Doch gibt es bisher keinen äußeren Anhaltspunkt, zwischen den verschiedenen vorgeschlagenen Lösungen zu entscheiden. Auch die Stützhermen wurden in diese Diskussion einbezogen. Es ist allerdings fraglich, inwiefern die auf Hermen aufgelehnten Figuren denselben Grundgedanken vertreten oder nicht.

Diese Fragen sind seit der Publikation der >Aphrodite Brazzàr 1894 vielfach diskutiert worden. Dabei erwiesen sich vor allem Verschiebungen der wissenschaftlichen Perspektive als nützlich, wie etwa die seit klassischer Zeit übliche gedankliche Trennung zwischen der Gottheit und ihrem (altertümlichen) Bild, auf das sie sich nach der am häufigsten vertretenen Interpretation lehnt. Seltener ergaben sich neue, die Frage erhellende Fakten wie das Fragment einer weiblichen Terrakottastatuette aus Elis, die ihren Fuß auf eine Schildkröte setzt, die Entdeckung der Aphrodite von Daphni und ihres Verhältnisses zu anderen Aphroditefiguren des 5. Jahrhunderts v. Chr. oder der Nachweis des Heiligtums der Aphrodite Urania nördlich des Hephaisteions und einer dort gefundenen kleinformatigen weiblichen Herme, die auf Aphrodite Urania bezogen werden kann 4 .

Wie auch immer man sich für die Deutung der Stütze entscheidet, die Grundlage der Erfindung des Motivs scheint zweifellos schon richtig erkannt. Es ist der Abstand zwischen den alten Götterstatuen und sonstigen altertümlichen Götterbildern in ihren Heiligtümern und den neuen Darstellungsformen der Götter seit der Klassik bzw. der Vorstellung von den lebendigen Göttern selbst in dieser Zeit.

Die folgende Untersuchung soll diesen methodischen Ansatz durch ein Argument, das aus der Masse des Materials gewonnen wird, vertiefen. Auf der Basis einer möglichst umfangreichen Sammlung von Darstellungen, bei denen sich Götter und göttliche Wesen auf figürlich gestaltete Stützen lehnen oder mit solchen kombiniert sind, sucht sie zunächst deren zeitliches und thematisches Spektrum auszuloten $^{5}$. Dies führt zu einem eindeutigen und in dieser Form bisher nicht

\footnotetext{
${ }^{4}$ Dazu s. Kap. 5.1..3.

5 Als Stützen kommen außer weiblichen Idolen und Hermen auch andere figürliche Stützen vor, für die übergeordnet der Begriff sikonische Stütze` verwendet wird. Es werden nur solche Bilder unter sucht, bei denen die Stützfigur wahrscheinlich eine Statue und nicht die lebendige Gottheit darstellt. `Technische Stützen, die beim Kopieren griechischer Bronzewerke in Marmor zur Stabilisierung
} 
bekannten Ergebnis. Bekannt ist, dass das Thema zahlreich durch Terrakottastatuetten und andere kleinplastische Darstellungen des Hellenismus und der Folgezeit belegt ist. Vorher ist es selten und wurde, auch dies ist bekannt, für Aphrodite im 5. Jahrhundert v. Chr. erfunden. Aphrodite blieb auch lange die einzige Göttin, für die das Motiv verwendet wurde. Die unmittelbare Folge und die Auswahl der Götter, die in späterer Zeit in diesem Schema dargestellt wurden, aber sind symptomatisch. Sie werfen ein Licht auf den Hintergrund der ursprünglichen Erfindung. Denn nach Aphrodite sind es vor allem Figuren aus ihrem Umkreis wie Eros und Hermaphrodit, die in diesem Schema dargestellt worden sind, zeitlich und zahlenmäßig folgt mit größerem Abstand Dionysos. Andere Götter erscheinen in diesem Schema erst bei spätklassischen und vor allem hellenistischen Terrakottastatuetten, bei denen sich das Motiv verselbständigt bis hin zu Jünglingen, die sich auf Hermen lehnen, die die Palästra anzeigen. Das Schwergewicht der aufgelehnten Darstellungen auf den beiden Gottheiten, die am stärksten über ihren Körper charakterisiert wurden und deren Darstellungsweise sich in klassischer Zeit stärker verändert hat als die aller anderen Götter, lässt die Stützen in einem Blickwinkel erscheinen, der die exakte Lösung der Frage, was genau die archaistischen Figuren darstellen, weniger wichtig macht. Auf dieser Grundlage soll die Erfindung des Motivs mit den dazugehörigen Fragen der Einordnung der aufgelehnten Aphrodite in den historischen Kontext und der daraus resultierenden Bedeutung der altertümlichen Stütze diskutiert werden.

Sinnvoll ist es darüber hinaus zu prüfen, inwieweit der Gedanke des Nebeneinanders alter und oft einfach gestalteter sowie neuer und repräsentativer Bilder im Kultgeschehen verschiedener Heiligtümer einen realen Hintergrund hatte - auch wenn dies für die Erfindung eines solchen Bildschemas nicht unbedingt notwendig ist. Dies wiederum setzt zuvor eine Beschäftigung mit dem problematischen weil neuzeitlichen Begriff des >Kultbildes` und seiner Verwendung in der Forschung wie auch der möglichen Realität in der griechischen Religion voraus. Mit diesen Fragen beschäftigt sich der zweite Teil dieser Arbeit.

angebrachten wurden werden nur ergänzend herangezogen. Zu dem Begriff `Technische Stützeく s. Muthmann 1951, 8.

Die im laufenden Text angegebenen Katalognummern beziehen sich auf den am Ende dieser Arbeit angefügten Katalogteil. Aphroditebildern wurden Katalognummern, die mit dem Buchstaben A beginnen zugeordnet, Bildern anderer Götter Katalognummern, die mit dem Buchstaben B beginnen. Die im Tafelteil abgebildeten Werke sind im Text kursiv gesetzt. Abbildungsnummern sind dem zweiten Tafelteil zugeordnet. Abkürzungen bei den Angaben der Literatur werden nach den vom Deutschen Archäologischen Institut vorgeschlagenen Richtlinien, zuletzt aktualisiert am 04.12.2007, <http://www.dainst.org/index_141_de.html> (30.09.09) sowie nach den im Abkürzungsverzeichnis angegebenen Siglen vorgenommen. Für die Quellen werden die Abkürzungen in DNP I (1996) XXXIX-XLVII und Liddel - Scott - Jones (1925) verwendet. 



\section{Die bisherige Forschung}

Menschengestaltige Idole und Hermen, aber auch andere Stützen z. B. in Form von Pfeilern und Baumstämmen, auf die sich verschiedene Figuren in Werken der griechischen wie auch der römischen Kunst lehnen, sind bisher nur unzureichend erforscht worden. Außerdem geschah dies z. T. lediglich im Rahmen der Untersuchung von `technischen`Statuenstützen römischer Werke nach griechischen Vorbildern, die oft als Kopistenzutaten einzustufen sind. Zudem wurden jeweils nur wenige Beispiele betrachtet. Eine zusammenhängende Untersuchung sich auflehnender Figuren sowie eine Betrachtung der Deutungsmöglichkeiten dieser Bilder liegt noch nicht vor. Deshalb soll mit dieser Arbeit eine Untersuchung auf ikonische Stützen gelehnter Figuren vorgelegt werden. Eine generelle Untersuchung zu allen Stützenformen und der auf sie Gelehnten kann jedoch aufgrund der Materialfülle nicht geleistet werden.

Als erste widmete sich A. Maviglia in ihrem 1913 erschienenen Aufsatz einigen Statuenstützen in der antiken Kunst ${ }^{6}$. Ziel der Untersuchung war eine Sammlung möglichst vieler Beispiele, um mit ihrer Hilfe die dargestellte Figur identifizieren zu können. A. Maviglia hat deshalb ausschließlich technische Stützen römischer Kopien nach griechischen Bronzeoriginalen, die ihrer Meinung nach attributhaft die dargestellte Person erläutern, untersucht. Sie behandelte nur Baumstammstützen, Tiere und Waffen, keine figürlich gebildeten Stützen. Weitere Beigaben, die ihrer Meinung nach eine Statue nicht weiter charakterisieren, wie Vasen, Pilaster und Säulen, hat sie nicht betrachtet.

Auf die Arbeit von A. Maviglia aufbauend hat F. Muthmann 1951 eine Monographie über Statuenstützen veröffentlich7 ${ }^{7}$ Die Intention seiner Arbeit war, die Stützen chronologisch zu ordnen, um über sie eine Datierungsmöglichkeit für die Statuen zu erhalten. Er ging dabei über die Untersuchung von A. Maviglia hinaus,

\footnotetext{
${ }^{6}$ A. Maviglia, Gli attributi dei sostegni nella statuaria antica, RM 28, 1913, 1-91.
}

${ }^{7}$ Muthmann 1951. 
indem er griechische und römische Beispiele betrachtete. Er hat Stützen in Form von Baumstämmen, Pfeilern, Dreifüßen, Waffen und Vasen wie auch figürliche Stützen in Form des archaistischen Idols und der Herme einbezogen. Dabei unterschied F. Muthmann zwischen Statuenstützen, die zu der ursprünglichen Erfindung gehören und solchen, die als technische Hilfsmittel von römischen Kopisten bei der Umsetzung griechischer Bronzewerke in Marmor hinzugefügt worden sind. Die ikonischen Stützen hat er als IKaryatiden bezeichnet. Sie hatten für ihn eine rein tektonische Funktion und stellen nur eine andere Form der Stützpfeiler dar, die in der antiken Kunst ebenfalls häufig als Auflager für einen aufgelehnten Arm, ein Gewand oder ein Attribut dienten ${ }^{8}$. Eine genauere Identifizierung dieser Figuren und darüber hinausgehend eine Deutung der Bilder insgesamt hat F. Muthmann nicht versucht. Die einzige weitere Bedeutung, die die Stützen für ihn hatten, ist die malerische Ausschmückung, also das Erzeugen einer »idyllischen Atmosphäre«?

St. Hiller hat 1976 einen Aufsatz zu Statuenstützen im 5. Jahrhundert v. Chr. veröffentlicht ${ }^{10}$. Darin hat er die inhaltliche Motivation einzelner Stützenformen anhand verschiedener Statuen untersucht wie der Athena Parthenos, die ihre rechte Hand auf eine Säule legt oder dem Amazonentypus Sciarra ${ }^{11}$ mit einem Pfeiler als Stütze. Auch an Pfeiler und ikonische Stützen gelehnte Aphroditedarstellungen hat er in seine Arbeit einbezogen. Für ihn stellten die Stützen bei den Götterbildern ein altes verehrtes Mal dar. Dieses verdeutliche die lange Kulttradition, in der das Bild der darauf gelehnten Göttin steht und steigere seine Göttlichkeit ${ }^{12}$. Darauf wird in Kapitel 7 noch einmal ausführlich zurückzukommen sein. Bei der Amazone hingegen stelle der Pfeiler ein ortsdefinierendes Attribut dar. Dieses besage, dass sich die verwundete Kriegerin in das Heiligtum der Artemis von Ephesos $^{13}$ geflüchtet habe. Das Heiligtum wird nach Ansicht von St. Hiller durch den Pfeiler als Abbild einer Stele oder eines Grenzsteines symbolisiert. Gleichzeitig könne der Pfeiler auch als Hinweis auf den bevorstehenden Tod der Amazone im Sinne eines Grabmales gesehen werden ${ }^{14}$.

Die einzige umfangreichere Untersuchung in der jüngeren Forschung zu Stützfiguren in der Skulptur stammt von T. Brahms ${ }^{15}$. Sie behandelt im Rahmen ihrer Monographie zur archaistischen Kunst von 1994 jedoch nicht ikonische Stützen im Allgemeinen, sondern lediglich archaistisch gestaltete weibliche Idole. Sie referiert zunächst die Meinungen der bisherigen Forschung, die man dahingehend

\footnotetext{
${ }^{8}$ Ebenda 18.

${ }^{9}$ Ebenda 19. 23-46.

${ }^{10}$ Hiller 1976.

${ }^{11} \mathrm{Zu}$ diesen Statuen vgl. auch S. 97 und Kap. 12.1 bzw. S. 92.134 f.

12 Hiller 1976, 32-36.

${ }_{13}$ Zur Verbindung der Amazonen mit der Artemis von Ephesos vgl. Kap. 12.9.

14 Hiller 1976, 37 f.

15 Brahms 1994, 183-190.
} 
zusammenfassen kann, dass die Idole entweder als altes Bild der auf sie gelehnten Göttin, als Bild einer die aufgelehnte Gottheit begleitenden, untergeordneten Göttin oder als Bild einer Adorantin gesehen wurden, was ich in Kapitel 7.1.1. noch genauer untersuchen werde. T. Brahms lehnt alle diese Deutungen ab. Ihrer Meinung nach sind in den Idolen Wiedergaben von >Votiven $z$ zu sehen. Diese setzen die gesamte Komposition in den Kontext eines Heiligtums. Sie dienen als ortsdefinierende Attribute ${ }^{16}$. Sowohl die von Brahms zitierten Arbeiten wie auch ihre eigene beschäftigen sich lediglich mit weiblichen Idolen, nicht aber mit Figuren allgemein, auf die sich Götter oder Menschen auflehnen. Aus diesem Grund soll auf sie erst in Kapitel 7.1.1.4, in dem die Bedeutung der Idole untersucht wird, ausführlicher eingegangen werden.

Eine übergreifende inhaltliche Interpretation der figürlichen Stützen, auf die sich Götter und Menschen lehnen, steht immer noch aus. Ebenso wenig ist bisher eine Deutung der auf sie gelehnten Figuren sowie der Komposition insgesamt versucht worden. Einen Beitrag zur Erforschung dieses Bildmotivs soll diese Arbeit leisten. 



\section{Aphroditebilder mit weiblichen Idolen und Hermen als Stütze}

Zunächst ist es wichtig, die Materialbasis darzulegen. In diesem Abschnitt sollen Aphroditedarstellungen betrachtet werden, die die Göttin auf ein weibliches Idol oder eine weibliche Herme gelehnt zeigen. Sie werden dabei nach typologischen Übereinstimmungen zusammengestellt. Eine wichtige Grundlage für diese Untersuchung bildet der Artikel >Aphroditer im LIMC, mit dem A. Delivorrias 1984 die bisher umfangreichste und ebenfalls nach typologischen Gesichtspunkten geordnete Untersuchung antiker Aphroditebilder vorgelegt hat ${ }^{17}$. Im Unterschied dazu liegt der Fokus hier jedoch nicht auf einer Typologisierung von Aphroditedarstellungen allgemein, sondern auf der Rekonstruktion und vor allem der Deutung der Bilder mit ikonischen Stützen, von denen ich hier deshalb mehr Beispiele als A. Delivorrias betrachten werde.

Die Identifizierung der Figuren ist nicht immer gesichert. Einige sind durch einen beigegebenen Eros als Aphrodite gekennzeichnet. Er steht entweder neben ihr oder sitzt auf ihrer Schulter (Kat. A21. A35. A39. A41. A45. A47-49. A51). Andere, vor allem hellenistische Darstellungen zeigen den Oberkörper unbekleidet. Hier liegt es nahe, in der Figur Aphrodite zu sehen. Diese weisen, wie auch die von Eros begleiteten, zumeist dieselben Haltungs- und Kompositionsschemata auf wie die älteren, vollständig bekleideten Bilder. Die Darstellungsweise der hier untersuchten Bilder setzt sich also ungebrochen fort. Daraus kann man wiederum den Rückschluss ziehen, dass auch die frühen Beispiele Aphrodite darstellen ${ }^{18}$.

\footnotetext{
17 Delivorrias 1984.

18 Bei den klassischen Beispielen ist zudem der Körper deutlich unter den Gewändern sichtbar. Dies lässt auf ein Bild der Aphrodite schließen, auch wenn dies am Ende des 5. Jahrhunderts v. Chr. allgemeiner Stil war, wie dies z. B. die Niken der Balustrade des Athena Nike-Tempels in Athen belegen. Die Mehrheit der Göttinnen wird aber auch in dieser Zeit nicht derartig körperbetont dargestellt, worauf ich in Kap. 7.2.2 noch einmal zurückkommen werde. Vgl. EAA I (1958) 122 f. s. v.
} 
Bereits eine erste Durchsicht des Materials lässt erkennen, dass die über lange Zeit entstandenen Bilder viele typologische Gemeinsamkeiten aufweisen. Dies wirft die Frage auf, ob es in der Antike ein bekanntes, oft wiederholtes bzw. zitiertes Urbild gegeben hat. Ein Attribut wird dabei eine wichtige Rolle spielen: eine Schildkröte, auf die einige der Dargestellten ihren linken Fuß setzen. Aufgrund der Materialfülle kann die Beschreibung der Werke sonst nur sehr summarisch gehalten werden.

Bei vielen der hier genannten Beispiele ist die Stütze in Form eines kleinen weiblichen Idols gebildet. Die Körperhaltung und das Standmotiv stimmen bei den meisten Stützfiguren typologisch überein. Auch die Gewanddrapierung ist im Großen und Ganzen gleich. Deshalb werden die Stützfiguren nicht bei jedem Beispiel im Einzelnen beschrieben. Es ist immer eine kleine weibliche Figur, die mit geschlossenen Beinen ohne Kontrapost auf einer Basis steht. Die Kleidung übernimmt Merkmale der archaischen Epoche wie Zick-Zack-Säume oder eine betonte Mittelfalte. Auch die Handhaltung ist archaistisch. Die Figuren greifen mit einer Hand ihr Gewand und ziehen es empor, wie es bei Darstellungen weiblicher Figuren in archaischer Zeit üblich gewesen ist ${ }^{19}$. Die andere Hand ist meist vor die Brust geführt und kann ein Attribut halten, etwa eine Blüte oder eine Frucht wie bei Kat. A13 und A18. Auf dem Kopf tragen die Idole einen Polos, der jedoch nicht bei allen zu sehen ist. Da das über die Stütze fallende Gewand der aufgelehnten Figur in diesen Fällen nicht unter dem Gewicht ihres Armes zusammengedrückt ist und zwischen dem Arm und dem Kopf der Stütze oft ein Abstand besteht, kann man vom Vorhandensein des Polos ausgehen ${ }^{20}$. In der Körperhaltung, der Gewanddrapierung und z. T. auch in der Frisur sind die Stützfiguren demnach archaistisch gestaltet. Durch die geschlossene Haltung und die Basis sind sie darüber hinaus als Statuen gekennzeichnet.

Außer auf weibliche Idole wird Aphrodite in der griechischen Kunst auch auf weibliche Hermen gelehnt dargestellt. Davon sind mir allerdings nur ein gesichertes Beispiel (Kat. A3) und möglicherweise zwei weitere (Kat. A22. A51) bekannt. Es handelt es sich jeweils um bekleidete Schulterhermen. Sie sind unbärtig und nicht ithyphallisch. Bei Kat. A3 zeichnen sich unter dem Gewand Brüste ab, das Haar ist lang und die Gesichtszüge weiblich. Die anderen beiden Hermen könnten auch weiblich sein, sind jedoch nicht eindeutig charakterisiert. Da das Gewand-

Afrodite (A. De Franciscis); Himmelmann-Wildschütz 1959, 11; Delivorrias 1984, 23; Chr. Landwehr, Die antiken Gipsabgüsse aus Baiae. Griechische Bronzestatuen in Abgüssen römischer Zeit (Berlin 1985) 94; Stewart 1990, 52; Himmelmann 2003, 59. Zur Nikebalustrade vgl. Muss - Schubert 1988, 75 f. Abb. 119; Mark 1993 bes. 76 Taf. 21 f.; Schneider - Höcker 2001, 166-171 Abb. 181 f.

${ }^{19}$ Vgl. E. Langlotz, Die Koren, in: H. Schrader (Hrsg.), Die archaischen Marmorbildwerke der Akropolis (Frankfurt a. M. 1939); G. M. A. Richter, Korai. Archaic Greek Maidens (London 1968); L. Schneider, Zur sozialen Bedeutung der archaischen Korenstatuen (Hamburg 1975); Karakasi 2001.

${ }^{20}$ Die Beschreibungen konnten oft nur anhand von Abbildungen oder Umzeichnungen angefertigt werden, die zumeist nur die Vorderansicht bieten. Es ist daher möglich, dass der Polos bei der Seiten- oder Rückansicht zu sehen ist. Die Verteilung der Bilder auf zahlreiche Sammlungen in verschiedenen Ländern macht es jedoch unmöglich, dies an den Originalen zu überprüfen. 
knäuel unter dem Arm der aufgelehnten Aphrodite bei Kat. A22 nicht zusammengedrückt ist, kann man darunter einen Polos vermuten, der bei den hier betrachteten Bildern mehr von den weiblichen als von den männlichen Stützfiguren getragen wird. Die Herme bei Kat. A51 hingegen hat anscheinend lange, zu einem Wulst um den Kopf eingeschlagene Haare, weshalb auch sie vielleicht weiblich ist.

\subsection{Die frühesten Bilder}

Zunächst sollen die ältesten Beispiele betrachtet werden, um zu klären, wann Aphroditedarstellungen mit ikonischen Stützen aufkamen. Die frühesten erhaltenen Bilder in diesem Haltungsschema sind eine Marmorstatue - die sog. Aphrodite Brazzà Kat. A1 - und eine Marmorstatuette aus Tarquinia (Kat. A2), die sich heute beide in den Sammlungen der Staatlichen Museen zu Berlin befinden. Beide werden in die 2. Hälfte des 5. Jahrhunderts v. Chr. datiert ${ }^{21}$. Das drittälteste Werk ist ein Relieffragment aus Marmor unbekannter Herkunft, das an den Anfang des 4. Jahrhunderts v. Chr. datiert wird. Es gehört heute zum Bestand der Vatikanischen Museen (Kat.A3).

\subsubsection{Die >Aphrodite Brazzàı}

Das älteste Beispiel einer Aphroditedarstellung mit einer möglicherweise ikonischen Stütze ist die nach einem früheren Besitzer benannte, in der Forschung bereits viel diskutierte >Aphrodite Brazzàr (Kat. A1). Sie ist eine überlebensgroße stehende Figur aus pentelischem Marmor mit einer auffallend lässigen Körperhaltung. Sie steht frontal gesehen auf dem rechten Bein. Das linke stellt sie mit angewinkeltem Knie nach vorn auf einen nicht erhaltenen Gegenstand, der heute durch eine modern ergänzte Schildkröte ersetzt ist. Mit dem linken Ellenbogen stützt sie sich auf eine ebenfalls nicht erhaltene Stütze. Dies führt zu ausladenden Körperbewegungen, besonders der rechten Hüfte. Der Oberkörper lehnt leicht nach hinten. Nicht erhalten sind der linke Unterarm, der rechte Arm und der Kopf mit dem Hals und einem Teil der linken Schulter. Sie waren vermutlich gesondert eingesetzt, worauf die erhaltenen, offenbar antiken Ansatzlöcher hinweisen ${ }^{22}$.

Die Figur ist mit einem eng anliegenden, knapp über dem Bauchnabel gegürteten Chiton und einem Himation bekleidet. Der Mantel verläuft von der linken

\footnotetext{
21 Die Datierung der >Aphrodite Brazzà ist umstritten, s. S. 38.

22 Laut Kekulé 1894, 3 f.; Blümel 1966, 91 Nr. 109; M. Hagelberg, Nr. E9 „Aphrodite auf der Schildkröte“, in: Stemmer 2001, 87 und Scholl 2001, 282 sind die rechteckigen Löcher am rechten Oberarm und linken Ellenbogen sowie das Zapfenloch für den Kopf antik und wurden bei einer neuzeitlichen Restaurierung wieder verwendet, während man die Ansatzflächen glättete, so dass die antike Oberfläche an den Ansatzflächen selbst verloren ist. Herrn Dr. Martin Maischberger (Berlin) danke ich für die Einsicht in die Museumsakten zu dieser Statue sowie den Restaurierungsbericht von P. Hofmann aus dem Jahr 2000/2001, die diese Ansicht bestätigen. Zu den modernen Ergänzungen s. auch S. 36 und Taf. 2, 1.
} 
Seite ausgehend, wo er um den aufgelehnten Arm gelegt ist, über den unteren Rücken zur rechten Seite, umspannt die rechte Hüfte mitsamt dem rechten Oberschenkel und fällt anschließend eng anliegend über den linken Oberschenkel23.

Bei einer Restaurierung am Anfang des 19. Jahrhunderts ist die Statue teilweise um- bzw. abgearbeitet worden. Dabei wurde vor allem das Himation unter dem linken Arm zurechtgeschnitten und die Bruchflächen geglättet. Der neuzeitliche Restaurator hat die fehlenden Teile anschließend zusammen mit einer mit Girlanden und Bukranien verzierten Vase, die er der Göttin als Stütze unter den Arm schob, in einem ergänzt. Weiterhin hatte er den rechten Arm, den linken Unterarm und den Kopf ergänzt sowie einige gebrochene Falten des Gewandes vervollständigt. Diese sind heute wieder abgenommen, so dass die modernen Schnittflächen erkennbar sind, besonders deutlich im Schulterbereich, am rechten Oberarm, am linken Unterarm sowie an der Außenkante des den Rücken hinabfließenden Himations ${ }^{24}$. Eine Aussage darüber zu treffen, wie die antike Stütze ausgesehen hat, ist durch diesen Befund schwierig. Möglicherweise war sie von dem antiken Bildhauer gesondert angefertigt worden, da die detailgenaue Ausarbeitung der Gewandfalten an der linken Seite der Statue sonst Schwierigkeiten bereitet hätte.

Unerklärlich bleibt die auf Tafel 3, 1 abgebildete Abarbeitung an der linken Seite der Statue. Unterhalb des Überfalls ist der Chiton an dieser Seite durch eine besonders breite und tiefe Falte gegliedert, deren Grate deutlich hervorstehen. Sie ist durch schmale Binnenfalten in sich weiter strukturiert. Im oberen Viertel, von der Unterkante des Chitonüberfalls an circa $0,30 \mathrm{~m}$ abwärts gemessen sind diese Binnenfalten weggemeißelt, so dass sich eine ungegliederte, leicht eingetiefte raue Fläche ergibt, während die äußeren Grate nicht abgearbeitet wurden. R. Kekulé, der die Statue 1894 erstmals publiziert hat, hat diese Abarbeitung damit erklärt, dass hier nachträglich - und zwar bereits in der Antike - Platz geschaffen wurde für die Stütze, die an dieser Stelle einen Vorsprung gehabt haben müsse. Dieser Vorsprung sei der Ellenbogen einer weiblichen Figur gewesen, weshalb er sich gegen die Rekonstruktion einer Pfeilerstütze aussprach, die überall gleich breit wäre ${ }^{25}$.

Wann die Abmeißelung allerdings vorgenommen wurde, ist offen. Weder die Anfügung einer Stütze in der Antike noch die der neuzeitlichen Vase würde erklären, warum nur die Faltentäler, nicht jedoch die Grate abgearbeitet wurden. Auch hat die neuzeitliche Stützvase nicht bis zu dieser Stelle gereicht. Ebenso wenig lassen sich triftige Gründe für eine antike Umarbeitung finden. Zum einen war die Statue aufgrund ihrer Körperhaltung von vorn herein mit einer Stütze konzipiert. Zum anderen verläuft die abgearbeitete Fläche senkrecht nach unten. Ein ange-

\footnotetext{
23 Zu einer näher charakterisierenden Beschreibung s. S. 133 f.

${ }^{24}$ s. Taf. 2, 3. 3, 1. Die Ergänzungen sind auf Taf. 2, 1 wiedergegeben. Eine ausführliche Beschreibung der Ergänzungen liefert Kekulé 1894, 2-4; vgl. auch Frickenhaus 1913, 363; Blümel 1966, 91 f. Nr. 109; Schneider - Höcker 1993, 110-112; Scholl 2001.

${ }^{25}$ Kekulé 1894, 8 f. Seine Rekonstruktion ist auf Taf. 2, 2 wiedergegeben.
} 
winkelter Arm mit ausgestrecktem Ellenbogen, wie sonst bei den Stützidolen, hätte jedoch in Höhe des Ellenbogens mehr Platz beansprucht als im Bereich der Schulter, was eine sich nach unten verbreiternde Abarbeitung erwarten ließe. Außerdem würde in die Falte nur ein sehr kleiner Arm passen, da die nicht zurückgearbeiteten Faltengrate den Platz begrenzen. Die Stützfigur wäre dann sehr klein gebildet und würde weit vorn stehen, wodurch sich wiederum ein Widerspruch zu der Tiefe, die sie eingenommen haben muss, ergibt. Zwischen dem Idol und dem hinter ihm herabfallenden Gewand der Göttin würde ein Stück leerer Raum übrig bleiben. Daher liegen keine triftigen Gründe vor, die Abarbeitung mit dem Ansatz eines Stützidols in der Antike in Verbindung zu bringen noch sie darüber zu datieren. Eine andere Erklärung für die Abarbeitung muss ich allerdings schuldig bleiben. Damit ist die Frage nach der Form der antiken Stütze noch nicht geklärt. Ein Pfeiler oder Baumstamm, der bei anderen Aphroditetypen als Stütze vorkommt ${ }^{26}$, wäre m. E. zu schmal und würde den Raum unter dem linken Arm der Statue nicht ausfüllen. Von dem Gewand der aufgelehnten Figur ist in der Neuzeit nicht so viel abgearbeitet worden, dass es ursprünglich deutlich mehr Raum eingenommen hätte. Eine anikonische Stütze scheint mir deshalb R. Kekulé folgend auszuschließen zu sein ${ }^{27}$. Es käme also in Analogie zu den anderen hier untersuchten Beispielen ein weibliches Idol oder eine Herme in Frage. Daraus ergibt sich jedoch noch immer kein wirklich gesicherter Hinweis auf das Aussehen der Stütze.

In seiner Monographie zur Aphrodite Urania von 1966 hat S. Settis die These vorgetragen, dass unter dem aufgelehnten Ellenbogen der >Aphrodite Brazzà Haare zu sehen seien. Diese können seiner Meinung nach nur zu einer Herme gehört haben, da die Idole immer einen Polos trügen. Dies kann jedoch nicht unwidersprochen hingenommen werden. Zum einen trägt das Idol der Terrakotte Kat. A49 keinen Polos, dafür aber die Herme auf dem Marmorrelief Kat. A3. Zum anderen scheinen mir die Spuren, die S. Settis als »tracciate assai nettamente, le prime linee dei capelli della testa dell'erma « ${ }^{28}$ bezeichnet hat, nicht auf Haar hinzuweisen. Es sind annähernd parallel und vor allem sehr gerade gemeißelte Kerben mit nahezu rechtwinkligen Kanten unterhalb der Ansatzstelle des Unterarms der aufgelehnten Aphrodite. Sie verlaufen vom Betrachter aus gesehen schräg von links oben nach rechts unten und wurden nur grob eingekerbt und nicht nachbearbeitet. Sie besitzen daher keine organische lebendige Struktur oder die Weichheit, die für Haare zu erwarten wären. Es kann sich daher um einen nur grob ausgearbeiteten Teil des Gewandes der aufgelehnten Göttin handeln, der durch den angestückten Unterarm verdeckt wurde. Weitere Anhaltspunkte zur Rekonstruktion der Stütze liegen nicht vor, so dass ihre einstige Form offen bleiben muss ${ }^{29}$.

\footnotetext{
26 s. Kap. 6.1.

27 Kekulé 1894, 7-9.

28 Settis 1966, 14. Vgl. hier die Abbildung auf Taf. 2, 3.

${ }^{29}$ Vgl. Scholl 2001, 283; A. Delivorrias, Bildwerk und Kopie, in: Klassik 2002, 347.
} 
Ein weibliches archaistisches Idol oder eine Herme ist aber einem Pfeiler oder ähnlich schlanken Gegenstand vorzuziehen, da letztere den vorhandenen Raum unter dem aufgelehnten Arm nicht ausreichend ausfüllen würden. Die Statue, die sowieso in ihrem unteren Teil bereits sehr schmal gearbeitet ist, würde noch schmaler, ja geradezu extrem schmal für eine Statue dieser Zeit wirken.

Auch das Objekt, das sich einst unter dem linken Fuß befand, ist verloren. Die Schildkröte, auf die die Göttin heute, wie hier auf Tafel 3, 2 abgebildet, tritt, war mitsamt dem Fuß, einem Teil des Unterschenkels und des Gewandes sowie eines Teiles der Standplatte zu Beginn des 19. Jahrhunderts ergänzt worden. Trotz dieser an einzelnen Stellen umfangreichen Ergänzungen und Umarbeitungen wird in der Forschung vermutet, dass dem neuzeitlichen Restaurator antike Reste einer Schildkröte zur Verfügung gestanden haben, die er als Vorlage verwendete ${ }^{30}$. Als Gründe dafür werden angeführt, dass eine freie Erfindung des Restaurators ein erstaunlicher Zufall wäre, da zu dem Zeitpunkt der Ergänzung die anderen heute bekannten Aphroditebilder mit den Schildkröten noch unentdeckt waren. Für unwahrscheinlich hält man auch die Verwendung der Beschreibung der Aphrodite Urania des Phidias bei Pausanias. In diesem Fall hätte man die Statue bereits zum Zeitpunkt der Restaurierung als ein Werk der Parthenonzeit erkennen müssen, für das die Statue heute zumeist gehalten wird. Dies ist jedoch nicht der Fall. Erst seit dem Ende des 19. Jahrhunderts wurde die Statue durch ihren Stil in die 2. Hälfte des 5. Jahrhunderts v. Chr. datiert ${ }^{31}$. Aufgrund der Körperhaltung ist es jedoch möglich, dass sie bereits in der Antike ihren linken Fuß auf eine Schildkröte gesetzt hat. Sie wäre demnach das früheste Beispiel, das diese ungewöhnliche Haltung zeigt.

Ebenso umstritten wie die Rekonstruktion der Stütze ist die Datierung der Statue und damit verknüpft auch die Frage nach einem eventuellen Original. Sie gehörte vormals der Sammlung Brazzà in Venedig an und ist am Ende des 19. Jahrhunderts für die Berliner Antikensammlung angekauft worden. Aufgrund des verwendeten pentelischen Marmors sowie stilistischer Merkmale ist sie überwiegend für ein klassisch-attisches Original erklärt und mit den Parthenon-Giebelfiguren verglichen worden, wie es als erster R. Kekulé in seiner Untersuchung zu der Statue von 1894 vorgeschlagen hat. Darauf aufbauend hat er vermutet, dass sie, wie viele andere vene-

30 Frickenhaus 1913, 363 f.; Langlotz 1947, 83; Brommer 1950, 83; Blümel 1966, 92 Nr. 109; Settis 1966, 10. 16. 21; M. Bauer, Aphrodite auf der Schildkröte, in: Stemmer 1995, 234 f.; M. Hagelberg, Nr. E9 „Aphrodite auf der Schildkröte“, in: Stemmer 2001, 87. Dass die Schildkröte sogar aus demselben Material besteht wie die Statue, wie P. C. Bol, Nichtphidiasische attische Bildwerke aus den Jahren nach der Vollendung des Parthenons, in: Bol 2004, 176 meint, ist m. E. nicht korrekt.

31 Kekulé 1894, 2. Er hielt die Schildkröte jedoch für eine Erfindung des Restaurators und setzt an ihre Stelle eine Gans in Anlehnung an die Zeichnung eines verschollenen Werkes (Kat. A13). Diese Statue ist jedoch die einzige mit einer Gans und zudem die Richtigkeit der Zeichnung nicht überprüfbar. Somit ist die von der späteren Forschung immer wieder angenommene Schildkröte auch unter Berücksichtigung der weiteren heute bekannten Werke mit diesem Attribut wahrscheinlicher. 
zianische Stücke im 17. Jahrhundert aus Griechenland dorthin gebracht worden sei ${ }^{32}$. Dass die Statue ein attisches Original sei, ist im Folgenden immer wieder angenommen worden: 1913 von A. Frickenhaus in einem Aufsatz zu der Aphrodite von Elis, 1950 von F. Brommer und 1951 von G. Becatti in ihren Untersuchungen zum Werk des Phidias, 1966 von C. Blümel im Katalog der klassischen Skulpturen der Berliner Museen sowie von S. Settis in seiner Monographie zur Aphrodite Urania, 1977 von M. Bieber in ihrem Werk zum antiken Kopienwesen, 1984 von E. B. Harrison in ihrem Aufsatz zu einem Marmorkopf, der vielleicht Aphrodite darstellt, um nur eine Auswahl zu nennen ${ }^{33}$. Dabei wurde häufig zugleich ein Bezug zu einer literarisch überlieferten Aphrodite Urania-Statue in Elis hergestellt, worauf ich später zurückkommen werde ${ }^{34}$. Auch M. Kunze und jüngst A. Scholl haben die These, die Statue stamme aus Attika, aufgegriffen ${ }^{35}$. M. Kunze wie auch Chr. Höcker und L. Schneider halten sie jedoch nicht für ein Original, sondern für eine kaiserzeitliche Kopie aufgrund von nicht entfernten Bearbeitungsspuren. Dies sind vor allem wenige nicht geglättete Bohrlöcher in einigen Gewandfalten an der linken Seite ${ }^{36}$. Dort wurden die kleinen Stege zwischen den einzelnen Ansätzen des Drillbohrers nicht weggemeißelt, während die übrige Oberfläche sorgfältig nachbearbeitet ist. Diese Spuren waren einst jedoch von der Stütze verdeckt und nicht zu sehen. Eine Abarbeitung war also nicht zwingend notwendig. Das Argument scheint mir deshalb nicht ausreichend, in der Statue eine Kopie zu sehen. Die ansonsten vorrangig mit dem Meißel und nicht mit dem Bohrer sehr sorgfältig bearbeitete Oberfläche mit ihren sanften Übergängen und der feinen, plastischen Differenzierung besonders der unterschiedlichen Stoffqualitäten weist auf ein griechisches Original hin ${ }^{37}$.

\subsubsection{Eine Aphroditestatuette aus Tarquinia}

Die unterlebensgroße Marmorstatuette aus Tarquinia in Berlin Kat. A2 wird in das letzte Jahrzehnt des 5. Jahrhunderts v. Chr. datiert. C. Blümel und M. Kunze ordneten sie aufgrund des Stils einer unteritalischen Werkstatt zu, die von der zeitgenössischen attischen Kunst beeinflusst worden $\operatorname{sei}^{38}$.

\footnotetext{
32 Kekulé 1894, 1 f. Er berief sich dafür zusätzlich auf eine nicht überprüfbare mündliche Überlieferung.

33 Frickenhaus 1913, 363; Brommer 1950, 83 f.; Becatti 1951, 208; Blümel 1966, 91 f. Nr. 109; Settis 1966, 19. 21; Bieber 1977, 94; Harrison 1984, 383 f.; M. Bauer, Aphrodite auf der Schildkröte, in: Stemmer 1995, 234 f. Ridgway 1981, 217 Nr. 5 hielt die Statue aufgrund des Stils hingegen für eine Kopie, die vielleicht wie viele weitere svenezianischer Statuen aus Kreta stamme.

34 s. Kap. 5.2.1.

35 Kunze 1992, 141 Nr. 48; Scholl 2001, 283.

36 Kunze 1992, 141 Nr. 48; Schneider - Höcker 1993, 112; ebenso M. Hagelberg, Nr. E9 „Aphrodite auf der Schildkröte“, in: Stemmer 2001, 87; vgl. hier Taf. 3, 3.

37 Vgl. z. B. die Erechtheionkoren und ihre augusteischen bzw. hadrianischen Kopien: E. E. Schmidt, Die Kopien der Erechtheionkoren, AntPl 13 (Berlin 1973); A. Scholl, Die Korenhalle des Erechtheion auf der Akropolis. Frauen für den Staat (Frankfurt a. M. 1998).

38 Blümel 1966, 99 Nr. 117; Kunze 1992, 141 Nr. 48.
} 
Aphrodite steht wie bei der zuerst beschriebenen Statue mit dem Gewicht auf dem gerade durchgedrückten rechten Bein. Der linke Fuß ist leicht vorgesetzt. Das Knie ist im Gegensatz zu der >Aphrodite Brazzàı nur leicht gebeugt. Der heute ergänzte - Fuß steht mit der gesamten Sohle auf dem Boden. Die ebenfalls ergänzte erhobene rechte Hand hat das über den Kopf gezogene Gewand gelüftet, wie an dem Faltenverlauf über der rechten Schulter zu sehen ist. Der linke Ellenbogen ist auf ein in Haltung, Gewanddrapierung und Frisur archaistisch gestaltetes weibliches Idol mit Polos gestützt. Die Stützfigur steht frontal in unbewegter Haltung neben der Göttin und rafft mit ihrer Linken das Gewand.

Die dargestellte Göttin ist wie die >Aphrodite Brazzà` vollständig bekleidet. Sie trägt einen gegürteten Chiton mit geknöpften Ärmeln und darüber ein Himation, das jedoch anders drapiert ist als bei jener. Der Mantel bedeckt von links kommend den aufgelehnten Arm und den Rücken. Er ist auch über den Hinterkopf gezogen. Anschließend ist er unter dem rechten Arm hindurch und vor dem Unterkörper entlang wieder nach links geführt, wo das andere Ende von dem aufgelehnten Arm gehalten wird. Der Mantel bedeckt die Beine, lässt jedoch den Oberkörper vorn frei.

\subsubsection{Ein Relief im Vatikan}

Bei der dritten frühen Darstellung handelt es sich um ein Fragment eines griechischen Marmorreliefs von unbekannter Herkunft im Vatikan (Kat. A3). Es zeigt eine stehende weibliche Figur, die sich mit dem linken Ellenbogen auflehnt. Das rechte Bein ist das Standbein, das linke ist gebeugt, der Fuß leicht zur Seite gestellt. Der Kopf und der rechte Arm sind nicht erhalten. Die Göttin trägt ein Untergewand und einen den Unterkörper und den Rücken bedeckenden Mantel, dessen Enden jeweils unter dem linken Arm festgesteckt sind.

Als Stütze dient dieser Figur eine weibliche Herme. Sie ist bekleidet und hat einen Polos auf dem Haupt wie die meisten der altertümlichen Idole. Unter dem archaistischen Schrägmantel drücken sich Brüste durch. Auch sind die Gesichtszüge weiblich und die Haare sind lang und fallen bis über die Ohren ${ }^{39}$. Die Stütze steht auf einer hohen Basis. Auf die Frage, wie eine solche weibliche Herme identifiziert und auch interpretiert werden kann, wird weiter unten einzugehen sein. Hier genügt der Hinweis, dass eine weibliche Herme in der antiken Kunst keinen

\footnotetext{
${ }^{39}$ Vgl. O. Benndorf - R. Schöne, Die antiken Bildwerke des Lateranischen Museums (Leipzig 1867) 342 Nr. 482; R. Lullies, Die Typen der griechischen Herme (Kaliningrad 1931) 55; H. K. Süsserott, Griechische Plastik des 4. Jahrhunderts vor Christus (Frankfurt a. M. 1938) 109 Anm. 80; Helbig I ${ }^{4}$ (Tübingen 1963) 719 Nr. 1001 (W. Fuchs); Harrison 1965, 139 Anm. 226; Delivorrias 1984, 10-12 Nr. 18; F. Sinn (Hrsg.), Reliefgeschmückte Gattungen römischer Lebenskultur. Griechische Originalskulptur. Monumente orientalischer Kulte, MAR 33 (Wiesbaden 2006) 49-51 Nr. 11.

Aphroditebilder mit männlichen Hermenstützen werden in Kap. 4 behandelt.
} 
Einzelfall darstellt, wenngleich sie auch nicht besonders häufig bezeugt sind ${ }^{40}$. Die Datierung des Werkes ist umstritten, die Forschung favorisiert allerdings die Datierung in das frühe 4. Jahrhundert v. Chr. ${ }^{41}$.

\subsection{Nachfolger der >Aphrodite Brazzàr}

\subsubsection{Vollständig bekleidete Darstellungen}

An die eben betrachteten Aphroditebilder, vorrangig die >Aphrodite Brazzà<, lassen sich aufgrund gleicher Haltungs- und Gewandmotive weitere Darstellungen der Göttin anschließen. Um eine Grundlage für die Frage nach dem zu vermutenden Original zu erhalten, werden zunächst die Beispiele betrachtet, die sich typologisch am engsten mit den eben beschriebenen Aphroditebildern verbinden lassen.

Das Haltungsschema mit dem vorgesetzten linken Bein und dem aufgelehnten linken Ellenbogen ist für mehrere, ebenfalls in Chiton und Himation gekleidete hellenistische und kaiserzeitliche Aphroditestatuen und -statuetten übernommen worden (Kat. A4-17). Von diesen werden Kat. A4. A6. A8. A15 in die Zeit des Hellenismus datiert, Kat. A5. A7. A9. A10. A13. A14 sind kaiserzeitlich. Kat. A11. A12. $A 16$ und $A 17$ können nicht genauer datiert werden. Die meisten Bilder sind kleinformatig. Bei Kat. A4. A6. A7. A12. A13 handelt es sich um unterlebensgroße Marmorstatuetten, Kat. $A 9$ und $A 15$ sind Terrakottastatuetten. Von größerem Format sind lediglich die beiden leicht unterlebensgroßen Marmorstatuen Kat. $A 10$ und $A 14$ sowie Kat. $A 8$, für die keine Angaben zum Material vorliegen ${ }^{42}$. Für Kat. A5. A11. $A 16$ und $A 17$ fehlen genaue Angaben zu Material oder Größe ${ }^{43}$.

Bei der Mehrzahl dieser Bilder (Kat. A4-8. A10. A12. A14) hat die Göttin den linken Fuß nach vorn und erhöht aufgesetzt, weshalb das Knie teils mehr, teils weniger stark gebeugt ist. Dies bewirkt, dass der Oberschenkel und das Knie betont in das Blickfeld des Betrachters gerückt werden. Im Zusammenhang mit dem Aufstützen des linken Armes und einer Verlagerung des Oberkörpers nach links führt dies dazu, dass die rechte Hüfte deutlich nach außen schwingt und die weiblichen Körperformen der Dargestellten betont zum Ausdruck gebracht werden. Zudem sind der Rücken durchgedrückt und die Schultern gestrafft, was wiederum die vorgestreckten Brustpartie hervorhebt. Die Haltung ist also sehr körperbetont.

\footnotetext{
40 s. Kap. 5.1.3.

41 O. Benndorf - R. Schöne, Die antiken Bildwerke des Lateranischen Museums (Leipzig 1867) 342 Nr. 482; EA 2226; Helbig I 4(Tübingen 1963) 719 Nr. 1001 (W. Fuchs); Delivorrias 1984, 11 Nr. 18; F. Sinn (Hrsg.), Reliefgeschmückte Gattungen römischer Lebenskultur. Griechische Originalskulptur. Monumente orientalischer Kulte, MAR 33 (Wiesbaden 2006) 49-51 Nr. 11.

Harrison 1965, 139 Anm. 226 hielt das Relief hingegen für die Arbeit einer neuattischen Werkstatt.

$42 \mathrm{Da}$ es sich um eine Statue handeln soll, wird sie am ehesten ebenfalls aus Marmor bestehen.

43 Kat. $A 5$ und $A 11$ bestehen aus Marmor, Kat. $A 17$ ist unterlebensgroß.
} 
Unter dem linken Fuß befinden sich verschiedene Objekte. Bei Kat. A7. A12 und $A 14$ ist es eine Schildkröte. Dies vermutet A. Delivorrias auch für Kat. $A 4$, allerdings ohne eine Begründung anzugeben ${ }^{44}$. Kat. $A 5$ setzt als einzige ihren linken Fuß auf eine Gans. Kat. A8 stellt ihn auf die Basis des Idols. Bei Kat. A6. A11 und $A 13$ ist die untere Partie zu sehr zerstört, um Aussagen zu dem Gegenstand unter ihren Füßen treffen zu können. Kat. A9. A10 und $A 17$ stellen den linken Fuß zwar vor, jedoch nicht auf eine Erhöhung. Bei Kat. A16 scheinen beide Füße auf einer Ebene zu stehen.

Die Arme sind selten erhalten und oft neuzeitlich ergänzt. Kat. A9 stützt die rechte Hand in die Hüfte. Der linke Unterarm war erhoben. Die heute abgebrochene Hand hat einen Teil des Gewandes empor gehalten, wie an dem Faltenverlauf zu erkennen ist. Bei Kat. A16 ist der rechte Arm quer vor dem Unterkörper entlang geführt. Die Hand ruht auf einem Teil ihres Gewandes, das über den Kopf des Idols gelegt ist. Der linke Ellenbogen ist auf die rechte Hand gestützt. Der linke Unterarm ist erhoben, die Hand ist nicht sicher zugehörig. Kat. 15 hält ein Füllhorn in der linken Armbeuge. Bei dieser Statuette ist der linke Arm jedoch nicht der aufgestützte, sie lehnt sich stattdessen mit dem rechten Arm auf die Basis eines kleinen weiblichen Idols. Das Schema der aufgelehnten Aphrodite ist hier also seitenvertauscht wiedergegeben ${ }^{45}$. Die kaiserzeitliche Marmorstatue Kat. A14 hält ebenfalls ein Füllhorn in der aufgestützten Linken. Sie ist dadurch in AphroditeTyche bzw. Venus-Fortuna verwandelt. Der rechte Arm ist gesenkt und am Ellenbogen gebrochen. Auch die Köpfe sind nur bei wenigen Darstellungen noch vorhanden. Die Blickrichtungen sind unterschiedlich. Die Göttinnen blicken sowohl mit leicht gesenktem Kopf nach rechts (Kat. A9. A15. A17) als auch nach links (Kat. A8. A14). Kat. A10 hat den Blick leicht nach oben erhoben.

Die Drapierung der Gewänder variiert. Allen gemeinsam ist, dass die Kleidung aus einem Chiton und einem Himation besteht. Der Chiton kann gegürtet als auch ungegürtet sein. Besonders eng mit der >Aphrodite Brazzàr zusammenschließen lassen Kat. A4-7. Ihr Chiton ist aufgrund ihrer späteren Entstehungszeit höher gegürtet als bei der älteren >Aphrodite Brazzàı, das Himation ist jedoch auf die gleiche Art drapiert wie bei dieser. Nur der Wulst, zu dem die Oberkante eingedreht ist, war bei der >Aphrodite Brazzàı noch nicht ausgeprägt. Das vordere Ende des Mantels kann sowohl links des vorgesetzten Beines herabfallen wie bei Kat. $A 4-A 6$. $A 12$ und $A 13$, als auch rechts wie bei Kat. $A 7$ und Kat. A14. Bei allen Beispielen reicht der Mantel bis zu den Unterschenkeln oder Knöcheln und damit weiter herab als bei der >Aphrodite Brazzàı. Auch bei der Aphrodite aus Tarquinia Kat. A2

\footnotetext{
${ }^{44}$ Delivorrias 1984, 45 Nr. 341. Ausschlaggebend war vermutlich die typologische Übereinstimmung mit der Aphrodite Brazzà Kat. A1 sowie die Überlegungen zur Aphrodite Urania, auf die ich in Kap. 5 noch eingehen werde.

45 Für die bei Winter 1903 aufgeführten Terrakottastatuetten ist nicht auszuschließen, dass sie seitenverkehrt abgebildet sind. Ein solcher Fehler ist z. B. bei S. 260 Nr. 10 unterlaufen.
} 
reicht der Mantel bis zu den Knöcheln.

Bei Kat. A8-10 ist der Mantelverlauf ähnlich, doch sind bei diesen beide Enden um den linken Arm gelegt. Bei Kat. A11 ist das vordere Ende des Mantels von der rechten Hüfte an schräg nach oben geführt und über die linke Schulter geschlagen und bedeckt so auch die linke Brust. Kat. A15 hingegen ist vollständig in ihren Mantel gehüllt, der zudem über den Kopf gezogen ist. Bei Kat. A16 ist der Mantel eng um den Körper geführt und das Ende über ihre linke Schulter und den Kopf des Idols gezogen. Nicht sicher zu bestimmen sind Details der Statuette Kat. A17, deren Material nicht bekannt und vielleicht Marmor ist. Sie scheint als einzige dieser Gruppe keinen Chiton unter dem bis auf die Füße reichenden Mantel zu tragen. Das Himation ist von ihrer linken Seite aus um ihren Rücken, anschließend unter dem rechten Arm hindurch und über ihre Brust zurück zu ihrer linken Seite geführt. Ein Stück des Mantels ist zusätzlich von hinten auf ihre rechte Schulter gelegt. Das Gewand fällt bis zum Boden ${ }^{46}$.

Das als Stütze dienende Idol ist bei allen Beispielen in gleicher Weise archaistisch gestaltet. Es ist allerdings nach unterschiedlichen Richtungen orientiert. Es kann frontal ausgerichtet sein wie bei Kat. A4. A9. A10. A12. A14, aber auch zur Seite gewendet sein bis hin zu einer Drehung um $90^{\circ}$ nach links bei Kat. $A 5$ und A13. Zumeist steht die kleine Stützfigur auf einer viereckigen oder runden profilierten Basis. Bei Kat. A10 steht das Idol auf einer kleinen Säule.

\subsubsection{Halbbekleidete Darstellungen}

Dreizehn weitere Aphroditedarstellungen der hellenistischen Epoche (Kat. A18-21. A23-31. A33) zeigen dieselbe Art des Sich-Auflehnens auf ein weibliches archaistisches Idol mit dem linken Unterarm. Sie unterscheiden sich von der vorherigen Gruppe dadurch, dass sie lediglich einen Hüftmantel tragen. Dazu zählen fünf Marmor- (Kat. A18. A19. A23. A24. A31) und neun Terrakottastatuetten (Kat. A20. A21. A25-30. A33). Eine kaiserzeitliche Marmorstatuette aus Kyrene (Kat. A22) lässt sich typologisch an diese anschließen. Sie lehnt sich jedoch wie Kat. A3 auf eine Herme. Allerdings ist bei dieser Statuette nicht genau feststellbar, ob die Herme männlich oder weiblich ist. Sie ist unbärtig und bekleidet, zeigt aber weder männliche noch weibliche Geschlechtsmerkmale. Der Typologie nach scheint es sich eher um eine weibliche Herme zu handeln. Die sicher weibliche Herme bei Kat. A3 zeigt auch einen bekleideten Oberkörper. Ebenfalls zu dieser Gruppe zu zählen ist die hellenistische Marmorstatuette Kat. A32, die sich auf einem profilierten Pfeiler lehnt, der als Basis einer nicht mehr vorhandenen Figur gedient hat ${ }^{47}$.

\footnotetext{
46 Die Beschreibung beruht allerdings auf einer wenig detailreichen Zeichnung des 19. Jahrhunderts, die mir als einzige Abbildung vorlag. Es ist gut deshalb möglich, dass die Kleidung vereinfacht dargestellt und der Chiton nicht erkennbar ist.

${ }^{47}$ H. Winnefeld, Bildwerke und Geräte aus Marmor, in: Th. Wiegand - H. Schrader, Priene. Ergebnisse der Ausgrabungen und Untersuchungen in den Jahren 1895-1898 (Berlin 1904) $370 \mathrm{f}$.
} 
Der linke Fuß ist, soweit erhalten, nach vorn gesetzt. Bei Kat. A18-28 und A31-33 ist er zusätzlich auf eine Erhöhung gestellt. Dafür wird oft ein nicht näher definierbarer Gegenstand und bei Kat. A20. A25. A32 sowie A33 die Basis des Idols benutzt, während bei Kat. $A 24$ und möglicherweise auch bei Kat. $A 19$ wieder eine Schildkröte unter dem Fuß zu sehen ist ${ }^{48}$. Es ist ein rundlicher, anhand der Abbildungen nicht näher zu bestimmender Gegenstand, bei dem der sich rechts des Fußes von Kat. A24 befindliche Teil möglicherweise der Kopf des Tieres ist. Sicher auf eine Schildkröte tritt der Fuß der Marmorstatuette Kat. A22.

Uneinheitlich ist die Haltung des rechten Armes. Einige Figuren strecken ihn gesenkt nach vorn wie Kat. A18, zumeist ist er aber mehr oder weniger ausgestreckt erhoben (Kat. A23-27). Kat. A31 hält ihn gesenkt und Kat. A21 angewinkelt nach vorn erhoben. Nur selten sind Attribute erhalten. Für die erhobene Hand bei Kat. A23-A27 würde sich ein Szepter anbieten, wie die Göttin es z. B. bei Darstellungen des Parisurteils hält ${ }^{49}$. Ansonsten hält Aphrodite oft Spiegel, Ölfläschchen, Blumen oder Vögel ${ }^{50}$. Kat. A18 hält ein kleines rundes Objekt in der linken Hand, wahrscheinlich eine Kugel oder einen Apfel. Das gleiche Objekt findet sich auch bei Kat. A36. Kat. A21 trägt auf dem aufgelehnten linken Arm einen kindlichen Eros mit großen Flügeln. Die Blickrichtungen der Göttinnen variieren.

Alle Dargestellten tragen einen Hüftmantel, dessen Drapierung mit kleinen Varianten typologisch der der vorher beschriebenen Bilder entspricht. Eine Variante des halbbekleideten Typus zeigt Kat. A33. Die Göttin hebt hier im Gegensatz zu den anderen Darstellungen den Mantel mit der rechten Hand hinter dem Rücken empor. Dieser bläht sich dabei wie eine Folie hinter der Göttin. Das eine Ende des Mantels ist wieder um den aufgelehnten linken Arm gelegt, das andere zwischen ihren Beinen festgeklemmt. Der Körper wird dadurch fast nackt präsentiert. Nur das rechte Bein und der linke Arm sind von dem Stoff bedeckt.

\subsubsection{Variante mit übergeschlagenem Bein}

Einige ebenfalls vollständig bekleidete Darstellungen der Aphrodite variieren die eben beschriebenen Merkmale der Körperhaltung und Gewanddrapierung (Kat. A34-43). Kat. A34 ist eine hellenistische Marmorstatuette, die anderen Darstellungen gehören der Gattung der Terrakottastatuetten und der hellenistischen Epoche an, soweit sie datierbar sind (Kat. A35. A40. A41. A42). Da in der Kaiserzeit kaum noch Terrakottastatuetten hergestellt wurden ${ }^{51}$, ist die Datierung auch der anderen in die Zeit des Hellenismus wahrscheinlich.

\footnotetext{
48 Auch Delivorrias 1984, 65 Nr. 553 sieht in dem Objekt unter dem linken Fuß von Kat. A24 eine Schildkröte.

$49 \mathrm{Zu}$ diesen Darstellungen vgl. Anm. 310.

$50 \mathrm{Vgl}$. dazu Delivorrias 1984.

${ }^{51}$ Einige kaiserzeitliche Terrakottastatuetten stammen aus den Gräbern von Myrina wie die in Kap. 3.2.1. genannte Kat. A9. Zu den Funden von Myrina allgemein s. Reinach - Pottier 1887.
} 
Der Hauptunterschied zu den bisher betrachteten Aphroditebildern liegt darin, dass die Göttin bei Kat. A34-43 das Spielbein vor das Standbein kreuzt und bei dem Spielbeinfuß nur mit den Zehen auftritt. Sie lehnt sich bei allen Beispielen auf ein weibliches archaistisches Idol, dass bei Kat. $A 34-A 40$ und $A 43$ zu ihrer linken Seite steht und bei Kat. $A 42$ zu ihrer rechten. Die Haltung des jeweils anderen Armes variiert. Kat. A34 hat die Hand auf die Brust gelegt, Kat. A35. A40 und A41 stützen die Hand in die Hüfte, Kat. A36-A39 haben den Arm auf den Rücken gelegt. Auch die Blickrichtungen sind verschieden, soweit die Köpfe erhalten sind. Kat. A35-A37 blicken geradeaus, Kat. A38. A40 und A41 nach links, Kat. $A 39$ gesenkt nach rechts. Bei Kat. $A 34$. $A 35$ und $A 41$ trägt die Göttin einen Chiton und ein Himation, bei Kat. A36. A40 und $A 42$ offenbar nur den Mantel. Bei Kat. A35. A39. A41 verdeutlicht ein kleiner Eros, dass es sich um Darstellungen der Aphrodite handelt.

Ein in seinen Details singuläres Bild stellt die aufgrund des Gewandstiles der aufgelehnten Aphrodite wahrscheinlich noch in die erste Hälfte des 4. Jahrhunderts v. Chr. zu datierende Terrakottastatuette Kat. A43 dar. Sie zeigt eine vollständig in einen Chiton und einen Mantel gehüllte Aphrodite, deren Körperformen sich sehr deutlich unter den Gewändern abzeichnen. Sie steht auf ihrem rechten Bein und hat das linke darüber geschlagen. Sie stützt die rechte Hand in die Hüfte und lehnt sich mit dem erhobenen linken Ellenbogen auf eine Stütze. Der Kopf ist nicht erhalten. Als Stütze dient diesmal nicht das Idol direkt, sondern ein kleiner Tempel ionischer Bauordnung. Darin steht ein weibliches Idol mit einem Polos auf dem Kopf. Vor dem Tempel steht ein Altar, der anzeigt, dass es sich hier um die Darstellung eines $>$ Kultbildes ${ }^{52}$ handelt. Dieses Beispiel wird für die Interpretation des Idols wie des gesamten Bildmotivs noch wichtig werden.

\subsubsection{Weitere Veränderungen und andere Körpertypen}

Weitere Darstellungen zeigen Aphrodite ebenfalls auf ein weibliches, altertümlich gestaltetes Idol gelehnt, unterscheiden sich von den zuvor betrachteten Bildern jedoch durch stärker geänderte Haltungs- und Gewandmotive bzw. durch die Verwendung anderer Körpertypen für die aufgelehnte Figur.

Die Terrakottagruppe Kat. A44 aus dem 4. Jahrhundert v. Chr. ist das einzige Beispiel, bei dem zwei Figuren nebeneinander stehen. Deshalb wurde sie nicht unter die Varianten der >Aphrodite Brazzàı eingereiht, wenn auch der Körpertypus der vom Betrachter aus linken Figur diesem weitgehend entspricht. Diese lehnt sich mit dem Ellenbogen auf den links von ihr stehenden Pfeiler mit dem Idol auf, während die rechte ihren Ellenbogen auf die Schulter der ersten stützt. Die linke Figur setzt ihr linkes Bein im gewohnten Schema nach vorn. Die rechte Figur

3.2.1. genannte Kat. A9. Zu den Funden von Myrina allgemein s. Reinach - Pottier 1887.

$52 \mathrm{Zu}$ diesem Begriff s. Kap. 11. 
überkreuzt die Beine und hält einen Spiegel in der gesenkten rechten Hand. Beide tragen einen Chiton und einen Mantel. Die Identifizierung der Figuren ist nicht sicher. Der Spiegel und der von der Schulter gerutschte Chiton bei der rechten Person und das Auflehnen auf die Basis des Idols, wie sonst auch bei Aphrodite, bei der linken Figur sowie die sich unter den Gewändern abzeichnenden Körper lassen aber an den aphrodisischen Kreis denken.

Bei zwei weiteren Bildern, die Aphrodite aufgelehnt zeigen, lehnt sich die Göttin nicht mit dem Ellenbogen oder Unterarm auf, sondern mit der rechten Hand (Kat. A45. A46). Der Arm ist dabei durchgestreckt. Die Körperhaltung ist dadurch verändert. Die gesamte Figur beschreibt eine Kurve in Richtung der Stütze. Auf der späthellenistischen Reliefschale Kat. A45 ist die Stütze ein Altar, auf dem eine kleine Figur steht und bei der kaiserzeitlichen Münze aus Thespiai Kat. A46 eine kleine weibliche Figur. Die Göttin trägt bei Kat. A46 einen Chiton und ein Himation, bei Kat. A45 hingegen vielleicht nur einen Hüftmantel.

Einer Terrakottastatuette einer Aphrodite beim Bade ist ebenfalls ein Idol beigegeben (Kat. A47). Die Göttin ist unbekleidet, nur die Haare sind in ein Tuch eingebunden. Ihr Kopf ist leicht nach rechts gesenkt. Sie steht im Kontrapost mit dem Gewicht auf dem rechten Bein. Der linke Unterarm ist auf einen hohen Pfeiler gelegt, vor dem reliefartig ein kleines Idol steht. In der Rechten hält sie ihr Gewand über eine Vase, wie es z. B. auch kaiserzeitliche Kopien der Aphrodite von Knidos zeigen $(A b b .1)^{53}$. Ein kleiner Eros schaut hinter ihrer linken Schulter hervor.

Auch eine sandalenlösende Venus ${ }^{54}$, eine kaiserzeitliche Marmorstatuette aus der Villa von Oplontis (Kat. A48) lehnt mit dem linken Arm auf einem archaistischen Idol, während sie mit der rechten Hand mit ihrer linken Sandale nestelt. Ein kleiner geflügelter Eros stützt den erhobenen linken Fuß. Die Göttin schaut nicht auf ihre Handlung, sondern wendet den Kopf nach rechts. Sie ist vollständig nackt.

Der sitzenden Terrakottastatuette Kat. A49 ist ebenfalls ein weibliches archaistisches Idol beigegeben. Das genaue Verhältnis beider Figuren muss allerdings aufgrund der nicht sehr deutlichen Umzeichnung, durch die die Statuette publiziert ist, unbestimmt bleiben. Die halbbekleidete Göttin sitzt auf einem Felsen und lehnt sich leicht nach hinten in Richtung des Idols, das auf einem Vorsprung des Felsens steht. Hinter dem Felsen schaut ein geflügelter Eros hervor. Am Fuß des Felsens liegt eine Muschel. Die Göttin trägt einen Hüftmantel, der in ihrem Schoß durch einen Knoten gehalten wird. Der Oberkörper ist entblößt. Die Beine sind übereinander geschlagen. Beide Unterarme sind angewinkelt und erhoben, den rechten Arm hält die Göttin etwas höher als den linken. S. Reinach hat die Armbewegung

\footnotetext{
53 Rom, Vatikanische Museen Inv. 812: Rizzo 1931, 45-59 Taf. 70-88; Fuchs 1969, 217 f. Abb. 234; B. Vierneisel-Schlörb (Hrsg.), Glyptothek München. Katalog der Skulpturen II. Klassische Skulpturen des 5. und 4. Jahrhunderts v. Chr. (München 1979) 323-352 Abb. 158-164; Delivorrias 1984, 49-52 Nr. 391-408; Ridgway 1997, 263-265 Taf. 66 f.; Maderna 2004, 328-330 Abb. 297-300.

54 Zu dem Typus der Sandalenlöserin vgl. Künzl 1970.
} 
als Parfümeingießen gedeutet ${ }^{55}$, die Armbewegung des Idols ist nicht zu bestimmen.

Auch bei einer weiteren auf einem Felsen gelagerten hellenistischen Terrakottastatuette mit neuzeitlichem Kopf (Kat. A50), die ihren linken Arm auf einen Pfeiler legt, vermutet S. Mollard-Besques eine kleine Figur auf der Stütze. Sie spricht von einem archaistischen Idol oder einem Priapos ${ }^{56}$. Die Göttin ist ausgestreckt auf einem Felsen gelagert. Unter sich hat sie ihren Mantel ausgebreitet, der auch ihr rechtes Bein bedeckt. Das unbedeckte linke Bein hat sie darüber geschlagen. Der rechte Arm ruht in ihrem Schoß. Der linke Unterarm ist abgebrochen.

Bei einem weiteren Beispiel mit einer möglicherweise weiblichen bekleideten Herme, einem Bild auf einer spätklassischen apulisch-rotfigurigen Amphora in Neapel (Kat. A51) sitzt Aphrodite auf einem würfelförmigen Sitz und hat den linken Ellenbogen auf den Kopf der Herme gelegt. Die Göttin trägt einen durchscheinenden Chiton, einen Mantel und reichen Schmuck. Ihre rechte Hand ruht in ihrem Schoß und hält ein rundes Objekt. Die linke ist erhoben, der Daumen und die Finger sind im Redegestus gespreizt. Sie hat den Blick der links von ihr stehenden Figur zugewendet. Die Herme steht auf einer zweistufigen Basis. Der stabartige Gegenstand auf der Basis ist nicht identifizierbar. Die auf eine ikonische Stütze gelehnte Aphrodite ist hier erstmals Teil einer größeren, mehr als zwei Figuren umfassenden Komposition, die als Darstellung der Entführung des Chrysippos durch Laios gedeutet wird, was allerdings nicht zweifelsfrei durch Beschriften bestätigt wird ${ }^{57}$.

\subsection{Nicht sicher zuzuordnende Idole}

Einige weitere Fragmente von Terrakottastatuetten zeigen nur das Stützidol, die einst auf sie gelehnte Figur ist nicht erhalten (Kat. A52a-e). In Kleidung und Haartracht sind sie den anderen Stützidolen vergleichbar und ebenfalls archaistisch gestaltet. Auf dem Kopf tragen die Figuren einen Polos. Bei Kat. A52a ist nur der Oberkörper erhalten, Kat. A52b-d sind nahezu vollständig. Bei Kat. A52e fehlt der Kopf und auch die Füße sind abgebrochen.

Bei Kat. A52b-d sieht man an der rechten Seite des Idols - genauer gesagt bei Kat. $A 52 b$ an der Schulter, bei Kat. $A 52 c$ am rechten Unterschenkel sowie bei Kat. A52d an der gesamten rechten Seite - noch Ansätze einer weiteren Figur. Dies sind Teile von Gewändern, die zur Bekleidung der aufgelehnten Figur gehört haben müssen. Besonders deutlich wird dies bei Kat. A52d, bei der das Gewand ein-

\footnotetext{
55 Reinach - Pottier 1887, 275 Nr. 45. Es bleibt allerdings unklar, warum die Göttin diese Tätigkeit im Freien auf einem Felsen sitzend ausüben soll.

56 Mollard-Besques 1972, 76 Taf. 101b.

57 C. Robert, Chrysippos and Antigone auf apulischen Vasen, JdI 29, 1914, 170 f. Abb. 2; A. D. Trendall - A. Cambitoglu, The Red-Figured Vases of Apulia II. Late Apulian (Oxford 1982) 498 Nr. 48; Delivorrias 1984, 11. 142 Nr. 17. 1494. Zu dem Mythos s. Apollod. 3, 5, 5.
} 
deutig zu einer im Vergleich zu dem Idol wesentlich größeren Figur gehört. Eine Rekonstruktion der Idole als Stützfigur ist wahrscheinlich, jedoch nur bei Kat. $A 52 b-d$ zu beweisen. Ob es sich allerdings bei der aufgelehnten Figur um Aphrodite gehandelt hat, muss offen bleiben, da sich auch andere Götter und auch Menschen auf weibliche Idole auflehnen, wofür im Verlauf dieser Arbeit noch Beispiele angeführt werden ${ }^{58}$.

\subsection{Zusammenfassung}

Es lässt sich feststellen, dass auf ikonische Stützen gelehnte Aphroditedarstellungen fast nur als Einzelfiguren vorkommen. In einem größeren Zusammenhang ist das Motiv nur zwei Mal verwendet worden, zum einen bei der spätklassischen Terrakottastatuette Kat. A44, bei der zwei weibliche Figuren zu einer Gruppe kombiniert worden sind, und zum anderen bei der ebenfalls spätklassischen rotfigurigen Vase aus Ruvo mit einer szenischen Darstellung (Kat. A51). Die meisten Beispiele stammen aus der Rundplastik und dort vorrangig aus der Kleinplastik. Vier Marmorstatuen (Kat. A1. A8. A10. A14), siebzehn Marmorstatuetten ${ }^{59}$ und dreiundzwanzig Terrakottastatuetten ${ }^{60}$ stehen einem Marmorrelief (Kat. A3), einer Reliefschale (Kat. A45), einem Vasenbild (Kat. A51) und einer Münze (Kat. A46) gegenüber.

Wie schon lange gesehen wurde, ist der Typus zum ersten Mal in der 2. Hälfte des 5. Jahrhundert v. Chr. verwendet worden. Aus dieser Zeit haben sich mit der Statue Kat. A1 ein großplastisches und mit der Statuette Kat. A2 ein kleinformatiges Beispiel erhalten. Das Relief Kat. A3 stammt vom Anfang des 4. Jahrhunderts v. Chr., die Terrakottastatuetten Kat. A43 und $A 44$ sind ebenfalls im 4. Jahrhundert v. Chr. entstanden. Spätklassisch ist die apulische Amphora Kat. A51. Besonders häufig tritt der Typus seit dem Hellenismus, vor allem in der Kleinkunst auf. Aus dieser Zeit konnten neun Marmorstatuetten ${ }^{61}$, vierzehn Terrakottastatuetten $^{62}$ und eine Reliefschale (Kat. A45), jedoch nur eine Marmorstatue (Kat. A8) nachgewiesen werden, zu der jedoch keine genauen Größenangaben vorliegen. Weitere großplastische Beispiele, die in der Tradition des Typus stehen, sind aus der Kaiserzeit überliefert (Kat. A10. A14). In die Kaiserzeit werden nur vier Marmorstatuetten (Kat. A7. A13. A22. A48) und eine Münze (Kat. A46) datiert. Entsprechend dem allgemeinen Rückgang der Terrakottenproduktion in dieser Zeit lässt sich nur ein Beispiel finden (Kat. A9).

\footnotetext{
${ }^{58}$ s. Kap. 6.3 und 8.

${ }^{59}$ Kat. A2. A4. A6. A7. A12-A14. A18. A19. A22-24. A31. A32. A34. A48, wahrscheinlich auch $A 17$.

${ }^{60}$ Kat. A9. A20. A21. A25-30. A33. A35-44. A47. A49. A50.

${ }^{61}$ Kat. A4. A6. A18. A19. A23. A24. A31. A32. A34.

${ }^{62}$ Kat. A15. A20. A21. A25-A30. A36. A40. A41. A42. A50.
} 
Der Typus der auf eine weibliche Figur aufgelehnten Aphrodite ist nach Ausweis der hier vorliegenden Beispiele in der Großplastik erfunden worden. Die meisten Aphroditebilder, die in der ikonographischen Tradition des Typus stehen, gehören jedoch der Kleinkunst an. Sie zeigen, dass seit dem 4 Jahrhundert v. Chr. bis in die Kaiserzeit hinein ein großes Interesse an dem Motiv bestanden hat. Die Übernahme beliebter Typen und Motive aus der Großplastik in die Kleinkunst und vor allem in die massenhaft hergestellte Terrakottaplastik war ein verbreitetes Phänomen ${ }^{63}$. Aus den zahlreichen nur leicht variierenden Repliken lässt sich auf ein Urbild zurückschließen, das typologisch der >Aphrodite Brazzàı entspricht. Der Typus wurde im Laufe der Zeit verändert. So wird bei vielen hellenistischen Varianten z. B. der Chiton fortgelassen (Kat. A18-33), entsprechend der allgemeinen Entwicklung, Aphrodite zunehmend unbekleidet zu zeigen ${ }^{64}$. Die aufgelehnte Haltung kam dem entgegen, da sie eine Möglichkeit bot, den Körper in einer erotischkörperbetonten Haltung darzustellen. Das ist sicherlich einer der Gründe für die Beliebtheit des Typus in dieser Zeit. So ließ sich auch eine gänzlich unbekleidete Darstellung in der Kleinplastik finden (Kat. A47). Doch auch bei den frühen, vollständig bekleideten Aphroditebildern fehlt die erotische Charakterisierung nicht, denn bei diesen drücken sich die Körperformen durch den Stoff durch, bei einigen ist zudem der Chiton von der Schulter gerutscht und entblößt zumindest einen Teil des Körpers (A1. A5. A9. A16. A17).

Bei anderen Werken, und zwar vorrangig in der Kleinkunst, hat man nur auf einzelne Merkmale des Typus zurückgegriffen. Es entstanden mehr oder weniger starke Abweichungen und auch Vermischungen mehrerer Typen. Zu den Variationen zählt z. B. das Überkreuzen der Beine, wobei der linke Fuß nur mit der Fußspitze auftritt. Es ergibt sich eine insgesamt labilere und schräger angelehnte Körperhaltung (Kat. A33-43). Bei zwei weiteren Darstellungen stützt sich die Figur nicht mit dem Ellenbogen oder Unterarm, sondern mit dem ausgestreckten Arm auf, so dass der gesamte Körper eine Kurve in Richtung der Stütze beschreibt (Kat. A45. A46). Stärker von der ursprünglichen Erfindung entfernen sich die Darstellungen, bei denen Motive anderer Typen übernommen wurden. Kat. A33 hebt ihr Gewand wie die Aphrodite Fréjus ${ }^{65}$. Kat. A48 verbindet das Motiv der sandalenlösenden Aphrodite mit einem weiblichen Idol als Stütze und Kat. A47 zeigt eine Aphrodite beim Bade. Kat. A49-51 stellen die Göttin sitzend dar.

Darüber hinaus wurde bei weiteren Darstellungen der Göttin auch die Form der Stütze verändert. Außer auf weibliche Idole und Hermen sowie auf männliche Stützfiguren, die im folgenden Kapitel betrachtet werden, lehnt sich Aphrodite

\footnotetext{
63 Zanker 1998, 15. 92. Um nur einige Beispiele zu nennen: Nachbildungen des Diadumenos, des Apollon Lykeios und der knidischen Aphrodite; s. Bieber 1955 Abb. 7 f. 20.26.

${ }^{64}$ Seit dem 4. Jahrhundert v. Chr. konnte die Göttin sogar gänzlich unbekleidet dargestellt werden, wie die Aphrodite von Knidos (Abb. 1) zeigt. Zu dieser Statue s. Anm. 53.

${ }^{65}$ Vgl. Anm. 384.
} 
auch auf Pfeiler, Säulen oder Baumstämme, wobei diese Darstellungen auch die übrigen Veränderungen wie den unbekleideten Oberkörper, die überkreuzten Beine und die variierten Arm- und Kopfhaltungen aufgreifen. Da in der 2. Hälfte des 5. Jahrhunderts v. Chr. mehrere aufgelehnte Aphroditetypen mit Pfeiler- oder Baumstammstütze und anderen Körperhaltung entstanden sind ${ }^{66}$ und viele der zumeist hellenistischen und kaiserzeitlichen kleinformatigen Darstellungen einerseits Merkmale dieser Typen wie auch des hier untersuchten Aphroditetypus aufnehmen, ist eine eindeutige Typenzuordnung oft nur schwer möglich. Sie soll hier auch nicht versucht werden, da es hier nicht um aufgelehnte Aphroditedarstellungen im Allgemeinen, sondern um solche mit ikonischen Stützen geht ${ }^{67}$. Für die Interpretation des hier betrachteten Typus sind diese Darstellungen jedoch wichtig, weshalb ich dort noch einmal auf sie zurückkommen werde ${ }^{68}$.

In der Kleinkunst bietet sich also ein reiches Bild an Varianten, sowohl in der Körperhaltung als auch in der Gewanddrapierung, und zwar über das Zitieren lediglich einzelner Merkmale oder das Ergänzen verschiedener Attribute bis hin zu Neukombinationen verschiedener Typen.

${ }^{66}$ s. Kap. 6.1.

${ }^{67}$ Eine detaillierte Zusammenstellung mit Typenzuweisung bei Delivorrias 1984, 27-33. 43-45. 67. 69-71.

${ }^{68}$ s. Kap. 7.2.2. 


\section{Aphroditebilder mit männlichen Stützfiguren}

Aphrodite ist in der Antike nicht nur auf weibliche Idole und Hermen gelehnt dargestellt worden. Nicht ungewöhnlich als Stütze, vor allem im Bereich der Kleinkunst sind auch Priaposfiguren und -hermen. Darüber hinaus sind Hermaphrodit, Eros, Dionysos und Pan unter den männlichen Stützfiguren identifizierbar. Sie werden im Folgenden getrennt nach den Stützfiguren betrachtet. Hermen, die keine Attribute aufweisen und deshalb nicht sicher benannt werden können, werden anschließend untersucht.

Von den hier betrachteten Darstellungen werden die Spiegelform Kat. A107, der Krater Kat. A108 und die Terrakottastatuette Kat. A109 in die klassische Zeit datiert. Alle anderen Bilder sind in der Zeit des Hellenismus und der Kaiserzeit entstanden. Die überwiegende Mehrzahl der Darstellungen gehört der Kleinkunst und vor allem der Gattung der Terrakottastatuetten an ${ }^{69}$. Bei Kat. A53. A57. A70. A71. A89. A91. A92. A95. A100. A104. A111. A120 handelt es sich um Marmorstatuetten, bei Kat. A67. A72-74. A76. A93. A101. A117 um Kleinbronzen, bei Kat. $A 54$ um eine Elfenbeinstatuette, bei Kat. $A 75$ um eine Silbernadel und bei Kat. A55. A56. A58. A59. A66. A82. A98 und A114 um Gemmen oder Glaspasten. Erhalten haben sich außerdem je ein Beispiel in der Wand- (Kat. A96) und Vasenmalerei (Kat. A108), ein Marmorrelief (Kat. A115), ein Sarkophag (Kat. A106) und eine Spiegelform aus Terrakotta (Kat. A107). Mir ist nur eine großplastische Darstellung bekannt, eine unterlebensgroße kaiserzeitliche Statue mit einer unidentifizierbaren männlichen Herme (Kat. A121).

Die Identifizierung der Aufgelehnten als Aphrodite fällt oft leichter als bei den Bildern mit weiblichen Stützfiguren. Zumeist sind die Dargestellten halb- oder sogar ganz unbekleidet. Viele Beispiele zeigen die Göttin zudem in der Haltung der Sandalenlöserin (Kat. A57-59. A70-76. A93. A116. A117), der Anadyomene (Kat. A55.

${ }^{69}$ Kat. A60-65. A68. A69. A77. A78. A80. A83-A88. A90. A94. A97. A99. A102. A103. A105. A109. A110. A112. A113. A116. A118. 119. 
A60-62. A77-81. A105. A119) oder im Pudica-Gestus (Kat. A82. A115), also Typen, die die Identifizierung als Aphrodite ermöglichen. Oftmals wird sie auch von einem kleinen Eros begleitet (Kat. A56. A57. A59. A60. A62. A71. A83-85. A94. A115. A118). Auch weitere Attribute wie das Badegefäß bei Kat. $A 98$ oder der Kontext wie auf dem apulisch-rotfigurigen Krater Kat. A108 ermöglichen die Identifizierung.

Für die Stütze ist bei den Ganzkörperfiguren durch Attribute und typische Haltungsmotive - z. B. dem vorgeschobenem Becken, dem leicht nach hinten gebogenem Rücken und dem Heben des Schurzes bei Priapos - eine Identifizierungsmöglichkeit gegeben. Die Identifizierung der Stützhermen ist oftmals schwieriger. Unter die jeweiligen Götter habe ich auch diejenigen Beispiele eingeordnet, die von der Forschung entsprechend identifiziert werden. Die Hermen meinen ganz sicher eine Statue des jeweiligen Gottes und nicht den lebendigen Gott. Von den Bildern mit Ganzkörperfiguren als Stütze habe ich nur diejenigen aufgenommen, bei denen die Stützfigur durch den geschlossenen Stand, eine Basis und/oder kleineres Format als Statue gekennzeichnet ist. Gerade bei Eros ist das letzte Kriterium jedoch nicht eindeutig. Die zahlreichen Bilder mit kleinen Eroten, die eine Handlung und damit den lebendigen Gott zeigen wie bei einer hellenistischen Terrakotte aus Myrina (Abb. 2) $)^{70}$ sind deshalb nicht aufgenommen.

\subsection{Priapos}

Eine späthellenistische, vollständig von einem eng um ihren Körper geschlungenen Mantel eingehüllte stehende Marmorstatuette lehnt sich an eine ebenfalls mit einem Mantel bekleidete Ganzkörperfigur des Priapos, die auf einer hohen profilierten Rundbasis steht (Kat. A53). Die Göttin steht auf dem rechten Bein und überkreuzt dieses mit dem linken, wie schon einige der Aphroditebilder mit weiblichen Idolen als Stütze (Kat. A34-43). Ihr rechter Arm war angewinkelt vorgestreckt, der linke lag auf dem Kopf des Priapos. Der nicht erhaltene Kopf war dem Ansatz nach leicht nach rechts geneigt. Eine weitere späthellenistische Aphroditestatuette aus Elfenbein lehnt sich mit dem linken Unterarm auf eine Ganzkörperdarstellung des Priapos, der mit beiden Händen sein Gewand hebt (Kat. A54). Er steht nicht auf einer Basis. Der statuenhafte Stand mit geschlossenen Beinen erlaubt aber, die Figur hier einzureihen. Aphrodite steht mit dem Gewicht auf dem rechten Bein, das linke ist gebeugt. Sie trägt einen Hüftmantel wie die Aphroditebilder mit den weiblichen Stützidolen. Auch zwei kaiserzeitliche Gemmen zeigen Aphrodite einer Ganzkörperfigur des Priapos als Stütze. Die Göttin ähnelt bei Kat. A55 im Standmotiv der vorigen, ist allerdings unbekleidet. Der rechte Arm ist zum Kopf geführt. Sie wendet den Blick nach links. Auf der zweiten Gemme

\footnotetext{
70 Paris, Louvre Inv. MYR 48: Delivorrias 1984 Nr. 586. Weitere Beispiele bei Mollard-Besques 1963,
} 30. 33 Taf. 32d. 33b. e. 36a; Delivorrias 1984, 67 f. Nr. 581-585. 
(Kat. A56) steht die Göttin mit überkreuzten Beinen da. Sie hat den rechten Arm gesenkt. Der linke ruht auf der Schulter des Priapos. Aphrodite ist unbekleidet und hat den Kopf nach rechts ins Profil gewandt. Sie wird von einem Eros begleitet, der einen Spiegel zu ihr empor hält.

Eine weitere, unbekleidete Priapos-Ganzkörperstatue auf einer hohen runden Basis wird von einer kaiserzeitlichen sandalenlösenden Marmorstatuette aus Pompeji als Halt benutzt (Kat. A57). Sie lehnt sich mit dem linken Arm auf seinen Kopf, während sie mit der Rechten an ihrer Sandale nestelt. Der erhobene Fuß wird von einem puttenhaften kleinen Eros gestützt. Die Göttin blickt geradeaus. Sie trägt reichen, in Goldauflage angegebenen Schmuck. Dasselbe Motiv zeigen auch zwei kaiserzeitliche Gemmen (Kat. A58. A59). Auf beiden ist eine unbekleidete, nach rechts ins Profil gewandte Aphrodite mit dem Lösen ihrer rechten Sandale beschäftigt. Dabei stützt sie sich mit der rechten Hand auf dem Kopf einer unbekleideten (Kat. A58) bzw. einer bekleideten (Kat. A59) Priaposfigur ab. Hinter Aphrodite fliegt bei Kat. A59 ein kleiner Eros mit einem Kranz heran, auf der Gemme Kat. A57 sind außer zwei Götterköpfen noch Sternsymbole angegeben.

In dem Terrakottanaiskos Kat. A60 ist einer halbbekleideten Anadyomene ein Priapos unter den rechten Arm gestellt, der sein Gewand hebt. Die Göttin steht im Kontrapost mit dem Gewicht auf dem durchgestreckten linken Bein. Sie hat beide Arme angewinkelt erhoben und ist mit ihrem Haar beschäftigt. Sie trägt einen im Schoß geknoteten Hüftmantel. Begleitet wird sie von zwei Eroten. Bei Bildern der Aphrodite Anadyomene kommen Priaposfiguren öfter vor. Sie sind jedoch oft so klein gebildet, dass sie dem erhobenen Arm keine Stütze bieten können wie bei den Terrakottastatuetten Kat. A61a-b und A62. Die inhaltliche Bedeutung der Begleitfigur ist jedoch als gleich anzusehen. Bei diesen Beispielen trägt Aphrodite einen vorn geknoteten Hüftmantel, wie er auch sonst beim Anadyomenetypus manchmal vorkommt ${ }^{71}$.

Häufiger als Priapos-Ganzkörperfiguren dienen Priaposhermen bei hellenistischen und kaiserzeitlichen Darstellungen als Stütze. Alle Beispiele sind kleinformatig. Aphrodite kann sowohl vollständig bekleidet (Kat. A63), halbnackt (Kat. A64 66) als auch gänzlich entblößt auftreten (Kat. A67). Bei den bekleideten Beispielen ist der Hüftmantel wieder in der bekannten Art um den Unterkörper geführt (Kat. A63. A64, abgewandelt bei A65. A66, wo die Kante zwischen den Beinen der Göttin hinab fällt). Die Herme kann links platziert sein wie bei Kat. A63. A66. A67, aber auch rechts wie bei Kat. A64 und A65. Die Göttin steht jeweils mit dem Gewicht auf dem einen Bein. Das andere, auf dessen Seite die Herme steht, ist gebeugt. Kat. A64 und A65 setzen zusätzlich den Fuß des Spielbeins auf die Basis der Herme. Je nach Höhe der Herme lehnt sich Aphrodite mit der Hand

${ }^{71}$ Vgl. Delivorrias 1984, 76 f. Nr. 667-687. 
4. Aphroditebilder mit männlichen Stützfiguren

oder dem Unterarm auf. Der andere Arm kann ausgestreckt sein (Kat. A63. A66), locker auf der Hüfte liegen (Kat. A64) oder in die Hüfte gestemmt sein (Kat. A65).

Aphrodite kann sich auch im Zuge des Be- oder Entkleidens auf eine Priaposherme lehnen. Bei den späthellenistischen Terrakottastatuetten Kat. A68 und A69 bindet sich die stehend wiedergegebene Göttin ein Busenband um, dessen eines Ende sie mit der linken Hand vor der Brust hält, während sie das andere mit der rechten um den Körper legt. Der linke Ellenbogen ruht bei Kat. A68 auf der Herme, die auf einer runden Basis steht. Priapos zieht sein Gewand empor und entblößt sein Geschlechtsteil wie bei den ganzfigurigen Darstellungen. Bei Kat. A69 ist die Herme sehr klein gebildet, so dass sich die Göttin nur anlehnt. Auch sie ist bekleidet.

Weitaus häufiger in Kombination mit einer Priaposherme als Stütze ist in der Kleinkunst des Hellenismus und der Kaiserzeit das Motiv der Sandalenlöserin. Dabei stützt sich die Göttin entweder mit der Hand (Kat. A70-72. A74) oder dem Unterarm (Kat. A73. A75. A76) auf. Bei allen Beispielen steht die Herme jeweils zur Linken der Göttin, deshalb ist es auch die linke Sandale, mit der sich Aphrodite beschäftigt. Nur bei Kat. A74 und $A 75$ ist der Blick auf die Handlung gerichtet, sonst geht er in die Ferne. Die Priaposhermen können ganz unterschiedlich gestaltet sein: bekleidet oder unbekleidet, mit in die Hüften gestützten Armen oder ohne Arme, frontal ausgerichtet oder zur Seite gedreht.

Auch Aphroditedarstellungen im Anadyomenetypus dienen Hermen des Priapos als Stütze. Bei der hellenistischen Terrakottastatuette Kat. A77 hat die Göttin beide Arme zu den Haaren erhoben. Dabei hat sie den rechten Ellenbogen auf die Herme gestützt und den linken auf einen nicht sicher zu identifizierenden Gegenstand auf einem Pfeiler ${ }^{72}$. Der Bezug zum Wasser bzw. zum Bad wird noch durch das Relief eines Wasserbeckens mit zwei Tauben auf der Basis der Statuette hervorgehoben. Eine zweite, kaiserzeitliche Terrakottastatuette aus Pantikapaion greift nur mit der rechten Hand in ihr Haar (Kat. A78a-c, bei denen es sich um 3 Exemplare aus derselben oder aus nur leicht veränderten Formen handelt und die deshalb als ein Beispiel gezählt werden). Der Ellenbogen ruht auf der Priaposherme, auf der die Göttin ihr Gewand abgelegt hat. Mit der linken Hand berührt sie einen kleinen Harpokrates zu ihrer Linken.

Die Herme kann manchmal so klein gebildet sein, dass sich die Göttin nicht auf sie lehnt (Kat. A79-81). Hier liegt aber sicherlich dieselbe inhaltliche Relation der Beifigur zu Aphrodite vor wie bei den Beispielen, bei denen sie als wirkliche Stütze dient. Bei Kat. $A 79$ handelt es sich um eine stehende Aphrodite im Anadyomenetypus. Sie ist mit einem Mantel bekleidet, der unterhalb der Brust um den Körper gelegt ist und trägt reichen Schmuck. Die hellenistische Terrakottastatuette Kat. A80 ist nicht vollständig erhalten, kann aber auch zum Anadyomenetypus gehören. Die Göttin ist unbekleidet, nur hinter ihrem Rücken fällt ein Mantel herab. Kat. A81

\footnotetext{
72 Delivorrias 1984, 56 Nr. 449 vermutet in dem Objekt einen Opferkuchen.
} 
gehört ebenfalls zum Typus der Anadyomene und zeigt den Körper der Göttin gleichfalls vollkommen unbedeckt. Sie hat beide Hände zur rechten Seite ihres Kopfes erhoben und fasst ihr Haar. Bei Kat. A82, die die Göttin stehend im Pudica-Motiv wiedergibt, ist der Körper ebenfalls entblößt. Aphrodite bedeckt mit der rechten Hand ihre Scham und verhüllt mit dem linken Unterarm ihre Brüste.

Bei den Terrakottastatuetten aus der Zeit des Hellenismus und der Kaiserzeit gibt es auch Bilder der sitzenden Aphrodite, die sich mit dem Rücken oder der Seite an die Herme anlehnen. Bei den nahezu identischen Bildern (Kat. A83. A84) sitzt die Göttin unbekleidet und nach links gewandt auf einem Felsen, auf dem sie ihren Mantel ausgebreitet hat. Sie stützt die rechte Hand auf den Untergrund, die linke lag möglicherweise auf dem Schoß. Am unteren Teil des Felsen sieht man zwei Eroten, von denen einer auf einem Delphin und der andere auf einem Vogel reitet $^{73}$. Ein dritter Eros lehnt sich mit der linken Hand an die Herme an. Unterschiedlich sind die beiden Hermen, die bei Kat. A83 der kanonischen Hermenform entspricht und bei Kat. A84 eine bekleidete Körperherme ist. Bei den Terrakottastatuetten Kat. A85-88 sitzt die Göttin hingegen nach rechts gewandt auf einem Felsen. Die ersten drei tragen ihren Mantel so um den Rücken und z. T. um die Beine gelegt, dass der Oberkörper frei bleibt. Bei Kat. A86 und A87 ist der Mantel zusätzlich hinter dem Kopf emporgezogen. Kat. A86 hat den linken Arm auf den Kopf der Figur und den rechten auf ihren eigenen gelegt. Kat. A85. A87 und die sich vollständig in ihren Mantel hüllende Kat. A88 lehnen sich mit dem Rücken an die Herme. Aufgrund der vollständigen Bekleidung kann bei Kat. A88 auch eine sterbliche Frau gemeint sein. Die Analogie zu den vorher genannten Beispielen macht eine Identifizierung als Aphrodite aber möglich. Bei Kat. A85-87 ist die Herme aus einem viereckigen Pfeiler mit einem Kopf gebildet, bei Kat. A88 als bekleidete Körperherme.

\subsection{Hermaphrodit}

Andere männliche Götter als Priapos sind seltener als Stütze für Aphrodite belegt. Die mit Chiton und Himation bekleidete hellenistische Marmorstatuette Kat. A89 lehnt sich mit ihrem linken Arm auf den Kopf eines Hermaphroditen, der auf einer runden profilierten Basis steht, wie Priapos das Gewand hebt und sein Geschlecht entblößt. Aphrodite ist stehend wiedergegeben und hat den linken Fuß auf die Basis der Stütze gesetzt. Der rechte Arm scheint erhoben gewesen zu sein. Der Kopf ist verloren.

Auf einer kleinen Figur eines Hermaphroditen, die im Anasyromenosmotiv auf einer rechteckigen Basis steht, lehnt auch die hellenistische Terrakottastatuette Kat. $A 90$ mit dem rechten Ellenbogen. Sie ist mit einem Hüftmantel bekleidet und

\footnotetext{
73 Reinach 1892, 113 Taf. 65.
} 
steht mit dem Gewicht auf dem linken Bein, das rechte Spielbein ist vorgesetzt. Die vorgestreckte rechte Hand hielt einst ein Attribut, die linke rafft das Gewand. Der Blick ist leicht nach rechts gesenkt.

Von einer weiteren hellenistischen, wahrscheinlich Aphrodite darstellenden Marmorstatuette aus Delos haben sich nur die unbekleideten Unterschenkel erhalten (Kat. A91). Das rechte Bein ist das Standbein, das linke ist stark gebeugt. Die Füße stehen direkt nebeneinander, bei dem linken tritt die Figur nur mit den Zehen auf. Rechts von ihr steht eine kleine Gestalt im Anasyromenosmotiv auf einer Basis. Ihr Kopf ist abgebrochen, weshalb die Identifizierung erschwert ist. J. Marcadé deutet sie als Hermaphrodit oder Priapos ${ }^{74}$. St. Oehmke hält die Identifizierung als Hermaphrodit für wahrscheinlicher, da dieser auf Delos häufig in dieser Haltung belegt ist, während sich für Priapos nur wenige Nachweise finden ${ }^{75}$.

Eine andere, diesmal unbekleidete stehende hellenistische Marmorstatuette aus Delos ist von J. Marcadé mit einer ebenfalls dort gefundenen Körperherme eines Hermaphroditen verbunden worden ${ }^{76}$ (Kat. A92). An ihrem linken Bein sieht man noch den Ansatz eines Verbindungssteges. Ihre Körperhaltung mit dem Ausschwingen der linken Hüfte, dem leichten Einknicken des Oberkörpers nach rechts und dem vorgeschobenen rechten Oberschenkel lassen jedoch vermuten, dass die Stütze an ihrer rechten Seite gestanden hat, so dass sich auf beiden Seiten der Göttin einst etwas befunden haben muss.

\subsection{Eros}

Ein ungewöhnliches Werk ist die hellenistische Bronzestatuette Kat. A93. Die Göttin entspricht zwar den anderen hier untersuchten sandalenlösenden Aphroditebildern, die kleine Figur neben ihr ist jedoch singulär. Ein kindlicher Oberkörper wächst aus einem vegetabil verzierten Pfeiler hervor, der Füße an seinem unteren Ende besitzt. Die Identifizierung ist umstritten, in der Literatur werden von Eros über einen bacchischen Genius bis zu Dionysos ${ }^{77}$ verschiedene Möglichkeiten genannt. Er dient als Auflage des linken Arms der Göttin, die mit ihrer rechten Hand an ihre linke Sandale fasst.

Der kaiserzeitlichen Terrakottastatuette Kat. A94 dient ein kleiner Eros als Stütze, wobei offen ist, ob mit diesem eine Statue oder der lebendige Gott gemeint ist. Er hat zwar keine Basis, ist aber durch seinen geschlossenen Stand von dem kleinen lebendigen Eros unterschieden, der auf der anderen Seite der Göttin steht und sich zu ihr emporreckt. Möglicherweise ist mit dem ersten eine Statue

\footnotetext{
74 Marcadé 1969, 235 Anm. 3 (Hermaphrodit); 240 Anm. 1 (Priapos); J. Marcadé, Reliefs Déliens, BCH Suppl. 1 (Paris 1973) 343 (Hermaphrodit).

75 Oehmke 2004, 112 Nr. 64.

76 Marcadé 1969, 235.

77 Eros/bacchischer Genius: de Ridder 1904, 67 f. Nr. 89; Dionysos: Muthmann 1951, 134 Anm. 44.
} 
gemeint. Aphrodite ist stehend wiedergegeben. Sie hebt ihren Mantel hinter dem Rücken empor wie Kat. A33. Die vordere Kante des Gewandes ist von links zwischen ihre Beine geklemmt und hüllt das linke Bein ein, während das rechte unbedeckt bleibt. Auf dem Kopf trägt sie einen üppigen Kopfschmuck.

Bei einer nur in einer Zeichnung veröffentlichten Aphroditestatuette unbekannter Herkunft ruht ihre linke Hand auf einem kleinen Eros, der auf einer profilierten Basis an ihrer linken Seite steht (Kat. A95). Durch die Basis ist er möglicherweise als Statue gekennzeichnet, weshalb auch diese Gruppe unter Vorbehalt zu den Bildern mit einer solchen Stütze gezählt werden kann. Die Göttin steht mit dem Gewicht auf dem linken Bein und trägt einen Chiton und einen Mantel, den sie mit der rechten Hand über ihre Schulter emporzieht und darin den Typus Fréjus ${ }^{78}$ zitiert.

Das einzige Beispiel aus der Wandmalerei ist die Darstellung der Venus Pompejana in dem namensgebenden Gemälde dritten Stils in der Casa delle Nozze d'Ercole in Pompeji ${ }^{79}$ (Kat. A96). Die Göttin steht vollständig bekleidet in einem Tempel und sieht Herakles beim Empfang seiner Braut zu. Sie hält einen stabartigen Gegenstand, wahrscheinlich ein Zepter, und lehnt sich mit dem linken Arm auf eine bekleidete Figur, die neben ihr auf einer hohen Basis steht. Diese trägt ein ungegürtetes Gewand, einen Mantel und eine Bulle um den Hals. Auf dem Kopf hat sie eine phrygische Mütze. Sie hält außerdem einen runden Gegenstand in der linken Hand und fasst mit der rechten das Szepter der Göttin. Die Kleidung und Attribute der Figur sind ungewöhnlich. Sie wird als Eros gedeutet, der einen Spiegel halte ${ }^{80}$. Auf der anderen Seite der Göttin steht ein Priapos mit geschürztem Gewand auf einer niedrigeren Basis.

Bei der Terrakottastatuette Kat. A97 ist die Figur, an deren Basis sich die gelagerte halbbekleidete Göttin lehnt, nur in Ansätzen erhalten. Auf der Basis sind die unbeschuhten Füße einer kleinen Figur zu sehen, am ehesten die eines Eros. Vielleicht stellt dieser eine Statue dar. In anderen Fällen steht oder sitzt er lebendig auf einer Basis, einem Pfeiler oder einer Säule, auf die sich Aphrodite lehnt, was sehr häufig bei Terrakottastatuetten vorkommt (Abb. 2) $)^{81}$. Das Bildschema der aufgelehnten Aphrodite wird durch die kleine Erosfigur also variiert und zugleich spielerisch belebt. Eine Entscheidung, ob Eros bei Kat. A97 als Statue oder lebendig gemeint ist, fällt deshalb schwer. Inhaltlich wird sich - zumindest was diese Untersuchung betrifft - aus einer Trennung von ^lebendigem Eros` und `Bild des Eros» nicht unbedingt ein Unterschied ergeben, da beide für den Gott Eros stehen. Seine Bedeutung für das Gesamtbild der aufgelehnten Aphrodite, wird in Kapitel

\footnotetext{
78 Vgl. Anm. 384.

79 Pompeji VII, 9, 47.

80 W. Helbig, Wandgemälde der vom Vesuv verschütteten Städte Campaniens (Leipzig 1868) $358 \mathrm{f}$. Nr. 1479; LIMC V (1990) 164 s. v. Herakles 3337 (A.-F. Laurens); Schmidt 1997, 226 Nr. 366; V. Sampaolo, Insula 9,47, in: G. Pugliese Caratelli u. a. (Hrsg.), Pompei. Pitture e mosaici VII. Regio VII. (Rom 1997) 373.

81 s. Anm. 70.
} 
7.3 besprochen werden. Da hier nur Bilder untersucht werden, bei denen sich Aphrodite auf eine Statue lehnt, sind Eroten in einer bewegten Haltung nicht aufgenommen worden, weil sie am ehesten den lebendigen Gott meinen. Sie sind im Vergleich zu denen, die im geschlossenen Stand und somit sstatuenhaft dargestellt sind, deutlich in der Überzahl.

\subsection{Dionysos}

Einige Stützfiguren können als Statuen des Dionysos identifiziert werden. Die hellenistische Glaspaste Kat. A98 zeigt eine fast unbekleidete Aphrodite, die sich mit ihrer linken Hand auf die Basis einer Dionysosstatue stützt. Mit der anderen Hand hebt sie ihren Mantel empor, der hinter ihren Beinen entlang geführt ist und ihren Körper wie ein ausgebreitetes Tuch hinterfängt. Das andere Ende hat sie unter der aufgestützten Hand festgeklemmt. Sie stützt sich mit dem durchgestreckten rechten Arm auf. Dionysos ist im Profil gesehen. Er trägt ein Himation und hält einen Thyrsos in der Rechten.

Bei der hellenistischen Terrakottastatuette Kat. A99 lehnt Aphrodite mit dem rechten Arm auf einer bärtigen Herme, die nach Ansicht von D. Graepler vielleicht Dionysos darstellt ${ }^{82}$. Die Göttin tritt mit einem Bein auf die Basis der Herme, was zu einem deutlichen Schwung in ihrer Haltung führt. Sie trägt ein Himation, dessen eine Seite um den in die Hüfte gestützten linken Arm gelegt ist. Er ist anschließend um den Rücken und die rechte Hüfte geführt und fällt vorn zwischen ihren Beinen hinab. Das andere Ende ist um den linken, in die Hüfte gestemmten Arm gelegt. Die Nacktheit ihres übrigen Körpers wird dadurch deutlich betont. Auf dem Kopf trägt sie einen Blätterkranz.

\subsection{Pan}

Pan dient Aphrodite nur einmal als Stütze, und zwar in Form einer Körperherme bei der späthellenistischen Marmorstatuette Kat. A100. Er hat ein Tuch um die Hüften geschlungen, das allerdings so zu einem Wulst eingedreht ist, dass es sein Geschlecht z. T. entblößt. Er spielt auf der Syrinx. Auf seinem Kopf ruht der linke Arm der stehenden Göttin. Sie hat das linke Bein vorgesetzt und trägt einen Mantel, der ihren Oberkörper unbedeckt lässt. Der Mantel ist wieder von links kommend um ihren Rücken, die rechte Hüfte und den Unterkörper geführt, sein Ende fällt an ihrer linken Seite hinab. Ihr Kopf und ihr rechter Arm sind verloren.

${ }^{82}$ Graepler 1997, 210. 


\subsection{Nicht identifizierbare Hermen}

Einige weitere bärtige Hermenstützen lassen sich nicht ohne weiteres identifizieren. Eine Bronzestatuette zeigt eine sich in einem Handspiegel betrachtende stehende Aphrodite mit entblößtem Körper, die sich mit der linken Hand auf dem Kopf einer bärtigen ithyphallischen Herme abstützt (Kat. A101). Bei einer halbbekleideten Terrakottastatuette steht Aphrodite in dem bereits bekannten Schema mit vorgesetztem linkem Bein da und hat den angewinkelten linken Arm auf den Kopf einer bärtigen Herme gelegt (Kat. A102). Sie trägt wieder einen Hüftmantel, dessen oberer Saum jedoch sehr schräg geführt ist und ihre rechte Hüfte freilässt. An sie schließt sich eine weitere Terrakottastatuette an, die eine ebenfalls nur mit einem Himation bekleidete Aphrodite zeigt, die sich auf eine bärtige Herme zu ihrer Linken lehnt (Kat. A103). Die Herme ist bestoßen und daher nicht identifizierbar. Eine weitere Aphroditestatuette aus Marmor mit bärtiger Herme als Stütze ist nicht mit einer Abbildung publiziert (Kat. A104) ${ }^{83}$.

Eine kaiserzeitliche unbekleidete Terrakottastatuette im Anadyomenetypus hat ihren linken Ellenbogen auf den Kopf einer bärtigen Figur gestützt (Kat. A105). Da diese jedoch vom Hals abwärts nicht mehr erhalten ist, kann nicht sicher bestimmt werden, ob es sich um eine Herme oder um eine Ganzkörperfigur handelt. Erstere sind bei den männlichen Stützfiguren jedoch in der Mehrzahl.

Sicher auf eine Herme lehnt sich eine weibliche Figur auf einem spätantoninischen Sarkophag (Kat. A106). Unsicher sind hingegen ihre Identifizierung und die Einreihung des Werkes unter die Bilder der Aphrodite. Der Sarkophag zeigt die Einweihung einer Frau in den dionysischen Kreis ${ }^{84}$. Bei der Aufgelehnten könnte es sich deshalb auch um eine Verehrerin des Dionysos oder eine Mänade oder Nymphe handeln. Sie lehnt leger mit beiden Unterarmen auf der Schulter der bärtigen Herme und schaut dem dionysischen Treiben zu. Ihr Gewicht ruht auf dem linken Bein, das rechte hat sie darüber geschlagen. Sie trägt einen Hüftmantel, dessen Enden sie gleichzeitig als Armpolster benutzt. Die Herme ist nicht durch Attribute oder andere ikonographische Merkmale identifizierbar. Da es sich aber um eine Einweihungsszene im dionysischen Milieu handelt, ist in ihr am ehesten eine Dionysosherme zu sehen. Die langen Haare der Herme bestätigen dies.

Ähnliche Schwierigkeiten wie bei der Identifizierung der bärtigen Hermen ergeben sich bei dem Versuch, die unbärtigen Hermen zu benennen, die der Göttin manchmal als Stütze dienen. Sie sind durch einen Phallos und eine Kurzhaarfrisur als männlich gekennzeichnet, so weit dies aufgrund des z. T. fragmentarischen Zustandes erkennbar ist. Dazu zählt der Abdruck einer heute verschollenen Tonform aus Athen. Er zeigt eine nach rechts gewandt sitzende Aphrodite. Sie ist vollstän-

\footnotetext{
83 Delivorrias 1984, 45 Nr. 337.

84 ASR 4, 3, 378-380 Nr. 210.
} 
dig in ihren Mantel gehüllt und lässt ihre Linke auf einer sehr kleinen Herme ruhen, vor der eine Taube sitzt (Kat. A107). Die rechte Hand war erhoben und fasste den Schleier ${ }^{85}$. Laut C. Watzinger kann die Tonform noch an das Ende des 5. Jahrhunderts v. Chr. datiert werden ${ }^{86}$. Sie belegt, dass schon früh mehrere Varianten des aufgelehnten Aphroditetypus vorkamen. Zugleich ist mit diesem Bild auch die Stütze in Form einer Herme bereits für die hochklassische Zeit gesichert.

Auf einem apulisch-rotfigurigen Krater aus der Zeit um 340 v. Chr. (Kat. A108) sieht man Aphrodite in einer mehrfigurigen Szene. Sie trägt einen Chiton und ein Himation. Sie steht mit überkreuzten Beinen in Frontalansicht da, lehnt sich mit dem linken Unterarm auf eine jugendliche Herme und hält ein Liebesrädchen in der rechten Hand. Sie wendet den Blick seitwärts zu Bellerophon, der gerade die Chimaira erlegt. Zuvor hat sie die Liebe der Stheneboia zu ihrem Gast entfacht und beobachtet jetzt das folgende Geschehen ${ }^{87}$.

Die spätklassische Terrakottastatuette Kat. A109 lehnt sich ebenfalls mit dem linken Arm auf eine jugendliche ithyphallische Herme. Aphrodite steht auf dem rechten Bein, das linke ist leicht angewinkelt, ihr Körper wird von ihrem Mantel kaum bedeckt. Ein Ende ist zwischen ihren Beinen festgeklemmt und um den aufgelehnten Arm und den Rücken geführt. Das andere, nicht erhaltene Ende zog die Göttin mit der ebenfalls nicht erhaltenen rechten Hand empor. Der Kopf ist verloren. Bei einer weiteren halbbekleideten Tonstatuette zieht Aphrodite gleichfalls mit der Rechten den Mantel, der ihre Beine einhüllt, über die Schulter, während sie die ebenfalls darin eingehüllte Linke auf eine unbärtige ithyphallische Herme mit langen Haaren stützt (Kat. A110).

Mit einem Hüftmantel bekleidet ist eine frühestens späthellenistische Marmorstatuette aus Thera, die sich mit dem rechten Arm auf eine unbärtige Herme lehnt (Kat. A111). Sie hat den rechten Fuß auf die Basis der Herme gestellt, auf die sie sich mit dem rechten Unterarm lehnt. Der linke Arm war wahrscheinlich in die Hüfte gestützt. Wie ein spiegelbildliches Gegenstück dazu erscheint die bereits beschriebene kaiserzeitliche Marmorstatuette aus Kyrene Kat. A22. Diese beiden Beispiele unterschiedlicher Herkunft zeigen deutlich die starke Tradition des Typus.

Zwei hellenistische Terrakottastatuetten sind sich untereinander im Standmotiv ebenfalls sehr ähnlich. Eine mit Chiton und Mantel bekleidete Aphrodite (Kat. A112) und eine, die nur einen Mantel um die Hüften gelegt hat (Kat. A113) stützen sich jeweils mit dem ausgestreckten rechten Arm auf eine unbärtige Herme. Bei beiden ist der Mantel von links kommend um den Rücken und die rechte Hüfte gelegt. Die Oberkante ist wulstförmig eingedreht, das Ende fällt zwischen den Beinen hinab. Das rechte Bein ist jeweils vorgesetzt, bei Kat. A112 ist der Fuß auf die Basis der Stütze gestellt.

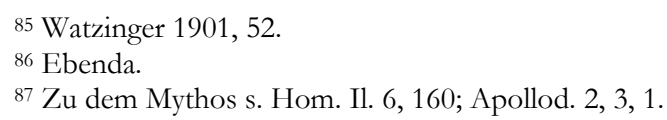


Die hellenistische Glaspaste Kat. A114 zeigt eine halbbekleidete, nach rechts gewandte Aphrodite, die sich mit dem linken Arm auf eine unbärtige kleine Herme lehnt. Laut A. Furtwängler betrachtet sie sich in einem Klappspiegel in der rechten Hand ${ }^{88}$. Ihr Gewicht ruht auf dem rechten Bein. Das linke ist angewinkelt vorgesetzt. Der Oberkörper ist leicht in Richtung der Stütze geneigt. Auch hier trägt die Göttin wieder einen Hüftmantel, dessen obere Kante zu einem Wulst gedreht ist.

Auf einem späthellenistischen Marmorrelief aus Delos lehnt Aphrodite in einer Variante des Typus Pudica an einer ithyphallischen jugendlichen Herme (Kat. A115). Sie hat den linken Arm an die Herme gelehnt, während sie mit der Rechten ihre Scham verdeckt. Mit der linken Hand hält sie ihr Gewand. Vor der Herme steht ein Gefäß, neben Aphrodite ein kindlicher Eros mit einer Muschel und einem Alabastron. Er blickt zu der Göttin auf.

Außerdem gibt es noch zwei sandalenlösende Aphroditebilder mit unbärtigen Hermen als Stütze. Die kaiserzeitliche Terrakottastatuette Kat. A116 stützt sich wie zwar gewohnt mit der linken Hand ab, nestelt mit der anderen aber diesmal an ihrer rechten Sandale. Ihr Körper wird von einem aufgeblähten Mantel hinterfangen. Die Bronzestatuette Kat. A117 beschäftigt sich hingegen mit der linken Sandale. Auch sie stützt sich mit der linken Hand auf eine unbärtige ithyphallische Herme. Beide blicken nicht auf ihre Handlung.

Bei einer kaiserzeitlichen Terrakottastatuette aus Thysdrus ist der Kopf der ithyphallischen Herme zerstört (Kat. A118). Die Göttin hat ein Ende ihres Gewandes auf sie gelegt und es dann um ihren Rücken geführt. Ihr rechter Arm, der das andere Ende hält, ruht auf einem kleinen Eros an ihrer Seite. Sie blickt mit erhobenem Kopf in die Ferne. Eine weitere Terrakottastatuette im Anadyomenetypus lehnt sich an eine bis zu ihrer Hüfte reichende ithyphallische unbärtige Herme (Kat. A119). Sie hat beide Hände erhoben, um ihr Haar auszuwringen und ist unbekleidet.

Neuzeitlich ist die Herme bei Kat. A120. Die Göttin steht mit dem Gewicht auf dem linken Bein, das rechte ist angewinkelt. Die linke Hand ist in die Hüfte gestützt. Sie trägt einen Hüftmantel, der auch den linken Arm bedeckt. Der rechte Arm ist durchgestreckt. Die Hand ist gesenkt, die Finger sind leicht gekrümmt. Die Figur kann sich deshalb nicht auf der Stütze gelehnt haben, sondern hat sie nur leicht berührt wie heute die neuzeitliche Herme. Dass es einst ein Objekt an der Seite der Göttin gab, beweist die erhaltene antike Basis. Es hat jedoch wahrscheinlich die Form eines Pfeilers gehabt, denn aufgrund des Körpertypus gehört diese Marmorstatuette zum Typus >Venus Marina`, der bei zahlreichen Kopien und Varianten den Pfeiler zeigt ${ }^{89}$. Einer nur in einer Umzeichnung veröffentlichten Aphrodite wurde ebenfalls in der Neuzeit eine Herme beigefügt (Kat. A121). Die Göttin steht auf dem rechten Bein. Der linke Fuß ist auf die Basis der

${ }^{88}$ Furtwängler 1900, 168.

${ }^{89} \mathrm{Zu}$ diesem Typus allgemein s. G. Becatti, Ninfe e divinità marine. Ricerche mitologiche iconografiche e stilistiche, Studi miscellanei 17 (Rom 1970/71); Delivorrias 1984, 65-67 Nr. 554-568. 
Stütze gesetzt. Sie ist mit einem Hüftmantel bekleidet, der an ihrer linken Seite bis unter die Hüfte gerutscht ist. Wie die Stütze bei Kat. A121 einst ausgesehen hat, kann nicht mehr nachvollzogen werden. Da die Basis der Stütze antik ist, muss sich aber etwas neben der Göttin befunden haben. Bei einer weiteren Statue kann die Herme ebenfalls neuzeitlich sein (Kat. A122). Sie ist nur in einer Zeichnung überliefert, eine Beschreibung ihres Zustandes existiert nicht. Die mit einem Hüftmantel bekleidete Göttin lehnt sich mit der linken Hüfte und dem gebeugten linken Arm an die Herme und beugt den Oberkörper stark nach rechts und nach vorn. Der rechte Arm ist gesenkt.

\subsection{Zusammenfassung}

Aphroditebilder, bei denen sich die Göttin auf eine Ganzkörperfigur oder Herme des Priapos lehnt, treten seit dem Hellenismus auf. In diese Zeit gehören auch die meisten Beispiele, darunter zahlreiche Terrakottastatuetten ${ }^{90}$, während das Motiv in der Kaiserzeit weniger häufig verwendet wurde ${ }^{91}$. Priaposfiguren und -hermen kommen als Stützfiguren für Aphrodite ausschließlich in der Kleinkunst vor. Die Aphroditebilder mit Priaposstütze zeigen häufig typologische Gemeinsamkeiten mit den bereits beschriebenen Bildern mit den weiblichen Stützen ${ }^{92}$. Insgesamt sind die Körperhaltungen bei den Bildern mit männlichen Stützen im Vergleich zu denen mit weiblichen Stützfiguren jedoch variantenreicher. So ließen sich zahlreiche Darstellungen im Sandalenlösertypus (Kat. A57-59. A70-76) sowie im Anadyomenetypus (Kat. A55. A60-62. A77-81) feststellen wie auch sitzende Figuren (Kat. A83-88). Aphrodite ist zumeist un- oder nur halbbekleidet dargestellt. Der erotische Aspekt spielt bei diesen Bildern eine sehr große Rolle, besonders bei den sandalenlösenden oder die Haare auswringenden Typen, die eine Form von inszeniertem Voyeurismus offenbaren, der mit dem Gedanken der Betrachter der Bilder spielt.

Auch die Aphroditedarstellungen mit anderen männlichen Götterbildern -identifizierbar sind Hermaphrodit, Eros, Dionysos und Pan - als Stütze, die ebenfalls fast ausschließlich der Kleinkunst angehören ${ }^{93}$, sind nur in wenigen Fällen vor die Zeit des Hellenismus zu datieren. Drei Bilder mit unbärtigen, nicht durch Attribute charakterisierten Hermen gehören noch der klassischen Epoche an. Es sind die

${ }^{90}$ Kat. A53. A54. A64. A65. A68-A72. A77. A80. A83-85. A88, Kat. A61a-b. A84. A85 können schon der Kaiserzeit angehören.

${ }^{91}$ Kat. A55-A59. A66. A67. A73. A75. A76. A78. A86, Kat. A73 kann noch hellenistisch sein. Die anderen Beispiele können nicht eindeutig datier werden, sie sind aber nicht früher als hellenistisch.

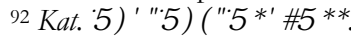

${ }^{93}$ Es handelt sich vor allem um Marmor- und Bronzestatuetten (Kat. A89. A91. A92. A95. A100. A104. A111. A120 bzw. Kat. A93. A101. A117) sowie zahlreiche Terrakottastatuetten (Kat. A90. A94. A97. A99. A102. A103. A105. A110. A112. A113. A116. A118. A119). Nur die kaiserzeitliche Statue Kat. A121 ist großformatig, ihre Stützherme allerdings neuzeitlich. 
Spiegelform Kat. A107, die C. Watzinger noch an das Ende des 5. Jahrhunderts v. Chr. setzt ${ }^{94}$, dann die Terrakottastatuette Kat. A109, die von K. Schefold aufgrund stilistischer Vergleiche in die Zeit um 360 v. Chr. datiert wird ${ }^{95}$, und der apulisch-rotfigurige Krater aus dem Umkreis des Lykurgos-Malers Kat. A108 aus der Zeit um 340 v. Chr. ${ }^{96}$. Bei den Bildern mit Hermaphrodit, Eros, Dionysos und Pan als Stütze lassen sich vielfältige Haltungsschemata feststellen. Die Bekleidung der Aphrodite ist wie bei den Bildern mit Priapos als Stütze meist spärlich.

Bei den Aphroditedarstellungen mit einer männlichen Stützfigur lassen sich demnach zahlreiche Varianten als Typenklittierungen feststellen, was sicherlich auch daran liegt, dass sie zumeist dem Hellenismus und der Kaiserzeit angehören und oft der Kleinkunst, vor allem der Koroplastik, zuzuordnen sind, die generell eine größere Variation bekannter Typen vorweisen.

94 Watzinger 1901, 52 f. Nr. 5 mit Abb.

${ }^{95}$ K. Schefold, Zwei tarentinische Meisterwerke, in: E. Howald u. a. (Hrsg.), Festgabe für A. von Salis (Basel 1951) 171-176.

96 Delivorrias 1984, 146 Nr. 1529. 



\section{Die Aphrodite Urania in Elis, in Athen und die >Aphrodite Brazzà - die ersten Bilder mit ikonischer Stütze?}

Die Betrachtung der einzelnen Werke hat ergeben, dass Aphrodite seit dem 5. Jahrhundert v. Chr. in aufgelehnter Haltung gezeigt wurde. Dabei konnte ein Haupttypus mit einem weiblichen archaistischen Idol oder einer weibliche Herme als Stütze festgestellt werden, während andere Stützenformen seltener und später sind. Die große Verbreitung des Haupttypus mit seinen Varianten hat schon lange zu der Diskussion geführt, ob diese Bilder auf eines oder mehrere Urbilder zurückzuführen sind. In der antiken Literatur wird an keiner Stelle eine Darstellung der Göttin mit ikonischer Stütze erwähnt. Dieses Argument scheidet daher bei der Suche nach einem frühen Vertreter des Typus aus. Über den Umweg eines weiteren Haltungsmotivs und eines Attributs kann jedoch eine Anbindung an ein bekanntes, in der Literatur erwähntes Werk versucht werden. Bei den meisten der hier gesammelten Bilder stellt Aphrodite den linken Fuß vor und oft auf eine Erhöhung. Bei Kat. A7. A12. A14. A22 und A24, eventuell auch bei Kat. A1. A4 und $A 19$ ist das Objekt unter dem Fuß eine Schildkröte. Aufgrund dieses Merkmales wurde bereits mehrfach eine Verbindung dieser Darstellungen zu einer Statue der Aphrodite Urania in Elis des Phidias hergestellt. Der Neufund eines Fragmentes einer Terrakottastatuette aus Elis hat diese Diskussion erneut angeregt ${ }^{97}$. Die Frage nach dem Urbild des hier untersuchten Typus führt zugleich auf die Frage zurück, ob das früheste Beispiel, die >Aphrodite Brazzàr Kat. A1, selbst diese Statue oder eine zeitgenössische Wiederholung ist und welche Stütze bei der >Aphrodite Brazzà bzw. ihrem eventuellen Vorbild zu rekonstruieren ist.

Die Aphroditestatue in Elis, ein berühmtes Werk des Phidias aus Gold und Elfenbein im Heiligtum der Aphrodite Urania ist durch Pausanias 6, 25, 1 überliefert:

${ }^{97}$ s. Kap. 5.1.2. 


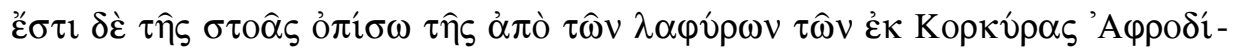

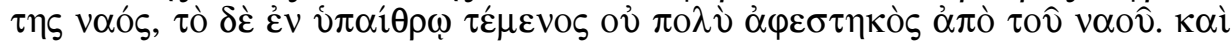

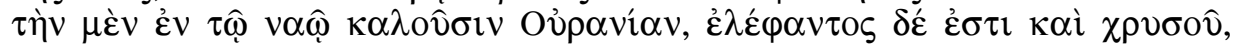

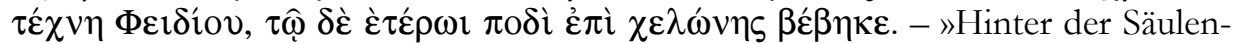
halle aus der Beute von Korkyra liegt ein Aphroditetempel, und der offene heilige Bezirk liegt nicht weit vom Tempel entfernt. Die Göttin im Tempel nennen sie Ourania, sie ist aus Elfenbein und Gold, ein Werk des Pheidias, und steht mit dem einen Fuß auf einer Schildkröte«. (F. Eckstein - P. C. Bol)

Bei dieser Statue hatte die Göttin also einen Fuß auf eine Schildkröte gesetzt, was den wichtigsten Anknüpfungspunkt für die Frage nach dem vermuteten Urbild der aufgelehnten Aphroditebilder darstellt. Eine andere Statue der Aphrodite Urania des Phidias hat Pausanias 1, 14, 7 in Athen in der Nähe des Hephaisto-

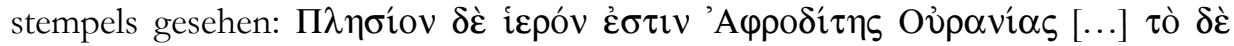

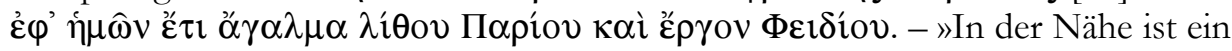
Heiligtum der Aphrodite Ourania [...] Die zu unserer Zeit noch vorhandene Statue ist aus parischem Marmor und ein Werk des Phidias«. (F. Eckstein - P. C. Bol)

Auf dieses Bild wird später noch einmal einzugehen sein ${ }^{98}$. Das Athener Heiligtum der Aphrodite Urania wurde zunächst nördlich des Panathenäenweges, westlich der Stoa Poikile vermutet, wo man einen spätarchaischen, in klassischer Zeit erneuerten Altar gefunden hat ${ }^{99}$. M. Osanna ist es gelungen, neue Argumente dafür anzuführen, dass das Heiligtum an der Nordostflanke des Kolonos Agoraios, nördlich des Hephaisteions und westlich der Stoa des Zeus Eleuterios zu lokalisieren ist. In diesem Heiligtum fand man zudem ein Bild der Göttin in Gestalt einer kleinformatigen Herme ${ }^{100}$. Ob sich eine Verbindung des Typus der auf eine ikonische Stütze gelehnten Aphrodite mit der Statue in Elis oder Athen herstellen lässt, wird Gegenstand der folgenden Kapitel sein. Zuvor ist es jedoch wichtig zu erläutern, wer Aphrodite Urania war und wie sie dargestellt wurde.

\subsection{Zur Darstellungsweise der Aphrodite Urania}

\subsubsection{Das Attribut der Schildkröte}

Das ungewöhnliche Attribut, das Phidias der Aphrodite von Elis beigegeben hat, verlangt nach einer Interpretation. In diesem Zusammenhang ist ebenso nach dem Charakter der Aphrodite Urania zu fragen und nach den weiteren ikonographischen Merkmalen der Urania-Darstellungen, die sich aus der Überlieferung ergeben.

\footnotetext{
98 s. Kap. 5.3.

99 T. L. Shear, The Athenian Agora: Excavations of 1980-1982, Hesperia 53, 1984, 1-57; Camp 1986, 57; in jüngerer Zeit noch Pirenne-Delforge 1994, 15-25.

100 Osanna 1988/89, vgl. Kap. 5.1.3. Zur Lage des Heiligtums s. I. Rotroff, Hellenistic Pottery. Athenian and Imported Moldmade Bowls, Agora 22 (Princeton 1982) 100 Taf. 99 G5:3
} 
Statuen, bei denen Götter einen Fuß auf ein Tier setzten, sind selten. Das einzige weitere mir durch die antike Literatur bekannte Beispiel ist bei Strabon

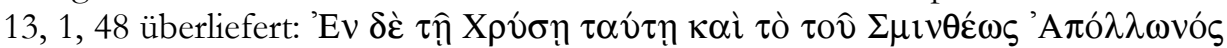

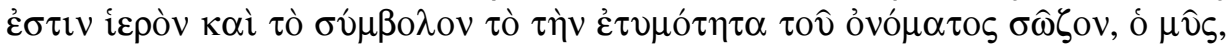

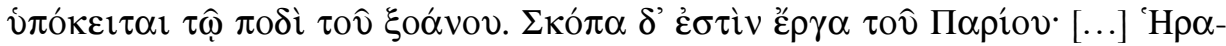

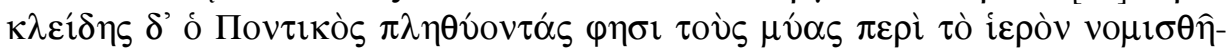

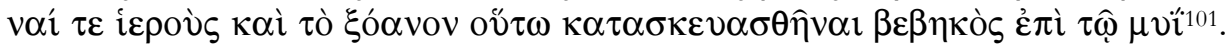
- In jenem Chrysa befindet sich auch das Heiligtum des Apollon Smintheus, und das Wahrzeichen, das an den Ursprung des Namens erinnert, die Maus, sitzt unter dem Fuß des Kultbildes: es sind Werke des Skopas von Paros [...] Herakleides der Pontiker sagt, die Mäuse, die in großen Mengen in dem Heiligtum leben, würden als heilig betrachtet und daher sei das Kultbild mit dem Fuß auf einer Maus gebildet worden«. (St. Radt)

Das Tier sagt etwas über den Kult des Apollon in diesem bestimmten Heiligtum aus. Es stellt sich die Frage, ob eine vergleichbare Aussage auch für die Schildkröte der Aphrodite von Elis gefunden werden kann. Pausanias 6, 25, 1 gibt keine

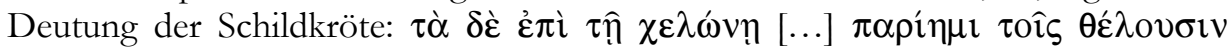

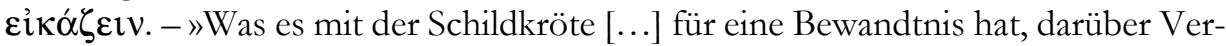
mutungen anzustellen, überlasse ich denen, die es wollen«. (F. Eckstein - P. C. Bol)

Plutarch mor. 142d bzw. mor. 381e liefert lediglich eine wenig zufrieden stellende moralisierende Interpretation im Zusammenhang mit seiner Deutung der Schlange, die Phidias neben der Athena Parthenos in Athen dargestellt hat: Tìv

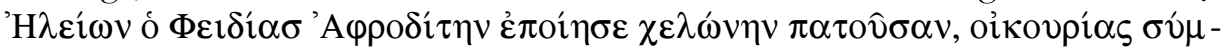

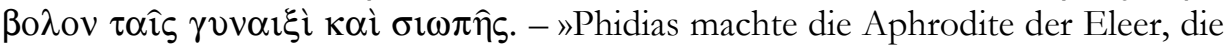
einen Fuß auf eine Schildkröte stellt, zum Zeichen dafür, dass die Frauen im Haus

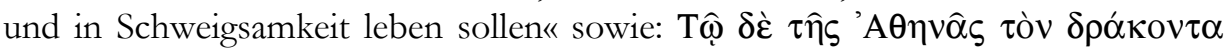

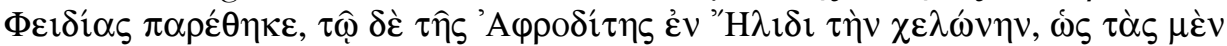

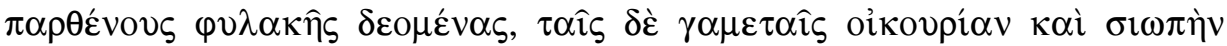
$\pi \rho \varepsilon ́ \pi 0 v \sigma \alpha \nu$. - »Phidias hat neben die Statue der Athena die Schlange gesetzt und neben die Statue der Aphrodite die Schildkröte, um zu zeigen, dass Mädchen Beaufsichtigung brauchen und es sich für Frauen gehöre, im Haus und in Schweigsamkeit zu leben«102.

101 Vgl. M. W. de Visser, Die nicht menschengestaltigen Götter der Griechen (Leiden 1903) 44. 159 f.; M. P. Nilsson, Geschichte der griechischen Religion I, HAW V,2,1 4(München 1976) $534 \mathrm{f}$. 102 Zur Interpretation der Plutarchstellen vgl. auch Settis 1966, bes. 173-191; L. Llewellyn-Jones, Aphrodite's tortoise. The Veiled Woman of Ancient Greece (Swansea 2003) 189-191.

Cicero nat. deor. 3, 59 erwähnt hingegen nur, dass es einen Tempel der Aphrodite, der Tochter des Himmels, in Elis gab: Venus prima Caelo et Die nata, cuius Elide delubrum vidimus. - „Die erste Venus [Cicero zählt verschiedene Mythen der Entstehung der Venus auf] war die Tochter des Caelus und der Dies, wir sahen ihren Tempel in Elis«. 
Akzeptabel erscheinen dagegen zwei Deutungen, die die Forschung vorgeschlagen hat. R. Kekulé sah in seiner Untersuchung zur >Aphrodite Brazzàı Kat.

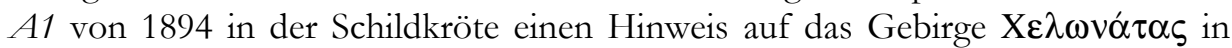
der Nähe von Elis ${ }^{103}$. Diese Deutung erscheint glaubwürdig, da der Wortstamm des Gebirgsnamens mit dem griechischen Wort für Schildkröte ( $\chi \varepsilon \lambda \omega \dot{v} \eta)$ übereinstimmt. In einem vergleichbaren Sinne kann man m. E. eine Athenastatue in

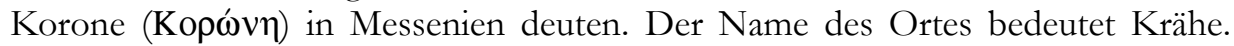
Die Statue hielt eine Krähe in der Hand, wie Pausanias 4, 34, 6 überliefert: $\chi \alpha \lambda$ -

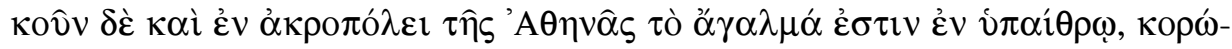

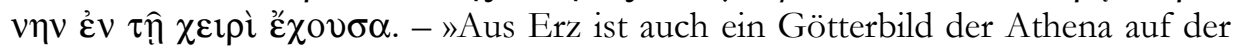
Burg; es hält eine Krähe in der Hand«. (F. Eckstein - P. C. Bol ).

Aphrodite Urania galt als Tochter des Uranos, die aus seinem durch Kronos abgeschlagenen und ins Meer gefallenen Glied geboren wurde und in der Nähe von Paphos auf Zypern an Land gestiegen ist, wie unter anderem die bekannte Stelle bei Hesiod theog. 188-197 bezeugt:

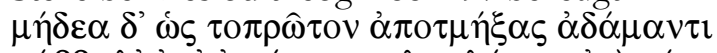

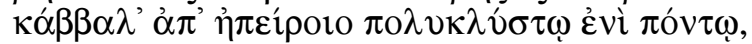

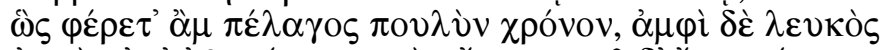

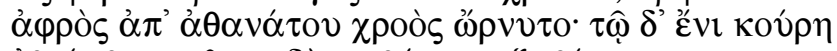

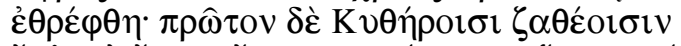

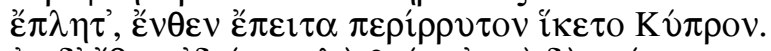

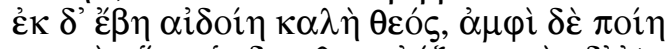

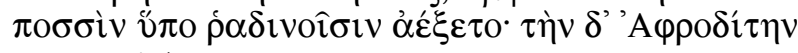

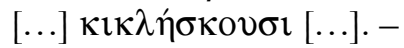

»Das Gemächte aber, als er die Tat gewagt

Und es mit der Sichel abgeschnitten

Und von der Feste in die vielwogende See geworfen,

Trieb so in die Weite dahin lange Zeit,

Ringsum aber erhob sich weißer Schaum

Aus dem unvergänglichen Fleisch.

Und in dem wuchs ein Mädchen heran.

Zuerst trieb es nahe an das hochheilige Kythera,

Von da kam es dann zum ringsumbrandeten Kypros.

Und heraus schritt da die ehrwürdige, schöne Gottheit,

Unter dem Tritt ihrer schlanken Füße

Schoß auf ringsum die Wiese.

Sie nennen sie Aphrodite [...]«. (W. Marg)

103 Kekulé 1894, 10, ebenso Frickenhaus 1913, 363. Der Name des Gebirges ist belegt bei Plin. nat. 4, 13; Strab. 8, 3, 4. 
Die Schildkröte kann deshalb auch als Zeichen für die Meeresgeburt der Göttin stehen, denn Schildkröten werden in der antiken Kunst häufig in Zusammenhängen mit Themen gezeigt, die mit dem Meer in Verbindung stehen - und zwar unabhängig davon, ob es sich im Einzelfall um Land- oder Meeresschildkröten handelt ${ }^{104}$. Die übrigen von der Forschung vorgetragenen Deutungen der Schildkröte der Aphrodite Urania von Elis hat H. Froning erst vor kurzem zusammengestellt und auf ihre Wahrscheinlichkeit hin überprüft, weshalb hier auf ihre Ausführungen verwiesen sei ${ }^{105}$.

\subsubsection{Ein Terrakottafragment aus Elis}

Durch ein von H. Froning erst kürzlich publiziertes Fragment einer Terrakottastatuette aus Elis $(A b b .3)^{106}$ wurden die aus der antiken Literatur gewonnenen Erkenntnisse über das Aussehen der Aphrodite Urania von Elis bestätigt. Das Fragment ist ein mit einer Sandale bekleideter rechter Fuß von annähernd einem Drittel Lebensgröße, der direkt über dem Spann abgebrochen ist. Er steht auf dem Panzer einer Schildkröte, von der der Kopf und die Beine fehlen. Auf dem Spann hat sich noch der Saum eines langen Gewandes erhalten. H. Froning konnte überzeugende Argumente dafür beibringen, dass die Statuette aufgrund der Form der Sandale noch vor die Zeit des Hellenismus datiert werden kann ${ }^{107}$. Im Gegensatz zu den oben betrachteten Aphroditedarstellungen befindet sich die Schildkröte bei diesem Terrakottafragment jedoch unter dem rechten Fuß. Aufgrund des Fundortes - Elis - vermutet H. Froning einen direkten Zusammenhang zwischen der Terrakottastatuette und der Statue des Phidias. Die Aphroditedarstellungen, die den linken Fuß auf eine Schildkröte setzen, möchte sie dagegen auf ein anderes Vorbild zurückführen. Dieses sei die andere von Phidias für Athen geschaffene Statue der Aphrodite Urania, deren Heiligtum M. Osanna in der Nähe des Hephaisteions lokalisieren konnte ${ }^{108}$. Die Aphrodite Urania von Elis und die Aphrodite Urania von Athen wären laut dieser These spiegelbildlich aufgebaut, was die Beinstellung betrifft. Darauf werde ich weiter unten noch einmal zurück-

104 Zur Verwendung von Landschildkrötenarten in Kontexten, die mit dem Meer in Verbindung stehen s. Froning 2005, 291 f. Eine genaue Identifizierung der Schildkröten der hier untersuchten Bilder ist daher nicht nötig und aufgrund des oft fragmentarischen Zustands auch unmöglich. Zu einer darüber hinausgehenden Interpretation der Schildkröte als Fruchtbarkeitssymbol s. Froning 2005, 292-294. Vgl. auch die auf Schildkröten stehenden Aphrodite-ähnlichen Figuren als Spiegelstützen archaischer Zeit: L. O. Keene Congdon, Caryatid Mirrors of Ancient Greece. Technical, Stylistic and Historical Considerations of an Archaic and Early Classical Bronze Series (Mainz 1981) 12-18. 127 f. 130 f. 136 f. 234 f. Kat. 2. 6. 14. Taf. 1. 2. 10; Delivorrias 1984, 18 Nr. 95.

105 Froning 2005, $290 \mathrm{f}$.

106 Elis, Archäologisches Museum Inv. $\Pi$ 302: Froning 2005 Taf. 52.

107 Ebenda 288.

108 Paus. 1, 14, 7, s. S. 66 und Kap. 5.3. 

- die ersten Bilder mit ikonischer Stütze?

kommen, da dazu weitere Untersuchungen nötig sind. So ist z. B. die Frage zu stellen, ob es im 5. Jahrhundert v. Chr. zwei replikenartig ähnliche Götterbilder an verschiedenen Orten gegeben haben kann und wie die Statuen der Aphrodite Urania in Elis und Athen sonst ausgesehen haben ${ }^{109}$.

Da sich die Ikonographie der Aphrodite mit der Schildkröte bei dieser Ansicht nicht nur auf Elis beschränken würde, wäre die oben erwähnte Deutung des Tieres als Hinweis auf das Chelonatas-Gebirge bei Elis hinfällig. Die Schildkröte kann dann nicht mehr als lokales Spezifikum gedeutet werden.

\subsubsection{Die Verbindung mit dem Orient und die Darstellung als Herme}

Die antiken Quellen zeigen, dass man sich in der Antike bewusst war, dass Aphrodite Urania aus dem Orient kam und mit der dort verehrten Astarte zu verbinden sei, was auch der aus dem Orient übernommene Mythos ihrer Geburt aus dem abgeschlagenen Glied des Uranos ausdrücken konnte ${ }^{110}$. Die Überlieferung bringt ihre Kulte mit dem Orient in Verbindung oder nennt sie an Orten, die enge Handelsbeziehungen vor allem mit dem phönizischen Raum besaßen ${ }^{111}$, wie z. B.

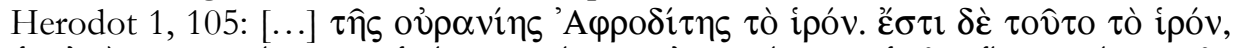

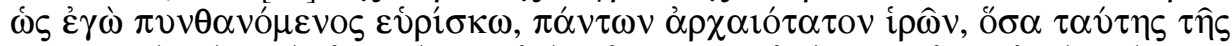

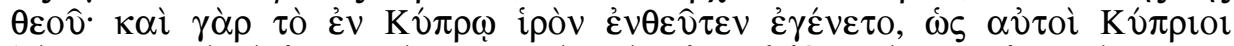

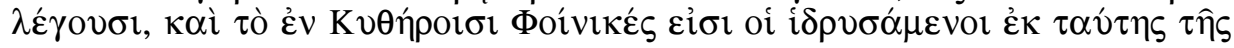

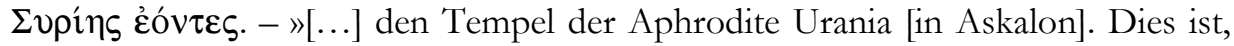
wie ich erfahren habe, der älteste aller Tempel, den die Göttin hat. Denn auch der Tempel auf Kypern ist von dort aus gegründet worden, wie die Kyprer selbst sagen. Auch den Tempel in Kythera haben Phoiniker gegründet, die aus diesem Syrien stammen«. (J. Feix)

An anderer Stelle überliefert Herodot 1, 131: $\dot{\varepsilon} \pi \mu \varepsilon \mu \alpha \theta \dot{\eta} \kappa \alpha \sigma \imath \delta \dot{\varepsilon} \kappa \alpha \grave{\imath} \tau \hat{\eta ̣ ~}$

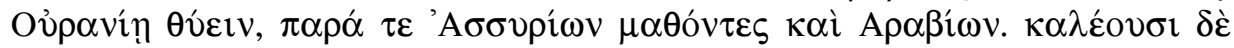

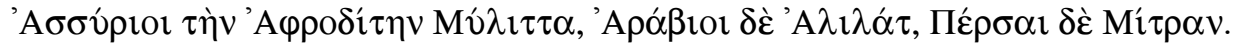
- »Dann haben sie [die Perser] auch gelernt, der Urania zu opfern, deren Kult sie von den Assyrern und Arabern übernahmen. Die Assyrer nennen die Aphrodite Mylitta, die Araber Alilat, die Perser Mitra«112. (J. Feix)

109 s. Kap. 5.3.1 und 5.2.

110 G. Steiner, Der Sukzessionsmythos in Hesiods "Theogonie" und ihren orientalischen Parallelen (Diss. Universität Hamburg 1958); A. Heubeck, Mythologische Vorstellungen des Alten Orients im archaischen Griechentum, in: E. Heitsch (Hrsg.), Hesiod (Darmstadt 1966) 545-570; A.

Lesky, Griechischer Mythos und Vorderer Orient, in: ebenda 571-601; P. Walcot, Hesiod and the Near East (Cardiff 1966); B. C. Dietrich, The Origins of Greek Religion (Berlin 1974) 53-64; W. Burkert, Die Griechen und der Orient. Von Homer bis zu den Magiern (München) 2003.

111 z. B. in Paphos, Theben, Kythera und Korinth, vgl. RE I (1894) 2729-2787 s. v. Aphrodite (F.

Dümmler); Roscher, ML VI (1924-1937) 98-105 s. v. Urania (M. Mayer); Osanna 1988/89, 74. 112 Vgl. auch Hdt. 1, 199; 3, 8. 


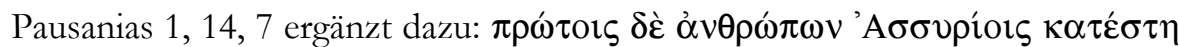

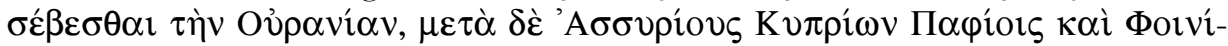

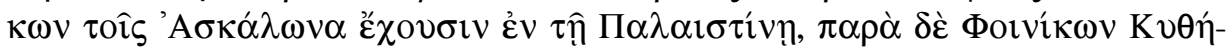

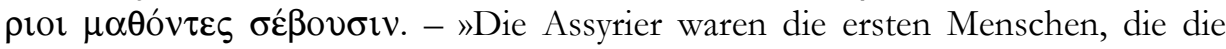
Ourania verehrten, nach den Assyriern die Paphier auf Kypros und in Phoinikien die Bewohner von Askalon in Palaistina. Von den Phoinikiern haben die Kytherier ihre Verehrung gelernt«. (F. Eckstein - P. C. Bol)

Eine der ältesten Kultstätten der Aphrodite Urania befand sich in Paphos auf Zypern. Dort wurde die Göttin in einem anikonischen Mal verehrt vergleichbar denen in orientalischen Heiligtümern. Es war kegelförmig, wie Tacitus ann. 2, 2 f. überliefert: Simulacrum deae non effigie humana, continuus orbis latiore initio tenuem in ambitum metae modo exsurgens, set ratio in obscuro. - »Das Bild der Göttin, nicht in menschlicher Gestalt, ist ein zusammenhängender, von breiterer Grundfläche aus in immer engerem Umfange, wie eine Spitzsäule sich erhebender Kreis; die Bedeutung aber bleibt dunkel ${ }^{113}$. (A. Schäfer)

Man hat dieses Mal auf kaiserzeitlichen Münzen aus Paphos dargestellt gefunden, ein kegelförmiger Stein aus Basalt im Cyprus Museum in Nikosia, der aus dem Heiligtum stammt, kann vielleicht sogar als das Kultmal selbst identifiziert werden ${ }^{114}$.

Ein Hauptzeuge für die Darstellung der orientalischen Aphrodite im griechischen Kulturraum in anikonischer oder zumindest nicht vollkommen menschlicher Gestalt ist die sog. Perservase, ein apulisch-rotfiguriger Volutenkrater des Dareiosmalers aus der Zeit um 330 v. Chr. (Abb. 4)115. Der berühmte Krater zeigt, vom Theater beeinflusst, Szenen kurz vor Ausbruch des Perserkrieges. Über einer Darstellung des zwischen seinem Hofstaat thronenden Dareios sind mehrere Götter und Personifikationen, die z. T. durch Beischriften identifiziert werden können, zu sehen. In der Mitte ist Hellas stehend dargestellt, umgeben von Athena, Zeus und

113 Vgl. Max. Tyr. 2, 8, der das Bild als pyramidenförmig ( $\pi \nu \rho \alpha \mu i ́ \delta \imath$ ) bezeichnet.

114 J. L. Myres, The Black Stone on the Site of the Paphian Temple at Kouklia, BSA 41, 1940-1945, 97 f.; RE XVIII 3 (1949) 937-964 s. v. Paphos (E. Oberhummer - J. Schmidt); F. G. Maier, Das Heiligtum der Aphrodite in Paphos, in: U. Jantzen (Hrsg.), Neue Forschungen in griechischen Heiligtümern. Symposion in Olympia 10. -12. Oktober 1974 (Tübingen 1976) 219-238;

Delivorrias 1984, 9 Nr. 1; F. G. Maier, Alt-Paphos auf Cypern. Ausgrabungen zur Geschichte von Stadt und Heiligtum 1966-1984, TrWPr 6 (Mainz 1984) 1-32; U. Kron, Heilige Steine, in: Froning 1992, 56-70. Weitere Quellen bei RE I (1894) 2756-2762 s. v. Aphrodite (F. Dümmler). Wie sich die Verbindung zwischen den anikonischen Darstellungen der Aphrodite Urania in Griechenland und denen der der orientalischen, ihr entsprechenden Göttinnen im Einzelnen gestaltet, kann im Rahmen dieser Arbeit jedoch nicht untersucht werden.

115 Neapel, Nationalmuseum Inv. 3253 (81947): T. Hölscher, Griechische Historienbilder des 5. und 4. Jahrhunderts v. Chr. (Würzburg 1973) 174-180; LIMC I (1981) 875 s. v. Apate 1 (G. G. Belloni); A. D. Trendall - A. Cambitoglu, The Red-Figured Vases of Apulia II. Late Apulian (Oxford 1982) 495 Nr. 38; LIMC II (1984) 857 s. v. Asia 1 (J. Ch. Balty); Delivorrias 1984, 11 Nr. 16; LIMC IV (1988) 628 s. v. Hellas 5 (O. Palagia); St. De Caro (Hrsg.), Il Museo Archeologico Nazionale di Napoli (Neapel 1994) 78. 

- die ersten Bilder mit ikonischer Stütze?

weiteren griechischen Göttern. Am rechten Bildrand sitzt Asia, mit der vor ihr stehenden Apate kommunizierend, auf einem Altar vor einem hermenförmigen Götterbild. Dieses hat weibliche entblößte Brüste, lange, im Nacken zusammengebundene Haare und trägt reichen Schmuck. Aufgrund des Kontextes kann damit nur ein Bild der orientalischen Aphrodite gemeint sein ${ }^{116}$.

Für das Heiligtum der Aphrodite »in den Gärten« in Athen berichtet Pausanias 1, 19, 2, dass es außer einer von Alkamenes geschaffenen Statue der Göttin ein

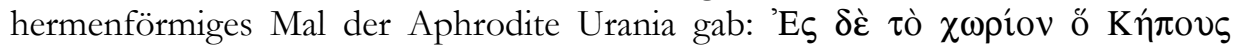

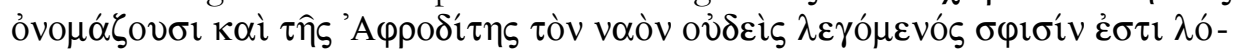

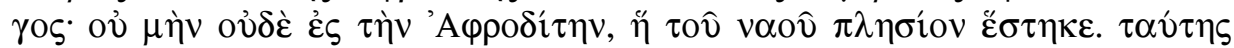

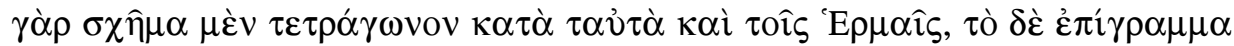

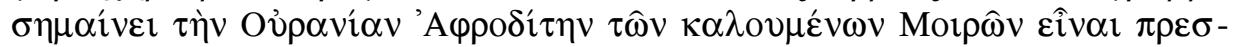
$\beta v \tau \alpha ́ \tau \eta \nu . ~-~ » I n$ bezug auf den Ort den sie »Gärten« nennen, und den Aphroditetempel wird keine Sage erzählt, auch nicht von der Aphrodite, die nahe bei dem Tempel steht; sie ist der Form nach ebenso viereckig wie die Hermen. Die Inschrift besagt, daß Aphrodite Ourania die älteste der sogenannten Moiren sei«. (F. Eckstein - P. C. Bol)

Eine weibliche Herme, die der auf dem oben beschriebenen Relief Kat. A3 erstaunlich ähnelt, ist in einem Brunnen nördlich des Hephaisteions in Athen gefunden worden (Abb. 5). Sie misst 0,3 $\mathrm{m}$ und wird in das 2. Jahrhundert v. Chr. datiert. Sie ist wie die Herme auf dem Relief bekleidet, hat ebenfalls keine Armbossen und auf ähnliche Weise zurückgesteckte lange gewellte Haare. Unter ihrem Gewand drücken sich Brüste durch. Sie trägt allerdings im Gegensatz zu der Stützherme von Kat. A3 keinen Polos ${ }^{117}$. Da Pausanias 1, 14, 7118 auch für das Gebiet nördlich der Agora, und zwar in der Nähe des Hephaisteions ein Heiligtum der Aphrodite Urania bezeugt, hat man die Herme aus dem Brunnen naheliegenderweise als Bild der Aphrodite identifiziert ${ }^{119}$. Der Zusammenhang zwischen dem von Pausa-

116 s. Anm. 115 sowie Hiller 1976, 32 und Osanna 1988/89, 77 f.

117 Athen, Agoramuseum Inv. S 1086: T. L. Shear, The Campaign of 1938, Hesperia 8, 1939, 238 f. Abb. 37; Langlotz 1954, 28; R. E. Wycherley, Literary and Epigraphical Testimonia, Agora 3 (Princeton 1957) 49 f. Nr. 106; Hiller 1976, 32 Anm. 20; Delivorrias 1984, 11 f. Nr. 20; Osanna 1988/89, 81 Abb. 2; Kunze 1992, 139 f. Nr. 47; Pirenne-Delforge 1994, 68.

118 s. S. 66.

119 s. Anm. 117. Ursprünglich haben Harrison 1965, 167-169 und Kahil 1984, 630 Nr. 76 die Herme als Artemis gedeutet, da die vielen Kinder- und Hundeskelette, die ebenfalls in dem Brunnen gefunden wurden, eher auf ein Heiligtum dieser Göttin hinweisen, wenn sie auch die Deutung als Aphrodite nicht ganz ausschließen, denn ihr Kult soll laut Paus. 1, 14, 7 in Athen wegen der Kinderlosigkeit des Aigeus eingeführt worden sein. Die Deutung als Aphroditeheiligtum ist durch Osanna 1988/89 noch einmal aufgegriffen und bekräftigt worden, wobei er die Bedeutung der Aphrodite als chthonische wie auch als Fruchtbarkeitsgöttin deutlich herausstellt. Die Häufung der Kinderknochen und ihre Bestattung innerhalb der Stadt scheinen nach Ansicht der Forschung auf eine Seuche zurückzugehen, wobei die Hunde als Reinigungsopfer anzusehen seien. 
nias überlieferten Heiligtum und der hellenistischen Herme aus dem Brunnen ist von M. Osanna mit überzeugenden Argumenten bewiesen worden ${ }^{120}$. Auch sonst sind eine Reihe von eindeutigen und weniger eindeutigen Fällen von Aphroditehermen wie auf dem bereits genannten Dareioskrater bezeugt ${ }^{121}$.

Weibliche Hermen wie die Stütze bei Kat. A3 können somit als Aphroditebild identifiziert werden. Darüber hinaus ist die Hermenform eindeutig mit dem Kult der Aphrodite Urania verbunden, was M. Osanna mit neuen Argumenten ausführlich dargelegt hat ${ }^{122}$. Hinter der Herme, auf die sich Aphrodite bei einigen Darstellungen lehnt, stehe laut M. Osanna »el legame col mondo orientale« dieser speziellen Kultform der Göttin ${ }^{123}$. Da die Statue der Aphrodite Urania in Elis einen Fuß auf eine Schildkröte gestellt hat, muss sie hingegen vollkommen menschlich gebildet gewesen sein. Damit ist für Darstellungen der Aphrodite Urania im griechischen Kulturraum einerseits die Hermenform, andererseits die vollkommen menschliche Gestalt bezeugt. Die antiken Quellen überliefern zum Aussehen der elischen Statue darüber hinaus nur die Schildkröte, auf die Aphrodite auch bei einigen der aufgelehnten Bilder ihren Fuß setzt. Daher stellt sich, wie in der Forschung schon

120 Osanna 1988/89.

121 s. S. 71, weitere Beispiele: Bleifiguren des 4. Jahrhunderts v. Chr. aus Olynth: D. M. Robinson, Metal and Minor Miscellaneous Finds. An Original Contribution to Greek Life, Olynthus 10 (Baltimore 1941) Taf. 2 f.; hellenistische Terrakottastatuetten aus Knidos und Kalymnos: Delivorrias 1984, 11 Nr. 19. Vgl. auch die weibliche Herme auf einem attisch-rotfigurigen Krater im Athener Nationalmuseum Inv. 1669, der Eros Opfer darbringt. Sie ist durch die Frisur, die Bartlosigkeit und die Bekleidung eindeutig von der neben ihr stehenden männlichen Herme unterschieden und wird von Delivorrias 1984, 11 Nr. 14 als Bild der Aphrodite gedeutet. Für weitere mögliche Aphroditehermen vgl. Delivorrias 1984, 10-12 Nr. 11-24; Wrede 1985, 17-31. Daneben gab es vereinzelt auch Darstellungen anderer Göttinnen in Hermenform, z. B. die von H. Herdejürgen publizierten Terrakottastatuetten der Artemis aus der 1. Hälfte des 4. Jahrhunderts, bei denen die Göttin auf einer sie selbst darstellende Herme lehnt und das hermenförmige Bild der Artemis Orthia aus Messene aus dem 1. Jahrhundert v. Chr., s. Kap. 6.3.3. und 12.11. Vgl. auch Wrede 1985, 17-31.

122 Osanna 1988/89.

123 Ebenda 77 f. Die Verbindung zu anikonischen Götterdarstellungen wie der Aphrodite von Paphos oder orientalischen, der Aphrodite entsprechenden Göttinnen lässt auch er offen, da bisher weder diese Verbindung noch der zeitliche Ursprung der Darstellung der Aphrodite Urania in Form einer Herme genau erforscht sind. Ähnlich auch schon Ferri 1927, 123; Helbig I ${ }^{4}$ (Tübingen 1963) 719 Nr. 1001 (W. Fuchs); Hiller 1976, 32, Delivorrias 1984, 10 f.; Kunze 1992, 139 f. Nr. 47. Dass die Hermenform selbst nicht aus dem Orient übernommen wurde, belegen die in Kap. 6.3.3. aufgeführten Artemishermen, für die im Gegensatz zu Aphrodite Urania kein enger Bezug zum Orient bestand. Vgl. dazu auch Wrede 1985; Rückert 1998.

Daneben greift Osanna 1988/89, 76-79 auch den bereits von Settis, 1966, 113. 158 f. vorgetragenen Vorschlag auf, die Herme aufgrund ihrer phallischen Form vielleicht in Verbindung mit der bei Hesiod theog. 188-199 (vgl. S. 68) bezeugten Geburt der Aphrodite aus dem durch Kronos abgeschlagenen Glied des Uranos zu sehen, die Aphrodite einerseits als himmlische Göttin, andererseits als »in qualche modo virile« charakterisiert. Auch nach Ansicht von S. Settis stand die Herme durch ihre Form für den männlichen Anteil am Wesen der Göttin wie auch für den Aspekt der Aphrodite als Himmelsgöttin, welche durch die Geburt aus dem Glied des Uranos begründet seien. 

- die ersten Bilder mit ikonischer Stütze?

lange diskutiert wurde die Frage, ob das Aussehen der elischen Statue mit Hilfe der hier betrachteten Aphroditebilder rekonstruiert werden kann und wenn ja, welche Form der Stütze man sich vorstellen muss. Denn die Herme ist zwar, wie gerade gesehen wurde, mit Aphrodite Urania besonders verbunden. Als Stütze für Bilder, bei denen die Göttin einen Fuß auf eine Schildkröte stellt sowie den übrigen zu diesem Typus gehörenden Darstellungen ist sie aber kaum belegt. Diese ist stattdessen häufig in Form einer weiblichen archaistischen Figur gebildet.

\subsection{Die Verbindung des Typus mit den Statuen in Elis und Athen und die Frage nach den Stützen dieser Statuen}

Die Verbindung zwischen den Aphroditebildern mit den ikonischen Stützen und der Statue der Aphrodite Urania in Elis wurde schon lange gezogen. H. Froning hat vor kurzem hingegen eine Verbindung des hier untersuchten Typus mit einer Statue der Aphrodite Urania in Athen vorgeschlagen, wie in Kapitel 5.1.2 bereits angesprochen worden ist. Damit hat sie die Diskussion um das gesuchte Urbild des Typus neu entfacht. Das hier zusammengestellte Material umfasst deutlich mehr Bilder als die bisherigen Untersuchungen. Es kann zwar nicht als vollständig, aber doch repräsentativ angesehen werden. Deshalb scheint es sinnvoll, die Frage nach der Verbindung mit der Aphrodite Urania in Elis bzw. Athen noch einmal aufzugreifen. Daran schließen sich die Fragen nach der dann auch für die elische oder athenische Statue anzunehmenden Stütze und der Form der verlorenen Stütze der >Aphrodite Brazzà an. Zunächst sollen die bisher von der Forschung vorgetragenen Meinungen referiert und anschließend das gesammelte Material auf die Frage nach der Verbindung des Typus der auf eine ikonische Stütze gelehnten Aphrodite mit den Statuen in Elis und Athen geprüft werden.

\subsubsection{Die Meinung der Forschung}

Die Schildkröte bot stets den Anlass, die Berliner Statue Kat. A1 mit dem durch Pausanias überlieferten Bild der Aphrodite Urania in Elis zu verbinden. Sie wird nahezu durchgängig in die Zeit um 430/20 v. Chr. datiert, also in die Zeit, als Phidias nach Ansicht der Forschung in Olympia und in Elis tätig gewesen ist ${ }^{124}$. Als erster hat A. Frickenhaus in einem Aufsatz zu der Aphrodite von Elis von 1913 in der >Aphrodite Brazzàr eine zeitgenössische Wiederholung des elischen

${ }^{124}$ W. Schiering, Archäologischer Befund, in: A. Mallwitz - W. Schiering, Die Werkstatt des Pheidias in Olympia, OF 5 (Berlin 1964) 272; Chr. Triebel-Schubert, Zur Datierung des Phidiasprozesses, AM 98, 1983, 101-112; Schneider - Höcker 1993, 14. 112; EAA Suppl. II 2 (1994) 644-658 s. v. Fidia (A. Delivorrias); N. Spivey, Understanding Greek Sculpture. Ancient Meanings, Modern Readings (London 1996) 158; DNP IX (2000) 760-763 s. v. Pheidias (R. Neudecker). 
Werkes angenommen ${ }^{125}$. Die Frage nach der Stütze hat er nicht problematisiert. In der Deutung der >Aphrodite Brazzàı als Wiederholung des Phidiaswerkes sind ihm B. Schweitzer, E. Langlotz, F. Brommer, A. De Franciscis und M. Bieber gefolgt ${ }^{126}$. Auch sie thematisierten die Frage nach einer möglichen Stütze bei der elischen Aphrodite nicht.

Eingegangen auf die Frage nach der Stütze sind hingegen A. Schober in seinem Aufsatz zur Aphrodite von Elis von 1924127 und H. Schrader in seiner ebenfalls 1924 veröffentlichten Monographie zu Phidias ${ }^{128}$. Für sie ging das in Scalanova gefundene Marmorfragment Kat. A12 auf die elische Aphrodite zurück, da der Gewandstil der Statuette auf ein Vorbild aus der 2. Hälfte des 5. Jahrhunderts v. Chr. und dem Phidiaskreis hinweise ${ }^{129}$. Da die Stütze bei dieser Figur in Form eines weiblichen Idols gebildet ist, hielten sie eine solche auch bei dem Werk des Phidias für sicher. Die >Aphrodite Brazzàı für eine Rekonstruktion der elischen Statue heranzuziehen, lehnten beide ab, da die Schildkröte neuzeitlich und der Gewandstil nicht passend seien ${ }^{130}$. Für H. Schrader kann die >Aphrodite Brazzà aber eine freie Variante des phidiasischen Typus sein, falls die Schildkröte bereits in der Antike vorhanden gewesen ist ${ }^{131}$.

Für G. Becatti gingen sowohl das Fragment Kat. A12 wie auch weitere Werke mit gleichen typologischen Merkmalen auf ein gemeinsames Urbild zurück, und zwar auf die Statue der Urania in Elis, wie er in seinen Untersuchungen zu Phidias von 1951 dargelegt hat ${ }^{132}$. Die >Aphrodite Brazzàı, deren Stütze G. Becatti als archaistisches Idol rekonstruierte, hielt er für die andere Statue der Aphrodite Urania des Phidias in der Nähe der Athener Agora, die eventuell eine Nachbildung der Statue in Elis gewesen sei ${ }^{133}$, worauf ich noch einmal zurückkommen werde. Letztere lehnte sich seiner Ansicht nach ebenfalls auf ein Idol ${ }^{134}$.

Andere Autoren rekonstruieren die Statue in Elis mit einer weiblichen Herme als Stütze mit Hilfe von Aphroditebildern, die ebenfalls einen Fuß auf eine Schildkröte setzen, sich jedoch auf eine (manchmal gleichfalls rekonstruierte) Herme lehnen. Da in Kapitel 5.1.3 bereits dargelegt worden ist, dass die Hermenform

125 Frickenhaus 1913, 363-367.

126 B. Schweitzer, Phidias der Parthenonmeister, JdI 55, 1940, 194; Langlotz 1947, 83 f.; Brommer 1950, 83; EAA I (1958) 120 s. v. Afrodite (A. De Franciscis); Bieber 1977, 94.

127 A. Schober, Zu den elischen Bildwerken der Aphrodite, ÖJh 21/22, 1922-24, 222-228.

128 Schrader 1924, 73 f.

129 A. Schober, Zu den elischen Bildwerken der Aphrodite, ÖJh 21/22, 1922-24, 223-225; Schrader $1924,73 \mathrm{f}$.

130 A. Schober, Zu den elischen Bildwerken der Aphrodite, ÖJh 21/22, 1922-24, 222. 224; Schrader 1924, $73 \mathrm{f}$.

131 Schrader 1924, 74.

132 Becatti 1951, $207 \mathrm{f}$.

133 Ebenda 209-211; die Statue in Athen ist bei Paus. 1, 14, 7 überliefert. Ausführlicher dazu Kap. 5.3.

134 Becatti 1951, $210 \mathrm{f}$. 

- die ersten Bilder mit ikonischer Stütze?

besonders mit Aphrodite Urania verbunden und in der Antike mehrfach belegt ist, ist die Rekonstruktion mit einer Hermenstütze sehr gut denkbar. Die umfangreichste Untersuchung zu diesem Thema ist die 1966 von S. Settis veröffentlichte Monographie zur Aphrodite Urania, in der er sich intensiv mit der ^Aphrodite Brazzàr auseinandergesetzt hat ${ }^{135}$. Er sah unter ihrem aufgelehnten Arm wie oben besprochen wurde noch Reste von Haaren, weshalb nur eine Herme als Stütze gedient haben könne ${ }^{136}$. Vergleichend dazu hat er weitere Bilder mit einer Hermenstütze herangezogen, darunter die Marmorstatuette Kat. A22, bei der die Herme nicht zweifelsfrei als weiblich identifiziert werden kann, sowie die oben bereits betrachteten Darstellungen der Aphrodite in Hermenform, ${ }^{137}$. Des Weiteren führte er an, dass durch den Stil der >Aphrodite Brazzàr eine Datierung in die Zeit des Phidias gegeben sei und durch die Schildkröte wiederum eine Abhängigkeit von dem phidiasischen Werk in Elis. Deshalb sah er in der Berliner Statue - natürlich noch ohne Kenntnis des Terrakottafragmentes aus Elis - »una fedele riproduzione«138 des elischen Aphroditebildes, das ebenfalls die Herme als Stütze gehabt habe. Aphroditebilder mit einem weiblichen Idol oder einem Pfeiler als Stütze stellten für S. Settis demzufolge Varianten der phidiasischen Statue dar, und zwar: wil pilastrino come un'ovvia semplificazione, l'idoletto panneggiato come un tentativo di rendere piú evidente il sesso della figura «139.

S. Settis' These von der weiblichen Herme als Stütze der >Aphrodite Brazzàr und der Statue von Elis ist mehrfach aufgegriffen worden, u. a. durch St. Hiller in seinem Aufsatz über Statuenstützen im 5. Jahrhundert v. Chr. von $1976^{140}$ und M. Kunze im Katalog der Antikensammlung der Berliner Museen von 1992141. Als weitere Belege nennen beide die Marmorstatuette Kat. A22 und das Marmorrelief Kat. $A 3$ - bei dem die Göttin jedoch nicht auf eine Schildkröte tritt - die beide eine Hermenstütze haben. Jedoch ist nur für Kat. $A 3$ gesichert, dass die Herme weiblich ist. Einen zusätzlichen Beweis sah St. Hiller in der von Pausanias ${ }^{142}$ erwähnten Aphrodite Urania-Herme in Athen und M. Kunze in der auf der Athener Agora gefundenen Herme ${ }^{143}$.

Für die Vorstellung, dass Aphrodite Urania in Athen in Form einer weiblichen Herme dargestellt werden konnte, hat M. Osanna in Aufsatz von 1988/89 entscheidende neue Argumente beigetragen. Durch die Klärung der Lage des von

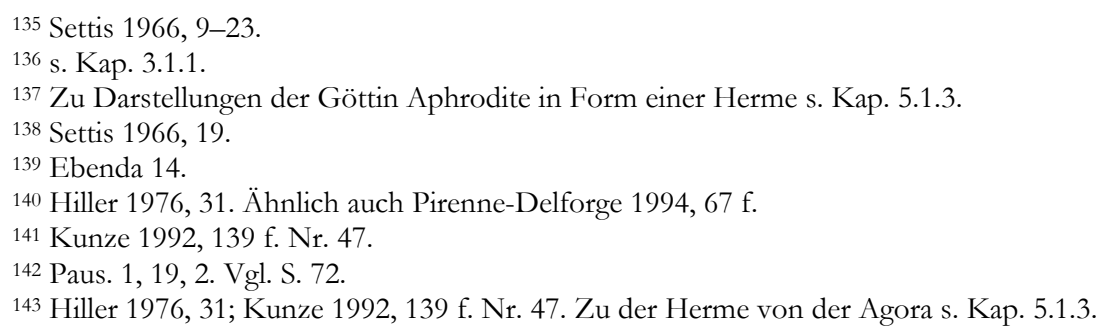


Pausanias 1, 14, 7144 in der Nähe des Hephaistostempels in Athen beschriebenen Heiligtums konnte er die Identifizierung der kleinen, in dieser Gegend gefundenen weiblichen Herme als Darstellung der Aphrodite Urania und damit zugleich alle anderen Indizien für diese Ikonographie der Göttin sichern ${ }^{145}$. Die Stütze der Aphrodite von Elis stellt er sich daher ebenfalls in dieser Form vor und auch die >Aphrodite Brazzàr, die für ihn »la «copia» più fedele« der elischen Statue ist, rekonstruiert er den Ausführungen von S. Settis zustimmend mit einer Stütze in Form einer weiblichen Herme ${ }^{146}$.

Weitere Autoren halten zwar eine Stütze bei der elischen Statue für sicher, legen sich aber nicht auf eine bestimmte Form für diese fest. So rekonstruierte $\mathrm{S}$. Ferri die Statue des Phidias in seinem Aufsatz von 1927 mit Hilfe der Marmorstatuetten Kat. A12 und A22, die beide ihren Fuß auf eine Schildkröte stellen ${ }^{147}$. An diese schloss er andere, ihnen typologisch entsprechende Beispiele ohne die Schildkröte, aber mit einem Idol, einer Herme oder einem Pfeiler als Stütze an. Da die Stütze damit variiert, hielt S. Ferri die Frage nach der Form der Stütze des Urbildes nicht für entscheidbar. Die >Aphrodite Brazzàr hatte seiner Meinung nach eine Hermenstütze ${ }^{148}$. Nach Ansicht von A. Delivorrias, der die $>$ Aphrodite Brazzà Kat. A1 im Rahmen der Klassik-Ausstellung in Berlin im Jahr 2002 nach ihrer Restaurierung neu publiziert hat, kann man mit ihrer Hilfe die Statue von Elis gedanklich wiederherstellen ${ }^{149}$. Da sich bei der Restaurierung keine neuen Anhaltspunkte dafür ergaben, welche Stütze zu ergänzen sei, hält auch er sowohl ein archaistisches Idol als auch eine Herme für möglich ${ }^{150}$.

E. B. Harrison hat in einem 1984 erschienen Aufsatz den Kopftypus »Sappho« der Aphrodite Urania zugeschrieben ${ }^{151}$. In diesem Aufsatz geht sie auch auf die Frage nach der Stütze bei der >Aphrodite Brazzàr sowie deren Urbild ein, in dem

144 Dazu s. Kap. 5.1.3.

145 Osanna 1988/89, bes. 77-79.

146 Schneider - Höcker 1993, 110-112. hingegen rekonstruieren eine männliche Herme, »ein Motiv, das für die Tochter des Uranos gut passen würde«, ohne dies näher auszuführen. Alle weiteren Bilder der Aphrodite mit der Schildkröte sind für sie freie Varianten nach dem elischen Typus. Zum männlichen Aspekt des Wesens der Aphrodite Urania vgl. die Deutung bei Settis 1966 und Osanna 1988/89, s. Anm. 123.

${ }^{147}$ Ferri 1927, 117-123.

148 Ebenda 123.

149 A. Delivorrias, Bildwerk und Kopie, in: Klassik 2002, 347.

${ }^{150}$ Ebenda. Ebenso M. Hagelberg, Nr. E9 „Aphrodite auf der Schildkröte“, in: Stemmer 2001, 87.

151 Sie begründet dies damit, dass der Kopf mehrfach in Hermenform überliefert ist und Paus. 1, 19, 2 (vgl. hier S. 72) diese Form für Aphrodite Urania bezeugt. Die Herme sei ihrer Ansicht nach » appropriate to the meaning of this Aphrodite, and that may indicate to us what kind of Aphrodite she was«. Durch Stilvergleiche ordnet sie den Typus Phidias zu. Aufgrund von Merkmalen, die das Urbild zumindest teilweise aus Metallwerk ausweisen, möchte sie den Kopf der Statue in Elis zuweisen, da diese aus Gold und Elfenbein war, s. Harrison 1984, das Zitat S. 382. 

- die ersten Bilder mit ikonischer Stütze?

sie aufgrund der Schildkröte die elische Statue sieht. Sie vermutet als einzige, dass es sich bei der Stütze um »a simple, stonelike form of column, which could symbolize the pillar that holds up the sky or the aniconic image of the eastern goddess with whom Ourania was identified « gehandelt hat ${ }^{152}$. Sie begründet ihre Rekonstruktion damit, dass einige Nachbildungen des elischen Werkes einen einfachen Pfeiler als Stütze haben und Aphrodite Urania auch als rechteckige Herme dargestellt wurde, wie es Pausanias für die Aphrodite $\dot{\varepsilon} \nu$ kn் $\pi$ oı bezeugt ${ }^{153}$. Eine Herme ist aber nicht unbedingt mit einem Pfeiler gleichzusetzen. Auch wenn anikonische Male und darunter auch solche in Pfeilerform durchaus verbreitet waren ${ }^{154}$, können Pfeiler nicht in jedem Fall als solche gedeutet werden. Darüber hinaus belegen die zahlreichen hier zusammengestellten Beispiele die Häufigkeit der ikonischen Stütze, die demnach für das Urbild nicht ausgeschlossen werden kann. Die Identifizierung des Kopftypus ॥Sappho« als zu der elischen Statue des Phidias gehörig scheint mir ebenfalls nicht ausreichend begründet ${ }^{155}$.

Als Ergebnis der Zusammenstellung der bisherigen Forschung lässt sich festhalten, dass häufig über die Schildkröte ein Bezug zwischen einigen Aphroditebildern mit einer ikonischen Stütze (Kat. A1. A3. A12 und A22) und der Statue in Elis hergestellt wird. Daran schloss sich die Frage an, ob demnach die Aphrodite von Elis als Urbild des Typus ebenfalls mit einer figürlichen Stütze zu rekonstruieren sei. Die aufgelehnten Aphroditedarstellungen bedienen sich einerseits eines weiblichen archaistischen Idols, andererseits einer Herme sowie eines Pfeilers als Stütze. In der Forschung wurde jeweils eine dieser Stützenformen der aufgelehnten Aphroditebilder - die, da einige von ihnen einen Fuß auf eine Schildkröte setzen, den Typus der Aphrodite von Elis wiedergeben sollen - bevorzugt.

\subsubsection{Rekonstruktion der Aphrodite Urania-Statuen durch das vorliegende Material}

In der Forschung ist, wie eben gesehen wurde, bereits mehrfach eine Verbindung zwischen den Aphroditebildern mit ikonischen Stützen und der elischen Statue der Aphrodite Urania hergestellt worden, während H. Froning eine Verbindung mit der athenischen Statue vorgeschlagen hat ${ }^{156}$. Im Folgenden soll deshalb das hier zusammengestellte Material auf die Frage hin geprüft werden, ob der Typus der auf eine ikonische Stütze gelehnten Aphrodite auf eine phidiasische Erfindung zurückgehen kann und ob das Material zusätzliche Argumente dafür bringt. Inzwischen sind weitere Aphroditebilder, bei denen die Göttin einen Fuß auf eine

\footnotetext{
152 Harrison 1984, 386.

153 Ebenda. Zu Paus. 1, 19, 2 vgl. S. 72.

154 Vgl. Anm. 211.

155 Zu den Argumenten von E. B. Harrison s. Anm. 151.

156 s. S. 69.85.
} 
Schildkröte setzt, entdeckt und publiziert worden. Deshalb erscheint es berechtigt, die Frage, ob Kopien oder Varianten der Aphrodite Urania des Phidias erhalten sind, erneut zu stellen.

Bei den in Kapitel 3 betrachteten Aphroditebildern mit einer weiblichen Stützfigur ist diese nahezu durchgängig in Form eines archaistischen Idols gebildet. Siebenundvierzig Exemplare mit einem Idol als Stütze stehen maximal drei Beispielen (wenn man die Herme bei Kat. A22 und $A 51$ als weiblich ansieht) mit einer Hermenstütze gegenüber. Vor allem für die >Aphrodite Brazzàı Kat. $A 1$, bei der die Schildkröte zwar neuzeitlich ergänzt, die Rekonstruktion des Tieres unter dem Fuß aber nicht unwahrscheinlich ist ${ }^{157}$, ist, wie erwähnt, bereits oft eine Verbindung zu dem Werk des Phidias hergestellt worden ${ }^{158}$. Ein zweites Werk des 5. Jahrhunderts stellt die Marmorstatuette aus Tarquinia Kat. A2 dar, die von der Forschung einhellig in die Zeit um $410 \mathrm{v}$. Chr. datiert wird. Bei ihr ist die als Stütze dienende Figur erhalten, ein archaistisches weibliches Idol. Aufgrund der Unterschiede in der Haltung und Gewanddrapierung können die beiden Berliner Aphroditebilder nicht als Repliken, jedoch als Varianten gelten. Das bei beiden gleiche Grundschema der Haltung mit dem aufgelehnten linken Unterarm, dem nach links verschobenen Oberkörper und dem vorgesetzten Fuß lassen aber den Gedanken aufkommen, dass auch die Aphrodite aus Tarquinia auf einen Typus in der Art der >Aphrodite Brazzàı zurückgeht.

$\mathrm{Zu}$ diesen beiden Aphroditebildern kommen weitere Werke, die zwar keine genauen Kopien sind, aber offensichtlich in den Attributen der Stütze und der Schildkröte als auch in der Haltung und Gewanddrapierung insgesamt den Typus leicht verändert wiedergeben. Dazu zählen die schon mehrfach zur Rekonstruktion des Urbildes herangezogene ${ }^{159}$, zeitlich nicht genau einzuordnende Marmorstatuette aus Scalanova Kat. A12 und eine kaiserzeitliche Marmorstatue in Madrid (Kat. A14), außerdem die hellenistischen und kaiserzeitlichen Marmorstatuetten Kat. A4. A7. A19. A22 und A24. Damit liegen mindestens 8 Aphroditebilder vor, die einen Fuß auf eine Schildkröte stellen und sich auf eine ikonische Stütze lehnen (bei Kat. $A 1$ sind die Form der Stütze und die Schildkröte aber nicht gesichert). Sie bzw. ihre Vorbilder werden selbst in das 5. Jahrhundert v. Chr. datiert, oder stehen nach Ansicht der Forschung zumindest in der Tradition eines hochklassischen Typus. Da sie in ihrer Haltung und Gewanddrapierung weitgehend übereinstimmen, kann man über sie das Aussehen des Urbildes erschließen ${ }^{160}$.

\footnotetext{
157 s. Kap. 3.1.1.

158 s. Kap. 5.2.1.

159 A. Schober, Zu den elischen Bildwerken der Aphrodite, ÖJh 21/22, 1922-24, 223-225; Schrader 1924, 73 f.; Becatti 1951, 207 f. bzw. EA 154.

${ }^{160}$ Die Abweichungen bei der unteritalischen Statuette Kat. $A 2$ können so erklärt werden, dass sie nach einem nach Italien exportierten Modell geschaffen wurde, das entweder nicht alle Einzelheiten genau wiederholte oder das der Bildhauer nach eigenem Geschmack umbildete. So auch
} 
Von den anderen hellenistischen und kaiserzeitlichen Aphroditebildern mit einem weiblichen Stützidol haben weitere sechzehn das Motiv des erhöht aufgesetzten Fußes dahingehend abgewandelt, dass sie ihn entweder auf die Basis des Idols (Kat. A8. A20. A25. A32. A33), eine Gans (Kat. A5) oder einen nicht mehr zu erkennenden Gegenstand stellen (Kat. A6. A18. A21. A23. A26-A31). Die übrigen setzen zumindest den linken Fuß nach vorn. Sie zeigen wieder die bereits bekannten Haltungs- und Gewandmotive wie das nach innen gedrehte linke Knie bei gleichzeitig nach außen gesetztem linken Fuß, die ausschwingende rechte Hüfte, den geraden Rücken und den zumeist mit einem Wulst um die Hüften geführten Hüftmantel. Dazu verlagern alle das Gewicht des Oberkörpers zu der Seite, an der die Stütze steht, haben aber gleichzeitig den Oberkörper gerade aufgerichtet.

Aufgrund der festgestellten Merkmale lassen sich die Aphroditedarstellungen mit den weiblichen Idolen typologisch zusammenschließen. Sie sind durch die eben noch einmal zusammengefassten Merkmale gekennzeichnet, lediglich in einzelnen Haltungs- oder Gewandmotiven variiert und daher von einem Typus abhängig ${ }^{161}$.

Hermen als Stützen sind für diesen Typus hingegen nur sehr selten festzustellen. Das älteste Beispiel ist das Relieffragment im Vatikan Kat. A3, das offenbar um 400 v. Chr. in einer attischen Werkstatt entstanden ist ${ }^{162}$. Es ist zeigt Aphrodite, die wie die anderen bereits betrachteten auch mit dem Gewicht auf dem rechten Bein steht. Der Fuß des Spielbeins ist aber bei dieser Darstellung nicht nach vorn, sondern mit angehobener Ferse leicht nach hinten gesetzt. Der linke Ellenbogen der Göttin ruht auf dem Polos einer weiblichen Herme.

Daran lässt sich die kaiserzeitliche Marmorstatuette aus Kyrene Kat. A22 anschließen. Auch sie hat eine Herme als Stützfigur. Ihre Körperhaltung stimmt bis auf marginale Abweichungen mit der der >Aphrodite Brazzàı sowie deren typologischen Nachfolgern überein, nur die rechte Schulter ist etwas mehr nach vorn gezogen und der Oberköper ein wenig mehr in Richtung der Stütze geneigt. Sie hat das linke Bein nach vorn auf eine deutlich erkennbare Schildkröte gesetzt.

Außer bei den genannten Beispielen kommt eine vermutlich weibliche Herme nur noch auf der szenischen Darstellung der apulisch-rotfigurigen Amphora (Kat. A51) vor. Diese zeigt allerdings eine sitzende Aphrodite. Für die Suche nach dem Original bringt das Vasenbild daher keine Hilfe, da zumindest die Statue in Elis laut Pausanias 6, 25, $1^{163}$ eine stehende Statue gewesen ist.

Bieber 1977, 95.

161 Vgl. Delivorrias 1984, 27.

162 s. Anm. 41.

163 s. S. 65 f. 


\subsubsection{Andere Aphroditebilder mit der Schildkröte}

Die Schildkröte kommt außer bei den genannten Aphroditebildern noch bei einigen weiteren Statuetten der Göttin vor, die keine ikonische Stütze haben. Diese lehnen sie sich typologisch an die Aphroditebilder mit den ikonischen Stützen an.

Eine späthellenistische Marmorstatuette von der Agora von Kyrene ist von C. Anti publiziert worden $(A b b .6)^{164}$. Erhalten ist der Unterkörper bis in Höhe des Bauchnabels sowie der aufgelehnte linke Unterarm. Die Figur hat einen Pfeiler als Stütze und trägt einen Chiton und einen Hüftmantel. Ihr linker Fuß ruht auf einer zwar bestoßenen, doch noch erkennbaren Schildkröte. Sie entspricht typologisch der Statuette Kat. A22165.

Eine hellenistische Marmorstatuette im Kanellopoulos-Museum in Athen (Abb. 7)166 entspricht in ihrem Aussehen der halbbekleideten Variante des Typus der Aphrodite mit der ikonischen Stütze (Kat. A18-33) und gehört daher ebenfalls zu dem hier untersuchten Typus. Der linke Fuß ist auf eine eindeutig erkennbare, frontal gesehene Schildkröte gesetzt, als Stütze dient wie bei der Statuette aus Kyrene ein Pfeiler. Der rechte Arm ist verloren. Eine Bruchstelle an der rechten Hüfte zeigt, dass die Hand an die Hüfte geführt war und den Mantel hielt wie Kat. A29. Der Kopf ist ebenfalls abgebrochen. Um den Unterkörper hat die Göttin einen Mantel geschlungen, der auch den Rücken und die linke Schulter bedeckt. Beide Enden werden von dem aufgelehnten Arm gehalten.

Ebenfalls einen Pfeiler als Stütze zeigt eine Marmorstatuette, die sich heute in Bern im Privatbesitz befindet und aus Kleinasien stammen soll $(A b b .8)^{167}$. Sie wird in das 1. Jahrhundert v. Chr. datiert. Auch diese Figur steht auf dem rechten Bein. Das linke ist entlastet und angewinkelt. Der Fuß ist auf eine Schildkröte gesetzt. Der linke Unterarm ruht auf einem schmalen, hüfthohen Pfeiler. Der rechte Arm ist vor den Bauch geführt. Mit der Hand hielt die Göttin ihren Mantel fest. Dieser ist um den Unterkörper gelegt und zwar so, dass beide Enden vorn zusammenlaufen, sich überkreuzen und beiderseits des linken Knies herabfallen. Unter dem Mantel trägt die Figur einen Chiton, der von der linken Schulter gerutscht ist. Der Kopf und die beiden Hände sind verloren. Die Gewanddrapierung ist also anders als bei den Aphroditen mit den ikonischen Stützen, die Abhängigkeit von dem Typus aber unverkennbar.

\footnotetext{
164 Shahat, Antikenmuseum Inv. 14.290: Anti 1927 Abb. 2; Delivorrias 1984, 43 Nr. 313; Dumoulin 1994, 70 Nr. 3.

165 Dazu s. auch Kap. 5.2.4.

166 Athen, Kanellopoulos-Museum Inv. 1600: M.-A. Zagdoun, Collection Paul Canellopoulos XI. Sculptures I, BCH 102, 1, 1978, 309-311 Abb. 22; Delivorrias 1984, 67 Nr. 579; Dumoulin 1994, 69 Nr. 1 Abb. 16.

167 Bern, Privatbesitz: D. Boschung, Eine späthellenistische Aphrodite-Statuette, HASB 4, 1978, 5-10 Taf. 1 f.; Dumoulin 1994, 70 f. Nr. 4 Abb. 18.
} 
Eine Marmorstatuette aus Viterbo in Kopenhagen ist ein eklektisches Werk und verbindet die Merkmale zweier verschiedener Aphroditetypen (Abb. 9) ${ }^{168}$. Der Körpertypus entspricht aufgrund des ausgestreckt aufgestützten Arms und der starken Körperneigung in Richtung des niedrigen Stützpfeilers mit dem Gefäß dem Typus >Venus Marinar aus spätklassischer Zeit ${ }^{169}$. Der erhöht vorgesetzte linke Fuß mit der Schildkröte ist hingegen von dem Typus mit der ikonischen Stütze übernommen. Die Figur trägt einen Hüftmantel, der Oberkörper ist entblößt. Der heute nicht mehr erhaltene rechte Arm war erhoben. Auch der Kopf ist verloren.

Eine weitere hellenistische Marmorstatuette, die einen Fuß auf eine Schildkröte stellt, sich aber nicht aufstützt, stammt aus Dura-Europos (Abb. 10)170. Sie steht auf dem rechten Bein, der linke Fuß ist erhöht aufgesetzt, die rechte Hüfte schwingt stark aus. Die Figur ist durch den gleichen S-Schwung gekennzeichnet wie die Darstellungen mit den Stützen, auch die Schultern sind kontrapostisch zu den Hüften schräg gestellt. Der Kopf und die Arme fehlen. Sie trägt einen hoch gegürteten Chiton und einen Hüftmantel, dessen Oberkante zu einem Wulst eingedreht ist. Der gleiche Typus liegt in einer weiteren, kaiserzeitlichen Marmorstatuette aus Paphos vor, die ebenfalls ihren Fuß auf eine Schildkröte setzt (Abb. 11)171. Sie stammt aus dem >Haus des Dionysos‘. Auch bei dieser Statuette sind der Kopf und die Arme verloren. Aufgrund der deutlichen typologischen Übereinstimmungen gehen beide Statuetten offenbar auf ein und dasselbe Vorbild zurück. Dieses war offenbar eine Variante des Typus der aufgelehnten Aphrodite ohne Stütze.

Die Übersicht hat gezeigt, dass die Rekonstruktion des Urbildes mit einer Stütze am wahrscheinlichsten ist. Die Variante ohne Stütze ist nur selten belegt und ist offenbar von demselben Typus abgeleitet. Die Pfeilerstütze kann als vereinfachte Stützenform aufgefasst werden oder von weiteren aufgelehnten Aphroditetypen, auf die ich in Kapitel 6.1 eingehen werde, übernommen sein. Dass solche Variationen vorgenommen wurden, ist allgemein bekannt. Als Beispiel möchte ich hier nur noch eine modern zu einer Melpomene ergänzte Marmorstatue in St. Petersburg nennen (Abb. 12)172. Sie gleicht der >Aphrodite Brazzà Kat. A1 sowohl in der Haltung als auch in der Gewanddrapierung deutlich und lehnt sich offenbar an denselben Typus an. Das Gewicht ihres Oberkörpers ist jedoch nicht so weit

\footnotetext{
168 Kopenhagen, Nationalmuseum Inv. 3422: B. Kapossy, Brunnenfiguren der hellenistischen und römischen Zeit (Zürich 1969) 15 Abb. 4; G. Becatti, Ninfe e divinità marine. Ricerche mitologiche iconografiche e stilistiche, Studi miscellanei 17 (Rom 1970/71) 31 Taf. 34, 60.

169 s. Anm. 89.

170 Paris, Louvre Inv. AO 20.126: F. Cumont, Fouilles de Doura-Europos (1922-1923) (Paris 1926) 206-216 Taf. 80 f. Anti 1927 Abb. 7; Delivorrias 1984, 45 Nr. 334; Dumoulin 1994, 71 f. Nr. 6.

171 Paphos, Museum Inv. 70/73: K. Nicolaou, Archaeological News from Cyprus, 1973, AJA 79, 1975, 131 Taf. 30b; Delivorrias 1984, 44 Nr. 327; Dumoulin 1994, 71 Nr. 5 Abb. 19.

172 St. Petersburg, Eremitage Inv. A378: Frickenhaus 1913 Abb. 8; Delivorrias 1984, 27 f. Nr. 176.
} 
nach links verschoben, weshalb sie keine Stütze benötigt. Im Umkehrschluss heißt dies: der Bildhauer wollte eine Statue ohne Stütze schaffen und hat deshalb die Ponderation des Körpers verändert.

\subsubsection{Zusammenfassung}

Von den hier untersuchten Aphroditebildern stellen mindestens 5, vielleicht sogar 8 ihren Fuß auf eine Schildkröte ${ }^{173}$. Für die von Pausanias erwähnte Statue der Aphrodite Urania des Phidias in Elis ist als einzige überliefert, dass sie in der 2. Hälfte des 5. Jahrhunderts v. Chr. dieses Motiv zeigte, für die zweite Statue der Aphrodite Urania des Phidias in Athen muss dies offen bleiben ${ }^{174}$. Da die ältesten hier untersuchten Bilder (Kat. A1. A2) in die 2. Hälfte des 5. Jahrhunderts v. Chr. datiert werden, und einige der jüngeren Beispiele den Stil dieser Zeit aufnehmen, liegt es nahe, über die Schildkröte eine Verbindung dieser Aphroditebilder mit dem phidiasischen Aphroditetypus herzustellen. Zahlreiche weitere auf eine ikonische Stütze aufgelehnte Aphroditedarstellungen, die ihren Fuß nicht auf eine Schildkröte, aber auf einen anderen Gegenstand setzen, können aufgrund gleicher Haltungsund Gewandmotive mit diesen Werken zusammengeschlossen werden und zeigen, dass der Typus bis in die Kaiserzeit im gesamten griechischen Kulturraum verbreitet und in immer neuen Varianten abgewandelt worden war.

Sonst kommen Aphroditebilder mit Schildkröten nur vereinzelt vor. Diese gehen sehr wahrscheinlich auf denselben Typus zurück, haben aber eine abgewandelte oder gar keine Stütze und zitieren nur bestimmte Merkmale des Typus. Es liegt also nahe, in dem Vorbild des Typus der auf eine ikonische Stütze aufgelehnten Aphrodite einen von Phidias entwickelten Typus zu sehen.

$\mathrm{Da}$ als Stütze am häufigsten das weibliche archaistische Idol dient, darf geschlossen werden, dass dieses möglicherweise zur ursprünglichen Komposition gehörte, sich also auch der phidiasische Aphroditetypus auf ein solches gelehnt hat. Auch die >Aphrodite Brazzàr, bei der die Form der Stütze anhand der Statue selbst nicht zu klären ist, könnte so rekonstruiert werden. Weil aber keine antiken Nachrichten über die Stützenform des phidiasischen Typus vorliegen, muss der Beweis dafür ausbleiben. Aber auch wenn sich die hier vorliegenden Aphroditebilder nicht an das Werk des Phidias anschließen, können sie doch als eine Erfindung dieser Zeit gelten.

Das Relief im Vatikan Kat. A3 beweist, dass es bereits kurz nach der Erfindung des Typus auch die Variante mit der Stütze in Hermenform gegeben hat, die besonders mit dem Kult der Aphrodite Urania in Verbindung stand ${ }^{175}$. Somit kommt auch eine Herme als Stütze für die >Aphrodite Brazzàı wie auch für Aphrodite in Elis und in Athen in Frage, die beide Aphrodite Urania waren. Die

173 Kat. A7. A12. A14. A22. A24, eventuell auch Kat. A1. A4. A19.

174 Zur Frage, inwiefern die athenische Statue dieselbe Ikonographie zeigte, s. S. 88.

175 s. Kap. 5.1.3. 

- die ersten Bilder mit ikonischer Stütze?

weibliche Herme kann als Hinweis auf diese besondere Kultform der Göttin gedeutet werden.

Auf dem damaligen Forschungsstand beruhend hatte C. Anti in einem Aufsatz von 1927 die Existenz einer weiteren klassischen Aphroditestatue in Kyrene mit einer Hermenstütze vorgeschlagen, auf die die in Kyrene gefundene Marmorstatuette Kat. A22 mit einer Stützherme sowie eine weitere, ebenfalls aus Kyrene stammende und typologisch mit dieser übereinstimmende Marmorstatuette mit einer Pfeilerstütze (Abb. 6) zurückgehen sollen ${ }^{176}$. Für die übrigen ihm bekannten Werke, die sich auf ein weibliches Idol lehnen (Kat. A5. A6. A14 und A18), nahm er aufgrund stilistischer Merkmale ein attisches Vorbild an. Einen Zusammenhang der von ihm rekonstruierten Originale mit dem phidiasischen Aphroditetypus schloss er aufgrund seiner Datierung dieser vermuteten Statuen um 400 v. Chr. aus. Damit müsste man im späten 5. Jahrhundert v. Chr. von drei Aphroditestatuen ausgehen, die einen Fuß auf eine Schildkröte setzen. Dabei erscheint jedoch fraglich, warum die attische als auch die kyrenische Statue unabhängig von dieser bekannten Statue eines der berühmtesten Bildhauer seiner Zeit entstanden sein sollen. Zudem bleibt unklar, warum Aphroditebilder, wenn sie einen Fuß auf eine Schildkröte stellen, nach C. Anti Aphrodite Urania meinen sollen, ohne dass jedoch eine Verbindung zu der elischen Statue besteht, für die doch als einzige das Stehen auf einer Schildkröte überliefert ist. Inzwischen ist es eindeutig erwiesen, dass die hier untersuchten Aphroditebilder stilistisch auf ein Urbild aus der Zeit des Phidias zurückgehen, von dem auch die von C. Anti betrachteten Bilder Varianten darstellen.

Die Variante mit der anikonische Stütze in Form eines seinfachen Steinmales, wie E. B. Harrison auch für das vermutete Original annimmt ${ }^{177}$, ließ sich außer bei der kyrenischen Marmorstatuette (Abb. 6) noch bei zwei weiteren Beispielen mit dem Attribut der Schildkröte feststellen. Die Marmorstatuetten in Athen (Abb. 7) und in Bern (Abb. 8) gehören typologisch ebenfalls zu dem hier untersuchten Typus. Da sie erst in hellenistischer Zeit und damit deutlich später als die ersten Belege für die ikonische Stütze entstanden sind und ein Pfeiler nur bei einem weiteren Aphroditebild mit einer Schildkröte vorkommt - einer stark veränderten Marmorstatuette in Kopenhagen (Abb. 9) - ist die Rekonstruktion einer solchen Stütze für das Urbild unwahrscheinlich. Die Variante ohne Stütze liegt nur in zwei hellenistischen bzw. kaiserzeitlichen Marmorstatuetten aus Dura Europos und Paphos (Abb. 10 und 11) vor und ist nur selten und erst spät dokumentiert, weshalb sie ebenfalls für die Suche nach dem Urbild entfällt.

176 Ebenda.

177 Harrison 1984, 386. 


\subsection{Die >Aphrodite Brazzà - ein >Kultbild ‘ aus Athen?}

Für die >Aphrodite Brazzà hatte G. Becatti in seiner Untersuchung zu Phidias von $1951^{178}$ vorgeschlagen, in ihr ein weiteres von Pausanias überliefertes Aphroditebild des Phidias zu sehen, und zwar die Statue des Heiligtums der Aphrodite Urania in der Nähe der Athener Agora. Somit besäßen wir in dieser Statue eines der wenigen erhaltenen griechischen $>$ Kultbilder ${ }^{179}$. Eine ähnliche Meinung vertrat vor kurzem H. Froning in der Publikation eines Fragments eines rechten Fußes einer Terrakottastatuette, der auf einer Schildkröte steht, in der sie eine Wiederholung der Aphrodite von Elis sieht, wie in Kapitel 5.1.2 bereits angesprochen wurde. Die Aphroditebilder, bei denen die Göttin den linken Fuß auf eine Schildkröte setzt, gehen ihrer Ansicht nach auf ein anderes Vorbild zurück, eben die Statue in Athen. Diese sei - im Gegensatz zu der Ansicht von G. Becatti - allerdings nicht im Original in der >Aphrodite Brazzà erhalten. Die `Aphrodite Brazzà w wie auch die anderen zu diesem Typus gehörenden Aphroditebilder stellen ihrer Ansicht nach Varianten der athenischen Statue dar. Die Aphrodite von Elis und die Aphrodite von Athen wären somit seitenvertauscht in der Körperhaltung. Diese These muss genauer geprüft werden. Eine Vorraussetzung dafür ist, dass es bereits in der Klassik Wiederholungen oder Nachbildungen von Statuen gegeben hat.

\subsubsection{Wiederholungen bekannter Werke im 5. Jahrhundert v. Chr.}

Die antiken Quellen schweigen zu dem Aussehen der athenischen Statue. Wiederholungen bekannter Werke bzw. \Kultbilder durch denselben oder anderen Bildhauer oder seine Werkstatt für einen anderen Zweck - z. B. als Gabe an die Gottheit oder als $>$ Kultbild $<$ in einem Filialheiligtum - sind jedoch durchaus belegt ${ }^{180}$. Dass eine einmal getätigte Erfindung mehrfach benutzt worden ist, konnte V. M. Strocka neben weiteren von ihm untersuchten Beispielen durch zwei ionische Grabreliefs des Strengen Stils nachweisen. Diese gleichen einander nicht nur in den Details des dargestellten Motivs, sondern auch exakt in den Maßen. Beide sind frühklassische Originale und keine kaiserzeitlichen Kopien ${ }^{181}$. Für die sog.

\footnotetext{
178 Becatti 1951, $210 \mathrm{f}$.

179 Paus. 1, 14, 7; vgl. S. 66. Zu dem Begriff des >Kultbildesく s. Kap. 11.

180 A. Furtwängler, Über Statuenkopien im Altertum (München 1896); P. Hauser, Die Aphrodite von Epidauros, RM 17, 1902, 232-245; G. Lippold, Kopien und Umbildungen griechischer Statuen (München 1923) 6-15; Langlotz 1947, 74 f. 83; F. Brommer, Vorhellenistische Kopien und Wiederholungen von Statuen, in: G. Mylonas (Hrsg.), Studies presented to D. M. Robinson (Saint Louis 1951) 674-683; S. Karouzou, An Underworld Scene on a Black-Figured Lekythos, JHS 92, 1972, 68; V. M. Strocka, Variante, Wiederholung und Serie in der griechischen Bildhauerei, JdI 94, 1979, 143-173; Ridgway 1981, 193-214; E. Bartman, Ancient Sculptural Copies in Miniature (Leiden 1992); A. Delivorrias, Bildwerk und Kopie, in Klassik 2002, 344-353.

181 Ödemiş, Sammlung Başoğlu und Ostia, Museum Inv. 1102: V. M. Strocka, Variante, Wiederholung und Serie in der griechischen Bildhauerei, JdI 94, 1979, 143-173 Abb. 1. 2.
} 
Grimanische Figurengruppe in Venedig hat R. Kabus-Jahn überzeugend dargelegt, dass sie auf berühmte, durch weitere spätere Kopien und Reliefs überlieferte großplastische klassische Demeter- und Korentypen zurückgehen und sie in Statuettenformat wiederholen. Die zu der `Grimanischen Figurengruppe gehörenden Bilder sind jedoch keine kaiserzeitlichen Kopien, sondern bereits zwischen 420 und 360 v. Chr. und damit ungefähr zeitgleich oder nur kurz nach den jeweiligen Urbildern entstanden ${ }^{182}$. Auch von dem $>$ Münchner König, einer bärtigen stehenden Statue klassischer Zeit haben möglicherweise bereits im 5. Jahrhundert v. Chr. mehrere Exemplare existiert. Ein Bronzekopf ${ }^{183}$, der diesem Typus angehört, war eventuell gegen Ende des 5. oder Anfang des 4. Jahrhunderts v. Chr. mit dem Schiff von Porticello untergegangen ${ }^{184}$. Da aus der Kaiserzeit weitere Exemplare des Typus in Kopien und Nachbildungen vorliegen ${ }^{185}$, muss mindestens eine weitere Statue in klassischer Zeit existiert haben. Ein genauer Nachweis der Zugehörigkeit des Kopfes zu der Ladung des bei Porticello untergegangenen Schiffes steht allerdings noch aus.

Antike Schriftquellen bezeugen ebenfalls die Praxis, denselben Typus für verschiedene Zwecke oder Aufstellungsorte zu verwenden. Ein Beispiel für einander in Aussehen und sogar in der Größe gleichende Götterbilder nennt Pausanias

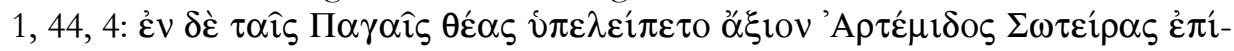

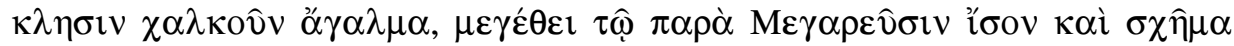

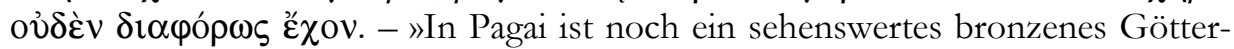
bild der Artemis mit dem Beinamen Soteira vorhanden, an Größe dem bei den Megarern gleich und auch an Gestalt nicht verschieden«. (F. Eckstein - P. C. Bol)

Das Bild in Megara war ein hochklassisches Werk des Strongylion ${ }^{186}$, für die Statue in Pagai gibt Pausanias keine Datierung an. Weitere, jedoch undatierte Bei-

182 R. Kabus-Jahn, die Grimanische Figurengruppe in Venedig, AntPl 11 (Berlin 1972), dazu auch schon G. Lippold, Kopien und Umbildungen griechischer Statuen (München 1923) 9-15.

183 Reggio Calabria, Museo Archeologico Nazionale: Basilea. Antikenmuseum, Consegna di testa maschile barbata in bronzo allo Stato italiano, in: BA 1991, 8, 163; E. Lattanzi, Testa maschile barbata, in: G. Pugliese Caratelli (Hrsg.), I Greci in Occidente (Mailand 1996) 637 f.; E. Lattanzi, Testa maschile barbata da Porticello, in: dies. (Hrsg.), Il Museo Nazionale di Reggio Calabria. I tesori della Magna Grecia (Rom 2007) $188 \mathrm{f}$.

184 Zur Datierung des Schiffswrackes s. C. Jones Eiseman - B. Sismondo Ridgway, The Porticello Shipwreck. A Mediterranean Merchant Vessel of 415-385 B. C. (College Station, Texas 1987).

185 B. Vierneisel-Schlörb (Hrsg.), Glyptothek München. Katalog der Skulpturen II. Klassische Skulpturen des 5. und 4. Jahrhunderts v. Chr. (München 1979) 117-135; V. M. Strocka, Eine Replik des Münchner Königs, in: M. Schmidt (Hrsg.), Kanon. Festschrift Ernst Berger (Basel 1988) 112-118; E. Voutiras, Zur Überlieferung des Münchner Königs, in: H. von Steuben - G. Lahusen - H. Kotsidu (Hrsg.), MOY $\Sigma$ EION. Beiträge zur Antiken Plastik. Festschrift Peter Cornelis Bol (Möhnesee 2007) 225-234.

186 Paus. 1, 40, 2 f. Zur Datierung des Strongylion s. Pollitt 1990, 71-73; DNP XI (2001) 1055 s. v. Strongylion (R. Neudecker). 
spiele sind durch antike Quellen überliefert ${ }^{187}$. Im Aussehen einander gleichende Bilder, darunter auch verschiedene `Kultbilder in unterschiedlichen Städten oder Heiligtümern sind in der Klassik demnach nichts Ungewöhnliches gewesen. Dabei ist zu unterscheiden zwischen der Übernahme der künstlerischen Konzeption eines Bildes auf der einen Seite. Auf der anderen Seite konnte auch die Funktion eines Bildes, genauer gesagt eines $/$ Kultbildes diesem Fall die Erkennbarkeit durch das Kopieren oder Zitieren des äußeren Erscheinungsbildes, aber auch durch die Übernahme der Kultformen ermöglicht wurde ${ }^{188}$. Auch bei den Bildern der Aphrodite in Elis und in Athen kann dieselbe Kultform dasselbe Darstellungsschema bedingt haben.

\subsubsection{Diskussion}

Die Möglichkeit, ein und denselben Typus bereits in der Hochklassik für verschiedene Bilder zu verwenden, ist durch die gerade genannten Belege gesichert. Doch wirft der von G. Becatti und H. Froning vorgetragene Bezug der >Aphrodite Brazzàı sowie der anderen zu diesem Typus gehörenden Bilder zu der Statue in Athen weitere Fragen auf, und zwar einerseits bezüglich der Verbindung des Typus der aufgelehnten Aphrodite mit der Statue in Athen generell, andererseits bezüglich der Frage, ob die >Aphrodite Brazzàr selbst die Statue in dem Athener Heiligtum gewesen sein kann.

Die Annahme, dass Phidias für die Statuen in Athen und in Elis dasselbe Standmotiv, jedoch in spiegelbildlichem Aufbau verwendet hat, beruht auf dem

187 Paus. 2, 25, 10 (2 Athenabilder auf der Akropolis von Argos und im argivischen Lessa, die o ỏ źv $\delta$ ióxpopov - nicht verschieden waren); Paus. 2, 36, 6 (Xoana der Dioskuren in der Nähe von

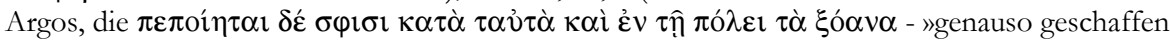
sind wie die Bilder in der Stadt«); Paus. 10, 19, 3 (ein Dionysosbild in Methymna und seine Nach-

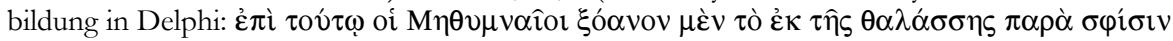

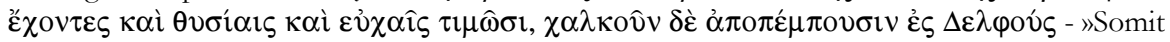
beten die Menschen aus Methymna das Xoanon aus dem Meer an und opfern diesem, das sie bei sich haben, ein bronzenes schickten sie jedoch nach Delphi«); Paus. 5, 26, 6 (eine Nike in Olympia, die ein Bild in Athen nachbildet: $\alpha \dot{\pi} \pi \mu \mu \mu o v ́ \mu \varepsilon v o \varsigma$ - »nachahmend«, vgl. dazu Kap. 12.7). Vgl. auch die Legende über hellenistische Kopien von Statuen aus Zypern in Antiocheia bei Libanios

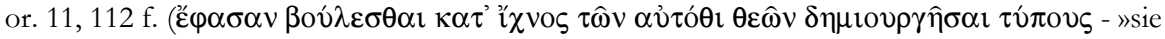
gaben an, dass sie genaue Abbilder der Götter anfertigen wollen«). Auch Filialkultbilder berühm-

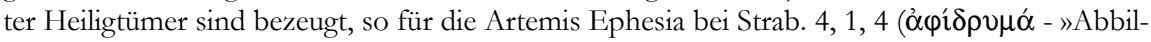

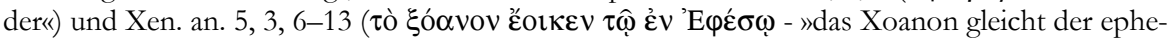
sischen Statue«); Paus. 9, 10, 2 (die Apollonbilder in Didyma und Theben sind $\mu \varepsilon \gamma \varepsilon \dot{\varepsilon} \theta \varepsilon \imath \tau \varepsilon$ í $\sigma o v$

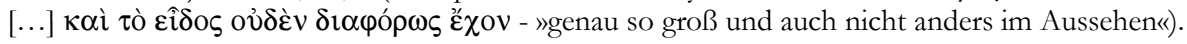
Wahrscheinlich hat auch das Bild der Artemis Laphria in Messene dem der Göttin in Patrai geglichen, s. Kap. 12.18.4. Vgl. auch die in Kap. 6.1 referierte Vermutung, die Statue der Aphrodite von Daphni könne sich an das Bild der Aphrodite $\dot{\varepsilon} \vee$ Kìं

188 Vgl. H. U. Cain, Hellenistische Kultbilder. Religiöse Präsenz und museale Präsentation der Götter im Heiligtum und beim Fest, in: Wörrle - Zanker 1995, 115-130. 
genannten Terrakottafragment aus Elis, bei dem die Göttin im Gegensatz zu den meisten anderen Darstellungen der Aphrodite Urania den rechten Fuß auf eine Schildkröte stellt. Dies kann jedoch auch auf den Koroplasten zurückgehen. So kann bei späteren Exemplaren der Aphrodite mit einer ikonischen Stütze diese ebenfalls auf der rechten Seite stehen ${ }^{189}$, während sie bei den frühen Beispielen auf der linken Seite platziert ist. Die Terrakottastatuette ist das einzige Beispiel, bei dem sich die Schildkröte unter dem rechten Fuß befindet, alle anderen Darstellungen zeigen sie unter dem linken. Solange nicht weitere Belege dafür gefunden werden, dass die Statue in Elis tatsächlich den rechten Fuß auf die Schildkröte gesetzt hat, muss die Frage, ob Phidias zwei Mal denselben Typus, jedoch mit seitenvertauschtem Aufbau für die von ihm geschaffenen Statuen der Aphrodite Urania in Elis und Athen verwendet hat, offen bleiben. Die Betrachtung des Materials hat jedenfalls gezeigt, dass die beiden vermuteten Varianten nicht gleichwertig waren, da die eindeutige Mehrheit die Stütze und den erhöht vorgesetzten Fuß auf der linken Seite zeigen ${ }^{190}$.

Sollte sich die These von H. Froning bewähren, erscheint es gut denkbar, dass die Aphroditebilder, die den linken Fuß auf eine Schildkröte setzen, auf die phidiasische Statue in Athen zurückgehen. Denn es wird wahrscheinlich kaum sehr viele Aphroditestatuen in der 2. Hälfte des 5. Jahrhunderts mit dieser Ikonographie gegeben haben. Zudem weist besonders die >Aphrodite Brazzàr aufgrund ihres Stiles und des pentelischen Marmors, aus dem sie besteht, auf den attischphidiasischen Kunstkreis hin. Zur oben gestellten Frage nach einer möglichen Stütze bei der Aphrodite von Elis trägt das Terrakottafragment nichts weiter bei, da es oberhalb des Fußes abgebrochen ist.

Was die Frage betrifft, ob die >Aphrodite Brazzàr einst in dem Athener Heiligtum gestanden hat, ergeben sich einige Schwierigkeiten, u. a. bezüglich der Datierung. Die >Aphrodite Brazzàı wird aufgrund ihres Stils in die Jahre um 430-420 v. Chr. datiert und damit erst in die Zeit, als Phidias nach Ansicht der Forschung nicht mehr in Athen tätig gewesen sei ${ }^{191}$. Deshalb müsste die Statue an einem anderen Ort, etwa in Elis geschaffen und dann nach Athen überführt worden sein. Oder man müsste von einem Irrtum des Pausanias ausgehen, der die Statue fälschlicherweise Phidias zugeschrieben hätte. Dafür lassen sich weder Anhaltspunkte noch Gegenargumente finden. Wenn man in der sAphrodite Brazzàr die von Pausanias erwähnte Statue in Athen sehen möchte, besteht außerdem das Problem des Materialunterschiedes. Die Berliner Statue besteht aus pentelischem Marmor, was zunächst auf den attischen Kunstkreis hinweist. Pausanias über-

${ }^{189}$ Kat. A15. A41. A45 aus späthellenistischer Zeit, Kat. A46 aus der Kaiserzeit.

${ }^{190}$ Von den 48 stehenden Bildern mit einer weiblichen Stütze steht diese lediglich bei Kat.

A15. A41. A45 und A46 auf der rechten Seite.

191 s. Anm. 124. 
liefert für die Statue in Athen jedoch parischen Marmor. Das Problem ließe sich zwar lösen, wie es auch schon G. Becatti und S. Settis vorgeschlagen haben ${ }^{192}$, wenn man sich die eingesetzten, sichtbaren Körperteile der >Aphrodite Brazzà<, die heute nicht mehr erhalten sind, in dem kostbaren Material, den Körper jedoch in dem weniger wertvollen denkt. Jedoch ist dies rein spekulativ. Damit gibt es keine ausreichenden Gründe, in der >Aphrodite Brazzàı das originale `Kultbild des Athener Heiligtums zu sehen ${ }^{193}$.

\subsection{Zusammenfassung}

In den vorangegangenen Kapiteln konnte die von der Forschung schon lange vertretene Meinung, dass die auf eine ikonische Stütze gelehnten Aphroditebilder auf eine literarisch überlieferte Statue der Aphrodite Urania des Phidias zurückgehen, weiter bestätigt werden.

Für die Aphrodite in Elis bezeugt Pausanias 6, 25, 1, dass sie einen Fuß auf eine Schildkröte setzte. Die Schildkröte kann sowohl auf den Standort der elischen Statue hinweisen wie auch auf die u. a. bei Hesiod theog. 188-197 bezeugte Meeresgeburt und ist somit ein Attribut, das die Göttin näher charakterisiert. Der Typus der auf eine ikonische Stütze aufgelehnten Aphrodite zeigt als einziger mit mehreren Exemplaren und einer langen Kette späterer Reflexe überlieferter Typus ebenfalls dieses Motiv. Inwiefern die andere, bei Pausanias 1, 14, 7 überlieferte Statue der Aphrodite Urania des Phidias in Athen dieselbe Ikonographie in seitenvertauschter Ansicht zeigte und damit ebenfalls als Vorbild gedient haben kann, bleibt offen, ebenso wie die Frage, ob dieses Bild in der >Aphrodite Brazzàı sogar erhalten sei. Fest steht jedenfalls, dass die Variante, bei der der linke Fuß erhöht aufgesetzt war und die Stütze auf derselben Seite stand, wesentlich häufiger verwendet wurde. Da die frühesten Beispiele des hier untersuchten Typus in die Zeit datiert werden können, in der die phidiasischen Statuen entstanden sind, erscheint eine Verbindung mit dem Typus der Aphrodite Urania des Phidias jedenfalls sehr gut denkbar. Weitere Aphroditebilder mit dem Motiv der Schildkröte kommen selten vor und konnten als Varianten desselben Typus eingeordnet werden.

192 Becatti 1951, 210 f.; Settis 1966, 21.

193 Die anderen von der Forschung für das Aphroditebild des Athener Heiligtums vorgetragenen Typen können hier nicht untersucht werden. E. B. Harrison, A Classical Maiden from the Athenian Agora, in: Studies in Athenian Architecture, Sculpture and Topography presented to H. A.

Thompson, Hesperia Suppl. 20 (Princeton 1982) 50 hat den Typus der Agrippina Lateran vorgeschlagen; A. Delivorrias, Über die letzte Schöpfung des Phidias in Athen: Die Diskontinuität der historischen Zeugnisse und die Kohärenz der übrigen Beweismittel, in: Pöhlmann - Gauer 1994, 263-273 hingegen den Typus der Aphrodite Doria-Pamphili. 
Aus der Verbindung des aufgelehnten Aphroditetypus mit dem phidiasischen Typus ging die Frage nach der Form der Stütze bei dem Urbild und seiner frühesten Überlieferung, der >Aphrodite Brazzàı Kat. A1 hervor. Der Typus ist sowohl mit weiblichen archaistischen Idolen als auch mit weiblichen Hermen als Stütze überliefert. Da die Herme besonders mit Aphrodite Urania zu verbinden ist, wie in Kapitel 5.1.3. referiert worden ist, würde sie sich als Stütze für die Statuen der Aphrodite Urania in Elis und Athen wie auch für die >Aphrodite Brazzàr eignen, bei der die Stütze nicht erhalten, aufgrund der Körperhaltung jedoch notwendig ist. Da jedoch das archaistische Idol wesentlich häufiger als Stützfigur belegt ist, ist es nicht unwahrscheinlich, dass dieses zur ursprünglichen Komposition gehört hat. Die Herme kann bei einigen Darstellungen anstatt des Idols Verwendung gefunden haben, um die Dargestellte deutlicher als Aphrodite Urania zu kennzeichnen. Die Bedeutung der Idole muss hingegen noch geklärt werden. Dabei müssen auch Darstellungen anderer aufgelehnter Götter einbezogen werden ${ }^{194}$.

194 s. Kap. 6. 


\section{Weitere Aphroditetypen und andere Götter in aufgelehnter Haltung}

Vor einer inhaltlichen Interpretation der archaistischen Statuenstützen ist weiter zu fragen, ob außer Aphrodite noch andere Götter in aufgelehnter Haltung nachweisbar sind oder ob dieses Haltungsschema ausschließlich für Aphrodite verwendet wurde. Es ist deshalb zu untersuchen, welche Götter außer Aphrodite in dieser Haltung gezeigt wurden, in welchen Bildmedien dieses Darstellungsschema Verwendung fand und wann derartige Bilder aufkamen.

Mit dem Übergang von der archaischen zur klassischen Epoche war, was schon lange bekannt und häufig untersucht worden ist, ein Wandel in der Kunst eingetreten. Dieser kam besonders deutlich in der veränderten Darstellung von Bewegungen und Körperhaltungen in der Freiplastik zum Ausdruck. Durch die Differenzierung zwischen tragenden und entlasteten, zwischen angespannten und entspannten Gliedern, war eine größere Bandbreite für die Darstellung des menschlichen Körpers gegeben ${ }^{195}$. Die neuen Möglichkeiten der klassischen Zeit, anatomische Einzelheiten, Haltungsmotive und Bewegungen darzustellen, kamen im 5. Jahrhundert v. Chr. in vielfältigen Darstellungen zum Ausdruck. Bei Athleten z. B. wurden die raumgreifenden Bewegungen im Zusammenhang mit der genauen Beobachtung des Spiels der Muskeln ein beliebtes Thema der Rundplastik. Doch experimentierten die antiken Bildhauer nicht ohne inhaltliche Motivation mit den neuen Möglichkeiten. Darstellungen von Bewegungen waren immer dadurch begründet, dass die gezeigten Menschen oder Götter aktiv handelnde Athleten oder Kämpfende oder anderweitig in einen szenischen Zusammenhang eingebettet waren wie Bürger, die sich auf ihren Bürgerstock lehnen, weil sie es sich erlauben können, »den ganzen Tag auf der Agora herumzustehen und die öffentlichen Dinge zu diskutie-

195 Hölscher 1974; T. Hölscher, Körper, Handlung und Raum als Sinnfiguren in der griechischen Kunst und Kultur, in: K.-J. Hölkeskamp u. a. (Hrsg.), Sinn (in) der Antike. Orientierungssysteme, Leitbilder und Wertkonzepte im Altertum (Mainz 2003) 163-192. 
ren «196. Auch die sSinnende Athena lehnt sich, formal ähnlich wie die Bürger, die sich auf einen Stock lehnen, weil sie sich im Freien aufhalten, aus der Achse auf einen Stock (womit allerdings keine Deutung des Motivs gegeben ist) ${ }^{197}$.

Darstellungen von Göttern und mythologischen Gestalten in aufgelehnter Haltung sind für das 5. Jahrhundert v. Chr. nur selten belegt und ebenfalls durch den Inhalt der Darstellung motiviert. So kann z. B. Herakles in einem vielleicht auf ein Werk des Myron zurückgehenden Typus seine Hand auf seine Keule legen, um sich nach getanem Werk auszuruhen, wobei er sich allerdings mit seinem Gewicht noch nicht einmal wirklich auflehnt ${ }^{198}$. Bei der Amazone vom Typus Sciarra (Abb. 13)199, die sich auf einen Pfeiler lehnt und dabei das Gewicht ihres Oberkörpers tatsächlich darauf abstützt ist das Motiv durch die Verwundung und Schwächung des Körpers im Kampf begründet. Die Bilder implizieren also einen szenischen Zusammenhang, der die Haltung begründet. Nicht handelnde Götter und Menschen hingegen wurden in aufrechter Haltung stehend oder thronend gezeigt ${ }^{200}$. Anders ist dies bei Darstellungen der Aphrodite. Für sie wurden bereits im 5. Jahrhundert v. Chr. gleich mehrere großplastische Typen geschaffen, die sie in aufgelehnter Haltung abbilden, wie im Folgenden dargelegt werden wird.

\subsection{Weitere aufgelehnte Aphroditebilder}

Die Möglichkeit, eine Gottheit in der Rundplastik in aufgelehnter und zugleich besonders körperbetonter Haltung ohne szenischen Zusammenhang darzustellen, ist eine Neuentwicklung der Kunst der 2. Hälfte des 5. Jahrhunderts v. Chr. Die frühesten Darstellungen zeigen die Göttin Aphrodite. Mit der >Aphrodite Brazzàr

196 P. Zanker, Brüche im Bürgerbild? Zur bürgerlichen Selbstdarstellung in den hellenistischen Städten, in: Wörrle - Zanker 1995, 251-273.

197 Athen, Akropolismuseum Inv 695: Boardman 1987, 90 Abb. 41; H. Jung, Die sinnende Athena. Zur Deutung des Reliefs Athen, Akropolismuseum 695, JdI 110, 1995, 95-147; G. Kaminski, Der Strenge Stil der frühen Klassik. Reliefplastik, in: Bol 2004, 58 f. Abb. 57.

198 Boston, Museum of Fine Arts Inv. 64: Fuchs 1969 Abb. 67; Boardman 1987 Abb. 72; P. C. Bol, Der Strenge Stil der frühen Klassik. Rundplastik, in: Bol 2004, 28 f. Abb. 38.

199 New York, Metropolitan Museum Inv. 32114 und Kopenhagen, Ny Carlsberg Glyptothek Inv. 1658: Boardman 1987, 271 f. Abb. 190a; R. Bol, Die Ephesischen Amazonenstatuen, in: Bol 2004, 146-158. Vgl. auch S. 134 f.

200 Vgl. z. B. die Götter auf Weihreliefs: G. Neumann, Probleme des griechischen Weihreliefs, Tübinger Studien zur Archäologie und Kunstgeschichte 3 (Tübingen 1979) Taf. 13c. 40a. b. 46b. 48b; M. Mangold, Athenatypen auf attischen Weihreliefs des 5. und 4. Jahrhunderts v. Chr. (Bern 1993) Taf. 2. 5-7; G. Güntner, Göttervereine und Götterversammlungen auf attischen Weihreliefs. Untersuchungen zur Typologie und Bedeutung (Würzburg 1994) bes. Taf. 14-16. 34 f.; F. T. van Straten, Hiera Kala. Images of Animal Sacrifice in Archaic and Classical Greece (Leiden, New York, Köln 1995) Abb. 58. 71. 75. 77. 80-82. 85. 89. 96. 97. 99; A. Filges, Standbilder jugendlicher Göttinnen. Klassische und frühhellenistische Gewandstatuen mit Brustwulst und ihre kaiserzeitliche Rezeption (Köln 1997) Kat. 57-59. 78-81. 83; A. Comella, I rilievi votivi greci di periodo arcaico e classico. Diffusione, ideologia, committenza (Bari 2002) bes. Abb. 92. 94. 112. 125. 128. 137. 
Kat. A1 und der Statuette Kat. A2 wurden einige dieser Bilder, die wahrscheinlich auf einen von Phidias um 430 v. Chr. geschaffenen Typus der Aphrodite Urania zurückgehen, in Kapitel 3 bereits betrachtet. Wie bedeutsam das neue Körperbild für die Darstellungen der Göttin war, zeigen weitere bekannte hochklassische Aphroditetypen, die die Göttin ebenfalls in lässiger, auf Pfeiler oder Baumstämme gelehnter Haltung zeigen. Bei allen Typen beeinflusst das Auflehnen deutlich die Haltung des gesamten Körpers. Sie wurden vor allem von A. Delivorrias behandelt ${ }^{201}$.

Die Aphroditebilder mit Pfeilerstütze lassen sich wie diejenigen mit ikonischen Stützen zu einer weiteren Gruppe zusammenschließen, deren Hauptvertreter eine Statue in Paris ist $(A b b .14)^{202}$. Ein Unterschied besteht darin, dass sie immer auf dem rechten Bein stehen und mit dem linken Bein das rechte überkreuzen. Die Stütze reicht bis unter die Achsel. Der Oberkörper bekommt dadurch eine ausgeprägte Schräglage und erscheint noch entspannter und zugleich noch stärker einer Stütze bedürfend als bei den Aphroditebildern mit den ikonischen Stützen. Bei diesen lehnt sich die Göttin immer mit dem Ellenbogen oder Unterarm auf und steht dadurch insgesamt stärker aufgerichtet. Bei den Darstellungen mit einem Pfeiler als Stütze trägt Aphrodite ebenfalls einen eng am Körper anliegenden Chiton mit einem weiten Halsausschnitt, der die linke Schulter frei lässt und darüber ein Himation. Dessen eines Ende ist unter dem aufgelehnten linken Arm festgesteckt und dann über den unteren Rücken und unter dem rechten Arm hindurch geführt. Das andere Ende ist von vorn ebenfalls unter den aufgelehnten Arm gesteckt. Das Himation bedeckt die Beine bis hinunter zu den Knöcheln sowie einen Teil des Pfeilers und folgt deutlich den Körperformen der Göttin. Die Forschung hat für diese Aphroditebilder immer ein anderes Urbild gefordert als für die hier gesammelten Darstellungen mit den ikonischen Stützen, worauf gleich noch einmal zurückzukommen sein wird.

Diesem Typus sehr nah verwandt ist ein weiterer, der ebenfalls Aphrodite auf einen Pfeiler gelehnt zeigt. Er ist u. a. durch den antiken Negativabdruck einer reliefierten Wangenklappe eines Helms überliefert. Der antike Abdruck ist zwar verschollen, neuzeitliche Positivabdrücke wie der schon mehrfach publizierte im Akademischen Kunstmuseum in Bonn übermitteln jedoch das dargestellte Motiv $(A b b .15)^{203}$. Gezeigt wird eine ebenfalls locker auf einen Pfeiler gelehnte Aphrodite,

201 Vgl. die gute Übersicht bei Delivorrias 1984, 29-33, zuvor schon Delivorrias 1968.

202 Eine der Kopien: Paris, Louvre Inv. 414: Romeo 1993 Abb. 8; Kreikenbom 2004, 194 f. Textabb.

73. Weitere Exemplare des Typus: Schrader 1924, 203-210. 270 Abb. 185-191. 245. 247; Langlotz 1947, 83-95 Taf. 28, 2; Schlörb 1964, 17-22; Bieber 1977, 94 Abb. 437-440; Delivorrias 1984, 30 f. Nr. 193-199; Romeo 1993 Abb. 1-9. 13-15.

203 Bonn, Akademisches Kunstmuseum Inv. D 697; Original verschollen, ehem. Athen, Slg. A. Rhousopoulos: W. Amelung, Aphrodite und Eros, BJb 101, 1897, 153-164 Taf. 6, 1; Langlotz 1947, 83-95 Taf. 30; Schlörb 1964, 17-22; W.-D. Heilmeyer, Kopierte Klassik, in: B. von Freytag - D. Mannsperger - F. Prayon (Hrsg.), Praestant Interna. Festschrift für Ulrich Hausmann (Tübingen 1982) 52-62; Delivorrias 1984, 29 f. Nr. 187; W.-D. Heilmeyer, Agora, Tonabfor- 
die sich wesentlich schräger auflehnt als die Aphroditebilder mit den ikonischen Stützen. Sie lehnt sich mit dem linken Ellenbogen auf, wobei sie einen Teil ihres Gewandes als Polster benutzt. Mit der erhobenen linken Hand lüftet sie ihr über den Kopf gezogenes Gewand. An ihre Beine schmiegt sich ein Eros, um dessen Schulter Aphrodite ihren rechten Arm legt. Der Typus ist außerdem durch eine kaiserzeitliche Marmorstatuette im Nationalmuseum von Neapel überliefert ${ }^{204}$. Von dem vorangegangenen Typus unterscheidet sich dieser vorrangig durch das über den Kopf gezogene Gewand sowie die niedrigere Stütze. Die Beispiele des zuerst genannten Typus sind alle barhäuptig. Außerdem ist bei diesen die linke Schulter entblößt, bei dem Typus mit der niedrigeren Stütze hingegen die rechte, gesenkte.

Einen weiteren bekannten Typus stellt die auf einen Baumstamm aufgelehnte Aphrodite dar, deren Urbild im «ultbild des Aphroditeheiligtums von Daphni in Attika gesehen wird, von dem sich ein originales Fragment erhalten hat (Abb. 16) ${ }^{205}$. Sowohl in der Haltung als auch in der Gewanddrapierung ähnelt dieser Typus der auf einen hohen Pfeiler gelehnten unverschleierten Aphrodite sehr stark. Die Göttin steht ebenso deutlich nach links geneigt da und erhält Halt durch die Baumstammstütze an dieser Seite, die bis unter ihre Achsel reicht. Mit dem linken Spielbein überkreuzt die Göttin das rechte Standbein. Ihre Kleidung besteht ebenfalls aus einem Chiton und einem Himation. Die Gewänder sind nach Ausweis der erhaltenen Fragmente wie bei dem Typus der auf einen niedrigen Pfeiler aufgelehnten Aphrodite drapiert und betonen deutlich die Körperformen der Göttin.

Interessant ist die Datierung der Urbilder dieser Typen. Die Arbeit des Phidias an der Statue des olympischen Zeus fällt nach Ansicht der Forschung in die 430er Jahre des 5. Jahrhunderts v. Chr. ${ }^{206}$. Während dieser Zeit dürfte auch die Statue der Aphrodite von Elis entstanden sein. Sollte diese wirklich das Vorbild für die Aphroditedarstellungen mit den ikonischen Stützen sein, stammt die Erfindung dieses Typus aus den 430er Jahren. Selbst wenn dies nicht der Fall ist, beweist die in dieser Zeit entstandene >Aphrodite Brazzà Kat. A1, dass die ikonische Stützenform um 430 v. Chr. aufkam, da sie - auch wenn die Form ihrer Stütze nicht bestimmt werden kann - zu dem Typus der Aphrodite mit der ikonischen Stütze und nicht zu einem der anderen hier besprochenen Typen gehört.

Der Typus der auf einen niedrigen Pfeiler gelehnten, verschleierten Aphrodite (Abb. 15) wird aufgrund seines Stils ebenfalls in die Jahre um 435-420 v. Chr.

mungen, in: Klassik 2002, 466 f. Nr. 325.

${ }^{204}$ Neapel, Nationalmuseum Inv. 6396: W. Amelung, Aphrodite und Eros, BJb 101, 1897, 153-164

Taf. 7; Langlotz 1947, 83-95 Taf. 28, 3; Schlörb 1964, 17-22; Delivorrias 1968, 19-21;

Delivorrias 1984, 29 f. Nr. 185; Romeo 1993 Abb. 10-12, allerdings mit Betonung, dass die verschleierten und die unverschleierten Darstellungen einem Typus angehören sollen.

205 Athen, Nationalmuseum Inv. 1604: Delivorrias 1968, 19-31 Abb. 1-7 Taf. 7-9b; Delivorrias

1984, 31 f. Nr. 200 f.; Dally 1997, 9 f.; Kreikenbom 2004, 195 f. Abb. 121 f.

206 Vgl. Anm. 124. 
datiert und mit Phidias in Verbindung gebracht ${ }^{207}$. Und auch das Vorbild der auf einen hohen Pfeiler gelehnten unverschleierten Aphrodite (Abb. 14) wird in die Zeit um 430 v. Chr. datiert. Es wird von der Forschung dem Phidiasschüler Alkamenes zugeschrieben ${ }^{208}$, in Anlehnung an die Erwähnung eines Aphroditebildes

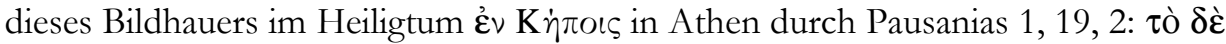

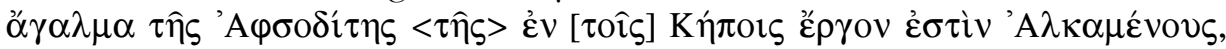

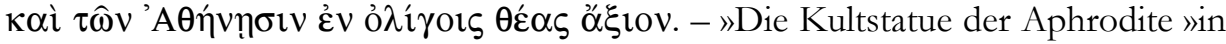
den Gärten« ist ein Werk des Alkamenes und sehenswert wie weniges andere in Athen«. (F. Eckstein - P. C. Bol)

Die Datierung des Typus der auf einen Baumstamm gelehnten Aphrodite konnte durch die Veröffentlichung des genannten Marmorfragments aus Daphni durch A. Delivorrias geklärt werden, das er in das letzte Jahrzehnt des 5. Jahrhunderts v. Chr. datiert (Abb. 16 $)^{209}$. Der Typus liegt noch in einem weiteren, zeitgleichen Fragment einer Marmorstatue sowie einem Marmorrelief aus dem frühen 4. Jahrhundert v. Chr. vor, die die Datierung in das späte 5. Jahrhundert v. Chr. bestätigen ${ }^{210}$. Die auf einen Baumstamm aufgelehnte Göttin stellt nach dem Vorschlag von A. Delivorrias das Aphroditebild des Heiligtums von Daphni dar und ist als Variante der Aphrodite $\mathfrak{\varepsilon} \nu$ K $\dot{\eta} \pi 0 ı \varsigma$ zu verstehen und kurz nach dieser entstanden. Der Baumstamm zeige die besondere Bedeutung der Vegetation im Kult von Daphni an. Er könne also, wie die Herme und eventuell auch der Pfeiler, als kultisches Element aufgefasst werden: »als Sinnbild des im Kult gefundenen pflanzlichen Charakters der Göttin« ${ }^{211}$.

207 W. Amelung, Aphrodite und Eros, BJb 101, 1897, 153-164; Langlotz 1947, 83-95; Schlörb 1964, 17-22; Delivorrias 1968, 20 f. ; Delivorrias 1984, 29 f. Nicht festlegen möchte sich W.-D. Heilmeyer, der den Typus jedoch auch in den »Bereich der perikleisch-phidiasischen Kunstauffassung« einordnet, s. W.-D. Heilmeyer, Kopierte Klassik, in: B. von Freytag - D. Mannsperger F. Prayon (Hrsg.), Praestant Interna. Festschrift für Ulrich Hausmann (Tübingen 1982) 60.

Die von B. Schlörb gezogene Verbindung zu einem bei Paus. 1, 22, 3 überlieferten Bild des Heiligtums der Aphrodite Pandemos am Südwestabhang der Akropolis ist rein hypothetisch, da Pausanias weder den Bildhauer der Statue nennt noch eine zeitliche Einordnung des Bildes vornimmt.

208 Schrader 1924, 203-210; Langlotz 1947, 83-95; Schlörb 1964, 17-22; Delivorrias 1968; Bieber 1977, 94; Delivorrias 1984, 30 f.; Romeo 1993; Dally 1997, 11. Ihre Argumente wirken in sich schlüssiger als die Deutung des Typus \Olympiası als Aphrodite $\mathfrak{\varepsilon} \vee$ Kìं vorgetragen hatte. Zu der Aphrodite Olympias s. auch Anm. 214. Delivorrias 1984, 90 sieht in ihr die Statue des Heiligtums am Nordhang der Akropolis, für das Dally 1997 hingegen einen Torso aus dem Athener Akropolismuseum vorschlägt, der typologisch den vermuteten Aphroditetypen der Heiligtümer $\dot{\varepsilon} \vee$ Kìं

${ }^{209}$ Es wird von Kreikenbom 2004, 196 aufgrund des Gewandstiles noch ein wenig früher, um 420 v. Chr. datiert, vgl. auch Dally 1997, 9 f.

${ }^{210}$ Delivorrias 1968, 19-31 Abb. 1-7 Taf. 7-9 b; Delivorrias 1984, 31 f. Nr. 200 f.; Kreikenbom 2004, 193-296 Abb. 121. 123.

${ }^{211}$ Delivorrias 1968, 29. Ähnlich auch Dally 1997, 19. Auch der Pfeiler ist bereits mehrfach kultisch gedeutet worden. Für B. Schlörb und St. Hiller stellte er einen Hinweis auf eine besondere, alte Form von Göttermalen dar. Von Paus. 1, 19, 2 wird für das Heiligtum $\dot{\varepsilon} \vee$ Kं̀ं Göttin überliefert, das hermenartig gebildet war, wie bereits erwähnt wurde (s. Kap. 5.1.3), und das 
Alle aufgelehnten Aphrodite-Typen werden ungefähr in dieselbe Zeit, in das letzte Drittel des 5. Jahrhunderts v. Chr. datiert. Sie zeigen, dass in dieser Zeit die aufgelehnte Körperhaltung für Aphroditedarstellungen besonders häufig vorkommt. Wie bei den Aphroditebildern mit ikonischen Stützen wird auch bei denen mit anikonischen Stützen das Motiv genutzt, um einen gelösten, in lockerer Haltung angelehnten Körper darzustellen. Dies kommt besonders deutlich bei dem Typus >Daphni wie auch bei dem verschleierten Typus zum Ausdruck. Bei beiden Typen ist die Stütze sehr hoch. Das Anlehnen müsste demnach nicht unbedingt Einfluss auf die Körperhaltung haben, wie es z. B. bei den zuvor genannten Bürgerdarstellungen der Fall ist, die ohne ihren Stock genauso aufrecht stehen könnten. Bei den angelehnten Aphroditetypen hingegen wird das Auflehnen benutzt, um die Darstellung besonders körperbetont zu gestalten und einzelne Formen des Körpers, wie z. B. die ausschwingende, betont weibliche, gerundete Hüfte, die Oberschenkel oder die vorgestreckte Brust hervorzuheben.

Weitere bekannte hochklassische Aphroditedarstellungen, die die Göttin ebenfalls in körperbetonter, aufgelehnter Haltung zeigen sind der Typus Este und der Typus >Venus Marina`212. Aus spätklassischer oder hellenistischer Zeit kann der ebenso körperbetonte, aufgelehnte Typus Pontia-Euploia genannt werden ${ }^{213}$. Auch bei Sitzbildern der Göttin wurde die Tendenz, Aphrodite möglichst körperbetont und entspannt darzustellen festgestellt. Die sog. Aphrodite Olympias (Abb. 17)214,

man sich nach dem Vorschlag von Schlörb 1964, 17 f. und Hiller 1976, 33 einem Pfeiler nicht unähnlich vorstellen müsse. Eine Herme ist jedoch nicht mit einem Pfeiler gleichzusetzen, so dass die Nachricht des Pausanias nicht unbedingt mit den auf einen Pfeiler gestützten Aphroditebildern zu verbinden ist. Pausanias hat jedenfalls definitiv von einem Bild in Hermenform und nicht in Pfeilerform gesprochen, so dass man demnach auch ein solches annehmen sollte. Die von B. Schlörb und St. Hiller davon abgeleitete Deutung des Pfeilers als verehrtes Mal der Göttin erscheint deshalb nicht zwingend. Sie ist aber zumindest möglich, da anikonische Male in der Antike keine Seltenheit waren, vgl. F. Oelmann, BJb 157, 1957, 15-19; Donohue 1988, bes. 199-230; U. Kron, Heilige Steine, in: Froning 1992, 56-70; D. Doepner, Steine und Pfeiler für die Götter. Weihgeschenkgattungen in westgriechischen Stadtheiligtümern (Wiesbaden 2002). Es kann sich bei dem Pfeiler aber ebenso um eine Vereinfachung sowohl in der künstlerischen Ausarbeitung als auch in der inhaltlichen Aussage handeln. Der Pfeiler würde in diesem Fall lediglich als Stütze dienen, ohne mit einem weiteren Inhalt belegt zu sein. Auf Gründe, warum sich Aphrodite generell aufstützen kann, wird in Kap. 7.2.2 noch einzugehen sein. Der Pfeiler könnte ebenso als 〉Ortstopos dienen, etwa im Sinne einer Grenzmarkierung, und somit anzeigen, dass sich die aufgelehnte Göttin in einem Heiligtum aufhält. Vgl. z. B. die Pfeiler auf Vasenbildern, die die dargestellte Szene in den Kontext eines Heiligtums setzen, das z. T. zusätzlich durch einen Altar gekennzeichnet ist: LCS II Taf. 44, 3. 57, 5. 129, 1. 149, 2; CVA Cleveland, Museum of Art (1) Taf. 43, 1. 3.

212 Delivorrias 1984, 32 Nr. 204 bzw. 65-67 und hier Anm. 89.

213 Delivorrias 1984, 69 f. Nr. 599-604.

214 Verona, Museo del Teatro Romano: Delivorrias 1984, 90 f. Nr. 821; C. Maderna-Lauter, Sitzende Frau, in: P. C. Bol (Hrsg.), Forschungen zur Villa Albani. Katalog der antiken Bildwerke II. Bildwerke in den Portiken, dem Vestibül und der Kapelle des Casino (Berlin 1990) 204-217; P. C. Bol, Nichtphidiasische attische Bildwerke aus den Jahren nach der Vollendung des Parthenons, in: Bol 2004, 182 f. Abb. 113. Die besondere Lockerheit des Sitzens betonte schon Himmelmann 
deren Vorbild in die Zeit um 430 v. Chr. datiert wird, thront nicht aufrecht und frontal gesehen. Sie lehnt sich stattdessen mit ihrem Oberkörper weit zurück und hat ganz ungezwungen ihre ausgestreckten Füße übereinander geschlagen. Außerdem legt sie ihren linken Arm locker auf die Lehne ihres Sitzmöbels und wendet dabei den Oberkörper leicht in dieselbe Richtung. Die rechte Hand ruht entspannt in ihrem Schoß. In der großformatigen Rundplastik ist eine Haltung, wie sie die >Aphrodite Olympias` und die stehenden aufgelehnten Aphroditebilder zeigen, von bis dahin ungewohnter Lässigkeit.

Andere Göttinnen werden im 5. Jahrhundert v. Chr. nicht in entspannter, aufgelehnter Haltung gezeigt. Die Athena Parthenos hatte zwar vielleicht ihre rechte Hand auf eine Säule gelegt ${ }^{215}$, doch diente diese nicht dazu, das Gewicht des Körpers der Göttin abzustützen, sondern nur als technische Stütze für die Hand, die die Nike trug. Die Körperhaltung der Athena ist aufrecht.

Nach den Gründen, warum eine solche Haltung gerade bei Darstellungen der Aphrodite möglich ist, wird in Kapitel 7.2.2 gefragt werden. Auch bleibt noch die Frage zu beantworten, was die ikonischen Stützen zu bedeuten haben. Für die Pfeiler- und Baumstammstützen sind Interpretationsmöglichkeiten eben bereits angesprochen worden. Der inhaltlichen Aussage der ikonischen Stützen werde ich mich in Kapitel 7 zuwenden. Zunächst ist es wichtig, zu klären, ob noch andere Götter in klassischer Zeit in statuarischen Bildern in aufgelehnter Haltung dargestellt werden, und welche dies sind.

\section{2. weitere Götter}

Außer bei Aphrodite waren aufgelehnte Haltungen im 5. Jahrhundert v. Chr. nur durch eine inhaltliche Motivation möglich wie bei der Amazone vom Typus Sciarra, die aufgrund ihrer Verwundung und der dadurch eingetretenen Schwächung einer Stütze bedurfte $(A b b \text {. 13 })^{216}$. Erst in der Mitte des 4. Jahrhundert v. Chr. änderte sich dies. Von dieser Zeit an entstanden auch Statuen anderer Götter, die sie in aufgelehnter Haltung ohne erzählenden Kontext zeigen. Die Durchsicht klassischer Götterstatuen bzw. ihrer Kopien und Nachbildungen zeigt, dass die neuen, gelösten Haltungen, wie sie bei Darstellungen der Aphrodite skizziert worden sind, in der Großplastik außer bei Bildern dieser Göttin vor allem bei Dionysos verwendet wurden. Darstellungen des Gottes, bei denen er sich weinselig auf einen Satyr oder Silen lehnt, kamen in der szenischen Vasenmalerei bereits seit dem Beginn des 5. Jahrhunderts v. Chr. vor ${ }^{217}$. Für einzelne großformatige

1959, 11.

215 N. Leipen, Athena Parthenos. A Reconstruction (Toronto 1971) 36-40; Nick 2002, $167 \mathrm{f}$.

216 s. Anm. 199.

217 E. Pochmarski, Dionysische Gruppen. Eine typologische Untersuchung zur Geschichte des Stützmotivs (Wien 1990) 14 f. In der Skulptur sind Darstellungen des Dionysos in entspannt 
Statuen des Gottes wird das aufgelehnte Schema hingegen erst seit der 1. Hälfte des 4. Jahrhunderts v. Chr., dann aber häufiger als bei anderen Göttern verwendet, und zwar ohne dass ein erzählender Kontext diese Haltung begründet. Den aufgelehnten Aphroditebildern in ihrer gelösten Haltung vergleichbar ist der Typus Woburn Abbey, dessen Original in die Zeit um 360 v. Chr. datiert wird (Abb. 18)218. Der unbekleidete Gott lehnt sich bei diesem Typus mit dem gebeugten linken Unterarm auf einen neben ihm stehenden Baumstamm. Er steht auf dem rechten Bein. Das linke Spielbein ist angewinkelt und der Fuß zurückgesetzt. Der rechte Arm ist gesenkt. Der Körper des Gottes ist, wie im 4. Jahrhundert v. Chr. üblich ${ }^{219}$, sehr weich gebildet. Weitere Dionysostypen des 4. Jahrhunderts v. Chr. und der folgenden Epochen, die den Gott in aufgelehnter Haltung zeigen, sind von C. Gasparri zusammengestellt worden. Es sind einerseits eigenständige, neu entwickelte Typen als auch Darstellungen, die sich an die eben genannte anlehnen ${ }^{220}$, nämlich die Typen Borghese-Colonna, Kopenhagen-Valentini, Horti Lamiani, Terme und Jacobsen. Auch sie zeigen den Gott in aufgelehnter, lässiger und körperbetonter Haltung, mit ausschwingender Hüfte, angewinkeltem Spielbein und entspannt auf eine Stütze gelehnt. Der Körper ist von weichen Formen geprägt und wenig athletisch. Dionysos ist entweder unbekleidet oder trägt einen Hüftmantel. Die obere Kante des Mantels ist bei letzterem wie bei Darstellungen der aufgelehnten Aphrodite zu einem Wulst eingedreht, das Ende um den aufgelehnten Arm geführt ${ }^{221}$. Auch eine großformatige Statue des sitzenden Dionysos, die den

sitzender bzw. gelagerter Haltung evtl. bereits im 5. Jahrhundert v. Chr. am Parthenon verwendet worden, wenn auch die Identifizierung der Figuren nicht zweifelsfrei bestimmt ist. Die männliche Figur auf dem Ostfries, die sich rückwärts gewandt auf Hermes lehnt wird als Dionysos gedeutet: E. Berger, Die Geburt der Athena im Ostgiebel des Parthenon, Studien der Skulpturenhalle Basel 1 (Basel 1974) 42; E. Berger - M. Gisler-Huwiler, Der Parthenon in Basel. Dokumentation zum Fries (Mainz 1996) 154. Ebenso wird die auf einem Raubkatzenfell gelagerte männliche Figur in der linken Ecke des Ostgiebels als Dionysos identifiziert: London, British Museum Inv. 303 D: F. Brommer, Die Skulpturen der Parthenon-Giebel. Katalog und Untersuchung (Mainz 1963) 7-9. 148-150 mit den weiteren Deutungen; E. Berger, Die Geburt der Athena im Ostgiebel des Parthenon, Studien der Skulpturenhalle Basel 1 (Basel 1974) 34. 36; O. Palagia, The Pediments of the Parthenon, Monumenta Graeca et Romana 7 (Leiden 1993) $19 \mathrm{f}$.

218 Woburn Abbey u. a.: K. Schefold, Der Basler Dionysos, ÖJh 39, 1952, 94 Abb. 36; Gasparri 1986, 435 Nr. 120; Cain 1997, 34 f. mit Abb.

219 Cain 1997, 14. 38. 74.

220 Gasparri 1986, 435 f. Nr. 121. 123-126.

221 Ebenda 436 Nr. 126. Weitere Dionysosstatuen in entspannter, aufgelehnter Haltung wurden in Anlehnung an Werke des 4. Jahrhunderts v. Chr. in der Kaiserzeit noch geschaffen, z. B. Rom, Vatikanische Museen Inv. 10402: EA 2137; Pochmarski 1974, 84 Nr. 20D; Chr. Vorster, Römische Skulpturen des späten Hellenismus und der Kaiserzeit II. Werke nach Vorlagen und Bildformeln hellenistischer Zeit sowie die Skulpturen in den Magazinen, MAR 34 (Wiesbaden 2004) 45 f. Nr. 16 Taf. 23; Kopenhagen, Ny Carlsberg Glyptothek. Inv.-Nr. I.N. 525: F. Poulsen, Ny Carlsberg Glyptothek. Katalog over antike Skulpturer (Kopenhagen 1940) 122 Nr. 156; evtl. auch Shahat, Antikenmuseum Inv. 14.230: G. Olivero, Campagna di scavi a Cirene nell' estate del 1928, Africa Italiana 3, 1930, 170; E. de Franchi, Statua di Dionysos giovanetto, in: C. Anti (Hrsg.), Sculture 
Gott in einer weniger strengen Haltung zeigt, kann in die spätklassische Zeit datiert werden. Der jugendliche Gott sitzt nicht streng frontal, sondern hat seinen Oberkörper nach rechts gedreht. Bei einer der römischen Marmorkopien ruht seine rechte Hand bequem auf dem Kopf eines, allerdings restaurierten Löwen ( $A b b$. 19)222. Eine zweite, heute verschollene Nachbildung zeigt Dionysos im selben Haltungsmotiv, doch ruht sein Arm hier auf der Lehne des Thrones, vor dem ein Panther sitzt ${ }^{223}$. Welche Statue dem Urbild näher steht, soll hier nicht geprüft werden. Das entspannte Haltungsmotiv erweist sich damit ebenfalls als häufig mit diesem Gott verbunden, wenn auch später als bei Aphrodite.

Deutlich seltener wurden andere, und zwar ausschließlich jugendliche Götter in angelehnter Haltung dargestellt. Außer bei Wesen, die zum Gefolge des Dionysos gehören wie etwa Satyrn lassen sich vor allem für Apollon und Hermes großplastische Darstellungen in aufgelehnter Haltung finden. Besonders Praxiteles hat dieses künstlerische Motiv mehrfach verwendet, etwa bei dem ihm zugeschriebenen ausruhenden Satyr ${ }^{224}$, dem Apollon Sauroktonos ${ }^{225}$, dem Hermes von Olympia 226 und dem Apollon Lykeios ${ }^{227}$. Sie lehnen sich wie Aphrodite und Dionysos auch auf Pfeiler, Säulen und Baumstämme. Alle sind durch eine entspannte Körperhaltung gekennzeichnet. Ebenfalls noch auf die spätere Klassik geht ein durch römische Kopien überlieferter Typus des Apollon zurück, bei dem er in der einen Hand einen Zweig hält und sich mit dem anderen Arm auf eine Säule oder einen Pfeiler lehnt ${ }^{228}$. Weitere aufgelehnte Darstellungen anderer Götter als Aphrodite und Dionysos entstanden in hellenistischer Zeit. Dazu zählen z. B. die Varianten des Apollon Kitharoidos, bei denen der Gott sein Instrument auf verschiedene

greche e romane di Cirene (Padua 1959) 209-226; Paribeni 1959, 113 Taf. 150 Nr. 317;

Pochmarski 1974, 82 Nr. 19A; Gasparri 1986, 435 Nr. 119. Zu möglichen Repliken s.

Pochmarski 1974, 82 Nr. 19B-D.

222 Philadelphia, Universitätsmuseum: Matz - von Duhn 1881, 94 Nr. 359; EA 2009; P. Moreno, Argomenti lisippei, Xenia 8, 1984, 21 f.; Gasparri 1986, 438 f. Nr. 141a; P. Moreno, Vita e arte di Lisippo (Mailand 1987) 68-72; T. Mikocki, Alte Zeichnungen und Stiche nach antiken Skulpturen in polnischen Sammlungen, JdI 107, 1992, 208-210.

223 Verschollen, ehemals Florenz, Uffizien: P. Moreno, Argomenti lisippei, Xenia 8, 1984, 21 f. Abb. 2; Gasparri 1986, 438 f. Nr. 141c.

224 Rizzo 1932, 34-37 Taf. 48-55; Boardman 1995, 98 Nr. 71; Maderna 2004, 323-327 Abb. 294 f..

225 Rizzo 1932, 39-41 Taf. 59-61; LIMV II (1984) 378 f. s. v. Apollon/Apollo 53 (E. Simon); Boardman 1995, 72 Nr. 27; W. Geominy, Die Zeit von 390 bis 360 v. Chr. Meisterwerke im Spiegel römischer Kopien, in: Bol 2004, 294 f. Abb. 258-262.

226 Rizzo 1932, 66-73 Taf. 99-101; LIMC V (1990) 321 s. v. Hermes 394 (G. Siebert); Boardman 1995, 70 Nr. 25; Maderna 2004, 326-328 Abb. 296.

227 Rizzo 1932, 79-85 Taf. 119-121; LIMV II (1984) 193 f. s. v. Apollon 39 (V. Lambrinudakis); St. F. Schröder, Der Apollon Lykeios und die attische Ephebie des 4. Jhs. v. Chr., AM 101, 1986, 167-184; Boardman 1995, 96 Nr. 65; C. Maderna, Die letzten Jahrzehnte der spätklassischen Plastik. Form und Raum, in: Bol 2004, 368 f. Abb. 331 f.

${ }^{228}$ LIMC II (1984) 214 f. s. v. Apollon 261 (V. Lambrinudakis). 
Stützen setzt oder sich selbst an einen Baumstamm, eine Säule oder seine Kithara lehnt ${ }^{229}$. Aus dieser Zeit gibt es auch Darstellungen der angelehnten Artemis. Diese sind jedoch im Gegensatz zu den zuvor genannten kleinformatig, wie eine Marmorstatuette aus Lesbos vom Ende des 4. Jahrhunderts v. Chr., bei der sich die Göttin auf einen Pfeiler lehnt oder hellenistische Terrakottastatuetten, die sie auf eine Fackel gestützt zeigen ${ }^{230}$.

Dies wirft natürlich die Frage auf, warum gerade Aphrodite - gefolgt mit einigem zeitlichen Abstand von Dionysos wesentlich früher als alle anderen Götter in einer lässigen Haltung gezeigt werden konnten und warum es sich bei den anderen so dargestellten Göttern immer um jugendliche Gottheiten handelte. Zuvor ist jedoch noch zu klären, ob auch die ikonische Stütze bei anderen Göttern als Aphrodite Verwendung gefunden hat.

\subsection{Ikonische Stützen bei anderen Göttern}

Das Motiv der ikonischen Stütze in Form einer Herme oder eines weiblichen archaistischen Idols wurde seit dem 4. Jahrhundert v. Chr. ebenfalls für Bilder anderer Götter rezipiert. Die Zahl der Beispiele ist allerdings deutlich geringer als bei Aphrodite, es lassen sich für die jeweiligen Götter nur einzelne Darstellungen finden. Deshalb werden sie nicht nach Körpertypus, Materialgattung oder Datierung getrennt betrachtet, sondern nur den jeweiligen Göttern zugeordnet. In diesem Kapitel soll es allerdings nicht um eine vollständige Aufzählung aller Beispiele gehen. Es sollen vielmehr exemplarisch die Möglichkeiten aufgezeigt werden, bei welchen Figuren und in welchem Zusammenhang die ikonische Stütze verwendet wurde.

\subsubsection{Eros und Hermaphrodit}

Nach den Darstellungen von Aphrodite mit ikonischen Stützen stellen Bilder des Eros und Hermaphrodit, also Götter aus dem Umkreis der Aphrodite, die zahlenmäßig größte Gruppe dar. Zu den frühesten Beispielen des Eros zählt die Attasche einer Bronzehydria in New York aus der Mitte des 4. Jahrhunderts v. Chr. oder kurz danach (Kat. B1). Sie soll aus einem Grab in Eretria stammen und zeigt einen halbbekleideten geflügelten Eros, der sich in entspannter Haltung auf ein weibliches archaistisches Idol lehnt und sich in einem Spiegel betrachtet. Am ehesten handelt es sich bei dieser Darstellung um eine Umdeutung der aufgelehnten Aphrodite in einen Eros. Das Idol, das nicht durch Attribute identifizierbar ist, wird also ein Bild der Aphrodite sein, denn Eros und Aphrodite gehören in der griechischen Antike zusammen. Auch die Haltung des Eros mit übereinander geschlagenen Beinen und die Art der Drapierung des Hüftmantels sind bereits von

229 Ebenda 208-213.

230 Kahil 1984, 642. 660 Nr. 204. 496-503. 
den Aphroditebildern bekannt. Auf einem Marmorrelief und bei einer Terrakottastatuette (Kat. B2. B3) steht Eros neben einer im gleichen Maßstab wiedergegebenen weiblichen Figur - am ehesten ist an Aphrodite zu denken - und hat ein kleines weibliches, archaistisch gestaltetes Idol neben sich, auf dessen Kopf er seinen Arm legt. Diese Gruppen fügen sich in den Bereich >Aphrodite leibhaftig neben einer Statue ein und sind nur durch einen Eros, der diesmal in seiner Größe an die der Göttin angeglichen ist, bereichert. Bei einer in dieselbe Rubrik gehörenden hellenistischen Terrakottastatuette steht Eros allein neben dem Idol (Kat. B4), die Aussage ändert sich aber nicht wesentlich.

Eros kann sich bei hellenistischen und kaiserzeitlichen Terrakottastatuetten auch auf einen Pfeiler auflehnen, auf dem eine mit Vogelflügeln versehene Gestalt steht (Kat. B5. B6). Am ehesten ist darin Nike zu sehen, die von der hellenistischen Zeit an auch sonst manchmal mit Eros zusammen dargestellt wurde ${ }^{231}$. Auch die oft mit Eros verbundene Psyche ${ }^{232}$ käme in Frage, sie wurde jedoch eher mit Schmetterlingsflügeln dargestellt ${ }^{233}$. Von einer möglichen weiteren Darstellung des aufgelehnten Eros hat sich nur der mit einem Polos bekrönte Kopf der weiblichen Stützfigur mit dem darauf gelegten Gewand erhalten (Kat. B7). A. Delivorrias datiert dieses Fragment einer Marmorstatuette in das 1. Viertel des 4. Jahrhunderts v. Chr. Da die Gesichtszüge des Kopfes nicht archaisierend sind, vermutet er, dass es sich eher um eine weibliche, eventuell bekleidete Herme handelt als um ein Idol. Allerdings sind die Stützidole nicht durchgängig archaistisch gestaltet. Die altertümlichen Züge kommen z. T. nur in der Kleidung und Körperhaltung zum Ausdruck, eine Rekonstruktion als Ganzkörperfigur ist daher ebenfalls denkbar. Die größere Gestalt, die sich mit dem linken Unterarm auf die Stütze gelehnt hat, deutet A. Delivorrias als Eros, der sein Himation auf der Stütze abgelegt hat, während Aphrodite in dieser Epoche mit dem Mantel bekleidet gewesen wäre, so dass nur ein kleinerer Teil des Gewandes auf der Stütze liegen würde.

Auch auf Hermen kann sich Eros lehnen (Kat. B8-B33). Das Motiv kommt vor allem bei hellenistischen und kaiserzeitlichen Terrakottastatuetten vor, die immer eine männliche Herme als Stütze haben. Eros trägt häufig Attribute der im Gymnasium bzw. der Palästra trainierenden Epheben wie Chlamys, Kranz oder Haarbinde. Darüber hinaus finden sich auch Wassergefäße, Aryballoi oder eine Strigilis. Eros ist also als Palästrit dargestellt und entspricht damit zeitgleichen Athletenbildern, die ebenfalls eine Hermenstütze haben können ${ }^{234}$. Die Herme

\footnotetext{
231 z. B. auf apulisch-rotfigurigen Vasen: K. Schauenburg, Flügelgestalten auf unteritalischen Grabvasen, JdI 102, 1987, 199-232; LIMC VI (1992) 850 - 904 s. v. Nike (A. Moustaka - A. GoulakiVoutira - U. Grote) bes. 870 Nr. 228-231.

232 Vgl. die Eros- und Psyche-Gruppen: LIMC VII (1994) 574. 576-583 s. v. Psyche (N. IcardGianolio); M. Yiangou Aspris, Statuarische Gruppen von Eros und Psyche (Diss. Rheinische Friedrich-Wilhelms-Universität Bonn 1996); DNP X (2001) 522 f. s. v. Psyche (N. Johannsen). ${ }^{233}$ Zur Ikonographie der Psyche s. LIMC VII (1994) 574. 576-583 s. v. Psyche (N. Icard-Gianolio). ${ }^{234}$ s. Kap. 8.
} 
kann deshalb als Hermes- oder Heraklesherme, die zur Ausstattung der Gymnasien und Palästren gehörten, gedeutet werden ${ }^{235}$.

Ebenfalls abgeleitet vom Motiv der aufgelehnten Aphrodite sind die angelehnten Hermaphroditbilder. Dazu zählen zwei hellenistische Terrakottastatuetten (Kat. B34. B35), eine eventuell noch hellenistische Kleinbronze (Kat. B36), zwei kaiserzeitliche Marmorreliefs (Kat. B37. B38) und ein Wandbild des 4. Stils (Kat. B39). Hermaphrodit lehnt sich entweder auf ein archaistisches weibliches Idol, mehr noch aber auf Priapos oder auch auf Pan, wobei wie bei den Aphroditebildern die sexuelle Anspielung im Vordergrund steht ${ }^{236}$.

\subsubsection{Dionysos}

Das Aufkommen aufgelehnter Dionysostypen bereits in spätklassischer Zeit ist bereits erwähnt worden. Auch ikonische Stützen vermutete man bereits für diese Zeit, doch werden die meisten Typen, die Dionysos mit einer ikonischen Stütze zeigen, in der neueren Forschung in die hellenistische Epoche und später datiert.

Noch in spätklassischer Zeit wurde der Dionysostypus Hope geschaffen, der in zwei kaiserzeitlichen Marmorkopien vorliegt (Kat. B40). Sie zeigen den Gott mit dem Gewicht auf dem rechten Bein stehend und mit einem kurzen Chiton, einem Mantel und der Nebris bekleidet. Der linke Fuß ist leicht zur Seite gestellt. Der erhobene linke Arm ruht auf dem Kopf einer weiblichen archaistischen Figur. Der andere Arm ist gesenkt. In die Mitte des 4. Jahrhunderts v. Chr. datiert W. Amelung eine Marmorstatue im Vatikan (Kat. B41) bzw. deren Vorbild ${ }^{237}$. Sie zeigt Dionysos mit dem linken Ellenbogen auf den Polos eines kleinen altertümlichen Idols gelehnt, das auf einer Basis steht. Er steht wie Aphrodite in dem oben beschriebenen Typus sehr körperbetont da mit vorgesetztem linkem Bein, ausschwingender Hüfte und vorgestreckter Brust. Er ist mit einem Mantel bekleidet, der die Brust und das Becken bis zur Scham unbedeckt lässt. Ähnlich in der Haltung, jedoch ohne dass der Mantel über den Rücken drapiert ist wird Dionysos in einer hellenistischen Marmorstatuette aus Samos gezeigt (Kat. B42). Der Gott lehnt sich mit dem linken Ellenbogen auf ein archaistisches Idol. Das linke Spielbein ist angewinkelt, der Fuß im Gegensatz zu Kat. B41 jedoch leicht zurückgestellt.

Ein weibliches Idol dient auch der vielleicht noch in das 4. Jahrhundert v. Chr. zu datierenden Terrakottastatuette Kat. B43 als Stütze. Sie zeigt Dionysos in ent-

235 Die Hermen bei Kat. B15 und B30 sind durch das Löwenfell eindeutig als Herakles identifizierbar. Zu Hermes und Herakles als Schutzgötter der Gymnasien und Palästren s. DNP V (1998) 20-27 s. v. Gymnasium (Chr. Höcker - I. Hadot); DNP V (1998) 387-394 s. v. Herakles (A. Ley), DNP V (1998) 426-432 s. v. Hermes (A. Ley); S. Aneziri-D. Damaskos, Städtische Kulte im hellenistischen Gymnasion, in: D. Kah - P. Scholz (Hrsg.), Das hellenistische Gymnasion (Berlin 2004) 247-271. 236 Vgl. Kap. 7.3.

237 W. Amelung, Die Sculpturen des Vaticanischen Museums II (Berlin 1908) 323 Nr. 102 $\pi$. Er ist sich allerdings unsicher, ob es sich um ein Original oder eine Kopie eines Typus dieser Zeit handelt. 
spannter Haltung mit dem linken Ellenbogen aufgelehnt. Sein Körper ist nahezu entblößt, nur das linke Bein, der linke Arm und ein Teil des Rückens sind mit einem Mantel bedeckt. Eine weitere nur in einer Umzeichnung bekannte Statue zeigt den Gott unbekleidet neben einer weiblichen Figur kleineren Maßstabs stehend, die auf einer Basis steht und auf einer Leier spielt (Kat. B44). Die Gruppe wurde stark ergänzt, die Torsen beider Figuren sind jedoch antik und möglicherweise zusammengehörig. Die Darstellung des Dionysos ist vom Typus des Apollon Lykeios abhängig und deshalb frühestens hellenistisch, als der Apollontypus auf Dionysos übertragen wurde 238 , wahrscheinlich aber eher kaiserzeitlich, als zahlreiche eklektische Werk entstanden sind. Wen die Statuette Kat. B45 aus Pompeji darstellt, bleibt offen. Sie zeigt eine unbekleidete stehende männliche Figur. An ihrer linken Seite steht eine weibliche Figur auf einer Basis, deren Kleidung z. T. archaistische Züge aufweist und anscheinend die Brüste unbedeckt lässt. Da weder der Oberkörper der männlichen Gestalt noch der Kopf des Idols erhalten sind, ist eine Identifizierung unmöglich. S. Reinach hat sie als Merkur und Proserpina gedeutet $^{239}$, wofür jedoch keine Anhaltspunkte vorliegen. Auch Dionysos ist möglich, ebenso wie andere Götter, die jugendlich-unbekleidet dargestellt wurden.

Dionysos ist auch auf männliche Stützfiguren gelehnt dargestellt worden ${ }^{240}$. So lehnt sich der Gott auf einer Figurenvase aus Kertsch aus dem 4. Jahrhundert v. Chr. auf Priapos (Kat. B46) ${ }^{241}$. Der Gott steht entspannt mit überkreuzten Beinen, die von einem Mantel bedeckt sind. Er lehnt sich mit dem linken Arm auf einen nicht sicher zu identifizierenden Gegenstand, vielleicht einen Baumstamm. In der Hand hält er einen Kantharos. Vor der Stütze steht eine Ganzkörperfigur des Priapos, die mit den Händen ihr Gewand hebt. Zu den Darstellungen mit männlichen Stützfiguren zählen auch die kaiserzeitlichen Marmorrepliken des Typus Dijon-Kyrene, der in das 3. Jahrhundert v. Chr. datiert wird (Kat. B47). Sie zeigen den Gott mit dem linken Unterarm auf eine bärtige Herme gelehnt. Das rechte Bein ist das Standbein, das linke ist leicht angewinkelt. Die Beine sind bis zur Mitte der Oberschenkel mit einem Mantel bedeckt, dessen obere Kante ähnlich wie bei den Aphroditebildern zu einem Wulst gedreht ist.

238 St. F. Schröder, Römische Bacchusbilder in der Tradition des Apollon Lykeios. Studien zur Bildformulierung und Bildbedeutung in späthellenistisch-römischer Zeit (Rom 1989) bes. 13. 15. 109.

239 Reinach 1897a, 341, 8.

240 Dazu zählen auch Beispiele, bei denen die Stütze eine Zutat römischer Kopisten ist wie der Typus Bacchus Richelieu oder Madrid-Varese aus dem 1. Jahrhunderts v. Chr., der sowohl mit Baumstammstütze (Abb. 20, Shahat, Antikenmuseum Inv. 14.231 u. a.: Cain 1997, 37 f. mit Abb. und Taf. 5.) als auch mit Hermestütze (Kat. B48) überliefert ist: Rizzo 1931, 76-78, Boardman 1995, 97 Nr. 68 und Cain 199737 f. mit veralteter Datierung; Schröder 2004, 239-243 Nr. 145.

241 M. Trumpf-Lyritzaki, Griechische Figurenvasen des Reichen Stils und der späten Klassik (Bonn 1969) 55 setzt die Vase vorsichtig in die Mitte des 4. Jahrhunderts v. Chr. oder kurz danach. Sie deutet die Stützfigur als Papposilen. Aufgrund der Zeichnung kann dies nicht entschieden werden. 
Ein anderes Beispiel eines auf eine ikonische Stützte gelehnten Dionysos zeigt eine frühkaiserzeitliche Gemme des Kestner-Museums in Hannover (Kat. B49). Der Körper des Gottes wird von einem Mantel hinterfangen, ist ansonsten aber unbekleidet. In der linken Hand trägt er den Thyrsos. Mit dem rechten Arm lehnt er sich auf eine unbekleidete ithyphallische Figur. Links von Dionysos schwebt ein Eros, hinter ihm ruht ein Panther. Eine Terrakottastatuette aus Kleinasien stellt den Gott stehend dar (Kat. B50). Nur sein rechtes Bein wird von einem Mantel bedeckt. In der erhobenen Linken hält er eine Traube, in der gesenkten Rechten einen Kantharos. Auf dem Kopf trägt er einen Blätterkranz. Zu seiner Linken, allerdings ohne direkt als Stützfigur zu dienen, steht eine bekleidete ithyphallische Herme, wahrscheinlich des Priapos. Bei dieser Statuette handelt es sich allerdings vermutlich um eine neuzeitliche Fälschung. Eine kleinformatige Darstellung aus Bronze, die vielleicht als Applik gedient hat, zeigt den Gott auf eine bärtige Herme gelehnt (Kat. B51). Er ist mit einer Nebris bekleidet, trägt einen Blattkranz und eine Binde auf dem Kopf und hält in der gesenkten Rechten eine Traube. An den Früchten knabbert ein Panther, der hinter dem Gott hockt.

Auch auf Eros kann sich Dionysos lehnen. Eine Glaspaste unbekannter Herkunft zeigt den Gott, wie er sich schwer lastend mit dem rechten Arm auf eine kleine Erosfigur auf einer Basis lehnt, die durch Pfeil und Bogen erkennbar ist (Kat. B52). Dionysos stützt sich zusätzlich mit der Linken auf seinen Thyrsos. Ebenfalls als Dionysos wurde von S. Reinach eine stehende unbekleidete Figur gedeutet, an deren rechter Seite eine bärtige Herme steht (Kat. B53) ${ }^{242}$. Weiteres ist über diese Darstellung nicht bekannt.

Auch für das Gefolge des Dionysos lassen sich einige wenige Beispiele mit ikonischen Stützen benennen. Dazu gehört die späthellenistische Darstellung einer stehenden halbbekleideten weiblichen Figur in der Villa unter der Farnesina in Rom (Kat. B54). Die weibliche Gestalt, neben der ein gelagerter Dionysos zu sehen ist, lehnt mit dem linken Unterarm auf der Basis einer nicht zu identifizierenden Herme oder Figur. Sie ist in Rückenansicht wiedergegeben. Ihr Gewand ist bis unter das Gesäß herabgerutscht. Auf einem kaiserzeitlichen Marmorrelief in Rom (Kat. B55) ist ein Syrinx-spielender, stehender Satyr wiedergegeben, der sich auf die Basis einer mit einem Löwenfell bekleideten bärtigen Herme des Herakles oder Pan lehnt. Als Polster unter dem aufgelehnten Arm dient ein weiteres Tierfell. Als Satyr wird auch die Darstellung einer Gemme, die sich ehemals in der Sammlung Medici in Florenz befand, gedeutet (Kat. B56) ${ }^{243}$. Sie zeigt eine stehende männliche Figur mit einem Mantel über dem Arm, die sich auf eine Schale stützt, die von einer weiblichen archaistischen Figur gehalten wird.

242 Reinach 1930, 23, 4.

${ }^{243}$ S. Reinach, Pierres gravées des Collections Marlborough et D'Orléans. Bibliothèque des Monuments Figurés Grecs et Romains (Paris 1895) 45 Taf. 43, 89, 6. 


\subsubsection{Weitere Götter und mythologische Gestalten}

Für Artemis lassen sich Hermen als Stützen seit der ersten Hälfte des 4. Jahrhunderts v. Chr. in der Terrakottaplastik mehrfach nachweisen. Diese frühen Beispiele stellen offenbar einen Sonderfall in der tarentinischen Kleinkunst dar, da weitere derartige Bilder aus anderen Orten erst deutlich später sind. Die Göttin ist erkennbar an ihrer charakteristischen Kleidung wie dem kurzen Chiton und den hohen Stiefeln sowie dem umgelegten Tierfell. Außerdem ist ihr oft ein Hund oder ein Reh beigegeben. Bei Kat. B57 und B58 hält sie zudem einen Bogen. Bei zwei Beispielen ist die Herme eindeutig männlich (Kat. B59 und B60). Bei einer weiteren ist sie weiblich (Kat. B57). Bei einer dritten Terrakottastatuette ist die Herme zu schlecht erhalten, um ihr Geschlecht identifizieren zu können (Kat. B58).

Auch das weibliche Idol findet sich als Stütze für Artemis, jedoch erst in hellenistischer Zeit. Eine Marmorstatuette aus Larnaka auf Zypern zeigt die Göttin stehend und mit einem langen Chiton und einem Himation bekleidet. Mit dem linken Unterarm lehnt sie sich auf den Polos eines weiblichen archaistischen Idols (Kat. B61). Die Göttin kann durch das Köcherband identifiziert werden. Die Statuette wurde von der Forschung zunächst für ein frühhellenistisches Werk aus dem Umkreis der Söhne des Praxiteles gehalten ${ }^{244}$. Inzwischen hat sich aber eine Datierung in das 2. Jahrhundert v. Chr. durchgesetzt ${ }^{245}$. Eine weitere Darstellung der Artemis auf einer kaiserzeitlichen Münze aus Eukarpia in Phrygien zeigt die Göttin ebenfalls als langgewandete Jägerin mit Bogen und Köcher (Kat. B62). Sie ist gerade dabei, einen Pfeil aus diesem zu nehmen. Der gesenkte linke Arm, der den Bogen hält, ist auf den Polos eines weiblichen altertümlichen Idols gelegt. Rechts von der Göttin steht ein Hirsch und blickt zu ihr auf. Ein hellenistisches Lampenfragment aus Knidos stellt die Göttin hingegen in kurzem Gewand und hohen Stiefeln dar (Kat. B63). Auch bei dieser Figur lehnt sich Artemis mit dem rechten Arm auf ein altertümliches weibliches Idol. Die Arme der Göttin sind erhoben, um die Lampenöffnungen zu stützen. Hinter ihr hockt ein Hund.

Für Athena lässt sich ebenfalls ein auf eine Herme gelehntes Beispiel anführen. Das von der Forschung in das 1. Jahrhundert v. Chr. datierte \Lanckoronski-Relief zeigt eine mit einem Peplos bekleidete Athena mit einem Helm auf dem Kopf in Dreiviertelansicht, die ihren Schild an eine bärtige Herme gelehnt hat, die neben

${ }^{244}$ H. Bulle, Archaisierende griechische Rundplastik (München 1918) 13. 20; M. Bieber, Die Söhne des Praxiteles, JdI 38/39, 1923/24, 242-275, bes. 257; Rizzo 1932, 13; Muthmann 1951, 18; Ch. Picard, Manuel d'Archéologie grecque IV. La sculpture. Période classique - IVe siècle I (Paris 1954) 356 f.; Bieber 1955, 16. 21; Kahil 1984, 694 Nr. 947.

245 H. Herdejürgen, Untersuchungen zur Thronenden Göttin aus Tarent in Berlin und zur archaischen und archaistischen Schrägmanteltracht (Waldsassen 1968) 85 Nr. d) 2; P. Nindazzini, La datazione dell' Artemis di Larnaka, ÖJh 49, 1968, 73-76; R. Kabus-Jahn, Die Artemis von Larnaka, Pantheon 31, 2, 1973, 115-121; Zagdoun 1989, 79 f. 176.257 Nr. 492; Brahms 1994, 185 f.; H-H. von Prittwitz und Gaffron, Die hellenistische Plastik von 160 bis 120 v. Chr., in: P. C. Bol (Hrsg.), Die Geschichte der antiken Bildhauerkunst III. Hellenistische Plastik (Mainz 2007) 248. 
ihr in Profilansicht steht. Die Göttin stützt ihren rechten Ellenbogen auf den Kopf der Herme und lässt einen kleinen Vogel aus ihrer Hand aufsteigen (Kat. B64).

Stadtrömische Multipla zeigen eine sitzende Concordia bzw. Pietas mit Patera und Füllhorn, die durch Beischriften identifizierbar sind. Sie lehnen sich auf ein weibliches archaistisches Idol (Kat. B75). Auch mythologische Figuren können sich darauf lehnen. Ein spätklassischer apulisch-rotfiguriger Krater in Moskau zeigt Iphigenie als Priesterin im Tempel der Artemis von Tauris stehend und auf das Bild der Göttin gelehnt (Kat. B76). Eine hellenistische Terrakottastatuette aus Myrina wird von S. Mollard-Besques als schlafende Ariadne bei einer Statue der Artemis identifiziert (Kat. B77) 246 . Sie zeigt eine gelagerte halbbekleidete weibliche Figur, neben der ein weibliches Idol steht. Eine weitere, späthellenistische Terrakottastatuette desselben Fundortes wird von S. Mollard-Besques ebenfalls als Darstellung der Ariadne bei einem Bild der Artemis gedeutet (Kat. B78) 247. Die Statuette zeigt eine stehende weibliche Figur, die mit einem Mantel, der die rechte Brust und Schulter unbedeckt lässt bekleidet ist und sich auf ein archaistisches Idol lehnt.

Als ein Beispiel für eine männliche Gottheit mit einer ikonischen Stütze lässt sich eine Terrakottastatuette anführen, die sich heute im Archäologischen Museum von Thessaloniki befindet. Sie wird von O. Palagia in das frühe 4. Jahrhundert v. Chr. datiert und zeigt einen stehenden Apollon im Hüftmantel, der sich mit dem linken Arm auf eine Herme auflehnt und in der Armbeuge eine Lyra hält (Kat. B65). Der untere Teil der Terrakottastatuette ist abgebrochen, so dass von der Herme nur der Kopf erhalten ist und dies auch nur sehr schlecht, so dass eine Identifizierung der Stützfigur nicht möglich ist. Weitere Darstellungen des Apollon mit ikonischen Stützen, und zwar in Gestalt eines weiblichen Idols sind frühestens späthellenistisch, und zwar eine Gemme aus dem 1. Jahrhundert vor bzw. nach Chr. (Kat. B66) und ein kaiserzeitliches Wandbild (Kat. B67). Sie zeigen den Gott stehend und die Kithara spielend, die er auf dem Kopf der Stützfigur abgesetzt hat.

Von dem in Kapitel 6.2 bereits erwähnten Typus des Apollon Lykeios, der vielleicht auf ein Werk des Praxiteles zurückgeht, gibt es außer der genannten römischen Kopie mit der Dreifußstütze eine weitere mit einem weiblichen archaistischen Idol als Stütze (Kat. B68). Bei anderen Kopien hingegen ist diese ein Dreifuß oder ein Baumstamm (Abb. 21)248. Wahrscheinlich handelt es sich bei dem Idol also um eine Kopistenzutat. Der Kopist kannte das Motiv des Idols als

\footnotetext{
246 Mollard-Besques 1963, 80 Taf. 96d.

247 Ebenda 79 Taf. 96f.

248 Dresden, Staatliche Kunstsammlung Inv. Hm 127: Rizzo 1932 Taf. 119 f.; K. Knoll (Hrsg.), Götter und Menschen. Antike Meisterwerke der Skulpturensammlung. Ausstellungskatalog Dresden (Dresden 2000) 14 Nr. 4.
} 
Stütze von anderen Werken und benutzte es als besonders reich gestaltetes Element. Eine inhaltliche Motivation ist nicht sicher zu bestimmen.

Bilder des Hermes mit weiblichem Stützidol sind mir nicht bekannt. Hermen kommen hingegen häufiger vor. Als Hermes am Wegesrand kann die Stütze eines Hermes gesehen werden, der das Dionysoskind auf dem Arm trägt, um es zu den Nymphen von Nysa zu bringen (Kat. B69). Gut möglich, dass es sich bei dem Original dieses Typus um die von Plinius ${ }^{249}$ erwähnte Statue des Hermes mit dem Dionysoskind von Kephisodot handelt. Da mehrere Kopien erhalten sind, ist ein berühmtes Vorbild vorauszusetzen. Palästra-Hermen kommen wie bei Eros bei Hermes ebenfalls vor. Bei einer hellenistischen Terrakottastatuette ist der stehende Gott wie ein junger Ephebe gebildet, unbekleidet und bekränzt. Er hat seinen rechten Ellenbogen auf das Kapitell einer Säule gelegt, auf der eine kleine ithyphallische bärtige Herme steht (Kat. B70). Eine kaiserzeitliche Marmorstatue und eine ebenfalls kaiserzeitliche Münze aus Pheneos (Kat. B71. B72) zeigen ein vergleichbares Bild des Gottes. Auch Herakles lehnt sich an Palästra-Hermen an, wie die hellenistischen Terrakottastatuetten Kat. B73 und B74 zeigen.

Auch Bilder männlicher Heroen und mythologischer Figuren in dieser Körperhaltung sind bekannt. Eine kaiserzeitliche Gemme unbekannter Herkunft zeigt Perseus stehend und unbekleidet (Kat. B79). In der erhobenen Rechten hält er das abgeschlagene Haupt der Gorgo Medusa. Er lehnt sich vielleicht mit dem Rücken an die Basis einer Athenastatue. Ein klassischer, apulisch-rotfiguriger Krater aus Bari zeigt den sitzenden Olympos, der von Marsyas das Flötenspiel lernt (Kat. B80). Dabei lehnt er sich an eine bärtige Herme. Ein kaiserzeitliches Münzbild aus Mantineia, das einen stehenden unbekleideten Mann zeigt, der sich ebenfalls auf eine Herme lehnt, ist von F. W. Imhoof-Blumer und P. Gardner als Darstellung des Arcas gedeutet worden (Kat. B81) ${ }^{250}$, was jedoch eine bloße Vermutung ist.

\subsection{Zusammenfassung}

Die Betrachtung des Materials hat ein ziemlich klares Bild sowohl vom Gebrauch aufgelehnter Körperhaltungen als auch der ikonischen Stütze in der antiken, vor allem der griechischen Götterikonographie ergeben. Die einzige Gottheit, die bereits im 5. Jahrhundert v. Chr. in aufgelehnter und entspannter Haltung gezeigt wurde, ohne dass die Darstellung in einem erzählenden Kontext stand, ist Aphrodite. Für sie sind mehrere großplastische Bildwerke in diesem Haltungsschema bereits für die Zeit der Hochklassik bezeugt. Aufgelehnte Haltungen waren sonst nur durch eine inhaltliche Motivation möglich, z. B. bei dem Amazonentypus Sciarra, wo damit der Grad der Verletzung gekennzeichnet ist (Abb. 13). Dazu

\footnotetext{
249 Plin. nat. 34, 87.

250 Imhoof-Blumer - Gardner, 1964, 94 f.
} 
kommt, dass bei der Amazone wie auch bei anderen aufgelehnten Figuren das Motiv nicht dazu diente, den Körper auf eine so betonte Weise zur Schau zu stellen wie bei Aphrodite ${ }^{251}$. Nur bei dieser Göttin wird das Auflehnen dazu verwendet, eine lässige, mit einer betonten Darstellung der Körperlichkeit verbundene Haltung zu zeigen. Andere Götter wurden in ihren Bildern, wenn diese nicht in einem erkennbaren erzählerischen Kontext standen, wie etwa die >Kultbilder in den Heiligtümern, im 5. Jahrhundert v. Chr. in aufrechter Haltung gezeigt. Darauf werde ich in Kapitel 7.2.2 noch einmal zurückkommen, um dies im Zusammenhang mit der historischen Situation weiter zu verdeutlichen. Die auf- oder angelehnten, stehend oder sitzend dargestellten Aphroditebilder brachen als erste aus diesem Schema aus. Erstmals war hier eine gelöste Körperhaltung für großplastische und vielleicht auch in einen Kult einbezogene Statuen möglich ${ }^{252}$

Erst seit dem 4. Jahrhundert v. Chr. und damit deutlich später als die ersten Darstellungen der aufgelehnten Aphrodite fanden sich auch Bilder anderer Götter in dieser Haltung, ohne dass diese durch einen erzählenden Kontext zu erklären wäre. Bei den anderen Göttern handelt es sich ausschließlich um jugendliche Götter und Heroen wie Apollon oder Hermes, vor allem aber um die Aphrodite nahe stehenden Götter Eros und Hermaphrodit sowie Dionysos. Für ältere, mütterliche oder väterliche Götter wie Hera, Demeter, Zeus oder Poseidon lässt sich kein Beispiel benennen. Diese Haltung entsprach also nicht ihrem Charakter bzw. ihrem Körperbild, was weiter unten noch dargelegt werden wird ${ }^{253}$.

Auf die anderen Götter wurde im Folgenden auch das Motiv der ikonischen Stütze übertragen. Die frühesten Darstellungen sind im Laufe der ersten Hälfte des 4. Jahrhunderts v. Chr., also ungefähr ein halbes Jahrhundert später als die der Aphrodite entstanden. Auch sind die Beispiele für die anderen Götter von deutlich geringerer Anzahl als bei dieser Göttin. Bei über 63\% Prozent aller mir bekannten und im Katalogteil dieser Arbeit zusammengestellten Fälle von Götterdarstellungen mit einer ikonischen Stütze handelt es sich um Bilder der Aphrodite. Sie stellen damit mit großem Abstand die umfangreichste Gruppe dar. Weitere 20\% sind Darstellungen des Eros und des Hermaphrodit, also Götter aus dem Umkreis der Aphrodite und $8 \%$ Bilder des Dionysos. Die Bilder aller anderen Götter zusammengenommen machen nur ca. $9 \%$ Prozent des gesamten Materials aus und sind damit deutlich weniger bezeugt. Selten sind auch Darstellungen anderer Götter als Aphrodite mit anderen Stützen wie Baumstämmen oder Pfeilern belegt. Dieser Befund liefert einen signifikanten Ansatz für die Interpretation des Bildmotivs im Rahmen der Entwicklung und Konzeption griechischer Götterbilder ${ }^{254}$.

251 Vgl. dazu Kap. 7.2.2.

252 s. Kap. 5. Zur Frage nach dem Kultbildbegriff s. Kap. 11.

253 Zum Zusammenhang zwischen dem Charakter der Götter und ihrer Darstellungsweise vgl. Kap. 7.2.2.

254 Dazu s. Kap. 7.2.2. 
Die frühesten Beispiele für andere Götter außer dem zum Kreis der Aphrodite gehörenden Eros zeigen Dionysos auf ein weibliches altertümliches Idol gelehnt sowie Artemis und Apollon mit Hermenstützen. Für diese Götter lassen sich einzelne Beispiele bereits in der späteren Klassik nachweisen. Die Bilder der Artemis und des Apollon gehören ausschließlich der Terrakottaplastik an und können von dem bekannten Motiv der aufgelehnten Aphrodite abgeleitet sein. Gleiches gilt für die Bilder des Dionysos, die jedoch z. T. der großformatig sind. Einige wenige weitere Bilder anderer Götter mit ikonischen Stützen aus den folgenden Epochen ließen sich anschließen. Dazu zählen Darstellungen des Dionysos mit Priaposund Hermenstütze, der Artemis und des Apollon mit dem weiblichen Stützidol, der Athena, des Hermes und des Herakles mit Hermenstütze und einige mythologische Gestalten. Von diesen Beispielen zu trennen sind Bilder, bei denen die Stützfigur nicht zur originalen Erfindung gehört, sondern eine Kopistenzutat darstellt. Bei diesen ist die Form der Stütze austauschbar und darf deshalb nicht zur Deutung der ursprünglichen Fassung herangezogen werden.

Auffallend ist, dass nahezu alle Beispiele der anderen auf eine ikonische Stützfigur aufgelehnten Gottheiten - im Gegensatz zu Aphrodite - der Kleinkunst angehören. Die hier vorliegenden Beispiele, namentlich die Terrakottastatuetten, haben eine geringere Bedeutung, wenn man die Häufigkeit des Vorkommens der Typen betrachtet, als etwa die bei Aphrodite wesentlich häufiger zu findenden großplastischen Beispiele. Da die Terrakottastatuetten in der Antike eine Massenware waren, die mit Hilfe von Matrizen weit verbreitet wurden, haben sie eine deutlich geringere Bedeutung für die Frage nach der Anzahl der Belege für einen Typus. Auch sind sie häufig freier in ihren Variationen und oft von großplastischen Typen beeinflusst, in diesem Fall von Darstellungen der Aphrodite oder großplastischen Bildwerken der jeweiligen Götter selbst ${ }^{255}$.

Dementsprechend kann man feststellen, dass für andere Götter als Aphrodite weniger aufgelehnte Typen sowie deutlich weniger Beispiele für die einzelnen Typen vorliegen. Sie lehnen sich zudem oft an Bilder der Aphrodite an, bei der ein derartiges Haltungsmotiv am ehesten ihrem Wesen entsprach und deshalb auch zuerst vorkam ${ }^{256}$. Denn dass Aphrodite die ersten Gottheit war, die in der Freiplastik in einer entspannten und zugleich besonders körperbetonten Haltung dargestellt wurde, ist aus den hier gesammelten Werken eindeutig hervorgegangen.

${ }^{255}$ G. Kleiner, Tanagrafiguren. Untersuchungen zur hellenistischen Kunst und Geschichte, JdI Ergh. 15 (Berlin 1942) 131; E. Bartman, Ancient Sculptural Copies in Miniature (Leiden 1992) 9-15;

Zanker 1998, 15. 92.

256 Vgl. dazu Kap. 7.2.2. 



\section{Interpretation}

In den folgenden Kapiteln soll eine Deutung des betrachteten Materials vorgeschlagen werden. Dabei ist einerseits zu fragen, warum gerade Aphrodite bereits im 5. Jahrhundert v. Chr. aufgelehnt und körperbetont dargestellt werden konnte, während dieses Bildmotiv erst in der Spätklassik und vor allem im Hellenismus auf andere Götter und dort vorrangig in der Kleinplastik übertragen wurde. Andererseits stellt sich die Frage, warum als Stütze für Aphrodite neben der Herme, deren Vorhandensein in Kapitel 5.1.3 bereits begründet wurde, sehr häufig ein weibliches Idol verwendet wurde und warum dieses archaistisch gestaltet ist. Von der Forschung wurden bereits verschiedene Vorschläge zur Deutung der Stützfiguren vorgeschlagen. Sie sollen zunächst referiert und bewertet werden. Das daraus abgeleitete Ergebnis soll im Anschluss dahingehend überprüft werden, wie es sich in den gesellschaftlichen und künstlerischen Kontext seiner Entstehungszeit einfügt.

\subsection{Diskussion der Deutungen der figürlichen Stütze der Aphrodite}

\subsubsection{Die Deutung des weiblichen Idols in der Forschung}

Die von der Forschung vorgeschlagenen Deutungen der altertümlichen Idole sollen hier noch einmal aufgegriffen und auf ihre Wahrscheinlichkeit geprüft werden, denn eine der Fragen, die am Anfang dieser Arbeit gestanden hat, war, ob es möglich ist, die Stützidole mit Hilfe der erweiterten Materialbasis zu identifizieren. Die bisher vorgeschlagenen Deutungen reichen von einem altertümlichen Bild der Aphrodite selbst über Statuen anderer Gottheiten wie Genetyllis, Eileithyia, Spes oder Artemis bis hin zur Identifizierung als Statue einer Priesterin oder Adorantin. 


\subsubsection{Die Deutung als altes Aphroditebild}

R. Kekulé hat 1884 in seiner Abhandlung über die >Aphrodite Brazzà Kat. A1 das von ihm rekonstruierte weibliche Stützidol dieser Figur als Aphroditebild gedeutet $^{257}$. Für ihn war das Idol aber nur dann Aphrodite, wenn auch die darauf gelehnte Figur die Göttin darstellte. Umgekehrt kann aus der Stütze nicht auf die aufgelehnte Figur geschlossen werden, da das Idol auch anderen Figuren, darunter auch männlichen, als Stütze dient. Eine einheitliche Deutung des Idols als Aphrodite lehnte er deshalb zu Recht $\mathrm{ab}^{258}$. Eine Erklärung, warum sich Aphrodite auf ihr eigenes Bild lehnt, hat er nicht versucht. Dieselbe Ansicht wurde von A. Furtwängler in seinem 1890 erschienen Artikel über die Göttin Aphrodite in W. H. Roschers Mythologischen Lexikon ${ }^{259}$, V. K. Müller im Rahmen seiner Ausführungen zu Vorkommen, Formen und Bedeutungen des Polos von $1915^{260}$ und M. Bieber in ihrer Monographie über Kopien von Bildwerken in der Antike aus dem Jahr 1977261 vertreten. Eine weitergehende Interpretation des Bildtypus insgesamt versuchten die genannten Autorinnen und Autoren jedoch nicht.

W. Deonna veröffentlichte 1950 einen Aufsatz zu Bildern der aufgelehnten Aphrodite ${ }^{262}$. Darin beschrieb er auch zwei Darstellungen mit weiblichen Stützidolen (die Marmorstatuette Kat. A2 und die Terrakottastatuette Kat. A43). Er sah in den Stützfiguren eine rarchaischer Statue derjenigen Gottheit, die sich auf sie lehnt, in diesem Fall also Aphrodite. Götterbilder zweier unterschiedlicher Epochen waren demnach in diesen Darstellungen zu einem einzigen Bild vereinigt ${ }^{263}$. Auch A. Delivorrias äußerte sich in dem Artikel >Aphroditer des LIMC von 1984 zu diesem Typus. Für ihn bezeichnet das Idol, auf das sich Aphrodite lehnt, ein altes Bild der Göttin selbst, »und zwar in einer durch spätere Kultbilder ersetzten Form« ${ }^{264}$. Vorsichtiger formulierte M. Kunze bei seiner Beschreibung der Marmorstatuette Kat. A2 im Katalog der Berliner Antikensammlungen von 1992 seine These, das Idol sei ein Bild der Aphrodite: »Der Sinn eines solchen Idols liegt vielleicht in dem Verweis auf ein älteres Kultbild« ${ }^{265}$.

257 Kekulé 1894, 15. Zur Problematik der Rekonstruktion der Stütze s. Kap. 3.1.1.

258 Kekulé 1894, 13.

${ }^{259}$ Roscher, ML I (1884-1890) 414 s. v. Aphrodite (A. Furtwängler) 390-419, bes. 413 f. Als Beispiele nennt er die verschollene Darstellung Kat. A16 mit einem Stützidol sowie die idolartige Herme auf dem Relief Kat. A3, die seiner Meinung nach dem Idol entspricht.

260 Müller 1915, 57. Er nennt in seiner Untersuchung die Terrakottastatuetten Kat. A41 und Kat. A44, erwähnte beide allerdings lediglich als Beispiele für einzelne Formen des Polos. Welche Funktion der Polos, den die Stützidole tragen, in dieser speziellen Verwendung haben könnte, ließ er offen.

261 Bieber 1977, 96. Sie nennt die Marmorstatuette Kat. A6 als Beispiel, bei der sich Aphrodite auf ein Idol lehnt.

262 Deonna 1950.

263 Ebenda 54-56.

264 Delivorrias 1984, 13.

265 Kunze 1992, 141 Nr. 48. 
In der Forschung wurde also bereits mehrfach vorgeschlagen, die Idole, auf die sich Aphrodite lehnt, als Darstellungen derselben Göttin zu deuten. Für die meisten Autoren war diese Deutung abhängig von der Identifizierung der aufgelehnten Göttin als Aphrodite. Sie lehne sich demnach auf ihre eigene Statue. Nach Ansicht von W. Deonna, A. Delivorrias und E. Kunze verweist die archaistische Gestaltungsweise der Idole auf ein altes Bild der Göttin und ihrer Meinung nach sogar auf ein raltes Kultbild, das mit einer zeitgenössischen Darstellung der Göttin verbunden worden sei $^{266}$.

\subsubsection{Die Deutung als chthonische Aphrodite}

Während die bisher genannten Autoren die Idole als altertümliche Bilder der Aphrodite sahen schlug E. Gerhard 1826 in einer Abhandlung über Aphrodite vor, sie als Darstellungen der Unterweltsgöttin Aphrodite-Persephone zu deuten weil sie den >Modius tragen und oft eine Blüte in der Hand halten, die typisch seien für Erdoder chthonische Gottheiten ${ }^{267}$. Auch die auf die Brust gelegte Hand war für ihn Zeichen für Schlaf oder Tod ${ }^{268}$. Die aufgelehnte Figur sei aufgrund der teilweisen Entblößung des Oberkörpers sowie der Stephane oder des Kranzes, den einige der Dargestellten tragen, eher Aphrodite als eine Sterbliche ${ }^{269}$. J. J. Bernoulli hat in seiner Monographie zu Aphroditedarstellungen von 1873 die Deutung der Idole als Aphrodite-Persephone von E. Gerhard übernommen. Er sah in den Aufgelehnten jedoch Darstellungen von Sterblichen, da die Gewänder bei den ihm bekannten Bildern untereinander variieren. Für eine Göttin wäre seiner Meinung nach ein bestimmter Gewandtypus bei allen derartigen Darstellungen zu erwarten ${ }^{270}$.

Die Deutung des Gewandraffens, des Haltens einer Blüte oder Frucht und des Tragens des >Modius als Symbole des Todes ist wenig verständlich. Zwar kommen die genannten Merkmale auch im sepulkralen Kontext vor, etwa bei archaischen Grabstatuen und Grabreliefs, jedoch auch bei zahlreichen Darstellungen, die nicht mit dem Grab in Verbindung stehen ${ }^{271}$. Außerdem wird die von E. Gerhard als

266 Deonna 1950, 54-56; Delivorrias 1984, 13; Kunze 1992, 141 Nr. 48.

267 Gerhard 1826, bes. 11-14. 21; ebenso E. Gerhard, Über die Venusidole, in: ders. 1866, 258-284 bes. $268 \mathrm{f}$.

268 E. Gerhard, Über die Venusidole, in: ders. 1866, 265.

269 Gerhard 1826, 59-67. Ihm waren das Marmorrelief Kat. A3, die Statuen Kat. A8 und A10 und die Statuetten Kat. A17 und Kat. A23 bekannt.

270 Bernoulli 1873, 133-136. Ihm waren außer den schon bei Gerhard 1826 aufgeführten noch die Statuetten Kat. A2 und Kat. A16 bekannt.

${ }^{271}$ z. B. die archaischen Mädchenstatuen aus zahlreichen antiken Heiligtümern: E. Langlotz, Die Koren, in: H. Schrader (Hrsg.), Die archaischen Marmorbildwerke der Akropolis (Frankfurt a. M. 1939) 8; G. M. A. Richter, Korai. Archaic Greek Maidens (London 1968) 3 f.; L. Schneider, Zur sozialen Bedeutung der archaischen Korenstatuen (Hamburg 1975); Boardman 1981, 80; F. Brommer, Gott oder Mensch, JdI 101, 1986, 37-53; Fuchs - Floren 1987, 94. 262; W. Martini, Die archaische Plastik der Griechen (Darmstadt 1990) 80-82; Karakasi 2001; M. Meyer, Athena und die Mädchen. Zu den Koren auf der Athener Akropolis, in: M. Meyer - N. Brüggemann, Kore 
Modius angesprochene Kopfbedeckung von allen griechischen Göttinnen getragen, und nicht nur von Persephone ${ }^{272}$. Die Deutung der Aufgelehnten als Aphrodite wiederum ist in Kapitel 3 bereits begründet worden, wenn es auch vereinzelt Darstellungen von Sterblichen gibt, die sie auf Götterbilder gelehnt zeigen ${ }^{273}$. Besonders die Entblößung des Oberkörpers, die bereits bei den klassischen Beispielen mit dem von der Schulter gerutschten Chiton beginnt und in hellenistischer Zeit zu einem vollständig unbekleideten Oberkörper führt, macht die Deutung als Aphrodite im Gegensatz zur Deutung als Sterbliche wesentlich wahrscheinlicher.

\subsubsection{Die Deutung als andere Göttin}

Anders als die bisher genannten Autoren sah L. Stephani bei seinen Beschreibungen der in Kertsch gefundenen Terrakottastatuetten Kat. A37 und A44 aus den Jahren 1876 und 1882 in dem Idol aufgrund seines kleineren Maßstabs eine untergeordnete Gottheit, nämlich die mit Aphrodite in Verbindung stehende Geburtsgöttin Genetyllis oder Eileithyia ${ }^{274}$. Diese repräsentierte für ihn die gebärende Kraft der Aphrodite, weil sie mit dem Kalathos geschmückt sei, »jenem von der alten Kunst so vielfach verwendeten Symbol schöpferischer Kraft und Fruchtbarkeit« ${ }^{275}$. Sie stelle das weibliche Gegenbild zu Priapos dar, der ebenso als Stützfigur diene und die zeugende Kraft repräsentiere ${ }^{276}$. Auch A. Cartault hat in seiner Beschreibung der Terrakottastatuette Kat. A41 in dem Katalog der Antikensammlung von C. Lecuyer aus dem Jahr 1882 das Idol für die Darstellung einer Aphrodite beigeordnete Göttin gehalten, da dass das Idol gegenüber der darauf gelehnten Figur eine untergeordnete Stellung einnehme ${ }^{277}$. Welche der Begleiterinnen der Aphrodite darin zu sehen sei, spezifizierte er jedoch nicht.

Die Deutungen der Idole als der Aphrodite nahe stehende Göttin wie Genetyllis oder Eileithyia brauchen heute keiner langen Widerlegung. Das kleinere Format dient dazu, die Figur als alte, kleinformatige Statue zu kennzeichnen ${ }^{278}$ und das Auflehnen zu ermöglichen. Über die archaistische Gestaltungsweise sind wir heute besser informiert ${ }^{279}$. Auch der von dem Idol getragene $>$ Kalathos`, den L. Stephani als »Symbol der gebärenden Kraft der Aphrodite $«^{280}$ angesprochen hat, hat zwar

und Kouros. Weihegaben für die Götter, Wiener Forschungen zur Archäologie 10 (Wien 2007).

272 Müller 1915. Ablehnend auch Zagdoun 1989, 79. Vgl. auch Kap. 7.1.3.

273 s. Kap. 8.

274 Stephani 1876, 11; L. Stephani, Erklärung einiger in den Jahren 1878 und 1879 im südlichen Russland gefundener Kunstwerke, CRPétersbourg 1880, 1882, 117.

275 Stephani 1876, 10.

${ }^{276}$ Ebenda. Zu Priapos als Stützfigur s. Kap. 7.3.

277 A. Cartault, Hydrophore, Femme portant un enfant, Aphrodite, in: F. Lenormant u. a., Collection Camille Lecuyer. Terres cuites antiques trouvées en Grèce et en Asie Mineure I (Paris 1882) Text zu Taf. $\mathrm{H}^{3}$.

278 Vgl. Oenbrink 1997, 55. 88. 198.

${ }^{279}$ Vgl. Kap. 7.2.1.

${ }^{280}$ Stephani 1876, 10. 
sicherlich religiöse Konnotationen, wie in Kapitel 7.1.3. referiert wird, war als Zeichen der "gebärenden Kraft« aber überbewertet. Generell können Darstellungen der Eileithyia oder Genetyllis nicht über eine bestimmte Ikonographie identifiziert werden, sondern nur durch den Kontext, in dem sie als Geburtshelferinnen auftreten oder durch Beischriften ${ }^{281}$, was beides bei diesen Bildern nicht gegeben ist.

1881 hat K. Dilthey in einem Aufsatz über die Marmorstatuette aus Pompeji Kat. A18 die Stütze als Spes sowie als orientalisch-fremdartig bezeichnet, ohne dies näher auszuführen ${ }^{282}$. Diese Deutung ergab sich für ihn offensichtlich daher, dass die römische Spes als archaistische Figur dargestellt wurde ${ }^{283}$. Das bedeutet jedoch nicht, dass jedes derartige Bild Spes meinen muss. Auch sind bisher keine Darstellungen der Spes bzw. ihres griechischen Pendants Elpis vor der Kaiserzeit bekannt ${ }^{284}$.

R. Pagenstecher ${ }^{285}$ vermutete in seiner Monographie über die calenische Reliefkeramik von 1909 in dem Idol auf der Schale Kat. A45 ein Bild der Hekate. Ev. Schmidt ist ihm 1997 bei ihrer kurzen Beschreibung antiker Venusbilder im LIMC gefolgt und sieht in dem Idol bei Kat. A45 ebenfalls Hekate ${ }^{286}$. Die bisher veröffentlichten Abbildungen der Schale sind aber von zu schlechter Qualität, um diese Meinung bestätigen oder widerlegen zu können. Es lassen sich keine ikonographischen Merkmale der Hekate wie Fackeln oder die Dreigestalt ${ }^{287}$ feststellen, die diese Identifizierung rechtfertigen könnten.

Das Stützidol bei der Terrakottastatuette Kat. A36 wurde von S. MollardBesques in dem 1963 erschienenen Katalog der Tonstatuetten im Louvre als Artemis bezeichnet ${ }^{288}$. Die für Artemis typischen Attribute wie Köcher und Bogen werden aber offenbar von keinem der Idole getragen. Die bisher veröffentlichten Abbildungen sind leider nicht qualitätvoll genug, um zu erkennen, ob das Idol bei Kat. A36 Attribute der Artemis trägt. Wenn dies der Fall sein sollte, stellt sich die Frage, warum sich Aphrodite, denn als solche wird sie auch von S. MollardBesques identifiziert, auf ein Idol der Artemis lehnt.

Für keine der bis in das 19. Jahrhundert zurückreichenden Deutungen der weiblichen Stützidole als Genetyllis, Eileithyia, Spes, Hekate oder Artemis ist eine Bestätigung zu finden. Die Idole tragen keine der Identifizierung dienenden Attribute. Die Frage, ob sich Aphrodite auf Bilder anderer Göttinnen lehnen kann, muss also offen bleiben. Da sich auch männliche Götter auf ein weibliches

281 S. Pingiatoglou, Eileithyia (Würzburg 1981); LIMC III (1986) 685-699 s. v. Eileithyia (R. Olmos);

DNP III (1999) 914 f. s. v. Eileithyia (F. Graf); DNP IV (1998) 914 f. s. v. Genetyllis (F. Graf).

282 K. Dilthey, Polychrome Venusstatuette, AZ 39, 1881, 131-138.

283 Zur Übernahme der Ikonographie für die Spes-Darstellungen s. Bernoulli 1873, 68-73; LIMC

VII (1994) 804-806 s. v. Spes (F. W. Hamdorf).

${ }^{284}$ LIMC III (1986) 722-725 s. v. Elpis (F. W. Hamdorf).

285 R. Pagenstecher, Die calenische Reliefkeramik (Berlin 1909) 56 f. Nr. 61c.

286 Schmidt 1997, 224 Nr. 354.

287 DNP V (1998) 267-270 s. v. Hekate (S. Iles Johnston).

288 Mollard-Besques 1963, 24 Taf. $26 \mathrm{~b}$. 
Idol auflehnen können ${ }^{289}$, das demnach nicht ihr eigenes saltes Bild darstellt, besteht die Möglichkeit, dass sich Aphrodite zumindest in hellenistischer Zeit auch auf die Bilder anderer Göttinnen lehnen kann.

\subsubsection{Die Deutung als $>$ Votivbild 290}

T. Brahms hat in ihrer Monographie zur archaistischen Kunst von 1994 den altertümlichen Stützidolen ein ausführliches Kapitel gewidmet, indem sie sich auch mit der bisherigen Forschung auseinandersetz $\mathrm{t}^{291}$. Sie lehnt die Deutung als Darstellung der Aphrodite, die sich auf ihr eigenes altes `Kultbild lehnt, ab, da weibliche Stützfiguren auch bei Dionysos und Apollon und damit auch bei männlichen Göttern vorkommen ${ }^{292}$. Auf ein Kultbild dürfe sich niemand auflehnen, weder eine Gottheit noch ein Mensch. Deshalb könne es sich bei der aufgelehnten Figur auch nicht um eine Priesterin oder Adorantin handeln, die sich auf ein verehrtes Götterbild lehnt, denn »durch die Funktion des Stützens wird die archaistische Figur der anderen untergeordnet, womit die Interpretation als verehrtes Kultbild wohl entfällt ${ }^{293}$. Für die Stützidole entschließt sie sich, »hier im ganz allgemeinen Sinne ein ,altertümliches Votivbild“ zu erkennen, das auf übertragene Weise als Ortsbezeichnung zu verstehen ist«. Die Stützfigur ist für sie ein Zeichen für ein heiliges Temenos, jedoch nicht das Abbild des dort verehrten «Kultbildes«, sondern sirgendeine Votivstatuette«, »primär ist sie aber als tragende Figur, als Karyatide, zu sehen «294.

Ob ein 〉Kult- $<$ oder ein >Votivbild gemeint ist, kann anhand der Mehrzahl der hier untersuchten Stützidole selbstverständlich nicht entschieden werden, denn für beide verwendete man grundsätzlich dieselben Typen, so dass man sie nur mit Hilfe des Kontextes unterscheiden kann ${ }^{295}$. Einige Argumente lassen sich jedoch dafür anführen, dass die Stützidole als Darstellungen von \Kultbildern` aufgefasst werden konnten. Bei der T. Brahms offenbar unbekannten spätklassischen Terrakottastatuette Kat. A43 lehnt sich Aphrodite auf einen kleinen Tempel, in dem ein weibliches Idol steht. Vor dem Tempel steht ein Altar, wie an den Pulvini deutlich erkennbar ist. Mit dem Idol kann demnach, zumindest bei diesem Beispiel, nur ein

\footnotetext{
289 s. Kap. 6.3.

290 Zu den Begriffen >Votivbild und $\gg$ Kultbild vgl. Kap. 11.

291 Brahms 1994, 183-190. Sie nennt als Beispiele die Marmorstatuetten Kat. A2. A4. A6. A12. A18. A34 und die Marmorstatue Kat $A 14$.

292 Ebenda 183 f.

293 Ebenda 184.

294 Ebenda.

295 Vgl. A. Furtwängler, Über Statuenkopien im Altertum (München 1896) 8; C. A. Hutton, Greek Terracotta Statuettes (London 1899) 3 f.; F. Brommer, Vorhellenistische Kopien und Wiederholungen von Statuen, in: G. Mylonas (Hrsg.), Studies presented to D. M. Robinson (Saint Louis 1951) 674; B. Alroth, Greek Gods and Figurines. Aspects of the Anthropomorphic Dedications, Boreas 18 (Uppsala 1989) 15-18; E. Bartman, Ancient Sculptural Copies in Miniature (Leiden 1992); G. Nick 2002, 83-88. Zudem entspricht die strikte Trennung in verehrte und nicht verehrte Bilder unseren heutigen Vorstellungen, nicht unbedingt jedoch den antiken, s. Kap. 11.
} 
>Kultbild gemeint sein. Außerdem lässt sich ein apulischer Krater anführen, der sich heute in Moskau befindet (Kat. B76) ${ }^{296}$. Er zeigt Iphigenie auf die in einem Tempel stehende Statue der Artemis von Tauris gelehnt ${ }^{297}$. Neben diesem befindet sich ein Altar, auf dem die lebendige Göttin selbst sitzt. Die Statue der Göttin ist dadurch eindeutig als $>$ Kultbild gekennzeichnet und dient dennoch als Stütze, diesmal sogar für eine Sterbliche. Auch die von T. Brahms selbst angeführte Herme, auf die sich Sisyphos II. in der Statuengruppe des Daochos in Delphi (Kat. B126 ${ }^{298}$ auflehnt, muss als ein Götterbild aufgefasst werden. Sie stellt eine Palästra-Herme dar, die von der Forschung häufig als verehrte Götterbilder angesehen werden $^{299}$. Es war also möglich, Sterbliche auf Götter- und sogar auf >Kultbilder gelehnt darzustellen.

Als Argument für die Deutung der archaistischen Stützidole als saltes Aphroditekultbild können auch andere Darstellungen alter Götterstatuen herangezogen werden. Die besonders häufigen Beispiele auf klassischen Vasenbildern sind schon mehrfach untersucht und ihre Kennzeichen herausgearbeitet worden. Die Götterbilder auf den Vasen sind durch verschiedene Merkmale als Abbild einer alten Statue gekennzeichnet: durch den Promachos- oder Palladiontypus vor allem bei den seit dem späten 6. Jahrhundert v. Chr. vorkommenden Darstellungen der Athena oder den archaistischen Typus für die seit der Mitte des 5. Jahrhunderts v. Chr. einsetzenden Darstellungen anderer Göttinnen, außerdem durch die strenge Vorderansicht, den verkleinerten Maßstab und die Basis, Säule oder Pfeiler, auf der sie stehen $^{300}$. Die Identifizierung des Götterbildes ist entweder durch Attribute oder durch den Kontext möglich. Als Beispiele für Aphroditebilder können eine attisch-rotfigurige Lekythos aus dem frühen 4. Jahrhundert v. Chr. in Basel (Abb. 22) 301 genannt werden, bei der die Göttin selbst neben dem altertümlichen Bild auftritt und eine attisch-rotfigurige Bauchlekythos aus der Zeit um 400 v. Chr. in London, bei der das archaistische Idol von Eros geschmückt wird (Abb. 23) ${ }^{302}$. In derselben Typologie finden sich Götterstatuen auch auf klassischen und hellenistischen Reliefs, z. B. auf den Metopen des Parthenon. Auf der 25. Metope der Nord-

${ }^{296}$ Vgl. Kap. 6.3.3. Vgl. dazu auch die Diskussion in Kap. 7.1.1.4.

${ }^{297} \mathrm{Zu}$ dem Mythos s. Eur. Iph. T., bes. 1156-1202. Dort trägt Iphigenie das Bild allerdings aus dem Tempel, um ein Reinigungsopfer zu vollziehen, das sie anschließend zu ihrer Flucht mitsamt dem Bild nutzt. Der Bezug zwischen der Priesterin und dem Bild ist also auch dort sehr eng.

298 Brahms 1994, 184. Zu der Statuengruppe des Daochos in Delphi s. Kap. 8.2.

299 Wrede 1985; Rückert 1998.

300 Langlotz 1954; K. Schefold, Statuen auf Vasenbildern, JdI 52, 1937, 30-75; G. SchneiderHerrmann, Kultstatue im Tempel auf italischen Vasenbildern, BaBesch 47, 1972, 30-42; LIMC II (1984) 13 f. s. v. Aphrodite 44-53; Oenbrink 1997; de Cesare 1997.

301 Basel, Privatbesitz: Delivorrias 1984, 47 Nr. 369; Oenbrink 1997376 Kat. B7 Taf. 22, 3; allgemein: Oenbrink 1997, 84-100.

302 London, British Museum Inv. E714: Delivorrias 1984, 14 Nr. 46; Oenbrink 1997, 377 Kat. B9. 
seite, wo Szenen des trojanischen Krieges gezeigt werden, flüchtet Helena zu einem kleinen, jetzt stark zerstörten Götterbild. Dieses ist vielleicht ein Bild der Aphrodite, die im Mythos besonders mit Helena verbunden ist ${ }^{303}$. Hier finden sich also dieselben Merkmale wie bei den Stützidolen. Dieser Vergleich ergibt die Möglichkeit, die Stützidole als alte Götterbilder zu identifizieren.

Durch den Kontext sind die altertümlichen Götterbilder auf den Vasen und Reliefs als in einen Kult eingebundene Bilder zu identifizieren. Sie stehen entweder in einem tempelartigen Schrein, vor ihnen werden Opfer vollzogen oder sie bieten Schutz für Verfolgte und liefern damit eine »Vorstellung, wie ein altehrwürdiges Kultbild aussah«304. Doch ist auch dieses Argument natürlich nicht ausreichend, um die Stützfiguren sicher als eine Bildformel für die Darstellung eines alten $\gg$ Kultbildes der Aphrodite identifizieren. Es stellt sich daher die Frage, welche genaue Bedeutung das altertümliche Idol für die aufgelehnte Göttin hat und wie das Bildmotiv insgesamt gedeutet werden kann. Darauf werde ich in Kapitel 7.2 zu sprechen kommen. Zunächst sind noch die weiteren von der Forschung vorgeschlagenen Deutungen der Idole zu prüfen.

\subsubsection{Die Deutung als Sterbliche}

Von der Forschung wurde auch vorgeschlagen, in den Stützidolen keine Götterbilder sondern Darstellungen von Sterblichen zu sehen. D. Burr Thompson hat in ihrem 1959 veröffentlichten Artikel über hellenistische Terrakottastatuetten die Deutung als eine alte Statue derselben Gottheit, die sich auf die Stützfigur lehnt, abgelehnt. Sie begründete dies damit, dass die weiblichen Idole auch bei männlichen Figuren als Stütze dienen. Dies ist jedoch kein ausreichendes Argument. Zum einen sind die Bilder von männlichen Figuren mit ikonischen Stützen deutlich später entstanden als die der Aphrodite, zum anderen ergäbe sich auch in diesem Fall die Möglichkeit, dass es sich zumindest um Götterbilder handeln kann. D. Burr Thompson hat vorgeschlagen, in den Stützfiguren Bilder von Adorantinnen oder Tempeltänzerinnen aufgrund der Geste des Gewandraffens zu sehen ${ }^{305}$ : »Since these supports appear to be merely the female counterparts of herms and Priapus figures (which later supersede them), why should they not be stylized

303 Fuchs 1969 Abb. 478; E. Berger, Der Parthenon in Basel. Dokumentation zu den Metopen, Studien der Skulpturenhalle Basel 2 (Mainz 1986) 25. 38 f. Vgl. auch die Metope 21 der Südseite mit zwei Frauen, die sich zu einer kleinen, der >Peplos-Kore ähnelnden Statue geflüchtet haben: Fuchs 1969 Abb. 473; Zur Deutung s. E. Berger, Der Parthenon in Basel. Dokumentation zu den Metopen, Studien der Skulpturenhalle Basel 2 (Mainz 1986) 91-93; U. Höckmann, Die Metope Süd 21 und das Thema der Südmetopen des Parthenon, in: Pöhlmann - Gauer 1994, 247-257. Weitere Beispiele alter Götterbilder auf Reliefs: Brahms 1994 Abb. 48 f.; W.-D. Heilmeyer (Hrsg.), Der Pergamonaltar. Die neue Präsentation nach Restaurierung des Telephosfrieses (Tübingen 1997) Abb. 8.

304 Oenbrink 1997, 21.

305 Burr Thompson 1959, 133 f. Sie hat mehrere hellenistische Idole aus Terrakotta betrachtet, die ihrer Meinung nach als Stützfiguren gedient haben (Kat. A52e). 
representations of actual statues of votaries that were seen by the artists and coroplasts in the sanctuaries? There is no reason to believe that these artists were not showing a contemporary type as they do in their other supports upon which figures lean « ${ }^{306}$. Ihre Aussage wirft die Frage auf, warum die Darstellung einer

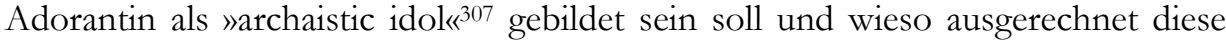
das Gegenbild von Hermen und Priaposstatuen sein sollen?

R. A. Higgins hat in seiner Monographie über griechische Terrakottaplastik aus dem Jahr 1967, in der er die hellenistische Statuette Kat. A25 anführt, weder die Deutung als raltes Bild der darauf gelehnten Gottheit noch als Weihgeschenk ausgeschlossen $^{308}$. Die Deutung archaischer Figuren im $>$ Korenschema als Darstellungen adliger Tänzerinnen ist jüngst von H. Kyrieleis in einem Aufsatz zum 〉üngling von Kap Phoneas von 1996 und K. Karakasi in ihrer Monographie zu archaischen Frauenstatuen von 2001 vorgetragen worden ${ }^{309}$. Besonders bei der Statue vom Kap Phoneas scheint das Motiv des Gewandraffens auf die Darstellung eines Tänzers hinzuweisen, da sie auf den Zehenspitzen steht und auch aufgrund ihrer sonstigen Charakterisierung wie der Gewandung in den Kontext der sich beim Fest präsentierenden adligen Jugend einzuordnen sei, wie H. Kyrieleis dargelegt hat. Doch zeigen auch nicht tanzende Figuren das Motiv des Gewandraffens. Dazu zählen z. B. Aphrodite, Hera und Athena auf archaischen Vasenbildern, die das Parisurteil wiedergeben ${ }^{310}$. Auch sonst werden Göttinnen bei mythologischen Szenen archaischer Vasenbilder gewandraffend gezeigt, bei denen aufgrund des Kontextes ausgeschlossen ist, dass sie tanzend gemeint sind ${ }^{311}$. Auch das $>$ Schweineopferrelief^ (Abb. 24)312 kann als Beispiel angeführt werden. Es wird zwar in die frühklassische Zeit datiert, weist die dargestellte Athena durch die archaistische Gestaltung jedoch als zu den altehrwürdigen Götterbildern der Vorzeit gehörend aus. Die Göttin wird auf dem Relief als Opfer empfangend gezeigt, vor sie sind die Stifter des Opfertieres getreten. Ein Tanz kann hier mit der Geste des Gewandraffens nicht gemeint sein. Das Motiv weist daher nicht immer auf eine Tanzdarstellung hin, weshalb auch Götter und Sterbliche nicht anhand dieser Geste unterschieden werden können. Das Gewandraffen ist nach L. Schneider als Zeichen für ein ele-

\footnotetext{
306 Ebenda.

307 Ebenda.

308 Higgins 1967, 115.

${ }^{309}$ H. Kyrieleis, Der Tänzer vom Kap Phoneas, IstMitt 46, 1996, 111-121; Karakasi 2001. Zum >Jüngling von Kap Phoneası s. auch P. Karanastassis, Hocharchaische Plastik, in: Bol 2002, 202 Abb. 281. 310 Delivorrias 1984, 135-138 Nr. 1417-1444; Kossatz-Deissmann 1994.

311 z. B. Artemis beim Streit um den Dreifuß auf einem chalkidischen Skyphos aus der Zeit um 530 v. Chr. in Neapel: Kahil 1984, 723 Nr. 1292; Artemis beim Streit zwischen Idas und Apollon um Marpessa auf einem attischen Psykter aus der Zeit um 480 v. Chr. in München: Kahil 1984, 735 Nr. 1433.

312 Athen, Akropolismuseum Inv. 581: Willers 1975, 55 f. Taf. 31, 1; Brahms 1994, 55-68. 281-284 Kat. 3 Abb. 1 f.; V. Brinkmann, Die Ausläufer der archaischen Skulptur und die archaischen Formelemente in der Zeit der Frühen Klassik, in: Bol 2002, 279 f. Abb. 364.
} 
gantes Auftreten (sowohl von Göttern als auch von Sterblichen) zu sehen ${ }^{313}$, in Anlehnung an ein Gedicht von Sappho, in dem ein Mädchen, das das Gewandraffen nicht beherrscht, als bäurisch bezeichnet wird ${ }^{314}$ - auch wenn es in einigen Fällen zum eleganten Auftreten von Tänzerinnen und Tänzern spezifiziert wird ${ }^{315}$.

Da die Geste des Gewandraffens nicht in jedem Fall eine tanzende Figur und schon gar nicht zwangsläufig eine Sterbliche meint, müssen auch die Idole nicht so gedeutet werden ${ }^{316}$. Außerdem gibt diese Deutung keinen Aufschluss darüber, weshalb die Idole archaistisch gestaltet sind. Eine Statue einer Sterblichen hätte auch im zeitgenössischen Stil unter Kennzeichnung des Bildes als Statue, z. B. mit Hilfe einer Basis dargestellt werden können ${ }^{317}$. Die archaistischen Elemente sind ein Rückgriff auf Merkmale archaischer Bilder und daher bei späteren Darstellungen ein Hinweis auf ein hohes Alter. Welche Bedeutung dieser Hinweis auf das hohe Alter des dargestellten Bildes hat, werde ich in Kapitel 7.2 noch darlegen. Die ebenfalls als Stütze dienende Herme stellt in jeden Fall ein Götterbild dar.

\subsubsection{Die Deutung als >Kore oder >Karyatide<}

E. Hübner hat das Stützidol der Marmorstatue Kat. A14 in seiner Beschreibung der antiken Werke im Museum des Prado aus dem Jahr 1862 als Kora bezeichnet ${ }^{318}$. S. Reinach hat das Stützidol der Tonstatuette Kat. A36 in seiner ca. 1887 heraus-

313 L. Schneider, Zur sozialen Bedeutung der archaischen Korenstatuen (Hamburg 1975) 29 f. Ähnlich auch M. Meyer, Athena und die Mädchen. Zu den Koren auf der Athener Akropolis, in: M. Meyer - N. Brüggemann, Kore und Kouros. Weihegaben für die Götter, Wiener Forschungen zur Archäologie 10 (Wien 2007) 46. Ablehnend stand der Deutung als Tanzmotiv auch K.

Fittschen, Rez. zu Karakasi 2001, GGA 255,1, 2003, 17-25 gegenüber.

314 Sappho fr. 61d.

315 Vgl. H. Kyrieleis, Der Tänzer vom Kap Phoneas, IstMitt 46, 1996, 118.

316 Auch die von einigen der Idole (Kat. A12. A18, vermutlich auch Kat. A4-A7. 14) gehaltenen Attribute wie Früchte oder Blüten bieten keine Identifizierungsmöglichkeit. Sowohl Sterbliche wie das Mädchen auf der sog. Geschwisterstele (Berlin, Staatliche Museen Inv. 1531: Boardman 1981 Abb. 232; C. Rolley, La sculpture grecque I. Des origines au milieu du Ve siècle [Paris 1994] 39; P. Karanastassis, Hocharchaische Plastik, in: Bol 2002, 211 f.; weitere bei Fuchs 1969 Abb. 162; Boardman 1981 Abb. 155; Karakasi 2001) als auch Göttinnen wie die bei Paus. 2, 10, 5 erwähnte Aphroditestatue in Sikyon weisen solche Attribute auf. Andere Idole berühren mit der Hand die Brust, wie auch einige der archaischen Statuen, woraus sich aber ebenfalls kein Anhaltspunkt für die Identifizierung als Sterbliche oder als Göttin ergibt, da auch dieses Motiv nicht für eine Gruppe festgelegt ist (z. B. die Kore von Auxerre und die Cheramyes-Kore, außerdem eine Marmor- und eine Bronzefigur in Berlin, die aber nicht sicher gedeutet sind: Boardman 1981 Abb. 28. 87 bzw. G. M. A. Richter, Korai. Archaic Greek Maidens [London 1968] Abb. 232-234. 309-312. Für Göttinnen ist dieses Motiv bereits in der orientalischen Kunst belegt: Boardman 1981 Abb. 23 [Astarte]; aus dem griechischen Kunstkreis lässt sich ein Marmorrelief aus Milet anführen: Fuchs - Floren 1987 Taf. 33, 6).

317 Bsp. dafür bei Oenbrink 1997 Kat. A13. A39. A47. A5. A47. A50. A55-59. B30. B35. C9. C10. C12. C14. D3. D4. D7-12. D14-18. E1. E3. E4. G3. G4. H1. H2. H4. H5. K3. K8. K9; Nick 2002 36. 56-60 Taf. 4, 1; 9, 5; 10, 1-4.

318 E. Hübner, Antike Bildwerke in Madrid (Berlin 1862) 53 Nr. 34. 
gegebenen Beschreibung der Terrakottastatuetten aus den Gräbern von Myrina als >Karyatider benannt ${ }^{319}$. Für das Idol bei einer weiteren Terrakottastatuette (Kat. A49) vermutete S. Reinach in derselben Publikation, dass es sich um Peitho handeln könnte, die einst vielleicht geflügelt gewesen ist ${ }^{320}$. Geflügelte Darstellungen der Peitho sind jedoch nicht bekannt ${ }^{321}$. Sollte das Idol wirklich Flügel gehabt haben wäre zumindest gesichert, dass es eine göttliche Figur darstellt. Bisher sind jedoch keine Rück- oder Detailansichten des Werkes veröffentlicht. Auch F. Muthmann hielt die Deutung, dass sich eine Göttin auf ihr eigenes altes, mit einem Kult bedachtes Bild lehnt in seiner Untersuchung zu Statuenstützen von 1951 nicht für überzeugend ${ }^{322}$. Er vermutete, dass es sich bei den Idolen eher um tektonische Elemente handelt, die dieselbe Funktion wie Pfeiler hätten und ohne inhaltliche Bedeutung wären, weshalb sie als $>$ Karyatider zu bezeichnen seien ${ }^{323}$. Dieselbe Ansicht vertrat M.-A. Zagdoun 1989 in ihrer Monographie zur archaistischen Kunst ${ }^{324}$. 1972 benannte D. Pinkwart in ihrer Beschreibung der bei einer Ausstellung über Pergamon in Ingelheim präsentierten Funde das Idol bei der Terrakottastatuette Kat. A25 ebenfalls als >Karyatide ${ }^{325}$.

Die Bezeichnung der Idole als \Karyatiden bzw. als >Kore in der Literatur geschah offenbar in Anlehnung an die Benennung weiblicher Stützfiguren bei Geräten und in der Architektur als >Karyatiden`326 bzw. an die Bezeichnung der archaischen Mädchenstatuen als $>$ Koren ${ }^{327}$. Doch ist das Bildmotiv der auf sie gelehnten Aphrodite damit nicht ausreichend erklärt. Zum einen haben die sog. Koren und Karyatiden ebenfalls eine inhaltliche Bedeutung, die im Einzelnen aber noch nicht sicher geklärt ist ${ }^{328}$. Zum anderen wurden die Idole bei den Aphroditebildern nicht allgemein als `Kore

319 Reinach - Pottier 1887, 517 Nr. 30.

320 Ebenda 520 Nr. 45.

321 Vgl. LIMC VII (1994) 242-250 s. v. Peitho (N. Icard-Gianolio).

322 Muthmann 1951, 18.

323 Ebenda.

324 Zagdoun 1989, 79-81.

325 D. Pinkwart, Terrakotten, Keramik, Glas, Gemme usw., in: Pergamon. Ausstellungskatalog Ingelheim am Rhein (Offenbach 1972) 47 Nr. 45.

326 E. Wurz, Plastische Dekoration des Stützwerkes in Baukunst und Kunstgewerbe des Altertums (Diss. Universität Zürich 1906) 48 f.; F. Schaller, Stützfiguren in der griechischen Kunst (Diss. Universität Wien 1973); A. Schmidt-Colinet, Antike Stützfiguren. Untersuchungen zu Typus und Bedeutung der menschengestaltigen Architekturstütze in der griechischen und römischen Kunst (Diss. Universität zu Köln 1977); Ev. Schmidt, Geschichte der Karyatide. Funktion und Bedeutung der menschlichen Träger- und Stützfigur in der Baukunst (Würzburg 1982); A. Scholl, Die Korenhalle des Erechtheion auf der Akropolis. Frauen für den Staat (Frankfurt a. M. 1998); DNP VI (1999) 310 f. s. v. Karyatiden (Chr. Höcker).

327 s. Anm. 271.

$328 \mathrm{Da}$ sie in einem anderen Kontext stehen, kann im Rahmen dieser Arbeit kein Beitrag zu dieser Diskussion geleistet werden. Hier muss auf die bereits vorliegende Literatur verwiesen werden s. Anm. 271 und 326. 
statuette Kat. A43 zeigt, bei der das Idol hinter einem Altar in einem Tempel steht und demnach definitiv ein sKultbild meint. Die Klärung der inhaltlichen Bedeutung der neuartigen Bilderfindung der Aphroditedarstellung ist durch die Bezeichnung der Stützfiguren als >Karyatide` oder `Kore` nicht beantwortet. Nach der weiteren Auswertung der bisher von der Forschung vorgetragenen Meinungen soll auf diese Frage eingegangen werden.

\subsubsection{Die Deutung der weiblichen Herme}

Auf die Interpretation der Hermenstütze, wie sie Kat. A3. A22 und A51 zeigen, als Darstellung der Aphrodite Urania wurde in Kapitel 5.1.3 bereits eingegangen. Da dort jedoch nicht die gesamte bisherige Forschung eingebunden werden konnte, will ich in diesem Zusammenhang noch einmal darauf zurückkommen.

C. Robert äußerte bei seiner Beschreibung des apulischen Kraters Kat. A51 in seinem Aufsatz über Chrysippos und Antigone von 1914, dass sich Aphrodite hier auf eine sie selbst darstellende Herme lehnen könnte, ohne näher auf die inhaltliche Bedeutung dieser Kombination einzugehen ${ }^{329}$. Ebenfalls als Bild der Aphrodite wurde die Herme von V. Pirenne-Delforge in ihrer Monographie zu Aphrodite in archaischer und klassischer Zeit von 1994 gedeutet $^{330}$.

Spezifischer sind die Ausführungen von S. Ferri in seinem Aufsatz über Aphrodite Urania von 1927, von W. Fuchs bei seiner Beschreibung der Denkmäler der Vatikanischen Museen aus dem Jahre 1963, von S. Settis in seiner Monographie zur Aphrodite Urania des Phidias in Elis von 1966, von St. Hiller in seinem Aufsatz über Statuenstützen im 5. Jahrhundert v. Chr. von 1976, von M. Osanna in seinem Aufsatz zu dem bei Pausanias 1, 14, 7 überlieferten Heiligtum der Aphrodite Urania in Athen von 1988/89 sowie von M. Kunze in seiner Beschreibung der Antiken des Pergamonmuseums in Berlin von 1992331. Die genannten Autoren haben die oben bereits vorgetragene Deutung der Herme als Bild speziell der Aphrodite Urania vertreten ${ }^{332}$. Darüber hinaus stellt die Herme laut S. Ferri, S. Settis, St. Hiller und M. Osanna ein altes Mal der darauf gelehnten Göttin dar ${ }^{333}$.

${ }^{329}$ C. Robert, Chrysippos und Antigone auf apulischen Vasen, JdI 29, 1914, 171.

330 Pirenne-Delforge 1994, $67 \mathrm{f}$.

${ }^{331}$ Ferri 1927; Helbig I 4(Tübingen 1963) 719 Nr. 1001 (W. Fuchs); Settis 1966, 9-23; Hiller 1976, 31-34; Osanna 1988/89; Kunze 1992, 139 f. Nr. 47.

332 Ferri 1927; Settis 1966, 9-23; Hiller 1976, 31-34; Osanna 1988/89, 78 f.; Kunze 1992, 139 f. Nr. 47; Pirenne-Delforge 1994, 67 f. beziehen sich u. a. jedoch auf eine von ihnen rekonstruierte Herme bei der Aphrodite Brazzà, die nicht gesichert ist; s. Kap. 3.1.1. Die Deutung der Herme bleibt davon jedoch unberührt, da sie als Stütze für Aphrodite durch andere Darstellungen gesichert ist. Die Gründe, warum die Hermenform mit Aphrodite Urania verbunden ist, sollen hier nicht wiederholt werden. Dazu sei auf Kap. 5.1.3 verwiesen.

333 Ferri 1927; Settis 1966, 9-23; Hiller 1976, 33 f.; Osanna 1988/89, 74 f. Für Ferri 1927, 123 stellten Hermen die frühere, vor der anthropomorphen Form verwendete Darstellungsform dar. Dass anikonische Bilder den menschengestaltigen vorausgingen ist inzwischen widerlegt, s. S. 289 f. 
S. Settis wollte seine Meinung durch Münzbilder hellenistischer Zeit aus Uranopolis bestätigt sehen, auf denen eine zeitgenössische Darstellung der Urania manchmal neben einem konischen Mal abgebildet sei $(A b b .25)^{334}$. Dieses sei das alte anikonische Mal des Aphroditekultes von Paphos auf Zypern, auf den sich der Uraniakult von Uranopolis beziehe: »L`antica meta di Paphos persiste accanto alla nuova iconografia della dea, simbolo certo dell'antichità del suo culto« ${ }^{335}$. Der Fund eines männlichen Kopfes in Uranopolis mit Stiftlöchern für den Einsatz von Strahlen sowie einem konischen Aufsatz auf dem Kopf wie sie die Figur auf den Münzen aufweist hat allerdings die alte Deutung des Bildes auf den Münzen als Darstellung der Aphrodite Urania endgültig widerlegt ${ }^{336}$. Dies bedeutet jedoch nicht, dass die Deutung der Hermenstützen als saltes Bild der Göttin ebenfalls abzulehnen wäre.

Für St. Hiller wiederum verdeutlicht die Herme als altes Mal, das im Gegensatz zu der darauf gelehnten Göttin nicht mehr den aktuellen künstlerischen Ansprüchen genüge, dass das neue Bild »nicht nur ein Ideal- und Repräsentationsbild« darstelle, sondern »kultischen Charakter« besitze. Durch das Auflehnen beziehe sich das neue Bild auf das alte, und zwar »auf dessen ererbte, in langer Tradition gewachsene und durch keinen Weihritus zu bewirkende Heiligkeit, gibt sich somit als dessen legitime kultische Nachfolgerin und Erbin zu erkennen« ${ }^{337}$. Er wies darauf hin, dass sich in der Kultpraxis häufiger ein altes und ein neues Bild einer Gottheit zeitgleich in einem Heiligtum befanden. Als Beispiel führt er das alte Xoanon der Athena Polias auf der Akropolis von Athen an, zu dem später die Athena Promachos und die Parthenos traten ${ }^{338}$. Eine vergleichbare Ansicht hat auch M. Osanna vertreten. Da die antiken Quellen häufig ein hohes Alter für die Kulte der Aphrodite Urania nennen, in dem sie die Stiftung der Kulte zumeist in die mythische Vorzeit setzen ${ }^{339}$, und für Aphrodite Urania Darstellungen in Hermenform gesichert sind ${ }^{340}$, deutet er die Herme als »«antica» immagine testimonianza dell’ alta antichità del suo culto«.

334 Winterthur, Münzkabinett: BMC, Greek Coins. Macedonia 133 f.; F. Imhoof-Blumer, Monnaies Grecques (Paris 1883) 96-98; H. Gaebler, Die antiken Münzen von Makedonia und Paionia II (Berlin 1935) 132 f. Taf. 25, 1-5; M. Bergmann, Die Strahlen der Herrscher. Theomorphes Herrscherbild und politische Symbolik im Hellenismus und in der römischen Kaiserzeit (Mainz 1998) 52 Taf. $8,1.2$.

335 Settis 1966, 152.

${ }^{336} \mathrm{~J}$. Vokotopoulou - E.-B. Tsigarida, Archaeological Research at Nea Rhoda of Chalcidice, AErgoMak 7, 1993, 450 Abb. 4 f. 10.

337 Hiller 1976, 33. Eine ähnliche Ansicht äußerte Schlörb 1964, 17 f., allerdings zu den Pfeilern, auf denen Aphrodite in Nachahmung der >Aphrodite in den Gärten des Alkamenes lehnen kann. Sie sah in ihnen ebenfalls einen »Hinweis auf jenes ursprüngliche und vielleicht hocharchaische, jedenfalls zu Pausanias`Zeiten noch immer im Heiligtum $\pi \lambda \eta \sigma i ̀ v ~ \tau o \hat{v} v \alpha \circ \hat{v}$ befindliche Kultbild«.

338 Hiller 1976, 34.

339 So die Heiligtümer in Athen und in Theben: Paus. 1, 14, 7 und 9, 16, 3. Weitere Beispiele bei Osanna 1988/89, $74 \mathrm{f}$.

340 s. Kap. 5.1.3. 
E. B. Harrison akzeptierte in ihrer Untersuchung zu den archaischen und archaistischen Funden von der Athener Akropolis von 1965 zwar, dass eine figürliche Stütze in Form einer Herme das altertümliche Bild der darauf gelehnten Figur sein kann, hielt dieses jedoch nicht für die ursprüngliche Idee ${ }^{341}$. Eigentlich stellten sie ihrer Meinung nach eher ein Attribut dar, wie die Palästra-Herme der als Sisyphos II. identifizierten Statue der Statuengruppe Daochos in Delphi (Kat. B126), oder die »roadside herm«, an die sich der Hermes des Kephisodot ausruhend anlehnt, als er das Dionysoskind zu den Nymphen bringt (Kat. B69)342. Für E. B. Harrison sind diese Hermen ein Orts- und Kontextdefinierendes Attribut. Die von ihr angeführten Beispiele sind aber jünger als die ersten Aphroditedarstellungen mit figürlich gebildeten Stützen und können demnach keine Umdeutung von diesen sein.

Die Deutung der Herme als Bild der Aphrodite Urania, wie sie M. Osanna dargelegt hat, ist überzeugend ${ }^{343}$. Hermen stellen nicht grundsätzlich alte Bilder dar, da sie auch in klassischer und hellenistischer Zeit parallel zu anthropomorphen Bildern geschaffen wurden ${ }^{344}$. Die Gründe, weshalb man unter der weiblichen Herme speziell die orientalische Aphrodite verstand, sind bereits dargestellt worden $^{345}$. Die Herme kann als Hinweis auf diese speziellen, mit dem Orient in Verbindung stehenden Kult interpretiert werden ${ }^{346}$.

\subsubsection{Zur Bedeutung des Polos}

Es hat sich abgezeichnet, dass sich die Identifizierung der Stützidole als durchaus schwierig gestaltet. Es stellt sich daher die Frage, ob der Polos, der von vielen Stützfiguren z. T. als einziges Attribut getragen wird, zur Lösung dieser Frage beitragen kann. Soweit es auf den Abbildungen erkennbar ist, tragen nahezu alle weiblichen Idole einen Polos. Einzig das Idol bei Kat. A49 trägt eine Stephane. Bei den weiblichen Hermen und den männlichen Stützfiguren kommt er hingegen selten vor (Kat. A3. A64. A73. A77. A79. A80. A83. A84. A89. A108. A110). Bis auf Kat. A89 haben von diesen alle eine Stütze in Hermenform. Bei Kat. A89 ist sie eine Ganzkörperfigur des Hermaphrodit. Der Polos ist demnach weder auf die Hermenform noch auf die Ganzkörperfigur beschränkt und ist sowohl bei weiblichen als auch bei männlichen ikonischen Stützen, nicht jedoch bei allen feststellbar.

Eine Möglichkeit wäre, den Polos als einfaches Stützelement aufzufassen. Er wird auch von weiblichen Stützfiguren in der Architektur, den \Karyatiden ge-

\footnotetext{
341 Harrison 1965, $135 \mathrm{f}$.

342 Ebenda. Zu der Statuengruppe des Daochos in Delphi s. Kap. 8.2, zu der Hermesstatue s. S. 107.

343 s. Kap. 5.1.3.

$344 \mathrm{Vgl}$. auch die nicht archaistischen Hermen, auf die sich Artemis auflehnen kann, s. Kap. 6.3.3.

345 s. Kap. 5.1.3.

346 Eine mögliche Verbindung zu den anikonischen Götterbildern des Orients muss an dieser Stelle offen bleiben, da dies eine für diese Arbeit zu umfangreiche Untersuchung erfordern würde.
} 
tragen, z. B. bei den Schatzhäusern von Knidos und Siphnos in Delphi ${ }^{347}$. Einige der hier untersuchten Idole dienen aber nicht als Stütze. Aphrodite lehnt sich bei diesen Beispielen, die alle der hellenistischen und kaiserzeitlichen Kleinkunst angehören auf ihre Basis (Kat. A15. A32. A40. A41. A44. A4ロ. A50) oder lehnt sich lediglich an sie an (Kat. A79-A8 Ш). Andererseits haben viele der männlichen Stützfiguren wiederum keinen Polos. In der Architektur tragen männliche Stützfiguren vor der hellenistischen Zeit nie einen Polos. Auch bei weiblichen Trägerfiguren wie Spiegelträgerinnen kommt der Polos nur bei einigen Beispielen vor ${ }^{348}$. Die Erklärung des Polos als Stützelement, als Element des Übergangs von der Stützfigur zu der auf sie gelehnten Göttin ist also nicht befriedigend, da er nicht einheitlich von allen Stützfiguren oder zumindest von bestimmten Gruppen der als Stütze dienenden Figuren getragen wird.

Eine zweite Möglichkeit wäre, in dem Polos ein Symbol der Göttlichkeit zu sehen. Bisher ist nur eine umfangreichere Untersuchung zur Bedeutung des Polos erschienen. In seiner 1915 veröffentlichten Monographie hat V. K. Müller herausgestellt, dass der Polos in der griechischen Kunst zumeist von göttlichen Wesen getragen wird und deshalb ein göttliches Symbol sei ${ }^{349}$. Die Stützfiguren wären demnach als göttliche Wesen zu deuten. Diese zweite Deutung würde auch erklären, warum der Polos auch von solchen Beifiguren getragen wird, auf die sich Aphrodite nicht direkt auflehnt und wo er demnach nicht als >Polster dient. Jedoch wird der Polos auch von Menschen getragen, z. B. beim Kult. So tragen tanzende Mädchen und Jünglinge auf einer korinthischen Pyxis in Berlin den Polos ${ }^{350}$ und auch noch wesentlich später ist er bei tanzenden und musizierenden Mädchen auf dem spätklassischen marmornen Relieffries des Propylons des Temenos der Großen Götter in Samothrake nachweisbar. Ebenso wird mit ihm die Braut auf einigen klassischen Vasendarstellungen bekrönt ${ }^{351}$. Die Identifizierung der Stützfiguren als Götterdarstellung über den Polos ist deshalb nicht überzeugend ${ }^{352}$.

347 Zu den `Karyatiden s. Anm 326.

348 z. B. Fuchs 1969 Abb. 172 mit Polos; Abb. 170 ohne Polos.

349 Müller 1915, 56; ebenso Himmelmann-Wildschütz 1959, 11; H. Cassimatis, Figurines dédaliques de Gortyne: Essai de typologie, BCH 106, 1982, 459; M. Dewailly, La divinità femminile con polos a Selinunte, SicA 16, 1983, 5-12 Nr. 52 f.

350 A. Furtwängler, Beschreibung der Vasensammlung im Antiquarium I (Berlin 1885) 109 f. Nr. 984; Müller 1915, 82 Taf. 5. Weitere Beispiele: Müller 1915, 81-85.

Auch Fackelläufer können eine polosartige Kopfbedeckung tragen: Daremberg - Saglio III, 2 (1904) 909-914 s. v. Lampadédromia mit Abb. 4328-4330 (A. Martin); Müller 1915, 84.

351 z. B. ein attisch-rotfiguriger Lebes Gamikos im Nationalmuseum von Athen, Inv. 1454: A. Brueckner, Athenische Hochzeitsgeschenke, AM 32, 1907, 79-122 Taf. 5, 2; Müller 1915, 85; H. Lohmann, Das Motiv der mors immatura in der griechischen Grabkunst, in: Froning 1992, 103-113.

352 Vgl. Müller 1915, 27 f. 74-88; E. Simon, Hera und die Nymphen. Ein böotischer Polos, RA 1972, 205-220; F. Brommer, Gott oder Mensch, JdI 101, 1986, 37-53; W. Martini, Die archaische Plastik der Griechen (Darmstadt 1990) 78-80; St. Böhm, Die nackte Göttin. Zur Ikonographie und Deutung unbekleideter weiblicher Figuren in der frühgriechischen Kunst (Mainz 1990) 137; 
Noch eine dritte Möglichkeit zur Deutung dieses Gegenstandes lässt sich anführen. Die auf Vasenbildern dargestellten altertümlichen Götterbilder tragen auch oft einen Polos ${ }^{353}$. Aus diesem Grund kann man fragen, ob er ein charakterisierendes Element einer altertümlichen Statue sein könnte ${ }^{354}$ oder ob er zumindest ein Ausstattungsstück darstellt, das die Figur als Statue im Allgemeinen ausweist ${ }^{355}$. Nicht jede altertümliche Götterstatue auf den Vasen trägt jedoch einen Polos ${ }^{356}$. Außerdem müsste man dann erwarten, dass auch wirkliche alte Götterstatuen für gewöhnlich einen Polos tragen, wenn er bei den späteren, in archaistischem Stil gehaltenen Götterbildern ein Erkennungsmerkmal für Altertümlichkeit sein soll. Oder man müsste zumindest voraussetzen können, dass Statuen generell einen Polos getragen haben, wenn er die Stützfiguren als solche ausweisen soll. Er wird aber weder besonders häufig von archaischen Götterbildern noch von Statuen generell getragen. Auch die hier untersuchten archaistischen Stützfiguren haben nicht durchgängig den Polos, während einige, aber eben nicht alle der nicht altertümlich gestalteten männlichen Figuren ihn wiederum tragen. Deshalb ist der Polos also auch kein Element, das die Stützfiguren als Statue oder gar als salter Statue ausweist.

Vielleicht beinhaltet jede der vorgeschlagenen Deutungen einen Teil der Lösung, doch kann die einheitliche Bedeutung des Polos nicht erwiesen werden. Eine ausschließlich an den Stützfiguren vorgenommene Untersuchung führt zu keinem Ergebnis. Offenbar braucht man dafür eine breitere Untersuchung.

\subsubsection{Zusammenfassung}

Bei der Zusammenfassung und Diskussion der von der Forschung vorgetragenen Deutungen der altertümlichen Idole und der Hermen, die Aphrodite als Stütze dienen, hat sich gezeigt, dass die Stützfiguren ganz unterschiedlich interpretiert wurden. In der Regel wurden jeweils nur wenige Beispiele in die Untersuchung einbezogen. Am häufigsten wird in dem Idol eine altertümliche Darstellung der Göttin, die sich darauf lehnt - in diesem Fall also Aphrodite - gesehen. Daneben wurden die weiblichen Idole auch als Bilder anderer Göttinnen wie Genetyllis oder Eileithyia, Spes, Hekate und Artemis interpretiert. Ebenso wurde von der

H. Lohmann, Das Motiv der mors immatura in der griechischen Grabkunst, in: Froning 1992, 103-113; DNP X (2001) 39 s. v. Polos (R. Hurschmann).

353 Vgl. Oenbrink 1997 Taf. 13, 1 (Athena); Taf. 21-25 (Aphrodite); Taf. 26-29 (Artemis); Taf. 47 (Dionysos).

354 So Bald Romano 1980, 404, wobei sie offen lassen muss, ob der Polos wirklich ein Element alter Götterbilder ist oder ein ikonographisches Symbol bei Darstellungen alter Bilder in späterer Zeit.

355 Durch andere Merkmale wie die Basis, die frontale, unbewegte Haltung, den kleineren Maßstab im Vergleich zu den shandelnden< Personen und den Kontext der Szenen ist die jeweilige Figur bereits als Statue gekennzeichnet; vgl. Kap. 7.1.1.4.

356 z. B. Langlotz 1954 Abb. 1.5 (Aphrodite); Delivorrias 1984, 14 Nr. 46 (Aphrodite); Oenbrink 1997 Taf. 9, 1. 11, 2. 20, 2 (Athena); Taf. 26, 2. 28, 2. 30, 2 (Artemis); Taf. 31-37 (Apollon); Taf. 38-40 (Zeus); Taf. 48 (Poseidon). 
Forschung der Vorschlag unterbreitet, es handele sich um Darstellungen von Adorantinnen oder Tempeltänzerinnen oder um `Koren` bzw. `Karyatiden`. Gegen die meisten genannten Vorschläge konnten Argumente vorgetragen werden, die die Deutungen wenig gesichert erscheinen lassen.

Da die archaistische Gestaltungsweise bei allen untersuchten Idolen vorkommt und das einzige durchgängig feststellbare Merkmal ist, erscheint die Deutung nahe liegend, das Idol als raltes Bild $\mathrm{zu}$ interpretieren. Die Forschung ist sich einig darin, dass archaistische Formen im 5. Jahrhundert v. Chr. nahezu ausschließlich für Götterbilder verwendet wurden ${ }^{357}$. Die Deutung der Idole als saltes Bild der Aphrodite ist daher am wahrscheinlichsten. Dafür sprechen mehrere Argumente. Zum einen werden die Idole parallel zu den Stützen in Hermenform verwendet, die definitiv nicht die lebendige Göttin oder gar eine Sterbliche darstellen, sondern das (łKult- ${ }^{358}$ ) Bild der Göttin. Zum anderen ist das Idol bei der Terrakottastatuette Kat. A43 durch den Altar und den Tempel eindeutig als >Kultbild ausgewiesen. Zudem beweist der oben erwähnte Krater mit der Darstellung der Iphigenie als Priesterin der Artemis von Tauris (Kat. B76) ${ }^{359}$, dass Götterstatuen und darunter sogar \Kultbilder als Stütze dienen konnten, wenn er auch später entstanden ist als die Erfindung des hier untersuchten Typus. Dass Darstellungen von Adorantinnen archaisiert wurden, um sie als alt zu kennzeichnen und im Sinne einer Ortsangabe als Bildchiffre für ein Heiligtum zu verwenden, kann zwar nicht ausgeschlossen werden. Gesicherte Zeugnisse dafür liegen jedoch nicht vor.

Eine Entscheidung, ob es sich bei dem Idol generell um ein \Kult-^ oder ein ,Weihbild handelt, was eine der Ausgangsfragen dieser Untersuchung war, kann zwar nicht mit Sicherheit getroffen werden. Einige Indizien für die Deutung als >Kultbild wie die eindeutige Darstellung bei der Terrakottastatuette Kat. A43 ließen sich jedoch anführen. Da es wenig wahrscheinlich ist, dass man unterschiedliche Bedeutungen für den Typus konzipiert hat, liegt die Kultbild-Theorie für alle Bilder nahe. Dennoch sollte die Frage nach der Deutung der Idole anders gestellt werden, indem nach ihrer Bedeutung für die auf sie gelehnte Aphrodite gefragt wird. Dabei wird die Untersuchung der aufgelehnten Aphrodite im Rahmen des historischen Kontextes dieser Bilder eine wichtige Rolle spielen.

Auch in der weiblichen Herme sah man die Darstellung eines alten Aphroditebildes der. Überzeugender sind die zuletzt von M. Osanna vorgetragenen Argumente für die Deutung der Herme als spezifische Darstellungsform der Aphrodite Urania, einer mit orientalischen Kulten in Verbindung stehenden Kultform der Göttin ${ }^{360}$.

357 Schmidt 1922, 64. 68; Harrison 1965, 64; Willers 1975, 7; Brahms 1994; A. H. Borbein, Klassische Kunst, in: Klassik 2002, 12.

358 Dass sich später ganz verschiedene Figuren auf Palästra-Hermen auflehnen, entkräftet das Argument nicht, denn zweifellos waren die Urania-Hermen echte `Kultbilder, wie z. B. der Dareioskrater zeigt und auch die Palästrahermen konnten Kult empfangen, s. S. 71 und 102. 117.

359 s. 106. 117.

360 s. Kap. 5.1.3. 


\subsection{Deutung der Aphroditebilder im Rahmen der klassischen Kunst}

Bei der Frage nach dem Sinn der Erfindung einer auf eine halbikonische - die weibliche Herme - oder auf eine archaistische Figur gelehnten Aphroditefigur muss einerseits der altertümliche Charakter der Stützfiguren Beachtung finden (die weibliche Herme ist bereits überzeugend von M. Osanna als Bild der Aphrodite Urania gedeutet worden). Andererseits ist aber auch die Charakterisierung der aufgelehnten Figur zu untersuchen, die ihre Deutung im Rahmen des klassischen Götterbildes erfahren muss.

\subsubsection{Das Stützidol als Element des Archaismus}

Die Stützfiguren sind, unabhängig von ihrer Deutung im Einzelnen zunächst im Kontext des Archaismus zu verstehen. Diese Gestaltungsform antiker Skulptur, die unmittelbar mit dem Ende der Archaik einsetzte, ist ausführlich untersucht worden. Die archaistische Gestaltungsweise wurde benutzt, um bestimmten Darstellungen den Charakter alter Ehrwürdigkeit und Göttlichkeit zu verleihen ${ }^{361}$. Zugleich drückte diese Gestaltungsform die bewusste Distanz aus, die man zu den Bildern der Vergangenheit gewonnen hatte, was auch W. Oenbrink in seiner Monographie über Götterstatuen auf antiken Vasenbildern von 1997 hat zeigen können ${ }^{362}$. Eines der frühesten Beispiele für die Verwendung archaischer Stilmittel in späterer Zeit ist das aufgrund stilistischer Merkmale in die frühe Klassik datierte sog. Schweineopferrelief von der Athener Akropolis (Abb. 24) ${ }^{363}$. Es zeigt einen Mann und seine Familie, die ein Schwein als Opfer zu Athena führen. Die Göttin ist in Kleidung, Haartracht und Gestik archaistisch wiedergegeben. Vor allem die Gestaltung ihres Gesichtes entspricht dem Stil des 6. Jahrhunderts v. Chr. Die archaistische Darstellungsweise der Athena ist absichtlich gewählt, um sie in die Tradition Götterdarstellungen der vergangenen Epoche einzureihen. Auch die übrigen von der Forschung untersuchten archaistischen Werke des 5. Jahrhunderts v. Chr. gehören religiösen Kontexten an, soweit ihre Darstellung und Funktion gedeutet werden konnten. Mit der archaistischen Gestaltung wurden die Götter als

\footnotetext{
361 Schmidt 1922; Harrison 1965, 61- 66; H. Herdejürgen, Untersuchungen zur Thronenden Göttin aus Tarent in Berlin und zur archaischen und archaistischen Schrägmanteltracht (Waldsassen 1968); J. J. Pollitt, Art and Experience in Classical Greece (Cambridge 1972) 60 f.; Willers 1975; Zagdoun 1989; A. Leibundgut, Künstlerische Form und konservative Tendenzen nach Perikles. Ein Stilpluralismus im 5. Jahrhundert v. Chr.?, TrWPr 10 (Mainz 1989) 19; Stewart 1990, 134 f.; Brahms 1994; N. Hackländer, Der archaistische Dionysos. Eine archäologische Untersuchung zur Bedeutung archaistischer Kunst in hellenistischer und römischer Zeit (Frankfurt a. M. 1996) 17. 92; Rückert 1998, 86; A. H. Borbein, Klassische Kunst, in: Klassik 2002, 12.

362 Oenbrink 1997, 292-302. 340-361.

363 s. Anm. 312.
} 
alt und als besonders ehrwürdig gekennzeichnet ${ }^{364}$, im Sinne der vieldiskutierten,

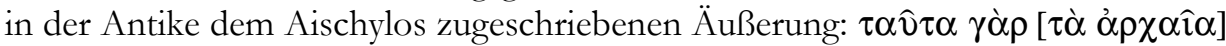

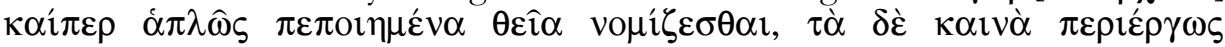

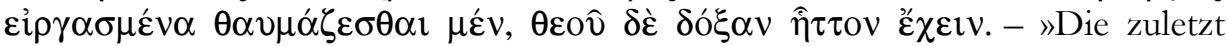
genannten [d. h. die alten Statuen] gelten als göttlich, obwohl sie einfach gearbeitet sind, die neuen aber, auch wenn sie sehr sorgfältig hergestellt sind, werden zwar bewundert, aber das Ansehen von Göttlichkeit finden sie weniger « ${ }^{365}$.

Hier wird deutlich zwischen alten und neuen, zeitgemäßen Bildern unterschieden ${ }^{366}$, genauer gesagt wird ein Zusammenhang zwischen dem religiösen Wert eines Götterbildes und seiner künstlerischen Gestaltungsweise, die einem zeitlichen Wandel unterlegen ist, hergestellt. Das zeitgenössische Bild sei nicht mehr wie das alte allein von göttlicher $>$ Wirkungskraft $\iota$ durchdrungen und seine religiöse Bedeutung geringer. Gewinn und Verlust der Veränderungen in der künstlerischen Ausgestaltung werden gegeneinander aufgewogen. Die neue Form der Götterdarstellung wird nicht als selbstverständlich hingenommen, sondern hinterfragt.

In diesen Rahmen fügt sich auch der Typus der auf eine alte Statue aufgelehnten Aphrodite ein. Das Motiv kann vor dem Hintergrund dieser Diskussion als Verbindung von Tradition und Innovation aufgefasst werden. Indem die Göttin in ihrer zeitgenössischen Gestalt auf eine - vielleicht ihre eigene - alte Statue gelehnt dargestellt wird, bezeugt diese Kombination die Kontinuität ihres Kultes und damit die Verehrungswürdigkeit auch ihrer neuen Darstellungsform. Das Besondere daran ist, dass hier nicht archaistische Elemente in eine zeitgenössische Darstellung integriert wurden, wie dies sonst bei Götterbildern bezeugt ist ${ }^{367}$, sondern dass ganz bewusst das archaistische Bild dem zeitgenössischen gegenübergestellt wurde. Die Göttin tritt dem Betrachter in ihrer neuen Gestalt gegenüber. Ihre Mächtigkeit und ihre göttliche Wirkungskraft werden aber gleichzeitig durch das hohe Alter des Kultes angezeigt, was durch die archaistische Gestaltung des

\footnotetext{
364 s. Anm. 361.

365 Sie ist überliefert bei dem kaiserzeitlichen Autor Porphyrios, Abst. 2, 18 und soll im Zusammenhang mit der Bitte der Delpher gestanden haben, einen Paian zu Ehren des Apollon zu schreiben. Dies soll Aischylos mit dem Verweis auf den älteren und besseren Paian des in die früharchaische Zeit datierten Dichters Tynnichus abgelehnt haben, wozu er den Vergleich der Götterbilder heranzog. Zur Frage, der Authentizität s. P. Zanker, JdI 89, 1974, 103 f.; Philipp 1968, 54 f. Vgl. auch A. H. Borbein, Kanon und Ideal. Kritische Aspekte der Hochklassik, AM 100, 1985, 253-270 Anm. 52. Zu Tynnichus s. DNP XII 1 (2002) s. v. Tynnichus (L. Käppel).

366 Zur Diskussion der Gegensätze zwischen der Kunst der vorangegangenen Epochen und der Kunst der eigenen Zeit in der Antike s. auch Xenophanes (21 B 18 DK); Eur. Hel. 262 f.; Platon Hipp. mai. 282a; Athen. 14, 614; Paus. 2, 4, 5. Vgl. Philipp 1968, 49-58; J. J. Pollitt, Art and Experience in Classical Greece (Cambridge 1972) 60-63; Hölscher 1974; T. Hölscher, Tradition und Geschichte. Zwei Typen der Vergangenheit am Beispiel der griechischen Kunst, in: J. Assmann - T. Hölscher (Hrsg.), Kultur und Gedächtnis (Frankfurt a. M. 1988) 115-149; Hölscher 1989, 13; Faulstich 1997, 32.

367 s. Anm. 361.
} 
Idols ausgedrückt wird. Das Bild der Aphrodite, die sich auf ein archaistisches weibliches Idol lehnt, fügt sich also in eine Denkrichtung des 5. Jahrhunderts v. Chr. ein, die die Würde der alten Götterbilder beschwörte, die der zeitgenössischen Bilder hingegen nicht immer als selbstverständlich ansah.

In einem vergleichbaren Sinn hat W. Oenbrink in seiner Untersuchung zu Götterstatuen auf klassischen Vasenbildern die Verwendung altertümlicher Statuentypen anstatt zeitgenössischer als Zeichen für den Verlust an religiösem Gehalt der neuen Statuen gegenüber den alten interpretiert ${ }^{368}$. Auch wenn man nicht unbedingt von einem Verlust an religiösem Gehalt bei den neuen Götterbildern sprechen will, beweist die häufige Verwendung altertümlichen Formengutes in der Götterdarstellung seit der klassischen Zeit, dass die neuen Bilder einer geänderten und nicht von allen als gleichwertig akzeptierten Vorstellung entsprachen und man deshalb auf alte Typen und Gestaltungsmerkmale zurückgriff, um die Altehrwürdigkeit der Götter herauszustellen.

\subsubsection{Die aufgelehnte Aphrodite im Rahmen des klassischen Götterbildes}

Wichtig für die Deutung des hier untersuchten Bildmotivs ist neben dem altertümlichen Idol auch die aufgelehnte Haltung der Aphrodite, die ein neues Motiv in der Gestaltung der Götterbilder in der 2. Hälfte des 5. Jahrhunderts v. Chr. darstellt. Sie gehört zunächst in den Bereich der mit dem Ende der Archaik einsetzenden Differenzierung von Haltung und Bewegung der Figuren ${ }^{369}$. Die Möglichkeit, einen Körper in angelehnter Haltung zu zeigen wurde unter den vielen Experimenten der klassischen Künstler offenbar als attraktiv empfunden, aber immer inhaltlich motiviert verwendet. Zu den ersten Figuren dieser Art gehören die verletzten Amazonen aus dem Heiligtum der Artemis von Ephesos (Abb. $13)^{370}$, bei denen mit dem Stützmotiv die Verletzung angezeigt wurde, wie in Kapitel 6 gesehen wurde. Besonders nachdrücklich und paradigmatisch wurde das Motiv jedoch für Aphrodite verwendet, so dass es für diese Göttin typisch wurde. Dies bezeugen neben dem hier untersuchten, in klassischer und hellenistischer Zeit oft rezipierten Typus die anderen in Kapitel 6.1 betrachteten Aphroditetypen aus dem Umkreis des Phidias und Alkamenes. Auch in der Vasenmalerei kommen am Ende des 5. Jahrhunderts v. Chr. Figuren auf, die sich an einen Pfeiler, eine

\footnotetext{
368 Oenbrink 1997, 292-302. 340-360.

369 Allgemein zu den neuen künstlerischen Ausdrucksmöglichkeiten s. Hölscher 1974, 92-108.; A. H. Borbein, Kanon und Ideal. Kritische Aspekte der Hochklassik, AM 100, 1985, 253-270; Hölscher 1989, 10-12; A. Leibundgut, Künstlerische Form und konservative Tendenzen nach Perikles. Ein Stilpluralismus im 5. Jahrhundert v. Chr.?, TrWPr 10 (Mainz 1989); Borbein 1995; T. Hölscher, Körper, Handlung und Raum als Sinnfiguren in der griechischen Kunst und Kultur, in: K.-J. Hölkeskamp u. a. (Hrsg.), Sinn (in) der Antike. Orientierungssysteme, Leitbilder und Wertkonzepte im Altertum (Mainz 2003) 181. Vgl. auch die Reflexe über die Suche nach neuen Darstellungsformen in der antiken Literatur: Lukian. Zeuxis 3; Athen. 12, 543d-e. Weitere Belege bei Hölscher 1974, 95. 370 s. Anm. 199.
} 
Säule oder einen Baumstamm lehnen. Die frühesten Darstellungen wie die auf einem attisch-rotfigurigen Oon aus der Zeit um 410 v. Chr. im Metropolitan Museum in New York (Abb. 26) 371 $^{371}$ eigen bezeichnenderweise Aphrodite, für die der Stützpfeiler geradezu zum kennzeichnenden Attribut wird.

Diese Darstellungsform der Aphrodite ist zweifellos im Zusammenhang mit der vielbesprochenen, differenzierenden neuen Charakterisierung der Götter in der klassischen Zeit zu sehen, die, wie immer wieder betont wird, keine neuen Eigenschaften der Götter wiedergab, sondern ihre immer vorhandenen Eigenschaften neu zum Ausdruck brachte. Anders als in der archaischen Epoche wurden die Götter in klassischen Darstellungen nicht mehr nur durch ihre Attribute und Beischriften charakterisiert, sondern zusätzlich durch Körperbildung, Haltung, Gesten und Blicke voneinander unterschieden, die ihr Wesen und ihre »Wirkungskräfte « ${ }^{372}$ zum Ausdruck brachten ${ }^{373}$. In der Gestaltung des Körpers und der Körperhaltung wurden seit dem 5. Jahrhundert v. Chr. der Charakter der Götter und damit einhergehend auch die Kräfte, die ihnen zugeschrieben wurden verstärkt sichtbar gemacht, so dass man mit N. Himmelmann-Wildschütz von dieser Zeit an von einem »Götterbildnis« ${ }^{374}$ sprechen kann.

Ein besonders anschauliches Beispiel für die Subtilität der Charakterisierung ist die Darstellung der Götter auf dem Parthenonfries, wo sie durch die Kleidung, Haartracht und besonders durch eine fein differenzierende Haltung und Gestik unterschieden sind, wie N. Himmelmann gezeigt hat. So ist etwa Demeter durch eine »schwere, matronale Gestalt« mit »in sich versunkener Haltung« gekennzeichnet, Ares an der »wippenden Haltung«, Apollon an seiner »gelöster sitzenden« Gestalt, Dionysos an einer »ekstatischen Haltung« und Aphrodite schließlich durch einen Diphros mit schräger Lehne erkennbar, auf dem »die weit zurückgelehnte Aphrodite wie auf einer Art Diwan zu ruhen scheint«375. Noch ungezwungener

371 Inv. 1971.258.3: Delivorrias 1984, 139 Nr. 1452; LCS II Taf. 15, 1. 31, 4. Vgl. auch die wahrscheinlich als Parisurteil zu deutende Darstellung auf einem hochklassischen attisch-rotfigurigen Aryballos im Athener Nationalmuseum Inv. 1702 mit einer auf einen Baumstamm gelehnten weiblichen Figur. Zwar ist die Deutung der einzelnen Figuren nicht vollständig geklärt, von allen weiblichen Figuren entspricht die Angelehnte jedoch mit ihrem eng anliegenden, den Körper betonenden Chiton am ehesten einer Darstellung der Aphrodite. Mit dem Motiv des Aufstützens auf dem Baumstamm zitiert diese Figur den Typus der Aphrodite von Daphni, s. Kap. 6.1. Der Aryballos ist publiziert bei Raab 1972, 180 Kat. B24 Taf. 6.

$372 \mathrm{Zu}$ diesem Begriff vgl. H. U. Cain, Hellenistische Kultbilder. Religiöse Präsenz und museale Präsentation der Götter im Heiligtum und beim Fest, in: Wörrle - Zanker 1995, 115-130.

373 Müller 1931, 502 f.; Himmelmann-Wildschütz 1959; N. M. Kontoleon, Rez. zu HimmelmannWildschütz 1959, Gnomon 35, 1963, 632-643; Stewart 1990, 81-83. 135. 146 f.; Cain 1997; K. Schefold, Der religiöse Gehalt der antiken Kunst und die Offenbarung (Mainz 1998) 261; Himmelmann 2003, bes. 53-88.

374 Himmelmann-Wildschütz 1959, 11 f.; Himmelmann 2003, 54. 57. 62; vgl. auch Zanker 1998, 19; Cain 1997, 42 f.; K. Schefold, Der religiöse Gehalt der antiken Kunst und die Offenbarung (Mainz 1998) 261.

375 Himmelmann 2003, 54-57. Vgl. auch E. Berger - M. Gisler-Huwiler, Der Parthenon in Basel. 
geben sich die in Kapitel 6.1 bereits erwähnte >Aphrodite Olympias` $(A b b .17)^{376}$, die sich weit zurücklehnt und die ausgestreckten Beine gleichfalls lässig übereinander geschlagen hat sowie die wie hingegossen sich auf einen Pfeiler lehnende stehende Darstellung der Göttin auf der >Bonner Helmwanger (Abb. 15) ${ }^{377}$.

Diese Neuerung in der Charakterisierung der Götter mit Hilfe ihres Körperbildes ist bereits am Übergang von der Archaik zur Klassik vorbereitet und im 5. Jahrhundert v. Chr. schließlich voll entwickelt. Besonders deutlich wird dies auch bei Darstellungen des Parisurteils. In der archaischen Vasenmalerei können Aphrodite, Hera und Athena nur durch ihre Attribute unterschieden werden $(A b b .27)^{378}$. Bei klassischen Bildern hingegen werden die Göttinnen auch durch ihr Körperbild und ihre Kleidung charakterisiert. So trägt Aphrodite zumeist einen dünnen Chiton unter dem Himation und eine Haube auf dem Kopf oder eine kunstvolle Frisur, Heras Kleidung besteht hingegen oft aus schwererem Stoff und sie ist häufig verschleiert oder hat ihr Himation über den Kopf gezogen ${ }^{379}$. Zwar kann auch Aphrodite, die an dem ihr beigegebenen Eros erkennbar ist so dargestellt werden (Abb. 28 ${ }^{380}$. Aphrodite und Hera sind auf einigen Vasenbildern ähnlich charakterisiert und können auch ihre Plätze tauschen, so dass sie - im Gegensatz zu Athena - nicht immer zweifelsfrei identifiziert werden können. Bei anderen Vasendarstellungen ist aber aufgrund des Körperbildes leicht zu entscheiden, ob es sich um eine Darstellung der Hera oder der Aphrodite handelt. Besonders deutlich wird dies auf einer frühklassischen attisch-rotfigurigen Hydria in London (Abb. 29)381. Auf diesem Vasenbild steht Aphrodite vor Paris, gefolgt von Athena und Hera. Athena ist an ihrer Aigis zu identifizieren. Und auch Aphrodite und Hera sind deutlich gekennzeichnet. Aphrodite hält den ihr als Siegerin zustehenden Apfel 382 und ist sehr körperbetont mit sich deutlich unter dem dünnen Chiton abzeichnenden Brüsten und einer Haube über dem Kopf dargestellt. Hera hingegen ist zur Gänze in ihren Mantel eingehüllt, der sämtliche Körperformen verdeckt und zugleich über den Kopf gezogen ist.

Dokumentation zum Fries (Mainz 1996) 153-164.

376 s. Anm. 214.

377 s. Anm. 203.

378 München, Sammlung Bareiss, attisch-schwarzfigurige Amphora: Raab 1972, 161 Kat. A I 3 Taf. 1; Kossatz-Deissmann 1994.

379 z. B. auf dem Deckel einer attisch-rotfigurigen Pyxis: Kopenhagen, Nationalmuseum Inv. 731:

Kossatz-Deissmann 1994, 180 Nr. 40. Allgemein zur Tracht und Frisur: Raab 1972, bes. 75-80. 88 f.

380 z. B. auf einer attisch-rotfigurigen Amphora: London, British Museum Inv. E 289: HimmelmannWildschütz 1959, 16 Abb. 15; Kossatz-Deissmann 1994, 179 f. Nr. 37; ebenso auf einer attischrotfigurigen Schale: Berlin, Staatliche Museen Inv. F 2536: Kossatz-Deissmann 1994, 180 Nr. 39 und einer attisch-weißgrundigen Pyxis: New York, Metropolitan Museum Inv. 1907.286.36: Kossatz-Deissmann 1994, 180 Nr. 46.

${ }^{381}$ London, British Museum Inv. E 178: Raab 1972, 173 Kat. A IV 16 Taf. 3: Kossatz-Deissmann 1994, 180 Nr. 38, jedoch mit anderer Deutung der Figuren.

382 Raab 1972, 49-60. 
Mit der Veränderung in der Körperhaltung hin zum Lässigeren und Lockeren geht bei klassischen Darstellungen der Aphrodite somit auch eine Änderung in der Art, wie und in welchem Maß der Körper durch die Kleidung verdeckt wird, einher. Während bei anderen Göttinnen zumeist die Gewänder jede Rundung verbergen, umspielen die Gewandfalten bei Aphrodite geradezu die Körperformen und betonen so zusätzlich die Weiblichkeit der Göttin. Besonders deutlich wird dies bei der >Aphrodite Brazzà Kat. A1, bei der sich das Gewand durch die schwingende Haltung an einzelnen Stellen staut, an anderen wiederum die Körperrundungen umspielt und dadurch hervorhebt. Auch bei anderen Aphroditebildern klassischer Zeit wird der Verlauf des Gewandes dazu benutzt, die Körperformen zu betonen, wie z. B. bei der Aphrodite Valentini (Abb. 30)383. Gegen Ende des 5. Jahrhunderts ist sogar schon teilweise eine Entblößung des Körpers der Aphrodite in der Großplastik möglich. Bei dem Typus Fréjus (Abb. 31) ${ }^{384}$ ist eine Brust unbedeckt. Bei der sog. Hera Borghese (Abb. 32) ist das Gewand von der Schulter gerutscht. Sie tragen beide einen sehr dünnen Chiton, der die weiblichen Körperformen deutlich hervorhebt. Deshalb wird der Typus der Hera Borghese vor allem von der neueren Forschung als Bild der Aphrodite und nicht der Hera gedeutet ${ }^{385}$.

In diesem Zusammenhang sind die aufgelehnten Aphroditedarstellungen zu verstehen. Aufgrund ihres Charakters teilte Aphrodite nicht die aufrechte Haltung der anderen Göttinnen, sondern konnte lässig gelagert oder aufgelehnt gezeigt werden. Sie wird in den aufgelehnten Bildern in ihrer gesamten physischen Anziehungskraft präsentiert. Besonders bei der >Aphrodite Brazzà kommt die körperliche Präsenz der dargestellten Figur durch die Haltung und Gewanddrapierung deutlich zum Ausdruck. Die Figur ist frontal gesehen, sie steht aufrecht, das rechte Bein ist das Standbein. Das Gewicht des Oberkörpers ruhte auf der nicht mehr vorhandenen Stütze zu ihrer linken Seite. Durch das Auflehnen mit dem linken Unterarm ist der Oberkörper deutlich nach links in Richtung der Stütze verschoben, es entsteht ein

383 Rom, Palazzo delle Province: E. Bielefeld, Ariane Valentini (sog. Aphrodite Valentini), AntPl 17 (Berlin 1978) 57-69 Taf. 35; Boardman 1987 Abb. 215.

384 Eine der kaiserzeitlichen Kopien: Paris, Louvre Inv. 525: Boardman 1987 Abb. 197, vgl. auch Delivorrias 1984, 34 f.; M. Brinke, Die Aphrodite Louvre - Neapel, AntPl 25 (Berlin 1996) 7-64; N. Kaltsas, Sculpture in the National Archaeological Museum, Athens (Athen 2002) 123 f. Nr. 231; Kreikenbom 2004, 199 f. Abb. 126-128.

385 Eine der kaiserzeitlichen Kopien: Kopenhagen, Ny Carlsberg Glyptothek Inv. 473: Boardman 1987 Abb. 214; ebenso E. Paribeni, Il Museo Nazionale Romano. Sculture greche del V secolo (Rom 1953) 63 Nr. 111; K. Schefold, Agorakritos als Erbe des Pheidias, in: E. Boehringer - W. Hoffmann (Hrsg.), Robert Boehringer. Eine Freundesgabe (Tübingen 1957) 570; D. Arnold, Die Polykletnachfolge. Untersuchungen zur Kunst von Argos und Sikyon zwischen Polyklet und Lysipp (Berlin 1969) 78. 154; Chr. Landwehr, Die antiken Gipsabgüsse aus Baiae. Griechische Bronzestatuen in Abgüssen römischer Zeit (Berlin 1985) 88-94; LIMC IV (1988) 671 s. v. Hera 102 (A. KossatzDeissmann); A. Delivorrias, Der statuarische Typus der sogenannten Hera Borghese, in: H. Beck - P. C. Bol (Hrsg.), Polykletforschungen (Berlin 1993) 221-252; Kreikenbom 2004, 193. 
s-förmiger Körperschwung. Zugleich ist der Oberkörper leicht nach hinten gelehnt. Dadurch wird die Brust weit geöffnet und der Bauch tritt hervor. Der linke Fuß ist nach vorn und erhöht aufgesetzt. Das Bein wird somit zum einen prononciert dargeboten, zum anderen trägt es überhaupt kein Gewicht und scheint fast über der neuzeitlichen Schildkröte zu schweben. Das Ausschwingen der rechten Hüfte wird noch zusätzlich dadurch betont, dass die Figur nach unten schmaler wird. Die Gewanddrapierung unterstreicht die körperliche Präsenz zusätzlich. Der knapp über dem Bauchnabel gegürtete Chiton ist von der linken Schulter gerutscht und liegt eng am Körper an, besonders an den Brüsten, wo keine Falten ihre Rundungen überspielen. Der Ansatz der Brüste liegt hoch. Sie stehen eng beieinander und sind nach vorn gerichtet. Über dem rundlichen, nach vorn gestreckten Bauch stauen sich die Falten des Chitonüberfalls. Zusammen mit dem oberhalb der Scham über die Oberschenkel geführten Himation umrahmen sie diese Körperpartie, während vom Bauchnabel ausgehende, nach unten zur Scham zusammenlaufende sichelförmigen Falten der Rundung des Bauches folgen und diesem Körperteil Volumen verleihen. Um den linken Unterschenkel liegt der Chiton sehr eng an und ist nur durch wenige Falten gegliedert, so dass das Bein und besonders das Knie in ihrer vollen Körperlichkeit herausgearbeitet sind. Das rechte Bein hingegen ist von eng geführten senkrechten Falten umgeben, die seine Funktion als Standbein, als tragendes Glied des Körpers hervorheben. Die wie dünne Seile wirkenden Falten des Mantels umspannen straff die rechte Hüfte und den Oberschenkel, so dass die Kontur des Körpers deutlich herausgearbeitet ist. Sie fallen anschließend locker, aber dicht den Körperformen folgend über den linken Oberschenkel. Dort sind die Falten zudem besonders eng geführt und betonen dadurch dessen Rundung.

Einen nützlichen Vergleich dazu bietet die Amazone vom Typus Sciarra ( $A b b$. 13 ${ }^{386}$. Auch sie wird mit dem Gewicht auf dem rechten Bein stehend gezeigt und lehnt sich mit dem linken Unterarm auf eine Stütze. Im Gegensatz zu der >Aphrodite Brazzàr ist ihr Oberkörper schräg nach links geneigt und wirkt dadurch weniger aufgerichtet, sondern schwerer auf der Stütze lastend. Die linke Schulter ruht tiefer als die rechte. Durch den über den Kopf gelegten rechten Arm ist diese Schulter nach vorn gezogen, so dass die Brustpartie weniger geöffnet ist als bei der Aphroditestatue. Die nach außen fallenden Brüste stehen weit auseinander. Durch den nach hinten gesetzten Spielbeinfuß verschwindet der Unterschenkel aus dem unmittelbaren Blickfeld des Betrachters. Der Chiton lässt zwar die Brüste unbedeckt, wird ansonsten aber kaum dazu verwendet, die Körperrundungen hervorzuheben. So verdecken z. B. die sich stauenden Falten und der Chitonüberfall die Taille, was der Figur senkrecht verlaufende Konturen verleiht. Die Rundung des Bauches wird durch gerade darüber fallende Faltenzüge negiert. Auch an den Außenseiten der Oberschenkel fällt das Gewand senkrecht hinab und folgt nicht den Körperformen.

386 s. Anm. 199. 
In der rechten Seitenansicht werden die Unterschiede in der Körperpräsentation ebenfalls deutlich. Bei der >Aphrodite Brazzà stehen die Brüste weit ab, der Rücken, der Bauch und das Gesäß treten als Rundung deutlich hervor. Die Körperlichkeit der Figur wird zusätzlich durch eine Einziehung des Gewandes jeweils oberund unterhalb dieser Partien hervorgehoben und dadurch ihre weiblichen Reize, besonders die Scham, die Brüste und das Gesäß stark betont. Bei der Amazone hingegen fügen sie die flachen Brüste in die Körperkontur ein. Der Bauch wird durch das Gewand verdeckt. Das Gesäß ist zwar gerundet, die Körperkontur jedoch wird von dem dahinter senkrecht herabfallenden Gewand bestimmt, das Gesäß bleibt innerhalb der Körperkontur. Auch die Rundung des Rückens wird durch den dahinter senkrecht herabgeführten linken Arm in die Kontur eingebunden.

Der Körper der Aphrodite, der Göttin der Liebe und der Erotik, wird bei den aufgelehnten Bildern, auch den in Kapitel 6.1 betrachteten mit einem Pfeiler oder einem Baumstamm als Stütze regelrecht in Szene gesetzt. Ihr betont weiblicher Körper zeigt eben diese Wirkmacht der Göttin an ${ }^{387}$. Bei keiner anderen Göttin ist eine derartige Präsentation des Körpers in der hochklassischen Kunst zu beobachten.

Eine weitere Möglichkeit, klassische Götterbilder zu interpretieren, ist von N. Himmelmann vorgetragen worden. Seiner Meinung nach werden die Götter bei klassischen Darstellungen als selbst ihre Kräfte erleidend - oder genießend gezeigt $^{388}$. Auch für die Bilder der aufgelehnten Aphrodite kann man fragen, ob die Göttin als eine ihre eigene Wirkung erlebende Figur gemeint ist. In der Antike schrieb man ihr, wie auch Dionysos eine sgliederlösender ( $\lambda v \sigma u \mu \varepsilon \lambda \dot{\eta} \varsigma) \mathrm{Kraft}_{\mathrm{zu}}{ }^{389}$. Eine aufgelehnte, entspannte Haltung entsprach daher ihrem Charakter und zeigte sie zugleich als selbst von ihrer göttlichen Macht beeinflusst. Besonders schön ist dies auf der bereits genannten Helmwange dargestellt, die durch einen Abdruck im Akademischen Kunstmuseum in Bonn erhalten ist $(A b b .15)^{390}$. Sie zeigt Aphrodite wie hingegossen auf einen Pfeiler lehnend, ohne den sie sich gar nicht halten könnte. Auch Dionysos torkelt bei Darstellungen seit der klassischen Zeit als weintrunkener Gott in langen, als weibisch verschrienen Gewändern zu einem Fest ${ }^{391}$, oder sein jugendlicher Körper wird zunächst immer jugendlicher, später dann immer weicher und weiblicher gebildet: »Dionysos selbst erscheint nicht mehr als würdiger, bärtiger Mann, sondern als verführerischer schöner Jüngling, nicht mehr als ruhig stehender, souveräner Gebieter über den wilden Schwarm seiner Begleiter, sondern in lockerer Haltung lässig sitzend - er kontrolliert die Kräfte, die

\footnotetext{
387 Vgl. Stewart 1990, 52; Hölscher 1998, 17-19; Himmelmann 2003, 59.

388 Himmelmann 1959; Himmelmann 2003.

389 Anth. Pal. 11, 414. Ursprünglich Eros zugeschrieben: Sappho fr. 137D. Vgl. auch Plut. mor. 613c;

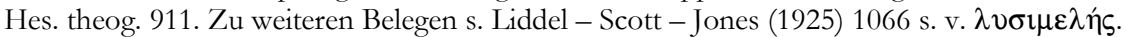

390 s. S. 93 f.

391 Eur. Bacch. 235. 353. 455-458; Aristoph. Thesm. 134-145. Vgl. Cain 1997.
} 
den tobenden Rausch unter seinen Begleitern entfachen, nicht mehr, sondern ist selber ergriffen von der erotisch-heiteren Stimmung, die er evoziert « ${ }^{392}$.

Derartige Bilder ordnen sich zugleich in das Streben nach Luxus und Lebensgenuss ein, das die Forschung für das spätere 5. Jahrhundert v. Chr. herausgearbeitet hat. Auch wenn Einsatzbereitschaft im militärischen Bereich und politisches Engagement in klassischer und hellenistischer Zeit weiterhin wichtiger Teil des Lebens waren ${ }^{393}$, wurde die öffentliche Zurschaustellung von Lebensgenuss nach Ansicht der Forschung immer weniger problematisch und nahm immer mehr $\mathrm{zu}^{394}$. Den Höhepunkt erreichte diese Entwicklung unter den hellenistischen Herrschern, die sich sogar selbst in aller Öffentlichkeit in Gestalt des Dionysos und der Aphrodite feiern ließen ${ }^{395}$. Auch im privaten Bereich lassen sich Ansätze dazu finden, dass Lebensgenuss bis hin zu Luxus seit dem späten 5. und im 4. Jahrhundert v. Chr. zunehmend wichtiger wurden ${ }^{396}$. Zu einer der großen Gottheiten dieser Zeit entwickelte sich neben Dionysos vor allem Aphrodite ${ }^{397}$. Sie war die Göttin des erotischen Genusses und der körperlichen Sinnlichkeit ${ }^{398}$, weshalb sie in ihrem Körperbild betont weiblich und sinnlich gezeigt wurde. Dazu eignete sich die aufgelehnte Haltung besonders gut, worin sicherlich einer der Gründe zu sehen ist, warum der aufgelehnte Typus seit dem Hellenismus zahlreich wiederholt und umgewandelt worden ist. Dionysos stand für die Freuden, aber auch die Folgen des Weingenusses und wurde in der klassischen und noch stärker in der hellenistischen Zeit besonders über seinen immer weicher und weiblicher wirkenden Körper definiert $^{399}$. Er wurde als Gott der Feiern und des Genießens gezeigt, der sich deshalb in seinen Bildern auch entspannt geben und aus diesem Grund ebenfalls auflehnen konnte. Es entstand eine »neue Bilderwelt des Genießens und der Üppigkeit« ${ }^{400}$.

392 A. Stähli, Die Verweigerung der Lüste. Erotische Gruppen in der antiken Plastik (Berlin 1999) 203; Vgl. W. Burkert, Greek Religion (Oxford 1985) 167; Cain 1997, 14. 25. 27. 38. 74; Cain 1997.

393 J. Bleicken, Die athenische Demokratie ${ }^{2}$ (Paderborn 1994) bes. 333-337; W. Eder, Die athenische Demokratie im 4. Jahrhundert v. Chr. Krise oder Vollendung?, in: Eder 1995, 11-28; H. Knell, Überlegungen zur öffentlichen Architektur des IV. Jahrhunderts v. Chr., in: ebenda 475-514; Chr. Habicht, Ist ein »Honoratiorenregime« das Kennzeichen der Stadt im späteren Hellenismus?, in: Wörrle - Zanker 1995, 87-92; P. Zanker, Brüche im Bürgerbild? Zur bürgerlichen Selbstdarstellung in den hellenistischen Städten, ebenda 251-273.

394 Fehr 1979, 30; Borbein 1995; Cain 1997, 37-73; Zanker 1998, 11-16.

395 Vgl. dazu M. Bergmann, Die Strahlen der Herrscher. Theomorphes Herrscherbild und politische Symbolik im Hellenismus und in der römischen Kaiserzeit (Mainz 1998); A. Stähli, Die Verweigerung der Lüste. Erotische Gruppen in der antiken Plastik (Berlin 1999) 233-300; R. Thomas, Eine postume Statuette Ptolemaios' IV. und ihr historischer Kontext, TrWPr 18 (Mainz 2001).

396 Fehr 1979, 44. 49; J. Bleicken, Die athenische Demokratie ${ }^{2}$ (Paderborn 1994) 66. 404; Borbein 1995; Zanker 1998, 14. Vgl. auch Kap. 9. Als antike Zeugnisse können Demost. or. 3, 29; Aristot. pol. 1334a. 1337b. 1339b; Platon rep. 373a angeführt werden.

397 Cain 1997; Zanker 1998.

398 Vgl. Roscher, ML I (1884-1890) 392. 398 s. v. Aphrodite (A. Furtwängler); Zanker 1998, 17.

399 Cain 1997; Zanker 1998, 17-22.

400 Zanker 1998, 14. 
Die Untersuchungen von B. Fehr haben ergeben, »daß bei den Griechen eine Tendenz bestand, Analogiebeziehungen zwischen Bewegungsweisen und charakterlichen Eigenschaften (d. h. Verhaltensdispositionen in Hinblick auf ethische Normen) anzunehmen «401. Bei den Göttern kann daher die Körperhaltung als Aussage über ihre Wirkungsmacht gedeutet werden ${ }^{402}$. Für gelöste Haltungen und legere Gesten hat B. Fehr herausgestellt, »daß diese Art der Bewegung im Zusammenhang mit dem Genuss angenehmer Lebenssituation gesehen wurde«, etwa wenn man bei einem Symposion bequem lagert, oder einen »nachlässig« 403 beschwingten Gang hat, der von Aristophanes den Menschen zugeschrieben wird, die ein genussreiches Leben führen ${ }^{404}$. Sie zeigten laut B. Fehr eine »glückhafte Gesamtsituation« an sowie ein "glückliches, leichtes Leben ${ }^{405}$ und eigneten sich deshalb besonders für Darstellungen der Aphrodite wie später auch des Dionysos, den Göttern des Lebensgenusses, und erregten deshalb bei ihnen auch in einer öffentlich aufgestellten Großplastik keinen Anstoß, da eine solche Haltung ihrem Wesen entsprach.

Für andere Götter hingegen wurde eine aufgelehnte Haltung offenbar nicht als passend empfunden. Sie wurden im strengen Stik und im weiteren Verlauf des 5. Jahrhunderts v. Chr. aufrecht stehend oder thronend, nicht jedoch lässig auf eine Stütze hingegossen gezeigt. Bei Göttinnen wurden zudem ihre weiblichen Rundungen von den Gewändern verdeckt. Das gilt für nahezu alle griechischen Götter, seien sie nun jugendlich wie Apollon - z. B. der Omphalos-Apollon, der Kasseler Apollon, der Tiber-Apollon oder der Hermes Ludovisi - oder auch reiferen Alters wie der Dresdner Zeus. Gleiches gilt für die weiblichen Götter. Nennen möchte ich hier nur die Nemesis aus Rhamnous, die Hestia Giustiniani, bei der es sich möglicherweise um eine Darstellung der Hera oder Demeter handelt (stellvertretend abgebildet, Abb. 33), die Demeter aus Eleusis, die Demeter Cherchel und die Kapitolinische Demeter, zahlreiche Athenastatuen wie die Athena Lemnia, die Athena Medici, die Athena Albani, Velletri, Giustiniani, Ince, HopeFarnese, außerdem die Artemis von Ariccia ${ }^{406}$. Die Aufzählung ließe sich leicht

401 Fehr 1979, 21 f. Daraus ableitend hat B. Fehr bestimmte Verhaltensweisen verabsolutiert und sie einzelnen gesellschaftlichen und politischen Gruppen zugeordnet. Dass dies nicht durch die Quellen begründet ist und daher zu abstrakt und zu stark verallgemeinernd ist, hat A. H. Borbein, Rez. zu Fehr 1979, Gnomon 58, 1986, 723-729 gezeigt, jedoch die Möglichkeit, Bildwerke nach physiognomischen Kriterien zu beurteilen nicht grundsätzlich abgelehnt. Seiner Meinung nach kann man durch eine Formanalyse das `Klima〈, in dem das Werk entstand definieren, in diesem Fall also das Streben nach Luxus und Lebensgenuss in klassischer und noch stärker in hellenistischer Zeit.

402 Vgl. Anm. 374.

403 Fehr 1979, 12.

404 Aristoph. Vesp. 1168-1171.

405 Fehr 1979, 14. 43. Vgl. auch A. H. Borbein, Rez. zu Fehr 1979, Gnomon 58, 1986, 723-729.

406 Rom, Villa Albani Inv. Torlonia 490: Boardman 1987 Abb. 74; R. Tölle-Kastenbein, Frühklassische Peplosfiguren. Typen und Repliken. AntPl 20 (Berlin 1986) 33-41 Taf. 37 f.; C. Rolley, La sculpture grecque I. Des origines au milieu du Ve siècle (Paris 1994) 354 Abb. 370. Zu den weiteren genannten Werken s. Boardman 1987 Abb. 66. 68 f. 227 f. bzw. 122. 137. 208. 212. 183. 
weiter fortführen. Allen diesen Göttern, seien sie nun höheren Alters oder jugendlich, ist ein aufrechter, von Körperspannung geprägter Stand mit gerade erhobenem Oberkörper gemeinsam. Sie lehnen sich nicht entspannt auf eine Stütze auf. Als Beispiel einer sitzenden Gottheit sei der thronende Zeus von Olympia erwähnt, wie ihn elische Münzbilder der Kaiserzeit zeigen $(A b b .34)^{407}$.

Erst im 4. Jahrhundert v. Chr. wurde die aufgelehnte Haltung auch auf diese Götter übertragen und z. B. von Praxiteles mehrfach verwendet. Bezeichnend ist aber, dass Aphrodite, Eros und andere aphrodisische Figuren wesentlich häufiger und auch früher als andere Götter so dargestellt worden sind, gefolgt von Dionysos, dass das Motiv also trotz der vereinzelten Verwendung bei anderen Göttern thematisch vorrangig auf diese Götter beschränkt bleibt. Bei den anderen Göttern handelt sich grundsätzlich um jugendliche Gottheiten, wie in den Kapiteln 6.2 und 6.3. gesehen wurde, niemals um ältere Gottheiten, auf die eine solche Haltung aufgrund ihrer Charakterisierung nicht übertragen werden konnte.

Daraus ergibt sich zugleich ein Anhaltspunkt, um die oben vorgetragene Deutung der altertümlichen Stützidole als Hinweis auf ein hohes Alter des Aphroditekultes noch stärker in den historischen Kontext einzubinden. Aphrodite war die Göttin, deren Körperbild sich im 5. Jahrhundert v. Chr. am deutlichsten verändert hatte, indem ihre Körperlichkeit nun besonders häufig und variabel hervorgehoben wurde. Allerdings bestand durch die betonte Körperlichkeit und Lässigkeit, wie sie in den aufgelehnten Bildern zum Ausdruck kam, die Gefahr des Würdeverlustes dieser Göttin, indem sie in ihren neuen Bildern allzu menschlich und allzu sehr ihrer eigenen Kraft erlegen erschien. Zudem wurde die Verbindlichkeit althergebrachter Werte, sowohl in sozialer und politischer, aber auch in religiöser Hinsicht und damit auch die Selbstverständlichkeit der Würde der Götter in der 2. Hälfte des 5. Jahrhunderts v. Chr. verstärkt diskutiert und nicht mehr als selbstverständlich hingenommen ${ }^{408}$. Besonders kritisch äußerten sich die Sophisten, die z. T. sogar die Götter selbst in Frage stellten ${ }^{409}$. Ihre Thesen mussten als Götterfrevel und zugleich als Gefahr für die Stabilität der gesellschaftlichen Ordnung aufgefasst werden. Sie stellten jedoch nicht die Mehrheit der Bevölkerung, sondern die Anhänger der gebührenden Achtung der altehrwürdigen Götter ${ }^{410}$. Die

200-204. 206. 198.

407 Florenz, Archäologisches Museum: Mallwitz 1972 Abb 14.

408 A. H. Borbein, Kanon und Ideal. Kritische Aspekte der Hochklassik, AM 100, 1985, 253-270; Hölscher 1989, 17-24; H. Scholten, Die Sophistik. Eine Bedrohung für die Religion und Politik der Polis? (Berlin 2003) 12.

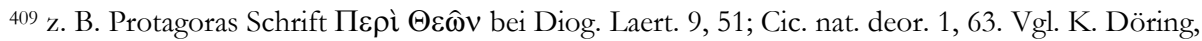
Sophistik, Sokrates, Sokratik, Mathematik, Medizin (Basel 1998); H. Scholten, Die Sophistik. Eine Bedrohung für die Religion und Politik der Polis? (Berlin 2003).

${ }^{410}$ s. etwa den Aufruhr, den der >Hermenfrevek in Athen hervorgerufen hat bei Thuk. 6, $27 \mathrm{f}$. Vgl. auch Plut. Perikles 32, 2. Allgemein dazu: H. Scholten, Die Sophistik. Eine Bedrohung für die Religion und Politik der Polis? (Berlin 2003) 61. 275-326. 
Aphroditebilder mit den altertümlichen Stützen fügen sich in diese Strömung ein, in der mit Hilfe archaistischer Stilmittel auf die Altehrwürdigkeit des Kultes einer derartig verlebendigten Göttin hingewiesen wurde ${ }^{411}$. Sei es, dass die archaistische Stützfigur ein Bild der Göttin meint oder als >Votiv a auf ein Heiligtum weist, die altertümliche Stütze betont jedenfalls das hohe Alter des Kultes, während die Göttin selbst bei diesen Bildern in ihrer zeitgenössischen göttlichen Präsenz und ,Wirklichkeitı dargestellt ist ${ }^{412}$.

Möglich ist sogar, dass das hier untersuchte Bildmotiv als Epiphanie der Göttin interpretiert werden kann. Das bedeutet, dass die Göttin bei diesen Darstellungen als leibhaftig und in ihrer ganzen Körperlichkeit bei ihrem eigenen Bild erscheinend dargestellt ist. Zum Vergleich können die bereits in Kapitel 7.1.1.4 betrachteten Vasenbilder mit altertümlichen Götterdarstellungen herangezogen werden $\left(A b b\right.$. 22) ${ }^{413}$. Seit der frühen Klassik mehren sich Darstellungen, auf denen die Gottheit in ihrer zeitgenössischen Gestalt neben ihrer alten Statue auftritt, was besonders ausführlich von W. Oenbrink in seiner Monographie zu Statuendarstellungen auf Vasenbildern von 1997 untersucht worden ist ${ }^{414}$. Durch den Kontext der Szenen ist auf den Vasen deutlich gemacht, dass dort die Göttin »lebendigく und >leibhaftig‘ ihr Heiligtum betreten hat. Dargestellt ist also die Epiphanie der Gottheit an ihrem Kultort. Auf einer attisch-rotfigurigen Lekythos in Athen aus der Zeit um 400 v. Chr. und einer weiteren in St. Petersburg aus dem frühen 4. Jahrhundert v. Chr. ${ }^{415}$ z. B. wird eine Kulthandlung an einem kleinen archaistischen Aphroditeidol vorgenommen. Die Göttin sitzt beide Male in snatürlicher` Größe daneben und kommuniziert auf der Lekythos in St. Petersburg mit dem ebenfalls anwesenden Eros. Sie ist also lebendig anwesend gedacht. Gleiches gilt auch für die bereits genannte Lekythos in Basel aus dem frühen 4. Jahrhundert v. Chr. (Abb. 22) $)^{416}$. Auch auf klassischen Reliefs treten Götter lebendig neben ihr Bild wie auf einem Fragment eines Marmorreliefs vom Ende des 5. oder Anfang des 4.

411 Vgl. A. H. Borbein, Kanon und Ideal. Kritische Aspekte der Hochklassik, AM 100, 1985, 260 f.; ebenso A. Leibundgut, Künstlerische Form und konservative Tendenzen nach Perikles. Ein Stilpluralismus im 5. Jahrhundert v. Chr??, TrWPr 10 (Mainz 1989) 19.

412 Zur Interpretation der Ikonographie der Götterbilder als »zeitlose, ihr Wesen charakterisierende Urbilder« vgl. Himmelmann 2003, 1-51, Zitat S. 43.

413 s. Anm. 301.

414 Oenbrink 1997, bes. 203-206. Vgl. auch de Cesare 1997, 91-106.

415 Athen, Nationalmuseum Inv. 1538: Delivorrias 1984, 14 Nr. 45 und St. Petersburg, Eremitage Inv. St. 1863a: ebenda Nr. 49.

416 s. Anm. 301. Zu weiteren Aphroditedarstellungen s. Langlotz 1954 Abb. 1. 5. 9 Taf. 1, 1. 7, 1; LIMC II (1984) 14 s. v. Aphrodite 41-53; Oenbrink 1997, 376-379 Kat. B3. B6. B7. B10. B13. B23-26 Taf. 21-23; de Cesare 1997, 91-106 Abb. 51. Beispiele für andere Götter: G. SchneiderHerrmann, Kultstatue im Tempel auf italischen Vasenbildern, BaBesch 47, 1972, 30-42 Abb. 1.6 (Apollon, Artemis); Oenbrink 1997, 346 Anm. 1726 (Athena, Apollon); de Cesare 1997, 91-106 Abb. 42-53 (Apollon, Artemis, Herakles). 
Jahrhunderts v. Chr. aus Athen (Abb. 35), auf dem Athena neben einem kleinen archaistischen Idol in einem Naikos zu sehen ist ${ }^{417}$.

Die Vasenbilder und Reliefdarstellungen fügen sich in eine Entwicklung der griechischen Göttervorstellung ein, in der seit der spätarchaischen Zeit zunehmend eine Trennung von Gottheit und Bild erkennbar wurde, wie W. Oenbrink deutlich gemacht hat ${ }^{418}$. Diese Trennung geht auch aus dem bekannten Scholion zu Aischylos' `Sieben Gegen Theben 304 hervor, das vermutlich auf ein verlore-

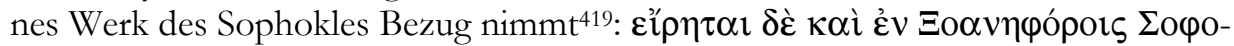

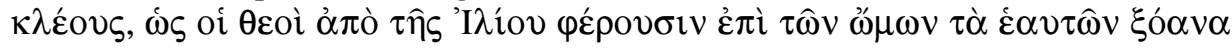

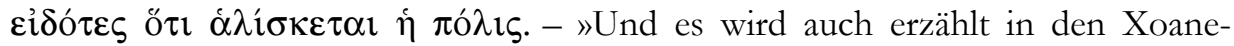
phoroi des Sophokles, wie die Götter ihre eigenen Xoana auf ihren Schultern aus Troja tragen, als sie sehen, daß die Stadt erobert wird«. (Oenbrink 1997, 346).

Aufgrund dieser Trennung von Gottheit und Bild konnte die eigentlich außerhalb der irdischen Welt weilende Gottheit neben ihrem der irdischen Sphäre angehörenden Bild erscheinen. Diese Trennung äußerte sich durch die seit spätarchaischer Zeit auftretende Kennzeichnung der Götterbilder als Statuen und ihre im Folgenden zunehmend archaistische Gestaltung in den bildlichen Darstellungen immer deutlicher. Diese Veränderung ist Teil des bereits mehrfach untersuchten Wandels der Gottesvorstellung, der auch die Wertschätzung der alten Bilder gegenüber den neuen Darstellungsformen beinhaltete, wie in Kapitel 7.2.1 gesehen wurde.

Vergleichbar dem Beisammensein von >lebendiger Gottheit und sStatue der Gottheits in einem Bild auf den Vasen kann man auch in den auf ein Idol oder eine Herme gelehnten Aphroditebildern den Besuch der ^lebendigen` Göttin in ihrem heiligen Bezirk dargestellt sehen. Die Göttin erscheint in ihrem Heiligtum neben ihrer eigenen, starren Statue. Und weil es ihrem Charakter entspricht, kann sie sich auflehnen, während sie in ihrem Heiligtum verweilt. Die altertümliche Gestaltung ihres Bildes, auf das sie sich lehnt, verweist dabei zugleich auf die Altehrwürdigkeit ihres Kultes, während die Herme anzeigt, dass es sich um ein Heiligtum der Aphrodite Urania handelt. Das Motiv der auf eine ikonische Stütze gelehnten Aphrodite zeigt zum ersten Mal ein `Bild im Bilde`420 in einer großplastischen Statue.

417 Athen, Akropolismuseum Inv. 2447. 2605. 4734: O. Walter, Beschreibung der Reliefs im Kleinen Akropolismuseum in Athen (Wien 1923) 46-47 Nr. 76; A. Comella, I Rilievi votivi greci di periodo arcaico e classico. Diffusione, ideologia, committenza (Bari 2002) Abb. 26. Die dargestellte Szene ist nicht mehr zu rekonstruieren. L. Beschi, Contributi di topografia ateniese, ASAtene 45/46, 1967/68, 531-536 Abb. 16 vermutet, dass es sich bei dem Idol um eine Darstellung des alten Bildes der Athena Nike in Athen handelt. Vgl. dazu auch Kap. 12.7.

418 Oenbrink 1997, bes. 340-360. Vgl. H. Herdejürgen, Zur Deutung tarentinischer Terrakotten, AA $1983,46$.

419 I. Rutherford, Two Heroic Prosodia. A Study of Pindar, "Paeans XIV-V”, ZPE 92, 1992, 59-72, bes. 72; Oenbrink 1997, 346 Anm. 1729.

420 Der Begriff ist übernommen von Oenbrink 1997. 


\subsubsection{Zusammenfassung}

Für Aphrodite waren in der klassischen Zeit viele neuen Typen und Darstellungsweisen erfunden worden, darunter auch die besonders körperbetonte aufgelehnte Haltung. Ihre äußere Gestaltung wurde in ihren Bildern seit der Archaik deutlich, und zwar grundlegender als bei allen anderen Gottheiten verändert. Es bestand daher die Gefahr, dass die neue Darstellungsweise der Göttin gegenüber der alten an Würde eingebüßt hatte bzw. nicht in gleichem Maße oder von allen akzeptiert wurde. Der Bildtypus der auf ihr eigenes raltes Bild gelehnten Aphrodite kann vor diesem Hintergrund gedeutet werden, denn er wird gleich zwei Ansprüchen gerecht. Einerseits entspricht er den religiösen Anforderungen, indem durch die Verbindung des neuen Bildes mit dem alten die Kontinuität des Kultes ausgedrückt und die Göttin als altehrwürdig und auch als mächtig gekennzeichnet wird $^{421}$. Das Stützidol stellt einen wichtigen Teil des Bildes dar, der unabdingbar ist für die Gesamtaussage. Es ist demnach kein untergeordnetes Element, wie es T. Brahms vorgeschlagen und gegen die Deutung als $\gg$ Kultbild angeführt hat $t^{422}$. Stattdessen lässt sich eine positive Einstellung zu alten Götterbildern feststellen, indem sich die sneuer Göttin auf die salter bezieht und durch deren Altehrwürdigkeit ihren Anspruch als machtvolle Gottheit begründet ${ }^{423}$. Andererseits entspricht dieser Bildtypus auch dem veränderten künstlerischen und religiösen Anspruch der neuen Zeit. Die in gelöster Haltung stehende, körperbetont präsentierte Aphrodite der Klassik erhält zwar durch das altertümliche Idol einen würdevolleren und feierlicheren Aspekt. Gleichzeitig wird die saktuelle Version der Aphroditedarstellung aber so präsent in das Blickfeld des Betrachters gerückt, dass auf ihr das Hauptaugenmerk liegt, sie also den Hauptinhalt darstellt. Das altertümliche Idol, das zumeist sehr klein gebildet ist und teilweise auch von dem Gewand der Göttin verdeckt wird, ist ihr zusätzlich beigegeben, um bildlich darauf hinzuweisen, dass die Göttin eben beides ist: zeitgenössisch und altehrwürdig.

Außer den archaistischen Idolen sind für Aphrodite auch Stützen in Form von Hermen, Pfeilern und Baumstämmen belegt. Neben der Tatsache, dass sich alle Bilder in die betont körperliche Darstellungsweise der Aphrodite in der 2. Hälfte des 5. Jahrhunderts v. Chr. einreihen, kann den Stützen eine besondere Bedeutung zugrunde liegen. Sie können als Hinweis auf ein bestimmtes Heiligtum bzw. eine bestimmte Kulttradition wie den Hermenkult im Heiligtum der Aphrodite Urania

421 Zur Bewahrung alter Bilder über lange Zeiträume hinweg s. den dritten Teil dieser Arbeit, Kap. 12. Vgl. auch Faulstich 1997, 176: »Zusammenfassend kann man festhalten, daß nach Möglichkeit alte Kultbilder bewahrt wurden. Bei Neuschöpfungen konnten Archaismus und Klassizismus als mögliche Ausdrucksform für hohes Alter eines Kultes oder als Implikation einer hieratisch empfundenen Epoche herangezogen werden«.

422 Brahms 1994, 184. Vgl. Kap. 7.1.1.4.

423 Vgl. Faulstich 1997, 33. 


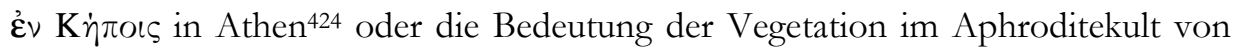
Daphni ${ }^{425}$ verstanden werden.

Zugleich können die Bilder der aufgelehnten Aphrodite auch als Epiphanie der Gottheit in ihrem Heiligtum, bei ihrer eigenen Statue oder einem das Heiligtum anzeigenden >Votiv aufgefasst werden. Und weil es dem Charakter der Göttin entspricht, sie sogar als selbst ihre Kräfte erleidend aufgefasst werden kann, wird sie in einer körperbetonten, aufgelehnten Haltung dargestellt. Die altertümliche Gestaltung der Idole verweist auch bei dieser Interpretation auf das hohe Alter und die lange Tradition des Kultes und damit zugleich auf seine Bedeutung. Vergleichbare Darstellungen finden sich auf antiken Vasenbildern und Reliefs. Sie ordnen sich in das seit spätarchaischer Zeit zunehmend deutlicher werdende Verständnis vom Wesen der Götter ein, die einerseits außerhalb der menschlichen Welt leben, zugleich aber durch ihre Bilder in der Welt der Menschen präsent und zugänglich sind ${ }^{426}$.

\subsection{Zur Bedeutung der männlichen Stützfiguren}

Beginnend in der Klassik, vor allem aber seit dem Hellenismus war Aphrodite bei zahlreichen Bildern auch auf eine männliche Figur gelehnt dargestellt worden ${ }^{427}$. Hier ist mit einer anderen Bedeutung als bei den weiblichen Stützfiguren zu rechnen.

Seit dem Hellenismus und vor allem in der Kleinkunst war besonders Priapos als Stützfigur für Aphrodite beliebt, was mit der inhaltlichen Deutung und der Funktion der Bilder zusammenhängt. Es fällt auf, dass die Göttin hier überwiegend un- oder halbbekleidet auftritt, sowie häufig in Typen, die sie im Kontext des Bades bzw. des Be- oder Entkleidens zeigen. Die größte Untergruppe bildet der Sandalenlösertypus (Kat. A57-59. A70-76), gefolgt von dem Anadyomenetypus (Kat. A55. A60-62. A77-81). Zweimal legt sich Aphrodite ein Busenband um (Kat. A68. A69), eine weitere ist im Pudica-Motiv dargestellt (Kat. A82). Der Kontext >Aphrodite beim Bader spielt also bei den Aphroditebildern mit Priapos-Stützfiguren eine große Rolle. Bei den Aphroditedarstellungen mit Idolen als Stütze war das Motiv der Göttin beim Bade bzw. beim Sandalenlösen hingegen nur einmal zu finden (Kat. A47. A48). Die anderen Motive kamen überhaupt nicht vor.

Der erotische Aspekt spielt also bei diesen Bildern eine große Rolle, indem er durch den Typus, in dem die aufgelehnte Göttin dargestellt ist, deutlich wird. Der Betrachter darf sich als sheimlicher Beobachter` der Göttin bei einer privaten Handlung fühlen und seine Phantasie schweifen lassen. Diese Typen gehen sehr spielerisch mit den weiblichen Reizen um. Der Priapos als Stütze wirkt dabei zusätzlich erotisierend, indem er, als der ithyphallische Gott schlechthin, ganz kon-

424 Paus. 1, 19, 2. Vgl. S. 72.

425 Delivorrias 1968.

426 Vgl. S. 140.

427 s. Kap. 4. 
kret auf den körperlichen Aspekt der Liebe, die durch Aphrodite verkörpert wird, hinweist. Er ist zumeist unbekleidet. Wenn er bekleidet ist, hebt er sein Gewand, um sein Geschlecht zu entblößen. Seine Sexualität wird also ganz demonstrativ gezeigt. Die Priapos-Stützfigur spielt also ganz stark auf die erotisch-körperliche Macht der Göttin an ${ }^{428}$.

Eine ähnliche Intention steht offenbar hinter den Aphroditedarstellungen mit Hermaphrodit als Stütze (Kat. A89-92). Auch hier gehören die Beispiele ausschließlich der Kleinkunst an. Der Hermaphrodit steht in der gleichen Weise da wie die Priapos-Ganzkörperfiguren. Er lehnt den Oberkörper zurück, schiebt das Becken vor und hebt sein Gewand. Er ist ithyphallisch. Der Hermaphrodit als Zwitterwesen, das beide Seiten der körperlichen Liebe kennt, war im Hellenismus eine besonders beliebte Figur, um mit erotischen Vorstellungen zu spielen. Man vergleiche etwa die aufreizende Gestalt des schlafenden Hermaphroditen ${ }^{429}$ oder die Satyr- und Hermaphrodit-Gruppen ${ }^{430}$. Hier wird durch den Überraschungseffekt, dass es sich um ein Zwitterwesen handelt, der Betrachter bekannterweise zusätzlich dazu angeregt, über einen möglichen Erfolg oder Misserfolg des Satyrs nachzudenken. Der Hermaphrodit als Stützfigur zeigt also, wie der Priapos, die Wirkung und die Kraft der Aphrodite im Bereich der Erotik und körperlichen Liebe an. Auch Pan wird Aphrodite als Stützfigur bei der Marmorstatuette Kat. A100 in der gleichen Absicht beigegeben worden sein. Pan ist wie Priapos ein triebhafter Gott. Die sexuelle Seite der Wirkungskraft der Aphrodite kommt in dieser Stützfigur demnach ebenso zum Ausdruck. Ein zweiter Aspekt ist, wie bei Priapos und Hermaphrodit, die erotische Stimulation des Betrachters.

Eros ist häufig der Begleiter der Aphrodite in der griechischen Kunst. Bekannt ist, dass beide für die zwischenmenschlichen Beziehungen im Bereich der Liebe und Erotik zuständig sind. Es ist deshalb nicht verwunderlich, dass sich die Göttin auch auf ihn lehnen kann (Kat. A93-97). Ob er dabei aber als Statue gemeint ist

428 Vgl. Zanker 1998, 74. Laut G. Cerulli Irelli, Katalog der Skulpturen, in: Pompeji. Leben und Kunst in den Vesuvstädten. Ausstellungskatalog Essen (Recklinghausen 1973) 142-144 Nr. 199 ist der Phallos bei Kat. A57 bereits in der Antike entfernt worden. Wenn das wirklich der Fall ist, so zeugt diese Tatsache davon, dass der Priapos manchmal sogar als zu sprovokant wahrgenommen worden ist. Zu einer vergleichbaren Deutung kam N. Hackländer, Der archaistische Dionysos. Eine archäologische Untersuchung zur Bedeutung archaistischer Kunst in hellenistischer und römischer Zeit (Frankfurt a. M. 1996) 115 für die Priapos- oder Hermaphroditfiguren, die auf einigen der von ihr betrachteten Reliefs neben Dionysos zu sehen sind, ohne jedoch im Stützmotiv verbunden zu sein. Ihrer Meinung nach spielt der Priapos bzw. der Hermaphrodit auf die »sexuelle Komponente« bzw. die Funktion des Dionysos als »Fruchtbarkeitsgott« an.

${ }^{429}$ Der Typus ist durch mehrere kaiserzeitliche Bilder überliefert: Bieber 1955 Abb. 623. 625; A. Stähli, Die Verweigerung der Lüste. Erotische Gruppen in der antiken Plastik (Berlin 1999) 269-275 Abb. 88-90.

430 Die einzelnen kaiserzeitlichen Statuen dieser Typen bei: Bieber 1955 Abb. 626; A. Stähli, Die Verweigerung der Lüste. Erotische Gruppen in der antiken Plastik (Berlin 1999) 15-69. 90-96 mit zahlreichen Abbildungen. 
oder als lebendiger Gott, kann bei ihm nicht mit Sicherheit gesagt werden. Das Kriterium des kleineren Maßstabs als Indiz für die Darstellung einer Statue entfällt hier. Auch das Stehen auf einer Basis, einer Säule oder einem Pfeiler ist kein sicheres Argument, da auch der lebendige Eros oft in dieser Weise gezeigt wird.

Schwieriger ist die Deutung der Dionysos-Stützfiguren (Kat. A99. A100). Gut möglich, dass hier die beiden Götter des `Lebensgenusses` verbunden wurden, um eben diese Bedeutung zu unterstreichen. Auch auf Vasenbildern wird Aphrodite seit dem 4. Jahrhundert v. Chr. in den dionysischen Bereich integriert, allerdings auf umgekehrte Weise wie bei einer Bauchlekythos in London. Dort wird ein archaistisches Idol gezeigt, das von dionysischen Figuren wie tanzenden Mänaden umgeben ist. Es wird von W. Oenbrink durch das Vorhandensein eines kleinen Eros als Aphroditebild identifiziert (Abb. 23) ${ }^{431}$.

Die männliche Stützfigur verdeutlicht also einen Aspekt des Wesens der Göttin. Die ithyphallischen Figuren des Priapos, des Pan und auch des Hermaphrodit zeigen, dass Aphrodite die Göttin der Erotik und der körperliche Liebe ist. Eros steht für die Liebe allgemein und die Liebessehnsucht, die er zusammen mit Aphrodite hervorruft. Dionysos ist ebenso wie Aphrodite Gott des Glücks und der Lebensfreude. Auffallend ist, dass nahezu alle Aphroditebilder mit männlichen Stützfiguren der Kleinkunst des Hellenismus und der Kaiserzeit angehören, wobei die zu vermutende Verwendung sicherlich eine Rolle spielt ${ }^{432}$. Aphrodite ist bei den Beispielen mit männlichen Stützfiguren zumeist un- oder halbbekleidet und oft bei Bade- oder Toilettenszenen dargestellt. Erotische Phantasien des Betrachters spielen hier also eine große Rolle. Sie werden durch die meist ithyphallischen Stützfiguren noch zusätzlich hervorgehoben. Die nicht identifizierbaren Hermen stellen vielleicht eine der genannten männlichen Gottheiten dar. Solange sie nicht näher bestimmt werden können, sind sie am ehesten allgemein als Götterstatue und Bildchiffre für einen heiligen Ort zusehen. Gleiches gilt natürlich auch für die identifizierbaren Stützfiguren. Das ganze Bildmotiv bedeutet dann, dass sich Aphrodite an einem Götterbild aufhält. Wessen Statue gemeint ist, und was diese über die Göttin aussagt, muss bei einigen Beispielen unbestimmt bleiben.

\subsection{Deutung der anderen Götterbilder und ihrer Stützfiguren}

Wie in den vorangegangenen Abschnitten gesehen wurde, dienen die ikonischen Stützen der näheren Charakterisierung der Aphrodite. Seit dem 4. Jahrhundert v. Chr. wurde die ikonische Stütze auch auf Bilder anderer Götter übertragen. Auch sonst sind diese oft von den Aphroditedarstellungen abhängig, da sie weitere

431 s. Anm. 302; weitere bei Oenbrink 1997, 377-380 Kat. B13. B15. B17. B23-B27. B34.

432 Vgl. Kap. 9. 
Merkmale der Körperhaltung und der Gewanddrapierung übernehmen. Sie gehören nahezu vollständig der Kleinkunst an, für die häufig Anleihen in der Großplastik genommen und frei umgewandelt wurden. Es stellt sich die Frage, wie weit auch inhaltliche Aussagen übernommen worden sind. Da jeweils nur wenige Exemplare nachgewiesen werden konnten, stehen die Deutungen der inhaltlichen Aussage der einzelnen Bilder auf keiner breiten Basis und sind nicht als gesichert anzusehen. Auch ist die Identifizierung der Stütze oftmals schwierig. Manchmal ist nicht einmal die darauf gelehnte Figur sicher zu identifizieren. Bei der Übernahme des Motivs ging die ursprüngliche Bedeutung verloren oder wurde umgewandelt. Möglicherweise sind die Stützfiguren auch lediglich als besonders reiche und ansprechende Stütze gewählt worden und deshalb nicht weiter mit einem Inhalt belegt, was vor allem für Darstellungen gilt, bei denen die Stützfigur als Kopistenzutat identifiziert werden kann.

Eros lehnt sich sowohl auf weibliche Idole als auch auf Hermen. Die Bilder mit dem weiblichen Idol sind wahrscheinlich von den Aphroditedarstellungen abgeleitet. Auch die Körperhaltung und die Gewanddrapierung einiger der Erosdarstellungen gleicht z. T. der der Aphrodite, besonders bei der New Yorker Hydriaattasche Kat. B1. Das Stützidol wird also am ehesten ein Bild der auch sonst eng mit Eros verbundenen Aphrodite sein. Bei Kat. B2 und B3 ist neben dem Eros mit der kleinen Stützfigur noch eine weitere weibliche Figur in gleichem Maßstab wie der Eros wiedergegeben. Diese ist am ehesten als Aphrodite anzusehen, wenn auch genaue Attribute fehlen. Die Darstellungen zeigen damit wahrscheinlich ebenfalls Aphrodite neben einem alten und vermutlich ihrem eigenen Bild, nur erweitert um Eros, der diesmal in seiner Größe an die der Göttin angeglichen ist. Für die geflügelten weiblichen Figuren, die einigen Erosdarstellungen beigegeben sind, bieten sich nur wenige Identifizierungsmöglichkeiten an. Möglich wären Nike oder Psyche. Da Eros mit beiden verbunden war ${ }^{433}$, sind beide Deutungen möglich.

Die Hermen, auf die sich Eros ebenfalls lehnt, weisen hingegen auf den Kontext des Gymnasions und der Palästra hin. Bei den bisher bekannt gewordenen Darstellungen ist die Herme immer männlich und Eros ist häufig als Palästrit gekennzeichnet. Er trägt zumeist eine Chlamys und einen Kranz oder eine Binde um das Haar, außerdem können ihm ein Aryballos, eine Strigilis oder ein Wassergefäß beigegeben sein. Bei der Herme handelt es sich also um eine der häufig belegten Hermen des griechischen Gymnasions. Sie stellt demnach Hermes oder Herakles, die beiden am engsten mit den Sportstätten verbundenen Götter dar ${ }^{434}$.

Ebenfalls von dem Motiv der aufgelehnten Aphrodite abgeleitet sind die Hermaphroditbilder mit ikonischen Stützen. Das als Stütze dienende weibliche Idol ist am ehesten als Bild der Aphrodite zu deuten. Häufiger kommt jedoch eine

433 s. Anm. 231 f.

434 s. Anm. 235. 
männliche Herme vor. Diese kann als Bild des Priapos oder Pan gedeutet, wobei die sexuelle Anspielung wie bei den Aphroditedarstellungen eine Rolle spielt.

Die Stützhermen bei Dionysos sind oft altertümlich (Kat. B47. B48. B51. B53). In Analogie zu den Aphroditedarstellungen kann diese darauf hinweisen, dass Dionysos ein altehrwürdiger Gott ist. Auch sein Körperbild hatte sich seit der Archaik stark verändert, so dass die z. T. archaistisch gestalteten Hermen auf das hohe Alter seines Kultes hinweisen können, unabhängig davon, ob sie den Gott selbst darstellen oder ein auf ein Heiligtum verweisendes altes $>$ Votiv ${ }^{435}$. Zugleich zeigen die Bilder des aufgelehnten Dionysos den Gott in seiner göttlichen >Wirklichkeit, zu der es aufgrund seines Charakters gehört, dass er sich auflehnen kann.

Andere Stützfiguren wiederum können Priapos darstellen und wie bei Aphrodite auf bestimmte Aspekte der Wirkungsmacht des Gottes hinweisen, wie seine Macht über den menschlichen Körper, die Sexualität und Fruchtbarkeit ${ }^{436}$. Aufgrund dieses sich überschneidenden Wirkungskreises zwischen Aphrodite und Dionysos kann sich der Gott auch auf Eros lehnen. Und so, wie sich Aphrodite auf Dionysos lehnen kann, kann sich der Gott auch auf Aphroditebilder lehnen. Auch wenn die weiblichen Idole keine eindeutig identifizierbaren Attribute oder Kleidungsstücke tragen, sind in ihnen am ehesten Aphroditebilder zu sehen, in Umkehrung der oben betrachteten Aphroditedarstellungen mit Dionysos als Stützfigur.

Auch bei den anderen weiblichen Götterbildern wie der sog. Artemis von Larnaka Kat. B61 können die altertümlichen Stützfiguren als Hinweis auf ein hohes Alter des Kultes der Göttin aufgefasst werden, in Analogie zu der für Aphrodite vorgeschlagenen Deutung. Der Bildhauer dieser Marmorstatuette hat sich offensichtlich an das Motiv der aufgelehnten Aphrodite angelehnt, denn auch die Körperhaltung und Gewanddrapierung der Artemis weist Analogien zu der der Aphrodite auf. Ebenso können die weiblichen Hermen, auf die sich Artemis lehnen kann, in Analogie zu den Aphroditebildern als ein Bild der auf sie gelehnten Göttin gedeutet werden, wie auch schon H. Herdejürgen in ihrem Aufsatz zu einigen Terrakottastatuetten aus Tarent von 1983 vorgeschlagen hat. Ihrer Meinung nach sei bei diesen Bildern die lebendige Gottheit neben ihrem eigenen Bild stehend wiedergegeben ${ }^{437}$. Ganz sicher ein Bild der Artemis ist auf einem spätklassischen apulisch-rotfigurigen Krater in Moskau gemeint (Kat. B76). Hier lehnt sich Iphigenie, die als Priesterin der Artemis von Tauris den Tempelschlüssel in der Hand hält, auf die Statue der Göttin. Iphigenie befindet sich bei der dargestellten Szene also in einem Heiligtum, was durch die Götterfigur und den Tempel, in dem diese steht, angezeigt wird. Gleichzeitig bezeugt sie ihre enge Verbundenheit mit der Göttin und ihr Priestertum durch das Auflehnen. Die Göttin

\footnotetext{
435 Zur Darstellung des Dionysos in Hermenform vgl. Gasparri 1986, 441 f. Nr. 161-171.

436 Im Mythos galt Priapos sogar als Sohn der Aphrodite und des Dionysos: Diod. 4, 6, 1; Paus.

9, 31, 2; s. auch DNP X (2001) 308 f. s. v. Priapos (Th. Heinze).

${ }^{437}$ H. Herdejürgen, Zur Deutung tarentinischer Terrakotten, AA 1983, 46.
} 
erscheint noch einmal lebendig neben dem Tempel, was auch sonst häufiger auf Vasenbildern vorkommt ${ }^{438}$. Auch die Idole bei den möglichen Ariadne-Darstellungen Kat. B77 und B78 können als Darstellungen der mit Ariadne verbundenen Artemis gedeutet werden. Eine solche Verbindung eines Heros mit einer ihm nahe stehenden Gottheit zeigt auch die Gemme Kat. B79. Sie stellt Perseus bei einem Bild der Athena dar. Die Hermen bei Kat. B80 und B81 können nicht identifiziert werden, bei Kat. B81 ist sogar die Deutung der aufgelehnten Figur als Arcas durch F. W. Imhoof-Blumer und P. Gardner ${ }^{439}$ nur eine Vermutung.

Bei der Kombination einer weiblichen Gottheit mit einer männlichen Stützfigur bzw. einer männlichen Gottheit mit einer weiblichen Stützfigur kann die Stütze nicht das Bild der auf sie gelehnten Gottheit darstellen. Sie kann allgemein auf den Kontext eines Heiligtums verweisen, so dass das Motiv insgesamt bedeutet, dass sich eine Gottheit in einem Heiligtum aufhält. Sie kann auch ein Bild einer Gottheit meinen, die der aufgelehnten Göttin bzw. dem Gott nahe steht. Bei Apollon könnte dies z. B. eine Muse oder auch Artemis $\operatorname{sein}^{440}$. Da die Stützfiguren aber nur sehr selten identifizierbar sind bleibt dies nur eine Möglichkeit der Interpretation. Es wäre aber auch möglich, dass eine spezifische Bedeutung der Stützfigur gar nicht immer intendiert war.

Die männlichen Hermen weisen hingegen oft auf den Kontext des Gymnasions und der Palästra hin. Sie kommen außer bei Eros (Kat. B8-B33) vor allem bei Hermes (Kat. B69-72) und Herakles (Kat. B73. B74) vor, also bei Göttern, die mit den Sportstätten in Verbindung stehen. Weitere Attribute, die die aufgelehnten Figuren mit sich führen wie eine Strigilis oder ein Kranz bestätigen diese Annahme. Hermen, die nicht durch die auf sie gelehnte Figur in den Palästrakontext gesetzt werden können, können als Abbilder von Wege- und Platzhermen angesehen ${ }^{441}$ werden, wie z. B. die Stütze des Hermes mit dem Dionysoskind Kat. B69, auf die sich der Gott auf dem Weg zu den Nymphen von Nysa ausruhend auflehnt. Die Stützhermen sind also allgemein >Ortstopoi<, deren spezielle Bedeutung erst im Zusammenhang mit der auf sie gelehnten Figur oder dem dargestellten Kontext bei umfangreicheren Szenen ermittelt werden kann. Ebenso ist es möglich, in den Hermen, wie es bereits für Aphrodite beschrieben wurde, ein Abbild der Figur zu sehen, die sich auf sie lehnt. Eine Gottheit oder eine mythologische Figur besucht also lebendig ihr bzw. ein Göttermal.

\footnotetext{
438 s. Kap. 7.1.1.4 und 7.2.2.

${ }^{439}$ Imhoof-Blumer - Gardner, 1964, 94 f.

440 Dies vermutet O. Palagia für die Münze SNG von Aulock Nr. 7361: s. LIMC II (1984) 211 s. v. Apollon 214. Gleiches gilt natürlich auch für Götter - auch für Aphrodite - mit gleichgeschlechtlichen Stützfiguren, auch wenn dafür keine gesicherten Anhaltspunkte vorliegen und dies in Kap. 7.1.1 deshalb für wenig wahrscheinlich erklärt wurde.

${ }^{441}$ Vgl. Wrede 1985; Rückert 1998.
} 
Oftmals ist eine genaue Deutung des jeweiligen Bildes nicht mehr möglich, da der jeweilige Kontext, in dem es einst eingebunden war, nicht mehr rekonstruiert werden kann. Wie schwierig eine solche Untersuchung ist, sei am Beispiel des sog. Lanckoronski-Reliefs Kat. B64 kurz erläutert. Es befindet sich heute in Richmond in den USA und gehörte zuvor der Sammlung Lanckoronski in Wien an. Das Relief ist eine neuattische Arbeit des 1. Jahrhunderts v. Chr. und zeigt Athena neben einer Herme stehend, auf deren Kopf sie ihren rechten Arm gelegt hat. Die Herme soll nach der Meinung der Forschung den Hermes Propylaios des Alkamenes zitieren und das Relief Athena am Eingang der Akropolis stehend wiedergeben $^{442}$. Aus der Darstellung geht jedoch nicht hervor, ob mit der Athena speziell die athenische Göttin gemeint ist. Die Diskussion um das Aussehen des Hermes Propylaios ist zwar nach wie vor nicht abgeschlossen ${ }^{443}$. Die Hermen aber, die laut der Forschung als Kopien oder Nachbildungen des Hermes Propylaios in Frage kommen - es sind dies die von D. Willers in seiner Untersuchung zum Hermes Propylaios von 1967 als Typus Ephesos und Typus Pergamon bezeichneten Hermentypen $\left(A b b\right.$. 36) ${ }^{444}$ - weisen kaum Gemeinsamkeiten mit der Herme auf dem Relief auf. Sie haben im Gegensatz zu der Herme auf dem Relief Buckel- oder Korkenzieherlocken, außerdem fallen ihnen lange Haarsträhnen auf die Schultern und die Barthaare sind zu wesentlich dickeren Strähnen eingedreht, Merkmale, die die Herme auf dem Relief nicht teilt. Die Herme auf dem Lanckoronski-Relief kann demnach kaum auf dasselbe Vorbild zurückgehen. Die Deutung der Darstellung als Athena am Eingang ihres Heiligtums auf der Athener Akropolis bleibt deshalb nur eine unsichere Vermutung.

Da die Stützfiguren nicht immer sicher zu identifizieren sind, bleibt die genaue Bedeutung und ihre Beziehung zu der aufgelehnten Figur oft unklar. Allgemein kann das Motiv so aufgefasst werden, dass sich eine Gottheit oder mythologische Figur bei einem Götterbild aufhält, wobei oftmals die Frage offen bleiben muss, ob es sich um eine bestimmte Statue und vielleicht sogar um ihre eigene handelt.

442 Harrison 1965, 135; B. Sismondo Ridgway, The Severe Style in Greek Sculpture (Princeton 1970) 110f. H. Schrader, Athena mit dem Käuzchen. Ein griechisches Votivrelief in der Sammlung des Grafen Lanckoronski, ÖJh 16, 1913, 1 f. hingegen sah in der Herme die Darstellung eines Vorgängers des Werkes des Alkamenes, das an gleicher Stelle als Hermes Propylaios gedient habe. Er datiert das Relief im Gegensatz zu den zuvor genannten Autoren, die es als neuattische Arbeit werten, in die 1. Hälfte des 5. Jahrhunderts.

443 s. Harrison 1965, 122-124; D. Willers, Zum Hermes Propylaios des Alkamenes, JdI 82, 1967, 37-109 mit Abb.; L. Capuis, Alkamenes. Fonti storiche e archeologiche (Florenz 1968) 29. 35-58; Zagdoun 1989, 151 f.; M. Giercke, Herme des Hermes Propylaios, in: Stemmer 1995, 187-189; J. E. Francis, Re-writing Attributions: Alkamenes and the Hermes Propylaios, in: K. J. Hartswick M. C. Sturgeon, $\Sigma T E \Phi A N O \Sigma$. Studies in Honour of Brunhilde Sismondo Ridgway (Philadelphia 1998) 61-68.

${ }^{444}$ Eine der Repliken: Rom, Kapitolinische Museen Inv. 397: D. Willers, Zum Hermes Propylaios des Alkamenes, JdI 82, 1967, 37-109 Abb. 6. 8. 10. 11; die anderen: ebenda und Anm. 443. 


\section{Sterbliche mit ikonischen Stützen}

\subsection{Männer und Jünglinge}

Bisher wurden Bilder von Göttern betrachtet, die sie auf ikonische Stützen gelehnt zeigen. Doch nicht nur Götter, auch Heroen und mythologische Figuren lehnen sich manchmal an Götterbilder an. Deshalb scheint es sinnvoll zu prüfen, ob auch Menschen in diesem Schema Haltung dargestellt worden sind, was von der Forschung mehrfach bezweifelt wurde ${ }^{445}$. Sicher als Menschen zu identifizieren sind die Bilder auf Grabreliefs sowie vermutlich auch einige Terrakottastatuetten, die Figuren im Kontext der Palästra zeigen, die sich auf Hermen lehnen ${ }^{446}$.

Besonders zahlreich sind Darstellungen von Sterblichen, die sich auf Götterbilder lehnen auf hellenistischen und kaiserzeitlichen Grabreliefs überliefert (Kat. B82-114). Bei allen ist die Stütze in Form einer Herme gebildet. Es sind immer Jünglinge, junge Männer oder deren Sklaven, selten auch ältere Männer, die eine Herme als Stütze benutzen, sich an sie anlehnen oder neben ihnen stehen. Die Hermen sind immer männlich. Sie sind oft jugendlich-unbärtig, andere sind bärtig und durch das Löwenfell als Herakles gekennzeichnet. Außerdem enthalten einige der Bilder zusätzliche Attribute wie Palmwedel, Aryballoi und andere im Gymnasion und der Palästra verwendete Gegenstände wie Buchrollen oder Schreibtafeln. Die Grabinhaber werden also als Palästriten gekennzeichnet. Die Hermen stellen demzufolge Palästra-Hermen, also Herakles oder Hermes, dar ${ }^{447}$. An die

445 z. B. Brahms 1994, 183-190; O. Palagia - N. Herz, Investigation of Marbles at Delphi, Asmosia 5, 2002, 246-247; G. I. Despinis, Iphigeneia und Orestes. Vorschläge zur Interpretation zweier Skulpturenfunde aus Brauron, AM 120, 2005, 241-267. Zu den Ansichten von T. Brahms s. Kap. 7.1.1.4. Zu den andern s. die folgenden Kapitel.

446 Ein wichtiges Argument für die Frage, ob sich Sterbliche auf Götterbilder auflehnen können ist auch der oben bereits angeführte apulische Krater in Moskau, der Iphigenie das `Kultbild der Artemis von Tauris gelehnt zeigt, die zwar eine mythologische Figur, zugleich aber auch eine Sterbliche ist (Kat. B76), s. S. 106. 117.

447 Zu Hermen in der Palästra vgl. Wrede 1985, 34-36. 
Grabreliefs schließt sich eine kaiserzeitliche Grabstatue aus Alexandria an (Kat. B140). Sie zeigt einen stehenden, vollständig in einen Mantel gehüllten Mann und zu seiner Rechten eine kleine Herme.

Bei zahlreichen hellenistischen Terrakottastatuetten, die Knaben oder Jünglinge abbilden - eine Identifizierung als ungeflügelter, kindlicher oder jugendlicher Eros ist dabei ebenso möglich - sind die Hermenstützen ebenfalls als PalästraHermen identifizierbar (Kat. B115-125. B130-B136). Einige der angelehnten Figuren halten zusätzlich einen Palmwedel oder eine Strigilis in der Hand. Außer diesen kleinformatigen Darstellungen gibt es einige großplastische, die im Folgenden betrachtet werden sollen.

\subsection{Sisyphos II. aus der Daochos-Weihung in Delphi}

Auch bei großplastischen Athletendarstellungen kommen Palästra-Hermen als Stützen vor. Das früheste Beispiel ist der Sisyphos II. aus der Statuengruppe des Daochos in Delphi Kat. B126. Die von einem Thessaler namens Daochos errichtete, schon häufig untersuchte Gruppe besteht aus acht großplastischen, mehr oder weniger vollständig erhaltenen Marmorstatuen. Sie können durch die beigegebenen Inschriften als Vorfahren und Familienmitglieder des Daochos identifiziert werden ${ }^{48}$. Die Datierung der Statuengruppe und damit verbunden die Identifizierung der einzelnen Familienmitglieder ist umstritten und reicht von ca. 330 bis 270 v. Chr. ${ }^{449}$. Das bekannteste Mitglied der Familie aus Pharsalos war ein Freund

448 Th. Homolle, Ex-voto trouvés à Delphes 3. Statues du Thessalien Daochos et de sa famille, BCH 21, 1897, 585-598; E. Will, A propos de la base des Thessaliens a Delphes, BCH 62, 1938, 289-304; Dorn 1968; P. Moreno, Lisippo I (Bari 1974) 65-70; D. Willers, Rez. zu Dorn 1968, Gnomon 47, 1975, 490-506; St. Lattimore, The Chlamys of Daochos I., AJA 79, 1975, 87 f. D. Willers, Rez. zu P. Moreno, Lisippo I (Bari 1974), BJb 179, 1979, 761-765; B. Hintzen-Bohlen, Die Familiengruppe - Ein Mittel zur Selbstdarstellung hellenistischer Herrscher, JdI 105, 1990, 129-154; Borbein 1995; Chr. Löhr, Agias vom Daochos-Weihgeschenk in Delphi, in: Stemmer 1995, 201-203; Geominy 1998; W. Geominy, The Daochos Monument at Delphi. The Style and Setting of a Family Portrait in Historic Dress, in: Schultz - von den Hoff 2007, 84-98.

${ }^{449}$ Die frühere Datierung vertreten Th. Homolle, Ex-voto trouvés à Delphes 3. Statues du Thessalien Daochos et de sa famille, BCH 21, 1897, 595; Dorn 1968, 50; P. Moreno, Lisippo I (Bari 1974) 65-70; B. Hintzen-Bohlen, Die Familiengruppe - Ein Mittel zur Selbstdarstellung hellenistischer Herrscher, JdI 105, 1990, 137; Chr. Löhr, Agias vom Daochos-Weihgeschenk in Delphi, in: Stemmer 1995, 201-203.

Die spätere Datierung befürworten Geominy 1998; H. von Steuben, Zur Komposition des Daochos-Monumentes, in: ders. (Hrsg.), Antike Portraits. Zum Gedächtnis von Helga von Heintze (Möhnesee 1999) 35-38. W. Geominy, The Daochos Monument at Delphi. The Style and Setting of a Family Portrait in Historic Dress, in: Schultz - von den Hoff 2007, 84-98. In das frühe 3. Jahrhundert v. Chr. wurde die Statuengruppe datiert von H. K. Süsserott, Griechische Plastik des 4. Jahrhunderts vor Christus (Frankfurt a. M. 1938) 167 Anm. 140 und L. Alscher, Griechische Plastik III. Nachklassik und Vorhellenismus (Berlin 1956) 161; L. Alscher, Griechische Plastik IV. Hellenismus (Berlin 1957) 187 f. Anm. 47a; D. Willers, Rez. zu P. Moreno, Lisippo I (Bari 1974), 
Philipps II. von Makedonien und wirkte zwischen 336 und 332 v. Chr. als Vertreter des thessalischen Koinons in der Amphiktyonie von Delphi ${ }^{450}$. Von den Vertretern der Frühdatierung des Werkes wird er mit dem Stifter der Statuengruppe identifiziert, von den Vertretern der Spätdatierung als Großvater des Stifters.

Einig ist sich die Forschung darin, in den Statuen ein Objekt politischer Repräsentation zu sehen. Der Stifter brachte mit der Statuengruppe den Besuchern des Heiligtums die Leistungen seiner Familie vor Augen. Drei seiner Vorfahren werden durch die Inschriften als erfolgreiche und gute Herrscher bezeichnet. Sie tragen eine Chlamys und Schuhe. Auch der Stifter selbst nennt seine Ämter in der Stifterinschrift. Er stellt sich somit in diese Tradition. Er trug wahrscheinlich dieselbe Kleidung, seine beschuhten Füße sind noch erhalten. Drei weitere seiner Ahnen sind hingegen unbekleidet dargestellt. Von ihnen berichten die Epigramme, dass sie besonders erfolgreiche Athleten gewesen sind und mehrfach Siege bei den großen panhellenischen Spielen errungen haben. Es besteht demnach eine Übereinstimmung in der Charakterisierung der Personen in den Bildern und in den Epigrammen. Die Einzelleistungen der Familienmitglieder stellen zusammengenommen die Leistungen und Tugenden von Herrschern dar, die gleichfalls auf den Stifter der Gruppe als »ihren Erben « zu übertragen seien, um seine Herrschaft zu legitimieren ${ }^{451}$.

Der Sohn des Stifters, Sisyphos II. ist im Gegensatz zu seinen Vorfahren noch jung und konnte noch keine Erfolge aufweisen. Deshalb wird er in der Inschrift nur als Sohn des Daochos II. bezeichnet, während die Epigramme seiner Vorfahren ausführlicher von ihren Taten berichten. Seine Jugend wird auch durch die geringere Größe seiner Statue im Gegensatz zu denen seiner Vorfahren zum Ausdruck gebracht ${ }^{452}$. Er ist im richtigen Alter für die Ausbildung in der Palästra. Deshalb wird er ebenfalls als unbekleideter Athlet gezeigt und daher auf eine Herme gelehnt dargestellt. Durch die >Palästra-Herme` wird er als vorbildlicher junger Mann vorgeführt, der eine gute Ausbildung genießt, um sich später der Nachfolge seines Vaters würdig zu erweisen ${ }^{453}$. In ihm einen Gott zu sehen, weil er sich auf

BJb 179, 1979, 763; St. Lattimore, The Chlamys of Daochos I., AJA 79, 1975, 87 f. D. Willers hatte zunächst selbst die These von der Frühdatierung vertreten, s. D. Willers, Zum Hermes Propylaios des Alkamenes, JdI 82, 1967, 83; D. Willers, Rez. zu Dorn 1968, Gnomon 47, 1975, 404-497. 450 DNP III (1997/1999) 310 s. v. Daochos (M. Meier - M. Strothmann); Geominy 1998, 369 f.

${ }^{451}$ Geominy 1998, 392. Durch die spätere Datierung verändere sich, wie W. Geominy selbst erwähnt, die allgemeine Aussage des Monuments nicht wesentlich, das Monument wäre jedoch anders legitimiert. Anstatt in einer Zeit, in der die Familie des Daochos in ihrer Macht gefestigt sei, wäre die Statuengruppe in einer Zeit politischer Unruhe entstanden, in einem Moment, in der die Daochiden ihre Macht über Thessalien kurzfristig wieder erneuert hätten, was laut Geominy 1998, 392 ein passenderer Anlass für die Dedikation wäre.

452 Nach dem Maßangaben von Dorn 1968, 33-53 misst die Statue des Sisyphos II. 1,85 m, für die anderen rekonstruiert er eine Höhe von 1,95-2,10 m. Laut Geominy 1998, 381 ist auch die Statue des Agelaos als jüngstem der drei Athletenbrüder kleiner. Dazu passt, dass dieser in seiner Inschrift als Knabensieger bezeichnet wird und somit ebenfalls als noch heranwachsend gedacht ist. 453 Vgl. A. H. Borbein, Rez. zu Fehr 1979, Gnomon 58, 1986, 728: »Offenbar noch zu jung für 
eine Götterherme auflehnt, wie es O. Palagia vorschlägt ${ }^{454}$, ist nicht notwendig, da die Grabreliefs und wahrscheinlich auch viele der Terrakottastatuetten Sterbliche in dieser Haltung zeigen, und sich demnach auch Sterbliche in ihren Darstellungen auf Götterhermen lehnen können.

Weitere ephebenhafte Jünglings- und Athletenstatuen mit Palästra-Hermen als Stützen lassen sich typologisch an diese Statue anschließen (Kat. B127-129. B137-B139). Die späthellenistische Tuff-Statuette aus Pompeji Kat. B138 zeigt einen Gladiator in weitem Ausfallschritt mit gezücktem Schwert, der sich mit seinem schildbewehrten Arm auf eine Priaposfigur stützt. Eine kaiserzeitliche Jünglingsstatue aus Marmor, die sich heute in Neapel befindet (Kat. B137), trägt die Schlagriemen der Faustkämpfer. Bei den übrigen, ebenfalls kaiserzeitlichen Marmorstatuen ist die Identifizierung des Dargestellten als Mensch nicht gesichert ist. Hinweisende Attribute haben sich nicht erhalten. Es kann sich auch um Darstellungen jugendlicher Götter wie Hermes handeln. Die Hermen sind durch ein Löwenfell oftmals als Herakleshermen gekennzeichnet, so dass die Einordnung des Gesamtbildes in den Palästrakontext erleichtert wird.

Bei einigen der kaiserzeitlichen Athletendarstellungen lehnen sich diese direkt auf die Hermen auf (Kat. B126. B127. B128. B137), bei andern sind die Hermen nur als technische, aber doch sprechende Stützen neben ihren Beinen beigefügt (Kat. B129. B138. B139). Letztere haben dieselbe Bedeutung wie die Stützen, auf die sich die Figuren auflehnen. Bei den aufgelehnten Figuren ist der Bezug zum Palästrakontext durch das Auflehnen lediglich deutlicher zum Ausdruck gebracht. Der Athlet kann aber auch als in der Palästra anwesend und neben einer dort errichteten Herme stehend gedacht sein.

\subsection{Drei nicht identifizierte Statuen}

Ein weibliches Idol kommt als Stütze für einen Jüngling nur ein einziges Mal vor (Kat. B141). Es ist eine bekannte Marmorstatue aus der 2. Hälfte des 4. Jahrhunderts v. Chr. Sie zeigt einen stehenden Jüngling in einem Chitoniskos und einer Chlamys. Er hat den linken Ellenbogen auf den Kopf eines archaistischen weiblichen Idols gelegt. Der Kopf, beide Unterarme und Teile der Beine der Jünglingsfigur sind verloren. Die Statue stammt aus dem Heiligtum der Artemis in Brauron. Aus diesem Grund wird das archaistische Idol von L. Kahil in ihrem Artikel >Artemis`

eigene Taten, veranschaulicht Sisyphos vor allem die Kontinuität der Dynastie«.

454 O. Palagia - N. Herz, Investigation of Marbles at Delphi, Asmosia 5, 2002, 246-247. W. Geominy, The Daochos Monument at Delphi. The Style and Setting of a Family Portrait in Historic Dress, in: Schultz - von den Hoff 2007, 94 f. hingegen deutet die Figur aufgrund der Herme hingegen als Darstellung eines heroisierten Verstorbenen. Dies ist $\mathrm{m}$ E. nicht zwingend notwendig, da das Vorhandensein der Herme bereits durch die Charakterisierung als Palästrit begründet ist. 
im LIMC von 1984 als Artemisbild identifiziert ${ }^{455}$. Was dieses Bildmotiv ausdrücken soll, ist unklar. Sollte es möglich gewesen sein, dass sich ein Verehrer einer Gottheit so hätte darstellen lassen ${ }^{456}$, wären mehrere solcher Bilder zu erwarten. Bis jetzt ist es aber das einzige seiner Art. G. I. Despinis hat die Interpretation als Sterblicher, der sich auf ein Bild einer Göttin lehnt abgelehnt, da es zwar zahlreiche Bilder gäbe, bei denen Menschen auf Palästra-Hermen lehnen, nicht jedoch auf Statuen von Göttinnen. Er schlägt vor, in der Jünglingsfigur einen Heros zu sehen. Seine Kleidung weise auf Reisende wie Hermes oder Apollon hin. Da Hermes keine Verbindung nach Brauron habe und Apollon im 4. Jahrhundert in Attika nicht in dieser Gewandung dargestellt worden sei, vermutet er, dass es sich bei der Figur um einen mit Artemis und Brauron in Verbindung stehenden Heros handelt, für den Reisekleidung typisch sei. Am ehesten sei deshalb Orestes gemeint, der u. a. in das Land der Taurer reiste und von dort ein wundertätiges Bild der Göttin mitbrachte ${ }^{457}$. Der bereits genannte apulische Krater in Moskau (Kat. B76)458 mit der Darstellung der auf das >Kultbild der Artemis gelehnten OrestesSchwester Iphigenie, die ebenso kein Göttin, sondern eine Sterbliche war - wenn auch eine Heroine mit einem besonderen Verhältnis zu dieser Göttin - beweist jedoch, dass sich auch Sterbliche auf Statuen von Göttinnen und nicht nur auf Palästra-Hermen auflehnen können. Die Deutung der Statue aus Brauron muss deshalb weiterhin offen bleiben.

Eine weitere ungewöhnliche Statue stammt aus dem Sarapieion im ägyptischen Memphis (Kat. B142). Sie gehört zu einer Statuengruppe griechischer Geistesgrößen, deren heute bekannte Aufstellung sekundär und vermutlich erst aus spätantiker Zeit ist ${ }^{459}$. Stilistisch gehören die Bilder allerdings zusammen, so dass eine ursprünglich gemeinsame Aufstellung durchaus wahrscheinlich ist ${ }^{460}$. Die bekannte Statue besteht aus Kalkstein und zeigt einen stehenden, vollständig mit einem Mantel bekleideten Mann, der sich auf eine links von ihm stehende bärtige Herme lehnt. Diese besteht aus einem Hermenschaft mit Armbossen und einem bärtigen Kopf. Sie trägt einen mit Blüten verzierten Kalathos, die Haare sind zu rafrikanischen Röhrenlocken gedreht, die in zwei Stufen übereinander angelegt sind. U.

455 Kahil 1984, 635 Nr. 118.

456 So z. B. Chr. Vorster, Römische Skulpturen des späten Hellenismus und der Kaiserzeit I. Werke nach Vorlagen und Bildformeln des 5. und 4. Jahrhunderts v. Chr. MAR 22 (Mainz 1993) 83; D. Bonanome, Il rilievo da Mondragone nel Museo Nazionale di Napoli (Neapel 1995) 106.

457 G. I. Despinis, Iphigeneia und Orestes. Vorschläge zur Interpretation zweier Skulpturenfunde aus Brauron, AM 120, 2005, 241-267 mit Hinweisen auf weitere Deutungsvorschläge. Vgl. auch Kap. 12.10 .

458 s. S. 106. 117.

${ }^{459}$ Die Statuen waren in zum Teil bereits fragmentiertem Zustand auf einer Lehmziegelmauer aufgestellt und durch Kalksteinblöcke gesichert worden, s. Bergmann 2007, 249.

${ }^{460}$ Lauer - Picard 1955, 148-172; F. Matz, Rez. zu Lauer - Picard 1955, Gnomon 29, 1957, 88; Bergmann 2007, 256-258. 
Wilcken ${ }^{461}$ und ihm folgend Chr. Picard ${ }^{462}$ haben in ihren Untersuchungen zu den Statuen aus Memphis von 1917 und 1955 die Herme als Bild des Sarapis gedeutet und darüber die auf sie gelehnte männliche Figur als Demetrios von Phaleron identifiziert, der eine besondere Beziehung zu diesem Gott gehabt habe ${ }^{463}$.

Diese Deutung ist inzwischen widerlegt. Die Statue stand zwar zusammen mit Statuen griechischer Dichter und Philosophen - wie aus den Attributen der Dargestellten (Kithara, Diptychon, Zeichenstab der Wissenschaftler) hervorgeht in einer Exedra, doch bedeutet dies nicht automatisch, dass alle Statuen Dichter und Denker darstellen müssen. F. Matz ${ }^{464}$, W. Hornbostel ${ }^{465}$ und in jüngster Zeit M. Bergmann 466 haben bei genauerer Prüfung 1957, 1973 bzw. 2007 übereinstimmend festgestellt, dass die Herme von allen anderen Sarapisdarstellungen abweicht, besonders was die Frisur, die Barttracht und den Kalathos als Kopfbedeckung betrifft. Sie kann demnach nicht Sarapis darstellen. Das Argument für die Deutung des Mannes als Demetrios von Phaleron ist damit hinfällig. Auch aufgrund der neuen Datierung der gesamten Anlage aus stilistischen Gründen in die 2. Hälfte des 3. bzw. die 1. Hälfte des zweiten Jahrhunderts v. Chr. ${ }^{467}$ - Chr. Picard datierte die Exedra aufgrund des Vorhandenseins der Statue des Demetrios von Phaleron in das frühe 3. Jahrhundert v. Chr. ${ }^{468}$ - ist die Identifizierung als Demetrios von Phaleron ausgeschlossen. Dieser war nach dem Tod von Ptolemaios I. in Ungnade gefallen, weshalb eine Aufstellung seines Porträts in späterer Zeit unwahrscheinlich ist ${ }^{469}$. Die Herme jedenfalls stellt einen unbekann-

461 U. Wilcken, Die griechischen Denkmäler vom Dromos des Serapeums in Memphis, JdI 32, 1917, 149-203 bes. $164 \mathrm{f}$.

462 Lauer - Picard 1955, 69-89.

463 Vgl. dazu Diog. Laert. 5, 76.

464 F. Matz, Rez. zu Lauer - Picard 1955, Gnomon 29, 1957, 84-93.

465 Hornbostel 1973, 408-417.

466 Bergmann 2007.

467 Die spätere Datierung wurde vorgeschlagen von F. Matz, Rez. zu Lauer - Picard 1955, Gnomon 29, 1957, 90-93 und Hornbostel 1973, 414. 416; die frühere von Bergmann 2007.

468 Lauer - Picard 1955, 82.

469 Auch ist der Kopf, den Lauer - Picard 1955, 83 mit Abb. 40 dieser Statue zugewiesene haben, nicht sicher zugehörig, da es keine anpassenden Bruchflächen gibt. In der dortigen Rekonstruktion erscheint er sogar etwas zu groß für den Körper zu sein. Bergmann 2007 hat in ihrer Untersuchung der erhaltenen Statuen zudem festgestellt, dass es sich bei den erhaltenen Stücken ausschließlich um Kalksteinfiguren handelt. Dieses Material ist nicht oder nur sehr schwer wieder verwendbar, weshalb die Statuen erhalten geblieben sind, während die übrige zu vermutende Ausstattung des Heiligtums der Wiederverwendung zum Opfer fiel. Die erhaltenen Werke hat man schließlich in der Spätantike zusammengestellt. Das unterschiedliche Format der einzelnen Werke spricht ebenfalls für diese These. Der Kopf kann deshalb auch von einer anderen Statue stammen. Die Identifizierung der Statue mit Hilfe der >Dichterbinde`, wie Lauer - Picard 1955, 78 den Kopfschmuck deuten, steht somit auf keiner gesicherten Grundlage. Auch scheint es sich dabei weder um eine Dichterbinde noch um ein Königsdiadem, wie F. Matz, Rez. zu Lauer - Picard 1955, Gnomon 29, 1957, 87. 92 den Befund interpretiert hat, zu handeln, sondern um ein in Bosse stehen gelassenes, mehrfach geteiltes Band, wie mir M. Bergmann freundlicherweise mitgeteilt hat. 
ten Gott oder eine Personifikation dar, möglicherweise im Sinne einer Ortsangabe eine Lokalgottheit oder Ortspersonifikation.

Unsicher ist auch die Deutung der eklektischen >Gruppe von San Ildefonsor Kat. B143, die sich heute im Museum des Prado in Madrid befindet. Sie ist im 1. Jahrhunderts v. Chr. entstanden. Sie zeigt zwei stehende unbekleidete bekränzte Jünglinge, deren Körperbilder sich an klassisch-griechische Typen anlehnen und bei denen das Antinoosportrait der linken Figur nachträglich hinzugefügt worden ist. Die linke Figur entzündet mit einer Fackel einen zwischen den Jünglingen stehenden, mit Bukranien und Girlanden geschmückten Altar, während sich die rechte Figur mit ihrem linken Arm auf ihren Gefährten stützt. Zur Linken der Gruppe steht ein archaistisches Idol mit einem Polos auf dem Kopf auf einer rechteckigen profilierten Basis. Der linke Jüngling lehnt sich mit seinem linken Bein an das Idol an.

Die Gruppe hat bisher ganz unterschiedliche Deutungen erfahren, da keine eindeutigen ikonographischen Hinweise zu ihrer Identifizierung vorliegen. Vorgeschlagen wurden u. a. die Dioskuren, Apollon und Hyakinthos, Orest und Pylades, Endymion und Hypnos, Hypnos und Thanatos oder auch Narkissos und Thanatos. Auch als Laren oder Genien oder Priester wurden die Jünglinge gedeutet. Bei dem altertümlichen Idol dachte man sowohl an Persephone als auch an Artemis, Nemesis oder Hekate ${ }^{470}$. Keine der bisher vorgeschlagenen Deutungen kann als gesichert gelten, die erst vor kurzem durch St. F. Schröder wiederholte Interpretation als Orest und Pylades, die nach der erfolgreichen Rückkehr von Tauris dem mitgebrachten Bild der Artemis opfern, erscheint allerdings durchaus denkbar ${ }^{471}$.

\subsection{Frauen und Mädchen}

Neben den Aphroditedarstellungen, bei denen sich die Göttin auf eine ikonische Stütze lehnt, gibt es auch viele Frauenfiguren unter den hellenistischen Terrakottastatuetten mit einem weiblichen Idol oder einer Hermen als Stütze. Ihre Deutung ist jedoch schwierig. Zahlreiche der häufig als >Tanagräerinnen bezeichneten Figuren besitzen keine oder keine eindeutigen Attribute, die sie genauer charakterisieren. Es handelt sich um zumeist mit Chiton und Mantel bekleidete Figuren, die oft Kränze, Tympana oder Masken, aber auch weniger spezifische Attribute wie Bälle oder Fächer, häufig jedoch auch gar keine Attribute tragen ${ }^{472}$. Sie wurden zumeist

470 Zu den verschiedenen Deutungen der Gruppe s. Schröder 1993, 214-216 Nr. 57; Schröder 2004, 371-379 Nr. 181.

471 s. Anm. 470.

472 Nur einige der zahlreichen hellenistischen Terrakottastatuetten sind durch typische Götterattribute zu identifizieren. Bekanntermaßen ist jedoch auch die Übernahme von Attributen in die menschliche Sphäre möglich. Musikinstrumente z. B. können laut Zimmer 1994, 25 auf den Stellenwert hinweisen, den Bildung im Hellenismus erlangt hatte, und sind deshalb nicht unbedingt als Attribute von Musen oder bestimmten Berufsgruppen zu deuten. Die ebenfalls häufig vorkommenden Efeukränze und Tympana gehören laut Graepler 1997, bes. 205-212 zum dionysischen Kreis und 
wenig differenzierend als `Ladies`, ımortak oder >draped woman oder einfach als >Frauen und Mädchen bezeichnet ${ }^{473}$. Auch die Körperhaltung, die Bekleidung und die Frisur liefern bei diesen Figuren keinen eindeutigen Hinweis darauf, wer in der Darstellung gemeint ist, bzw. sie sind bislang noch nicht näher auf ihren Aussagegehalt untersucht worden ${ }^{474}$.

D. Graepler hat in seiner detaillierten Untersuchung weiblicher Terrakottastatuetten aus den Gräbern von Tarent vorgeschlagen, die sog. Tanagräerinnen als Darstellungen von jungen heiratsfähigen Mädchen zu deuten ${ }^{475}$, da auch die weiteren Grabbeigaben auf den Hochzeitskontext hinweisen. Dazu zählt die charakteristische Keramik, die anderen Terrakottentypen wie die thronenden weiblichen Figuren, die möglicherweise Bräute darstellen sowie die eindeutig als Aphrodite, Eros, Artemis oder Nymphen und damit als mit dem Hochzeitskontext in Verbindung stehende göttliche Wesen identifizierbaren Figuren. Der Gesamtzusammenhang, den D. Graepler für die Beigaben in den tarentinischen Gräbern herausgestellt hat, lässt die Deutung der stehenden weiblichen Figuren als Darstellungen von Bräuten denkbar erscheinen. Doch sind weitere Forschungen abzuwarten, die, wenn möglich, mehr als nur einen Fundkomplex einbeziehen ${ }^{476}$. Aufgrund des unvollständigen Erhaltungszustandes einiger Figuren können auch eventuell einst vorhandene Attribute verloren gegangen sein. Die Identifizierung dieser Terrakottastatuetten als Sterbliche ist demnach nicht gesichert.

Unter den stehenden oder sitzenden bekleideten weiblichen Figuren kommen auch solche vor, die die Dargestellte auf ein weibliches Idol oder eine Herme aufoder angelehnt zeigen (Kat. B144-B159). Es ist möglich, dass das aus dem Bereich der Götterbilder bekannte und beliebte Motiv hier übernommen und zu einer Art 〉Genre-Darstellung` wurde: Frauen verweilen bei Götterbildern. Noch weniger Anhaltspunkte als für die Identifizierung der Figuren liegen für eine weiter spezifizierte Deutung vor, die über das Thema `Frau bei Götterbild ${ }^{477}$ « hinausgeht. Des-

damit in die göttliche Sphäre, werden jedoch genauso von menschlichen Kultteilnehmern getragen und dienen damit ebenso wenig der eindeutigen Identifizierung der Dargestellten.

${ }^{473}$ R. Higgins, Tanagra and the Figurines (Princeton 1986), bes. 117-140 (lladiess); J, P. Uhlenbrock, The Hellenistic Terracottas of Athens and the Tanagra Style, in: Uhlenbrock 1990, 48-53 (rmortal womanı, sdraped womanı); Zimmer 1994, 24 f. (’Frauen und Mädchen`). Vgl. auch Graepler 1997, 201. 223.

${ }^{474}$ Vgl. Rumscheid 2006, bes. 178-194.

475 Graepler 1994; Graepler 1997.

476 So auch Graepler 1997, bes. 223. 226. 237.

477 Besonders kompliziert ist die Deutung eines Wandgemäldes aus Pompeji, das eine Frau zeigt, die sich auf eine Herme auflehnt (Kat. B159). Vor ihr sitzt eine deutlich größere, halbbekleidete weibliche Gestalt mit einer Taube auf der Hand auf einem reich verzierten Hocker, vielleicht ein Aphroditebild. Hinter ihr steht eine altertümliche weibliche Statue auf einem Sockel. Damit könnte es sich um eine Darstellung eines älteren neben einem jüngeren Götterbildes handeln, was Thema des dritten Teils der Arbeit sein wird. Unabhängig davon kann man in der Aufgelehnten eine Frau sehen, die ein Heiligtum aufsucht. Die Herme ist allerdings bärtig und damit männlich. Die Verehrung mehrerer Gottheiten in einem Heiligtum ist mehrfach belegt, z. B. durch den 
halb kann nur spekuliert werden, welche individuelle oder übergreifende Vorstellung die antike Besitzerin oder der antike Besitzer mit dem Bild verknüpft hat. Denkbar wäre z. B., dass die Eigentümer neben dem Genremotiv noch einen besonderen Inhalt in diesen Bildern sahen. So wäre es möglich, dass die Besitzerin sich selbst in der Frau sah ${ }^{478}$ und in dem Götterbild eine Göttin bzw. einen Gott, $\mathrm{zu}$ dem sie einen besonderen Bezug hatte ${ }^{479}$. Dies ist aber nicht zu belegen und soll nur eine Möglichkeit der Interpretation aufzeigen. Die persönliche Bedeutungsebene antiker Terrakottastatuetten vermutet auch F. Rumscheid in seiner ausführlichen Monographie zu den Terrakottastatuetten von Priene, indem er fragt, ob z. B. in Heiligtümern gefundene Bilder, die Kinder darstellen, sich auf die Kinder der Stifter beziehen und »speziell auf die Situation, in der die Figuren geweiht wurden, abgestimmt wurden « ${ }^{480}$.

\subsection{Zusammenfassung}

Seit dem 4. Jahrhundert v. Chr. wurden auch Menschen auf ein archaistisches Idol oder eine Herme gelehnt dargestellt. Die Hermen, die als Stützen für männliche Gestalten dienen, können aufgrund der Attribute der aufgelehnten Figuren als Palästra-Hermen identifiziert werden. Sie kennzeichnen die auf sie gelehnten Jüng-

Hermes Propylaios von der Athener Akropolis, vgl. Anm. 443 sowie Kap. 12.1. Eine weitere Spezifizierung der Dargestellten ist zurzeit nicht möglich.

$478 \mathrm{Vgl}$. die Identifizierung der >Tanagräerinnen als Abbilder ihrer Käufer durch M. Bell, Hellenistic Terracottas of Southern Italy and Sicily, in: Uhlenbrock 1990, 64-70, bes. 66; Zimmer 1994, 19 f.; Graepler 1994, 53.

${ }^{479}$ Die Verbindung, die D. Graepler für die >Tanagräerinnen bei den Stützfiguren der bekleideten weiblichen Terrakottastatuetten an Schutzgötter der >Parthenoi wie Artemis, Aphrodite oder Nymphen denken. Vgl. bes. Graepler 1997, 227, wo er vorschlägt, die weiblichen bekleideten Figuren, die in Heiligtümern dieser Göttinnen gefunden wurden, als Darstellungen der »Mädchen und Frauen selbst, die bei bestimmten rituellen Anlässen, z. B. vor der Hochzeit, Terrakottastatuetten in die Heiligtümer ihrer Schutzgottheiten weihten« vorschlägt. Das Bild der Kertscher Deckelschale Kat. B158 zeigt, wie bei der Schmückung einer Braut eines der anwesenden Mädchen auf einer Herme lehnt. Diese ist also im Haus der Braut stehend gedacht und hat damit eine besondere Bedeutung für die Braut.

${ }^{480}$ Rumscheid 2006, 307. Vgl. auch die zahlreichen, reale Kinder darstellenden Statuen, vor allem bei Kourotrophos- und Heil-Kulten, die zum Teil aufgrund von Inschriften als Fürbitte oder Dank an die Götter ausgewiesen sind oder aus Heiligtümern stammen, in denen Kinder bei bestimmten Riten eine Rolle gespielt haben: L. Kahil, L’Artémis de Brauron: Rites et Mystère, AntK 20, 1, 1977, 86-98; Chr. Vorster, Griechische Kinderstatuen (Diss. Rheinische Friedrich-WilhelmsUniversität Bonn 1983) 48-84; H. Rühfel, Das Kind in der griechischen Kunst. Von der minoisch-mykenischen Zeit bis zum Hellenismus (Mainz 1984) 213-268; L. Ganzmann - H. van der Meijden - R. A. Stucky, Das Eschmounheiligtum von Sidon. Die Funde der türkischen Ausgrabungen von 1901 bis 1903 im Archäologischen Museum in Istanbul, IstMitt 37, 1987, 81-130, bes. 110-112; R. A. Stucky, Die Skulpturen aus dem Eschmun-Heiligtum bei Sidon. Griechische, römische, kyprische und phönizische Statuen und Reliefs vom 6. Jahrhundert v. Chr. bis zum 3. Jahrhundert n. Chr, AntK Beih. 17 (Basel 1993) 29-39. 56-60. 
linge und Männer als Palästriten. Die weiblichen Stützfiguren hingegen scheinen nicht auf eine spezifische Funktion festgelegt zu sein und sind für verschiedene, jedoch selten genau bestimmbare Darstellungen benutzt wurden. Auch für die weiblichen aufgelehnten Figuren kann keine sichere Deutung vorgeschlagen werden. Oftmals ist nicht einmal ihre Identifizierung als Menschenbild gesichert.

Die meisten Beispiele stammen aus der Epoche des Hellenismus und der Kaiserzeit und gehören zur Gattung der Terrakottastatuetten. Für sie ist deshalb vorgeschlagen worden, sie als >Genrefiguren zu interpretieren: sie zeigen Menschen, die sich bei Götterbildern aufhalten. Ob der Besitzer oder die Besitzerin noch eine tiefere Bedeutungsebene in ihnen gesehen hat, z. B., ob er oder sie sich selbst in der aufgelehnten Figur gesehen hat und in der Stützfigur eine Gottheit, die für ihn oder sie eine besondere Bedeutung hatte, muss Spekulation bleiben. 


\section{Verwendung der Aphroditebilder}

In Kapitel 5 wurde der Typus der auf eine ikonische Stütze gelehnten Aphrodite auf die phidiasischen Aphroditestatuen in Elis bzw. Athen zurückgeführt. Das Urbild des Typus war also eine kultisch verehrte Statue in einem öffentlichen Heiligtum. In den folgenden Jahrhunderten war der Typus weit verbreitet. Es stellt sich daher die Frage, für welchen Zweck die zahlreichen hier untersuchten Varianten verwendet wurden. Daher soll in diesem Kapitel nach Fundkontexten und der daraus ableitbaren Verwendung der Bilder der auf eine ikonische Stütze gelehnten Aphrodite gefragt werden, soweit sie bekannt sind.

Nur für einige der hier vorgelegten Aphroditebilder ist durch den Fundkontext eine bestimmte Art der Verwendung nachgewiesen. Die Terrakottastatuetten aus Myrina, Kertsch, Tanagra und Tarent sind sicher bzw. mit hoher Wahrscheinlichkeit in Gräbern gefunden worden ${ }^{481}$. Aus Privathäusern stammen die Marmorstatuetten Kat. A18. A32. A48. A57, die Terrakottastatuette Kat. \$ $\square$ und das Wandgemälde Kat. $A 96^{482}$. Die Marmorstatue Kat. A10 diente als Ausstattung der

${ }^{481}$ Kat. A9. A15. A25-30. A33. A36-38. A40. A41. A49. A52ロA60. A61. A65. A68. A78. A80. A83-86. A88. A97. A99. A109. A110. Ob die Statuetten speziell für den Totenkult gekauft worden sind oder zum Besitz des Verstorbenen oder der Hinterbliebenen gehört haben, kann im Einzelnen nicht mehr nachvollzogen werden. Der Kauf von Keramik wie auch von Terrakottastatuetten speziell für den Totenkult ist durch die Untersuchung der Nekropolen von Tarent durch Graepler 1997 belegt worden. Da Grabbeigaben auf das Geschlecht, das Alter und den Status bzw. die Rolle, die der oder die Verstorbene im Leben innegehabt hatte, hinweisen sollen, werden für die Beigaben jedoch dieselben Typen verwendet, mit denen die Verschiedenen auch im Leben Kontakt gehabt hatten. Deshalb werden dieselben Typen sowohl als Grabbeigaben verwendet und kommen genauso auch in Heiligtümern und Privathäusern vor, s. Graepler 1997, bes. 245-249.

482 Aus Pompeji: Kat. A18: aus einer Nische im Peristyl des Wohnhauses I, 2, 17; Kat. A57: aus dem Tablinum des Wohnhauses II, 4, 6; Kat. A96: noch in situ im oecus des Wohnhauses VII, 9, 47; Kat. A119: aus dem Wohnhaus IX, 3, 5; aus Priene: Kat. A32: aus dem südöstlichen Raum des Wohnhauses 33 Ost; aus der Villa von Oplontis: Kat. A48: war zusammen mit weiteren, z. T. reparaturbedürftigen Statuen in Raum 35 gelagert. 
Thermen von Baiae ${ }^{483}$. Die Marmorstatuette Kat. A22 ist im Apollontempel von Kyrene gefunden worden ${ }^{484}$. Aus dem Heiligtum der syrischen Götter in Delos stammt die Marmorstatuette Kat. A24485 und aus einem ländlichen Heiligtum bei Tarent die Terrakottastatuette Kat. A20486. Die Verwendungsmöglichkeiten der aufgelehnten Aphroditebilder sind demnach sehr vielfältig und individuell von den Besitzern der Werke bestimmt worden. Selten bekannt sind allerdings die genauen Fundorte innerhalb der genannten Gebäude.

Einige Beispiele stammen also wie das Urbild aus einem Heiligtum und dienten wahrscheinlich als $>$ Weihgeschenke ${ }^{487}$. Für andere ist die Verwendung im privaten Kontext gesichert. Der Ausstattungsluxus griechischer Häuser ist bereits

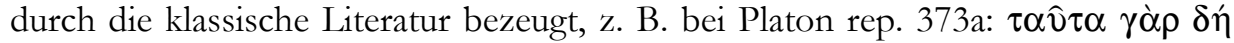

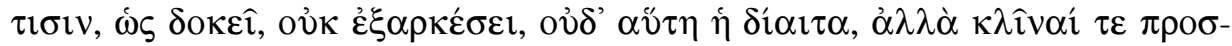

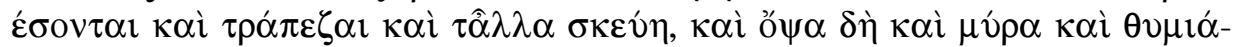

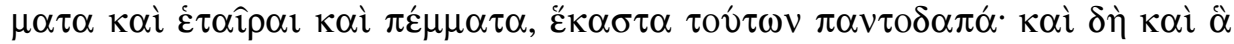

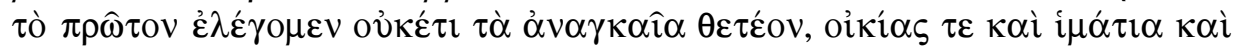

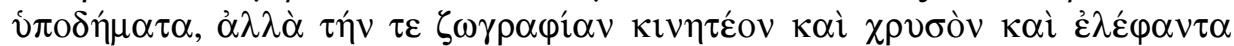

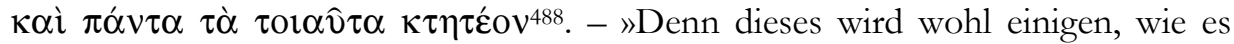
scheint, nicht Genüge leisten, auch nicht die Lebensart selbst; sondern es sollen Polster da sein und Tische und anderes Hausgerät, und Zukost und Salben und Räucherwerk und Freudenmädchen und Backwerk, dies alles aufs mannigfaltigste. Ja auch, was wir vorher aufstellten, gilt nun nicht mehr, nämlich das Notwendige einzurichten, Häuser, Kleider und Schuhe; sondern man muß die Malerei in Bewegung setzen und die bunte Weberei, und Gold und Elfenbein und alles dergleichen muß angeschafft werden«. (W. F. Otto - E. Grassi - G. Plamböck)

Auch wenn Platon keine Skulpturenausstattung nennt, ist sie inzwischen durch zahlreiche Ausgrabungen bereits für die spätere Klassik wie auch für die folgenden Epochen bezeugt, z. B. in Delos, Olynth, Priene und Pompeji ${ }^{489}$. Jedoch ist ihre Funktion in den Häusern aufgrund der Fundsituation nur selten zu bestimmen, da sie fast immer in Zerstörungsschichten gefunden wurden, so dass die Werke we-

483 Der genaue Fundort ist unbekannt, vgl. P. Mingazzini, Due statue ercolanesi rivendicate a Baia, in: P. E. Arias, Scritti in onore di Guido Libertini (Florenz 1958) 111-116.

484 Die Statue wurde offenbar bei der kaiserzeitlichen Erneuerung des Apollontempels im Fundament eingemauert, vgl. Anti 1927, 41.

485 Auch bei dieser Statue ist kein genauer Fundort bekannt, vgl. Marcadé, 1969, 227. 230 f. 301.353.

486 Aus der Grube 6 des Heiligtums an der Satyrionquelle, in der in der Antike Kultgerät deponiert worden war, s. L. Monetti, La favissa 6 del santuario della sorgente di Satyrion, Taras 24/25, 2004/2005, 77-105.

${ }^{487} \mathrm{Zu}$ den Begriffen des $\gg$ Kult- $<$ bzw. ,Weihbildes« s. Kap. 11.

488 Weitere Quellen bei Harward 1982. Vgl. auch Anm. 396.

489 Delos: Kreeb 1988; Zanker 1998, 82; Olynth: G. Kleiner, Tanagrafiguren. Untersuchungen zur hellenistischen Kunst und Geschichte, JdI Ergh. 15 (Berlin 1942) 9; Zimmer 1994, 22 f.; Priene: J. Raeder, Priene. Funde aus einer griechischen Stadt (1984); Miller Ammerman 1990, 43; Zimmer 1994, 22. 24; Rumscheid 2006; Pompeji: Higgins 1967, 7 f.; allgemein: Harward 1982. 
der einzelnen Räumen eindeutig zugeordnet werden können noch ihre einstige Aufstellung im Raum zweifelsfrei rekonstruiert werden kann ${ }^{490}$. Zudem ist eine spezifische Funktion von Räumen in antiken Häusern nicht festzustellen und hat vermutlich nicht existiert, was die Suche nach der Bedeutung der Skulptur für den Raum zusätzlich erschwert.

In Privathäusern konnten Götterbilder dem privaten Kult dienen, wie es durch die antike Literatur mehrfach belegt ist ${ }^{491}$ und inzwischen auch durch Ausgrabungen bestätigt werden konnte, da mehrfach Götterbilder in Verbindung mit Kultgeräten wie Altären oder Thymiaterien gefunden wurden ${ }^{492}$. Andere Götterbilder können Teil der Ausstattung der Räume gewesen $\operatorname{sein}^{493}$. Eine rein dekorative Funktion erscheint fraglich, eine Charakterisierung des Raumes für bestimmte Verwendungskontexte jedoch denkbar. Gerade Aphrodite- und Dionysosbilder waren in Gelageräumen beliebt, weil sie die Symposiumsteilnehmer assoziativ an Lebensfreude und Lebensgenuss erinnert haben dürften. Erotische Anspielungen, wie sie durch Priapos, Pan oder Hermaphrodit als Stützfiguren und durch den Typus der auf sie gelehnten Aphrodite zum Ausdruck kamen, eigneten sich gut, um Festräume in dieser Funktion zu kennzeichnen ${ }^{494}$.

Wie schwierig eine Trennung nach Funktionen ist, zeigt besonders die >Pantoffelgrupper (Abb. 37), eine rundplastische hellenistische Marmorgruppe, bei der sich Aphrodite spielerisch mit ihrem Schuh gegen Pan wehrt. Sie hat im größten und repräsentativsten Raum des Hauses der Poseidoniasten in Delos gestanden

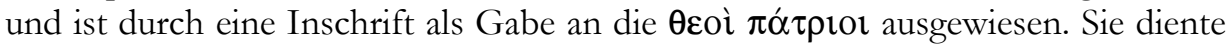
jedoch zugleich auch der Kennzeichnung des Raumes als Ort der Versammlung und der Feiern ${ }^{495}$. Wie vielseitig die Funktion besonders der kleinformatigen Bil-

490 Harward 1982, 114; Kreeb 1988; Rumscheid 2006. Auch vermutet man, dass die zumeist kleinformatigen Werke in der Regel auf Tischen, Regalen oder in Schränken standen, die sich kaum nachweisen lassen, da sie zumeist aus Holz bestanden, s. Kreeb 1988, 46; Rumscheid 2006, 60.

491 Thuk. 6, 27; Theophr. char. 16, 10; Athen. 10, 437b; 11, 460e; 15, 676a-b; Lycurg., Leokrates 25.

492 Harward 1982; Kreeb 1988, bes. 63-69; Rumscheid 2006 bes. 56-58. 82. 126-131.

493 Harward 1982; Kreeb 1988; Miller Ammerman 1990, 43; E. D. Reeder, Some Hellenistic Terracottas and Sculpture in Asia Minor, in: Uhlenbrock 1990, 81-88; Zanker 1998.

494 Vgl. Kreeb 1988 bes. 63-69; Miller Ammerman 1990, 43; Zanker 1998, 92 f.; Rumscheid 2006, 27-30. 83. Diese Verwendung ist sicherlich einer der Gründe, warum die Aphroditebilder mit den männlichen Stützfiguren fast ausschließlich im Kleinformat geschaffen worden sind. Zur Verwendung mythologischer Bilder zur Erzeugung eines "glücklich-heiteren Lebensgefühls«, Aufforderung zum Lebensgenuss und erotischer Stimulation in der römischen Kunst s. S. Muth, Erleben von Raum - Leben im Raum. Zur Funktion mythologischer Mosaikbilder in der römisch-kaiserzeitlichen Wohnarchitektur (Heidelberg 1998); dort S. 271 das Zitat; vgl. auch A. Geyer, Das Problem des Realitätsbezuges in der dionysischen Bildkunst der Kaiserzeit (Würzburg 1977); P. Zanker B. Chr. Ewald, Mit Mythen leben. Die Bilderwelt der römischen Sarkophage (München 2004).

495 Athen, Nationalmuseum Inv. 3335: Bieber 1955 Abb. 629 f.; Fuchs 1969, 377 Abb. 418; Harward 1982, 126 f. 162 f. Kat. 22 Taf. 12; Kreeb 1988, 25-29. 108 Kat. S 1. 9; Zimmer 1994, 24; Zanker 1998, 7; Chr. Vorster, Die Plastik des späten Hellenismus - Portraits und rundplastische Gruppen, in: P. C. Bol (Hrsg.), Die Geschichte der antiken Bildhauerkunst III. Hellenistische Plastik (Mainz 
der gewesen ist, hat auch die Untersuchung der Terrakottastatuetten aus Priene durch F. Rumscheid gezeigt. Einige gehören zum Typus der Knidischen Aphrodite, bilden also ein berühmtes Bild aus einem Heiligtum nach ${ }^{496}$. Sie $» k o ̈ n n t e n$ also ebenso als private Aphrodite-Kultbilder wie als kleine Kunstwerke in den Häusern aufgestellt gewesen sein, ohne daß sich diese Funktionen ausgeschlossen haben müssen «497. Von den Händlern werden die Götterbilder dementsprechend wahrscheinlich oft als vielseitig verwendbar angeboten worden sein ${ }^{498}$. Ein beredtes Beispiel dafür liefert eine der Fabeln des Aisopos, in der ein Händler ein Bild des Hermes feilbietet und seine Kunden den Wunsch äußern, es einerseits als Grabmal, andererseits als privat verehrtes Götterbild zu verwenden (Aisop. 80 Hausrath):

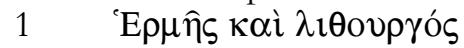

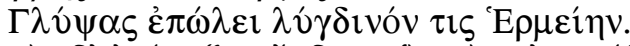

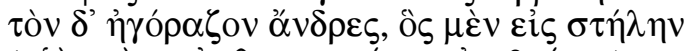

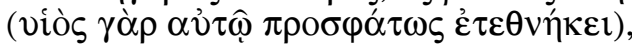

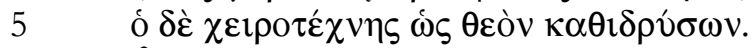

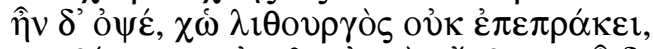

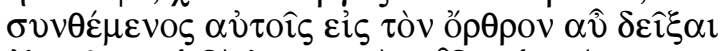

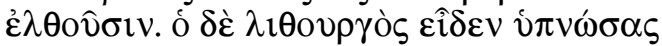

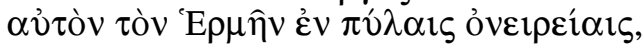

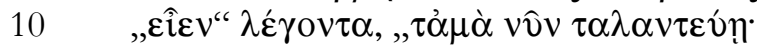

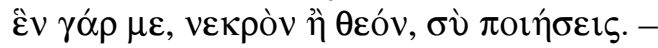

$1 \gg$ Hermes und der Bildhauer

Ein Steinmetz bot ein Hermesbild zum Kauf aus.

Zwei Käufer bieten: Einer will als Grabmal es an des jüngst verstorbnen Sohnes Grab setzen,

5 der andre will zum Schutzgott ihn als Handwerker.

Doch es ist spät - man kommt zu keinem Abschluß, und an dem nächsten Morgen soll der Steinmetz das Bild von neuem zeigen. In der Nacht nun sieht er den Hermes an des Traums Toren,

10 der spricht: „Sieh’ an, du darfst nun mein Geschick wägen!

Du kannst zum Toten, du kannst mich zum Gott machen!“"«(A. Hausrath)

2007) 301.

$496 \mathrm{Zu} \mathrm{dem} \mathrm{Typus} \mathrm{s.} \mathrm{Anm.} 53$.

497 Auch als Grabbeigaben kommen Terrakottastatuetten dieses Typus vor, vgl. Rumscheid 2006, bes. 347-350, Zitat S. 220; ebenso Miller Ammerman 1990, 43; J. P. Uhlenbrock, East Greek Coroplastic Centers in the Hellenistic Period, in: ders. 1990, 72-80. Vgl. auch eine Statuette des gleichen Typus in Delos, die von Harward 1982, 134. 181 Kat. 55 Taf. 15a ähnlich interpretiert wird.

498 Vgl. R. Higgins, Tanagra and the Figurines (Princeton 1986) 65; Kreeb 1988, 96; Zanker 1998, 94. 


\section{Zusammenfassung}

In diesem ersten Teil der Arbeit wurde nach der Erfindung und Ausgestaltung des Motivs der auf eine ikonische Stütze gelehnten Aphrodite gefragt. Es hat sich erneut gezeigt, dass die Bilder der auf eine solche Stütze gelehnten Aphrodite auf einen Typus der 2. Hälfte des 5. Jahrhunderts v. Chr. zurückgehen. Dieser stellt eine der hochklassischen Varianten der aufgelehnten Aphrodite dar, für die bekannterweise außer dem Idol und der weiblichen Herme auch Pfeiler und Baumstämme als Stützen vorkommen. Die Herme ist mit der speziellen Kultform der Aphrodite Urania verknüpft, ebenso die Darstellungen, in denen die Göttin einen Fuß auf eine Schildkröte setzt. Aufgrund dieses Motivs wurde der Typus schon lange als eine Erfindung aus dem Umkreis des Phidias erkannt. Sowohl die Herme als auch das weibliche archaistische Idol sind bereits für die Zeit der Hochklassik bezeugt (Kat. A2. A3) und kommen daher als Stütze für das Urbild in Frage. Die späteren Varianten übernehmen jedoch häufiger die Idole als die Herme. Besonders beliebt wurde das Motiv seit dem Hellenismus. Die große Bedeutung, die Aphrodite in dieser Zeit generell zukam und die sich durch die größere Anzahl von Darstellungen dieser Göttin gegenüber denen anderer Götter ausdrückt, hat dabei sicherlich zur Verbreitung und immer neuen Variation des Motivs wie auch zur Verknüpfung mit anderen Typen geführt.

Zur Frage nach der Identifizierung der ikonischen Stützen, insbesondere der sehr umstrittenen archaistischen Idole, konnte die erweiterte Materialbasis zunächst keine durchschlagenden neuen Erkenntnisse beitragen. Es konnten aber Argumente beigebracht werden, dass die am häufigsten vertretene Meinung, dass es sich bei diesen Figuren um ein saltes Bild der darauf gelehnten Göttin handelt, am wahrscheinlichsten ist. Dafür spricht, dass sich die Bilder in den Rahmen des Phänomens des Archaismus einordnen, das die Verehrungswürdigkeit alter Götterbilder bezeugte. Darüber hinaus konnten Argumente dafür angeführt werden, dass die Idole wahrscheinlich als $>$ Kultbild gedeutet wurden, was besonders deutlich bei der Terrakottastatuette Kat. A43 zum Ausdruck kommt. 
Die Sammlung möglichst zahlreicher aufgelehnter Götterdarstellungen hat gezeigt, dass Aphrodite die erste Gottheit war, die in einer Statue in aufgelehnter Haltung dargestellt wurde, mit einigem zeitlichen Abstand gefolgt von Dionysos und in geringerer Zahl von weiteren jugendlichen Göttern. Der Grund dafür ist darin zu vermuten, dass von der Zeit der Klassik an das Wesen der Götter auch in der Gestaltung ihrer Körper und ihrer Haltung zum Ausdruck gebracht wurde. Da beide Götter des angenehmen Lebens und des Genusses waren und in dieser Zeit am stärksten über ihr Körperbild definiert wurden, war eine lässig hingegossene Haltung zuerst bei ihnen möglich. Sie bezeugt die sgliederlösende Kraft ${ }^{499}$ dieser Götter, der sie seit der Klassik in ihren Darstellungen auch selbst unterlagen, wie besonders N. Himmelmann gezeigt hat ${ }^{500}$. Wie die Aphroditetypen mit Pfeileroder Baumstammstütze fügen sich die Darstellungen der Göttin mit ikonischen Stützen in den Kontext der erotisierten Wiedergabe des Körpers der Göttin seit der Zeit der Klassik ein, mit der ihr Charakter zum Ausdruck kam.

Diese Deutung gibt zugleich einen Fingerzeig für die Interpretation der altertümlichen Stützfiguren. Denn bedenkt man, dass Aphrodite neben Dionysos die Gottheit war, deren Körperbild sich in der Zeit der Klassik am deutlichsten gewandelt hatte, wird die Veranlassung, auf das hohe Alter und die Ehrwürdigkeit des Kultes hinzuweisen unmittelbar einsichtig. Indem sich die sneues, die zeitgenössischen Vorstellungen widerspiegelnde Aphrodite auf ihr eigenes raltes« Bild lehnt, bezeugt sie zugleich das hohe Alter und die Kontinuität und damit den hohen Rang des Kultes. Für diese Deutung muss man bei den archaistischen Idolen nicht unbedingt zwischen einem $\gg$ Kult- oder einem Weihbild unterscheiden, da beide das hohe Alter des Aphroditekultes anzeigen können. Ebenso muss nicht gefragt werden, ob es sich bei diesem Motiv um die Darstellung eines alten und eines neuen Bildes der Göttin handelt oder ob es die Epiphanie der lebendigen Göttin bei ihrem alten Bild darstellt, wobei es jedoch durchaus möglich ist, die Bilder so zu deuten. Die Aufstellung eines jüngeren, oft sehr aufwändigen und kostspieligen Bildes in einem Heiligtum, das bereits ein verehrtes altes Bild besaß, ist häufig belegt. Allerdings ist die Funktion der jüngeren Bilder in der Forschung umstritten, oft ist ihnen eine Funktion im Kult abgesprochen worden. Die Untersuchung verschiedener Heiligtümer in einem weiteren Teil dieser Arbeit soll einen Beitrag zu dieser Diskussion leisten.

Die ebenfalls schon seit dem 5. Jahrhundert v. Chr. belegte weibliche Herme als Stütze der Göttin war bereits von M. Osanna überzeugend als spezifische Darstellungsform der Aphrodite Urania gedeutet worden ${ }^{501}$. Für die von der Zeit des Hellenismus an häufigen männlichen Stützfiguren der Aphrodite ließ sich eine Bedeutungsverschiebung feststellen. Die häufig belegten Priapos-, Hermaphrodit-

\footnotetext{
${ }^{499}$ s. Anm. 389.

500 s. S. 131.

${ }^{501}$ s. Kap. 5.1.3.
} 
und Panfiguren kennzeichnen Aphrodite als Göttin der körperlichen Liebe. Deshalb ist sie bei dieser Kombination auch häufig unbekleidet und in einer Haltung dargestellt, die erotische Phantasien hervorruft, etwa wenn sie sich zum Bade auszieht, ihre Haare auswringt oder hochsteckt oder sich ein Busenband umlegt. Eros ist in der griechischen Kunst häufig Begleiter von Aphrodite. Deshalb kann sich Aphrodite auf ihn lehnen, genauso wie er sich auf ihr Bild lehnen kann. Beide Götter vertreten den Bereich der Liebe, ihre Verbindung verstärkt diese Wirkungskraft noch. Dionysos als Stützfigur ist nicht sicher zu erklären. Möglicherweise lehnt sich die eine Gottheit auf die andere, um dadurch noch stärker ihre Wirkungskraft als Gottheit des Glücks und des Genusses zum Ausdruck zu bringen.

Erst seit dem 4. Jahrhundert - zu diesem Zeitpunkt noch in sehr wenigen Beispielen - etwas häufiger dann seit der hellenistischen Zeit wurde das für Aphrodite erfundene Motiv auch auf andere Götter sowie auf Menschen übertragen. Die häufigsten Beispiele unter den Göttern stellen Eros und Hermaphrodit sowie Dionysos dar, daneben gibt es auch vereinzelte Darstellung anderer Götter. Die Zahl dieser Beispiele bleibt deutlich hinter der der Aphrodite zurück. Außerdem gehören die Darstellungen zumeist der Kleinkunst an, die freier in ihrer Gestaltung ist als die Großplastik. Neben Baumstämmen und Pfeilern werden ebenso die figürlichen Stützen übernommen. Oftmals wird sich dadurch die Bedeutung verändert haben. Bei einigen wird mit der Stützfigur nach wie vor ein raltes Götterbild gemeint sein. Die Identifizierung hängt von der Figur ab, die sich auf sie auflehnt, da die Stützfigur oft nicht durch Attribute oder andere Merkmale gekennzeichnet ist. Die Hermen können häufig als Darstellungen der in Palästren aufgestellten Hermen interpretiert werden. Gerade in späterer Zeit konnte die figürliche Stütze auch rein dekorativ verwendet werden, oder sie ist mit einer sekundären, nicht sofort erschließbaren Bedeutung belegt, die möglicherweise auch von den antiken Betrachtern unterschiedlich wahrgenommen wurde. Dies ist vor allem bei den Bildern der Fall, bei denen die Stütze erst von kaiserzeitlichen Bildhauern während des Kopiervorgangs griechischer Werke hinzugefügt wurde und deshalb nichts mit der ursprünglichen Bilderfindung zu tun hatte. 



\section{Zum Begriff >Kultbildk}

Aphrodite war - wie später Dionysos - die Göttin, deren Körperbild sich im 5. Jahrhundert v. Chr. besonders stark verändert hatte und seit dieser Zeit ihre Eigenschaften und Wirkungskräfte zum Ausdruck brachte. Deshalb konnte die rgliederlösende ${ }^{502}$ Göttin auch in einer lässigen, aufgelehnten Haltung gezeigt werden. Um einem damit einhergehenden Würdeverlust zu begegnen und zu betonen, dass sie eine altehrwürdige Göttin war, konnte sie seit dem späteren 5. Jahrhundert v. Chr. auf eine altertümliche Stützfigur gelehnt dargestellt werden, die wahrscheinlich ihr eigenes saltes Bild meint. Dabei stellt sich die Frage, ob es sich bei dem Motiv nur um eine Erfindung der Kunst handelt, oder ob sich Zeugnisse dafür finden lassen, dass es tatsächlich mehrere unterschiedlich alte und unterschiedlichen Kunststilen angehörende /Kultbilder` einer Gottheit in einem Heiligtum gegeben hat. Es muss allerdings betont werden, dass das Nebeneinander verschiedener Bilder einer Gottheit die im ersten Teil der Arbeit betrachteten Darstellungen der Aphrodite nicht begründet. Denn die Aufstellung neuer Bilder neben bereits vorhandenen älteren kam bei allen Göttern vor. Die aufgelehnten Darstellungen waren jedoch Aphrodite aufgrund ihres Charakters eigen, wie bereits dargelegt wurde. Die folgende Untersuchung sei dennoch erlaubt, um die vorgeschlagene Deutung dieses Statuentypus besser mit den - so weit wir sie heute fassen können - antiken religiösen Gepflogenheiten verbinden zu können. Dass die Heiligtümer im Laufe der Zeit erweitert worden sind, braucht nicht betont zu werden. Die Frage ist jedoch, wie oft ein zweiter Tempel gebaut wurde, wenn es bereits einen älteren gab, und welche Funktion dieser erfüllen sollte. Diente er der Ausübung des Kultes oder als Schatzhaus, wie dies in der älteren Forschung vor allem für den Parthenon ${ }^{503}$ diskutiert worden ist? Und welche Funktion erfüllte das neue, oft sehr kostbare Bild der Gottheit, dessen Aufstellung häufig mit dem 
Neubau verbunden war? Galt nur das alte Bild als >Kultbildı, während das jüngere lediglich ein wertvolles Weihgeschenk in Form einer kostbaren Statue war oder erhielten beide kultische Verehrung? Oder sollte das neue Bild das alte ersetzen?

Bisher wurden Fragen wie diese zumeist nur bei der Betrachtung einzelner Heiligtümer gestellt. Der Versuch, dieses Phänomen der antiken griechischen Religion in einem weiteren Rahmen $\mathrm{zu}$ fassen, ist bisher noch nicht unternommen worden, wie auch J. Whitley erst vor kurzem festgestellt hat: "'Double' temples and 'double' cult images present us with a less familiar picture of Classical temples and cult than the one we are used to. If sanctuaries had two cult images, which one was real? Or do 'double' cult images necessarily reflect different aspects of the deity herself? «504. Es stellt sich also die Frage, wie viele der in einem Heiligtum aufgestellten Götterbilder in den Kult einbezogen worden sind, welche Funktion sie hatten und wodurch sie sich unterschieden. Diese Fragen sollen in Kapitel 12 anhand einer Untersuchung verschiedener Heiligtümer beantwortet werden.

Das Nebeneinander mehrerer Bilder in einem Heiligtum erfordert jedoch zunächst eine Auseinandersetzung mit dem Begriff des \Kultbildes` und seiner Aussagekraft bzw. seiner Verwendung in der heutigen Zeit. Welche Bilder bezeichnen wir heute als $>$ Kultbild ${ }^{505}$ und werden wir mit diesem Begriff der antiken griechischen Religion gerecht ${ }^{506}$ ? Wurden damals $>$ Kultbilder von anderen Götterstatuen

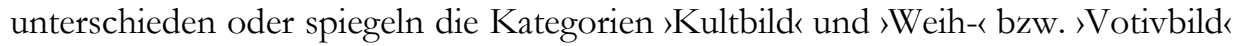
lediglich unser Verständnis wider? Und wie wird der Begriff in der Forschung in Bezug auf andere Religionen verwendet?

Vorauszuschicken ist, dass der Begriff `Kultbild ^ neuzeitlichen Ursprungs ist. Er scheint, wie G. Nick in ihrer Untersuchung zur Athena Parthenos des Phidias aus dem Jahr 2002 dargelegt hat, erst im 19. Jahrhundert entstanden zu sein. Die vielleicht früheste Erwähnung dieses Begriffes in der archäologischen Literatur findet sich in dem Aufsatz von L. Roß aus dem Jahr 1846, der dem Thema Hypäthraltempel galt. Andere von ihm verwendete Begriffe sind `Bild«, `Götterbild und >Weihbild, wobei er mit den ersten beiden dieselbe Statue bezeichnete wie mit dem Begriff `Cultusbild`, also die Statue der Gottheit, die in der Mitte der Cella des jeweiligen

504 Whitley 2001, 301.

505 Um die folgende Untersuchung nicht zu weiträumig anzulegen, beschränke ich mich auf die offiziellen, von der Gemeinschaft im Kult verehrten Götterbilder in öffentlichen Heiligtümern. Bilder des privaten Kultes wie auch einzelner religiöser Gruppen werden deshalb ausgeklammert.

506 Die griechische Religion hat es zwar nicht gegeben, doch »fühlten sich die Griechen dennoch einem gemeinsamen religiösen System zugehörig, das alle Poleis griechischer Sprache miteinschloß. Griechentum wird geradezu durch Zugehörigkeit zu diesem System definiert«, so Scheer 2000,

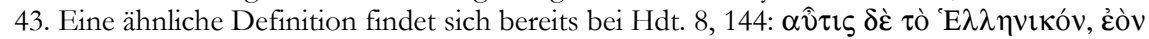

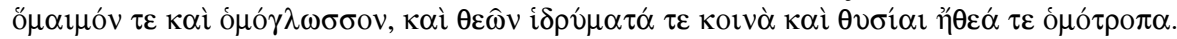
- »Dazu haben wir gleiches Blut und gleiche Sprache mit den Griechen, die gleichen Heiligtümer und Opfer, die gleichgearteten Sitten«. (J. Feix) Eine regionale oder zeitliche Differenzierung kann hier nicht geleistet werden und ist auch nicht zwingend notwendig. 
Tempels ${ }^{507}$ und häufig zusätzlich durch erhöhende Basen oder Schranken herausgehoben aufgestellt gewesen ist. Diese Bilder seien zur Verehrung bestimmt gewesen. Dazu zählten für ihn die Athena Polias und die Athena Parthenos in Athen und die Nemesis von Rhamnus ${ }^{508}$. Die übrigen Götterbilder, die das Kultbild` umgaben, gehörten für L. Roß wie die anderen Gaben zu den >Weihgeschenken<, zu den in einem Heiligtum aufgewahrten Schätzen ${ }^{509}$.

Kurz darauf wurde der Begriff des `Kultbildes` von C. Boetticher in seiner Entgegnung zu L. Roß verwendet. Für ihn hatten Bilder wie die Athena Parthenos oder der Zeus von Olympia ebenfalls Kultbedeutung, da sie Opfer empfingen und in die Kultfeiern einbezogen worden seien und sich dadurch von den »Weihbildern« unterschieden ${ }^{510}$. Doch schon kurz darauf sprach er der Athena Parthenos und dem Zeus von Olympia die Funktion als »Kultusbild« ab, da sie nicht rituell geweiht worden seien und zudem weder ein Brandopferaltar vor dem Tempel noch ein Gabentisch in seinem Inneren belegt seien. Sie dienten seiner Ansicht nach nur als »illustrirende Staffage« während der agonalen Feste ${ }^{511}$. Auch von der neueren Forschung wurde die kultische Funktion von Bildern wie der Athena Parthenos in Athen aus diesem Gründen oft abgelehnt ${ }^{512}$. Inthronisierungs- und Weihzeremonien sind für das antike Griechenland jedoch nur in wenigen Ausnahmefällen belegt und waren offenbar kein unabdingbarer Bestandteil bei der Einsetzung eines Kultbildes $^{513}$. Deshalb muss geprüft werden, wie der Begriff heute verwendet wird und ob ein sinnvolles inhaltliches Konzept für diesen Begriff möglich ist.

\subsection{Die heutige Verwendung des \Kultbild-〈 Begriffes}

1998 definierte B. Gladigow den Begriff `Kultbild in dem bekannten Handbuch über Religion und Religionswissenschaft so: »Als Kultbild wird die bildliche Wiedergabe eines Gottes bezeichnet, der unmittelbare kultische Verehrung zukommt,

\footnotetext{
507 Auch die Definition des Tempels beruht auf heutigen Kriterien, worauf hier aber nicht eingegangen werden kann. Vgl. D. Steuernagel, Erscheinung und Funktionen griechischer Tempel in der Zeit römischer Herrschaft, in: J. Rüpke (Hrsg.), Antike Religionsgeschichte in räumlicher Perspektive. Abschlussbericht zum Schwerpunktprogramm 1080 der Deutschen Forschungsgemeinschaft „Römische Reichsreligion und Provinzialreligion“ (Tübingen 2007) 157-161.

${ }^{508}$ L. Roß, Keine Hypäthraltempel mehr, Hellenika 1, 1846, 1-39.

${ }^{509}$ Ebenda.

510 C. Boetticher, Der Hypäthraltempel, aufgrund des Vitruvischen Zeugnisses gegen Prof. Dr. L. Roß (Berlin ca. 1846).

511 C. Boetticher, Wissenschaftliche Vereine, AZ 1854, 425-430, Zitat S. 426; C. Boetticher, Über den Parthenon zu Athen und den Zeustempel zu Olympia, je nach Zweck und Benutzung, in: Zeitschrift für Bauwesen 2, 1952, 194-210. 498-520, ders, Über den Parthenon zu Athen und den Zeustempel zu Olympia, je nach Zweck und Benutzung, in: Zeitschrift für Bauwesen 3, 1853, 35-44. 127-142. 269-292. Zur Weihe griechischer Götterbilder s. S. 187.

512 s. Kap. 12.1.

513 s. S. 187.
} 
die also ständig oder zeitweilig mit dem Gott gleichgesetzt wird oder ihn repräsentiert. Polytheistische Religionen kennen in der Regel anthropomorphe oder tiergestaltige Kultbilder, schließen freilich in Sonderfällen wenig gestaltete oder anikonische Kultbilder nicht aus. Eine feste Verbindung von Kultbild und Kultort oder Tempel mündet in den meisten Fällen in die Verpflichtung zu regelmäßiger Versorgung des Bildes, zu einem $>$ Tempeldienst $<$, und stellt so die Grundanforderungen religiöser Institutionen und Organisationen her« ${ }^{514}$.

Als traditionelles Gegenteil zum $>$ Kultbild wird in der bereits im 19. Jahrhundert aufgekommenen Diskussion das >Votiv-^ oder >Weihbild gesehen ${ }^{515}$. Es kann wie das $>$ Kultbild eine - oft rundplastische - bildliche Wiedergabe der jeweiligen Gottesvorstellung sein ${ }^{516}$ und unterscheidet sich rein optisch nicht von den $>$ Kultbildern . Es ist jedoch kein Objekt der Verehrung. Ein solches Bild geht wie andere Gaben auch zumeist auf ein Versprechen oder Gelübde zurück oder wird aus Dankbarkeit, besonders für die Errettung aus einer Notsituation der helfenden Gottheit gegeben. Es ist also ein Bitt- oder Dankopfer, das öffentlich von dem Gelübde und dem Gnadenerweis der angerufenen höheren Macht Kunde gibt, nicht um ein die Gottheit im Kult repräsentierendes Bild.

Mit der oben zitierten Definition des >Kultbildes` hat B. Gladigow versucht, den Begriff so allgemein zu fassen, dass er auf alle Religionen angewendet werden kann. Es stellt sich allerdings die Frage, wie der Begriff bezüglich verschiedener Religionen konkret verwendet wird.

In der heutigen Forschung über das antike Ägypten wird das `Kultbild klar bestimmt als eine rundplastische Statue einer Gottheit, die vor den Blicken der Öffentlichkeit verborgen im Allerheiligsten des Tempels, der als >Wohnstätte der Gottheit galt, aufgestellt gewesen ist. Das Bild war in der Regel kleinformatig und aus kostbaren Materialien in Menschen-, Tier- wie auch in Mischgestalt geschaf-

514 Gladigow u. a. 1998, 9. Zur Definition von Kult s. Müller 1931; Bald Romano 1980, 2; Goldammer 1985, 339 s. v. Kultus; H. Cancik - B. Gladigow - K.-H. Kohl (Hrsg.), Handbuch religionswissenschaftlicher Grundbegriffe III (1993) 474-488 s. v. Kult (B. Lang); Donohue 1997; Chr. Auffarth - J. Bernard - H. Mohr (Hrsg.), Metzler Lexikon der Religionen II (1999) 267-274 s. v. Kult/Ritual (B. Lang); Waldenfels 1999, 360 f. s. v. Kult/Gottesverehrung (K. Hoheisel); ebenda 367 f. s. v. Kult und Kultur (K. Richter); DNP VI (1999) 892-900 s. v. Kult, Kultus (F. Graf); Berlejung u. a. 1999a; Damaskos 1999, 1; Linant de Bellefonds u. a. 2004.

515 s. S. 168 f. Vgl. auch H. Sachs - E. Badstübner - H. Neumann, Christliche Ikonographie in Stichworten $^{2}(1980) 364$ s. v. Votivbild; Goldammer 1985, 669 f. s. v. Votivbild; DNP XII (2003) 345 f. s. v. Votivkult (M. Haase); ebenda 419-422 s. v. Weihung, Weihgeschenk (J. Renger-Chr. Frateantonio).

516 Dabei ist zu unterscheiden zwischen einem Götterbild als solchem als Votiv und der Darstellung einer Gottheit auf einem Votiv. Dies kann z. B. eine (szenische) Darstellung auf einem Vasenbild oder Relief sein, bei der die Gottheit handelnd auftritt, z. B. mit dem Stifter agierend. Auf die übrigen Formen von Votivgaben braucht hier nicht eingegangen zu werden, vgl. dazu W. H. D. Rouse, Greek Votive Offerings. An Essay in the History of Greek Religion (Hildesheim 1976). 
fen ${ }^{517}$. Bevor ein neu gefertigtes Bild seine Funktion im Kult erfüllen und seine Wirkungsmacht entfalten konnte, musste es erst sgeweiht Daher unterschieden sich diese Bilder von anderen, die ohne eine solche Zeremonie aufgestellt worden sind. Vor der Durchführung des Rituals der >Mundöffnung، war das Bild nur ein lebloses Abbild des Gottes. Während der Zeremonie trat der Gott nach Ansicht der Forschung in das Bild ein, das von diesem Zeitpunkt an als der leibhaftige Gott galt ${ }^{518}$.

Mit der Vorstellung, dass das Bild ganz oder zumindest zeitweilig mit der Gottheit identisch war, ging der Glaube an die Notwendigkeit seiner Versorgung durch die Priester einher. Die allmorgendliche Reinigungs-, Bekleidungs- und Speisezeremonie bestand aus mehreren, in festgelegter Reihenfolge durchgeführten Phasen, die spätestens seit dem Neuen Reich bis in die römische Kaiserzeit durch zahlreiche Papyri sowie Reliefs in den Heiligtümern detailreich belegt sind. Sie galt nicht dem Bild als materiellem Gegenstand, sondern der im Bild dargestellten Gottheit: »Die jeweilige Gottheit des Tempels war dabei in ihrem Bild gegenwärtig, sie beseelte es, und das Allerheiligste galt als ihre Wohnung. Die Pflege des Bildes richtete sich daher unmittelbar an die Gottheit selbst, stattete sie mit Lebenskräften aus und garantierte ihr immerwährendes Zugegensein« ${ }^{519}$. Außer beim täglichen Tempelkult wurden Götterbilder auch während der Feste direkt in den Kult einbezogen. Sie konnten dabei das Allerheiligste oder sogar den Tempel verlassen, denn an Festtagen brachte man die Bilder zum Tempeldach oder in den Tempelvorhof oder sie besuchten andere Heiligtümer. ${ }^{520}$.

517 LÄ II (1977) 660-664 s. v. Tiergötter (L. Kakosy); Berlejung u. a. 1999a; R. H. Wilkinson, Die Welt der Götter im Alten Ägypten. Glaube - Macht - Mythologie (Stuttgart 2003).

518 S. Morenz, Ägyptische Religion, Die Religionen der Menschheit 8 (Stuttgart 1960) 161-165; Asmussen - Lœssøe I, 363-429 s. v. Ägyptische Religion (H. Ludin Jansen); LÄ II (1977) 671-674 s. v. Götterbild (D. Wildung); LÄ III (1980) 839-848 s. v. Kult (W. Barta); LÄ IV (1982) 223-225 s. v. Mundöffnungsritual (R. Grieshammer); LÄ V (1984) 271-285 s. v. Ritual (W. Helck); E. Hornung, Götterwort und Götterbild im alten Ägypten, in: Klimkeit 1984, 37-60; Gladigow u. a. 1998, 12; Waldenfels 1999, 213-233 s. v. Gott (H.-J. Klimkeit); R. H. Wilkinson, Die Welt der Götter im Alten Ägypten. Glaube - Macht - Mythologie (Stuttgart 2003) 44; Linant de Bellefonds u. a. 2004, $418 \mathrm{f}$.

519 LÄ III (1980) 839-848 s. v. Kult (W. Barta) Zitat S. 840. Vgl. auch S. Morenz, Ägyptische Religion, Die Religionen der Menschheit 8 (Stuttgart 1960) 6. 91 f.; Asmussen - Løssøe I, 363-429 s. v. Ägyptische Religion (H. Ludin Jansen); LÄ II (1977) 671-674 s. v. Götterbild (D. Wildung); Goldammer 1985, 10-13 s. v. Ägyptische Religion; R. H. Wilkinson, Die Welt der Götter im Alten Ägypten. Glaube - Macht - Mythologie (Stuttgart 2003); J. Baines, Visual Representations. Egypt, in: Johnston 2004, 599-601.

520 Allerdings waren die Bilder auch während dieser Zeit nicht sichtbar, sondern in `Barkenschreinen verborgen LÄ I (1975) 619-625 s. v. Barke (A. Kitchen); ebenda 625-627 s. v. Barkenraum (A. Eggebrecht); LÄ II (1977) 707 f. s. v. Götterprozession (E. Schott); ebenda 669-671 s. v. Götterbesuch (U. Rößler-Köhler); LÄ III (1980) 839-848 s. v. Kult (W. Barta); LÄ IV (1982) 1160-1164 s. v. Prozessionen (R. Stadelmann); ebenda 574-579 s. v. Opetfest (W. J. Murnane); LÄ VII (1986) 187-189 s. v. Talfest (E. Graefe). 
Neben diesen `offiziellen Kultbildern gab es jedoch weitere Götterdarstellungen, die ebenfalls Kult empfangen konnten. Aufgrund der Tatsache, dass die im Allerheiligsten des Tempels aufgestellten Bilder nicht für die Allgemeinheit zugänglich waren, entwickelten sich weitere Darstellungen der Götter zu Kult empfangenden Bildern. Besondere Bedeutung erlangten die an der Rückseite des Allerheiligsten oder an den sich dahinter befindenden Umfassungsmauern angebrachten Reliefs, an die sich die Teile der Bevölkerung mit ihren Bitten und Danksagungen wenden konnten, die keinen Zutritt zu dem im Allerheiligsten verborgenen Bild hatten - was die Mehrheit der Bevölkerung betraf. Und auch für die anderen Götterdarstellungen in den Tempelbezirken ist ein Kult denkbar ${ }^{521}$. Auch die Art und Weise, wie Amasis laut Herodot 2, 172 den Menschen verdeutlicht haben soll, dass er der wahre Pharao ist, auch wenn er aus einfachen Verhältnissen stammte, zeigt, wie wenig festgelegt die Verehrung von Götterbildern in der all-

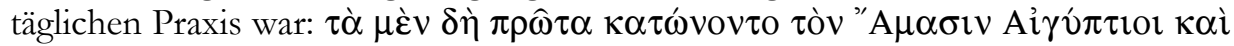

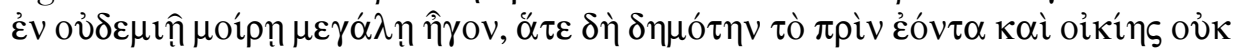

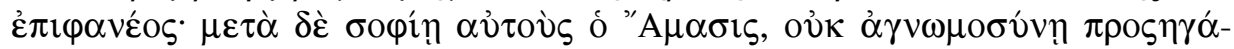

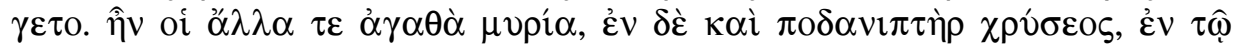

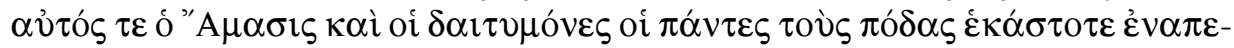

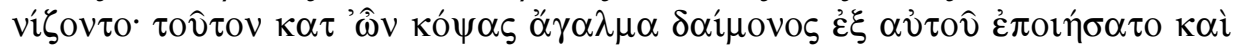

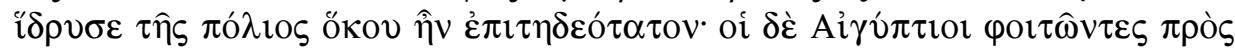

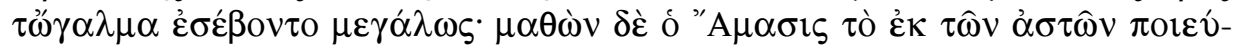

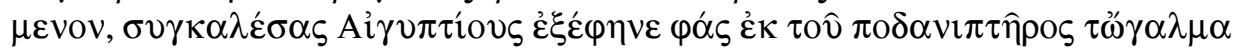

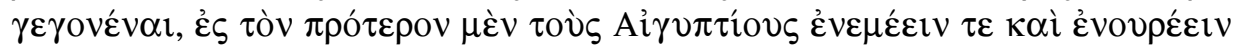

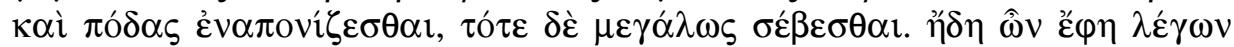

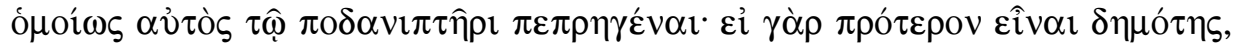

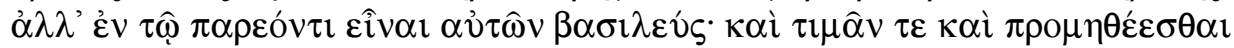

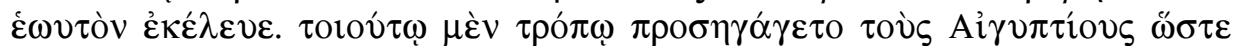

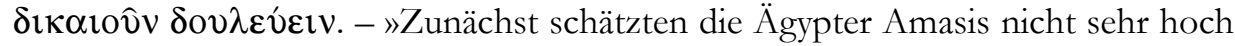
und achteten ihn wenig, weil er vorher ein einfacher Mann aus dem Volke war und aus keinem angesehenen Hause stammte. Später aber gewann Amasis die Menschen durch eine kluge, gar nicht ungeschickte Art. Neben anderen zahllosen Kostbarkeiten besaß er eine goldene Wanne, in der er selbst und alle seine Gäste jeweils die Füße zu waschen pflegten. Diese Wanne zerschlug er, ließ das Bild einer Gottheit daraus machen und stellte es an der passendsten Stelle der Stadt auf. Die Ägypter gingen zum Götterbild und beteten andächtig davor. Als Amasis von diesem Verhalten der Bürger erfuhr, ließ er sie zu sich rufen und erklärte ihnen, daß er es aus dem Waschbecken habe herstellen lassen, in das sie früher gespien, ihr Wasser gelassen und sich die Füße gewaschen hätten; jetzt aber verehrten sie es derartig. Dann fuhr er fort: Ähnlich wie dem Waschbecken sei es ihm

${ }^{521}$ LÄ III (1980) 859-862 s. v. Kultstatue (W. Helck); LÄ VII (1986) 411-414 s. v. Tempelstatuen (H. Sourouzian). 
gegangen. Früher sei er nur einer aus dem Volke gewesen, jetzt aber ihr König. Er forderte sie auf, ihm Ehre und Achtung zu erweisen. So gewann er die Ägypter für sich, so daß sie es als recht erkannten, ihm willig zu dienen«. (J. Feix)

Amasis hat das Götterbild nicht fertigen lassen, um den Menschen die Sinnlosigkeit oder Absurdität ihres Handelns vor Augen zu führen. Sein Ziel war es zu zeigen, dass es weder auf das Material oder auf das, was früher einmal daraus gemacht war noch auf eine offizielle Weihung ankam, damit ein Bild eine Funktion im Kult ausüben konnte, auch wenn natürlich wertvolle Materialen wie Gold als den Göttern angemessen galten. Seine Intention war es, aufzuzeigen, dass das Götterbild den Gott genauso inkarniert wie er den Pharao, und dass im Prinzip jede Götterstatue diese Funktion erfüllen konnte. Im antiken Ägypten hat es also ein besonders verehrtes Bild gegeben, dessen Einsetzung mit einer Zeremonie verbunden war. Daneben existierten aber weitere Bilder, die unterschiedliche Funktionen erfüllten und ebenfalls Verehrung empfangen konnten.

Auch im alten Mesopotamien waren die Kultbilder laut der Forschung klar bestimmt. Die Tempel galten als die irdische Residenz der Götter. Dem Tempelkult dienten wie im alten Ägypten anthropomorphe Götterstatuen. Sie galten nicht nur als Sinnbild für die ferne Gottheit, sondern stellten die Gottheit selbst dar, die auf der Erde weilte und für die Menschen erreichbar war. Um ihre herausragende Stellung hervorzuheben standen sie im Allerheiligsten des Tempels auf einem Podest oder einer Basis oder in einer Nische, die sie vom übrigen Raum abgrenzte ${ }^{522}$. Daneben gab es jedoch weitere Kult empfangende Bilder innerhalb der Heiligtümer, wie mehrfach betont worden ist. Diese brachten einen spezifischen Aspekt der Gottheit zum Ausdruck und trugen daher verschiedene Beinamen oder dienten als Ersatz bei einer zeitweiligen, zumeist unfreiwilligen Abwesenheit des eigentlichen >Tempelkultbildes« etwa durch Raub ${ }^{523}$.

Mesopotamische Götterbilder waren zumeist aus kostbarem Material gefertigt, weshalb sie selten erhalten sind. Vor der Einsetzung einer Statue als \Kultbild wurde sie ähnlich wie in Ägypten in einer komplexen Zeremonie geheiligt. Dabei wurde sie zugleich von Verunreinigungen befreit, die während der Herstellung in der Werkstatt entstanden waren. Das Ritual trennte das Bild nach Ansicht der

522 H. Schützinger, Bild und Wesen der Gottheit im alten Mesopotamien, in: Klimkeit 1984, 61-80; Berlejung 1998; Berlejung u. a. 1999a; Berlejung 1999b; Linant de Bellefonds u. a. 2004, 418 f.; B. Groneberg, Aspekte der „Göttlichkeit“ in Mesopotamien. Zur Klassifizierung von Göttern und Zwischenwesen, in: Kratz - Spieckermann 2006a, 131-165; A. Nunn, Kulttopographie und Kultabläufe in mesopotamischen Tempeln: drei Beispiele, in: ebenda 167-195.

${ }_{523}$ B. Menzel, Assyrische Tempel I. Untersuchungen zu Kult, Administration und Personal (Rom 1981) 70; Berlejung 1998, 33. 148; M. B. Dick, The Mesopotamian Cult Statue: A Sacramental Encounter with Divinity, in: N. H. Walls (Hrsg.), Cult Image and Divine Representation in the Ancient Near East (Boston 2005) 43-67; T. Ornan, the Triumph of the Symbol. Pictorial Representations of Deities in Mesopotamia and the Biblical Image Ban (Göttingen 2005) 112. 
Forschung von allem, was an seine handwerkliche Vergangenheit erinnern konnte. Es war nun nicht mehr eine leblose Statue, sondern konnte hören, reden und essen. Deshalb konnte das Ritual als irdische Geburt der Gottheit angesehen werden. Dementsprechend galt auch der Herstellungsprozess als von der im Bild dargestellten Gottheit gewünscht und von ihr oder einem der Weisheits- oder Handwerkergötter betreut und begleitet. Dem Bild wurde also eine übernatürliche Herkunft zugeschrieben. Anschließend wurde es in einer feierlichen Prozession zum Tempel geleitet und dort inthronisiert. Auch wenn ein Bild beschädigt und deshalb restauriert worden war, führte man die Belebungszeremonie durch ${ }^{524}$.

Den Götterbildern, die als sichtbare Körper der Götter galten, wie in der Forschung immer wieder betont wird, schrieb man körperliche Sinne und Bedürfnisse wie den Göttern selbst zu. Sie konnten Wahrnehmungs- und Handelsbeziehungen zu den Menschen eingehen, also zuhören, sprechen, sich bewegen oder sich auf andere Weise äußern. Im Gegenzug mussten sie mit Nahrung, Kleidung und Schmuck versorgt, aber auch gereinigt werden. Die Gaben und Wohltaten kamen dabei dem Gott über das Bild zu. Der Versorgung dienten festgelegte tägliche Riten, in denen das Bild umsorgt wurde wie ein lebendiges Wesen. Der allägliche Kult fand wie in Ägypten unter Ausschluss der Bevölkerung durch Priester statt. An Feiertagen konnten die Bilder jedoch auch hier die Tempel verlassen und in einer Prozession zur vorübergehenden Verehrung an eine andere Kultstätte gebracht werden ${ }^{525}$.

524 Asmussen - Lœssøe I, 497-525 s. v. Babylonische und assyrische Religion (J. Lœssøe); H. Ringgren, The Symbolism of Mesopotamian Cult Images, in: H. Biezais (Hrsg.), Religious Symbols and their Functions (Stockholm 1979) 104-109; H. Schützinger, Bild und Wesen der Gottheit im alten Mesopotamien, in: Klimkeit 1984, 61-80; A. Berlejung, Washing the Mouth: The Consecration of Divine Images in Mesopotamia, in: K. van der Toorn (Hrsg.), The Image and the Book. Iconic Cults, Aniconism, and the Rise of Book Religion in Israel and the Ancient Near East (Leuven 1997) 45-72; Gladigow u. a. 1998, 12; Berlejung 1998; Berlejung u. a. 1999a; Berlejung 1999b; Chr. Walker - M. B. Dick, The Introduction of the Cult Image in Ancient Mesopotamia: The Mesopotamian mìs pî Ritual, in: M. B. Dick (Hrsg.), Born in Heaven, Made on Earth. The Making of the Cult Image in the Ancient Near East (Winona Lake 1999) 55-121; K. Radner, Kompositstatuen vom Typus der Ephesia aus dem vorkroisoszeitlichen Heiligtum. Zur Herstellung und Pflege von Götterstatuen im östlichen Mittelmeerraum und im Vorderen Orient im frühen ersten Jahrtausend, in: U. Muss (Hrsg.), Der Kosmos der Artemis von Ephesos (Wien 2001) 253-256; Chr. Walker - M. Dick, The Introduction of the Cult Image in Ancient Mesopotamia. The Mesopotamian Mīs Pî Ritual (Helsinki 2001); Linant de Bellefonds u. a. 2004, 418 f.; F. Wiggermann, Visual Representations. Mesopotamia, in: Johnston 2004, 601-607; B. Groneberg, Aspekte der „Göttlichkeit“ in Mesopotamien. Zur Klassifizierung von Göttern und Zwischenwesen, in: Kratz - Spieckermann 2006a, 131-165.

525 H. Schützinger, Bild und Wesen der Gottheit im alten Mesopotamien, in: Klimkeit 1984, 61-80; Berlejung 1998; Berlejung 1999b; K. Radner, Kompositstatuen vom Typus der Ephesia aus dem vorkroisoszeitlichen Heiligtum. Zur Herstellung und Pflege von Götterstatuen im östlichen Mittelmeerraum und im Vorderen Orient im frühen ersten Jahrtausend, in: U. Muss (Hrsg.), Der Kosmos der Artemis von Ephesos (Wien 2001) 256-262; W. Sallaberger, Sacred Times and Spaces. Mesopotamia, in: Johnston 2004, 250-253; B. Groneberg, Aspekte der „Göttlichkeit“ in 
In der hinduistischen Religionsforschung verwendet man den Begriff >Kultbild für anthropomorphe und tiergestaltige Götterdarstellungen, die sich dadurch auszeichnen, dass sich die Gottheit in ihnen niedergelassen hat. Dies geschieht vor der Einsetzung der Bilder, indem sie, ähnlich wie im antiken Mesopotamien oder Ägypten rituell sgeweiht werden. Dabei wird das Bild wie in den eben betrachteten antiken Religionen durch einen Priester belebt und der Gott in ihm inkarniert. Nur in einem durch diesen Ritus hervorgehobenen Bild gilt der Gott in der theologischen Auslegung als gegenwärtig 526 . Hier liegt demnach eine klare Trennung zwischen Bildern, in denen sich der Gott manifestiert und die deshalb kultisch verehrt werden, und solchen, die ihn lediglich darstellen, vor. In der alltäglichen rituellen Praxis wird die Trennung jedoch selten strikt eingehalten, so dass auch nicht zuvor mit dem pratisthā-Ritus 'geweihte Bilder in die Verehrung einbezogen werden, wie mehrfach festgestellt worden ist ${ }^{527}$. Außer den offiziellen und den zahlreichen privaten $>$ Kultbildern gibt es weitere mit unterschiedlicher Funktionalisierung, vor allem für Prozessionen und andere Riten, die eine Bewegung des Bildes einschlossen. Für diese Riten sind die fest im Tempel installierten Statuen z. T. aufgrund ihres Formates und Materials nicht geeignet ${ }^{528}$.

Die anthropomorphe oder tiergestaltige Vorstellung der Götter führt dazu, dass auch den hinduistischen Göttern ähnliche Bedürfnisse zugeschrieben werden wie den Menschen oder Tieren, was dann auch auf ihre slebendigen tragen wird: »Die unüberschaubare Zahl unterschiedlicher hinduistischer Riten reicht von im Haus vollzogenen bis hin zu großen öffentlichen Feiern im Tempel, bei denen das Götterbild durch Wecken, Baden, Speisen usw. wie ein lebendiges Wesen behandelt wird. Tatsächlich wird durch solche Handlungen das Bild aktiviert, d. h. der Gott manifestiert sich in ihm«529. Die regelmäßige Versorgung sichert die Existenzmöglichkeit der Gottheit im Bild. Das Bild wird dadurch mit Lebenskräften ausgestattet und die Götter durch die Gaben gnädig gestimmt ${ }^{530}$.

Mesopotamien. Zur Klassifizierung von Göttern und Zwischenwesen, in: Kratz - Spieckermann 2006a, 131-165.

526 Auch die traditionellen afrikanischen Geistermasken werden von Priestern vor ihrem ersten Einsatz mit magischer Kraft beladen: s. R. Ekkehart, Traditionelle Religionen in Afrika, in: Harenberg 2002, 912-923.

${ }_{527}$ M. Thiel-Horstmann, Gestalthaft - Jenseits von Gestalt: Hinduistische Diskussionen zum heiligen Bild, in: Klimkeit 1984, 137-159; K. Fischer, Kultbilder indischer Höhlen, Stūpas und Tempel, in: ebenda 115-136; C. J. Fuller, The Camphor Flame. Popular Hinduism and Society in India (Princeton 1992) bes. 59-62; B. Hauser-Schäublin, Traces of Gods and Men. Temples and Rituals as Landmarks of Social Events and Processes in a South Bali Village (Berlin 1997); Waldenfels 1999, 361 f. s. v. Kult/Gottesverehrung im Hinduismus (A. Thannippara); Harenberg 2002, 548-631 s. v. Hinduismus (K.-H. Golzio).

528 C. J. Fuller, The Camphor Flame. Popular Hinduism and Society in India (Princeton 1992) bes. 58; Harenberg 2002, 548-631 s. v. Hinduismus (K.-H. Golzio).

529 Harenberg 2002, 548-631 s. v. Hinduismus (K.-H. Golzio) Zitat S. 576.

530 Asmussen - Løssøe II, 373-513 s. v. Indische Religionen (F. Møller-Kristensen); M. Thiel- 
Das frühe Christentum lehnte wie das Judentum zunächst die Verehrung von Bildern ab. Umgeben von unzähligen heidnisch-antiken Götterbildern, aber auch in Abgrenzung dazu entwickelten jedoch auch die Christen sehr schnell eine eigene Ikonographie, zu der Darstellungen Jesu, Marias und der Heiligen in Gräbern und Handschriften, bald auch in den Kirchenräumen gehörten. Ihr Verhältnis zu den Bildern blieb jedoch lange Zeit gespalten und entwickelte unterschiedliche Ausprägungen in den einzelnen christlichen Strömungen. Die Vorstellung von der Geistigkeit Gottes, des Glaubens und der Anbetung blieb dominant und warf immer wieder Konflikte bezüglich der Bilder auf. Problematisch war auch, den strengen Monotheismus mit der sich bereits in der Frühzeit ausbreitenden Heiligenverehrung in Einklang zu bringen sowie die Ansicht, dass Göttliches mit irdischen Mitteln nicht darstellbar sei ${ }^{331}$. Bilder galten deshalb in den ersten Jahrhunderten vor allem als Lehr- und Erziehungsmittel im Sinne einer sbiblia pauperum ${ }^{532}$, während die Frage nach der Verehrungswürdigkeit die Theologen über Jahrhunderte hinweg beschäftigte. Immer wieder, vor allem in der Westkirche, wurde dabei die Anbetung der Bilder verboten ${ }^{533}$. Auch in der Ostkirche entzündete sich

Horstmann, Gestalthaft - Jenseits von Gestalt: Hinduistische Diskussionen zum heiligen Bild, in: Klimkeit 1984, 137-159; B. Hauser-Schäublin, Traces of Gods and Men. Temples and Rituals as Landmarks of Social Events and Processes in a South Bali Village (Berlin 1997); Harenberg 2002, 548-631 s. v. Hinduismus (K.-H. Golzio).

531 So z. B. Eus. ad Const. (PG 20, 1548). Vgl. RAC II (1954) 313-341 s. v. Bild, christlich (J. Kollwitz); W. Schöne, Die Bildgeschichte des christlichen Gottesgestalten in der abendländischen Kunst, in: Schöne 1957, 7-56; Campenhausen 1957; Kollwitz 1957a; H. Sachs - E. Badstübner - H. Neumann, Christliche Ikonographie in Stichworten 2(1980) 63 f. s. v. Bilderverehrung; Theologische Realenzyklopädie VI (1980) 525-531 s. v. Bilder IV. Alte Kirche (H. G. Thümmel); A. Effenberger, Vom Zeichen zum Abbild - Frühzeit christlicher Kunst, in: M. Brandt - A. Effenberger (Hrsg.), Byzanz. Die Macht der Bilder. Ausstellungskatalog Hildesheim (Hildesheim 1998) 14-39; R. Pillinger, Anthropomorphe Darstellungen Gott-Vaters in alt-testamentlichen Szenen der frühchristlichen Kunst, in: I. Baldermann - E. Dassmann - O. Fuchs u. a. (Hrsg.), Die Macht der Bilder. Jahrbuch für Biblische Theologie 13, 1998 (Neukirchen-Vluyn 1999) 171-194; H. G. Thümmel, Die theologische Auseinandersetzung um die Ikone, in: ebenda 197-208; J. Wirth, Soll man Bilder anbeten? Theorien zum Bilderkult bis zum Konzil von Trient, in: C. Dupeux - P. Jetzler - J. Wirth (Hrsg.), Bildersturm. Wahnsinn oder Gottes Wille? Ausstellungskatalog Bern (Bern 2000) 28-37; Th. Schirrmacher, Christentum, in: Harenberg 2002, 8-267; J. Zangenberg, Visual Representations. Christianity, in: Johnston 2004, 619-621; J.-M. Spieser, Die Anfänge der christlichen Ikonographie, in: Hoeps 2007, 139-170.

532 z. B. Greg. M epist. 11, 13: Aliud est enim picturam adorare, aliud per picturae bistoriam quid sit adorandum addiscere. Nam quod legentibus scriptura, hoc idiotis praestat pictura cernentibus, quia in ipsa etiam ignorantes vident quid sequi debeant, in ipsa legunt qui litteras nesciunt. Unde et praecipue gentibus pro lectione pictura est. »Man muss unterscheiden zwischen einer Anbetung des Bildes und der Belehrung, die wir durch die Bilder über den Gegenstand unserer Anbetung erfahren. [...] Denn was für die Lesenden die Schrift ist, das ist für die Augen der Ungebildeten das Bild, denn auf ihm sehen sogar die Ungebildeten, was sie nachahmen müssen, auf ihm lesen die des Lesens Unkundigen. Daher ist vor allem für die Heiden das Bild eine Lesung«. (Kollwitz 1957b, 109); vgl. Greg. M. epist. 9, 52; Nilus, Epist. ad Olympiod. Eparch 4, 61.

533 z. B. Greg. M. epist. 9, 105: Si quis imagines facere voluerit, minime probibe, adorari vero imagines modis 
vor allem im 8. und 9. Jahrhundert n. Chr. an der Frage der Verehrungswürdigkeit der Bilder ein heftiger Streit, der im Verbot der Bilder gipfelte (Ikonoklasmos). Das Ergebnis war eine Trennung zwischen der Verehrung, die den Bildern zugestanden wurde, und der Anbetung, die allein Gott direkt und ohne Vermittlung durch ein Bild zukam, nicht jedoch eine grundsätzliche Ablehnung der Bilderverehrung an sich. Allerdings verzichtete man in der Ostkirche auf plastische Bildwerke, da bei zweidimensionalen Bildern die Gefahr der Verwechslung von Darstellung und Dargestelltem anscheinend weniger stark war ${ }^{534}$. Auch erhielten die Bilder zunächst ihren Platz nicht mehr auf oder in der Nähe des Altars, entwickelten sich aber schnell wieder zu wichtigen Bestandteilen des Kultes. Ihre Anbetung wurde nicht nur geduldet, sondern ausgebaut und theologisch untermauert. In den Ostkirchen spielen zweidimensionale Bilder in Form von Ikonen, Fresken und Mosaiken bis heute eine große Rolle, wobei die Dargestellten oftmals auf mehr als einem Bild in den einzelnen Kirchen vertreten sind ${ }^{535}$. Die Bilder dienen nicht nur der Veranschaulichung von Glaubensinhalten. Aufgrund ihrer Funktion als Mittler zwischen der irdischen und der himmlischen Welt werden sie stattdessen mit der eigentlich den Heiligen geltenden Verehrung bedacht. Die auf den Ikonen dargestellten Personen können dabei als im Kult tatsächlich anwesend gelten ${ }^{536}$.

In den Westkirchen hingegen wurde streng zwischen der Abbildung und dem Abgebildeten unterschieden. Die Bilder galten als leblose, von Menschenhand gefertigte Materie, die zwar zum Schmuck der Kirchen und zur Erinnerung an die Heilstaten diente, aber weder verehrt noch angebetet werden sollte ${ }^{537}$. Ihnen wurde nur ein rein hinweisender Sinn zugestanden. Die Auseinandersetzung fand jedoch allein in der Theologie statt. Die alltägliche religiöse Praxis war davon wenig be-

omnibus veta. - » Wenn jemand Bilder fertigen will, dann hindere ihn nicht; die Anbetung der Bilder aber verhindere mit allen Mitteln«. (Kollwitz 1957b, 109).

534 RAC II (1954) 313-341 s. v. Bild, christlich (J. Kollwitz); Kollwitz 1957a; Belting 1993, bes. 164-207; P. Speck, Bilder und Bilderstreit, in: M. Brandt - A. Effenberger (Hrsg.), Byzanz. Die Macht der Bilder. Ausstellungskatalog Hildesheim (Hildesheim 1998) 56-67; B. Schellewaldt, Die Bilder nach dem Ende des Bilderstreites, in: ders. 68-87; N. Wolf, Die Macht der Heiligen und ihrer Bilder (Stuttgart 2004) bes. 87-114; F. Dünzl, Bilderstreit im ersten Jahrtausend, in: Garhammer 2007, 46-76.

535 Kollwitz 1957a; H. P. Gerhard, Welt der Ikonen 2(Recklinghausen 1963); Theologische Realenzyklopädie VI (1980) 532-540 s. v. Bilder V. Mittelalter I. Byzanz (H. G. Thümmel); K. Weitzmann u. a., Die Ikonen (Freiburg 1982); H. Fischer, Die Ikone. Ursprung - Sinn - Gestalt (Freiburg 1989); Belting 1993; G. Lange, der byzantinische Bilderstreit und das Konzil von Nikaia (787), in: Hoeps 2007, 171-190.

536 W. Schöne, Die Bildgeschichte des christlichen Gottesgestalten in der abendländischen Kunst, in: Schöne 1957, 7-56; L. Rydén, The Role of the Icon in Byzantine Piety, in: H. Biezais (Hrsg.), Religious Symbols and their Functions (Stockholm 1979) 41-52; H. G. Thümmel, Die theologische Auseinandersetzung um die Ikone, in: I. Baldermann - E. Dassmann - O. Fuchs u. a. (Hrsg.), Die Macht der Bilder. Jahrbuch für Biblische Theologie 13, 1998 (Neukirchen-Vluyn 1999) 197-208; Harenberg 2002, 8-267 s. v. Christentum (Th. Schirrmacher).

537 Libri Carolini 3, 16; Durandus, Rationale (divinorum officiorum) 1, 3. 
troffen. Der Volksglaube hielt die Heiligen in ihren Bildern für gegenwärtig. Sie konnten deshalb als ihr Stellvertreter fungieren, um Gebete zu erhören, Eide, Rechtsverträge und Eheschließungen zu bekräftigen oder Schutz zu gewähren. So äußer-

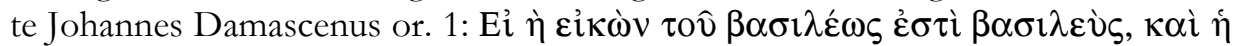

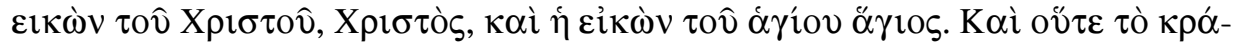

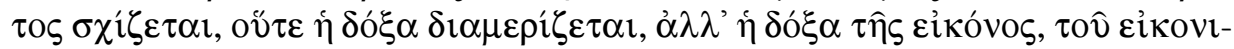

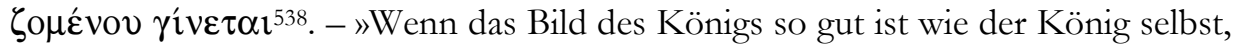
so ist auch das Bild Christi so gut wie Christus und das Bild des Heiligen so gut wie der Heilige. Weder Gewalt noch Ehre wird hierdurch geteilt, denn die dem Bilde gezollte Verehrung gilt der dargestellten Persönlichkeit«. (Kollwitz 1957a, 68)

Die Bilder schienen beseelt und galten als wundertätig, weshalb sich die Menschen mit ihren Anliegen an sie wandten und sie eben auch verehrten, wie zahlreiche Untersuchungen zeigen ${ }^{539}$. Sie spielten wie in der Ostkirche eine wichtige Rolle in der religiösen Praxis. Sie wurden gewaschen und gesalbt, vor ihnen wurden Lichter angezündet und Weihrauch verbrannt, sie wurden geküsst, berührt, man verbeugte sich vor ihnen. Als Gegenleistung erwartete man von den Bildern Hilfe und Heilung. Den Bildern wurden demnach dieselben Kräfte zugeschrieben wie den Dargestellten, und ihre Verehrung entsprach dem sich ebenfalls ausbreitenden Reliquienkult. Welche Bedeutung die Bilder im rituellen Umgang erlangten, zeigt allein schon ihre häufige Aufstellung auf oder hinter dem Altar, dem Zentrum des Gottesdienstes ${ }^{540}$.

Ein erneuter Streit um die Bilder brach in der Reformationszeit zu Beginn des 16. Jahrhunderts in der Westkirche aus. Die Reformatoren prangerten den Um-

${ }^{538}$ Damit übereinstimmend finden sich bis heute zahlreiche Zeugnisse für die Lebendigkeit der Bilder wie Weinen oder Bluten. Zudem gelten einige Bilder als Werke der Apostel und damit als authentisch, gemalt nach dem lebendigen Vorbild. Auch gab es Bilder, die als vom Himmel gefallen und damit von göttlicher Herkunft galten und deshalb besonders mächtige Schutzsymbole darstellten. Vgl. Kollwitz 1957a; Kollwitz 1957b; Campenhausen 1957; H. Sachs - E. Badstübner - H. Neumann, Christliche Ikonographie in Stichworten 2(1980) 63 f. s. v. Bilderverehrung; Belting 1993; J. Trips, Bilder und private Devotion, in: C. Dupeux - P. Jetzler - J. Wirth (Hrsg.), Bildersturm. Wahnsinn oder Gottes Wille? Ausstellungskatalog Bern (Bern 2000) 38-45.

539 Zahlreiche Zeugnisse für die wundermächtige Wirkung der Bilder hat Belting 1993 zusammengestellt. Vgl. auch RAC II (1954) 313-341 s. v. Bild, christlich (J. Kollwitz); Theologische Realenzyklopädie VI (1980) 540-546 s. v. Bilder V. Mittelalter II. Im Westen (W. von Loewenich); C. Dupeux - P. Jetzler - J. Wirth (Hrsg.), Bildersturm. Wahnsinn oder Gottes Wille? Ausstellungskatalog Bern (Bern 2000); N. Wolf, Die Macht der Heiligen und ihrer Bilder (Stuttgart 2004) bes. 106-108; W. Weiß, Bilderzauber - Zauberbilder. Bild und Plastik in den westlichen Kirchen des Mittelalters, in: Garhammer 2007, 77-114.

${ }^{540}$ Campenhausen 1957; Kollwitz 1957b; Belting 1993, bes. 331-333. 446-452; Th. Schirrmacher, Christentum, in: Harenberg 2002, 8-267. Der Gottesdienst galt in der Regel zwar nicht dem Bild, weshalb ein Bild nicht automatisch verehrt wird, wenn es auf dem Altar steht. Seine Bedeutung wird dadurch aber deutlich vor Augen geführt. Außerhalb der Messe waren sie Zentrum zahlreicher Formen der Verehrung. Dies konnte sogar soweit führen, dass zum Kult der Bilder eigens Kapellen eingerichtet wurden, vgl. dazu Belting 1993, 541. 
gang der katholischen Kirche mit den Bildern, vor allem ihr Heilswirken an. Zahlreiche Bildwerke wurden aus den Kirchen entfernt, denn viele lehnten ihre Existenz konsequent ab, damit keine Gefahr der Anbetung bestand. Martin Luther hielt die Bilder für nützlich, um das Heilsgeschehen zu vergegenwärtigen, eine Verehrung hat aber er ebenso strikt abgelehnt. In Lutherischen Kirchen behielten Bilder deshalb bis heute eine Daseinsberechtigung als Lehrmittel, wenn lutherische Kirchen auch deutlich weniger mit Bildern ausgestattet sind als katholische. Ihre Stiftung und Betrachtung hat im Gegensatz zur katholischen Kirche keine Bedeutung für das Seelenheil, sie sind nur hinweisende Zeichen und können als solche sogar einen Platz am oder auf dem Altar erhalten, ohne jedoch in die Kultpraxis einbezogen zu sein, wie immer wieder betont wird ${ }^{541}$.

In der Gegenreaktion der katholischen Kirche wurde die Verehrung der Bilder nur noch stärker. Kirchliche Orden und Kongregationen förderten und verwalteten den Bilderkult und die damit verbundene Gnadenvermittlung ${ }^{542}$. Das katholische Kirchenrecht von 1983 hat die Verehrungswürdigkeit der Bilder für die heutige Zeit noch einmal bestätigt: »Der Brauch, in Kirchen heilige Bilder für die Verehrung durch die Gläubigen anzubringen, ist beizubehalten; sie sind jedoch in mäßiger Zahl und in angemessener Ordnung aufzustellen, damit beim christlichen Volk nicht Verwunderung entsteht und kein Anlaß für eine weniger rechte Ver-

541 W. Wendland, Die Kunst der Kirche (Berlin 1953); H. C. von Haebler, Das Bild in der evangelischen Kirche (Berlin 1957); E. Ullmann (Hrsg.), Kunst und Reformation (Leipzig 1982); W. Hofmann (Hrsg.), Luther und die Folgen für die Kunst. Ausstellungskatalog Hamburg (München 1983); Kunst der Reformationszeit. Ausstellungskatalog Berlin (Berlin 1983); G. May, Die Kirche und ihre Bilder, in: R. Beck - R. Volp - G. Schmirber (Hrsg.), Die Kunst und die Kirchen. Der Streit um die Bilder heute (München 1984) 57-67; W. Hofman, Luther und die Folgen für die Kunst, in: ebenda 67-82; A. Mertin - H. Schwebel (Hrsg.), Kirche und moderne Kunst. Eine aktuelle Dokumentation (Frankfurt a. M. 1988); K. Winnekes, Christusbilder der Neuzeit, in: dies. (Hrsg.), Christus in der bildenden Kunst. Von den Anfängen bis zur Gegenwart (München 1989) 31-38; W. Lück, Das Bild in der Kirche des Wortes. Eine Einführung in die Bilderwelt evangelischer Kirchen (Münster 2001); A. Stock, Bilderfrage. Theologische Gesichtspunkte (Paderborn 2004); J. Wirth, Die Bestreitung des Bildes von Jahr 1000 bis zum Vorabend der Reformation, in: Hoeps 2007, 191-212; Th. Lentes, Zwischen Adiaphora und Artefakt. Bildbestreitung in der Reformation, in: ebenda 213-240; D. Burkard, Bildersturm? Die Reformation(en) und die Bilder, in: Garhammer 2007, 115-140.

542 W. von Loewenich, Der moderne Katholizismus vor und nach dem Konzil (Witten 1952); A. Henze, Neue kirchliche Kunst (Recklinghausen 1958); W. Hofmann (Hrsg.), Luther und die Folgen für die Kunst. Ausstellungskatalog Hamburg (München 1983); E. Karcher, Ursache und Wirkung des Bildverständnisses des Konzils von Trient, in: R. Beck - R. Volp - G. Schmirber (Hrsg.), Die Kunst und die Kirchen. Der Streit um die Bilder heute (München 1984) 82-92; J. H. Emminghaus, Der gottesdienstliche Raum und seine Ausstattung, in: H. B. Meyer (Hrsg.), Gottesdienst der Kirche. Handbuch der Liturgiewissenschaft III. Gestalt des Gottesdienstes. Sprachliche und nichtsprachliche Ausdrucksformen ${ }^{2}$ (Regensburg 1990) 347-416; F. Bœspflug - O. Christin, Das Konzil von Trient und die katholischen Traktate De imaginibus (1522-1680), in: Hoeps 2007, 241-261; D. Ganz - G. Henkel, Kritik und Modernisierung. Der katholische Bildkult des konfessionellen Zeitalters, in: ebenda 262-285. 
ehrung gegeben wird «543. Und so werden die Bilder Jesu, Marias und der Heiligen auch heute gegrüßt, berührt und geküsst und mit Blumen, Weihrauch und Lichtern verehrt, und zwar sowohl privat als auch öffentlich. Sie werden in verehrenden Prozessionen alljährlich durch die Straßen ihrer Heimatstädte getragen ${ }^{544}$. Interessant ist, dass dabei oft mehr als ein Bild Jesus, Marias oder der Heiligen mitgeführt wird. So führt Á. Brachetti in ihrer Untersuchung der Karwoche in Spanien und anderen spanischsprachigen Ländern für die Prozession in Malaga 43 Christusbilder an, die 17 verschiedene Themen umfassen, darunter allein 14 Bilder des gekreuzigten Christus und 8 des Büßers ${ }^{545}$.

Bezeichnend für den christlichen, besonders den katholischen und orthodoxen Kult generell ist die Tatsache, dass es kaum eine Kirche gibt, die nur ein Bild ihres Namenspatrons sowie weiterer Heiliger besitzt. Sie befinden sich sowohl im Hauptraum des Gotteshauses als auch in den z. T. zahlreich vorhandenen Kapellen und Nebenräumen. Alle diese Bilder können in die Verehrung einbezogen werden, wobei einerseits die im liturgischen Jahr festgelegten Handlungen und Feste als auch das individuelle Bedürfnis der einzelnen Gläubigen ausschlaggebend sind ${ }^{546}$. Eine Unterscheidung im Sinne von speziell zu kultischen Zwecken geschaffenen und rituell eingesetzten Bildern und solchen, bei denen dies nicht zutrifft, wird im Christentum nicht getroffen, denn prinzipiell kann jedes Bild den oder die Heilige repräsentieren. Stattdessen zeichnen sich einige der Bilder durch eine besondere Wirkmächtigkeit und Wundertätigkeit aus. Oder sie unterscheiden sich durch spezifische Funktionen, die sie ihm Kult erfüllen ${ }^{547}$. Somit wird nicht generell zwischen Bildern, die Kult empfangen und solchen, die keinen Kult empfangen unterschieden, sondern nur in der Funktion, die die Bilder im Kult erfüllen.

${ }^{543}$ Codex Iuris Canonici 1188. Weitere liturgische Vorschriften bei G. Fuchs, Heilige Zeichen, die zu Gott führen. Über die vielfältige Verwendung der Bilder in der Liturgie, in: Garhammer 2007, 187-200; H. Hallermann, Kitsch oder Kunst? Bilder, Bilderstreit und Bilderverehrung im Kirchenrecht, in: ebenda 169-185.

${ }^{544}$ Besonders bekannt sind die Fronleichnams- und Palmsonntagsprozessionen und die Prozessionen der Semana Santa in Spanien und Lateinamerika H. Schüttel, Die große Leidensprozession in Heiligenstadt (Eichsfeld) ${ }^{2}$ (Heiligenstadt 2003); J. Keppler, Die Heiligenstädter Leidensprozession am Palmsonntag, Eichsfelder Heimatzeitschrift 48, 2004, 117-119; G. Fuchs, Fronleichnam. Ein Fest in Bewegung (Regensburg 2006); Á. Brachetti, La pasión de Cristo: representaciones religiosas en Andalucía, Paraguay, Perú y Filipinas (Malaga 2007).

545 Á. Brachetti, La pasión de Cristo: representaciones religiosas en Andalucía, Paraguay, Perú y Filipinas (Malaga 2007) 242.

546 Bekannt ist auch, dass der Übergang von der einzelnen Wiedergabe Gottvaters Christus', Marias oder der Heiligen, , wie sie in den antiken Religionen für Kultbilder üblich war, hin zu szenischen Darstellungen etwa in der Tafel- oder Wandmalerei im christlichen Kult fließend war. Verbreitet sind sowohl rundplastische Darstellungen als auch Reliefs, Wand- oder Tafelgemälde und sogar Stoffmalereien. Die Vielfalt der Formen verehrter Bilder zeigt besonders die ausführliche Darstellung bei Belting 1993.

547 Ebenda. 
Bei der Untersuchung des religiösen Phänomens des >Kultbildes denen Religionen hat sich gezeigt, dass es in den hier betrachteten, sehr unterschiedlichen Religionen nicht das eine >Kultbild in einem Heiligtum oder einer Kirche gegeben hat, sondern dass man in die differenzierte religiöse Praxis verschiedene Bilder einbezieht, die unterschiedlichen Vorstellungen und Ansprüchen gerecht werden und unterschiedliche Aufgaben erfüllen. Die nun folgenden Abschnitte sollen dazu dienen, die Bedeutung und Funktion antiker griechischer Götterbilder im Kult in einem allgemeineren Sinn zu beleuchten, um einen Hintergrund für die in Kapitel $12 \mathrm{zu}$ stellende Frage zu erhalten, ob ein griechisches Heiligtum mehr als ein >Kultbild besitzen konnte.

\section{2. >Kultbilder in der griechischen Antike}

\subsubsection{Antike Terminologie}

Vorwegnehmend kann gesagt werden, dass es für den neuzeitlichen Begriff >Kultbild in der griechischen Antike keine Entsprechung gab ${ }^{548}$. Die Quellen bezeich-

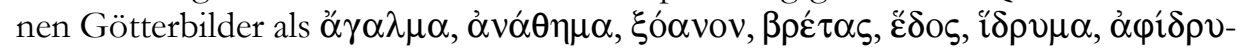

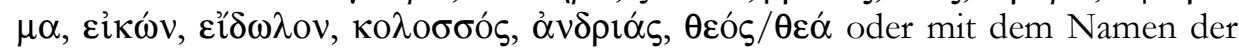
Gottheit. Die Verwendung dieser Begriffe in der antiken Literatur wurde bereits mehrfach untersucht, weshalb hier darauf zurückgegriffen werden kann. Unter der neueren Literatur sind besonders die Ausführungen von T. S. Scheer zur Funktion griechischer $/ K u l t b i l d e r<$ in Religion und Politik aus dem Jahr 2000 und die Untersuchungen von G. Nick zur Athena Parthenos aus dem Jahr 2002 hervorzuheben. Beide haben unabhängig voneinander festgestellt, dass es in der antiken Terminologie keinen explizit das deutsche Wort `Kultbild`, das im 19. Jahrhundert als Bezeichnung für verehrte Götterbilder aufkam ${ }^{549}$, widerspiegelnden Begriff gibt.

Die älteste wie auch besonders häufige Bezeichnung für ein Götterbild - neben der bereits bei Homer vorkommenden Verwendung des Eigennamens der Gottheit - ist ״̈ $\gamma \alpha \lambda \mu \alpha$. Mit diesem Begriff wurde seit der homerischen Zeit ein »Gegenstand der Freude und des Stolzes, Schmuck (sinnlich sowohl als ethisch), Zier, Kleinod « bezeichnet ${ }^{550}$. Mit dem Begriff konnte demnach der materielle oder künstlerische Wert eines Gegenstandes bezeichnet werden, nicht jedoch seine Funktion. Deshalb finden sich unter den mit ő $\gamma \alpha \lambda \mu \alpha$ bezeichneten Objekten nicht nur Götterstatuen, sondern auch Bilder von Menschen wie die bekannte Statue des Chares, die

548 Donohue 1997; Faulstich 1997, 26-30; Berlejung u. a. 1999a; Scheer 2000, 8-34; Nick, 2002, 9-28; Linant de Bellefonds u. a. 2004, $418 \mathrm{f}$.

549 s. S. 168 f.

${ }^{550}$ RE I (1894) 718 f. s. v. Agalma (E. Reisch); Philipp 1968, 103-105; W. Burkert, From Epiphanie to Cult statue: Early Greek Theos, in: A. B. Lloyd (Hrsg.), What is a God? Studies in the Nature of Greek Divinity (London 1997) 15-34. 
dieser in archaischer Zeit zu Ehren Apollons bei Didyma aufgestellt hatte und die in ihrer Inschrift als ö $\gamma \alpha \lambda \mu \alpha$ benannt wird ${ }^{551}$. Doch auch andere Gegenstände wie Waffen, Siegeskränze oder Schmuck konnten so bezeichnet werden. Die Benennung von Götterbildern mit dem Begriff scheint sogar erst in der 2. Hälfte des 6. Jahrhunderts v. Chr. und damit später als dessen früheste Belege aufgekommen zu sein. Nur bei einigen Bildern geht aus der Textstelle oder einem anderen Zusammenhang, nicht jedoch aus dem Begriff ö $\gamma \alpha \lambda \mu \alpha$ hervor, dass es sich um verehrte Bilder handelte, bei den meisten bleibt ihre Funktion unklar. Eine Vereinheitlichung der Begriffsbedeutung hat nicht stattgefunden, und auch in klassischer Zeit konnten ganz unterschiedliche Gegenstände als $\alpha \dot{\gamma} \alpha \dot{\lambda} \lambda \mu \alpha \tau \alpha$ bezeichnet werden, so dass das Wort kein Äquivalent zu dem deutschen Begriff >Kultbild darstellt ${ }^{552}$.

Eine ähnliche Bedeutung hatte laut der Forschung der Begriff ỏvó $\theta \eta \mu \alpha$. Er bezeichnete den Göttern dargebrachte Geschenke, also das, »was man der Gottheit hinsetzt«. Diese gingen dadurch in göttlichen Besitz über und wurden heilig. Der Begriff wird deshalb ebenso wie das Wort ő $\gamma \alpha \lambda \mu \alpha$ häufig mit >Weihgeschenkı übersetzt und war nicht auf eine bestimmte Gattung von Gegenständen, schon gar nicht auf Bilder von Göttern festgelegt ${ }^{553}$.

Auch die Bezeichnung eines Bildes als $\theta \varepsilon o ́ \varsigma$ bzw. $\theta \varepsilon \alpha ́$ impliziert ebenfalls keine gesicherte kultische Funktion des Bildes. Mit diesem Begriff sei lediglich eine Abgrenzung zu Darstellungen von Menschen vorgenommen worden, wenn es auch scheint, dass viele der mit dem Begriff $\theta \varepsilon$ ó $\varsigma$ bezeichneten Bilder in einen Kult einbezogen waren ${ }^{554}$.

Der Begriff $\beta \rho \varepsilon ́ \tau \alpha \varsigma$ ist seit dem 5. Jahrhundert v. Chr. belegt und bezeichnete vorrangig Götterbilder, die allerdings selten genauer definiert sind. In der Forschung hielt man die so benannten Bilder zumeist für kleinformatig, alt und aus Holz gefertigt. Viele als $\beta \rho \varepsilon ́ \tau \alpha \varsigma$ bezeichnete Bilder galten in der antiken Literatur tatsächlich als alt, ansonsten liefern die antiken Zeugnisse jedoch nur wenige Hinweise auf die Größe oder das Material, so dass eine Verallgemeinerung der Begriffsbedeutung nicht möglich ist, wie bereits mehrfach festgestellt wurde. Eine Kultfunktion scheint in vielen Fällen nahe liegend und wird auch z. T. direkt erwähnt, jedoch kommt der Begriff $\beta \rho \varepsilon ́ \tau \alpha \varsigma$ nur sehr selten vor und kann deshalb kaum als allgemeine Bezeichnung für die in der Antike allgegenwärtigen verehrten Bilder gedient haben. T. S. Scheer hat außerdem festgestellt, dass der Begriff häufig in einem Zusammenhang verwendet wird, bei dem sich Menschen in Not zu

551 London, British Museum Inv. B 278: B. S. Ridgway, The Archaic Style in Greek Sculpture (Princeton 1977) 125-129 Abb. 31; Boardman 1981, 85 Abb. 95.

552 Belege bei Müller 1931, 490; Philipp 1968, 103-105; Damaskos 1999, 304-309; Scheer 2000, 8-18; Bettinetti 2001, 31 f.; Nick, 2002, 12-15.

553 DNP I (1996) 659 f. s. v. Anathema (H. S. Versnel), dort das Zitat; RE I (1894) 2069 s. v.

'Avó $\theta \eta \mu \alpha$ (E. Reisch); W. H. D. Rouse, Greek Votive Offerings. An Essay in the History of Greek Religion (Hildesheim 1976) 323 f. Scheer 2000, 17.

554 Nick, 2002 16-18. 
einem Götterbild retten, das demnach besonderen Schutz gewährte und aus diesem Zusammenhang heraus sicherlich auch kultisch verehrt wurde. Oder von dem

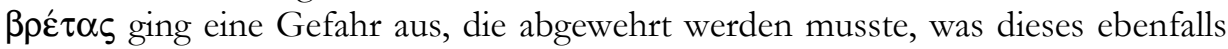
von anderen Bildern abhob. Ein $\beta \rho \varepsilon ́ \tau \alpha \varsigma$ besaß demnach eine besondere Wirkmacht, jedoch wurde nicht jedes wundertätige Bild als $\beta \rho \varepsilon ́ \tau \alpha \varsigma$ bezeichnet, so dass auch hier kein allgemein gültiger Begriff vorliegt ${ }^{555}$.

Eine ähnliche Bedeutung wie dem Begriff $\beta \rho \varepsilon ́ \tau \alpha \varsigma$ hat besonders die ältere Forschung auch dem Wort కóovov beigelegt. Damit seien besonders alte Bilder bezeichnet worden, die am Beginn der Erschaffung von Götterbildern standen und deshalb noch kaum künstlerisch bearbeitet waren. Außerdem sollten diese Bilder aus Holz gefertigt worden sein, bevor man andere Techniken beherrschte ${ }^{556}$. A. A. Donohue konnte diese Thesen jedoch in einer umfangreichen Untersuchung aus dem Jahr 1988 widerlegen. Die von ihm untersuchten Zeugnisse zeigen, dass mit diesem Begriff nicht immer ein altes Götterbild, ja besonders bei den frühen Belegen des Wortes, also im 5. Jahrhundert v. Chr., noch nicht einmal unbedingt ein

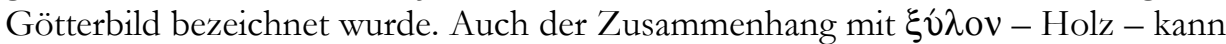
nicht durchgängig aufrechterhalten werden, wie außer A. A. Donohue auch T. S. Scheer gezeigt hat. Lediglich Pausanias sowie nach Ansicht von A. A. Donohue auch Plutarch scheinen mit dem Wort $\xi o ́ \alpha v o v$ hölzerne Bilder zu bezeichnen ${ }^{557}$.

Auch die weiteren in der antiken griechischen Literatur verwendeten Begriffe für Götterbilder wurden nicht ausschließlich für diese verwendet und schon gar nicht mit der Einschränkung, dass damit nur verehrte Statuen in Abgrenzung zu nicht verehrten Bildern bezeichnet wurden, wie verschiedene Untersuchungen

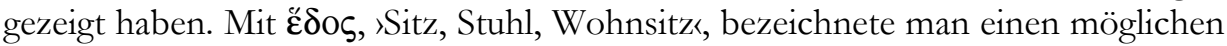
Aufenthaltsort für Götter. Dies konnte sowohl ein Tempel oder Schrein sein, seit dem Ende des 5. Jahrhunderts v. Chr. auch eine Götterstatue. Dabei war es nicht ausschlaggebend, wie oder aus welchem Material die Statue gefertigt worden war. Auch musste nicht unbedingt ein Sitzbild gemeint sein ${ }^{558}$, da z. B. auch die Athena

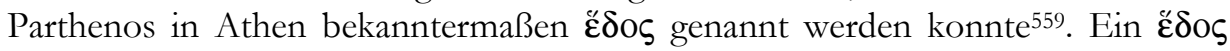
stand nach Ansicht der Forschung zwar in sakralem Zusammenhang, doch bezeichnete der Begriff nicht ausschließlich statuarische `Göttersitze`, weshalb auch

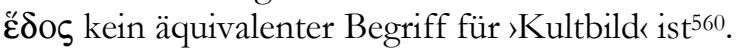

\footnotetext{
555 Scheer 2000, 24-33; Bettinetti 2001, 42; Nick, 2002, 20 f. mit beibehaltener Deutung als altes Holzbild; B. Rabe, Tropaia. $\tau \rho \circ \pi \eta \dot{~ u n d ~} \sigma \kappa \hat{v} \lambda \alpha$ - Entstehung, Funktion und Bedeutung des griechischen Tropaions, Tübinger Archäologische Forschungen 5 (2007) $24 \mathrm{f}$.

556 Zusammenstellung der bisherigen Forschungsmeinungen bei Donohue 1988, bes. 1-8. 175-231.

Die antiken Quellen, auf denen die Aussagen der älteren Forschung beruhen: ebenda 123-150.

557 Donohue 1988; Scheer 2000, 19-21; ebenso Müller 1931, 490; Faulstich 1997, 26-30; Bettinetti 2001, 42.49 f.; Nick, 2002, 20-22.

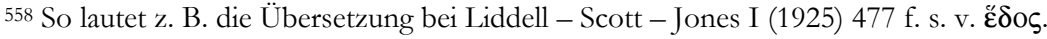

${ }_{559}$ Belege bei Nick, 2002, 23.

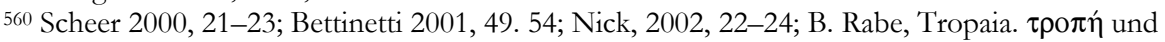




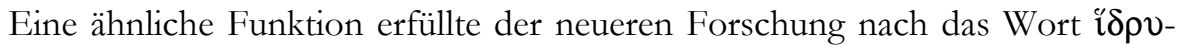
$\mu \alpha$. Auch mit diesem etwas weiter gefassten Begriff konnten Heiligtümer, Tempel und Götterbilder bezeichnet werden ${ }^{561}$. Mit $\alpha \dot{\alpha} \varphi \hat{\delta} \delta \rho \mu \alpha$ wurde ursprünglich eine Filialgründung eines Kultes bezeichnet, später auch ein heiliges Objekt oder eine Statue, die bei der Gründung des neuen Kultes Verwendung fand und optisch die Anwesenheit der vertrauten Gottheit in dem neuen Heiligtum und damit die Fortführung des Kultes deutlich machen konnte. Dabei konnte es sich um eine Kopie der Statue des Mutterheiligtums oder um eine Anlehnung an den Typus handeln, dies war jedoch nicht zwingend ${ }^{562}$. Da es jedoch nicht in jedem Fall ein Götterbild war, ist auch der Begriff $\alpha \varphi^{i} \delta \rho v \mu \alpha$ keine genaue Entsprechung zu

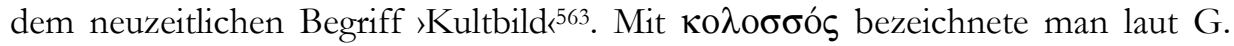
Nick ein aufrecht stehendes Werk, das nicht transportabel war. Seit der hellenistischen Zeit verband man mit dem Begriff außerdem den Gedanken der außer-

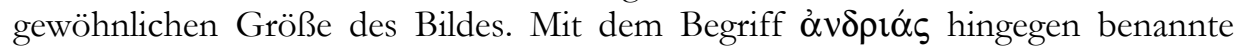
man nach G. Nick in der Antike vorrangig menschlich gestaltete männliche Statuen, worunter auch verehrte Bilder fallen konnten, jedoch nicht ausschließ-

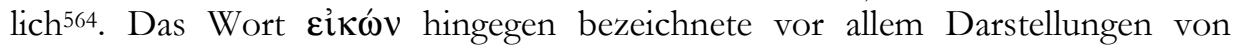
Menschen. Für Götterbilder sei es selten belegt und deute hier nicht auf eine Funktion des Bildes als $\gg$ Kultstatue hin. Gleiches gelte für den Begriff $\varepsilon \imath ̌ \delta \omega \lambda ం \nu^{565}$.

Es bleibt mit G. Nick und T. S. Scheer festzuhalten, dass es zwar viele antike Begriffe zur Bezeichnung von Götterbildern gab, dass jedoch keiner von diesen inhaltlich eindeutig festgelegt war. Außerdem wandelte sich die Bedeutung einzelner Begriffe im Laufe der Zeit. Ob ein Bild eine Funktion im Kult erfüllt hat, ist deshalb aus seiner Bezeichnung nicht zu erkennen, sondern geht allein aus den Kenntnissen über den Umgang mit dem Bild im Kult hervor ${ }^{566}$. Ein weiterer problematischer Punkt für die Frage nach der antiken Bezeichnung von >Kultstatuen ist die bekannte Vorliebe einiger antiker Autoren für einzelne Begriffe, vor allem bei Pausanias, der wichtigsten Quelle für diese Arbeit. Ein zu enger Bezug zu einzelnen Quellen und ihrer Wortwahl könnte deshalb ebenfalls das Bild, das wir versuchen, uns von den antiken Göttern und Kultformen zu machen verschieben $^{567}$. Eine klare Unterscheidung in verschiedene Kategorien, wie wir sie heute

$\sigma \kappa \hat{v} \lambda \alpha$ - Entstehung, Funktion und Bedeutung des griechischen Tropaions, Tübinger Archäologische Forschungen 5 (2007) 25.

561 Nick, 2002, 24.

562 s. z. B. die Filialkulte der Artemis von Ephesos, s. Anm. 187.

563 Scheer 2000, 245 f.; Nick 2002, 100.

564 Donohue 1988, 27; Nick 2002, 16.

565 Damaskos 1999, 304-309; Scheer 2000, 14-16. 33; Nick 2002, 18-20.

566 Ähnlich auch W. Burkert, Mythen - Tempel - Götterbilder. Von der Nahöstlichen Koiné zur griechischen Gestaltung, in: Kratz - Spieckermann 2006b, 3-20.

567 Donohue 1988, 140. 
vornehmen, kann den antiken Begriffen nicht entnommen werden. Auch aus den Quellen, die vom Umgang mit Götterbildern berichten, geht keine strikte Trennung hervor. Besonders deutlich zeigt dies eine Überlieferung bei Athenaios

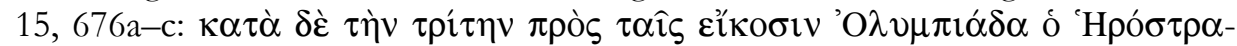

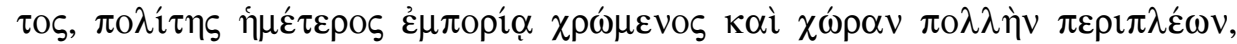

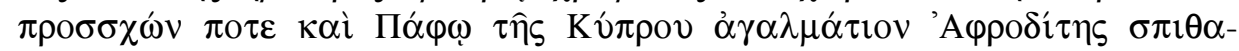

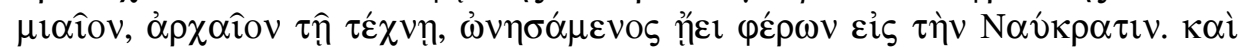

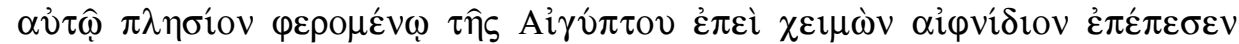

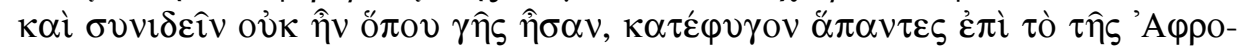

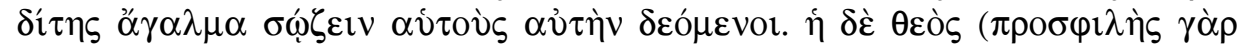

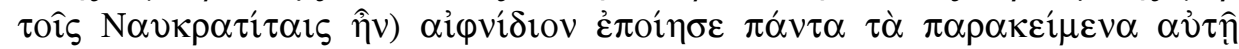

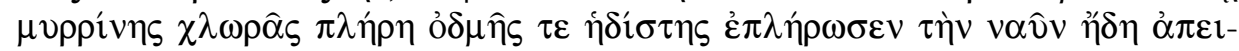

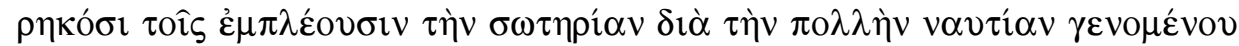

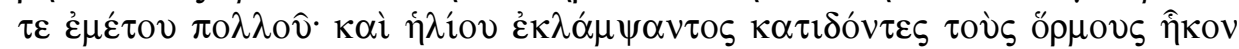

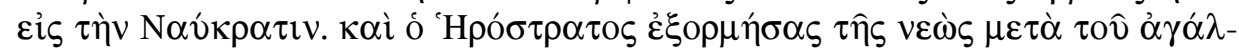

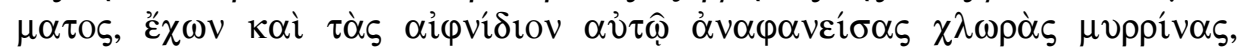

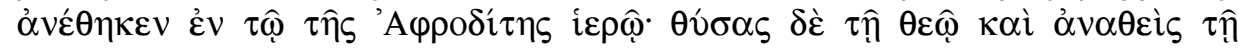

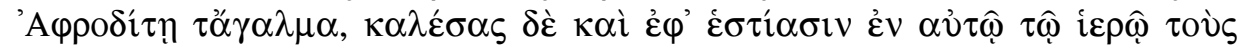

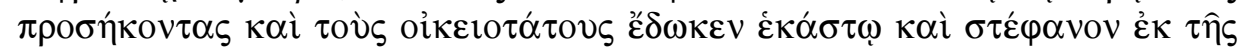

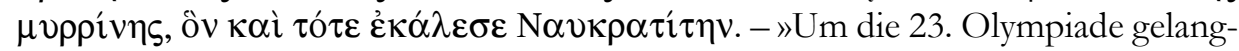
te unser Mitbürger Herostratos, der im Fernhandel tätig war und weit herumkam, einmal auch nach Paphos auf Zypern. Dort kaufte er eine Statuette der Aphrodite, eine Spanne hoch, im alten Stil gearbeitet, und nahm sie mit auf die Heimreise nach Naukratis. Als er sich Ägypten näherte, überfiel ihn ein plötzlicher Sturm, und es war unmöglich auszumachen, wo in aller Welt sie waren. Da nahmen alle ihre Zuflucht zu dem Standbild der Aphrodite und flehten sie an, sie zu erretten. Die Göttin aber, die den Naukratiten wohlgesonnen war, ließ plötzlich alles in ihrer Umgebung von grüner Myrte voll werden und erfüllte das Schiff mit dem köstlichsten Duft, als die Mitreisenden schon die Hoffnung auf Rettung aufgegeben hatten, gab es doch schlimme Seekrankheit und viel Erbrechen. Dann brach die Sonne durch, der Hafen zeigte sich ihren Blicken, und so kamen sie nach Naukratis. Und Herostratos verließ das Schiff mit dem Götterbild nebst den ihm so plötzlich erschienen grünen Myrtenzweigen und brachte sie als Weihgabe in das Heiligtum der Aphrodite. Er opferte der Göttin, weihte der Aphrodite die Statue, lud zu einem Gastmahl direkt im Heiligtum seine Verwandten und nächsten Freunde ein und schenkte einem jeden einen Kranz aus Myrtenzweigen, dem er bei dieser Gelegenheit den Namen Naukratis-Kranz gab«. (U. Treu - K. Treu)

Bei diesem Bild handelte es sich also zunächst um ein Handelsgut, dessen Funktion vor dem Verkauf noch nicht festgelegt war. Aufgrund einer ungewöhnlichen Situation wurde es nach dem Kauf zum Zentrum eines Kultes, indem sich die in Not geratenen Seeleute mit ihren Gebeten an das Bild wandten, die von der Göttin erhört wurden. Als Dank für die Rettung stiftete der Händler das Bild an- 
schließend in ein bestehendes Heiligtum, das sicherlich bereits ein oder mehrere $>$ Kultbilder besaß, da es keine Neugründung war. Die Statuette würde von diesem Zeitpunkt an als private Gabe unter den Begriff des $>$ Weihgeschenks im heutigen Sinne fallen, obwohl sie vorher Kult empfangen hatte. Dieses Beispiel belegt, wie fließend die Kategorien sind, die wir mit unseren heutigen Begriffen an griechische Götterbilder herantragen, oder besser gesagt, dass unsere heutigen Begriffe das antike Verständnis und den antiken Umgang mit den Bildern nicht wirklich fassen.

\subsubsection{Anwendung des Kultbildbegriffes auf die griechische Antike}

Es gab also innerhalb der antiken griechischen Terminologie keinen adäquat das Wort 'Kultbild widerspiegelnden Begriff. Dennoch wird er in der Forschung immer wieder verwendet. Daher ist zu prüfen, ob und für welche Bilder eine Verwendung des Begriffes sinnvoll sein kann.

Der Ort, wo die Gemeinschaft sich zum Opfer und Gebet versammelte, war in der Antike in der Regel nicht das Bild der Gottheit, sondern der Altar ${ }^{568}$. Dieser stand zumeist im Freien vor dem Tempel. Das `Kultbild nahm deshalb für gewöhnlich nicht direkt an den Opferfeiern teil. Bekannt ist auch, dass der Tempel zumeist kein Versammlungsraum für die Gemeinde, sondern das Haus einer Götterstatue war ${ }^{569}$. Ein Götterbild war in der Antike nicht Voraussetzung, um einen Kult auszuüben. An manchen Kultstätten war kein Bild vorhanden, wie in

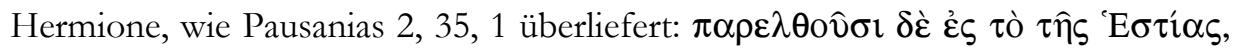

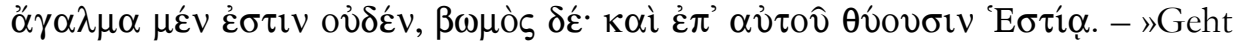
man weiter ins Hestiaheiligtum, so ist da kein Kultbild mehr, aber ein Altar, und auf dem opfert man der Hestiar. (F. Eckstein - P. C. Bol)

Die zahlreichen Zeugnisse für Riten, die speziell für und mit den Bildern begangen wurden ${ }^{570}$, bezeugen jedoch die Wichtigkeit von Bildern im Kult. Für das antike Griechenland wird der Begriff /Kultbild « von der Forschung, wie zuletzt die Definition von B. Gladigow ${ }^{571}$ gezeigt hat, für Götterbilder verwendet, die in kultische Rituale eingebunden waren bzw. an oder mit denen Kulte vollzogen wurden $^{572}$. Die Bilder waren grundsätzlich weder durch ihren Aufstellungsort

568 RE I (1894) 1640-1691 s. v. Altar (E. Reisch); B. Bergquist, The Archaic Greek Temenos. A Study of Structure and Function (Lund 1967) 5 f.; Bald Romano 1980, 4; Whitley 2001, 134;

H.-G. Nesselrath, Tempel, Riten und Orakel. Die Stellung der Religion im Leben der Griechen, in: Kratz - Spieckermann 2006b, 50.

${ }^{569}$ H. Cancik - B. Gladigow - K.-H. Kohl (Hrsg.), Handbuch religionswissenschaftlicher Grundbegriffe IV (1998) 32-43 s. v. Kultort (Chr. Elsas); Goldammer 1985, 605 s. v. Tempel; H.-G. Nesselrath, Tempel, Riten und Orakel. Die Stellung der Religion im Leben der Griechen, in: Kratz - Spieckermann 2006b, 45-67.

570 s. Kap. 15.2.1.

571 s. S. 169 f.

572 Müller 1931; Berlejung u. a. 1999a; Linant de Bellefonds u. a. 2004; B. Gladigow, Präsenz der Bilder - Präsenz der Götter. Kultbilder und Bilder der Götter in der griechischen Religion, 
noch durch ihr Material, ihre Herstellungstechnik oder ihre Größe definiert. >Kultbilder standen zwar häufig in Tempeln, sie konnten aber auch im Freien in Hainen oder an öffentlichen Plätzen oder auch in Höhlen stehen ${ }^{573}$. In Griechenland wie auch später in Rom waren verehrte Bilder vorrangig rundplastisch in Gestalt von frei stehenden anthropomorphen Statuen oder Statuetten. In Form von Reliefs oder Gemälden kamen sie nur selten vor ${ }^{574}$. Daneben gab es aber auch anikonische Göttermale oder solche, die nur z. T. menschengestaltig waren ${ }^{575}$.

Inthronisierungs- und Weihzeremonien wie bei den oben betrachteten Religionen oder auch im römischen Kult ${ }^{576}$ sind für das antike Griechenland kaum belegt und scheinen deshalb nicht unabdingbarer Bestandteil bei der Einsetzung eines zur Verehrung bestimmten Bildes gewesen zu sein ${ }^{577}$. Die wenigen bekannten Beispiele betonen, dass es sich um eine Ausnahmesituation handelt, so etwa die Überlieferung bei Diodor 4, 51, 1, wo er berichtet, wie die orientalische Zauberin Medeia ein Bild der Artemis mit magischen Praktiken behandelt habe, um ihm Wirkmächtigkeit einzuflößen ${ }^{578}$. Ein $>$ Kultbild lässt sich daher allein durch die ihm zuteil werdenden Handlungen definieren.

Um seine Funktion als Kommunikationspartner erfüllen zu können, muss ein Götterbild in der Vorstellung der Verehrer mehr sein als ein lebloser Stein oder ein geschnitztes Holz. Es muss fähig sein, die Wünsche und Bitten der Menschen zu hören und aufzunehmen. Wie in allen Kulturen stößt man deshalb auch in den antiken griechischen Quellen immer wieder auf Zeugnisse für die Vorstellung der Lebendigkeit der Bilder, die dann als die Götter selbst galten, wie besonders T. S. Scheer herausgearbeitet hat ${ }^{579}$. Das früheste Beispiel für die Erwähnung eines \Kultbildes in der Literatur ist die Ilias Homers, die gleichzeitig das früheste Zeugnis dafür liefert, dass das Bild die Gottheit sein konnte. Im 6. Abschnitt der Ilias begeben sich die Frauen von Troja zum Bild der Athena, um Hilfe zu erbitten:

VisRel 4/5, 1985/86, 114-133; ders., Epiphanie, Statuette, Kultbild. Griechische Gottesvorstellungen im Wechsel von Kontext und Medium, VisRel 7, 1990, 98-121.

573 z. B. Trophonios in Lebadeia: s. Kap. 12.16.

574 z. B. die Reliefs im Kult des Mithras oder die gemalten römischen Lararienschreine: Müller 1931, 473; R. Merkelbach, Mithras (Königstein 1984); M. J. Vermaseren, Mithras. Geschichte eines Kultes (Stuttgart 1965); V. J. Walters, The Cult of Mithras in the Roman Provinces of Gaul (Leiden 1974); T. Fröhlich, Lararien- und Fassadenbilder in den Vesuvstädten. Untersuchungen zur volkstümlichen pompejanischen Malerei(Mainz 1991); dies., Pompejanische Lararienbilder, AW 26, 3, 1995, 203-210.

575 Paus. 1, 44, 2; 2, 9, 6; 4, 33 ,3; 8, 31, 7; 8, 48, 6; 9, 24, 3; 9, 40, 11 f.; Clem. Al. Protr. 4, 46, 3.

576 Zur Consecratio im römischen Kult s. RE IV (1901) 896-902 s. v. Consecratio (G. Wissowa); DNP III (1999) 127 s. v. Consecratio (Chr. Frateantonio); Scheer 2000, 111-115.

577 Scheer 2000; H.-G. Nesselrath, Tempel, Riten und Orakel. Die Stellung der Religion im Leben der Griechen, in: Kratz - Spieckermann 2006b, 45-67. Ähnlich auch Oenbrink 1997, 330. 338.

578 Vgl. auch Linant de Bellefonds u. a. 2004, 418 f.; Scheer 2000, 111-115.

579 Scheer 2000, bes. 46-54. 66-75. Vgl. auch Gladigow u. a. 1998, 9-14; Steiner 2001, 156-184. 


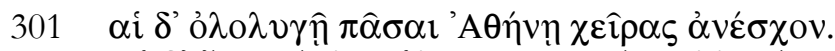

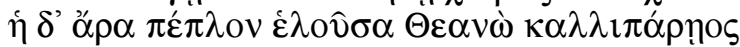

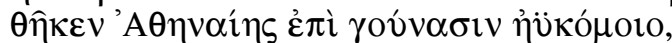

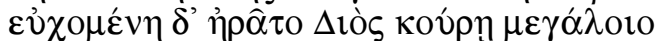

305 „Пó $\tau v \imath$ 'A 'A

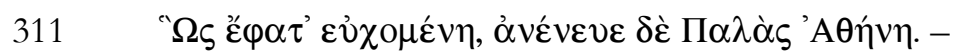

301 »All erhuben die Hände mit jammerndem Laut zur Athene;

Aber es nahm das Gewand die anmutvolle Theano, Leg't es hin auf die Knie der schöngelockten Athene, Flehete dann gelobend zu Zeus' des allmächtigen Tochter:

305 Pallas Athene voll Macht, Stadtschirmerin, edelste Göttin! [...]

311 Also sprach sie betend; es weigerte Pallas Athene«. (J. H. Voß)

Homer macht in dieser Textstelle keinen Unterschied zwischen der Statue und der Göttin und liefert damit einen eindeutigen Hinweis für die Vorstellung, dass in dem Bild die Gottheit gesehen wurde ${ }^{580}$. T. S. Scheer deutet die von ihr untersuchten Zeugnisse für die Lebendigkeit der Bilder so, dass ein Bild ein Angebot an die jeweilige Gottheit war, sich in diesem niederzulassen, was bedeutet, dass sie es auch wieder verlassen konnte und deshalb nur für eine gewisse Zeit im Bild

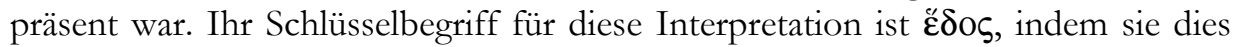
ausgedrückt findet ${ }^{581}$. Eine derart rationalistische Denkweise entspricht unseren heutigen Vorstellungen. In der Antike hingegen scheint eine Götterstatue je nach Bedarf und Blickwinkel unterschiedlich funktionalisiert worden zu sein und war entweder ein materielles Bild einer Gottheit oder die Gottheit selbst, ohne dass sich eine rationale Vorstellung oder genaue Definition, wie wir sie heute gerne an die antiken Bilder herantragen, dahinter verbarg. Aus diesem Grund können Götter während der Kultausübung auch neben ihrem Bild auftreten, wie dies auf Vasenbildern häufig dargestellt ist und wie auch der Typus der aufgelehnten Aphrodite gedeutet werden kann ${ }^{582}$. Die Funktion eines Götterbildes war damit nicht konstant, wie gerade auch der schon mehrfach erwähnte spätklassische Krater in Moskau (Kat. B76) 583 zeigt, auf dem sich Iphigenie auf das $>$ Kultbild der Artemis von Tauris lehnt, das in diesem Moment also die Statue der Göttin meint, während es zu anderen Zeitpunkten die Göttin im Kult repräsentierte.

\footnotetext{
580 Vgl. Scheer 2000, 47; Steiner 2001, 135.

581 Scheer 2000 bes. 96-130, ähnlich V. Izzet, Sacred Times and Spaces. Greece, in: Johnston 2004, 266-273; H.-G. Nesselrath, Tempel, Riten und Orakel. Die Stellung der Religion im Leben der Griechen, in: Kratz - Spieckermann 2006, 45-67; B. Bäbler - H.-G. Nesselrath, Der Stoff, aus dem die Götter sind - zum Material griechisch-römischer Götterbilder und seiner ideellen Bedeutung, in: B. Groneberg - H. Spieckermann (Hrsg.), die Welt der Götterbilder (Berlin 2007) 145-168.

582 s. Kap. 7.2.2.

583 s. S. 106.117.
} 
Darüber hinaus stellt sich die Frage, wie viele Bilder einer Gottheit in einem Heiligtum verehrt werden konnten, bzw. ob es jeweils nur ein in die Riten einbezogenes Bild oder auch mehrere gegeben haben kann. Bekannt ist, dass bei Verlust eines Bildes ein Ersatz aufgestellt und mit diesem der Kult fortgeführt werden konnte, wie Pausanias 8, 42, 4-7 aus Phigaleia überliefert: $\alpha \varphi \alpha v i \sigma \theta \dot{\varepsilon} v \tau o \varsigma$ $\delta \dot{\varepsilon} \tau 0 \widehat{v}$

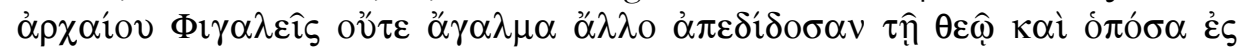

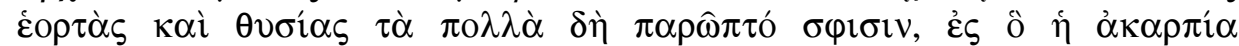

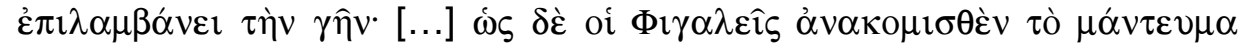

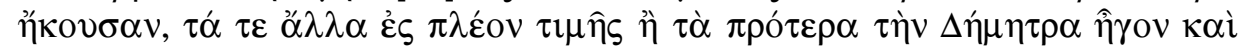

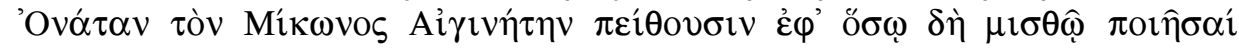

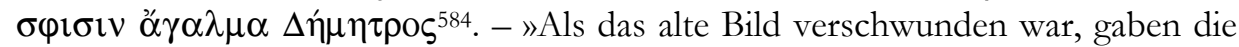
Phigaleer der Göttin kein anderes Bild wieder und vernachlässigten auch die Feste und Opfer größtenteils, bis die Unfruchtbarkeit über das Land kam. [...] Wie die Phigaleer das überbrachte Orakel hörten, da brachten sie allgemein den Kult der Demeter zu größerer Ehre als früher und überredeten den Aigineten Onatas, den Sohn des Mikon, gegen was für Lohn auch immer, ihnen eine Statue der Demeter zu schaffen $[. .$.$] «. (F. Eckstein - P. C. Bol)$

Der Verlust eines Bildes bedeutete daher nicht unbedingt das Ende des Kultes, da das Ersatzbild seine Funktionen übernehmen konnte. So ging z. B. die überlieferte Reinigungszeremonie im Heiligtum der Aphrodite Pandemos in Athen von den alten, zerstörten Bildern auf die Ersatzbilder über ${ }^{585}$. Ein einziges wahres, dem Kult dienendes Bild der Gottheit lässt sich daraus nicht ableiten. Beispiele für eine zumindest temporäre Verehrung mehrerer Bilder einer Gottheit in einem Heiligtum können für die griechische Antike ebenfalls benannt werden. So

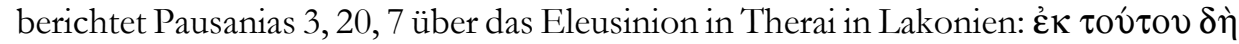

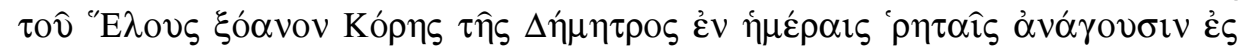

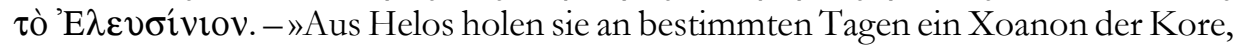
der Tochter der Demeter, in das Heiligtum der Eleusinier«. In Sikyon wurden jedes Jahr zwei Dionysosbilder in einer nächtlichen Prozession aus dem Kosmeterion in das Dionysion gebracht, in dem noch ein drittes, dort ständig anwesendes Dionysosbild stand, wie Pausanias 2, 7, 5 f. ${ }^{586}$ überliefert. Für Patrai bezeugt Pausanias 7, 21, 6587, dass dort während des Dionysosfestes verschiedene Statuen zur Verehrung in einem Heiligtum zusammengebracht wurden. Auch beim Fest der Artemis Limnatis in Patrai wurde eine Statue der Göttin aus Mesoa in das Heiligtum in Patrai gebracht, wie ebenfalls Pausanias 7, 20, 7 f. berichtet: $\tau \hat{\eta} \varsigma \delta \grave{\varepsilon}$

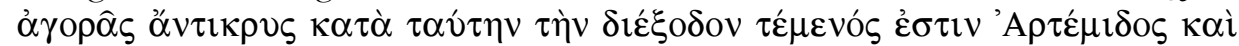

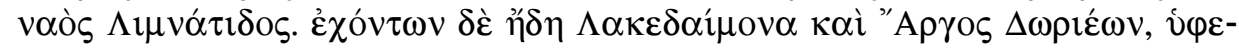

\footnotetext{
584 s. auch S. 295.

585 Paus. 1, 22, 3. Vgl. auch Lib. or. 11, $112 \mathrm{f}$.

586 s. S. 282 f.

587 s. S. 283.
} 


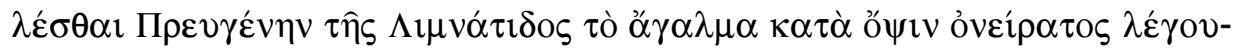

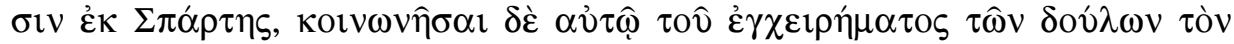

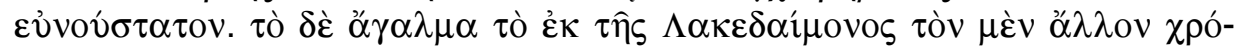

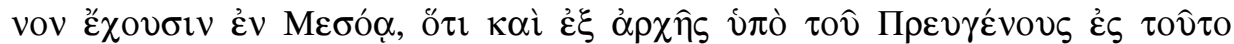

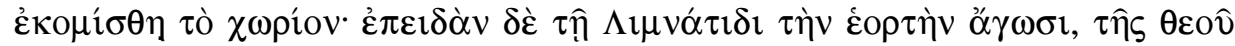

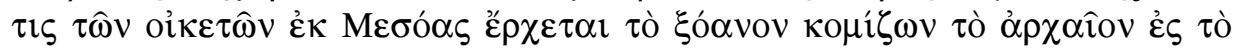

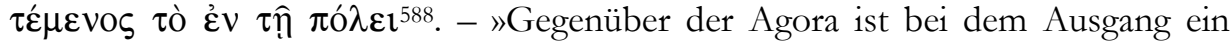
heiliger Bezirk und ein Tempel der Artemis Limnatis. Als die Dorer in Besitz von Lakedaimon und Argos waren, wird gesagt, hat Preugenes aufgrund eines Traumes das Bild der Limnatis aus Sparta geholt, und an diesem Unternehmen soll der frommste seiner Sklaven teilgenommen haben. Das Bild aus Lakedaimon wird normalerweise in Mesoa aufbewahrt, weil es durch Preugenes zuerst an diesen Ort gebracht worden war. Aber wenn man das Fest der Limnatis feiert, kommt einer der Diener aus Mesoa und bringt das Bild zu dem Bezirk in der Stadt«.

Da die zeitweilige gemeinsame Verehrung mehrerer Bilder einer Gottheit in einem Heiligtum nicht zu einem Widerspruch geführt hat, kann man fragen, ob nicht auch eine dauerhafte Verehrung mehrerer Bilder an einer Kultstätte möglich ist. Hierzu werden in den folgenden Kapiteln einzelne griechische Heiligtümer untersucht werden, für die mehrere Bilder der dort verehrten Götter bezeugt sind.

\subsection{Zusammenfassung}

In vielen Religionen bestand und besteht noch heute das Bedürfnis, im Kult ein Bild der verehrten Gottheit zu benutzen. Dieses unterscheidet sich von anderen Darstellungen einer Gottheit durch die ihm zu Teil werdende Verehrung und die Einbeziehung in Kulthandlungen. Die Bilder konnten dabei die Gottheit repräsentieren oder sogar als sie selbst gelten. So war z. B. das `Kultbild in Mesopotamien ein Bild, »das als der lebendige Körper der in ihm präsenten anthropomorph und personal vorgestellten Gottheit verstanden wurde« ${ }^{589}$. Für viele Kulturen ließ sich ein magischer Glaube feststellen, dass zwischen dem Bild und dem Dargestellten ein innerer Zusammenhang besteht, der bis zur Wesenseinheit gehen kann. Auch

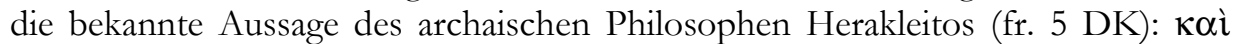

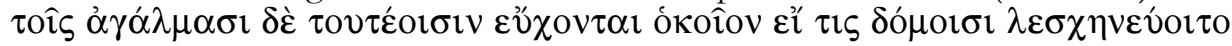

\footnotetext{
588 Da Patrai aus dem Zusammenschluss mehrerer Orte, darunter Mesoa hervorgegangen ist, ist anzunehmen, dass das Heiligtum auf der Agora ein Filialkult war. Wahrscheinlich hat in dem neuen Heiligtum ein zweites Bild der Göttin gestanden, wie auch in Eleutherai eine Nachbildung des nach Athen überführten Dionysosbildes aufgestellt worden war (s. Kap. 12.5), so dass hier ebenfalls zumindest zeitweilig zwei Bilder an einer Kultstätte verehrt wurden. Vgl. M. P. Nilsson, Griechische Feste von religiöser Bedeutung mit Ausschluss der attischen (Leipzig 1906) 212

589 Berlejung 1999b, Zitat S. 110.
} 


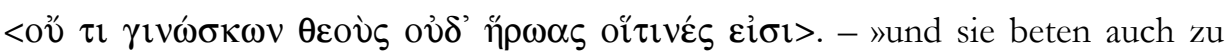
diesen Götterbildern, wie wenn einer mit Gebäuden Zweisprache pflegen wollte. Sie kennen eben die Götter und Heroen nicht nach ihrem wahren Wesen« $(\mathrm{H}$. Diels) kann auf dieselbe Art aufgefasst werden. Für ihn scheinen die Statuen zwar leer und unbelebt zu sein, für die Masse der Bevölkerung, von der er sich abgrenzt, konnte das Bild jedoch die Gottheit sein, ein mit verschiedenen Sinnen ausgestattetes lebendiges Wesen und nicht nur ein toter Stein oder Holzblock. Und genauso, wie die Bewohner ein Haus lebendig machen und man mit ihnen in Kontakt treten kann, kann man auch mit der im Bild dargestellten Gottheit kommunizieren ${ }^{590}$. Die Bilder ermöglichen dem Gläubigen also im Gegensatz zu den sonst numinosen Göttern ein personales Gegenüber für ihre Gebete und ihren Dank. Der Wunsch, den Göttern leibhaftig gegenübertreten zu können, wird in den Quellen immer wieder deutlich zum Ausdruck gebracht. So lassen sich z. B. die Frauen von Ilion in der Ilias des Homer den Tempel öffnen, um direkt vor das Bild der Athena treten und der Göttin von Angesicht zu Angesicht gegenüber stehen zu können ${ }^{591}$. Auch die Priesterin der Hera von Argos trat vor das Bild der Göttin, um für ein positives Schicksal ihrer Söhne Kleobis und Biton zu beten ${ }^{592}$, ebenso eine spartanische Amme mit dem ihr anvertrauten Kind im Heiligtum der Helena ${ }^{593}$. Dabei kann der Wunsch, seinem Anliegen Gehör zu verschaffen, auch durch die direkte Berührung eines Bildes verstärkt werden ${ }^{594}$. Bilder dienen dazu, den Menschen die für gewöhnlich nicht sichtbar gedachten Götter vor Augen zu führen und ermöglichen ihnen ein personelles Gegenüber.

Grundsätzlich kann jedes Bild diese Funktionen übernehmen und damit auch Kult empfangen. Ein gutes Zeugnis dafür ist die Überlieferung der Gründung des Heiligtums der Fortuna Muliebris in Rom bei Dionysios von Halikarnassos 8, 56, 2-4. Für den Tempel hatte man auf Staatskosten ein Bild geschaffen. Gleichzeitig wurde auf private Veranlassung ein zweites Bild aufgestellt. Letzteres würde der Forschungsmeinung nach eher als >Votiv «, als ein der Gottheit gestiftetes Geschenk, das nicht von vorn herein zur Verehrung gedacht ist, gelten. Dennoch ist es

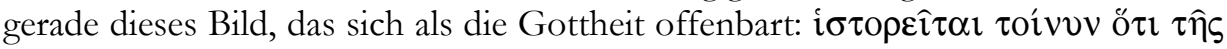

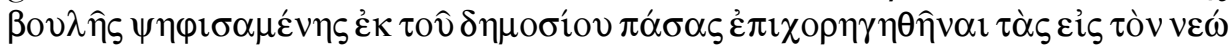

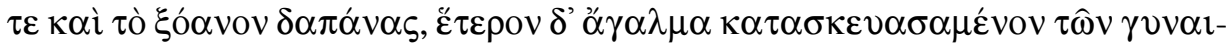

\footnotetext{
$590 \mathrm{Vgl}$. Steiner 2001, 79.

591 Hom. Il. 6, 297-311, vgl. S. 187 f.

592 Hdt. 1, 31.

593 Hdt. 6, 61. Vgl. auch Paus. 2, 10 , 4; Dion Chrys. 12, 59; Lukian. Syr.D 34; s. auch Goldammer 1985, 90 s. v. Bilderverehrung; Waldenfels 1999, 57-62 s. v. Bild (Chr. Dohmen); Gladigow u. a. 1998, 12.

594 Scheer 2000, 66-77; T. Mattern, Architektur und Ritual. Architektur als funktionaler Rahmen antiker Kultpraxis, in: J. Mylonopoulos - H. Roeder (Hrsg.), Archäologie und Ritual. Auf der Suche nach der rituellen Handlung in den antiken Kulturen Ägyptens und Griechenlands (Wien 2006) 167-183.
} 


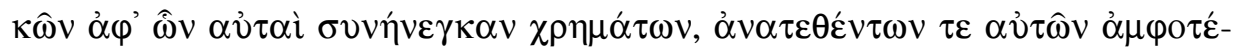

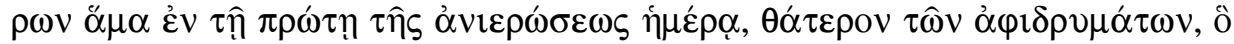

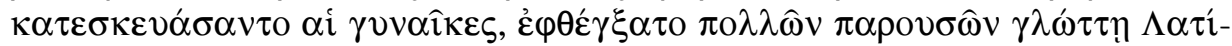

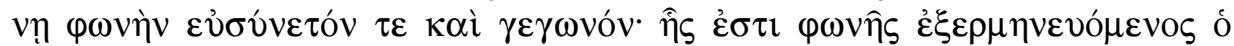

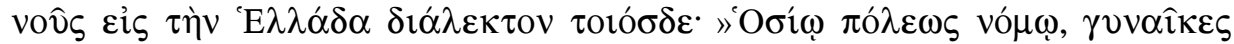
$\gamma \alpha \mu \varepsilon \tau \alpha^{\prime}, \delta \varepsilon \delta \dot{\omega} \kappa \alpha \tau \varepsilon \dot{\varepsilon} \mu \varepsilon «^{595}$. - Es wird also berichtet, dass - als der Senat beschlossen hatte, dass die gesamten Kosten für den Tempel und die Statue von der Staatskasse getragen werden sollten, und die Frauen veranlasst hatten, dass eine weitere Statue geschaffen werden sollte mit dem Geld, das sie selbst bereitgestellt hatten, und beide Statuen zusammen aufgestellt wurden am Tag der Tempeleröffnung - eine der Statuen, und zwar die, die die Frauen gestiftet hatten, einige Worte in lateinischer Sprache geäußert haben soll, und zwar laut und deutlich, als viele anwesend waren. Die Worte bedeuten in die griechische Sprache übersetzt: Ihr habt das Gesetz der Stadt bewahrt, ihr Frauen, indem ihr mich weihtet«.

Die Statuen verkörperten in der Antike demnach einerseits den Gott, andererseits wurden sie als Bilder der Götter aufgefasst, je nach Blickwinkel. Dieser Konflikt ist in den Bildern selbst angelegt und nicht auflösbar und gilt für jedes Bild ${ }^{596}$. Dennoch wurden in einigen der betrachteten Religionen, und zwar im altägyptischen, mesopotamischen und hinduistischen Kult bestimmte Bilder von anderen unterschieden, indem sie vor ihrer Einsetzung in den Tempel rituell geweiht wurden und damit zu einem verbindlichen `Hauptkultempfänger` wurden, während für die griechische Antike wie auch das Christentum keine Institutionalisierungsriten überliefert sind, die ein Bild zu einem $>$ Kultbild machten $^{597}$. Trotzdem ist der Begriff - mit allen Einschränkungen - auch für die griechische Antike nützlich, da auch dort einzelne Bilder häufiger und regelmäßiger in den Kult einbezogen wurden als andere, so dass man damit den `Hauptkultempfänger eines Heiligtums bezeichnen kann ${ }^{598}$. Dass Konzept ist jedoch sehr offen, so dass es neben dem fest im Tempel installierten Bild auch weitere gegeben hat, die z. B. bei bestimmten Riten wie Prozessionen Verwendung fanden, wie in den folgenden Kapiteln noch dargelegt werden wird. Da in Kapitel 11.2.2 bereits Zeugnisse dafür angeführt worden sind, dass auch in der griechischen Antike zumindest temporär mehrere Bilder einer Gottheit in einem Heiligtum Verehrung empfangen konnten, stellt sich die Frage, ob es auch dauerhaft mehrere repräsentative Bilder einer Gottheit in einem Tempel gegeben haben kann welche Funktionen die Bilder im Einzelnen erfüllten. Dazu werden im Folgenden Heiligtümer untersucht, für die mehrere Bilder, zumeist aus unterschiedlichen Epochen bezeugt sind.

595 Vgl. Plut., Coriolanus 37, 3-38.

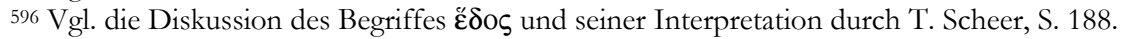

597 s. S. 187.

598 Deshalb habe ich bei den Übersetzungen der Quellen auf die vorhandenen zurückgegriffen, auch wenn sie oft den Begriff `Kultbild ‘ für das repräsentative Bild der Gottheit im Tempel verwenden. 


\section{Heiligtümer mit mehr als einem möglichen >Kultbildk}

Im ersten Teil der Arbeit wurden die altertümlichen Idole des untersuchten Aphroditetypus als Zeugnis für das hohe Alter und Bedeutung des Kultes der Göttin gedeutet. Sie stellen vielleicht - zumindest symbolisch - sogar ein raltes Bild ‘ der Göttin selbst dar, das später durch ein jüngeres ergänzt worden war. Es stellt sich daher die Frage, wie viele Kultstätten neben einem bestehenden älteren ein jüngeres $\gg$ Kultbild in oben definiertem Sinn erhalten haben. Selbstverständlich besaß jedes Heiligtum mehr als eine Darstellung der Gottheit, da es üblich war, ihr als Dank oder zur Unterstützung einer Bitte neben jeglicher anderer Form von Gaben auch Bilder von ihr selbst zu stiften. Um diese soll es hier aber nicht gehen. Um das schier unendlich erscheinende Thema zu begrenzen, sollen hier nur solche Bilder betrachtet werden, die eine (mögliche) Funktion im Kult erfüllt haben. Von der Forschung wurde oft die Kultfunktion von Bildern wie der Athena Parthenos abgelehnt, weil sie in Kultstätten aufgestellt wurden, die bereits ein $>$ Kultbild besaßen. Diese Ansicht ist inzwischen widerlegt ${ }^{599}$. Deshalb kann gefragt werden, ob es weitere Heiligtümer mit mehr als einem `Kultbild gegeben hat. Es wird aber weder Vollständigkeit angestrebt noch ist sie möglich, da neue Forschungen die Kenntnisse über antike Heiligtümer und ihre Bilder beständig erweitern.

Die Quellenlage zu den einzelnen Heiligtümern ist sehr unterschiedlich. Neben der antiken Literatur stehen archäologische Quellen wie der Baubefund, Inschriften, Darstellungen der Bilder auf Reliefs, auf Münzen oder in späteren Kopien und Nachbildungen und im besten Falle Fragmente der Bilder selbst zur Verfügung. Der Wert dieser Quellen ist sehr unterschiedlich. So ist z. B. die Befunddokumentation der einzelnen Kultstätten sehr verschieden, besonders frühe Ausgrabungen sind bekanntermaßen oft sehr selektiv durchgeführt und dokumentiert 
worden. Darstellungen der Götterbilder lassen sich bestenfalls auf Münzen oder in späteren und damit vom Stil des Kopisten beeinflussten Nachbildungen wieder finden ${ }^{600}$. Dort sind die $>$ Kultbilder oft deutlich verkleinert wiedergegeben, weshalb Details entweder fehlen oder überbetont sind. Außerdem hing es von der Intention des Handwerkers ab, welche Aspekte des Bildes er übernahm und welchen Stellenwert er ihnen einräumte. Hier wäre eine genaue Kopienkritik nötig, was jedoch außerhalb der Möglichkeiten dieser Arbeit liegt. Deshalb wird hier auf die Urteile der Forschung zurückgegriffen, ansonsten sei auf die jeweilige Literatur verwiesen. Bei literarischen Quellen wiederum hängt der überlieferte Inhalt bekanntermaßen stark von der Intention und dem Stil des Autors ab, was bedeutet, dass die Informationen nicht automatisch als Fakten akzeptiert werden können, sondern mit Hilfe anderer Quellen überprüft und ergänzt werden müssen. Die umfangreichste Schriftquelle zu antiken Götterbildern ist die Reisebeschreibung des Pausanias aus der 2. Hälfte des 2. Jahrhunderts n. Chr., auf die hier besonders häufig zurückgegriffen wird. Dieses Werk stellt einen Sonderfall in der antiken Literatur dar, da der Autor nach Ansicht der Forschung bestrebt war, das niederzuschreiben, was er tatsächlich gesehen hat (wenn er auch literarische Quellen benutzte ${ }^{601}$. Ebenso wichtig war ihm die Aufzeichnung der überlieferten Traditionen und Mythen, der $\lambda$ ó ${ }_{01}{ }^{602}$ der von ihm besuchten Orte. Diese $>$ Exkurser spielen eine wichtige Rolle bei der Untersuchung antiker Kulte, da sie Einblicke in die damalige Vorstellungswelt vermitteln. Zudem dienen sie oft als Erklärung für Kultbräuche oder das Aussehen der Bilder und liefern somit weitere wichtige Angaben.

Die Zahl und auch die Qualität der nutzbaren Informationsquellen zu den einzelnen Heiligtümern schwanken beträchtlich. Im Folgenden werden einzelne Kulte und Heiligtümer in Einzelstudien behandelt. Kulte, für die nur wenige Informationsquellen zur Verfügung stehen, werden anschließend zusammen betrachtet.

\subsection{Athena auf der Athener Akropolis}

Ein Paradigma für den lange währenden Streit um die mögliche Existenz zweier oder mehrer \Kultbilder in einem Heiligtum ist der Kultbezirk der Athena auf der Akropolis von Athen. Die Diskussion hat sich entzündet, weil man lange nur von

\footnotetext{
${ }^{600}$ Vgl. die Diskussion bei H. Brandt, Kulte in Aspendos, IstMitt 38, 1988, 237-250.

${ }^{601}$ Chr. Habicht, Pausanias und seine »Beschreibung Griechenlands« (München 1985); F. De Angelis, Pausania e i periegeti. La guidistica antica sulla grecia, in: E. Vaiani, Dell'antiquaria e dei suoi metodi (Pisa 1998) 1-14; M. Della Santa, La religiosità di Pausania (Diss. Universität Freiburg/ Schweiz 1999); DNP III (1999) 445-449 s. v. Pausanias, der Perieget (A. A. Donohue) mit weiterer Literatur; E. Meyer, Einleitung, in: F. Eckstein - P. C. Bol, Pausanias. Reisen in Griechenland I. Athen (Düsseldorf, Zürich 2001) 10-59.

602 Besonders deutlich bei Paus. 1, 39, 3.
} 
einem Athenakult auf der Akropolis ausgegangen war. Dies führte zu der Frage, weshalb man in der 2. Hälfte des 5. Jahrhunderts v. Chr. mit der Athena Parthenos ein neues Bild aufgestellt hat, obwohl doch das alte Bild der Athena Polias ${ }^{603}$ weiterhin Bestand hatte, und welche Funktion dem neuen Bild zugekommen war. Dieser Streit konnte inzwischen beigelegt werden, denn die Forschung hat gezeigt, dass es sich bei dem Kult der Athena Polias und dem der Athena Parthenos um zwei verschiedene, beide gleichermaßen alte Kulte gehandelt hat, was hier anhand der Quellen und des Baubefundes noch einmal kurz dargelegt werden soll.

\section{Schriftquellen zu dem Bild der Athena Polias:}

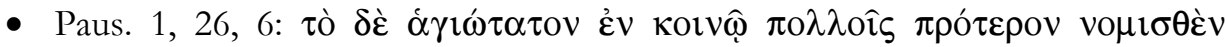

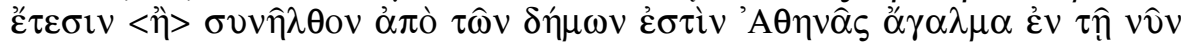

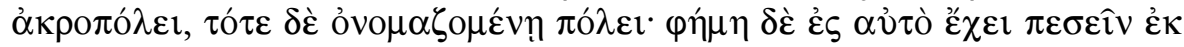
$\tau o \widehat{v}$ ov̉pavôิ. - »Das heiligste gemeinsame Kultobjekt jedoch schon viele Jahre vor der Zusammensiedlung aus den einzelnen Gemeinden ist ein Athenabild auf der jetzigen Akropolis, die damals einfach Polis hieß, von dem die Sage geht, es sei vom Himmel gefallen«. (F. Eckstein - P. C. Bol)

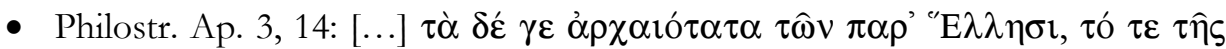

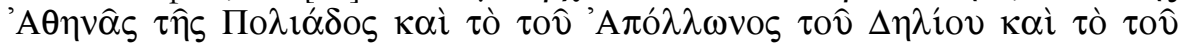

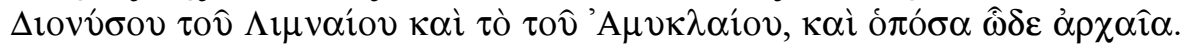
- »[...] solche [Bilder], die bei den Hellenen das höchste Alter aufweisen. Es sind dies die Bilder der Athene Polias, des Apollon von Delos, des Dionysos von Limnai, des Phoibos von Amyklai und ähnliche Statuen aus dieser Zeit«. (V. Mumprecht)

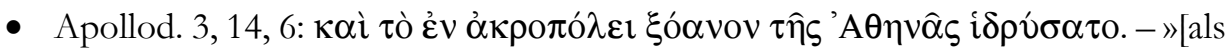
Erichthonios König war] errichtete er das Bild der Athena auf der Akropolis«.

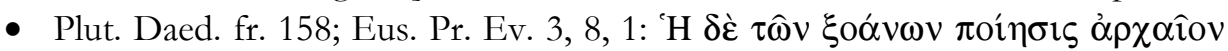

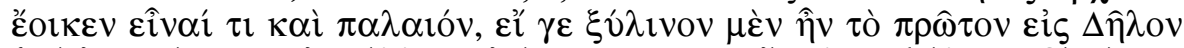

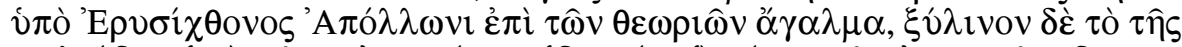

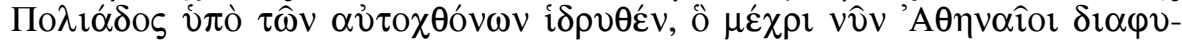
$\lambda \alpha ́ \tau \tau o v \sigma \imath v .-»$ Die Herstellung der Xoana scheint etwas Altes und weit Zurückreichendes zu sein, wenn das erste Agalma, das nach Delos zu Apollon geschickt wurde von Eurysichthon aufgrund der Feste aus Holz gewesen ist, und wenn das der Polias aus Holz ist, das die autochthonen Einwohner errichtet hatten und die Athener bis heute bewahren«.

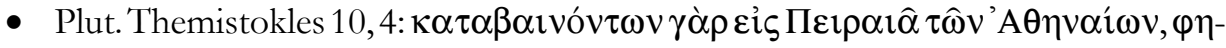

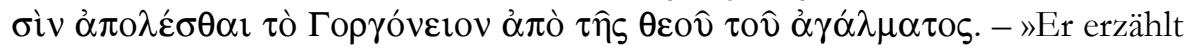

${ }^{603}$ Die Bezeichnungen Athena Polias und Athena Parthenos sind erst spät belegt, werden hier aber verwendet, weil damit eine eindeutige und heute geläufige Bezeichnung gegeben ist. In den klassischen Quellen werden die Bilder in der auch sonst üblichen Art der Benennung von Göttersta-

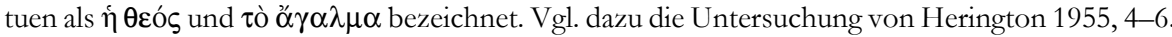


nämlich, man habe im Augenblick, als die Athener in den Piräus hinunterziehen wollten, das Medousenhaupt am Standbild der Athene vermisst«. (K. Ziegler)

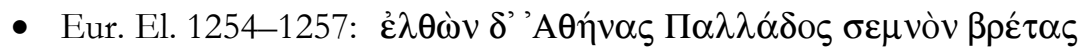

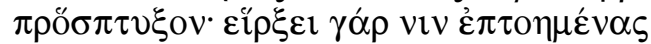

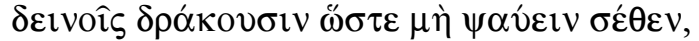

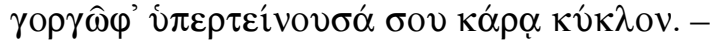
»In Athen umklammere das heilige Bild

Der Pallas: sie wird mit den Schlangen den Schwarm Vertreiben und ihn dir halten vom Leib, Mit dem Gorgo-Schild beschirmend dein Haupt«. (G. A. Seeck)

- IG II 1424 (Schatzinschrift von der Athener Akropolis, ca. 370 v. Chr.):

Z $11 \sigma \tau \varepsilon \varphi[\alpha ́ \alpha \eta, \hat{\eta} \nu]$

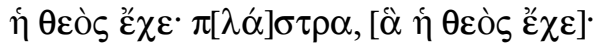

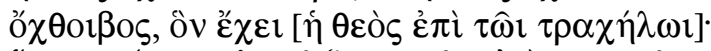

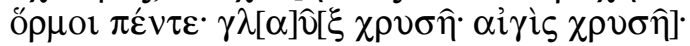

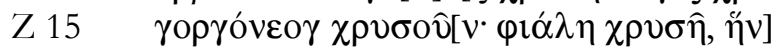
غ่V $\tau \hat{\eta} \imath \chi \varepsilon[1] \rho i ̀ ~ \varepsilon ้ \chi \varepsilon i^{604}$. -

Z 11 »Ein Kranz, den die Göttin hat, Ohrringe, die die Göttin hat, ein Band, dieses hat die Göttin um dem Kopf, fünf Ketten, eine goldene Eule, eine goldene Aigis,

Z 15 ein goldenes Gorgoneion, eine goldene Phiale, diese hat sie in ihrer Hand «.

- IG I 474 (Bauabrechnung des Erechtheions, 409/8 v. Chr.):

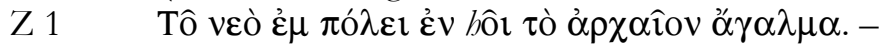

Z 1 »der Tempel in der Stadt in dem das alte Bild ist"

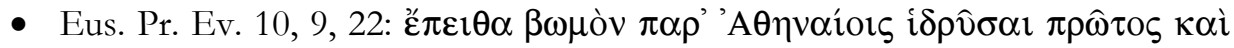

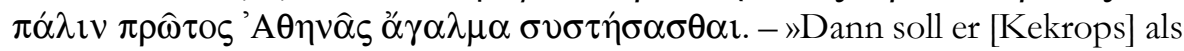
erster von den Athenern den Altar errichtet und außerdem zuerst das Bild der Athena aufgestellt haben«.

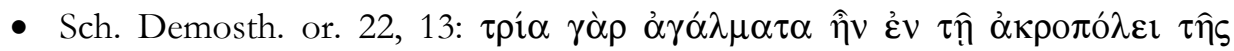

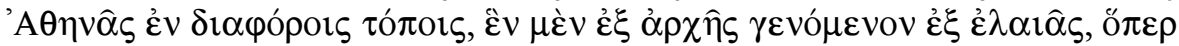

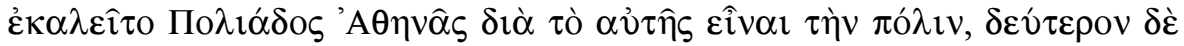

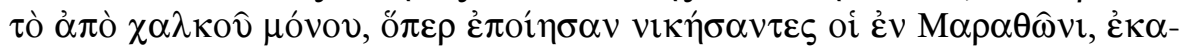

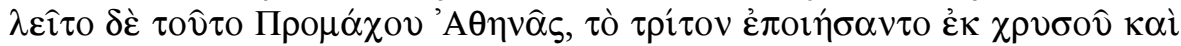

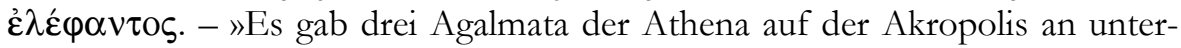
schiedlichen Orten. Das erste war aus Olivenholz, welches auch Athena Polias genannt wird, weil ihr die Stadt ist. Das zweite, das sie schufen nach dem Sieg 
in Marathon, war rein aus Erz, es wurde auch Athena Promachos genannt. Das dritte wurde aus Gold und Elfenbein gemacht«.

- Tert. apol. 16, 6 f.: Et tamen quanto distiguitur a crucis stipite Pallas Attica et Ceres Pharia, quae sine effigie rudi palo et informi ligno prostant? Pars crucis est omne robur, quod erecta statione defigitur. - »Und doch, wie wenig unterscheiden sich die Pallas von Attica oder die Ceres von Pharos von einem Kreuzesholze, da sie sich ohne Menschenantlitz nur unter einem rohen Pfahl und gestaltlosen Holz darbieten? Denn jedes Holz, das in aufrechter Stellung befestigt ist, bildet ja einen Teil eines Kreuzes«. (K. A. H. Kellner)

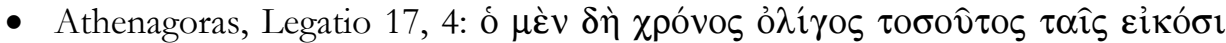

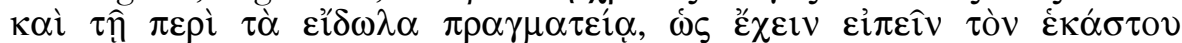

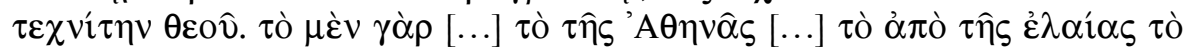

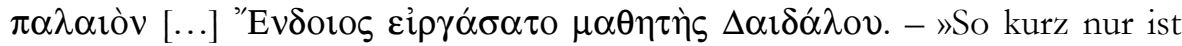
die Zeit seit dem Beginn der Bilder und der Herstellung der Statuen, dass es möglich ist, die Bildhauer jedes Gottes zu benennen. Endoios, ein Schüler des Daidalos, machte $[. .$.$] die alte Olivenholzstatue der Athena [\ldots] \ll$.

Schriftquellen zu dem Bild der Athena Parthenos:

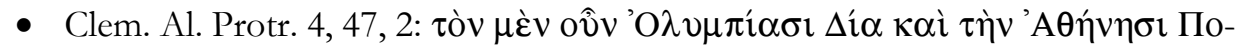

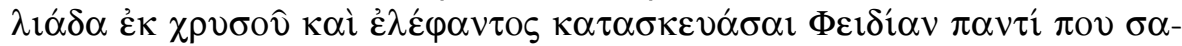

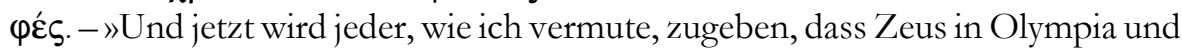
Athena Polias in Athen gebildet wurden aus Gold und Elfenbein durch Phidias«.

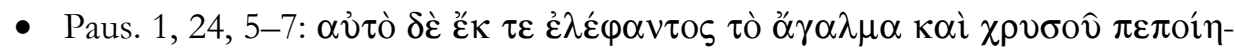

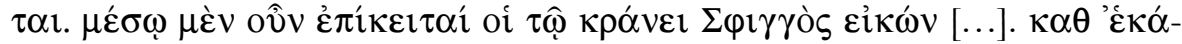

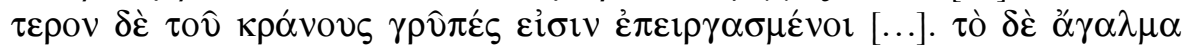

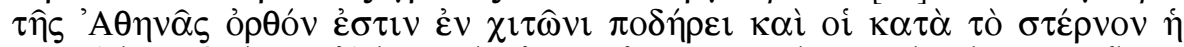

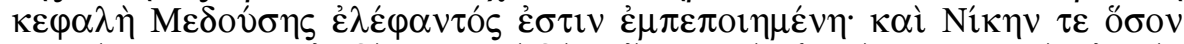

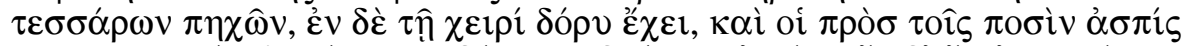

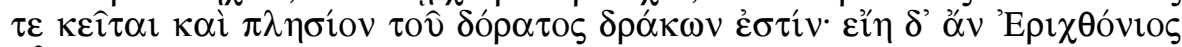

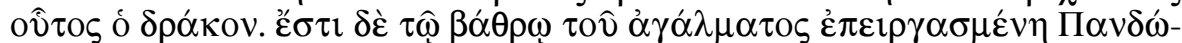
$\rho \alpha \varsigma \gamma \varepsilon \dot{\varepsilon} \varepsilon \sigma \imath \varsigma$. - »Das Kultbild selbst [des Parthenon] ist aus Gold und Elfenbein gemacht. Mitten auf dem Helm sitzt die Figur einer Sphinx [...] beiderseits an dem Helm aber sind Greifen angebracht [...]. Das Kultbild der Athena ist aufrechtstehend mit einem Chiton bis zu den Füßen, und an ihrer Brust ist das Medousenhaupt aus Elfenbein angebracht. Und eine Siegesgöttin, gegen vier Ellen hoch, hat sie in der Hand und eine Lanze, und zu ihren Füßen steht der Schild, und neben der Lanze befindet sich eine Schlange, und diese Schlange mag wohl Erichthonios darstellen. An der Basis des Kultbildes ist die Geburt der Pandora dargestellt«. (F. Eckstein - P. C. Bol)

- Plin. nat. 36,18: Phidian clarissimum esse [...] nemo dubitat [...]. neque ad hoc Iovis Olympii pulchritudine utemur, non Minervae Athenis factae amplitudine, cum sit ea cubitorum XXVI - ebore haec et auro constat -, sed in scuto eius Amazonum proelium caelavit intumescente ambitu, in parmae eiusdem concava parte deorum et Gigantum dimicationes, in soleis vero 
Lapitharum et Centaurorum. adeo momenta omnia capacia artis illi fuere. in basi autem

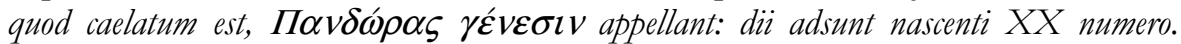
Victoria praecipue mirabili, periti mirantur et serpentem ac sub ipsa cuspide aeream sphinghem. - »Daß Pheidias als berühmtester <Künstler> gilt [...] bezweifelt niemand [...]. Wir wollen dazu nicht die Schönheit seines olympischen Zeus, nicht die Größe seiner zu Athen geschaffenen Athene, obgleich diese 26 Ellen hoch ist - sie besteht bekanntlich aus Elfenbein und Gold - heranziehen, sondern < nur erwähnen>, daß er auf ihrem Schild am sich vorwölbenden Rand die Amazonenschlacht, im konkaven Teil die Kämpfe der Götter und Giganten, an den Sandalen aber die der Lapithen und Kentauren darstellte. Jedes Detail bot ihm Anlass für eine kunstvolle Darstellung. Was aber auf dem Sockel eingearbeitet ist, nennt man Pandoras Genesis (Geburt der Pandora): Zwanzig Gottheiten sind bei der Geburt zugegen. Seine Nike ist vor allem bewundernswert; Kenner bestaunen auch die Schlange und die eherne Sphinx $<$ am Helm> unterhalb der Speerspitze«. (R. König)

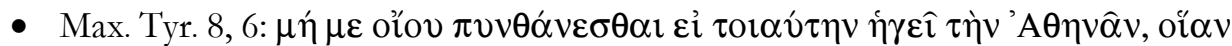

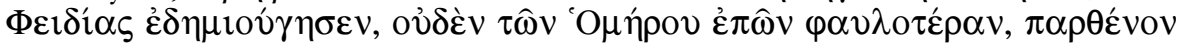

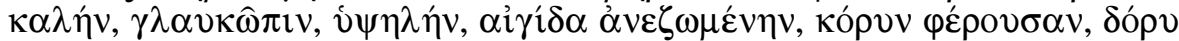

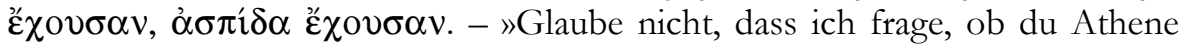
für eine solche hältst, welche Phidias gebildet hat um nichts schlechter als die homerischen Worte, als schöne Jungfrau, eulenäugig, erhaben, Aigis umgürtet, einen Helm tragend, mit einem Speer bewaffnet, mit einem Schild bewehrt«.

Darstellungen: Von dem Bild der Athena Polias ist bisher keine gesicherte Darstellung nachgewiesen. Die Forschung hat verschiedene Rekonstruktionsvorschläge vorgebracht. A. Frickenhaus hatte ihr Aussehen mit Hilfe von auf der Akropolis gefundenen archaischen Terrakottastatuetten und Vasenbildern als Sitzstatue wiederhergestellt ${ }^{605}$. Diese zeigen zwar die für die Polias überlieferte Stephane und Phiale, vermitteln allerdings nur generell ein Bild einer sitzenden Athena und müssen nicht direkt auf die Polias zurückgehen. Die Attribute sind zu allgemein und werden von zahlreichen Athenadarstellungen und auch von anderen Göttern getragen ${ }^{606}$. Zudem weisen sie untereinander zu große Unterschiede auf, um auf ein einziges Vorbild zurückzugehen ${ }^{607}$. J. H. Kroll hingegen rekonstruierte ein stehen-

${ }^{605}$ Frickenhaus 1908, 17-32 mit Abb. 1. 3 f. Die These wurde u. a. akzeptiert von Lehnstaedt 1970, 85-87.

606 Auf den Vasen ist durch den Altar und die Pflanzen auch eindeutig, dass sich Athena im Freien befindet.

607 Ablehnend auch Herington 1955, 24; H. Jung, Thronende und sitzende Götter. Zum griechischen Götterbild und Menschenideal in geometrischer und früharchaischer Zeit (Bonn 1982) 54-64. Bei der Aufzählung sitzender Götterbilder durch Strab. 13, 1, 41 fehlt die Athena Polias, die jedoch nicht weniger gekannt gewesen sein muss als die dort genannten Bilder der Athena in Ilion, Phokaia, Massilia, Rom und Chios. 
des Bild mit Hilfe hellenistischer Münzen. Aufgrund der nicht-konstrapostischen Haltung sieht er auf ihnen eine vorklassische Statue wiedergegeben ${ }^{608}$. Jedoch tragen die Athenbilder auf den Münzen einen Helm und nicht die überlieferte Stephane ${ }^{609}$. Auch geben die Münzen seiner Meinung nach ein spätarchaisches Bild wieder. Die antiken Quellen belegen jedoch ein höheres Alter, was auch aufgrund des Baubefundes zu vermuten ist ${ }^{610}$. Somit können keine Darstellungen sicher auf das Bild der Athena Polias bezogen werden ${ }^{611}$.

Das Aussehen der Statue der Athena Parthenos ist durch zahlreiche hellenistische und kaiserzeitliche Münzbilder und verkleinerte Nachbildungen, die das Bild mehr oder weniger getreu wiedergeben, bekannt. Die Göttin steht aufrecht auf dem rechten Bein. Das linke Bein ist angewinkelt nach hinten gesetzt. Auf der ausgestreckten rechten Hand hält sie eine geflügelte Nike. Mit der gesenkten linken Hand hält die Göttin einen aufrecht neben ihr stehenden Schild. Zwischen dem Schild und dem linken Bein der Göttin windet sich die athenische Burgschlange. Auf dem Kopf trägt die Göttin einen Helm mit reichem Helmschmuck. Ihre Kleidung besteht aus einem gegürteten Peplos sowie einer Aigis mit dem Gorgoneion. Durch Marmorstatuetten wie die sog. Statuette Lenormant (Abb. 38) ist auch das Aussehen der Basis mit ihren Reliefs überliefert ${ }^{612}$.

${ }^{608}$ J. H. Kroll, in: The Ancient Image of Athena Polias, in: Studies in Athenian Architecture, Sculpture and Topography presented to H. A. Thompson, Hesperia Suppl. 20 (Princeton 1982) 65-76 Taf. 11, 1-4. 6-12.

${ }^{609}$ Laut J. H. Kroll wurde der Helm, da er nicht aus kostbarem Material bestanden habe, in den Inschriften, die vorrangig goldene Attribute auflisten, nicht erwähnt. Dies scheint mir kein ausreichendes Argument zu sein.

${ }^{610} \mathrm{~J}$. H. Kroll versucht dies damit zu erklären, dass das Bild durch bekannten archaischen Bildhauer Endoios umgestaltet worden sei. Doch ist keine Verbindung des Endoios zur Athena Polias oder eine Umarbeitung belegt. Der Standort der bei Athenagoras, Legatio 17, 4 erwähnten Athena des Endoios ist unklar. Weitere Athenastatuen des Endoios, die ebenfalls mit dem von Athenagoras genannten Bild gemeint sein können, standen laut Paus. 7, 5, 9 und 8, 46, 1. 5 in Erythrai und Tegea. Paus. 1, 26, 4 erwähnt noch ein sitzendes Athenabild des Endoios, das von Kallias auf der Athener Akropolis aufgestellt wurde. Damit kann nicht die Athena Polias gemeint sein. Mit diesem Bild wird eine archaische Sitzstatue, die am Nordhang der Akropolis gefunden wurde, verbunden: Athen, Akropolismuseum Inv. 625: H. Schrader, Archaische Marmor-Skulpturen im Akropolismuseum zu Athen (Wien 1909) 44 Abb. 37; ders., Die archaischen Marmorbildwerke der Akropolis (Frankfurt a. M. 1939) 109-111 Taf. 85; Boardman 1981, 104 f. Abb. 135; Viviers 1992, 62-67. 162-169; P. A. Marx, Acropolis 625 (Endoios Athena) and the Rediscovery of its Findspot, Hesperia 70, 2001, 221-254; C. Maderna-Lauter, Spätarchaische Plastik, in: Bol 2002, 248 f. Abb. 321; G. I. Despinis, Zu Akrolithstatuen griechischer und römischer Zeit (Göttingen 2004) 80 f. Zu Endoios s. E. Homann-Wedeking, Die Anfänge der griechischen Großplastik (Berlin 1950) 47; Pollitt 1990, 20 Anm. 2; Viviers 1992, bes. 67-101.

611 Vgl. auch Bald Romano 1980, 47; Ridgway 1992; H. von Heintze, Athena Polias am Parthenon als Ergane, Hippia und Parthenos, Gymnasium 100, 1993, 412; Nick 2002, 143.

612 Athen, Nationalmuseum Inv. 128: Nick 2002, 239 f. Taf. 18, 1. Die Münzen: Lacroix 1949, 266-281 Taf. 23, 1-12 Taf. 24, 1-5; Imhoof-Blumer - Gardner 1964, 126-128 Taf. Y Nr. 18-25; Die weiteren rundplastischen Nachbildungen: N. Leipen, Athena Parthenos. A Reconstruction (Toronto 1971); Nick 2002, bes. 177-205 Taf. 17-24. 
Baubefund: Das Plateau der Akropolis war schon im 2. Jahrtausend v. Chr. Kern der athenischen Siedlung und diente als Wohn- und Kultstätte. Der Bau monumentaler Tempel begann spätestens im 7. Jahrhundert v. Chr ${ }^{613}$. Für das 6. Jahrhundert v. Chr. sind zwei nebeneinander stehende Tempel nachgewiesen, der >Alte Athenatempek aus der 2. Hälfte des 6. Jahrhunderts v. Chr. und ein etwas früherer Peripteros vom Anfang des 6. Jahrhunderts v. Chr. an der Stelle des heutigen Parthenon, der sog. Ur-Parthenon ${ }^{614}$. Dieser war bereits in spätarchaischer Zeit durch einen Neubau ersetzt worden, der noch unfertig Zerstörungen während der Perserkriege erlitt 615 . Teile seines Fundamentes wurde wiederverwendet, als in den Jahren nach 448/7 v. Chr. der Parthenon errichtet wurde. In der Mitte der Cella hat sich die Basis der monumentalen Athenastatue des Phidias erhalten ${ }^{616}$. Auch der >Alte Athenatempek wurde während der Perserkriege zerstört und anschließend nur notdürftig wiederhergerichtet ${ }^{617}$. Im Zuge der Neugestaltung der Akropolis in der 2. Hälfte des 5. Jahrhunderts v. Chr. errichtete man mit dem `Erechtheion einen neuen Bau für den Kult der Athena Polias. Der Standort des Bildes im Erechtheion ist noch nicht endgültig geklärt, in der Forschung scheint sich aber ein Standplatz im Osten des Gebäudes durchzusetzen ${ }^{618}$.

Ergebnis: Das Bild der Athena Polias auf der Athener Akropolis galt als ein Diipetes und trug nach Ausweis einiger Schatzinschriften, die auf es bezogen werden können, realen Schmuck ${ }^{619}$. Zudem war es wahrscheinlich kleinformatig ${ }^{620}$. Ob es sich um ein stehendes oder ein sitzendes Bild gehandelt hat, ist umstritten, da bisher keine gesicherten Darstellungen identifiziert werden konnten ${ }^{621}$. Tertullianus' Vergleich der Pallas von Attica mit dem christlichen Kreuz könnte auf ein stehendes Bild hindeuten, falls sich diese Stelle auf die Athena Polias bezieht. Allerdings

613 Korres 1997.

${ }^{614}$ Diesem Bau weist Korres 1997 die >H-Architektur« sowie Fragmente großer Porosgiebel zu.

615 Muss - Schubert 1988, 55; Hurwitt 1999, 133 f.; Gruben 2001, 171 f.; Schneider - Höcker 2001, 107 f.; Korres 1997, 225. 240.

616 Muss - Schubert 1988, 12-17. 51-71. 77-79; Gruben 2001, 166-190. 209-222; Schneider Höcker 2001; Korres 1997.

${ }^{617}$ Dachziegel aus der Zeit nach den Perserkriegen beweisen, dass der Bau nach einer Reparatur seine Funktion zumindest teilweise weiter erfüllen konnte: E. Buschor, Die Tondächer der Akropolis (Berlin 1929) 76 Notdach Nr. 16; Herington 1955, 23; Muss - Schubert 1988, 151.

618 Muss - Schubert 1988, 78; Ridgway 1992, 126 f.; Hurwitt 1999, 203.

${ }^{619}$ Frickenhaus 1908, 17-32; Herington 1955, 17-21. Vgl. auch Eur. El. 1254-1257. Aus der Formu-

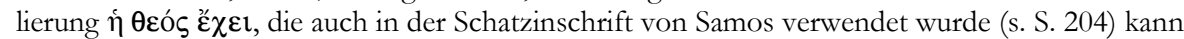
man erschließen, dass die genannten Gegenstände zur Ausstattung des Bildes gehört haben. Die Phiale hat das Bild in der Hand gehalten und das in den Inschriften genannte Band war um seinen Kopf gelegt. Deshalb kann man auch für die übrigen genannten Gegenstände vermuten, dass sie zum Schmuck des Bildes gehörten.

620 Plut. Themistokles 10, 4. Zu den vielleicht mit diesem Bild verbundenen Riten der Plynterien s. Kap. 15.2.1.

621 s. S. 198 f. 
bleibt dies eine bloße Vermutung, ebenso wie das genaue Alter des Bildes. Die Quellen schreiben ihm einen mythischen Ursprung zu, der Baubefund bezeugt seine Existenz spätestens seit dem 7. Jahrhundert v. Chr ${ }^{622}$. Ende des 5. Jahrhunderts v. Chr. wurde es offenbar in das neu gebaute Erechtheion überführt, da die oben zitierte Bauinschrift ein ỏ $\rho \chi \alpha \hat{\imath} o v$ ơ $\gamma \alpha \lambda \mu \alpha$ im Erechtheion erwähnt. Damit ist am wahrscheinlichsten das alte Bild der Athena Polias gemeint ${ }^{623}$.

Dieses Bild bestand also weiter, als Athena nach der Mitte des 5. Jahrhunderts v. Chr. ein neues, monumentales Bild erhielt, die Parthenos des Phidias. Die Kultfunktion dieser Statue wurde lange bestritten, da weder ein eigener Altar noch eine Priesterin überliefert sind. Der Parthenon galt als Schatzhaus und die Statue als >Weihgeschenk` für Athena Polias ${ }^{624}$. Ein gemeinsamer Altar für mehrere $>$ Kultbilder`, umgeben von mehreren Tempeln ist jedoch nichts Einmaliges. Auch im Kultbezirk des Dionysos Eleuthereus in Athen konnte bisher nur ein Altar nachgewiesen werden, obwohl es zwei Tempel und zwei Bilder gegeben hat ${ }^{625}$. Letztlich ist der Altar der eigentliche Mittelpunkt des gemeinschaftlichen Kultes, deshalb konnte er von mehreren Tempeln umgeben werden, ohne selbst verdoppelt werden zu müssen ${ }^{626}$. Gemeinsame Opfer an verschiedene Götter auf einem Altar waren in der Antike weit verbreitet. Daneben sind aber auch Heiligtümer überliefert, bei denen einer Gottheit, jedoch unter verschiedenen Aspekten auf nur

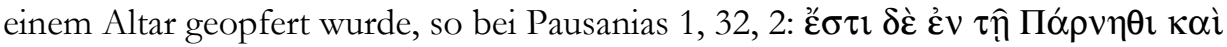

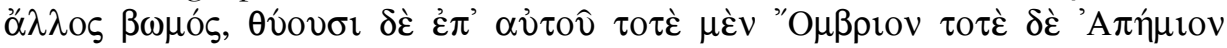

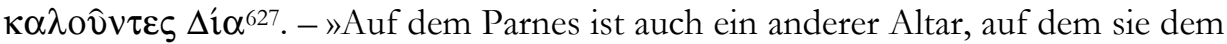
Zeus opfern, den sie bald Ombrios, bald Apemios nennen«. (F. Eckstein - P. C. Bol)

Auch bei Athena Polias und Athena Parthenos handelt es sich um zwei verschiedene Kulte, die vielleicht wie in dem Zeusheiligtum auf einem Altar begangen wurden. Ein eigener Altar für jedes Bild ist daher nicht Voraussetzung, um in ihnen \Kultbilder zu sehen. Darüber hinaus wurde Athena auf der Akropolis noch als Athena Nike, Hygieia, Promachos und Ergane verehrt ${ }^{628}$, weshalb nicht nur von

${ }^{622}$ Vgl. H. Jung, Thronende und sitzende Götter. Zum griechischen Götterbild und Menschenideal in geometrischer und früharchaischer Zeit (Bonn 1982) 53.

${ }^{623}$ IG I$^{3} 474$. Zur Identifizierung vgl. D. Harris, The Treasures of the Parthenon and Erechtheion (Oxford 1995) 201-206; Nick 2002, 137.

${ }^{624}$ Herington 1955, 6-14; F. Preisshofen, Zur Funktion des Parthenon nach den schriftlichen Quellen, in: E. Berger (Hrsg.), Parthenon-Kongress Basel. Referate und Bericht. 4. bis 8. April 1982. I (Mainz 1984) 15-18; G. Zinserling, Perikles - Parthenon - Phidias, ebenda 26-29; Muss - Schubert 1988, 116; H. Wrede, Einleitende Bemerkungen zum Fries, in: E. Berger - M. Gisler-Huwiler (Hrsg.), der Parthenon in Basel. Dokumentation zum Fries, Studien der Skulpturenhalle Basel 3 (Mainz 1996) 24-34, bes. 33 f.; B. Schmaltz, Die Parthenos des Phidias - zwischen Kult und Repräsentanz, in: Hoepfner 1997, 25-30; Faulstich 1997, 41. 43-53. 83-85; Hurwitt 1999, 27. 163 f. 625 s. Kap. 12.5.

${ }^{626} \mathrm{Vgl}$. Anm. 568.

${ }^{627}$ Vgl. auch Paus. 1, 26, 5; 1, 31, 1; 2, 31, 3.

${ }^{628}$ Muss - Schubert 1988, 27; Ridgway 1992; Nick 2002, 140-157. Zu Athena Nike s. Kap. 12.7. 
einem \Kultbild auszugehen ist. Die jüngsten Untersuchungen des Parthenongeländes durch M. Korres haben zudem ergeben, dass der Parthenon kein Neubau im Zusammenhang mit der Verlagerung der Bundeskasse des Delisch-Attischen Seebundes nach Athen war, sondern ein bereits in langer Tradition stehender Bau, dem demnach eine Kultfunktion unbedingt zukommt ${ }^{629}$. Aus der Zeit um 500 v. Chr. sind außerdem mehrere Weihinschriften von der Akropolis an Athena Parthenos belegt, woraus sich ebenfalls Zeugnisse für einen Kult ergeben ${ }^{630}$. Die Selbständigkeit des Parthenonkultes in vorklassischer Zeit wurde vor kurzem von M. Meyer bestärkt ${ }^{631}$. Für die weiteren Gründe, in der Athena Parthenos ein >Kultbild zu erblicken, sei auf die 2002 veröffentlichten ausführlichen Untersuchungen von G. Nick verwiesen ${ }^{632}$. Über das Aussehen des in den Vorgängerbauten des Parthenon aufgestellten Bildes besitzen wir keine Nachrichten ${ }^{633}$.

Das Beispiel des Athenaheiligtums auf der Akropolis von Athen hat gezeigt, dass zeitgleich verschiedene Kulte in einem Heiligtum möglich gewesen sind, die auch zu unterschiedlichen Zeiten mit Bildern ausgestattet worden sein konnten. Daneben stellt sich jedoch die Frage, ob auch ein Kult mit mehreren Bildern aus unterschiedlichen Zeiten ausgestaltet werden konnte. Die folgende Untersuchung einzelner Heiligtümer soll dieser Frage nachgehen.

\subsection{Hera auf Samos}

\section{Schriftquellen:}

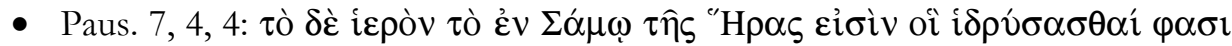

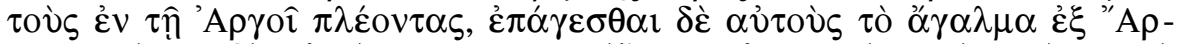

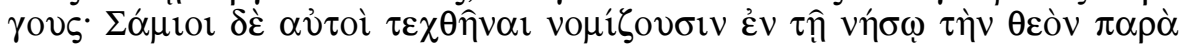

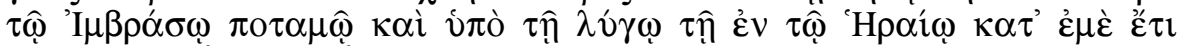

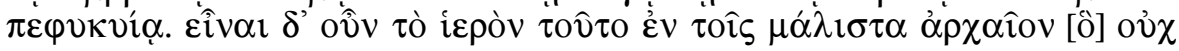

${ }^{629}$ Korres 1997, dort auch die ältere Literatur. In der Peristase des Parthenon konnte M. Korres zudem ein kleines Heiligtum nachweisen, das bereits in archaischer Zeit existiert hatte und in den Parthenon integriert worden war. Vgl. auch Ridgway 1992, 125.

${ }^{630}$ M. Lipka, Anmerkungen zu den Weihinschriften der Athena Parthenos und zur HekatompedonInschrift, in: Hoepfner 1997, 37-44; Nick 2002, 116 f.

${ }^{631}$ M. Meyer, Athena und die Mädchen. Zu den Koren auf der Athener Akropolis, in: M. Meyer -

N. Brüggemann, Kore und Kouros. Weihegaben für die Götter, Wiener Forschungen zur Archäologie 10 (Wien 2007) 13-89.

632 Nick 2002; G. Nick, Die Athena Parthenos - ein griechisches Kultbild, in: Hoepfner 1997, 22-24.

${ }^{633}$ Herington 1955, 38-42; Lehnstaedt 1970, 81 f.; G. Nick, Die Athena Parthenos - ein griechisches Kultbild, in: Hoepfner 1997, 22-24; Nick 2002, 148-157 haben ein Bild im Promachos-Typus vorgeschlagen. Ablehnend E. B. Harrison, Rez. zu Herington 1955, AJA 61, 1957, 208 f.; F. Preisshofen, Zur Funktion des Parthenon nach den schriftlichen Quellen, in: E. Berger (Hrsg.), Parthenon-Kongress Basel. Referate und Berichte. 4. bis 8. April 1982. I (Mainz 1984) 17; Ridgway 1992, 127; Oenbrink 1997, 390 f. 177 f. 208-213. 228. 290; B. Schmaltz, Die Parthenos des Phidias - zwischen Kult und Repräsentanz, in: Hoepfner 1997, 27. 


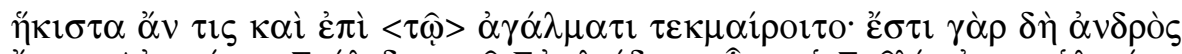

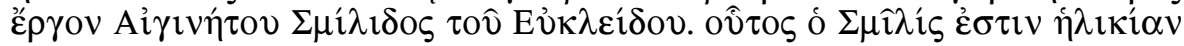

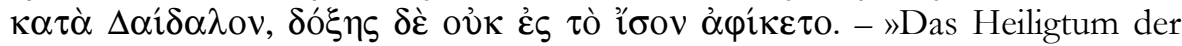
Hera in Samos sollen, wie die einen sagen, die Argonauten gegründet haben, und sie hätten das Kultbild aus Argos mitgebracht. Die Samier selber aber glauben, die Göttin sei auf der Insel geboren worden, am Fluss Imbrasos unter dem Lygosstrauch, der im Heraion noch zu meiner Zeit wuchs. Daß dieses Heiligtum also zu den allerältesten gehört, kann man nicht zum wenigsten auch aus dem Kultbild erschließen. Es ist das Werk eines Aigineten Smilis, Sohnes des Eukleides. Dieser Smilis lebte zur Zeit des Daidalos, kam ihm aber an Ruhm nicht gleich «. (F. Eckstein - P. C. Bol)

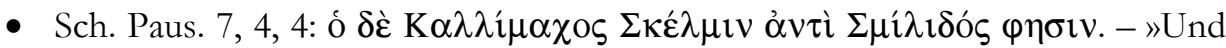
Kallimachos sagt Skelmis anstatt Smilis«.

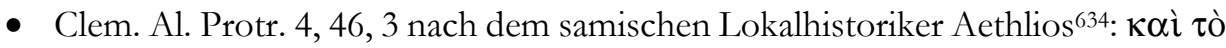

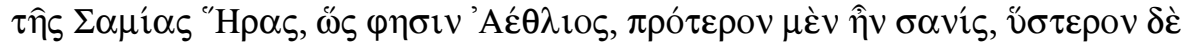

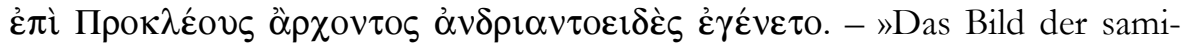
schen Hera war ursprünglich eine Holzbohle, später aber, unter dem Archon Prokles, wurde es menschengestaltig«. (Kyrieleis 1981, 15)

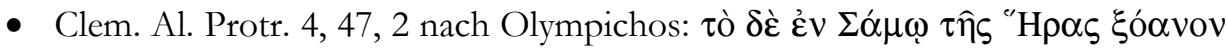

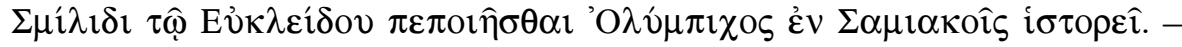
»und Olympichos in seiner Samischen Geschichte erzählt, dass das Xoanon der Hera in Samos gemacht worden war von Smilis, dem Sohn des Eukleides«.

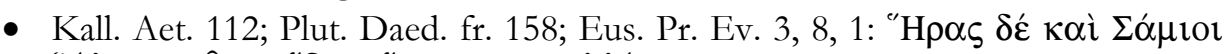

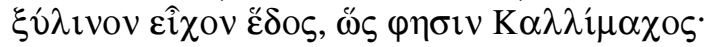

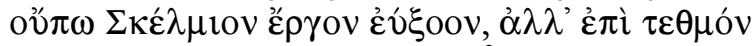

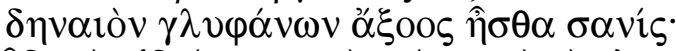

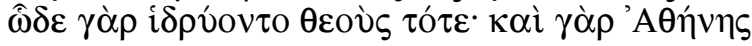

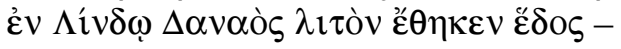

»Die Samier hatten ein hölzernes Hedos der Hera, wie Kallimachos berichtet:

„Noch nicht das gut geglättete Werk des Skelmis, sondern nach langjährigem Brauch eine Bohle warst du, ungeglättet von Beiteln. So nämlich stellte man sich die Götter auf damals; denn auch Athenes Statue auf Lindos errichtete Danaos schlicht"«. (M. Asper)

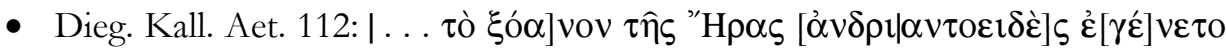

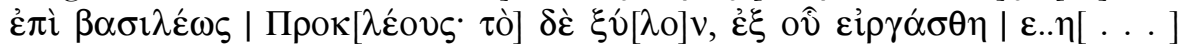

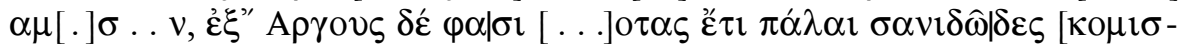

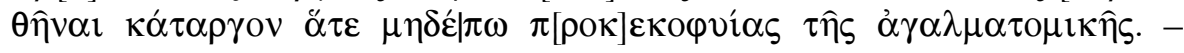
"[...] das Xoanon der Hera wurde [menschengestaltig] erst zur Zeit des Königs Prokles. Doch das Holz, aus dem gefertigt wurde [etwa: das erste Kultbild] aus Argos, sagt man, [...] sei es noch in alter Zeit bohlen-gleich gebracht worden 
und völlig unbearbeitet, da ja die Standbildschnitzerei noch keinerlei Fortschritte gemacht hatte«. (M. Asper)

- Arnob. 6, 11 nach Aethlius: ut Aethlius memorat, ante usum disciplinamque fictorum pluteum Samios (coluisse) pro Iunone. - „Wie Aethlios erinnert, verehrten die Samier vor der Ausübung der Bildhauerkunst ein Brett anstatt der Iuno«.

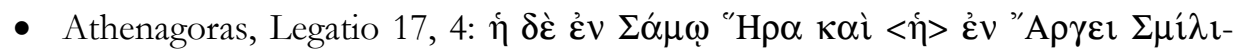

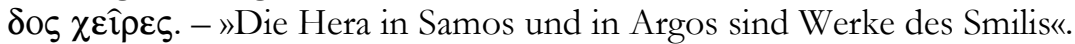

- Schatzinschrift aus Samos, die den Besitz der Hera auflistet (346/5 v. Chr.):

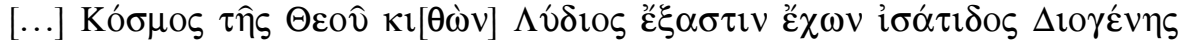

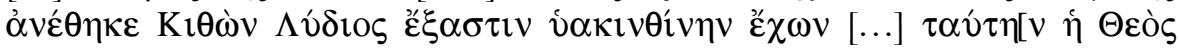

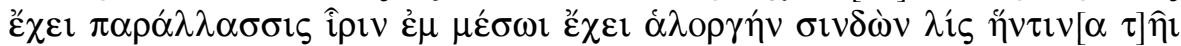

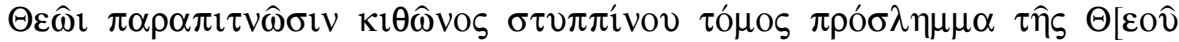

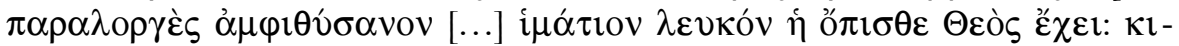

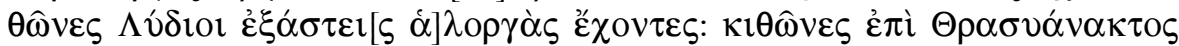

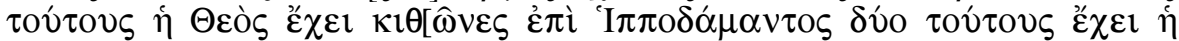

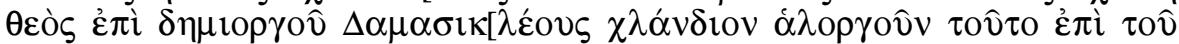

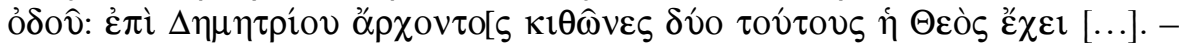
»[...] Schmuck der Göttin sie hat einen lydischen Chiton mit einer blauen Borte, geweiht von Diogenes, sie hat einen lydischen Chiton mit einer hyazinthfarbenen Borte [...] die die Göttin hat, sie hat eine irisfarbene Paralassis mit Purpur in der Mitte, ein Sindon aus Leinen, das ausgebreitet war vor der Göttin, ein aus Flachs geschnittener Chiton, ein Proslemma der Göttin mit purpurfarbenen Fransen [...] ein weißes Himation, das die bintere Göttin hat, zwei lydische Chitone mit purpurnen Borten, unter Thrasyanax Chitone, die die Göttin hat, unter Hippodamos zwei Chitone, alle hat die Göttin, unter dem Demiurgen Damasikleos ein purpurnes Chlandion, alles bei dem Gang, unter dem Archonten Demetrios zwei Chitone, die die Göttin hat [...]《.

Darstellungen: Amphorenstempel des 4. Jahrhunderts v. Chr. sowie hellenistische und kaiserzeitliche Münzen und Siegelabdrücke aus Samos zeigen ein altertümliches Bild der Hera. Es steht unbewegt und aufrecht auf einer flachen Basis und trägt reiche Gewänder, Schmuck und einen Polos. Die Unterarme sind angewinkelt und vorgestreckt. Von den Händen hängen Wollbinden herab. Auf einigen Münzen steht die Figur im Tempel ${ }^{635}$. Eine von Chr. Kardara publizierte kaiserzeitliche Münze aus Samos (Abb. 39) zeigt neben dem altertümlichen Bild eine jüngere, frühestens klassische weibliche Figur. Sie steht mit dem Gewicht auf dem rechten Bein, das entlastete linke ist angewinkelt, der Fuß zur Seite gestellt.

635 Lacroix 1949, 207-216 Taf. 17, 3-11; Ohly 1953 Beil. 1; V. R. Grace, Samian Amphoras, Hesperia 40, 1971, 57-58 Nr. 28-29 Taf. 13; Fleischer 1973, 202-223 Taf. 85a. b. 86a. b. 87a. b. 88a; Kyrieleis 1981, 16 Abb. 5. 64; Walter 1990, 86 f. Abb. 96 f.; M.-F. Boussac, Les sceaux de Délos I (Paris 1992) 174 Nr. AE30 Taf. 67; Held 1995, 14 mit Anm. 3; Fleischer 1999, 607 Taf. 151, 4. 
Der linke Arm ist gesenkt, der rechte unter dem Mantel verborgen, der auch über den Kopf gezogen ist. Der Kopf ist leicht nach rechts gewandt ${ }^{636}$.

Baubefund: Die Untersuchung des Baubefundes ergab zwei Tempel aus geometrischer und früharchaischer Zeit, die nacheinander an derselben Stelle errichtet worden waren. In beiden war die Cella durch eine Mittelstützenreihe in zwei Schiffe geteilt. Hinter der letzten Stütze befand sich jeweils eine kleine Basis für eine Statue der Göttin. In der 1. Hälfte des 6. Jahrhunderts v. Chr. wurde an derselben Stelle der erste Dipteros errichtet. Er nahm in seinem Pronaos die alte, erhaltene Kultstätte auf, wie D. Ohly und W. Held haben übereinstimmend festgestellt haben, was bedeutet, dass sie weiterhin in Funktion gewesen ist ${ }^{637}$. In der Mitte der Cella gab es außerdem eine zweite, größere Basis, wahrscheinlich für ein weiteres Herabild. Bereits in der 2. Hälfte des 6. Jahrhunderts v. Chr. wurde leicht versetzt der zweite Dipteros errichtet. Die alte, geometrische Basis lag jetzt außerhalb des Tempels. Sie wurde bereits zu diesem Zeitpunkt mit einem Baldachin überdacht, der mehrfach erneuert wurde und bis in die Spätantike bestand. Dies bezeugt eindeutig die weiter bestehende Funktionalität der Basis ${ }^{638}$. Der letzte Tempel war, im Gegensatz zu seinem auf den Altar ausgerichteten Vorgänger, auf die alte Basis ausgerichtet, ein weiteres Zeichen dafür, dass diese nicht in Vergessenheit geraten war ${ }^{639}$. Eine andere Basis gab es im Pronaos des Tempels. Diese stammt jedoch erst aus hellenistischer oder römischer Zeit. Eine weitere Basis wird in der Mitte der Cella vermutet, da auch der erste Dipteros dort eine Basis besaß ${ }^{640}$.

Ergebnis:_Die Quellen bezeugen mehrere unterschiedlich alte Bilder der Hera von Samos. Die eine Statue galt wie der Kult selbst als uralt. Sie soll einst eine rohe Holzbohle, also anikonisch oder nur andeutungsweise menschlich gewesen sein und wurde später anthropomorph umgestaltet ${ }^{641}$. Die angebliche Ansicht des

636 Chr. Kardara, Problems of Hera's Cult-Images, AJA 64, 1960, 343-358 Taf. 101, 30.

637 Ohly 1953, 29-33; Held 1995, 13-23. Ähnlich Schleif 1933, 216; Kyrieleis 1981, 81; Walter Clemente 1986, 139-141; H. Kienast, Topographische Studien im Heraion von Samos, AA 1992 , 188 mit Anm. 70.

638 Schleif 1933, 212-217; Ohly 1953, 29 f. 33; Kyrieleis 1981, 48. 82; Gruben 2001, 360; Held 1995, 13-23. Zu den Bauphasen des Monopteros siehe Walter - Clemente 1986, 137-147. Nach Ansicht von Ohly 1953, 33 f. 37 f. war das Herabild eventuell nur bei Festen auf der alten Basis aufgestellt, während es sonst im Pronaos des Polykrates-Tempels gestanden hat; ebenso Bald Romano 1980, 261; Walter - Clemente 1986, 141-143; Gruben 2001, 360. Die dort befindliche Basis stammt jedoch frühestens aus dem Hellenismus. Eine Basis im Pronaos ist vorher nicht gesichert. Vgl. Held 1995, 17-21.

639 Dies hatte auch schon Kyrieleis 1981, 81 festgestellt.

640 Buschor 1930; Schleif 1933; Ohly 1953; Bald Romano 1980, 261; Kyrieleis 1981; Walter Clemente 1986; H. J. Kienast, Topographische Studien im Heraion von Samos, AA 1992, 171-213; Held 1995; Gruben 2001, 348-365.

641 Bei den im Zusammenhang mit der Umarbeitung überlieferten Bildhauern Smilis und Skelmis hat

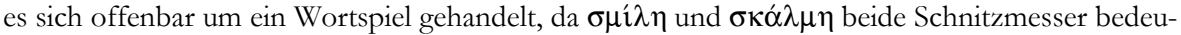


Aischylos, dass die einfachen alten Götterbilder ehrwürdiger waren als die späteren, künstlerisch wertvolleren wurde demnach nicht von allen geteilt ${ }^{642}$. Wichtig ist aber, dass das Bild trotz seines zunächst nicht mehr akzeptablen Äußeren bis in die Spätzeit verehrt wurde, wie seine vielfache Erwähnung bis in die Kaiserzeit hinein belegt. Der Baubefund bezeugt durch die erhaltene Kultbildbasis, dass es spätestens seit der geometrischen Zeit existiert hat ${ }^{643}$. Es scheint transportabel und nicht sehr groß gewesen zu sein, da es bei Kultfesten den Tempel verlassen konnte ${ }^{644}$. Seit der spätarchaischen Zeit befand sich die seit geometrischer Zeit bestehende und offenbar immer in Funktion gebliebene Basis vor der Front des zu seinen Vorgängern leicht versetzt errichteten letzten Tempels, das Bild stand also nicht mehr in der Cella, sondern vor dem Tempel ${ }^{645}$.

Aus dem bekannten, oben zitierten Inventar des Heraheiligtums geht hervor, dass es im 4. Jahrhundert v. Chr. mindestens zwei \Kultbilder der Hera gegeben hat, denen jeweils Kleidung geweiht wurde. Sie werden als $\dot{\eta} \theta \varepsilon$ ò $\varsigma$ und $\dot{\eta}$ ö $\pi \imath \sigma \theta \varepsilon$ $\theta \varepsilon$ ò $\zeta$ unterschieden. Dabei kann es sich nur um Statuen der Göttin handeln ${ }^{646}$. Zu

ten, also bezeichnende Namen darstellen. Dies wurde auch schon in der Antike vermutet, so ein Scholion zu Paus. 7, 4, 4. Ebenso Ohly 1953, 39-44. Plinius nat. 36, 90 datiert Smilis in die 1. Hälfte des 6. Jahrhunderts v. Chr.: architecti fecere Zmilis et Rhoecus et Theodorus indigenae - ßBaumeister waren Zmilis, Rhoikos und Theodoros, alle Ortsansässige«. (R. König). Zu Rhoikos und Theodoros vgl. Hdt. 3, 60 bzw. Vitr. 7 praef. 12. Der in den Quellen ebenfalls genannte Prokles gehört in die mythische Vorzeit, woraus sich keine reale Datierung ergibt, vgl. RE 2. Reihe I (1914) 2211 s. v. Samos (H. von Geisau); Kyrieleis 1981, 15 f.

${ }^{642} \mathrm{Zu}$ Aischylos s. S. 129. Die Umarbeitung eines nicht mehr dem zeitgenössischen Geschmack entsprechenden Bildes ist durch Pausanias 3, 16, 1 auch für das Heiligtum der Hilaeira und Phoibe in

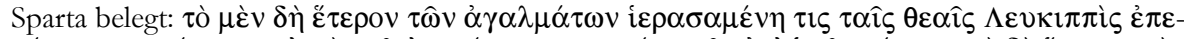

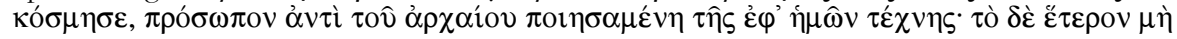

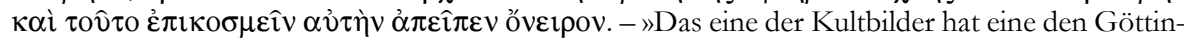
nen als Priesterin dienende Leukippide ausgeschmückt, indem sie an Stelle des alten ein Gesicht in moderner Art einsetzen ließ. Das andere ebenso auszustatten, verbot ihr ein Traum«. (F. Eckstein - P. C. Bol). Laut Hyperides 3, 35-37 wurde auch Statue der Dione in Dodona umgearbeitet:

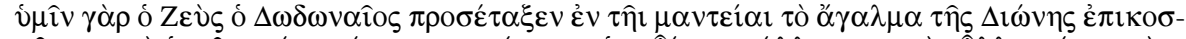

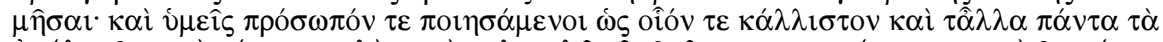

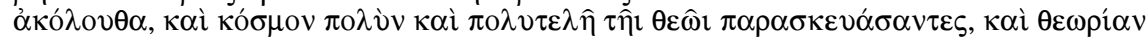

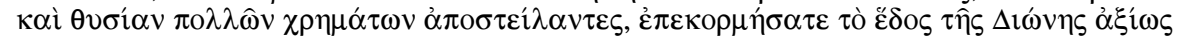

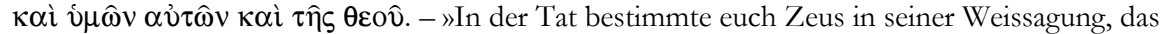
Agalma der Dione wiederherzustellen. Also machtet ihr ein Gesicht, das schönste welches mögich war, und auch die anderen diesem entsprechenden Teile, ihr habt der Göttin ein Kleid bereitgestellt, reich und prächtig, und ihr schicktet ihr eine Festgesandtschaft und ein Opfer von hohem Wert. Damit habt ihr das Hedos der Dione euch und der Göttin angemessen instand gesetzt«. Auch das alte Holzbild des Dionysos Kadmeios in Theben, auf das in Kap. 12.6 noch genauer einzugehen sein wird, war laut Pausanias 9, 12, 4 umgearbeitet worden.

${ }^{643} \mathrm{Zu}$ den unterschiedlichen Rekonstruktionen der frühen Phasen s. Ohly 1953, 26; Walter Clemente 1986, 141 f.; Walter 1990, 35. 53; H. J. Kienast, Topographische Studien im Heraion von Samos, AA 1992, 174.

${ }^{644} \mathrm{Zu}$ den Quellen s. S. 302 f.

645 s. Anm. 638.

646 Ohly 1953, 46-48 Anhang 7; Walter 1990, Abb. 37. 
dem alten Bild war demnach irgendwann, spätestens aber im 4. Jahrhundert v. Chr. ein weiteres hinzugetreten. Der Baubefund zeigt, dass dies am wahrscheinlichsten im Zusammenhang mit der Errichtung des ersten Dipteros in der 1. Hälfte des 6. Jahrhunderts v. Chr. geschah, da der Tempel neben der alten, im Pronaos erhaltenen gebliebenen geometrischen Basis eine weitere in der Mitte der Cella besaß ${ }^{647}$. Der Neubau des Tempels und das neue Bild ergäben somit eine Einheit.

Somit hat der erste Dipteros nach dem gegenwärtigen Stand der Forschung zwei Bilder besessen, der zweite Dipteros hingegen nur noch eines, denn die alte Statue stand seit der spätarchaischen Zeit vor dem Tempel ${ }^{648}$. Dieser Befund passt, wie bereits mehrfach dargelegt wurde, zu der Benennung der Statuen in der

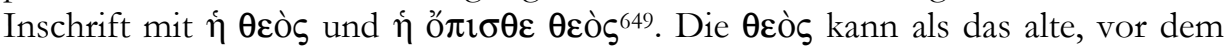
Tempel stehende Bild aufgefasst werden, dem laut der Inschrift reiche Kleidung geweiht wurde. Die ö $\pi \imath \sigma \theta \varepsilon \theta \varepsilon$ ò $\varsigma$ war das in der Cella und damit shinterı der $\theta \varepsilon o ̀ s$ stehende jüngere Bild, das ein Himation besaß. Aufgrund der Formulierung $\dot{\eta}$

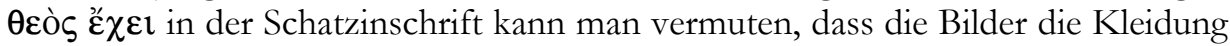
tatsächlich getragen haben ${ }^{650}$. Daher ist denkbar, dass die Statuen auf hellenistischen und kaiserzeitlichen Münzen und Siegeln dargestellt sind (Abb. 39)651. Diese zeigen ein altertümliches, reich gekleidetes Bild, das mit dem alten Herabild

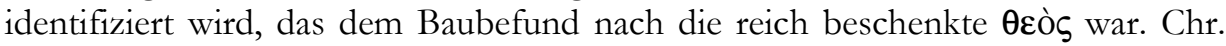
Kardara vermutet darüber hinaus, dass auch die ő $\pi \_\sigma \theta \varepsilon \theta \varepsilon$ ò auf Münzen abgebildet ist (Abb. 39). Einige Münzen zeigen neben dem alten Bild die frühestens spätklassische Darstellung einer in einen Mantel gehüllten weiblichen Figur ${ }^{652}$. Allerdings kann es sich aufgrund des Typus nicht um die vermutlich in archaischer Zeit aufgestellte Statue handeln, sondern vielleicht um ein jüngeres Ersatzbild dieser Statue, worüber aber keine Zeugnisse vorliegen.

${ }^{647}$ In dem jüngeren Dipteros ist in der Cella eine Basis erst aus der Kaiserzeit erhalten. Aufgrund der im ersten Dipteros nachgewiesenen Basis wird jedoch auch eine archaische Basis für den jüngeren Bau vermutet: Ohly 1953, 33; Gruben 2001, 360; Held 1995, 15-17. Der Bildhauer Smilis, der nach den Quellen das alte Bild der Hera umgearbeitet hat und in das 6. Jahrhundert v. Chr. datiert werden kann, wird von Buschor 1930, 50; Walter 1990, 85; Gruben 2001, 360 und Nick 2002, 94 mit der jüngeren Statue in Verbindung gebracht. Dagegen sprachen sich Ohly 1953, 34. 37. 41-44; Kyrieleis 1981, 15 f. und Held 1995, 14 aus.

${ }^{648} \mathrm{Ob}$ die Bilder in der Kaiserzeit in die zwei vor dem Dipteros erbauten Tempel überführt wurden, wie Buschor 1930, 97 f.; Schleif 1933, 218; Ohly 1953, 28. 38; Kyrieleis 1981, 51 und Walter 1990, 197 meinten, ist laut Held 1995, 21-23 unsicher. Seiner Meinung nach kann es sich auch um Kaiserkulttempel handeln.

649 Buschor 1930, 50; Ohly 1953, 34. 37. 41-44; Walter 1990, 129; Held 1995, 14.

${ }^{650}$ So auch Ohly 1953, 34-37. Statuen, die durch zahlreiche Kleidungstücke z. T. regelrecht verdeckt wurden überliefert Paus. 1, 18, 5; 2, 11, 6; 6, 25, 5 f.; 7, 23, 5 f.; 7, 25, 9.

651 s. Anm. 636.

652 s. Anm. 636. 


\subsection{Hera in Argos}

Schriftquellen zu dem alten Bild:

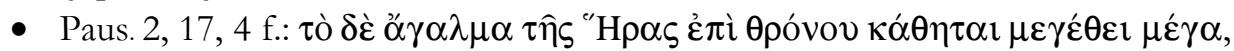

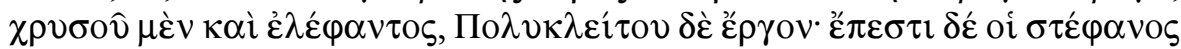

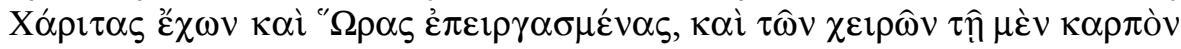

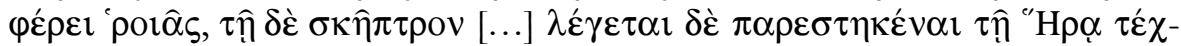

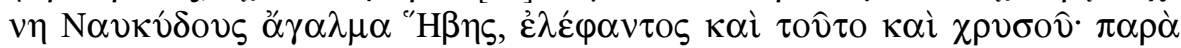

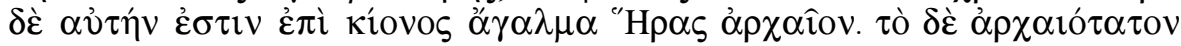

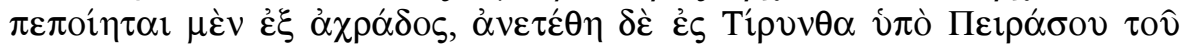
"A

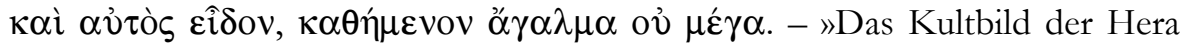
sitzt auf einem Thron und ist von bedeutender Größe, aus Gold und Elfenbein, ein Werk des Polyklet. Sie trägt eine Krone, an der Chariten und Horen dargestellt sind, und hält in der einen Hand einen Granatapfel, in der anderen ein Szepter [...]. Neben der Hera soll eine Statue der Hebe gestanden haben, Werk des Naukydes, auch diese aus Gold und Elfenbein, und neben ihr befindet sich auf einer Säule ein altes Herabild. Die älteste Statue ist aus dem Holz des wilden Birnbaums gemacht und wurde von Peirasos, dem Sohn des Argos, nach Tiryns geweiht, und als die Argiver Tiryns einnahmen, brachten sie es ins Heraion. Ich habe es noch selbst gesehen, ein nicht großes Sitzbild«. (F. Eckstein - P. C. Bol)

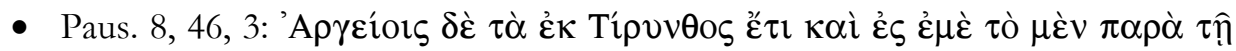

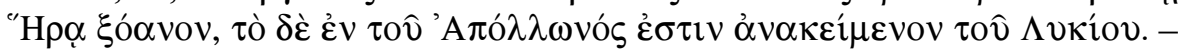
$»$ Aber die Argiver haben bis auf den heutigen Tag das, was sie aus Tiryns nahmen, und zwar ein Xoanon bei der Hera, das andere ist bei dem Apollon Lykios aufbewahrt«.

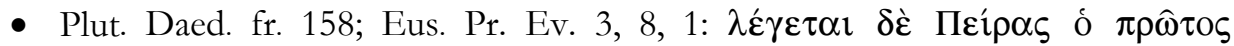

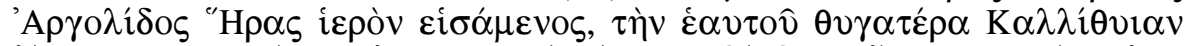

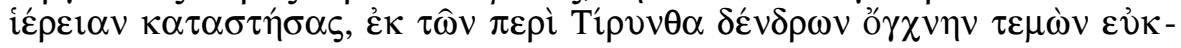

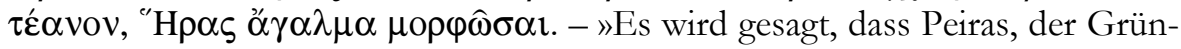
der des Heiligtums der Hera der Argolis, nachdem er seine eigene Tochter Kallithyia zur Priesterin gemacht hatte, aus einen gerade gewachsenen Birnbaum von denen, die um Tiryns wuchsen, das Agalma der Göttin schnitzte«.

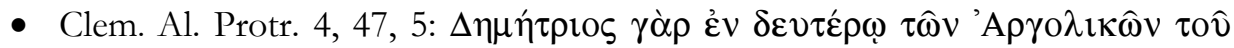

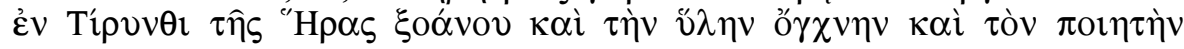

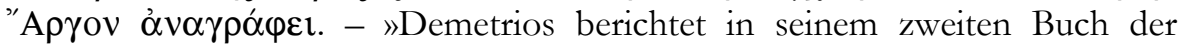
Geschichte der Argolis von dem Xoanon der Hera in Tiryns, sowohl von dessen Material - Birnenholz - als auch von seinen Erschaffer - Argos«.

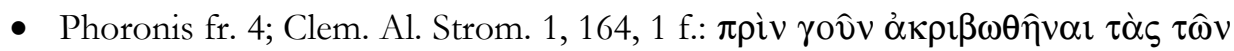

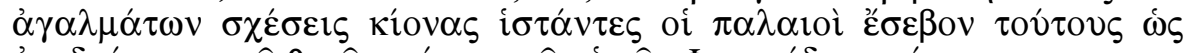

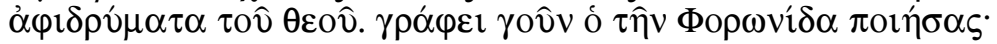

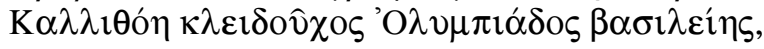




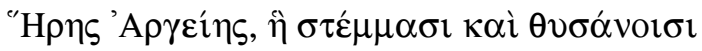

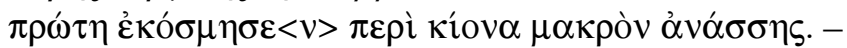

»Bevor man ja erlernt hatte, genaue Bildgestalten zu fertigen, stellten die Alten Säulen auf und verehrten sie als Bildsäulen Gottes. Es schreibt z. B. der Dichter der Phoronis:

„Kallithoe, der olympischen Königin Schlüsselbehüt'rin welche zuerst geschmückt hat im Kreis mit Kranz und Gewinde Heras, der Fürstin von Argos, zur Höhe ragende Säule“«. (C. A. Bernoulli - L. Früchtel)

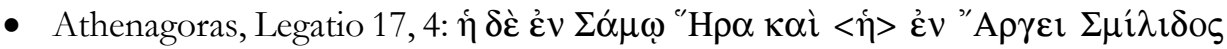

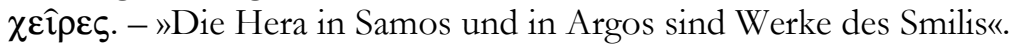

Schriftquellen zu dem neuen Bild:

- Tert. de corona 7: Iunoni vitem Callimacbus induxit. Ita et Argi signum eius palmite redimitum subiecto pedibus corio leonino, insultantem ostentat novercam de exwviiss utriusque privigni. - »Der Juno hat Callimachus eine Weinranke umgelegt. Ihr mit einer Weinrebe umwundenes Symbol zu Argos und die unter ihren Füßen ausgebreitete Löwenhaut gibt dem Beschauer zu verstehen, daß die Stiefmutter über ihre beiden Stiefsöhne triumphiere«. (K. A. H. Kellner)

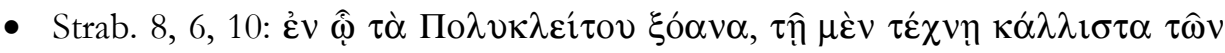

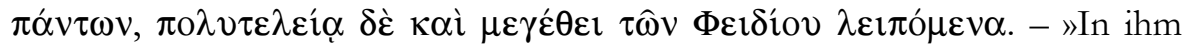
[dem Tempel] befinden sich die Kultstatuen von Polyklet, künstlerisch die schönsten von allen, an Kostbarkeit und Größe jedoch hinter denen des Phidias zurückstehend «. (St. Radt)

- Mart. 10, 89: Inno labor, Polyclite, tuus et gloria felix,

Phidiacae cuperent quam meruisse manus, ore nitet tanto quanto superasset in Ide iudice convictas non dubitante deas. Iunonem, Polyclite, suam nisi frater amaret, Iunonem poterat frater amare tuam. »Dir Polyklet, einst Müh und rühmliche Ehre, die Juno selbst des Phidias Hand wünschte, sie wäre ihr Werk strahlt so hehr im Gesicht: so hätt sie die Göttinnen glänzend auf dem Ida besiegt, nie hätt der Richter geschwankt. Wenn, Polyklet, der Bruder die eigene Juno nicht liebte, könnte der Bruder gar wohl lieben die Juno von dir«. (R. Helm)

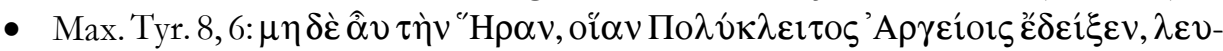

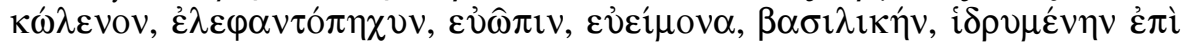

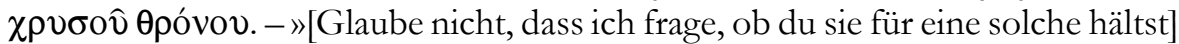
die Hera, die Polyklet den Argeiern schuf mit weißen Armen, Ellen aus Elfenbein, schöngesichtig, schön gekleidet, königlich, auf goldenem Thron sitzend«. 
Darstellungen: Von dem oder den überlieferten alten Bildern der Hera von Argos sind bisher keine Wiedergaben bekannt. Die Statue des Polyklet fand man auf kaiserzeitlichen Münzen wiedergegeben (Abb. 40). Sie zeigen die Göttin auf einem reich verzierten Thron sitzend. Sie hat die rechte Hand nach vorn ausgestreckt und hält einen nur schwer erkennbaren Gegenstand, der laut Pausanias 2, 17, 4 f. ein Granatapfel sein wird. Der linke Arm ist erhoben, mit der Hand fasst die Göttin ein neben ihr stehendes Szepter. Sie ist reich gewandet und trägt eine Krone mit pflanzlichen Verzierungen auf dem Kopf, die Haare fallen ihr lang in den Nacken. Auf einigen der Münzen steht neben der sitzenden Hera eine kleinere weibliche Figur, die als das von Naukydes geschaffene Bild der Hebe gedeutet wird ${ }^{653}$.

Baubefund: Die frühesten bisher erforschten baulichen Strukturen des Heiligtums stammen aus dem 8. Jahrhundert v. Chr. Der erste gesicherte Tempel war im 7. Jahrhundert v. Chr. auf einer künstlichen Terrasse errichtet worden ${ }^{654}$. Er wurde in den 420er Jahren v. Chr. bei einem Brand vollständig zerstört. In der 2. Hälfte des 5. Jahrhunderts v. Chr. errichtete man auf einem tiefer gelegenen Plateau einen zweiten Tempel. Unsicher ist, ob der neue Kultbau bereits geplant oder sogar schon begonnen wurde, als der alte noch bestand, oder ob er ein Ersatzbau für diesen ist ${ }^{655}$.

Ergebnis: Das Heiligtum der Hera in Argos galt wie in Samos als sehr alt ${ }^{656}$. Als Pausanias es im 2. Jahrhundert n. Chr. besuchte, konnte er dort mehrere Herabilder aus unterschiedlichen Zeiten in ein und demselben Tempel bewundern: eine thronende Statue von Polyklet und ein altes Bild, das daneben auf einer Säule

653 Winterthur, Münzkabinett: Imhoof-Blumer - Gardner 1964, 34 Taf. I Nr. 15; weitere bei Waldstein, 1902, 22 Abb. 11a-b; Lacroix 1949, 254-259 Taf. 21, 5-14; Imhoof-Blumer - Gardner 1964, 34 Taf. I Nr. 13 f.12; Lapatin 2001, 102 Abb. 201 f.

${ }^{654}$ Die Datierung der Terrassenmauer ist umstritten und reicht von der mykenischen bis zur geometrischen Zeit. Die Terrasse ist also älter als der Tempel, weshalb mehrfach vermutet wurde, dass sie im 8. Jahrhundert v. Chr. zunächst einen kleinen Kultschrein beherbergt hat. Das Gebiet des Heiligtums war zwar schon in mykenischer Zeit besiedelt, eine Kultkontinuität konnte jedoch bisher noch nicht nachgewiesen werden: Waldstein 1902 Abb. 50 Taf. 8 mit unhaltbarer Datierung in die 1. Hälfte des 2. Jahrtausends v. Chr.; P. Amandry, Observations sur les monuments de l'Héraion d'Argos, Hesperia 21, 1952, 222-274; H. Lauter, Zur frühklassischen Neuplanung des Heraions von Argos, AM 88, 1973, 175-187; J. C. Wright, The Old Temple Terrace at the Argive Heraeum and the Early Cult of Hera in the Argolid, JHS 102, 1982, 186-201; H. Plommer, The Old Platform in the Argive Heraeum, JHS 104, 1984, 183-184; G. M. Antonaccio, Terraces, Tombs and the Early Heraion, Hesperia 61, 1992, 85-105; Gruben 2001, 108-111; C. A. Pfaff, The Argive Heraion I. The Architecture of the Classical Temple (Athens 2003) 1.

655 Gruben 2001, 108-111. Der jüngere Tempel wurde evtl. in der Mitte des 5. Jahrhundert v. Chr. begonnen: Waldstein 1902, 20.118; P. Amandry, Observations sur les monuments de l'Héraion d'Argos, Hesperia 21, 1952, 258. 272. 274; G. Roux, L'architecture de l'Argolide au IVe et III siècles avant J.-C. (Paris 1961) 58; H. Lauter, Zur frühklassischen Neuplanung des Heraions von Argos, AM 88, 1973, 182-183; Gruben 2001, 111; Lapatin 2001, 104; Whitley 2001, 301; C. A. Pfaff, The Argive Heraion I. The Architecture of the Classical Temple (Athens 2003) 6 f. 191-194. 656 Vitr. 4, 1, 3. 
stand. Dieses war wahrscheinlich nicht sehr groß, da Darstellungen von Götterbildern, die auf einer Säule oder einem Pfeiler stehen z. B. auf Vasenbildern immer kleinformatig sind ${ }^{657}$. Außerdem sah er vielleicht noch eine Sitzstatue, die einst in Tiryns gestanden habe, wenn sie nicht mit dem Bild auf der Säule identisch war ${ }^{658}$. Ihre Entstehung soll bis in die mythische Zeit zurückzuführen sein ${ }^{659}$.

Da ein erster Tempelbau für das 7. Jahrhundert v. Chr. nachgewiesen ist, ist die Existenz eines ersten Herabildes spätesten von dieser Zeit an wahrscheinlich. Als dieser Tempel 423 v. Chr. abbrannte ${ }^{660}$, möglicherweise jedoch sogar schon eher, als er noch unbeschadet seine Funktion erfüllen konnte, wurde auf der darunter liegenden Terrasse ein neuer Bau begonnen. Die Statue des Polyklet war wahrscheinlich für den Neubau geschaffen worden und stand auf der großen Basis in dessen Cella ${ }^{661}$. Ihr Aussehen kann mit Hilfe der literarischen Beschreibung und kaiserzeitlichen Münzen rekonstruiert werden $(A b b .40)^{662}$. Das alte Bild muss die Zerstörung des alten Tempels überlebt haben und neben dem neuen aufgestellt worden sein, wo es Pausanias noch im 2. Jahrhundert n. Chr. gesehen hat. Auch das aus Tiryns überführte Bild wurde neben den argivischen Statuen aufgestellt.

Das von Peirasos in Tiryns aufgestellte Herabild scheint auch in dem archaischen Epos >Phoronis` überliefert zu sein, denn die dort genannte Priesterin war seine Tochter ${ }^{663}$. Das dort erwähnte Bild war jedoch kein kleines Sitzbild sondern großformatig säulenförmig ${ }^{664}$. Einen bestechenden, wenn auch nicht zu beweisenden Vorschlag zur Interpretation der Phoronis hat A. Frickenhaus in seiner Untersuchung des Heraheiligtums von Tiryns von 1912 vorgetragen. Dort war seiner Meinung nach im 8. oder 7. Jahrhundert v. Chr. über den Resten des mykenischen

${ }^{657}$ Vgl. Kap. 7.1.1.4 und Anm. 915.

${ }^{658}$ Laut Lapatin 2001, 105 wurde das Bild aus Tiryns erst bei der Eroberung der Stadt 468 v. Chr. nach Argos gebracht, so dass ein älteres Bild als das des Polyklet in Argos angenommen werden muss, da das Heiligtum deutlich älter ist. In einem grob behauenen Steinpfeiler aus dem Heraion ein weiteres, noch älteres Herabild zu sehen, wie es Waldstein 1902, 42.139 mit Abb. 15.70 vorschlug, scheint durch nichts begründet und geht wahrscheinlich auf die von ihm angenommene, unhaltbare Heiligtumsgründung in der 1. Hälfte des 2. Jahrtausends v. Chr. zurück. Auch der vermutete Naiskos des 8. Jahrhunderts v. Chr. ist noch nicht nachgewiesen, so dass ein damit verbundenes drittes argivisches Bild nicht bezeugt ist. Zu den Anfängen des Heiligtums vgl. Anm. 654.

${ }^{659} \mathrm{Zu}$ Peirasos s. DNP IX (2000) 475 s. v. Peiras (S. Antoni). Athenagoras Legatio 17, 4 nennt als Bildhauer der Hera von Argos Smilis, der auch das Herabild auf Samos geschaffen haben soll. Vermutlich handelt es sich hierbei um eine Angleichung oder Verwechslung, da Smilis sonst nicht weiter mit Argos verbunden ist.

${ }^{660}$ Paus. 2, 17, 7; Thuk. 2, 2; 4, 133.

661 Waldstein, 1902, Taf. 16.

662 s. Anm. 653. Strab. 8, 6, 10; Max. Tyr. 8, 6; Mart. 10, 89 und Tert. de corona 7 rühmen das Werk des Polyklet als eine der schönsten Statuen, die es je gegeben hat.

${ }^{663}$ Zur Datierung des Epos in das 7. oder 6. Jahrhundert v. Chr. s. RE XX 1 (1941) 646-650 s. v. Phoronis (F. Stoessl); DNP VI (1999) 953 s. v. Phoronis (N. Forgó).

${ }^{664} \mathrm{Vgl}$. H. Jung, Thronende und sitzende Götter. Zum griechischen Götterbild und Menschenideal in geometrischer und früharchaischer Zeit (Bonn 1982) 64. 
Palastes und unter Einbeziehung von dessen Fundamenten ein kleiner Antentempel errichtet worden. Auch der mykenische Altar wurde weiter verwendet und durch eine neue Ummantelung vergrößert ${ }^{665}$. In der Mitte der Cella, genau an der Stelle, wo in griechischen Tempel für gewöhnlich das $>$ Kultbild seine Aufstellung fand, war nach Aussage von A. Frickenhaus eine der Säulen des Palastes erhalten geblieben. Darin könnte man das säulenförmige Bild der Hera erblicken ${ }^{666}$. Dies erscheint nicht abwegig, da auch das Bild des Dionysos Kadmeios in Theben der Überlieferung nach die einzige erhaltene Säule des thebanischen Palastes gewesen sein soll667. Da jedoch die Befundsituation noch nicht ausreichend geklärt ist und auch die Funktion und die Datierung des Gebäudes umstritten sind ${ }^{668}$, sollte dies weiterhin als unbewiesene Thesen behandelt werden. Auf jeden Fall kann das Heraheiligtum von Argos als ein Beispiel für die Aufstellung einer kostbaren, von einem berühmten Bildhauer geschaffenen Statue neben einem alten Bild gelten.

\subsection{Zeus in Olympia}

\section{Schriftquellen zu dem alten Bild:}

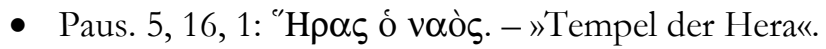

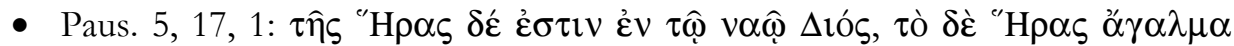

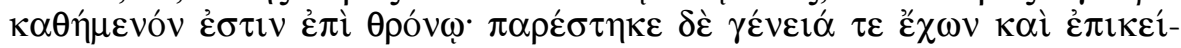

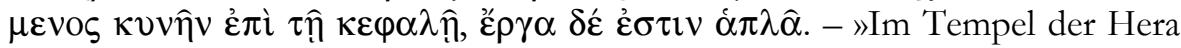
befindet sich ein Kultbild des Zeus ... (und der Hera); dasjenige der Hera sitzt auf einem Thron, Zeus steht daneben, bärtig und mit einem Helm auf dem Kopf. Es sind schlichte Werke«. (F. Eckstein - P. C. Bol)

\section{Schriftquellen zu dem neuen Bild:}

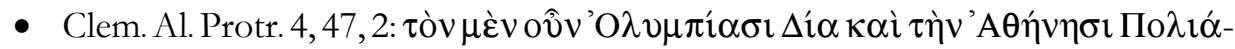

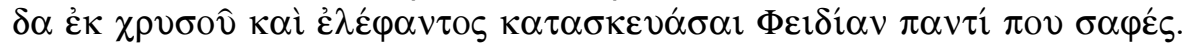
- »Und jetzt wird jeder, wie ich vermute, zugeben, dass Zeus in Olympia und Athena Polias in Athen gebildet wurden aus Gold und Elfenbein durch Phidias«.

665 A. Frickenhaus, Die Hera von Tiryns, Tiryns I (Athen 1912) 2-12; U. Jantzen (Hrsg.), Führer durch Tiryns (Athen 1975) 97-99; R. A. Tomlinson, Greek Sanctuaries (London 1976) 195-197; A. Mazarakis Ainian, From Rulers' Dwellings to Temples. Architecture, Religion and Society in Early Iron Age Greece (1100-700 B.C.) (Jonsered 1997) 159-162.

666 A. Frickenhaus, Die Hera von Tiryns, Tiryns I (Athen 1912) 39. Der Tempel schien A. Frickenhaus sogar um die Säule herumgebaut und auf sie ausgerichtet zu sein. Das später nach Argos überführte Sitzbild, das Pausanias kannte, habe ebenso in diesem Tempel gestanden, vielleicht auf einer mykenischen Basis, die in dem neuen Tempel bewahrt worden war.

667 Zu Dionysos Kadmeios in Theben s. Kap. 12.6.

668 Ablehnend: C. W. Blegen, Korakou. A Prehistoric Settlement near Corinth (Boston 1921) 130-134; vorsichtig zustimmend: M. P. Nilsson, The Minoan-Mycenaean Religion and its Survival in Greek Religion (Lund 1950) 475-479. 


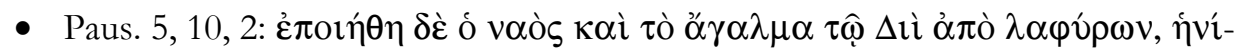

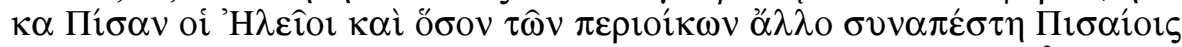

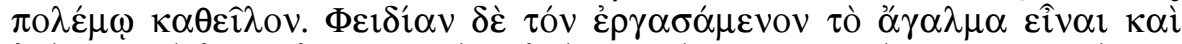

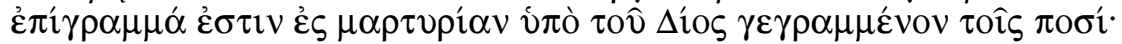

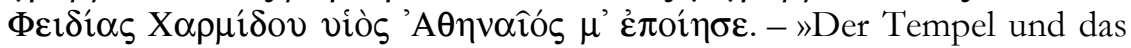
Kultbild für Zeus wurden hergestellt aus der Beute, als die Eleer Pisa und die sonstigen Perioiken, die mit den Pisaiern zusammen abgefallen waren, im Krieg vernichteten. Daß Pheidias der Künstler der Kultstatue war, dafür dient als Beweis auch eine Inschrift, die unter den Füßen des Zeus steht:

„Pheidias, Charmides' Sohn, Athener, machte mich“". (F. Eckstein - P. C. Bol)

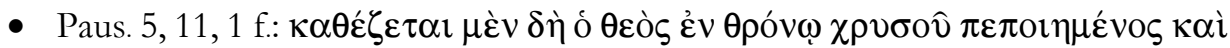

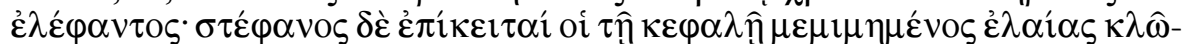

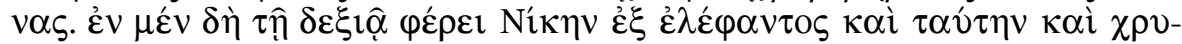

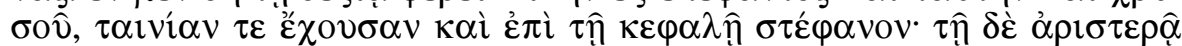

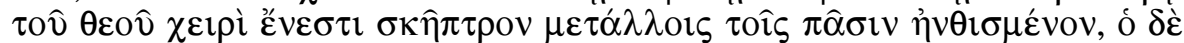

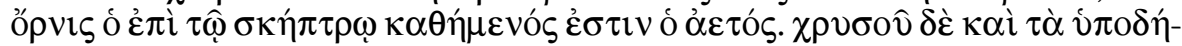

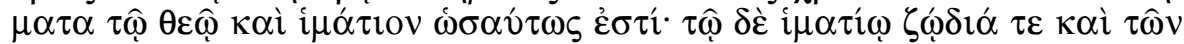

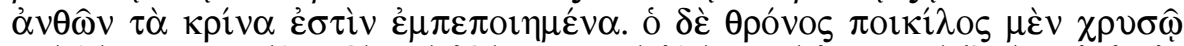

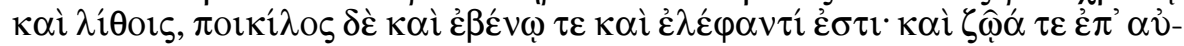

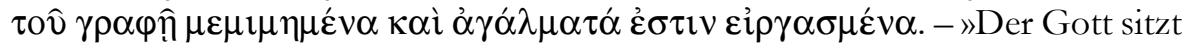
auf einem Thron und ist aus Gold und Elfenbein gemacht, und ein Kranz liegt auf seinem Haupt in Form von Ölbaumzweigen. In der rechten trägt er eine Nike, ebenfalls aus Elfenbein und Gold, die ein Band hält und auf dem Kopfe einen Kranz hat. In der linken Hand des Gottes befinde sich ein Szepter, mit lauter Metalleinlagen verziert. Der Vogel, der auf dem Szepter sitzt, ist der Adler. Aus Gold sind auch die Sandalen des Gottes und sein Gewand ebenso; an dem Gewand sind Figuren und Lilien angebracht. Der Thron ist in abwechslungsreicher Arbeit aus Gold und Steinen und Ebenholz und Elfenbein, und an ihm sind Figuren gemalt und Bildwerke angebracht [...]«. (F. Eckstein - P. C. Bol)

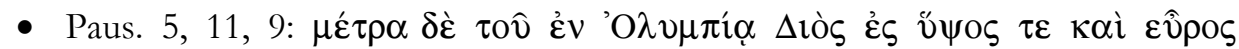

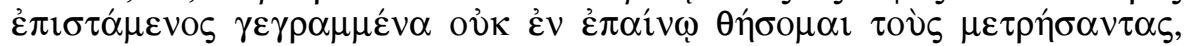

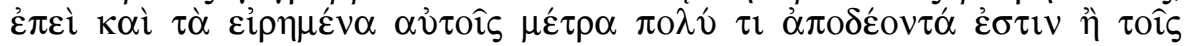

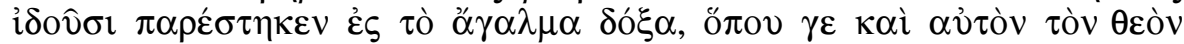

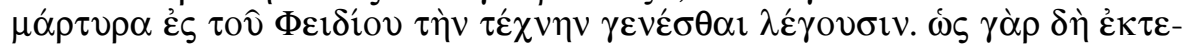

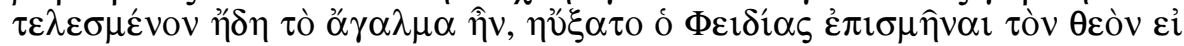

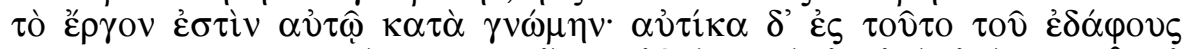

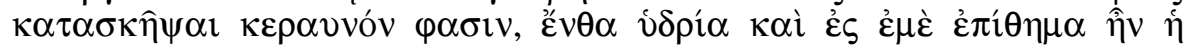
$\chi \alpha \lambda \kappa \hat{\eta}$. - »Obwohl ich weiß, daß die Maße des Zeus in Olympia nach Höhe und Breite aufgezeichnet sind, möchte ich diejenigen doch nicht loben, die sie gemessen haben, da auch die von ihnen angegebenen Maße weit zurückbleiben hinter dem Eindruck, den das Kultbild auf den Beschauer macht, wo man ja doch erzählt, daß der Gott selbst Zeuge für die Kunst des Pheidias geworden sei. Denn als die Statue fertig war, betete Pheidias zum Gott, er möge ihm ein Zeichen geben, ob ihm das Werk nach Wunsch sei, und er habe sofort an der 
Stelle des Bodens einen Blitz niederfahren lassen, wo noch zu meiner Zeit die bronzene Hydria daraufstand«. (F. Eckstein - P. C. Bol)

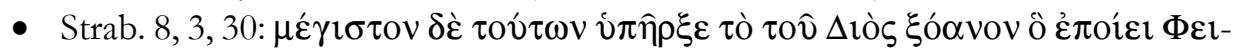

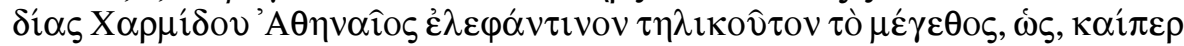

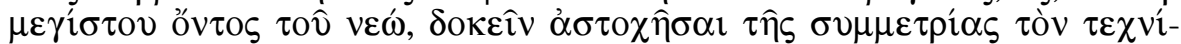

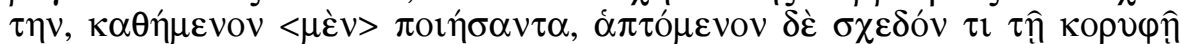

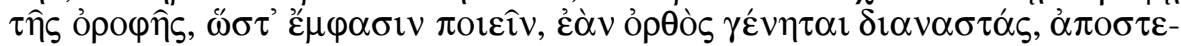

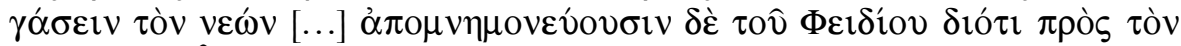

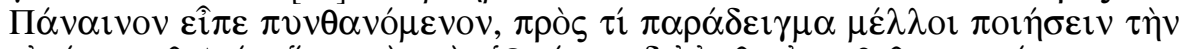

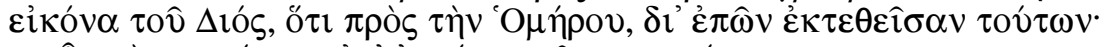

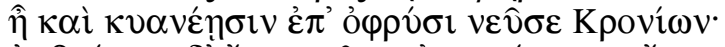

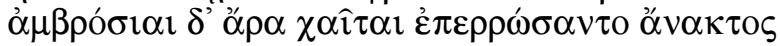

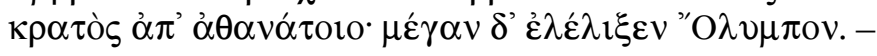

"Aber das größte [Bild] ist das Xoanon des Zeus, geschaffen aus Elfenbein von Phidias dem Athener, Charmides' Sohn, und war so groß, dass, obwohl der Tempel sehr groß war, der Bildhauer die rechte Symmetrie nicht beachtet hat, denn er zeigte Zeus sitzend und doch nahezu mit seinem Kopf die Decke berührend, so dass der Eindruck entsteht, erhebe sich Zeus und stünde aufrecht, würde er das Dach abheben. [...] Es wird erzählt, dass Phidias auf die Frage des Panainos, nach welchem Vorbild er Zeus gestalten will, geantwortet habe, er werde ihn nach Homers Beschreibung machen, die lautet:

„Der Kronide sprach und nickte bejahend mit seinen dunklen Brauen, und dann flossen ambrosische Locken um seinem unsterblichen Kopf, und der Olymp erbebte" $[\ldots] \ll$.

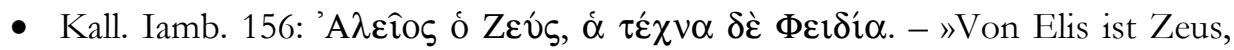
die Kunst aber von Phidias«. (M. Asper)

Darstellungen: Von dem alten Bild des Zeus von Olympia sind bisher keine Darstellungen bekannt. Das jüngere Bild wurde auf kaiserzeitlichen Münzen aus Elis identifiziert (Abb. 34). Sie zeigen ein den Beschreibungen in den Schriftquellen entsprechendes Bild. Der Gott sitzt auf einem hochlehnigen Thron. Diesen zierten Szenen aus der griechischen Mythologie. Zeus trägt einen stoffreichen Hüftmantel über dem ansonsten unbekleideten Körper sowie Sandalen an den Füßen. Er hat einen langen Bart und langes gelocktes Haupthaar und einen Olivenkranz auf dem Kopf. Auf der erhobenen und ausgestreckten Rechten hält er eine stehende Nike und in der Linken ein Szepter, auf dem ein Adler saß669.

Baubefund: Die Altis mit dem später in ganz Griechenland berühmten Heiligtum war bereits vor dem 1. Jahrtausend besiedelt ${ }^{670}$. H. Kyrieleis konnte durch Ausgrabungen im Zentrum des Heiligtums den Beginn des Kultes im 11. Jahrhundert

${ }^{669}$ Lacroix 1949, 259-266 Taf. 22, 2-11; Imhoof-Blumer - Gardner 1964, 71 Taf. P Nr. $20-22$.

${ }^{670}$ Dörpfeld 1935, 73-102; J. Rambach, Olympia. 2500 Jahre Vorgeschichte vor der Gründung des 
v. Chr. feststellen, was zahlreiche Weihgaben sowie die Überreste der Opfer beweisen $^{671}$. Der erste gesicherte Tempel, ein dorischer Peripteros, wurde um 600 v. Chr. errichtet. Er ist in der antiken Literatur als Heratempel bekannt und bestand zunächst aus Lehmziegelmauern und Holzsäulen, die nach und nach durch Stein ersetzt wurden ${ }^{672}$. In der Cella haben sich noch Reste der Statuenbasis erhalten $^{673}$. In der 1 . Hälfte des 5. Jahrhunderts kam der zweite, deutlich größere Tempel hinzu, ebenfalls ein dorischer Peripteros. Im Inneren zeichnet sich noch heute die Basis des Zeusbildes des Phidias ab. Sie war von Schranken umgeben, um das Bild vor Berührungen zu schützen ${ }^{674}$. Für die Basis des monumentalen GoldElfenbein-Bildes musste der Boden der Cella umgebaut werden. Die Errichtung des Tempels und die des Bildes waren also nicht in einem Zuge geplant ${ }^{675}$.

eisenzeitlichen griechischen Heiligtums, in: H. Kyrieleis (Hrsg.), Olympia 1875-2000. 125 Jahre deutsche Ausgrabungen. Internationales Symposion, Berlin 9. - 11. November 2000 (Mainz 2002) 177-212.

${ }^{671}$ Kyrieleis 2006, bes. 27. 35. 39. 50; vgl. auch O.-W. von Vacano, Das Problem des alten Zeustempels in Olympia (Diss. Universität zu Köln 1937) 21-27; W.-D. Heilmeyer, Olympia und die Entdeckung der geometrischen Plastik, in: H. Kyrieleis (Hrsg.), Olympia 1875-2000. 125 Jahre deutsche Ausgrabungen. Internationales Symposion, Berlin 9. - 11. November 2000 (Mainz 2002) 85-89; N. Himmelmann, Frühe Weihgeschenke in Olympia, ebenda 91-107; H. Kyrieleis, Zu den Anfängen des Heiligtums von Olympia, ebenda 213-220; C. Rolley, Delphes de 1500 à 575 av. J.-C. Nouvelles données sur le problème »ruptures et continuité«, ebenda 273-279.

${ }^{672}$ Dagegen neuerdings M. Donderer, Das Heraion in Olympia und sein Säulenkranz, BABesch 80, 2005, 7-20 mit der älteren Literatur.

673 Mallwitz 1972, 21 f. 138; Moustaka 2002, 307; Sinn 2004, 80. Zu dem Problem der eventuellen Vorgängerbauten und ihrer Datierung vgl. H. E. Searls - W. B. Dinsmoor, The Date of the Olympia Heraeum, AJA 49, 1945, 62-80; H. Riemann, Die Bauphasen des Heraions von Olympia, JdI 61, 1946, 30-54; ablehnend: Mallwitz 1966; Mallwitz 1972, 138; Gruben 2001, 50 f.

${ }^{674}$ Dörpfeld 1935, 247-256; E. Kunze, Zeusbilder in Olympia, AuA 2, 1946, 110 f.; Mallwitz 1966; Mallwitz 1972, 137-149. 211-234; Gruben 2001, 46-62; Lapatin 2001, 79; Sinn 2004, 21. 213; Kyrieleis 2006.

${ }^{675}$ F. Forbat, Der Fußboden im Inneren des Zeus-Tempels und seine Veränderungen bei Aufstellung des Gold-Elfenbein-Bildes, in: Dörpfeld 1935, 226-247. Die Diskrepanz zwischen der Errichtung des Tempels und des Bildes versuchten Dörpfeld 1935, 223 und Ekschmitt 1984, 136 damit zu überbrücken, dass das Bild des $\gg$ Heratempels` vorübergehend in den Neubau überführt worden sei, wofür es aber keine Anhaltspunkte gibt. Mallwitz 1972, 95 dachte an ein von einem anderen Bildhauer neu für diesen Tempel zu schaffendes Bild, das evtl. durch seinen Tod nicht ausgeführt oder vollendet wurde, so dass man später Phidias beauftragte. Diese These erscheint mir einleuchtender, da sie auch den Umbau des Fußbodens erklären würde. Ähnlich auch Lapatin 2001, 79; Bald Romano 1980, 144 f.

Der Tempel kann jedoch auch erst später mit einem Bild ausgestattet worden sein, wie z. B. auch der $\gg$ Naiskos D in Aigeira aus dem 3. Jahrhundert v. Chr. Die in ihm gefundenen Fragmente einer männlichen Kolossalstatue, vermutlich das `Kultbild, werden erst in das 2. Jahrhundert v. Chr. datiert. Das Bild ist demnach deutlich später als der Tempel entstanden: O. Walter, Ein Kolossalkopf des Zeus in Aigeira, ÖJh 19/20, 1919, 1-14; S. Gogos, Naiskoi beim Theater, in: W. Alzinger u. a., Aigeira-Hyperesia und die Siedlung Phelloë in Achaia, Klio 68, 1, 1986, 31-50; W. Alzinger, Der Zeus des Eukleides, in: ebenda 50-52; B. Madigan, A Transposed Head, Hesperia 60, 1991, 503; R. Trummer, Zwei Kolossalköpfe aus Aigeira, AntPl 22 (Berlin 1993) 141-152; Damaskos 1999, 36. 
Ergebnis: Für das berühmte Heiligtum von Olympia sind durch die Quellen zwei Bilder des Zeus überliefert. Das ältere stand in dem nach Ausweis der Bauforschung um 600 v. Chr. errichteten sog. Heratempel zusammen mit einer Statue der Hera ${ }^{676}$. Die beiden Bilder waren dem Kunsturteil des Pausanias nach einfach gestaltet. Lange Zeit glaubte man, in einem beim Heraion gefundenen Kalksteinkopf den Kopf der Herastatue und damit ein originales Fragment der Statuengruppe zu besitzen. Dieser stellte sich inzwischen als Kopf einer Sphinx heraus, die wahrscheinlich zur Bauplastik des Tempels gehörte ${ }^{677}$, so dass außer der sehr knappen Beschreibung bei Pausanias kein weiterer Hinweis auf die Gestaltung der Bilder vorliegt. Die jüngere Statue des Zeus war das monumentale GoldElfenbeinbild des Phidias. Sie stand in dem in frühklassischer Zeit neben dem >Heratempek erbauten großen Zeustempel. Das Aussehen des ca. zwölf Meter hohen thronenden Zeus ist durch antike Beschreibungen und Darstellungen auf kaiserzeitlichen Münzen aus Elis (Abb. 34)678 detailreich überliefert.

Auch in diesem Heiligtum hätte man in klassischer Zeit ein monumentales Bild neben einem älteren aufgestellt, falls der ältere Bau ebenfalls dem Zeuskult diente. Es ist nicht bewiesen, ob es sich bei dem >Heratempek wirklich um einen Kultbau der Göttin handelte, auch wenn in der Forschung die Bezeichnung durch Pausanias lange Zeit wörtlich genommen wurde. Zeus soll bis zur Errichtung des klassischen Tempels unter freiem Himmel auf dem großen Aschenaltar verehrt worden $\operatorname{sein}^{679}$. Unwahrscheinlich ist dies nicht, wie das Heiligtum von Dodona belegt, in dem erst im frühen 4. Jahrhundert v. Chr. ein kleiner Oikos errichtet wurde, obwohl der Kult wesentlich älter ist ${ }^{680}$. Es erscheint jedoch merkwürdig, dass in einem dem Zeus geweihten Heiligtum der Hera bereits in archaischer Zeit ein Tempel errichtet worden sein soll, dem Zeus jedoch erst in klassischer Zeit ${ }^{681}$. Antike Quellen belegen zudem die Einbindung des sog. Heratempels in den Zeuskult ${ }^{682}$.

${ }^{676}$ Das Heiligtum selbst ist älter, der Beginn des Kultes konnte durch H. Kyrieleis für das 11. Jahrhundert v. Chr. festgestellt werden, s. Anm. 671. J. Rambach, Dörpfelds Bau VII in der Altis von Olympia. Ein früheisenzeitliches Apsidenhaus und > Haus des Oinomaos<?, AA 2002/1, 119-134 hat kürzlich vermutet, dass es sich bei dem nordöstlich des klassischen Zeustempels gelegenen Bau VII, den er in die frühe Eisenzeit datiert, evtl. um einen noch früheren Kultbau des Zeus handelt. Es ist daher möglich, dass es sogar ein noch älteres Bild des Zeus gegeben hat.

677 O.-W. von Vacano, Das Problem des alten Zeustempels in Olympia (Diss. Universität zu Köln 1937) 8-20; Mallwitz 1972, 146-148 Abb. 117; Gruben 2001, 55 Abb. 34; Moustaka 2002, 306; Sinn 2004, 83 Abb. 28.

678 s. Anm. 669.

${ }^{679}$ E. Kunze, Zeusbilder in Olympia, AuA 2, 1946, 95-113.

680 S. I. Dakaris, Dodona (Athen 1993) 13; S. I. Dakaris, Archaeological Guide to Dodona (o. J., o. Ort) 39 f.; Gruben 2001, 116-119; J. Mylonopoulos, Das Heiligtum des Zeus in Dodona. Zwischen Orakel und venatio, in: ders. - H. Roeder (Hrsg.), Archäologie und Ritual. Auf der Suche nach der rituellen Handlung in den antiken Kulturen Ägyptens und Griechenlands (Wien 2006) 185-214.

681 In benachbarten Orten wie in Babes gab es bereits in der Spätarchaik Zeustempel, s. Moustaka 2002, 304.

${ }^{682}$ In ihm stand laut Paus. 5, 20, 1 f. u. a. der Tisch des Kolotes. Darauf lagen die Siegerkränze für 
Diese bereits 1937 von O.-W. von Vacano bemerkten Widersprüche sind vor kurzem von A. Moustaka aufgegriffen worden. Sie hat bei ihren Untersuchungen zum Herakult in Olympia festgestellt, dass sich in archaischer und klassischer Zeit weder Gaben speziell für Hera belegen lassen noch Inschriften, die sich nur auf die Göttin beziehen ${ }^{63}$. Da in dem Tempel sowohl ein Bild der Hera als auch des Zeus stand, erscheint es glaubwürdiger, dass beide dort Verehrung fanden, wobei der Herakult möglicherweise sogar später ist als der des Zeus ${ }^{684}$. Auch in diesem Fall handelt es sich demnach wieder um ein Heiligtum, das im Laufe seiner Geschichte zwei Tempel und zwei bedeutende Statuen des dort verehrten Gottes erhalten hat. Beide Bilder standen über Jahrhunderte gemeinsam in demselben Heiligtum, so dass sie Pausanias noch im 2. Jahrhundert n. Chr. zusammen sehen konnte.

\subsection{Dionysos Eleuthereus in Athen}

\section{Schriftquellen:}

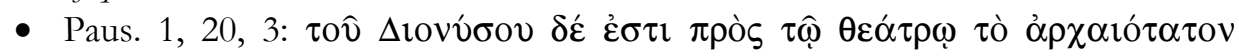

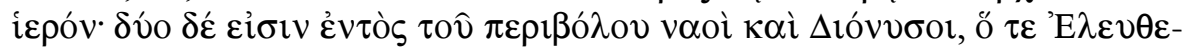

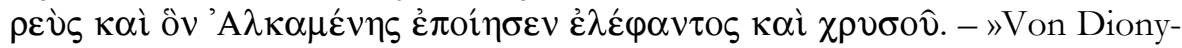
sos liegt das älteste Heiligtum [in Athen] beim Theater. Es sind nämlich innerhalb der Umfassungsmauer zwei Tempel und zwei Dionysosstatuen, der Dionysos Eleuthereus und derjenige, dessen Statue Alkamenes aus Elfenbein und Gold gemacht hat «. (F. Eckstein - P. C. Bol)

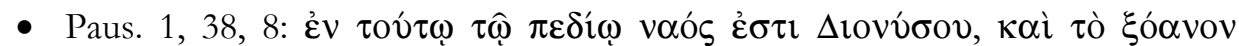

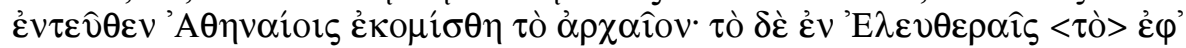

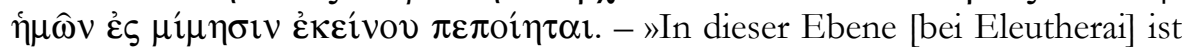
ein Dionysostempel, von dort wurde das alte Xoanon zu den Athenern

die zu Ehren des Zeus veranstalteten Spiele.

683 Moustaka 2002, 301-315; A. Moustaka, On the Cult of Hera at Olympia, in: R. Hägg, Peloponnesian Sanctuaries and Cults. Proceedings of the Ninth International Symposium at the Swedish Institute at Athens, 11-13 June 1994 (Stockholm 2002) 199-205.

684 Möglicherweise ist der Kult der Hera erst später in den Tempel integriert worden. Die Basis, auf der die Bilder gestanden haben, wurde in unbestimmter Zeit erweitert. Der Name >Heraion h hat sich vielleicht nach der Errichtung des neuen Zeustempels verstärkt durchgesetzt, vgl. Dörpfeld 1935, 204. 212 f.; O.-W. von Vacano, Das Problem des alten Zeustempels in Olympia (Diss. Universität zu Köln 1937); H. Riemann, Die Bauphasen des Heraions von Olympia, JdI 61, 1946, 52 f.; Mallwitz 1966, 325; Ekschmitt 1984, 124; U. Sinn, Olympia, Kult, Sport und Fest in der Antike (München 1996) 45-53; Gruben 2001, 50; Moustaka 2002; Sinn 2004, 81. 92; Kyrieleis 2006, 60. Sollte der `Bau VII tatsächlich der älteste Tempels des Zeus aus protogeometrischer Zeit sein, wie kürzlich J. Rambach vermutet hat, erscheint es noch unwahrscheinlicher, dass es zwischen der Zerstörung dieses Baus und der Errichtung des klassischen Tempels keinen Zeus-, jedoch einen Heratempel gegeben haben soll. Zu der Vermutung von J. Rambach s. Anm. 676. Zur Datierung des Baus VII in die frühe Eisenzeit vgl. auch Kyrieleis Jahresbericht 2002, AA 2003, 2, 179-181 sowie ders., 2006, 49 Anm. 169. 
gebracht. Das, welches sich jetzt in Eleutherai befindet ist als Nachahmung des alten geschaffen «.

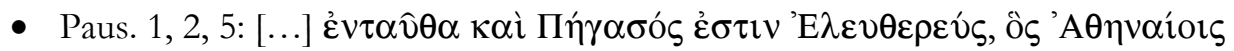

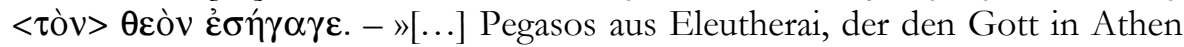
einführte«. (F. Eckstein - P. C. Bol)

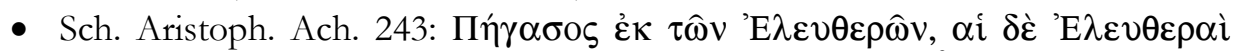

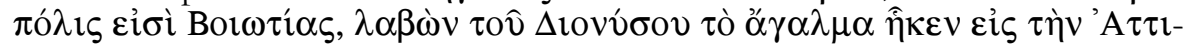

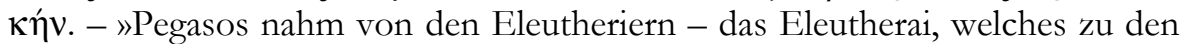
böotischen Städten zählt - das Bild des Dionysos und brachte es nach Attika«.

Darstellungen: Von der alten Statue des Dionysos Eleuthereus in Athen sind bisher keine Wiedergaben bekannt. Die Statue des Alkamenes ist nach Ansicht einiger Forscher auf athenischen Münzen des 1. Jahrhunderts v. Chr. wiedergegeben (Abb. 41)685. Diese zeigen eine männliche bärtige Figur auf einem hochlehnigen Thron. Die rechte Hand liegt gesenkt in ihrem Schoß. In dem Gegenstand, den sie hält, möchte K. D. S. Lapatin einen Kantharos erkennen ${ }^{686}$. In der linken erhobenen Hand hält die Figur einen stabartigen Gegenstand, wahrscheinlich einen Thyrsos. Sie trägt einen Hüftmantel, der auch über die linke Schulter gezogen ist, darunter ist die Figur möglicherweise entblößt. Sie hat langes Haupthaar und einen Bart. Eine Münze zeigt vor dem thronenden Gott einen Tisch mit darauf liegenden Gaben, weshalb es sich um die Darstellung eines `Kultbildes handeln kann.

E. Langlotz hingegen wollte den von Alkamenes geschaffenen Typus in einer kaiserzeitlichen Statue im Vatikan erkennen $(A b b .42)^{687}$. Sie zeigt den Gott stehend und in einen langen Chiton gehüllt, mit einem auf der linken Schulter zusammengefassten Tierfell. Da dieser Typus zudem in einer freien Wiedergabe am PhaidrosBema des Dionysostheaters sowie auf einem in der Nähe des Theaters gefundenen Relief und damit zweimal in unmittelbarer Nähe des Tempelbezirks dargestellt ist, schloss er, dass es sich um Wiedergaben des überlieferten Bildes handele ${ }^{688}$.

685 Winterthur, Münzkabinett: Imhoof-Blumer - Gardner 1964, 142 Taf. CC Nr. 4; weitere bei Lacroix 1949, 291-293 Taf. 26, 2f. Imhoof-Blumer - Gardner 1964, 142 Taf. CC Nr. 2 f.; Lapatin 2001, 98 Abb. 200.

686 Lapatin 2001, 98; ebenso Imhoof-Blumer - Gardner 1964, 142.

687 Rom, Vatikan, Giardino della Pigna: E. Langlotz, Alkamenes-Probleme, 108. BWPr (Berlin 1952) 3-9 Abb. 2. Vgl. W. Amelung, Die Sculpturen des Vaticanischen Museums I (Berlin 1903) 909 Nr. 236 Taf. 120.

688 E. Langlotz, Alkamenes-Probleme, 108. BWPr (Berlin 1952). Das Bema-Relief: R. Herbig, Das Dionysos-Theater in Athen II. Die Skulpturen vom Bühnenhaus. Antike griechische Theaterbauten VI (Stuttgart 1935) 36-59 Taf. 10, 2. 13, 2; A. Frantz, The Date of the Phaidros Bema in the Theatre of Dionysos, in: Studies in Athenian Architecture, Sculpture and Topography presented to H. A. Thompson, Hesperia Suppl. 20 (Princeton 1982) 34-39. Das andere Relief: Athen, NM 1489: EA 1262; C. Friederichs - P. Wolters, Königliche Museen zu Berlin. Die Gipsabgüsse antiker Bildwerke in historischer Folge erklärt (Berlin 1885) 746 f. Nr. 1884. 
Baubefund: Das Dionysosheiligtum am Fuße der Athener Akropolis besaß zwei kleine Tempel. Der erste, kleinere der beiden war in spätarchaischer Zeit errichtet worden, wie G. I. Despinis durch die Zuweisung zweier Giebelfiguren sowie Fragmenten der Metopen vor kurzem nachweisen konnte. Diese können durch stilistische Vergleiche in die ersten Jahre des 5. Jahrhunderts v. Chr. datiert werden und waren in bzw. in der Nähe des Heiligtums gefunden worden. Ein von der älteren Forschung dem ersten Tempel zugewiesenes Giebelrelief des 3. Viertels des 6. Jahrhunderts v. Chr. aus dem Heiligtum kann laut G. I. Despinis von einer ersten Bauphase des Tempels, einem noch nicht weiter verifizierten Vorgänger oder einem Altar stammen ${ }^{689}$. Der zweite, größere Tempel kam kurz nach der Mitte des 4. Jahrhunderts v. Chr. hinzu, während der erste weiterhin Bestand hatte ${ }^{690}$.

Ergebnis: Das Heiligtum des Dionysos Eleuthereus in Athen beherbergte ebenfalls zwei Bilder des Gottes aus unterschiedlichen Zeiten in zwei verschiedenen Tempeln. Bei der einen Statue handelt es sich laut der Aussage des Pausanias um ein altes Bild, das ursprünglich in Eleutherai verehrt worden war und nach Athen überführt wurde, als sich dieser Ort unter den Schutz der Athener gestellt hatte. Der Einholung des Bildes wurde jährlich mit einer Prozession mit Beteiligung des Bildes gedacht ${ }^{691}$. Diese Bild stand mit hoher Wahrscheinlichkeit in dem nachgewiesenen spätarchaischen Tempel ${ }^{692}$.

Die jüngere Statue, ein Werk des Alkamenes, hat vermutlich in dem jüngeren, kurz nach der Mitte des 4. Jahrhunderts v. Chr. errichteten größeren Tempel gestanden. Da die Datierung der Statue und die des Tempels nicht übereinstimmen, muss das Bild vorher an einer anderen Stelle gestanden haben ${ }^{693}$. Dem alten Bild war also

${ }^{689}$ G. I. Despinis, Il tempio arcaico di Dioniso Eleutereo, ASAtene 74/75, 1996/97, 193-214. Die Giebelfiguren: Athen, Nationalmuseum Inv. 2324 und Magazin der Hadriansbibliothek Inv. PA 1262, das Giebelrelief: Athen, Nationalmuseum Inv. 3131.

690 W. Dörpfeld - E. Reisch, Das griechische Theater (Athen 1896) 6-24; Judeich 1931, 317; A. W. Pickard-Cambridge, The Theatre of Dionysos in Athens (Oxford 1946) 3 f.; Travlos 1971, 537-552; Muss - Schubert 1988, 25 f. Lapatin 2001, 98.

691 s. S. 298 f.

692 Die Datierung des Anschlusses von Eleutherai an Athen kann nicht genau bestimmt werden. Vielleicht kam es wie das benachbarte Plataiai in spätarchaischer Zeit unter den Schutz Athens, worüber Hdt. 6, 108 und Thuk. 3, 55 berichten. Diese Ansicht vertreten Parke 1977, 125; Bald Romano 1980, 78 und Garland 1992, 42. R. Parker, Athenian Religion. A History (Oxford 1996) 94 sieht hingegen keinen Grund, das Ereignis in historische Zeit zu setzen. Die Datierung in das 6. Jahrhundert v. Chr. erscheint glaubhaft, denn sie entspricht der Einrichtung des Heiligtums. Auch scheinen in dieser Zeit mehrere attische Kulte Einzug in Athen gehalten zu haben, so wahrscheinlich auch der Kult der Artemis Brauronia, s. Kap. 12.10. Auch Eleusis scheint unter verstärkten athenischen Einfluss geraten zu sein, so Hurwitt 1999, 106.

693 Wenn man nicht von einem späteren Polyklet als dem berühmten Bildhauer des 5. Jahrhunderts v. Chr. aus Argos ausgehen will, wozu jedoch keine Quellen vorliegen, vgl. dazu Lapatin 2001, 100. In der älteren Forschung wurde der Tempel an den Beginn des 4. Jahrhunderts v. Chr. datiert, so von W. Dörpfeld - E. Reisch, Das griechische Theater (Athen 1896) 6-24 und Judeich 1931, 317. 
schon im 5. Jahrhundert v. Chr. ein neues und vermutlich aufwändigeres Bild an die Seite gegeben worden, obwohl es noch bis in die Kaiserzeit weiter bestand und daher kein Ersatz erforderlich gewesen ist. Die erhaltene Basis des jüngeren Tempels nimmt fast die gesamte Breite der Cella ein. Das Bild muss sie demnach ähnlich ausgefüllt haben wie der Zeus des Phidias den Tempel in Olympia und die Athena Parthenos den Parthenon. Aufgrund der Form und der Größe der Basis von knapp 5 mal 5 Metern hatte W. Judeich angenommen, dass sie ein Sitzbild trug, das vielleicht auf einigen hellenistischen Münzen aus Athen wiedergegeben ist (Abb. 41) ${ }^{694}$. Diese These erscheint glaubwürdiger als die von E. Langlotz angenommene stehende Statue, denn der von ihm zur Rekonstruktion herangezogene Typus wird von der neueren Forschung erst in die späteste Klassik oder sogar in die Zeit des Hellenismus datiert ${ }^{695}$, so dass eine Identifizierung mit dem Werk des Alkamenes unmöglich ist.

\subsection{Dionysos Kadmeios in Theben}

\section{Schriftquellen:}

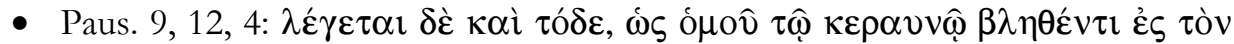

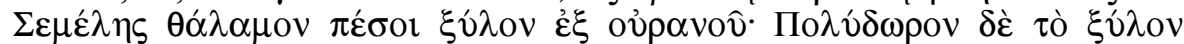

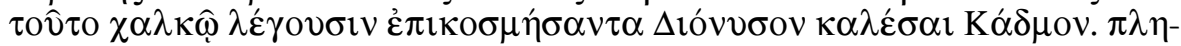

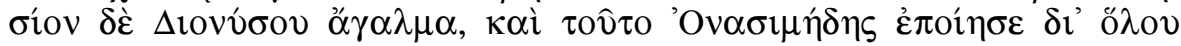
$\pi \lambda \hat{\eta} \rho \varepsilon \varsigma$ i $\pi$ ò $\tau 0 \hat{v} \chi \alpha \lambda \kappa o \hat{v}$. - »Erzählt wird auch das, daß zugleich mit dem in das Gemach der Semele geschleuderten Blitz ein Holzstück vom Himmel gefallen sei. Polydoros habe dieses Stück Holz mit Erz geschmückt und Dionysos Kadmeios genannt. In der Nähe ist ein Dionysosstandbild, und dieses hat Onasimedes gemacht ganz aus Bronze«. (F. Eckstein - P. C. Bol)

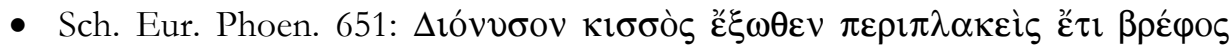

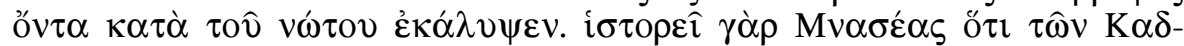

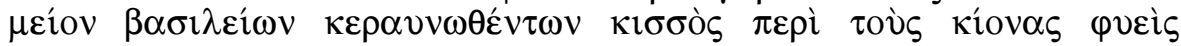

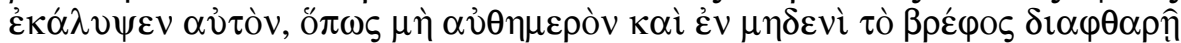

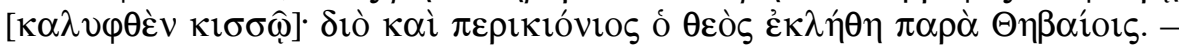

W. Dörpfeld hat deshalb sogar die Frage aufgeworfen, ob die Statue nicht ebenfalls in das beginnende 4. Jahrhundert v. Chr. datiert werden könne. Die in der neueren Forschung favorisierte spätere Datierung des Tempels schließt dies jedoch aus. Das Bild muss demnach vor der Errichtung des Tempels woanders gestanden haben.

${ }^{694}$ Judeich 1931, 317. Zu den Münzen s. Anm. 685 f.

${ }^{695}$ Spätklassisch in Verbindung mit dem Typus Hope: D. Zancani, Della Testa di Dionysos del Museo Capitolino e del tipo statuario al quale appartiene, BCom 52, 1924, 65-91; Gasparri 1986, 436 f. Nr. 128e; Pochmarski 1974, 69-72 Nr. 16E; hellenistisch mit Ablehnung der Verbindung zum Typus Hope: Chr. Vorster, Römische Skulpturen des späten Hellenismus und der Kaiserzeit II. Werke nach Vorlagen und Bildformeln hellenistischer Zeit sowie die Skulpturen in den Magazinen, MAR 34 (Wiesbaden 2004) 40-44 Nr. 14 Taf. 20 f. 
»Efeu, dass von außen herum gewickelt war, hat Dionysos verhüllt, als er noch ein Kind war. Denn Mnaseas berichtet, dass, nachdem der Palast der Kadmeier vom Blitz getroffen worden war, Efeu, das die Säule umwachsen hat, ihn verhüllte, damit das Kind nicht zugrunde gerichtet wird desselben Tages und durch nichts, da es vom Efeu bedeckt worden war. Deshalb wird der Gott bei den Thebanern auch der mit Säulen umgebene genannt«.

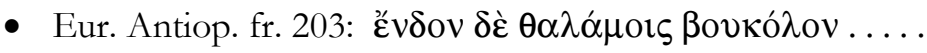

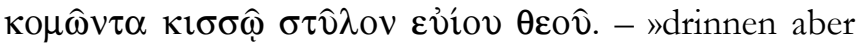
im Gemach den Hirten ... die mit Efeu bekränzte Säule des jubelnden Gottes (Dionysos)«. (G. A. Seeck)

- Clem. Al. Strom. 1, 163, 4 f.:

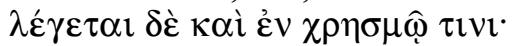

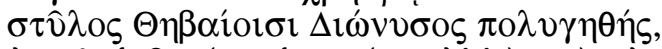

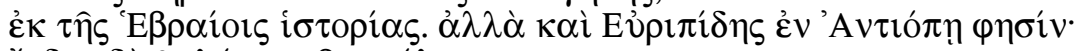

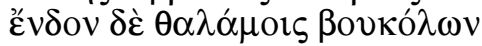

$\kappa о \mu \hat{\omega} \nu \tau \alpha \kappa \imath \sigma \sigma \hat{\omega} \sigma \tau \hat{v} \lambda$ ov Ev̉íov $\theta \varepsilon \circ \hat{v}$.

»Auch heißt es in irgend einem Orakelspruch:

„Eine Säule den Thebanern ist der herzerfreuende Dionysos“

aus der Geschichtserzählung der Hebräer. Aber auch Euripides sagt in der Antiope: „drin im Gemach der Rinderhirt bekränzt

mit Efeu die Säule des Gottes Euios“«. (C. A. Bernoulli - L. Früchtel)

Darstellungen/Baubefund: Eine kaiserzeitliche böotische Münze zeigt Dionysos in Schrittstellung. Er ist nach links im Profil dargestellt. Der rechte Unterarm ist angewinkelt nach vorn gestreckt. Auf der Hand trägt er einen Kantharos. Der Gott ist bärtig und trägt ein langes Gewand. F. W. Imhoof-Blumer und P. Gardner hielten das Münzbild für die Wiedergabe einer archaischen Figur ${ }^{696}$. Die von ihnen vorgebrachte Verbindung mit der durch die Schriftquellen bekannten Statue des Onasimedes ist allerdings unsicher, da weitere Dionysosheiligtümer für Theben überliefert sind ${ }^{697}$, auf deren Bilder die Münzdarstellung ebenfalls bezogen werden kann, sollte sie überhaupt eine Statue des Gottes zeigen. Das Heiligtum wurde bisher nicht archäologisch untersucht.

Ergebnis: Für Dionysos ist durch die antike Literatur ein mythisches und daher ebenfalls alt zu denkendes Bild in Theben überliefert. Es galt als ein hölzernes Diipetes und wurde in dieser Stadt unter dem Namen Dionysos Kadmeios verehrt. Einer anderen antiken Überlieferung zufolge handelte es sich bei dem auch Dionysos Kadmos genannten Bild um eine Säule des alten Palastes von The-

${ }^{696}$ Imhoof-Blumer - Gardner 1964, 112 Taf. X Nr. 1. Ein anderes Dionysosheiligtum erwähnt Paus. 9, 16, 6 .

${ }^{697}$ Paus. 9, 16, 6. 
ben $^{698}$. Beide Überlieferungen scheinen unvereinbar und lassen an zwei verschiedene Bilder denken. Gemeinsam ist den Quellen jedoch, dass sie ein uraltes Bild des Gottes mit der Legende seiner Geburt verbinden. Es kann sich daher auch um zwei verschiedene Überlieferungen zu ein und demselben Bild handeln.

Aus den Quellen geht außerdem hervor, dass das zunächst recht einfache säulenförmige Mal später durch metallene Zutaten verändert und ausgestaltet worden ist. Offen bleibt dabei, ob das Bild anthropomorphisiert wurde wie das der Hera von Samos, das in Kapitel 12.2 bereits betrachtet wurde, da keine weiteren Details zu seinem Aussehen überliefert sind.

In der Nähe des alten Bildes befand sich laut der Überlieferung bei Pausanias nach noch ein jüngeres und damit definitiv ein zweites Dionysosbild. Dieses war eine Bronzestatue, die ein Erzgießer namens Onasimedes gefertigt hatte. Über ihn ist sonst nichts weiter bekannt, daher kann dieses Bild nicht datiert werden ${ }^{699}$. Auch hier kann man sich deshalb fragen, ob der Gott in zwei verschiedenen Bildern - einem einfach gestalteten älteren und einem künstlerisch aufwändigeren jüngeren - verehrt worden ist, was aufgrund der für andere Heiligtümer nachgewiesenen Tatsache durchaus denkbar ist. Beide Bilder standen jedenfalls über lange Zeit gemeinsam in einem Heiligtum.

\subsection{Athena Nike in Athen}

Schriftquellen zu dem alten Bild:

- IG I3 64A (Baudekret von der Athener Akropolis, 440-415 v. Chr.):

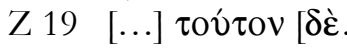
$. \dot{\varepsilon} \pi]-$

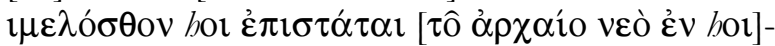

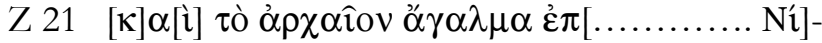

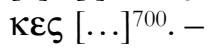

Z $19 »$ Dies $[\ldots]$ soll

beaufsichtigt werden durch die Aufseher des alten Tempels

Z 21 in dem auch das alte Bild ist [...] Nike«.

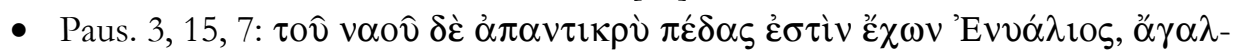

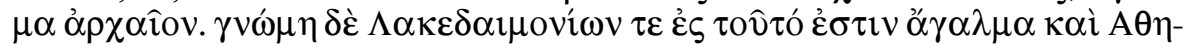

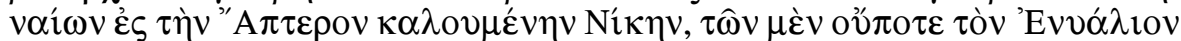

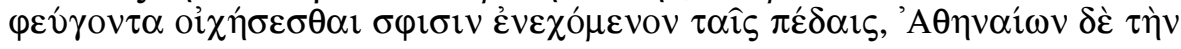

${ }^{698}$ Vgl. O. Kern, Dionysos Perikionios, JdI 11, 1896, 113-116; F. Hampl, Kultbild und Mythos. Eine ikonographisch-mythologische Untersuchung, in: F. Krinzinger - B. Otto - E. Walde-Psenner (Hrsg.), Forschungen und Funde. Festschrift Bernhard Neutsch (Innsbruck 1980) 173-185.

${ }^{699}$ RE XVIII 1, 2 (Stuttgart 1942) 406 s. v. Onasimedes (G. Lippold), R. Vollkommer (Hrsg.), Künstlerlexikon der Antike (2004) 155 s. v. Onasimedes (R. Vollkommer).

${ }^{700}$ Nach der Rekonstruktion von Mark, 1993, 108-110. Der Bezug der Inschrift auf Athena Nike

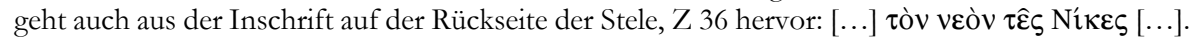




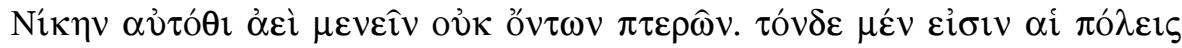

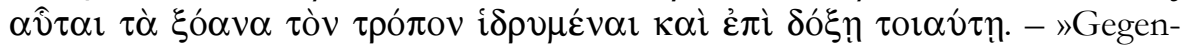
über von diesem Tempel [in Sparta] ist ein altes Bild des Enyalios in Fesseln. Die Ansicht, die die Lakedaimonier von dieses Bild haben, ist dieselbe, die die Athener von der Nike Apteros haben; die ersten denken, dass Enyalios niemals von ihnen weglaufen wird, da er gefesselt ist, während die Athener denken, dass Nike, da sie keine Flügel hat, immer dort bleiben wird wo sie ist. Auf diese Art und mit dieser Ansicht haben diese Städte die Xoana bei sich aufgestellt«.

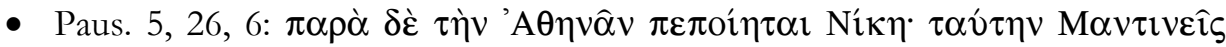

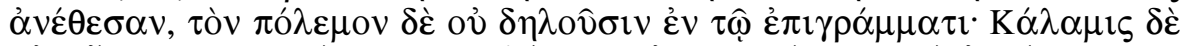

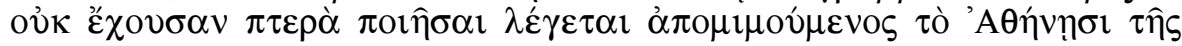

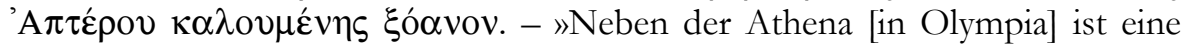
Nike aufgestellt. Die Mantineer weihten sie, aber sie erwähnen den Krieg in der Inschrift nicht. Kalamis soll sie ohne Flügel gemacht haben in Nachahmung des Xoanons der Nike Apteros in Athen«.

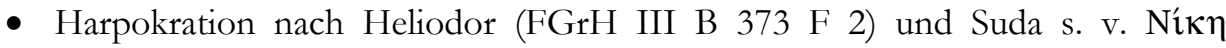

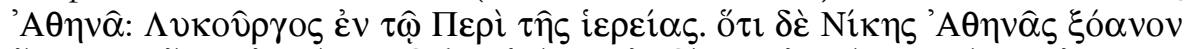

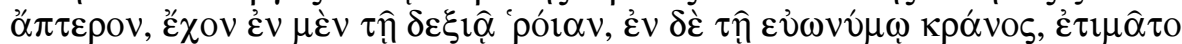

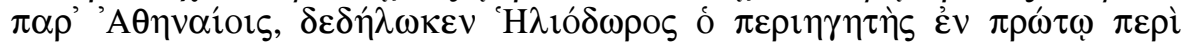
'Aкро $\pi$ ó $\lambda \varepsilon \omega \varsigma$. - NNike Athena: Lykurg in „Über die Priesterin“. Das flügellose Xoanon der Nike Athena, hat in der rechten Hand einen Granatapfel und in der linken einen Helm und wird von den Athenern verehrt, offenbart der Perieget Heliodoros in seinem ersten Buch „Über die Akropolis“«.

\section{Schriftquellen ₹u dem neuen Bild:}

- IG II 403 (Dekret zur Erneuerung einer Athena Nike-Statue aus Athen, 338-

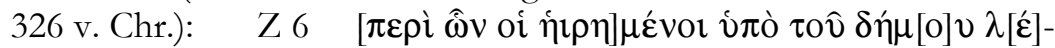

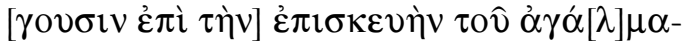

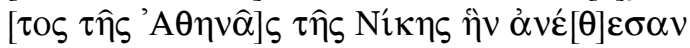

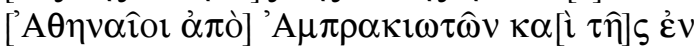

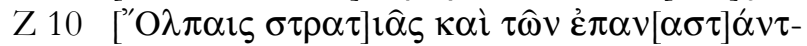

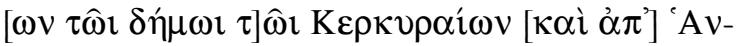

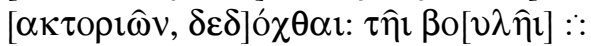

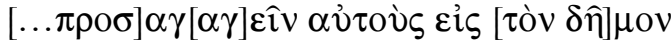

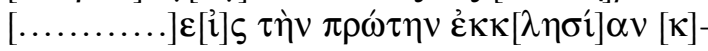

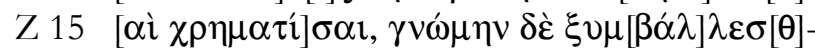

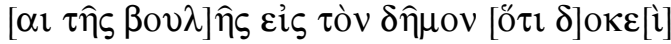

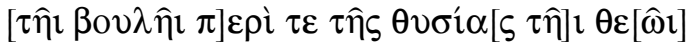

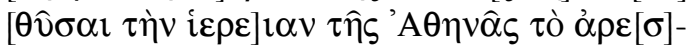

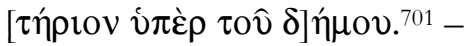

\footnotetext{
${ }^{701}$ Nach der Rekonstruktion von Mark, 1993, 113.
} 
Z 6 »In Betreff des Berichts [des Ausschusses] des Volkes über die Wiederherstellung des Bildes der Athena Nike, welches errichtet wurde von der Beute bei den Ambrakioten und dem Heer

Z 10 in Olpai und dem Aufruhr bei den Kerkyrern und den Anaktoriern: Der Rat veranlasst, dass [für den Ausschuss] Audienz verschafft wird vor dem Volk in der ersten Versammlung,

Z 15 um Bericht zu erstatten. Hinzugefügt wird der Beschluss des Rates an das Volk bezüglich des Opfers an die Göttin, dass die Priesterin das Sühneopfer der Athena durchführen soll zum Wohl des Volkes«.

Darstellungen: Bisher sind keine gesicherten Darstellungen der Bilder der Athena Nike bekannt. Eine altertümliche Figur auf einem Relief des 4. Jahrhunderts v. Chr. von der Athener Akropolis wurde von L. Beschi als Darstellung des alten Bildes der Athena Nike angesehen $(A b b .35)$. Es handelt sich um eine - im Vergleich zu der daneben dargestellten sitzenden Athena - kleinformatige weibliche Figur ${ }^{702}$. Die geringe Größe und die Frontalansicht lassen an eine Statue denken ${ }^{703}$. Problematisch allerdings sind der Kontrapost und die nicht archaische Kleidung. Außerdem sind keine Attribute erhalten, so dass man die dargestellte Göttin nicht sicher identifizieren kann.

Baubefund: Für das 6. Jahrhundert v. Chr. sind bisher nur ein Altar und das Bild der Göttin, aber kein Tempel nachgewiesen. Ein Schutzbau für das Bild ist jedoch wahrscheinlich. Reste der Basis der Statue haben sich erhalten. Sie besteht aus zwei Blöcken mit einer rechteckigen Einlassung in der Oberseite. Laut I. S. Mark, der die Befunde des Heiligtums 1993 in einer Monographie vorgelegt hat, wurde darin eine leicht unterlebensgroße Sitzstatue aus Marmor eingelassen ${ }^{704}$. Für G. Nick hingegen diente das Zapfenloch der Basis für die Einlassung eines stehenden

702 L. Beschi, Contributi di topografia ateniese, ASAtene 45/46, 1967/68, 531-536. G. Neumann, Probleme des griechischen Weihreliefs, Tübinger Studien zur Archäologie und Kunstgeschichte 3 (Tübingen 1979) 61 vermutet sogar dass es sich bei der daneben sitzenden Figur um das jüngere Bild der Athena Nike handeln kann. Beide Ansichten konnten bisher nicht verifiziert werden und müssen, wie G. Neumann selbst sagt, Vermutungen bleiben. Die kleine Figur ist nicht durch Attribute identifizierbar, die sitzende Figur kann auch die lebendige Göttin meinen. Ablehnend auch Donohue 1988, 55-57. Zu dem Relief vgl. auch O. Walter, Beschreibung der Reliefs in Kleinen Akropolismuseum in Athen (Wien 1923) 46 f. Nr. 76.

703 Vgl. Anm. 300.

704 Mark 1993, 20-31. 
Holzbildes $^{705}$. Laut. G. Gruben errichtete man bereits kurz nach der Zerstörung durch die Perser in der 1. Hälfte des 5. Jahrhunderts v. Chr. einen kleinen Nais$\operatorname{kos}^{706}$. I. S. Mark datiert hingegen den Naiskos sowie zwei zugehörige Altäre in die Mitte des 5. Jahrhunderts v. Chr. und vertritt die Ansicht, dass das Heiligtum nicht sofort wieder aufgebaut worden ist. In dem Naikos wurde die Basis des alten Bildes als Votivdepot weiter verwendet, wozu die Einlassung in der Oberseite vertieft wurde ${ }^{707}$. In den 420 er Jahren v. Chr. erbaute man den heute wiederaufgerichteten Marmortempel und den Marmoraltar ${ }^{708}$. Weder in dem Naiskos noch in dem Marmortempel haben sich Reste einer Statuenbasis erhalten. Aufgrund ihrer geringen Größe können beide kein sehr großes Bild beherbergt haben.

Ergebnis: Außer den in Kapitel 12.1 bereits besprochenen Kulten der Athena Polias und der Athena Parthenos gab es noch weitere Athenakulte auf der Akropolis von Athen. Dazu zählt das Heiligtum der Athena Nike, das im Zusammenhang mit der Umgestaltung der Akropolis um 580-560 v. Chr. zunächst mit einem Altar und einem Bild der Göttin ausgestattet wurde, von dem nur die Basis erhalten ist ${ }^{709}$. Vielleicht war diese Statue das durch die Quellen überlieferte Bild der Nike Apteros. Pausanias bezeichnet es als Xoanon, was bei ihm auf Holz als Material schließen lässt ${ }^{710}$. Da es als Vorbild für die Nike der Mantineer in Olympia gedient haben soll und deren Bildhauer Kalamis in die frühklassische Zeit datiert wird ${ }^{711}$, muss es sich um ein mindestens ebenfalls frühklassisches, eher noch um ein archaisches Bild handeln. Die Verbindung dieses Bildes mit dem Kultbezirk auf der Akropolis beruht allerdings lediglich auf dem Beinamen der Göttin in diesem Heiligtum. In den Quellen wird das Bild nur als Nike bezeichnet, es kann demnach auch anderswo aufgestellt gewesen sein. Die Flügellosigkeit erscheint dadurch jedoch verständlich, da es sich in diesem Fall um Athena Nike und nicht um Nike handelt ${ }^{712}$.

Als die Akropolis während der Perserkriege stark in Mitleidenschaft gezogen wurde ${ }^{713}$, scheint das Bild die Zerstörung überlebt zu haben. Die oben genannte Inschrift aus der 2. Hälfte des 5. Jahrhunderts v. Chr., die Baumaßnahmen im Athena Nike-Heiligtum überliefert, nennt ein dort aufgestelltes $\alpha \rho \chi \alpha \hat{\imath} o v$ ó $\gamma \alpha \lambda$ -

\footnotetext{
705 Nick 2002, 78.

706 Gruben 2001, 203.

707 Mark 1993, 20-31. 42-52. 58-68.

708 Mylonas Shear 1963, 377; Travlos 1971, 148-157; Bald Romano 1980, 62; Muss - Schubert 1988, 74-77; Mark 1993; Gruben 2001, 202-209; Schneider - Höcker 2001, 166-171.

709 Mylonas Shear 1963, 377; Muss - Schubert 1988, 77; Mark 1993, 69-92; Gruben 2001, 205.

710 Zur Verwendung des Begriffes Xoanon speziell für Holzbilder bei Pausanias s. Müller 1931, 490; Donohue 1988; Scheer 2000, 19-21; ebenso Nick, 2002, 20-22. Sonst ist der Begriff nicht auf Holzbilder beschränkt, s. S. 183.

711 Pollitt 1990, 46-48; DNP VI (1999) 147 f. s. v. Kalamis (R. Neudecker).

712 Vgl. auch Mark 1993, 93-98; Gruben 2001, 203.

713 Mark 1993, 36-41.
} 
$\mu \alpha^{714}$. Da damit nur ein archaisches Bild gemeint sein kann, liegt eine Identifizierung mit dem alten Bild der Athena Nike nahe ${ }^{715}$. Es war demnach weiterhin in dem Heiligtum aufgestellt, weshalb es von Pausanias noch im 2. Jahrhundert n. Chr. beschrieben werden konnte ${ }^{716}$.

Durch eine weitere, ebenfalls schon lange bekannte Inschrift aus dem 3. Viertel des 4. Jahrhunderts v. Chr. ist eine andere Statue der Athena Nike überliefert ${ }^{717}$. Die Inschrift überliefert die Erneuerung eines Bildes, das um 425 v. Chr. entstanden sein muss, wie aus den historischen Bezügen mit den in der Inschrift genannten Kriegsereignissen hervorgeht ${ }^{718}$. Da anschließend Opfer und eine Priesterin genannt werden, scheint es sich bei diesem Bild ebenfalls um ein ২Kultbild gehandelt zu haben. Es war wahrscheinlich im Zusammenhang mit dem in den 420er Jahren v. Chr. erbauten Tempel geschaffen worden. Auch hier trat demnach ein klassisches Bild neben ein archaisches in ein und demselben Heiligtum, und zwar wie bei den anderen hier untersuchten Heiligtümern auch im Zusammenhang mit dem Neubau eines Tempels.

\subsection{Athena Lindia in Lindos}

Schriftquellen zu dem alten Bild:

- Kall. Aet. 112; Plut. Daed. fr. 158; Eus. Pr. Ev. 3, 8, 1: "H

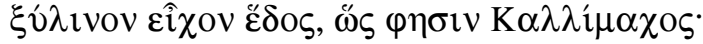

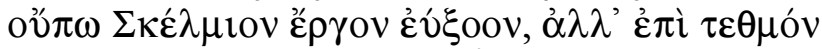

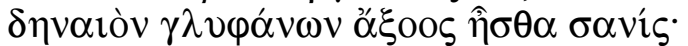

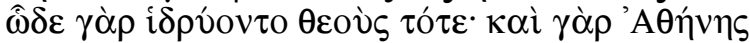

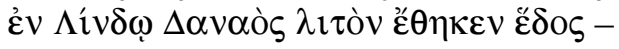

»Die Samier hatten ein hölzernes Hedos der Hera, wie Kallimachos berichtet:

„Noch nicht das gut geglättete Werk des Skelmis, sondern nach langjährigem Brauch eine Bohle warst du, ungeglättet von Beiteln. So nämlich stellte man sich die Götter auf damals; denn auch Athenes Statue auf Lindos errichtete Danaos schlicht"«. (M. Asper)

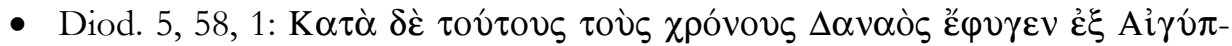

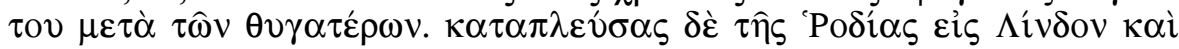

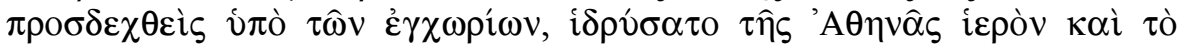

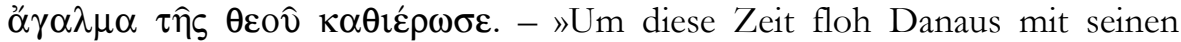
Töchtern aus Ägypten und landete in Lindos auf Rhodos. Freundlich von den

\footnotetext{
714 IG I3 64.

715 Mark 1993, 97. 108-110. 123. Vgl. dazu die Inschriften bezüglich der Artemis Brauronia, Kap.

12.10 und der Athena Polias, Kap. 12.1.

716 so auch Mark 1993, $124 \mathrm{f}$.

717 IG II 403.

718 Mark 1993, 114. Die Quellen: Thuk. 3, 108. 111; 4, 46. 49.
} 
Einwohnern aufgenommen, errichtete er einen Tempel der Athene und weihte der Göttin darin das Standbild«. (Th. Nothers - P. Wirth - O. Veh) ${ }^{719}$

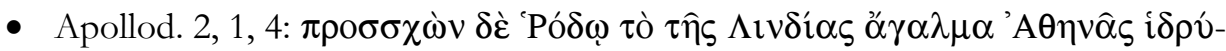
$\sigma \alpha \tau$. $-»$ Und in Rhodos landend errichtete er (Danaos) das Bild der Athena Lindia«.

- Lindische Tempelchronik C XXIII (99 v. Chr.):

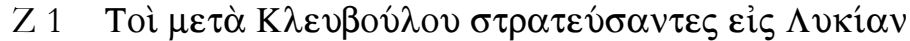

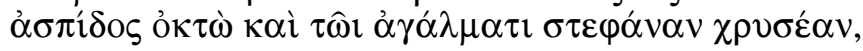

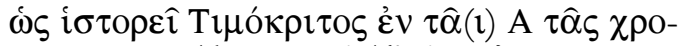

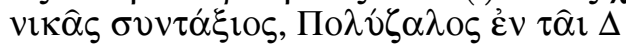

Z $5 \tau \hat{\alpha} \nu$ i $\sigma \tau$ opiôे $\nu^{720}$.-

Z 1 »Die unter Kleobulos gegen Lykien in den Krieg zogen (weihten) acht Schilde und den goldenen Kranz für das Agalma wie Timokritos im ersten Teil seiner Chronik berichtet sowie Polyzalos im 4. Teil

Z 5 seiner Geschichte«.

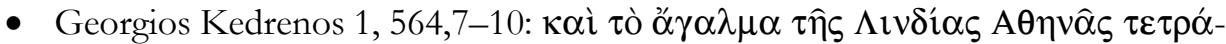

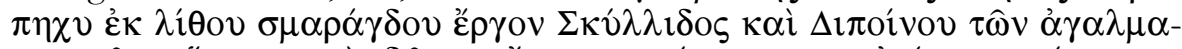

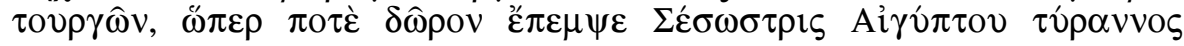

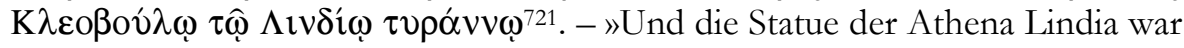
vier Ellen groß und aus Edelstein gefertigt, eine Arbeit der Bildhauer Skyllis und Dipoinos; diese Statue hatte Sesostris, Herrscher von Ägypten, einst als Geschenk an Kleobulos, den Herrscher von Lindos gesandt«.

Schriftquellen zu dem neuen Bild:

- Lindische Tempelchronik D (99 v. Chr.):

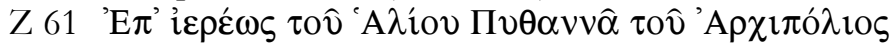

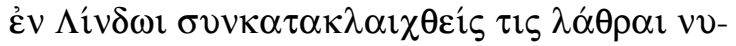

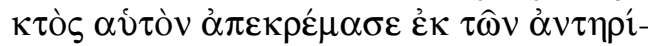

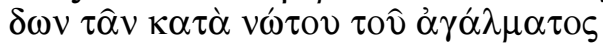

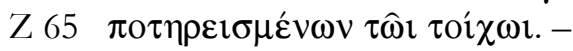

Z 61 »Als Pythannas, der Sohn des Archipolis Priester des Halios war, hat sich in Lindos jemand, der heimlich nachts im Tempel eingeschlossen war, selbst erhangen an den Stützen,

Z 65 die an der Rückseite der Statue an der Wand angebracht waren«.

\footnotetext{
$719 \mathrm{Zu}$ der Tempelgründung durch Danaos s. auch Hdt. 2, 182; Strab. 14, 2, 11.

720 Zu den lokalen Chroniken von Rhodos vgl. Higbie 2003, 188-203.

721 Nach Higbie 2003, 231.
} 
Darstellungen: Chr. Blinkenberg hat in seiner Untersuchung zu dem Bild der Athena Lindia von 1917 versucht, die ältere Statue mit Hilfe von Terrakottastatuetten des 6. und 5. Jahrhunderts v. Chr. als Sitzstatue zu rekonstruieren. Die Statuetten stammen aus der Kolonie Lindos', Gela und deren Pflanzstadt Akragas, in denen der Kult der Athena Lindia eine bedeutende Rolle gespielt habe. Allerdings ist keine derartige Terrakottastatuette in Lindos selbst gefunden worden, so dass diese These sehr fraglich erscheint. Auch die jüngere Statue der Athena Lindia kann nach Ansicht von Chr. Blinkenberg vielleicht mit Hilfe von hellenistischen Terrakottastatuetten, die im Gebiet von Lindos gefunden worden sind, als von der Athena Parthenos des Phidias beeinflusste, stehende und bewaffnete Athena rekonstruiert werden $^{722}$. Es gibt jedoch keinen Nachweis, dass die Terrakottastatuetten die Statue im Tempel wiederholen, da weder Fragmente von ihr noch sonstige Darstellungen bisher identifiziert werden konnten. Da die Tonstatuetten außerdem verschiedenen Typen angehören, können sie das Bild maximal in einzelnen Zügen oder Reflexen wiedergeben. Daher bleibt auch diese Rekonstruktion hypothetisch.

Baubefund: Die Frühzeit des Heiligtums ist noch nicht endgültig erforscht. Das Gebiet des Geländes war bereits im 2. Jahrtausend v. Chr. besiedelt. Ein erster Kultbau wurde vielleicht schon in der geometrischen oder früharchaischen Zeit errichtet, da Diog. Laert. 1, 89 überliefert, dass unter dem Tyrannen Kleobulos im 6. Jahrhundert v. Chr. ein Tempel erneuert, nicht jedoch neu gebaut wurde: $\dot{\alpha} \lambda \lambda \dot{\alpha}$

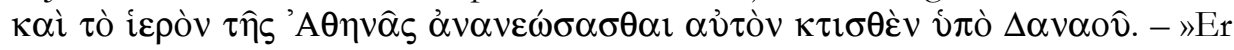
[Kleobulos] soll außerdem den Tempel der Athena erneuert haben, den Danaos gegründet hatte«. Zuvor gab es nach Ansicht der Forschung bereits eine Kultstätte in der natürlichen Höhle unterhalb des Tempelplateaus. Seit dem 6. Jahrhundert v. Chr. ist ein Tempel gesichert. Als dieser zu Beginn des 4. Jahrhunderts. v. Chr. abbrannte, wurde gegen Ende desselben Jahrhunderts ein neuer, amphiprostyler Tempel und mit ihm ein großes Götterbild, von dessen Basis sich noch Reste mit dem Einzapfloch erhalten haben, errichtet. Der Neubau nahm die langgestreckten Proportionen seines Vorgängers auf und lag an derselben Stelle $\mathrm{f}^{723}$.

Ergebnis: Die Statue der Athena von Lindos galt als ein besonders altes Bild. Da für das 6. Jahrhundert v. Chr. ein Tempel gesichert ist, kann man spätestens für diese Zeit von der Existenz eines Bildes ausgehen. Noch nicht vollständig geklärt ist die Möglichkeit, dass es bis in die geometrische Zeit hinauf datiert werden

${ }^{722}$ Chr. Blinkenberg, L'image d'Athana Lindia, Lindiaka I (Kopenhagen 1917) 40-51. Vgl. I. Ch. Papachristodoulou, Lindos. Ein historischer Abriss - Die Monumente (Athen 2006) 33.

${ }^{723}$ E. Dyggve (Hrsg.), Le sanctuaire d'Athana Lindia et l'architecture lindienne I, Lindos 3 (Berlin 1960) bes. 80-154; Kähler 1971a; Kähler 1971b; Lippolis 1988/89; Gruben 2001, 449-459; I. Ch. Papachristodoulou, Lindos. Ein historischer Abriss - Die Monumente (Athen 2006) 14-17. 31-34. Zur Datierung des Kleobulos von Lindos vgl. RE 2. Reihe II (1921) 2242-2264 s. v. Sieben Weisen (O. Barkowski); DNP VI (1999) 575 s. v. Kleobulos (M. G. Albiani); Higbie 2003, 103. 
kann. Das Bild der Athena Lindia wird in der antiken Überlieferung als sehr einfache, vielleicht noch wenig menschlich gestaltete Statue mit mythischem Ursprung geschildert. Sie trug nach der oben in Ausschnitten zitierten Lindischen Tempelchronik aus dem 1. Jahrhundert v. Chr. realen Schmuck ${ }^{724}$.

Der spätantike Autor Georgios Kedrenos überliefert, dass Kleobulos von Lindos ein Athenabild von einem Pharao namens Sesostris geschenkt bekommen hatte $^{725}$. Wahrscheinlich handelt es sich hier um eine Verwechslung. Pharaonen mit diesem Namen gehören der 18. Dynastie an und sind unmöglich mit Kleobulos zeitgleich. Eher handelt es sich um Amasis, der laut Herodot ${ }^{726}$ mehrere Statuen der Athena Lindia in das Heiligtum geweiht haben soll und wie Kleobulos im 6. Jahrhundert v. Chr. gelebt hat. Bei diesen Bildern handelt es sich eher um privat gestiftete Gaben und nicht um eines der əöffentlichen<, zur Verehrung im Tempel aufgestellten Bilder, wenn auch eine Einbeziehung dieser Bilder in den Kult gleichfalls möglich ist ${ }^{727}$. Auch das höhere Alter des Heiligtums legt nahe, dass die bei Georgios Kedrenos bezeugte Statue kaum mit dem aus den anderen Quellen bekannten alten Bild der Athena Lindia identisch ist, denn das Geschenk des Pharaos soll eine Arbeit von Skyllis und Dipoinos gewesen sein. Pausanias nennt beide Schüler des mythisch-vorzeitlichen Daidalos ${ }^{728}$. Plinius datiert ihre Schaffenszeit hingegen in die 1. Hälfte des 6. Jahrhunderts v. Chr., worin ihm auch die Forschung gefolgt ist und die gleichfalls zur Lebenszeit des Kleobulos und Amasis passt ${ }^{729}$.

Als der archaische Tempel zu Beginn des 4. Jahrhunderts v. Chr. einem Brand zum Opfer fiel, scheint das alte Bild nicht mit untergegangen zu sein. Es wird von den Quellen noch in hellenistischer Zeit erwähnt. Bereits kurze Zeit nach dem Brand wurde ein neuer Tempel errichtet. Dieser erhielt nach Ansicht der Forschung auch ein neues, anscheinend sehr großes Bild der Göttin, das an der Rückwand der Cella befestigt war. Reste der Befestigung haben sich erhalten. Für eine Marmor- oder Bronzestatue ist eine solche Befestigung nicht notwendig. Es wird sich daher wahrscheinlich um einen Akrolith gehandelt haben.

724 Die weitere in der Lindischen Tempelchronik C XXXIV Z 80-84 erwähnte Schmückung eines Bildes der Athena kann nicht datiert werden. Higbie 2003, 128 vermutet, dass das Ereignis aufgrund der Reihenfolge der Chronik im 4. oder 3. Jahrhundert v. Chr. stattgefunden haben kann. Es kann sich also sowohl um das alte als auch um das neue Bild handeln. Vgl. auch IG XII, 1, 764.

725 Vgl. Kähler 1971a, 26; Kähler 1971b, 5; Lippolis 1988/89, 112.

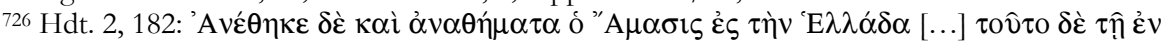

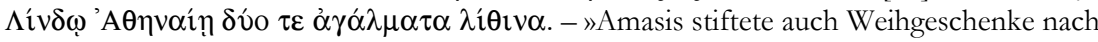
Griechenland [...] ferner zwei Standbilder aus Stein [...] der Athene in Lindos«.

727 Higbie 2003, 231 f. Zur Datierung der Pharaonen mit Namen Sesostris sowie Amasis vgl. LÄ V (1975) 890-907 s. v. Sesostris (W. K. Simpson); DNP XI (2001) 474 s. v. Sesostris (J. Quack) bzw. LÄ I (1975) 181 f. s. v. Amasis (H. J. de Meulenaere); DNP I (1996) 572 s. v. Amasis (K. Jansen-Winkeln). Zur Datierung des Kleoboulos s. Anm. 723.

728 Paus. 2, 15, 1.

${ }^{729}$ Plin. nat. 36, 9 f.; Vgl. RE V (1905) 1159-1161 s. v. Dipoinos (C. Robert); Pollitt 1990, 19 f.; DNP III (1999) 684 s. v. Dipoinos (R. Neudecker). 
In der oben zitierten Lindischen Tempelchronik wird überliefert, dass sich einst ein Mann im Tempel einschließen ließ und sich an der Befestigung der Statue erhängte $^{730}$. Bei dem erwähnten Bild muss es sich auf jeden Fall um ein großes Bild gehandelt haben, da nur so das Erhängen möglich gewesen ist. Das Ereignis lässt sich daher eher mit dem jüngeren Bild, das laut der Erforschung des Baubefundes groß gewesen sein soll, verbinden als mit dem älteren. Die Größe des alten Bildes ist zwar unbekannt. Da die meisten der hier betrachteten alten Bilder jedoch von kleinem Format waren, kann dies auch für das ältere Bild der Athena Lindia zumindest vermutet werden. Die Quellen bezeugen, dass auch zu diesem Bild in klassischer Zeit eine jüngere und deutlich größere Statue hinzugetreten war, die offensichtlich nicht als Ersatz gedient hat.

\subsection{Artemis in Ephesos}

Schriftquellen zu dem alten Bild:

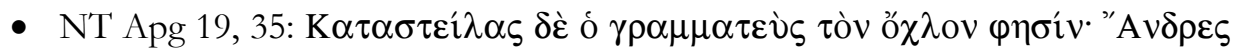

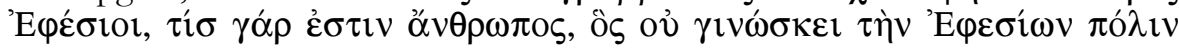

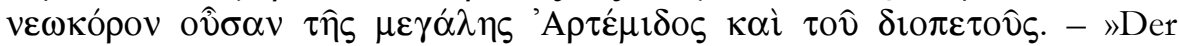
Stadtschreiber aber brachte die Menge zur Ruhe und sagte: Männer von Ephesus! Wer wüsste nicht, daß die Stadt der Epheser die Tempelhüterin der Großen Artemis und ihres vom Himmel gefallenen Bildes ist?« (Einheitsübersetzung der Heiligen Schrift)

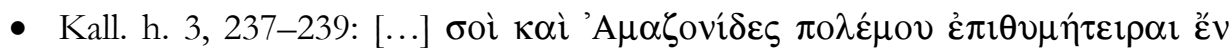

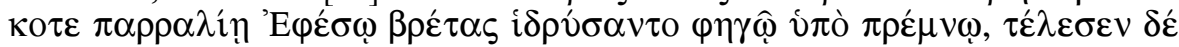

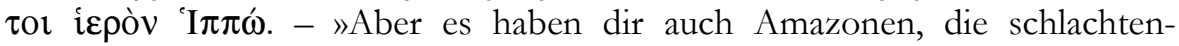
trunkenen, an Ephesos' Küste einst ein Standbild errichtet unter dem Strunk einer Eiche; und Hippo erbaute den Tempel«. (E. Howald - E. Staiger)

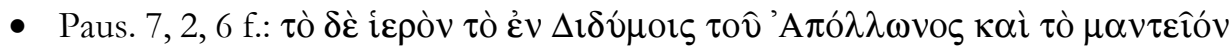

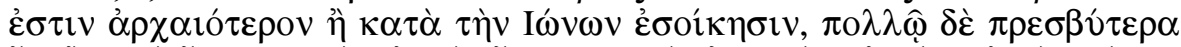

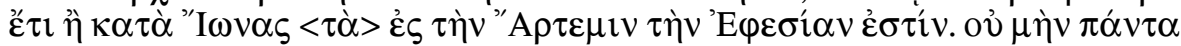

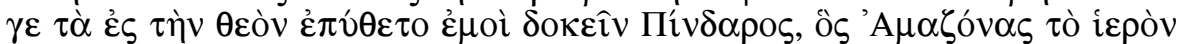

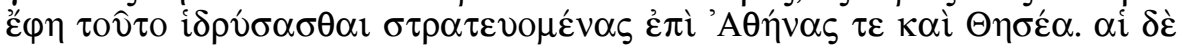

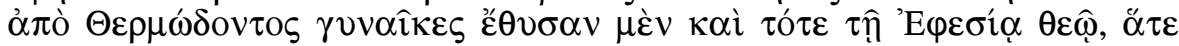

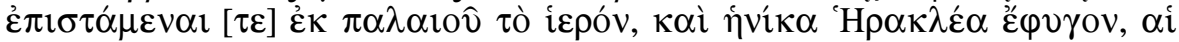

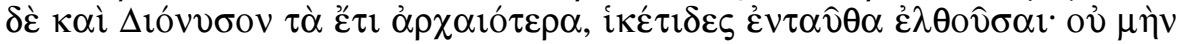

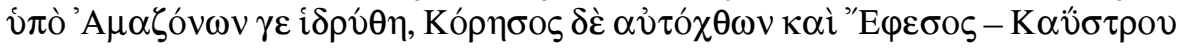

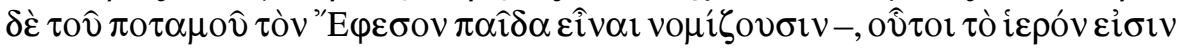

${ }^{730}$ Lindische Tempelchronik D Z 65-78. Eine Datierung des Ereignisses ist nicht möglich, da der erwähnte Priester des Halios in den zurzeit bekannten Listen dieser Kultbeamten nicht erscheint. Vgl. L. Morricone, I sacerdoti di Halios. Frammento di catalogo rinvenuto a Rodi, ASAtene 27-29, 1949-51, 351-80; Higbie 2003, 148. 


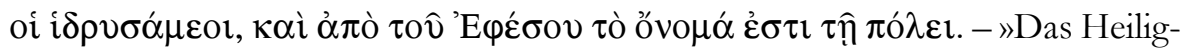
tum des Apollon in Didymoi und das Orakel ist älter als die Einwanderung der Ionier. Viel älter aber noch als die Ionier ist der Kult der ephesischen Artemis. Nicht alles nämlich hat, wie mir scheint, Pindar über die Göttin erfahren, der sagte, dieses Heiligtum hätten die Amazonen gegründet auf ihrem Zug gegen Athen und Theseus. Die Frauen vom Fluss Thermodon opferten nämlich schon damals der ephesischen Artemis, weil sie das Heiligtum von alters her kannten, und auch als sie vor Herakles flohen; einige noch früher auf der Flucht vor Dionysos, die als Schutzsuchende dahin kamen. Es wurde also nicht von Amazonen gegründet, sondern der Autochthone Koresos und Ephesos, den man für einen Sohn des Flusses Kaÿstros hält, diese gründeten das Heiligtum, und nach Ephesos erhielt die Stadt ihren Namen «731. (F. Eckstein - P. C. Bol)

- Vitr. 2, 9, 13: Item cedrus et iuniperus easdem habent virtutes et utilitates [...]. Ephesi in aede simulacrum Dianae, etiam lacunaria et ibi et in ceteris nobilius fanis propter aeternitatem sunt facta. - »Ebenso haben die Zeder und der Wacholder die gleichen guten Eigenschaften und Vorteile [...] In Ephesus sind (aus diesem Holz) im Tempel das Bild der Diana und auch die getäfelte Decke, dort wie in anderen berühmten Heiligtümern, wegen der Dauerhaftigkeit hergestellt«. (C. Fensterbusch)

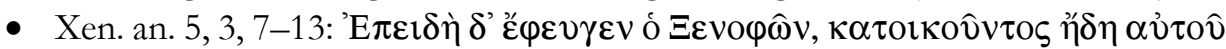

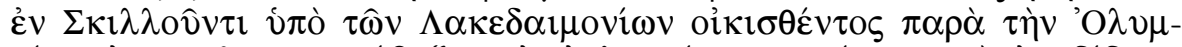

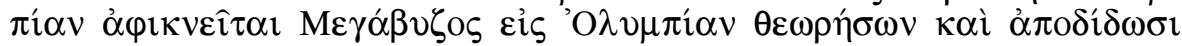

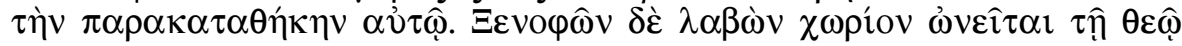

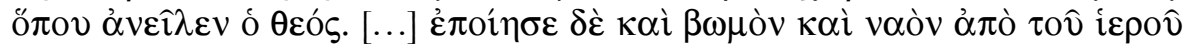

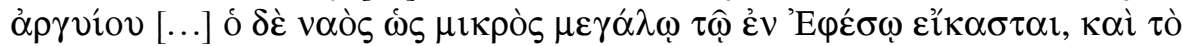

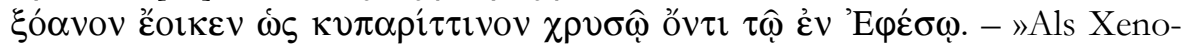
phon verbannt war und schon in Skillus wohnte, von den Lakedämoniern in der Nähe von Olympia angesiedelt, kam Megabyzos nach Olympia zum Fest und brachte ihm das anvertraute Gut zurück. Xenophon kaufte damit der Göttin ein Stück Land, wo ihm der Gott weissagte [...] er ließ auch aus dem geweihten Gelde einen Altar und einen Tempel errichten. [...] Der Tempel ist, abgesehen von der Größe, demjenigen in Ephesos nachgebildet, und das Götterbild gleicht demjenigen in Ephesos, soweit eines aus Zypressenholz einem goldenen gleichen kann«. (W. Müri)

\section{Schriftquellen zu dem neuen Bild:}

- Plin. nat. 16, 213 f.: de simulacro ipso deae ambigitur. ceteri ex habeno esse tradunt, Mucianus III cos. ex iis, qui proxime viso eo scripsere, vitigineum et numquam mutatum septies restituto templo, hanc materiam elegisse Endoeon, etiam nomen artificis nuncupans, quod equidem miror, cum antiquiorem Minerva quoque, non modo Libero pare, vetustatem ei tribuat. Adicit multis foraminibus nardo rigari, ut medicatus umor alat teneatque iuncturas -

\footnotetext{
${ }^{731}$ Vgl. auch Solinus Memorabilia 40, 2 f.
} 
quas et ipsa esse modico admodum miror [...]. - »Allein über das Bild der Göttin gibt es strittige Auffassungen: Die übrigen sagen, es sei aus Ebenholz; Mucianus aber, der dreimal Konsul war und zu denen gehört, die es persönlich in Augenschein genommen und darüber vor kurzem geschrieben haben, sagt, es sei aus Rebenholz, und niemals ausgetauscht worden, obwohl der Tempel siebenmal wiederhergestellt wurde; diese Holzart sei von Endoios ausgewählt worden; erstaunlicherweise weiß er nämlich auch den Namen des Künstlers zu nennen, obwohl er der Statue ein höheres Alter zuteilt als der der Athene und erst recht der des Vaters Liber. Er fügt noch hinzu, daß < die Statue $>$ durch viele Öffnungen mit Nardenöl benetzt werde, damit diese heilsame Flüssigkeit es tränke und die Fugen zusammenhalte - ich wundere mich aber nachgerade, daß ein mäßig großes Standbild solche hat [...]«. (R. König)

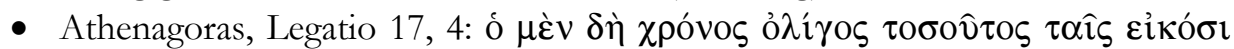

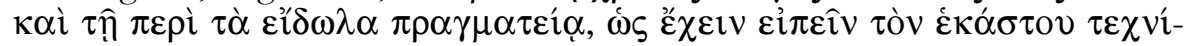

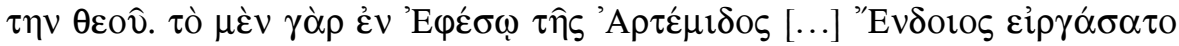

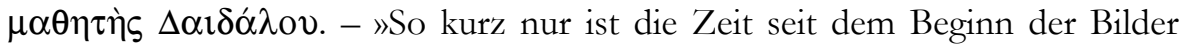
und der Herstellung der Statuen, dass es möglich ist, die Bildhauer jedes Gottes zu benennen. Endoios, ein Schüler des Daidalos, machte die Statue der Artemis in Ephesos [...] .

Darstellungen: Kaiserzeitliche Münzen aus Ephesos zeigen ein aufrecht stehendes Bild der Göttin, das sich auf einigen Wiedergaben in einem Tempel befindet und deshalb vielleicht ein `Kultbild der Göttin wiedergibt. Das Bild wirkt altertümlich aufgrund seines unbewegten Standes mit eng geschlossenen Beinen. Die Unterarme sind angewinkelt und vorgestreckt. Von den Händen hängen Wollbinden herab. Die Göttin trägt ein überaus reich geschmücktes Gewand, auf dem in mehreren Zonen übereinander Tierprotomen angebracht sind. Die Brust ist mit Ketten geschmückt. Darunter befinden sich die heute als Stierhoden gedeuteten eiförmigen Gebilde. Auf dem Kopf trägt die Göttin einen hohen reliefverzierten Kopfschmuck und ein Schleiertuch, das ebenfalls mit Tierprotomen geschmückt ist. Außerdem haben sich zahlreiche Nachbildungen besonders aus dem Hellenismus und der Kaiserzeit erhalten. Sie reichen von kleinformatigen Statuetten bis hin zu monumentalen Marmorstatuen. Sie geben die Göttin wie auf den Münzdarstellungen wieder, lassen aber Details besonders der Kleidung und des Schmuckes wie die Tierprotomen auf dem Gewand besser erkennen $(A b b .43)^{732}$.

\footnotetext{
732 Selçuk, Museum Inv. 718: Bammer - Muss 199614 Abb. 84. Die anderen Darstellungen bei: Lacroix 1949, 176-192 Taf. 15, 10-15 Taf. 16, 1-12; Fleischer 1973, 1-137 Taf. 1-57; Seiterle 1979, 3-16 Abb. 13. 16; Ekschmitt 1984, 71. 76-85 Taf. 11. 21 f.; Elliger 1985, 49 f.; Karwiese 1995, 39; Bammer - Muss 1996, 14. 71-78 Abb. 3. 7. 83 f.; Hueber 1997, 40 f. Abb. 41; S. P. Morris, The Prehistoric Background of Artemis Ephesia: A Solution to the Enigma of Her 'Breasts'?, in: U. Muss (Hrsg.), Der Kosmos der Artemis von Ephesos (Wien 2001) 135-151.
} 
Baubefund: Die Kultbauten des Heiligtums der Artemis von Ephesos reichen mindestens bis in das 8. Jahrhundert v. Chr. zurück. Bevor um die Mitte des 6. Jahrhunderts der erste monumentale Dipteros erbaut wurde, hatte man in dem Kultbezirk bereits mehrere über- und nebeneinander liegende Gebäude errichtet. Dazu zählen die sog. Tempel A-C, eine Plattform, die eine Säulenstellung getragen hat und der sog. Hekatompedos ${ }^{733}$. Die Funktion dieser Gebäude ist noch nicht im Einzelnen geklärt. Fest steht jedenfalls, dass es mit dem >Tempel B <spätestens seit dem 8. Jahrhundert v. Chr. einen Kultbau gegeben hat, der eventuell über einer noch älteren Kultstätte errichtet worden war. Er scheint im 7. Jahrhundert v. Chr. zerstört worden zu sein und wurde durch den $>$ Tempel $\mathrm{C}_{<}$ersetzt, der vielleicht nie vollendet wurde ${ }^{734}$. Alle diese Bauten verschwanden um 560 v. Chr. unter dem Fundament des ersten marmornen Dipteros ${ }^{735}$. Innerhalb der offenen Cella des Tempels, erhöht und monumental ausgestaltet entstand über dem alten Kultplatz ein neuer kleiner Kultschrein für das Artemisbild ${ }^{736}$. Der Tempel wurde um die Mitte des 4. Jahrhunderts v. Chr. zerstört. Direkt danach wurde an derselben Stelle mit einem Neubau begonnen ${ }^{737}$. Der neue Tempel bewahrte die Formen und Proportionen seines Vorgängers sehr genau. Innerhalb der gleichfalls offenen Cella entstand ein neuer kleiner Schrein für das Bild an derselben Stelle wie bei dem Vorgänger ${ }^{738}$.

Ergebnis: Die antiken Schriftquellen sprechen von einer Gründung des Heiligtums der Artemis von Ephesos in mythischer Vorzeit, was jedoch kein Beweis für eine Datierung noch in das 2. Jahrtausend v. Chr. ist. Die noch anhaltenden Forschungen scheinen aber zu einer Bestätigung dieser Ansicht zu tendieren ${ }^{739}$. Sicher

733 A. Bammer, Das Heiligtum der Artemis von Ephesos (Graz 1984) 165-184; Ekschmitt 1984, 107-110. 117 f.; Elliger 1985, 129; P. Karakatsanis, Studien zu archaischen Kolossalwerken (Frankfurt 1986) 212; Bammer 1991; Bammer 1993; Scherrer 1995, 48. 50; Bammer - Muss 1996; Hueber 1997, 30.

734 Ekschmitt 1984, 107-110; Bammer 1991 mit abweichender Deutung des >Tempels A‘; Karwiese $1995,34$.

735 Bammer 1968, 401; Seiterle 1979, 3; Ekschmitt 1984, 110; Elliger 1985, 130; P. Karakatsanis, Studien zu archaischen Kolossalwerken (Frankfurt 1986) 213-215; Bammer 1991, 64; Karwiese 1995, 35; Scherrer 1995, 46. 52; Bammer - Muss 1996, 28. 45-46.

736 Seiterle 1979, 3; Scherrer 1995, 52; Bammer - Muss 1996, 33.

737 Strab. 14, 1, 22; Plut. Alexander 3, 3; Solinus, Memorabilia 40, 2 f.; Val. Max. 8, 14, 5; vgl. Bammer 1968, 401; Seiterle 1979, 4; Ekschmitt 1984, 73. 119; Elliger 1985, 131; Scherrer 1995, 17. 53 f.; Bammer - Muss 1996, 46. 54; Hueber 1997, 37.

738 Bammer 1968; Seiterle 1979; A. Bammer, Das Heiligtum der Artemis von Ephesos (Graz 1984); Ekschmitt 1984, 69-121; Elliger 1985, 129-131; Bammer 1991; Bammer 1993; Scherrer 1995, 46-59; Karwiese 1995; Bammer - Muss 1996; Gruben 2001, 380-395.

${ }^{739}$ Auch aus mykenischer Zeit liegen Funde vor, die auf einen Kultbetrieb hinweisen. Eine Kultkontinuität seit dieser Zeit wird für möglich erachtet von Bammer 1991, 73; Bammer 1993, Beibl. 141; A. Bammer, Mykene im Artemision von Ephesos, ÖJh 63, 1994, Beibl. 20-40; Bammer Muss 1996, 7. 27 f.; Hueber 1997, 30; A. Bammer, Zur Bronzezeit im Artemision, in: Friesinger - Krinzinger 1999, 399-404; U. Muss, Vom Mythos zur Archäologie eines Heiligtums: Ein 
nachgewiesen reicht die Bautradition bis in das 8. Jahrhundert v. Chr. zurück. Auch von einem Bild der Göttin kann man in dieser Zeit ausgehen. Der neben einer als Standort der Statue in dem geometrischen Tempel gedeuteten Basis gefundene Schmuck soll einst dem Bild umgehängt worden sein. Es kann demnach reale Gewänder und Schmuck getragen haben ${ }^{740}$. Laut Vitruv bestand es aus $\mathrm{Holz}^{741}$. Xenophon hingegen überliefert Gold als Material, womit wahrscheinlich eine Vergoldung des Gewandes gemeint ist.

Das Aussehen der Statue ist durch rundplastische Nachbildungen und ephesische Münzen aus dem Hellenismus und der Kaiserzeit bekannt (Abb. 43) ${ }^{742}$. In der Forschung ist man sich allerdings nicht einig, ob diese das alte Bild oder ein neues, erst in hellenistischer Zeit geschaffenes wiedergeben, da sie stilistische Merkmale dieser Zeit aufweisen. Das neue Bild könnte für den zweiten Dipteros aus spätklassisch-frühhellenistischer Zeit geschaffen worden sein ${ }^{743}$. Da die Nachbildungen jedoch altertümliche Besonderheiten der Ephesischen Artemis bis hin zu einzelnen Details der Kleidung wie den Schmuckgürtel ${ }^{744}$ bewahren, muss die Erinnerung an das alte Bild sehr lebendig gewesen sein. Es ist deshalb wenig wahrscheinlich, dass es bereits früh verloren gegangen ist ${ }^{745}$. Eine kleine, tragbare Statue ${ }^{746}$ kann durchaus aus dem 356 v. Chr. abgebrannten Tempel gerettet worden sein. Auch in anderen Heiligtümern wie auf der Athener Akropolis, dem Heraion von Argos und Samos haben die alten Bilder die Zerstörung der Tempel überstanden. R. Fleischer deutet die hellenistischen Elemente der Nachbildungen deshalb so, dass sie auf die ständige Ausgestaltung und Schmückung des alten Bildes mit realer Kleidung und realem Schmuck zurückgehen, so dass sein Aussehen sich immer wieder änderte und jeweils auch zeitgenössische Elemente zeigte ${ }^{747}$.

bronzezeitlicher Kopf aus dem Artemision, in: U. Muss (Hrsg.), Der Kosmos der Artemis von Ephesos (Wien 2001) 153-168.

740 Elliger 1985, 120; Bammer 1993, Beibl. 137 f. 155; Scherrer 1995, 46; Bammer - Muss 1996, 35 f. 77 f. Abb. 90-92; Hueber 1997, 32; U. Muss, Zur Dialektik von Kultstatue und Statuetten im Artemision von Ephesos, in: Friesinger - Krinzinger 1999, 597-603.

${ }^{741}$ Das Material Holz wird auch vermutet aufgrund der Tatsache, dass einige Nachbildungen die unbedeckten Körperteile wie das Gesicht, die Hände und die Füße in dunklem Material wiedergeben. Vgl. dazu Fleischer 1973, 76. 121; Ekschmitt 1984, 79; Bammer - Muss 1996, 74 f.; Fleischer 1999.

742 s. Anm. 732.

${ }^{743}$ Die erste Ansicht vertreten Fleischer 1973, 1-137, bes. 124-130; Fleischer 1999; Damaskos 1999, 239; die zweite Fuchs - Floren 1987, 298; Viviers 1992, 154 f.; Bammer - Muss 1996, 72.

${ }^{744}$ Zwei geometrische Gürtel aus dem Heiligtum wurden von Bammer - Muss 1996, 78 zur Rekonstruktion des alten Bildes und zum Nachweis, dass das hellenistische Bild dieses nachbilde, herangezogen.

${ }^{745}$ So Bammer - Muss 1996, 72. Für das Weiterbestehen des alten Bildes plädieren Fleischer 1973, 57. 124-130; Ekschmitt 1984, 84; G. Klebinder, Bronzegürtel aus dem Artemision von Ephesos, in: U. Muss (Hrsg.), Der Kosmos der Artemis von Ephesos (Wien 2001) 111-122.

${ }^{746}$ Das Bild der Artemis wurde bei Kultfeiern regelmäßig aus dem Tempel getragen, s. S. 298.

${ }^{747}$ Fleischer 1973, 1-137, besonders 124-130; Fleischer 1999; ebenso Damaskos 1999, 239. 
Sicher erscheint hingegen, dass das alte Bild nicht das einzige geblieben ist. Die Quellen erwähnen ein Werk des Endoios, dessen Schaffenszeit in das 3. Viertel des 6. Jahrhunderts v. Chr. datiert werden kann ${ }^{748}$. Es stellt sich die Frage, ob dieser Statue mit den erwähnten Legenden ein mythisch hohes Alter und damit eine besondere Verehrungswürdigkeit zugeschrieben worden ist und sich alle Quellen auf nur ein Bild beziehen. Da der erste Tempel jedoch bereits in geometrischer Zeit errichtet worden ist und in diesem eine Statuenbasis nachgewiesen werden konnte, ist es sehr wahrscheinlich, dass es bereits vor der archaischen Zeit ein Artemisbild gegeben hat. Es ist daher wahrscheinlich, dass es sich bei der Statue des Endoios um ein zweites Bild gehandelt hat. Es stand vielleicht im Zusammenhang mit der Errichtung des ersten großen Dipteros ${ }^{74}$. Der Befund würde demnach eine Parallele zu dem des Heiligtums der Hera von Samos sowie den anderen hier betrachteten Heiligtümern darstellen, bei denen häufig der Neubau eines Tempels mit der Aufstellung eines neuen Bildes einherging, obwohl das alte Bild weiter Bestand hatte.

\subsection{Artemis Brauronia in Brauron und Athen}

Die Quellen zu den Bildern der Artemis Brauronia sind bisher noch nicht zweifelsfrei den beiden bekannten Heiligtümern in Brauron und auf der Akropolis von Athen zugewiesen, weshalb beide Heiligtümer zusammen behandelt werden.

\section{Schriftquellen:}

Schatzinschriften von der Athener Akropolis, die den Besitz der Artemis Brauronia auflisten $(347 / 6-336 / 5 \text { v. Chr. })^{750}$ :

- $\mathrm{IG} \mathrm{I}^{2} 386 / 7$ :

Z 3

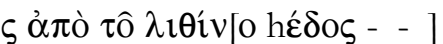

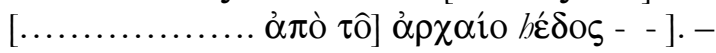

Z $3 \quad » .$. um das steinerne Hedos

... um das alte Hedos«.

- $\mathrm{IG} \mathrm{II}^{2}$ 1514:

Z 23

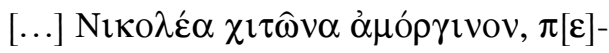

pì $\tau \hat{\omega} \iota \check{\varepsilon} \delta \varepsilon \imath .[\ldots]$

Z 26

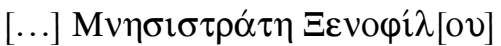

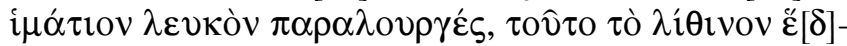

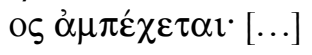

\footnotetext{
748 s. Anm. 610.

${ }^{749}$ Elliger 1985, 120; Fuchs - Floren 1987, 297 f. (sie gehen jedoch von einer Umarbeitung des alten Bildes durch Endoios aus, wofür keine Anhaltspunkte vorliegen); Viviers 1992, 60. 154; Karwiese 1995, 35; Bammer - Muss 1996, 72; U. Muss, Zur Dialektik von Kultstatue und Statuetten im Artemision von Ephesos, in: Friesinger - Krinzinger 1999, 597-603; Nick 2002, 94.

750 Zur Lokalisierung der genannten Statuen s. Anm. 756.
} 
Z 34

$$
[\ldots] \stackrel{\alpha}{\alpha} \mu \pi \dot{\varepsilon} \chi 0 \mathrm{vov}[\ldots]
$$

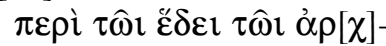

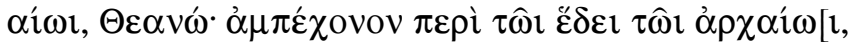

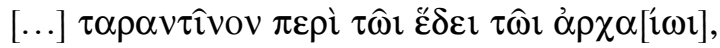

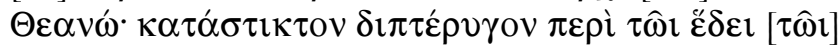
$\dot{\alpha} \rho \chi \alpha i \omega r \cdot[\ldots]$

$$
[\ldots] \chi 1[\tau]-
$$

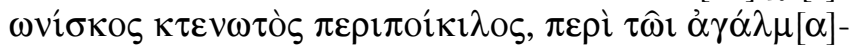
$\tau \imath \tau \hat{\omega} \iota ~ o ̉ \rho \theta \hat{\imath} \cdot[\ldots] .-$

Z $23 »[\ldots]$ ein purpurner Chiton, geweiht von Nikolea, um das Hedos [...]

Z $26[\ldots]$ von Mnesistrate, Tochter des Xenophilos, ein weißes Himation mit purpurner Borte, dies alles hat das steinerne Hedos umgelegt [...]

$$
[\ldots] \text { umgelegt }[\ldots]
$$

um das alte

Hedos von Theano; umgelegt um das alte Hedos [...] ein Tarantinon, um das alte Hedos von Theano; ein doppeltes Katastikton um das alte Hedos $[\ldots]$

gemusterter Chitoniskos um das $[\ldots]$ ein aufrechte Agalma $[\ldots] \ll$.

- IG II ${ }^{2} 1515$ :

Z $14 \quad[\ldots]$ Niко $[\lambda \dot{\varepsilon}] \alpha \chi \imath \tau \hat{\omega}[v \alpha \dot{\alpha} \mu o ́ \rho \gamma \imath v]$, $[\pi] \varepsilon \rho \grave{\imath} \tau \hat{\omega} \iota$ ह̌ $\delta \varepsilon \imath \cdot[\ldots]$

Z 18

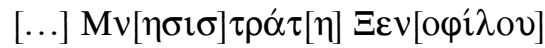

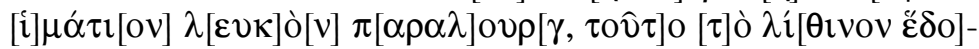
$[\varsigma \alpha \hat{\alpha} \mu \pi \varepsilon \varepsilon \varepsilon] \tau[\alpha \imath \cdot[\ldots]$

Z 26

$$
[\ldots] \stackrel{\alpha}{\alpha} \mu \pi] \dot{\varepsilon} \chi \operatorname{ovov}[\ldots]
$$

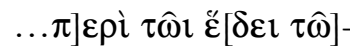

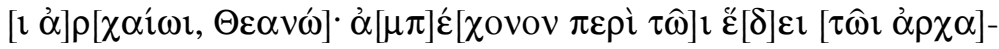

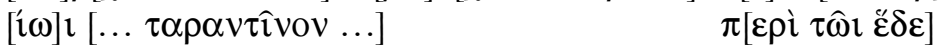

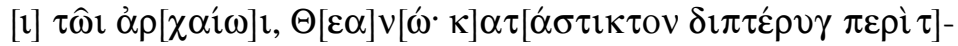

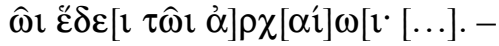

Z $14 »[. .$.$] ein purpurner Chiton, geweiht von Nikolea,$ um das Hedos [...]

Z $18 \quad[\ldots]$ von Mnesistrate, Tochter des Xenophilos, ein weißes Himation mit purpurner Borte, dies alles hat das steinerne Hedos umgelegt $[\ldots]$ 
Z 26

$[\ldots]$ umgelegt $[\ldots]$

um das alte

Hedos von Theano; umgelegt um das alte

Hedos [...] ein Tarantinon [...] um das

alte Hedos von Theano; ein doppeltes Katastikton

um das alte Hedos [...]

- $\mathrm{IG} \mathrm{II}^{2}$ 1516:

Z 2 [...] [Nıкод

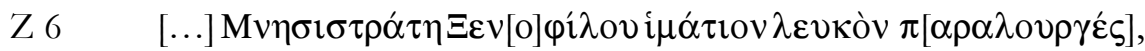

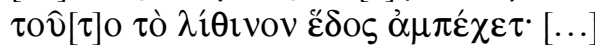

Z $13 \quad[\ldots] \stackrel{\alpha}{\alpha} \mu \pi \dot{\varepsilon}] \chi \mathrm{ov}[\mathrm{ov} \ldots$

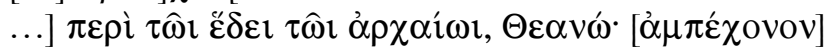

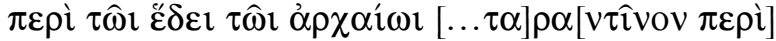

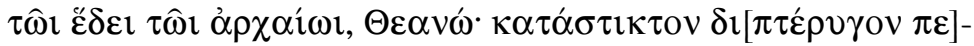

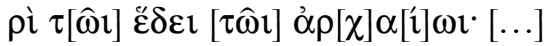

Z 19

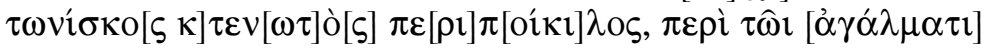
$\tau \hat{\omega} \imath$ ỏ $\rho \theta \hat{\omega} \imath] \cdot[\ldots] .-$

Z $2 \gg[\ldots]$ ein purpurner Chiton, geweiht von Nikolea, um das Hedos [...]

Z $6[\ldots]$ von Mnesistrate, Tochter des Xenophilos, ein weißes Himation mit purpurner Borte, dies alles hat das steinerne Hedos umgelegt [...]

Z $13 \quad[\ldots]$ umgelegt $[\ldots]$

um das alte Hedos von Theano; umgelegt

um das alte Hedos [...] ein Tarantinon, um

das alte Hedos von Theano; ein doppeltes Katastikton

um das alte Hedos [...]

Z 19

$$
[\ldots] \text { ein }
$$

gemusterter Chitoniskos um das aufrechte Agalma $[\ldots] \ll$.

- $\mathrm{IG} \mathrm{II}^{2} 1517$ B II:

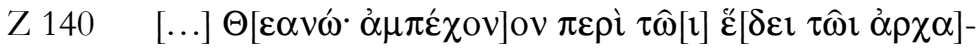

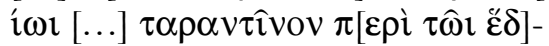

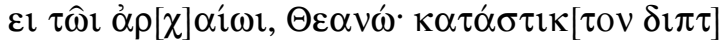

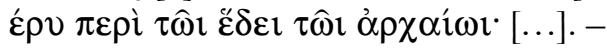

Z $140 \gg[\ldots]$ von Theano; umgelegt um das alte

Hedos [...] ein Tarantinon, um das alte

Hedos von Theano; ein doppeltes Katastikton um das alte Hedos [...]

- $\mathrm{IG} \mathrm{II}^{2}$ 1522:

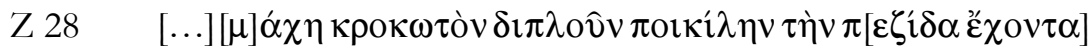




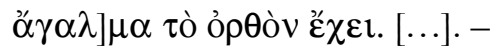

Z $28 \gg[. .$.$] ein doppelter Krokoton mit buntem Saum,$

den das aufrechte Agalma hat $[\ldots] \ll$.

- $\mathrm{IG} \mathrm{II}^{2}$ 1523:

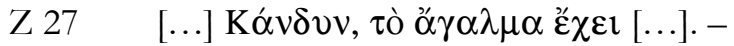

Z $27 \gg[. .$.$] ein Kandys, den das Agalma hat [...]«.$

- $\mathrm{IG} \mathrm{II}^{2}$ 1524:

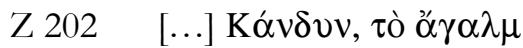

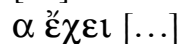

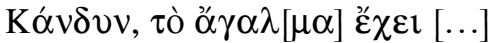

Z 206

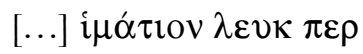

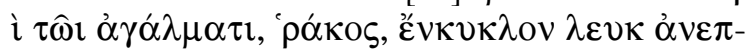

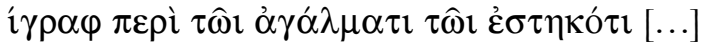

Z 214

$[\ldots]{ }^{\mathrm{I}} \mathrm{I} \pi \boldsymbol{\pi}^{\prime} \mathrm{i} \sigma-$

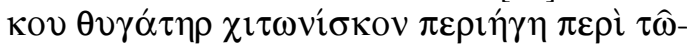

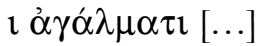

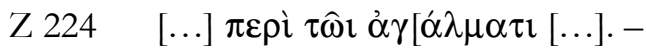

Z 202 »Ein Kandys, den

das Agalma hat [...];

Ein Kandys, den das Agalma hat [...];

Z 206

[...] ein weißes Himation

um das Agalma, ein weißes Tuch darum,

nicht bezeichnet um das stehende Agalma [...]

Z 214

$[\ldots]$ von der Tochter des

Hippiskos ein Chitoniskos

rundherum um das Agalma [...]

Z $224 \quad[\ldots]$ um das Agalma $[\ldots] \ll$.

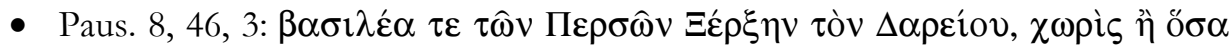

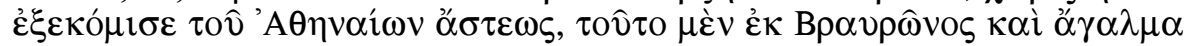

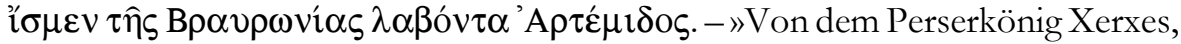
dem Sohn des Dareios, wissen wir, daß er außer dem, was er in der Hauptstadt Athen erbeutete, auch aus Brauron das Kultbild der brauronischen Artemis raubte«. (F. Eckstein - P. C. Bol)

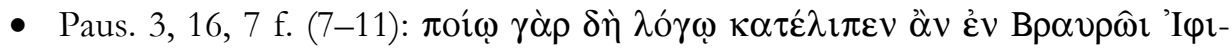

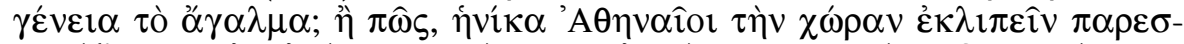

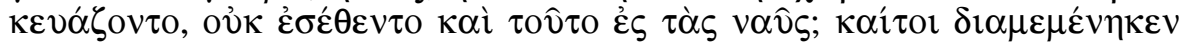

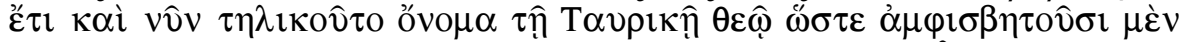

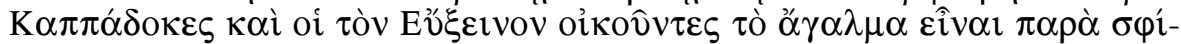

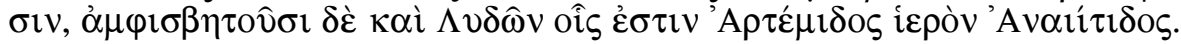

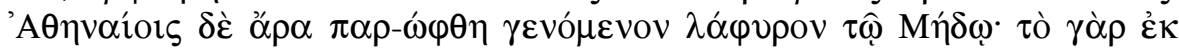




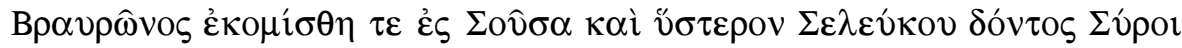

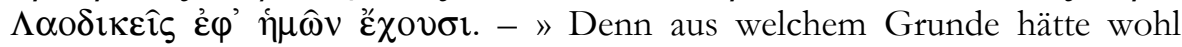
Iphigeneia das Bild in Brauron zurücklassen sollen? Oder weshalb hätten die Athener es, als sie sich anschickten, ihr Land zu räumen, nicht auch auf die Schiffe gebracht? Wo doch der Name der taurischen Göttin noch jetzt so berühmt ist, daß sogar die am Schwarzen Meer wohnenden Kappadoker behaupten, das Bild sei bei ihnen, und ebenso die Lyder, die das Heiligtum der anaïtischen Artemis besitzen; da sollen es die Athener haben geschehen lassen, daß es eine Beute der Perser wurde? Denn aus Brauron wurde die Statue nach Susa gebracht, und später erhielten sie die syrischen Laodikeer von Seleukos als Geschenk und haben sie jetzt noch«.( F. Eckstein - P. C. Bol)

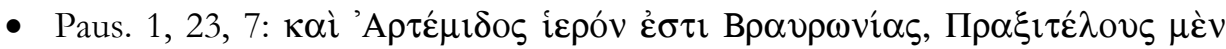

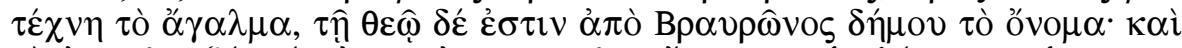

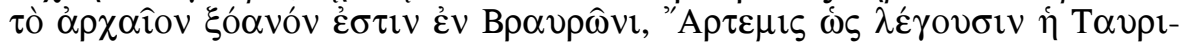
$\kappa \eta ́$. - »Dort [auf der Athener Akropolis] gibt es auch ein Heiligtum der Artemis Brauronia; das Bild ist eine Arbeit des Praxiteles, die Göttin erhielt den Beinamen nach dem Demos von Brauron. Das alte Xoanon ist in Brauron, die taurische Artemis wird sie genannt«.

Erhaltene Fragmente: Vor kurzem hat G. I. Despinis Fragmente von Akrolithstatuen aus dem Heiligtum der Artemis von Brauron veröffentlicht, darunter Fragmente von Händen und Füßen sowie von einem oder sogar mehreren Köpfen. Sie bestehen aus Marmor und konnten von G. I. Despinis aufgrund ihrer unterschiedlichen Größe mindestens vier verschiedenen Akrolithbildern zugewiesen werden. Die Statuen waren leicht unterlebensgroß bis dreifach lebensgroß. Sie können stilistisch in das 5. und 4. Jahrhundert v. Chr. datiert werden ${ }^{751}$.

Des Weiteren hat er vorgeschlagen, in einem auf der Akropolis von Athen gefundenen Marmorkopf ein Fragment der bei Pausanias erwähnten Statue des Praxiteles zu sehen. Er wurde wahrscheinlich im oder nahe beim Heiligtum der Athena Hygieia an der Südost-Ecke der Proypläen gefunden und misst 0,56 m, ist also deutlich überlebensgroß. Die langen Haare sind in zwei geflochtenen Zöpfen um den Kopf gelegt sowie zu einem Scheitelzopf zusammengenommen. Das Gesicht ist stark bestoßen und wurde wahrscheinlich absichtlich zerstört ${ }^{752}$.

Baubefund: Brauron war bereits in neolithischer Zeit besiedelt. Der Kultbezirk der Artemis ist seit dem 7. Jahrhundert v. Chr. zu fassen. Seine Blütezeit erlebte das Heiligtum in der spätarchaischen und klassischen Epoche. In dieser Zeit, genauer gesagt in der 1. Hälfte des 5. Jahrhunderts v. Chr. entstand der dorische Tempel,

\footnotetext{
751 Despinis 2004.

752 Athen, Akropolismuseum Inv. 13601 bzw. 1352; G. I. Despinis, Neues zu einem alten Fund, AM 109, 1994, 173-198 Taf. 32-36; Despinis 1997.
} 
dessen Überreste noch heute zu sehen sind. Er ersetzte einen älteren Bau aus archaischer Zeit, dessen Standort unter der Kapelle des Heiligen Georg vermutet wird. Er war laut. A. Alavanou während der Perserkriege zerstört worden ${ }^{753}$. Das Artemis Brauronia-Heiligtum auf der Akropolis von Athen hingegen war entweder im Zuge der Vereinigung der attischen Demen während der sog. Dunklen Jahrhunderte und einer damit verbundenen möglichen Einholung von Kulten des attischen Landes nach Athen oder im 6. Jahrhundert v. Chr. unter den Peisistratiden, die aus Brauron stammten gegründet worden, wobei die neuere Forschung die spätere Datierung favorisiert. Es besaß eine u-förmige Stoa mit anschließenden Räumen aus dem 5. Jahrhundert v. Chr. An den nordöstlichen Flügel anschließend errichtete man später noch eine weitere Stoa. Ein Tempel ist bisher nicht nachgewiesen, wird aber für die klassische Zeit von G. Despinis vermutet ${ }^{754}$.

Ergebnis: Die oben genannten Schatzinschriften von der Athener Akropolis lassen erkennen, dass es mehr als eine Statue der Göttin in einem einzigen Heiligtum gegeben haben muss. Es ist unwahrscheinlich, dass dasselbe Bild in ein und derselben Inschrift verschiedentlich bezeichnet worden ist. Die Inschriften nennen $\tau$ tó

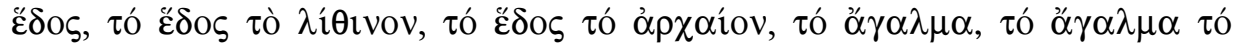

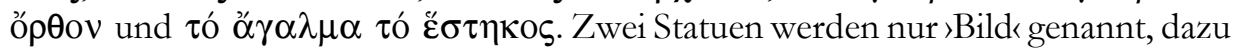
gab es eine weitere, steinerne, wahrscheinlich also marmorne Statue, ein altes Bild und ein vermutlich aufrecht stehendes, wenn man alle als einzelne Statuen ansieht, wie es kürzlich G. I. Despinis vorgeschlagen hat ${ }^{755}$. Wahrscheinlicher ist es, dass sich hinter den einzelnen Nennungen nur zwei oder drei Bilder verbergen, da sich die Bezeichnungen nicht immer gegenseitig ausschließen. Sicher ist, dass eines älter war als die anderen. Die Weihungen von Kleidung bedeuten jedenfalls, dass es sich bei allen Statuen um verehrte Bilder handelte.

Daraus ergibt sich die Frage, auf welches Heiligtum sich die Inschriften beziehen. Für T. Linders, die die Zeugnisse 1972 publiziert hat, stellen sie Abschriften von Inschriften aus dem Mutterheiligtum Brauron dar, wo vergleichbare Inschriften gefunden wurden ${ }^{756}$. Die Statuen hätten demnach in Brauron gestanden. Pausanias über-

753 P. G. Themelis, Brauron, Guide to the Site and Museum (Athen 1971); A Alavanou, Brauron and Halai Araphenides (Athen 1972); J. Mylonopoulos - F. Bubenheimer, Beiträge zur Topographie des Artemision von Brauron, AA 1996, 7-23; P. G. Themelis, Contribution to the Topography of the Sanctuary at Brauron, in: B. Gentili - F. Perusino (Hrsg.), Le orse di Brauron. Un rituale di iniziazione femminile nel santuario di Artemide (2002) 103-116.

${ }^{754}$ Travlos 1971, 124 f.; R. F. Rhodes - J. J. Dobbins, The Sanctuary of Artemis Brauronia, Hesperia 48, 1979, 325-341; Muss - Schubert 1988, 27 f.; Despinis 1997; Schneider - Höcker 2001, 97.

755 Despinis 2004, 261-315.

756 T. Linders, Studies in the Treasure Records of Artemis Brauronia found in Athens (Stockholm 1972) 70-73, ebenso Bald Romano 1980, 86; LIMC II (1984) 620 s. v. Artemis (L. Kahil); Mark 1993, 97; J. Mylonopoulos - F. Bubenheimer, Beiträge zur Topographie des Artemision von Brauron, AA 1996, 8; Despinis 1997, 210 f.; Hurwitt 1999, 198; Despinis 2004, 261 f.; L. Cleland, The Brauron Clothing Catalogues. Text. Analysis, Glossary and Translation (Oxford 2005). Vorsichti- 
liefert, dass dort das alte Holzbild der taurischen Artemis verwahrt wurde, das mit

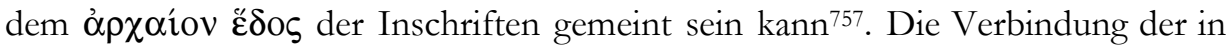
den Inschriften genannten Bilder mit den von G. I. Despinis identifizierten Akrolithstatuen gestaltet sich jedoch schwierig, weshalb er selbst nicht über die mögliche Verbindung einer monumentalen Sitzstatue mit dem ö $\gamma \alpha \lambda \mu \alpha$ der Inschriften hinausgeht. Ein Bezug der anderen Akrolithe zu den übrigen in den Inschriften erwähnten Statuen ist ebenfalls wahrscheinlich, doch muss dies offen bleiben ${ }^{758}$. Sollte auch nur eine der vier Statuen als $>$ Kultbild fungiert haben, stellt das Heiligtum in Brauron ein weiteres Beispiel dar, bei dem ein altes Bild in klassischer Zeit durch ein weiteres ergänzt worden ist. Der dargelegte Baubefund bestätigt diese Annahme, da für das seit archaischer Zeit bestehende Heiligtum ein Tempel aus klassischer Zeit bezeugt ist. Die Inschriften bezeugen auf jeden Fall, dass es in der klassischen Epoche zeitgleich mehrere verehrte, aus unterschiedlichen Zeiten stammende Statuen der Artemis Brauronia gegeben hat.

Das Heiligtum der Artemis Brauronia in Athen beherbergte ebenfalls mehrere Bilder der Göttin, wobei jedoch nicht sicher ist, ob sie zusammen aufgestellt gewesen sind. Da der Kultbezirk spätestens seit dem 6. Jahrhundert v. Chr. bestand $^{759}$ ist zu vermuten, dass es seit dieser Zeit auch ein Bild der Göttin gab. Für die klassische Zeit überliefert Pausanias eine Statue von Praxiteles. Von dieser hat sich vielleicht ein originales Fragment erhalten, wie G. I. Despinis dargelegt hat. Aufgrund der vorgetragenen Argumente wie der deutlichen Überlebensgröße, der Frisur und dem Ohrloch, die für eine weibliche Gottheit sprechen sowie der stilistischen Einordnung des Kopfes in die Jahre um 330 v. Chr. ${ }^{760}$ besitzt seine These einige Wahrscheinlichkeit ${ }^{761}$. Ob das alte Bild zur Zeit der Aufstellung des

ger ist C. Calame, Offrandes à Artémis Braurônia sur l'Acropole: rites de puberté?, in: B. Gentili-F. Perusino (Hrsg.), Le orse di Brauron. Un rituale di iniziazione femminile nel santuario di Artemide (Pisa 2002) 43-64, der sich die Weihungen an beiden Orten vorstellen kann. Die ältere Forschung ist zusammengefasst bei J. Tréheux, Sur le nombre des statues cultuelles du Brauronion et la date de l'Artémis Brauronia de Praxitèle, RA 1964, 1, 1-6 und Despinis 2004, 261 f. Da sich auch Abschriften von Inschriften aus Delos und Eleusis auf der Akropolis fanden, ist die These von T. Linders nicht unwahrscheinlich. Die Fragmente aus Brauron sind bisher noch nicht ausreichend publiziert, s. J. M. Cook, Archaeology in Greece, 1949-1950, JHS 71, 1951, 237 f.; M. S. F. Hood, Archaeology in Greece, 1956, JHS 77, 1957, 5; ders., Archaeology in Greece, 1958, JHS 79, 1959, 3 f.

${ }^{757}$ Falls das Bild wirklich von Xerxes geraubt wurde, muss es ein weiteres altes Bild gegeben haben, das die Inschriften des 4. Jahrhunderts v. Chr. erwähnen. Vielleicht gab es ein Ersatzbild, das damals selbst schon als alt galt. Oder die Bezeichnung war auf das Ersatzbild übergegangen.

758 Despinis 2004.

759 Travlos 1971, 124; Muss - Schubert 1988, 25. 90; Garland 1992, 40; Schneider - Höcker 2001, 97.

760 s. Anm. 752.

${ }^{761}$ In der Forschung wurde verschiedentlich vermutet, dass die kaiserzeitliche Artemis von Gabii, den Typus der Artemis Brauronia des Praxiteles wiedergebe: Lippold 1950, 239-240 Taf. 83, 4; J. Tréheux, Sur le nombre des statues cultuelles du Brauronion et la date de l'Artémis Brauronia de Praxitèle, RA 1964, 1, 1-6. L. Kahil hat in ihrer umfangreichen Untersuchung zu Artemisbildern im LIMC jedoch festgestellt, dass es weder Anhaltspunkte für noch gegen diese These gibt: 
neuen jedoch noch bestanden hat, bleibt zurzeit offen. Wenn ja, so liegt hier ein weiteres Beispiel für die Aufstellung einer klassischen Statue neben einer archaischen vor.

\subsection{Artemis Orthia in Messene}

Schriftquellen:

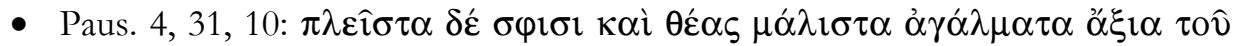

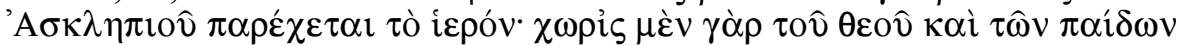

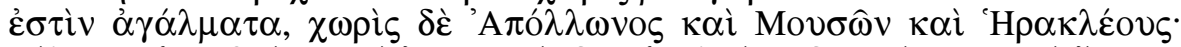

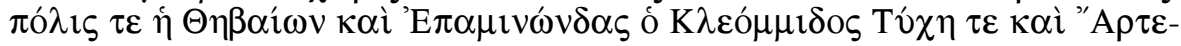

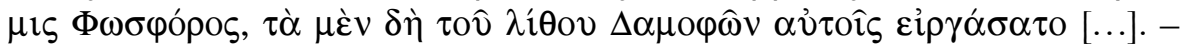
"Aber die meisten und sehenswertesten Statuen enthält das Asklepiosheiligtum. Denn außer der des Gottes sind da Statuen seiner Söhne und ferner von Apollon und den Musen und Herakles und die Stadt Theben und Epameinondas, der Sohn des Kleommis, und Tyche und Artemis Phosphoros. Die Marmorstatuen sind Arbeiten des Damophon [...]«. (F. Eckstein - P. C. Bol)

- Inschrift auf einer Ehrenbasis aus dem jüngeren Heiligtum (1. Jh. v. Chr.):

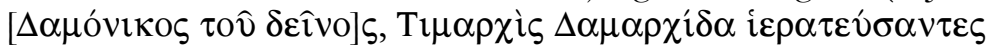

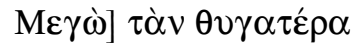

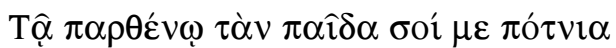

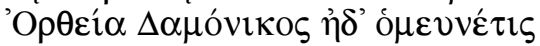

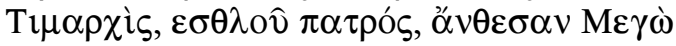

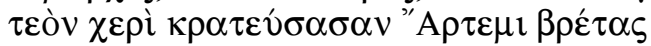

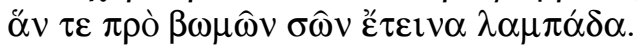

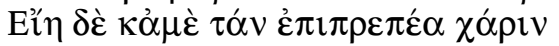

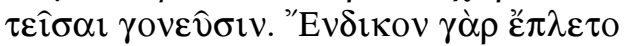

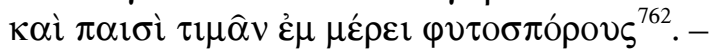

»[Damonikos, Sohn des ...und] Timarchis, Tochter des Damarchidas, als sie

Priester waren (haben das Bild geweiht) ihrer Tochter Mego.

Dir, der Jungfrau, oh Herrin Orthia,

haben Damonikos und seine Frau

Timarchis, von edler Herkunft, mich geweiht, ihre Tochter Mego,

die das Bretas der Artemis in der Hand getragen hat,

und (sie haben geweiht) die Fackel, die ich vor deinem Altar gehalten habe.

Möge es auch mir erlaubt sein, meinen Eltern Dank

abzustatten, da es sich für die Kinder gehört,

ihren Eltern im Gegenzug Ehre zu erweisen«. 
Baubefund: Der Kult der Artemis Orthia in Messene wurde nacheinander in zwei unterschiedlichen, nicht direkt in Verbindung stehenden Kultbauten durchgeführt. Nach der Neugründung der Stadt im Jahre 369 v. Chr. übte man den Kult zunächst in einem kleinen prostylen Tempel nordwestlich des späteren sog. Asklepieions aus. Dieser ist inschriftlich als Kultstätte der Artemis Orthia gesichert ${ }^{763}$. Als um 200 v. Chr. das >Asklepieion< errichtet wurde, beschnitt man das Terrain des Artemistempels. Er blieb zwar bestehen und erhielt Zugang über eine neue Treppe, doch der offene Bereich vor dem Tempel mit dem Altar wurde zerstört und der Kult in den nordwestlichsten Raum des >Asklepieions verlegt. Dieser ist ein rechteckiger Raum, der durch zwei Säulenreihen in drei Schiffe geteilt ist. An der Rückseite des Mittelschiffes findet sich noch heute die Basis einer kolossalen steinernen Statue. Davor haben sich ein Gabentisch und ein Opferstock erhalten. Um die jüngere Artemisstatue standen im Halbkreis Ehrenstatuen von Artemispriesterinnen und jungen Mädchen, die am Kult teilgenommen hatten ${ }^{764}$.

Erhaltene Fragmente: In bzw. in der Nähe der beiden Kultbauten der Artemis Orthia fanden sich Reste der jeweiligen Artemisstatue. Das ältere, lebensgroße Bild besteht aus Marmor und zeigt Artemis als Jägerin in kurzem Chiton und Nebris. Die Statue wird an das Ende des 4. oder den Anfang des 3. Jahrhunderts v. Chr. datiert ${ }^{765}$. Hellenistische Terrakottastatuetten aus diesem Heiligtum wiederholen wahrscheinlich das in dem Tempel aufgestellte Bild ${ }^{766}$. Nach der Umsiedelung des Kultes in das >Asklepieion` errichtete man der Göttin eine neue Statue. Auch von dieser fanden sich Überreste. Das kolossale Marmorbild zeigt, wie die alte Statue, Artemis als Jägerin in kurzem Chiton und Nebris. Außerdem hielt die Göttin eine Fackel in der Hand $(A b b .44)^{767}$. Beide Statuen zeigen demnach dieselbe Ikonographie, die Kontinuität des Kultes wird dadurch deutlich vor Augen geführt.

763 Themelis 1994, 101-122; Damaskos 1999, 42 f.; Themelis 2003, 85-87; Müth 2007, 141-202, bes. $164 \mathrm{f}$.

764 Themelis 1994, 101-122; Y. Morizot, Le hiéron de Méssene, BCH 118, 1994, 2, 399-405; Damaskos 1999, 50-52. 225; Themelis 2003, 74-76. 85-87; Müth 2007, 141-202, bes. 160-167. Orlandos 1962, 108 möchte auf der Basis des jüngeren Kultraumes eine Statuengruppe ähnlich der von Damophon in Lykosoura geschaffenen sehen. Anhaltspunkte dafür liegen nicht vor.

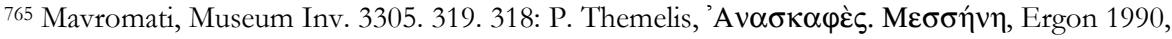

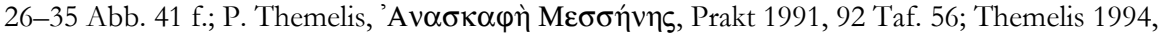
105 f. Abb. 8a-b; Y. Morizot, Le hiéron de Méssene, BCH 118, 1994 II, 399-405; Damaskos 1999, 42 f.; Themelis 2003, 85-87. 138 Abb. 74; Müth 2007, 165-167 Abb. 95.

766 Sie stammen aus Fundschichten und Opfergruben, die in die 1. Hälfte des 2. Jahrhunderts v. Chr. datiert werden: Themelis 2003, 86 Abb. 73; Müth 2007, 166 Abb. 95.

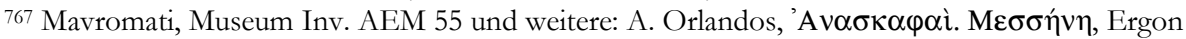

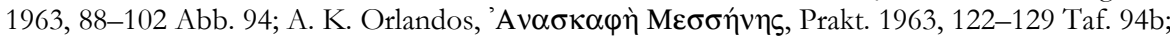
Themelis 1994, 111 Abb. 13. 14a-b; P. Themelis, Damophon of Messene: New Evidence, in: K. A. Sheedy (Hrsg.), Archaeology in the Peloponnese. New Excavations and Research (Oxford 1994) 1-37, bes. 21 f. Taf. 16; Damaskos 1999, 50-52; Themelis 2003134 Abb. 136. 
Zusätzlich gab es neben der jüngeren Statue noch ein kleines tragbares Bild. Von diesem haben sich zwar keine Fragmente, jedoch eine Darstellung erhalten. Eine späthellenistische Marmorstatue einer Kultteilnehmerin, die einst links des großen, zentral aufgestellten Artemisbildes gestanden hat, trägt ein deutlich unterlebensgroßes hermenartiges Bild in ihrer linken Hand. Es ist bekleidet und trägt ein rundes Medaillon auf der Brust und steht auf einer rechteckigen Basis. Der Kopf ist abgebrochen $(A b b .45)^{768}$.

Ergebnis: Der Kult der Artemis Orthia in Messene wurde seit dem 4. Jahrhundert v. Chr. in einem kleinen prostylen Tempel ausgeübt und in frühhellenistischer Zeit in einen Raum des südöstlich davon errichteten `Asklepieions` verlagert. Beide Kulträume besaßen eine eigene Statue der Göttin. Das jüngere Bild kann aufgrund der genauen Ortsbeschreibung bei Pausanias mit dem von ihm überlieferten Werk des berühmten messenischen Bildhauers Damophon identifiziert werden.

Von den elf um dieses Bild aufgestellten Basen von Ehrenstatuen ist besonders die oben aufgeführte Inschrift von der Basis links des Bildes der Göttin für die vorliegende Untersuchung interessant, denn sie bezeugt, dass es neben diesem Bild ein weiteres, wesentlich kleineres gegeben hat. Die Inschrift überliefert, dass ein Bild der Göttin während der Kulthandlungen von jungen Mädchen zum Altar getragen wurde, der im Freien innerhalb der Kolonnaden des >Asklepieions in axialer Ausrichtung auf die Basis des kolossalen Artemisbildes stand. Die Statue des Damophon kann aufgrund ihres Formates nicht gemeint sein. Stattdessen zeigen die erhaltenen Fragmente der einst auf der Basis aufgestellten Statue, dass die geehrte Mego der Inschrift entsprechend dargestellt gewesen ist und ein hermenförmiges Bild von deutlich unterlebensgroßem Format im Arm hielt (Abb. $457^{769}$. Damit ist ein zweites, tragbares Bild spätestens seit dem 1. Jahrhundert v. Chr. bezeugt, das während der Kultfeiern am Altar präsent war. Es wird vermutet, dass das kleine Bild während der Opferfeiern auf dem rechteckigen Pfeiler mit einer zweistufigen, ebenfalls rechteckigen Einlassung an der Oberseite, der noch heute neben dem Altar steht, abgesetzt werden konnte ${ }^{770}$. Als sein Standort außerhalb der Kultfeiern wird eine kleine runde Basis links des monumentalen Artemisbildes in dem Kultraum der Göttin angesehen ${ }^{771}$.

Dass auch das kolossale Marmorbild als $\gg$ Kultbild gedient hat, belegen eindeutig der Gabentisch und der Thesauros, die noch heute vor seiner Basis stehen. Es

\footnotetext{
${ }^{768}$ Mavromati Museum Inv. 245. 247: Orlandos 1962, 112 $\sigma \tau$ Taf. 117; Themelis 1994, 115 Abb. 19 f.; Themelis 2003, 74-76 Abb. 59 f.; Müth 2007, 162 f.

769 s. Anm. 768.

770 Themelis 1994, 122 Abb. 26; Müth 2007, 163.

${ }^{771}$ F. Felten, Heiligtümer oder Märkte?, AntK 26, 2, 1983, 84-106 Abb. 2; L. Schramm-Lymperopoulos, Messene. Stadtgründung im 4. Jh. v. Chr. Geschichte und bauliche Entwicklung der Stadt (Magisterarbeit Universität Hamburg 1988) 71; Themelis 1994, 122; Müth 2007, 162. Zu der Rundbasis vgl. auch Orlandos 1962, $108 \mathrm{f.}$
} 
handelt sich hierbei also nicht um ein lediglich prachtvolles `Weihgeschenkı, wie es in der Forschung lange Zeit z. B. von der Athena Parthenos in Athen gedacht wurde, sondern, zusammen mit dem kleinen tragbaren Bild um zwei verschiedene, unterschiedlichen Ansprüchen dienende `Kultbilder` ein und derselben Göttin in einem einzigen Kultbau.

\subsection{Apollon in Delphi}

\section{Schriftquellen zu dem alten Bild:}

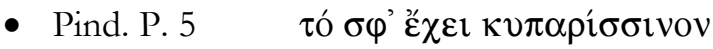

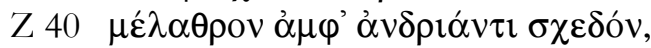

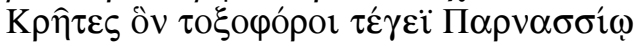

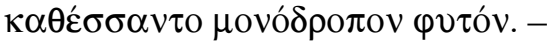
Und das birgt ein zypressner Schrein,

Z 40 Dem Standbild nah, das an parnassischer Felsenwand Kreter einmal, bogenbewehrte, dorthin Sich aufgestellt, aus einem Stück geformt «772. (O. Werner)

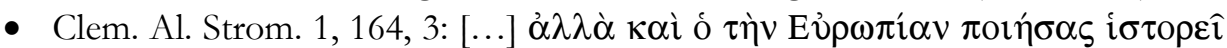

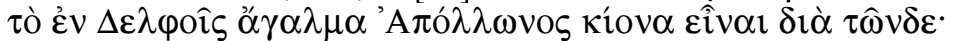

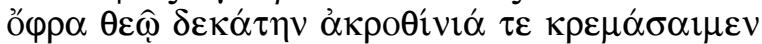

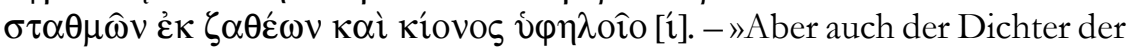
Europia erzählt, das Bild des Apollon in Delphi sei eine Säule, mit den Worten: „Daß wir hängen den Zehnten und Erstlingsfrüchte dem Gotte an die herrlichen Pfeiler und an die mächtige Säule“«. (C. A. Bernoulli - L. Früchtel)

\section{Schriftquellen zu dem neuen Bild:}

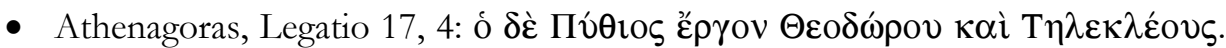
- »Der Pythische Apollon ist das Werk von Theodoros und Telekles«.

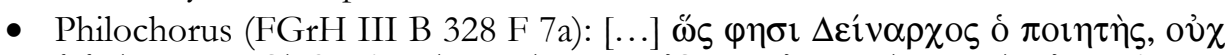

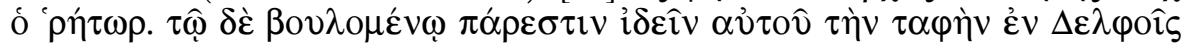

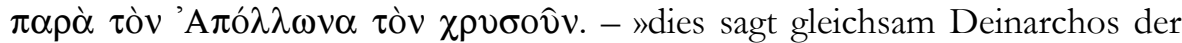
Dichter, nicht der Redner. Jedem, der sehen will, dass das Grab dessen ist in Delphi bei dem goldenen Apoll«.

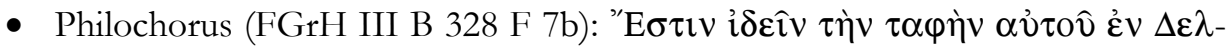

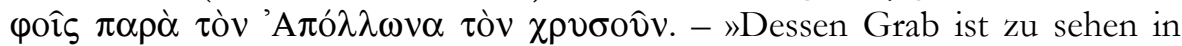
Delphi bei dem goldenen Apollon«.

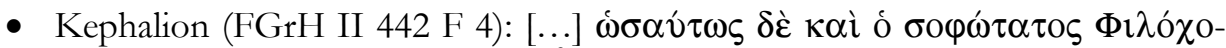

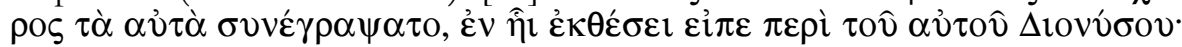

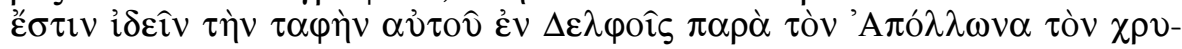

\footnotetext{
772 Auch in Hom. h. Ap. 388-546 werden Kreter mit der Frühzeit des Heiligtums verbunden.
} 
бov̂v. - »So aber schrieb der sehr weise Philochoros an jener Stelle, an der er über denselben Dionysos sprach, dass man sein Grab in Delphi in der Nähe des goldenen Apollon sehen kann«.

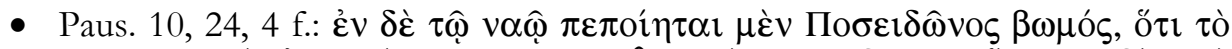

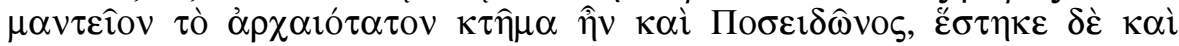

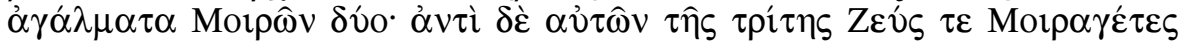

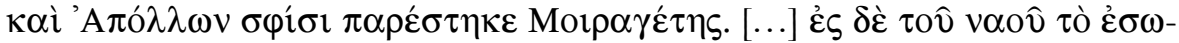

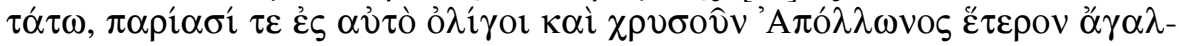

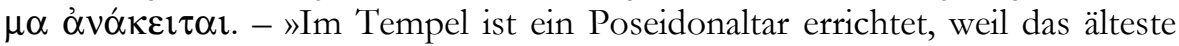
Orakel auch Besitz des Poseidon war. Es stehen da auch zwei Statuen der Moiren, und statt der dritten steht Zeus Moiragetes (»Moirenführer«) und Apollon Moiragetes (»Moirenführer«) neben ihnen. [...] In das Innerste des Tempels dürfen nur wenige eintreten, und es ist dort eine andere goldene Statue des Apollon aufgestellt«. (F. Eckstein - P. C. Bol)

Darstellungen: Kaiserzeitliche Münzen aus Delphi zeigen verschiedene Apollontypen, die die Forschung mit dem überlieferten alten Bild des Gottes in Verbindung gebracht hat. Einige geben einen unbekleideten Apollon wieder. Er steht z. T. in einem Tempel. Der Gott steht aufrecht mit dem Gewicht auf dem linken Standbein. Das rechte Bein ist auf einigen Münzen angewinkelt nach hinten gesetzt. Andere Münzbilder zeigen anscheinend denselben Typus, jedoch steht der Gott hier auf zwei gestreckten Beinen. Er stützt sich bei beiden Varianten mit dem linken Unterarm auf eine Säule. Die rechte Hand hat er ausgestreckt und hält darin eine Phiale. Der zweite Typus zeigt einen gleichfalls unbekleideten Apollon. Er steht auf dem linken Bein. Das entlastete rechte Bein ist angewinkelt vorgesetzt. Der rechte Arm hängt an der Seite herab. Der Gegenstand in der Hand ist nicht erkennbar. Mit dem linken Ellenbogen lehnt sich der Gott eventuell auf einen Dreifuß. Weitere Münzen zeigen Apollon langgewandet als Kitharaspieler. Er steht nach links ins Profil gewandt. Das linke Bein ist das Standbein, das rechte Spielbein ist leicht nach hinten gesetzt. In der erhobenen Linken hält der Gott die Kithara, auf der er mit der Rechten spielt. Um den Kopf trägt er einen Kranz oder eine Binde ${ }^{773}$.

Baubefund: Der Baubefund liefert eine reiche Geschichte des Tempelbaus in Delphi. Der Ort diente bereits in der Bronzezeit als Heiligtum ${ }^{774}$. Der Kult soll laut den antiken Quellen ursprünglich der Gaia gegolten haben und später durch den Kult des Apollon überlagert und verdrängt worden sein ${ }^{775}$. Der Apollonkult ist

\footnotetext{
773 Imhoof-Blumer - Gardner 1964, 119-122 Taf. X Nr. 24-26; Taf. Y Nr. 1. 4; Roux 1971 Abb. 36; J.-F. Bommelaer, Guide de Delphes. Le site (Paris 1991) Abb. 2 i.

774 Roux 1971, 25. 31. 37-39; Maass 1993, 3. 56.

775 Hom. h. Ap. 244-304. 355-374; Kall. h. 2, 100-104; Paus. 10, 5, 5-8; Plut. de Pyth. Or. 402d-e; Vgl. auch die Forschungsliteratur: P. Hoyle, Delphi und sein Orakel. Wesen und Bedeutung des antiken Heiligtums (Wiesbaden 1968) 76 f.; Roux 1971, 25-30. 40. 47; Maass 1993, 3; Gruben
} 
spätestens seit dem 7. Jahrhundert v. Chr. gesichert ${ }^{776}$. Ein erster Tempel, laut Pausanias von Trophonios und Agamedes erbaut, ist für die Zeit um 600 v. Chr. nachgewiesen. Er brannte in der Mitte des 6. Jahrhunderts v. Chr. ab. Der Legende nach besaß er drei Vorgänger aus Lorbeer, Wachs und Federn sowie Erz ${ }^{777}$. Nach dem Brand errichtete man in den letzten Jahrzehnten des 6. Jahrhunderts v. Chr. einen Neubau mit finanzieller Hilfe der Alkmeoniden aus Athen, gleichfalls ein dorischer Peripteros. Er stürzte 373 v. Chr. ein. Der danach an derselben Stelle begonnene Neubau, der sich im Grundriss stark an seinen Vorgänger orientierte, wurde um 320 v. Chr. fertig gestellt. Zahlreiche Abrechnungsurkunden belegen detailliert den Bauvorgang. Ein Brand machte einen erneuten Wiederaufbau im 1. Jahrhundert v. Chr. nötig ${ }^{778}$.

Ergebnis: Das alte Bild des Apollon von Delphi soll laut Pindar aus einem einzigen Stück vermutlich eines Baumstammes gefertigt worden sein, während Clemens Alexandrinus ein Agalma in Gestalt einer Säule wie für die argivische Hera und den Dionysos Kadmeios in Theben überliefert. Beide Quellen können sich auf ein und dasselbe Bild beziehen. Dieses könnte demnach ein sehr einfaches Holzbild gewesen sein, wenn man auch nicht unbedingt davon ausgehen muss, dass es gänzlich anikonisch gewesen ist.

Weitere Quellen erwähnen jüngere Bilder des Gottes. Athenagoras überliefert ein Werk des Theodoros und Telekles, zwei Bildhauer der archaischen Zeit, die laut Diodor Söhne des Rhoikos waren, des Architekten des ersten Dipteros im Heraheiligtum von Samos ${ }^{779}$. Pausanias, Philochoros und Kephalion überliefern wiederum ein goldenes Bild ohne Angabe der Datierung ${ }^{780}$. Damit kann vielleicht das Werk der Rhoikossöhne gemeint sein.

Wie schon bei der Artemis von Ephesos stellt sich die Frage, ob es wirklich mehrere Bilder des Gottes nebeneinander in einem Tempel gegeben hat. Es wäre möglich, dass dem von Theodoros und Telekles in archaischer Zeit geschaffenem Bild durch Legendenbildung ein höheres Alter zugeschrieben wurde. Für die Artemis von Ephesos wurde dies für unwahrscheinlich erklärt und verschiedene Statuen angenommen ${ }^{781}$. Für die Bilder des Apollon von Delphi liegen zwar keine

2001, 68.

776 Maass 1993, 5. 126-136.

777 Paus. 10, 5, 9-13.

778 Roux 1971, 25-54; J.-F. Bommelaer, Guide de Delphes. Le site (Paris 1991) 14-24. 92-102. 170-184; Gruben 2001, 67-81; Maass 1993, bes. 89-126. Vgl. die Quellen: Hom. h. Ap. 294 f.; Pind. Paian fr. 8; Hdt. 2, 180; Paus. 10, 5, 9-13; Strab. 9, 3, 9.

779 Diod. 1, 98, 5-9.

780 Aus der Formulierung bei Pausanias geht hervor, dass sich in dem Tempel anscheinend noch eine weitere Statue des Gottes, ebenfalls aus Gold, befunden haben muss. Es sei denn, Pausanias bezog sich dabei auf das Bild des Apollon Moiragetes, das er vor dem Tempel gesehen hat.

781 s. Kap. 12.9. 
stichhaltigen Argumente vor, doch lässt der bis in die geometrische Zeit zurückreichende Kultbetrieb die Vermutung zu, dass es bereits vor der archaischen Zeit eine Apollonstatue gegeben haben kann. Möglicherweise war die Statue des Theodoros und Telekles auch ein Ersatzbild für ein älteres, verlorenes. Das Heiligtum war im Laufe der Zeit von verschiedenen Unglücken heimgesucht worden, die mehrfach den Neubau des Tempels erzwangen, wie der Baubefund zeigt. Da die überlieferten Bilder aber bis in die Spätantike Erwähnung in der antiken Literatur fanden, erscheint es durchaus denkbar, dass sie nicht mit ihren Tempeln untergegangen, sondern gemeinsam in dem Heiligtum aufgestellt gewesen sind.

Kaiserzeitliche Münzen aus Delphi sollen nach Ansicht der Forschung eines der Bilder des Apollon in Delphi wiedergeben ${ }^{782}$. Da es sich bei den durch die antiken Schriftquellen überlieferten Statuen um archaische oder sogar noch ältere Bilder handelt, erscheint es ausgeschlossen, dass einer der auf den Münzen dargestellten Typen diese wiedergeben. Die auf den Münzen dargestellten Typen können nicht in diese Zeit datiert werden. Einzig das bei Pausanias, Philochoros und Kephalion überlieferte goldene Bild ist nicht durch die Quellen datiert. Es kann sich dabei aber um das Bild des Theodoros und Telekles handeln. Diese Statue wäre dann ebenfalls in die archaische Zeit zu datieren, was eine Identifizierung mit den durch die Münzen bezeugten Typen unwahrscheinlich macht.

\subsection{Apollon auf Delos}

\section{Schriftquellen zu dem alten Bild:}

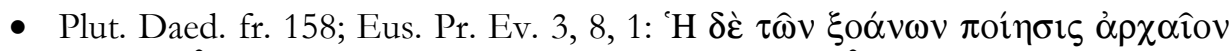

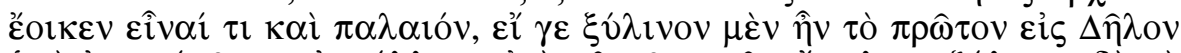

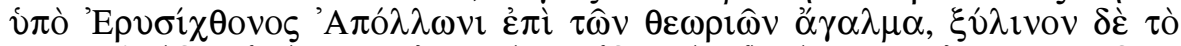

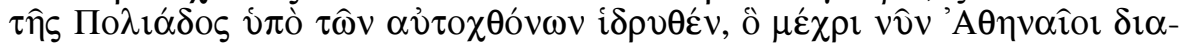

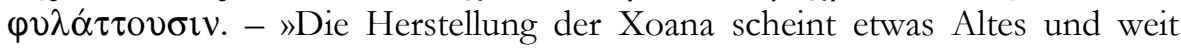
Zurückreichendes zu sein, wenn das erste Agalma, das nach Delos zu Apollon geschickt wurde von Eurysichthon aufgrund der Feste aus Holz gewesen ist, und wenn das der Polias aus Holz ist, das die autochthonen Einwohner errichtet hatten und die Athener bis heute bewahren«.

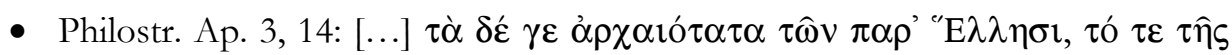

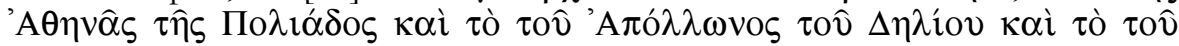

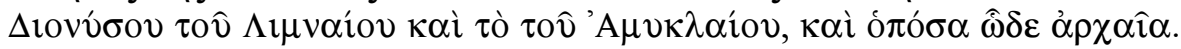
- $\gg[. .$.$] solche [Bilder], die bei den Hellenen das höchste Alter aufweisen. Es$ sind dies die Bilder der Athene Polias, des Apollon von Delos, des Dionysos von Limnai, des Phoibos von Amyklai und ähnliche Statuen aus dieser Zeit«. (V. Mumprecht) 
Schriftquellen zu dem neuen Bild:

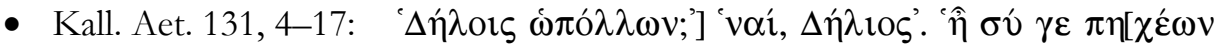

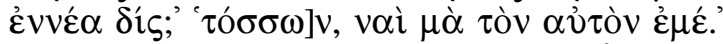

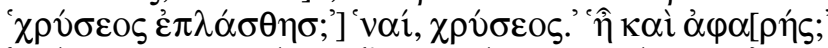

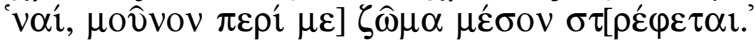

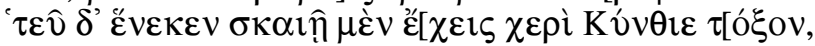

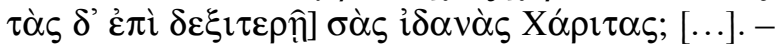
$»\left[{ }^{\circ}\right.$ Der Apollon auf Delos?'] - Ja, der auf Delos. - 'Du bist [zweimal neun Ellen] groß?' - [Genau so viele,] wahrhaftig, bei mir selbst! ['Golden bist du gebildet?'] - Ja, golden. - 'Auch ohne Bekleidung?' [Ja, nur ein Gürtel] ist um meine Mitte gewunden. -

['Weswegen hältst du in der linken] Hand, Kynthios, einen Bogen [und auf der rechten] deine schöngestaltigen Grazien?' [...] «. (M. Asper)

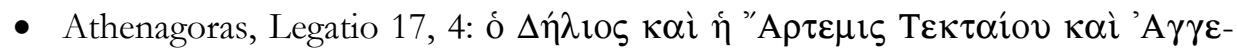

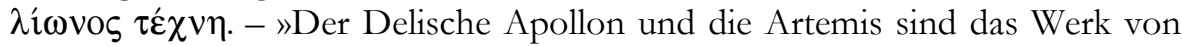
Tektaios und Angelion «.

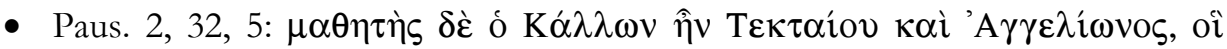

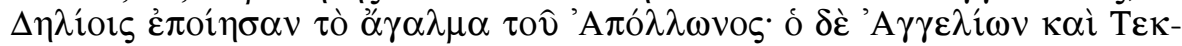

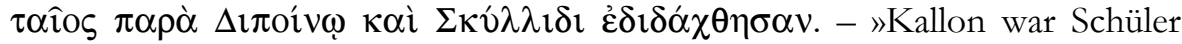
des Tektaios und Angelion, die den Deliern das Kultbild des Apollon herstellten; Angelion und Tektaios hatten bei Dipoinos und Skyllis gelernt«. (F. Eckstein - P. C. Bol)

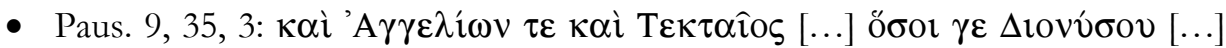

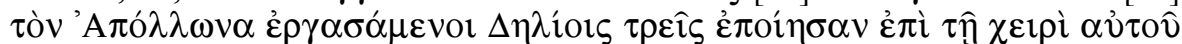
Xópı $\tau \varsigma_{\varsigma}$. - Angelion und Tektaios [...] welche den Deliern den Apollon des Dionysios geschaffen haben, stellten auf seiner Hand drei Chariten dar«. (F. Eckstein - P. C. Bol)

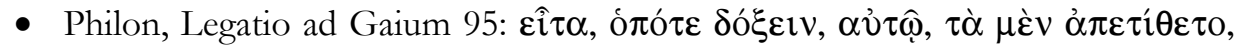

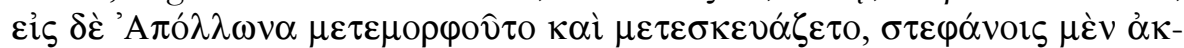

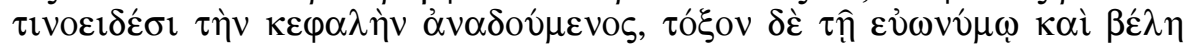

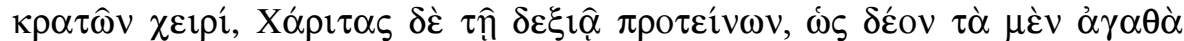

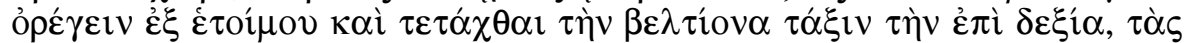

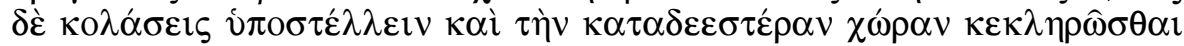

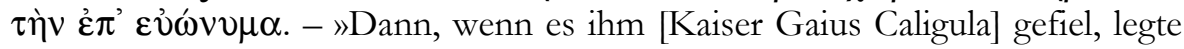
er diese Attribute ab und kleidete sich als Apoll, seinen Kopf umwand er mit einer Strahlenkrone, hielt einen Bogen und Pfeile in der linken Hand und streckte mit der rechten die Grazien hervor um anzuzeigen, dass es richtig für ihn war, die guten Dinge bereit zu halten und das diese die bessere Position auf der rechten Seite erhielten, während der Bestrafung die niedere Position, auf der linken, zugewiesen wird «.

- Macr. Sat. 1, 17, 13: Sed quia perpetuam praestat salubritatem et pestilens ab ipso casus rarior est, ideo Apollinis simulacra manu dextera Gratias gestant, arcum cum sagittis sinistra, quod ad noxam sit pigrior et salutatem manus promptior largiatur. - »Aber, da 
[die Sonne] beständig die Gesundheit erhält und selten Krankheiten sendet, tragen die Statuen des Apollon auf ihrer rechten Hand die Grazien und in ihrer linken Pfeil und Bogen, um zu zeigen, dass die Sonne langsam ist im Bestrafen und dass Apollon viel lieber Gesundheit schenkt«.

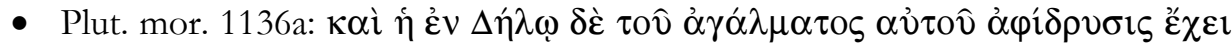

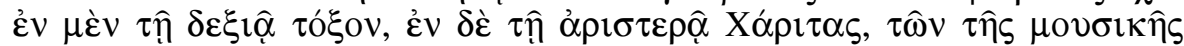

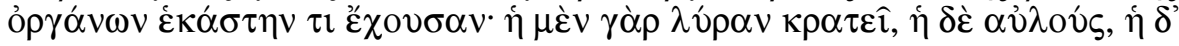

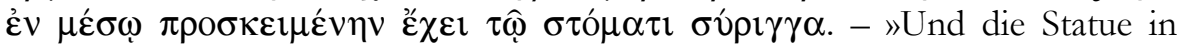
Delos hält einen Bogen in der rechten Hand, und die Grazien in der linken; jede von diesen hält ein Musikinstrument, die eine eine Lyra, die andere Auloi, und die in der Mitte hat hält eine Panflöte an ihre Lippen.«.

Darstellungen: Attische Münzen und Siegelabdrücke aus Delos aus dem 2. und 1. Jahrhunderts v. Chr. zeigen wahrscheinlich das berühmte Bild des Tektaios und Angelion (Abb. 46). Der Gott steht aufrecht mit geschlossenen Beinen. Seine beiden Unterarme sind angewinkelt vorgestreckt. Auf der rechten Hand trägt er die Chariten, die auf einem gemeinsamen tablettartigen Untersatz stehen. In der linken Hand hält der Gott seinen Bogen. Er ist unbekleidet, lange Haarsträhnen fallen ihm auf die Schultern und den Rücken ${ }^{783}$.

Baubefund: Delos ist als Kultstätte für Apollon und Artemis seit dem 1. Jahrtausend v. Chr. bezeugt. Besiedelt war das Gebiet bereits in vorgriechischer Zeit und diente eventuell auch schon zu dieser Zeit als Kultort. Die ersten gesichert als Kultbauten anzusprechenden Gebäude, der Naxieroikos ${ }^{784}$ und der Poros-Tempel ${ }^{785}$, stammen aus dem frühen bzw. späten 6. Jahrhundert v. Chr. Im 3. Jahrzehnt des 5. Jahrhunderts. v. Chr. begann man in unmittelbarer Nähe mit der Errichtung des sog. Großen Tempels, während die älteren Bauten weiterhin Bestand hatten. Seine Fertigstellung zog sich bis zum Ende des 4. Jahrhunderts v. Chr. hin. Im letzten Viertel des 5. Jahrhunderts v. Chr. erfolgte noch einmal ein Neubau, der sog. Tempel der Athener ${ }^{786}$.

783 London, British Museum: Imhoof-Blumer - Gardner 1964, 144 Taf. CC Nr. 14; weitere bei Lacroix 1949, 202-205 Taf. 17, 1 f.; M. Thompson, The New Style Silver Coinage of Athens (New York 1961) 226-130 Taf. 64 f.; Imhoof-Blumer - Gardner 1964, 144 Taf. CC Nr. 12-15; Marcadé 1969, 161-163 Taf. 28; Bruneau 1970, 57 Taf. 1, 3; Bruneau - Ducat 1983, Abb. 56; M.-F. Boussac, Les sceaux de Délos I (Paris 1992) 21-29 Nr. A $\pi$ 1-82 Taf. 3-7; Ph. Bruneau u. a. (Hrsg.), Délos. Ile sacrée et ville cosmopolite (Paris 1996) Abb. S. 21.

784 Bruneau - Ducat 1983, 49. 121 f.; D. Mertens, Gnomon 58, 1986, 431-436; P. Courbin, Le temple archaïque de Délos, BCH 111, 1987, 63-78; Gruben 1997, 301-350.

785 Courby 1931, 215; Gallet 1958, 138; Ch. Picard, Deux temples successifs de la Purification, à Délos, RA 1959, 2, 1959, 113-117; Bruneau 1970, 53; Roux 1979, 112; Ph. Bruneau, Deliaca (IV), BCH 105, 1981, 100; Bruneau - Ducat 1983, 48. 128; Gruben 1997, 372-376.

786 Courby 1931; Gallet 1958; Bruneau - Ducat 1983, 17 f. 35 f. 119-123. 128-133; Ph. Bruneau u. a. (Hrsg.), Délos. Ile sacrée et ville cosmopolite (Paris 1996) 20-26; Gruben 1997; Gruben 2001, 
Ergebnis: Die Quellen schreiben dem hölzernen Bild des Apollon auf Delos ein mythisch hohes Alter $\mathrm{zu}^{787}$. Andere nennen hingegen Tektaios und Angelion als Bildhauer eines goldenen Bildes, zwei Künstler, deren Existenz für das 6. Jahrhundert v. Chr. gesichert ist ${ }^{788}$. Daher stellt sich die Frage, ob einem archaischen Bild durch Legendenbildung ein höheres Alter zugeschrieben worden ist. Die überlieferten Materialien lassen sich durchaus zu einem vergoldeten Holzbild vereinen ${ }^{789}$. Das schon lange nachgewiesene höhere Alter der Kultstätte lässt jedoch zumindest die Frage aufkommen, ob es bereits vor dem 6. Jahrhundert v. Chr. ein Bild des Gottes gegeben hat. Die Anfänge des Kultes konnten zwar noch nicht sicher bestimmt werden, reichen jedoch auf jeden Fall vor diese Zeit zurück ${ }^{790}$, so das das Vorhandensein eines Bildes vor dem 6. Jahrhundert v. Chr. nicht ausgeschlossen kann ${ }^{791}$. Sollten mehrere Bilder überliefert sein, hätten wir hiermit neben den Heiligtümern der Hera von Samos, der Artemis von Ephesos und des Apollon von Delphi ein weiteres Beispiel für die Aufstellung eines jüngeren Bildes neben einem älteren bereits in archaischer Zeit ${ }^{792}$. Für das Heiligtum der Aphaia auf Aigina ist die Errichtung eines zweiten Bildes für den Übergang von der archaischen zur klassischen Epoche gesichert ${ }^{793}$.

Der Standort das oder der Bilder ist umstritten. Vorgeschlagen wurden der Naxieroikos ${ }^{794}$, der Porostempel ${ }^{795}$ und der Tempel, der im Guide de Délos von P. Bruneau und J. Ducat die Nummer 42 trägt $^{796}$. Das zuletzt genannte Gebäude wurde erst in der 1. Hälfte des 4. Jahrhunderts v. Chr. gebaut ${ }^{797}$. Es entfällt demnach bei der Suche nach dem Aufstellungsort der Bilder. Für die übrigen Gebäude kann keine präzise Aussage getroffen werden. In der Forschung wurde auch eine

153-160.

787 Zu dem mythischen Stifter s. RE VI (1909) 573 f. s. v. Erysichthon (O. Kern); DNP IV (1998) 106 s. v. Erysichthon (E. Kearns).

788 Zu Tektaios und Angelion s. Bruneau 1970, 56 f.; Bald Romano 1980, 174 f.; Pollitt 1990, 22.

789 So auch Gruben 2001, 158.

${ }^{790}$ s. die in Anm. 784 genannte Literatur.

791 Ähnlich auch Gruben 1997, 293.

792 Ebenso Nick 2002, 95.

793 s. Kap. 12.14.

794 P. Courbin, L’oikos des Naxiens, Délos 33 (Paris 1980) 133; Bruneau - Ducat 1983, 123 ; D. Mertens, Rez. zu P. Courbin, L’oikos des Naxiens, Délos 33 (Paris 1980) Gnomon 58, 1986, 431-436; P. Courbin, Le temple archaïque de Délos, BCH 111, 1987, 63-78; R. Étienne, The Development of the Sanctuary of Delos: New Perspectives, in: M. Stamatopoulou - M. Yeroulanou (Hrsg.), Excavating Classical Culture. Recent Archaeological Discoveries in Greece (Oxford 2002) 285-293.

795 Gallet 1958, 140; Marcadé 1969, 162; Bruneau 1970, 58; Roux 1979; Ph. Bruneau, Deliaca (IV), BCH 105, 1981, 79-125; H. Gallet de Santerre, L'oikos des Naxiens à Délos était-il un temple?, BCH 108, 2, 1984, 671-693; P. Karakatsanis, Studien zu archaischen Kolossalwerken (Frankfurt 1986) 32; Gruben 1997, 287-293; Gruben 2001, 157.

796 Roux 1979.

${ }^{797}$ Ebenda 122; Ph. Bruneau, Deliaca (IV), BCH 105, 1981, 82. 
spätere Versetzung des alten Bildes vorgeschlagen - dabei ging man von der Existenz nur eines alten Apollonbildes aus. Es wurden der `Große Tempek ${ }^{798}$ und der $>$ Tempel der Athener ${ }^{799}$ in Betracht gezogen. Im >Tempel der Athener gab es eine große halbkreisförmige Statuenbasis, die dort sekundär errichtet worden sein soll. Der Bau wird deshalb mit dem inschriftlich überlieferten \Tempel der sieben Statuen identifiziert ${ }^{800}$. Für eine Versetzung der Basis konnten aber keine Beweise gefunden werden ${ }^{801}$. Deshalb liegen keine Anhaltspunkte vor, die sieben Statuen sicher zu benennen, noch eines der alten Bilder unter sie zu zählen. Es war eine selbständige Gruppe, in die am wahrscheinlichsten ein weiteres Bild des Apollon, außerdem Artemis und Leto als Hauptgottheiten von Delos einzureihen sind. Zumindest eine Statue der Leto ist durch ihr geweihte Kränze, die nach Ausweis antiker Inschriften im >Tempel der Athener aufgewahrt wurden, wahrscheinlich ${ }^{802}$. Die Umsetzung eines der alten Apollonbilder ist deshalb nicht sicher. Eine Inschrift aus

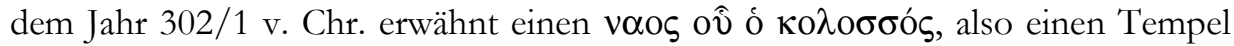

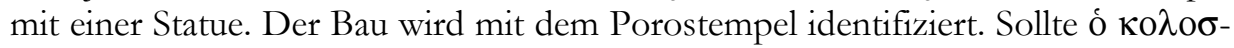
бós eines der alten Apollonbilder bezeichnen, stand es noch in hellenistischer Zeit an seinem angestammten Platz, falls dies der Porostempel gewesen is $\mathrm{t}^{803}$.

\subsection{Aphaia auf Aigina}

Schriftquellen zu dem alten Bild:

- IG IV 1580 (Gründungsurkunde des Heiligtums, um 550 v. Chr.)

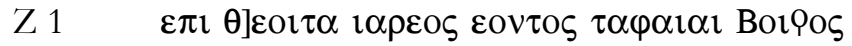

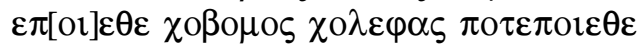

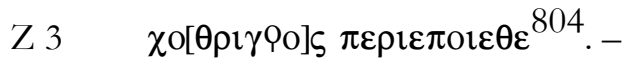

798 Marcadé 1969, 161; Bruneau 1970, 58; Bald Romano 1980, 179 f.; Bruneau - Ducat 1983, 131 f.; H. Gallet de Santerre, L'oikos des Naxiens à Délos était-il un temple?, BCH 108 II, 1984, 675; Gruben 2001, 159; Nick 2002, 107.

799 O. Fritsch, Delos. Die Insel des Apollon (Gütersloh 1908) 29 f.; Gallet 1958, 251. 271. 302; Mylonas Shear 1963, 399-402; D. Mertens, Gnomon 58, 1986, 431-436.

${ }^{800}$ IG XI, 2, 145 Z 61: [o]

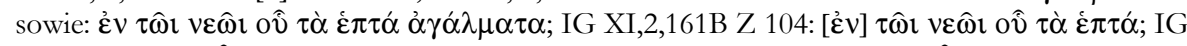

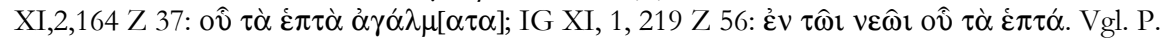
Roussel, Délos. Colonie athénienne (Paris 1916) 389; Courby 1931, 189-194. 227; Gallet 1958, 302; Ch. Picard, Deux temples successifs de la Purification, à Délos, RA 1959, 2, 1959, 115; Mylonas Shear 1963, 402; Bruneau 1970, 53. 60; Roux 1979, 112; Bald Romano 1980, 176; Bruneau - Ducat 1983, 129; Lapatin 2001, 105-109.

801 Bruneau 1970, 60 f. Lapatin 2001, 105-107 datiert die Basis aufgrund der Technik in das 5. Jahrhundert v. Chr. und damit in die Erbauungszeit des jüngeren Tempels.

802 Bald Romano 1980, 177; Lapatin 2001, 107 f.

803 IG XI, 145 Z 24; Vgl. Courby 1931, 227; Bald Romano 1980, 176 f. 187 Anm. 70; Gruben 1997, 287-293. Laut Bruneau 1970, 53 f. handelt es sich um einen bisher nicht identifizierten Bau.

804 Nach der Rekonstruktion von Williams 1982. 
Z 1 "Zur Zeit, als (Th)eoites Priester war, wurde der Aphaia das Haus gebaut und der Altar; das Elfenbein (-kultbild?) wurde hinzugemacht

Z 3 und die Umhegung wurde herumgemacht«. (Gruben 2001, 122)

Erhaltene Fragmente: D. Ohly, dessen Forschungen wir die umfangreichsten Kenntnisse des Heiligtums der Aphaia von Aigina verdanken, hat einige Statuenfragmente als Teile des jüngeren Bildes der Aphaia gedeutet, darunter einen unbekleideten überlebensgroßen rechten Arm aus Marmor. Dieser war erhoben und gebeugt. Die Finger sind gekrümmt und hielten einst einen stabartigen Gegenstand, z. B. eine Lanze. Des Weiteren sind ein Auge aus Elfenbein sowie eine Schlange aus Blei, die einst zur Kleidung oder einem Attribut gehört haben muss, erhalten. Daraus rekonstruiert D. Ohly eine Akrolithstatue im Promachos-Typus ${ }^{805}$.

Baubefund: Der erste Tempel der Aphaia von Aigina wurde in der 1. Hälfte des 6. Jahrhunderts v. Chr. errichtet. Sein Inneres konnte bisher nicht erforscht werden, da der jüngere Tempel der zweiten Phase genau darüber liegt ${ }^{806}$. Der Kult selbst scheint älter zu sein, eine Kontinuität über die sog. Dunklen Jahrhunderte hinweg ist aber noch nicht nachgewiesen ${ }^{807}$. Der ältere Tempel wurde nach einem Brand um 500 v. Chr. durch einen Neubau ersetzt, der bis auf verstreute Architekturglieder die Überreste des alten Baus vollständig unter sich begrub. Der Neubau besaß eine große Statuenbasis in der Mitte der Cella. Eine weitere, wesentlich kleinere Basis mit einem Einzapfloch für eine kleine Statue ist an der Rückwand der Cella erhalten ${ }^{808}$.

Ergebnis: Das Heiligtum der Aphaia auf Aigina besaß dem Baubefund und den Quellen nach ebenfalls zwei Bilder der Göttin aus unterschiedlichen Zeiten. In der ersten architektonisch fassbaren Phase war der Göttin in der 1. Hälfte des 6. Jahrhun-

805 Athen, NM 4506: D. Ohly, Glyptothek München. Griechische und römische Skulpturen ${ }^{2}$ (München 1972) 53 f. mit falscher Deutung der Statue als Athena. Richtig gedeutet als Aphaia wird das Bild von LIMC I (1981) 876 f. s. v. Aphaia (D. Williams); Bankel 1993, 1; Lapatin 2001, 61. Auch Ohly 1977, 16 f. 40 Anm. 16 hat darauf hingewiesen, dass es keinen Hinweis auf einen Athenakult in diesem Heiligtum gab, allerdings ohne seine Identifizierung der Akrolithstatue zu überdenken. Abbildungen finden sich bei E. Walter-Karydi, Die Äginetische Bildhauerschule (Mainz 1987) Taf. 21 f. 25 und D. Ohly, Die Aegineten II-III (München 2001) Taf. 235-238.

806 Furtwängler 1906, 151; F. Eckstein, Neue archäologische Forschungen auf Aigina, AntW 3, 2, 1972, 22-28; E.-L. Schwandner, Der ältere Aphaiatempel auf Aegina, in: U. Jantzen (Hrsg.), Neue Forschungen in griechischen Heiligtümern. Symposion in Olympia 10. -12. Oktober 1974

(Tübingen 1976) 103-120; Ohly 1977, 26; E. L. Schwandner, Der ältere Porostempel der Aphaia auf Aegina (Berlin 1985) 112. 129; Gruben 2001, 122.

807 Furtwängler 1906, 370-375. 434-436. 470 f.; Ohly 1977, 24; U. Sinn, Aphaia und die >Aegineten<. Zur Rolle des Aphaiaheiligtums im religiösen und gesellschaftlichen Leben der Insel Aigina, AM 102, 1987, 130-167; Bankel 1993, 1; K. Pilafidis-Williams, The Sanctuary of Aphaia on Aigina in the Bronze Age (München 1998); Gruben 2001, 122.

808 Furtwängler 1906, 66 f.; Ohly 1977, 30; E. L. Schwandner, Der ältere Porostempel der Aphaia auf Aegina (Berlin 1985) 1. 72; Bankel 1993, 1. 158. 163.169 f.; Gruben 2001, 121-127. 
derts v. Chr. ein Tempel errichtet worden. Die oben genannte archaische Inschrift, die den Bau eines Tempels und eines Altars erwähnt, wird von der Forschung auf diesen ersten Bau bezogen. In der Inschrift wird darüber hinaus ein nicht näher bezeichneter Gegenstand aus Elfenbein angeführt ${ }^{809}$. Damit kann ein Bild der Aphaia gemeint sein, bei dem es sich dann am ehesten um einen Akrolith gehandelt hat ${ }^{810}$.

Nach der Zerstörung des ersten Tempels wurde in spätarchaischer Zeit der aufgrund seines Skulpturenschmuckes heute noch berühmte jüngere Tempel errichtet. Das alte Bild scheint nicht zerstört worden zu sein, denn in dem Neubau gab es an der Rückwand der Cella eine kleine Basis mit einem Einzapfloch, geeignet für die Aufstellung eines kleinen Akrolithbildes. Es gibt zwar keinen Beweis, doch sprechen auch keine Gründe dagegen, sich hier das `Elfenbein denken ${ }^{811}$. Man hat festgestellt, dass das Material der Basis nicht dem des neuen Tempels entspricht. Vielleicht stammt auch sie aus dem ersten Tempel, was die Ansicht verstärken würde, dass das alte Bild weiter existiert habe ${ }^{812}$. In der Mitte der Cella hat man gleichzeitig mit dem neuen Tempel eine große Basis für die Aufstellung einer neuen, wesentlich größeren Statue errichtet. Es muss sich um ein kostbares Bild gehandelt haben, da es durch Schranken geschützt wurde wie das Zeusbild in Olympia. D. Ohly weist ihm einige überlebensgroßen Fragmente eines Akrolithbildes zu, die er zu einer Statue im Promachos-Typus rekonstruiert ${ }^{813}$. Das ältere und das jüngere Bild standen in diesem Heiligtum offenbar nah beieinander im selben Tempel, wobei das jüngere Bild den prominenteren Standort erhalten hat.

\subsection{Chariten in Orchomenos}

\section{Schriftquellen:}

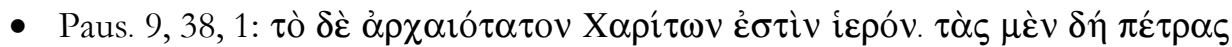

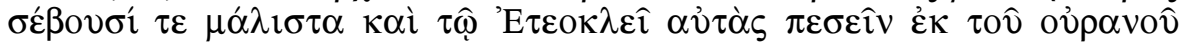

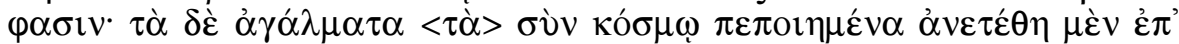

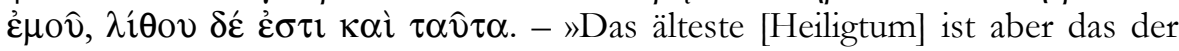
Chariten. Die Steine verehren sie am meisten und sagen, sie seien dem Eteokles vom Himmel gefallen; die sorgfältig gearbeiteten Statuen wurden erst

\footnotetext{
809 Nach der Rekonstruktion von Williams 1982.

810 Ohly 1977, 17; Williams 1982, 64 f.; E. Walter-Karydi, Die Äginetische Bildhauerschule (Mainz 1987) 12; Gruben 2001, 122; Lapatin 2001, 56. Furtwängler 1906, 3. 481 hatte in dem Elfenbein Schmuck für Türen oder Wände eines noch älteren Vorgängerbaus gesehen, der bisher aber noch nicht nachgewiesen werden konnte.

811 So D. Ohly, Glyptothek München. Griechische und römische Skulpturen² (München 1972) 53 f.; LIMC I (1981) 876 s. v. Aphaia (D. Williams); Williams 1982, 65 Abb. 5; Bankel 1993, 144 Taf. 54; Lapatin 2001, 56 Abb. 112 f.; G. I. Despinis, Zu Akrolithstatuen griechischer und römischer Zeit (Göttingen 2004) 252.

812 Lapatin 2001, 56.

813 s. Anm. 805.
} 
zu meiner Zeit aufgestellt, auch sie sind aus Stein«. (F. Eckstein - P. C. Bol)

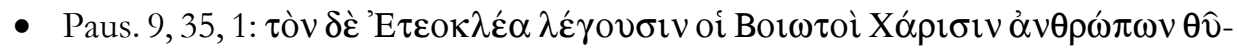

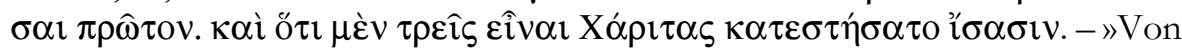
diesem Eteokles sagen die Boioter, daß er als erster Mensch den Chariten geopfert habe. Auch wissen sie, daß er drei Chariten einsetzte«. (F. Eckstein - P. C. Bol)

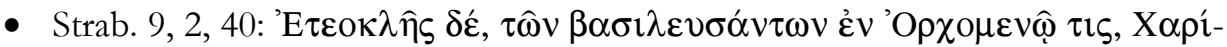

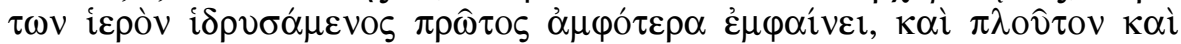
$\delta u ́ v \alpha \mu \imath v$. - »Und Eteokles, einer der Könige von Orchomenos, lässt mit seiner Errichtung des Chariten-Heiligtums zuerst beides, Reichtum sowohl als Macht, erkennen«. (St. Radt)

Darstellungen/Baubefund: Das Heiligtum der Chariten in Orchomenos wurde bisher noch nicht untersucht. Darstellungen der Bilder sind ebenfalls nicht bekannt.

Ergebnis: Die drei Chariten sind in Orchomenos laut Pausanias in uralten heiligen Steinen, also in anikonischen Kultmalen verehrt worden, die laut seiner Aussage bis in die Zeit des mythischen orchomenischen Königs Eteokles zurückgereicht haben sollen ${ }^{814}$. In der mittleren Kaiserzeit - wenn man die Angabe des Pausanias wörtlich nimmt und wogegen nichts spricht ${ }^{815}$, zumindest aber deutlich später als der Beginn des Kultes - hat man neben den alten Steinen neue Bilder aufgestellt.

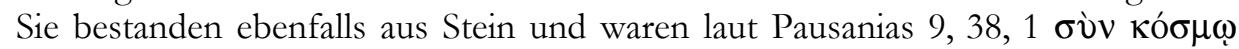
$\pi \varepsilon \pi \mathrm{o} \eta \mu \varepsilon \dot{\varepsilon} \nu \alpha \rightarrow$ sorgfältig gearbeitet«, also wahrscheinlich vollkommen menschlich gebildete Statuen in zeitgenössischem Stil und aus Marmor.

Obwohl es sich bei den alten Bildern nur um un- oder wenig bearbeitete Steine gehandelt zu haben scheint, wie aus der Gegenüberstellung mit den sorgfältig gefertigten jüngeren Statuen hervorgeht, galten sie als verehrungswürdiger als diese und wurden nicht von den künstlerisch wertvolleren Statuen verdrängt. Die alten und die jüngeren Bilder standen gleichzeitig in demselben Heiligtum. Da der Kultbezirk bisher noch nicht archäologisch untersucht wurde, bleiben Details zum Aufstellungsort der Bilder und ihrem Verhältnis zueinander zurzeit noch ungeklärt.

\subsection{Trophonios in Lebadeia}

\section{Schriftquellen:}

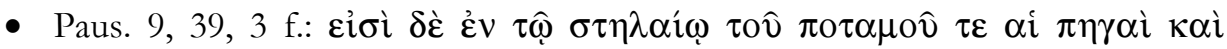

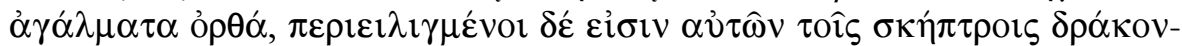

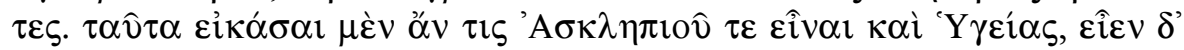

${ }^{814}$ Zu Eteokles s. RE VI (1909) 707 s. v. Eteokles (E. Bethe); DNP IV (1998) 160 s. v. Eteokles (R. Bloch).

815 Vgl. Chr. Habicht, Pausanias und seine »Beschreibung Griechenlands« (München 1985) 181-185. 


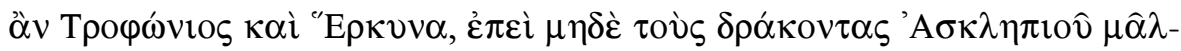

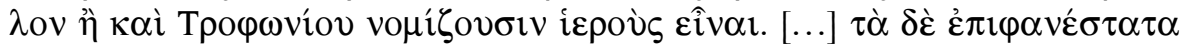

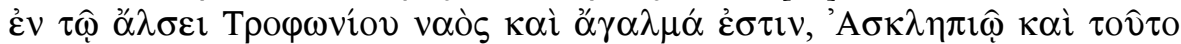

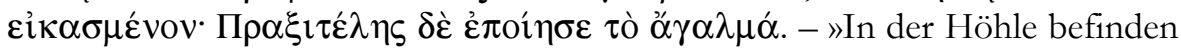
sich die Quellen des Flusses und aufrecht stehende Statuen, um deren Szepter sich Schlangen ringeln. Man könnte danach vermuten, daß es Asklepios und Hygieia seien, es mögen aber auch Trophonios und Herkyna sein, da man meint, auch die Schlangen seien dem Asklepios nicht mehr heilig als dem Trophonios [...] Das Hervorragendste im Hain des Trophonios ist ein Tempel und Kultbild, auch dies dem Asklepios ähnlich; Praxiteles schuf das Kultbild«. (F. Eckstein - P. C. Bol)

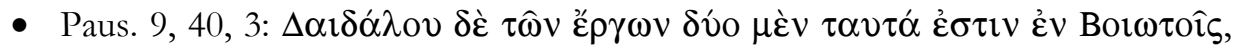

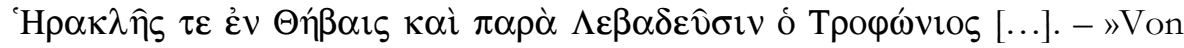
den Werken des Daidalos existieren also diese beiden in Boiotien, ein Herakles in Theben und in Lebadeia der Trophonios [...]«. (F. Eckstein - P. C. Bol)

- Plin. nat. 34, 66: itaque optume expressit Herculem Delphis et Alexandrum Thespiis venatorem et proelium equestre, simulacrum ipsum Trophonii ad oraculum, quadrigas complures, equum cum fiscinis, canes venantium. - $\gg \mathrm{Er}$ [Euthykrates] bildete daher ganz hervorragend einen Herakles zu Delphi und einen Alexander als Jäger zu Thespiai, einen Reiterkampf, eine Statue des Trophonios bei dessen Orakel, mehrere Viergespanne, ein Pferd mit Körben und Jagdhunde«. (R. König)

Darstellungen/Baubefund: Bisher sind keine gesicherten Darstellungen bekannt. Auch das Heiligtum ist bisher nicht systematisch untersucht worden. Es lag südlich der Stadt in einer Schlucht, in der sich die bei Pausanias erwähnten Quellen befinden. Die bisher gefundenen Reste von Gebäuden sowie Felsbearbeitungen konnten noch nicht eindeutig den aus der Beschreibung bei Pausanias bekannten Teilen des Heiligtums wie dem heiligen Hain mit dem Tempel, der Höhle mit den Statuen sowie dem Orakelbezirk zugewiesen werden ${ }^{816}$.

Ergebnis: In dem heiligen Hain bei Lebadeia gab es mehrere unterschiedliche Bilder des Trophonios. Das älteste Bild soll von Daidalos geschaffen worden sein. Daneben gab es eine weitere Statue in dem Tempel des Kultbezirkes, die das Werk eines spätklassischen oder frühhellenistischen Bildhauers ${ }^{817}$ war und eine stehende Statue in einer Kulthöhle ${ }^{818}$. Die beiden zuletzt genannten Statuen glichen in ihrer

816 P. Bonnechere, Trophonios de Lébadée. Cultes et mythes d'une cité béotienne au miroir de la mentalité antique (Leiden 2003) 7-26.

817 Die Quellen überliefern sowohl Praxiteles als auch Euthykrates, ein Sohn oder Schüler des Lysipp, s. Pollitt 1990, 108 f.; DNP IV (1998) 318 s. v. Euthykrates (R. Neudecker).

${ }^{818}$ Laut Anti 1916, 194 ist das Bild aus der Kulthöhle in einer Statue der Florentiner Uffizien identifiziert worden. Er beruft sich dabei auf W. Amelung, Führer durch die Antiken in Florenz (München 1897) 68-71 Nr. 95. W. Amelung ist sich der Zuordnung jedoch keineswegs sicher. 
Ikonographie Bildern des Asklepios. Deshalb ist sich Pausanias bei der Benennung der Statuen auch unsicher. Doch kann es sich jeweils nur um den Inhaber des Kultortes handeln, da von Pausanias keine weiteren Bilder genannt werden. Deshalb ist es durchaus wahrscheinlich, dass es sich hiermit um ein weiteres Beispiel für doppelte >Kultbilder in ein und demselben Heiligtum handelt. Sie standen in diesem Fall jedoch nicht nebeneinander, sondern an zwei getrennten Kultplätzen innerhalb desselben Heiligtums und verkörperten den Gott an zwei unterschiedlichen, für den Kult wichtigen Orten.

Da die Quellen keine weiteren Angaben zu der Statue in der Höhle liefern kann dieses Bild eventuell mit dem Werk des Daidalos übereinstimmen. Falls es sich um verschiedene Bilder gehandelt hat und alle verehrt worden sind hätten wir hiermit eines der seltenen Beispiele, dass einem alten Bild gleich zweimal ein jüngeres an die Seite gestellt worden ist, wie es auch für das Heraheiligtum von Argos vermutet werden kann ${ }^{819}$.

\subsection{Eros in Thespiai}

\section{Schriftquellen:}

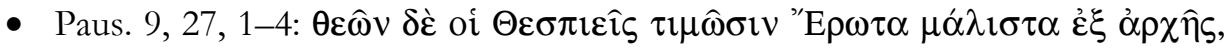

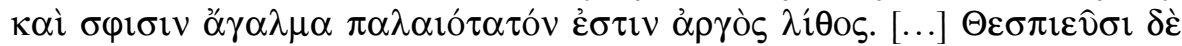

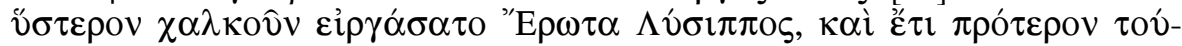

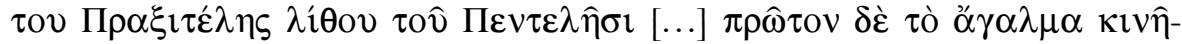

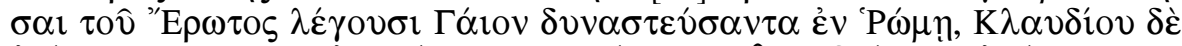

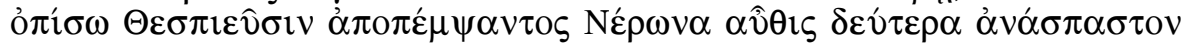

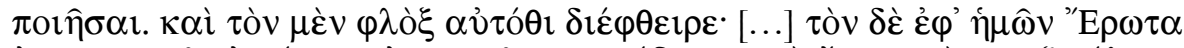

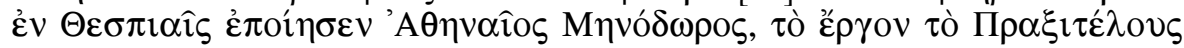

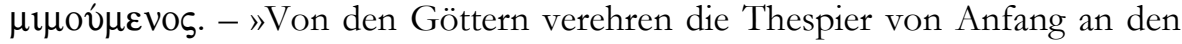
Eros am meisten, und als ältestes Kultbild besitzen sie einen unbearbeiteten Stein. [...] Den Thespiern schuf später Lysippos einen bronzenen Eros und vor diesem Praxiteles einen aus pentelischen Marmor. [...] Zuerst soll Gaios, der in Rom herrschte, das Standbild des Eros fortgenommen haben, und nachdem Claudios es den Thespiern zurückgeschickt habe, Nero es dann wiederum fortgeschleppt haben. Die Statue vernichtete dort eine Feuersbrunst [...] Den jetzt vorhandenen Eros in Thespiai schuf der Athener Menodoros in Nachahmung des Werkes des Praxiteles«. (F. Eckstein - P. C. Bol)

- Plin. nat. 36, 22: eiusdem est et Cupido, obiectus a Cicerone Verri ille, propter quem Thespiae visebantur, nunc in Octaviae scholis positus. - Von ihm [Praxiteles] stammt auch

${ }^{819}$ s. Kap. 12.3. Vgl. auch das Heiligtum der Artemis Brauronia, Kap. 12.10 und des Eros in Thespiai, Kap. 12.17. 
jener Eros, den Cicero dem Verres vorhielt [und] „um dessen Willen man Thespiai besuchte“; er steht jetzt in den Galerien der Octavia«. (R. König)

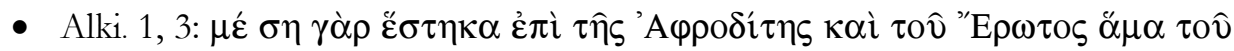
бov̂. - »a, ich [das Standbild der Phryne] stand in der Mitte des Bezirks bei der Aphrodite und deinem Eros«.

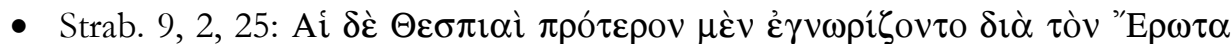

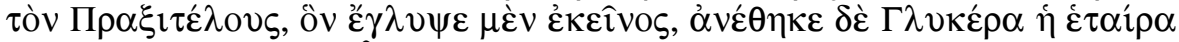

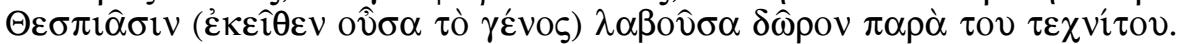

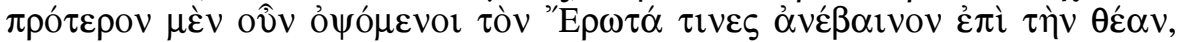

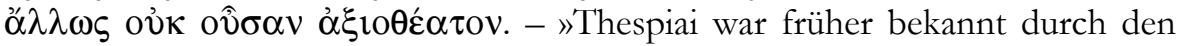
Eros des Praxiteles, den dieser gemeißelt und die Hetäre Glykera in Thespiai (woher sie stammte) geweiht hat, die ihn von dem Künstler als Geschenk bekommen hatte. Früher stiegen manche zu der Stadt (die im übrigen nicht sehenswert ist) hinauf um den Eros zu sehen«. (St. Radt)

- Cic. Verr. 2, 4, 4: Idem, opinor, artifex eiusdem modi Cupidinem fecit illum qui est Thespiis, propter quem Thespiae visuntur, nam alia visendi causa nulla est. - »Derselbe Künstler [Praxiteles] hat, glaube ich, den ganz ähnlichen Cupido zu Thespiai geschaffen, dessentwegen man Thespiai besucht, denn einen anderen Grund, den Ort zu besuchen, gibt es nicht«. (M. Fuhrmann)

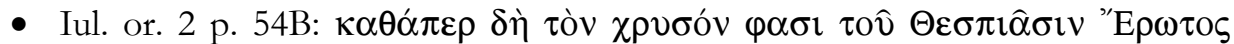

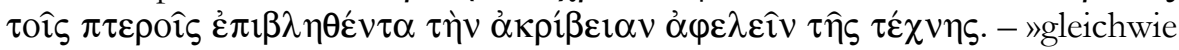
das Gold, das, als es über die Flügel des Eros von Thespiai gebreitet wurde, etwas von der exzellenten Kunstfertigkeit übernahm, so sagen sie«.

Darstellungen/Baubefund: G. E. Rizzo hat einen durch römische Kopien überlieferten Statuentypus des 4. Jahrhunderts v. Chr. als mögliche Überlieferung des Erosbildes des Praxiteles gedeutet ${ }^{820}$. Der jugendliche Gott ist unbekleidet und geflügelt. Er steht mit dem Gewicht auf dem linken Bein. Der rechte Arm war über den Kopf erhoben, wie der Ansatz an der Schulter zeigt. Der linke Arm ist gesenkt und gebeugt. Der Kopf ist bei keiner der römischen Statuen erhalten. Der Ansatz zeigt, dass er leicht nach rechts gewandt war.

Der Eros des Lysipp wird von der Forschung in dem Typus einer geflügelten jugendlichen Figur gesehen, die durch zahlreiche römische Kopien sowie Darstellungen auf Gemmen überliefert ist. Sie zeigen Eros am Übergang von der Kindheit zur Jugend. Er ist unbekleidet, seine Körperhaltung zeigt einen ausgeprägten S-Schwung. Die Beine sind gebeugt. Die Arme hat der Gott weit nach rechts gestreckt, in den Händen hält er den Bogen. Der Kopf ist ebenfalls nach rechts gewen$\operatorname{det}(A b b .47)^{821}$. Das Heiligtum wurde bisher noch nicht archäologisch untersucht.

820 Typus Eros Farnese oder Eros vom Palatin: Rizzo 1932, 20-24 Taf. 27 f.; M. Pfrommer, Ein Eros des Praxiteles, AA 1980, 532-544.

${ }^{821}$ Rom, Kapitolinische Museen Inv. 410: H. Döhl, Der Eros des Lysipp; Frühhellenistische Eroten 
Ergebnis: In Thespiai gab es mehrere unterschiedlich alte Bilder des Eros, die laut Pausanias gleichzeitig in demselben Heiligtum gestanden haben. Das früheste war ein anikonisches Kultmal, das besonders alt gewesen sein soll. In klassischer Zeit beauftragte man berühmte Bildhauer, weitere Bilder anzufertigen. Die von ihnen geschaffenen Typen wurden von der Forschung in kaiserzeitlichen Kopien erkannt.

$\mathrm{Ob}$ alle Erosbilder $>$ Kultbilder gewesen sind, ist nicht zweifelsfrei zu bestimmen. Pausanias erwähnt die Verehrung nur für das alte anikonische Bild. Dieses blieb auch das `Kultmak, als nacheinander die zwei berühmten jüngeren Statuen des Gottes aufgestellt wurden. Bei den Werken des Praxiteles und des Lysipp kann man zunächst an >Weihgeschenker gemäß der allgemein gängigen Definition dieses Begriffes in der Forschung denken. Das Bild des Praxiteles wurde durch eine Nachbildung ersetzt, nachdem es zunächst römischem Statuenraub und anschließend den Flammen zum Opfer gefallen war. Ob es sich lediglich um eine besonders wertvolle Statue gehandelt hat, deren Verlust nicht hingenommen wurde oder um ein sKultbild, dessen Vorhandensein zugleich auch die Fortsetzung des Kultes sicherte, bleibt offen. Der besondere Wert dieser Statue lässt aber zumindest den Gedanken zu, dass es sich um ein verehrtes Bild gehandelt haben kann ${ }^{822}$. Für das dritte Bild des Eros in Thespiai kann man dies nur vermuten. In den vorangegangenen Kapiteln konnten allerdings bereits einige Heiligtümer benannt werden, in denen mehr als ein Bild in den Kult einbezogen worden war. So bezeugen die Kleiderweihungen an verschiedene Statuen, wie im Heiligtum der Artemis Brauronia oder der Hera von Samos, dass mehrere Kultbilder einer Gottheit in einem Heiligtum möglich waren. Auch in Messene ist der Kult für zwei unterschiedliche Bilder der Artemis Orthia gesichert. Deshalb kann zumindest gefragt werden, ob dies auch für die Bilder des Eros in Thespiai gilt, genauso wie auch für die möglicherweise drei Statuen der Hera in Argos und die anderen hier genannten Götterbilder. Eine eindeutige Antwort ist jedoch nicht möglich.

(Diss. Georg-August-Universität Göttingen 1968); Hermary 1986, 880 Nr. 352; J. J. Pollitt, Art in the Hellenistic Age (Cambridge 1986) 48 Abb. 40; B. S. Ridgway, Hellenistic Sculpture I: The Style of ca. 331-200 B.C. (Madison 1990) 75. 99 Anm. 6 Taf. 36; Ridgway 1997, 291; Maderna 2004, 345 f. Abb. 314-317.

822 Cic. Verr. 2, 4, 4 bezeichnet das Bild als consecratus, weshalb die Statue nicht wie viele andere Bilder in republikanischer Zeit dem römischen Kunstraub zum Opfer gefallen war, ein Schicksal, das diese Statue erst in der frühen Kaiserzeit erlitten hat. Denselben Status der Statue kann man zwar für die vorangegangenen Jahrhunderte daraus nicht ableiten, dennoch zeigt dies ihren besonderen Wert an. 


\subsection{Weitere, nicht gesicherte Beispiele unterschiedlich alter Bilder}

\subsubsection{Meter in Athen}

Schriftquellen zu dem neuen Bild:

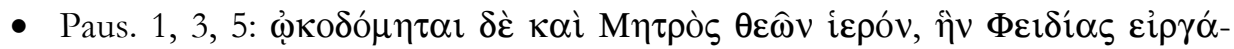
$\sigma \alpha \tau$. $-»$ Auch ein Heiligtum der Göttermutter ist dort errichtet, die Pheidias geschaffen hat«. (F. Eckstein - P. C. Bol)

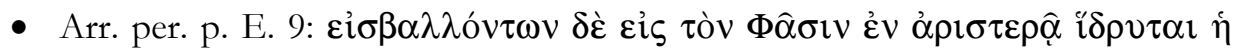

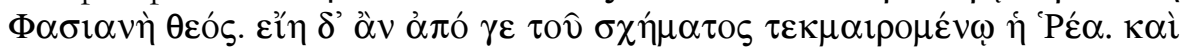

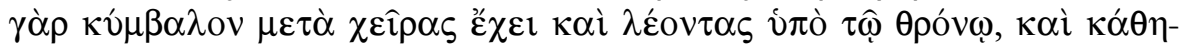

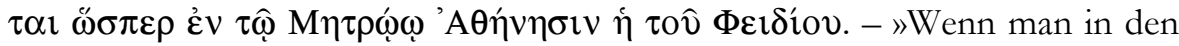
Phasis hineingelangt, befindet sich links die Phasische Göttin. Ihren Attributen nach würde man Rhea sagen. Sie hat ein Cymbalon in den Händen und Löwen an den Füßen des Thrones; sie sitzt wie [die Statue] des Phidias im Metroon von Athen «.

- Plin. nat. 36, 17: est et in Matris Magnae delubro eadem civitate Agoracriti opus. »Auch im Tempel der Kybele in derselben Gemeinde [Athen] steht ein Werk des Agorakritos«. (R. König)

- Zu dem alten Bild liegen keine Schriftquellen vor.

Darstellungen: Den Typus des Agorakritos (bzw. Phidias) sieht die Forschung durch mehrere Marmorstatuen überliefert, deren älteste in die Mitte des 4. Jahrhunderts v. Chr. datiert wird (Abb. 48) ${ }^{823}$. Hellenistische Terrakottastatuetten von der Athener Agora geben ebenfalls diesen Typus wieder ${ }^{824}$. Sie zeigen die Göttin auf einem Thron sitzend und mit einem Tympanon in der linken Hand, das sie auf der Thronlehne abstützt. Sie trägt einen Chiton und einen über den Schoß gelegten Mantel. Bei einigen Bildern hockt ein Löwe an ihrer Seite.

Baubefund: Der Baubefund weist für die spätarchaische Zeit einen kleinen Tempel auf der Athener Agora aus. Nach der Zerstörung durch die Perser zu Beginn des 5. Jahrhunderts v. Chr. wurde der Bau nicht erneuert und der Kult vermutlich in das benachbarte >Alte Bouleuterion verlegt, das in den folgenden Jahrhunderten als Staatsarchiv diente. Als im 3. Viertel des 2. Jahrhunderts v. Chr. ein neues

823 Piräus, Archäologisches Museum: F. Naumann, Die Ikonographie der Kybele in der Phrygischen und der griechischen Kunst (Tübingen 1983) 159-169. 310 Nr. 123 Taf. 22, 1; LIMC VIII (1997) 753 Nr. 47 s. v. Kybele (E. Simon); G. Steinhauer, TA MNHMEIA KAI TO APXAIO

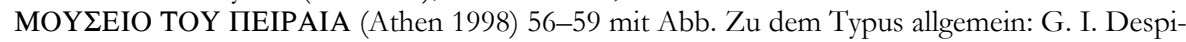
nis, $\Sigma$ YMBO $\Lambda$ H $\Sigma$ TH ME $\Lambda$ TH TOY ЕРГОY TOY АГОРАКРITOY (Athen 1971) 113-123.

${ }^{824}$ H.-A. Thompson - R. E. Wycherley, The Agora of Athens, Agora 14 (Princeton 1972) 31. 
Archiv gebaut wurde, wurde in diesem ein Kultraum eingerichtet. Fundamente des zugehörigen Altars haben sich erhalten. Da auch dieser Bau den Namen Metroon trug bzw. noch kaiserzeitliche Quellen von einer Statue der Göttermutter berichten, ist von einer Fortsetzung des Kultes in dem Neubau auszugehen. Das Gebäude bestand bis zur Zerstörung durch die Heruler 267 n. Chr. ${ }^{825}$.

Ergebnis: Die Quellen weisen für Athen ein mögliches weiteres Beispiel für die Praxis, ein neues Bild neben einem bereits bestehenden aufzustellen, aus. Da der erste nachgewiesene Kultbau der Göttermutter während der Perserkriege stark in Mitleidenschaft gezogen und nicht wieder aufgebaut worden war, vermuten $\mathrm{J}$. Travlos und J. M. Camp ${ }^{826}$, dass das dort verehrte Bild in das benachbarte $>$ Alte Bouleuterion gebracht worden ist, das in der Antike die Bezeichnung Metroon trug ${ }^{827}$, was auf einen Kult der Göttermutter in diesem Gebäude schließen lässt. Wie lange die alte Statue bestanden hat und ob sie auch die Umsetzung des Kultes in das neue Staatsarchiv im 2. Jahrhundert v. Chr. erlebt hat, muss offen bleiben ${ }^{828}$.

Aus den Quellen geht jedenfalls hervor, dass bereits in klassischer Zeit ein neues Bild hinzugetreten war oder das alte Bild ersetzt hatte, falls dieses nicht mehr bestand. Auch dieses Bild wird von der Forschung im Alten Bouleuterion aufgestellt gedacht, sollte es keinen anderen Bau während dieser Zeit gegeben haben, der das Bild beherbergt hätte ${ }^{829}$. Eine Vorstellung vom Aussehen des Bildes liefern die oben genannten Marmor- und Terrakottastatuetten. Sie zeigen die Göttin thronend mit einem Tympanon in der Hand und z. T. einem Löwen an ihrer Seite, wie sie von Arrianos beschrieben worden war ${ }^{830}$.

\subsubsection{Iakchos in Athen}

\section{Schriftquellen zu dem alten Bild:}

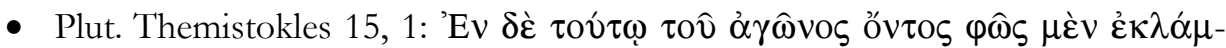

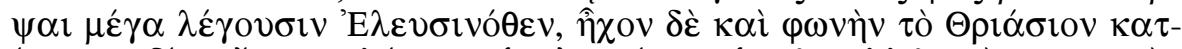

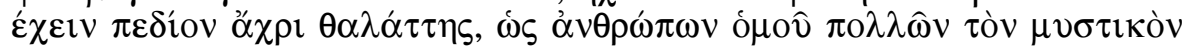

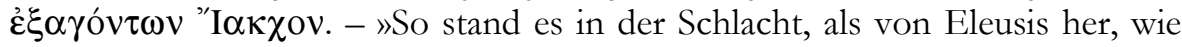
erzählt wird, ein helles Licht herüberleuchtete, während brausender Jubelruf die thriasische Ebene bis hinunter ans Meer erfüllte, als ob eine große Menschenmenge den Iakchos zur Mysterienfeier nach Eleusis geleite«. (K. Ziegler)

\footnotetext{
825 Travlos 1971, 352-356; Camp 1986, 91-94.179 f.; Thompson 1976, 64-67; Thompson 1937, 115-217.

826 s. Anm. 825.

827 Schol. Aischin. 3, 187; Deinarch. 1, 86.

828 T. L. Shear, The Campaign of 1934, Hesperia 4, 1935, 350-352; Thompson 1937, 115-217; Travlos 1971, 352; H.-A. Thompson - R. E. Wycherley, The Agora of Athens, Agora 14 (Princeton 1972) 35-38; Thompson 1976, 64-67; Camp 1986, 91-94.

${ }^{829}$ H.-A. Thompson - R. E. Wycherley, The Agora of Athens, Agora 14 (Princeton 1972) 31. 830 s. S. 260.
} 
- IG II2 1006 (Ephebenliste aus Athen, 122/1 v. Chr.):

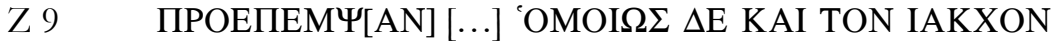

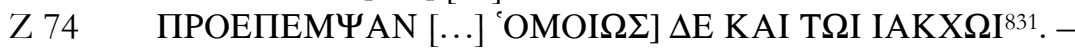

Z 9 》Gleichfalls geleiteten sie den Iakchos.

Z $74 \quad$ Gleichfalls geleiteten sie den Iakchos«.

- IG II 1092 (Kultvorschrift aus Eleusis, ca. 131 n. Chr.):

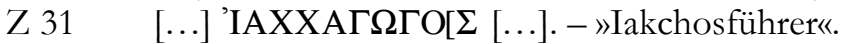

- IG II2 4771 (Stiftungsinschrift, 120-130 n. Chr.):

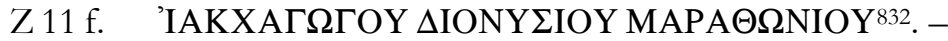

»Des Iakchosführers Dionysios Marathonios«.

- IG II 5044 (Inschrift auf einem Sitz des Athener Dionysostheaters, 120-130

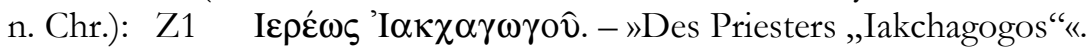

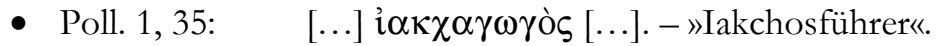

\section{Schriftquellen zu dem neuen Bild:}

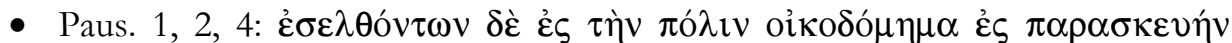

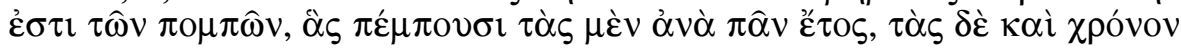

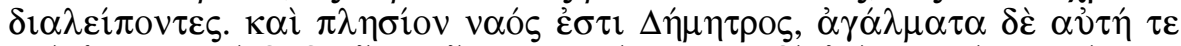

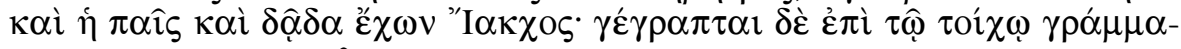

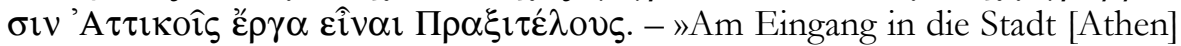
steht ein Gebäude zur Herrichtung der Festzüge, die sie teils jedes Jahr, teils in Zwischenräumen veranstalten, und in der Nähe ein Demetertempel und Standbilder, sie selbst und ihre Tochter und Iakchos mit Fackel; an der Wand steht in attischer Schrift, es seien Werke des Praxiteles«. (F. Eckstein - P. C. Bol)

Darstellungen/Baubefund: Bisher sind weder Darstellungen der überlieferten Iakchosbilder noch Details zum Baubefund des Heiligtums bekannt. In einer 1936 in der

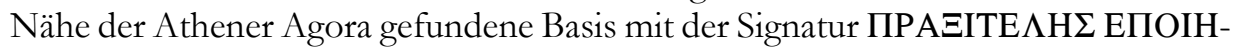
$\Sigma$ EN und einer Weihung an Demeter und Kore hat T. L. Shear die Basis der bei Pausanias überlieferten Statuengruppe des Praxiteles vermutet ${ }^{833}$. Da die Basis jedoch im 1. Jahrhundert v. Chr. sekundär in eine Mauer verbaut worden ist, erscheint seine These wenig wahrscheinlich, da Pausanias die Statuen noch rund 300 Jahre später zusammen aufgestellt gesehen hat. Man müsste davon ausgehen, dass die Statuen auf eine neue Basis umgesetzt worden sind, wofür jedoch keine Anhaltspunkte vorliegen. Mit Hilfe der Basis können daher keine Rückschlüsse auf die Gestaltung des Heiligtums gezogen werden.

${ }^{831}$ Ebenso IG II² 1008, Z 8; IG II² 1011, Z 8; IG II² 1028, Z 9.

$832 \mathrm{Vgl}$. IG II ${ }^{2} 3733$, Z $20 \mathrm{f}$.

833 T. L. Shear, The Campaign of 1936, Hesperia 6, 1937, 339-342. 
Ergebnis: Das Bild des Iakchos aus Athen wurde in der großen Prozession, die die Mysten und Einzuweihenden einmal im Jahr von Athen nach Eleusis veranstalteten, mitgeführt ${ }^{834}$. Den Rest des Jahres wurde es wahrscheinlich im Tempel der Demeter im Gebiet des Kerameikos in Athen aufbewahrt. Laut Pausanias stand dort eine Statue des Iakchos neben den Statuen der Demeter und Persephone und wurde durch eine Inschrift als Werk des Praxiteles ausgewiesen. Da Praxiteles berühmt war für seine Marmor- und Bronzestatuen, von denen die bisher bekannten selten kleinformatig sind ${ }^{835}$, erscheint es unwahrscheinlich, dass ein solches, wenig zu einem regelmäßigen Transport geeignetes Bild jährlich nach Eleusis und wieder zurück nach Athen gebracht worden sein soll. Außerdem stammen die ältesten Quellen zur Figur des Iakchos bereits aus dem 5. Jahrhundert v. Chr. und sind früher als die Schaffenszeit des Praxiteles. Daher kann man hier von zwei Bildern ausgehen. Das eine verblieb ständig im Demetertempel in Athen. Das andere Bild wurde von dem 'I $\alpha \kappa \chi \alpha \gamma \omega \gamma$ ó $\varsigma$-Priester sowie den Epheben Athens in der großen Prozession nach Eleusis geleitet ${ }^{836}$. Da mehrfach Wagen bei der Großen Prozession nach Eleusis belegt sind, vermutete G. E. Mylonas, dass das Bild des Iakchos wie die anderen heiligen Gegenstände nicht getragen wurde, sondern auf einem Wagen fuhr ${ }^{837}$. Zumindest über die Brücke an den Rheitoi mussten es aber getragen werden, da diese für Wagen zu schmal war ${ }^{838}$. Es ist daher zu vermuten, dass das Bild eher kleinformatig gewesen ist.

Über das Aussehen der Bilder schweigen die Quellen. Iakchos wird in der antiken Literatur mehrfach mit Dionysos gleichgesetzt ${ }^{839}$. Bei bildlichen Darstellungen erscheint Iakchos in einer Gestalt, die dem jungendlichen Dionysos ähnelt. Er

834 Plut. Themistokles 15, 1; Poll. 1, 35; IG II 2 1006. 1008. 1011. 1028. 1092. 4771. 5044. Vgl. auch Aristoph., Ran. 318-345. 395-403; P. Ailios Aristeides 22, 6.

835 Rizzo 1932, RE XXII (1953) 1787-1809 s. v. Praxiteles (G. Lippold); DNP X (2001) 280-283 s. v. Praxiteles (R. Neudecker).

836 P. Foucart, Les Mystères d’Éleusis (Paris 1914) 208; J. H. Oliver, The Eleusinian Endowment, Hesperia 21, 1952, 381-399; Mylonas 1961, 252; M. Maass, Die Prohedrie des Dionysostheaters in Athen (München 1972) 119; K. Clinton, The Sacred Officials of the Eleusinian Mysteries (Philadelphia 1974) 96 f.; F. Graf, Pompai in Greece. Some Considerations about Space and Ritual in the Greek Polis, in: R. Hägg (Hrsg.), The Role of Religion in the Early Greek Polis. Proceedings of the Third International Seminar on Ancient Greek Cult organized by the Swedish Institute at Athens, 16-18 October 1992 (Stockholm 1996) 55-65.

837 Mylonas 1961, $252 \mathrm{f}$.

838 Ebenda.

839 Strab. 10, 3, 10; Arr. an. 2, 16, 3; Soph. Ant. 1146-1152; P. Ailios Aristeides 41, 12-13; Aristoph., Ran. 318-345. 395-403. Vgl. auch P. Foucart, Les Mystères d'Éleusis (Paris 1914) 110-113; Lehnstaedt 1970, 110; F. Graf, Eleusis und die orphische Dichtung Athens in vorhellenistischer Zeit (Berlin 1974) 41-66 mit weiteren Quellen; Parke 1977, 65; E. Simon, Festivals of Attica. An Archaeological Commentary (Madison 1983) 32; F. Graf, Pompai in Greece. Some Considerations about Space and Ritual in the Greek Polis, in: R. Hägg (Hrsg.), The Role of Religion in the Early Greek Polis. Proceedings of the Third International Seminar on Ancient Greek Cult organized by the Swedish Institute at Athens, 16-18 October 1992 (Stockholm 1996) 55-65; LIMC V (1999) 612-614 s. v. Iakchos (E. Simon). 
wird als Jüngling dargestellt und trägt ein kurzes Gewand mit langen Ärmeln und die hohen, für Dionysos typischen Stiefel. Er hält außerdem meist eine oder zwei Fackeln in den Händen ${ }^{840}$. Keines der bisher bekannten Bilder überliefert jedoch sicher das Aussehen einer der beiden anzunehmenden Iakchosstatuen, da sie ihn lebendig innerhalb szenischer Darstellungen wiedergeben ${ }^{841}$.

\subsubsection{Nemeseis in Smyrna}

\section{Schriftquellen:}

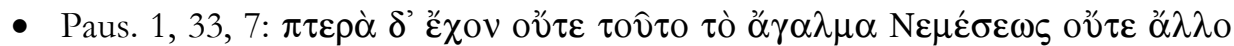

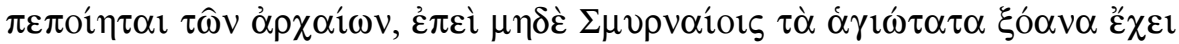
$\pi \tau \varepsilon \rho \alpha ́$. $-»$ Mit Flügeln hat man jedoch weder dieses Bild der Nemesis noch ein anderes von den alten hergestellt, weil auch die allerheiligsten Xoana in Smyrna keine Flügel haben«.

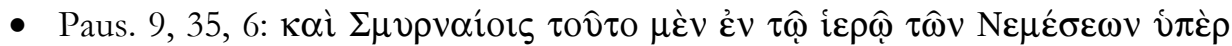

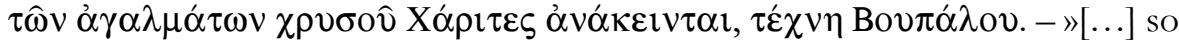
sind bei den Smyrnaiern im Heiligtum der Nemeseis über deren goldenen Statuen Chariten aufgestellt, Kunstwerke des Bupalos«. (F. Eckstein - P. C. Bol)

Darstellungen/Baubefund: Kaiserzeitliche Münzen aus Smyrna sowie Statuen und Reliefs überliefern zwei nebeneinander stehende weibliche Figuren. Sie stehen entweder in Frontalansicht nebeneinander oder blicken sich an und tragen einen

840 Lippold 1950, 241; Mylonas 1961, 205-221 Abb. 81. 83-85. 88; LIMC IV (1988) 43-46 s. v. Eubouleus (G. Schwarz), K. Clinton, Myth and Cult. The Iconography of the Eleusinian Mysteries. The Martin P. Nilsson Lectures on Greek Religion delivered 19-21 November at the Swedish Institute at Athens (Stockholm 1992) 64-71. 96.136-139.

${ }^{841}$ Lippold 1950, 241 mit Taf. 90,1 hat vermutet, dass es sich bei einem in Eleusis gefunden Kopf aus der Zeit um 340-320 v. Chr. (heute im Nationalmuseum von Athen, Inv. 181) um eine Werkstattwiederholung der praxitelischen Statue handelt. Der Kopf wird sonst zumeist als Eubouleus, Bruder des Triptolemos, gedeutet, was vorrangig auf einer an gleicher Stelle gefundenen Weihinschrift, IG II 4615 beruht. Zudem belegt ein kopfloser Hermenschaft im Vatikan (Inv. 274) mit der Inschrift EYBO $\Lambda$ EY $\Sigma$ ПPA $\Xi I T E \Lambda O Y \Sigma$, dass es eine Statue des Eubouleus von Praxiteles gegeben hat. Vgl. Rizzo 1932, 103-108; K. Clinton, Myth and Cult. The Iconography of the Eleusinian Mysteries. The Martin P. Nilsson Lectures on Greek Religion delivered 19-21 November at the Swedish Institute at Athens (Stockholm 1992) mit weiterer Literatur. Die Herme ist veröffentlicht bei Helbig I ${ }^{4}$ (Tübingen 1963) 59 Nr. 75 (W. Fuchs).

G. Schwarz deutete den Kopf hingegen als Triptolemos, da es zahlreiche Repliken mit einem weiten Verbreitungsgebiet gibt. Deshalb sei die Deutung als Eubouleus wenig wahrscheinlich, dessen Bedeutung auf Eleusis beschränkt gewesen sei und der auch im eleusinischen Kontext nur selten dargestellt wurde, s. G. Schwarz, Zum sogenannten Eubouleus, GettyMusJ 2, 1975, 71-84; dies., Triptolemos - Alexander, in: F. Krinzinger - B. Otto - E. Walde-Psenner (Hrsg.), Forschungen und Funde. Festschrift Bernhard Neutsch (Innsbruck 1980) 449-455; LIMC IV (1988) 43-46 s. v. Eubouleus Nr. 3 (G. Schwarz). Die Deutung des Kopfes ist also sehr umstritten. In ihm deshalb eine Werkstattwiederholung zu sehen und diese zur Rekonstruktion der praxitelischen Statue heranzuziehen erscheint deshalb zu unsicher. Das Aussehen dieser Statue muss unbekannt bleiben. 
hoch gegürteten Chiton und einen Hüftmantel sowie Sandalen. In ihren Händen halten sie verschiedene Attribute wie Elle, Zügel und Rad. Neben ihnen kann ein Greif hocken. Einige Darstellungen zeigen die beiden Gestalten geflügelt. Aufgrund stilistischer Merkmale kann dieser Typus in die frühhellenistische Zeit datiert werden $(A b b .49)^{842}$. Das Heiligtum ist bisher noch nicht archäologisch untersucht worden.

Ergebnis: Die Bilder der Nemeseis in Smyrna galten laut Pausanias als besonders alt und heilig ${ }^{843}$. Die von ihm erwähnte Verbindung mit den Chariten des archaischen Bildhauers Bupalos ${ }^{844}$ verstärkt ebenfalls den Eindruck eines hohen Alters der Bilder. Kaiserzeitliche Münzen aus Smyrna zeigen hingegen einen frühhellenistischen Typus und damit zwei weitere Nemesisstatuen (Abb. 49). Die mehrfachen Wiederholungen dieser Statuen in rundplastischen Nachbildungen und Reliefs bezeugen, dass es sich um berühmte Statuen gehandelt haben muss. Es ist also nicht unwahrscheinlich, dass es sich ebenfalls um ein repräsentatives Statuenpaar aus dem Nemesisheiligtum von Smyrna handelt, dem der Kult galt. Demnach hätte man auch hier neue Bilder zu den alten gestellt.

Die alten Bilder haben neben den jüngeren offenbar noch bis in die Kaiserzeit bestanden und konnten daher von Pausanias noch in der Kaiserzeit beschrieben werden. Daher ist es möglich, dass es auch in diesem Heiligtum mehrere unterschiedlich alte Statuen gegeben hat.

\subsubsection{Artemis Laphria in Kalydon}

\section{Schriftquellen:}

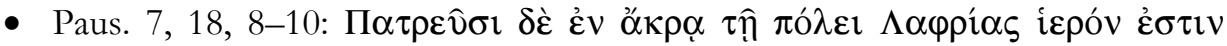

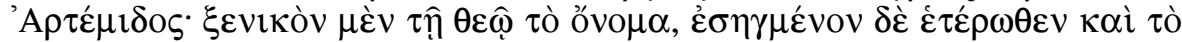

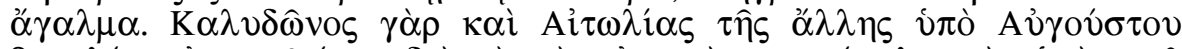

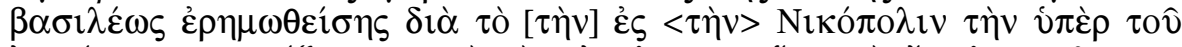

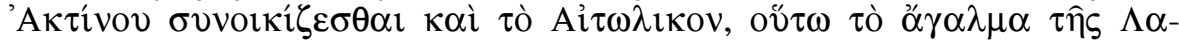

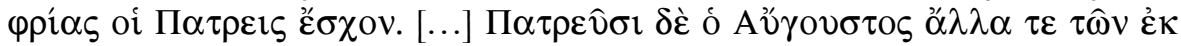

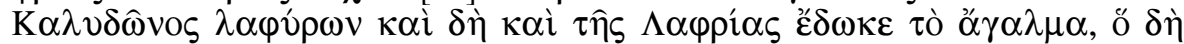

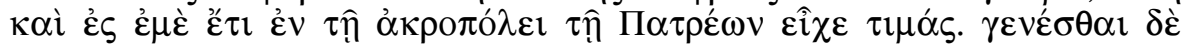

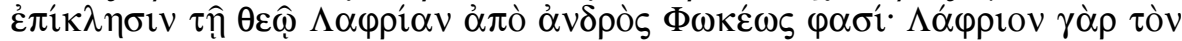

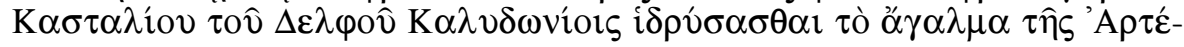

\footnotetext{
842 Thasos, Museum Inv. 2106: R. Fleischer, Eine neue Darstellung der doppelten Nemesis von Smyrna, in: M. B. de Boer - T. A. Edridge (Hrsg.), Hommages à Maarten J. Vermaseren I (Leiden 1978) 392-396 Taf. 78, 2; ebenso Roscher ML III (1897-1909) 117-166 s. v. Nemesis (O. Rossbach); H. Usener, Dreiheit, RhM 58, 1903, 190; B. Schweitzer, Die Nemesis Regina, JdI 46, 1931, $175-$ 246, bes. 202-205; C. Rolley, Sculptures Nouvelles a l'Agora de Thasos, BCH 88, 1964, 496-524, bes. 496-506; Damaskos 1999, 162-164. Zu den Attributen Vgl. Ammianus, Marc. XIV 11, 26.

$843 \mathrm{Zu}$ der besonderen Verdoppelung der Nemesis in Kleinasien vgl. Anm. 842.

844 RE III (1897) 1054 s. v. Bupalos (C. Robert); DNP II (1997-1999) 853 s. v. Bupalos (R. Neudecker).
} 


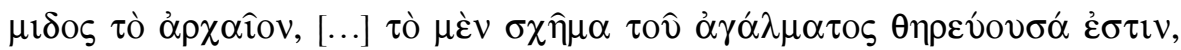

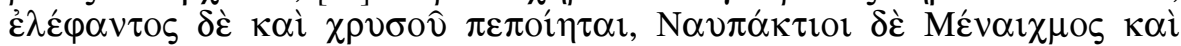

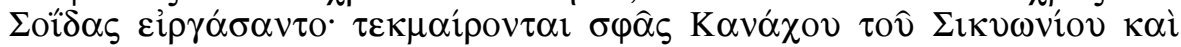

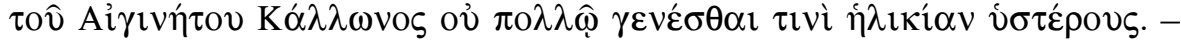
»In Patrai befindet sich zuoberst in der Stadt ein Heiligtum der Artemis Laphria; das ist ein fremder Name für die Göttin, von anderswoher eingeführt wie auch das Kultbild. Als nämlich Kalydon und das übrige Aitolien vom Kaiser Augustus entvölkert wurde, weil er auch die Aitoler in Nikopolis bei Aktion ansiedelte, erhielten die Patreer das Kultbild der Laphria. [...] so schenkte Augustus den Patreern andere Beute aus Kalydon und so auch das Kultbild der Laphria, das noch zu meiner Zeit auf der Akropolis von Patrai verehrt wurde. Den Beinamen Laphria erhielt die Göttin von einem Phoker namens Laphrios. Dieser, Sohn des Kastalios und Enkel des Delphos, soll bei den Kalydoniern das alte Kultbild der Artemis gestiftet haben [...]. Das Kultbild hat die Gestalt einer Jägerin, und es ist aus Elfenbein und Gold gemacht. Die Naupaktier Menaichmos und Soïdas schufen es; sie sollen an Lebenszeit nicht viel später gewesen sein als der Sikyonier Kanachos und der Aiginete Kallon«. (F. Eckstein - P. C. Bol)

Darstellungen: Kaiserzeitliche Münzen aus Patrai zeigen die Göttin im Kontrapost mit dem Gewicht auf dem rechten Bein stehend. Das linke, entlastete Bein ist leicht gebeugt und der Fuß zur Seite gestellt. Der Kopf ist nach links gewendet. Die rechte Hand hat die Göttin in die Hüfte gestützt, mit der angewinkelt erhobenen linken hält sie ihren Bogen. Sie trägt einen knielangen Chiton, einen über die linke Schulter geworfenen Mantel und hohe Stiefel. Links der Göttin ist auf einigen Münzen ein Altar zu sehen, rechts von ihr sitzt oft ein Hund. Die Beischriften bezeichnen die Göttin als Diana Laphria (Abb. 50) ${ }^{845}$.

Baubefund: Das Heiligtum der Artemis Laphria in Kalydon ist von E. Dyggve und F. Poulson untersucht worden, die die Ergebnisse 1948 veröffentlicht haben. Sie konnten drei größere Bauphasen für den Tempel feststellen. Der früheste Bau entstand bereits im späteren 7. Jahrhundert v. Chr. Ein erster Umbau erfolgte wenig später in der 1. Hälfte des 6. Jahrhunderts v. Chr. Ein dritter Tempel entstand an derselben Stelle im 4. Jahrhundert v. Chr. Nach der Umsiedlung der Einwohner von Kalydon und der Umsetzung der Götterbilder nach Patrai unter Augustus scheint der Kult zum Erliegen gekommen und das Heiligtum aufgegeben worden zu sein, da seit dieser Zeit kaum noch Kultaktivitäten durch Funde nachgewiesen werden können ${ }^{846}$.

\footnotetext{
845 London, British Museum: Imhoof-Blumer - Gardner 1964, 76 f. Taf. Q Nr. 7. Weitere bei Anti 1916; Lacroix 1949, 232-238 Taf. 19, 8-12; Imhoof-Blumer - Gardner 1964, 76 f. Taf. Q Nr. 6-10; Lapatin 2001, 111 Abb. 216.

${ }^{846}$ Dyggve - Poulson 1948.
} 
Ergebnis: Für das Heiligtum der Artemis Laphria in Kalydon sind durch Pausanias ebenfalls zwei Bilder überliefert. Das eine schreibt er einem mythischen Stifter zu, das andere war eine Gold-Elfenbein-Statue des Menaichmos und Soïdas aus Naupaktos, die nicht viel später als Kanachos aus Sikyon und Kallon aus Aigina gelebt haben sollen. Die zuletzt genannten Bildhauer werden von der Forschung in die späte archaische Zeit datiert, Menaichmos und Soïdas gehören somit in die frühe Klassik ${ }^{847}$. Kaiserzeitliche Münzen aus Patrai sollen die von ihnen geschaffene Statue wiedergeben $(A b b .50)^{848}$. Denselben Typus fand C. Anti zudem in mehreren Statuetten und auf einem Relief aus Marmor wieder, die auf einen hellenistischen Typus zurückgehen ${ }^{849}$. Hier ergibt sich eine Diskrepanz zur angenommenen Datierung der Bildhauer. C. Anti löst das Problem damit, dass man ein hellenistisches Bild - das er als Werk des Damophon von Messene identifiziert - auf der Basis eines älteren, verlorenen Bildes aufgestellt habe. Die Basis habe die Signatur des Menaichmos und Soïdas getragen, so dass Pausanias die zu dem alten Bild gehörende Inschrift auf das Ersatzbild bezogen habe ${ }^{850}$. Allerdings herrschte bereits in der Antike keine Einigkeit über die zeitliche Einordnung der nur wenig bekannten Bildhauer Menaichmos und Soïdas. Auch für Kallon und Kanachos finden sich widersprüchliche Angaben, so dass hier sogar von mehreren Bildhauern gleichen Namens ausgegangen werden kann. Die zunächst von der Forschung angenommene Datierung des Kallon und Kanachos in die spätarchaische Zeit be-

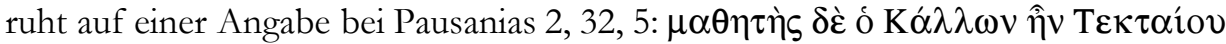

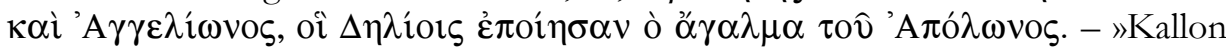
war Schüler des Tektaios und Angelion, die den Deliern das Kultbild des Apollon

847 Anti 1916, 182; Pollitt 1990, 33-35. 42.

848 s. Anm. 845.

849 Anti 1916 194. 196 Abb. 6-12; Vgl. auch LIMC II (1984) 641 f. s. v. Artemis Nr. 191-209 (L. Kahil), allerdings mit Ablehnung der Identifizierung des Typus mit der kalydonischen Statue aufgrund der Datierung der Bildhauer. Anti 1916 hat auch gut begründet die von F. Studniczka, Die archaische Artemisstatuette aus Pompeii, RM 3, 1888, 277-302 vorgetragene Identifizierung eines anderen, frühkaiserzeitlich-archaistischen Typus mit der Artemis Laphria von Patrai abgelehnt.

850 Imhoof-Blumer - Gardner 1964, 76 f. und Lapatin 2001, 111-113 verbinden die Münzbilder ebenfalls mit der kalydonischen Statue. Sie datieren Menaichmos und Soïdas aber in die 2. Hälfte des 5. Jahrhunderts v. Chr. und versuchen auf diese Weise, die schriftliche Überlieferung mit dem Typus in Einklang zu bringen. Ähnlich auch schon J. Herbillon, Les cultes de Patras (Baltimore 1929) 62-64. Laut D. von Detten, Darstellungen der Artemis Laphria (Diss. Ruhr-Universität Bochum 1983) wiederholen die von C. Anti zusammengestellten Werke einen hellenistischen Typus, der vielleicht auf ein Werk des Damophon von Messene zurückgehe und sich an das von Menaichmos und Soïdas geschaffene klassische Vorbild anlehne. Der klassische Typus sei durch weitere, von C. Anti nicht verwendete römische Kopien erhalten. Anscheinend gehören jedoch alle Kopien und Nachbildungen zu demselben Typus. Lacroix 1949, 237 hingegen hielt es für möglich, dass Pausanias zwar die Statue gesehen, seine Beschreibung aber nachträglich aus einer Schriftquelle ergänzt hatte, als er ihr Aussehen nicht mehr direkt vor Augen hatte.

Zu der Statue des Damophon s. Paus. 4, 31, 7. Vgl. Themelis 2003, 95. 139 f. Abb. 85. 147. 
herstellten; Angelion und Tektaios hatten bei Dipoinos und Skyllis gelernt«. (F. Eckstein - P. C. Bol)

Plinius nat. 34, 49 datiert die Schaffenszeit des Kallon hingegen bekanntermaßen um 430 v. Chr.: et deinde olympiade LXXXVII Hagelades, Callon, Gorgias Lacon. - »Und schließlich in der 87. Olympiade Hagelades, Kallon, der Lakedaimonier Gorgias«. Und Kanachos wird von Plinius nat. 34, 50 sogar in die ersten Jahre des 4. Jahrhunderts v. Chr. gesetzt: LXXXXV olympiade floruere Naucydes, Dinomenes, Canachus, Patroklus. - »Und in der 95. Olympiade waren Naukydes, Deinomenes, Kanachos und Patroklos besonders angesehen«. Und sogar Pausanias 6, 13, 7 selbst kennt einen Kanachos aus Sikyon, der um 400 v. Chr. oder

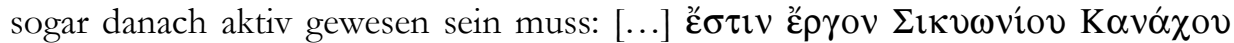

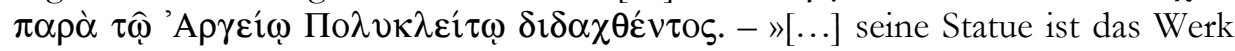
des Sikyoniers Kanachos, der ein Schüler des Argivers Polykleitos war«. (F. Eckstein - P. C. Bol)

Kallon und Kanachos können laut diesen Quellen auch in das spätere 5. oder frühe 4. Jahrhundert v. Chr. datiert werden, so dass Menaichmos und Soïdas auch in die spätere und vielleicht sogar in die späteste Klassik datiert werden können. Die Zuweisung des durch die Münzen und rundplastischen Nachbildungen überlieferten Typus an die beiden Bildhauer bietet aufgrund dieser Überlegungen weniger Schwierigkeiten. Eine genaue Kopienkritik könnte hier weiter Klarheit verschaffen.

Da die Erforschung des Baubefundes des Heiligtums drei Bauphasen ergeben hat, müssen die beiden literarisch überlieferten Bilder nicht unbedingt zusammengestanden haben. Die jüngere Statue kann auch ein Ersatz für das alte, vielleicht schon zerstörte Bild gewesen sein. Sie wird in der Forschung mit der zweiten Bauphase in Verbindung gebracht und wäre demnach jünger als der Tempel ${ }^{851}$. Ebenso erscheint mir eine Entstehung des jüngeren Bildes im Zuge der Erbauung des dritten Tempels denkbar aufgrund der eben genannten Spätdatierung der Bildhauer. Dort stand zumindest das jüngere der beiden Bilder noch, als Augustus die Stadt auslöschen ließ. Da laut den Quellen nur das jüngere Bild nach Patrai versetzt worden ist, scheint das ältere zu diesem Zeitpunkt bereits verloren gewesen zu sein. Denn nach der augusteischen Zeit kam es in dem Kult zu einem massiven Einbruch, wie E. Dyggve und F. Poulson festgestellt haben. Die Kultbauten wurden fortan als Steinbruch benutzt. Das Kultgeschehen konnte für die folgenden Jahrhunderte nur noch in sehr geringem Umfang nachgewiesen werden ${ }^{852}$. Dies lässt darauf schließen, dass auch das alte Bild der Artemis nicht mehr vorhanden gewesen ist.

851 Dyggve - Poulson 1948, 240; Lapatin 2001, 112.

${ }^{852}$ Dyggve - Poulson 1948, 302. 


\subsection{Weitere Belege für die Aufstellung neuer Bilder neben den alten}

Außer den in den vorangegangenen Abschnitten betrachteten Heiligtümern sind in der antiken Literatur noch weitere Kultbezirke belegt, die mehr als ein Bild der dort verehrten Gottheit aus unterschiedlichen Zeiten besaßen. Allerdings bleibt offen, ob es sich bei allen Bildern um >Kultbilder im hier argumentierten Sinn handelt oder um >Weihgeschenker. Besonders Pausanias scheint ein großes Interesse an alten Bildern gehabt zu haben, da er sie besonders häufig erwähnt. Sein Werk stellt deshalb die wichtigste Quelle dar. Außer den Angaben in den Schriftquellen liegen zurzeit keine weiteren Details über die jeweiligen Heiligtümer vor, weshalb sie hier nur kurz aufgeführt werden.

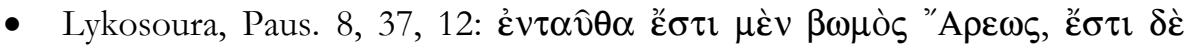

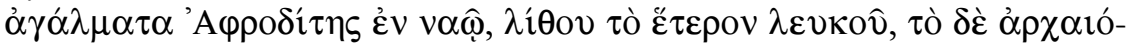
$\tau \varepsilon \rho \circ \nu \alpha \hat{\tau} \tau \hat{\omega} \nu \xi \hat{v} \lambda$ ov. - »Dort ist ein Altar des Ares und Statuen der Aphrodite in einem Tempel, die eine aus Marmor, die ältere von ihnen aus Holz«. (F. Eckstein - P. C. Bol)

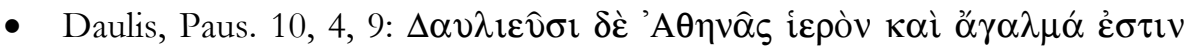

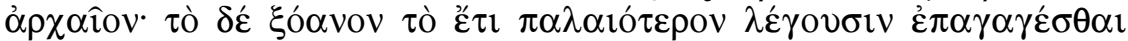

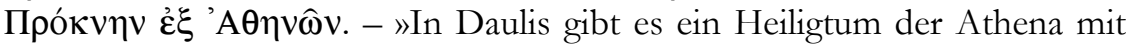
einer alten Statue, und das noch ältere Xoanon, sagen sie, soll Prokne aus Athen geholt haben .

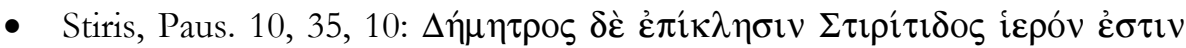

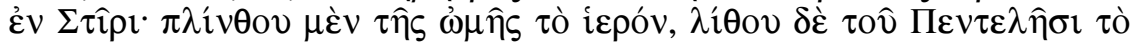

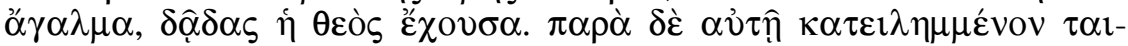

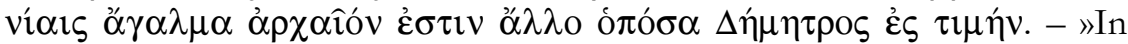
Stiris gibt es ein Heiligtum der Demeter mit dem Beinamen der stiritischen; das Heiligtum besteht aus ungebrannten Ziegeln, die Statue aus pentelischem Marmor, die Göttin mit Fackeln darstellend. Neben ihr steht eine mit Binden umwickelte Statue, die alt ist wie nur irgendeine, die es zu Ehren der Demeter gibt«. (F. Eckstein - P. C. Bol)

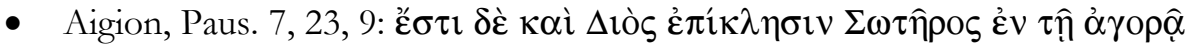

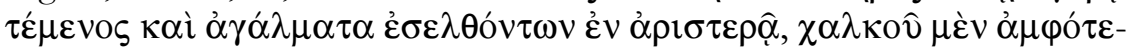

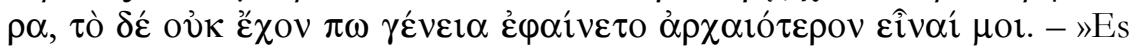
gibt auch ein Heiligtum des Zeus mit dem Beinamen Soter (»Retter«) auf dem Markt, und Statuen stehen links vom Eingang, beide aus Bronze, und die eine noch ohne Bart schien mir älter zu sein«. (F. Eckstein - P. C. Bol)

- Ein mögliches weiteres Beispiel ist das Heiligtum der Artemis Proseioa in Histiaia. Es bestand laut Herodot spätestens der 1. Hälfte des 5. Jahrhun- 
derts v. Chr. ${ }^{853}$. Eine Stifterinschrift aus hellenistischer Zeit belegt den Wiederaufbau des Tempels für die zweite Hälfte des 2. oder den Anfang des 1. Jahrhunderts v. Chr. Dabei wurde auch ein Bild der Göttin aufgestellt, wofür die Bürger der Stadt Geld gaben ${ }^{854}$ IG XII 9, 1189 (Ende 2./Anf. 1.

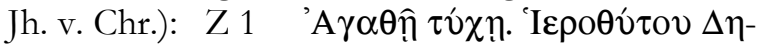

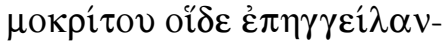

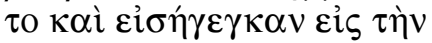

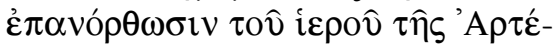

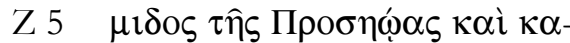

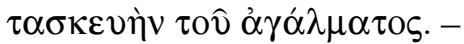

Z 1 »Mit viel Glück. Unter dem

Opferpriester Demokritos verkündeten

die folgenden und brachten hinein in die

Erneuerung des Tempels der

Z 5 Artemis Proseioa und zur

Errichtung der Statue ${ }^{855} \ll$.

Das Heiligtum ist bisher kaum erforscht. Deshalb muss es zum gegenwärtigen Zeitpunkt unbekannt bleiben, ob es sich bei dem in der Inschrift genannten Agalma um eine Restaurierung wie bei dem Tempel oder um neues Bild handelt. Wie lange das alte Bild noch existiert hat und ob beide Bilder zeitgleich in dem Heiligtum standen, ist ebenfalls unbekannt. Anhand der anderen hier untersuchten Heiligtümer ist letzteres zumindest denkbar.

\subsection{Zusammenfassung}

Alle hier untersuchten Heiligtümer zeichneten sich dadurch aus, dass sie jeweils mehrere Statuen derselben Gottheit aus unterschiedlichen Epochen beherbergten, die vielleicht in kultische Handlungen einbezogen worden sind. Die Datierung der jeweils älteren Bilder konnte zumeist nicht genau bestimmt werden. Einigen alten Bildern wurde der Überlieferung nach eine Entstehung in mythischer Vorzeit zugeschrieben, weshalb sie als besonders heilig galten. Dazu zählen die uralten Bilder der Hera von Samos und Argos, der Artemis von Brauron, das einst in Tauris verehrt worden sein soll, der Artemis von Ephesos und Kalydon, der Athena von Lindos und Daulis, des Dionysos von Athen und Theben, des Trophonios in Lebadeia, der Nemeseis von Smyrna, des Apollon von Delphi und Delos. Das Bild der

${ }^{853}$ Hdt. 7, 175; 8, 23.

${ }^{854}$ Die Inschrift liegt in zwei geringfügig verschiedenen Versionen vor: H. G. Lolling, Das Artemision auf Nordeuböa, AM 8, 1883, 7-23; ders., Ausgrabungen am Artemision auf Nordeuböa, AM 8, 1883, 200-210; F. Cairns, A 'Duplicate' Copy of IG XII 9,1189, ZPE 54, 1984, 133-144; SEG 34, 1984, 237 f. Nr. 909; Damaskos 1999, 73.

${ }^{855}$ Es folgt eine Aufzählung der Stifter und der von ihnen gegebenen Mittel. 
Athena Polias von Athen und die heiligen Steine der Chariten von Orchomenos galten als Diipetes und ebenfalls besonders wertvolle Bilder. Auch diese hielt man für uralt, genauso wie den anikonischen Stein des Eros in Thespiai, die Statuen der Aphrodite in Lykosoura, der Demeter in Stiris und des Zeus in Aigion. Eine genauere Datierung ist für das ältere Bild der Aphaia von Aigina möglich, das aufgrund der oben zitierten Stifterinschrift von der Forschung in die archaische Zeit datiert wird. Die älteren Bilder der Athena Nike und der Meter aus Athen sind ebenfalls in die archaische Zeit datierbar, wie aus dem Baubefund der Heiligtümer hervorgeht. Auch die älteren Bilder des Zeus in Olympia und der Artemis Brauronia auf der Athener Akropolis gehören mit hoher Wahrscheinlichkeit in diese Zeit. Das ältere Bild der Artemis in Histiaia bestand spätestens seit der 1. Hälfte des 5. Jahrhunderts v. Chr., da seit dieser Zeit der Kult literarisch überliefert ist.

Als Material für die alten Götterbilder überwiegt Holz ${ }^{856}$. Das ältere Bild der Aphaia von Aigina bestand vermutlich aus Elfenbein und war damit ein Akrolith wie vielleicht auch das jüngere Bild, wenn die Zuweisung des erhaltenen Armes zu diesem Bild richtig ist. Das alte Bild der Athena Nike in Athen bestand aus Marmor oder Holz, der erhaltenen Basis nach zu urteilen. Ebenfalls aus Stein bestanden die alten Bilder der Chariten in Orchomenos sowie des Eros in Thespiai. Die ältere Statue des Zeus in Aigion bestand hingegen aus Bronze. Für die übrigen hier zusammengestellten alten Bilder ist das Material nicht überliefert.

Soweit Nachrichten über die Größe der alten Bilder vorliegen, bezeugen sie deren kleines Format. Die meisten dieser Bilder werden in den Quellen entweder direkt als klein bezeichnet oder sie waren transportabel, was auf eine geringe Größe schließen lässt. Zeugnisse dafür liegen für die Bilder der Hera von Samos und Argos, der Athena Polias, des Dionysos Eleuthereus und des Iakchos aus der gleichen Stadt und der Artemis von Ephesos vor ${ }^{857}$. Einige waren aus einem anderen Ort in das Heiligtum gebracht worden, wie die beiden Herastatuen von Samos und Argos, die Artemis in Brauron, der Dionysos Eleuthereus in Athen und der Apollon auf Delos.

Das kleine Format ermöglichte es, die Bilder bei Gefahr aus dem Heiligtum zu retten. Mehrere Bilder scheinen die Zerstörung ihrer Tempel überstanden zu haben, worauf ihre Erwähnungen und Beschreibungen in Quellen hindeuten, die meist noch Jahrhunderte nach der Zerstörung ihrer einstigen Tempel entstanden sind. Ein genaues Zeugnis liegt für das alte Bild der Athena Polias von Athen vor, das die Athener zu Beginn des 5. Jahrhunderts v. Chr. vor den anrückenden Persern aus ihrer Stadt retteten. Aufgrund ihres kleinen Formats konnten die alten Bilder auch während der Kulthandlungen regelmäßig transportiert und direkt in bestimmte Riten eingebunden werden ${ }^{858}$.

\footnotetext{
856 Hera von Samos und Argos, Athena Polias in Athen, Dionysos in Athen und Theben, Artemis von Ephesos und Brauron, Apollon von Delos, Aphrodite in Lykosoura.

857 s. Kap. 15.2.1.

${ }^{858}$ Dazu ausführlicher s. Kap. 15.2.1.
} 
Allen in den vorangegangenen Abschnitten betrachteten alten Götterbildern ist es gemeinsam, dass sie nicht die einzigen Repräsentanten der Gottheit in dem jeweiligen Heiligtum geblieben sind. Neben ihnen wurden im Laufe der Zeit neue, vom Material und dem künstlerischen Aufwand her oftmals wesentlich wertvollere Statuen aufgestellt. Dabei wurden hier allerdings nur solche Bilder betrachtet, bei denen eine kultische Verehrung denkbar ist.

Die frühesten Beispiele für die Praxis, neue Bilder neben alten aufzustellen, finden sich im Heiligtum der Hera von Samos, der Artemis von Ephesos und des Apollon in Delphi und Delos. Für diese Heiligtümer ist durch die Schriftquellen ein erstes Bild aus mythischer Vorzeit überliefert. Weitere Quellen berichten jeweils von Statuen, deren Bildhauer in die archaische Zeit datiert werden können. Aufgrund der unterschiedlichen Stifter, des anderen Materials oder Aussehens kann man jeweils von zwei verschiedenen Bildern ausgehen, sollte es nicht zwei Überlieferungsstränge gegeben haben und es sich doch jeweils nur um eine Statue handeln. Möglich wäre dies bei dem Apollon von Delos. Hier wird einerseits ein altes Holzbild erwähnt, andererseits eines aus Gold. Beide Überlieferungen ließen sich zu einem vergoldeten Holzbild zusammenführen. Für die anderen Heiligtümer lassen sich die Quellen und Baubefunde nicht so leicht verbinden, so dass damit zu rechnen ist, das die Praxis, ein zweites Bild der Gottheit in ein und demselben Heiligtum oder sogar Tempel aufzustellen, bereits in der Archaik ihren Anfang genommen hat bzw. für diese Epoche zum ersten Mal belegt ist.

Viele der jüngeren Bilder stammen aus klassischer Zeit. Noch am Übergang von der Archaik zur Klassik entstand das jüngere Bild der Aphaia auf Aigina, das vielleicht ein Akrolith gewesen ist. Am berühmtesten von den jüngeren, klassischen Statuen waren die beiden monumentalen Gold-Elfenbein-Bilder des Phidias auf der Athener Akropolis und im Heiligtum von Olympia. Phidias wird auch als Bildhauer des jüngeren Bildes im Metroon auf der Athener Agora genannt, das einer anderen Überlieferung nach ein Werk seines Schülers Agorakritos war. Das jüngere Bild des Dionysos Eleutheros in Athen stammte von Alkamenes. Auch dieses bestand aus Gold und Elfenbein, ebenso wie das des Heraheiligtums von Argos, das Polyklet geschaffen hatte. Für das Heiligtum der Athena Nike auf der Athener Akropolis ist durch eine erhaltene Inschrift ebenfalls ein jüngeres Bild für die 2. Hälfte des 5. Jahrhundert v. Chr. überliefert. Im Heraheiligtum von Samos gab es spätestens seit dem 4., wahrscheinlich aber schon seit dem 6. Jahrhundert v. Chr. ein weiteres `Kultbild der Göttin. Sicher im 4. Jahrhundert v. Chr. erhielten der Kultbezirk der Artemis Brauronia auf der Athener Akropolis und das Athenaheiligtum von Lindos ein weiteres Bild. Wenn sich die auf der Akropolis von Athen gefundenen Schatzinschriften der Artemis Brauronia auf das Heiligtum in Brauron beziehen, muss auch dort von klassischen Bildern neben einem älteren ausgegangen werden. Die jüngere Statue der Göttin in Athen war ein Werk des Praxiteles aus spätklassischer Zeit, wie auch das jüngere Bild des Iakchos in Athen und das des Eros in Thespiai. Diesem wurde im 4. Jahrhundert v. Chr. noch eine 
dritte Statue, ein Werk des Lysipp hinzugesellt. Praxiteles soll auch eine Statue des Trophonios in Lebadeia geschaffen haben, die nach anderen Quellen eine Arbeit des Euthykrates war. Vermutlich ebenfalls aus dem 4. Jahrhundert v. Chr. stammt die jüngere Statue der Artemis in Kalydon. Für die folgenden Epochen konnten nur wenige Beispiele bestimmt werden. In die hellenistische Zeit gehört das jüngere Bild der Artemis von Histiaia. Kaiserzeitlich sind die jüngeren Bilder der Chariten von Orchomenos, wenn man Pausanias wörtlich nimmt. Sie sind jedenfalls deutlich später entstanden als die vom Himmel gefallenen Steine.

Viele dieser jüngeren Bilder wurden demnach von berühmten Bildhauern gefertigt. Als Material überwiegen Gold und Elfenbein sowie Marmor oder Bronze. Es waren demnach sehr kostbare Bilder von z. T. monumentalem Format.

Angaben zum Standort und zum Verhältnis des neuen Bildes zu dem alten können für die meisten hier untersuchten Heiligtümer zumindest in Ansätzen getroffen werden. Gemeinsam in einem Gebäude standen die Bilder der Hera von Argos, der Artemis von Ephesos, Messene und Kalydon, der Aphaia auf Aigina und der Athena Lindia, wahrscheinlich auch der Athena Nike in Athen und des Apollon in Delphi. Sollte das alte Bild der Meter in Athen noch bestanden haben, als das jüngere errichtet wurde, standen auch sie in einem Bau zusammen. Die Bilder der Athena Polias und Athena Parthenos, des Dionysos Eleuthereus in Athen und des Zeus in Olympia standen jeweils in einem eigenen Gebäude. Gleiches war möglicherweise auch in Argos vorgesehen, der Brand des älteren Tempels verursachte jedoch die gemeinsame Aufstellung der Bilder in dem jüngeren Gebäude. Die Bilder des Trophonios in Lebadeia standen einerseits im Tempel des Heiligtums, andererseits in einer Kulthöhle. Einen Sonderfall bildet das Heiligtum der Hera in Samos. Anhand des Baubefundes sowie eines Heiligtumsinventars aus dem 4. Jahrhundert v. Chr. konnte für diesen Kultort festgestellt werden, dass das alte Bild mit hoher Wahrscheinlichkeit immer an demselben Platz gestanden hat. Aufgrund der baulichen Situation kam das Bild durch den versetzten Neubau des Tempels in spätarchaischer Zeit außerhalb des Gebäudes zu stehen. Sein Standort wurde durch einen Monopteros geschützt und hervorgehoben. Das jüngere Bild nahm den Platz in der Cella des Tempels ein. Beide Bilder waren an prominenten Stellen innerhalb des Heiligtums aufgestellt. In den übrigen Heiligtümern ist die bauliche Situation bisher noch unerforscht.

Auffällig ist, dass die Aufstellung der meisten der jüngeren Bilder im Zusammenhang mit der Errichtung eines neuen Tempels stand ${ }^{859}$. Es war also adäquat, einen im Gegensatz zu dem ersten Tempel oft deutlich vergrößerten und aufwändigeren Neubau zugleich auch mit einer neuen Statue auszustatten, die aufgrund

${ }^{859}$ Hera von Samos und Argos, Athena und Dionysos in Athen, Zeus in Olympia, Artemis in Ephesos, Kalydon und Histiaia, Aphaia auf Aigina, Athena in Lindos, vielleicht auch Athena Nike in Athen, Apollon in Delphi und Delos. 
ihres z. T. monumentalen Formats den Raum erkennbarer mit ihrer Präsenz ausfüllte als das alte und zumeist kleine Bild.

Da der Baubefund in den meisten Heiligtümern in vielen Details noch ungeklärt ist oder keine Angaben mehr zum genauen Standort der Bilder zulässt, können nur wenige Angaben zum Verhältnis der Bilder zueinander getroffen werden. Die Bilder, die jeweils in einem eigenen Gebäude aufgestellt waren, besaßen beide einen als annähernd gleichwertig anzusehenden Standort. Das jüngere Bild hat in diesen Fällen das alte nicht verdrängt - wenn auch der jüngere Bau oftmals größer und deshalb repräsentativer war als der alte. Wenn beide Bilder in einem Tempel ihre Aufstellung fanden, standen sie manchmal nebeneinander, wie die Bilder der Hera von Argos, der Artemis in Messene und der Demeter in Stiris. Einzig das ältere Bild der Aphaia auf Aigina stand an untergeordneter Stelle an der Rückwand der Cella, während das jüngere einen zentralen Platz in der Cella erhielt. Besonders herausgehoben wurde hingegen der Standort des alten Bildes der Hera von Samos. Soweit sich dies feststellen ließ, behielten die meisten der alten Bilder demnach einen bedeutenden Platz in dem jeweiligen Heiligtum.

Nicht für alle Bilder ist jedoch eine Kultfunktion überliefert. Sicher als Heiligtümer mit mehr als einer $>$ Kultstatue aus unterschiedlichen Zeiten sind die Kultstätten der Hera auf Samos und der Artemis von Ephesos ${ }^{860}$, Brauron und Messene identifiziert. Aufgrund der Tatsache, dass die Quellen für die übrigen Kultbezirke jeweils nur die genannten Bilder überliefern, die demnach etwas Besonderes dargestellt haben müssen, kann man für sie ebenfalls nach einer Funktion im Kult fragen. Für die bei Pausanias 7, 23, 9 überlieferten Statuen des Zeus in Aigion lässt sich hingegen eher das Gegenteil vermuten. Da beide Statuen vor dem Eingang zum Tempel standen, hat es sich wahrscheinlich nicht um zur Verehrung aufgestellte Bilder gehandelt. Man kann stattdessen eine weitere Statue im Tempel, der der eigentliche Kult galt, vermuten.

${ }^{860}$ Dazu s. auch S. 304 f. 


\section{Weitere Doppel- oder Mehrfachbilder}

Bei den bisher betrachteten Beispielen handelte es sich immer um unterschiedlich alte Statuen. Die antike Literatur, vorrangig Pausanias, überliefert weitere Heiligtümer mit mehr als einer Statue derselben Gottheit. Allerdings ist nur für wenige Bilder das Alter angegeben und damit auch das zeitliche Verhältnis der jeweiligen Statuen zueinander bestimmbar. In einigen Fällen handelt es sich vielleicht um mehrere Kultbilder . Doch nur bei wenigen Bildern geht dies aus den Quellen hervor. Im Folgenden sollen die Heiligtümer und ihre Bilder kurz aufgeführt werden.

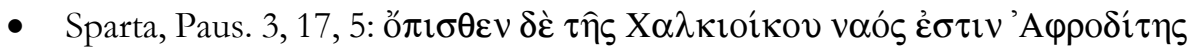

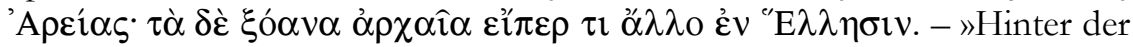
Chalkioikos gibt es einen Tempel der Aphrodite Areia; die Xoana sind alt wie keine sonst bei den Griechen«.

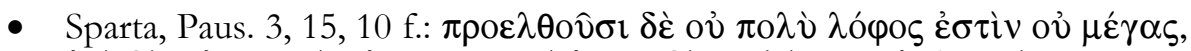

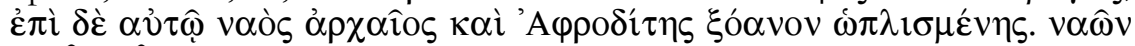

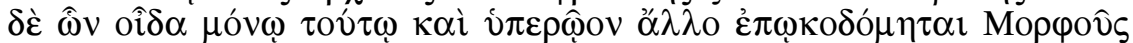

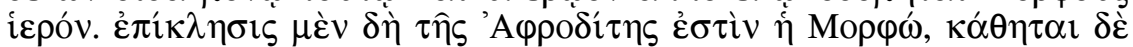

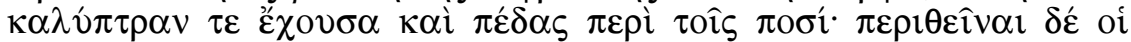

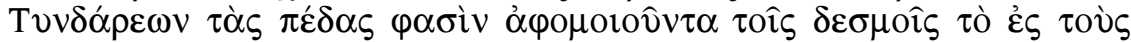

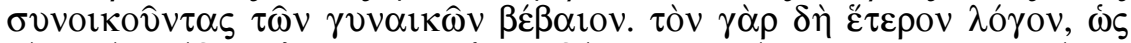

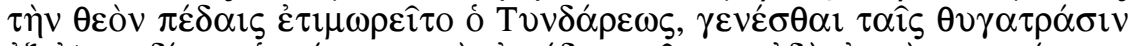

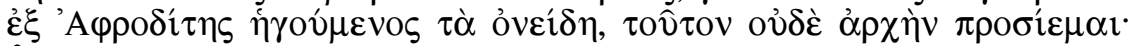

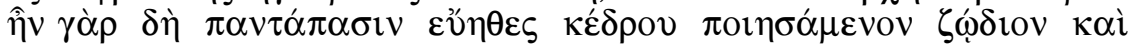

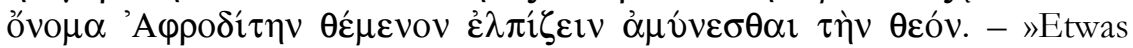
weiter ist ein nicht großer Hügel und darauf ein alter Tempel und ein Holzbild einer bewaffneten Aphrodite. Von allen Tempeln, die ich gesehen habe, ist nur diesem noch ein oberes Geschoß aufgebaut, das der Morpho heilig ist. Morpho ist ein Beiname der Aphrodite; sie sitzt mit einem Schleier und mit Fesseln an den Füßen. Die Fesseln soll ihr Tyndareos angelegt haben, um mit den Fesseln die eheliche Treue der Frauen anzudeuten. Den die 
andere Erzählung, daß Tyndareos die Göttin mit den Fesseln strafen wollte, da er glaubte, die Schande für seine Töchter komme von Aphrodite, lasse ich durchaus nicht gelten. Es wäre ja wahrhaft töricht, ein Bild aus Wacholderholz zu machen, es Aphrodite zu nennen und zu glauben, man könne sich damit an der Göttin rächen«. (F. Eckstein - P. C. Bol)

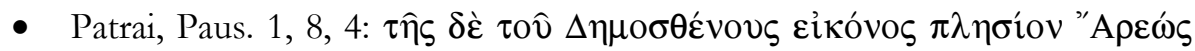

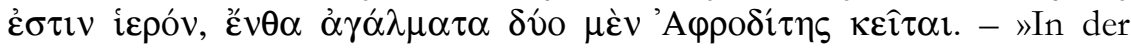
Nähe der Demosthenesstatue befindet sich ein Heiligtum des Ares. Dort stehen zwei Standbilder der Aphrodite«. (F. Eckstein - P. C. Bol)

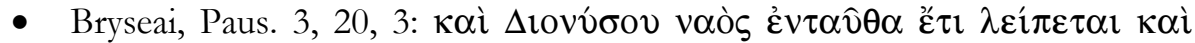

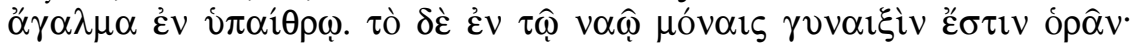

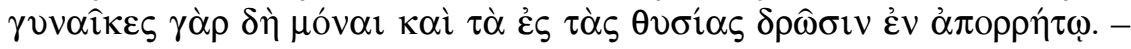
$»$ Hier ist noch ein Tempel des Dionysos übrig und eine Statue im Freien. Diejenige im Tempel dürfen nur Frauen sehen, Frauen allein verrichten auch die Opfer im Geheimen«. (F. Eckstein - P. C. Bol)

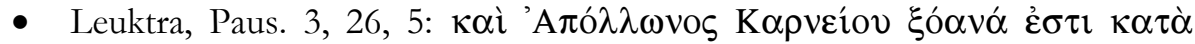

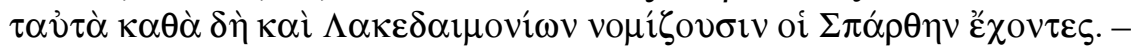
»Es gibt Xoana des Apollon Karneios, ganz nach derselben Art wie man sie bei den Lakedaimoniern in Sparta hat«.

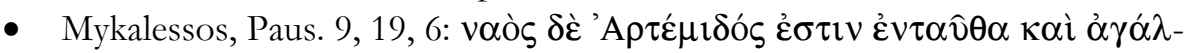

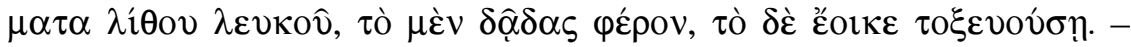
»Ein Tempel der Artemis ist hier und Statuen aus Marmor, die eine mit Fackeln, die andere gleicht einer Bogenschützin«. (F. Eckstein - P. C. Bol)

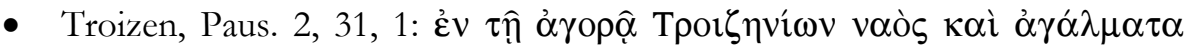

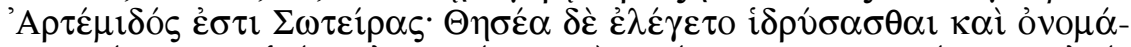

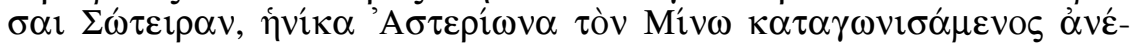

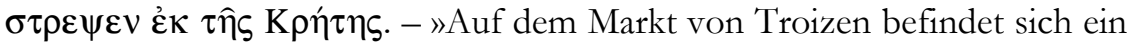
Tempel mit Agalmata der Artemis Soteira. Theseus soll ihn gegründet haben und die Artemis Soteira genannt haben, weil er nach Überwindung des Asterion, des Sohnes des Minos, aus Kreta zurückgekehrt sei«.

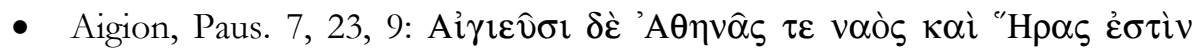

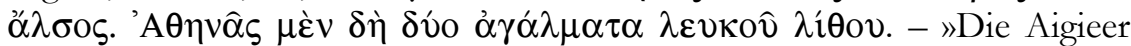
haben einen Tempel der Athena und einen Hain der Hera. Athena hat zwei Statuen aus Marmor«. (F. Eckstein - P. C. Bol)

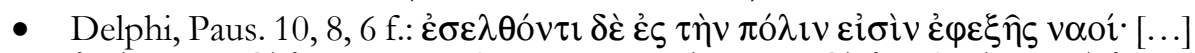

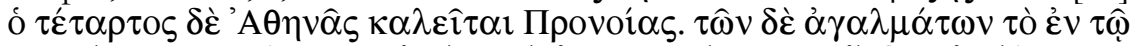

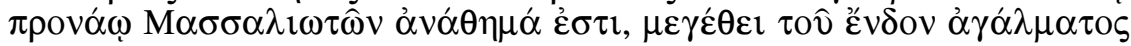

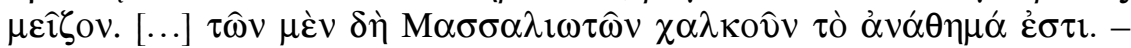
$»$ Wenn man die Stadt hineingeht, sieht man mehrere Tempel hintereinander [...] der vierte wird Tempel der Athena Pronaia genannt. Von seinen zwei Statuen ist die im Pronaos eine Gabe der Massalioten, und sie ist größer als die Statue im Tempel. [...] Die Gabe der Massalioten ist aus Bronze«. 


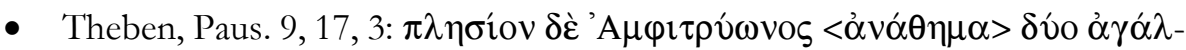

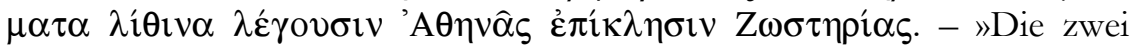
Athenen mit dem Beinamen Zosteria in der Nähe, sagen sie, sollen von Amphitryon aufgestellt sein«.

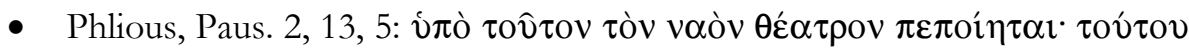

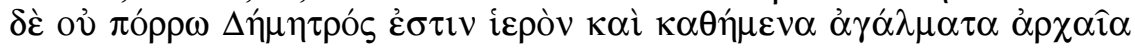
- »Unter diesem Tempel ist ein Theater gebaut, und von diesem nicht weit ein Heiligtum der Demeter mit alten Sitzstatuen«. (F. Eckstein - P. C. Bol)

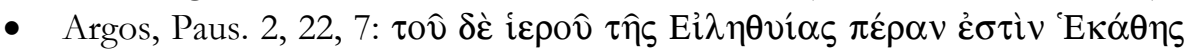

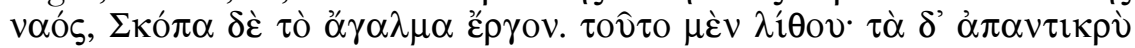

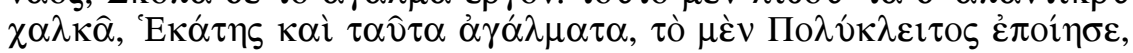

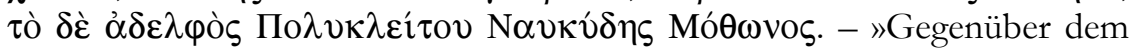
Heiligtum der Eileithyia liegt ein Tempel der Hekate mit einem Kultbild von Skopas. Dieses ist aus Marmor, diejenigen gegenüber aber aus Bronze, auch diese Hekatestatuen, und das eine machte Polyklet, das andere Polyklets Bruder Naukydes«. (F. Eckstein - P. C. Bol)

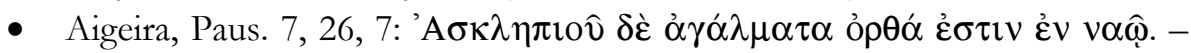
»Standbilder des Asklepios stehen in einem Tempel«. (F. Eckstein - P. C. Bol)

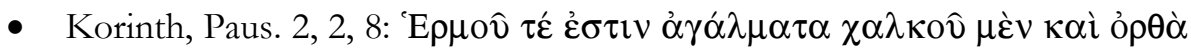

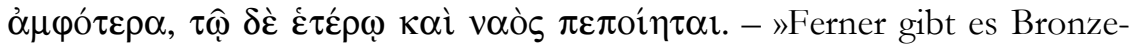
statuen des Hermes, beide stehend, und für die eine ist auch ein Tempel gebaut«. (F. Eckstein - P. C. Bol)

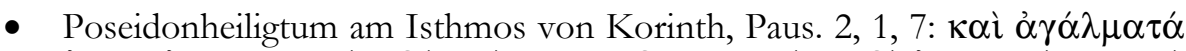

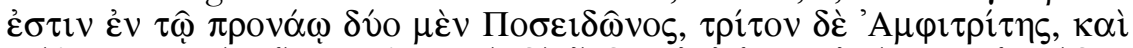

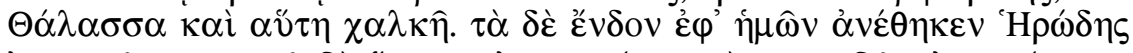

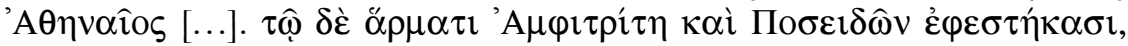

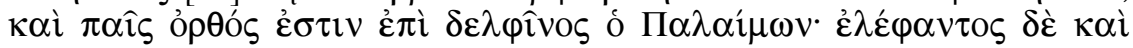

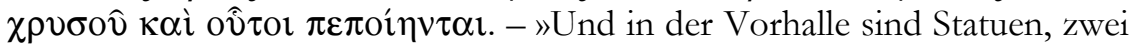
von Poseidon, eine dritte von Amphitrite und eine Thalassa (»Meer»), auch diese aus Bronze. Die jetzige Gruppe im Inneren hat der Athener Herodes geweiht [...]. Auf dem Wagen stehen Amphitrite und Poseidon, und ein Kind steht auf einem Delphin, Palaimon. Auch diese sind aus Gold und Elfenbein«. (F. Eckstein - P. C. Bol)

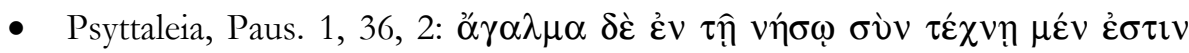

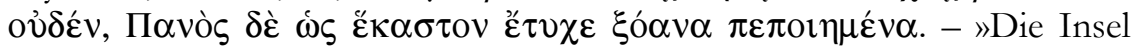
hat keine künstlerisch gefertigten Bilder, nur Xoana des Pan, wie man sie eben antrifft«.

Auch in heiligen Hainen hat es mehrere Bilder der dort verehrten Gottheit geben:

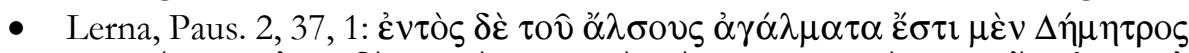

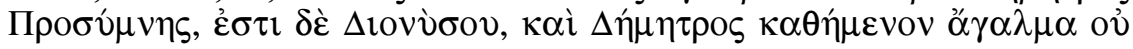
$\mu \varepsilon \dot{\varepsilon} \gamma \alpha \cdot \tau \alpha \hat{v} \tau \alpha \mu \dot{\varepsilon} \nu \lambda \hat{i} \theta 0 v \pi \varepsilon \pi \mathrm{o} \eta \mu \dot{\varepsilon} v \alpha$. - »Innerhalb des Haines stehen Sta- 
tuen der Demeter Prosymna und auch des Dionysos, ferner ein nicht großes Sitzbild der Demeter. Diese sind aus Marmor«. (F. Eckstein - P. C. Bol)

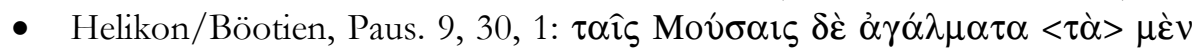

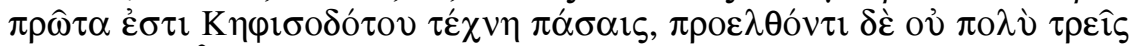

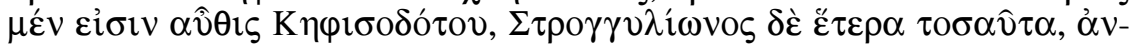

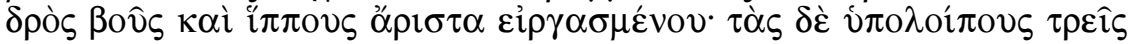

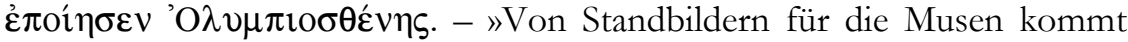
zuerst die ganze Gruppe von der Hand des Kephisodotos, etwas weiter folgen drei, die wieder von Kephisodot sind, und ebenso viele andere von Strongylion, einem Mann, der besonders Rinder und Pferde am besten darstellte, die übrigen drei schuf Olympiosthenes«. (F. Eckstein - P. C. Bol)

Die aufgeführten Quellen berichten von weiteren griechischen Heiligtümern mit mehreren Bildern der dort verehrten Gottheit. Die Funktion der überlieferten Bilder kann jedoch nur selten bestimmt werden, da sich in den Quellen keine Angaben dazu finden. Oft wird es sich um Dankes- oder Bittgaben gehandelt haben und nicht um Bilder, die von vorn herein zum Zweck der Verehrung aufgestellt worden sind. Zu demselben Ergebnis würde eine Betrachtung der Funde statuarischer Ausstattung griechischer Heiligtümer führen, worauf hier jedoch nicht weiter eingegangen werden kann. Antike Kultbezirke waren voll von Götterdarstellungen in den unterschiedlichsten Formen, von kleinen Terrakottastatuetten bis zu großen Marmor- oder Bronzestatuen ${ }^{861}$. Da die genannten Bilder jedoch Eingang in die antike Literatur gefunden haben und damit etwas Besonderes darstellten und in den vorangegangenen Abschnitten mehrere gesicherte Beispiele für mehr als ein >Kultbild benannt werden konnten, besteht zumindest die Möglichkeit, dass es sich auch bei diesen Statuen um mehrere, zusammen in einem Heiligtum stehende `Kultbilder gehandelt haben kann.

Die Angaben zum Standort beschränken sich meist darauf, dass die Bilder in einem Heiligtum bzw. in einem Tempel stehend beschrieben werden. Genauer sind die Angaben zu den Statuen der Artemis in Troizen, des Asklepios in Aigeira und der Hekate in Argos, die zusammen in einem Tempel standen, die zuletzt genannten standen einander gegenüber. In Bryseai befand sich ein Bild des Dionysos im Tempel, das zweite davor, gleiches ist von den Hermesstatuen in Korinth zu vermuten. Eine Aufteilung der Statuen auf die Cella und den Pronaos des jeweiligen Tempels gab es im Heiligtum der Athena Pronaia in Delphi und im Poseidonheiligtum bei Korinth. Wie schon bei den beiden Bildern des Zeus in Aigion in Kapitel 12.19 vermutet wurde, wird es sich bei Statuen, die vor einem Tempel bzw. im Pronaos gestanden haben, nicht unbedingt um zum Zweck der Vereh-

861 Man denke hier nur an die zahlreichen Zeusstatuen aus dem Heiligtum in Olympia. Bei den meisten handelt es sich um Dankes- oder Bittgabe an die Gottheit, die nicht mit primär mit dem Ziel der Verehrung aufgestellt worden sind, s. Mallwitz 1972, 34; Sinn 2004, 62 f. 
rung aufgestellte Bilder gehandelt haben. Die Statue im Tempel, war wahrscheinlich das eigentliche $>$ Kultbild ${ }^{862}$.

Die Angaben zur Datierung der Bilder sind oft nur ungenau, wenn das Alter überhaupt angegeben ist. Als ganz besonders alt galten die Bilder der Aphrodite Areia in Sparta, der Athena Zosteria in Theben und der Artemis Soteira in Troizen, der Demeter in Phlious sowie zumindest das eine Bild der Aphrodite Morpho in Sparta. Von berühmten klassischen Bildhauern stammten die Bilder der Hekate in Argos und die Musengruppen im Heiligen Hain des Helikon in Böotien. Die Statuengruppe in der Cella Poseidontempels am Isthmos von Korinth stammt erst aus der Kaiserzeit und ersetzte wahrscheinlich eine ältere Gruppe. Das Alter und das zeitliche Verhältnis der jeweiligen Bilder sind demnach nicht in allen Fällen bestimmbar. Einige stammen aus verschiedenen Zeiten, andere waren gleichzeitig entstanden wie die Bilder der Athena in Theben und vielleicht auch die der Aphrodite in Sparta. In den meisten Fällen ist nicht die Rede von Ersatz der alten Bilder durch die neuen, falls sie unterschiedlichen Alters waren. Es ist demnach nicht unwahrscheinlich, dass die Statuen jeweils zusammen aufgestellt worden sind, was auch schon in den vorigen Kapiteln festgestellt werden konnte.

Angaben zum Material liegen häufiger vor und bezeugen sowohl Holz, Marmor und Bronze als auch Bilder in Akrolithtechnik. Das Aussehen der Bilder wird hingegen selten beschrieben. Das eine Bild der Aphrodite Morpho in Sparta war bewaffnet. Das andere hingegen ein bekleidetes und gefesseltes Sitzbild ${ }^{863}$. Sitzend waren die beiden Demeterbilder in Phlious sowie das eine derselben Göttin in Lerna dargestellt. Von den beiden Artemisstatuen in Mykalessos stellte die eine die Göttin als Jägerin dar, die andere trug Fackeln. Die beiden Statuen des Hermes in Korinth zeigten den Gott stehend. Der Poseidon im Inneren des Tempels am Isthmos von Korinth war als Lenker eines Wagengespanns dargestellt.

${ }^{862}$ Dass sowohl Statuen im Tempel als auch davor Kult empfangen konnten, belegen einige Beispiele für verschiedene Kulte an einem Ort, die in Kap. 14 noch betrachtet werden sollen. So gab es z. B. im Tempel des Apollon auf der Athener Agora eine Statue des Patroos in der Cella und eine des Alexikakos vor dem Tempel. Die verschiedenen Beinamen lassen auf zwei unterschiedliche Kulte schließen. Gleiches gilt auch für den Tempel der Aphrodite sin den Gärten in Athen, vor dem zusätzlich ein Bild der Aphrodite Urania stand. Auch in Megalopolis gab es drei Aphroditestatuen im Pronaos des Tempels mit unterschiedlichen Beinamen. Da der Pronaos der einzig erhaltene Teil des Tempels gewesen ist, spricht der Standort dort nicht gegen eine Funktion der Bilder im Kult.

863 Das Bild der Aphrodite Morpho fanden einige Forscher auf einem Relief, dass sich heute im Museum von Sparta, Inv. 3363, befindet, dargestellt: G. Steinhauer, in: O. Palagia, W. Coulson (Hrsg.), Sculpture from Arcadia and Laconia. Proceedings of an International Conference held at the American School of Classical Studies at Athens, April 10-14, 1992 (Oxford 1993) 231 Abb. 8; A. Faustoferri, Il trono di Amyklai e Sparta. Bathykles al servizio del potere (Perugia 1996) 225 Anm. 270. 



\section{Weitere Belege für verschiedene Kulte}

Den Beginn dieses dritten Teils der Arbeit bildete die Untersuchung der Kulte der Athena Polias und der Athena Parthenos in Athen. Nachdem man lange Zeit geglaubt hat, es handelte sich um einen Kult mit nur einem `Kultbild - nämlich den der Athena Polias, haben die Untersuchungen der letzten Jahrzehnte gezeigt, dass es sich um zwei unterschiedliche Kulte gehandelt hat, so dass die Existenz zweier >Kultbilder unproblematisch ist. Pausanias nennt weitere antike Kulte, bei denen die Gottheiten den Namen einer großen griechischen Gottheit, aber verschiedene Beinamen trugen, und zwar den der Aphrodite Urania, Pandemos und Apostrophia in Theben, den der Aphrodite Urania und Pandemos in Megalopolis, den der Aphrodite sin den Gärten mit einem Bild der Aphrodite Urania in Athen, den des Dionysos Patroos und Dasyllios in Megara, den des Dionysos Bakcheios und Lysios in Sikyon und in Korinth, den des Dionysos Mesateus, Antheus und Aroëus sowie zeitweilig auch des Aisymnetes in Patrai, den der Hera Teleia und Nympheuomene in Plataiai, den der Demeter Erinys und Lousia in Onkeion, den des Zeus Chthonios und Hypsistos in Korinth, den des Apollon Karneios und Aphetaios in Sparta, den des Apollon Pythios, Dekatephoros und Archegetes in Megara, den des Apollon Klariotis, Hippothoïtis, Apollonitis und Athanaiatis in Tegea und den des Apollon Patroos und Alexikakos in Athen. Athenaios erwähnt, dass das Heiligtum des Dionysos Meilichius und Bakcheus von Naxos ebenfalls mehr als ein Bild beherbergte. Die Untersuchung dieser Statuen dient demnach nicht wirklich der Beantwortung der Frage, ob es zwei Kultbilder ein und derselben Gottheit in einem Heiligtum gegeben hat. Der Vollständigkeit des Phänomens mehrfacher `Kultbilder halber sollen sie hier aber kurz betrachtet werden.

- Theben, Paus. 9, 16, 3 f.: 'A

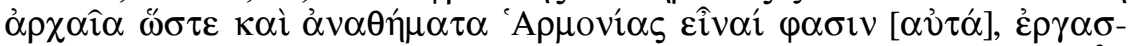

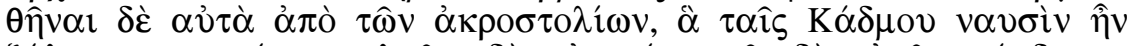

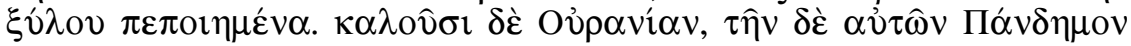

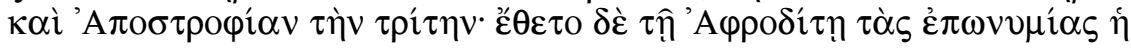




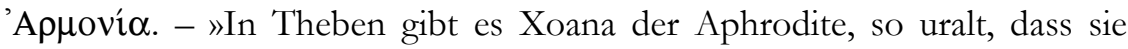
Gaben der Harmonia sein sollen, und die Geschichte besagt, dass sie aus den Zierraten der Schiffe des Kadmos gefertigt sein sollen. Sie nennen die erste Urania, die zweite Pandemos und die dritte Apostrophia. Die Beinamen gab Harmonia der Aphrodite

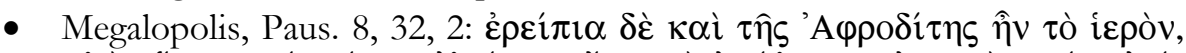

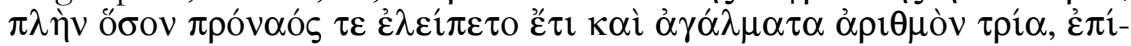

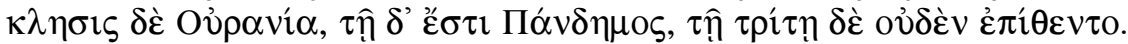
- »In Ruinen lag auch das Heiligtum der Aphrodite, von dem nur noch der Pronaos übrig war und drei Statuen; sie tragen die Beinamen Ourania (»die Himmlische«), die andere Pandemos (»die allen Zugewandte«), während sie der dritten keinen Beinamen beilegten«. (F. Eckstein - P. C. Bol)

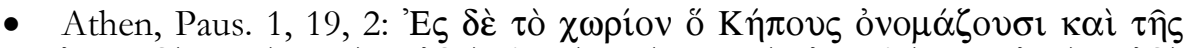
'A

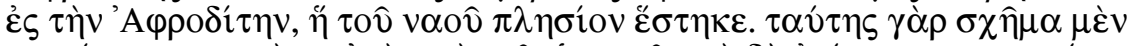

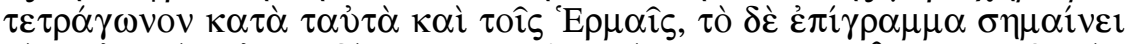

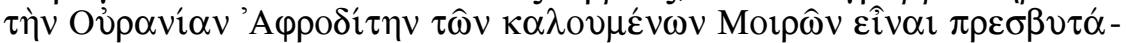

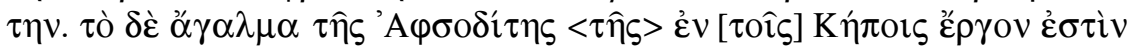

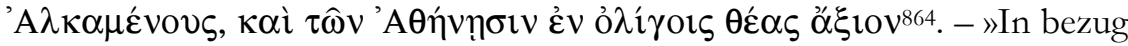
auf den Ort den sie »Gärten« nennen, und den Aphroditetempel wird keine Sage erzählt, auch nicht von der Aphrodite, die nahe bei dem Tempel steht; sie ist der Form nach ebenso viereckig wie die Hermen. Die Inschrift besagt, daß Aphrodite Ourania die älteste der sogenannten Moiren sei. Die Kultstatue der Aphrodite »in den Gärten« ist ein Werk des Alkamenes und sehenswert wie weniges andere in Athen«. (F. Eckstein - P. C. Bol)

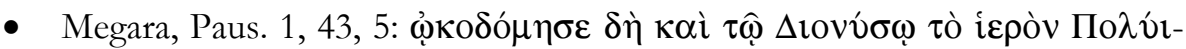

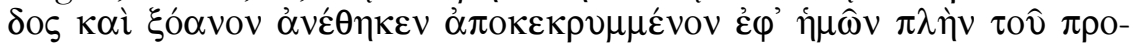

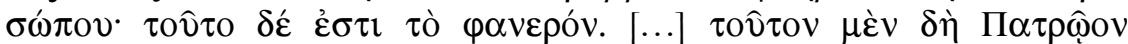

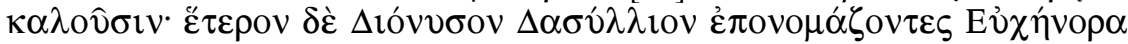

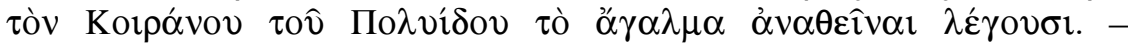
»Polyeidos errichtete auch das Heiligtum für Dionysos und stiftete ein Xoanon, das heutzutage verhüllt ist bis auf das Gesicht, das allein sichtbar ist. [...] Diesen Dionysos nennen sie Patroos, und einen anderen Dasyllios, dessen Statue, sagen sie, ist geweiht worden von Euchenor, dem Sohn des Koiranos, dem Sohn des Polyeidos«.

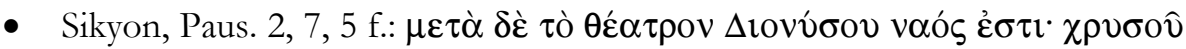

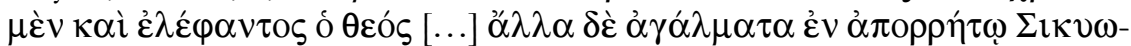

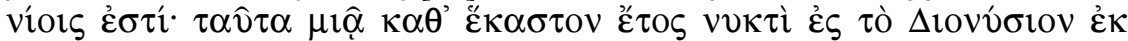

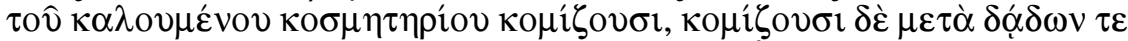

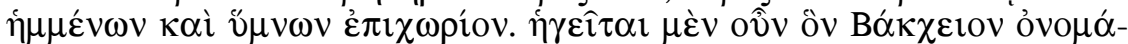

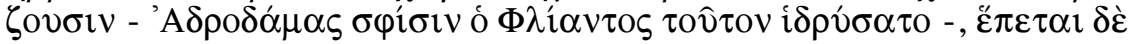




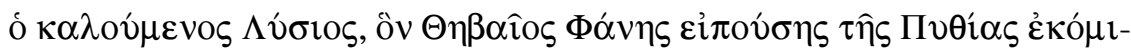

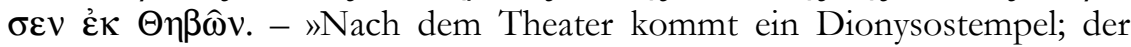
Gott ist aus Gold und Elfenbein, neben ihm stehen marmorne Bakchen. Andere Kultbilder haben die Sikyonier im Verborgenen; diese bringen sie jedes Jahr in einer Nacht aus dem so genannten Kosmeterion ins Dionysion mit brennenden Fackeln und einheimischen Hymnen. Voran geht der, den sie Bakcheios nennen, dessen Kult Andromadas, der Sohn des Phlias, einrichtete, und es folgt der so genannte Lysios, den der Thebaner Phanes auf Geheiß der Pythia aus Theben brachte«. (F. Eckstein - P. C. Bol)

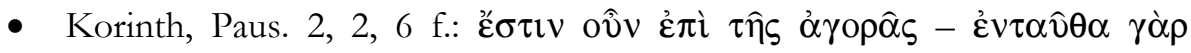

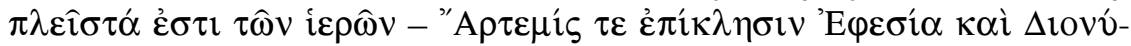

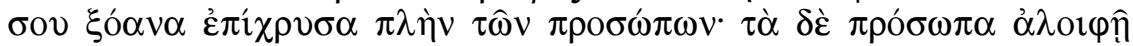

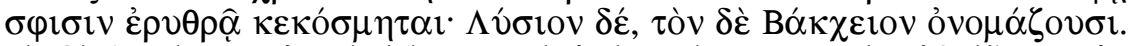

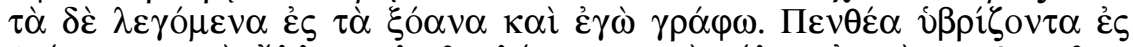

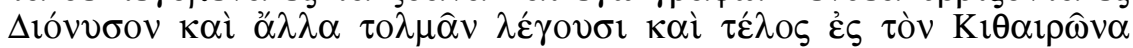

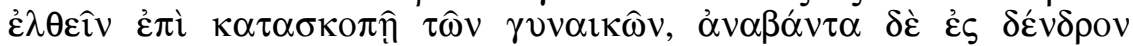

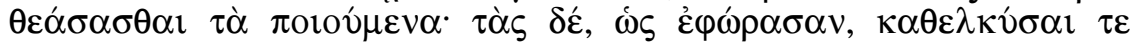

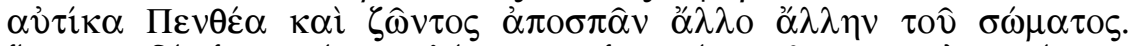

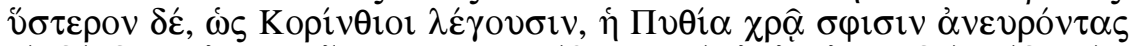

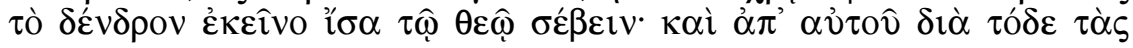

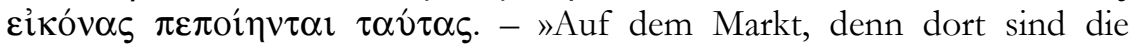
meisten Heiligtümer, steht eine ephesische Artemis mit Beinamen und Holzbilder des Dionysos, die außer an den Gesichtern vergoldet sind. Die Gesichter sind mit einem roten Überzug versehen, und den einen nennt man Lysios, den anderen Bakcheios. Die Legende über die Holzbilder will ich auch erzählen. Pentheus soll in seinem Frevel gegen Dionysos auch noch anderes gewagt haben und schließlich auch auf den Kithairon gekommen sein, um die Frauen zu belauschen. Er sei dabei auf einen Baum gestiegen, um zu beobachten, was sie tun. Diese aber hätten den Pentheus, wie sie ihn erspähten, herabgezogen und bei lebendigem Leibe zerrissen. Später aber, so berichten die Korinther, habe die Pythia ihnen befohlen, den Baum aufzusuchen und ihn wie einen Gott zu verehren. Aus diesem Grunde verfertigten sie damals diese Schnitzbilder«. (F. Eckstein - P. C. Bol)

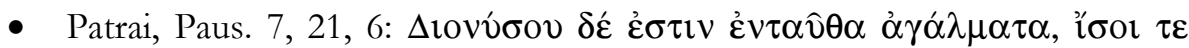

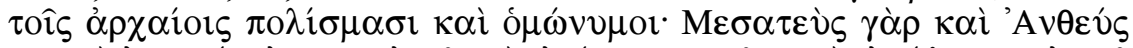

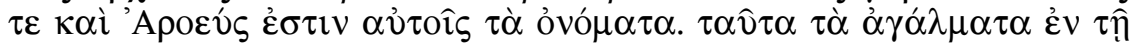

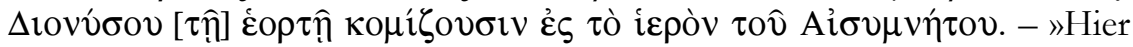
stehen Kultbilder des Dionysos, ebenso viele wie die alten Städte und mit den gleichen Namen; denn sie heißen Mesateus und Antheus und Aroëus. Diese Statuen bringen sie beim Dionysosfest in das Heiligtum des Aisymnetes« (F. Eckstein - P. C. Bol)

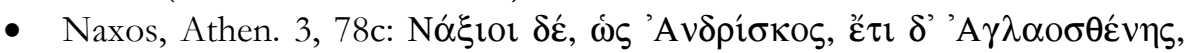

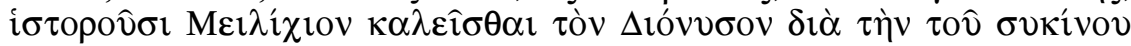

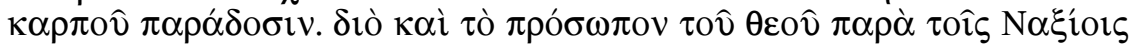




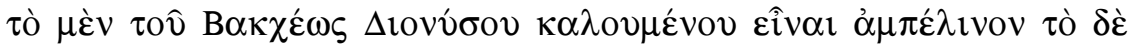

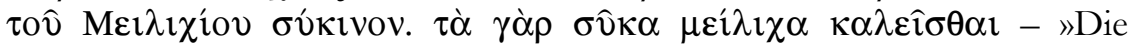
Bewohner von Naxos aber - so Andriskos, ferner auch Aglaosthenes - berichten, daß Dionysos wegen der Überreichung der Feigenfrucht 'Meilichos' genannt werde. Deswegen sei bei den Bewohnern von Naxos das Angesicht des Gottes, einerseits das des Bakcheus Dionysos genannten von Rebenholz, das des Meilichios von Feigenholz; denn die Feigen werden 'meílicha' genannt«. (C. Friedrich - Th. Nothers)

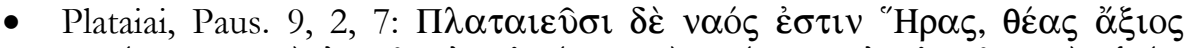

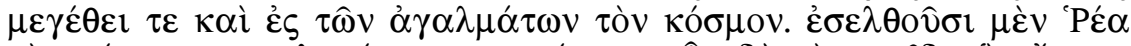

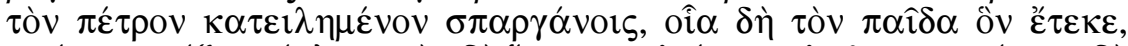

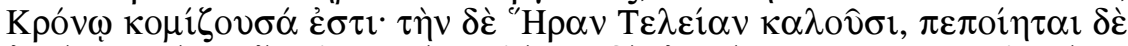

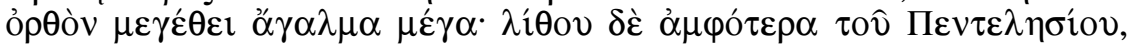

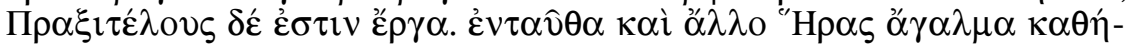

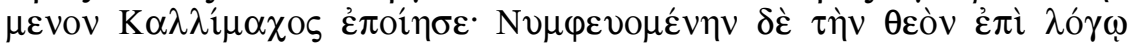

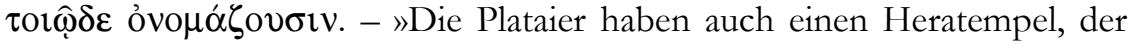
sehenswert ist wegen seiner Größe und der Ausführung der Statuen. Wenn man eintritt, ist Rhea dargestellt, wie sie dem Kronos den in Windeln gewickelten Stein als das Kind bringt, das sie gebar; die Hera nennen sie Teleia (,die Vollenderin“), und sie ist als großes Standbild stehend dargestellt. Beide sind aus pentelischem Marmor und Werke des Praxiteles. Hier hat auch Kallimachos ein anderes Sitzbild der Hera geschaffen; sie nennen die Göttin die bräutliche $[. ..] \ll$. (F. Eckstein - P. C. Bol)

- Onkeion bei Thelpousa, Paus. 8, 25, 6 f.: $\tau \dot{\alpha} \delta \dot{\varepsilon} \alpha \dot{\alpha} \gamma \alpha \dot{\alpha} \mu \alpha \tau \alpha \dot{\alpha} \varepsilon \dot{\varepsilon} \sigma \tau \tau \grave{\alpha}<\dot{\varepsilon} v$

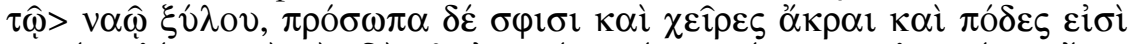

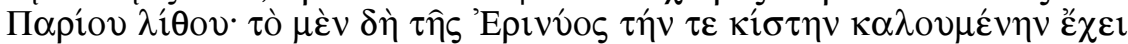

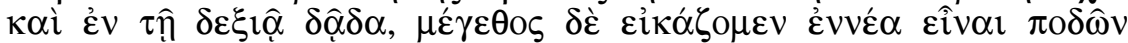

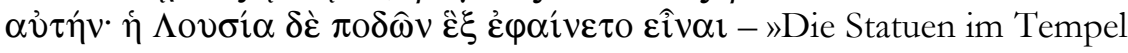
sind aus Holz, aber Gesicht und Hände und Füße sind aus parischem Marmor. Das Standbild der Erinys hält die so genannte Cista und in der rechten Hand eine Fackel, ihre Größe schätze ich auf neun Fuß; die Lousia schien sechs Fuß hoch zu sein«. (F. Eckstein - P. C. Bol)

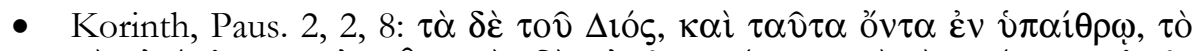

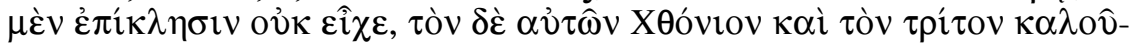
$\sigma \iota v " Y \psi \iota \sigma \tau o v . ~-~ »$ Von den Zeusstatuen, auch diese stehen unter freiem Himmel, hatte die eine keinen Beinamen, die andere davon nennen sie Chthonios und die dritte Hypsistos«. (F. Eckstein - P. C. Bol)

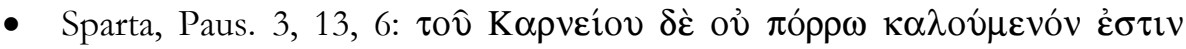

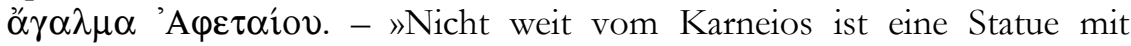
Namen Aphetaios«. (F. Eckstein - P. C. Bol)

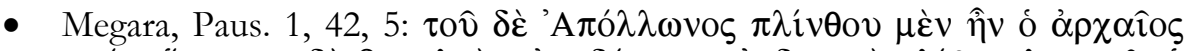

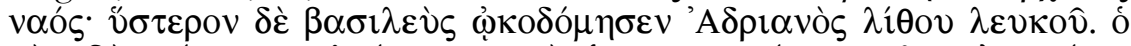

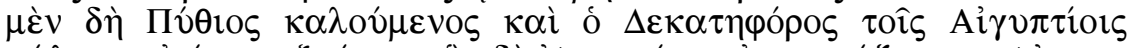

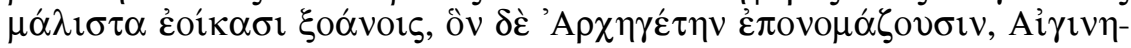




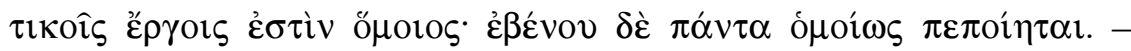
»Der alte Tempel des Apollon war aus Ziegeln, später baute ihn Kaiser Hadrian aus Marmor. Der sogenannte Pythios und der Dekatephoros gleichen am meisten den aigyptischen Holzstatuen, der, den sie Archegetes nennen, ist aiginetischen Werken ähnlich; alle sind sie gleichermaßen aus Ebenholz«. (F. Eckstein - P. C. Bol)

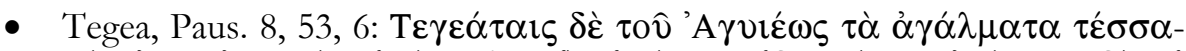

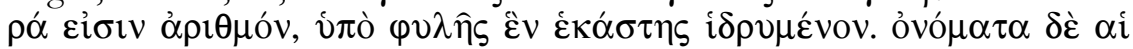

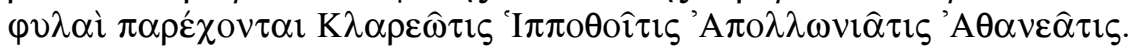
- »Die Tegeaten haben vier Statuen des Agyieus, eine von jeder Phyle, aufgestellt. Die Phylen heißen Klariotis, Hippothoïtis, Apolloniatis, Athanaiatis«. (F. Eckstein - P. C. Bol)

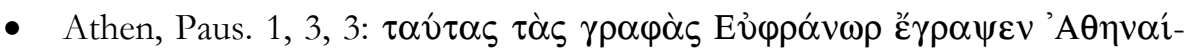

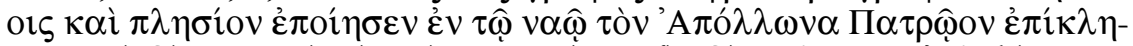

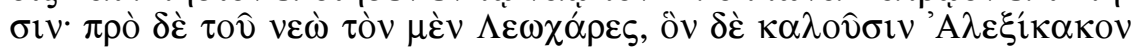

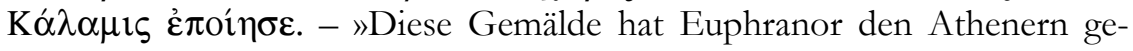
malt, und in der Nähe hat er auch den Apollon mit Beinamen Patroos in seinem Tempel gemacht. Vor dem Tempel haben eine Statue Leochares, die andere, die Alexikakos (»der Übelabwehrende«) heißt, Kaiamis gemacht«. (F. Eckstein - P. C. Bol)

Dieses Heiligtum bestand vielleicht schon seit dem 6. Jahrhundert v. Chr. ${ }^{865}$. Gesichert ist ein Tempel aus der 2. Hälfte des 4. Jahrhunderts v. Chr. Die Bilder dienten laut Pausanias verschiedenen Kulten, auch wenn nur die eine Statue im Tempel gestanden hat, die anderen hingegen davor. Es waren Werke des Euphranor und Leochares aus dem 4. Jahrhundert v. Chr. ${ }^{866}$

865 Auf dem Areal des Heiligtums waren Reste einer Gussform gefunden worden, mit der um $550 \mathrm{v}$. Chr. ein Kouros von ca. $2 / 3$ Lebensgröße hergestellt wurde. In diesem sah H. A. Thompson vor Ort gegossene Bild des archaischen Tempels, da keine weiteren Zeugnisse für einen regelmäßigen oder länger andauernden Werkstattbetrieb vorliegen. Die Identifizierung der Statue als Apollon oder gar als Bild des Tempels ist jedoch nicht gesichert. Der Tempel scheint während der Perserkriege zerstört worden zu sein, eine Kontinuität in das 4. Jahrhundert, als ein weiterer Tempel gebaut wurde, ist noch nicht belegt: Thompson 1937, 77-115; Thompson 1976, 74-76; Bald Romano 1980, 309-313; O. Palagia, Euphranor (Leiden 1980) 13 f.; Camp 1986, 139 f. 159-162; M. Flashar, Apollon Kitharodos. Statuarische Typen des musischen Apollon (Köln 1992$) 50$ f.; H. Knell, Der jüngere Tempel des Apollon Patroos auf der Athener Agora, JdI 109, 1994, 217-237; Knell 1995. Ein Grenzstein mit einer Inschrift an Apollon Patroos war südöstlich der Agora gefunden worden. Er wird von R. E. Wycherley, Literary and Epigraphical Testimonia, Agora 3 (Princeton 1957) 53; B. D. Meritt, Greek Inscriptions III. Decrees and other Texts, Hesperia 26, 1957, 51-97 Nr. 38; Knell 1995, 480 als Grenzmarkierung des weiter bestehenden Heiligtums aus dem späteren 5. Jahrhundert gedeutet.

Zu dem Kouros s. auch W.-D. Heilmeyer, Technischer Fortschritt beim Klassischen Bronzeguss?, in: Pöhlmann - Gauer 1994, 213-227; Knell 1995, 480; G. Zimmer, Die Bronzegusswerkstatt des Pheidias am Südabhang der Akropolis, in: Klassik 2002, 501-506.

866 RE VI (1909) 1191-1194 s. v. Euphranor (C. Robert); DNP IV (1998) 268 f. s. v. Euphranor (R. 
sowie des Kalamis, dessen Datierung umstritten ist. Zumeist wird er mit einem für die 1. Hälfte des 5. Jahrhundert v. Chr. bezeugten Kalamis identifiziert ${ }^{867}$. Laut Ch. W. Hedrick handelt es sich hingegen um einen jüngeren Kalamis aus dem 4. Jahrhundert v. Chr., da es vorher keinen Tempel in dem Heiligtum gab ${ }^{868}$. Er kann sich nicht vorstellen, dass die Statue nach dem Bau des Tempels versetzt worden ist. Dies ist aber durchaus möglich. Das jüngere Bild des Dionysos Eleuthereus in Athen ist gleichfalls älter als der Tempel und wurde erst nach dessen Erbauung dort aufgestellt, wie in Kapitel 12.5 dargelegt worden ist. Ch. W. Hedrick nimmt an, dass der Apollonkult erst im 4. Jahrhundert v. Chr. auf der Agora Einzug gehalten hat. Dabei ist er jedoch gezwungen, die Kulte für die davor liegende Zeit im Heiligtum des Apollon Pythios am Ilissos anzusiedeln, da der des Apollon Patroos und vielleicht auch der des Alexikakos bereits vor dem 4. Jahrhundert v. Chr. bezeugt sind ${ }^{869}$. Dafür gibt es jedoch keine Belege. Mit dem benachbarten Metroon liegt zudem ein Beispiel für die Zerstörung eines archaischen Tempels während der Perserkriege vor, der nicht wieder aufgebaut worden ist, und wo der Kult stattdessen verlagert worden zu sein scheint ${ }^{870}$.

Nach E. Lippolis hingegen diente der nördliche Raum des benachbarten Metroons, in dem die Euphranor zugeschriebene Statue des Apollon Patroos gefunden wurde, als Apollontempel. Da die Statue zu groß für eine Umsetzung sei und deshalb immer an der Stelle gestanden habe, an der sie gefunden wurde, schließt er, dass es sich hierbei um das gesuchte Heiligtum han-

Neudecker) sowie RE XII (1925) 1992-1998 s. v. Leochares (G. Lippold); Pollitt 1990, 90-94; DNP VII (1999) 5f. s. v. Leochares (R. Neudecker). Ein nur wenig südlich des als Tempel des Apollon Patroos gedeuteten Gebäudes gefundener Marmortorso aus der Zeit um 330 v. Chr. ist als Fragment der Statue des Euphranor identifiziert worden (Athen, Agoramuseum Inv. S 2154). Durch kaiserzeitliche Kopien sowie Darstellungen auf Reliefs kann ihr Aussehen rekonstruiert werden. Sie zeigte Apollon als Kitharspieler in einem bodenlangen Gewand: Thompson 1976, 180; Thompson 1937, 107 f.; O. Palagia, Euphranor (Leiden 1980) 13-20 Abb. 6-28; Camp 1986, 159-162; Hedrick 1988, 198-200; M. Flashar, Apollon Kitharodos. Statuarische Typen des musischen Apollon (Köln 1992) 50-60 Abb. 37-43; H. Knell, Der jüngere Tempel des Apollon Patroos auf der Athener Agora, JdI 109, 1994, 231-234; Knell 1995 Abb. 17; Ridgway 1997, 335-337; C. Maderna, Die letzten Jahrzehnte der spätklassischen Plastik. Form und Raum, in: Bol 2004, 369 f. Abb. 335.

${ }^{867}$ F. Studniczka, Kalamis. Ein Beitrag zur griechischen Kunstgeschichte (Leipzig 1907) 64-68; RE X (1917) 1532-1536 s. v. Kalamis (G. Lippold); Thompson 1937, 109; G. M. A. Richter; The Sculpture and Sculptors of the Greeks ${ }^{3}$ (New Haven, 1950) 203-207; Pollitt 1990, 46-48; Knell 1995, 487; DNP VI (1999) 148-149 s. v. Kalamis (R. Neudecker).

868 Hedrick 1988, 190 f. deutet das archaische Gebäude als Bronzegießerwerkstatt, wie sie auch sonst auf der Agora belegt sind und schließt damit die ältere Phase des Heiligtums aus.

${ }^{869}$ Hedrick 1988.

870 s. Kap. 12.18.1. Der Tempel der Hera, der zwischen Athen und Phaleron gelegen hat, soll laut Pausanias 1, 1, 5 ebenfalls durch die Perser beschädigt worden sein. Er besaß weder ein Dach noch Türen. Dennoch stand in ihm eine Statue der Göttin, die Alkamenes geschaffen haben soll. 
deln muss ${ }^{871}$. Da das Gebäude, in dem die Statue gefunden worden ist, aus dem 2. Jahrhundert v. Chr. stammt, die Statue jedoch aus dem 4., wäre eine, zumindest temporäre Umsetzung während des Neubaus auch für die These von E. Lippolis unabdingbar. Außerdem hätten dann alle Statuen dieser Größe direkt an ihrem Aufstellungsort gefertigt sein müssen, was kaum jemand behaupten wolle ${ }^{872}$. Pausanias 1, 3, 3 f. spricht außerdem eindeutig von getrennten Gebäuden für die Göttermutter und den Apollon Patroos in Athen. Die genaue Entwicklung des Apollonheiligtums muss zurzeit offen bleiben, so dass auch eine gemeinsame Aufstellung verschieden datierter Bilder unsicher ist. Gesichert ist hingegen, dass es seit der 2. Hälfte des 4. Jahrhunderts v. Chr. mehrere Bilder für unterschiedliche Kulte gegeben hat.

Bei den eben genannten Bildern handelt es sich offenbar wie im Fall des Kultes der Athena Polias und der Athena Parthenos auf der Athener Akropolis um mehrere `Kultbilder verschiedener Kulte am selben Ort, wie die unterschiedlichen Beinamen bezeugen, wenn auch nicht für alle Bilder eine Kultfunktion gesichert ist. Für die Bilder des Dionysos Lysios und Bakcheios in Korinth bestätigt Pausanias explizit ihre Verehrung. Gesichert ist auch die Verehrung des Dionysos Bakcheios und Lysios in Sikyon bzw. des Dionysos Mesateus, Antheus, Aroëus und Aisymnetes in Patrai, vermutet werden kann dies für die vier nach den Phylen von Tegea benannten Statuen des Apollon sowie die Apollonbilder auf der Athener Agora.

Das Alter der Bilder ist oft nur ungenau angegeben. Die Statuen der Aphrodite in Theben sowie des Dionysos in Korinth und Sikyon sollen in mythischer Vorzeit aufgestellt worden sein. Aufgrund des Vergleiches der Bilder des Apollon in Megara mit ägyptischen und aiginetischen Werken durch Pausanias kann man für sie ebenfalls ein hohes Alter vermuten ${ }^{873}$. Alt war vielleicht auch das hermenförmige Bild der Aphrodite Urania in dem Athener Heiligtum sin den Gärten ${ }^{874}$. Seine Inschrift besagte, dass Aphrodite Urania die älteste der Moiren sei, woraus man eventuell auf ein gewisses Alter des Bildes schließen kann. Das zweite Bild dieses Heiligtums war von Alkamenes. Von Praxiteles bzw. Kallimachos waren die Statuen der Hera in Plataiai. Diese Bilder sind demnach nacheinander im 5. sowie im 4. Jahrhundert v. Chr. aufgestellt worden. Aus der Formulierung bei Pausanias

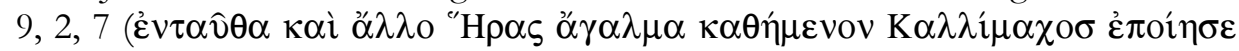

\footnotetext{
${ }^{871}$ E. Lippolis, Apollo Patroos, Ares, Zeus Eleutherios. Culto e architettura di stato ad Atene tra la democrazia e i Macedoni, ASAtene 76-78, 1998-2000, 139-218.

872 Mit einer Gesamtgröße von ca. drei Metern - der bis den fehlenden Kopf erhaltene Torso misst 2,54 m - erscheint mir die Statue wirklich nicht zu groß für einen Transport. Die Omphaloi, die zusammen mit dem Torso gefunden worden waren, können auch nicht ursprünglich in diesem Gebäude gestanden haben, da sie sehr verwittert sind, was auf eine einstige Aufstellung im Freien hindeutet, s. Thompson 1937, 110. Ablehnend auch Hedrick 1988, 198.

${ }^{873}$ H. Usener, Dreiheit, RhM 58, 1903, 206.

${ }^{874} \mathrm{Zu}$ diesem s. auch Kap. 5.1.3.
} 
- »hier hat auch Kallimachos ein anderes Sitzbild der Hera geschaffen« [F. Eckstein - P. C. Bol]) geht hervor, dass sich in dem Tempel anscheinend noch eine weitere Statue befunden haben muss. Somit enthielt der Tempel möglicherweise drei Statuen aus unterschiedlichen Zeiten, mindestens aber zwei. Einige Bilder waren demnach zeitgleich aufgestellt worden wie die Bilder des Dionysos in Korinth und der Aphrodite in Theben, vielleicht auch die des Apollon in Tegea, andere wiederum stammten aus unterschiedlichen Zeiten.

Angaben zum Material liegen ebenfalls vor. Aus Holz bestanden die drei Statuen der Aphrodite in Theben, die Apollonbilder in Megara und die Dionysosstatuen auf Naxos und in Korinth, die zusätzlich bis auf die Gesichter vergoldet waren $^{875}$. Die beiden Demeterbilder in Onkeion waren Akrolithe. Aus Marmor bestand die von Praxiteles für das Heiligtum der Hera in Plataiai gefertigte Statue. Zum Aussehen der Bilder ist nur wenig überliefert. Hermenförmig war das Bild der Aphrodite Urania in Heiligtum in den Gärten in Athen. In Plataiai gab es eine stehende und eine sitzende Statue der Hera. Die beiden Demeterstatuen in Onkeion hielten unterschiedliche Attribute, die eine eine Cista, die andere eine Fackel.

Obwohl es sich bei den genannten Beispielen um verschiedene Kulte handelte, konnten die Bilder der verehrten Götter zusammen in einem Tempel stehen wie die Bilder der Demeter in Onkeion. Auch die Statuen des Apollon Karneios und Aphetaios in Sparta standen nah beieinander. Im Freien waren die Zeusstatuen aufgestellt, die Pausanias in Korinth gesehen hat. Im Heiligtum der Aphrodite in den Gärten in Athen stand ein Bild im Tempel, das zweite davor. Für die übrigen Bilder liegen keine Angaben zum Standort vor.

875 Laut F. Frontisi-Ducroux, Le dieu-masque. Une figure du Dionysos d'Athènes (Paris 1991) $192 \mathrm{f}$. handelt es sich bei diesen Bildern nicht um ganze Figuren, sondern um Masken wie bei dem

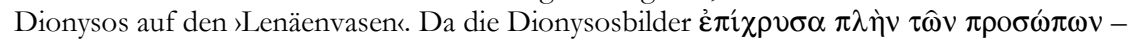
»vergoldet sind bis auf die Gesichter«, wie Paus. 2, 2, 6 f. sagt, können sie jedoch nicht nur aus Masken bestanden haben. Zu den Lenäenvasen s. A. Frickenhaus, Lenäenvasen, BWPr 72 (Berlin 1912); Lehnstaedt 1970, 97 f.; Bald Romano 1980, 70-73; R. Hamilton, Choes and Anthesteria. Athenian Iconography and Ritual (Ann Arbor 1992) 134-138. 


\section{Ergebnisse der Untersuchung}

In den vorangegangenen Kapiteln wurden antike Quellen betrachtet, die von griechischen Heiligtümern mit mehr als einem Bild der dort verehrten Gottheit sprechen. Dabei wurde unterschieden zwischen Bildern, die Kult erhielten und solchen, von denen dies nicht sicher ist, die aber dennoch so bedeutend gewesen sind, dass sie Eingang in die antike Literatur gefunden haben, während $>$ Weihgeschenke $\mathrm{im}$ traditionellen Sinn nicht betrachtet wurden. Um die Angaben der Quellen zu bestätigen und zu ergänzen wurden zudem, soweit dies bisher möglich ist, archäologische Zeugnisse wie der Baubefund der Heiligtümer, Darstellungen der Bilder, und, falls sie erhalten und identifiziert sind, originale Fragmente herangezogen. Ziel war es, einen gewissen Überblick über das Vorkommen dieses Phänomens zu gewinnen, wobei kein Anspruch auf Vollständigkeit erhoben wurde. Die Ergebnisse dieser Untersuchung sollen hier noch einmal zusammengefasst und ergänzt werden.

\subsection{Alter, Material und Standort der Bilder}

Die antiken Quellen bezeichnen häufig anikonische oder sehr einfach gestaltete Bilder als der Frühzeit angehörig. Daher hatte sich in der Forschung die Meinung entwickelt, dass anikonische Bilder den menschengestaltigen vorausgingen und sich letztere über mehrere Zwischenstufen aus ersteren entwickelt haben. Man stellte sich die frühen griechischen Götterbilder als zunächst gar nicht, später wenig gestaltete Idole aus Holz vor, die nach und nach immer menschlichere Züge annahmen, eine Entwicklung, die schließlich im 7. Jahrhundert v. Chr. in die vollkommen menschlich gebildete Steinskulptur eingemündet haben soll ${ }^{876}$. Inzwischen sind jedoch genug Beweise zusammengetragen worden, die diese Ansicht widerlegen. So-

876 Diese Ansichten wurden bereits von J. J. Winkelmann, Geschichte der Kunst des Altertums. Nachdr. der Erstausgabe von 1764 (Wien 1934) vertreten und im Folgenden immer wieder aufgegriffen: H. Brunn. Griechische Kunstgeschichte (München 1894-1897); J. Evans, Mycenaean 
wohl Steinskulptur als auch anthropomorphe Figuren gab es bereits im Neolithi$\mathrm{kum}^{877}$. Es hat weder eine fortschreitende Entwicklung von anikonischen zu ikonischen Bildern gegeben noch gingen hölzerne den steinernen Statuen generell voraus, wenn auch festgestellt wurde, dass anikonische Bilder teilweise als sehr alt angesehen wurden bzw. viele der als alt geltenden Bilder aus Holz bestanden. Dass alte Bilder immer aus Holz gefertigt waren, geht daraus jedoch nicht hervor. Auch anikonische und anthropomorphe Götterbilder existierten in allen Epochen parallel ${ }^{878}$.

Genaue Angaben zum Alter der untersuchten Bilder finden sich in den Quellen nur selten. Viele der alten Bilder sollen in mythischer Vorzeit aufgestellt oder sogar vom Himmel gefallen sein ${ }^{879}$, andere wiederum galten als alt, ohne dass dies näher bestimmt werden kann. Alten Bildern wurde eine besondere Heiligkeit und Wirkmächtigkeit zugeschrieben, die sie bereits über einen langen Zeitraum bewiesen hatten, was ihre besondere Verehrungswürdigkeit hervorrief. Aus diesem Grund wurden alte Bilder lange Zeit bewahrt und verehrt. Dies führte auch dazu, dass jüngeren Bildern z. T. durch Legendenbildung ein höheres Alter zugeschrieben wurde, um damit ihren Wert zu steigern. Dass eine lokale Überlieferung oder literarische Tradition einen Kult älter wähnt als dieser bisher archäologisch nachgewiesen werden konnte, scheint nicht selten gewesen zu sein ${ }^{880}$. Auch wenn sich immer häufiger eine real existierende Kultkontinuität bis in das zweite Jahrtausend nachweisen lässt ${ }^{881}$, scheint es in der Antike generell eine Tendenz gegeben zu haben, einen Kult so alt wie möglich zu machen, zumindest aber älter und damit

Tree and Pillar Cult and it's Mediterranean Relations, JHS 21, 1901, 99-204; M. P. Nilsson, The Minoan-Mycenaean Religion and its Survival in Greek Religion (Lund 1950) 341; B. S. Ridgway, The Archaic Style in Greek Sculpture (Princeton 1977) 37; B. Rutkowski, Frühgriechische Kultdarstellungen (Berlin 1981) 116 f. 174; B. C. Dietrich, Tradition in Greek Religion (Berlin 1986) 74; in jüngster Zeit noch Whitley 2001, 198. Die übrige Literatur findet sich zusammengefasst bei Donohue 1988, 175-231; vgl. auch H.-V. Hermann, Zum Problem der Entstehung der griechischen Großplastik, in: Wandlungen. Studien zur antiken und neueren Kunst. Ernst HomannWedeking gewidmet (Waldsassen 1975) 35-48.

877 Müller 1931, 498; P. Demargne, Die Geburt der griechischen Kunst. Die Kunst im ägäischen Raum von vorgeschichtlicher Zeit bis zum Anfang des 6. vorchristlichen Jahrhunderts (München 1965) 27-78; Donohue 1988, bes. 199-230.

878 s. Anm. 211.

${ }^{879}$ Hera in Samos und Argos, Artemis in Brauron, Ephesos, Kalydon und Troizen, Athena in Athen, Lindos, Theben und Daulis, Apollon in Delphi und Delos, Dionysos in Athen, Theben, Megara und Korinth, Aphrodite in Theben und Sparta, Trophonios in Lebadeia, Chariten in Orchomenos, Nemeseis in Smyrna, Eros in Thespiai.

880 Vgl. z. B. die Legenden zu der Statue des Sarapis in Alexandria: E. Schmidt, Kultübertragungen, Religionsgeschichtliche Versuche und Vorarbeiten 8,2 (Gießen 1909) 47-81; A. J. B. Wace, Recent Ptolemaic Finds in Egypt, JHS 65, 1945, 106-109; J. E. Stambaugh, Sarapis under the Early Ptolemies (Leiden 1972) 1-13; Hornbostel 1973; G. Grimm, Alexandria. Die erste Königsstadt der hellenistischen Welt (Mainz 1998) 81-83; Wilkinson 2003, 127 f.; M. Bommas, Heiligtum und Mysterium. Griechenland und seine ägyptischen Gottheiten (Mainz 2005) 22-24.

881 s. S. 292. 
auch bedeutender als den der benachbarten Poleis ${ }^{882}$.

Wie auch immer man die Historizität mythischer Stifter bewerten möchte, hat man die Bilder nach Ausweis der Quellen für uralt gehalten. Viele griechische Heiligtümer, darunter auch einige der hier beschriebenen ${ }^{883}$, wurden an Orten gegründet, an denen noch Spuren der Bronzezeit sichtbar waren. Mit diesen Bauresten wurde oft eine Legende verknüpft, die die Gründung des Kultes erzählte oder eine Erklärung für einzelne Kulthandlungen lieferte. So soll das Heiligtum des Zeus in Olympia durch Herakles am heiligen Mal des Pelops gegründet worden sein ${ }^{884}$. Inzwischen ist bekannt, dass die Legende mit Bezug auf ein in historischer Zeit verehrtes Kultmal entstanden ist, das ein prähistorischer Tumulus war ${ }^{885}$. Ähnlich wird auch die pseudo-kyklopische Mauer, auf der im 7. Jahrhundert v. Chr. der erste gesicherte Heratempel im Heiligtum von Argos errichtet worden ist, als gezielte Imitation mykenischer Mauern, wie sie in Mykene oder Tiryns zu finden sind, gedeutet ${ }^{886}$.

Die Legenden über mythische Stifter sind in diesem Zusammenhang als ein bewusstes Anknüpfen an eine sheroisch gedachte Vergangenheit und ehrwürdige Altertümer zu sehen: »Abgesehen davon, dass auch in archaischer und klassischer Zeit und später immer wieder Kultgründungen an bedeutungsvollen, durch irgendeine ältere Überlieferung oder durch sichtbare Spuren der Vergangenheit vorgeprägten Orten erfolgten, wird es auch bei vielen der älteren Heiligtümer Griechenlands immer deutlicher, daß sie an Stellen liegen, deren Geschichte sich anhand von Funden oder Bauresten in die Bronzezeit zurückverfolgen läßt. Genauer besehen läßt sich kaum eines der größeren alten Heiligtümer olympischer Götter benennen, das nicht über bronzezeitlichen Resten errichtet worden wäre. Es scheint, daß die Erinnerung an das hohe Alter sakraler Orte, als mythische Gründungslegenden weitergetragen oder auch in sichtbaren Zeugnissen in der Form von Bauresten oder reliquienartigen Gegenständen konserviert, als besonderes Zeichen der Würde und Bedeutung solcher Heiligtümer angesehen wurde« ${ }^{887}$.

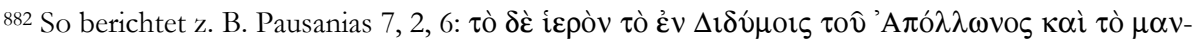

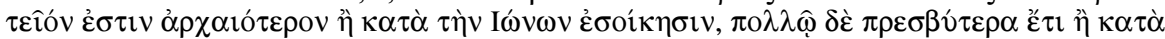

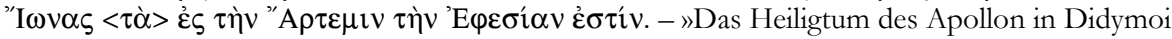
und das Orakel ist älter als die Einwanderung der Ionier. Viel älter aber noch als die Ionier ist der Kult der ephesischen Artemis«. (F. Eckstein - P. C. Bol).

883 z. B. die Heiligtümer von Olympia, Aigina, Delphi, Argos und Tiryns und die Athener Akropolis; weitere Beispiele bei Kyrieleis 2006, 61-83.

884 Pind. O. 10, $24 \mathrm{f}$.

${ }^{885}$ Kyrieleis 2006, 61-79, dort auch weitere Zeugnisse für diesen Brauch.

$886 \mathrm{~J}$. C. Wright, The Old Temple Terrace at the Argive Heraeum and the Early Cult of Hera in the Argolid, JHS 102, 1982, 186-201; J. M. Hurwitt, The Art and Culture of Early Greece, 1100-580 B.C. (Ithaka 1985) 120; A. Mazarakis Ainian, From Rulers' Dwellings to Temples. Architecture, Religion and Society in Early Iron Age Greece (1100-700 B.C.) (Jonsered 1997) 156-158; C. Morgan, The Late Bronze Age Settlement and Early Iron Age Sanctuary, Isthmia 8 (Princeton 1999) 376; Kyrieleis 2006, 67.

887 Kyrieleis 2006, 62. 
Die Anfänge griechischer Heiligtümer sind noch nicht endgültig erforscht. Bisher konnte nur selten eine Kontinuität von der Bronzezeit über die sog. Dunklen Jahrhunderte hinweg in die geometrische und archaische Zeit nachgewiesen werden, jedoch liefern die Forschungen der jüngsten Zeit ständig neue Ergebnisse. Eine Kontinuität seit der Bronzezeit wird immer öfter bezeugt ${ }^{888}$. Die Mythen von uralten Götterbildern scheinen demnach in Einzelfällen durchaus auf reale Hintergründe zurückzugreifen, wenn sie auch sicherlich in zahlreichen Fällen im Laufe der Zeit ausgeschmückt und verändert worden $\operatorname{sind}^{889}$.

888 Artemis Elaphebolos bei Kalapodi: R. C. S. Felsch - H. J. Kienast - H. Schuler, Apollon und Artemis oder Artemis und Apollon? Bericht von den Grabungen im neu entdeckten Heiligtum bei Kalapodi 1973-1977, AA 1980, 38-118; R. C. S. Felsch u. a., Kalapodi. Bericht über die Grabungen im Heiligtum der Artemis Elaphebolos und des Apollon von Hyampolis 1978-1982, AA 1987, 1, 1-99; ders., Mykenischer Kult im Heiligtum bei Kalapodi?, in: Hägg - Marinatos 1981, 81-89; Kyrieleis 2006, 63; Heiligtum von Ayia Irini auf Keos: J. L. Caskey, Excavations in Keos, 1960 1961, Hesperia 31, 1962, 263-283; E. Townsend Vermeule, Götterkult, Archaeologia Homerica 3,5 (Göttingen 1974) 35-37; M. E. Caskey, Ayia Irini, Kea: The Terracotta Statues and the Cult in the Temple, in: Hägg - Marinatos 1981, 127-136; M. E. Caskey, Keos II. The Temple at Ayia Irini I: The Statues (Princeton 1986); J. N. Coldstream, Geometric Greece 900 - 700 B.C. ${ }^{2}($ London 2003) 209 f. 239 f.; eventuell auch das Athena Alea-Heiligtum in Tegea: A. Mazarakis Ainian, From Rulers' Dwellings to Temples. Architecture, Religion and Society in Early Iron Age Greece (1100 - 700 B.C.) (Jonsered 1997) 80-82; Kyrieleis 2006, 65 und das Apollon Maleatas-Heiligtum bei Epidauros: V. Lambrinudakis, Remains of the Mycenaean Period in the Sanctuary of Apollon Maleatas, in: Hägg - Marinatos 1981, 59-63; ders., Conservation and Research: New Evidence on a Long-living Cult. The Sanctuary of Apollo Maleatas and Asklepios at Epidauros, in: M. Stamatopoulou - M. Yeroulanou (Hrsg.), Excavating Classical Culture. Recent Archaeological Discoveries in Greece (Oxford 2002) 213-224. Vgl. auch die Entwicklung des Heiligtums in Isthmia von der Spätbronzezeit über die frühe Eisenzeit hinweg: C. Morgan, The Late Bronze Age Settlement and Early Iron Age Sanctuary, Isthmia 8 (Princeton 1999). Weitere Zeugnisse bei Kyrieleis 2006, 61-79. Ein wichtiges Argument für die Kontinuität sind auch die Namen der Götter und Kultbeamten, die bereits in den Linear-B-Schriften vorhanden sind. Auch die Funktion und Zuständigkeitsbereiche der Götter sowie die Mythologie scheinen bereits in der Bronzezeit ausgebildet worden zu sein. Ein weiteres Argument ist die Kontinuität in der Ikonographie. Bronzezeitliche Typen finden sich auch in den folgenden Jahrhunderten. Außerdem wurden Votiv-Depots und Kultschreine weiterhin besucht. Vgl. St. Casson, The Technique of Early Greek Sculpture (Oxford 1933) 50-65; M. P. Nilsson, The Minoan-Mycenaean Religion and its Survival in Greek Religion (Lund 1950); R. V. Nicholls, Greek votive statuettes and religious continuity, c. 1200 - 700 B.C., in: B. F. Harris (Hrsg.), Auckland Classical Essays: presented to E. M. Blaiklock (Auckland 1970) 1-37; E. Townsend Vermeule, Götterkult, Archaeologia Homerica 3, 5 (Göttingen 1974); B. C. Dietrich, The Origins of Greek Religion (Berlin 1974) 128-298; R. A. Tomlinson, Greek Sanctuaries (London 1976) 15. 20. 141; St. Hiller, Mycenaean Traditions in Early Greek Cult Images, in: R. Hägg (Hrsg.), The Greek Renaissance of the Eight Century B.C.: Tradition and Innovation. Proceedings of the Second International Symposium at the Swedish Institute in Athens, 1-5 June, 1981 (Lund 1983) 91-99; B. C. Dietrich, Tradition in Greek Religion, in: ebenda, 85-90; B. C. Dietrich, Tradition in Greek Religion (Berlin 1986); Whitley 2001, 137 f.; J. N. Coldstream, Geometric Greece 900-700 B.C. ${ }^{2}(L o n d o n ~ 2003)$ 327-332.

${ }^{889}$ Vgl. Kyrieleis 2006, 61-83. Vgl. auch die Heroenkulte an bronzezeitlichen Gräbern: D. Boehringer, Heroenkulte in Griechenland von der geometrischen bis zur klassischen Zeit: Attika, Argolis, Messenien (Berlin 2001). 
Einige der jeweils älteren Bilder können jedoch genauer, und zwar in die archaische bzw. klassische Zeit datiert werden ${ }^{890}$. Als Material für die alten Bilder überwiegt Holz, soweit Angaben dazu vorliegen ${ }^{891}$. Einige alte Bilder wurden in den Quellen als kleinformatig beschrieben. Für andere kann man ein geringes Format aufgrund der Größe der Basis oder aus der Tatsache erschließen, dass sie regelmäßig bei Kulthandlungen aus dem Tempel getragen wurden ${ }^{892}$.

Zu den hier beschriebenen alten Bildern sind im Laufe der Zeit jüngere Statuen hinzugetreten, wobei die zahlreichen kleinformatigen Weihgeschenke hier unbeachtet geblieben sind. Die untersuchten jüngeren Bilder fanden jedoch das Interesse antiker Autoren. Es muss sich demnach um besondere Bilder gehandelt haben. Die Praxis, jüngere Bilder neben bereits bestehenden aufzustellen kann vielleicht bis in die archaische Zeit zurückverfolgt werden ${ }^{893}$. Die meisten der jüngeren Bilder stammen aus der Zeit der Klassik ${ }^{894}$, andere aus späterer Zeit ${ }^{895}$.

Häufig sind sie in Akrolithtechnik gefertigt worden ${ }^{896}$. Andere bestanden aus Marmor oder Bronze ${ }^{897}$. Es waren demnach besonders kostbare, aufwändig herzu-

890 Archaisch: Zeus in Olympia, Athena Nike, Dionysos Eleuthereus, Meter Theon und eventuell Apollon Patroos in Athen, Aphaia auf Aigina, Athena von Lindos, Artemis Brauronia in Athen. Klassisch: Artemis in Histiaia, Hekate in Argos, Hera in Plataiai.

${ }^{891}$ Hera in Samos und Argos, Athena Polias in Athen, Artemis in Ephesos, Apollon in Delos und Megara, Aphrodite in Lykosoura, Theben und Sparta, Dionysos in Korinth, Theben und Naxos, vielleicht auch Athena Nike in Athen, Athena in Daulis, Dionysos Eleutheros in Athen, Artemis in Brauron, Nemeseis in Smyrna, Dionysos in Megara, Leto, Aphrodite Areia in Sparta, Pan auf Psyttaleia, Apollon in Leuktra. Auffällig ist, dass viele dieser Bilder als besonders alt galten bzw. in die archaische Zeit datiert werden konnten, während seit der Klassik keine aus diesem Material gefertigten Bilder unter den hier untersuchten mehr vorkamen. Da die betrachteten Bilder aber nur einen Ausschnitt aller bekannten Götterbilder darstellen, kann daraus kein Gesamtbild über alte Bilder generell erschlossen werden (was auch nicht Ziel dieser Arbeit war). Aus Stein bestanden die alten Bilder der Chariten in Orchomenos, des Eros in Thespiai, eventuell der Athena Nike in Athen, Akrolithe waren die älteren Bilder der Aphaia von Aigina und der Demeter in Onkeion, aus Bronze war die ältere Statue der Hekate in Argos.

892 Hera in Argos und Samos, Athena Polias, Dionysos Eleuthereus und Iakchos in Athen, Artemis in Ephesos; vgl. dazu auch Kap. 15.2.1.

893 Hera von Samos, Artemis von Ephesos, Apollon in Delphi und eventuell auch Apollon in Delos. Das jüngere Bild der Aphaia auf Aigina entstand an der Wende der Archaik zur Klassik. Für das jüngere Bild des Dionysos in Megara überliefert Paus. 1, 43, 5 sogar einen mythischen Stifter, Euchenor, was jedoch nicht als reale Datierung gelten kann. Zu Euchenor s. RE VI (1909) 881 s. v. Euchenor (J. Escher-Bürkli).

894 Athena, Athena Nike, Artemis Brauronia, Meter Theon, Iakchos, Dionysos Eleuthereus und Apollon Patroos in Athen, Zeus in Olympia, Hera in Argos, Athena in Lindos, Eros in Thespiai, Trophonios in Lebadeia, Artemis in Kalydon.

895 Hellenistisch: Artemis in Histiaia, Nemeseis in Smyrna. Kaiserzeitlich: Chariten in Orchomenos, Poseidon und Amphitrite am Isthmos von Korinth.

896 Hera in Argos, Athena Parthenos und Dionysos Eleutheros in Athen, Zeus in Olympia, Artemis in Kalydon und Brauron, Aphaia auf Aigina, Poseidon und Amphitrite am Isthmos von Korinth. ${ }^{897}$ Marmor oder anderer Stein: Eros in Thespiai, Hekate in Argos, Hera in Plataiai, Demeter in Stiris, 
stellende Bilder, die z. T. monumentales Format hatten, soweit dies bestimmt werden konnte ${ }^{898}$. Zudem wurden mit Phidias, Alkamenes, Agorakritos, Polyklet, Skopas, Praxiteles, Lysipp, Naukydes, Euthykrates, Kalamis, Euphranor und Leochares berühmte Bildhauer engagiert. Es wurde also keine Mühe gescheut, den Göttern besonders wertvolle Bilder aufzustellen, um sie zu erfreuen oder ihnen mit besonderem Nachdruck seine Ehrerbietung zu erweisen ${ }^{899}$.

Die Aufstellung eines neuen Bildes ging oftmals mit der architektonischen Ausgestaltung des jeweiligen Heiligtums ${ }^{900}$. Es lässt sich ein Trend feststellen, der Tempel und Bild als Einheit erscheinen lässt, dass also der Bau eines neuen Tempels oftmals auch die Aufstellung eines neuen Bildes nach sich zog. Die Auftraggeber der Bilder sind in den meisten Fällen nicht überliefert. Besonders für die kostspieligen Bilder ist anzunehmen, dass die Bürger der jeweiligen Stadt, manchmal sogar die Priester als Auftraggeber zeichneten. Für die Artemis von Histiaia ist dies durch ein Dekret überliefert.

Die Angaben zum Standort der Bilder sind wenig ausführlich. Dies erschwert Aussagen über das Verhältnis der Bilder untereinander sowie über ihr Verhältnis zu dem sie umgebenden Raum. In einigen Heiligtümern wurden die alten Bilder versetzt, als ein neuer Tempel gebaut worden ist. Die Mitte der Cella des Neubaus nahm ein jüngeres und oftmals durch seine Größe und den Prunk seines Materials präsenteres Bild ein. Die alten Bilder wurden z. T. neben den jüngeren aufgestellt ${ }^{901}$. Einige Male wurde auch ein neuer Tempel errichtet, so dass jedes Bild in einem eigenen Gebäude stand ${ }^{902}$. Auch hier fällt auf, dass dem Tempel des neuen

Artemis Brauronia und Apollon Patroos in Athen, Chariten in Orchomenos. Bronze: Eros in Thespiai.

898 Zeus in Olympia, Athena Parthenos in Athen, Athena in Lindos, Hera in Argos, Aphaia auf Aigina, eventuell auch Dionysos Eleutheros in Athen und Apollon in Delos.

899 Zur Bedeutung des Wortes ő $\gamma \alpha \lambda \mu \alpha$, mit dem Götterstatuen häufig benannt wurden, als Bezeichnung eines Gegenstandes, an dem sich die Gottheit erfreut, s. S. 181 f. Auch die Konkurrenz der Städte untereinander spielte sicherlich eine Rolle, war jedoch nicht allein ausschlaggebend für die Erschaffung neuer Bilder, mit denen die Städte Reichtum, Macht und Religiosität zum Ausdruck bringen konnten. Dazu s. Herington 1955, 37; Donohue 1988, 30; Ridgway 1981, 10 f.; H. Wrede, Einleitende Bemerkungen zum Fries, in: E. Berger - M. Gisler-Huwiler (Hrsg.), Der Parthenon in Basel. Dokumentation zum Fries, Studien der Skulpturenhalle Basel 3 (Mainz 1996) 24-34.

900 Samos, Argos, Athen (Athena, Athena Nike, Dionysos Eleuthereus), Olympia, Ephesos, Aigina, Lindos, Histiaia, Kalydon, vielleicht auch Delphi und Delos.

901 Hera in Argos und Plataiai, Aphaia auf Aigina, Athena in Lindos und Aigion, Artemis in Kalydon, Ephesos, Troizen und Mykalessos, Aphrodite in Megalopolis, Lykosoura und Sparta, Demeter in Stiris, Phlious und Onkeion, Hekate in Argos, Apollon in Delphi und Megara, Asklepios in Aigeira und Zeus in Korinth. Einen Sonderfall bildete das Heraheiligtum von Samos, in dem das alte Bild wahrscheinlich immer auf seiner angestammten Basis aus geometrischer Zeit gestanden hat, und zwar auch, als diese außerhalb des in spätarchaischer Zeit neu errichteten Tempels zu liegen kam. In der Cella des Tempels stand ein jüngeres Bild.

902 Athena Parthenos und Dionysos Eleuthereus in Athen, Zeus in Olympia. Auch das Heiligtum von Argos kann hier vielleicht in Zukunft eingereiht werden, wenn sichere Zeugnisse gefunden werden, dass der jüngere Tempel bereits vor der Zerstörung des älteren begonnen worden ist. Die Zer- 
Bildes ein prominenterer Platz eingeräumt worden ist und dieser $z$. T. auch durch seine schiere Größe und die Pracht seines Bauschmuckes den alten Tempel deutlich überragte. Die alten Bilder wurden allerdings nicht durch die neuen ersetzt - außer sie waren schon vorher verloren gegangen und das neue Bild bewusst als Ersatz geschaffen worden. So diente ein von dem Bildhauer Menodoros in der Kaiserzeit geschaffenes Bild des Eros in Thespiai als Ersatz für die geraubte und anschließend zerstörte Statue des Praxiteles. Es ersetzte jedoch nur die jüngste Statue in diesem Heiligtum. Die älteren Bilder scheinen nicht verloren gegangen zu sein, sondern wurden von Pausanias noch im 2. Jahrhundert n. Chr. erwähnt. Ein Ersatzbild erhielt hingegen das Heiligtum der Demeter Melaina in Phigaleia. Das alte Bild war bei einem Brand untergegangen. Als nach dem Brand kein neues geschaffen und auch die Opfer und Feste vernachlässigt wurden, wurde das Land von Unfruchtbarkeit getroffen, woraufhin man ein Orakel aus Delphi einholte, das zu einer Wiederherstellung des Kultes riet. Dafür wurde auch eine neue Demeter-

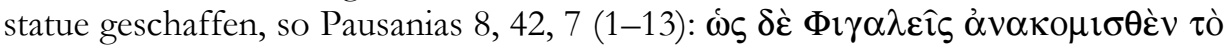

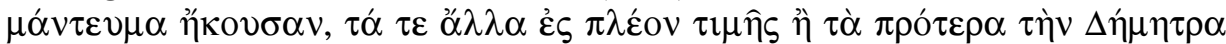

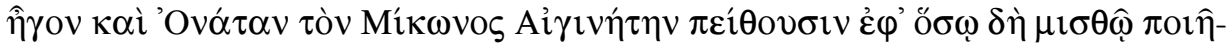

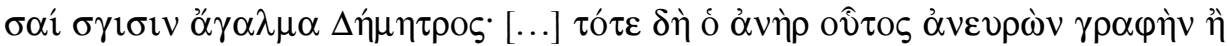

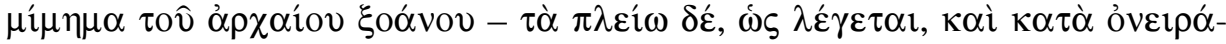

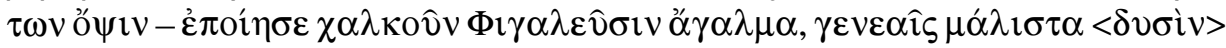

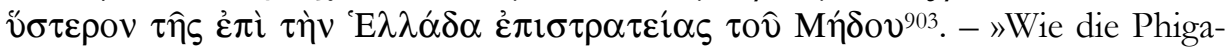
leer das überbrachte Orakel hörten, da brachten sie allgemein den Kult der Demeter zu größerer Ehre als früher und überredeten den Aigineten Onatas, den Sohn des Mikon, gegen was für Lohn auch immer, ihnen eine Statue der Demeter zu schaffen. [...] Damals schuf dieser Mann nun nach einer aufgefundenen Zeichnung oder Nachbildung des alten Holzbildes ${ }^{904}$, zur Hauptsache aber, wie es heißt, auch nach Traumgesichten den Phigaleern eine Bronzestatue etwa eine Generation später als der Zug des Meders gegen Griechenland«. (F. Eckstein - P. C. Bol)

Bei den hier untersuchten Heiligtümern standen die Bilder jedoch zusammen, da sie gemeinsam Eingang in die Quellen gefunden haben - und zwar oft noch Jahrhunderte nach ihrer Entstehung - ohne einen Hinweis darauf, dass sie nicht mehr existiert hätten.

störung des alten Tempels begründete dort die gemeinsame Aufstellung der Bilder in einem Tempel. 903 s. auch S. 189. Vgl. U. von Wilamowitz-Moellendorf, Der Glaube der Hellenen I (Berlin 1931)

221. 402 f.; RE XIX (1937) 2079 f. s v. Phigaleia (E. Meyer); J. Dörig, Onatas of Aegina (Leiden

1977); M. Jost, Sanctuaires et cultes d'Arcadie (Paris 1985) 89; Pollitt 1990, 36-39; RE XVIII, 1.2

(1992) 408-411 s. v. Onatas (J. Sieveking); DNP VIII (2000) 1203 f. s. v. Onatas (R. Neudecker).

Ein weiteres Beispiel für Ersatzstatuen: Paus. 6, 21, $1 \mathrm{f}$.

${ }_{904}$ Dass es ein Holzbild war geht aus Paus. 8, 42, 3 hervor, wo er es ein $\alpha$ ’ $\alpha \lambda \mu \alpha \xi \xi \dot{\lambda}$ ov nennt. 


\subsection{Gründe für die Existenz mehrerer \Kultbilder` und ihre Einbindung in die Kultpraxis}

Die Existenz mehrerer >Kultbilder` an einem Ort kann, wie die in Kapitel 12.1 und 14 genannten Beispiele zeigen, manchmal damit erklärt werden, dass es sich um unterschiedliche, an ein und demselben Ort durchgeführte Kulte handelt. In diesen Fällen handelt es sich vielleicht ursprünglich um verschiedene `Gottheiten`, die den Namen einer großen griechischen Gottheit erhalten hatten und deren Individualität sich im Beinamen zu erkennen gibt bzw. die Beinamen drücken verschiedene Aspekte der Gottheit aus wie bei Athena Polias und Athena Parthenos auf der Athener Akropolis ${ }^{905}$. Für zwei unterschiedliche Kulte an einem Ort lassen sich noch zahlreiche weitere Beispiele in der antiken Literatur finden ${ }^{906}$. Auch drei oder mehr verschiedene Kulte einer Gottheit sind an einem Ort belegt. So gab es auf der Athener Akropolis neben dem Kult für Athena Polias und Athena Parthenos einen Kult für Athena Nike, Athena Hygieia, Athena Promachos und Athena Ergane ${ }^{907}$. Es ist anzunehmen, dass zumindest einige der Kultstätten auch ein `Kultbild besaßen, wobei für die Athener Akropolis Bilder der Athena Polias, Parthenos und Nike gesichert sind. Damit ließe sich auch erklären, warum einige Heiligtümer wie das des Dionysos in Korinth, der Athena sowie der Aphrodite in Theben oder der Aphrodite in Sparta von Anbeginn an mehrere Bilder besaßen.

Offen bleibt jedoch die Funktion, wenn nur eines der Bilder durch einen Beinamen spezifiziert ist, wie im Heiligtum der Demeter Prosymna in Lerna. Hier kann, jedoch muss es sich nicht um zwei >Kultbilder» gehandelt haben. Auch bei Statuen, für die ein Platz vor dem Tempel oder im Pronaos desselben überliefert

905 s. Kap. 12.1, ebenso Demeter Erinys und Lousia in Onkeion, Zeus Chthonios und Hypsistos in Korinth, Apollon Patroos und Alexikakos in Athen, Apollon Karneios und Aphetaios in Sparta, Dionysos Lysios und Bakcheios in Sikyon und in Korinth, Dionysos Meilichius und Bakcheus auf Naxos und in Megara, Aphrodite Urania und Pandemos in Megalopolis, Aphrodite sin den Gärten und Urania in Athen, Hera Teleia und Nympheuomene in Plataiai.

906 Aphrodite Pandemos und Urania in Elis (Paus. 4, 25, 1; zu Aphrodite Urania s. auch Kap. 5); Athena Alea und Poliatis in Tegea (Paus. 8, 45, 4; 8, 47, 5); Zeus Ombrios und Hymettios auf dem Hymettos; Zeus Soter und Epidotes in Mantineia (Paus. 8, 9, 2); Hermes Kriophoros und Promachos in Tanagra (Paus. 9, 22, 1 f.); Dionysos Polites und Auxites in Heraia (Paus. 8, 26, 1); Apollon Epikurios und Parrhasios in Lykosoura (Paus. 8, 38, 8); Athena Leïtis und Ergane in Olympia, ebenso gab es neben dem großen Aschealtar zwei weitere für Zeus Hypsistos (Paus. 5, 14, 5; 5, 15, 5).

907 s. Anm. 628, ebenso Apollon Klariotis, Apollonitis, Hippothoïtis und Athanaiatis in Tegea, Apollon Pythios, Dekatephoros und Archegetes in Megara, Apollon Patroos, Alexikakos und eine weitere Statue in Athen, Dionysos Mesateus, Antheus, Aroëus und Aisymnetes in Patrai, Aphrodite Urania, Pandemos und Apostrophia in Theben. Weitere Beispiele: Aphrodite Doritis, Akraia und Euploia in Knidos (Paus. 1, 1, 3); Zeus Ombrios, Parnethios und Semaleos auf dem Parnes (Paus. 1, 32, 2); Apollon Pythaeus, Horios sowie eine dritte Statue in Hermione (Paus. 2, 35, 2); Athena, Athena Nike und Athena Aiantis in Megara (Paus. 1, 42, 4); Hera Pais, Teleia und Chera in Stymphalos (Paus. 8, 22, 2). 
ist, während die Cella noch ein weiteres Bild beherbergte ${ }^{908}$, lässt sich vermuten, dass es sich bei ersteren um WWeihgeschenker im traditionellen Sinn handelte. Doch auch hier zeigt das Beispiel des Heiligtums des Apollon auf der Agora von Athen, dass unsere heutigen Kategorien dem antiken Verständnis nicht unbedingt entsprechen, denn sowohl das Bild im Tempel als auch die Statue vor dem Tempel trugen jeweils einen eigenen Beinamen. Gleiches gilt auch für das Bild der Aphrodite Urania vor dem Tempel der >Aphrodite in den Gärten in Athen. Bei den anderen genannten Statuen handelt es sich jedoch um verschiedene Bilder ein und desselben Kultes, bei denen im Folgenden ebenfalls nach Gründen für die Aufstellung mehrerer Kultbilder gefragt werden soll.

\subsubsection{Zur Funktion der Bilder im Kult}

Dass die alten Bilder eine Rolle im Kult gespielt haben, wurde nie bezweifelt. An ihrer Kultfunktion hat sich durch die Aufstellung der neuen nichts geändert. Sie blieben oft über Jahrhunderte erhalten, wurden regelmäßig gepflegt, geschmückt und verehrt und spielten weiterhin eine wichtige Rolle im Kult. Oft konnten die neuen Bilder aufgrund ihres großen bis überdimensionalen Formats sowie ihrer Herstellungstechnik, was z. B. Akrolithstatuen betrifft, bestimmte Kultfunktionen auch gar nicht übernehmen. Dazu zählen z. B. Prozessionsriten, bei denen die Bilder zu einem rituellen Bad oder einer Speisung an einen anderen Ort gebracht wurden. Gabentische für unblutige Opfer waren zwar nichts Unübliches in antiken Tempeln ${ }^{909}$. Allgemein bekannt ist jedoch, dass die Versammlung der Opfergemeinschaft, die oft aus zahlreichen Personen bestand und die Opferung von Tieren beinhaltete, außerhalb des Tempels am Altar vollzogen wurde. Einige $>$ Kultbilder konnten während der Opferfeierlichkeiten den Tempel verlassen und direkt dem Opfer am Altar beiwohnen. Das sicherlich bekannteste Beispiel ist der Kult der Artemis Orthia in Sparta, von dem Pausanias 3, 16, 10 f. ausführlich berichtet:

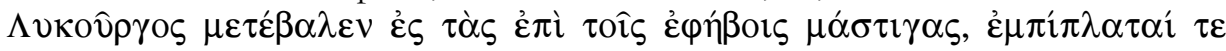

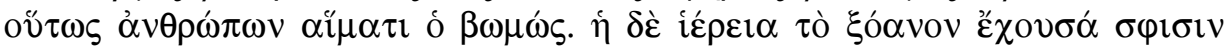

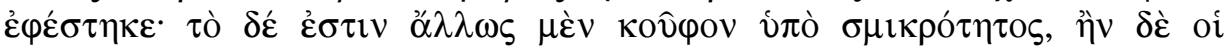

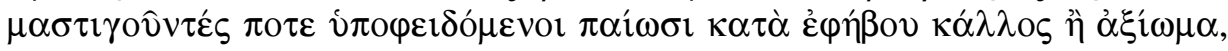

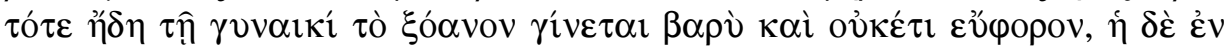

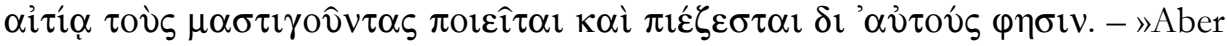
Lykurg veränderte den Brauch hin zu der Geißelung der Epheben. Und auf diese Art wird nun der Altar mit menschlichem Blut getränkt. Dabei steht die Priesterin daneben, das Xoanon tragend. Nun ist dies klein und leicht, aber immer wenn

908 Athena Pronaia in Delphi, Poseidon am Isthmos von Korinth, Apollon Patroos in Athen, Dionysos in Bryseai, Hermes in Korinth, Zeus in Aigion.

909 Vgl. das Heiligtum der Artemis Orthia in Messene, Kap. 12.11. Weitere Belege bei: H. Mischkowski, Die Heiligen Tische im Götterkultus der Griechen und Römer (Diss. Albertina Universität Kaliningrad 1917). 
einer der Geißelnden wegen der Schönheit oder dem hohen Rang eines Jünglings zu leicht schlägt, wird das Bild für die Priesterin plötzlich so schwer, dass sie es kaum noch halten kann. Sie beschuldigt die Schlagenden und sagt, dass es deren Schuld ist, dass sie so nieder gedrückt werde«.

Als weiteres mögliches Beispiel kann das Artemisheiligtum von Ephesos genannt werden. Eine Basis innerhalb des dortigen Altarhofes wird in der Forschung als möglicher Aufstellungsort des $>$ Kultbildes während der Opferungen interpretiert. Die Basis stammt nach der Ansicht von A. Bammer aus der Zeit des ersten Dipteros, also aus dem 6. Jahrhundert v. Chr. Sie wurde bei der Erbauung des zweiten Dipteros und seines neuen Altares im 4. Jahrhundert v. Chr. erhalten, blieb weiter in Funktion und bezeugt die lange währende Bedeutung des alten Bildes $^{910}$. Sollte es sich bei dem alten Artemisbild um ein kleines tragbares Holzbild gehandelt haben, worauf die Indizien hindeuten ${ }^{911}$, so erscheint es nicht abwegig, dass es während der Opfer am Altar präsent war.

Auch das alte Bild des Dionysos Eleuthereus in Athen wohnte einmal im Jahr während der Großen Dionysien dem Opfer bei. Hellenistische und kaiserzeitliche Ephebenlisten aus Athen berichten, dass das Bild von den Epheben zum Altar gebracht wurde: ЕI $\Sigma$ HГAГON $\Delta \mathrm{E}[\mathrm{K}] \mathrm{AI}$ TON $\Delta \mathrm{IONY} \Sigma \mathrm{ON}$ АПO TH $\Sigma$ E $\Sigma \mathrm{XA}-$ PA $\Sigma$ EI $\Sigma$ TO $\Theta E A T P O N$ META $\Phi \Omega T O \Sigma^{912}$. - „Und sie führten Dionysos von

910 Bammer 1968, 401; A. Bammer, Das Heiligtum der Artemis von Ephesos (Graz 1984) 130-139 mit Abb. 75 f.; Bammer 1993, Beibl. 151; ebenso Seiterle 1979, 15 mit Plan Abb. 19, dort Nr. D; Elliger 1985, 134; Scherrer 1995, $53 \mathrm{f}$.

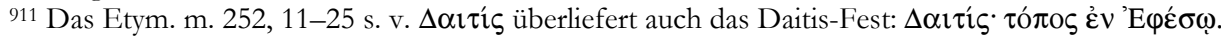

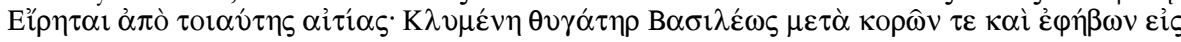

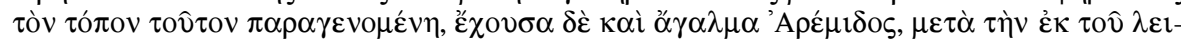

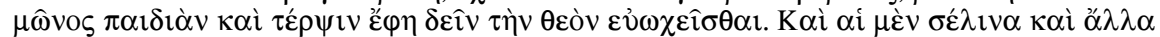

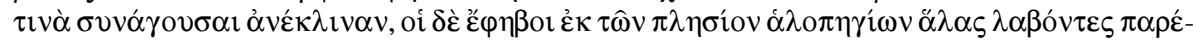

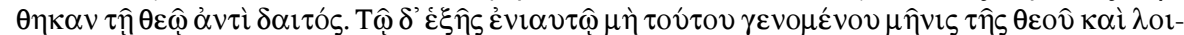

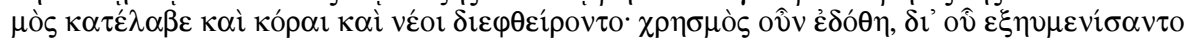

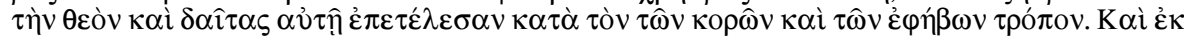

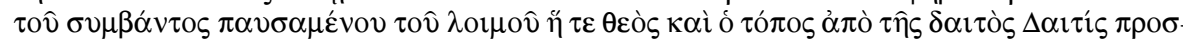
$\eta \gamma о \rho \varepsilon v ́ \theta \eta$. - Daitis. Ein Ort in Ephesos. Man nennt dafür folgenden Grund: Klymene, die Tochter des Basileus, kam mit den Mädchen und Jungen zu diesem Ort, mit sich führend das Agalma der Artemis. Nachdem sie sich auf der Wiese an Spiel und Vergnügen erfreut hatten, befahl sie, die Göttin zu bewirten. Und sie [die Mädchen] sammelten Eppich und anderes und legten das Bild darauf; die Epheben aber holten aus den nahen Salinen Salz und setzten es der Göttin als Mahl vor. Als im nächsten Jahr selbiges nicht geschah, zürnte die Göttin und sandte eine Seuche, an der die Mädchen und Jungen starben, bis ein Orakel erklärte, wie sie die Göttin versöhnen können, indem sie das Mahl nach der Art und Weise der Mädchen und Jungen darbringen. Durch dieses Ereignis endete die Seuche und die Göttin wie auch der Ort werden nach dem Mahl Daitis genannt«. Vgl. R. Heberdey, $\Delta \alpha \mathbf{\imath} \tau$ í. Ein Beitrag zum ephesischen Artemiskult, ÖJh 7, 1904, 210-215; M. P. Nilsson, Griechische Feste von religiöser Bedeutung mit Ausschluss der attischen (Leipzig 1906) $245 \mathrm{f}$.

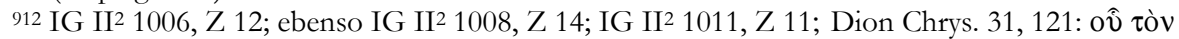

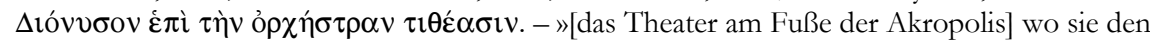
Dionysos auf der Orchestra aufstellen«. (W. Elliger). 
der Eschara ins Theater unter Fackelschein«. Während des Festes gedachte man gleichzeitig der einstigen Überführung des Bildes von Eleutherai nach Athen ${ }^{913}$. Im Vorfeld des Festes der Großen Dionysien wurde das Bild des Gottes laut Pausanias 1, 29, 2 zu einem kleinen Tempel in der Nähe der Akademie und damit zwar nicht zurück an seinen alten Kultort, aber zumindest an einen anderen Ort geführt, so dass der anschließende Einzug in sein neues Heiligtum real vonstatten

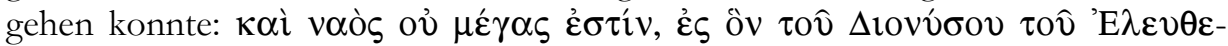

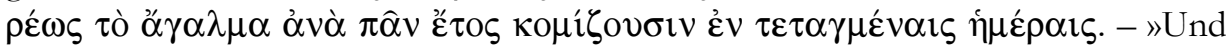
es ist da ein nicht großer Tempel, in den sie das Kultbild des Dionysos Eleuthereus jedes Jahr an bestimmten Tagen bringen«. (F. Eckstein - P. C. Bol)

Am Vorabend des Beginns der großen Dionysien wurde das Bild dann bekanntermaßen feierlich zurück zum Kultbezirk beim Theater geleitet ${ }^{914}$.

Auch Vasenbilder zeigen häufig Opferszenen im Freien, bei der ein Bild der Gottheit anwesend ist. Oft handelt es sich um ein kleinformatiges Bild, das auf einer Säule oder einer hohen Basis steht ${ }^{915}$. Da auf Darstellungen der Flächenkunst jedoch nicht unbedingt von einer Einheit von Ort und Zeit auszugehen ist, stellen diese Bilder keinen definitiven Beweis für die Anwesenheit von kleinformatigen, transportablen >Kultbildern` während der Opferfeiern am Altar dar. Sie können auch als Bildchiffre im Sinne einer Kennzeichnung des Ortes als Opferstätte aufgefasst werden. Die zuvor genannten Beispiele für ein Beiwohnen des `Kultbildes beim Opfer bezeugen jedoch, dass die Darstellungen auf den Vasen auch nicht ganz unrealistisch sind.

Ebenfalls mehrfach belegt ist der Brauch, Götterbilder zu reinigen, was oft außerhalb des Tempels geschah. Natürlich ist es selbstverständlich, dass die Bilder wie jeder andere kostbare Gegenstand auch regelmäßig gepflegt wurden. So waren laut Pausanias 5, 14, 5 die Nachkommen des Phidias für die Reinigung des Zeus von Olympia zuständig. Sie opferten zwar vor dem Beginn der Reinigung, diese ist jedoch selbst nicht als Kultakt überliefert und hatte vielleicht rein praktische

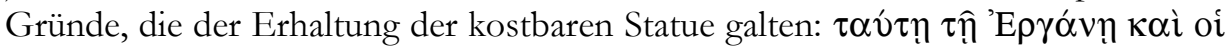

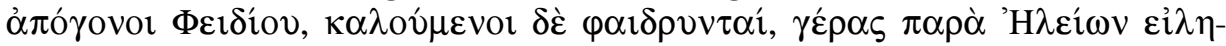

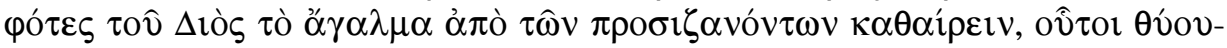

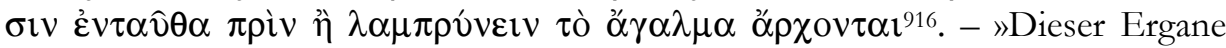

913 Paus. 1, 2, 5; 1, 38, 8; 1, 20, 3; vgl. auch Kap. 12.5. Weitere antike Beispiele für Feste und Prozessionen, durch die an Kultübertragungen erinnert wird: Paus. 2, 7, 7 f.; 7, 21, 6; 7, 20, 7 f. Vgl. E. Schmidt, Kultübertragungen, Religionsgeschichtliche Versuche und Vorarbeiten 8, 2 (Gießen 1909).

914 L. Deubner, Attische Feste (Berlin 1932) 142; Parke 1977, 125-135; E. Simon, Festivals of Attica. An Archaeological Commentary (Madison 1983) 101-104.

915 K. Schefold, Statuen auf Vasenbildern, JdI 52, 1937, 30-75; F. van Straten, Hiera Kala. Images of Animal Sacrifice in Archaic and Classical Greece (Leiden 1995); Oenbrink 1997.

916 Für weitere Vorsorgemaßnahmen vgl. Plin. nat. 15, 32; Paus. 5, 11, 10; Phot. 234. Dennoch waren von Zeit zu Zeit Reparaturen nötig, wie etwa Paus. 4, 31, 6 für den Zeus von Olympia überliefert. 
opfern auch die Nachkommen des Pheidias, die sogenannten Phaidryntai, die es als Ehrenamt von den Eleern erhalten haben, das Kultbild des Zeus von den daranhaftenden Verunreinigungen zu säubern; sie opfern hier, bevor sie das Kultbild zu reinigen beginnen«. (F. Eckstein - P. C. Bol)

Es sind jedoch auch Kulte überliefert, bei denen die Reinigung in einem öffentlichen Festakt institutionalisiert gewesen ist und eine symbolische religiöse Bedeutung hatte wie bei der Hera von Argos, wie Pausanias 2, 38, 2 f. berichtet: Koì $\lambda_{\text {l- }}$

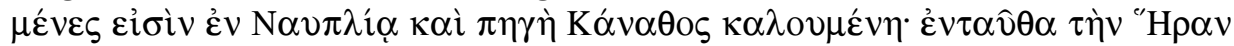

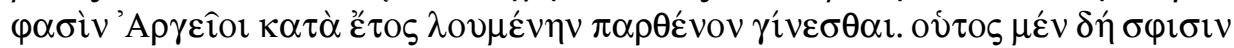

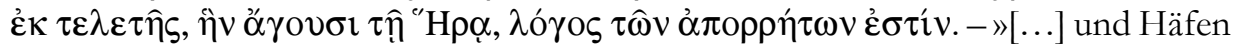
sind in Nauplia und eine Kanathos genannte Quellen; hier, sagen die Argiver, bade Hera jährlich und werde wieder Jungfrau. Diese Legende aus dem Festspiel, das sie der Hera veranstalten, gehört zu den geheimen Dingen«. (F. Eckstein - P. C. Bol)

In Athen wurde im Sommer für Athena das Plynterienfest gefeiert, wie Xeno-

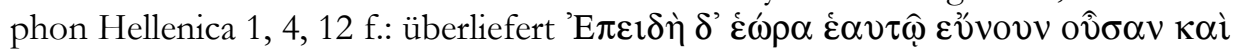

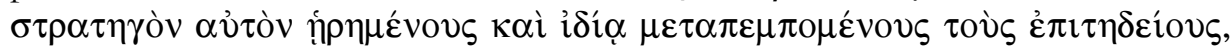

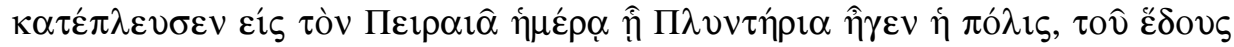

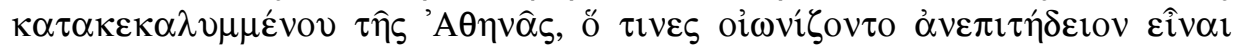

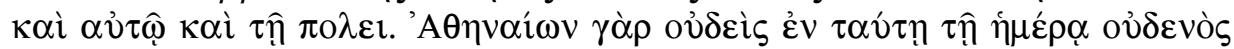

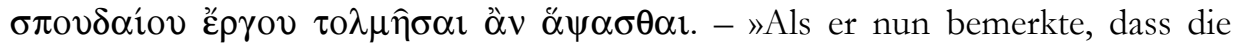
Athener ihm freundlich gesonnen waren und ihn zum Feldherrn gewählt hatten, und das zudem seine Anhänger ihn mit persönlichen Nachrichten zurückriefen, landete er im Piräus an dem Tag, an dem die Stadt das Fest der Plynterien feierte und das Hedos der Athena verhüllt war, ein Umstand, den einige als ungünstiges Vorzeichen betrachteten für ihn als auch für die Stadt; denn von den Athenern würde es gewiss keiner wagen, an diesem Tag eine wichtiges Werk in Angriff zu nehmen«. Laut Plutarch Alkibiades 34, 1 f. fand das Fest im Monat Thargelion statt:

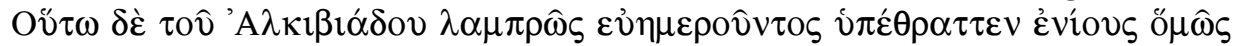

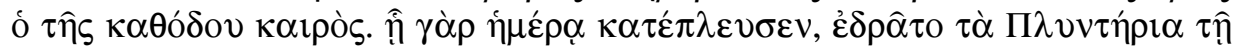

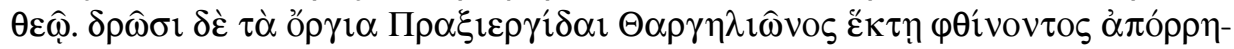

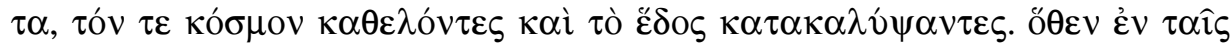

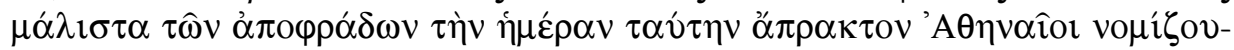

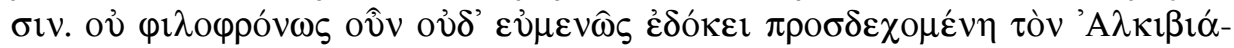

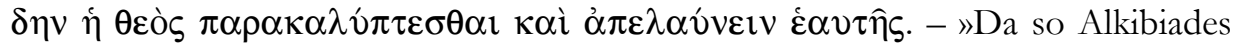
auf dem glänzenden Gipfel seines Glückes stand, ängstigte einige Leute doch der Zeitpunkt seiner Rückkehr. Denn an dem Tage, da er anlangte, wurde gerade das Plynterienfest für die Göttin gefeiert. Vollzogen wird der geheime Weihedienst von den Praxiergiden am sechstletzten Tage des letzten Drittels des Monats Thargelion, und sie nehmen dem Bilde den Schmuck ab und verhüllen es. Daher gilt dieser Tag vor allen anderen bei den Athenern als ein Unglückstag. So schien es also, als ob die Göttin den Alkibiades nicht freundlich und gnädig empfange, sondern sich verhülle und ihn von sich weise«. (K. Ziegler) 
An diesen Tag wurde also eine Statue der Göttin in einem geheimen Ritus

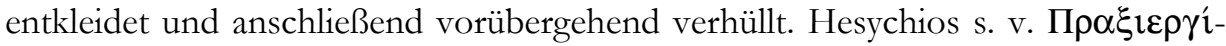
$\delta \alpha \iota$ ergänzt, dass das Bild, mit dem die Praxiergidai die Riten durchführen, eine

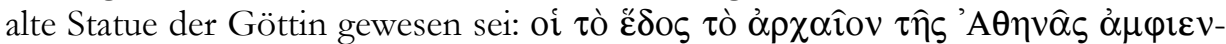

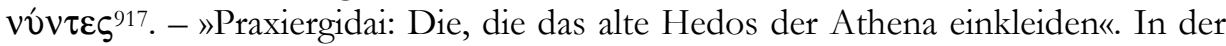
Forschung wird das Bild zumeist als das der Athena Polias gedeutet ${ }^{918}$. Ob das Bild nach der Entkleidung zum Strand von Phaleron gebracht wurde, um dort gebadet zu werden, ist umstritten, kann jedoch durchaus mit den Quellen verein-

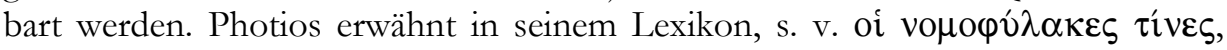
dass die Nomophylaken für die Organisation einer Prozession zuständig waren,

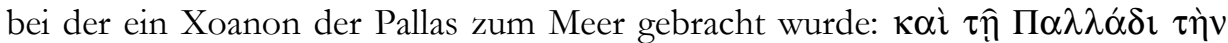

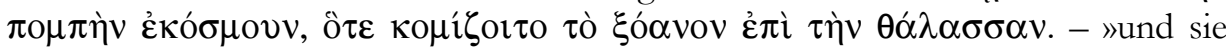
übten die Prozession für die Pallas aus, bei der das Xoanon zum Meer gebracht wird«. Hellenistische Ephebenlisten aus Athen, die sich ebenfalls auf das Plynte-

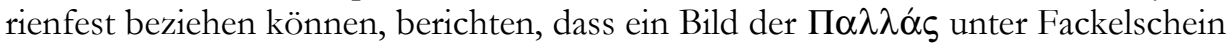

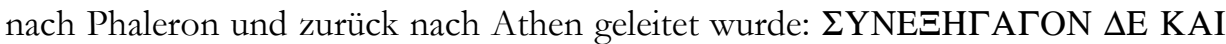

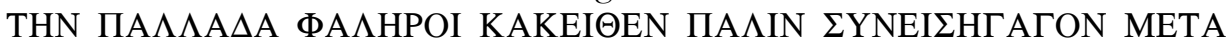
$\Phi \Omega T O \Sigma$ META ПА $\Sigma$ H $\Sigma$ EYKO $\Sigma$ MIA $\Sigma^{919}$. - »Sie geleiteten die Pallas nach

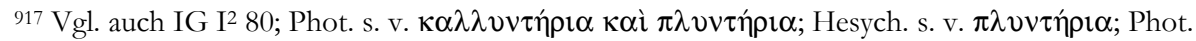

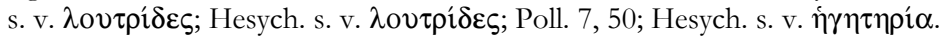

918 L. Deubner, Attische Feste (Berlin 1932) 17-22; RE XXI (1951) 1060-1062 s. v. Plynteria (L. Ziehen); Herington 1955, 29 f.; Lehnstaedt 1970, 8; Parke 1977, 152-155; R. Parker, Miasma. Pollution and Purification in Early Greek Religion (1983) 26 f.; Garland 1992, 101; H. von Heintze, Athena Polias am Parthenon als Ergane, Hippia und Parthenos, Gymnasium 100, 1993, 416; DNP IX (2000) 1180 f. s. v. Plynteria (R. Parker); Bettinetti 2001, 150. D. M. Lewis, Notes on Attic Inscriptions, BSA 49, 1954, 17-21 hielt nur die Reinigung des Tempels für möglich, doch sprechen die Quellen eindeutig von Riten im Zusammenhang mit einem Bild.

Die Verbindung der Pallas mit der Polias ist jedoch nicht gesichert. Parke 1977, 153; Ridgway 1992, 129. 211 Anm. 18; Scheer 2000, 60 mit Anm. 336 bezogen die Ephebeninschriften auf das athenische Palladion. Die von B. Nagy, The Procession to Phaleron, Historia 40, 3, 1990, 288-306 vorgeschlagene These, die Ephebenprozession (Vgl. Anm. 919) wiederhole die Evakuierung der Athena Polias während der Perserkriege erscheint unglaubwürdig. Erinnerungen an die Kriege spielten zwar bei der Ausbildung der Epheben eine Rolle. Dies erscheint mir jedoch nicht ausreichend, um daraus eine jährlich wiederholte, sonst nicht belegte Prozession zu erschließen. Zudem ist B. Nagy dazu gezwungen, die Diskrepanz zwischen der Angabe bei Plut. Themistokles 10, 4, dass die Athener das Bild zum Piräus evakuierten und nicht nach Phaleron (s. S. 195 f.), mit einer Änderung des Prozessionszieles durch Demetrios von Phaleron zu erklären, der damit seinen Geburtsort ehren wollte. Da es sich bei der Prozession nach B. Nagy um eine Feier der eigenen Traditionen und Leistungen der Athener in der Vergangenheit handelte, erscheint diese Erklärung jedoch mehr als unbefriedigend. Darüber hinaus ist es kaum glaubwürdig, dass die Athener Jahr für Jahr eine der düstersten Episoden ihrer eigenen Geschichte gefeiert haben sollen.

919 IG II ${ }^{2}$ 1006, Z 11 f.; ebenso IG II² 1008, Z 9 f.; IG II² 1011, Z 10 f. Die Verbindung zu dem Bild der Athena Polias befürworteten auch Deubner, Attische Feste (Berlin 1932) 18 f.; RE XXI (1951) 1060-1062 s. v. Plynteria (L. Ziehen); Lehnstaedt 1970, 8; H. von Heintze, Athena Polias am Parthenon als Ergane, Hippia und Parthenos, Gymnasium 100, 1993, 416; unsicher ist sich Herington 1955, 30 mit Anm. 2. 
Phaleron und führten sie zurück hinein unter Fackelschein gemäß der Ordnung«. Bei der Reinigung des Athenabildes handelt es sich um eine religiös motivierte Aktion, da der Tag als Unglückstag galt. Das einfache Entfernen von Staub und Schmutz hätte sicherlich keine solche Reaktion hervorgerufen.

Auch das Bild der Hera von Samos wurde regelmäßig gereinigt. Die Zeremonie fand am Meer statt. Der Ursprung der Kulthandlung wird von Athenaios 15, 672

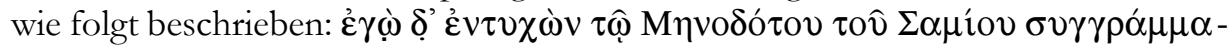

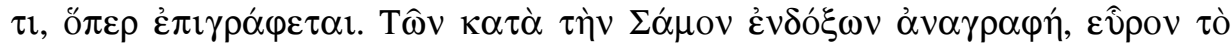

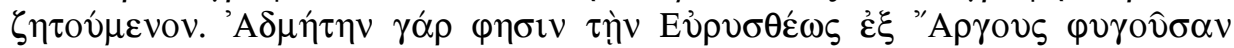

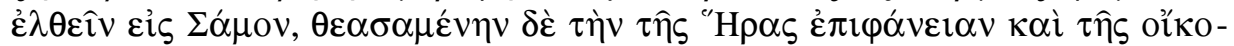

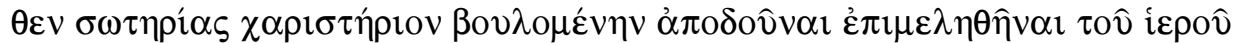

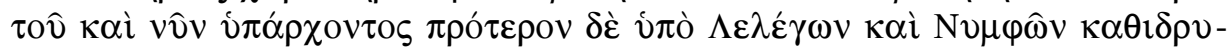

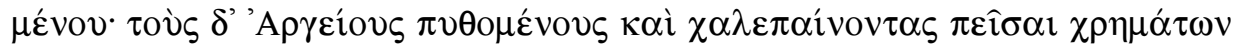

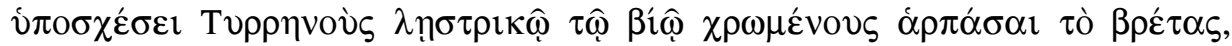

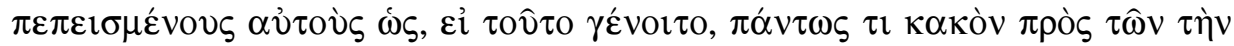

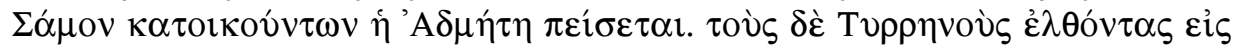

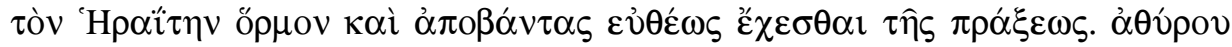

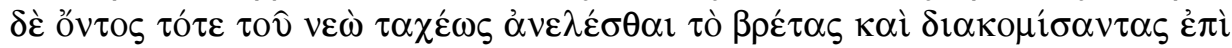

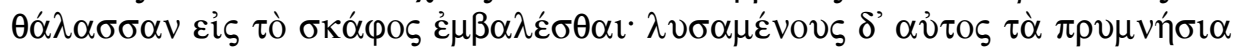

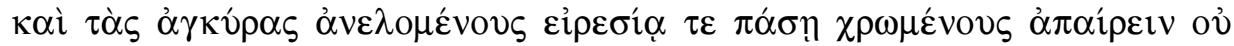

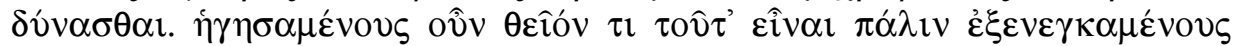

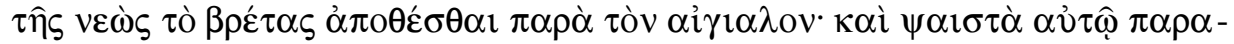

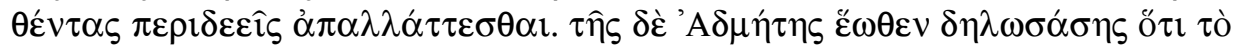

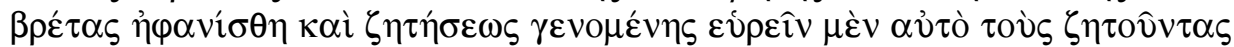

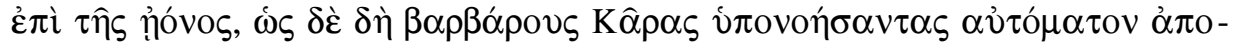

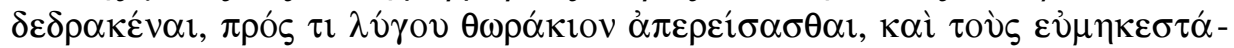

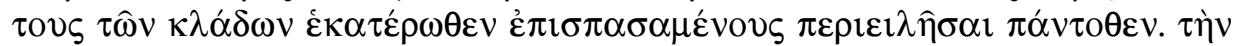

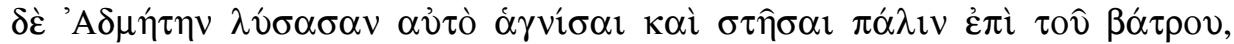

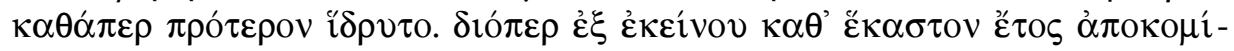

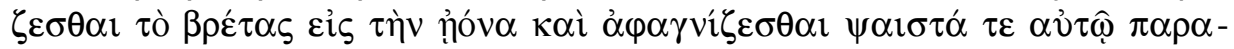

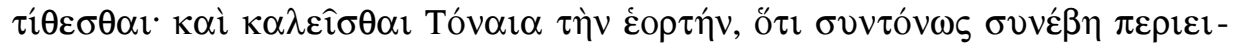

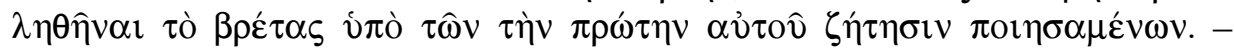
$»$ Menodotos von Samos erzählt in seiner Schrift >Aufzeichnungen der Merkwürdigkeiten von Samos<: Admete, die Tochter des Eurystheus, kam auf ihrer Flucht aus Argos nach Samos. Dort sah sie eine Erscheinung der Hera, und um ihren Dank für die Errettung aus ihrer Heimat abzustatten, übernahm sie die Sorge für das Heiligtum, das noch heute vorhanden ist und einst von den Lelegern und Nymphen begründet worden war. Die Argeier erfuhren davon, gerieten in Zorn und überredeten, indem sie ihnen Gold versprachen, die Tyrrhener, die ein Piratenleben führten, das Kultbild der Hera zu rauben, da sie überzeugt waren, wenn dies geschehe, werde Admete unbedingt die Rache der Samier zu spüren bekommen. Die Tyrrhener liefen in den Hafen der Hera ein, gingen an Land und 
machten sich alsbald an ihr Vorhaben. Da der Tempel damals noch kein Tor hatte, konnten sie sich schnell des Kultbildes bemächtigen, sie schleppten es zum Meer und verstauten es in ihrem Schiff. Dann lösten sie die Taue, hievten die Anker und legten sich in die Ruder. Aber trotz aller Anstrengungen gelang es ihnen nicht, von der Stelle zu kommen. Das hielten sie für ein göttliches Wunderzeichen, und so trugen sie das Kultbild wieder aus dem Schiffe hinaus und setzten es am Ufer ab. Dann stellten sie Opferkuchen vor ihm hin und entfernten sich voll großer Furcht. Am nächsten Morgen ließ Admete wissen, das Kultbild sei verschwunden. Man begab sich auf die Suche, und als die Suchenden das Bild am Stande entdeckten, glaubten die Karer - Barbaren, wie sie waren -, es sei von sich aus davongelaufen. So befestigten sie es mit einem Geflecht von Weidenruten, zogen die längsten Zweige rechts und links herum und umwanden es von allen Seiten. Admete löste das Kultbild, vollzog Reinigungsriten und setzte es wieder auf den Sockel, wo es zuvor gestanden hatte. Daher bringt man seit jener Zeit das Bild jedes Jahr ans Ufer, weiht es neu und stellt Opferkuchen davor. Dieses Fest nennt man Tonaia, das Engzurren, weil die Männer, die das Kultbild beim ersten Mal aufgesucht hatten, es so eng umwunden hatten«. (U. Treu - K. Treu)

Inwiefern die einzelnen Überlieferungen Mythen und reale Begebenheiten verweben, soll hier nicht untersucht werden. Kulte, Feste und Rituale waren oft mit Legenden über die Gründungs des Kultes oder die Einführung von Bräuchen verbunden. ${ }^{920}$. Die mit der Reinigung verbundenen Zeremonien, die begleitenden Feste und die mythischen Legenden vom Ursprung der Akte belegen eindeutig den Kultcharakter dieser Handlungen. Die Bilder standen dabei um Mittelpunkt, d. h. diese Kulthandlungen galten speziell den Bildern. ${ }^{921}$.

\subsubsection{Zweitkultbilder für bestimmte Riten}

Auffallend an den eben beschriebenen Riten ist, dass sie in der Regel mit den jeweils älteren Bildern durchgeführt worden sind. Die jüngeren waren aufgrund ihrer Größe und ihre Gewichtes in der Regel nicht zum Transport geeignet. Auch das Material und die Herstellung, z. B. bei Akrolithstatuen wie der Athena Parthenos oder dem Zeus von Olympia, erlaubten oft nicht, die Bilder in Kulthandlungen einzubeziehen, bei denen sie (regelmäßig) ihren Standplatz verließen. Daneben konnte aber auch gerade neue, z. T. speziell für solche Riten vorgesehene Götterbilder angefertigt werden. So wurde im Heiligtum der Artemis Orthia in

920 Vgl. Garland 1992, 152; H. U. Cain, Hellenistische Kultbilder. Religiöse Präsenz und museale Präsentation der Götter im Heiligtum und beim Fest, in: Wörrle - Zanker 1995, 115-130; Chr. Auffarth - J. Bernard - H. Mohr (Hrsg.), Metzler Lexikon der Religionen II (1999) 267-274 s. v. Kult/Ritual (B. Lang ); Steiner 2001, 109-112.

921 Gladigow u. a. 1998, 9-14; Steiner 2001, 106-112; ThesCRA II (2004) 220-229 s. v. Banquets des dieux (L. Bruit - F. Lissarrague); Linant de Bellefonds u. a. 2004. Weitere Beispiele bei M. P. Nilsson, Griechische Feste von religiöser Bedeutung mit Ausschluss der attischen (Leipzig 1906) 256. 
Messene in hellenistischer Zeit ein kleines Bild der Göttin, das nach Ausweis einer erhaltenen Darstellung halb hermenförmig war, von Kultteilnehmerinnen zum Altar getragen und war bei den Opferfeiern anwesend wie auch einige der oben genannten alten Bilder. Da es außer diesem Bild noch ein größeres, ständig im Heiligtum anwesendes gegeben hat, kann es sich auch bei dem tragbaren um ein speziell für diesen Ritus angefertigtes Zweitbild handeln ${ }^{922}$. Der Gabentisch und der Opferstock vor der monumentalen Statue bezeugen, dass auch diese Kult empfangen hat. Somit sind hier eindeutig zwei verschiedenen Ansprüchen gerecht werdende Bilder zu selben Zeit in ein und demselben Heiligtum belegt.

Im Heiligtum des Iakchos in Athen gab es offenbar ebenfalls zeitgleich mehrere Bilder, von denen eines fest im Heiligtum installiert gewesen ist, während das andere regelmäßig in der Mystenprozession nach Eleusis mitgeführt worden ist $\mathrm{t}^{923}$. Ein weiteres Beispiel für in Prozessionen eingebundene Bilder ist aus Delos überliefert. An den Dionysien wurde ein hölzernes Agalma des Gottes in einem Festzug auf einem Wagen mitgeführt. Das Bild wurde jedes Jahr neu angefertigt, wie Inschriften aus unterschiedlichen Jahren des 3. Jahrhunderts v. Chr. belegen. Es wurde also nur für einen begrenzten Zeitraum benutzt und speziell für die Prozession hergestellt. Da seine Herstellung nur geringe Kosten verursachte, kann es sich nur um ein recht einfaches Bild gehandelt haben ${ }^{924}$. In der Kaiserzeit waren auch verkleinerte Nachbildungen der Ephesischen Artemis, die C. Vibius Salutaris 104 n. Chr. gestiftet hatte, Teil regelmäßiger Prozessionen. Die Bestimmungen der Stiftung waren am ephesischen Theater angebracht:

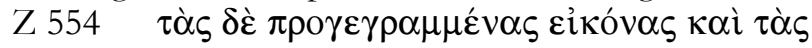

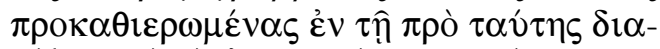

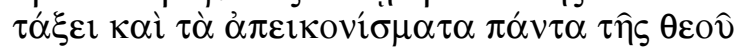

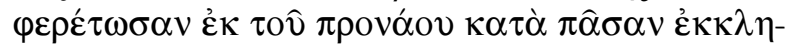

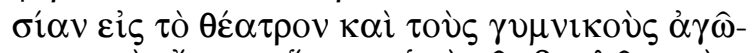

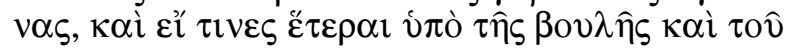

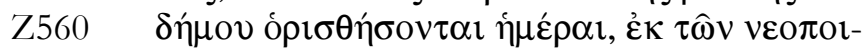

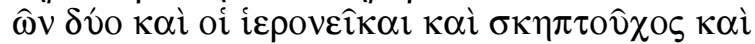

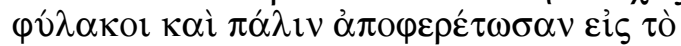

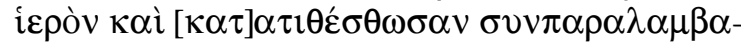

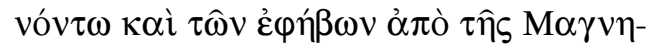

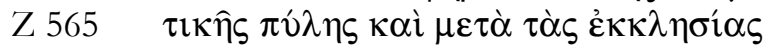

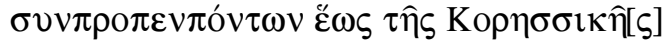

\footnotetext{
922 s. Kap. 12.11.

923 Vgl. Kap. 12.18.2.

${ }^{924}$ IG XI, 2, 144. 154. 158. 161 f. 179. 203. 219. 234. 278. Weitere Belege bei Th. Homolle, Comptes des Hiéropes du temple d'Apollon Délien, BCH 6, 1882, 1-167; ders., Inscriptions de Délos, BCH 27, 1903, 62-103; R. Vallois, L’ « Agalma » des Dionysies de Délos, BCH 46, 1922, 94-112. Weitere Beispiele bei M. P. Nilsson, Die Prozessionstypen im griechischen Kult, JdI31, 1916, 309-339; RE XXI (1951) 1878-1994 s. v. Pompa (F. Bömer).
} 


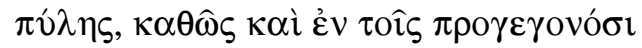

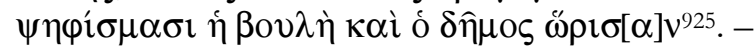

Z 554 »Die genannten Statuen und die schon vorher in der früheren Stiftung gestifteten und alle Statuenkopien der Göttin sollen vom Pronaos ins Theater zu jeder regulären Volksversammlung und zu den gymnischen Agonen und anderen Tagen, falls Rat und

Z 560 Volk solche noch bestimmen, von zwei Neopoioi und den Hieroniken und einem Stabträger und den Wächtern gebracht und wieder ins Heiligtum zurückgebracht und aufgestellt werden; vom Magnesischen Tor an

Z 565 übernehmen sie die Epheben mit und begleiten sie nach den Volksversammlungen bis zum Koressischen Tor, so wie es Rat und Volk auch in den vorausgegangenen Beschlüssen bestimmt haben«. (H. Wankel)

Diese Bilder vertraten wie im Fall des Artemiskultes von Messene zu bestimmten Anlässen das im Tempel aufgestellte Bild. Damit ist eindeutig bewiesen, dass es verschieden funktionalisierte Bilder zur selben Zeit im selben Heiligtum geben konnte.

Ein wichtiges Ergebnis, das sich aus der Untersuchung der einzelnen Heiligtümer und den eben vorgetragenen Kultpraktiken ableiten lässt, ist die Tatsache, dass die jeweiligen $>$ Kultbilder an unterschiedlichen Formen der Kultausübung Anteil hatten. Besonders deutlich ist dies am Beispiel des Heiligtums der Artemis Orthia in Messene geworden. Hier gab es neben der fest installierten Statue, die die Göttin ständig präsent und zugänglich machte, ein kleines tragbares Bild, das die Göttin während des Kultvorgangs am Altar vergegenwärtigte. Für beide Bilder konnte die kultische Verehrung nachgewiesen werden. Auch die Heiligtümer der Hera von Samos, der Artemis von Ephesos und Brauron sowie des Dionysos in Patrai, Korinth und Sikyon besaßen mehrere, im Kult z. T. unterschiedlich funktionalisierte Bilder. Deshalb kann die Frage gestellt werden, ob auch die übrigen Heiligtümer, bei denen nicht für jedes Bild im Einzelnen der Kult nachgewiesen werden konnte, mehr als ein >Kultbild ‘ beherbergten.

Aus den hier zusammengestellten Quellen kann man außerdem ableiten, dass die alten Bilder, auch wenn sie nicht mehr dem ästhetischen Anspruch genügten $^{926}$, weil sie entweder im Laufe der Zeit unansehnlich geworden waren oder

925 IvE I 27, vgl. auch Z 48-56. 156-158. 202-214. 268-284. 419-425. Von der Mitführung des Tempelbildes der Artemis, wie Elliger 1985, 124 meint, ist in der Inschrift nicht die Rede.

$926 \mathrm{Vgl}$. den Aischylos zugeschriebenen Ausspruch, S. 129. Einige alte Bilder wurden jedoch modernisiert: Hera von Samos, Hilaeira oder Phoibe in Sparta, Dione in Dodona, Dionysos in Theben; 
nicht mehr dem künstlerischen Stil entsprachen, teilweise sogar überhaupt nicht künstlerisch bearbeitet waren wie der Stein des Eros in Thespiai oder die Chariten in Orchomenos, über einen langen Zeitraum einen kultischen Mittelpunkt der jeweiligen Heiligtümer darstellten, wie es auch in dem oben zitierten, dem Dichter Aischylos zugeschriebenen Ausspruch ${ }^{927}$ zum Ausdruck kommt.

Doch auch die jüngeren Bilder waren mehr als nur wertvolle, schön anzusehende ,Weihgeschenker. Sie waren allerdings keine Konkurrenz zu den alten, oft einfachen und z. T. sogar als unansehnlich beschriebenen Bildern, sondern eine Ergänzung sowohl im Hinblick auf die Vorstellung, die man von den Göttern hatte als auch im Hinblick auf Bedürfnisse der kultischen Praxis und können durchaus als mit einem Kult bedachte Bilder angesprochen werden. Ein weiterer wichtiger Grund neben der unterschiedlichen Funktionalisierung der Statuen im Kultgeschehen ist daher sicherlich die schon lange bekannte Tatsache, dass sich die Vorstellung, die man von den Göttern hatte im Laufe der Zeit veränderte, was ich im ersten Teil der Arbeit am Beispiel der Aphrodite bereits dargelegt habe. Diese Veränderung geht auch aus den nicht immer geglückten Erklärungsversuchen hervor, zu denen sich spätere Autoren für bestimmte Riten oder das Aussehen und die Attribute einzelner Götterbilder genötigt sahen. Ein beredtes Zeugnis ist die Überlieferung des Pausanias zum Bild der Aphrodite Morpho in Sparta ${ }^{928}$.

Auch die architektonische Umgestaltung eines Heiligtums durch den Neubau eines Tempels kann anhand der untersuchten Beispiele als Grund für die Errichtung eines neuen Bildes festgestellt werden, so dass Tempel und Bild oft eine Einheit bildeten. Die neuen Bilder erfüllten diese Aufgabe aufgrund ihrer prachtvollen und oft monumentalen Präsenz in den im Vergleich zu den alten Tempeln ebenfalls vergrößerten Neubauten eher als die alten und oft kleinformatigen, $z$. T. sogar im Laufe der Zeit unansehnlich gewordenen Bilder. Auch aus diesem Grund wird es verständlich, dass mehrere Bilder ein und derselben Gottheit in einem Heiligtum gestanden haben können, die alle in den Kult einbezogen wurden. Die von J. Whitley noch im Jahr 2001 am Beispiel des Heraions von Argos festgestellte Wissenslücke: »At the Argive Heraion, we are at a loss to explain the need for a „doubling” of both temple and cult statue « ${ }^{929}$ kann damit auf verschiedene Weise geschlossen werden.

s. S. 205 f. mit Anm. 642. 220.

927 s. S. 129.

928 Paus. 3, 15, 10 f. Vgl. S. 275 f.

929 Whitley 2001, 305. 


\section{Schluss}

Ausgangspunkt und Thema des ersten Teils der Arbeit waren Darstellungen der Aphrodite, die die Göttin auf ein weibliches archaistisches Idol oder eine weibliche Herme gelehnt zeigen. Die Untersuchung dieser Bilder unter Einbeziehung der Darstellungen anderer Götter mit ikonischen Stützen hat gezeigt, dass diese Darstellungsform in der zweiten Hälfte des 5. Jahrhunderts v. Chr. für Aphrodite erfunden worden ist. Erst wesentlich später und mit deutlich geringerer Anzahl an Beispielen wurde das Motiv auch auf andere Götter übertragen.

Für den Typus der Aphrodite war schon lange eine Verbindung zu zwei Werken des Phidias, den Statuen der Aphrodite Urania in Elis und in Athen hergestellt worden. Für das früheste Beispiel dieses Typus, die >Aphrodite Brazzà h hat man vermutet, dass sie sogar selbst die Statue aus Athen ist, was jedoch nicht sicher verifiziert werden konnte. Die Verbindung des Typus mit dem phidiasischen Typus der Aphrodite Urania ist hingegen sehr wahrscheinlich. Zum einem setzen die zahlreichen Varianten ein berühmtes Vorbild voraus. Zum anderen zeigt der auf eine ikonische Stütze gelehnte Aphroditetypus als einziger mehrfach das Attribut der Schildkröte unter dem Fuß, die die Quellen auch für die Statue in Elis überliefern.

Deutungen des Typus und vor allem der altertümlichen Stützidole wurden ebenfalls bereits mehrfach vorgetragen. Am häufigsten wurde in den Idolen ein saltes (Kult-) Bild der auf sie gelehnten Göttin gesehen. Sicher erkennbar ist dies jedoch nur bei der Terrakottastatuette Kat. A43. Aufgrund ihrer altertümlichen Gestaltung fügen sich die Stützidole in die archaistische Kunst des 5. Jahrhunderts v. Chr. ein, mit der auf die alte Ehrwürdigkeit und Heiligkeit der Götterkulte hingewiesen wurde - unabhängig davon, ob mit den Idolen ein altes `Kultbild oder ein auf ein Heiligtum verweisendes >Votiv ' gemeint ist.

Diese Deutung konnte durch die Betrachtung des Körperbildes der aufgelehnten Aphrodite mit weiteren Argumenten verstärkt werden. Die untersuchten Bilder fügen sich in das klassische Körperbild der Göttin ein, das auch durch andere aufgelehnte Typen dieser Zeit bezeugt ist. Es konnte festgestellt werden, dass Aphrodite die erste Gottheit war, die überhaupt in einer Statue in aufgelehnter und zugleich 
besonders körperbetonter Haltung dargestellt wurde, und dass für diese Göttin auch die meisten Typen in dieser Haltung und davon wiederum die meisten Beispiele geschaffen worden sind. Dies ist dadurch bedingt, dass von der Zeit der Klassik an die Wirkungsweise und der Charakter der Götter nicht mehr nur durch Attribute, sondern vor allem auch durch die Darstellungsweise ihrer Körper und ihrer Körperhaltungen zum Ausdruck gebracht wurden. Die Götter wurden aufgrund ihrer Körperdarstellung erkennbar, auch, weil sie seit der Klassik in ihren Bildern selbst ihrer eigenen Macht unterlegen gezeigt wurden. Eine angelehnte, entspannte Haltung kam deshalb der sgliederlösenden ${ }^{930}$ Aphrodite zu. Zudem ermöglichte diese Haltung eine besondere Betonung, ja sogar exponierte Darstellung der weiblichen Körperformen, was zu dieser Zeit nur bei Aphrodite möglich war.

Die Tatsache, dass Aphrodite neben Dionysos die Gottheit war, deren Körperdarstellung sich in der klassischen Kunst besonders stark verändert hatte, legt die Möglichkeit nahe, in ihren Bilder darauf hinzuweisen, dass sie zugleich auch eine altehrwürdige Göttin war, deren Kult weit zurückreichte. Die neuen Darstellungen der klassischen Zeit wurden zwar den veränderten Ansprüchen dieser Epoche gerecht, brachten jedoch diesen Aspekt nicht unbedingt zum Ausdruck. Deshalb wurden sie mit einem alten Bild in Gestalt eines archaistischen Stützidols verbunden. Für die Herme bei Aphrodite hingegen hat M. Osanna ausführlich begründet, dass es sich um die Darstellung der Aphrodite Urania, einer mit dem Orient in Verbindung stehenden Kultform der Göttin handelt ${ }^{931}$. Die seit dem Hellenismus vorkommenden männlichen Stützfiguren, vorrangig Priapos, Hermaphrodit und Pan weisen hingegen auf die Wirkungsweise der Aphrodite als Göttin der Liebe, der Erotik und des Lebensgenusses hin. Dies geht deutlich daraus hervor, dass häufig nur das Motiv des Auflehnens auf eine ikonisch gebildete Stütze von dem Urtypus übernommen wurde, Aphrodite hingegen in einem anderen Körpertypus dargestellt ist, nämlich vor allem im Typus der Sandalenlöserin oder der Anadyomene, also Typen, die eindeutig erotisch konnotiert sind.

Die Ambivalenz einerseits zwischen einem hohen Alter eines Kultes, verbunden mit einem alten, zumeist einfachen und wenig künstlerisch gestalteten Bild und dem Wunsch nach einer neuen, den zeitgenössischen religiösen Vorstellungen, künstlerischen Fähigkeiten und finanziellen Mitteln entsprechenden Einrichtung eines Kultortes wurde in einem weiteren Teil der Arbeit durch die Untersuchung der Ausstattung einzelner griechischer Heiligtümer mit möglichen `Kultbildern vertiefend betrachtet. Bekannt ist, dass für zahlreiche Heiligtümer alte oder als alt geltende Bilder überliefert sind. Seit dem 6. Jahrhundert v. Chr. und verstärkt von der klassischen Zeit an erlebten die besprochenen Heiligtümer einen Ausbau, in dem entweder der alte Tempel erneuert oder sogar um einen zweiten ergänzt

930 s. Anm. 389.

931 s. Kap. 5.1.3. 
wurde. Dabei wurde zugleich oder seltener auch erst in späterer Zeit ein weiteres Bild der verehrten Gottheit aufgestellt. Dabei stellte sich jedoch die Frage nach der Funktion der jüngeren Bilder, verbunden mit der Frage nach dem neuzeitlichen - Begriff des $>$ Kultbildes`. Ein Exkurs zu diesem Begriff sowie seiner Anwendung in verschiedenen religions-(historischen) Wissenschaften ergab, dass eine strenge Auslegung dieses Wortes in dem Sinne, dass es nur ein $>$ Kultbild für eine Gottheit in einem Heiligtum gegeben haben könne, keiner der betrachteten Religionen gerecht wird. Es gab bzw. gibt nicht das >Kultbild schlechthin, stattdessen sind für viele Heiligtümer verschiedene Bilder mit unterschiedlichen Funktionen im Ritus belegt. Man kann höchstens unterscheiden zwischen Bildern, die von vorn herein zum Zweck der Verehrung errichtet worden sind, und solchen, die erst im Laufe ihrer Existenz in den Kult einbezogen worden sind. Deshalb konnten auch in Heiligtümer, die bereits ein Bild besaßen, immer neue Bilder gestiftet und dort verehrt werden.

Wenn man den Begriff >Kultbild verwenden möchte, dann am ehesten für solche Bilder, die dazu gedacht waren, regelmäßig im Kult repräsentativ für die Gottheit zu stehen - eine Funktion, die zumeist das zentral im Tempel aufgestellte Bild erfüllte. Davon konnte es jedoch auch mehrere in einem Heiligtum geben, je nach den Bedürfnissen und auch dem zeitlichen Wandel des Kultes. Dies wurde besonders deutlich in dem Heiligtum der Artemis Orthia in Messene, in dem zwei unterschiedlich funktionalisierte Bilder in ein und demselben Kultraum nebeneinander gestanden haben, außerdem in dem Heiligtum der Artemis in Ephesos. Dort gab es neben den eigentlichen >Tempelkultbildern kleinere Nachbildungen, die auf eine private Stiftung zurückgingen und bei einer strikten Anwendung unserer heutigen Begriffe als >Votiv bezeichnet werden müssten. Doch wurden diese bei Volksversammlungen und anderen wichtigen Ereignissen in einer Prozession aus dem Heiligtum in die Stadt getragen und vertraten demnach in gewissem Sinne die Göttin bzw. das eigentliche >Tempelkultbild und waren damit genauso verehrungswürdig wie dieses. Es konnte demnach mehr als ein in verschiedene Kultaktivitäten eingebundenes Bild einer Gottheit in einem Heiligtum geben.

Weitere Zeugnisse für die Einbindung mehrere Bilder in den Kult liegen für die Heiligtümer der Hera auf Samos und der Artemis Brauronia vor. Deshalb erscheint es legitim, auch für die übrigen Heiligtümer, für die mehr als ein Bild literarisch überliefert ist, zumindest die Vermutung zu äußern, dass auch diese in einzelne Formen des Kultes einbezogen worden sein konnten. Dies gilt vor allem für die Heiligtümer, in denen die Bilder unterschiedliche Aspekte der jeweiligen Götter zum Ausdruck brachten. Die Bilder erfüllten unterschiedliche Ansprüche und Aufgaben im Kult, je nachdem, ob sie z. B. transportfähig waren oder nicht, und/oder sie repräsentierten jeweils spezifische Aspekte der Gottheit. Im Kult standen sie jedenfalls alle für die Gottheit, unabhängig davon, ob sie im Einzelfall älter oder materiell wertvoller waren als die anderen. Auch die Vorstellungen, die man von den Göttern hatte und die Ansprüche, die man an sie stellte, veränderten 
sich im Laufe der Jahrhunderte. Mit einem neuen Bild konnte man die zum Zeitpunkt seiner Entstehung herrschenden Auffassungen von der Gottheit zum Ausdruck bringen. Mit einem alten konnte man hingegen auf das hohe Alter und auf die damit verbundene lange währende Bedeutung des Kultes hinweisen. Obwohl die jüngeren Bilder ungleich aufwändiger gearbeitet waren, was Material und künstlerische Ausführung betrifft, ist deutlich ist geworden, dass die alten Bilder bis in die Spätzeit hinein bewahrt und verehrt worden sind. W. Burkert hatte kürzlich die Ansicht vertreten, die neuen, prachtvollen Bilder hätten die alten, oft nur wenig qualitätvollen verdrängt und ihre Bedeutung auf ein Minimum reduziert: »diese angeblichen Originale [d. h. die Palladien, die angeblich aus Ilion stammten] spielen gar keine Rolle mehr; sie sind in ein paar Kulte eingebaut, aber nicht ,Glaubenszentrum' - sonst schaut man auf die Qualität und Pracht, auf die ,Prunkstücke' (agālmata), nicht auf den Fetisch « ${ }^{332}$. Dass auch diese Meinung dem antiken griechischen Verständnis widerspricht, konnte durch zahlreiche Zeugnisse von der weitreichenden Bedeutung der alten Bilder im Kult belegt werden, wenn sie auch - zumindest nach Ansicht einiger antiker Autoren - von der Größe und vom Glanz des Materials des jüngeren Bildes überstrahlt worden sein sollen.

932 W. Burkert, Mythen - Tempel - Götterbilder. Von der Nahöstlichen Koiné zur griechischen Gestaltung, in: Kratz - Spieckermann 2006b, 3-20, Zitat S. 13. 


\section{Katalog}

\section{Katalog der besprochenen Aphroditebilder}

Wenn Angaben zu Herkunfts- und Aufbewahrungsort, Material, Größe oder Datierung fehlen, waren sie der Literatur nicht zu entnehmen. Die Angaben zur Datierung beziehen sich auf Vorschläge der genannten Literatur. Abkürzungen bei den Literaturangaben werden nach den vom Deutschen Archäologischen Institut vorgeschlagenen Richtlinien, zuletzt aktualisiert am 04.12.2007, <http://www.dainst.org/index_141_de.html> (30.09.09) bzw. nach den im Abkürzungsverzeichnis angegebenen Siglen vorgenommen. Außer den dort genannten werden folgende Abkürzungen verwendet:
AO: Aufbewahrungsort
$\mathrm{H}$ : Herkunft
M: Material
UG: ursprüngliche (rekonstruierte) Größe
EH: erhaltene Höhe (des Fragments)
Dat.: Datierung

Die Abbildungen sind der jeweils zuerst angegebenen Literatur entnommen. 


\section{A1}

Taf. 1, 1-3, 3

AO: Berlin, Staatliche Museen Inv.

SK 1459

H: Kunsthandel

M: pentelischer Marmor

UG: überlebensgroß

EH: $1,58 \mathrm{~m}$

Dat.: um 430/20 v. Chr.

Weibliche stehende Statue in Chiton und Hüftmantel. Der linke Fuß ist erhöht vorgesetzt, mit dem linken Arm lehnte sich die Figur einst auf eine Stütze. Es fehlen der angestückte Kopf, rechte Arm, linke Unterarm und die Stütze. Ergänzt ist der linke Fuß mit der Schildkröte.

Lit.: Taf. 1,1-1, 2: (C) Staatliche Museen zu Berlin, Antikensammlung, Foto: Gisela Geng; Taf. 2, 1-2, 2: Kekulé 1894 Abb. S. 1. 26; Taf. 2, 3-3, 3: (C) Staatliche Museen zu Berlin, Antikensammlung, Foto: Johannes Laurentius; weitere Lit.: A. Frickenhaus, Phidias und Kolotes, JdI 28, 1913, 363-367 Abb. 7; Blümel 1966, 91 f. Nr. 109 Abb. 161-169; Settis 1966, 9-23 Taf. 1; Delivorrias 1984, 28 Nr. 177; Kunze 1992, 139 f. Nr. 47; P. C. Bol (Hrsg.), Die Geschichte der antiken Bildhauerkunst II. Klassische Plastik (Mainz 2004) 176 Abb. 96; Scholl 2001 [Auswahl].

\section{A2} Taf. 4, 1

AO: Berlin, Staatliche Museen Inv.

SK 586

H: Tarquinia (Corneto)

M: Marmor

UG/EH: $0,83 \mathrm{~m}$

Dat.: um 410 v. Chr.

Weibliche stehende Figur mit archaistischem Stützidol unter dem linken Arm. Bekleidet mit Chiton und Mantel, der auch über den Kopf gezogen ist. Der linke Fuß ist vorgesetzt. Ergänzt sind die erhobene rechte Hand und die aufgestützte linke mit der Spendenschale.

Lit.: (C) Staatliche Museen zu Berlin, Antikensammlung, Foto: Johannes Laurentius; Blümel 1966, 98 f. Nr. 117 Abb. 192-195; Ridgway 1981, 116 f.; Delivorrias 1984, 33 Nr. 223; Kunze 1992, 141 Nr. 48.

A3

Taf. 4, 2-4, 3

AO: Rom, Museo Gregoriano

Profano Ex Laterense Inv. 9561

M: Marmor

UG: unterlebensgroß

EH: $0,445 \mathrm{~m}$

Dat.: um 390-380 v. Chr.

Relieffragment mit weiblicher stehender Figur mit weiblicher bekleideter Herme als Stütze unter dem linken Ellenbogen. Der linke Fuß ist zurückgesetzt. Sie trägt Chiton und Hüftmantel. Kopf der stehenden Figur abgebrochen, stark bestoßen.

Lit.: Arachne Nr. 21524, Neg. Nr. FA383109_21524 und FA3832-08_21524,04; O.

Benndorf - R. Schöne, Die antiken Bildwerke des Lateranischen Museums (Leipzig 1867) 342 Nr. 482 Taf. 13; EA 2226; Helbig I ${ }^{4}$ (Tübingen 1963) 719 Nr. 1001 (W. Fuchs); Harrison 1965, 139 Anm. 226; Delivorrias 1984, 11 Nr. 18; F. Sinn (Hrsg.), Reliefgeschmückte Gattungen römischer Lebenskultur. Griechische Originalskulptur. Monumente orientalischer Kulte, MAR 33 (Wiesbaden 2006) 49-51 Nr. 11 Taf. 12, 1. 2.

A4 Taf. 5, 1 AO: Athen, Agoramuseum Inv. S 443 $\mathrm{H}$ : Agora M: Marmor 
UG: unterlebensgroß

Dat.: 1. Jh. v. Chr.

Weibliche stehende Figur mit archaistischem Stützidol unter dem linken Arm und erhöht vorgesetztem linken Fuß. Bekleidet mit hoch gegürtetem Chiton und Hüftmantel. Nicht erhalten sind der Kopf, rechte Arm, linke Unterarm, bestoßen sind der untere Gewandsaum und die Füße.

Lit.: Delivorrias 1984, 43 Nr. 314; G. Karo, Archäologische Funde vom Juli 1933 bis Juli 1934. Griechenland und Dodekanes, AA 49, 1934, 132-134 Abb. 5.

\section{A5}

M: Marmor

Dat.: kaiserzeitlich

Skizze von E. Wolf

Wie Kat. A4, nur mit ungegürtetem Chiton. Linker Fuß auf hockende Gans gestellt. Es fehlen der Kopf, der rechte Arm und der linke Unterarm.

Lit.: Delivorrias 1984, 28 Nr. 182; Kekulé 1894, 11 f. mit Abb.

A6

Taf. 5, 3

AO: Venedig, Archäolog. Museum

Inv. 84

$\mathrm{H}$ : Griechenland?

M: Marmor

UG: unterlebensgroß

EH: $0,79 \mathrm{~m}$

Dat.: späthellenistisch

Wie Kat. A4, Oberkörper jedoch stärker nach rechts gelehnt, rechte Hüfte schwingt stärker aus. Es fehlen der Kopf, rechte Arm, linke Unterarm, rechte Unterschenkel und linke Fuß.
Lit.: Foto D-DAI-Rom-1982.0509

(Schwanke); Anti 1927, 45 Abb. 5; EA

2527; Delivorrias 1984, 43 Nr. 309.

\section{A7}

Taf. 6, 1

AO: Rom, Nationalmuseum Inv.

125773

H: Rom

M: Marmor

UG: unterlebensgroß

EH: $0,91 \mathrm{~m}$

Dat.: kaiserzeitlich

Wie Kat. A5, linkes Knie jedoch weiter nach innen gedreht und Brust stärker vorgestreckt. Linker Fuß eventuell auf Schildkröte gestellt. Es fehlen der Kopf und die Arme.

Lit.: Foto D-DAI-Rom-1976.0804 (Rossa); A. Giuliano (Hrsg.), Museo Nazionale Romano. Le sculture I 2 (Rom 1981) 287291 Nr. IV, 11; Schmidt 1997, 201 Nr. 62.

\section{A8}

Taf. 6, 2

AO: - (ehem. Rufinella sopra Frascati)

$\mathrm{H}$ : Tusculum

UG: lebensgroß?

Dat.: hellenistisch

Weibliche Statue, Standmotiv ähnlich Kat. A4. Linker Fuß auf die Basis des Stützidols gestellt, rechter Arm auf den Rücken gelegt. Bekleidet mit ungegürtetem Chiton und Hüftmantel, der auch um den linken Arm gelegt ist. Bis auf den linken Unterarm erhalten.

Lit.: E. Gerhard, Venere Proserpina Illustrata (Florenz 1826) 61 Taf. 9.

\section{A9}

Taf. 6, 3

AO: München, Staatliche Antikenslg.? $\mathrm{H}$ : Myrina

M: Terrakotta 
UG/EH: 0,254 m

Dat.: kaiserzeitlich

Weibliche stehende Figur, mit dem linken Ellenbogen auf eine archaistische Figur gelehnt, rechte Hand in die Hüfte gestützt, linker Fuß vorgesetzt. Trägt Chiton und Hüftmantel, Manteldrapierung wie bei Kat. A8. Erhalten ist die gesamte Figur bis auf die linke Hand.

Lit.: J. Sieveking, Die Terrakotten der Sammlung Loeb II (München 1916) 38 f. Taf. 99.

A10 Taf. 7, 1

AO: Neapel, Nationalmuseum Inv. 6121

H: Baiae

M: Marmor

$\mathrm{UG} / \mathrm{EH}: 1,51 \mathrm{~m}$

Dat.: kaiserzeitlich

Wie Kat. A9, jedoch Kopf erhoben, ebenso der rechte Unterarm. In der vorgestreckten Linken Spendenschale. Ergänzt sind die Unterarme und die Schale.

Lit.: Pozzi 1989, 108 Nr. 62.

\section{A11}

Taf. 7, 2

AO: Sparta, Museum Inv. MA 6664

H: Sparta

M: Marmor

Torso einer weiblichen stehenden Figur, die sich mit dem linken Unterarm auf ein archaistisches Idol lehnt. Sie trägt über einem hochgegürteten Chiton einen Mantel, der die rechte Brust und Schulter frei lässt.

Lit.: Kahil 1984, 635 Nr. 116.
A12

Taf. 7, 3

AO: Wien, Privatbesitz

$\mathrm{H}$ : erworben in Scalanova bei

Ephesos

M: Marmor

UG: kleinformatig

EH: 0,277 m

Fragment einer weiblichen stehenden Statuette in Chiton und Mantel, die ihren linken Fuß auf eine Schildkröte setzt. Zu ihrer Linken kleine archaistische Figur. Erhalten sind die Beine und das Idol bis auf den Kopf.

Lit.: Schrader 1924, 74 Abb. 60 f.;

Delivorrias 1984, 28 Nr. 183.

\section{A13}

Taf. 8, 1

AO: Shahat, Antikenmuseum

$\mathrm{H}$ : Kyrene

M: Marmor

UG: unterlebensgroß

EH: 0,66 m

Dat.: kaiserzeitlich?

Ähnlich Kat. A12, jedoch stark beschädigt. Erhalten sind die Beine der stehenden, mit Chiton und Mantel bekleideten Figur und der Körper des Idols ohne Kopf.

Lit.: Paribeni 1959, 93 Nr. 241 Taf. 124.

A14

Taf. 8, 2

AO: Madrid, Prado Inv. 274

M: Marmor

$\mathrm{UG} / \mathrm{EH}: 1,35 \mathrm{~m}$

Dat.: kaiserzeitlich

Weibliche stehende Venus-Fortuna mit Füllhorn im linken Arm, mit dem sie sich auf ein archaistisches Idol lehnt. Linker Fuß auf eine Schildkröte 
gesetzt. Bekleidet mit hochgegürtetem Chiton und Hüftmantel. Es fehlen die Unterarme.

Lit.: EA 1544; E. Hübner, Antike Bildwerke in Madrid (Berlin 1862) 52 f. Nr. 34.

\section{A15}

Taf. 8, 3

AO: Athen, Nationalmuseum Inv.

Misthos 264

$\mathrm{H}$ : Myrina?

M: Terrakotta

$\mathrm{UG} / \mathrm{EH}: 0,31 \mathrm{~m}$

Dat.: um 100 v. Chr.

Vollständig in Mantel und Chiton gehüllte stehende weibliche Figur. Rechter Fuß vorgestellt. Lehnt sich mit dem rechten Ellenbogen auf die Basis einer kleinen archaistischen Figur und hält in der Linken ein Füllhorn. Vollständig erhalten ${ }^{933}$.

Lit.: E. Töpperwein-Hoffmann, Terrakotten von Priene, IstMitt 21, 1971, 149 Taf. 46, 4; Winter 1903, 88, 6. 172, 6.

\section{A16} Taf. 9, 1

AO/H: - (ehem. Paris, Slg. Rollin)

Weibliche stehende Figur mit archaistischem Stützidol unter dem linken Ellenbogen. Rechte Hand liegt auch auf der Stütze. Linkes Bein nicht vorgesetzt. Trägt einen Chiton und einen Mantel, die die rechte Schulter unbedeckt lassen. Der Mantel reicht nur bis zu den Oberschenkeln.

933 Die Bezeichnung vollständig erhalten bezieht sich nicht auf kleinere Fehlstellen, die unwesentlich sind für die Erkennbarkeit der Darstellung.
Lit.: E. Gerhard, Ueber die Venusidole, in: Gerhard 1868, 258-285 Taf. 29, 6; Reinach 1897b, 378, 7.

A17 Taf. 9, 2

AO: Florenz, Slg. Villa Poggio

Imperiale

UG: unterlebensgroß

Stehende Aphrodite oder Hermaphrodit, mit dem linken Arm auf archaistisches Idol gelehnt. Rechter Arm gesenkt, linker Fuß vorgesetzt. Bekleidet mit bodenlangem Gewand, das von der rechten Schulter gerutscht ist.

Lit.: E. Gerhard, Venere Proserpina Illustrata (Florenz 1826) 61-63 Taf. 10; Reinach 1897a, 341, 2.

A18 Taf. 9, 3

AO: Neapel, Nationalmuseum Inv. 109608

H: Pompeji I, 2, 17

M: Marmor

$\mathrm{UG} / \mathrm{EH}: 1,04 \mathrm{~m}$

Dat.: späthellenistisch

Wie Kat. A6, aber ohne Chiton unter dem Mantel. Linker Fuß erhöht nach vorn gesetzt. Linker Arm auf weibliches Idol gelegt, rechter gesenkt. Vollständig erhalten.

Lit.: Foto D-DAI-Rom-1983.2330

(Schwanke); Pozzi 1989, 146 Nr. 255.

A19

Taf. 9, 4

AO: Cambridge, Fitzwilliam Museum

Inv. Gr. 2.1865

H: Skepsis (Kurşunen Tepe)

M: Marmor

UG: unterlebensgroß

Dat.: späthellenistisch 
Wie Kat. A18; oberer Saum des Mantels vor dem Schoß jedoch gerader geführt. Linker Fuß eventuell auf Schildkröte gestellt. Erhalten sind der Unterkörper der Figur sowie das Idol bis zu den Unterschenkeln.

Lit.: Delivorrias 1984, 70 Nr. 609; L. Budde - R. Nichols, A Catalogue of the Greek and Roman Sculpture in the Fitzwilliam Museum Cambridge (Cambridge 1964) 57 f. Nr. 91 Taf. 31.

\section{A20} Taf. 10, 1

AO: Tarent, Nationalmuseum Inv.

I.G. 180.034

$\mathrm{H}$ : Tarent, Heiligtum an der

Satyrionquelle

M: Terrakotta

UG: kleinformatig

Dat.: späthellenistisch

In Körperhaltung und Gewanddrapierung wie Kat. A18. Der Kopf ist nach links gewandt. Es fehlt der rechte Arm und linke Unterarm.

Lit.: L. Monetti, La favissa 6 del santuario della sorgente di Satyrion, Taras 24/25, 2004/2005, 96 Abb. 29.

\section{A21}

Taf. 10, 2

AO: Würzburg, Martin von Wagner

Museum Inv. H 642

M: Terrakotta

UG: kleinformatig

Dat.: 2. Jh. v. Chr.

In Körperhaltung und Gewanddrapierung wie Kat. A18. Der rechte Arm ist allerdings angewinkelt nach vorn erhoben, auf dem linken trägt sie einen geflügelten Eros. Vollständig erhalten.
Lit.: Delivorrias 1984, 70 Nr. 614; Winter 1903, 96, 8; E. Simon, Führer durch die Antikenabteilung des Martin von Wagner Museums der Universität Würzburg (Mainz 1975) 232.

A22

Taf. 10, 3

AO: Shahat, Antikenmuseum Inv. 14.289

$\mathrm{H}$ : Kyrene, Apollonheiligtum

M: Marmor

UG: unterlebensgroß

EH: 0,36 m

Dat.: 1. Jh. n. Chr.

Wie Kat. A18, jedoch auf eine bekleidete Herme gestützt. Der linke Fuß ist auf eine Schildkröte gesetzt. Kopf, rechter Arm und linker Unterarm abgebrochen.

Lit.: Foto D-DAI-Rom-1958.2140

(Bartl); Paribeni 1959, 94 Nr. 242 Taf. 125; Delivorrias 1984, 70 Nr. 605.

A23

Taf. 10, 4

AO: Rom, Palazzo Doria-Pamphili

M: Marmor

$\mathrm{UG} / \mathrm{EH}: 0,875 \mathrm{~m}$

Dat.: hellenistisch

Stehende weibliche Figur in Hüftmantel, dessen Enden um den linken Arm gewunden sind. Linker Fuß nach links erhöht aufgesetzt, linker Arm auf Kopf der Stützfigur gelegt, rechter nach rechts erhoben ausgestreckt. Blick leicht nach rechts gerichtet. Bis auf das Attribut in der Rechten erhalten.

Lit.: EA 2288a; R. Calza (Hrsg.), Antichità di Villa Doria Pamphili (Rom 1977) 75 Nr. 77 Taf. 52. 
A24

Taf. 11, 1

AO: Delos, Museum Inv. A 1818

H: Delos, Heiligtum der syrischen

Götter

M: Marmor

UG: unterlebensgroß

Dat.: spätes 2. Jh. v. Chr.

Wie Kat. A23, Oberkörper mehr in Richtung der Stütze geneigt. Linker Fuß eventuell auf Schildkröte gesetzt. Erhalten sind der Torso mit dem rechten Arm, linken Bein und rechten Oberschenkel, Fragmente des linken Fußes sowie das Idol ohne Kopf.

Lit.: Delivorrias 1984, 65 Nr. 553; Marcadé, 1969, 227. 230 f. 301.353 Taf. 44.

A25 Taf. 11, 2

AO: Boston, Museum of Fine Arts

Inv. 01.7751

H: Myrina

M: Terrakotta

UG/EH: 0,336 m

Dat.: $150-100$ v. Chr.

Wie Kat. A23. Tritt mit dem linken Fuß auf die Basis der Stützfigur, Kopf nach links gesenkt. Bis auf kleinere Fehlstellen erhalten.

Lit.: Delivorrias 1984, 65 Nr. 552; Schmidt 1997, 201 Nr. 74; D. Burr Thompson, Terracottas from Myrina. Catalogue of the Boston Collection (o. O. 1934) 33 Nr. 10 Taf. 4, 2; Higgins 1967, 115 Taf. 53D.

A26 Taf. 11, 3

AO: Paris, Louvre Inv. MYRINA 931

H: Myrina

M: Terrakotta

UG: kleinformatig

EH: 0,315 m

Dat.: um 150 v. Chr.
Wie Kat. A23, aber Kopf nach links gesenkt. Es fehlen das rechte Bein, die rechte Hand und der linke Unterarm, große Fehlstelle auch am Unterkörper des Idols.

Lit.: Mollard-Besques 1963, 24 Taf. 26g.

A27

Taf. 12, 1

AO: München, Galerie Ulla Lindner

$\mathrm{H}$ : Myrina?

M: Terrakotta

UG: unterlebensgroß

EH: $0,25 \mathrm{~m}$

Dat.: um 150 v. Chr.

Wie Kat. A23, Blick jedoch stärker gesenkt. Bis auf die Hände und Basis vollständig erhalten.

Lit.: D. Pinkwart, Terrakotten, Keramik, Glas, Gemme usw., in: Pergamon. Ausstellungskatalog Ingelheim am Rhein (Offenbach 1972) 47 Nr. 45.

\section{A28}

Taf. 12, 2

AO: Paris, Louvre Inv. MYRINA 967

$\mathrm{H}$ : Myrina

M: Terrakotta

UG: kleinformatig

EH: 0,247 m

Dat.: um 150 v. Chr.

Wie Kat. A23. Erhalten sind der Unterkörper der aufgestützten Figur sowie der Oberkörper und Kopf des Idols.

Lit.: Mollard-Besques 1963, 25 Taf. 27a.

\section{A29}

Taf. 12, 3

AO: Paris, Louvre Inv. MYRINA 968

$\mathrm{H}$ : Myrina

M: Terrakotta 
UG: kleinformatig

EH: $0,16 \mathrm{~m}$

Dat.: um 150 v. Chr.

Vermutlich selber Typus wie Kat. A23.

Erhalten sind der Kopf und unbekleidete Oberkörper der aufgestützten Figur, der stark nach links in Richtung der zu vermutenden Stütze gelehnt ist.

Lit.: Mollard-Besques 1963, 25 Taf. 26d.

A30

Taf. 13, 1

AO: Paris, Louvre Inv. MYRINA 958

$\mathrm{H}$ : Myrina

M: Terrakotta

UG: kleinformatig

EH: $0,235 \mathrm{~m}$

Dat.: 2. H. 2. Jh. v. Chr.

Vermutlich demselben Typus wie Kat. A23 angehörend. Erhalten ist der unbekleidete Oberkörper mit dem Kopf und dem aufgestützten linken Arm, um den der Mantel geführt ist.

Lit.: Mollard-Besques 1963, 25 Taf. $26 f$.

\section{A31}

Taf. 13, 2

AO: Neapolis/Lakonien, Archäolog.

Slg.

H: Nekropole von Pavlopetri

M: Marmor?

UG: unterlebensgroß

Dat.: späthellenistisch

Wie Kat. A23. Der rechte Arm ist jedoch gesenkt und das Stützidol als Relief gebildet. Es fehlt der Kopf der stehenden Figur. Stark verwittert.

Lit.: A. Delivorrias, Arkadia - Lakonia, ADelt 24, 1969, Chron. 140 Taf. 136;

Delivorrias 1984, 67 Nr. 580.
A32

Taf. 13, 3

AO: Istanbul, Archäolog Museum

Inv. 1052

H: Priene, Haus 33

M: Marmor

$\mathrm{UG} / \mathrm{EH}: 0,55 \mathrm{~m}$

Dat.: hellenistisch

Wie Kat. A23. Als Stütze jedoch ein Pfeiler, der eventuell ein Idol trug. Es fehlen der rechte Arm, der linke Unterarm und der Aufsatz des Pfeilers.

Lit.: Rumscheid 2006, 52 Nr. 1. 3 Beil. 14, 3; H. Winnefeld, Bildwerke und Geräte aus Marmor, in: Th. Wiegand - $\mathrm{H}$. Schrader, Priene. Ergebnisse der Ausgrabungen und Untersuchungen in den Jahren 1895-1898 (Berlin 1904) 370 f. Abb. 466.

A33 Taf. 14, 1

H: Myrina

M: Terrakotta

UG: kleinformatig

$\mathrm{EH}: 0,28 \mathrm{~m}$

Im Standmotiv wie Kat. A23. Sie zieht jedoch den Mantel mit der erhobenen Rechten hinter dem Rücken empor. Sein vorderes Ende ist zwischen den Beinen festgesteckt, so dass das linke unbedeckt bleibt. Tritt mit dem linken Fuß auf die Basis der Stütze. Vollständig erhalten.

Lit.: Winter 1903, 98, 6.

\section{A34}

Taf. 14, 2

AO: Athen, Nationalmuseum Inv. 238

$\mathrm{H}$ : Melos

M: Marmor

UG: unterlebensgroß

Dat.: 2. Jh. v. Chr. 
Weibliche, in Chiton und Mantel gekleidete stehende Figur. Mit dem linken Unterarm auf archaistisches Idol gestützt, die rechte Hand ruht auf der Brust. Das linke Bein ist vor das rechte gekreuzt. Es fehlen der Kopf und der linke Unterarm.

Lit.: B. S. Ridgway, Hellenistic Sculpture II. The Styles of ca. $200-100$ B. C. (Madison 2000) 166 Taf. 54; R. Horn, Stehende weibliche Gewandstatuen in der hellenistischen Plastik, RM Ergh. 2 (München 1931) 88 Taf. 44, 1; Delivorrias 1984, 45 Nr. 341.

\section{A35} Taf. 14, 3

AO: - (ehem. Slg. Lecuyer)

$\mathrm{H}$ : Kleinasien

M: Terrakotta

$\mathrm{UG} / \mathrm{EH}: 0,235 \mathrm{~m}$

Gleichfalls mit gekreuzten Beinen stehende weibliche Figur in Chiton und Hüftmantel. Die linke Hand ruht auf einem Pfeiler mit archaistischem Idol im Relief, die rechte ist in die Hüfte gestützt. Auf der rechten Schulter hockt ein Eros. Vollständig erhalten.

Lit.: Winter 1903, 85, 8; A. Cartault, Hydrophore, Femme portant un enfant, Aphrodite, in: F. Lenormant u. a., Collection Camille Lecuyer. Terres cuites antiques trouvées en Grèce et en Asie Mineure I (Paris 1882) Text zu Taf. H3.

\section{A36} Taf. 14, 4

AO: Paris, Louvre Inv. MYR 30 (119)

$\mathrm{H}$ : Myrina

M: Terrakotta

$\mathrm{UG} / \mathrm{EH}: 0,215 \mathrm{~m}$

Dat.: 2. H. 1. Jh. v. Chr.
Weibliche stehende Figur, das linke Bein vor das rechte gekreuzt. Mit dem linken Arm auf ein archaistisches Idol gelehnt, der rechte ruht auf dem Rücken. In einen Mantel gehüllt, der die rechte Schulter frei lässt. Vollständig erhalten.

Lit.: Mollard-Besques 1963, 24 Taf. 26b; Reinach - Pottier 1887, 517 Taf. 6, 3; Winter 1903, 85, 1.

A37

Taf. 15, 1

AO: St. Petersburg, Eremitage

$\mathrm{H}$ : Kertsch? (Kunsthandel)

M: Terrakotta

UG: kleinformatig

Wie Kat. A36, Kopf etwas mehr nach rechts geneigt. Vollständig erhalten.

Lit.: L. Stephani, Erklärung einiger in den Jahren 1878 und 1879 im südlichen Russland gefundener Kunstwerke, CRPétersbourg 1880, 1882, 115-117 Taf. 5, 7.

\section{A38}

Taf. 15, 2

AO: Privatbesitz

$\mathrm{H}$ : vermutlich aus Myrina

M: Terrakotta

UG: kleinformatig

EH: $0,31 \mathrm{~m}$

Vermutlich wie Kat. A36. Die Beinstellung ist nicht klar erkennbar. Der Kopf ist nach links gewandt, der linke Unterarm erhoben. Bis auf den unteren Gewandsaum erhalten.

Lit.: Winter 1903, 87, 1.

A39

Taf. 15, 3

AO/H: - (ehem. Slg. Calvert)

M: Terrakotta

UG/EH: 0,105 m 
Im Standmotiv ähnlich Kat. A36. Blickt nach rechts unten auf einen kleinen Eros, der einen Spiegel hält. Der Mantel ist über den Kopf gezogen, sie fasst mit der Linken den oberen Saum vor der Brust. Vollständig erhalten.

Lit.: Winter 1903, 85, 2.

\section{A40}

Taf. 15, 4

AO: Paris, Louvre Inv. MYRINA 941

H: Myrina

M: Terrakotta

UG: kleinformatig

EH: 0,18 m

Dat.: Anf. 1. Jh. v.

Wie Kat. A35, jedoch ohne Chiton unter dem Mantel. Der Oberkörper ist mehr nach rechts geneigt. Mit der linken Hand auf einen Pfeiler gestützt, auf dem ein archaistisches Idol steht. Unterste Partie mit den Füßen abgebrochen.

Lit.: Mollard-Besques 1963, 31 Taf. 34d.

\section{A41}

Taf. 16, 1

AO: Athen, Nationalmuseum Inv.

Misthos 318

H: Myrina

M: Terrakotta

UG/EH: 0,37 m

Dat.: späthellenistisch

Seitenvertauscht $\mathrm{zu}$ der vorigen und zudem vollständig in den Mantel gehüllt. Das Idol steht auf einer Säule, auf die sich die Figur mit dem rechten Arm lehnt. Auf der linken Schulter ein kleiner Eros. Vollständig erhalten.
Lit.: Winter 1903, 88, 4; Delivorrias 1984 , 45 Nr. 346.

A42

keine Abb.

AO: Athen, Nationalmuseum Inv.

4999

H: Myrina

M: Terrakotta

UG: kleinformatig

Dat.: späthellenistisch

Von dieser Statuette wurde bisher keine Abbildung publiziert. Sie soll sich auf ein Idol lehnen und die Beine überkreuzen.

Lit.: Delivorrias 1984, 45 Nr. 345.

A43

Taf. 16, 2

AO: Genf, Musée d'Art et d'Histoire

Inv. PP.546

M: Terrakotta

$\mathrm{UG} / \mathrm{EH}: 0,17 \mathrm{~m}$

Dat.: 1. H. 4. Jh. v. Chr.

Weibliche, vollständig in Chiton und Mantel gehüllte stehende Figur, kreuzt mit dem linken Bein das rechte, beide Beine sind durchgestreckt. Die rechte Hand ruht auf der Hüfte, der linke Arm auf einem Naiskos mit einem archaistischen Idol darin, davor ein Altar. Kopf abgebrochen.

Lit.: Deonna 1950, 52-56 Taf. 4.

\section{A44}

Taf. 16, 3

$\mathrm{H}$ : Athen

M: Terrakotta

UG/EH: 0,24 m

Dat.: 4. Jh. v. Chr. 
Zwei stehende weibliche Figuren in Chiton und Hüftmantel. Die linke stützt sich mit dem linken Arm auf einen Pfeiler mit einem archaistischen Idol und stellt ihren linken Fuß auf dessen Basis. Die rechte überkreuzt mit dem linken Bein das rechte, hält in der gesenkten Rechten einen Spiegel und stützt sich mit dem linken Ellenbogen auf die Schulter der linken Figur. Vollständig erhalten.

Lit.: Delivorrias 1984, 30 Nr. 192; Winter 1903, 3, 7; L. Stephani 1876, 11.

\section{A45}

Taf. 17, 1

AO: Paris, Louvre Inv. CP 3537

M: calenische Reliefschale

UG: kleinformatig

Dat.: späthellenistisch

Weibliche, stehende Figur im Hüftmantel, hat den rechten Arm nach unten ausgestreckt und stützt sich mit der Hand auf die Basis eines Idols. Die linke Hand ist gesenkt, der rechte Fuß auf die Basis des Idols gestellt. $\mathrm{Zu}$ ihrer Linken fliegender und auf Pfau reitender Eros. Vollständig erhalten, Rand bestoßen.

Lit.: Schmidt 1997, 224 Nr. 354; R. Pagenstecher, Die calenische Reliefkeramik (Berlin 1909) 56 f. Nr. 61c Taf. 9.

\section{A46}

Taf. 17, 2

AO: Winterthur, Münzkabinett

$\mathrm{H}$ : Thespiai

M: Kupfermünze

UG: kleinformatig

Dat.: domitianisch

Weibliche stehende Statue in Chiton und Hüftmantel, legt die rechte Hand auf ein archaistisches Idol. Der linke
Arm ist angewinkelt erhoben, der rechte Fuß scheint vorgesetzt. Vollständig erhalten, aber abgerieben.

Lit.: Imhoof-Blumer - Gardner 1964, 117. 172-174 Taf. 3, 2, Taf. X Nr. 19.

A47

Taf. 17, 3

M: Terrakotta

UG: kleinformatig

Unbekleidete stehende weibliche Figur, das linke Bein ist leicht gebeugt. Mit dem linken Arm auf Reliefpfeiler mit archaistischem Idol gestützt, Eros auf der linken Schulter, hält in der Rechten ihr Gewand über eine Vase.

Lit.: Winter 1903, 210, 5.

\section{A48}

Taf. 17, 4

AO: Oplontis, Museum Inv. OP 1252

$\mathrm{H}$ : Villa von Oplontis

M: Marmor

$\mathrm{UG} / \mathrm{EH}: 0,525 \mathrm{~m}$

Dat.: kaiserzeitlich

Unbekleidete sandalenlösende Aphrodite, mit dem linken Arm auf ein archaistisches Idol gestützt. Greift mit der Rechten an den erhobenen linken Fuß, der von einem Eros gestützt wird. Blickt nach rechts. Bestoßungen, sonst vollständig erhalten.

Lit.: St. De Caro, Sculture della Villa di Poppea a Oplontis, CronPomp II, 1976, 219-226 Abb. 30-33; R. Neudecker, Die Skulpturenausstattung römischer Villen in Italien (Mainz 1988) 241 Nr. 71, 2; Schmidt 1997, 210 Nr. 183.

\section{A49} Taf. 18, 1

AO: Paris, Louvre Inv. 106

$\mathrm{H}$ : Myrina 
M: Terrakotta

UG: kleinformatig

EH: 0,30 m

Weibliche, mit gekreuzten Füßen nach hinten gelehnt auf Felsen sitzende Figur im Hüftmantel. Beide Arme angewinkelt erhoben, die einstigen Attribute sind verloren. Hinter ihr steht ein archaistisches Idol, Eros schaut hinter dem Felsen hervor. Es fehlen der Kopf und die linke Hand, der rechte Unterarm des Idols, die Hände und der linke Unterschenkel des Eros.

Lit.: Winter 1903, 201, 6; Reinach Pottier 1887, 520 Nr. 45 Taf. 6, 1.

\section{A50}

Taf. 18, 2

AO: Paris, Louvre Inv. CA 1970

$\mathrm{H}$ : Amisos

M: Terrakotta

UG/EH: 0,325 m

Dat.: um 150 v. Chr.

Weibliche nach hinten gelehnt sitzende Figur, die leicht ausgestreckten Beine von einem Mantel bedeckt, der Oberkörper unbekleidet. Lehnt mit dem linken Arm auf einem Pfeiler, die einst darauf angebrachte Figur ist abgebrochen. Die rechte Hand ruht im Schoß, der Kopf ist modern.

Lit.: Delivorrias 1984, 93 Nr. 871;

Mollard-Besques 1972, 76 Taf. 101b; J.

Schneider-Lengyel, Griechische Terrakotten (München 1936) 132 Abb. 65.

\section{A51}

Taf. 18, 3

AO: Neapel, Nationalmuseum Inv.

H 1769

H: Ruvo

M: apulisch-rotfigurige Amphora
UG: kleinformatig

EH (des gesamten Gefäßes): 1,00 m

Dat.: um 340 v. Chr., Dareiosmaler

Weibliche Figur, vollständig in Chiton und Mantelgehüllt aufrecht auf Hocker sitzend. Linker Ellenbogen ruht auf weiblicher bekleideter Herme, die rechte Hand ruht im Schoß und hält ein Attribut. Der Blick ist zurückgewendet. Szenenbild mit Raub des Chrysippos durch Laios. Vollständig erhalten.

Lit.: Delivorrias 1984, 11. 142 Nr. 17. 1494; C. Robert, Chrysippos and Antigone auf apulischen Vasen, JdI 29, 1914, 170 f.

Abb. 2.

A52a

Taf. 19, 1

AO: Paris, Louvre Inv. MYR 216

H: Myrina

M: Terrakotta

UG: kleinformatig

EH: 0,08 m

Weibliches archaistisches Idol mit Polos. Erhalten sind der Oberkörper und der Kopf.

Lit.: Mollard-Besques 1963, 25 Taf. 26e.

A52b Taf. 19, 2

AO: Paris, Louvre Inv. MYR 17

H: Myrina

M: Terrakotta

UG: kleinformatig

EH: 0,11 m

Weibliches archaistisches Idol mit Polos. Vollständig erhalten, Reste des Gewandes der aufgelehnten Figur an der Schulter.

Lit.: Mollard-Besques 1963, 25 Taf. 26a. 
A52c

Taf. 19, 3

AO: Paris, Louvre Inv. MYRINA 125

H: Myrina

M: Terrakotta

UG: kleinformatig

EH: $0,04 \mathrm{~m}$

Weibliches archaistisches Idol mit Polos. Vollständig erhalten, Reste des Gewandes der aufgelehnten Figur am rechten Bein.

Lit.: Mollard-Besques 1963, 25 Taf. 26c.

A52d

Taf. 19, 4

AO: Berlin, Staatliche Museen Inv.

P 178

H: Pergamon

M: Terrakotta

UG: kleinformatig

EH: $0,08 \mathrm{~m}$

Weibliches archaistisches Idol mit Polos. Bis auf die Füße und den Polos vollständig erhalten, Reste des Gewandes der aufgelehnten Figur an der rechten Seite.

Lit.: A. Conze u. a., Stadt und Landschaft, AvP 1, 2 (Berlin 1913 ) 259 f. Abb. 6.

A52e

Taf. 20, 1

AO: Athen, Agoramuseum?

$\mathrm{H}$ : Agora

M: Terrakotta

UG: kleinformatig

Dat.: um 100 v. Chr.

Weibliches archaistisches Idol mit Polos. Erhalten sind Torso, Oberschenkel und Arme. Vom selben Fundplatz stammen mindestens 14 weitere Fragmente solcher Idole aus dem 4. bis 1. Jh. v. Chr. Kat. A51e ist aufgrund des besseren Erhaltungszustandes ausgewählt worden.

Lit.: D. Burr Thompson, Three Centuries of Hellenistic Terracottas, Hesperia 28, 1959, 134 f. Taf. 27, 3. Zu den anderen Beispielen s. ebenda 133-138 Taf. 27 f.

A53

Taf. 20, 2

AO: Dresden, Staatliche Kunstslg. Inv. 9315

M: Marmor

UG: unterlebensgroß

EH: $1,08 \mathrm{~m}$

Dat.: späthellenistisch

Weibliche, vollständig in einen Mantel gehüllte stehende Figur mit Priaposstütze links. Der rechte Arm ist angewinkelt, das linke Bein vor das rechte gekreuzt. Es fehlen der Kopf, rechte Unterarm und linke Arm.

Lit:: Delivorrias 1984, 45 Nr. 342; R. Horn, Stehende weibliche Gewandstatuen in der hellenistischen Plastik, RM Ergh. 2 (München 1931) 87 f. Anm. 1 Taf. 44, 3; H. Hettner, Die Bildwerke der Königlichen Antikensammlung zu Dresden ${ }^{4}($ Dresden 1881) 55 Nr. 13; K. Zimmermann, Die Vorgeschichte und Anfänge der Dresdner Skulpturensammlung, in: ders., Die Dresdener Antiken und Winkelmann (Berlin 1977) 17. 24 Taf. 1.

\section{A54}

Taf. 20, 3

AO: Basel, Slg. Ackermann

M: Elfenbein

UG: unterlebensgroß

Dat.: späthellenistisch

Wie Kat. A22, jedoch mit Priapos als Stütze, gesenktem rechten Arm und nicht erhöht aufgestelltem linken Fuß. Der Oberkörper ist stärker in Rich- 
tung der Stütze verschoben. Es fehlen der Kopf und der rechte Unterarm.

Lit.: Delivorrias 1984, 68 Nr. 589.

\section{A55}

M: Gemme

UG: kleinformatig

Dat.: kaiserzeitlich

Unbekleidete stehende weibliche Figur mit Priaposstütze unter dem linken Arm. Die rechte Hand ist erhoben und fasst das Haar. Der linke Fuß ist leicht zur Seite gestellt, vollständig erhalten.

Lit.: Furtwängler 1900, 207 Taf. 43, 38.

\section{A56} Taf. 21, 1

AO: Kopenhagen, Nationalmuseum Inv. 348

M: Gemme

UG: kleinformatig

Dat.: kaiserzeitlich

Unbekleidete stehende weibliche Figur, überkreuzt mit dem linken Bein das rechte. Der linke Arm ruht auf einem Priapos, der rechte ist gesenkt. $\mathrm{Zu}$ ihrer Rechten steht Eros und hält einen Spiegel. Vollständig erhalten.

Lit.: Schmidt 1997, 226 Nr. 367.

\section{A57}

Taf. 21, 2

AO: Neapel, Nationalmuseum Inv. 152798

H: Pompeji II, 4, 6

M: Marmor

$\mathrm{UG} / \mathrm{EH}:$ 0,62 m

Dat.: 1. Jh. n. Chr.
Wie Kat. A48, jedoch mit Priapos als Stützfigur. Es fehlt die linke Hand.

Lit.: Foto D-DAI-Rom-1959.0816

(Koppermann); Pozzi 1989, 146 Nr. 254;

Schmidt 1997, 210 Nr. 182; LIMC VIII

Suppl. (1997) 1031 s. v. Priapos 15 (W.-

R. Megow).

A58

Taf. 21, 3

AO: München, Münzslg. Inv. A 1855

$\mathrm{H}$ : Kunsthandel

M: Gemme

UG: kleinformatig

Dat.: 2. Jh. n. Chr.

Sandalenlösende, im Profil gesehene unbekleidete Aphrodite, fasst mit der linken Hand den erhobenen rechten $\mathrm{Fuß}$ und stützt sich mit der rechten auf einem Priapos ab. Unterer Teil mit linkem Fuß der Göttin und Standfläche des Priapos abgebrochen.

Lit.: Schmidt 1997, 210 Nr. 189; E. Brandt u. A., Gemmen und Glaspasten der römischen Kaiserzeit sowie Nachträge, AGD 1, 3 (München 1972) 15 Nr. 2177.

A59 Taf. 22, 1

AO: Wien, Kunsthistorisches

Museum Inv. IX B 389

M: Plasma

UG: kleinformatig

Dat.: kaiserzeitlich

Wie Kat. A58, jedoch aufgerichteter in der Haltung. Vollständig erhalten.

Lit.: Schmidt 1997, 210 Nr. 190; E.

Zwierlein-Diehl, Die antiken Gemmen des Kunsthistorischen Museums in Wien II. Die Glasgemmen. Die Glaskameen. Nachträge zu Band I. Die Gemmen der späteren römischen Kaiserzeit. Teil I: Götter (München 1979 ) 202 Nr. 1478b. 
A60

Taf. 22, 2

AO: Paris, Louvre Inv. CA 1632

H: Myrina

M: Terrakotta

UG/EH: 0,24 m

Naiskos mit Aphrodite Anadyomene, beide Hände zum Haar erhoben, trägt Hüftmantel, Oberkörper unbekleidet, mit rechtem Ellenbogen auf Priapos gestützt, Eroten und Wasserbecken neben ihr. Vollständig erhalten.

Lit.: Mollard-Besques 1963, 155 Taf. 90a.

\section{A61a}

Taf. 22, 3

AO: Berlin, Antiquarium Inv. 8027

$\mathrm{H}$ : Myrina

M: Terrakotta

UG/EH: 0,245 m

Dat.: spätes 1. Jh. v. Chr. oder frühes

1. Jh. n. Chr.

Selber Körpertypus wie Kat. A60, nur ohne die Architekturrahmung. Der Priapos steht $\mathrm{zu}$ ihrer Linken, der Arm ist so weit erhoben, dass sie sich nicht aufstützt. Vollständig erhalten.

Lit.: Winter 1903, 212, 3; A. Furtwängler, Erwerbungen der königlichen Museen zu Berlin 1887, JdI 3, 1888, 253 Nr. 2.

A61b Taf. 23, 1

AO: Boston, Museum of Fine Arts

Inv. 87.378

H: Myrina

M: Terrakotta

UG: kleinformatig

Dat.: spätes 1. Jh. v. Chr. oder frühes 1. Jh. n. Chr.

Wie Kat. A61a, rechter Arm und Haarsträhnen abgebrochen.
Lit.: Delivorrias 1984, 77 Nr. 680; D. Burr

Thompson, Terracottas from Myrina.

Catalogue of the Boston Collections (o.

O. 1934) 33 Nr. 9 Taf. 4, 1.

\section{A62}

Taf. 23, 2

AO: London, British Museum

$\mathrm{H}$ : Italien

M: Terrakotta

UG: kleinformatig

EH: $0,12 \mathrm{~m}$

Wie Kat. A61a, jedoch oberhalb der Hüfte nicht erhalten. Zu ihrer Rechten ein kleiner Eros.

Lit.: Winter 1903, 213, 8; Th. Panofka, Britisches Museum. Teil B. Die Terrakottensammlung, AZ 4, 1846, 225.

A63

Taf. 23, 3

AO: Berlin, Antiquarium Inv. 328

M: Terrakotta

UG/EH: 0,155 m

Weibliche stehende Figur in Chiton und Hüftmantel, lehnt mit dem linken Arm auf Priaposherme. Der rechte Arm ist ausgestreckt, die Hand fehlt. Der linke Fuß ist leicht vorgesetzt.

Lit.: Winter 1903, 90, 7; Th. Panofka, Terracotten des Königlichen Museums zu Berlin (Berlin 1842) 65-70 Taf. 19.

A64

AO: Neapel, Nationalmuseum

H: Heraklea (Policoro)

M: Terrakotta

UG/EH: $0,19 \mathrm{~m}$

Dat.: 2. Jh. v. Chr.

In Standmotiv und Gewanddrapierung wie Kat. A18, aber seitenvertauscht und mit männlicher Herme 
als Stütze. Die gesenkte linke Hand ist in den Mantel eingehüllt, der rechte Fuß auf die Basis der Herme gesetzt. Vollständig erhalten.

Lit.: B. Neutsch, Herakleiastudien, RM Ergh. 11 (Heidelberg 1967) 179 Taf. 43, 1; Delivorrias 1984, 66 Nr. 558.

\section{A65} Taf. 24, 1

AO: Berlin, Antiquarium Inv. 5040

$\mathrm{H}$ : Tarent

M: Terrakotta

UG/EH: 0,205 m

Dat.: hellenistisch

Wie Kat. A64 mit der rechten Hand auf männliche Herme gestützte weibliche stehende Figur. Der Arm ist jedoch durchgestreckt, der andere in die Hüfte gestützt. Ein Mantel bedeckt den unteren Rücken und das rechte Bein, die linke Hand hält ihn auf Hüfthöhe. Vollständig erhalten.

Lit.: Winter 1903, 99, 2; Delivorrias 1984, 80 f. Nr. 721.

\section{A66}

Taf. 24, 2

AO: Berlin, Staatliche Museen Inv.

6766

M: Gemme

UG: kleinformatig

Dat.: kaiserzeitlich

Wie Kat. A65, jedoch seitenvertauscht und mit ausgestrecktem rechten Arm. Vollständig erhalten.

Lit.: Furtwängler 1900, 207 Taf. 43, 43.

\section{A67}

Taf. 24, 3

AO: Bad Deutsch-Altenburg,

Museum Carnuntinum Inv. 11952
$\mathrm{H}:$ Carnuntum

M: Bronze

UG: kleinformatig

Dat.: 2. Jh. n. Chr.

Weibliche unbekleidete stehende Figur, der linke Fuß ist zur Seite gestellt, die nach unten ausgestreckte Linke auf Priaposherme gelegt, der rechten Arm angewinkelt nach vorn gestreckt, der ist Unterarm abgebrochen.

Lit.: Schmidt 1997, 207 Nr. 152; R. Fleischer, Die römischen Bronzen aus Österreich (Mainz 1967) 77 f. Nr. 87 Taf. 50.

A68 Taf. 24, 4

AO: Paris, Louvre Inv. MYR 23

H: Myrina

M: Terrakotta

$\mathrm{UG} / \mathrm{EH}:$ 0,30 m

Dat.: späthellenistisch

Weibliche stehende Figur, die sich ein Busenband umlegt. Sie hält es mit der Linken vor der Brust und zieht es mit der Rechten um den Rücken. Der linke Ellenbogen ruht auf einer Priaposherme, das linke Bein ist zur Seite gestellt. Vollständig erhalten.

Lit.: Delivorrias 1984, 62 Nr. 513; Winter 1903, 215, 7; Mollard-Besques 1963, 20 Taf. 20f.

A69

Taf. 25, 1

AO: Paris, Louvre Inv. D 2164

$\mathrm{H}$ : Tarsos

M. Terrakotta

UG: kleinformatig

EH: $0,13 \mathrm{~m}$

Dat.: 2. H. 1. Jh. v. Chr. 
Wie Kat. A68. Füße der Aphrodite sowie Kopf und Basis der Herme abgebrochen.

Lit.: Mollard-Besques 1972, 272 Taf. 341e.

A70

Taf. 25, 2

AO: Berlin, Staatliche Museen Inv. 23

$\mathrm{H}$ : Aigion

M: Marmor

$\mathrm{UG} / \mathrm{EH}:$ 0,64 m

Dat.: spätes 2. Jh. v. Chr.

Wie Kat. A48, jedoch mit Priaposherme als Stütze. Es fehlen der rechte Arm und der linke Unterschenkel.

Lit.: Künzl 1970, 139 Nr. M 15 Abb. 15; A. Furtwängler, Die Sammlung Sabouroff. Kunstdenkmäler aus Griechenland I (Berlin 1883-1887) Taf. 37; Delivorrias 1984, 58 Nr. 463; Kunze 1992, 181 Nr. 80.

\section{A71}

Taf. 25, 3

$\mathrm{H}$ : Balaneia (Baniyas)

M: Marmor

UG: unterlebensgroß

Dat.: hellenistisch?

Wie Kat. A48, aber mit Priaposherme als Stütze. Eros unter dem erhobenen Fuß. Vollständig erhalten.

Lit.: Reinach 1897b, 349, 2; Künzl 1970, 139 Nr. M 12.

\section{A72}

Taf. 25, 4

AO: Rotterdam, Museum Boijmans

Van Beuningen

M: Bronze?

Dat.: späthellenistisch
Wie Kat. A48, jedoch mit Priaposherme als Stütze. Delphin unter dem erhobenen Fuß. Vollständig erhalten.

Lit.: Reinach 1897a, 334, 1; F. de Clarac, Musée de sculpture antique et moderne ou description historique du Louvre et de toutes ses parties de statues, bustes, basreliefs et inscription du Musée royal des antiques et des Tuileries et de plus de 2500 statues antiques: tirées des principaux musées et des diverses collections de l'Europe accomp. d'une iconographie Egyptienne, Grecque et Romaine et terminé par l'iconographie Française du Louvre et des Tuileries IV. Statues (Paris 1836/37) Taf. 622A, 1; Muthmann 1951, 17.

A73 Taf. 26, 1

AO: Paris, Louvre Inv. BR 4422

$\mathrm{H}$ : Amrith

M: Bronze

UG/EH: 0,26 m

Dat.: hellenistisch oder

frühkaiserzeitlich

Wie Kat. A48, mit Priaposherme als Stütze. Der linke Arm ist ausgestreckt, die Finger abgebrochen.

Lit.: LIMC II (1984) 163 s. v. Aphrodite in peripheria orientali 206 (M.-O. Jentel); de Ridder 1904, 69 Nr. 91 Taf. 16; Künzl 1970, 153 f. Nr. B 50.

A74

Taf. 26, 2

AO: Florenz

M: Bronze?

UG: kleinformatig

Wie Kat. A48, jedoch mit Priaposherme als Stütze. Der linke Ellenbogen ist stärker erhoben. Vollständig erhalten.

Lit.: Reinach 1924, 158, 2. 


\section{A75}

AO: London, British Museum

M: Silber

UG: kleinformatig

Dat.: kaiserzeitlich

Wie Kat. A48, jedoch aufrechter stehend und mit Stützherme. Figuren vollständig erhalten.

Lit.: Reinach 1904, 114, 12; O. M.

Dalton, Catalogue of Early Christian

Antiquities and Objects from the

Christian East in the Department of

British and Medieval Antiquities and

Ethnography (London 1901) 37 Nr. 232.

\section{A76}

Taf. 26, 4

AO: Kopenhagen, Ny Carlsberg

Glyptothek Inv. 1021

$\mathrm{H}$ : Sidon?

M: Bronze

UG: kleinformatig

Dat.: kaiserzeitlich

Wie Kat. A48, jedoch mit dem Unterarm auf Priaposherme gestützt. Vollständig erhalten.

Lit.: LIMC II (198) 163 s. v. Aphrodite in peripheria orientali 202 (M.-O. Jentel); LIMC VIII Suppl. (1997) 1031 s. v. Priapos 14 (W.-R. Megow); Künzl 1970, 148 Nr. B 18 Abb. 27; EA 4751; Ny Carlsberg Glyptothek. Billedtavler til Kataloget ober Antike Kunstwerker (Kopenhagen 1907) Nr. Br. 11 Taf. 17; F. Poulsen, Ny Carlsberg Glyptothek. Katalog over antike Skulpturer (Kopenhagen 1940) 607 Nr. Br 11.

\section{A77} Taf. 27, 1

AO: Würzburg, Martin von Wagner

Museum Inv. H 5359

H: Gegend von Smyrna

M: Terrakotta
UG: kleinformatig

Dat.: 1. Jh. v. Chr.

Stehende unbekleidete Aphrodite Anadyomene mit Priaposherme als Stütze unter dem rechten Arm, zu ihrer Linken Pfeiler mit rundem Objekt (Opferkuchen?). Vollständig erhalten.

Lit.: Delivorrias 1984, 56 Nr. 449; E.

Simon (Hrsg.), Führer durch die Antikenabteilung des Martin von Wagner $\mathrm{Mu}$ seums der Universität Würzburg (Mainz 1975) 231 Taf. 57, 2.

\section{A78a}

Taf. 27, 2

AO: St. Petersburg, Eremitage

H: Pantikapeion (Kertsch)

M: Terrakotta

UG: kleinformatig

Dat.: kaiserzeitlich

Unbekleidete stehende Aphrodite (-Isis), mit der Rechten ihr Haar fassend und dabei den Ellenbogen auf eine Priaposherme stützend. Die gesenkte Linke ruht auf Harpokrates. Der rechte Fuß ist leicht zur Seite gestellt. Vollständig erhalten.

Lit.: L. Stephani, Erklärung einiger im südlichen Russland gefundener Kunstwerke, CRPétersbourg 1870/1871, 1874, 174 f. Taf. 3, 5; LIMC IV (1988) 441 s. v. Harpokrates 399 (Tran Tam Tinh).

\section{A78b}

Taf. 27, 3

AO: St. Petersburg, Eremitage

H: Pantikapeion (Kertsch)

M: Terrakotta

UG: kleinformatig

Dat.: kaiserzeitlich

Wie Kat. A78a.

Lit.: Stephani 1876, 5 f. Taf. 1, 1. 
A78c

AO: St. Petersburg, Eremitage

H: Pantikapeion (Kertsch)

M: Terrakotta

UG: kleinformatig

Dat.: kaiserzeitlich

Wie Kat. A78a.

Lit.: L. Stephani, Erklärung einiger im Jahre 1876 im südlichen Russland gefundener Kunstwerke, CRPétersbourg 1877, 1880, 254 f. 259 Taf. 5, 7.

A79 Taf. 28, 1

AO: - (ehem. Paris, Slg. Rothschild)

Aphrodite Anadyomene, trägt einen Hüftmantel, der bis unter die Brust hochgezogen ist. Zu ihrer Rechten Priaposherme, auf die sich jedoch nicht aufstützt, da diese sehr klein ist. Vollständig erhalten.

Lit.: Reinach 1904, 103, 8.

A80

Taf. 28, 2

AO: Paris, Louvre Inv. D 314

H: Pantikapeion (Kertsch)

M: Terrakotta

UG: kleinformatig

EH: $0,18 \mathrm{~m}$

Dat.: 2. H. 1. Jh. v. Chr.

Stehende Aphrodite vermutlich im Anadyomenetypus, von Mantel hinterfangen, sonst unbekleidet. $\mathrm{Zu}$ ihrer Rechten Priaposherme. Nur Herme und Beine der Göttin erhalten.

Lit: Mollard-Besques 1972, 57 Taf. 67b.

A81

Taf. 28, 3

AO: - (ehem. Paris, Slg. Pourtales)
Unbekleidete Aphrodite Anadyomene, fasst mit beiden Händen ihr Haar an der rechten Seite des Kopfes. Zu ihrer Linken Priaposherme, auf die sie sich nicht aufstützt. Vollständig erhalten.

Lit.: Reinach 1897a, 332, 3.

A82

Taf. 28, 4

M: Gemme

UG: kleinformatig

Unbekleidete stehende Aphrodite Pudica, zu ihrer Rechten Priaposherme. Bedeckt mit der Rechten die Scham und mit der Linken die Brust. Stützt sich nicht auf, da die Herme sehr klein ist. Vollständig erhalten.

Lit:: S. Reinach, Pierres Gravées des Collections Marlborough et D’Orléans. Bibliothèque des Monuments Figurées Grecs et Romains (Paris 1895) 39 Taf. 35, 73, 5.

\section{A83}

Taf. 29, 1

AO: St. Petersburg, Eremitage Inv. $\Pi$ 1829.3

H: Pantikapeion (Kertsch)

M: Terrakotta

UG/EH: 0,25 m

Dat.: späthellenistisch

Weibliche, aufrecht sitzende Figur, mit dem Rücken an Priaposherme gelehnt, neben ihr stehender Eros. Unbekleidet, ein Mantel dient als Unterlage. Mit der Rechten auf den Felsen gestützt, linker Unterarm abgebrochen.

Lit.: Delivorrias 1984, 93 Nr. 870; Winter 1903, 201, 2; Reinach 1892, 113 Taf. 65, 1.

\section{A84}

AO: St. Petersburg, Eremitage

H: Pantikapeion (Kertsch) 
M: Terrakotta

UG: kleinformatig

EH: 0,22 m

Dat.: späthellenistisch?

Ähnlich Kat. A83, die Herme jedoch bekleidet. Der als Unterlage dienende Mantel bedeckt das linke Bein. Kopf und linker Unterarm abgebrochen.

Lit.: Reinach 1892, 113 Taf. 65, 2.

\section{A85}

AO: St. Petersburg, Eremitage

H: Pantikapeion (Kertsch)

M: Terrakotta

$\mathrm{UG} / \mathrm{EH}: 0,19 \mathrm{~m}$

Dat.: hellenistisch?

Ähnlich Kat. A83, jedoch seitenvertauscht. Der als Unterlage dienende Mantel bedeckt auch die Beine. Vollständig erhalten.

Lit.: Reinach 1892, 113 Taf. 65, 5.

\section{A86}

H: Pantikapeion (Kertsch)

Taf. 30, 1

M: Terrakotta

UG: kleinformatig

Dat.: kaiserzeitlich

Ähnlich Kat. A83, jedoch seitenvertauscht. Der linke Arm ruht auf der Herme, der rechte liegt auf ihrem Kopf. Der Mantel ist über den Kopf und das rechte Bein gezogen, linker Unterarm und Unterschenkel fehlen.

Lit.: L. Stephani, Erklärung einiger in den Jahren 1878 und 1879 im südlichen Russland gefundener Kunstwerke, CRPétersbourg 1880, 188215 f. Taf. 5, 6.
A87

Taf. 30, 2

AO: Berlin, Antiquarium Inv. 7677

$\mathrm{H}$ : Kleinasien

M: Terrakotta

$\mathrm{UG} / \mathrm{EH}: 0,11 \mathrm{~m}$

Ähnlich der vorigen, der Mantel jedoch folienartig hinter ihr gebläht, fasst ihn mit der Rechten. Die Haltung des linken Arms nicht erkennbar, er ist jedoch nicht auf die Herme gelegt. Vollständig erhalten.

Lit.: Winter 1903, 130, 5, G. Treu, Erwerbungen der Königlichen Museen im Jahre 1880. Teil II. Antiquarium, AZ 39, 1881, 254.

A88 Taf. 30, 3

AO: Paris, Louvre Inv. MNB 556

$\mathrm{H}$ : Tanagra

M: Terrakotta

$\mathrm{UG} / \mathrm{EH}: 0,19 \mathrm{~m}$

Dat.: hellenistisch

Weibliche, aufrecht sitzende, vollständig in ihren Mantel gehüllte Figur, mit dem Rücken an Priaposherme gelehnt. Beide Arme vor die Brust geführt, der rechte in den Mantel gehüllt. Vollständig erhalten.

Lit.: Winter 1903, 109, 4; Delivorrias 1984, 93 Nr. 865; Mollard-Besques 1963, 28

Taf. 31a.

A89

Taf. 30, 4

AO: Korfu, Museum im Gymnasion

Inv. 158

H: Korfu

M: Marmor

UG: unterlebensgroß

EH: $0,47 \mathrm{~m}$

Dat.: hellenistisch 
Wie Kat. A10, jedoch mit Hermaphrodit als Stütze. Es fehlen der Kopf, der rechte Arm und der linke Unterarm.

Lit.: Foto D-DAI-ATH-Korfu 80; EA 604b; G. Dontas, A Guide to the Archaeological Museum of Corfu (Athen 1973) 62 Nr. 158; LIMC V (1990) 277 s. v. Hermaphroditos 62 (A. Ajootian); Oehmke 2004, 111 Nr. 61.

A90 Taf. 31, 1

AO: Hamburg, Museum für Kunst und Gewerbe Inv. 1896.459

M: Terrakotta

UG/EH: 0,204 m

Dat.: frühellenistisch

Stehende weibliche Figur im Hüftmantel, mit dem rechten Ellenbogen auf Hermaphrodit gestützt, rechtes Spielbein vorgestellt, linke Hand fasst den Mantel, blickt nach rechts. Bestoßen, sonst vollständig erhalten.

Lit.: Oehmke 2004, 112 Nr. 65; E. von Mercklin, Führer durch das Hamburgische Museum für Kunst und Gewerbe II. Griechische und römische Altertümer (Hamburg 1930) 72 f. Nr. 278.

\section{A91}

Taf. 31, 2

AO: Delos, Museum Inv. A 5095

H: Delos

M: Marmor

UG: kleinformatig

EH: 0,115 m

Dat.: späthellenistisch

Stehende unbekleidete weibliche Figur, oberhalb der Knie abgebrochen. Linkes Spielbein stark gebeugt, beide Füße parallel nebeneinander stehend. Zu ihrer rechten kleine Figur im Anasyromenos-Motiv ohne Kopf.
Lit.: Marcadé 1969, 235. 240 Taf. 48; J. Marcadé, Reliefs Déliens, BCH Suppl. 1 (Paris 1973) 343 f. Nr. 17; Oehmke 2004, 112 Nr. 64.

A92

Taf. 31, 3-4

AO: Delos, Museum Inv. A 5001.

A 5002

H: Delos

M: Marmor

UG: unterlebensgroß

EH: 0,44 bzw. 0,23 m

Dat.: späthellenistisch

Weibliche unbekleidete, auf dem linken Bein stehende Statuette. Hat sich eventuell auf Hermaphroditherme gestützt. In mehrere Teile zerbrochen, Arme und Unterschenkel fehlen.

Lit.: Marcadé 1969, 235 Taf. 45; S.

Reinach, Monuments Figurées de Délos, BCH 8, 1884, 171 Nr. 6; Delivorrias 1984, 63 Nr. 518.

\section{A93}

Taf. 32, 1

AO/: - (ehem. Slg. de Clercq)

M: Bronze

UG/EH: 0,308 m

Dat.: hellenistisch

Wie Kat. A48, auf Erosherme, die aus vegetabilen Elementen erwächst, aufgestützt, vollständig erhalten.

Lit.: de Ridder 1904, Nr. 89 Taf. 15.

A94

Taf. 32, 2

AO: Deutschland, Privatbesitz

M: Terrakotta

UG: kleinformatig

Dat.: spätes 2. Jh. n. Chr. 
Stehende, fast nackte weibliche Figur. Mit dem linken Ellenbogen auf Eros gestützt, zweiter kleinerer Eros zu ihrer Rechten. Ein Mantel bedeckt das linke Spielbein, mit der erhobenen Rechten zieht die Figur den Mantel hinter dem Rücken empor. Vollständig erhalten.

Lit.: Schmidt 1997, 209 Nr. 174.

\section{A95}

Taf. 32, 3

AO: - (ehem. Paris, Slg. Trubert)

M: Marmor?

UG: unterlebensgroß

EH: $0,40 \mathrm{~m}$

Weibliche, mit Chiton und Mantel bekleidete stehende Figur. Zieht mit der erhobenen Rechten den Mantel hinter dem Rücken empor, hat die Linke auf Eros gelegt. Der rechte Fuß ist leicht zur Seite gestellt. Kopf abgebrochen.

Lit.: Reinach 1897b, 378, 3. 4.

\section{A96}

Taf. 33, 1

AO/H: Pompeji VII, 9, 47, oecus, in situ

$\mathrm{M}$ : Wandgemälde

UG: unterlebensgroß

Dat.: 3. Stil

Mit Chiton und Mantel bekleidete Venus Pompeiana in einem Tempel stehend, mit dem linken Ellenbogen auf Eros? gestützt, zu ihrer Rechten Priapos. Hält Szepter in der linken Armbeuge, rechte Hand vor die Brust geführt. Szenische Darstellung der Hochzeit des Herakles.

Lit.: LIMC VIII Suppl. (1997) 1035 s. v. Priapos 87 (W.-R. Megow); W. Helbig, Die Wandgemälde der vom Vesuv ver- schütteten Städte Campaniens (Leipzig 1868) 358 f. Nr. 1479; K. Schefold, Die Wände Pompejis. Topographisches Verzeichnis der Bildmotive (Berlin 1957) 198; Schmidt 1997, 226 Nr. 366.

A97

Taf. 33, 2

AO: - (ehem. Smyrna, Slg. Gaudin)

$\mathrm{H}$ : Myrina

M: Terrakotta

UG: kleinformatig

EH: $0,13 \mathrm{~m}$

Gelagerte weibliche Figur im Hüftmantel, mit dem Rücken an kleine Figur auf Basis (Eros?) gelehnt. Linker Ellenbogen auf der Unterlage aufgestützt, die erhobene Hand den Kopf. Rechte Hand ruht im Schoß. Unterschenkel der Gelagerten und Figur auf der Basis bis auf die Beine abgebrochen.

Lit.: Winter 1903, 130, 6.

A98

Taf. 33, 3

AO: Berlin, Staatliche Museen Inv.

2261

M: Glaspaste

UG: kleinformatig

Dat.: 2. H. 1. Jh. v. Chr.

Weibliche stehende Figur, der rechte Fuß ist leicht zurückgesetzt, mit der rechten Hand auf Basis einer Dionysosherme gestützt, der Arm ist durchgestreckt. Mit der Linken zieht sie einen Mantel hinter ihrem Rücken empor, sonst ist der Körper unbedeckt. Vollständig erhalten.

Lit.: Furtwängler 1900, 175 Taf. 36, 25;

G. Horster, Statuen auf Gemmen (Bonn 1970) 54 f. Taf. 10, 1, 2. 
A99

AO: Tarent, Museum Inv. 7581

H: Tarent, Contrada Tesoro, Grab 8

M: Terrakotta

UG: kleinformatig

Dat.: hellenistisch

Wie Kat. A65, jedoch mit dem rechten Ellenbogen aufgestützt. Tritt mit dem rechten Bein auf die Basis der Herme. Vollständig erhalten.

Lit.: Graepler 1997 Abb. 208 Nr. 31, 1.

A100

Taf. 34, 2

AO: Kos, Museum

$\mathrm{H}$ : Kos?

M: Marmor

UG: unterlebensgroß

EH: $0,49 \mathrm{~m}$

Dat.: späthellenistisch

Stehende weibliche Statuette im Hüftmantel, mit dem linken Arm auf Panherme gestützt. Linkes Bein ist vorgesetzt. Kopf, rechter Arm, linker Unterarm und Füße abgebrochen.

Lit.: N. Marquart, Pan in der hellenistischen und kaiserzeitlichen Rundplastik (Bonn 1995) 240 f. Nr. 9 Taf. 24, 2.

\section{A101} Taf. 34, 3

AO: - (ehem. Berlin, Slg. Bartholdy)

M: Bronze

UG: unterlebensgroß

Stehende unbekleidete weibliche Figur, sich im Spiegel betrachtend, den sie in der erhobenen Rechten hält. Mit dem ausgestreckten linken Arm auf bärtige Herme gestützt. Der linke Fuß ist leicht zur Seite gestellt. Vollständig erhalten.
Lit.: Reinach 1897b, 359, 8; E. Gerhard, Ueber Agathodaemon und Bona Dea, in: Gerhard 1868, 21-57 Taf. 51, 2; Bernoulli 1873, 356.

A102

Taf. 34, 4

AO: Rom, Konservatorenpalast

M: Terrakotta

UG: kleinformatig

EH: $0,25 \mathrm{~m}$

Standmotiv und Gewanddrapierung ähnlich Kat. A31, oberer Mantelsaum jedoch tiefer. Mit dem linken Arm auf bärtige Herme gestützt. Kopf, rechter Arm und Fuß fehlen.

Lit.: Winter 1903, 101, 8.

A103

Taf. 35, 1

AO: Berlin, Antiquarium

H: Korinth

M: Terrakotta

UG: kleinformatig

EH: $0,238 \mathrm{~m}$

Vermutlich ähnlich Kat. 100, jedoch mehr nach links in Richtung der Herme geneigt. Stark zerstört.

Lit.: Winter 1903, 82, 3; G. Treu, Erwerbungen der Königlichen Museen im Jahre 1880. Teil II. Antiquarium, AZ 39, 1881, 254.

A104

keine Abb.

AO: Volos, Museum Inv. 1548

H: Volos?

M: Marmor

UG: unterlebensgroß

Die Statuette ist nicht mit einer $\mathrm{Ab}$ bildung veröffentlicht. Sie soll sich auf eine bärtige Herme stützen und 
einen Apfel in einer Hand halten. Auf der linken Schulter ein kleiner Eros.

Lit.: Delivorrias 1984, 45 Nr. 337.

\section{A105}

AO: Korinth

H: Korinth

M: Terrakotta

UG: kleinformatig

EH: 0,068 m

Dat.: kaiserzeitlich

Unbekleideter Oberkörper einer Aphrodite Anadyomene, beide Hände erhoben, fassen das Haar. Von der bärtigen Stütze unter dem linken Arm ist nur der Kopf erhalten.

Lit.: G. R. Davidson, The Minor Objects, Corinth 12 (Princeton 1952) 55 Nr. 378 Taf. 34.

\section{A106}

AO: Rom, Villa Medici

Taf. 35, 3

M: Sarkophag

EH: L. 2,05 m, H. 0,425 oder 0,37 m

Dat.: spätantoninisch

Weibliche stehende Figur (Aphrodite, Mänade, Nymphe?) im Hüftmantel, mit verschränkten Armen auf die bärtige Herme vor ihr gelehnt, überkreuzt mit dem rechten Bein das linke. Teil eines dionysischen Sarkophages. Figur vollständig erhalten.

Lit.: ASR 4, 3, 378-380 Nr. 210 Taf. 221 Beil. 96 f. 99.

\section{A107}

$\mathrm{H}$ : Athen

M: Terrakotta

UG: kleinformatig
Dat.: Ende 5. Jh. v.?

Vollständig in Chiton und Mantel gehüllte, aufrecht sitzende weibliche Figur. Der linke Arm ruht auf Herme, der rechte im Schoß. Relief, eventuell Abdruck einer Spiegelform. Kopf und Rest der Darstellung nicht erhalten.

Lit.: Watzinger 1901, 52 f. Nr. 5 mit Abb.; W. Züchner, Griechische Klappspiegel, JdI Ergh. 14 (Berlin 1942) 222.

A108

Taf. 36, 2

AO: Karlsruhe, Badisches Landesmuseum Inv. B 4

$\mathrm{H}$ : Ruvo

M: Volutenkrater, apulisch-rotfigurig UG: kleinformatig

EH (des gesamten Gefäßes): 1,16 m

Dat.: um 340 v. Chr.

Körperhaltung wie Kat. A34, der rechte Arm jedoch nicht in den Mantel gehüllt, hält Liebesrädchen. Linke, auf Herme gestützte Hand im Redegestus erhoben. Szenische Darstellung des Kampfes des Bellerophon mit der Chimaira. Figur vollständig erhalten.

Lit.: Delivorrias 1984, 146 Nr. 1529; CVA Karlsruhe (2) 20-31 Taf. 62, 2. 64, 3; A. D. Trendall - A. Cambitoglou, The RedFigured Vases of Apulia I. Early and Middle Apulian (Oxford 1978) 431 Nr. 81 Taf. $160,1$.
A109

AO: Tarent?

$\mathrm{H}$ : Tarent?

M: Terrakotta

UG: kleinformatig

EH: $0,138 \mathrm{~m}$

Dat.: um 360 v. Chr. 
Wie Kat. A94, jedoch den Mantel auch um den auf eine Herme gestützten linken Arm gehüllt. Es fehlen der Kopf, rechte Arm und linke Unterarm, die Unterschenkel und der untere Teil der Herme.

Lit.: K. Schefold, Zwei tarentinische Meisterwerke, in: E. Howald u. a. (Hrsg.), Festgabe für A. von Salis (Basel 1951) 171-176 Abb. 3. 4.

\section{A110} Taf. 37, 1

AO: Athen, Nationalmuseum Inv.

Misthos 94

H: Myrina?

M: Terrakotta

UG/EH: 0,29 m

Wie Kat. A33, jedoch beide Beine von dem Hüftmantel verhüllt und auf Herme gestützt. Vollständig erhalten.

Lit.: Winter 1903, 98, 3.

\section{A111}

AO: Thera, Museum

Taf. 37, 2

H: Thera?

M: Marmor

UG: unterlebensgroß

Dat.: hellenistisch oder

frühkaiserzeitlich

Wie Kat. A18, jedoch mit dem rechten Arm auf Herme gelehnt. Kopf, rechter Unterarm, linker Arm und Fuß abgebrochen.

Lit.: Delivorrias 1984, 66 Nr. 563; EA 735; Muthmann 1951, 17.

\section{A112} Taf. 37, 3

AO: Paris, Louvre Inv. D 3345

H: Ruvo?
M: Terrakotta

UG/EH: 0,215 m

Dat.: Anf. 3. Jh. v. Chr.

Weibliche, stehende Figur in Chiton und Mantel, der den unteren Rücken und das rechte Bein bedeckt. Mit dem ausgestreckten rechten Arm auf eine Herme gelehnt, die linke Hand in die Hüfte gestützt. Der rechte Fuß ist vorgestellt. Fast vollständig erhalten.

Lit.: Mollard-Besques 1986, 5 Taf. 3d.

A113

Taf. 37, 4

AO: Istanbul, Archäolog Museum

Inv. 1287

$\mathrm{H}$ : Kleinasien

M: Terrakotta

UG: kleinformatig

Dat.: späthellenistisch

Wie Kat. A112, jedoch ohne Chiton. Kopf abgebrochen.

Lit.: Delivorrias 1984, 81 Nr. 722; G.

Mendel, Musées Impériaux Ottomans.

Catalogue des Figurines Grecques de

Terre Cuite (Istanbul 1908) 503 Nr. 3170.

A114

Taf. 38, 1

AO: Berlin, Staatliche Museen Inv.

1060

M: Glaspaste

UG: kleinformatig

Dat.: hellenistisch

Weibliche, stehende Figur im Hüftmantel, mit dem ausgestreckten linken Arm auf Herme gestützt. Der rechte Arm ist angewinkelt erhoben, der linke Fuß zur Seite gestellt. Vollständig erhalten.

Lit.: Furtwängler 1900, 168 Taf. 34, 46. 
A115

Taf. 38, 2

AO: Delos, Museum Inv. A 4017

$\mathrm{H}$ : Delos

M: Marmor

UG: kleinformatig

EH: $0,325 \times 0,25 \mathrm{~m}$

Dat.: späthellenistisch

Unbekleidete stehende Aphrodite im Pudica-Typus, mit dem linken Arm auf Herme gelehnt, hält ihr Gewand in der Hand. Mit der Rechten die Scham bedeckend, der linke Fuß leicht zur Seite gestellt. $\mathrm{Zu}$ ihrer Rechten Eros. Bestoßen, sonst vollständig erhalten.

Lit.: Delivorrias 1984, 51 Nr. 400; J. Marcadé, Reliefs Déliens, in: Études Déliennes. BCH Suppl. 1 (Paris 1973) 329-369, bes. 342. 346-349 Nr. 9 Abb. 22 ; Marcadé 1969, 402. 440.

A116 Taf. 38, 3

AO: Paris, Louvre Inv. D/E 4583

$\mathrm{H}$ : Thysdrus

M: Terrakotta

UG/EH: 0,19 m

Dat.: Anf. 1. Jh. n. Chr.

Stehende, sandalenlösende Aphrodite, mit der Linken auf Herme gestützt. Ihr Mantel bläht sich hinter ihrem Rücken, bedeckt sie sonst aber nicht. Die rechte Hand in Richtung des erhobenen rechten Fußes gesenkt. Vollständig erhalten.

Lit.: Mollard-Besques 1992, 147 Taf. 90a.

A117 Taf. 39, 1

AO: Privatbesitz, ehem. Slg. de Clercq

$\mathrm{H}$ : Sidon

M: Bronze
UG/EH: 0,112 m

Dat.: hellenistisch oder kaiserzeitlich

Wie Kat. A48, Oberkörper jedoch stärker aufgerichtet, Herme als Stütze des linken Arms. Vollständig erhalten.

Lit.: de Ridder 1904, 66 Nr. 87 Taf. 14, 1;

Reinach 1910, 214, 5; Künzl 1970, 153

Nr. B 46; Delivorrias 1984, 32 Nr. 204.

A118

Taf. 39, 2

AO: Paris, Louvre

H: Thysdrus

M: Terrakotta

UG: kleinformatig

EH: 0,212 m

Dat.: Ende 1. Jh. n. Chr.

Weibliche unbekleidete stehende Figur, hat den linken Arm auf eine Herme gelegt, den rechten auf Eros neben ihr. Das linke Bein ist gebeugt. Den Rücken bedeckt ein Mantel. Füße der Göttin, des Eros und Kopf der Herme abgebrochen.

Lit.: Mollard-Besques 1992, 148 Taf. 90d.

A119

Taf. 39, 3

AO: Neapel, Nationalmuseum Inv. 4262

H: Pompeji IX, 3, 5

M: Terrakotta

UG/EH: $0,17 \mathrm{~m}$

Stehende unbekleidete Aphrodite Anadyomene, beide Hände zu den Haaren erhoben. Mit dem linken Bein an Herme gelehnt. Vollständig erhalten.

Lit.: Winter 1903, 213, 2; H. von Rohden, Die Terrakotten von Pompeji, Die antiken Terracotten I (Stuttgart 1880) 50 Taf. 38, 2. 
A120

Taf. 39, 4

AO: Rom, Vatikan, Museo

Chiaramonti Inv. 451

M: Marmor

UG/EH: $1,15 \mathrm{~m}$

Dat.: kaiserzeitlich

Stehende weibliche Figur im Hüftmantel, mit ausgestrecktem rechten Arm auf Herme gestützt. Der in die Hüfte gestützte linke Arm ist ebenfalls in den Mantel gehüllt. Herme und rechte Hand neuzeitlich ergänzt. Basis der Herme wahrscheinlich antik.

Lit.: Foto D-DAI-Rom-1990Vat.0978; Reinach 1897a, 323, 5; Bernoulli 1873, 367; G. Becatti, Ninfe e divinità marine. Ricerche mitologiche iconografiche e stilistiche, Studi miscellanei 17 (Rom 1970/71) 19 Nr. 7 Taf. 12 Abb. 13.

A121 Taf. 40, 1

AO: - (ehem. Rom, Slg. Doria

Pamphili)

M: Marmor

UG/EH: $1,42 \mathrm{~m}$

Dat.: kaiserzeitlich

Wie Kat. A18, stützt sich nicht auf die Herme, da diese sehr klein ist. Unterarme abgebrochen. Herme neuzeitlich.

Lit.: R. Calza (Hrsg.), Antichità di Villa Doria Pamphili (Rom 1977) 75 f. Nr. 78 Taf. 48.

A122 Taf. 40, 2

keine Angaben.

Wie Kat, A23, jedoch der Oberkörper stark nach rechts geneigt, der rechte Arm gesenkt. Als Stütze eine neuzeitliche? bärtige Herme.
Lit.: F. de Clarac, Musée de sculpture antique et moderne ou description historique du Louvre et de toutes ses parties de statues, bustes, bas-reliefs et inscription du Musée royal des antiques et des Tuileries et de plus de 2500 statues antiques: tirées des principaux musées et des diverses collections de l'Europe accomp. d'une iconographie Egyptienne, Grecque et Romaine et terminé par l'iconographie Française du Louvre et des Tuileries IV. Statues (Paris 1836/37) Taf. 599, 4. 


\section{Katalog weiterer Darstellungen mit ikonischer Stütze}

\section{Eros und Hermaphrodit}

\section{B1}

Taf. 40,3

AO: New York, Metropolitan

Museum Inv. 44.11.9

H: Eretria?

$\mathrm{M}$ : Bronze

UG/EH: 0,146 m (ges. Gefäß: 0,5 m)

Dat.: 2. H. 4. Jh. v. Chr.

Stehender geflügelter Eros, dessen Hüftmantel bis unter das Geschlecht gerutscht ist, überkreuzt mit dem linken Bein das rechte, lehnt sich mit dem linken Arm auf ein weibliches archaistisches Idol, die Hand hält einen Spiegel, in dem er sich betrachtet, die Rechte fasst ins Haar. Vollständig erhalten, Attasche einer Bronzehydria.

Lit.: G. M. A. Richter, A Fourth-Century Bronze Hydria in New York, AJA 50, 1946, 361-367 Taf. 22 f.; G. M. A. Richter, The Metropolitan Museum of Art. Handbook of the Greek Collection (Cambridge 1953) 110 f. Taf. 90 a. c; Delivorrias 1984, 13 Nr. 40; Hermary 1986, 863 Nr. 85b.

\section{B2} Taf. 41, 1

AO: Rom, Museo Torlonia

$\mathrm{H}$ : Rom

M: Marmor

Stehender unbekleideter geflügelter Eros, linkes Bein zur Seite gestellt, linker Arm ruht auf einem weiblichen archaistischen Idol, die Rechte ist erhoben. $\mathrm{Zu}$ seiner Rechten sitzende weibliche Figur (Aphrodite) in Chiton und Hüftmantel. Relief, Figuren vollständig erhalten.

Lit.: Langlotz 1954 Abb. 9; E. Gerhard, Über die Venusidole, in: Gerhard 1866, 258-284 Taf. 33, 2.

\section{B3}

AO: St. Petersburg, Eremitage Inv.

$912 \mathrm{a}$

$\mathrm{H}$ : Kertsch?

M: Terrakotta

$\mathrm{UG} / \mathrm{EH}: 0,22 \mathrm{~m}$

Stehender unbekleideter geflügelter Eros, hat die Rechte in die Hüfte gestemmt, umarmt mit der Linken eine stehende weibliche Figur (Aphrodite) in Chiton und Mantel. Neben seinem rechten Bein archaistisches Idol, auf das er sich nicht aufstützt. Vollständig erhalten. Ein weiteres Exemplar dieser Gruppe befindet sich in London, British Museum.

Lit.: Winter 1903, 225, 9. Weitere Beispiele: ebenda.

\section{B4}

AO: Paris, Louvre Inv. MYR 89

$\mathrm{H}$ : Myrina

M: Terrakotta

UG/EH: 0,27 m

Dat.: 1. Jh. v. Chr.

Stehender geflügelter Eros mit Chlamys, überkreuzt mit dem linken Bein das rechte, mit dem linken Arm auf die Basis eines archaistischen Idols 
gestützt, der rechte ist vor den Bauch geführt, vollständig erhalten.

Lit.: Mollard-Besques 1963, 46 Taf. 54a. 252c.

\section{B5}

AO: Paris, Louvre MNB 1006

$\mathrm{H}$ : Megara

M: Terrakotta

$\mathrm{UG} / \mathrm{EH}: 0,35 \mathrm{~m}$

Dat.: Ende 2. Jh. v. Chr.

Flötespielender stehender geflügelter Eros, kreuzt das linke Bein vor das rechte, mit der linken Schulter an die Basis einer geflügelten weiblichen Figur gelehnt, vollständig erhalten.

Lit.: Hermary 1986, 884 Nr. $413 a$.

B6

AO: Boston

$\mathrm{H}$ : Myrina?

M: Terrakotta

$\mathrm{UG} / \mathrm{EH}: 0,175 \mathrm{~m}$

Dat.: 1. Jh. n. Chr.

Stehender, ganz in seinen Mantel gehüllter geflügelter Eros, mit dem rechten Arm auf die Basis einer geflügelten weiblichen Figur (Nike?) gelehnt, beugt sich nach unten, Knabe bindet ihm Sandale, vollständig erhalten.

Lit.: Hermary 1986, 884 Nr. 405.

\section{B7}

AO: Athen, Museum für Kykladische und Antike Griechische Kunst, Slg.

Polites Inv. 139

H: - (eventuell Athen)
M: Marmor

UG: kleinformatig

EH: $0,16 \mathrm{~m}$

Dat.: 1. V. 4. Jh. v. Chr.

Kopf einer weiblichen Stützfigur, darüber Gewand gelegt. An der Oberseite hat sich die Auflagefläche des Arms einer aufgestützten Figur (Eros?) erhalten.

Lit.: A. Delivorrias, Was von einem klassischen Eros übrig geblieben ist, in: $\mathrm{H}$. von Steuben - G. Lahusen - H. Kotsidu (Hrsg.), MOY $\Sigma$ EION. Beiträge zur Antiken Plastik. Festschrift Peter Cornelis Bol (Möhnesee 2007) 209-216 Abb. 1-7.

\section{B8}

AO: Thessaloniki, Archäolog Museum Inv. 11.644

M: Bronze

UG: kleinformatig

Dat.: um 330-320 v. Chr.

Stehender unbekleideter geflügelter Eros, mit dem rechten Unterarm auf bärtige Herme gelehnt, Oberkörper deutlich in Richtung der Stütze geneigt. Die Linke ist in die Hüfte gestützt. Attasche eines Hydriahenkels, vollständig erhalten.

Lit.: Hermary 1986, 863 Nr. 85a.

\section{B9} Taf. 41, 2

AO: München, Staatliche Antikenslg. Inv. TC 5464

H: Madytos

M: Terrakotta

$\mathrm{UG} / \mathrm{EH}: 0,173 \mathrm{~m}$

Dat.: späthellenistisch 
Stehender unbekleideter geflügelter Eros, mit dem linken Arm auf bärtige Herme gestützt, der rechte liegt auf dem Bauch. Neben ihm Amphora. Es existieren mehrere Exemplare des Typus: Canberra, Australian National University, Classics Department $\mathrm{Mu}-$ seum Inv. 79.06 und Budapest, Szépmüvészeti Museum Inv. 58.21.A.

Lit.: M. Söldner, Der sogenannte Agon, in: G. Hellenkemper-Salies (Hrsg.), Das Wrack. Der antike Schiffsfund von Mahdia (Köln 1994) 399-429 Abb. 15. 16. Weitere Beispiele: ebenda sowie L. Castiglione, EP $\Omega \Sigma$ ENAГ $\Omega$ NIO $\Sigma$, BMusHongr 13, 1958, 7-20 Abb. 5 f.

\section{B10}

AO: Madrid, Archäolog. Museum Inv. 3326

M: Terrakotta

$\mathrm{UG} / \mathrm{EH}: 0,17 \mathrm{~m}$

Stehender geflügelter Eros, sein Mantel bedeckt nur den Rücken und die Arme, mit dem linken Arm auf eine auf bärtige (Silens-?) Herme gelehnt, die Rechte in die Hüfte gestützt, vollständig erhalten.

Lit:: A. Laumonnier, Catalogue des terres cuites du Musée archéologique de Madrid (Bordeaux 1921) 171 f. Nr. 807 Taf. 96.

\section{B11}

AO: Athen, Nationalmuseum Inv. 4815

H: Myrina

M: Terrakotta

UG/EH: 0,22 m

Dat.: 1. Jh. v. Chr.
Mit dem Gewicht auf dem rechten Bein stehender geflügelter Eros, Mantel auf der rechten Schulter geknüpft, lässt den Bauch und die Beine unbedeckt. Mit dem linken Arm auf bärtige Herme gestützt, der rechte ruht auf dem Rücken, Kopf nach rechts gewandt. Vollständig erhalten.

Lit.: G. Kleiner, Tanagrafiguren. Untersuchungen zur hellenistischen Kunst und Geschichte, JdI Ergh. 15 (Berlin 1942) 245 Taf. 46, 3.

\section{B12}

AO: Istanbul, Archäolog. Museum

Inv. 342

H: Myrina

M: Terrakotta

UG/EH: 0,22 m

Dat.: Ende 1. Jh. v. Chr.?

Wie Kat. B11, der Kopf jedoch geradeaus gerichtet. Vollständig erhalten. Vergleichbare Terrakotten, vielleicht sogar aus derselben Form befinden sich in Istanbul, Archäolog. Museum Inv. 408 und 552, London, British Museum und Paris, Louvre, Inv. M 42.

Lit.: Winter 1903, 249, 4. Weitere Beispiele: ebenda; Burn - Higgins 2001 Taf. 53 Nr. 2294; Mollard-Besques 1963, 46 Taf. 54c.

\section{B13}

AO: Paris, Louvre Inv. MYR 210

$\mathrm{H}$ : Myrina

M: Terrakotta

UG/EH: 0,28 m

Dat.: augusteisch? 
Wie Kat. B11, nur ohne Flügel. Weitere Exemplare dieses Typus befinden sich in Istanbul, Archäolog. Museum.

Lit.: Mollard-Besques 1963, 121 Taf. 146b. 257e. Weitere Beispiele: ebenda.

\section{B14}

AO: verschollen

H: Priene, Demeter-Kore-Heiligtum

M: Terrakotta

UG/EH: 0,06 m

Wie Kat. B13, unsicher, ob auf Herme oder Pfeiler gestützt, diese steht an seiner rechten Seite, Kopf und Unterschenkel nicht erhalten.

Lit.: Rumscheid 2006, 489 Nr. 259 Taf. 107, 9.

\section{B15}

AO: Dresden, Albertinum Inv. ZV

H: Myrina?

M: Terrakotta

$\mathrm{UG} / \mathrm{EH}: 0,26 \mathrm{~m}$

Dat.: spätes 2. Jh. v. Chr.

Wie Kat. B11, jedoch seitenvertauscht und mit größeren Flügeln, vollständig erhalten.

Lit.: Winter 1903, 247, 3.

\section{B16}

AO: Paris, Louvre Inv. M 41

$\mathrm{H}$ : Myrina

M: Terrakotta

UG/EH: 0,197 m

Dat.: Ende 1. Jh. v. Chr.
Wie Kat. B11, jedoch vollständig in Mantel eingehüllt, rechter Arm gesenkt, vollständig erhalten. Eine weitere Statuette dieses Typus befindet sich in Paris, Louvre Inv. Bo 102.

Lit.: Mollard-Besques 1963, 46 Taf. 55a. Weitere Beispiele: ebenda 46 Taf. 55c.

\section{B17}

AO: Berlin, Antiquarium Inv. 338

$\mathrm{H}$ : Unteritalien

M: Terrakotta

$\mathrm{UG} / \mathrm{EH}: 0,15 \mathrm{~m}$

Wie Kat. B11, die Herme jedoch auf der rechten Seite, Blick gesenkt, vollständig erhalten.

Lit.: Winter 1903, 253, 1.

\section{B18}

AO: Berlin, Antiquarium Inv. 8036

$\mathrm{H}$ : Myrina

M: Terrakotta

$\mathrm{UG} / \mathrm{EH}: 0,13 \mathrm{~m}$

Wie Kat. B11, die Herme jedoch gröBer, daher der aufgestützte linke Arm stärker erhoben, der rechte gesenkt, die Flügel kleiner, vollständig erhalten.

Lit.: Winter 1903, 248, 2.

\section{B19}

AO: Istanbul, Archäolog. Museum

Inv. 1493

H: Priene, Haus 25

M: Terrakotta

UG: kleinformatig

EH: 0,156 m

Dat.: vor 135 v. Chr. 
Stehender geflügelter Eros, dessen Mantel nur den Rücken bedeckt, überkreuzt mit dem linken Bein das rechte, mit dem linken Arm an bärtige Herme gelehnt, der rechte gesenkt. Kopf des Eros abgebrochen.

Lit.: Rumscheid 2006, 277. 486 f. Nr. 250 Taf. 105, 4.

\section{B20}

AO: - (ehem. Slg. M. Gréau)

$\mathrm{H}$ : Kleinasien

M: Terrakotta

$\mathrm{UG} / \mathrm{EH}: 0,21 \mathrm{~m}$

Vollständig in einen Mantel gehüllter stehender Eros, lehnt mit dem rechten Arm an bekleideter Herme, die Hand greift das Gewand, die linke ruht auf der Brust, vollständig erhalten.

Lit.: Winter 1903, 239, 11.

\section{B21}

AO: Thessaloniki?

H: Olynth, Nekropole

M: Terrakotta

$\mathrm{UG} / \mathrm{EH}: 0,125 \mathrm{~m}$

Dat.: frühes 4. Jh. v. Chr.

Stehender Eros, auf kleine Säule zu seiner Linken gestützt, an seiner Rechten eine kleine Herme. Überkreuzt mit dem rechten Bein das linke. Zieht mit der erhobenen Rechten den Mantel hinter sich empor, sonst unbekleidet. Vollständig erhalten. Aus Olynth liegen weitere Exemplare dieses $\mathrm{Ty}$ pus, z. T. aus derselben Form vor.

Lit.: D. M. Robinson, The Terra-Cottas of Olynthus found in 1928, Olynthus 4
(Baltimore 1931) 74 Nr. 372-373a Taf.

39; D. M. Robinson, The Terra-Cottas of Olynthus found in 1931. Olynthus 7

(Baltimore 1933) 71 f. Nr. 265-271 Taf.

34. Weitere Beispiele: ebenda.

\section{B22}

AO: Berlin, Antiquarium Inv.

TC 8599

$\mathrm{H}$ : Priene, Demeter-Kore-Heiligtum

M: Terrakotta

UG: kleinformatig

EH: 0,09 m

Dat.: hellenistisch

Stehender Eros im Hüftmantel, mit dem linken Arm auf bärtige Herme gelehnt, der rechte ist gesenkt, Kopf abgebrochen, die Flügel einst angesetzt.

Lit.: Rumscheid 2006, 280. 489 Nr. 258

Taf. 107,8 .

\section{B23}

AO: verschollen

$\mathrm{H}$ : Priene, Demeter-Kore-Heiligtum

M: Terrakotta

UG: kleinformatig

EH: $0,095 \mathrm{~m}$

Wie Kat. B22, Kopf des Eros nicht erhalten.

Lit.: Rumscheid 2006, 280. 488 Nr. 257

Taf. 107, 7.

\section{B24}

AO: Paris, Louvre Inv. MYR 81 bis

$\mathrm{H}$ : Myrina

M: Terrakotta

UG/EH: 0,173 m

Dat.: Ende 1. Jh. v. Chr. 
Stehender geflügelter Eros in Chlamys, die nur die linke Schulter und den Rücken bedeckt, mit der gesenkten Rechten auf die Basis einer Herakliskos-Herme gelehnt, die Linke in die Hüfte gestützt, vollständig erhalten.

Lit.: Mollard-Besques 1963, 46 Taf. 54e.

\section{B25}

AO: St. Petersburg, Eremitage Inv. 899D

H: Kertsch

M: Terrakotta

$\mathrm{UG} / \mathrm{EH}: 0,14 \mathrm{~m}$

Dat.: kaiserzeitlich

Stehender geflügelter Eros in Chlamys, die nur die Brust und den linken Arm bedeckt, mit diesem auf eine unbärtige ithyphallische Herme gestützt, mit dem gesenkten rechten Arm umfasst er eine Gans, die er aus einer Schale in der linken Hand füttert, vollständig erhalten.

Lit.: Winter 1903, 286, 2.

\section{B26}

AO: London, British Museum Inv. 1514

H: Colchester

M: Intaglio eines Goldringes (Granat)

UG: kleinformatig

EH: $0,09 \times 0,08 \mathrm{~m}$

Dat.: kaiserzeitlich

Auf den Zehenspitzen stehender geflügelter Eros mit Chlamys über der rechten Schulter, berührt mit der ausgestreckten Rechten den Kopf einer Herme, die Linke ist vor die Brust geführt, vor ihm Gans, vollständig erhalten.

Lit:: B. Walters (Hrsg.), Catalogue of the Engraved Gems and Cameos. Greek, Etruscan and Roman in the British $\mathrm{Mu}-$ seum (London 1926) 166 Nr. 1514.

\section{B27}

AO: New York, Metropolitan

Museum Inv. 57.12.21

M: attisch-rotfigurige Schale

UG: kleinformatig

Dat.: Mitte 5. Jh. v. Chr.

Stehender unbekleideter geflügelter Eros, berührt mit der Rechten bärtige Herme, hält in der gesenkten Linken Band oder Kranz, vollständig erhalten.

Lit.: Hermary 1986, 887 Nr. 440.

\section{B28}

AO: Delos, Museum Inv. A 3450

H: Delos

M: Terrakotta

$\mathrm{UG} / \mathrm{EH}: 0,155 \mathrm{~m}$

Dat.: Ende 1. Jh. v. Chr.

Geflügelter unbekleideter Eros in Schrittstellung vor bärtiger Herme, an der er evtl. mit dem Rücken anlehnt, beobachtet Ringkampf zweier weiterer Eroten vor ihm. Ringkampfgruppe und Basis fragmentarisch erhalten.

Lit.: Hermary 1986, 883 Nr. 395a.

\section{B29}

AO: Istanbul, Archäolog. Museum Inv. 1380

H: Priene, Wohnhaus 
M: Terrakotta

UG: kleinformatig

EH: $0,183 \mathrm{~m}$

Dat.: vor 135 v. Chr.?

Aufrecht sitzender, vollständig in einen Mantel gehüllter knabenhafter Eros, mit der linken Schulter an ithyphallische Herme gelehnt. Die Linke ist vor die Brust geführt, die Rechte ruht im Schoß. Kopf der Herme abgebrochen.

Lit.: Rumscheid 2006, 281. 490 Nr. 261

Taf. 110, $1 \mathrm{f}$.

\section{B30}

AO: - (ehem. Slg. Lecuyer)

$\mathrm{H}$ : Megara?

M: Terrakotta

UG/EH: 0,14 m

Aufrecht auf Felsen sitzender geflügelter Eros, dessen Mantel den Rücken und rechten Arm bedeckt, neben ihm bärtige Herme, an die er sich nicht anlehnt, vollständig erhalten.

Lit.: Winter 1903, 260, 10, dort seitenvertauscht abgebildet.

\section{B31}

AO: Paris, Louvre Inv. CA 802

\section{$\mathrm{H}$ : Aigina}

M: Terrakotta

UG/EH: $0,14 \mathrm{~m}$

Dat.: 3. Jh. v. Chr.

Auf würfelförmigem Sitz aufrecht sitzender, geflügelter, Kithara-spielender Eros, sein Mantel dient als Unterlage, sonst unbekleidet. Bekleidete ithyphallische jugendliche Herme zu seiner Rechten, an die er sich mit der rechten Schulter anlehnt, vollständig erhalten.

Lit.: Mollard-Besques 1972, 50 Taf. 59d.

\section{B32}

AO: Paris, Louvre Inv. IHA 15

M: Terrakotta

UG/EH: 0,138 m

Dat.: 1. Jh. n. Chr.

Unbekleideter geflügelter sitzender Eros, mit dem erhobenen rechten Arm an bärtige Herme gelehnt, die Linke ist gesenkt und hält Trauben, ein Hund läuft auf ihn zu. Vollständig erhalten.

Lit.: Mollard-Besques 1963, 59 Taf. 74a.

\section{B33}

AO: München; Original in Paris?

M: Gipsabguss; Original Gerätegriff aus Bronze?

UG: kleinformatig

Dat.: spätetruskisch?

Stehende unbekleidete weibliche Figur (Aphrodite?), überkreuzt mit dem rechten Bein das linke, der rechte Arm gesenkt, mit dem linken eine stehende unbekleidete männliche Figur (Eros?) umarmend, diese hat ebenfalls den Arm um die weibliche gelegt und stützt sich mit der gesenkten Linken auf eine bärtige Herme. Gesamte Gruppe auf Säule stehend, Figuren vollständig erhalten.

Lit.: P. Wolters, München. Abgüsse nach Antiken für wissenschaftliche Sammlungen (München 1912) 23 Nr. 340;

Reinach 1924, 164, 4. 


\section{B34}

AO: Paestum, Nationalmuseum

$\mathrm{H}$ : Paestum, Athenaheiligtum

M: Terrakotta

UG: kleinformatig

Dat.: hellenistisch

Mit dem Gewicht auf dem rechten Bein stehender, mit Chiton bekleideter Hermaphrodit, mit dem linken Arm auf bärtige Herme gestützt, der rechte ist gesenkt. Mehrfach gebrochen, es fehlen der Kopf, linke Unterarm, rechte Hand und die Füße.

Lit.: Oehmke 2004, 115 Nr. 73.

\section{B35}

AO: Athen, Nationalmuseum Inv. 4894

H: Myrina?

M: Terrakotta

UG/EH: 0,22 m

Dat.: späthellenistisch

Stehender Hermaphrodit, zieht mit der erhobenen Linken seinen Mantel hinter dem Rücken empor, sonst ist der Körper unbedeckt, stützt sich mit dem rechten Arm auf die Basis einer bekleideten Herme, vollständig erhalten.

Lit.: Winter 1903, 357, 3; Oehmke 2004, 75 Nr. 4.

\section{B36}

AO: Paris, Louvre Inv. Br. 788

M: Bronze

UG/EH: 0,132 m

Dat.: 1. Jh. v. Chr.?

Stehender Hermaphrodit, dessen Hüftmantel bis unter die Scham ge- rutscht ist, lehnt mit dem linken Unterarm auf unbärtiger ithyphallischer Herme, berührt mit der Rechten einen Knaben mit Panflöte neben ihm. Vollständig erhalten.

Lit.: LIMC V (1990) 282 s. v. Hermaphroditos 78 (A. Ajootian); Oehmke 2004, 95 f. Nr. 35.

\section{B37}

AO: Rom, Palazzo Colonna Inv. 1714

M: Marmor

UG: $2 / 3$ Lebensgröße

EH: $1,20 \times 0,75$ m

Dat.: hadrianisch

Stehender Hermaphrodit in Chlamys, mit dem rechten Ellenbogen auf die Basis eines weiblichen archaistischen Idols gelehnt, trägt Eros im linken Arm, der eine bärtige Herme zu seiner Linken bekränzt. Im Hintergrund Gebäude und Baum. Bis auf kleine Ergänzungen vollständig erhalten. Relief, gehört vermutlich in denselben Zusammenhang wie Kat. B38. B55.

Lit:: Matz - von Duhn 1882, 66 f. Nr. 3576; LIMC V (1990) 281 s. v. Hermaphroditos 74 (A. Ajootian).

\section{B38}

AO: Rom, Slg. Colonna Inv. 1714

M: Marmor

UG: $2 / 3$ Lebensgröße

Dat.: hadrianisch

Stehender Hermaphrodit oder Satyr in Chlamys, überkreuzt mit dem linken Bein das rechte, lehnt mit dem 
linken Unterarm auf einer bärtigen Panherme. Fasst mit der erhobenen Rechten ein Band in seinem Haar, zu seiner Rechten kleine weibliche Statue auf hoher Basis. Ergänzt sind die Beine, der rechte Arm des Hermaphroditen, der linke Arm, der untere Teil der Herme sowie der Pfeiler mit der weiblichen Figur. Relief, gehört vermutlich in denselben Zusammenhang wie Kat. B37. B55.

Lit.: Matz - von Duhn 1882, 66 Nr. 3575.

\section{B39}

H: Pompeji VII 7,5

M: Wandmalerei

UG/EH: 0,39 m

Dat.: kaiserzeitlich (4. Stil)

Stehender Hermaphrodit in Chlamys bekleidet, die den linken Arm und das Bein bedeckt, mit dem linken Arm auf Priapos?-Herme gestützt, hält in der Hand einen Spiegel, kämmt sich mit der anderen, hat den linken Fuß auf die Basis der Herme gesetzt.

Lit.: Oehmke 2004, 97 Nr. 40.

\section{Dionysos}

\section{B40}

Taf. 42, 1

AO: St. Petersburg, Eremitage Inv.

A 104

H: Frascati

M: Marmor

$\mathrm{UG} / \mathrm{EH}: 2,07 \mathrm{~m}$

Dat.: traianisch-hadrianisch
Stehender Dionysos im Typus Hope in kurzem Chiton, Himation und Pardalis, mit dem erhobenen linken Arm auf ein weibliches archaistisches Idol gestützt, hält Trauben in der Hand. Die Rechte ist gesenkt vorgestreckt, der linke Fuß zur Seite gestellt. Ergänzt sind die Unterarme des Gottes, der von der rechten Schulter fallende Mantelteil, der obere Teil der Stützfigur von den Hüften an und die linke Hand des Idols mit dem Gewand. Von dem Typus liegt eine weitere Repliken vor: New York, Metropolitan Museum of Art Inv. 1990.247.

Lit.: D. Zancani, Della Testa di Dionysos del Museo Capitolino e del tipo statuario al quale appartiene, BCom 52, 1924, 6591 Taf. 2. 3; Gasparri 1986, 436 f. Nr. 128; Cain 1997, 30-34 mit Abbildungen. Weitere Beispiele: Ebenda und C. A. Picón u. a., Art of the Classical World in the Metropolitan Museum of Art. Greece - Cyprus - Etruria - Rome (New Haven 2007) 489 f. Nr. 429.

\section{B41}

Taf. 42, 2

AO: Rom, Vatikan, Cortile del

Belvedere

M: Marmor

UG: lebensgroß

EH: $1,58 \mathrm{~m}$

Stehender Dionysos, dessen offener Mantel die Brust, den Bauch und die rechte Schulter frei lässt, mit dem linken Arm auf ein archaistisches weibliches Idol gestützt, die Rechte fasst eine Haarsträhne auf der Schulter, der linke Fuß ist leicht zur Seite gestellt.

Lit.: Foto D-DAI-Rom-01315; Reinach 1897a, 341, 7; EA 3430; W. Amelung, 
Die Sculpturen des Vaticanischen $\mathrm{Mu}$ seums II (Berlin 1908) 323 Nr. 102 $\pi$;

Pochmarski 1974, 84-89 Nr. 20D.

\section{B42}

Taf. 42,3

AO: Vathy, Museum Inv. 82

$\mathrm{H}$ : Samos

M: Marmor

UG: unterlebensgroß

EH: 0,69 m

Dat.: 1. Jh. v. Chr.

Stehender Dionysos im Hüftmantel, der auch den linken Arm einhüllt, mit diesem Arm auf ein weibliches archaistisches Idol gestützt, linkes Bein leicht zur Seite gestellt. Kopf, rechter Arm und Füße nicht erhalten.

Lit.: R. Horn, Hellenistische Bildwerke auf Samos, Samos 12 (Bonn 1972) $34 \mathrm{f}$. 108 f. Nr. 77 Taf. 55 f.; M. Schede, Mitteilungen aus Samos, AM 37, 1912, 202 f. Abb. 1.

\section{B43}

AO: - (ehem. Slg. Calvert)

H: Troas (Tabolia)

M: Terrakotta

UG/EH: 0,195 m

Dat.: 4. Jh. v. Chr.?

Stehender Dionysos, sein Mantel bedeckt nur das linke Bein und den linken Arm, mit diesem auf weibliches Idol gestützt, dass ein rundes Tablett auf dem Kopf trägt. Der rechte Arm ist gesenkt, der linke Fuß leicht zur Seite gestellt, vollständig erhalten.

Lit.: Winter 1903, 367, 1.

\section{B44}

AO: Rom, Vatikan, Gärten

M: Marmor

UG: überlebensgroß

EH: ca. 2,00 m

Stehender unbekleideter Dionysos, mit dem linken Arm auf weibliche Statue (Nymphe, Muse?) auf einer Basis gestützt. Der rechte Arm war erhoben, der linke Fuß leicht zur Seite gestellt. Die Köpfe sind nicht zugehörig, ergänzt sind die Arme und Beine des Dionysos, die Arme und Oberschenkel und die Leier der Stützfigur.

Lit.: Reinach 1897a, 383, 1.

\section{B45}

AO: Pompeji, Magazin

$\mathrm{H}$ : Pompeji

UG: kleinformatig

EH: ca. 0,15 m

Unbekleidete männliche, mit dem Gewicht auf dem rechten Bein stehende Gestalt, neben ihr weibliche archaistische Figur mit nackten Brüsten auf einer Basis. Die männliche Figur ist nur bis zum Bauch erhalten, der Kopf der weiblichen Gestalt fehlt, daher bleibt offen, ob sie als Stütze diente.

Lit.: Reinach 1897a, 341, 8.

\section{B46}

AO: St. Petersburg, Eremitage Inv.

$110 \mathrm{~B}$

H: Kertsch

M: Terrakotta

UG/EH: 0,14 m

Dat.: (3. Viertel? des) 4. Jh. v. Chr. 
Stehender Dionysos im Hüftmantel, überkreuzt mit dem linken Bein das rechte, mit dem linken Ellenbogen auf Baumstamm? gelehnt, davor Priapos. Der rechte Arm ruht auf dem Rücken. Figurenvase, Unterseite gebrochen.

Lit.: Winter 1903, 245, 1; M. TrumpfLyritzaki, Griechische Figurenvasen des Reichen Stils und der späten Klassik (Bonn 1969) 55.

\section{B47}

Taf. 43, 1

AO: Shahat, Antikenmuseum Inv.

\subsection{7}

$\mathrm{H}$ : Kyrene?

M: Marmor

UG: unterlebensgroß

EH: $0,76 \mathrm{~m}$

Dat.: neronisch

Stehender Dionysos im Typus DijonKyrene, dessen Hüftmantel bis auf die Oberschenkel hinabgerutscht ist, der linke ist Fuß leicht zurückgesetzt, stützt sich mit dem linken Arm auf eine bärtige Herme. Es fehlen der Kopf, rechte Arm, linke Fuß.

Lit.: Foto D-DAI-Rom-1958.2370; Paribeni 1959, 117 Nr. 332; Gasparri 1986, 436 Nr. 127b; Gasparri 1986, 436 Nr. 127b.

\section{B48} Taf. 43, 2

AO: Madrid, Prado Inv. E-87

M: Marmor

$\mathrm{UG} / \mathrm{EH}: 1,73 \mathrm{~m}$

Dat.: um 150 n. Chr.

Stehender unbekleideter Dionysos im Typus Richelieu/Madrid-Varese, der linke Fuß ist leicht zurückgestellt, mit dem linken Unterarm auf eine bärtige archaistische Herme gestützt, auf der sein Gewand liegt. Ergänzt sind die Hände und der linke Unterschenkel. Weitere Kopien des Typus vom Ende des 2. Jhs. v. Chr. sind u. a. in Varese, Villa Pogliaghi und Rom, Vatikan.

Lit.: Rizzo 1931, 76-78 Taf. 115; Boardman 1995, 97 Nr. 68; Schröder 2004, 239-243 Nr. 145. Weitere Beispiele: ebenda.

\section{B49}

AO: Hannover, Kestner-Museum, Inv. K 215

M: Karneol-Gemme

UG/EH: 0,0187 x 0,0136 m

Dat.: 1. H. 1. Jh. n. Chr.

Stehender, von einem Mantel hinterfangener Dionysos, sonst unbekleidet, mit dem rechten Arm auf ithyphallische Figur gestützt, hält in der Linken Thyrsos, neben ihm Panther und fliegender Eros, vollständig erhalten.

Lit.: LIMC III (1986) 549 s. v. Dionysos/ Bacchus 103 (C. Gasparri).

\section{B50}

AO: - (ehem. Slg. Milani)

$\mathrm{H}$ : Kleinasien

M: Terrakotta

$\mathrm{UG} / \mathrm{EH}: 0,275 \mathrm{~m}$

Dat.: Fälschung?

Stehender Dionysos, ein Mantel bedeckt nur das rechte, leicht zurückgestellt Bein. In der erhobenen Linken Trauben, in der gesenkten Rechten Kantharos. Lehnt mit dem linken Bein an Priaposherme. Vollständig, aber vermutlich neuzeitliche Fälschung. 
Lit.: W. Froehner, Terres cuites d'Asie Mineure (Paris 1881) 33 f. Taf. 13.

\section{B51}

AO: Kassel

M: Bronze, Applik?

$\mathrm{UG} / \mathrm{EH}: 0,1 \mathrm{~m}$

Stehender Dionysos, den Oberkörper mit einer Nebris verhüllt. Linker Fuß leicht zur Seite gestellt, linke Hand auf eine bärtige Herme gestützt, die rechte ist gesenkt, hält Trauben, an denen ein Panther knabbert, vollständig erhalten.

Lit.: M. Bieber, Die antiken Skulpturen und Bronzen des Königl. Museum Fridericianum in Cassel (Marburg 1915) 64 Nr. 168 Taf. 43.

\section{B52}

M: Glaspaste

UG: kleinformatig

Stehender unbekleideter Dionysos, hält in der erhobenen Linken einen Stab, mit dem rechten Arm auf einen unbekleideten stehenden Eros gestützt, dieser trägt Pfeil und Bogen und steht auf einer niedrigen Basis. Dionysos tritt mit dem rechten Fuß auf die Basis des Eros.

Lit.: E: Gerhard, Über den Gott Eros, in: ders.: Gesammelte Akademische Abhandlungen und kleine Schriften I (Berlin 1868) 58-93 Taf. 52, 14.

\section{B53}

AO/H: - (ehem. London, Kunsthandel)
Stehender unbekleideter Dionysos, lehnt mit dem rechten Bein an einer bärtigen Herme, der rechte Fuß ist weit vorgesetzt, der linke zurück, der rechte Arm ist gesenkt, der linke angewinkelt erhoben.

Lit.: Reinach 1930, 23, 4.

\section{B54}

AO: Rom, Nationalmuseum Inv.

1187, D 3

H: Villa unter der Farnesina

M: Wandmalerei

UG: kleinformatig

Dat.: Ende 1. Jh. v. Chr.

Stehende weibliche Figur in Rückansicht, deren Hüftmantel bis unter das Gesäß gerutscht ist, mit dem linken Unterarm auf die Basis einer Herme? gestützt, der rechte Arm ist gesenkt. Daneben mit ausgestreckten Beinen sitzender unbekleideter Dionysos mit Thyrsos in der Linken und Tierfell als Unterlage, weitgehend erhalten.

Lit.: I. Bragantini - M. de Vos (Hrsg.), Museo Nazionale Romano. Le pitture II 1. Le decorazioni della villa romana della Farnesina (Rom 1982) 191 Taf. 99.

\section{B55}

AO: Rom, Palazzo Colonna Inv. 1714

M: Marmor

UG: $2 / 3$ Lebensgröße

EH: $1,20 \times 0,60 \mathrm{~m}$

Dat.: hadrianisch

Syrinx spielender stehender unbekleideter Satyr, mit dem linken Ellenbogen auf Basis einer mit einem Löwen- 
fell bekleideten Herme (Herakles oder Pan) gelehnt. Im Hintergrund Baum. Kopf der Herme ergänzt, Kopf des Satyrs nicht sicher zugehörig. Relief, gehört vermutlich in denselben $\mathrm{Zu}$ sammenhang wie Kat. B37. B38.

Lit:: Matz-von Duhn 1882, 65 f. Nr. 3574.

\section{B56}

AO/H: - (ehem. Florenz, Slg. Medici)

M: Karneol-Gemme

$\mathrm{UG} / \mathrm{EH}: 0,024$ x 0,017 m

Stehender Satyr? mit Mantel über dem rechten Arm, sonst unbekleidet, der linke Fuß weit zur Seite gestellt, mit dem ausgestreckten linken Arm auf eine Schale gestützt, die von einer weiblichen archaistischen Figur gehalten wird, der ausgestreckte rechte Arm hält einen Stab. Vollständig erhalten.

Lit.: S. Reinach, Pierres gravées des Collections Marlborough et D'Orléans. Bibliothèque des Monuments Figurés Grecs et Romains (Paris 1895) 45 Taf. 43, 89, 6.

weitere Götter und mythologische Gestalten

\section{B57}

Taf. 43, 3

AO: Tarent, Nationalmuseum

$\mathrm{H}$ : Tarent

M: Terrakotta

UG: kleinformatig

Dat.: frühes 4. Jh. v. Chr.
Stehende Artemis in kurzem Chiton, Mantel und Tierfell, mit dem rechten Unterarm auf weibliche Herme gestützt, trägt Reh oder Hirschkuh. Der linke Fuß ist deutlich zur Seite gestellt. Von diesem Typus existieren weitere Exemplare.

Lit.: H. Herdejürgen, Zur Deutung tarentinischer Terrakotten, AA 1983, 45-55 Abb. 1 f. Weitere Beispiele: ebenda.

\section{B58}

AO: Amsterdam, Allard Pierson

Museum, ehem. Den Haag, Slg.

Scheurleer Inv. 1138

H: Tarent?

M: Terrakotta

UG: kleinformatig

EH: 0,505 m

Dat.: 2. H. 4. Jh. v. Chr.

Stehende Artemis in kurzem Chiton, Nebris und hohen Stiefeln, der linke Fuß ist zur Seite gestellt, der linke Arm gesenkt. Zu ihrer Rechten eine Herme auf einer Basis. Rechter Arm der Göttin und Kopf der Herme nicht erhalten, daher ist offen, ob sie sich aufgestützt hat.

Lit.: C. W. Lunsingh Scheurleer, Die Göttin Bendis in Tarent, AA 1932, 314-334 Abb. 2; weitere werden im Text erwähnt.

B59

AO: Cambridge, Fogg Art Museum

Inv. 1960.621

M: Terrakotta

UG: kleinformatig

Dat.: 4. Jh. v. Chr. 
Stehende Artemis in kurzem Chiton und Mantel, mit dem linken Arm auf eine unbärtige ithyphallische Herme gestützt, der rechte ist gesenkt. Der linke Fuß tritt leicht vor. Hund $\mathrm{zu}$ ihrer Rechten, vollständig erhalten.

Lit.: Kahil 1984, 694 Nr. 947.

\section{B60}

AO: Paris, Louvre Inv. C 40

$\mathrm{H}$ : Böotien?

M: Terrakotta

$\mathrm{UG} / \mathrm{EH}: 0,31 \mathrm{~m}$

Dat.:1. H. 4. Jh. v. Chr.

Stehende Artemis in kurzem Chiton und Mantel, der auch über den Kopf gezogen ist, mit dem linken Ellenbogen auf eine bärtige Herme gestützt, hält Rehkitz, der rechte Arm ist gesenkt. Vollständig erhalten. Ein weiteres Exemplar des Typus ist in Paris, Louvre Inv. CA 1137.

Lit.: Mollard-Besques 1954, 89 Taf. 62

Nr. C 40. Weitere Beispiele: Kahil 1984, 691 Nr. 919

\section{B61}

Taf. 44,1

AO: Wien, Kunsthistorisches

Museum Inv. I 603

H: Larnaka

M: Marmor

$\mathrm{UG} / \mathrm{EH}: 0,78 \mathrm{~m}$

Dat.: 2. Jh. v. Chr.

Stehende Artemis in Chiton und Hüftmantel, Köcher auf dem Rücken. Mit dem linken Unterarm auf ein weibliches archaistisches Idol gestützt, der rechte Unterarm ist angewinkelt er- hoben. Tritt mit dem linken Fuß auf die Basis der Stütze. Beide Hände abgebrochen.

Lit.: Rizzo 1932, 13 Taf. 15; Kahil 1984, 654 Nr. 406.

\section{B62}

H: Eukarpia

M: Münze

UG: kleinformatig

Dat.: hadrianisch

Wie Kat. B57, in der gesenkten Linken den Bogen haltend, mit der rechten einen Pfeil aus dem Köcher greifend. $\mathrm{Zu}$ ihrer Rechten Hirsch, vollständig erhalten.

Lit.: J. Friedländer, Gruppe der Artemis, AZ 38, 1880,184 Taf. 17,2.

\section{B63}

AO: London, British Museum

$\mathrm{H}$ : Knidos

M: Terrakottalampe

UG: kleinformatig

EH: $0,17 \mathrm{~m}$

Dat.: hellenistisch

Stehende Artemis in kurzem, doppelt gegürtetem Chiton und hohen Stiefeln, die erhobenen Arme stützen die Lampenöffnungen. Linker Arm auf ein weibliches archaistisches Idol gestützt, hinter ihr ein Hund. Kopf und linker Fuß abgebrochen.

Lit.: J. Friedländer, Gruppe der Artemis, AZ 38, 1880,184 Taf. 17,3; F. Schaller, Stützfiguren in der griechischen Kunst (Diss. Universität Wien 1973) 58. 163 f. Nr. 151. 


\section{B64}

Taf. 44,2

AO: Richmond, Virginia Museum of

Fine Arts Inv. 60.5

M: Marmor

UG: unterlebensgroß

EH: $0,74 \times 0,484 \mathrm{~m}$

Dat.: 1. Jh. v. Chr.

Stehende Athena mit Peplos und Helm im Profil, leichte Schrittstellung, der rechte Arm nach vorn ausgestreckt, lässt Vogel aufsteigen, hat den Arm auf eine bärtige archaistische Herme gestützt, an dieser lehnt auch ihr Schild. Der linke Arm ist gesenkt und hält einen Stab. Vollständig erhalten.

Lit.: Harrison 1965, 135 Taf. 65c-d; W. Fuchs, Die Vorbilder der neuattischen Reliefs (Berlin 1959) 173 Nr. 23; LIMC II (1984) 976 s. v. Athena Nr. 207 (P.

Demargne).

\section{B65}

AO: Thessaloniki, Archäolog.

Museum Inv. O.2519

H: Olynth

M: Terrakotta

UG: kleinformatig

EH: $0,136 \mathrm{~m}$

Dat.: frühes 4. Jh. v. Chr.

Stehender Apollon im Hüftmantel, hält eine Leier in der Linken, diese ist auf eine Herme abgestützt, die Rechte ist gesenkt. Unterkörper des Gottes und unterer Teil der Herme nicht erhalten.

Lit.: LIMC II (1984) 211 s. v. Apollon 218 (O. Palagia).

\section{B66}

AO: New York, Metropolitan

Museum Inv. 81.6.64
M: Karneol-Gemme

UG/EH: 0,032 x 0,024 m

Dat.: 1. Jh. v. Chr. oder 1. Jh. n. Chr.

Stehender Apollon, dessen Hüftmantel bis unter die Scham gerutscht ist, hält Leier in der Linken, diese ist auf ein archaistisches Idol gestützt. Die Rechte ist über den Kopf gelegt und greift das Instrument, der linke Fuß ist zur Seite gestellt. Vollständig erhalten. Von diesem Typus und seinen Varianten existieren zahlreiche Darstellungen auf Gemmen und Münzen.

Lit.: S. Reinach, Pierres gravées des Collections Marlborough et D’Orléans. Bibliothèque des Monuments Figurés Grecs et Romains (Paris 1895) 6. 35 Taf. 3, 17. 32, 66, 3. 5; Furtwängler 1900, 122. 155. 206 Taf. 24, 56. 31, 33. 43, 34; G. Sena Chiesa, Gemme del Museo Nazionale di Aquileia (Aquileia 1966) $108 \mathrm{Nr} .51 \mathrm{f}$. Taf. 3; G. Horster, Statuen auf Gemmen (Diss. Rheinische Friedrich-Wilhelms Universität Bonn 1970) 49-54 Taf. 9, 1-4; LIMC II (1984) 399 s. v. Apollon/Apollo 218 (E. Simon); SNG von Aulock Nr. 7361.

\section{B67}

Taf. 45,1

AO: London, British Museum Inv. 1857,0415.1

H: Pompeji, Casa dei Dioscuri

M: Wandmalerei

UG/EH: 0,626 m

Dat.: neronisch

Stehender Apollon mit auf der rechten Schulter geknüpftem Mantel, der den Torso und das rechte Bein unbedeckt lässt, hält in der Linken Leier, die auf einem archaistischen Idol abgestützt ist. Greift mit der Rechten das Instrument, linker Fuß auf die Basis der Stütze gestellt, vollständig erhalten. 
Lit.: LIMC II (1984) 403 s. v.

Apollon/Apollo 274 (E. Simon).

\section{B68}

Taf. 45,2

AO: Neapel, Nationalmuseum Inv.

145078

H: Formia

M: Marmor

UG: Statue

Dat.: kaiserzeitlich

Stehender unbekleideter Apollon im Lykeios-Typus, mit dem linken Arm auf ein archaistisches weibliches Idol (Artemis?) gestützt, rechter Arm ruht auf dem Kopf, linker Fuß leicht zur Seite gestellt. Gesicht und linker Fuß des Apollon zerstört.

Lit.: Rizzo 1932, 79-85 Taf. 129; Kahil 1984, 635 Nr. 119.

\section{B69}

AO: Prag, Gipsabgussslg. der Taf. 45, 3

Universität

M: Gipsrekonstruktion nach kaiserzeitlichen Marmorkopien

UG: annähernd lebensgroß

Stehender unbekleideter Hermes, trägt Dionysoskind auf der linken Hand, die auf eine bärtige archaistische Herme gestützt ist, die Haltung der Rechten ist uneinheitlich bei den Repliken. Der linke Fuß ist zur Seite gestellt, er blickt in Richtung des Kindes. Rekonstruiert mit Hilfe von verschiedenen Exemplaren des Typus. Hermes mit Dionysoskind des Kephisodot?

Lit.: Rizzo 1932, 7-10 Taf. 12-14; Harrison 1965 Taf. 56 Nr. 210 Taf. 56.
B70

Taf. 45,4

AO: Paris, Louvre Inv. MYRINA 676

$\mathrm{H}$ : Myrina

M: Terrakotta

UG/EH: 0,265 m

Dat.: 2. Jh. v. Chr.

Stehender unbekleideter jugendlicher Hermes mit Geldbeutel in der angewinkelt vorgestreckten Hand, der Arm ist auf die Basis einer bärtigen Herme gestützt, der linke ist gesenkt. Der rechte Fuß ist vorgestellt. Es fehlt der linke Unterarm.

Lit.: Mollard-Besques 1963, 87 Taf. $106 f$. 240b.

\section{B71}

AO: Side, Museum Inv. 266

$\mathrm{H}$ : Side

M: Marmor

UG/EH: 1,65 m

Dat.: kaiserzeitlich

Stehender Hermes in Chlamys, hält Geldbeutel in der gesenkten Rechten, der linke Arm ist angewinkelt erhoben. Lehnt sich mit dem linken Oberschenkel an eine bärtige Herme, stützt sich aber nicht auf. Füße und linke Hand nicht erhalten.

Lit.: LIMC VI (1992) 505 s. v. Mercurius 10 (E. Simon).

\section{B72}

AO: Berlin

$\mathrm{H}$ : Pheneos

M: Kupfermünze

UG: kleinformatig

Dat.: Caracalla 
Stehender, mit Chlamys bekleideter Hermes, hält Caduceus in der Linken und Geldbeutel in der gesenkten Rechten, diese ruht auf einer Herme, vollständig erhalten, aber abgerieben.

Lit.: Imhoof-Blumer-Gardner, 1964, 97 Taf. T Nr. 6.

\section{B73}

AO: Paris, Louvre Inv. MYR 202

$\mathrm{H}$ : Myrina

M: Terrakotta

$\mathrm{UG} / \mathrm{EH}: 0,152 \mathrm{~m}$

Dat.: Ende 2. Jh. v. Chr.

Stehender unbekleideter Herakles mit Keule in der rechten Hand und Löwenfell über dem linken Arm, zu seiner Linken unbärtige ithyphallische Herme, vollständig erhalten. Es existieren weitere Exemplare des Typus: Paris, Louvre Inv. 455, Paris Louvre Inv. Bo 26 sowie Athen Nationalmuseum Inv. Misthos 326 und D 38.

Lit.: Mollard-Besques 1963, 86 Taf. 105b. Weitere Beispiele: Winter 1903, 378, 3a-c; Mollard-Besques 1963, 86 Taf. 105a. 243a.

\section{B74}

AO: München, Staatliche Antikenslg.

$\mathrm{H}$ : Russland

M: Terrakotta

UG/EH: 0,115 m

Dat.: hellenistisch

Stehender unbekleideter Herakles mit Keule in der gesenkten Linken, mit dem erhobenen rechten Ellenbogen auf eine Heraklesherme mit Löwenfell gestützt, rechtes Bein leicht zur Seite gestellt, vollständig erhalten.
Lit.: J. Sieveking, Die Terrakotten der Sammlung Loeb II (München 1916) 2 f. Taf. 69.

\section{B75}

M: Medaille

UG: kleinformatig

Dat.: kaiserzeitlich

Aufrecht sitzende Concordia bzw. Pietas (Beischriften) in Tunika und Hüftmantel, der bei einigen Darstellungen auch über den Kopf gezogen sein kann. Hält in der ausgestreckten Rechten Patera, mit dem linken Ellenbogen auf ein weibliches Idol, das hinter ihrem Stuhl steht, gestützt. Vollständig erhalten. Es existieren mehrere kaiserzeitliche Varianten.

Lit.: E. Gerhard, Über die Venusidole, in: Gerhard 1866, 258-284 Taf. 33, 4-6.

B76

Taf. 46, 1

AO: Moskau, Puschkin-Museum Inv. 504

M: apulischer Glockenkrater

UG: kleinformatig

Dat.: um 340 v. Chr.

Iphigenie in Chiton und Mantel im Artemistempel von Tauris stehend, mit dem rechten Bein das linke überkreuzend, den Tempelschlüssel in der Linken. Mit dem linken Unterarm auf archaistisches Artemisidol gestützt, die Rechte erhoben. Artemis selbst sitzt vor dem Tempel auf einem Altar. Vollständig erhalten.

Lit.: LIMC V (1990) 715 s. v. Iphigeneia 22 (L. Kahil). 


\section{B77}

AO: Paris, Louvre Inv. MYR 688

$\mathrm{H}$ : Myrina

M: Terrakotta

UG: kleinformatig

EH: 0,167 m

Dat.: Ende 2. Jh. v. Chr.

Ariadne? auf Felsen ausgestreckt schlafend, im Hüftmantel, linker Arm auf dem Felsen aufgestützt, Kopf ruht darin, rechte Hand ruht im Schoß. Mit dem Rücken an Artemis?Idol gelehnt. Unterkörper der Ariadne und des Idols nicht erhalten.

Lit.: Mollard-Besques 1963, 80 Taf. 96d.

\section{B78}

AO: Paris, Louvre Inv. MYRINA 1041

H: Myrina

M: Terrakotta

UG/EH: 0,3 m

Dat.: Anf. 1. Jh. v. Chr.

Stehende weibliche Figur (Ariadne?) im Mantel, der die rechte Brust und Schulter unbedeckt lässt, mit dem linken Arm auf ein archaistisches Artemis?- Idol gestützt, die Rechte ruht auf der Hüfte, Unterschenkel nicht erhalten.

Lit.: Mollard-Besques 1963, 79 Taf. $96 f$.

\section{B79}

AO: Florenz

M: Chalcedon-Gemme

UG/EH: $0,02 \times 0,015 \mathrm{~m}$

Dat.: kaiserzeitlich
Stehender unbekleideter Perseus, rechter Fuß zur Seite gestellt, rechter Arm über den Kopf gelegt, hält Haupt der Gorgo Medusa in der Hand, Linke ist gesenkt, hält Lanze, neben ihm Schild mit Spiegelbild der Medusa, in seinem Rücken bewaffnete Statue der Athena auf Basis, an die er sich vielleicht anlehnt, vollständig erhalten.

Lit.: S. Reinach, Pierres gravées des Collections Marlborough et D'Orléans. Bibliothèque des Monuments Figurés Grecs et Romains (Paris 1895) 57 Taf. 56, 34, 5.

\section{B80}

H: Bari

M: apulisch-rotfiguriger

Volutenkrater

UG: kleinformatig

Dat.: 380-365 v. Chr.

Sitzender unbekleideter Olympos, sein Mantel dient als Unterlage, hält in der erhobenen Rechten Flöte, in der Linken Stab mit Aryballos, neben ihm bärtige Herme, von seinem Mantel berührt. Lernt von Marsyas das Flötenspiel. Eros, Muse/Aphrodite, Satyr anwesend, vollständig erhalten.

Lit.: LIMC VII (1994) 40 s. v. Olympos I Nr. 11 (A. Weis).

\section{B81}

AO: Berlin

$\mathrm{H}$ : Mantineia

M: Kupfermünze

UG: kleinformatig

Dat.: kaiserzeitlich

Stehender unbekleideter Mann, mit der ausgestreckten Rechten auf Herme gestützt, die Linke hält stabartigen 
Gegenstand, rechter Fuß zur Seite gestellt. Laut Imhoof-Blumer - Gardner, 1964, 94 f. evtl. Arcas. Bildfeld vollständig erhalten.

Lit.: Imhoof-Blumer - Gardner, 1964, 94 f. Taf. S Nr. 20.

\section{Menschen - Grabreliefs}

\section{B82}

Taf. 46,2

AO: Berlin, Staatliche Museen Inv.

Sk. 784

H: Halikarnass, beim Maussolleion

M: Marmor

EH: 0,93 x 0,61 x 0,19 m

Dat.: 2. Jh. v. Chr.

Stehender Mann in Chiton und Mantel, mit der rechten Hand auf Heraklesherme gestützt, die linke greift in den Mantel. Rechts der Herme Pais und Palmwedel. Rand unvollständig.

Lit.: Pfuhl - Möbius 1977, 86 Nr. 141

Taf. 32.

\section{B83}

AO: Rhodos, Archäolog. Museum

H: Rhodos

M: Marmor

EH: 0,123 x 0,43 bzw. 0,505 x 0,16 m

Dat.: Ende 4. Jh. v. Chr.

Stehender unbekleideter Jüngling, mit dem linken Arm auf Heraklesherme gestützt. Rechter Arm über den Kopf gelegt, überkreuzt mit dem linken
Bein das rechte. Links der Herme stehender Pais. Vollständig erhalten.

Lit.: Pfuhl-Möbius 1977, 86 Nr. 138 Taf. 32.

\section{B84}

AO: Leiden, Rijksmuseum Inv. Pb. 18 $\mathrm{H}$ : Smyrna

M: Marmor

EH: 0,50 x 0,42 x 0,08 m

Dat.: Mitte 2. Jh. v. Chr.

Stehender Knabe in kurzem Mantel, hält in der ausgestreckten Rechten Trauben, zu denen ein Hund aufblickt. Links des Knaben stehender Pais an Basis einer Heraklesherme gelehnt, rechts sitzender Knabe, vollständig erhalten.

Lit.: Pfuhl-Möbius 1977, 198 Nr. 730

Taf. 110.

\section{B85}

AO: Leiden, Rijksmuseum Inv. S. N.

Ns. 1

H: Smyrna

M: Marmor

EH: 0,113 x 0,52 × 0,09 m

Dat.: 2. H. 2. Jh. v. Chr.

Stehender Mann in Chiton und Mantel, fasst mit der Rechten den über die linke Schulter fallenden Mantel, die Linke ist gesenkt. Links von ihm stehender Pais an Basis einer Heraklesherme gelehnt, rechts weiterer Pais. Kopf des Mannes fehlt.

Lit.: Pfuhl-Möbius 1977, 108 f. Nr. 256 Taf. 48. 


\section{B86}

AO: Ince Blundell Hall

$\mathrm{H}$ : Smyrna

M: Marmor

EH: $0,90 \times 0,56 \times 0,14 \mathrm{~m}$

Dat.: 2. H. 2. Jh. - 1. H. 1. Jh. v. Chr.

Vollständig in Mantel gehüllter stehender Mann. Linke Hand gesenkt, rechte vor der Brust in den Mantel gehüllt. Links von ihm stehender Pais an Basis einer Heraklesherme gelehnt, rechts weiterer Pais. Vollständig erhalten.

Lit.: Pfuhl-Möbius 1977, 92 Nr.161 Taf. 35.

\section{B87}

AO: Padua, Museo Civico Inv. 85

M: Marmor

EH: $0,90 \times 0,70 \times 0,31 \mathrm{~m}$

Dat.: 2. H. 3. Jh. - 1. H. 2. Jh. v. Chr.

Sitzender Mann, die Rechte ruht im Schoß, die Linke auf dem Sitz. Sein Mantel lässt die rechte Schulter und den Arm frei. Rechts von ihm stehender Pais an archaistische bärtige Herme gelehnt. Kopf des Mannes fehlt.

Lit.: Pfuhl-Möbius 1977, 215 Nr. 821

Taf. 119.

\section{B88}

AO: Berlin, Staatliche Museen Inv.

Sk. 785

H: Smyrna

M: Marmor

EH: $0,60 \times 0,27 \times 0,14 \mathrm{~m}$

Dat.: 2. H. 2. Jh. v. Chr.

Stehender Mann im Hüftmantel, hat die gesenkte Rechte auf die Basis einer archaistischen bärtigen Herme ge- stützt, davor stehender Pais mit Palmwedel. Die Linke hält den Mantel auf Hüfthöhe. Kopf des Mannes und linker Rand der Stele abgebrochen.

Lit.: Pfuhl-Möbius 1977, 86 Nr. 140 Taf. 32.

\section{B89}

AO: Vathy, Museum Inv. 244

H: Samos

M: Marmor

EH: $0,58 \times 0,42 \times 0,09 \mathrm{~m}$

Dat.: Ende 2. Jh. v. Chr.

Stehender Knabe in Chiton und Mantel, der die rechte Schulter und den Arm frei lässt, hat die erhobene Linke auf archaistische bärtige Herme gelegt, rechts von ihm stehender Pais und Hund, dessen Kopf er mit der gesenkten Rechten berührt.

Lit:: Pfuhl-Möbius 1977, 85 Nr.136 Taf. 31.

\section{B90}

AO: Sofia, Nationalmuseum

$\mathrm{H}$ : Apollonia am Pontos

M: Marmor

EH: $0,36 \times 0,23 \times 0,065 \mathrm{~m}$

Dat.: 1. H. 2. Jh. v. Chr.

Stehender Knabe, dessen Mantel seine rechte Seite unbedeckt lässt. Hat die ausgestreckte Rechte auf eine unbärtige ithyphallische Herme gelegt, hält in der Linken zwei Speere, links von ihm stehender Pais. Linke obere Ecke der Stele mit Kopf des Knaben abgebrochen.

Lit.: Pfuhl-Möbius 1977, 83 f. Nr. 127 Taf. 30. 


\section{B91}

AO: Leiden, Rijksmuseum Inv. Pb. 77

$\mathrm{H}$ : Kleinasien

M: Marmor

EH: 0,55 x 0,32 x 0,01 m

Dat.: 2. Jh. v. Chr.

Stehender Jüngling in Chiton und Mantel, der die rechte Schulter frei lässt, die erhobene Rechte auf unbärtige ithyphallische Herme gelegt, die Linke greift den Mantel auf Hüfthöhe. Rechts von ihm stehender Pais, links Kasten mit Schriftrollen. Oberer und unterer Stelenrand abgebrochen.

Lit.: Pfuhl-Möbius 1977, 84 Nr. 132 Taf. 30.

\section{B92}

AO: Eresos, Archäolog. Slg. Inv. 19

$\mathrm{H}$ : Eresos

M: Marmor

EH: 0,41 x 0,22 x 0,06 m

Dat.: 2. Jh. v. Chr.

Stehender Mann in Chiton und Mantel, mit dem linken Ellenbogen auf unbärtige ithyphallische Herme gestützt, die Rechte ist gesenkt. Kopf und Hals des Mannes und unterer Rand der Stele nicht erhalten.

Lit.: Pfuhl-Möbius 1977, 110 Nr. 267 Taf. 50.

\section{B93}

AO: St. Petersburg, Eremitage Inv.

A 212

H: Rheneia

M: Marmor

$\mathrm{EH}: 1,2 \times 0,58 \mathrm{~m}$

Dat.: 2. Jh. v. Chr.
Stehender Mann im Hüftmantel, mit dem linken Ellenbogen auf die Basis einer unbärtigen ithyphallischen Herme gelehnt, rechte Hand erhoben. Rechts des Mannes Hund, auf der Basis der Herme hockt ein Pais. Vollständig erhalten.

Lit.: Couilloud 1974, 207 Nr. 473 Taf. 83.

\section{B94}

AO: Berlin, Staatliche Museen Inv.

Sk. 771

H: Smyrna oder Umgebung

M: Marmor

EH: 1,02 x 0,41 x 0,01 m

Dat.: 2. Jh. v. Chr.

Stehender Jüngling in Chiton und Mantel, der die rechte Schulter und den Arm frei lässt, hält in der erhobenen Rechten ein Diptychon, die Linke ist in den Mantel gehüllt. Rechts neben ihm stehender Pais an Basis einer unbärtigen ithyphallischen Herme gelehnt, zwischen ihnen ein Hund. Vollständig erhalten.

Lit.: Pfuhl-Möbius 1977, 84 Nr. 131 Taf. 30.

\section{B95}

AO: Wien, Kunsthistorisches

Museum Inv. I 753

$\mathrm{H}$ : Rheneia

M: Marmor

EH: 0,69 x 0,62 x 0,08 m

Dat.: Ende 2. Jh. v. Chr.

Stehender Mann in Chiton und Mantel, der die rechte Schulter und den Arm frei lässt, mit der Hand auf unbärtige ithyphallische Herme gestützt, 
die Linke ist gesenkt. Links von ihm stehender Pais. Vollständig erhalten.

Lit.: Couilloud 1974, 155 f. Nr. 297 Taf. 58.

\section{B96}

AO: Athen, Nationalmuseum Inv.

E M 1318

$\mathrm{H}$ : Rheneia

M: Marmor

EH: 0,69 x 0,41 x 0,08 m

Dat.: Ende 2. Jh. v. Chr.

Wie Kat. B95, der Pais jedoch rechts der Herme. Vollständig erhalten.

Lit.: Couilloud 1974, 156 Nr. 298 Taf. 58.

\section{B97}

H: Rheneia

EH: 0,66 m

Wie Kat. B95, der Pais jedoch rechts der Herme. Oberer Stelenrand fehlt.

Lit.: Couilloud 1974, 156 f. Nr. 299 Taf. 58.

\section{B98}

AO: Verona, Museo Maffei

$\mathrm{H}$ : Rheneia

M: Marmor

EH: 0,48 x 0,42 x 0,08 m

Dat.: Ende 2. Jh. v. Chr.

Wie Kat. B95, jedoch ohne Chiton. Oberer Stelenrand nicht erhalten.

Lit.: Couilloud 1974, 157 Nr. 300 Taf. 58.

\section{B99}

AO: Wien, Kunsthistorisches

Museum Inv. I 1061

$\mathrm{H}$ : Rheneia
M: Marmor

EH: $0,69 \times 0,45 \times 0,09 \mathrm{~m}$

Dat.: Ende 2. Jh. v. Chr.

Stehender Mann im Mantel, der die rechte Schulter und den Arm frei lässt, hat die Rechte zum Handschlag mit einer ihm gegenüber sitzenden Frau ausgestreckt, die Linke greift den Mantel auf Hüfthöhe. Im Hintergrund stehender Pais an Basis einer unbärtigen Herme gelehnt. Vollständig erhalten.

Lit.: Couilloud 1974, 96 f. Nr. 90 Taf. 20.

\section{B100}

AO: Izmir, Archäolog. Museum Inv. B 3244

M: Marmor

EH: $1,03 \times 0,455 \times 0,16 \mathrm{~m}$

Dat.: 1. Jh. v. Chr.

Stehender Mann in Chiton und Mantel, der die rechte Brust unbedeckt lässt, mit der gesenkten Rechten auf eine Herme gestützt, die Linke ist in den Mantel gehüllt. Links von ihm stehender Pais. Kopf des Mannes und Rand des Bildfeldes zerstört.

Lit.: Pfuhl-Möbius 1977, 85 Nr. 133 Taf. 31.

\section{B101}

AO: München, Glyptothek Inv. 509

$\mathrm{H}$ : Erythrai

M: Marmor

EH: $1,44 \times 0,65 \times 0,17 \mathrm{~m}$

Dat.: 1. Jh. v. Chr.

Stehender Mann, dessen Mantel die rechte Seite des Torsos unbedeckt lässt. Rechte Arm auf die Basis einer archaistischen bärtige Herme gelegt, 
die Linke in die Hüfte gestützt, neben ihm zwei stehende Paides. Kopf des Mannes nicht erhalten.

Lit.: Pfuhl-Möbius 1977, 85 f. Nr. 137

Taf. 31.

\section{B102}

AO: Wien, Universität, Slg. des

Archäolog. Instituts

$\mathrm{H}$ : Rhodos

M: Marmor

EH: 0,75 x 0,31 m

Dat.: 2. H. 1. Jh. v. Chr.

Stehender, ganz in einen Mantel gehüllter Jüngling, die Rechte ruht auf der Brust, die Linke ist gesenkt. Links von ihm stehender Pais an Basis einer Herme gelehnt. Vollständig erhalten.

Lit:: Pfuhl-Möbius 1977,92 Nr.163 Taf. 36.

\section{B103}

AO: Bologna, Museo Civico

M: Marmor

EH: 0,47 x 0,27 m

Dat.: Ende 1. Jh. v. Chr.

Stehender Mann im Mantel, der die rechte Seite des Torso frei lässt, hat die ausgestreckte Rechte auf eine Herme gelegt, die Linke in die Hüfte gestützt. Kopf der Herme unkenntlich.

Lit.: Pfuhl-Möbius 1977, 86 Nr.139 Taf. 32.

\section{B104}

AO: Vathy, Museum Inv. 253

H: Samos

M: Marmor

EH: 0,49 x 0,35 x 0,08 m

Dat.: frühe Kaiserzeit
Stehender Jüngling in Chiton und Mantel, der die Brust und die rechte Schulter frei lässt, mit dem linken Arm auf unbärtige archaistische Herme gelehnt, davor sitzende Frau. Zu seiner Rechten stehender Pais.

Lit.: Pfuhl-Möbius 1977,112 f. Nr. 280

Taf. 52.

\section{B105}

AO: Piräus, Museum Inv. 218

$\mathrm{H}$ : Piräus

M: Marmor

EH: $1,07 \times 0,51 \mathrm{~m}$

Dat.: 1. H. 2. Jh. n. Chr.

Stehender Jüngling in kurzem Mantel, der nur den Oberkörper und den gesenkten rechten Arm bedeckt, die gesenkte Linke ruht auf einer unbärtigen ithyphallischen Herme, vollständig erhalten.

Lit.: von Moock 1998, 178 Nr. 494 Taf. 63b.

\section{B106}

AO: Piräus, Museum Inv. 388

$\mathrm{H}$ : Salamis

M: Marmor

EH: $1,28 \times 0,64 \times 0,14 \mathrm{~m}$

Dat.:1. H. 2. Jh. n. Chr.

Stehender Mann, dessen Mantel nur die Beine, die rechte Schulter und den Arm bedeckt. Hat die gesenkte Rechte auf unbärtige Herme gelegt, links von ihm Hund. Kopf des Mannes zerstört.

Lit.: von Moock 1998, 179 Nr. 499 Taf. 64c. 


\section{B107}

$\mathrm{H}$ : Athen

M: Marmor

EH: $0,95 \times 0,71 \mathrm{~m}$

Dat.: kaiserzeitlich

Wie Kat. B106. Kopf des Mannes nicht erhalten.

Lit.: von Moock, 1998, 189 Nr. 550 Taf. $67 \mathrm{c}$.

\section{B108}

H: Eretria

Wie Kat. B106. Kopf des Mannes abgebrochen.

Lit.: E. Pfuhl, Zur Darstellung von Buchrollen auf Grabreliefs, JdI 22, 1907, 113132 Abb. 5.

\section{B109}

AO: Athen, Nationalmuseum Inv. 1353

H: Athen, beim Asklepieion

M: Marmor

EH: $0,74 \times 0,47 \times 0,11 \mathrm{~m}$

Dat.: kaiserzeitlich

Stehender Jüngling mit Chlamys und nacktem Torso, zu seiner Linken unbärtige Herme, viele Fehlstellen, daher ist offen, ob er sich aufstützt.

Lit.: von Moock 1998,137 Nr. 273 Taf. 41d.

\section{B110}

AO: Athen, Nationalmuseum,

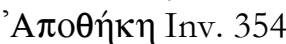

M: Marmor

EH: $0,62 \times 0,27 \mathrm{~m}$

Dat.: kaiserzeitlich
Stehender Mann im Mantel, der die rechte Schulter und das linke Bein unbedeckt lässt, mit der gesenkten Rechten auf unbärtige ithyphallische Herme gestützt. Kopf und linker Arm des Mannes sowie oberer und linker Stelenrand abgebrochen.

Lit.: A. Conze (Hrsg.), Die attischen Grabreliefs IV (Berlin 1911-1922) 71f. Nr. 2015 mit Abb.

\section{B111}

AO: Athen, Nationalmuseum, 'А $\pi \circ \theta \dot{\eta} \kappa \eta$

M: Marmor

EH: $0,38 \times 0,36 \mathrm{~m}$

Dat.: kaiserzeitlich

Stehender Mann, von Mantel bis zu den Füßen eingehüllt, hat die Linke auf eine unbärtige ithyphallische Herme gelegt, nur untere Hälfte der Stele erhalten.

Lit.: A. Conze (Hrsg.), Die attischen Grabreliefs IV (Berlin 1911-1922) 72 Nr. 2016.

\section{B112}

AO: Leiden, Rijksmuseum Inv. I. $91 / 8.3$

H: Smyrna

M: Marmor

EH: $0,57 \times 0,44 \times 0,08 \mathrm{~m}$

Dat.: 2. H. 2. Jh. v. Chr.

Stehender, vollständig in Mantel gehüllter Jüngling, links von ihm stehender Pais an Basis einer archaistischen bärtigen Herme gelehnt, rechts Baum. Vollständig erhalten.

Lit.: Pfuhl-Möbius 1977, 81 Nr.114Taf. 27. 


\section{B113}

AO: Izmir, Archäolog. Museum

H: Metropolis (Torbali)

M: Marmor

EH: $0,58 \times 0,42 \times 0,12 \mathrm{~m}$

Dat.: 2. H. 2. Jh. v. Chr.

Selber Typus wie Kat. B112, oberer Teil der Stele mit dem Kopf des Mannes und der Herme abgebrochen.

Lit.: Pfuhl-Möbius 1977, 81 Nr.115 Taf. 27.

\section{B114}

AO: Eresos, Archäolog. Slg. Inv. 121

$\mathrm{H}$ : Eresos

M: Marmor

EH: $0,67 \times 0,42 \times 0,13 \mathrm{~m}$

Dat.: späthellenistisch?

Sitzende Frau, daneben stehender Mann, beide im Handschlag verbunden? Rechts davon Herme und stehende Frau mit Kind, Oberfläche fast vollständig zerstört.

Lit.: Pfuhl-Möbius 1977, 272 Nr. 1101

Taf. 165.

\section{Menschen - Knaben, Jünglinge und Männer}

\section{B115}

AO: Leipzig, Universität, Slg. des Archäolog. Instituts Inv. T 1894

H: Tanagra

M: Terrakotta

UG/EH: 0,131 m

Dat.: frühhellenistisch
Stehender Knabe in kurzem Mantel, mit dem linken Arm auf bärtige Herme gelehnt, Rechte fasst das Gewand auf Hüfthöhe. Vollständig erhalten.

Lit.: E. Paul, Antike Welt in Ton. Griechische und römische Terrakotten des archäologischen Instituts in Leipzig (Leipzig 1959) 46 Taf. 55.

\section{B116}

AO: Athen, Nationalmuseum Inv. 3986

H: Eretria

M: Terrakotta

$\mathrm{UG} / \mathrm{EH}: 0,1 \mathrm{~m}$

Stehender Knabe in Chlamys, mit der linken Seite an bärtige Herme gelehnt. Linke Hand zum Kinn erhoben, rechte in die Hüfte gestützt. Vollständig erhalten.

Lit.: Winter 1903, 243, 6

\section{B117}

AO: Paris, Louvre Inv. 354

$\mathrm{H}$ : Myrina

M: Terrakotta

$\mathrm{UG} / \mathrm{EH}: 0,125 \mathrm{~m}$

Stehender Knabe im Mantel, der nur den Rücken und den linken Arm bedeckt, lehnt sich mit der linken Seite an bärtige Herme. Linke Hand greift Mantel, rechte hält einem Hund Trauben hin, vollständig erhalten.

Lit.: Winter 1903, 282, 7

\section{B118}

AO: London, British Museum Inv. 2193

H: Kertsch 
M: Terrakotta

$\mathrm{UG} / \mathrm{EH}:$ 0,125 m

Dat.: 1. Jh. v. Chr.

Stehender, vollständig in Mantel gehüllter Knabe, mit dem linken Ellenbogen auf bärtige Herme gelehnt, rechter Arm gesenkt. Kopf abgebrochen. Weitere Exemplare des Typus, ebenfalls aus Kertsch, befinden sich in St. Petersburg, Eremitage.

Lit.: Burn - Higgins 2001, 90 Nr. 2193

Taf. 35. Weitere Beispiele: Stephani 1876, 18 Taf. I, 5; Winter 1903, 239, 8.

\section{B119}

AO: Wien, Antikenkabinett Inv. 257

$\mathrm{H}$ : Sizilien

M: Terrakotta

$\mathrm{UG} / \mathrm{EH}: 0,13 \mathrm{~m}$

Stehender Knabe, dessen Mantel den Rücken, den linken, in die Hüfte gestützten Arm und die Füße bedeckt. Mit dem rechten Arm auf ithyphallische Herme gelehnt, vollständig erhalten.

Lit.: Winter 1903, 253, 5.

\section{B120}

AO: Berlin, Antiquarium Inv. 3727

$\mathrm{H}$ : Italien

M: Terrakotta

UG/EH: 0,155 m

Stehender Knabe im Hüftmantel, lehnt mit dem erhobenen rechten, über den Kopf gelegten Arm an einer bekleideten Herme, die Linke ruht ebenfalls auf der Stütze, vollständig erhalten.

Lit.: Winter 1903, 253, 3.

\section{B121}

AO/H: - (ehem. Slg. Calvert)

M: Terrakotta

UG/EH: 0,15 m

Stehender Knabe, dessen Mantel nur den Rücken bedeckt, lehnt mit der erhobenen Rechten an unbärtiger Herme, tritt mit dem rechten Fuß auf die Basis der Herme. Vollständig erhalten.

Lit.: Winter 1903,244, 6.

\section{B122}

AO: London, British Museum Inv. 1907.5-19.6

M: Terrakotta

UG/EH: 0,153 m

Dat.: frühes 1. Jh. v. Chr.

Stehender Knabe in Chlamys, mit dem rechten Arm auf unbärtige Herme gelehnt, hält Palmwedel in der Hand, die Linke greift zu dem Kranz auf seinem Kopf. Vollständig erhalten.

Lit.: Burn - Higgins 2001, 123 Nr. 2291

Taf. 52.

\section{B123}

AO: Paris, Louvre Inv. Bo 130

$\mathrm{H}$ : Myrina

M: Terrakotta

$\mathrm{UG} / \mathrm{EH}: 0,195 \mathrm{~m}$

Dat.: Ende 1. Jh. v. Chr.

Stehender Knabe, dessen langer Mantel nur den Rücken und die linke Schulter bedeckt, hat den linken Arm auf eine unbärtige Herme und die Rechte in die Hüfte gestützt, vollständig erhalten. Von demselben Typus befinden sich noch weitere Exemplare in Paris, Louvre Inv. D 353-355. 
Lit:: Mollard-Besques 1963, 130 Taf. 156b. 257d. Weitere Beispiele: MollardBesques 1972, 62 Taf. 77c. d. 78a

\section{B124}

AO: Istanbul, Archäolog. Museum

Inv. 250

H: Myrina

M: Terrakotta

$\mathrm{UG} / \mathrm{EH}: 0,14 \mathrm{~m}$

Stehender Knabe in Chlamys, mit dem linken Arm auf unbärtige Herme gelehnt, spielt mit einem Hund zu seiner Rechten, vollständig erhalten.

Lit.: Winter 1903, 281, 4.

\section{B125}

AO: München, Staatliche Antikenslg.? $\mathrm{H}$ : Myrina?

M: Terrakotta

UG/EH: 0,115 m

Dat.: hellenistisch

Stehender Knabe, dessen Mantel seine Vorderseite bis auf die linke Schulter frei lässt, mit dem rechten Arm an einen Pfeiler mit einer kleinen Figur darauf gelehnt, vollständig erhalten.

Lit.: Winter 1903, 248, 7; J. Sieveking, Die Terrakotten der Sammlung Loeb II (München 1916) 5 Taf. 72, 1.

\section{B126}

Taf. 46, 3

AO: Delphi, Museum

H: Delphi, Daochos-Weihung

M: Marmor

UG: leicht überlebensgroß

EH: 1,52 m

Dat.: 4. oder 3. Jh. v. Chr.
Stehender Jüngling mit Chlamys über der linken Schulter, mit dem linken Arm auf bärtige archaistische Herme gestützt, rechter Arm war gesenkt. Kopf, Arme, linkes Bein, rechter Fuß nicht erhalten.

Lit.: Foto D-DAI-ATH-Delphi 387 (G. Hellner); E. Will, A propos de la base des Thessaliens a Delphes, BCH 62, 1938, 289304 Taf. 30; Dorn 1968, 41 f. Taf. 33-35.

\section{B127}

AO: Neapel, Nationalmuseum?

UG: Statue oder Statuette

Stehender unbekleideter Jüngling, mit dem linken Arm auf eine bärtige Herme gestützt, rechter Arm gesenkt.

Lit.: Reinach 1897a, 537, 6.

\section{B128}

AO: Rom, Museo Chiaramonti

M: Marmor

UG/EH: 2,27 m

Dat.: hadrianisch

Stehender unbekleideter Jüngling, mit der gesenkten Linken auf bärtige Herme gestützt, rechter Arm erhoben. Kopf nicht zugehörig, neuzeitlich zu Hermes ergänzt.

Lit.: B. Andreae (Hrsg.), Bildkatalog der Skulpturen des vatikanischen Museums I. Museo Chiaramonti II (Berlin 1995) 681683 Nr. 450.

\section{B129}

AO: Paris, Louvre

Stehender unbekleideter Jüngling, beide Arme gesenkt, mit dem linken Bein an Heraklesherme gelehnt. 
Lit.: Reinach 1897a, 136, 4.

\section{B130}

AO: Paris, Louvre

M: Terrakotta

$\mathrm{UG} / \mathrm{EH}: 0,14 \mathrm{~m}$

Sitzender, vollständig in Mantel gehüllter Knabe, mit der linken Seite an bärtige Herme gelehnt, die Hände ruhen im Schoß. Vollständig erhalten.

Lit.: L. Heuzey, Les figurines antiques de terre cuite du Musée du Louvre (Paris 1883) 21 Taf. 34, 3.

\section{B131}

AO: London, British Museum Inv. 1891.1-10.4

$\mathrm{H}$ : Athen?

M: Terrakotta

$\mathrm{UG} / \mathrm{EH}: 0,125 \mathrm{~m}$

Dat.: 2. H. 3. Jh. v. Chr.

Auf seinem Mantel sitzender Knabe, das rechte Bein von dem Gewand bedeckt, zu seiner Rechten bärtige Herme, an die er sich aber nicht anlehnt. Vollständig erhalten.

Lit.: Burn - Higgins 2001, 36 f. Nr. 2013 Taf. 3.

\section{B132}

H: Tanagra?

M: Terrakotta

$\mathrm{UG} / \mathrm{EH}: 0,23 \mathrm{~m}$

Sitzender, vollständig in einen Mantel gehüllter Jüngling, hat das linke Bein über das rechte geschlagen, stützt den rechten Ellenbogen darauf und das
Kinn in die Hand. Die Linke ruht im Schoß. Mit dem Rücken an bärtige Herme gelehnt, vollständig erhalten.

Lit.: Winter 1903, 258, 1.

\section{B133}

AO: - (ehem. Slg. Piot)

$\mathrm{H}$ : Tanagra

M: Terrakotta

UG/EH: 0,114 m

Ähnlich dem vorigen, ohne jedoch die Hand und den Kopf aufzustützen, vollständig erhalten.

Lit.: Winter 1903, 257, 2.

\section{B134}

AO: Berlin, Antiquarium Inv. 7384

$\mathrm{H}$ : Capua

M: Terrakotta

$\mathrm{UG} / \mathrm{EH}: 0,128 \mathrm{~m}$

Auf seinem Mantel sitzender, sonst unbekleideter Jüngling, mit der linken Seite an bärtige Herme gelehnt, die Rechte ist gesenkt. Linker Arm und Kopf der Herme nicht erhalten.

Lit.: Winter 1903, 264, 4.

\section{B135}

AO: Athen, Polytechnion Inv. 490M 26

$\mathrm{H}$ : Athen

M: Terrakotta

UG: kleinformatig

EH: 0,13 m

Sitzender Knabe, dessen Mantel als Unterlage dient und das rechte Bein bedeckt, hat den linken Arm auf eine 
bärtige Herme gelegt, die Rechte ruht im Schoß, Kopf abgebrochen.

Lit.: Winter 1903, 260, 4.

\section{B136}

AO: Würzburg, Martin von Wagner-

Museum Inv. K 1933

$\mathrm{H}$ : Sizilien

M: Terrakotta

UG/EH: 0,179 m

Dat.: um 300 v. Chr.

Auf seinem Mantel sitzender unbekleideter Jüngling mit Leier in der Linken, die Rechte ruht auf dem Felsen, mit dem Rücken an Herme gelehnt, vollständig erhalten.

Lit.: E. Simon (Hrsg.), Die Sammlung Kiseleff II. Minoische und griechische Antiken (Mainz 1989) 176 Nr. 284 Taf. 110.

\section{B137}

AO: Neapel, Nationalmuseum Inv. 119917

H: Sorrent

M: Marmor

$\mathrm{UG} / \mathrm{EH}: 1,80 \mathrm{~m}$

Dat.: 1. Jh. n. Chr.

Stehender unbekleideter Faustkämpfer, beide Arme gesenkt, zu seiner Rechten Heraklesherme, auf die er sich nicht aufstützt. Linker Unterarm fehlt.

Lit.: Pozzi 1989, 108 Nr. 70.

\section{B138}

AO: Pompeji, Antiquarium

H: Pompeji I 20, 2. 3

M: Tuff
UG: kleinformatig

Dat.: 1. Jh. v. Chr.

Schreitender Gladiator in knielangem Schurz, das gezückte Schwert in der Rechten, den schildbewehrten erhobenen linken Arm auf Priapos gestützt.

Lit.: LIMC VIII (1997) 1035 s. v. Priapos 88 (W.-R. Megow)

\section{B139}

AO: Istanbul, Archäolog. Museum

Inv. 1998

$\mathrm{H}$ : Milet, Faustinatherme

M: Marmor

$\mathrm{UG} / \mathrm{EH}: 1,96 \mathrm{~m}$

Dat.: antoninisch

Stehender unbekleideter Mann, zu seiner Rechten Heraklesherme. Es fehlen das linke Bein und beide Arme.

Lit.: F. Manderscheid, Die Skulpturenausstattung der kaiserzeitlichen Thermenanlagen (Berlin 1981) 96 Nr. 225 Taf. 32.

\section{B140}

AO: Wien, Kunsthistorisches

Museum? ehem. kaiserl. Hofmuseum

$\mathrm{H}$ : Alexandria

M: Marmor

Dat.: kaiserzeitlich

Stehender, vollständig in Mantel gehüllter Mann, die Rechte ruht auf der Brust, die Linke ist gesenkt. Zu seiner Rechten Herme, auf die er sich nicht aufstützt. Grabstatue, Kopf und Füße nicht erhalten.

Lit.: Reinach 1910, 391, 9. 


\section{B141}

Taf. 47,1

AO: Brauron, Museum Inv. NE 1107

$\mathrm{H}$ : Brauron, Artemisheiligtum

M: Marmor

UG: unterlebensgroß

Dat.: 2. H. 4. Jh. v. Chr.

Stehender, mit kurzem Mantel bekleideter Jüngling, mit dem linken Arm auf ein archaistisches Idol gestützt, die rechte ist gesenkt. Kopf, Unterarme, rechter Unterschenkel und linker Fuß nicht erhalten.

Lit.: Kahil 1984, 635 Nr. 118; S. G. Miller, Menon's Cistern, Hesperia 43, 1974, 212. 213 Taf. 37; G. I. Despinis, Iphigeneia und Orestes. Vorschläge zur Interpretation zweier Skulpturenfunde aus Brauron, AM 120, 2005, 241-267 Taf. 47, 1-4.

\section{B142}

AO/H: Memphis, Sarapieion

M: Kalkstein

UG: überlebensgroß

EH: $1,72 \mathrm{~m}$

Dat.: hellenistisch

Stehender, in einen Mantel eingehüllter Mann, mit dem linken Ellenbogen auf eine bärtige Herme gestützt. Kopf, Beine und Unterarme abgebrochen.

Lit.: Hornbostel 1973, 408-417 Abb. 365; U. Wilcken, Die griechischen Denkmäler vom Dromos des Serapeums in Memphis, JdI 32, 1917, 149-203 bes. 164-165 Abb. 5; Lauer - Picard 1955, 69-89 Abb. 33 f. Taf. 8; der von Chr. Picard zugeschriebene Kopf: ebenda, Abb. 41 f. Taf. 9; Bergmann 2007.

\section{B143}

AO: Madrid, Prado Inv. 28-E

H:- (ehem. Rom, Horti Sallustiani)
M: Marmor

UG/EH: 1,61 m

Dat.: Ende 1. Jh. v. Chr.

'Gruppe von Ildefonsos: zwei stehende unbekleidete Jünglinge nach klassisch-griechischen Vorbildern, zu ihrer Linken archaistisches Idol, zwischen ihnen ein Altar, den der linke Jüngling mit einer Fackel entzündet. Antinoosportrait der linken Figur erst unter Hadrian hinzugefügt. Evtl. Orest und Pylades beim Opfer an Artemis (zu weiteren Deutungen s. Lit.)

Lit.: Schröder 1993, 214-216 Nr. 57;

Schröder 2004, 371-379 Nr. 181.

\section{Menschen - Frauen}

\section{B144}

AO: Athen? (Kunsthandel)

H: Megara

M: Terrakotta

UG/EH: 0,28 m

Mit dem Gewicht auf dem rechten Bein stehende Frau in Chiton und Mantel, mit dem linken Ellenbogen auf weibliches archaistisches Idol gelehnt. Der rechte Arm ist quer vor den Bauch gelegt, die Hand berührt den linken Arm, vollständig erhalten.

Lit.: Winter 1903, 83, 1.

\section{B145}

AO: Athen, Nationalmuseum Inv.

Misthos 487

H: Myrina

M: Terrakotta

UG/EH: 0,21 m 
Stehende, ganz in ihren Mantel eingehüllte Frau, mit dem linken Unterarm auf die Basis eines weiblichen Idols gelehnt, die Rechte ist in die Hüfte gestützt, vollständig erhalten.

Lit.: Winter 1903, 84, 7.

\section{B146}

AO: - (ehem. Slg. Herfurth)

H: Myrina

M: Terrakotta

UG/EH: 0,215 m

Ähnlich Kat. B145, der Mantel ist jedoch auch über den Kopf gezogen, der linke Unterarm erhoben, vollständig erhalten.

Lit.: Winter 1903, 26, 9.

\section{B147}

Taf. 47,3

AO: Istanbul, Archäolog. Museum

Inv. 1258

H: Myrina

M: Terrakotta

$\mathrm{UG} / \mathrm{EH}: 0,17 \mathrm{~m}$

Stehende, ganz in ihren Mantel gehülte Frau, kreuzt das rechte Bein vor das linke, hat den linken Arm quer vor der Brust entlang geführt und legt ihn auf ein weibliches archaistisches Idol, der rechte Ellenbogen ist darauf gestützt, die Hand stützt das Kinn. Vollständig erhalten.

Lit.: G. Mendel, Catalogue des figurines grecques de terre cuite (Istanbul 1908) 512 f. Nr. 3199 Taf. 11, 1.

\section{B148}

AO: St. Petersburg, Eremitage

$\mathrm{H}$ : Tanagra
M: Terrakotta

$\mathrm{UG} / \mathrm{EH}: 0,18 \mathrm{~m}$

Dat.: hellenistisch

Stehende, vollständig in einen Mantel gehüllte Frau mit Hut, mit dem linken Arm auf einem weiblichen archaistischen Idol lehnend, die Rechte in die Hüfte gestützt. Hat das linke Bein diagonal hinter das rechte gestellt, vollständig erhalten.

Lit.: Winter 1903, 81, 7.

\section{B149}

AO: - (ehem. Slg. Sabouroff)

H: Tanagra

M: Terrakotta

$\mathrm{UG} / \mathrm{EH}: 0,23 \mathrm{~m}$

Auf Felsen sitzende, in Chiton und Mantel gehüllte Frau. Kreuzt die Füße, die Linke ruht im Schoß, die rechte ist zur Brust erhoben, hinter ihr archaistisches Idol, vollständig erhalten.

Lit.: A. Furtwängler, Die Sammlung Sabouroff. Kunstdenkmäler aus Griechenland II (Berlin 1873-1878) Taf. 83.

\section{B150}

AO: Istanbul, Archäolog. Museum

Inv. 1273

H: Kyrenaika (Benghazi?)

M: Terrakotta

$\mathrm{UG} / \mathrm{EH}: 0,285 \mathrm{~m}$

Stehende, ganz in Chiton und Mantel gehüllte Frau, Mantel auch über den Kopf gezogen. Hat die Linke auf einen Silen? und die Rechte in die Hüfte gestützt, vollständig erhalten, eventuell Fälschung. 
Lit.: G. Mendel, Catalogue des figurines grecques de terre cuite (Istanbul 1908) 513 Nr. 3200 Taf. 5, 3.

\section{B151}

AO: - (ehem. Slg. Lecuyer)

$\mathrm{H}$ : Tanagra

M: Terrakotta

$\mathrm{UG} / \mathrm{EH}: 0,152 \mathrm{~m}$

Auf Felsen gelagerte Frau in Chiton und einem Mantel, der nur die Beine bedeckt, überkreuzt mit dem rechten Bein das linke, hat den rechten Ellenbogen auf den rechten Oberschenkel gestützt, der auf dem Felsen ruhende linke Arm berührt eine hinter ihr stehende Priaposherme, vollständig erhalten.

Lit.: A. Cartault, Femme assise auprès d'un Priape. Silène au Bélier, in: F. Lenormant u. a., Collection Camille Lecuyer. Terres cuites antiques trouvées en Grèce et en Asie Mineure II (Paris 1885) Taf. P3.

\section{B152} Taf. 48, 1

AO: Berlin, Staatliche Museen Inv. 1982.11

H: Tanagra

M: Terrakotta

$\mathrm{UG} / \mathrm{EH}: 0,251 \mathrm{~m}$

Dat.: 3. Jh. v. Chr.

Stehende Frau in Chiton und Mantel, überkreuzt mit dem linken Bein das rechte, stützt sich mit dem linken Arm auf bärtige Herme, der rechte war ausgestreckt und ist abgebrochen.

Lit.: W. D. Heilmeyer, Antikenmuseum Berlin. Die ausgestellten Werke (Berlin 1988) 227 Nr. 6.

\section{B153}

AO: München, Staatliche

Antikenslg.?

$\mathrm{H}$ : Griechenland

M: Terrakotta

$\mathrm{UG} / \mathrm{EH}: 0,147 \mathrm{~m}$

Ganz in ihren Mantel gehüllte Frau, dieser auch über den Kopf gezogen, überkreuzt mit dem rechten Bein das linke, mit dem rechten Ellenbogen auf eine Herme gestützt, der Arm ist quer vor der Brust entlang geführt, der linke ruht auf dem Rücken, vollständig erhalten.

Lit.: J. Sieveking, Die Terrakotten der Sammlung Loeb I (München 1916) 38 Taf. 57, 2.

\section{B154}

AO: Rom, Orto Botanico

M: Terrakotta

$\mathrm{UG} / \mathrm{EH}: 0,17 \mathrm{~m}$

Stehende, mit ungegürtetem Gewand bekleidete Frau, überkreuzt mit dem linken Bein das rechte, stützt sich mit dem linken Arm auf unbärtige ithyphallische Herme, die Rechte greift das Gewand auf Hüfthöhe. Kopf abgebrochen.

Lit.: Winter 1903, 91, 1.

\section{B155}

AO: - (ehem. Slg. Sabouroff)

$\mathrm{H}$ : Tanagra

M: Terrakotta

$\mathrm{UG} / \mathrm{EH}: 0,21 \mathrm{~m}$

Auf Felsen sitzende Frau in Chiton und Mantel, beide Arme sind vor 
dem Bauch verschränkt, hinter ihr bärtige Herme, vollständig erhalten.

Lit.: A. Furtwängler, Die Sammlung Sabouroff. Kunstdenkmäler aus Griechenland II (Berlin 1873-1878) Taf. 84.

\section{B156}

AO: - (ehem. Rouen, Slg. Bellon)

$\mathrm{H}$ : Kleinasien (Kyme?)

M: Terrakotta

$\mathrm{UG} / \mathrm{EH}: 0,26 \mathrm{~m}$

Dat.: um 300 v. Chr.

Ähnlich Kat. B155, der Oberkörper jedoch aufgerichteter, die Rechte ruht im Schoß, die linke auf dem Felsen, vollständig erhalten.

Lit.: Winter 1903, 113, 4.

\section{B157}

AO: London, South-Kensington

Museum Inv. 619-84.

$\mathrm{H}$ : Tanagra?

M: Terrakotta

UG/EH: 0,133 m

Auf dem Boden hockende Frau im Chiton, mit dem linken Arm auf Felsen gestützt, der rechte ist vor die Brust erhoben. Auf dem Felsen jugendliche Herme, vollständig erhalten.

Lit.: Winter 1903, 115, 6.

\section{B158}

Taf. 48, 2

AO: St. Petersburg, Eremitage Inv. St 1791

H: Kertsch

M: rotfigurige Deckelschale

EH: kleinformatig
Dat.: 4. Jh. v. Chr.

Szenische Darstellung der Schmückung einer Braut. Eine Teilnehmerin steht mit rückwärts auf die Szene gewandtem Blick da und lehnt mit dem rechten Ellenbogen auf einer Herme.

Lit.: K. Schefold, Kertscher Vasen

(Berlin 1930) Taf. $13 \mathrm{f}$.

\section{B159}

Taf. 48, 3

H: Pompeji

M: Wandmalerei

Rechts eine stehende, ganz in ihren Mantel gehüllte, im Profil gesehene Frau, mit dem linken Arm auf eine vor ihr stehende bärtige Herme gelehnt. Hat den rechten Ellenbogen darauf und den Kopf in die Hand gestützt. In der Mitte eine weitere, im Format größere sitzende Frau im Hüftmantel mit ausgestreckten Beinen, die Hände erhoben, hält Taube. Links auf einer Basis stehende archaistische weibliche Statue von kleinerem Format. Vollständig erhalten. S. Reinach gibt weder Fundort noch Datierung an.

Lit.: S. Reinach, Répertoire des peintures grecques et romaines (Paris 1927) 265 Nr. 2. 


\section{Quellenregister}

Aischylos, Sept.

Sch. 304

140

Aisopos

80

$162 \mathrm{f}$.

Alkiphron

1 fr. 3

257

Apollodoros

$2,1,4$

$3,14,6$

195

Aristophanes, Ach.

Sch. 243

Arnobius

6, 11

204

Arrianos, per. p. E.

9

Athenaios

$\begin{array}{ll}3,78 \mathrm{c} & 283 \mathrm{f} . \\ 15,672 & 302 \mathrm{f} . \\ 15,676 \mathrm{a}-\mathrm{c} & 185\end{array}$

Athenagoras, Legatio

17,4

197. 204. 209.

232. 245.249

Cicero, nat. deor.

3, 59

67 Anm. 102

Cicero, Verr.

$2,4,4$

258

Clemens Alexandrinus, Protr.

$\begin{array}{ll}4,46,3 & 203 \\ 4,47,2 & 197.203 .212 \\ 4,47,5 & 208\end{array}$

Clemens Alexandrinus, Strom.

1, 163, $4 \mathrm{f}$.

221

$1,164,1 \mathrm{f}$.

$208 \mathrm{f}$.

$1,164,3$

245

Demosthenes, or.

Sch. 22, 13

$196 \mathrm{f}$.

Diodorus Siculus

$5,58,1$

$226 \mathrm{f}$.

Diogenes Laertios

1,89

228

Dion Chrysostomos

31, 121

298 Anm. 912

Dionysios Halicanasseus, ant.

8, 56, 2-4

$191 \mathrm{f}$.

Georgios Kedrenos

1, 564, 7-10

227

Gregorius Magnus, epist.

9, 105

176 Anm. 533

11,13

176 Anm. 532

Etymologicum magnum

252, 11-25

298 Anm. 911

Euripides, Antiop.

fr. 203

Euripides, El.

1254-1257

196

Euripides, Phoen.

Sch. 651

$220 \mathrm{f}$.

Eusebios, Pr. Ev.

$3,8,1$

195. 203. 208.

$10,9,22$

226. 248

196 


\section{Harpokration}

nach Heliodor (FGrH III

B 373 F 2)

223

Herakleitos

(fr. 5 DK)

190

\section{Herodot}

$\begin{array}{ll}1,105 & 70 \\ 1,131 & 70 \\ 2,172 & 172 \mathrm{f} . \\ 2,182 & 229 \text { Anm. } 726 \\ 8,144 & 168 \text { Anm. 506 }\end{array}$

Hesiod, theog.

188-197

68

Hesychios

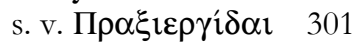

Homer, Il.

6, 301-305. 31

$187 \mathrm{f}$.

Hypereides

3, 35-37

206 Anm. 642

Iulianos, or.

2 p. $54 \mathrm{~B}$

258

Johannes Damascenus or.

1

178

Kallimachos, Aet.

112

Dieg. 112

131, 4-17

226

203

249

Kallimachos, h.

3, 237-239

230

Kallimachos, Iamb.

156

214

Kephalion

(FGrH II 442 F 4) 245 f.

Libanios, or.

11, $112 \mathrm{f}$.

87 Anm. 187
Macrobius, Sat.

$1,17,13$

$249 \mathrm{f}$.

\section{Martialis}

10, 89

209

Maximos Tyrios

8, 6

198. 209

NT Apostelgeschichte

19, 35

230

\section{Pausanias}

1, 2, 4

262

$1,2,5$

218

$1,3,3$

285

$1,3,5$

260

$1,8,4$

276

$1,14,7$

66. 71

$1,19,2$

72. 95.282.

1, 20, 3

217

$1,23,7$

239

$1,24,5-7$

197

1, 26, 6

195

1, 29, 2

1, 32, 2

$1,33,7$

$1,36,2$

$1,38,8$

$1,42,5$

$1,43,5$

1, 44, 4

$2,1,7$

2, 2, $6 \mathrm{f}$.

$2,2,8$

$2,7,5 \mathrm{f}$.

$2,13,5$

$2,17,4 \mathrm{f}$.

2, 22,7

2, 25,10

2, 31, 1

2, 32, 5

2, 35, 1

2, 36, 6

$2,37,1$

2, 38, 2 f.

3, 13, 6
299

201

264

277

$217 \mathrm{f}$.

$284 \mathrm{f}$.

282

86

277

283

277. 284

$282 \mathrm{f}$.

277

208

277

87 Anm. 187

276

249. 267

186

87 Anm. 187

$277 \mathrm{f}$.

300

284 


\begin{tabular}{|c|c|c|c|}
\hline $3,15,7$ & $222 \mathrm{f}$. & $9,38,1$ & $254 \mathrm{f}$. \\
\hline $3,15,10 \mathrm{f}$. & $275 \mathrm{f}$. & $9,39,3 \mathrm{f}$ & $255 \mathrm{f}$. \\
\hline $3,16,1$ & 206 Anm. 642 & $9,40,3$ & 256 \\
\hline $3,16,7 \mathrm{f}$ & $238 \mathrm{f}$. & $10,4,9$ & 269 \\
\hline $3,16,10 \mathrm{f}$ & $297 \mathrm{f}$. & $10,8,6 \mathrm{f}$ & $276 \mathrm{f}$ \\
\hline $3,17,5$ & 275 & $10,19,3$ & 87 Anm. 187 \\
\hline $3,20,3$ & 276 & $10,24,4 \mathrm{f}$. & 246 \\
\hline $3,20,7$ & 189 & $10,35,10$ & 269 \\
\hline $3,26,5$ & 276 & & \\
\hline $4,31,10$ & 242 & \multicolumn{2}{|l|}{ Philochoros } \\
\hline $4,34,6$ & 68 & \multicolumn{2}{|c|}{ (FGrH III B 328 F 7) 245} \\
\hline $5,10,2$ & 213 & \multirow{2}{*}{\multicolumn{2}{|c|}{ Philon, Legatio ad Gaium }} \\
\hline $5,11,1 \mathrm{f}$ & 213 & & \\
\hline $5,11,9$ & $213 \mathrm{f}$. & \multirow[t]{2}{*}{95} & 249 \\
\hline $5,14,5$ & $299 \mathrm{f}$. & & \\
\hline $5,16,1$ & 212 & \multicolumn{2}{|c|}{ Philostratos, Ap. } \\
\hline $5,17,1$ & 212 & \multirow[t]{2}{*}{3,14} & 195. 248 \\
\hline \multirow[t]{2}{*}{$5,26,6$} & 87. Anm. 187ロ & & \\
\hline & 223 & \multicolumn{2}{|l|}{ Phoronis } \\
\hline $6,13,7$ & 268 & \multirow[t]{2}{*}{ fr. 4} & $208 \mathrm{f}$. \\
\hline $6,25,1$ & $65-67$ & & \\
\hline \multirow[t]{2}{*}{$7,2,6 \mathrm{f}$. } & 230 f. 291 & \multicolumn{2}{|l|}{ Photios } \\
\hline & Anm. 882 & \multicolumn{2}{|c|}{ 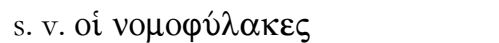 } \\
\hline $7,4,4$ & $202 \mathrm{f}$. & \multirow[t]{2}{*}{ tíves } & 301 \\
\hline Sch. $7,4,4$ & 203 & & \\
\hline $7,18,8-10$ & $265 \mathrm{f}$. & \multicolumn{2}{|l|}{ Pindar, $\mathbf{P}$. } \\
\hline $7,20,7$ f. & 189 & \multirow[t]{2}{*}{$5,39-42$} & 245 \\
\hline $7,21,6$ & 283 & & \\
\hline $7,23,9$ & 269.276 & \multicolumn{2}{|l|}{ Platon, rep. } \\
\hline $7,26,7$ & 277 & \multirow[t]{2}{*}{$373 a$} & 160 \\
\hline $8,25,6 \mathrm{f}$ & 284 & & \\
\hline $8,32,2$ & 282 & \multicolumn{2}{|l|}{ Plinius, nat. } \\
\hline $8,37,12$ & 269 & $16,213 \mathrm{f}$ & $231 \mathrm{f}$. \\
\hline $8,42,4-7$ & 189. 295 & 34,49 & 268 \\
\hline $8,46,3$ & 208. 238 & 34,50 & 268 \\
\hline $8,53,6$ & 285 & 34,66 & 256 \\
\hline $9,2,7$ & 284. $287 \mathrm{f}$. & 36,17 & 260 \\
\hline $9,10,2$ & 87 Anm. 187 & 36,18 & $197 \mathrm{f}$. \\
\hline $9,12,4$ & 220 & 36,22 & $257 \mathrm{f}$ \\
\hline $9,16,3 \mathrm{f}$ & $281 \mathrm{f}$. & 36,90 & 206 Anm. 641 \\
\hline $9,17,3$ & 277 & & \\
\hline $9,19,6$ & 276 & \multicolumn{2}{|c|}{ Plutarchos, Alkibiades } \\
\hline $9,27,1-4$ & 257 & $34,1 \mathrm{f}$ & 300 \\
\hline $9,30,1$ & 278 & \multicolumn{2}{|c|}{ Plutarchos, Themistokles } \\
\hline $9,35,1$ & 255 & 10,4 & $195 \mathrm{f}$. \\
\hline $9,35,3$ & 249 & 15,1 & 261 \\
\hline $9,35,6$ & 264 & & \\
\hline
\end{tabular}


Plutarchos, mor.

$142 d$

$381 \mathrm{e}$

1136 a

Plutarchos, Daed.

fr. 158

195. 203. 208.

226. 248

Pollux

1, 35

262

Porphyrios, Abst.

2, 18

\section{Strabon}

$4,1,4$

$8,3,30$

$8,6,10$

$9,2,25$

$9,2,40$

$13,1,48$

87 Anm. 187

214

209

258

255

67

Suda

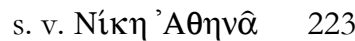

Tacitus, ann.

2, 2f.

71

Tertullianus, de corona

7

Tertullianus, apol.

16, $6 \mathrm{f}$.

197

Vitruvius

2, 9,13

231

Xenophon, an.

5, 3, 6-13

87. Anm. $\square 87$ 231.

Xenophon, hell.

1, 4, 12 f.

300
IG I I $^{386 / 7}$

235

IG $\mathrm{I}^{3}$ 64A

IG I ${ }^{3} 474$

IG II 403

IG II ${ }^{2} 1006$

IG II ${ }^{2} 1092$

IG II ${ }^{2} 1424$

IG II $^{2} 1514$

IG II ${ }^{2} 1515$

IG II ${ }^{2} 1516$

IG II ${ }^{2} 1517$ B

IG II $^{2} 1522$

IG II 1523

IG II $^{2} 1524$

IG II $^{2} 4771$

IG II ${ }^{2} 5044$

IG IV 1580

IG XII 9, 1189

IvE I 27

Schatzinschrift Samos

Lindische

Tempelchronik

Inschrift Messene
222

196

$223 \mathrm{f}$.

262

262

196

$235 \mathrm{f}$.

$236 \mathrm{f}$.

237

237

$237 \mathrm{f}$.

238

238

262

262

$252 \mathrm{f}$.

270

$304 \mathrm{f}$.

204

227

$242 \mathrm{f}$. 


\section{Verzeichnis der verwendeten Übersetzungen}

\author{
Aischylos, Sept. \\ Aisopos \\ Athenaios
}

Cicero

Clemens Alexandrinus, Protr.

Clemens Alexandrinus, Strom.

Diodorus

Diogenes Laertios

Dion Chrysostomos

Euripides

Gregorius Magnus, epist. Apostelgeschichte

Herakleitos

Herodot

Hesiod

Homer

Johannes Damascenus, or. Kallimachos

Libanios

Martialis

Pausanias

Philostratos
Oenbrink 1997, 346.

A. Hausrath, Aesopische Fabeln (München 1944).

C. Friedrich - Th. Nothers, Athenaios. Das Gelehrtenmahl (Stuttgart 1998 - 2001).

U. Treu - K. Treu, Athenaios von Naukratis. Das

Gelehrtenmahl (Leipzig 1985).

M. Fuhrmann, Marcus Tullius Cicero. Sämtliche Reden (Zürich 1970-1982).

Kyrieleis, Heraion 15.

C. A. Bernoulli - L. Früchtel (Hrsg.), Titus Flavius Klemens von Alexandria. Die Teppiche (Stromateis) (Basel 1936).

Th. Nothers - P. Wirth - O. Veh, Diodoros Griechische Weltgeschichte (Stuttgart 1992/1993).

O. Apelt, Diogenes Laertius. Leben und Meinungen berühmter Philosophen (Leipzig 1921).

W. Elliger, Dion Chrysostomos. Sämtliche Reden (Zürich 1967).

G. A. Seeck, Euripides. Sämtliche Tragödien und Fragmente (Darmstadt 1972-1981).

Kollwitz 1957b, 109.

Einheitsübersetzung der Heiligen Schrift. Die Bibel. Psalmen und Neues Testament. Ökumenischer Text (Stuttgart 1987).

H. Diels, Herakleitos von Ephesos (Berlin 1901).

J. Feix, Herodot. Historien (München 1963).

W. Marg, Hesiod. Sämtliche Gedichte. Theogonie. Erga. Frauenkataloge (Zürich 1970).

J. H. Voß, Homer. Ilias - Odyssee (München 1971).

Kollwitz 1957a, 68.

M. Asper (Hrsg.), Kallimachos Werke (Darmstadt 2004).

E. Howald - E. Staiger, Die Dichtungen des Kallimachos (Zürich 1955).

G. Fatouros - T. Krischer, Libanios. Antiochikos (Or.

XI). Zur heidnischen Renaissance in der Spätantike

(Wien 1992).

R. Helm, Martial. Epigramme (Zürich 1957).

F. Eckstein - P. C. Bol, Pausanias. Reisen in Griechenland I-III (Düsseldorf 2001).

V. Mumprecht, Philostrat. Das Leben des Apollonius von Tyana (Zürich 1983). 
Pindar

Platon

Plinius maior

Plutarchos

Strabon

Tacitus

Tertullianus

Vitruvius

Xenophon

IvE I 27

IG IV 1580
O. Werner, Pindar. Siegesgesänge und Fragmente (München 1967).

W. F. Otto - E. Grassi - G. Plamböck (Hrsg.), Platon. Sämtliche Werke (Hamburg 1957-1959).

R. König, C. Plinius Secundus d. Ä. Naturkunde (Darmstadt 1973-1994).

K. Ziegler, Plutarch. Grosse Griechen und Römer (Zürich 1954-1965).

St. Radt, Strabons Geographika (Göttingen 2002-2006).

A. Schäfer, Publius Cornelius Tacitus. Sämtliche erhaltene Werke (Essen 2006).

K. A. H. Kellner, Tertullians apologetische, dogmatische und montanistische Schriften (Kempten 1915).

C. Fensterbusch, Vitruv. Zehn Bücher über Architektur (Darmstadt 1964).

W. Müri (Hrsg.), Xenophon. Anabasis. Der Zug der Zehntausend (Darmstadt 1990).

H. Wankel (Hrsg.), Die Inschriften von Ephesos Ia, Inschriften griechischer Städte aus Kleinasien 11, 1 (Bonn 1979).

Gruben 2001, 122. 


\section{Abbildungsverzeichnis}

Zu den im Katalog verzeichneten Werken siehe die dort angegebene Literatur.

Abb. $1 \quad$ Fuchs 1969 Abb. 234.

Abb. 2 Delivorrias 1984 Nr. 586.

Abb. 3 Froning 2005 Taf. 52.

Abb. 4 LIMC I (1981) 875 s. v. Apate 1 (G. G. Belloni).

Abb. 5 T. L. Shear, The Campaign of 1938, Hesperia 8, 1939 Abb. 37.

Abb. $6 \quad$ Anti 1927 Abb. 2.

Abb. 7 Dumoulin 1994 Abb. 16.

Abb. 8 Dumoulin 1994 Abb. 18.

Abb. $9 \quad$ B. Kapossy, Brunnenfiguren der hellenistischen und römischen Zeit (Zürich 1969) Abb. 4.

Abb. $10 \quad$ Anti 1927 Abb. 7.

Abb. 11 K. Nicolaou, Archaeological News from Cyprus, 1973, AJA 79, 1975, Taf. 30b.

Abb. 12 Delivorrias 1984 Nr. 176.

Abb. 13a-b P. C. Bol (Hrsg.), Die Geschichte der antiken Bildhauerkunst II. Klassische Plastik (Mainz 2004) Abb. 97 f.

Abb. 14 Romeo 1993 Abb. 8.

Abb. 15 Delivorrias 1984 Nr. 187.

Abb. 16 Foto D-DAI-ATH-NM 6033 (G. Hellner).

Abb. 17 Foto D-DAI-Rom-1981.3371 (Schwanke).

Abb. 18 Arachne Nr. 31878, Neg. Nr. FA1243-02_31878.

Abb. 19 EA 2009.

Abb. 20 Cain 1997, 37 f. mit Abb.

Abb. 21 K. Knoll (Hrsg.), Götter und Menschen. Antike Meisterwerke der Skulp-

Abb. 22 Delivorrias 1984 Nr. 369.

Abb. 23 Delivorrias 1984 Nr. 46.

Abb. 24 Brahms 1994 Abb. 1.

Abb. 25 M. Bergmann, Die Strahlen der Herrscher. Theomorphes Herrscherbild und politische Symbolik im Hellenismus und in der römischen Kaiserzeit (Mainz 1998) Taf. 8,1.

Abb. 26 Delivorrias 1984 Nr. 1452.

Abb. 27 Raab 1972 Taf. 1.

Abb. 28 Himmelmann-Wildschütz 1959 Abb. 15.

Abb. 29 Raab 1972 Taf. 3

Abb. $30 \quad$ Boardman 1987 Abb. 215.

Abb. $31 \quad$ Boardman 1987 Abb. 197.

Abb. $32 \quad$ Boardman 1987 Abb. 214.

Abb. $33 \quad$ Boardman 1987 Abb. 74.

Abb. $34 \quad$ Mallwitz 1972 Abb. 14. 
Abb. 35 A. Comella, I Rilievi votivi greci di periodo arcaico e classico. Diffusione, ideologia, committenza (Bari 2002) Abb. 26.

Abb. 36 Foto D-DAI-Rom-1981.3564 (Schwanke).

Abb. 37 Fuchs 1969 Abb. 418.

Abb. 38 Foto D-DAI-ATH-NM 5164 (E.-M. Czakó).

Abb. 39 Chr. Kardara, Problems of Hera's Cult-Images, AJA 64, 1960 Taf. 101, 30.

Abb. 40 Imhoof-Blumer - Gardner 1964 Taf. I Nr. 15.

Abb. 41 Imhoof-Blumer - Gardner 1964 Taf. CC Nr. 4.

Abb. 42

Abb. 43

E. Langlotz, Alkamenes-Probleme, 108. BWPr (Berlin 1952) Abb. 2.

Abb. 44

Bammer - Muss 1996 Abb. 84.

Abb. 45

Themelis 2003 Abb. 136.

Abb. 46

Themelis 2003 Abb. 60.

Abb. 47

Imhoof-Blumer - Gardner 1964 Taf. CC Nr. 14.

Abb. 48

Arachne Nr. 15894, Neg. Nr. Mal2238_15894 (B. Malter).

Abb. 49

F. Naumann, Die Ikonographie der Kybele in der Phrygischen und der griechischen Kunst (Tübingen 1983) Taf. 22, 1.

Abb. 50

C. Rolley, Sculptures Nouvelles a l'Agora de Thasos, BCH 88, 1964 Abb. 1. Imhoof-Blumer - Gardner 1964 Taf. Q Nr. 7. 
Tafeln 
Tafel 1
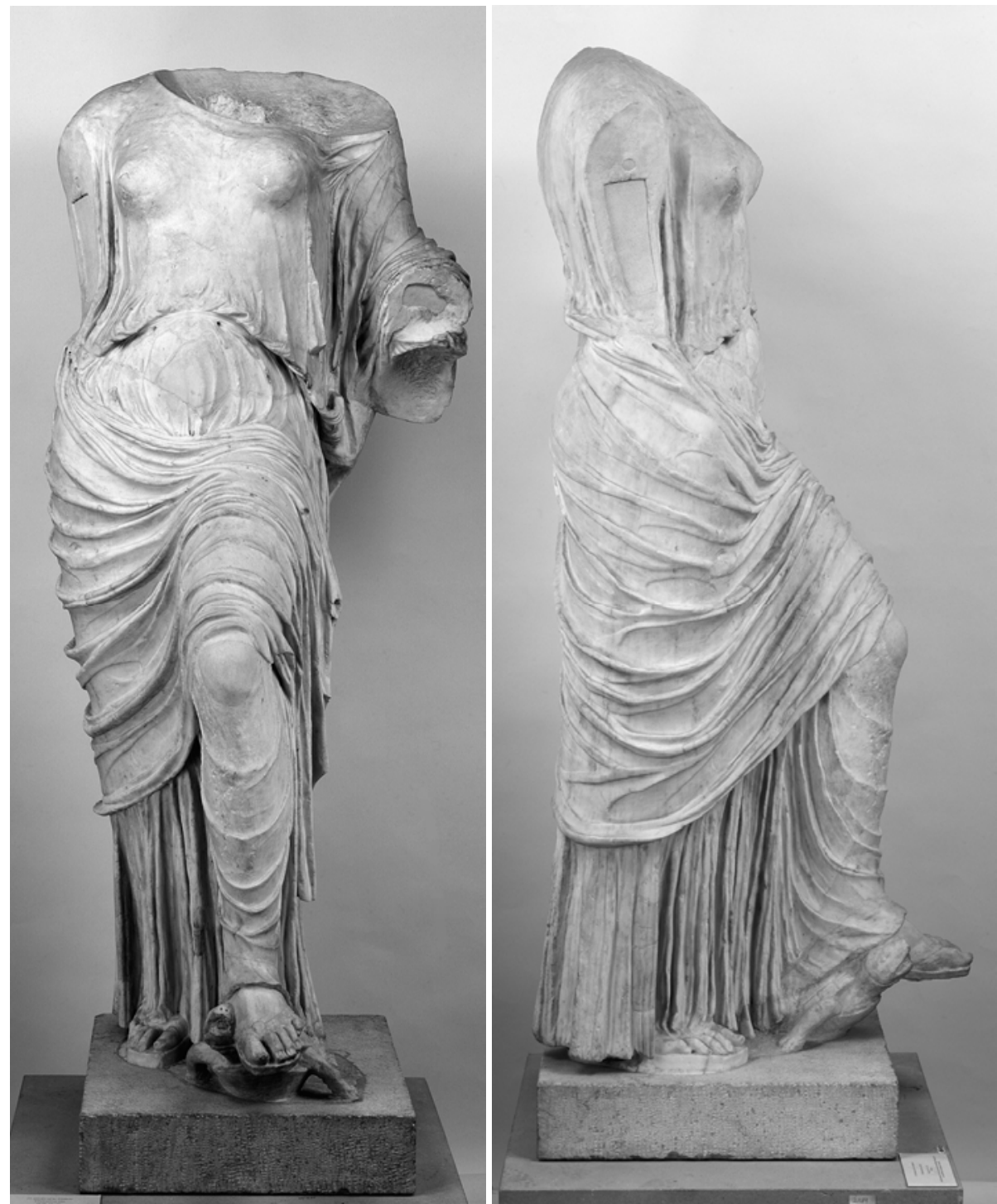

Kat. A1 Berlin, Staatliche Museen

Kat. A1 Berlin, Staatliche Museen 


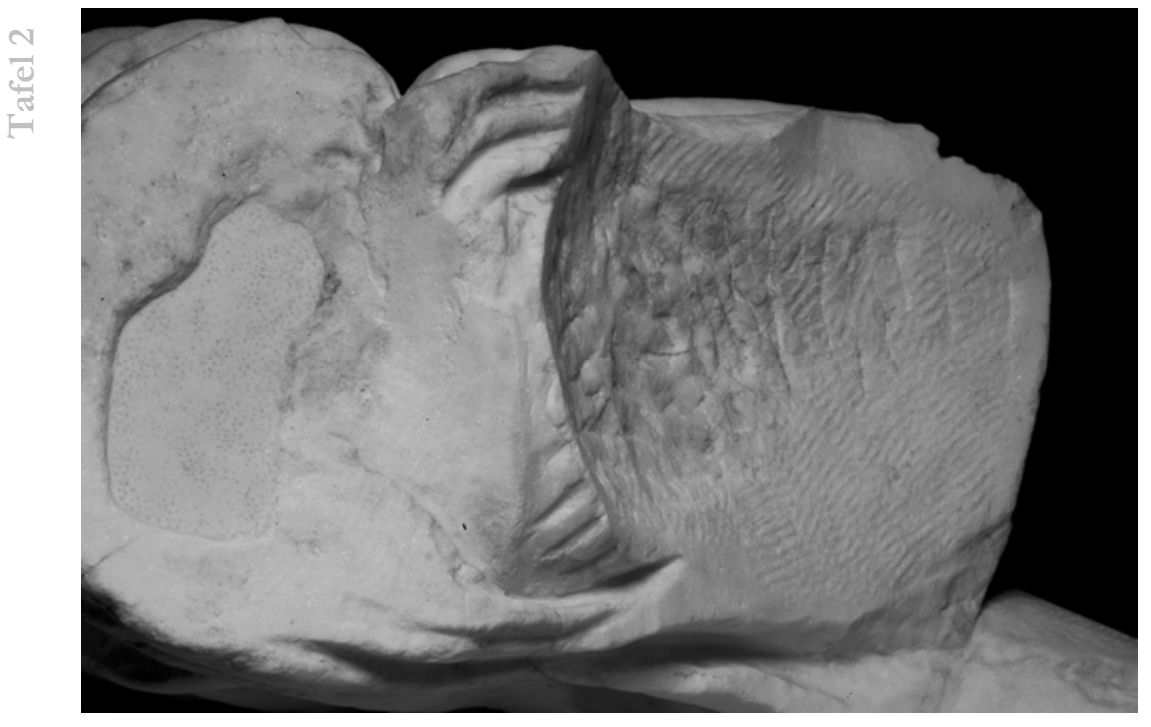

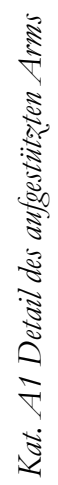

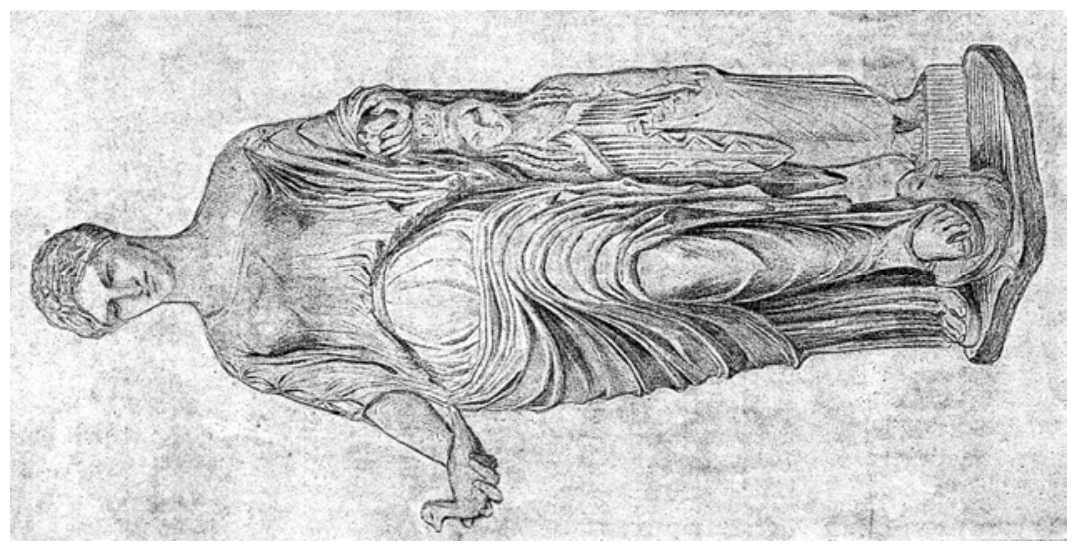

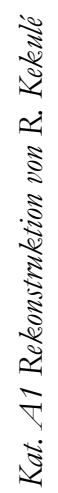

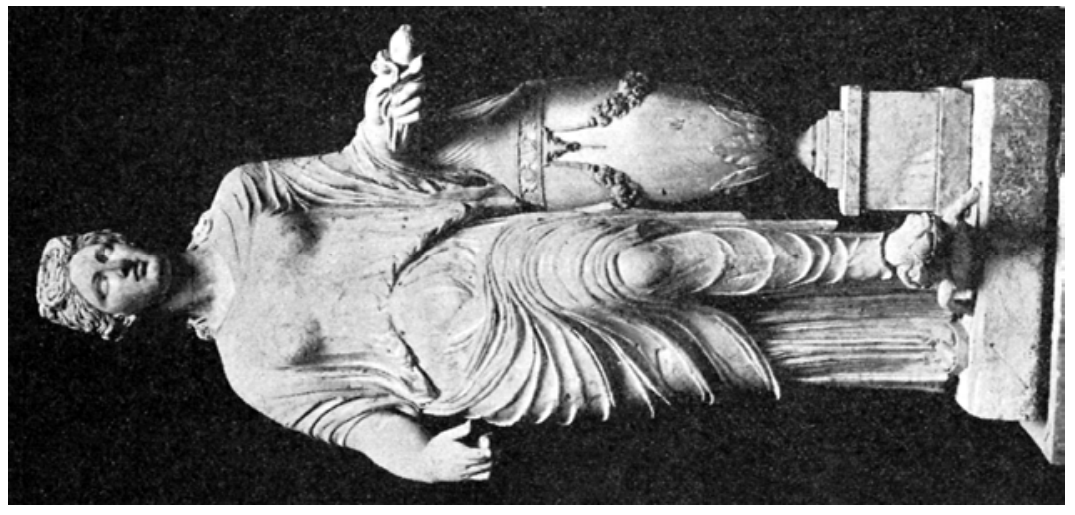

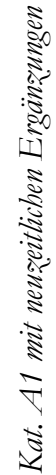




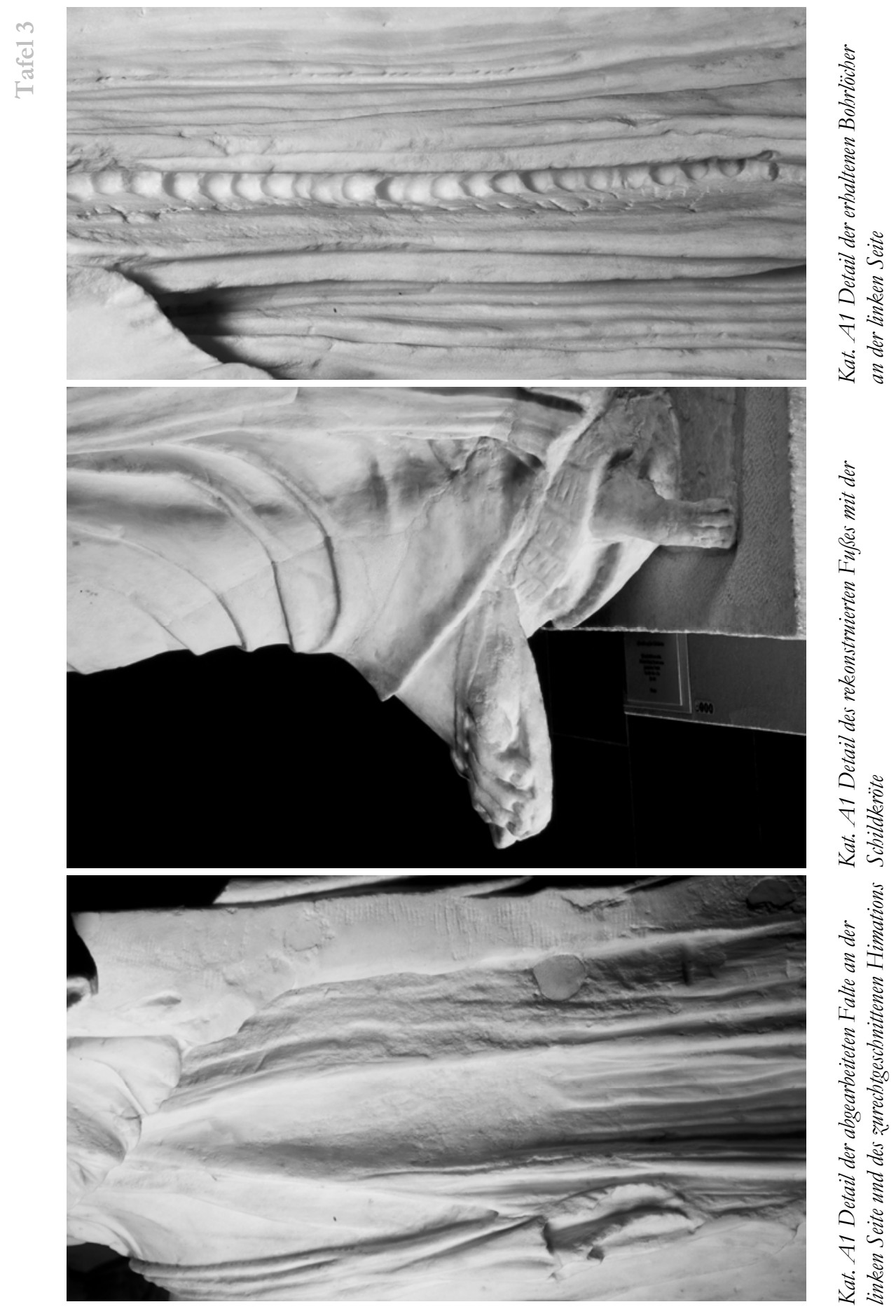




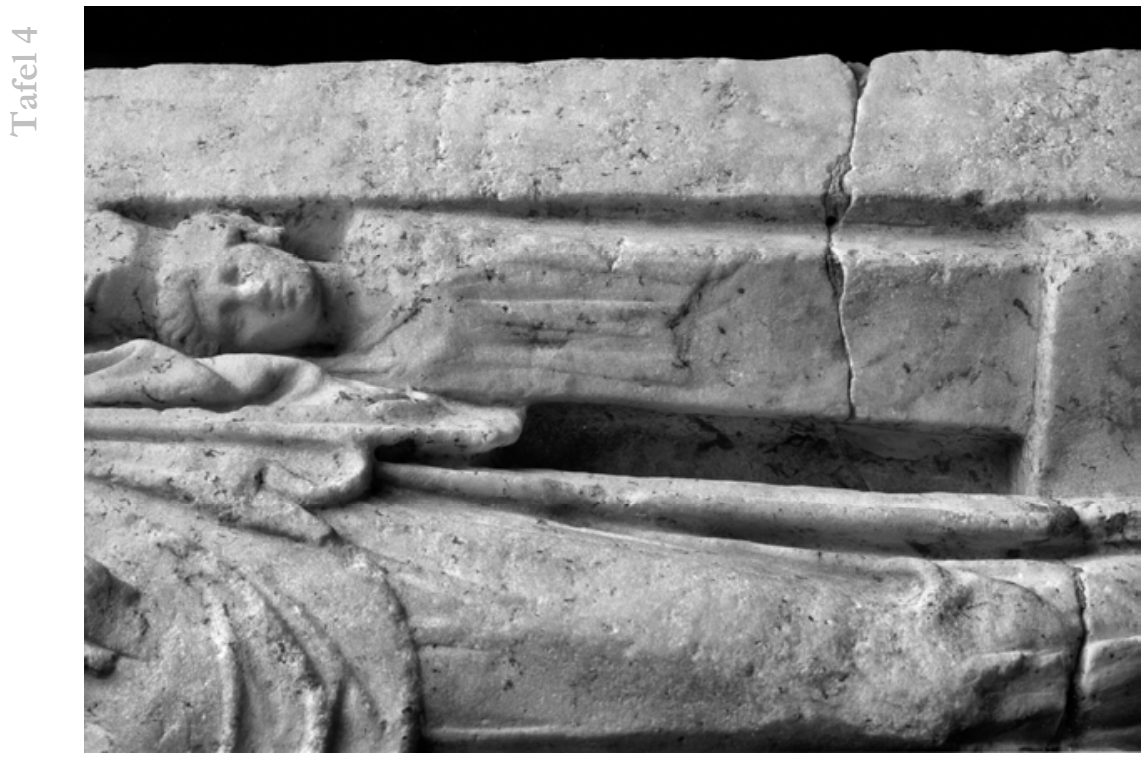

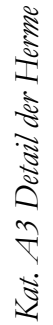

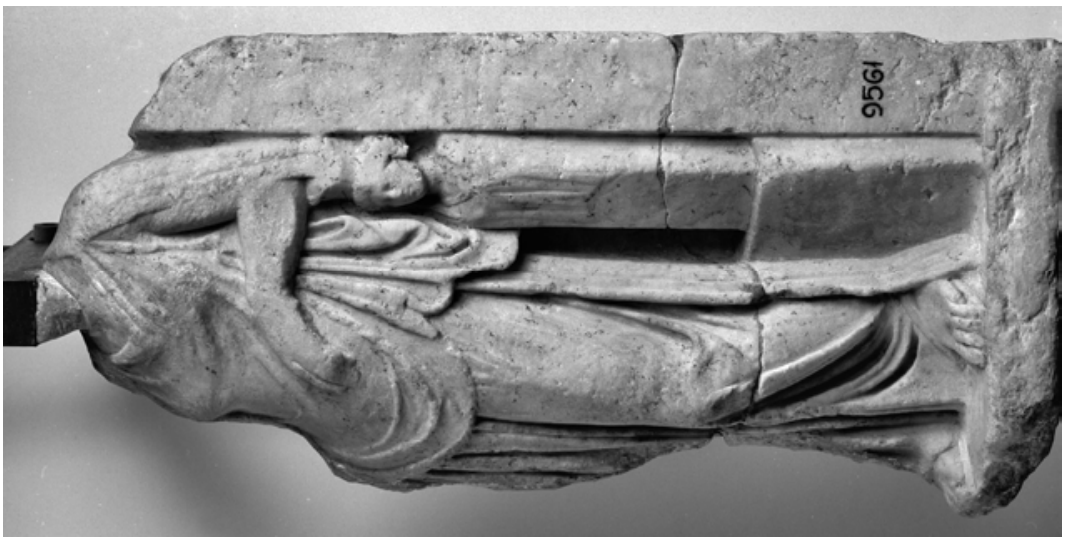

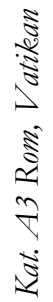

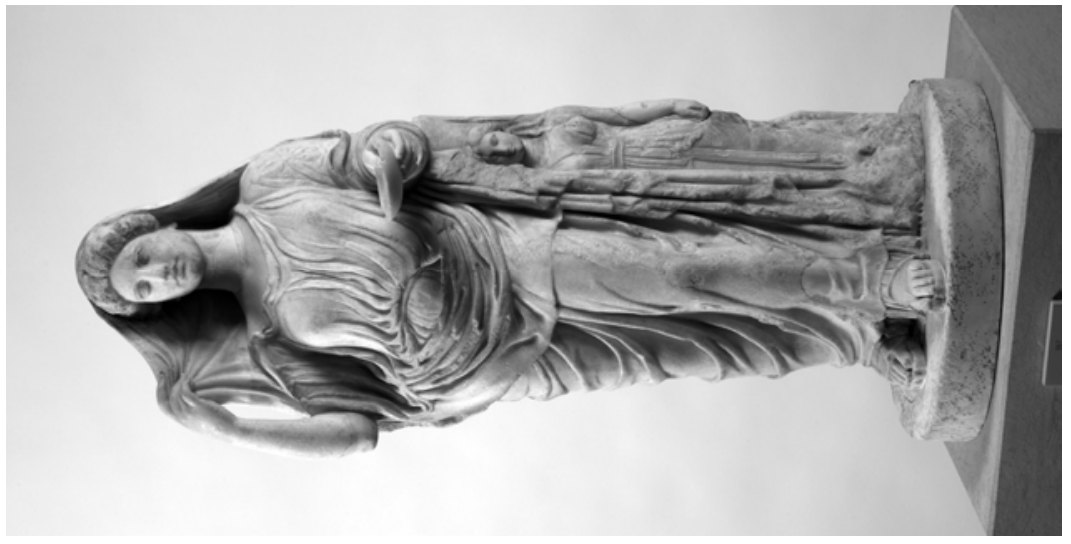

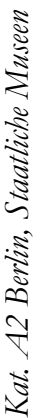


哭

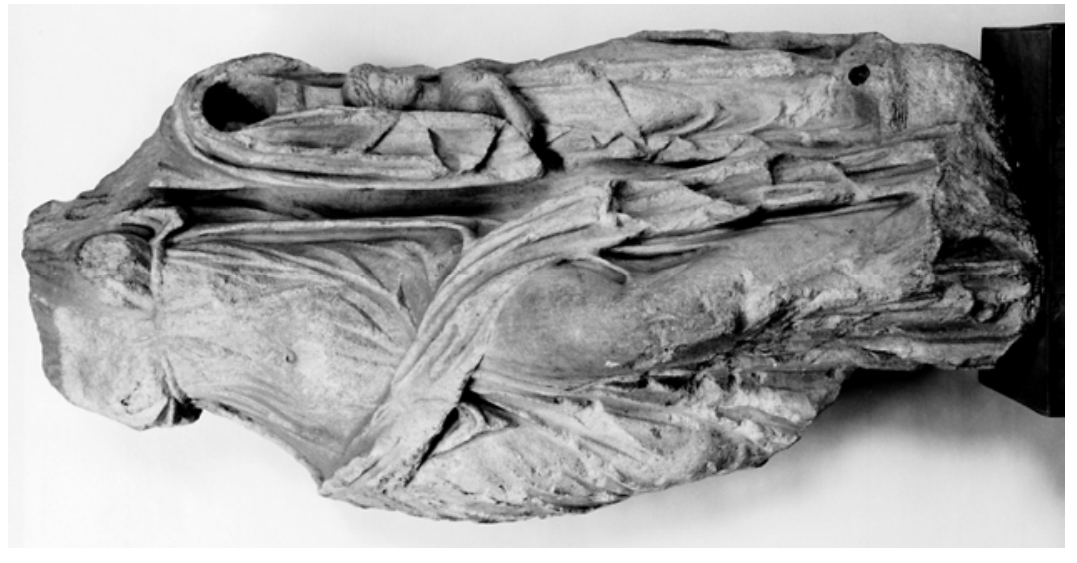

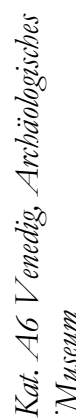

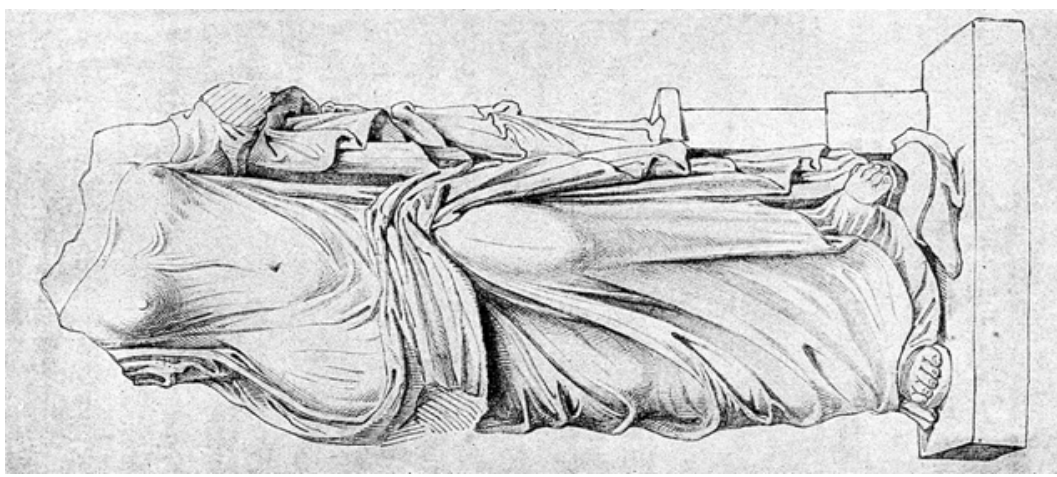

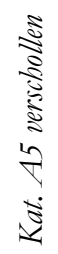

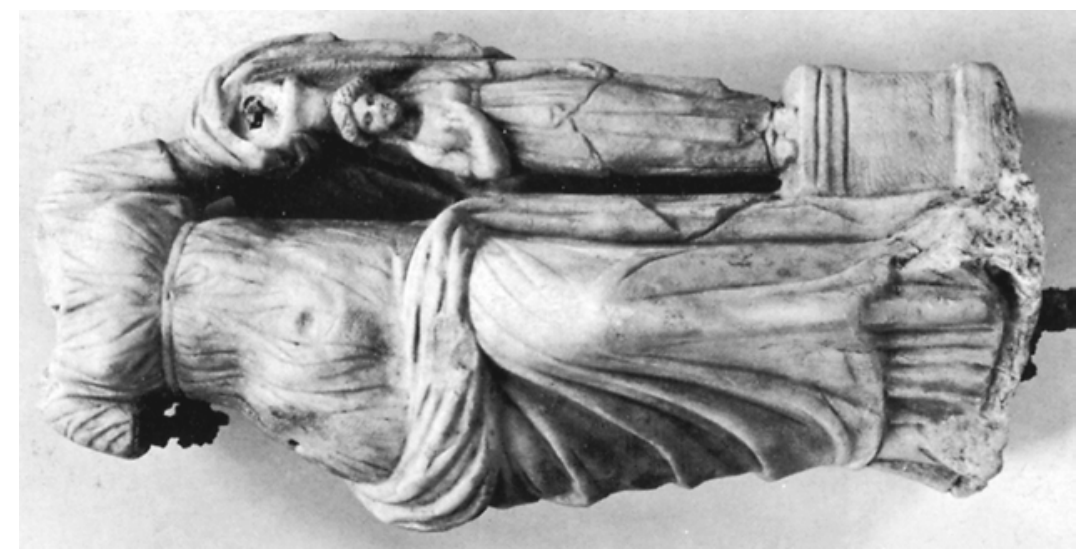

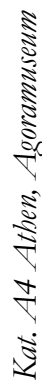



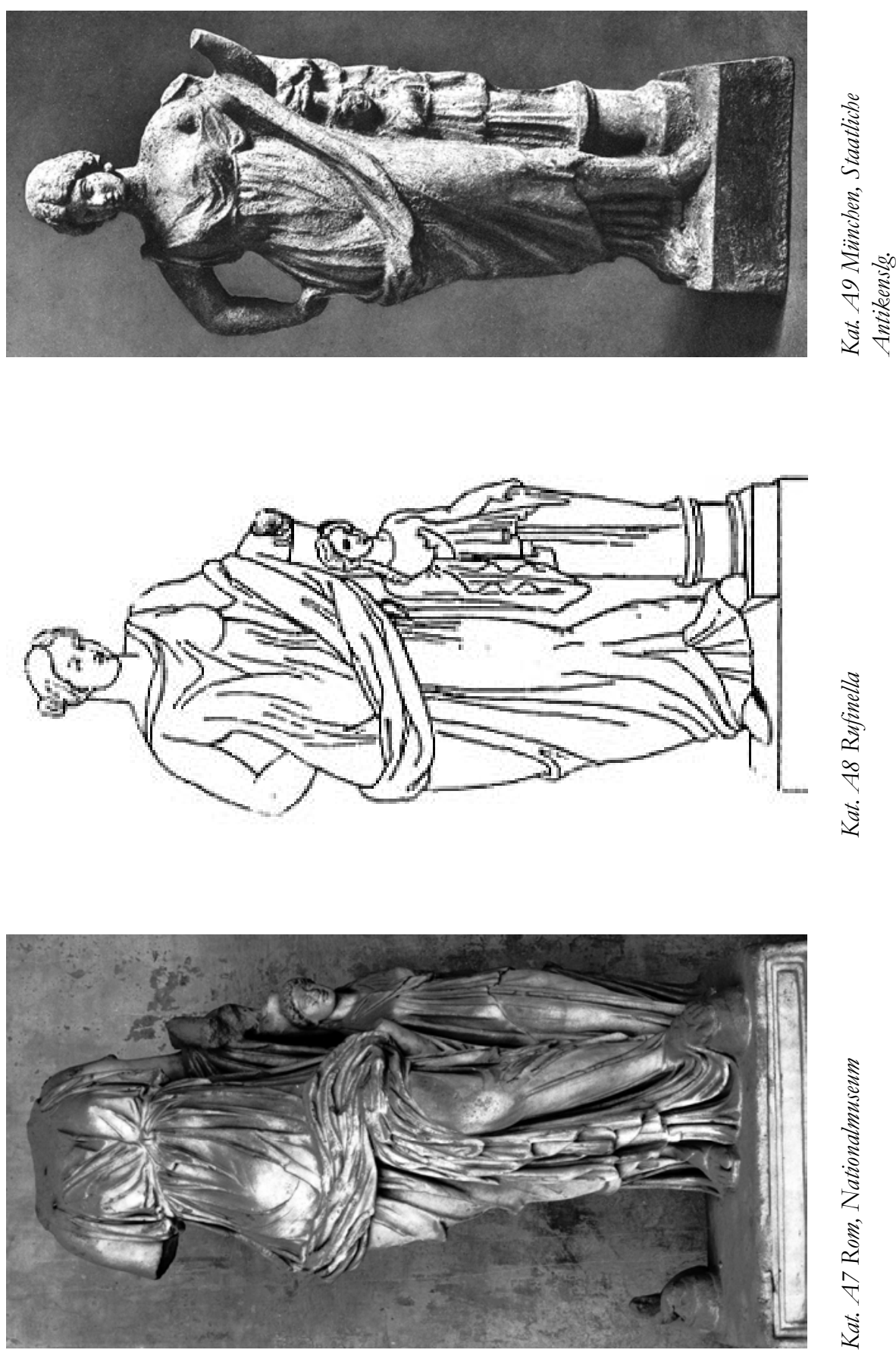

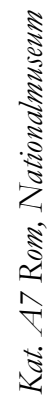




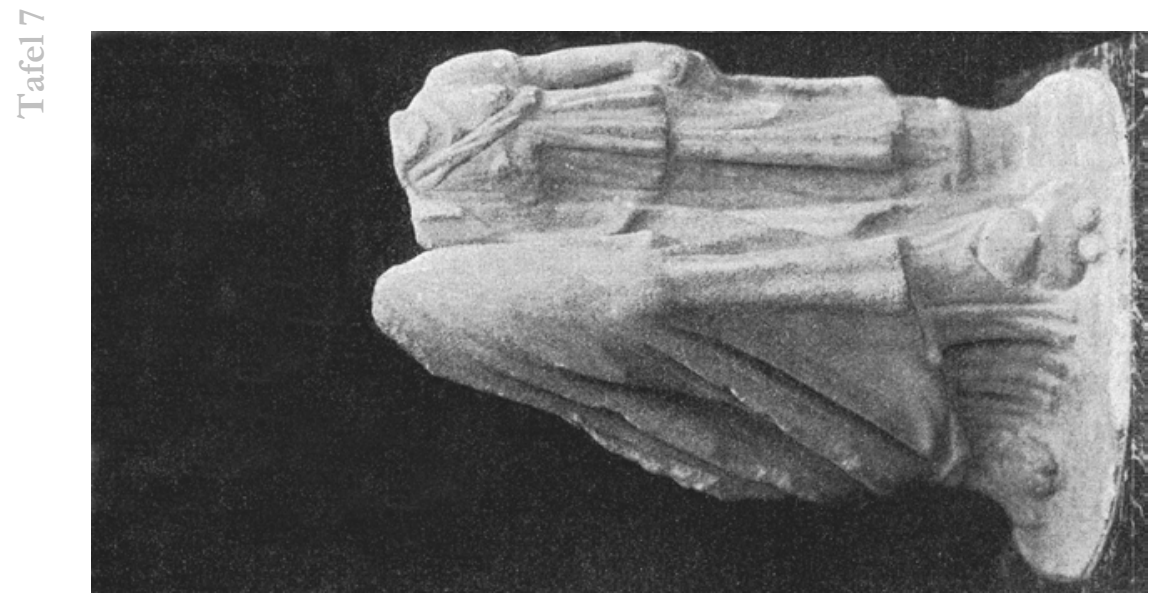

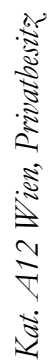

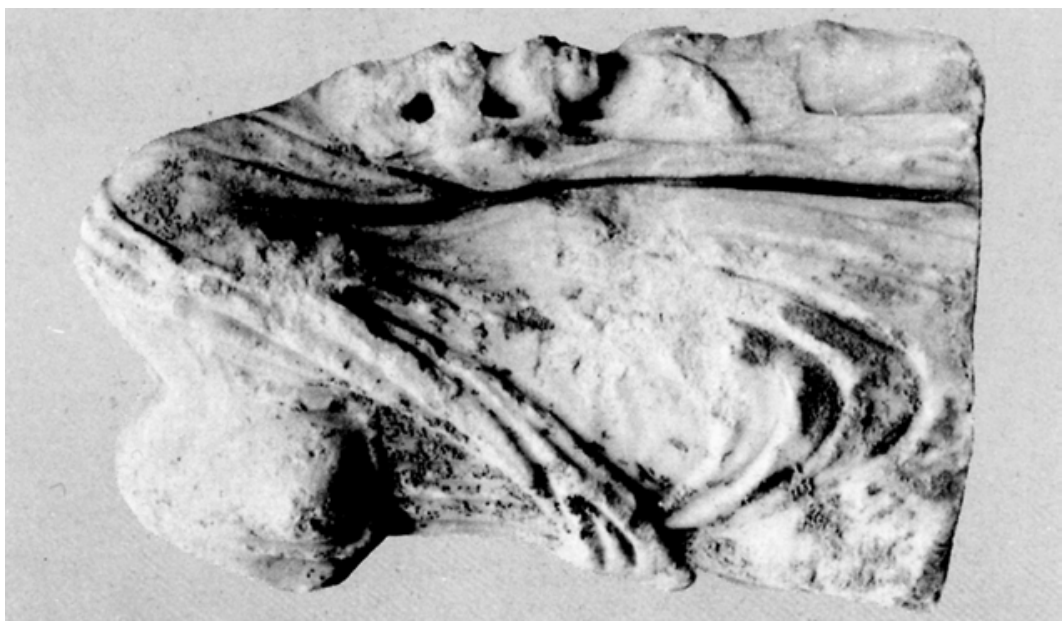

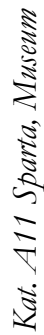

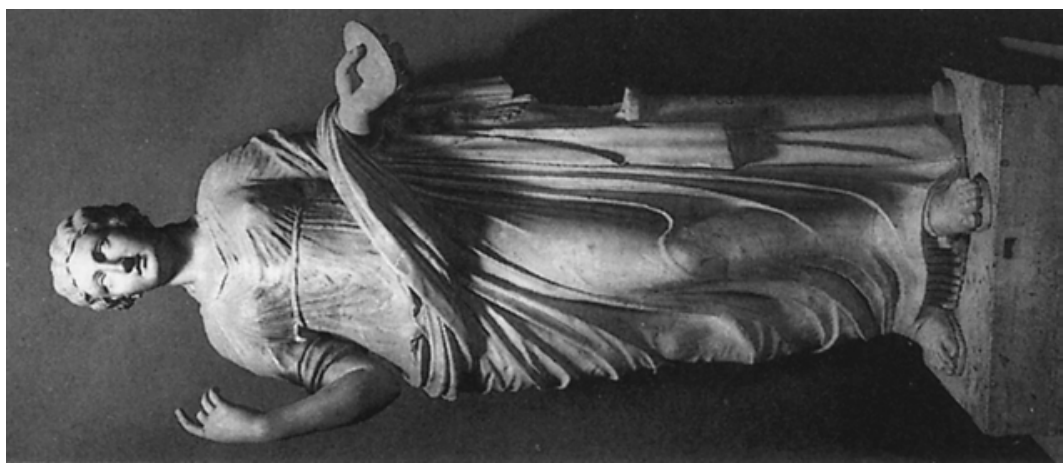

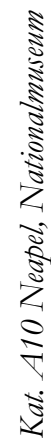


$\frac{\infty}{\pi}$
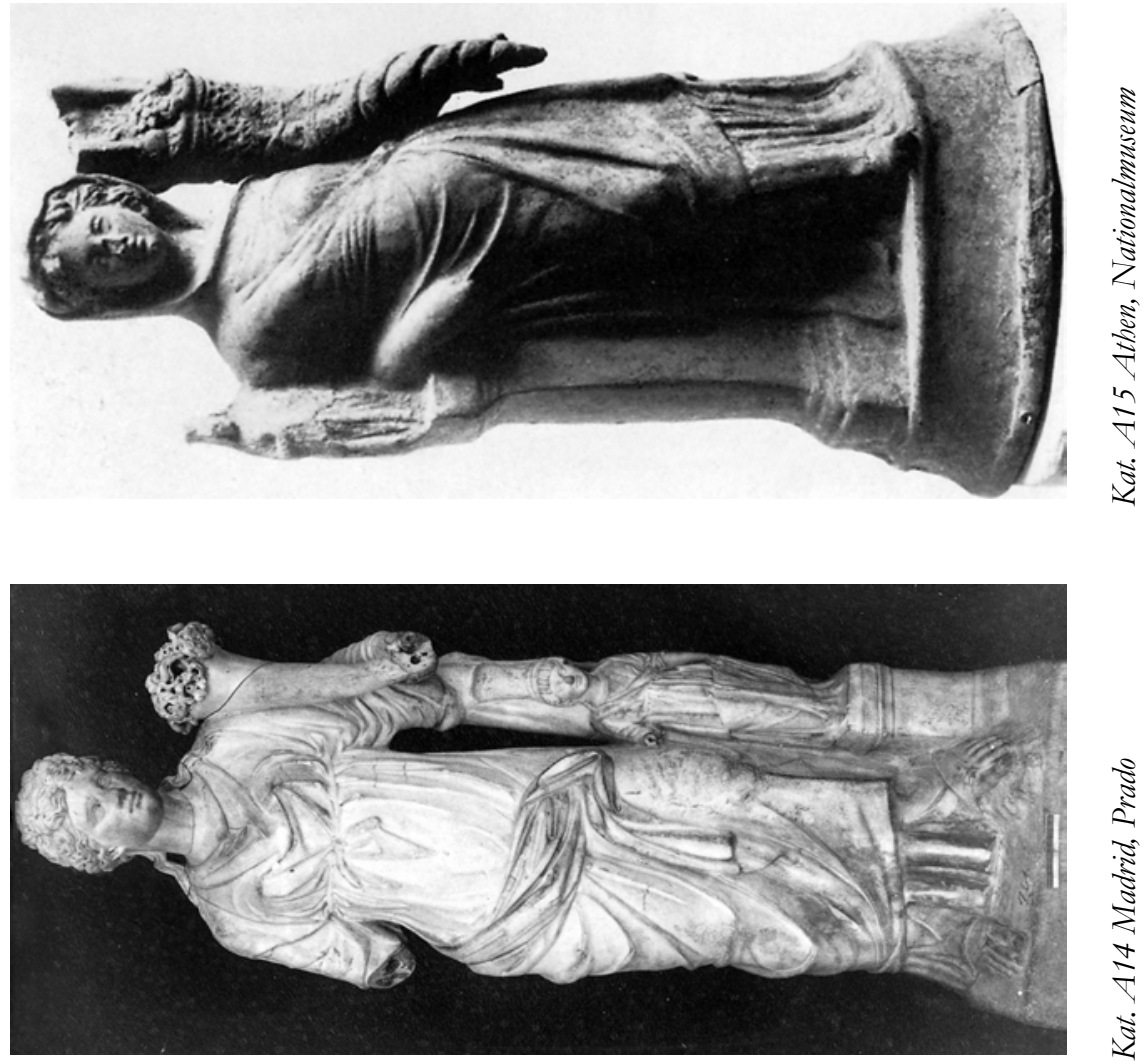

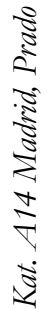

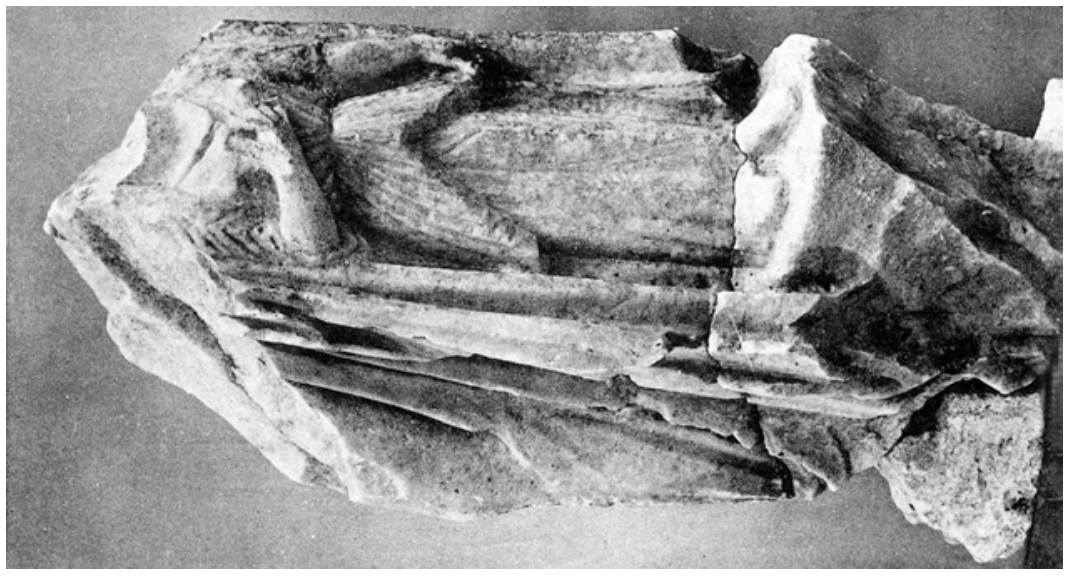

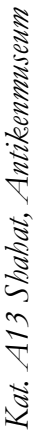




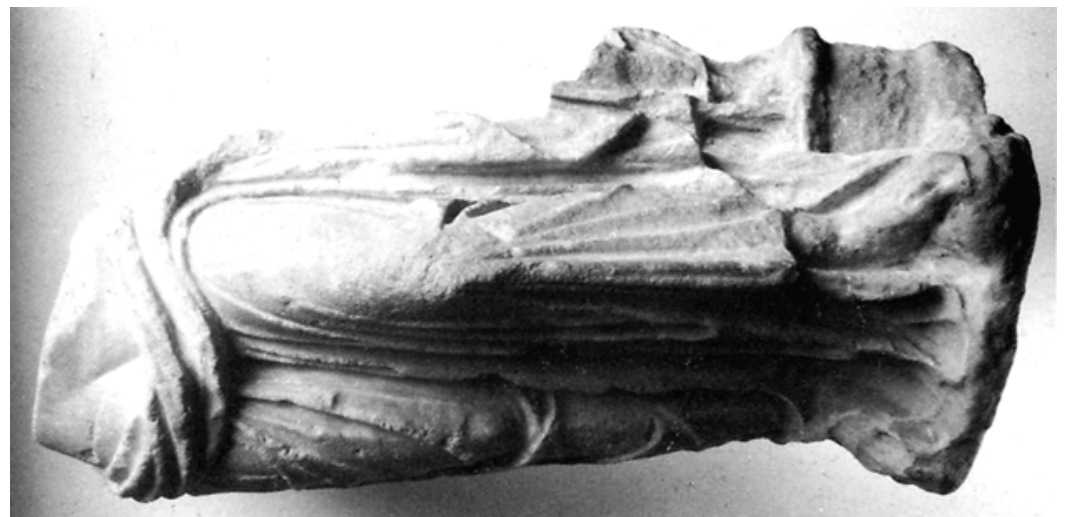

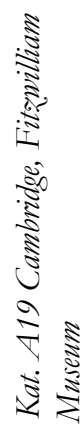

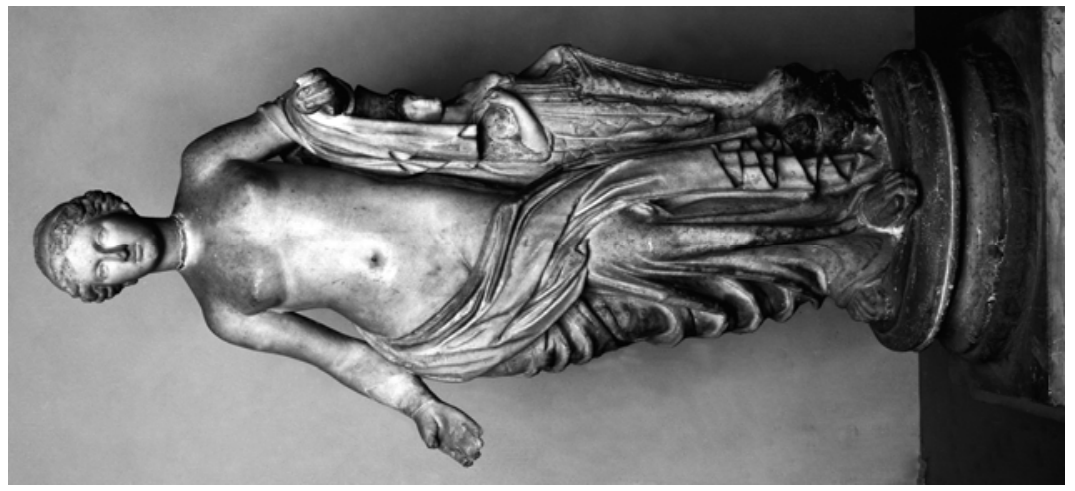

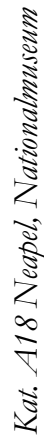

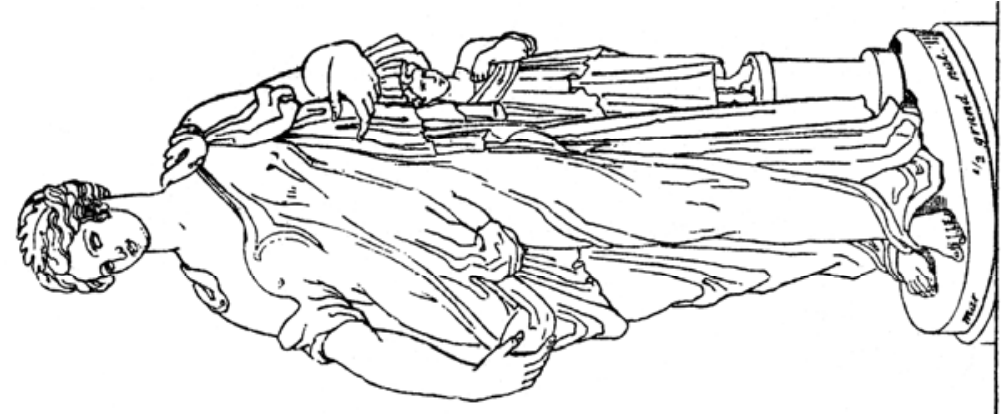

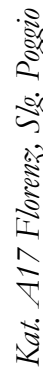

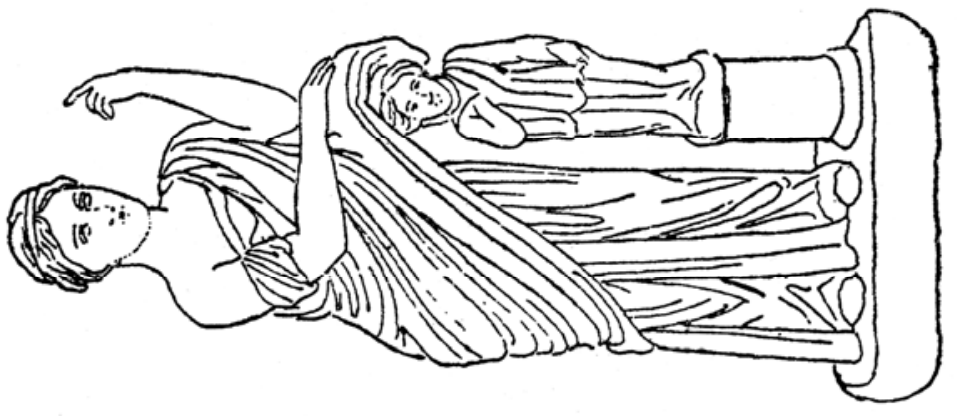

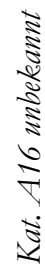




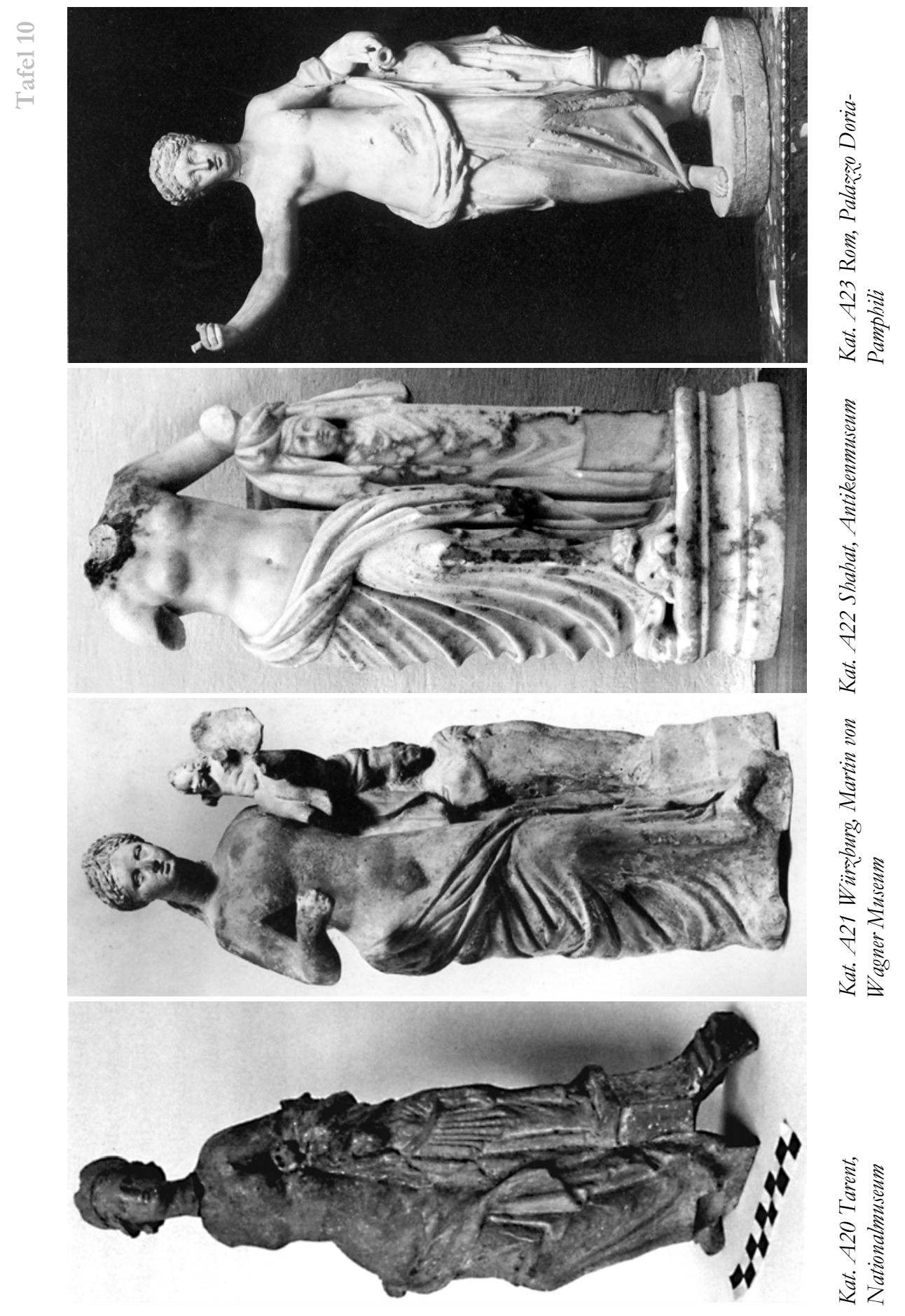




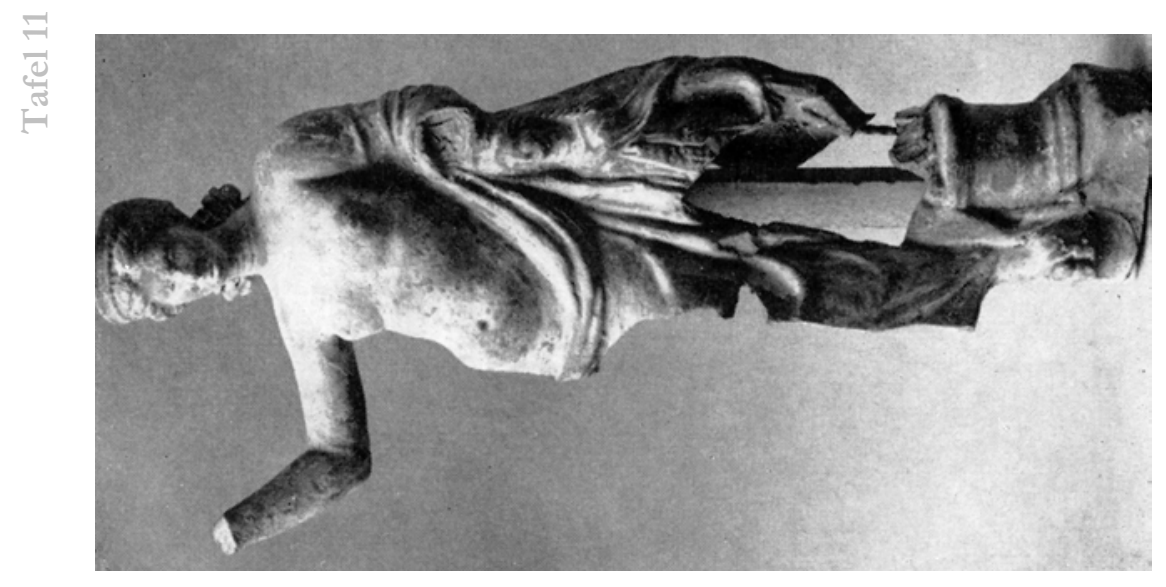

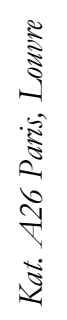

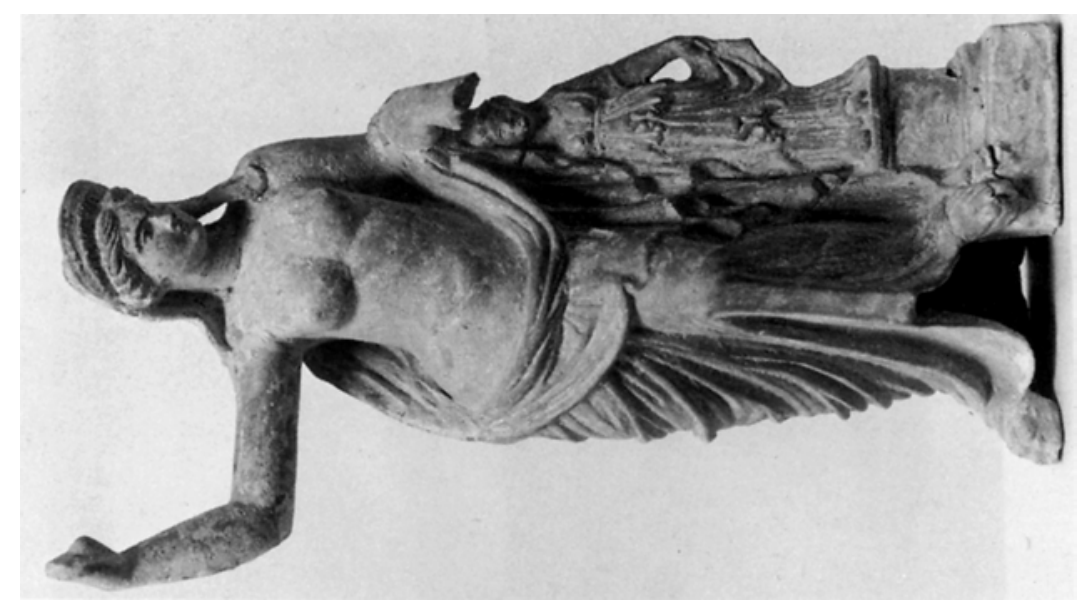

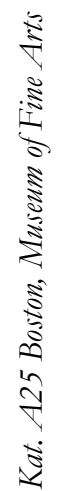

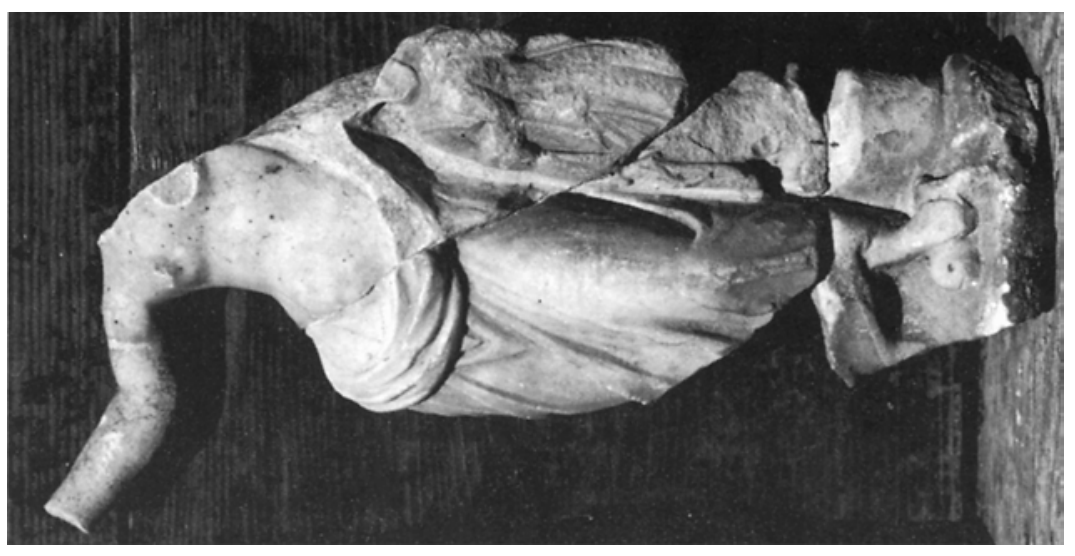

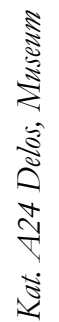




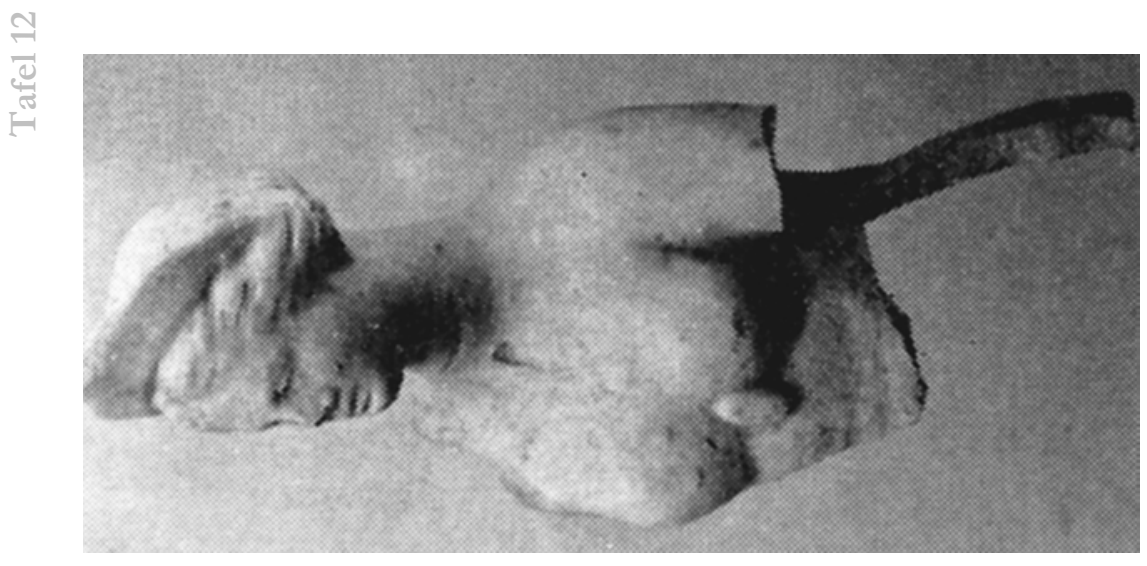

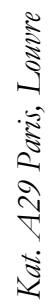
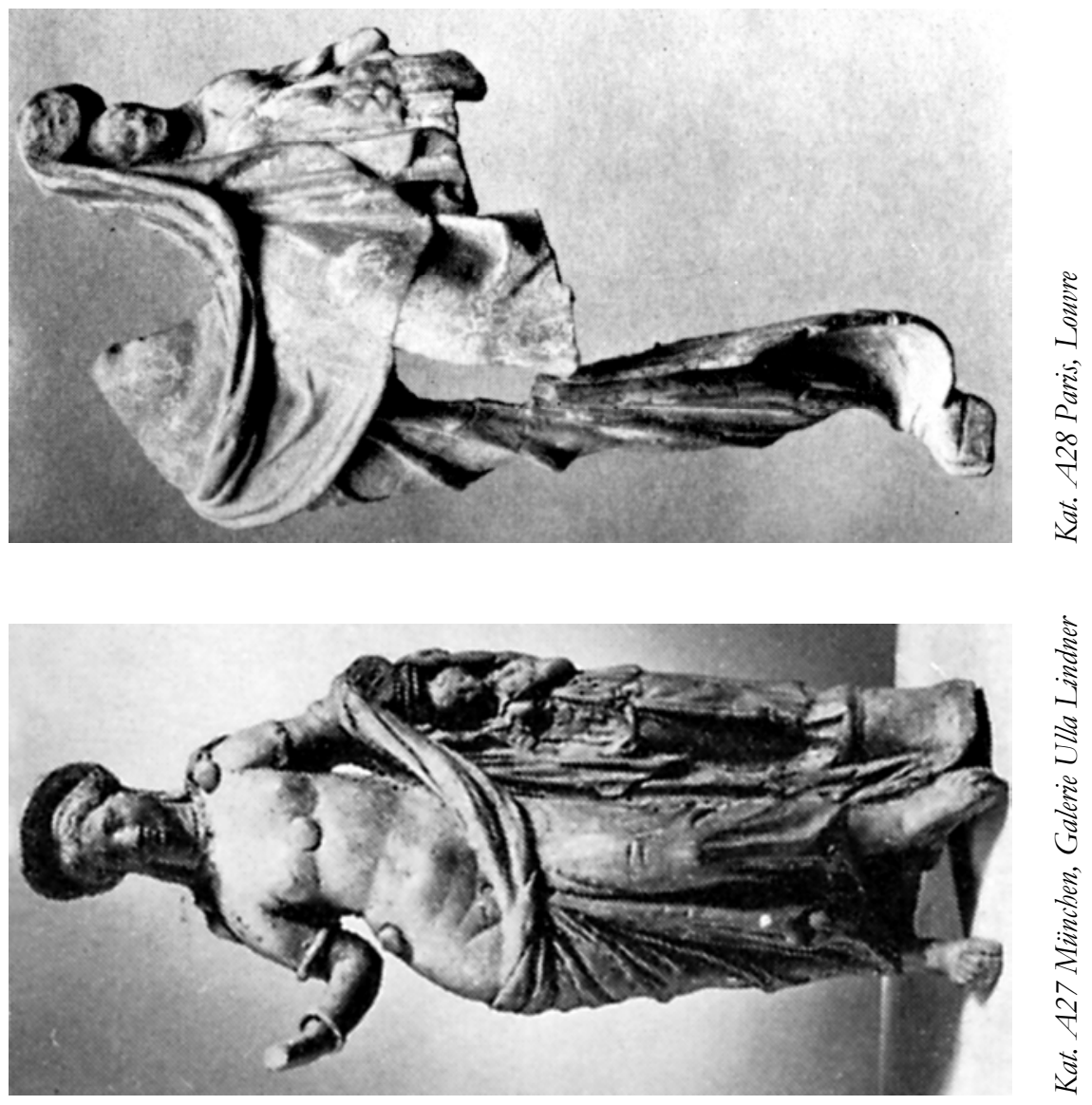


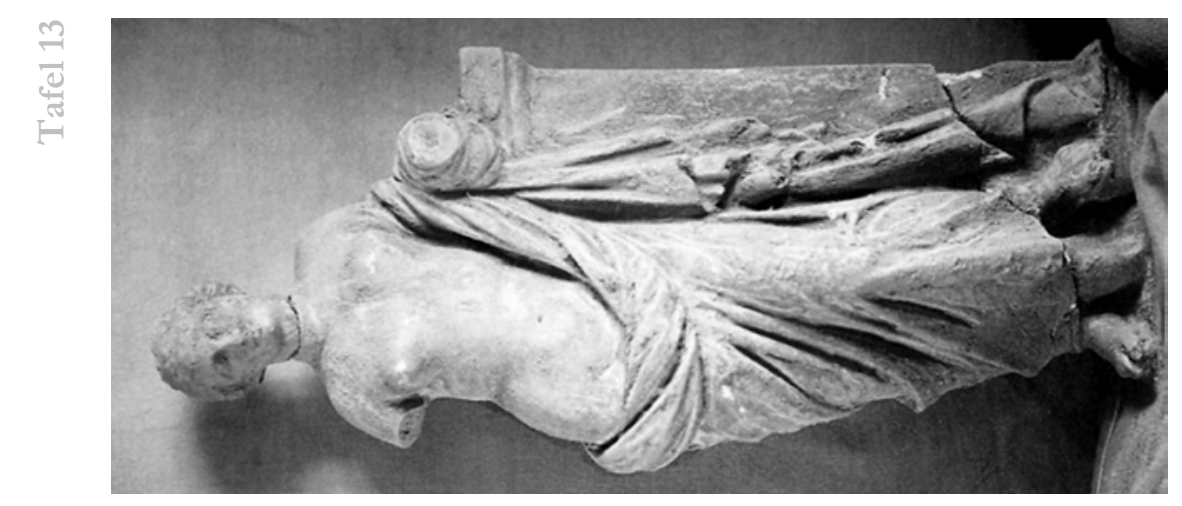

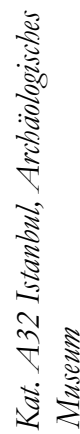

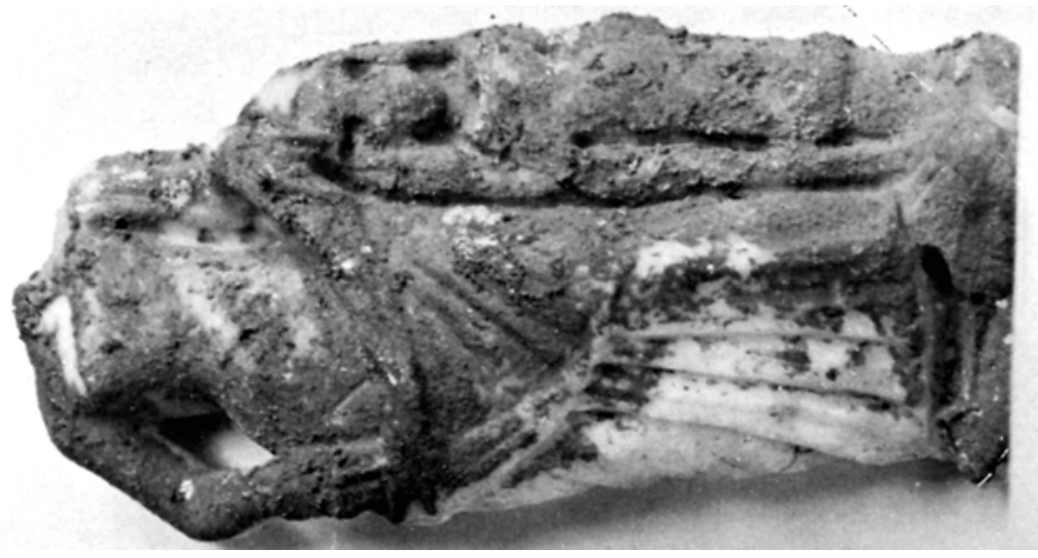

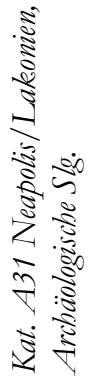

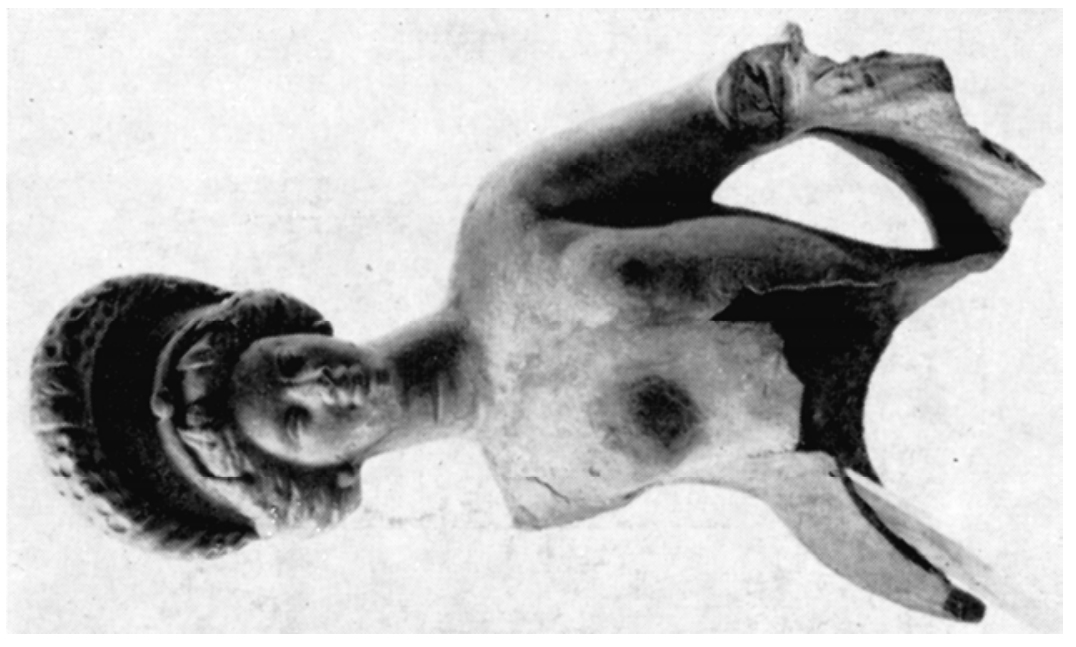

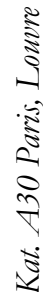




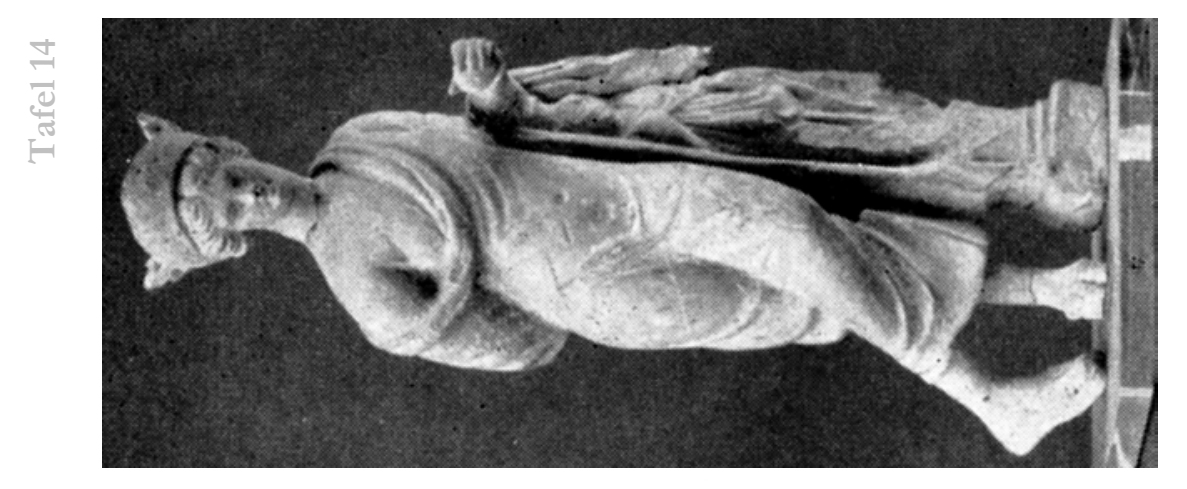

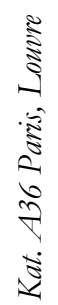
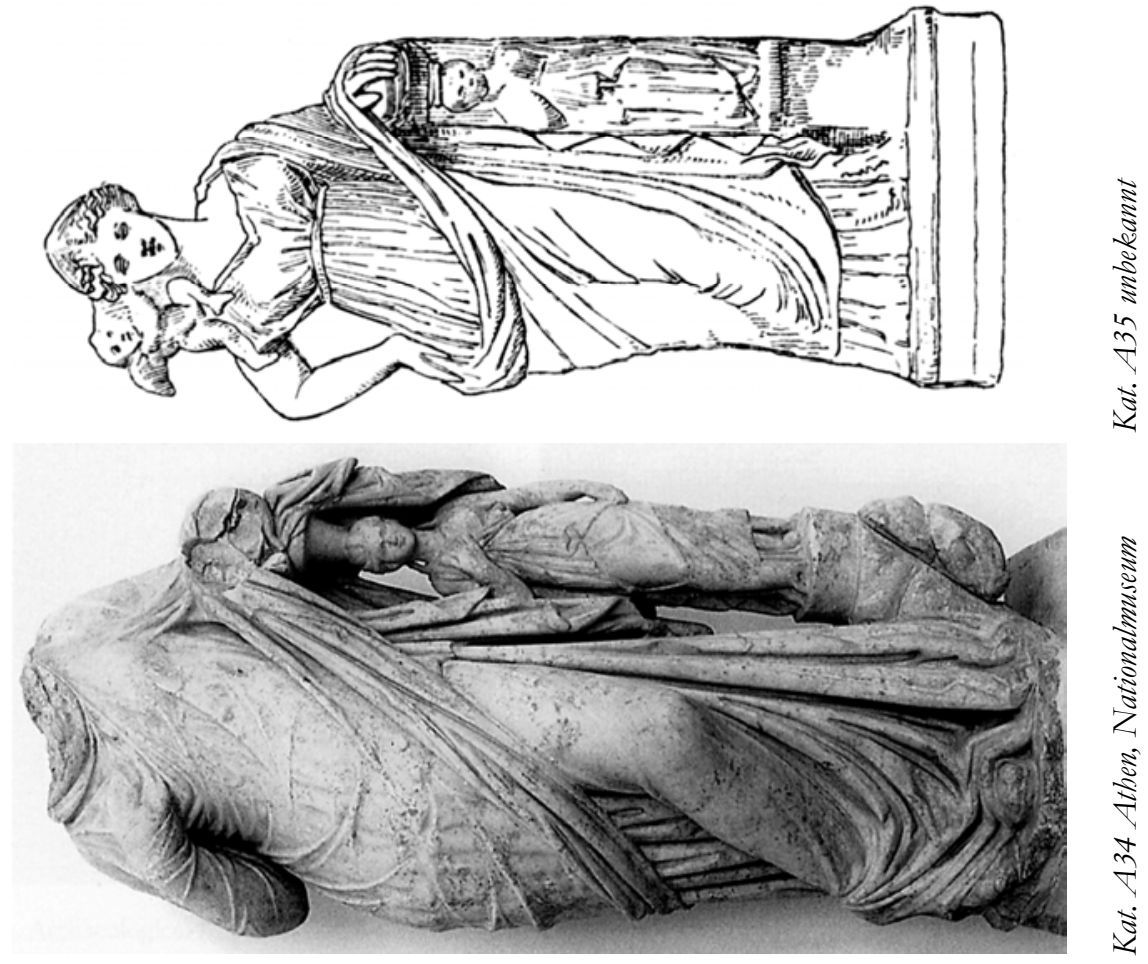

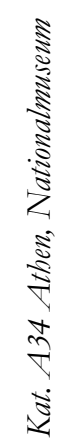

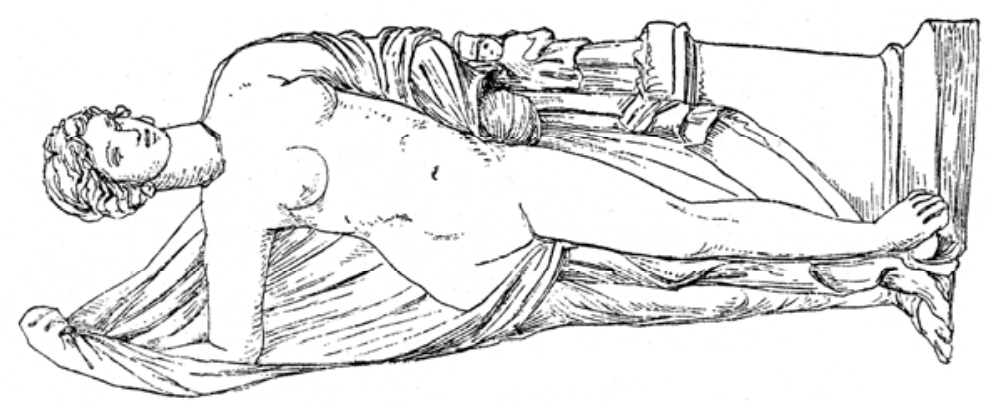

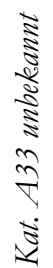




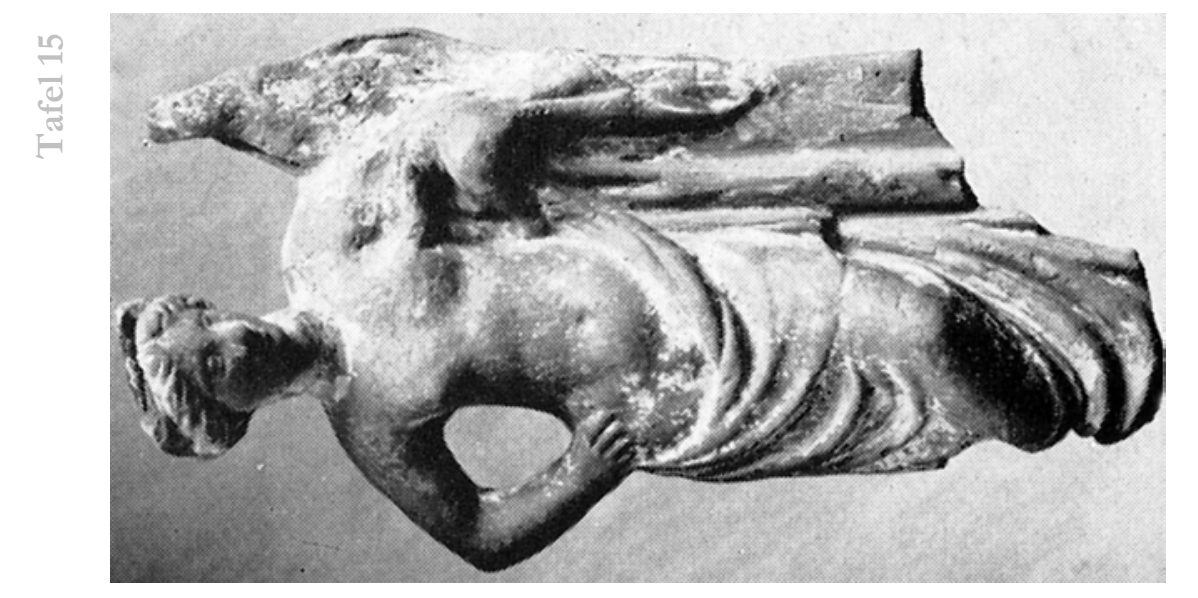

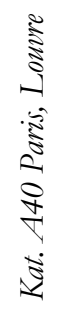

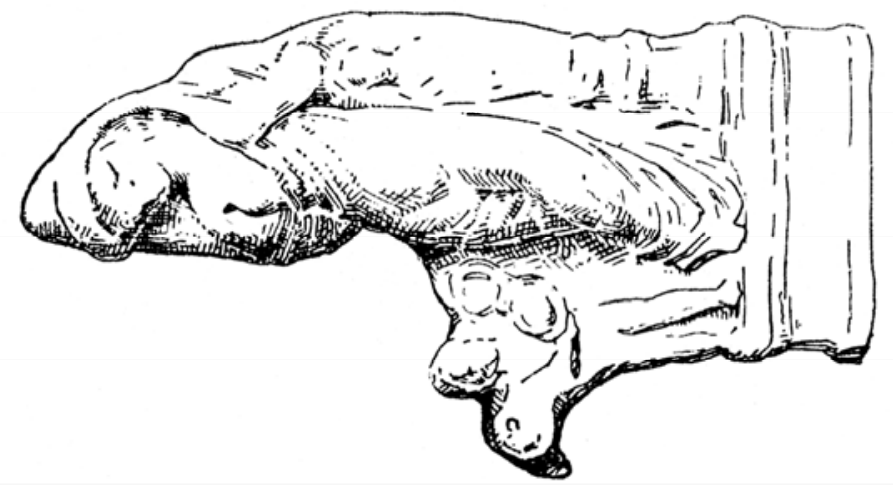

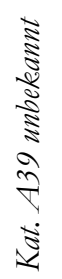
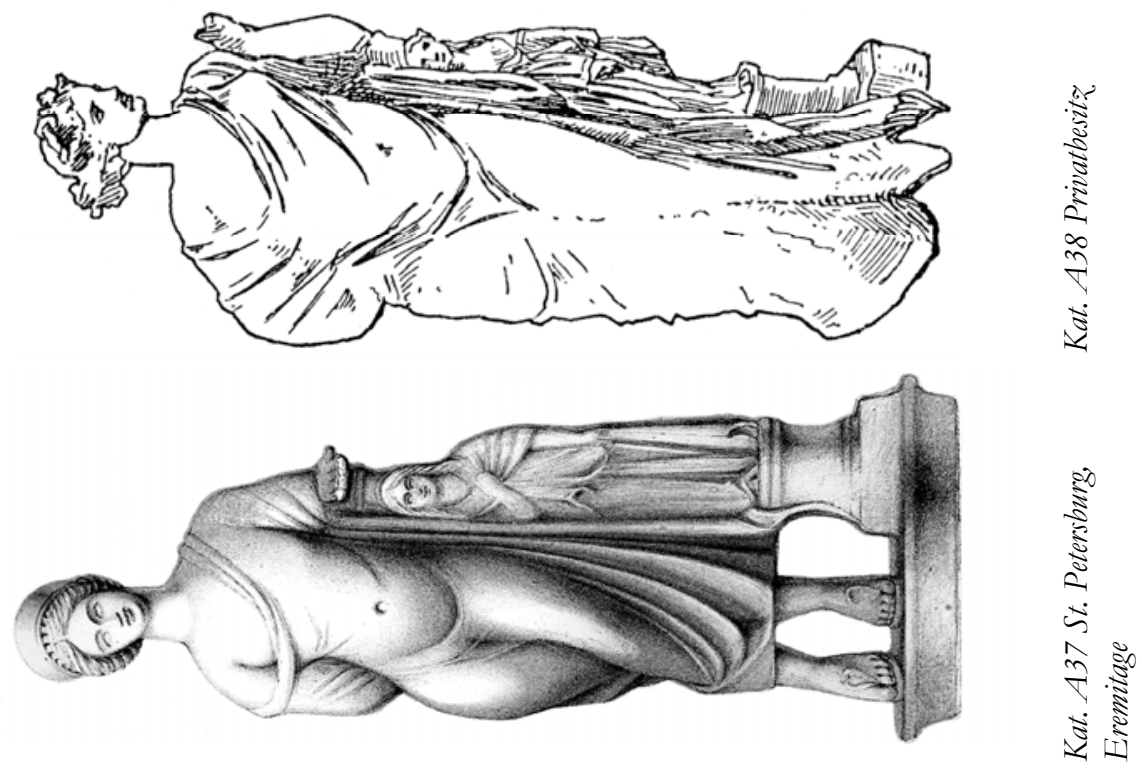
鄫

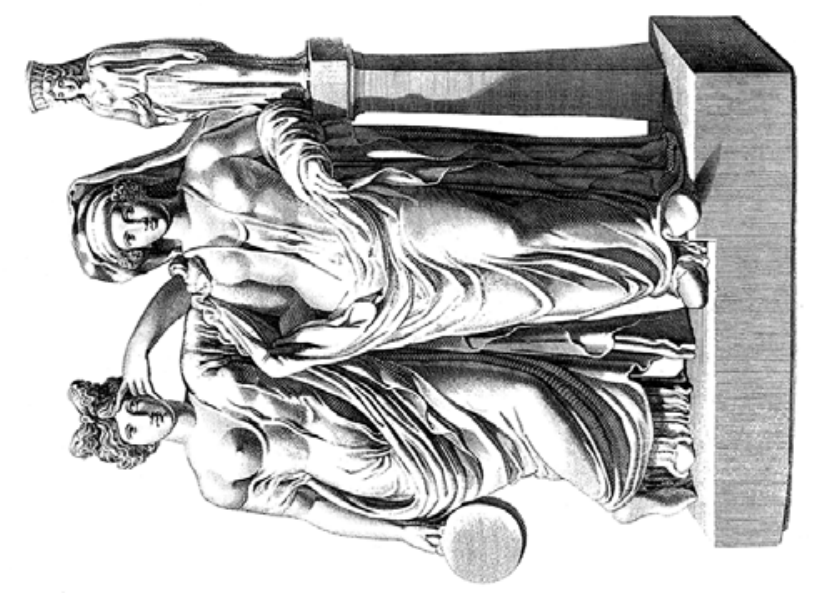

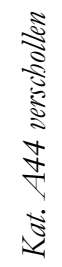

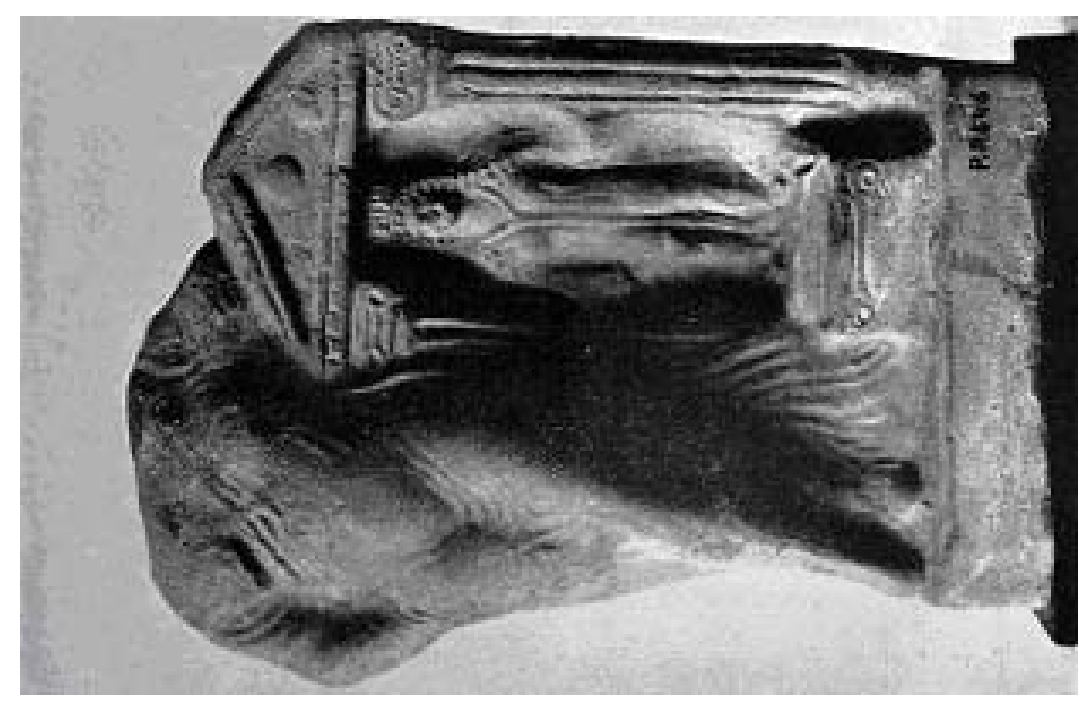

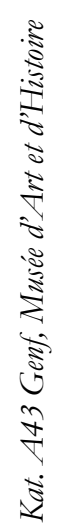

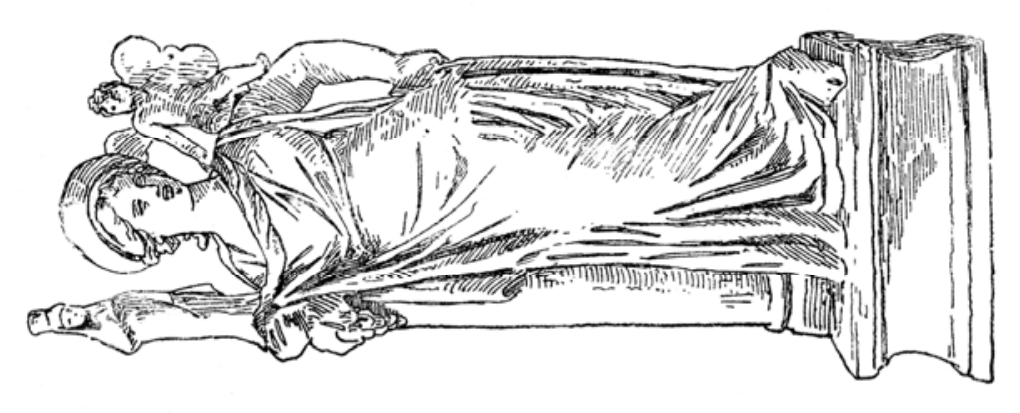

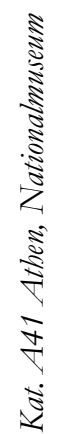



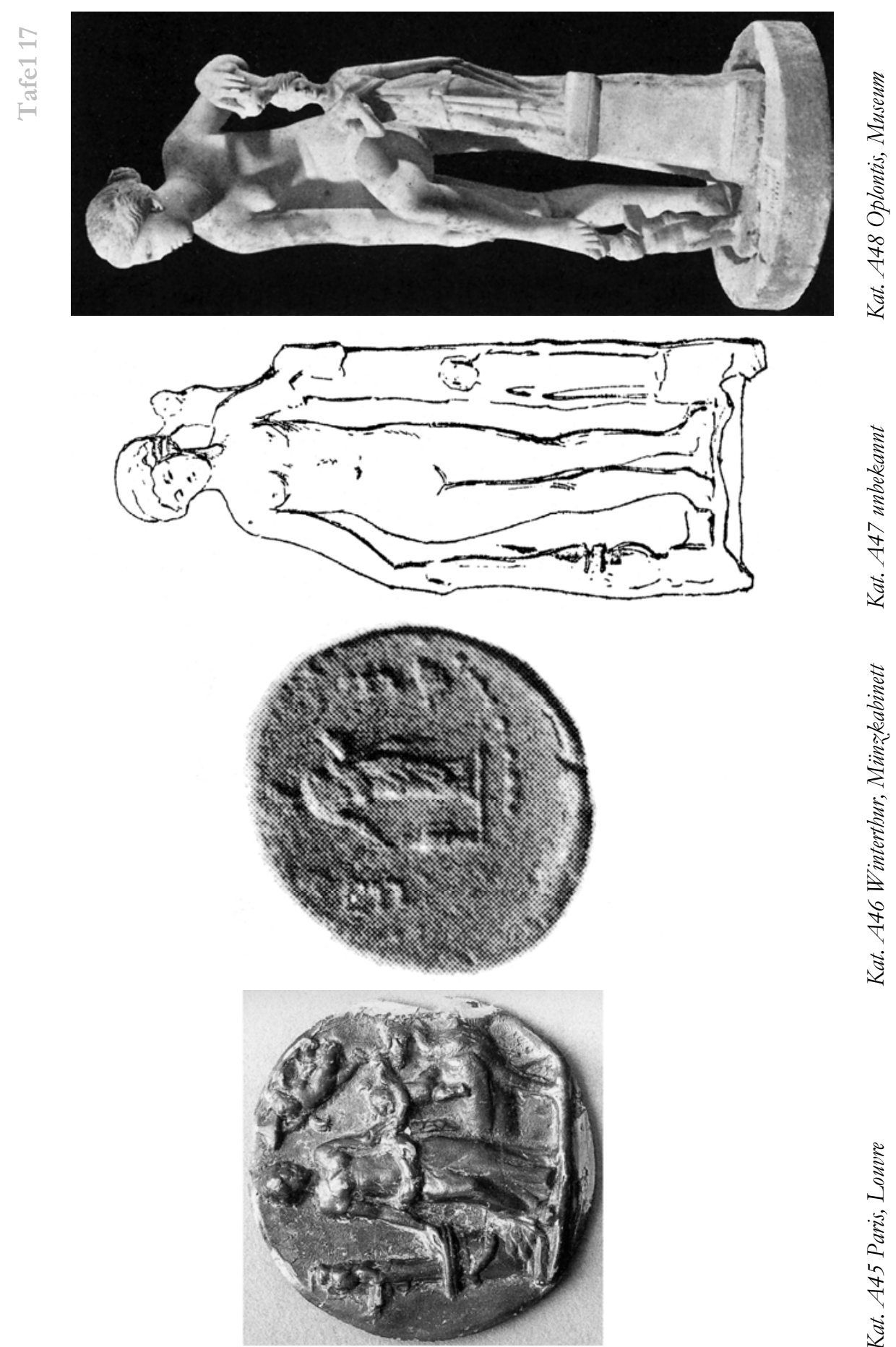

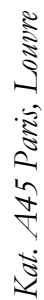


एँ

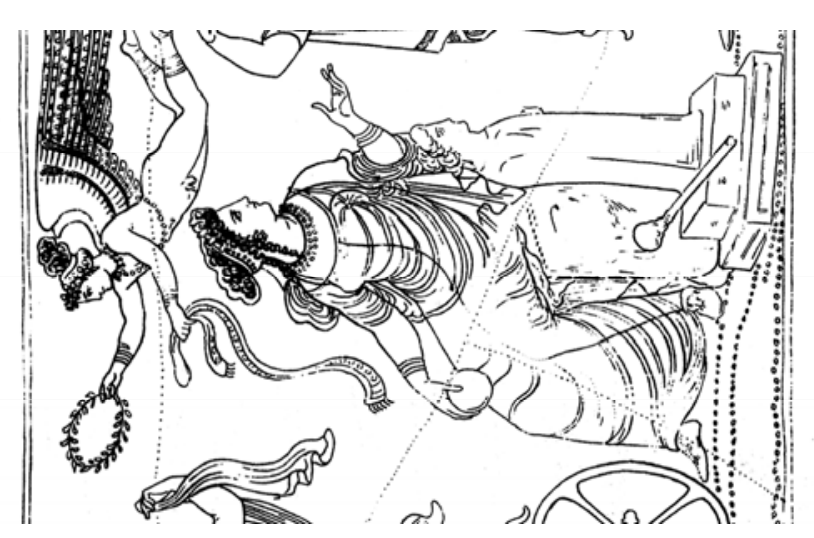

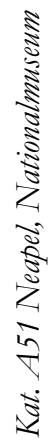

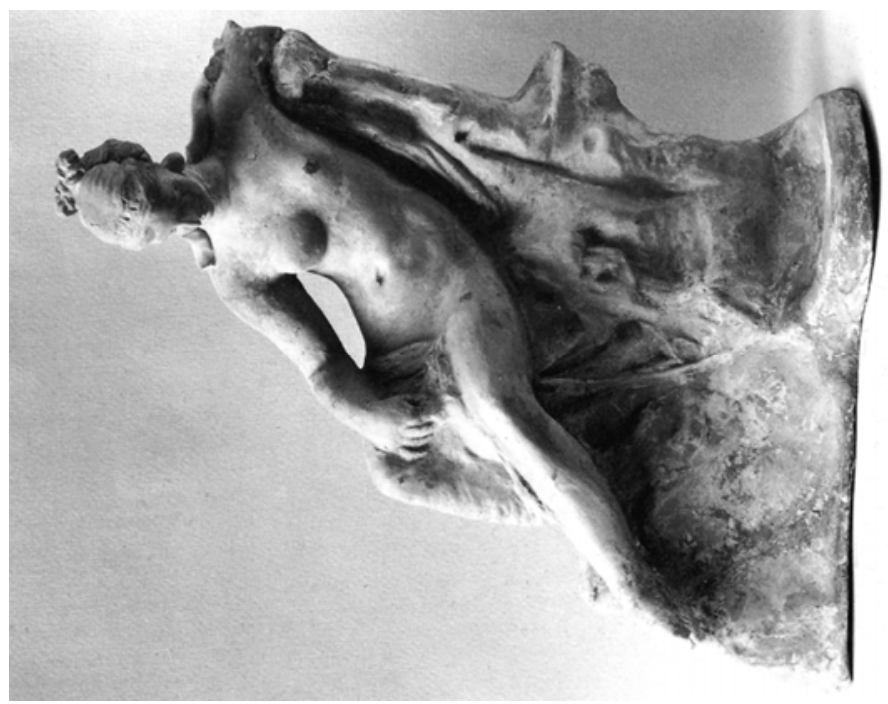

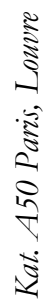

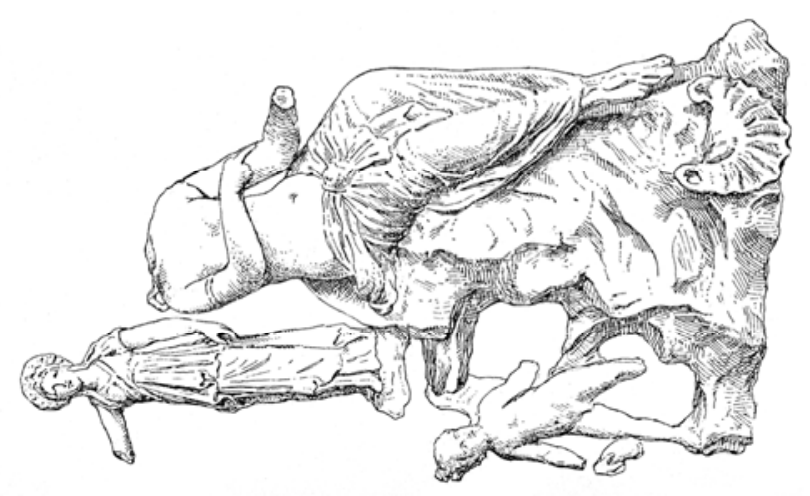

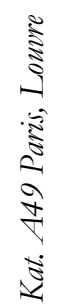


욜
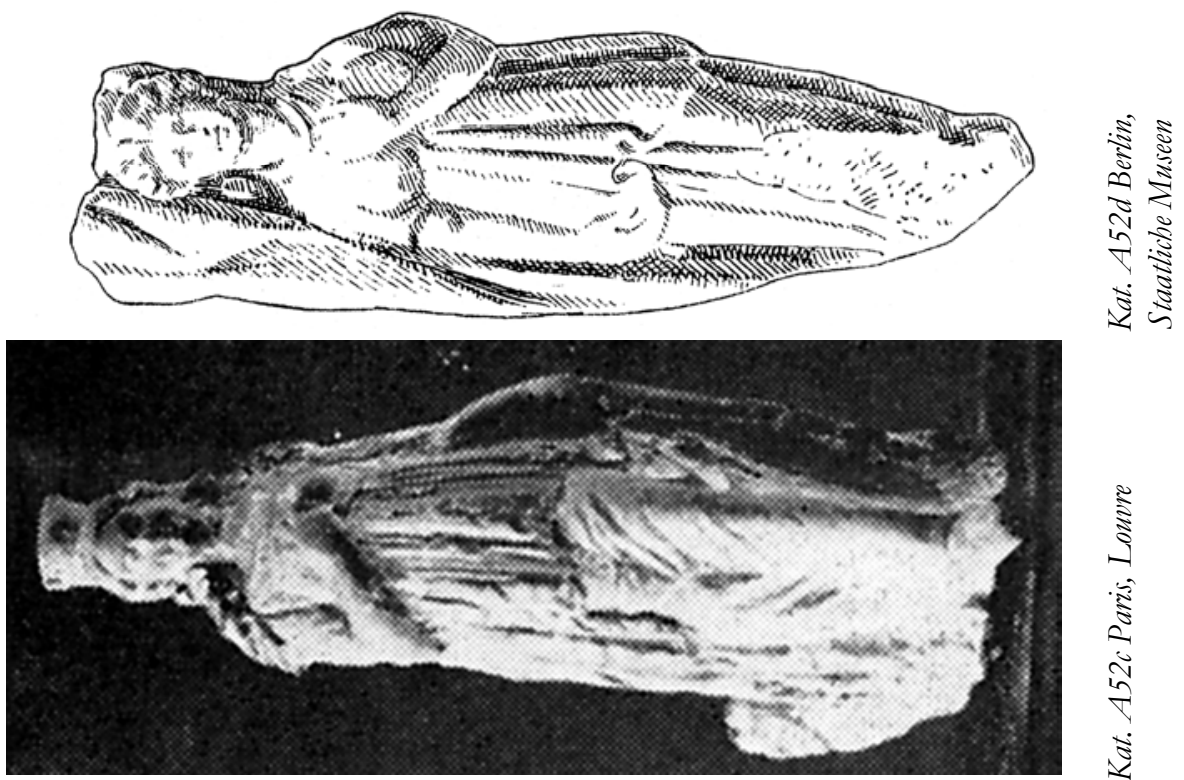

ב⿱艹

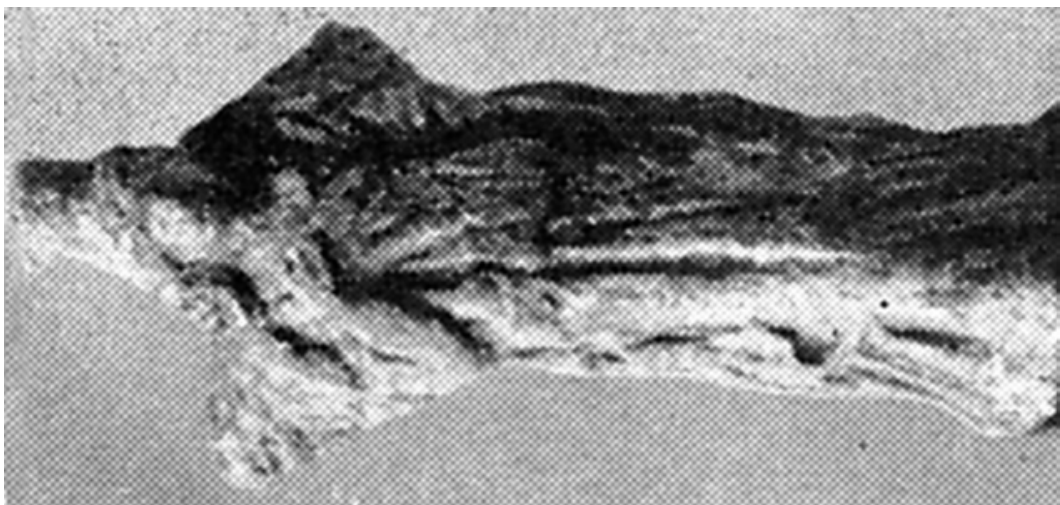

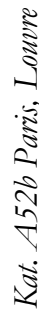

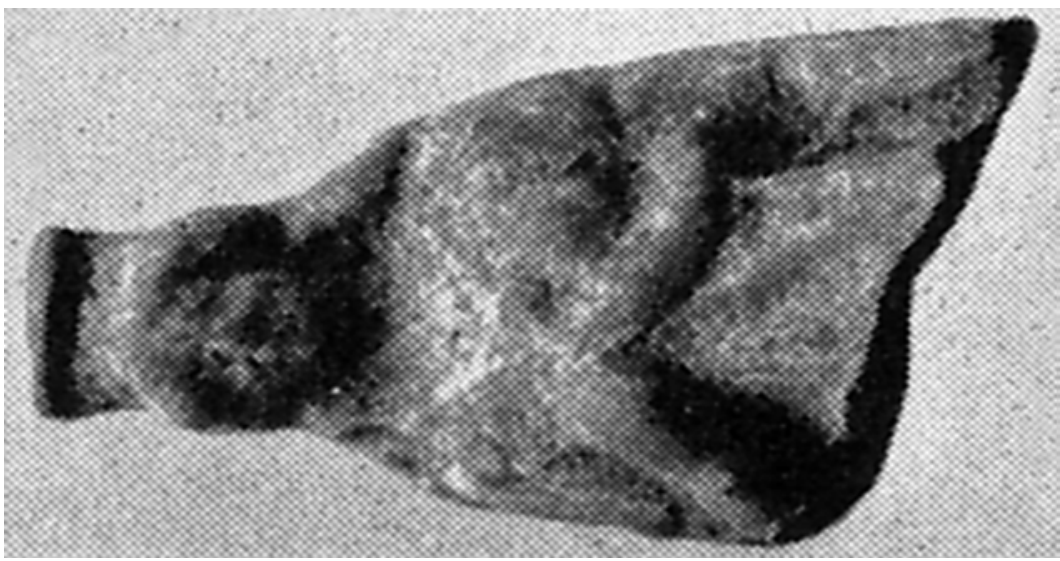

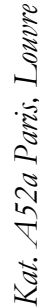


$\frac{2}{\sqrt{0}}$

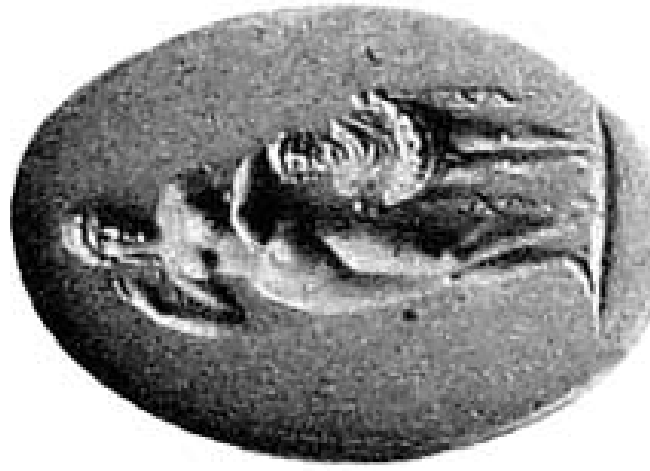

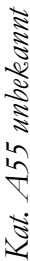

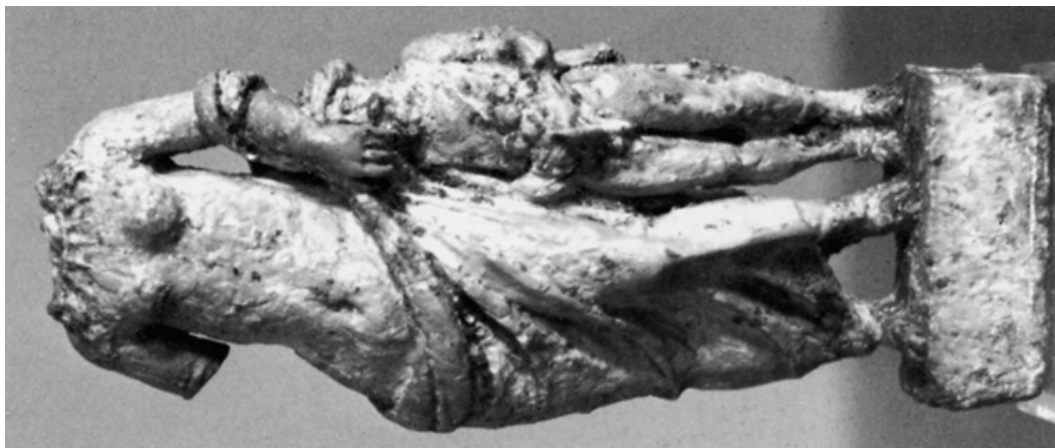

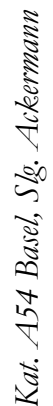

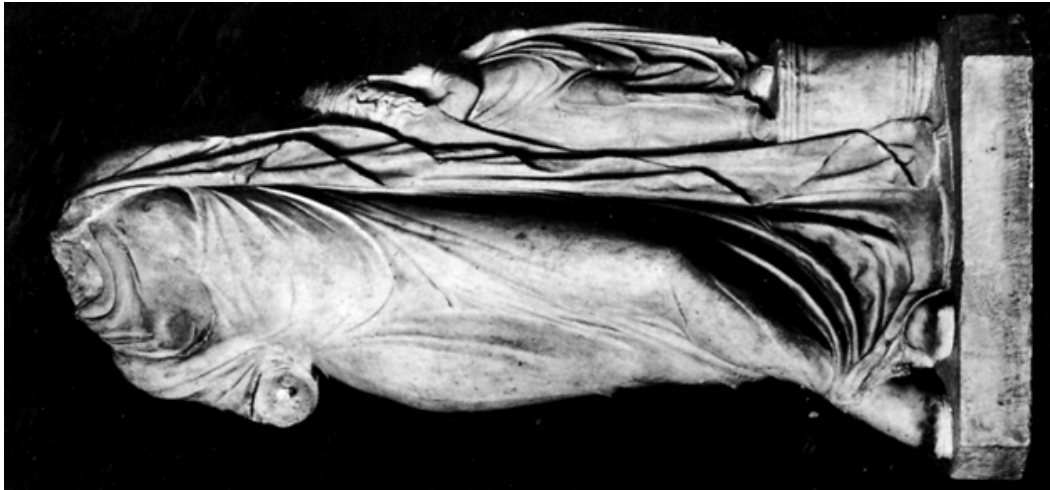

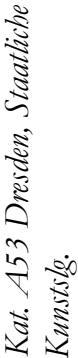

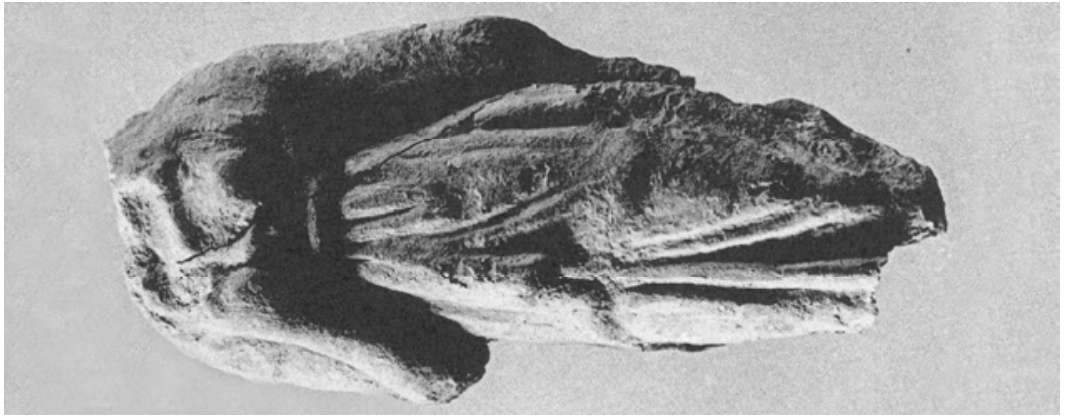

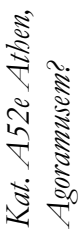


焉

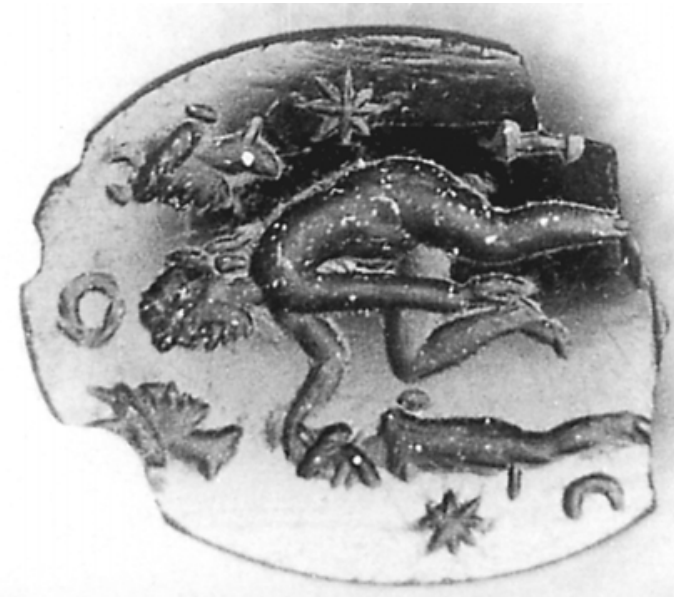

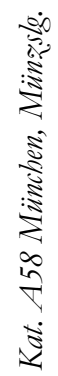

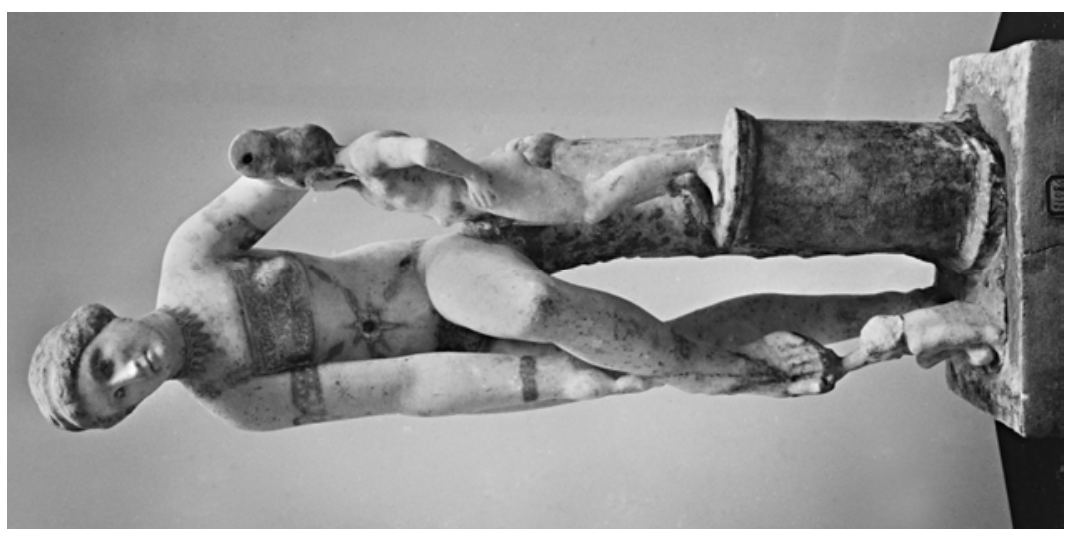

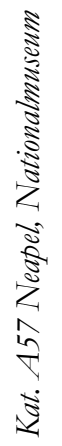

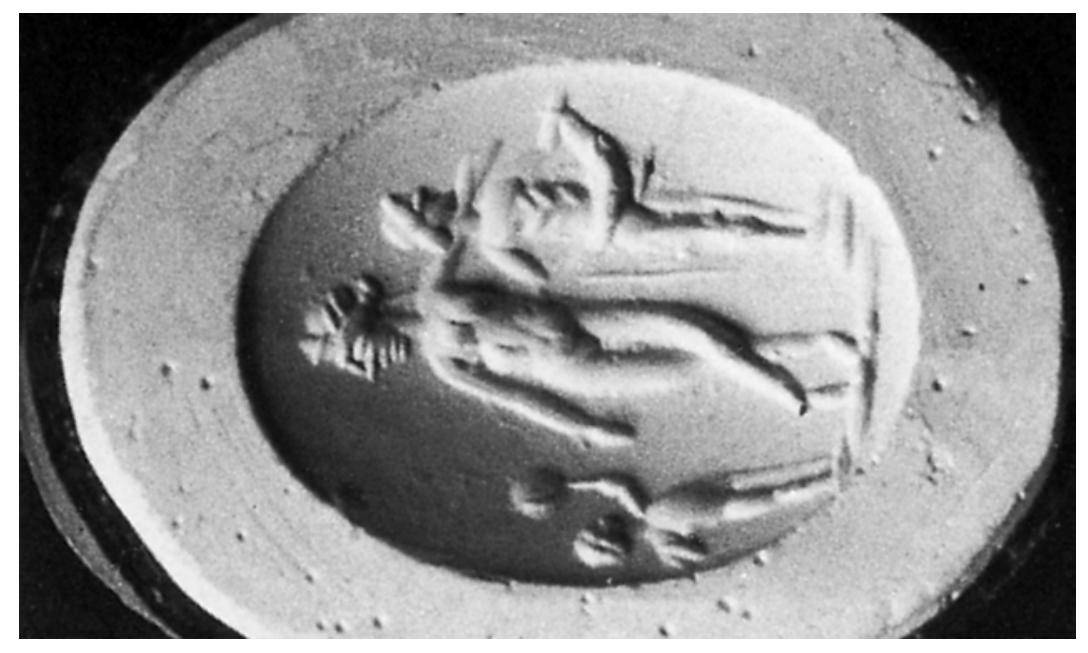

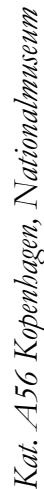


건
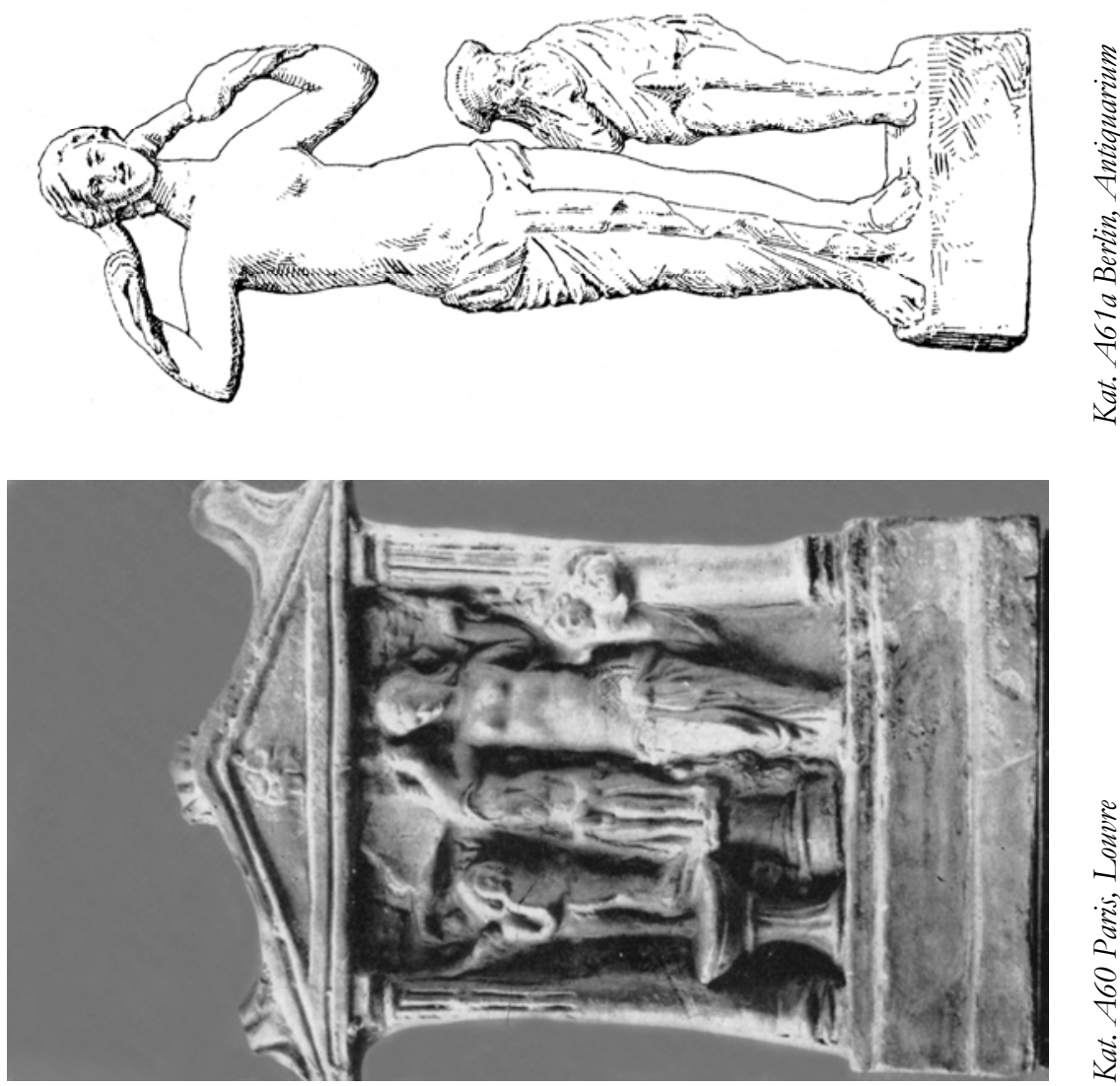

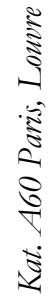

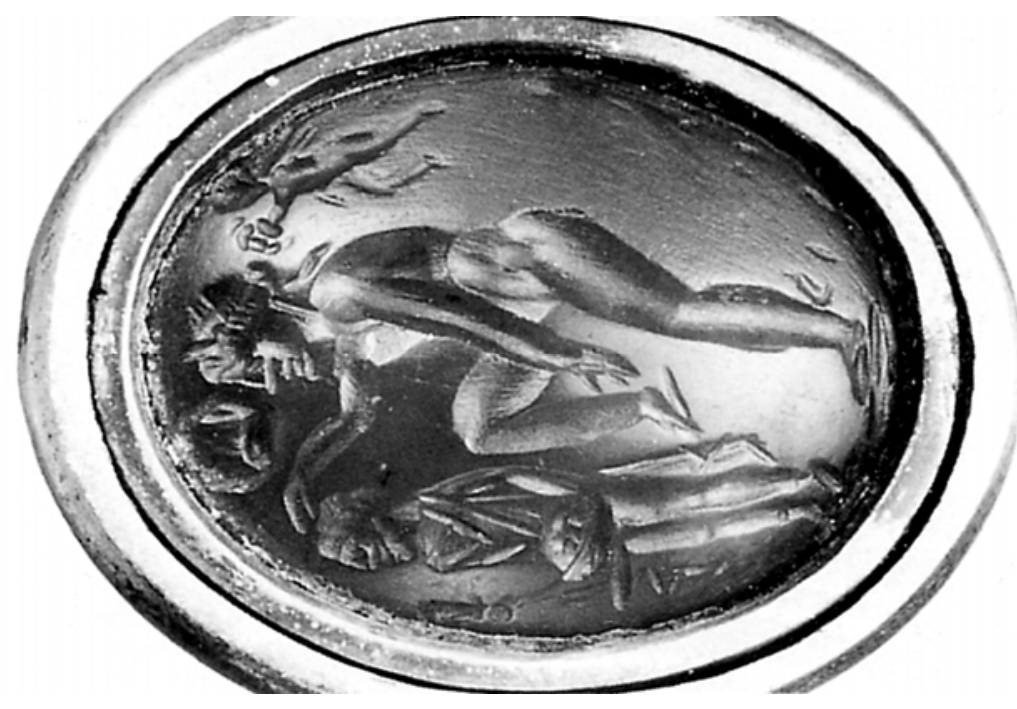

है 

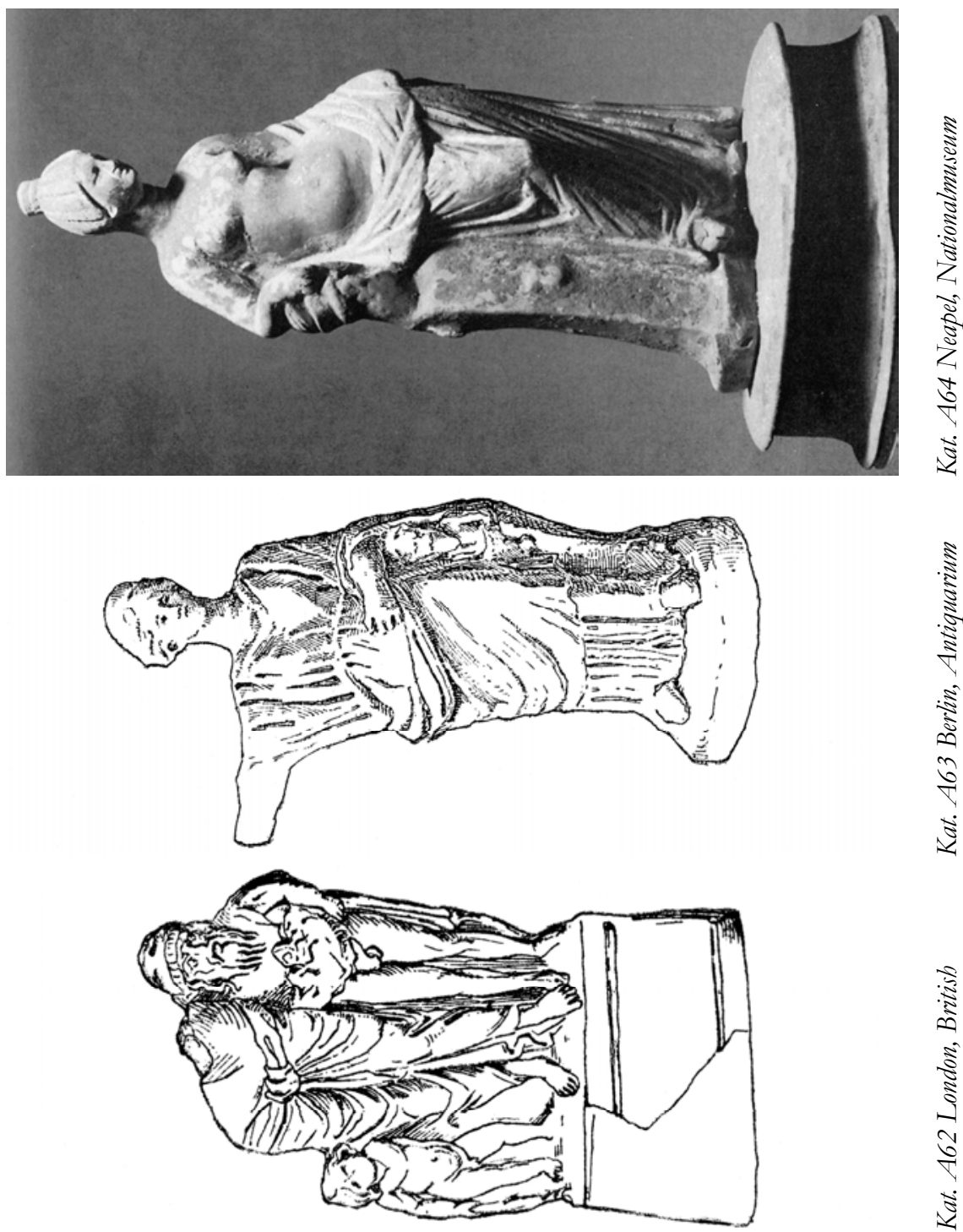

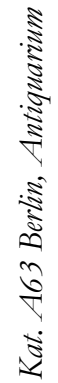

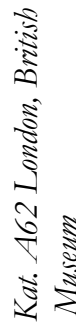

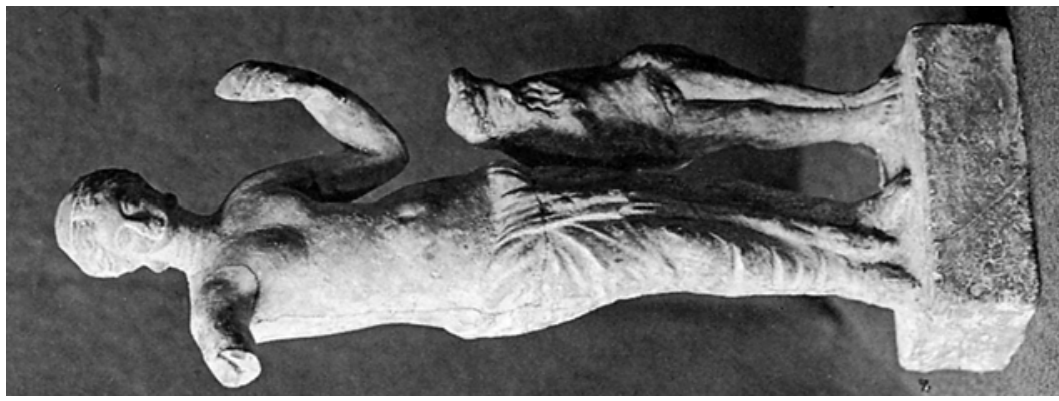

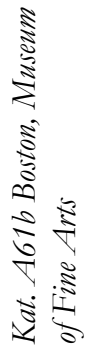



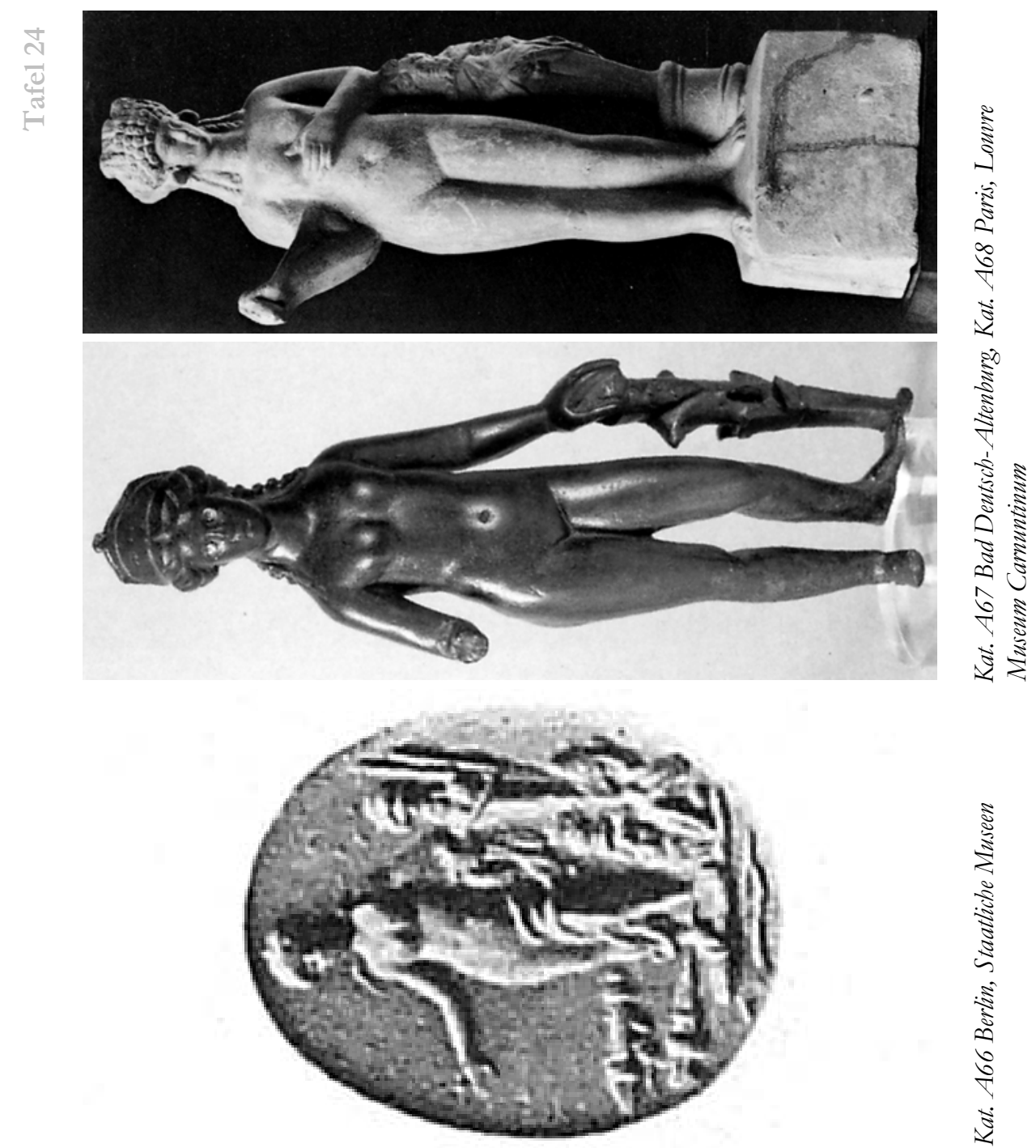

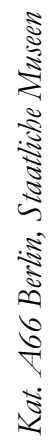

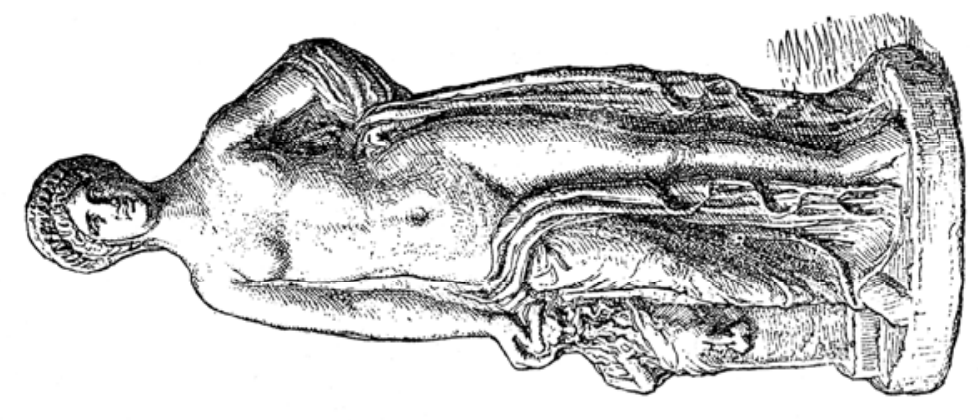

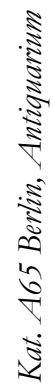



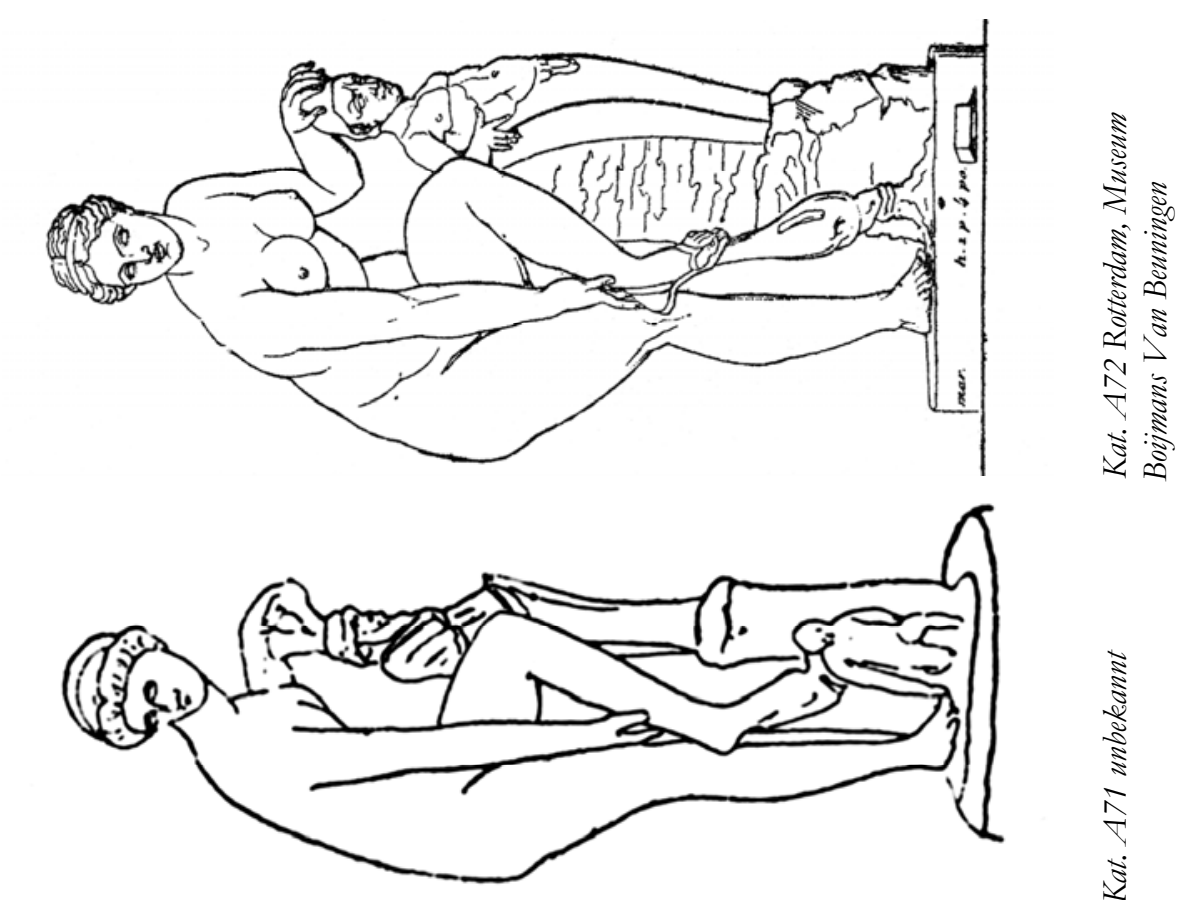

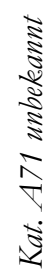

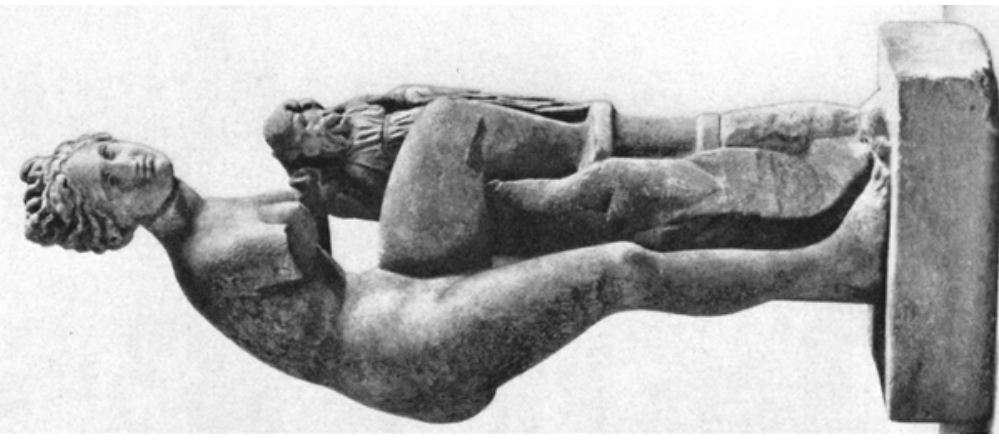

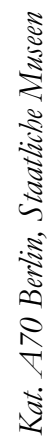

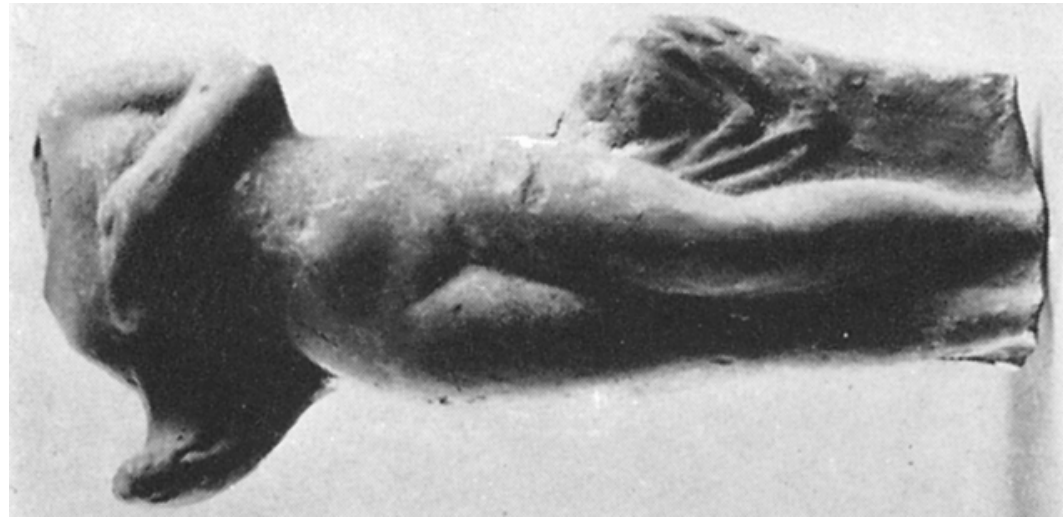

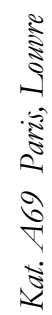



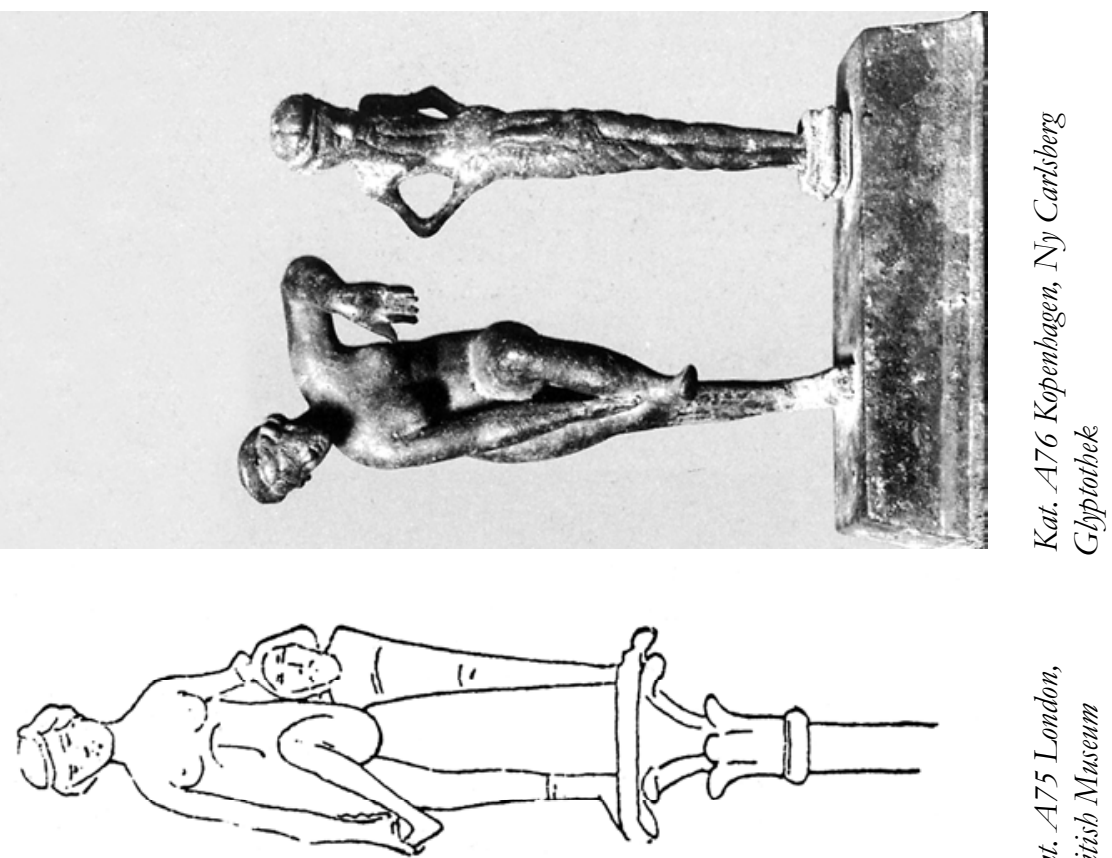

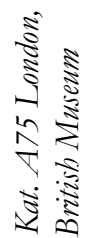

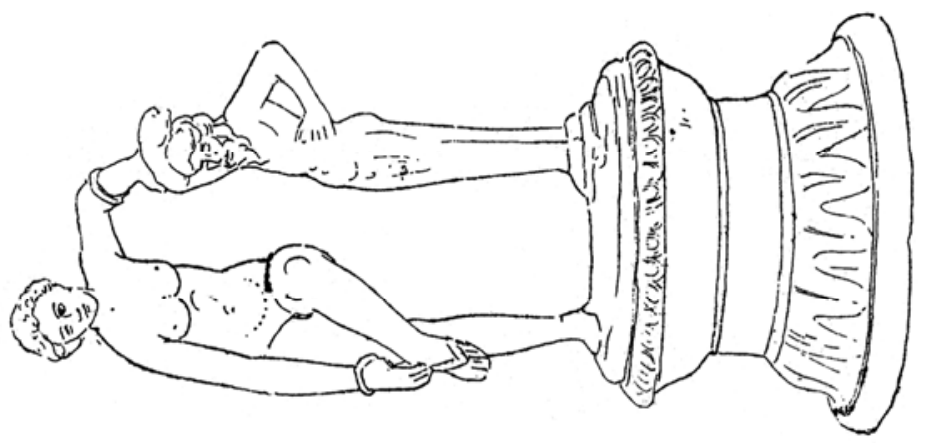

$\frac{\sqrt{2}}{\frac{1}{2}} \frac{\pi}{2}$

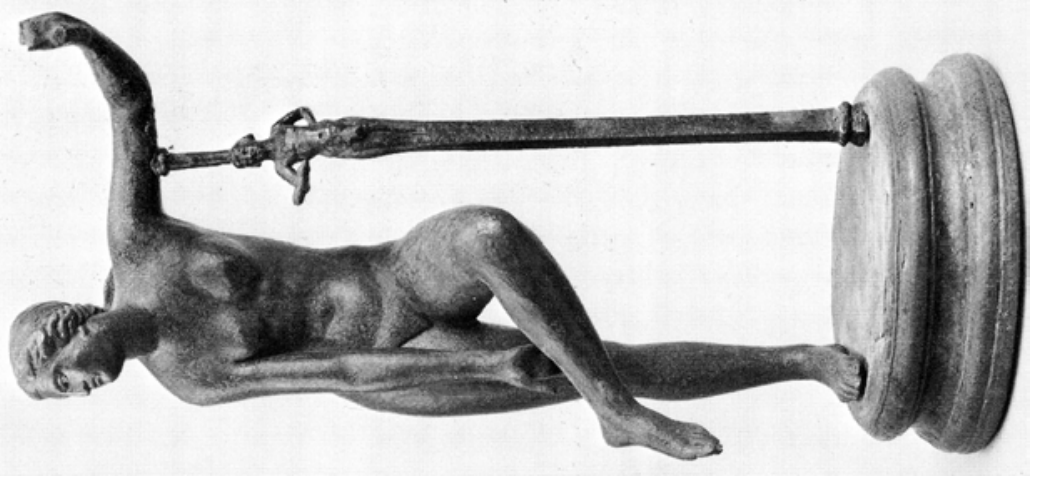

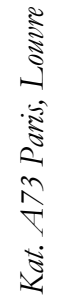



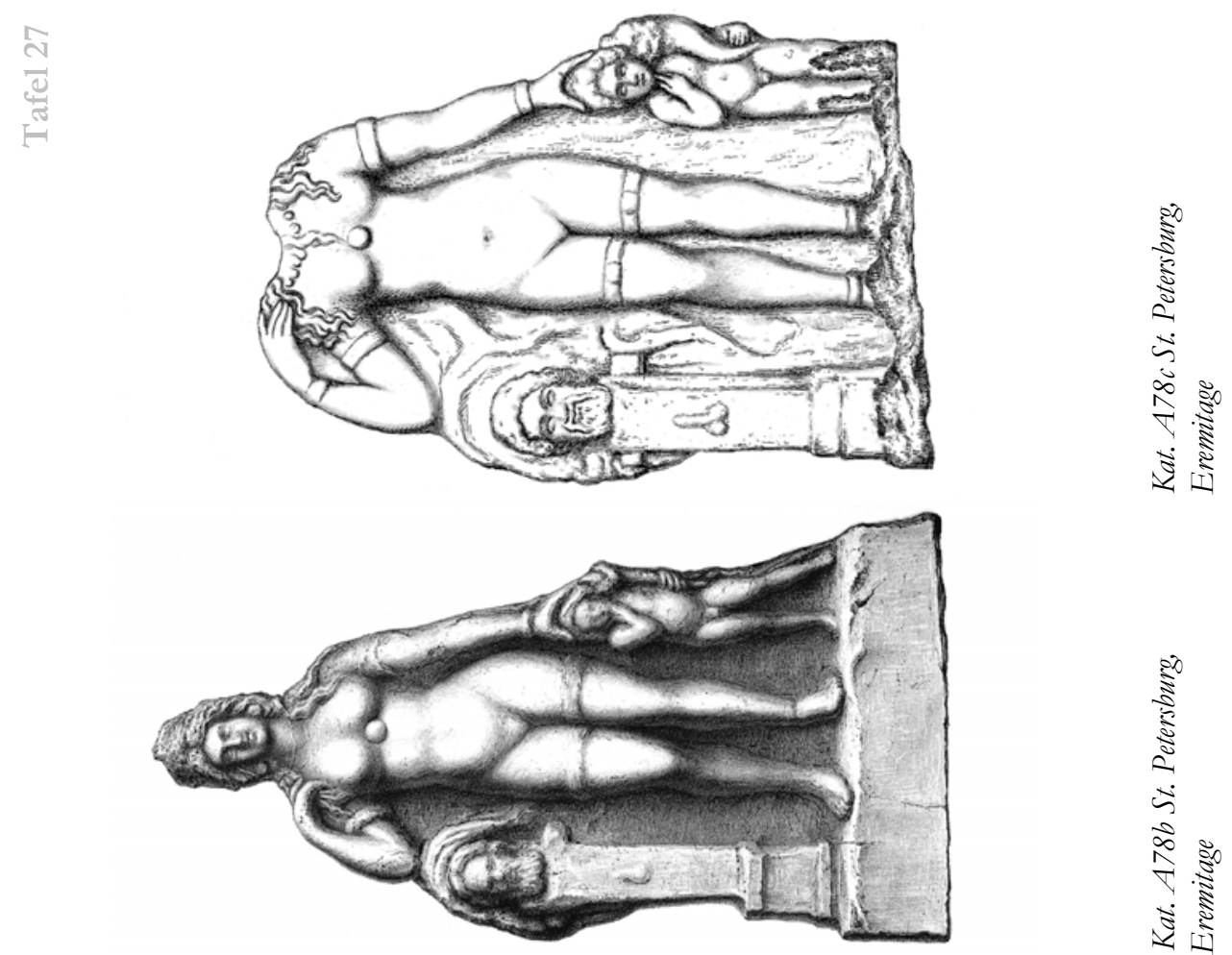

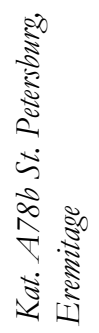
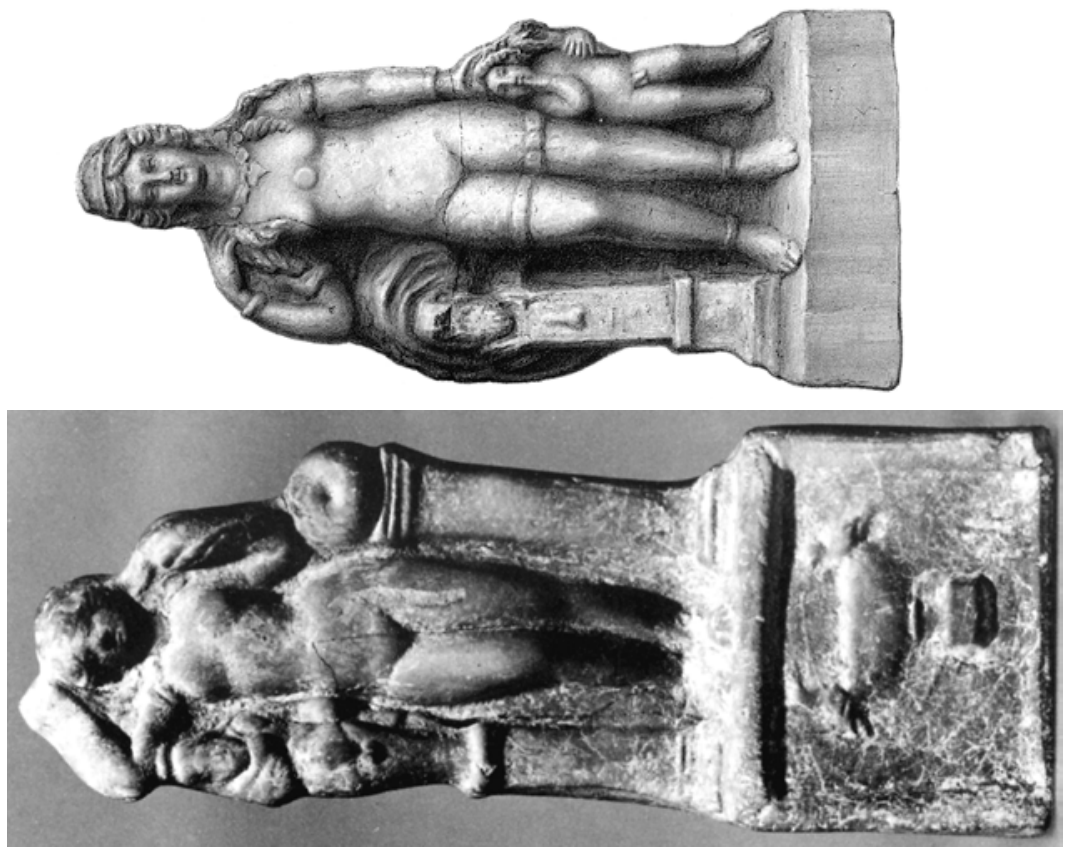

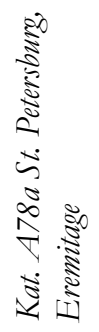

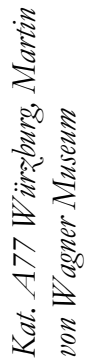



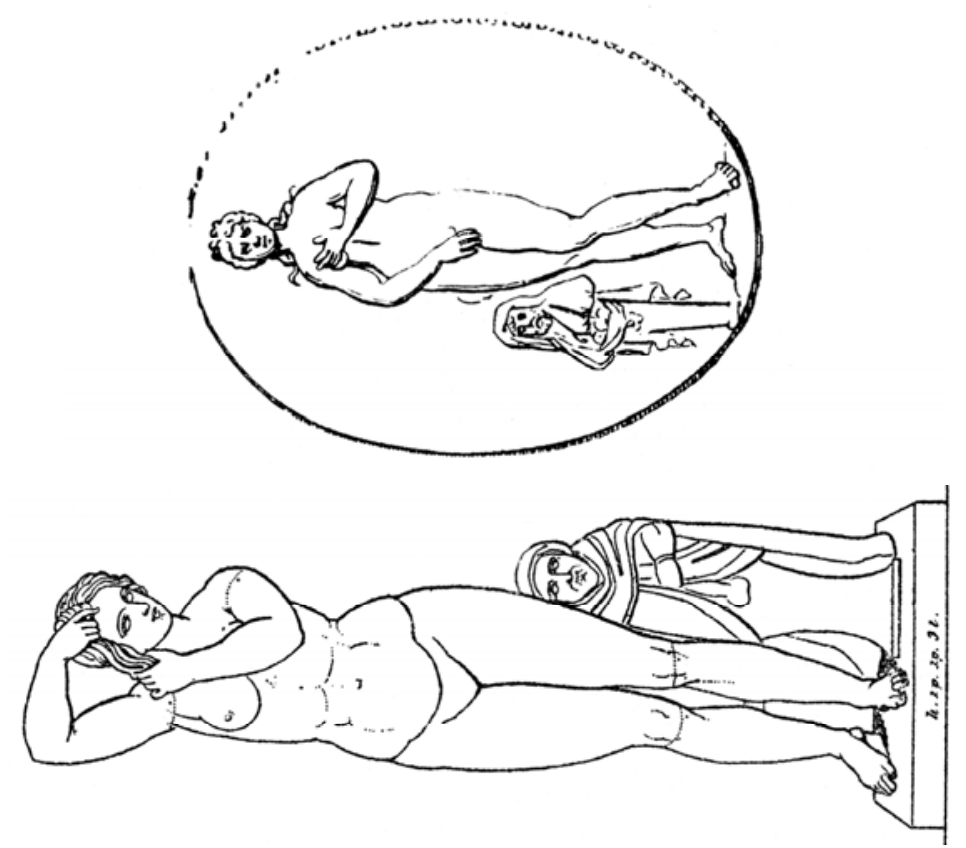

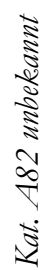

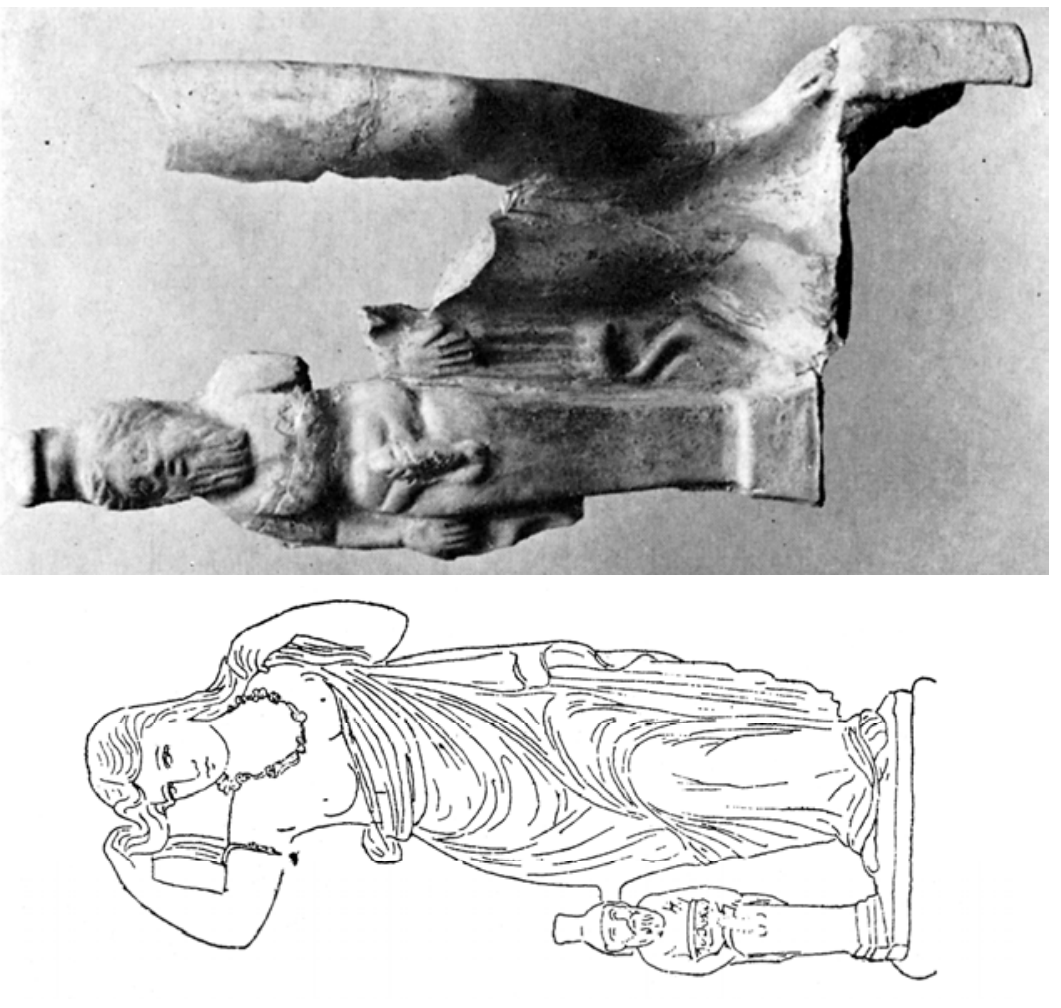

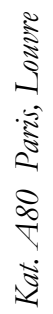

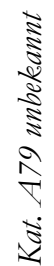


踏

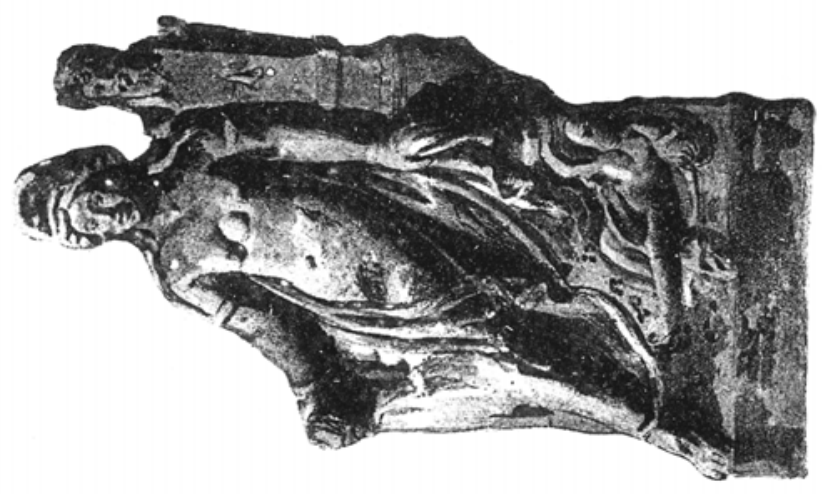

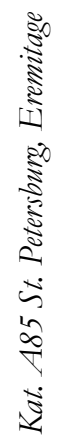

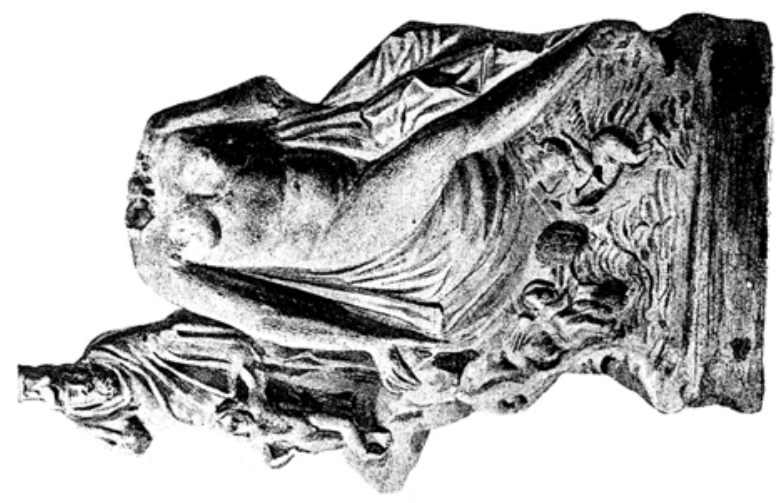

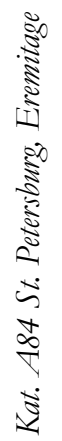

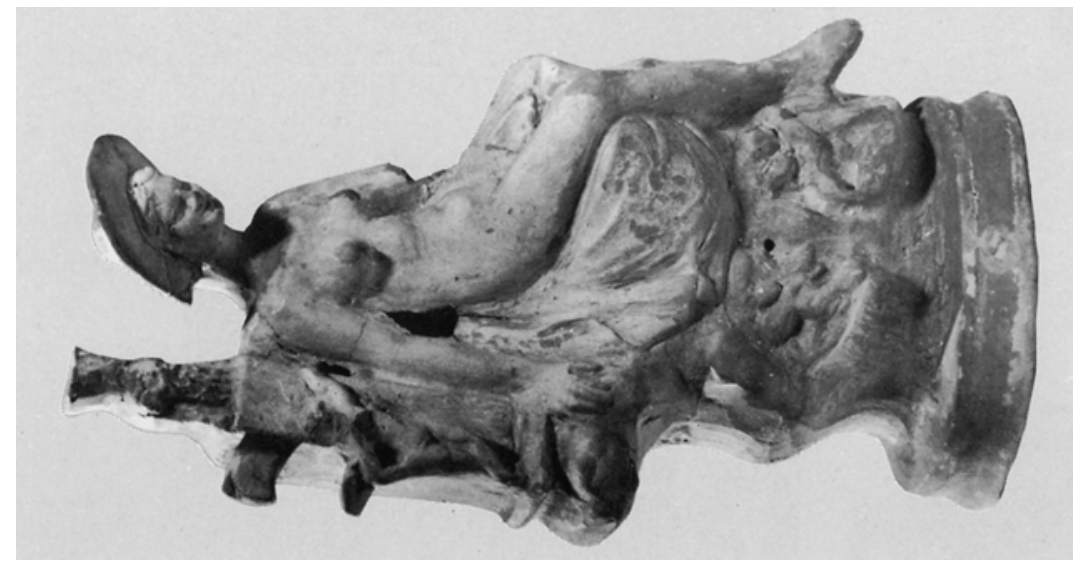

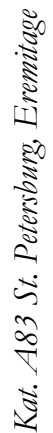




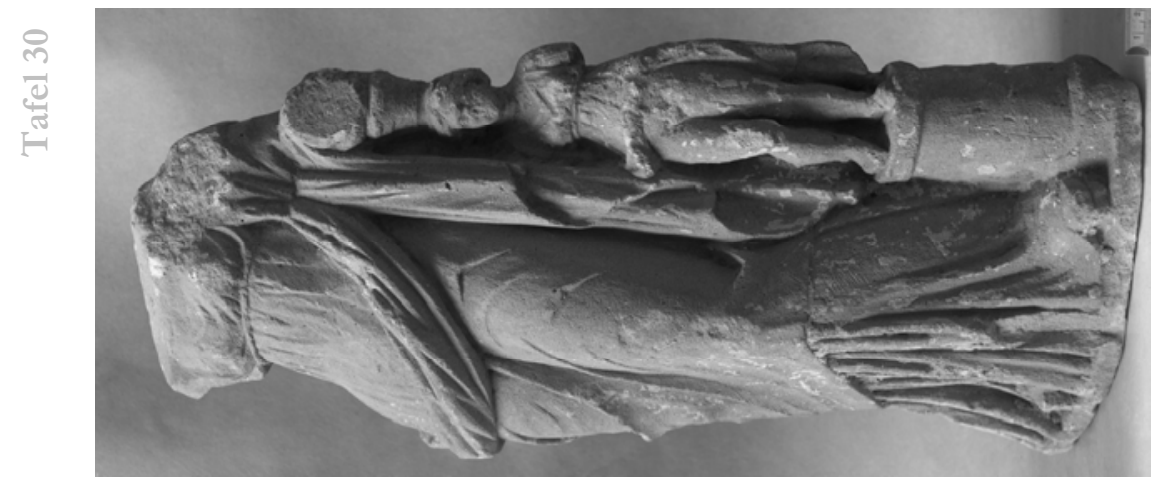

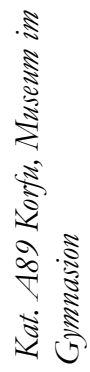
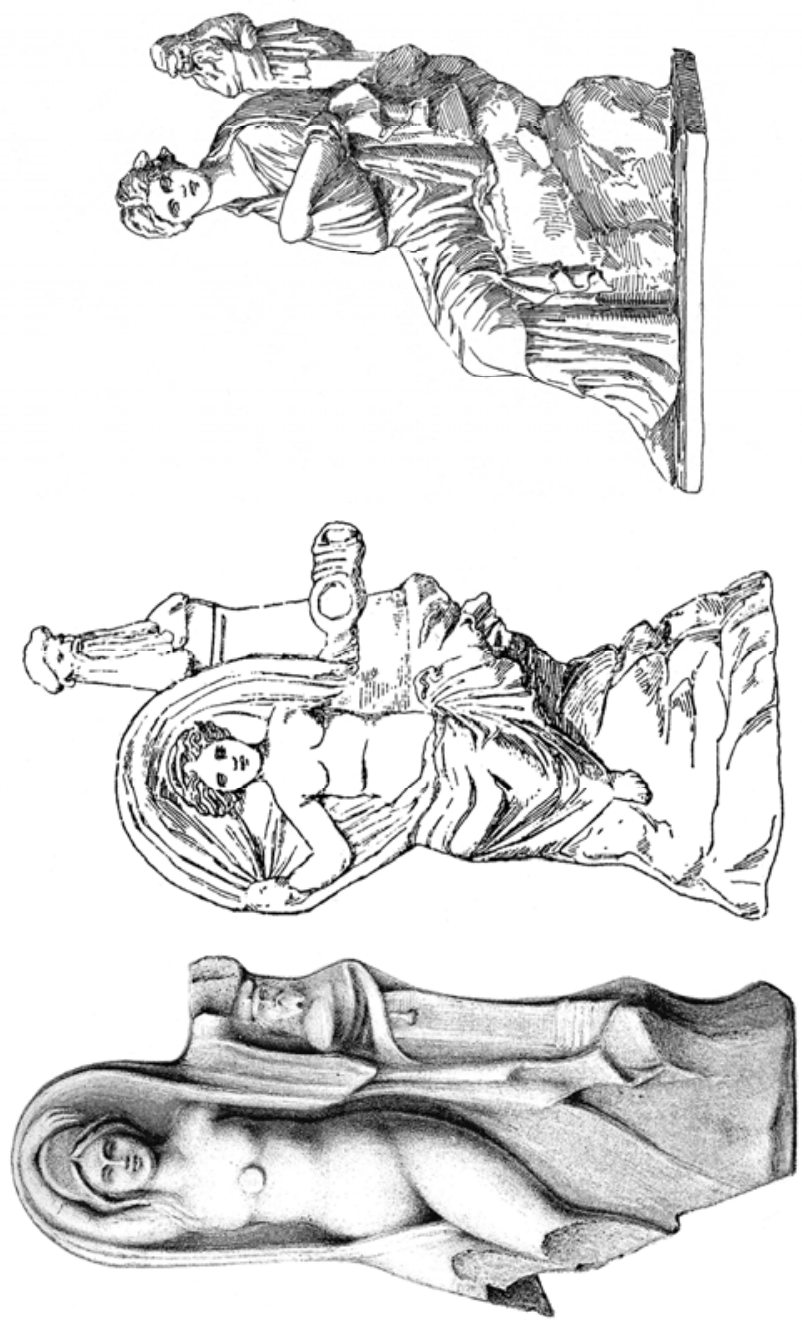

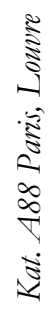

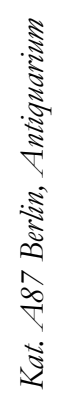

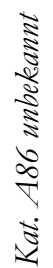




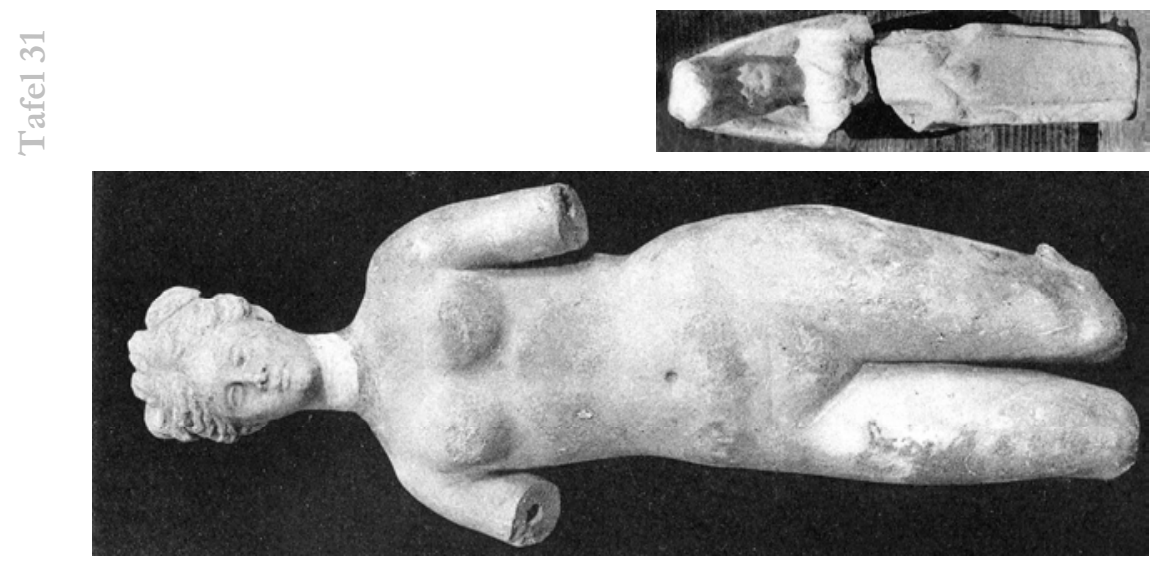

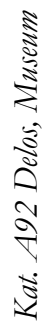

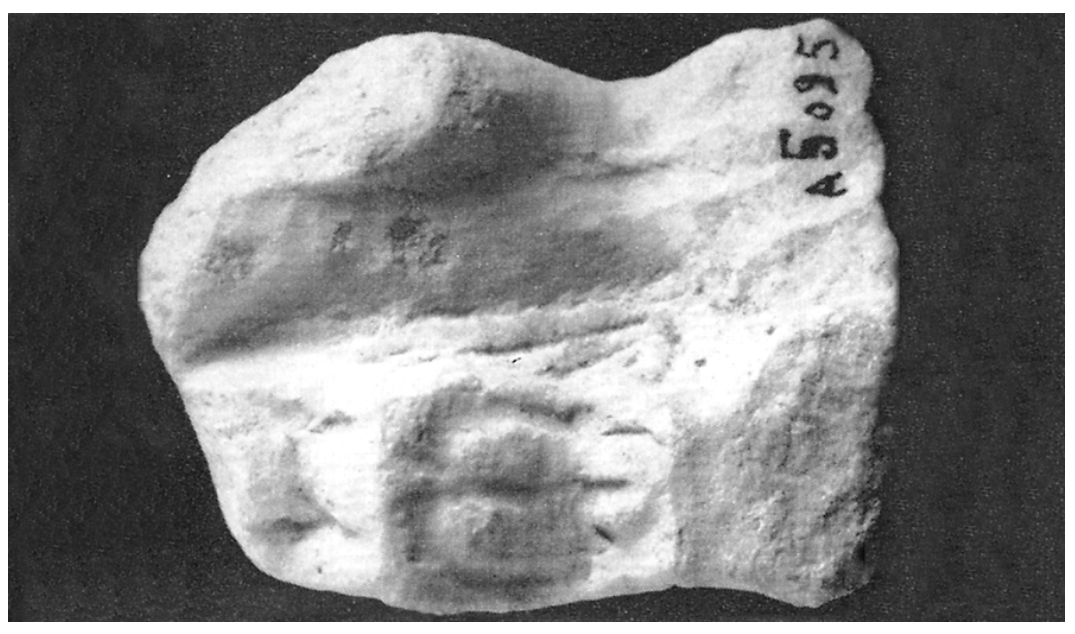

है

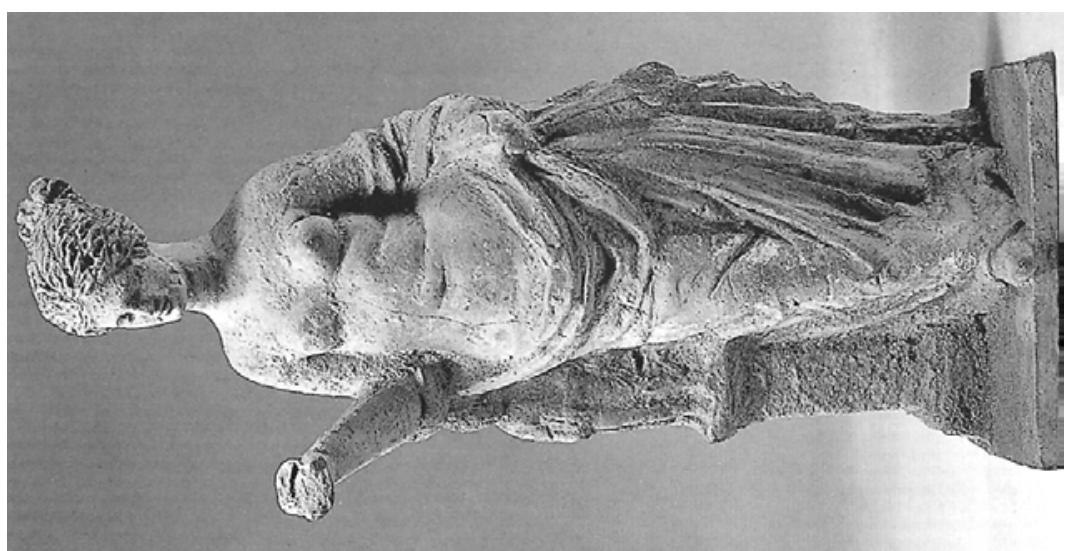

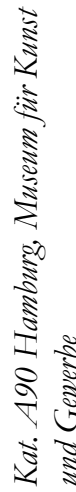




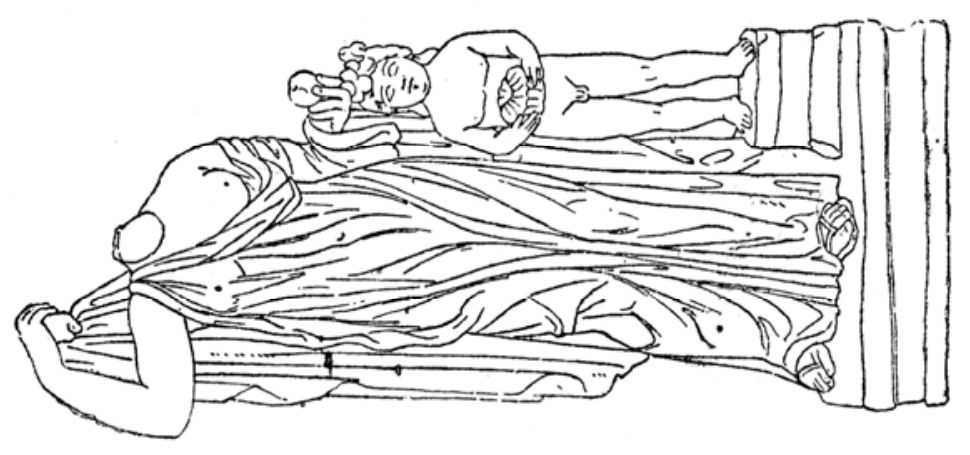

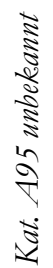

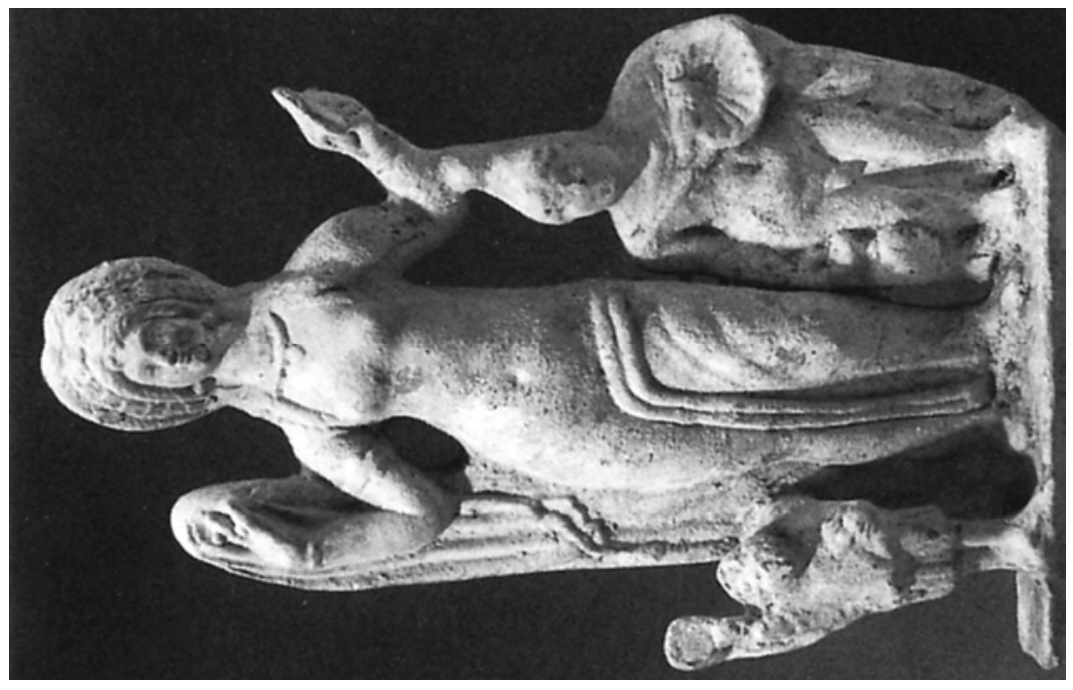

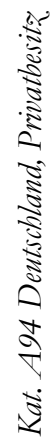

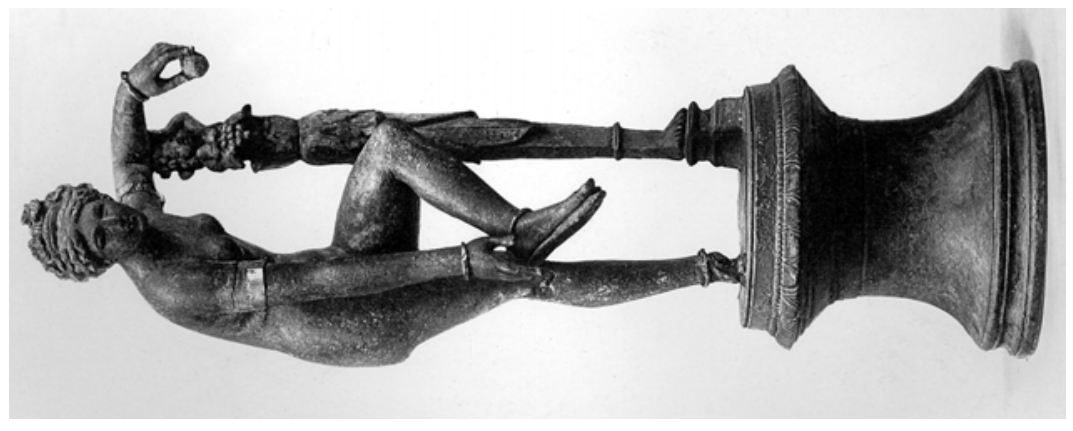

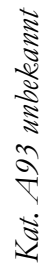


लै

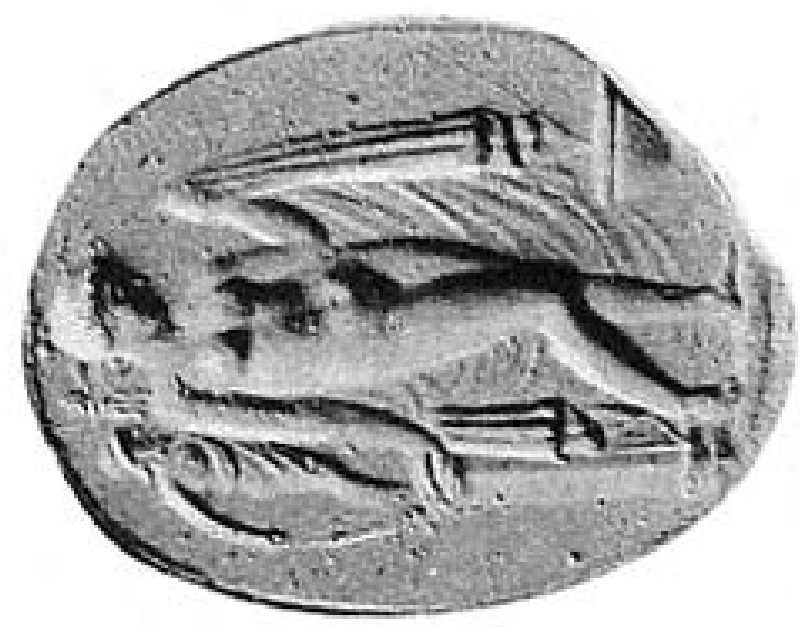

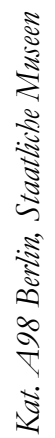

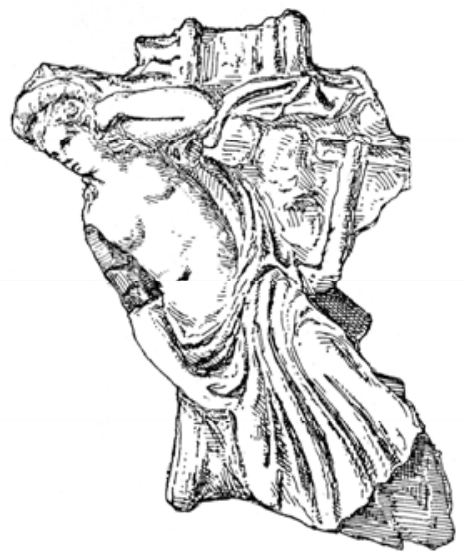

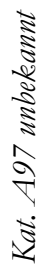
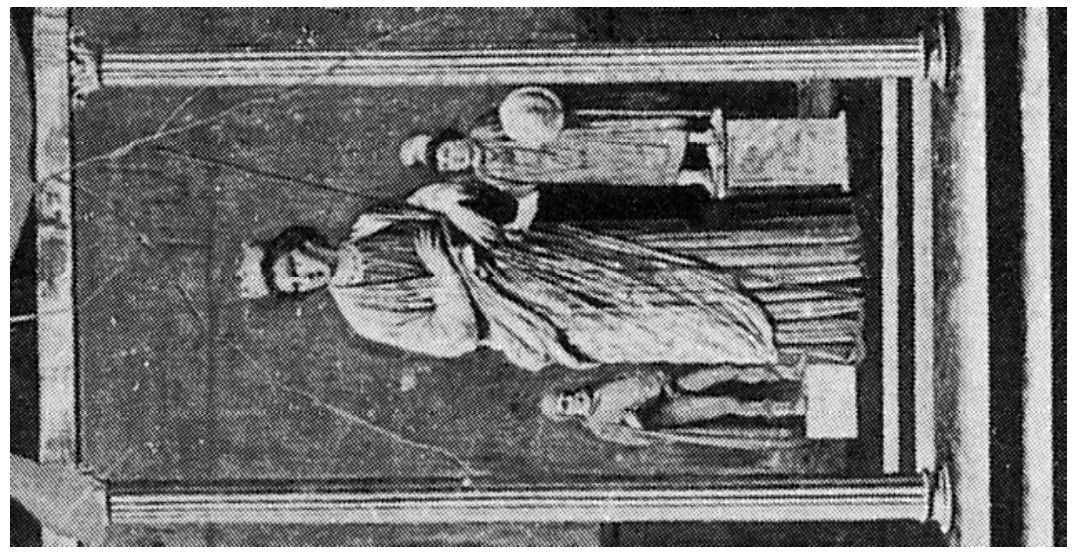

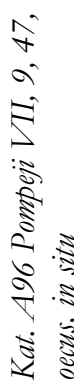




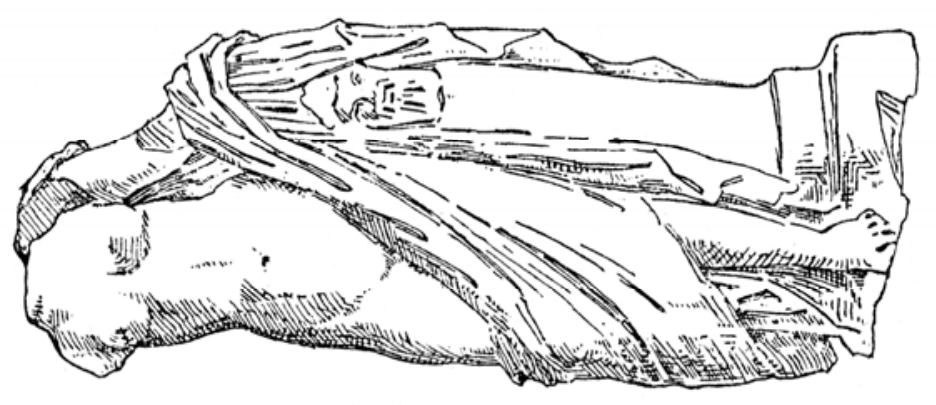

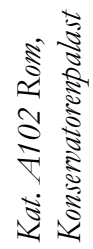

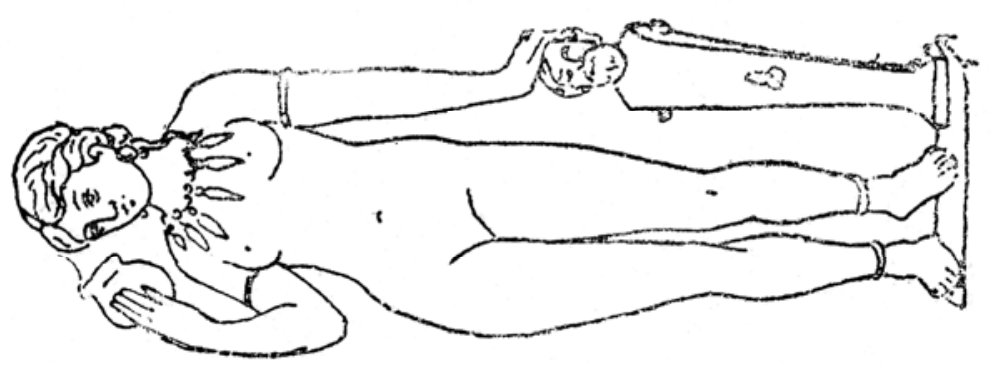

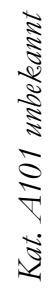

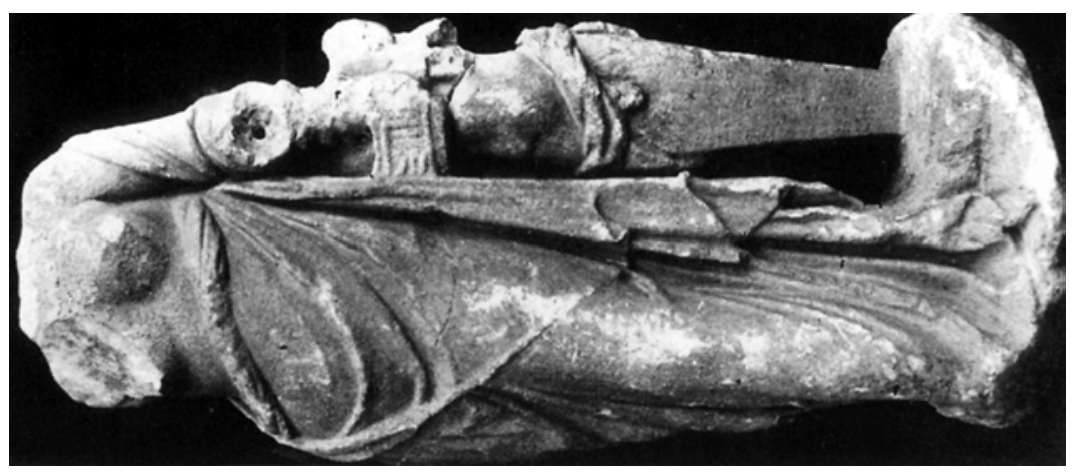

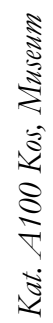

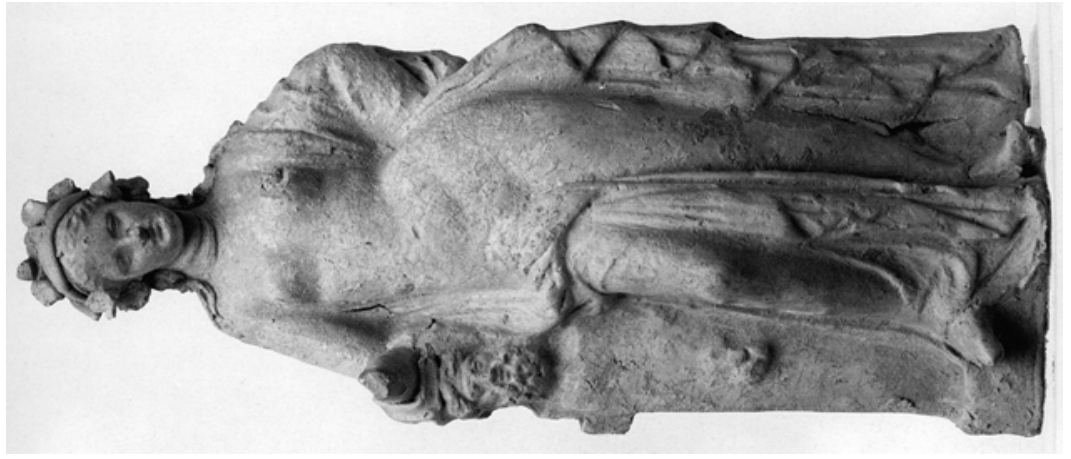

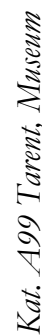




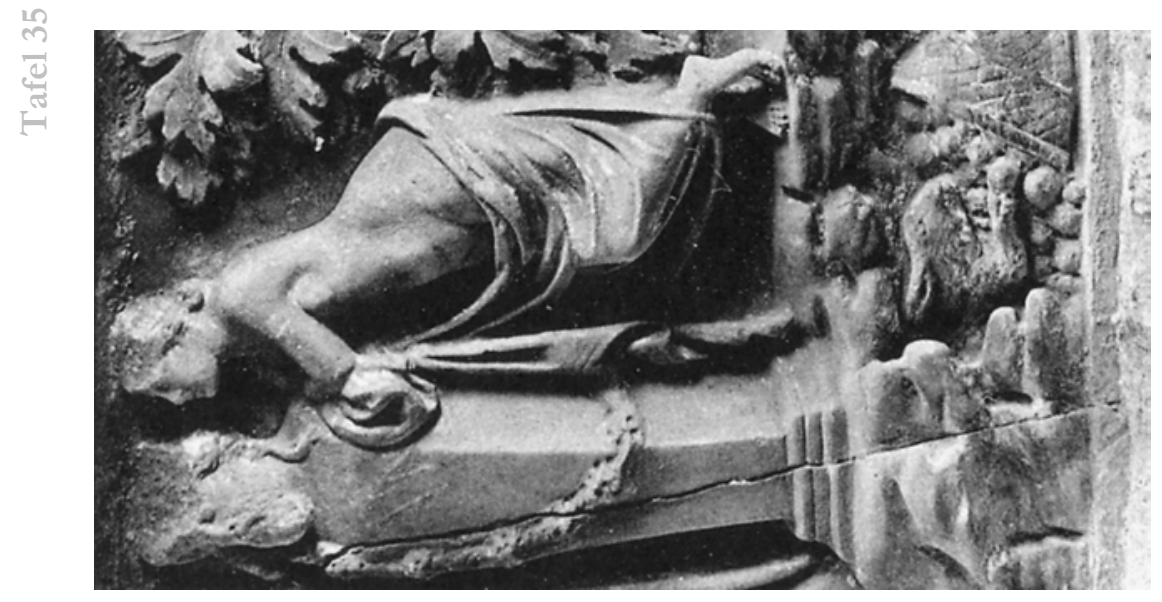

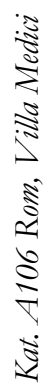

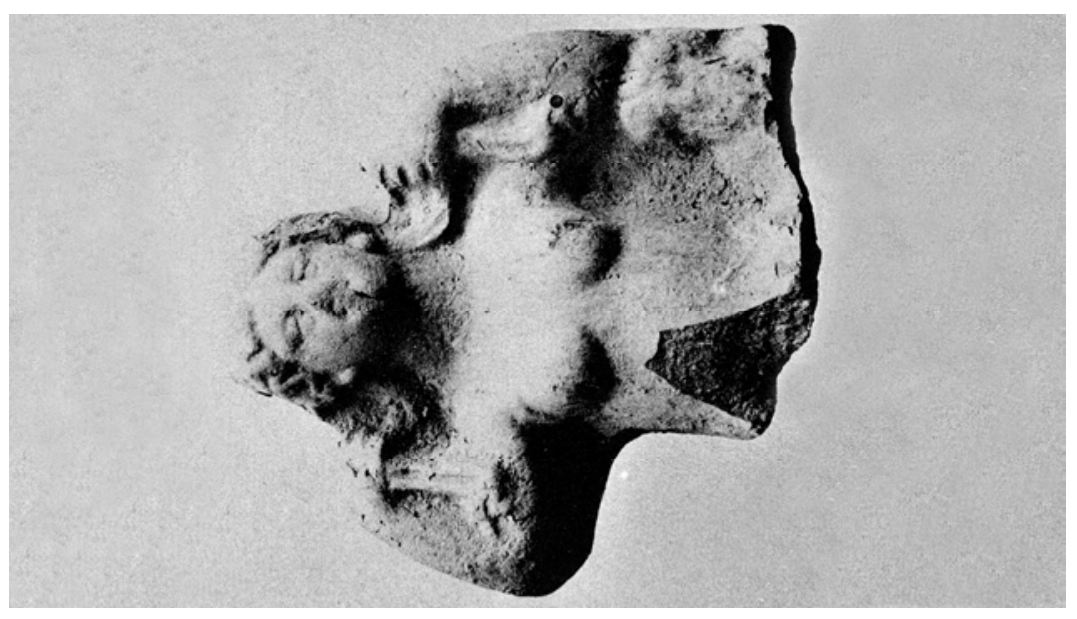

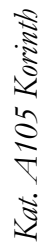

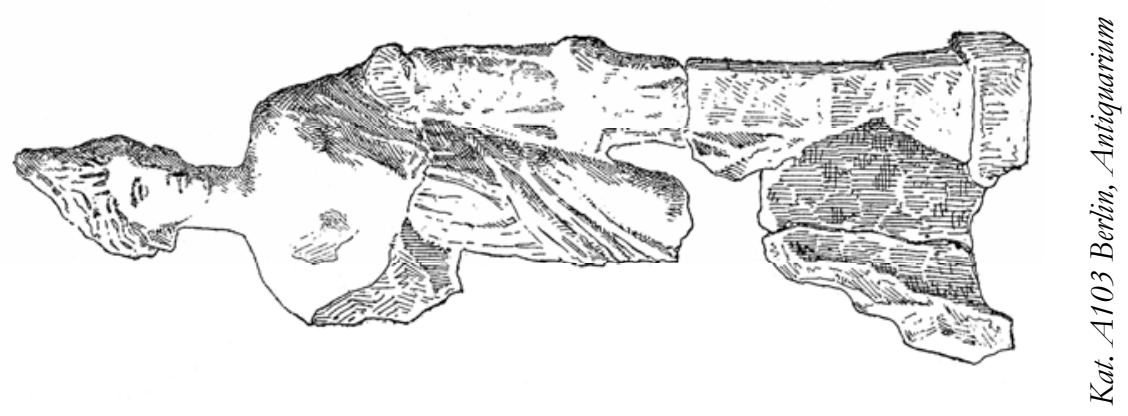




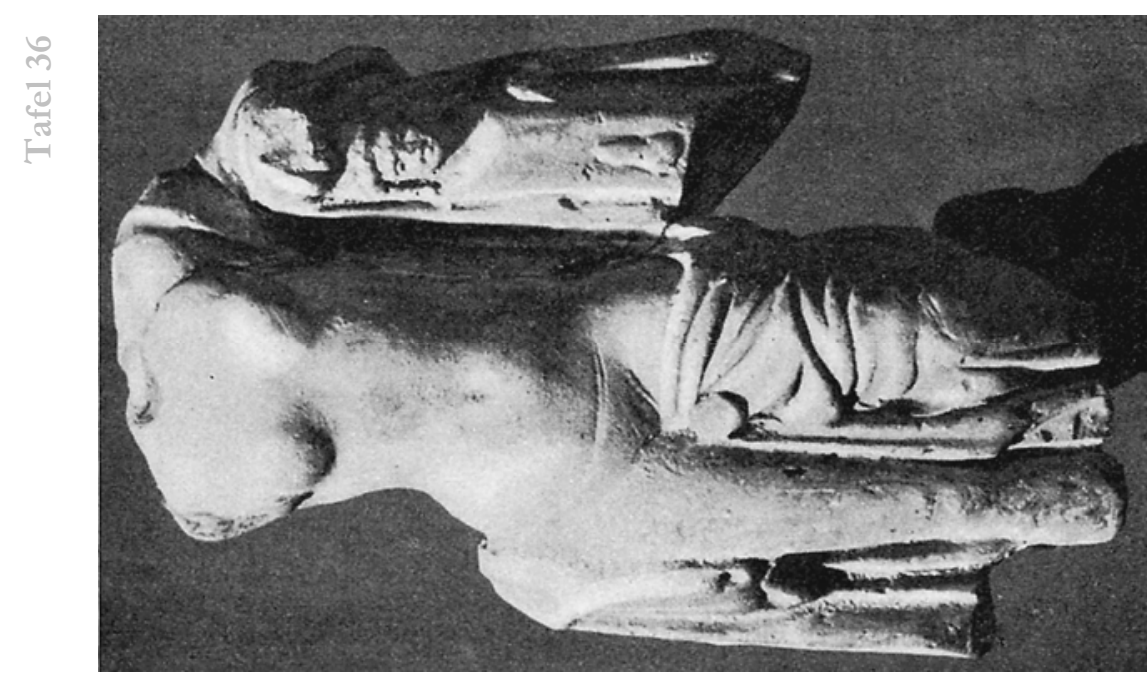

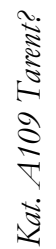

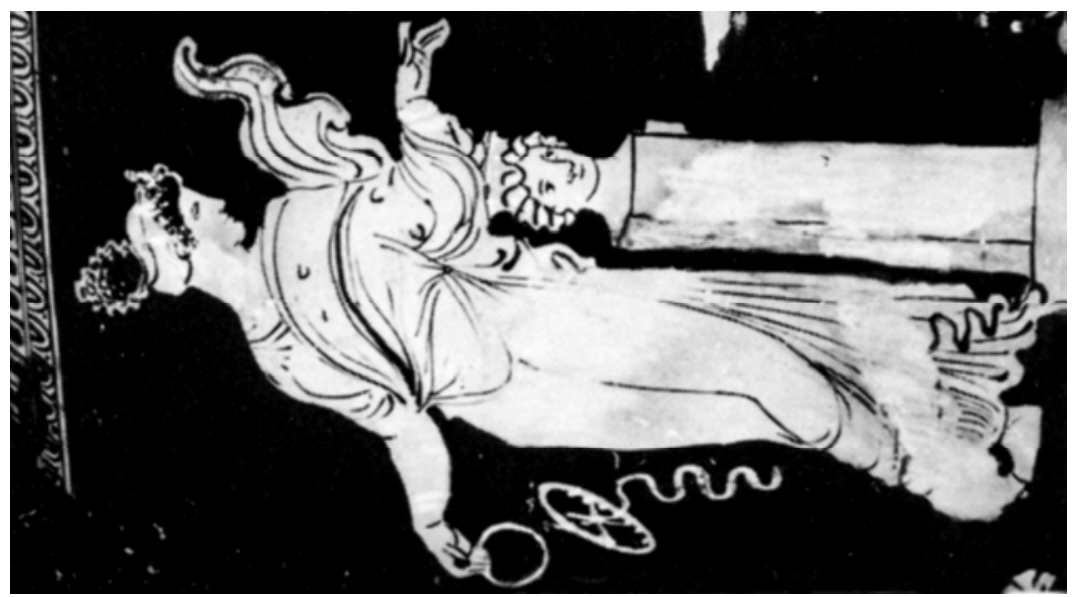

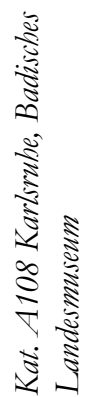

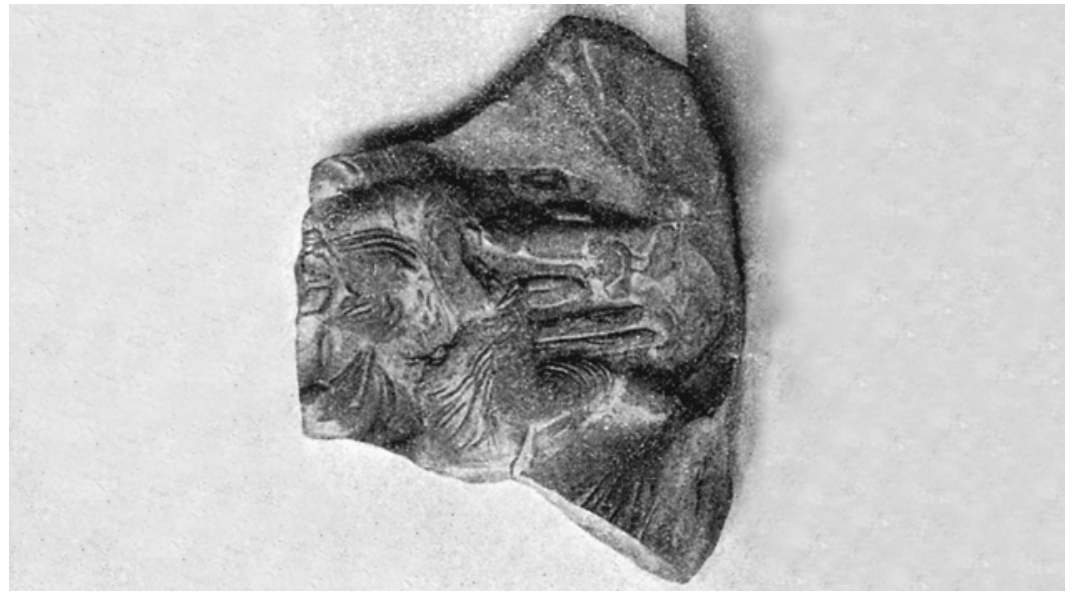

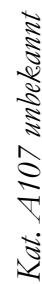




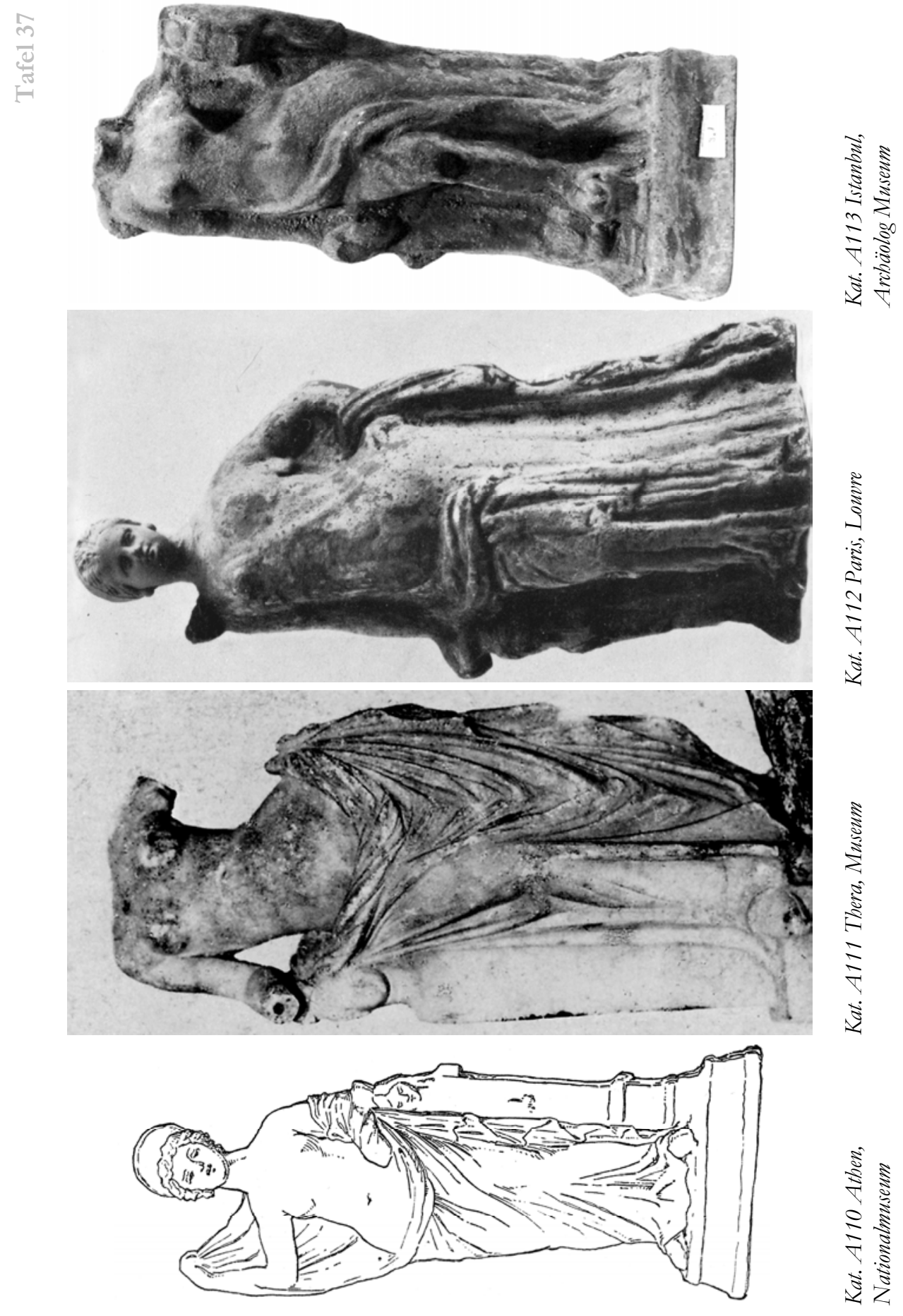




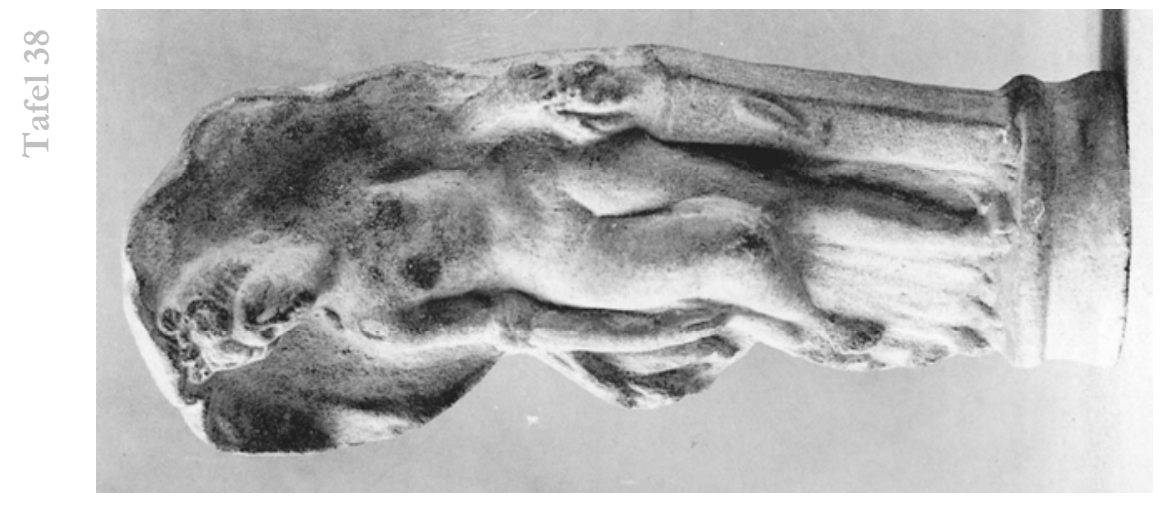

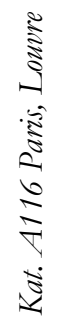

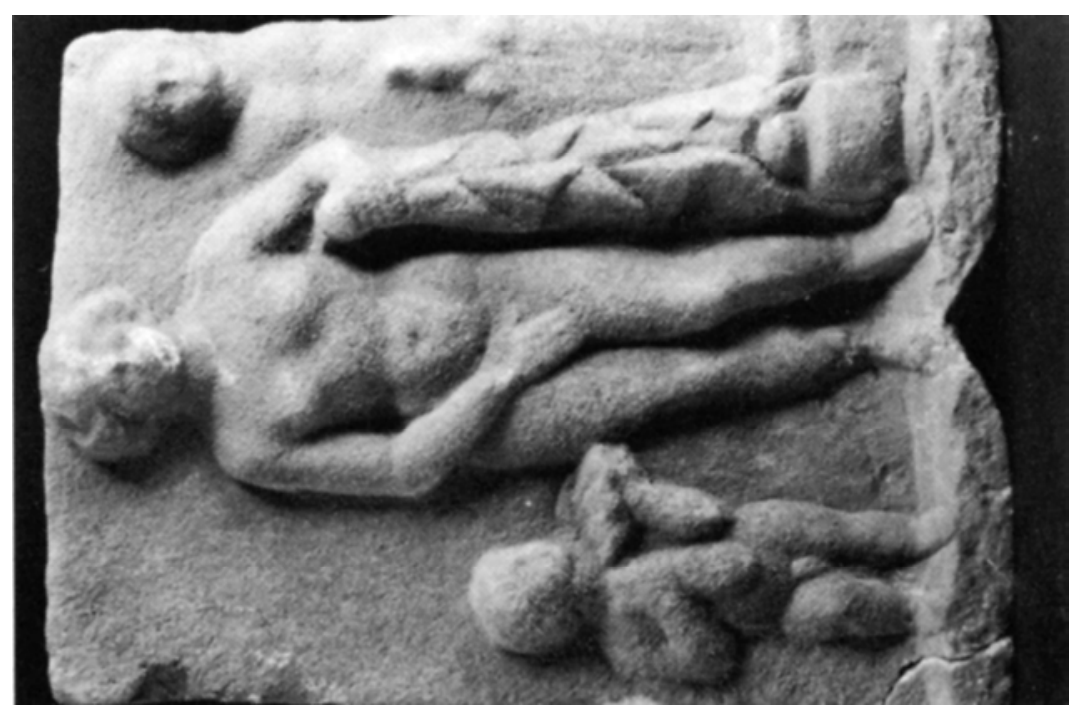

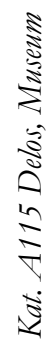

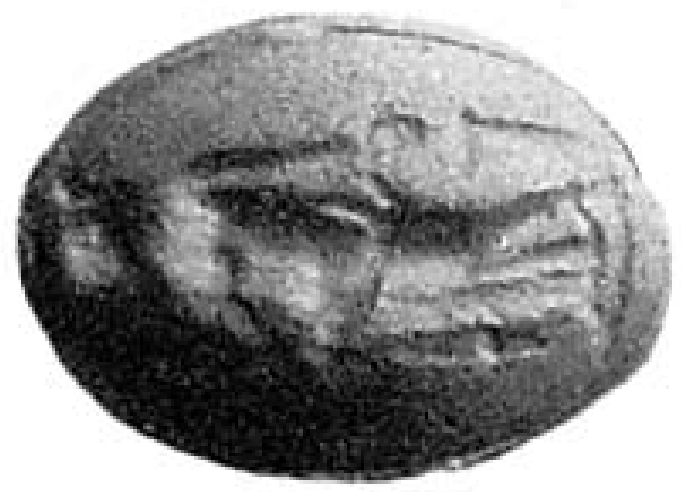

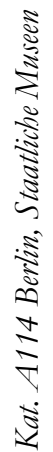



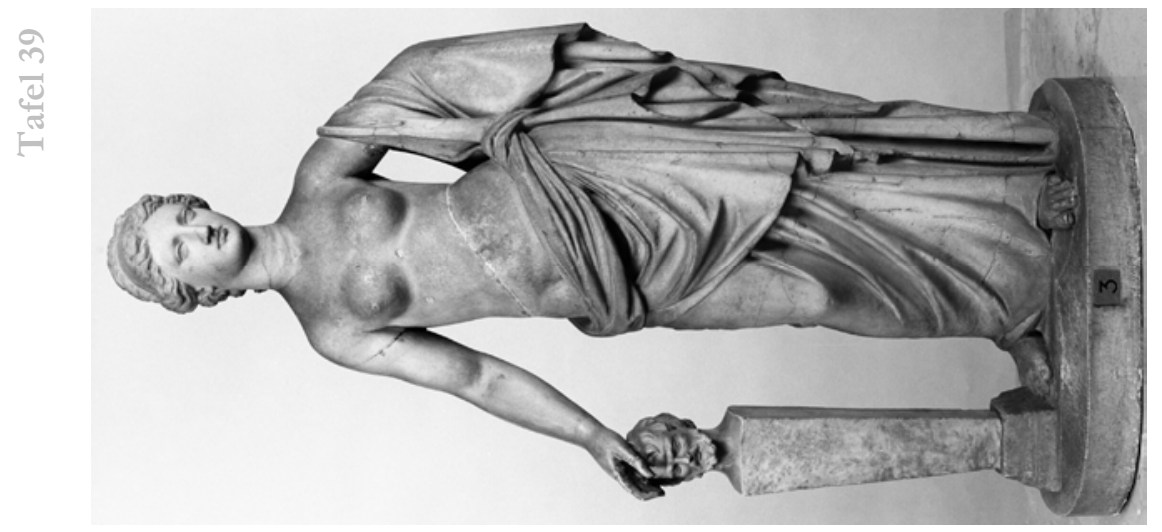

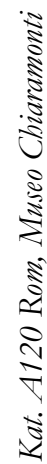

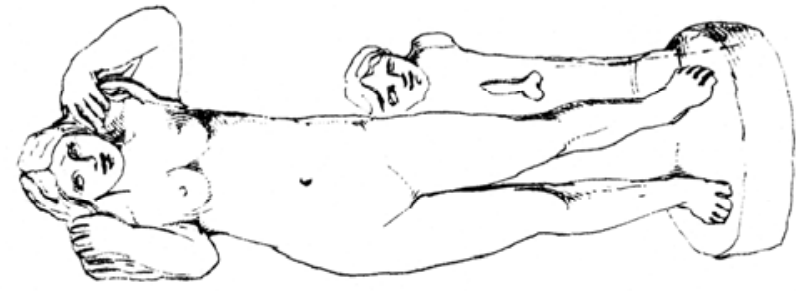

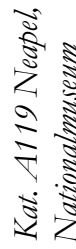

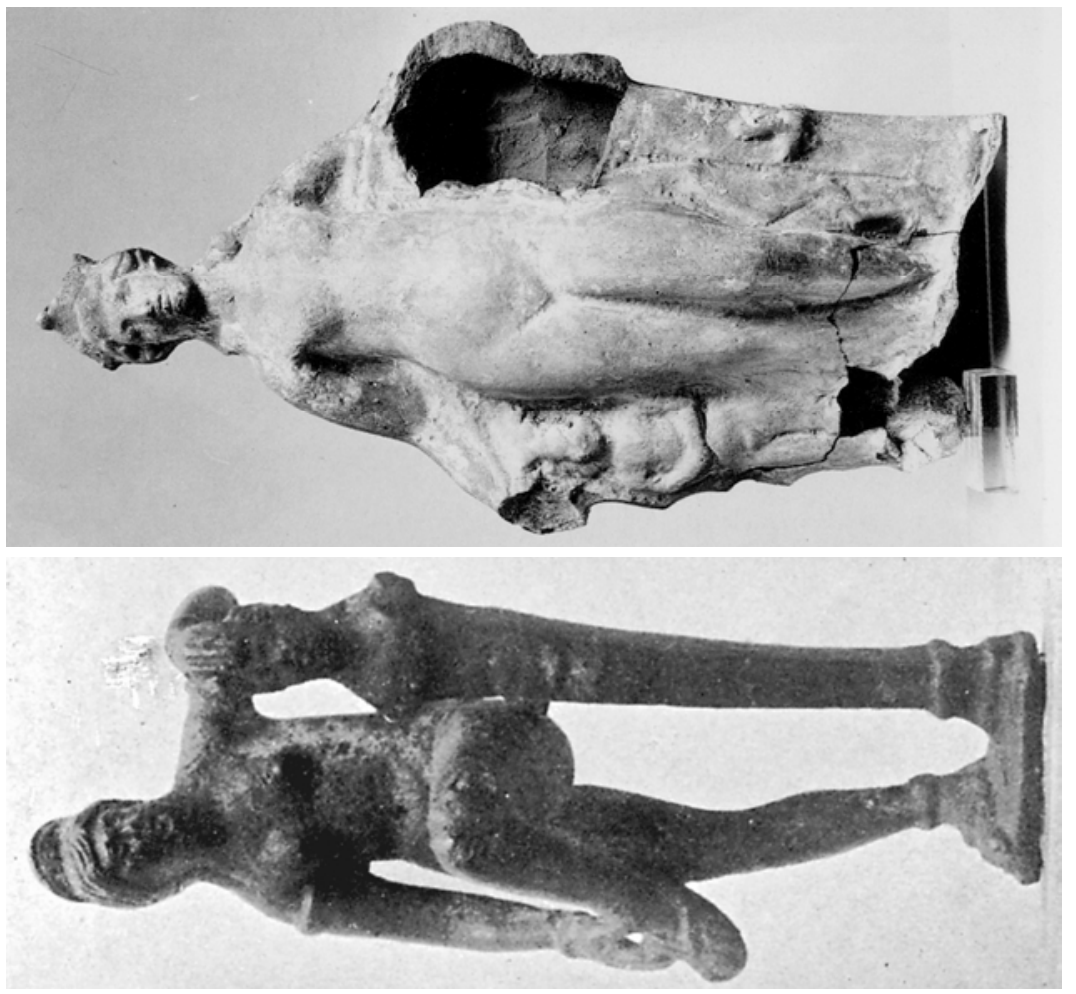

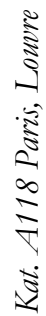

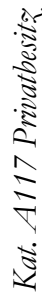


$\frac{}{\stackrel{+}{U}}$

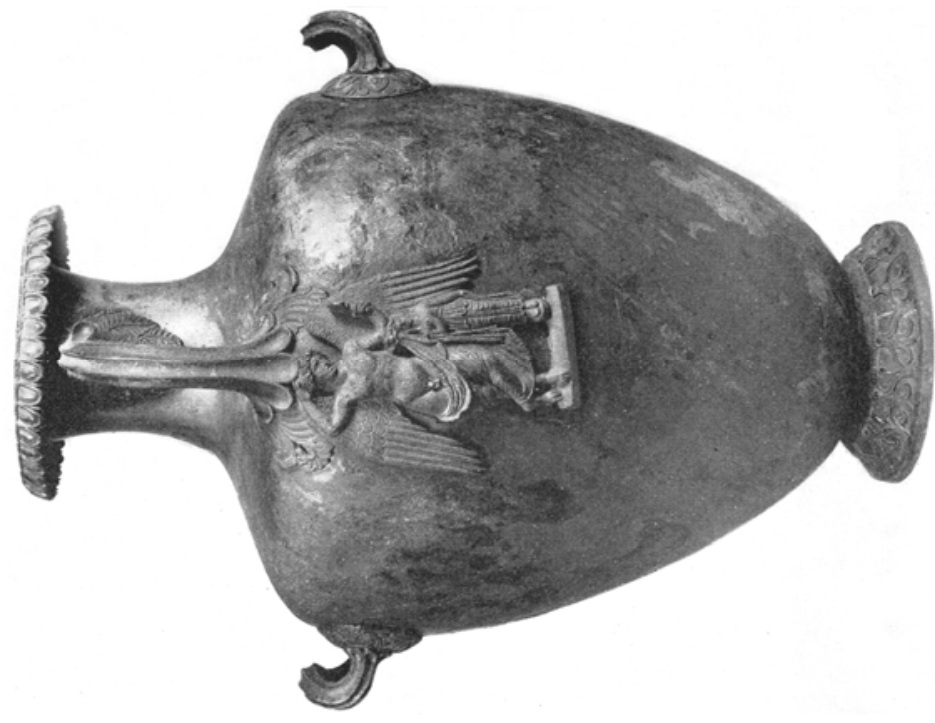

है

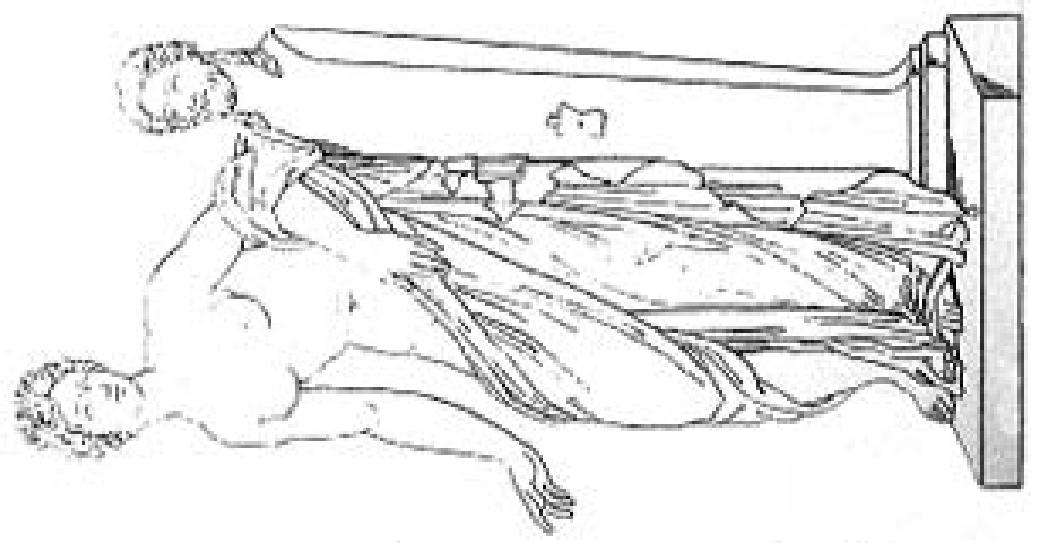

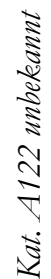

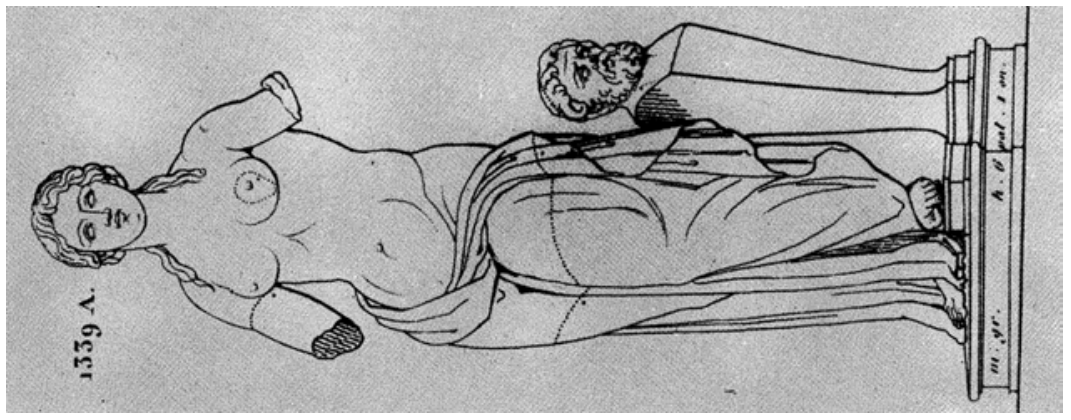

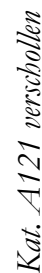



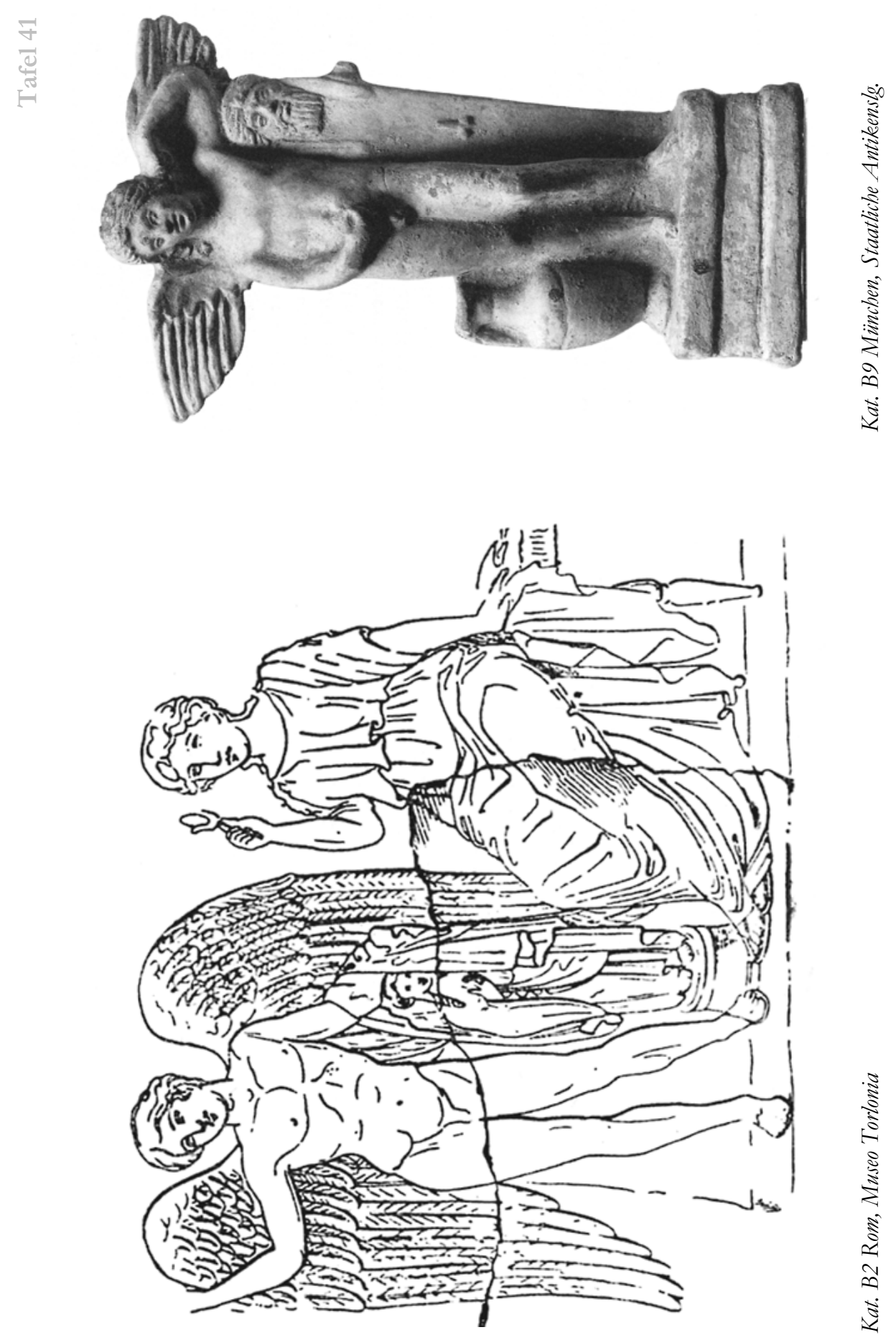
$\frac{\text { ำ }}{\mathcal{H}}$

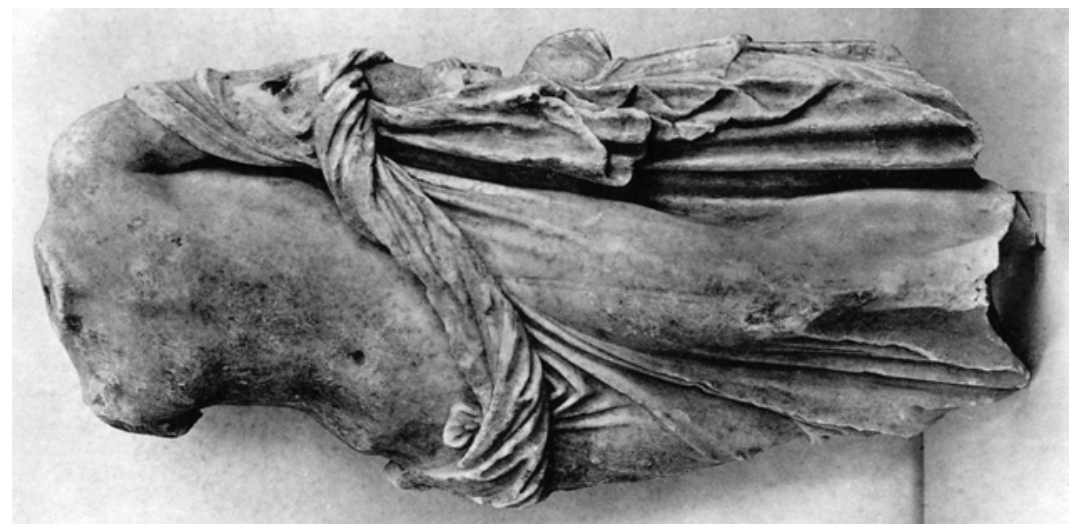

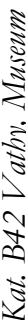

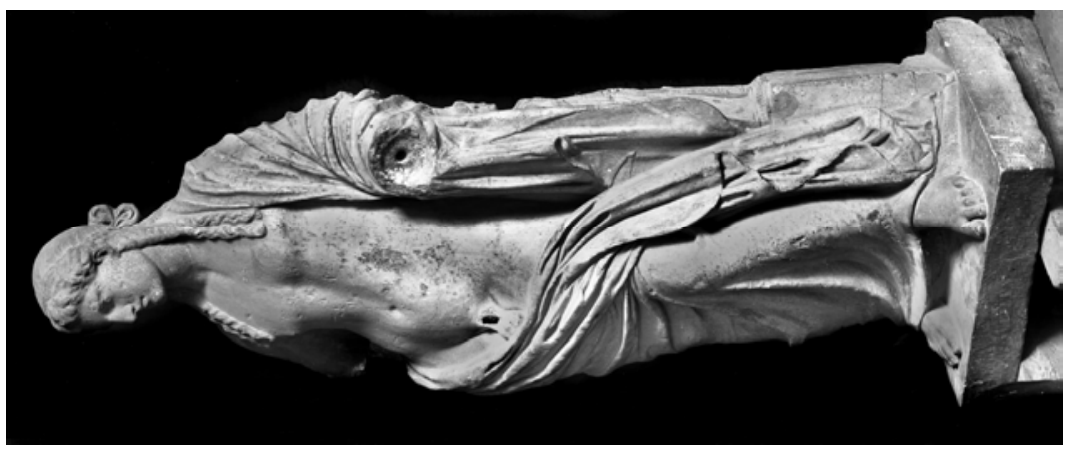

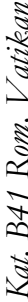

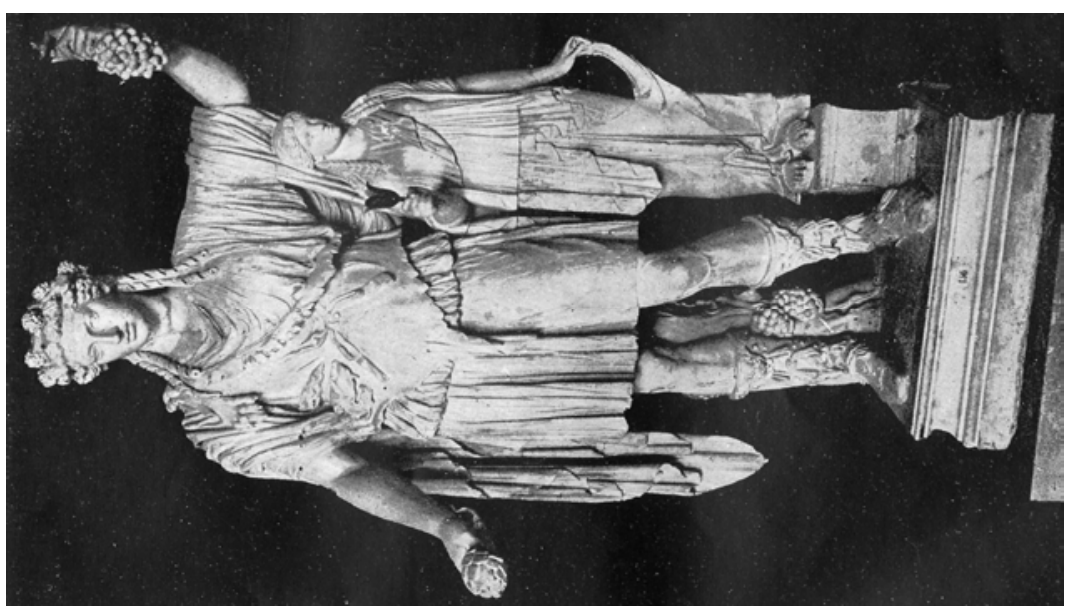

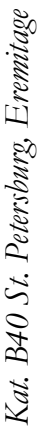


舀
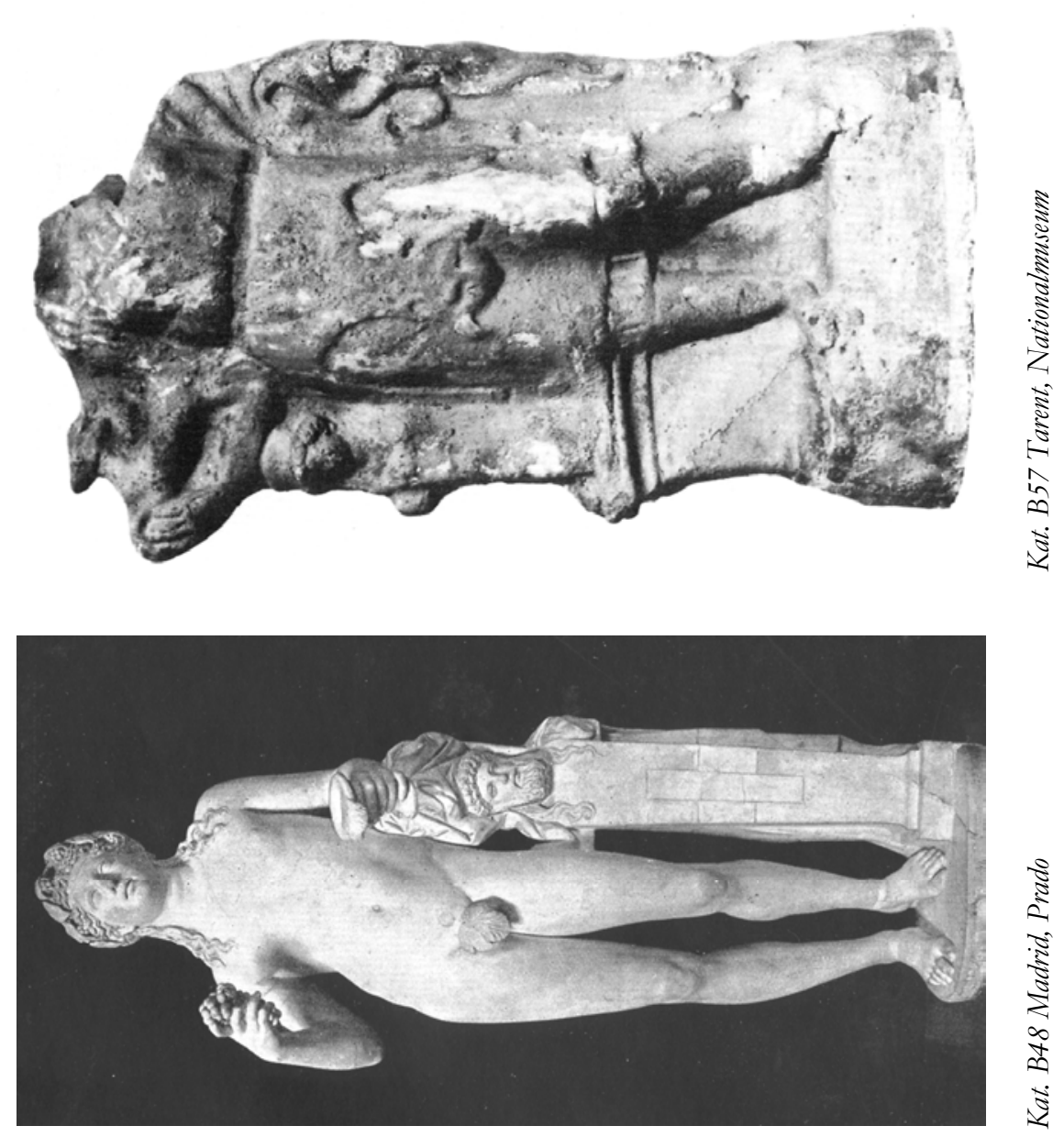

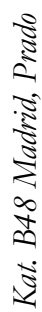

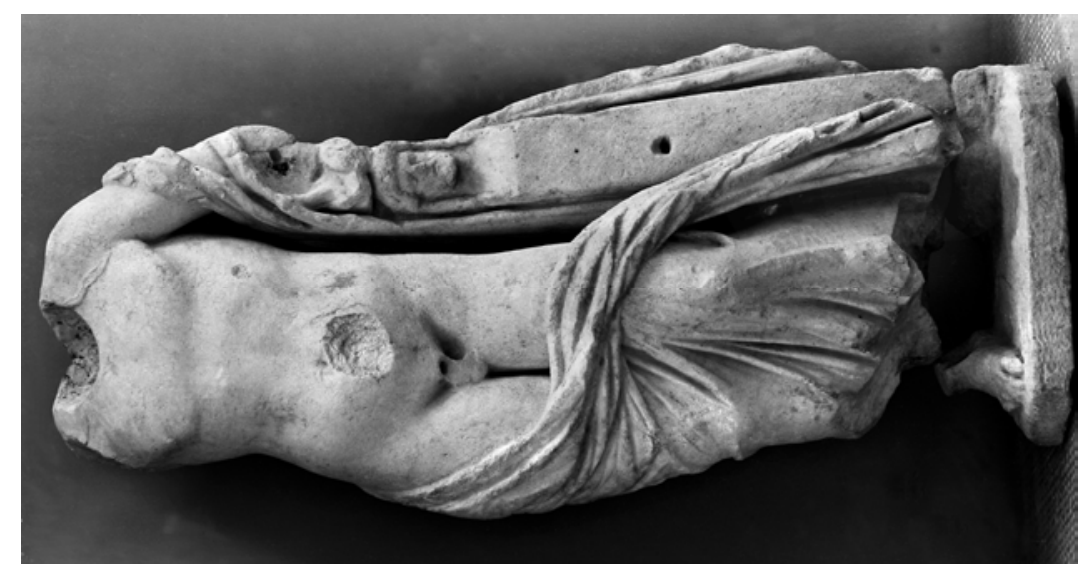

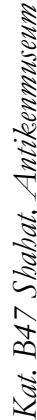




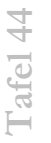
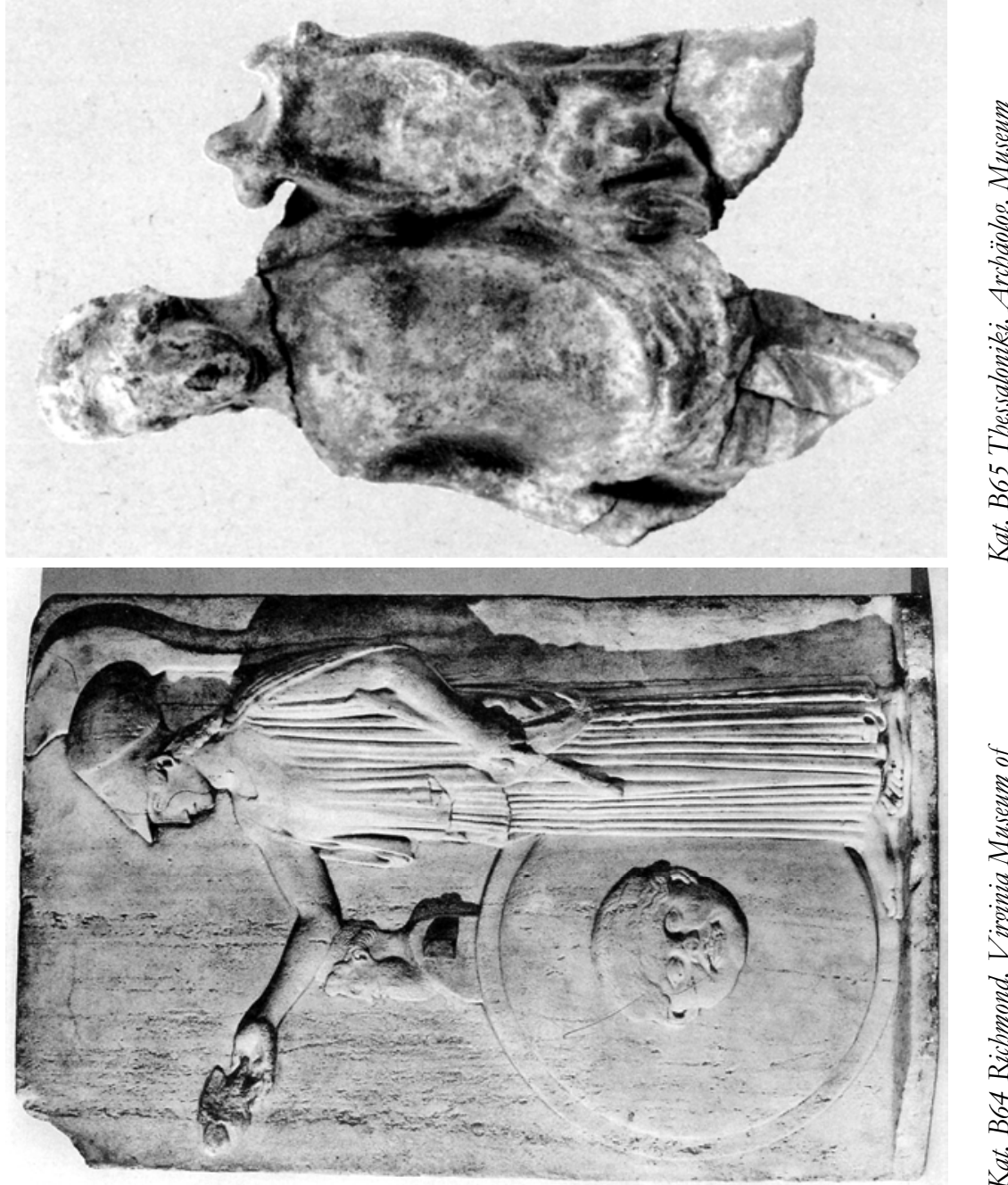

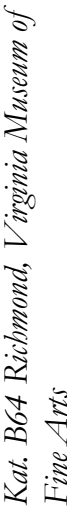

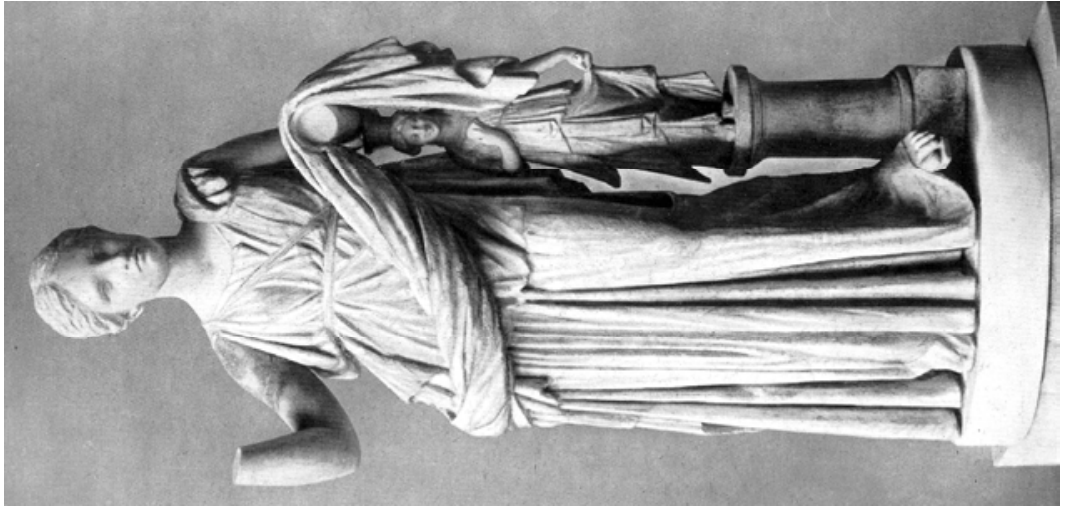

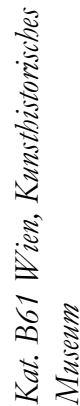



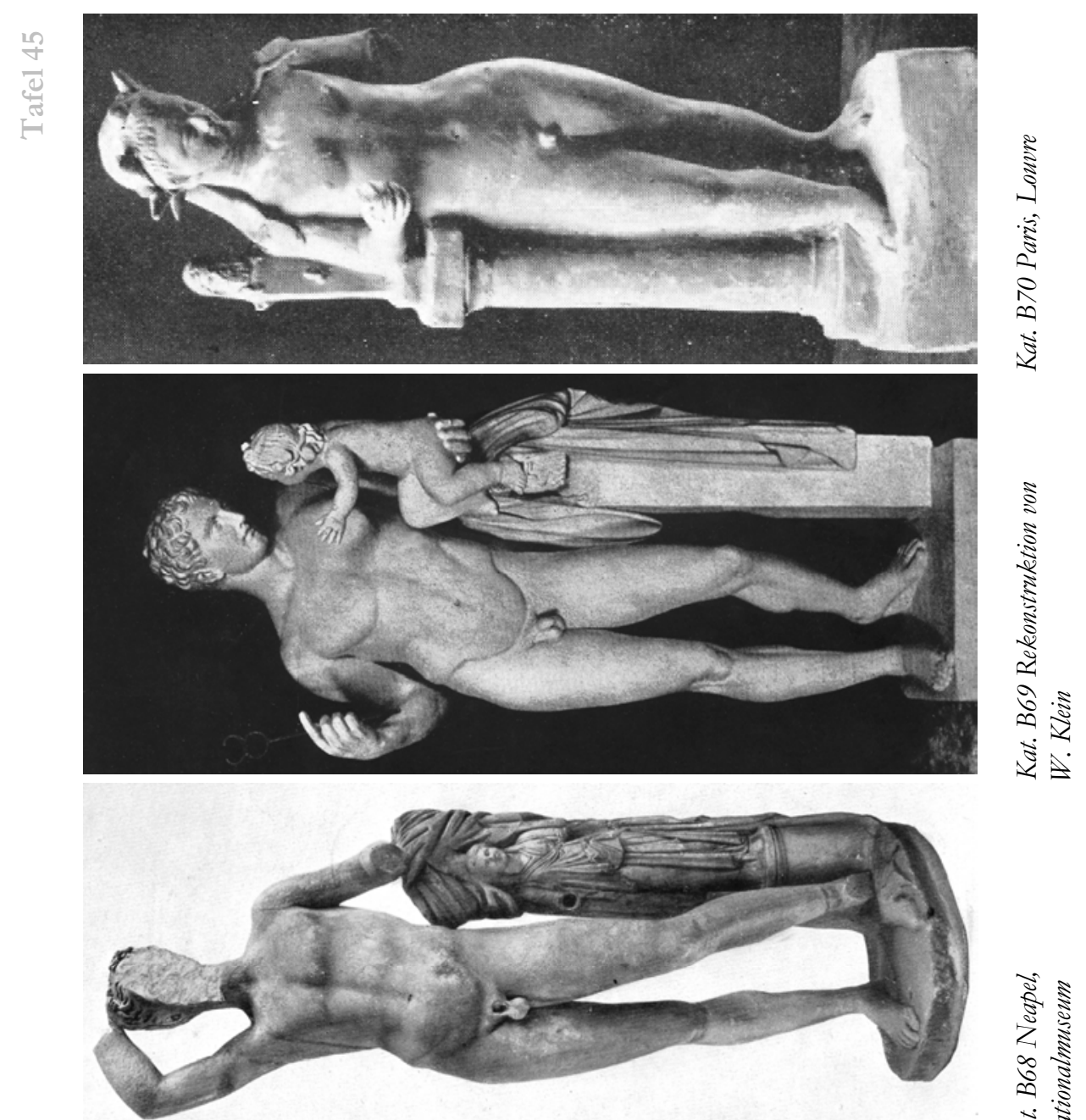

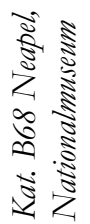

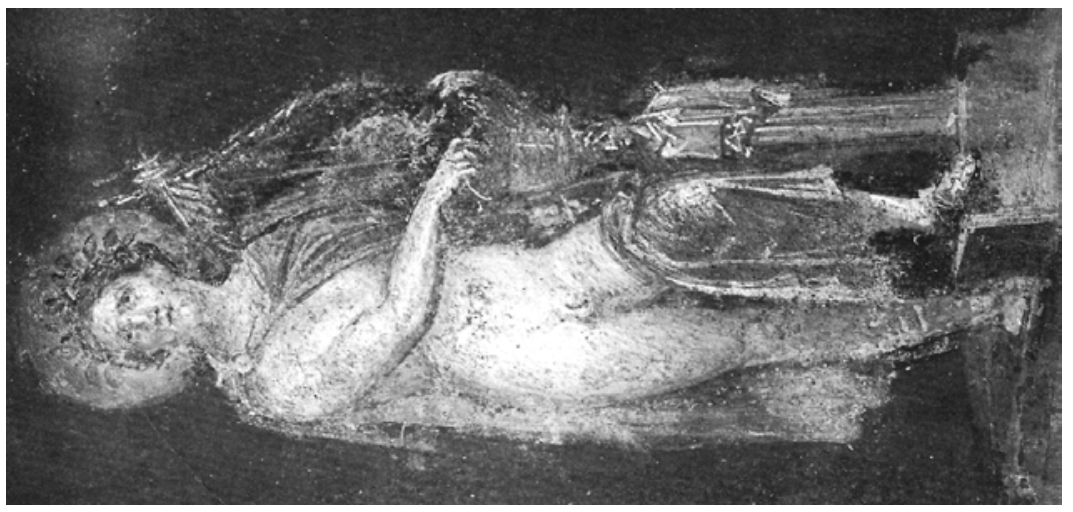

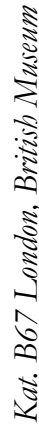




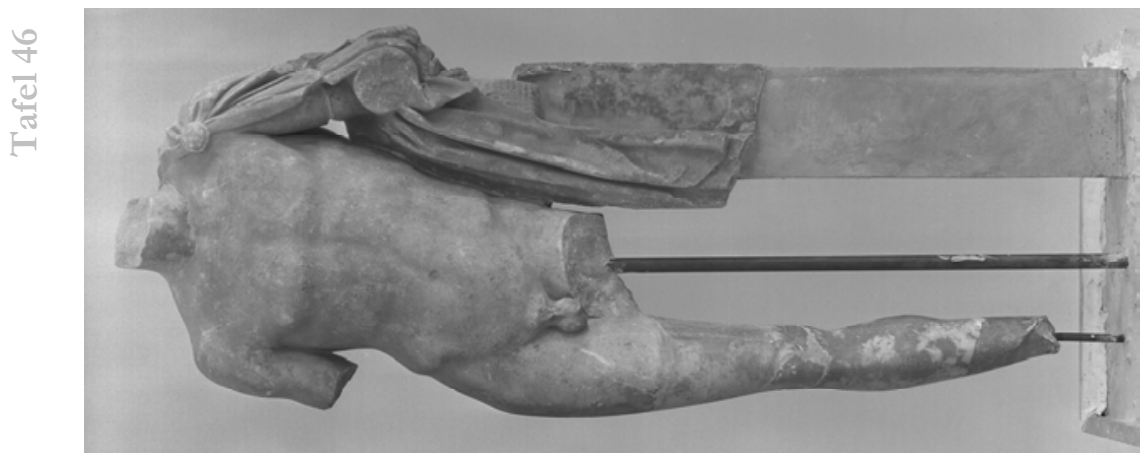

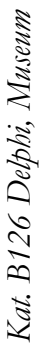

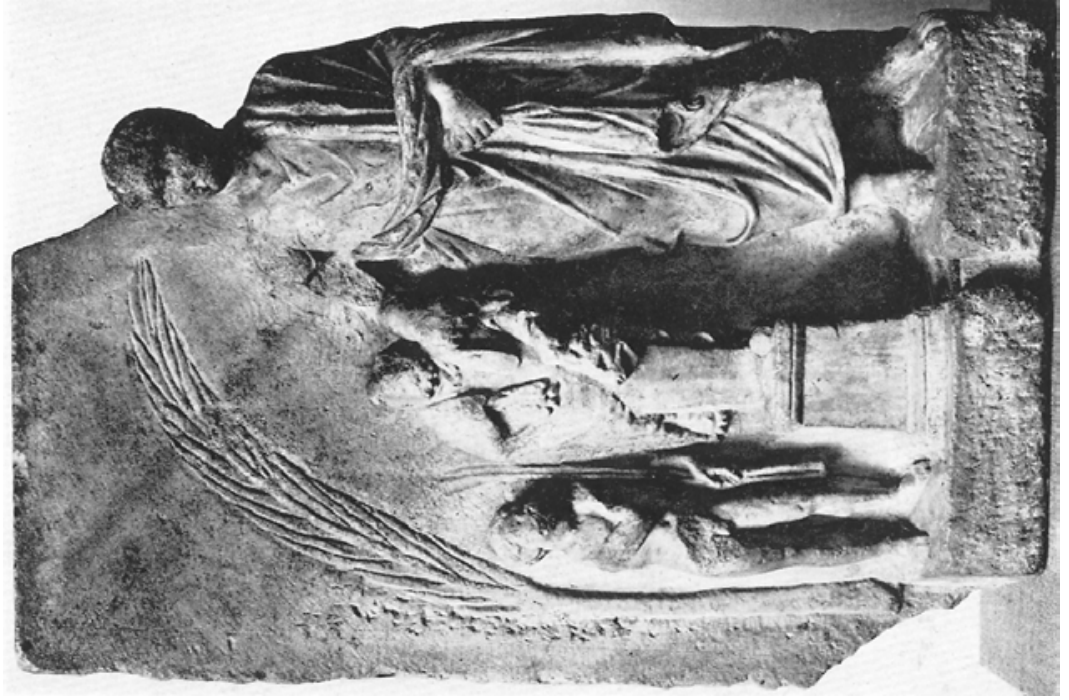

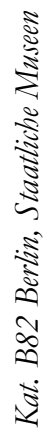

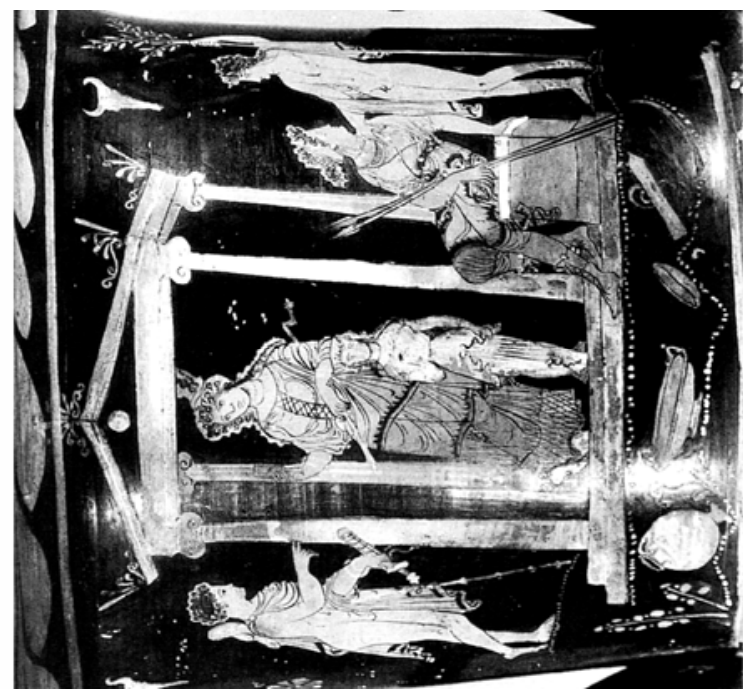

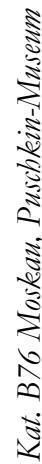




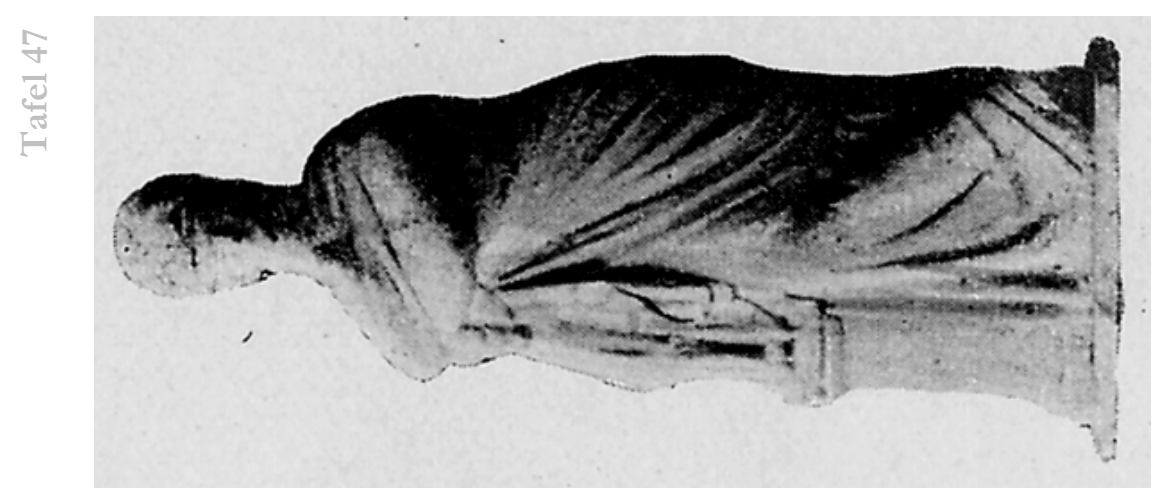

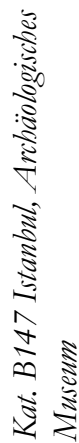

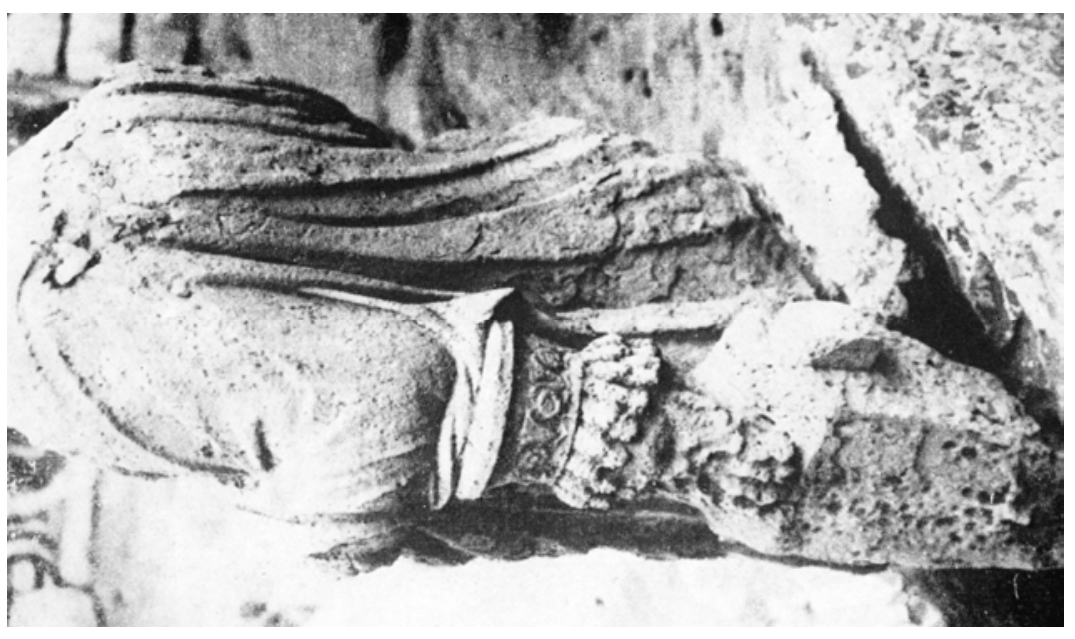

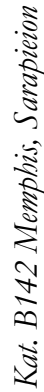

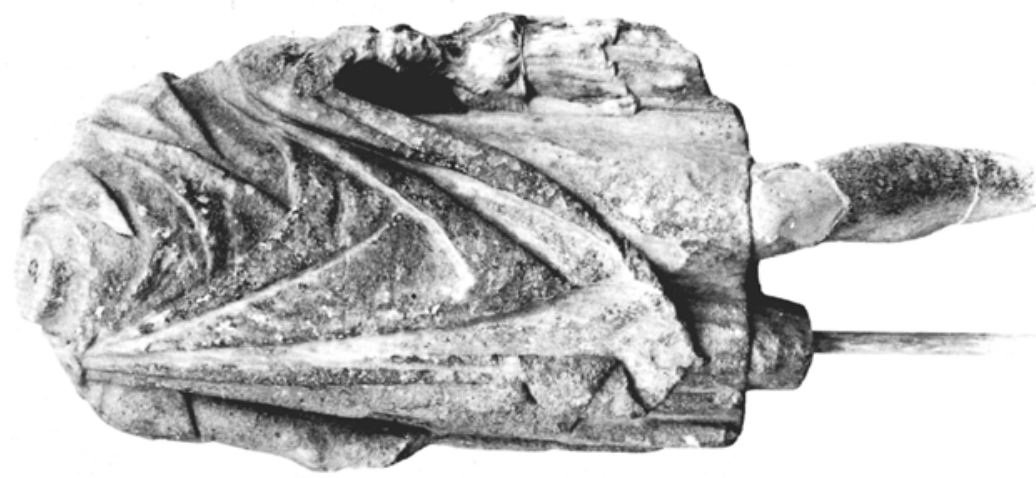

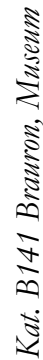




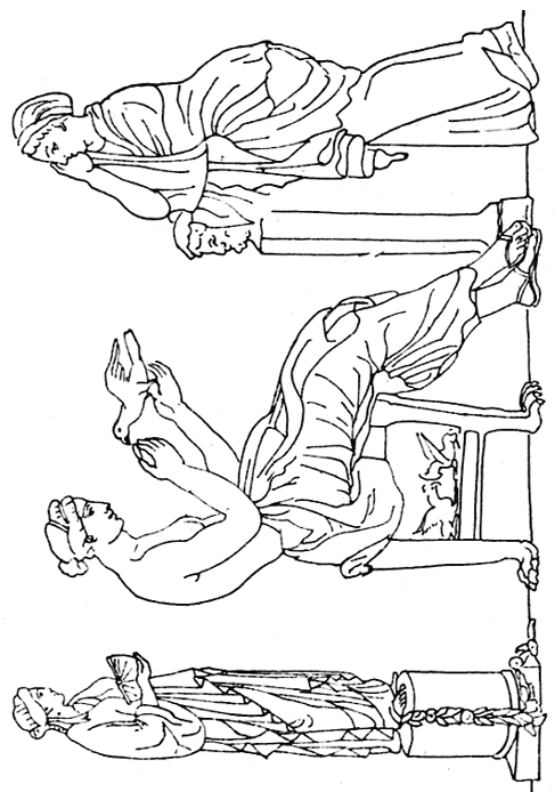

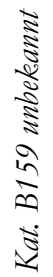

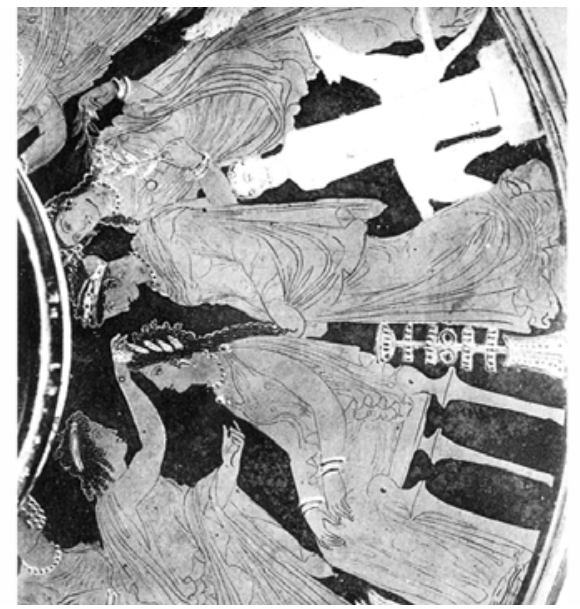

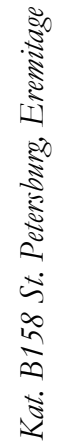

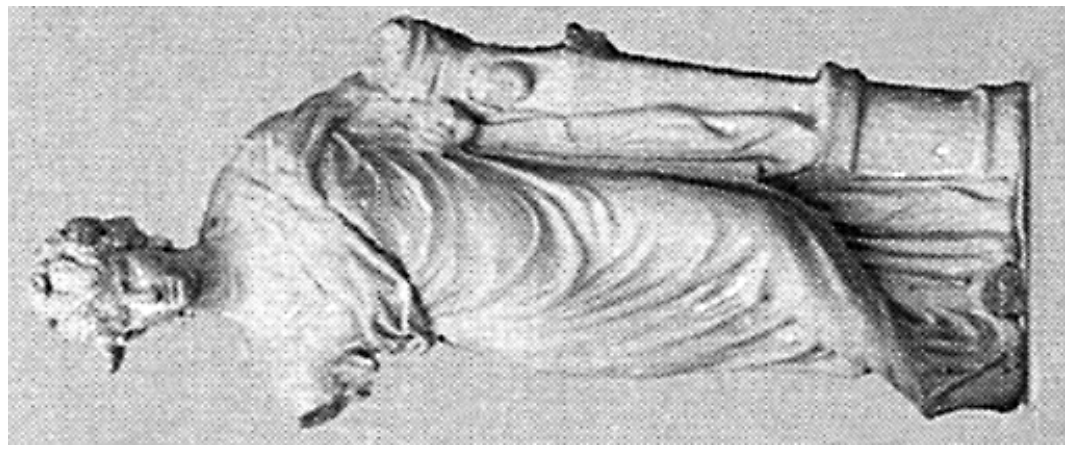

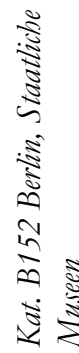


Abbildungen 


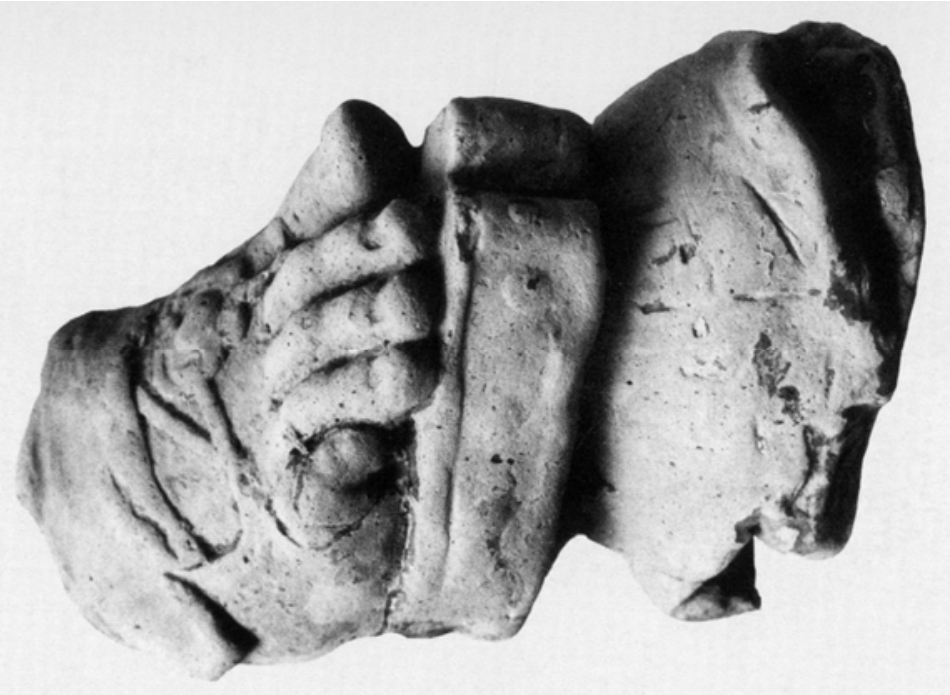

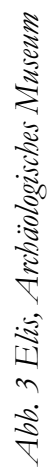

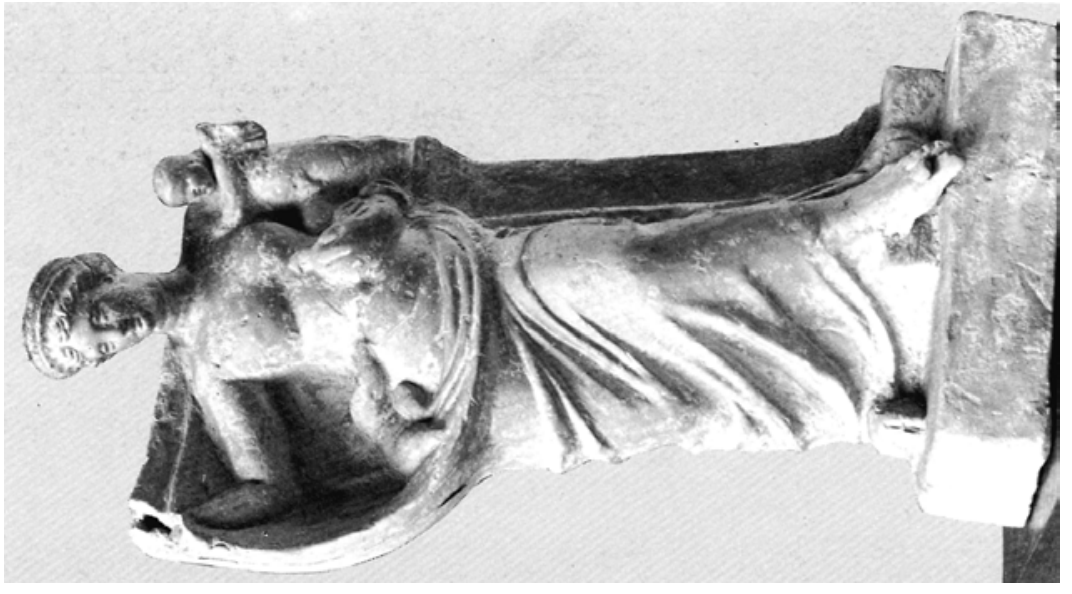

है
है
है
2
है
है

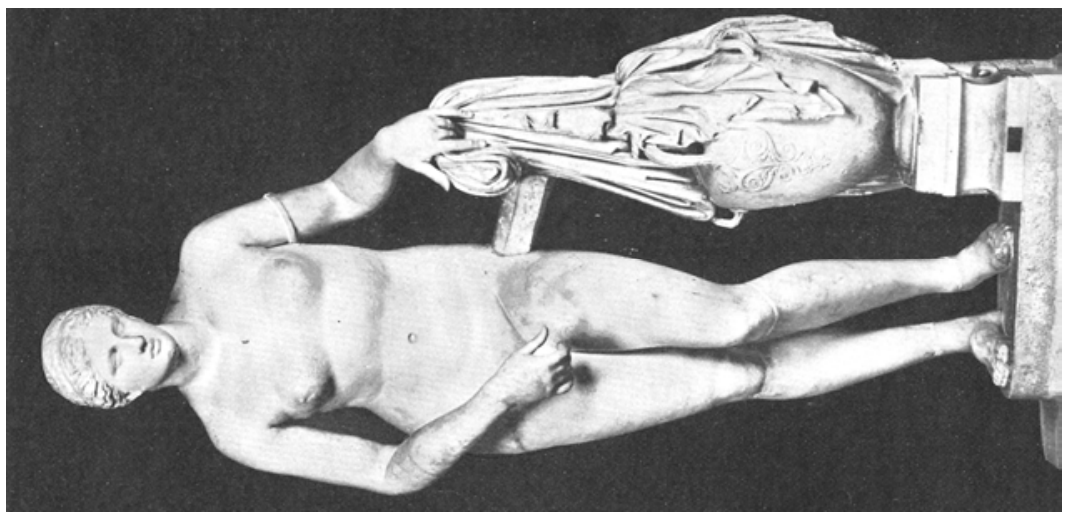

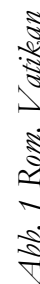




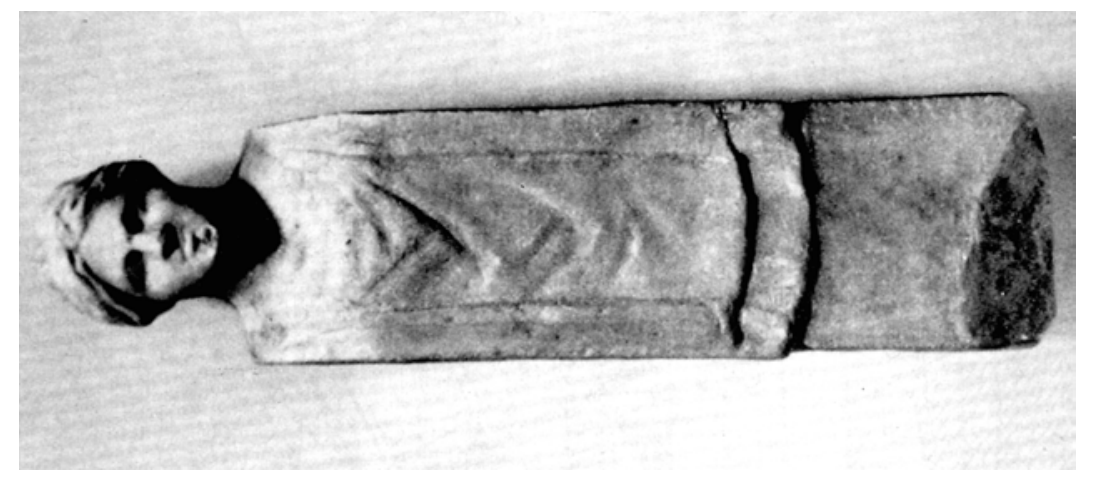

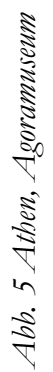

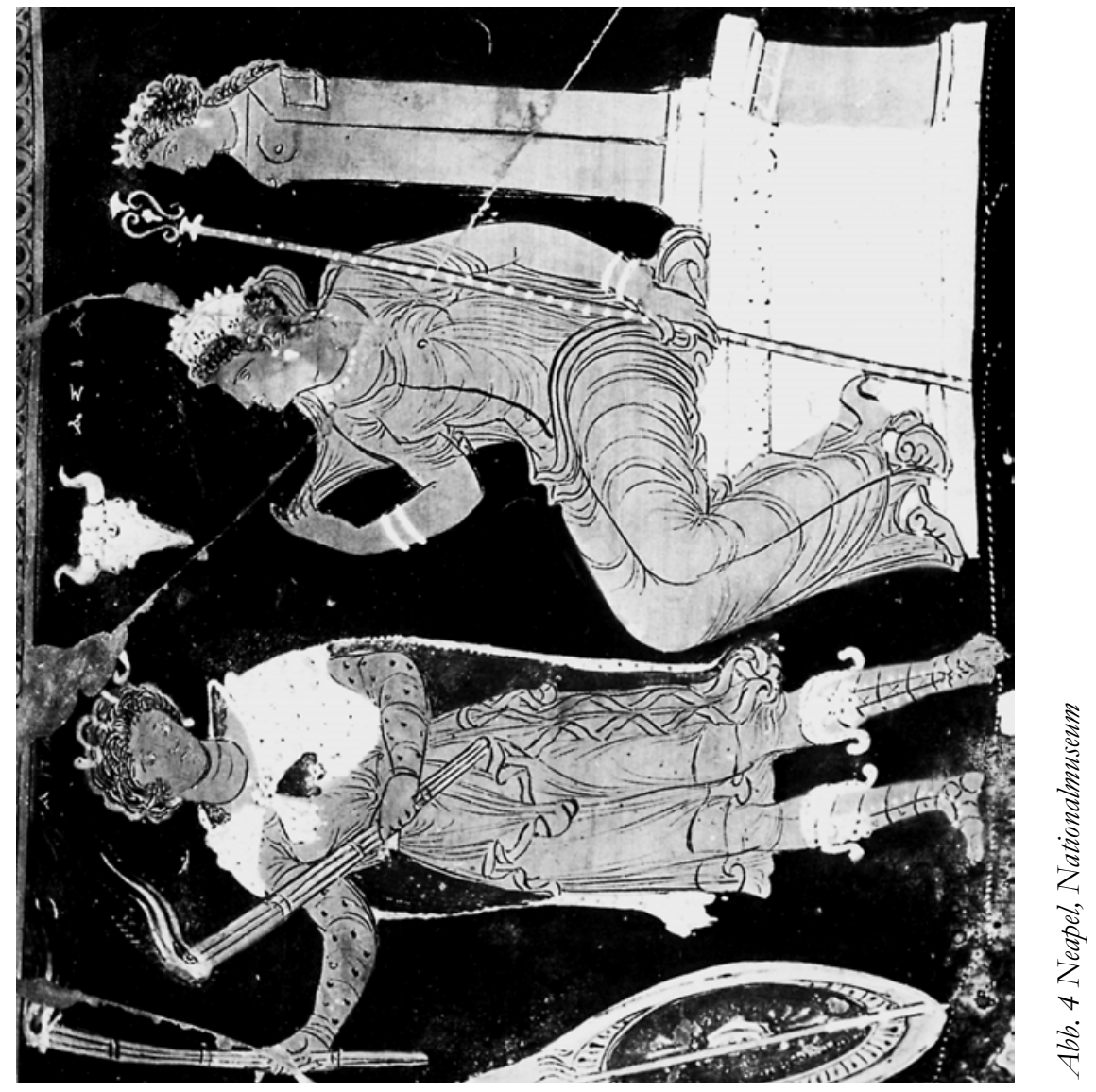




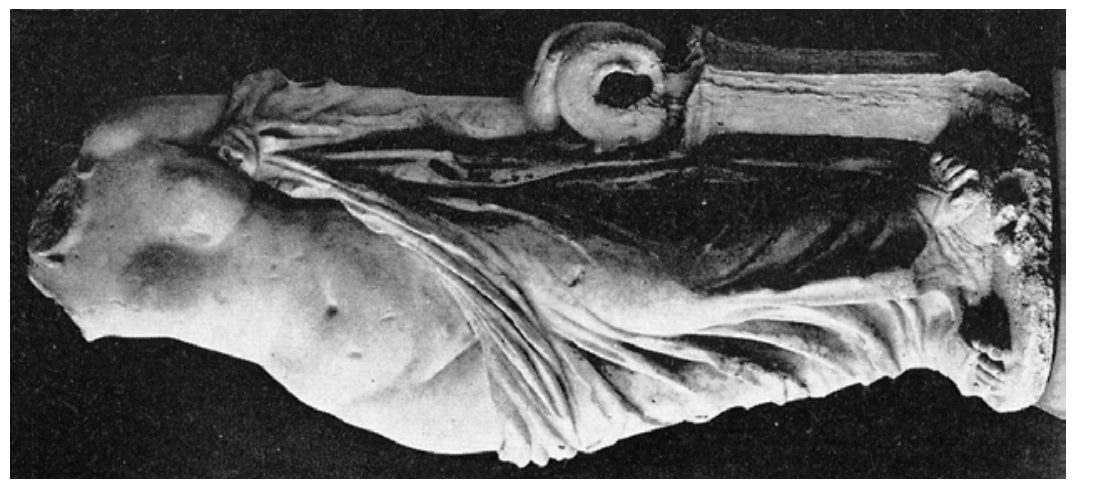

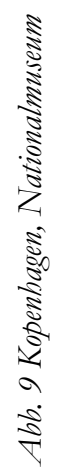

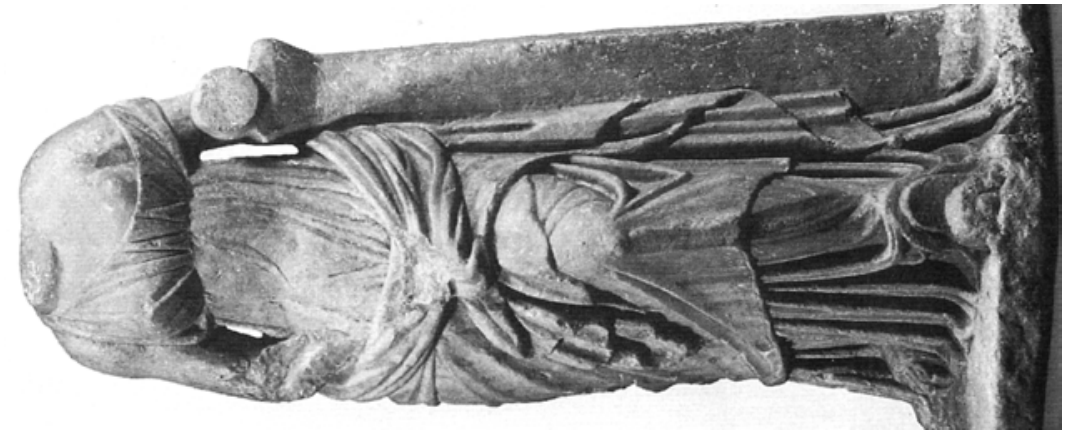

है
है
है
है
है
है
है

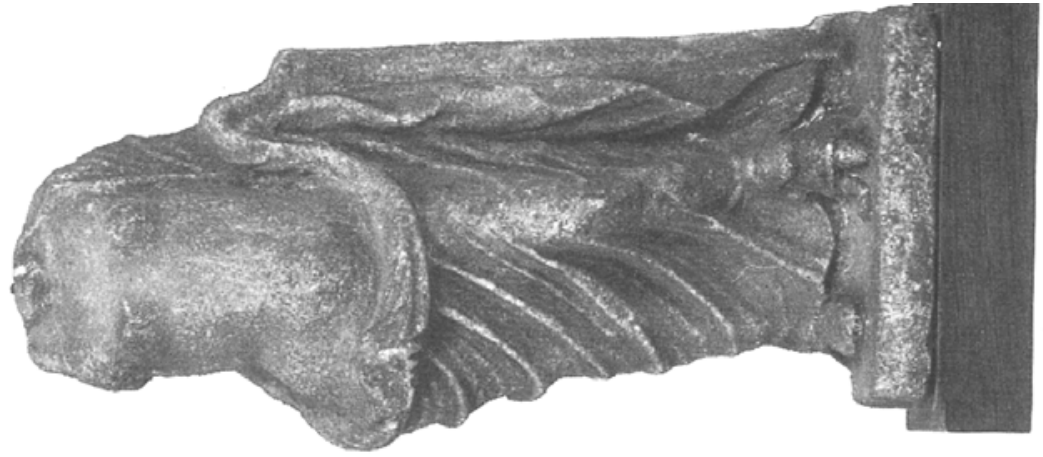

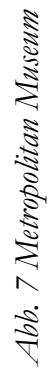

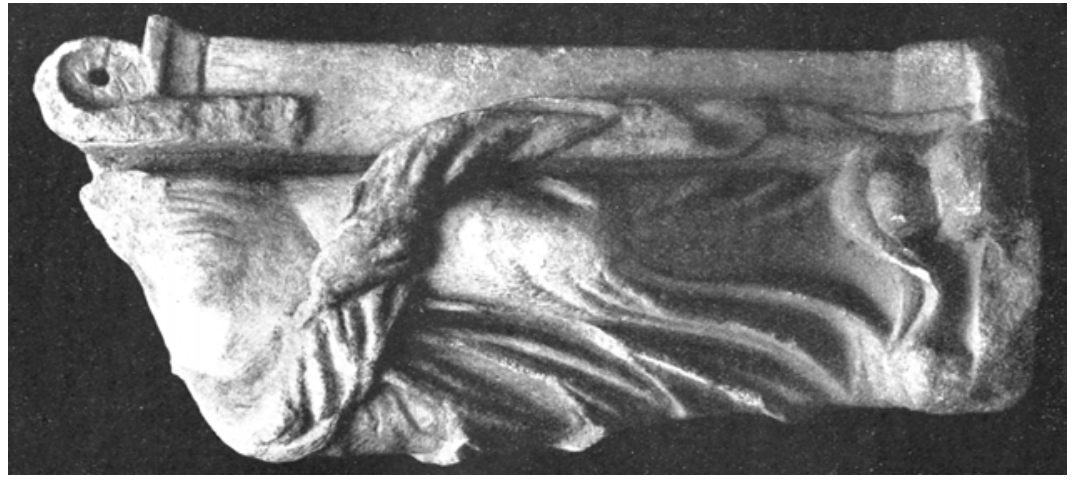

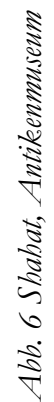




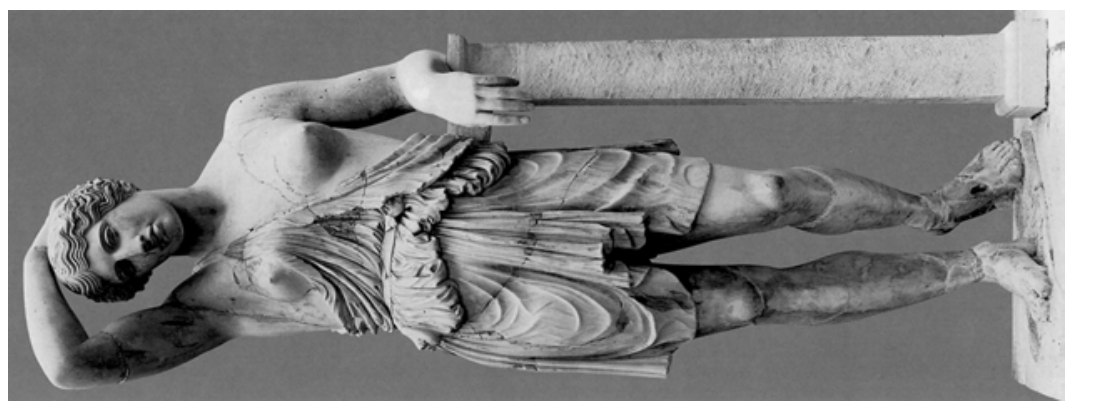

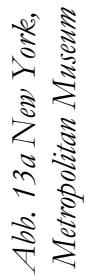

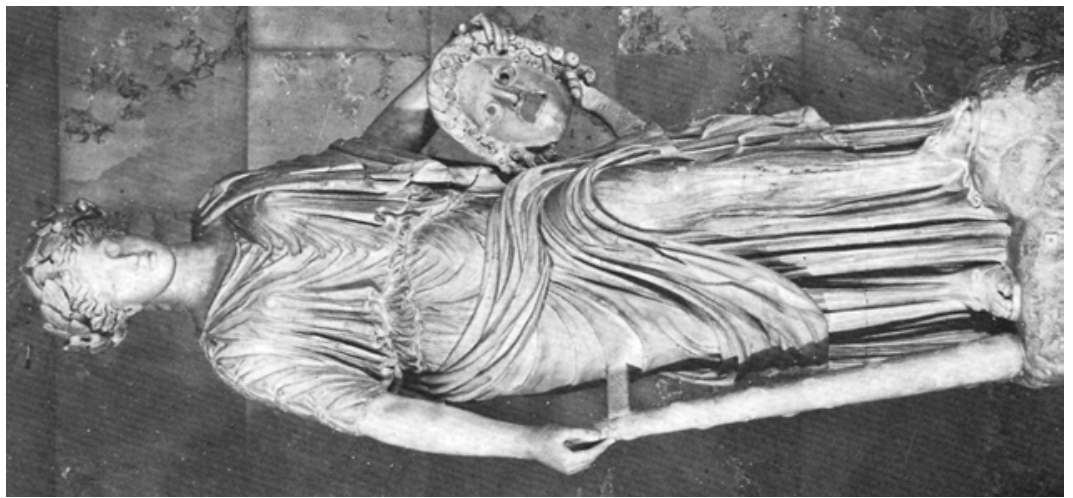

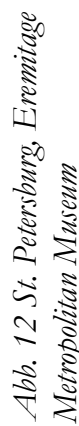

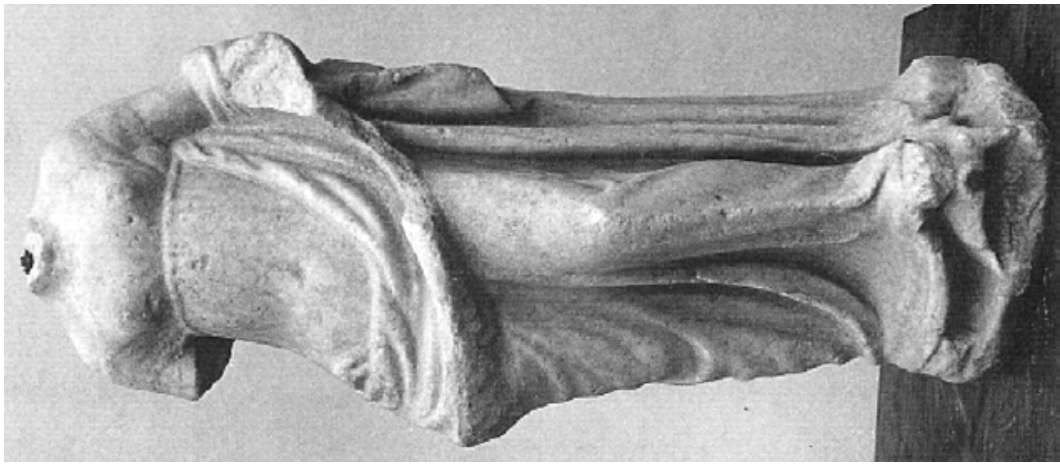

है

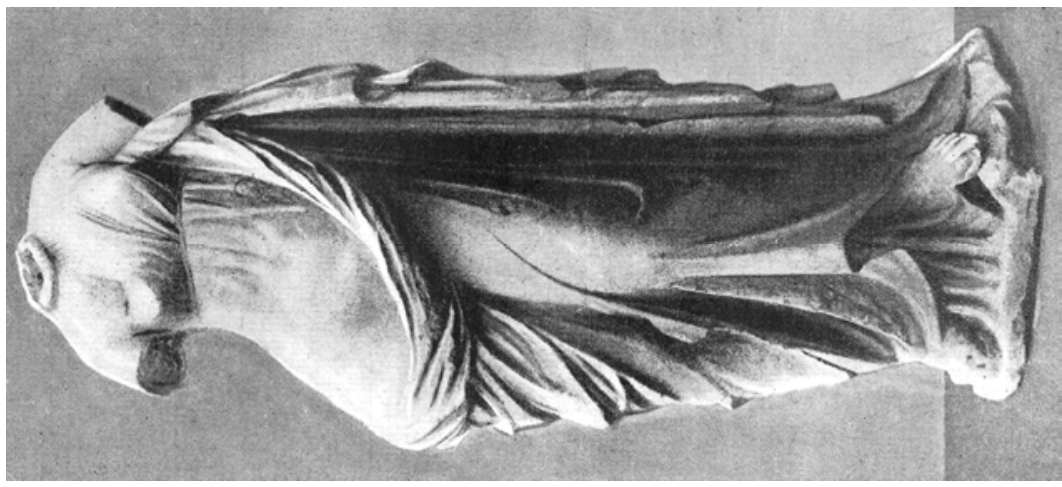

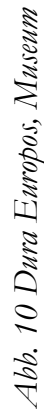




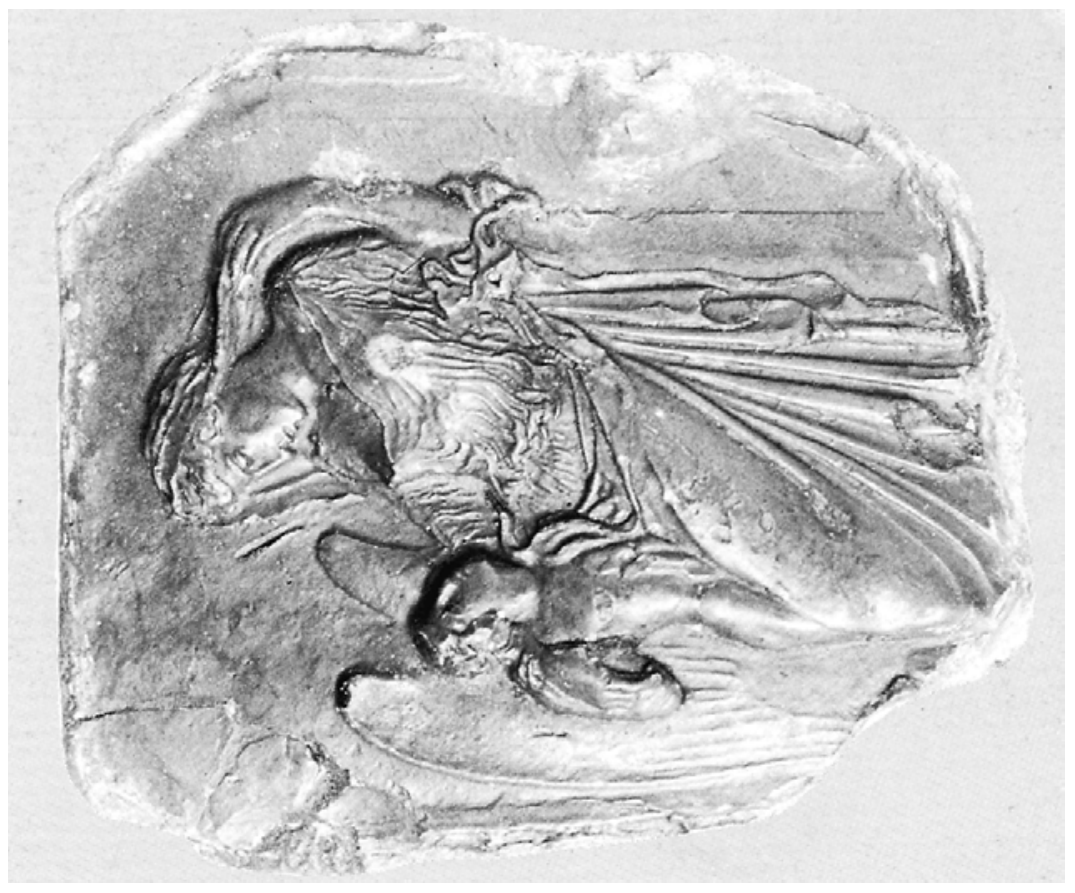

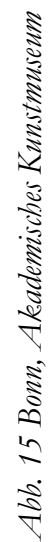

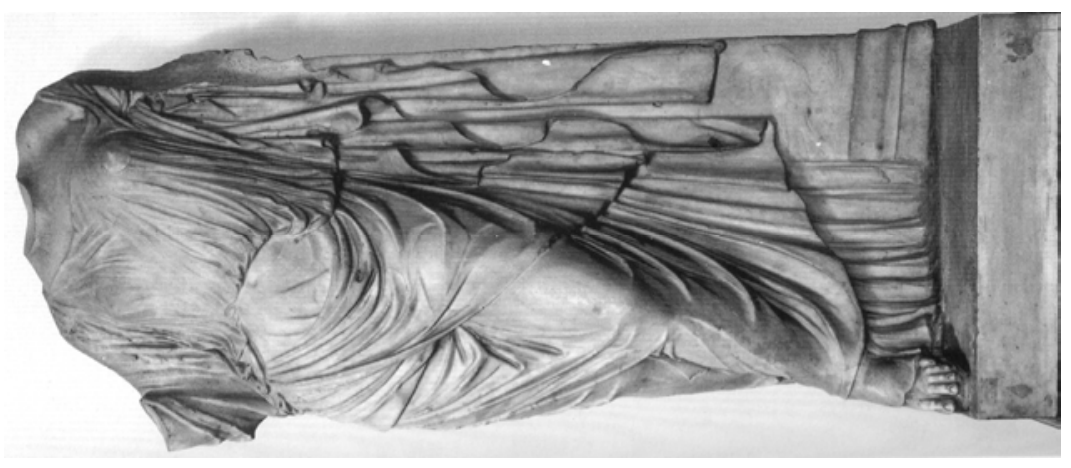

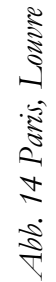

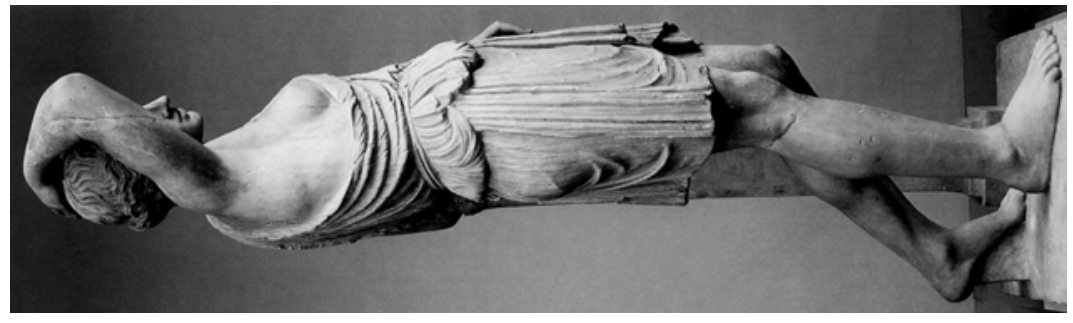

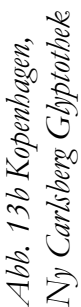




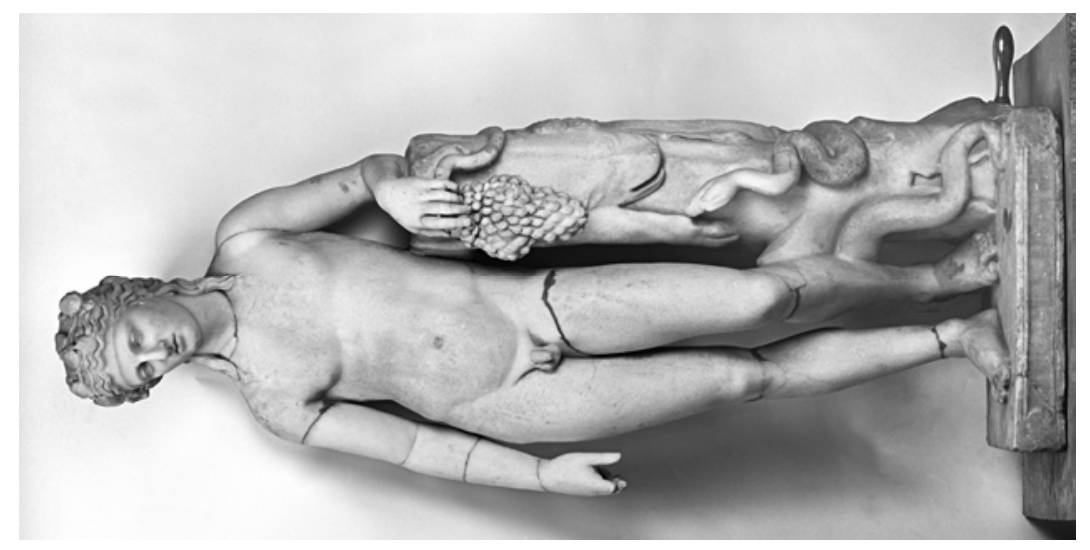

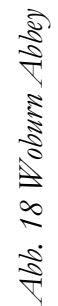

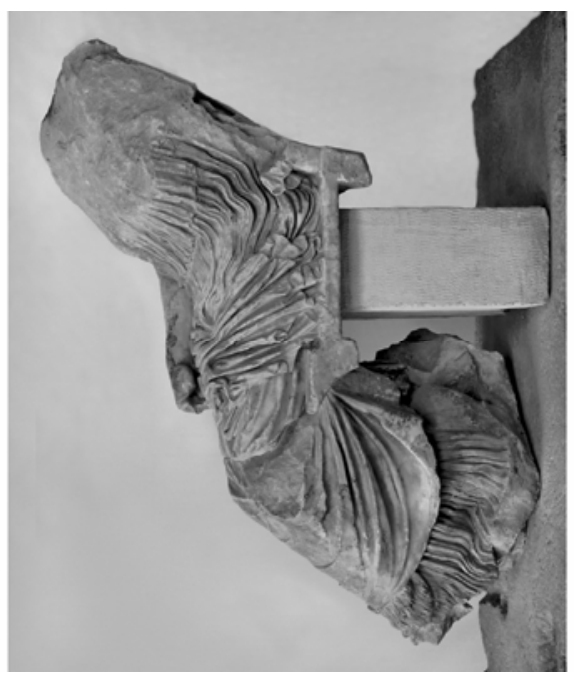

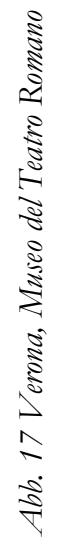

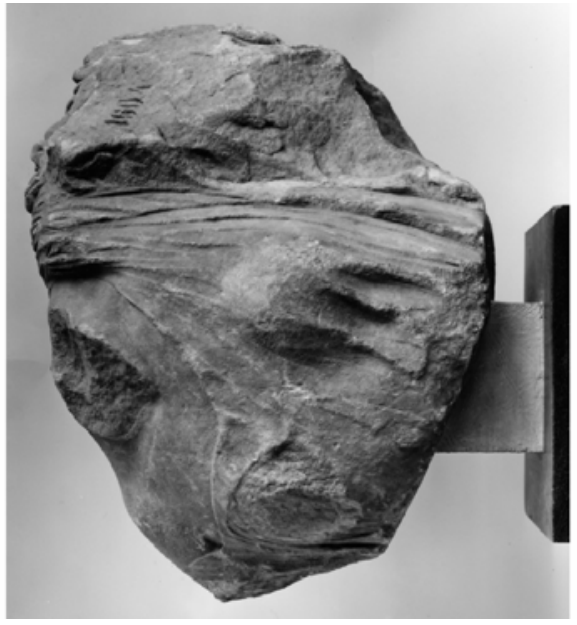

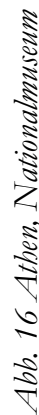




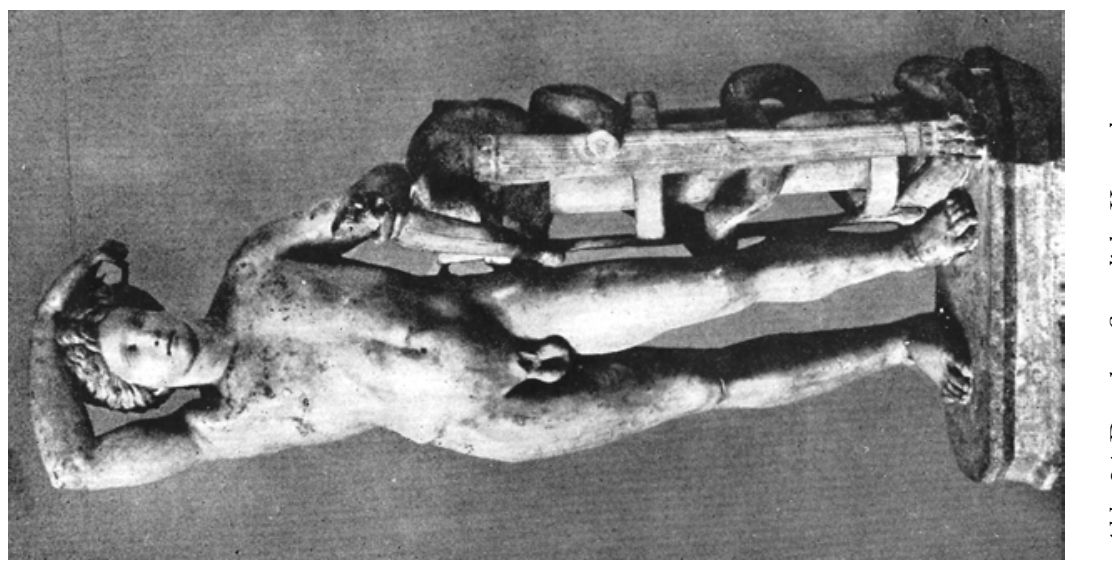

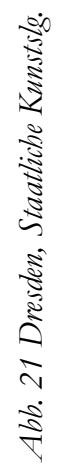

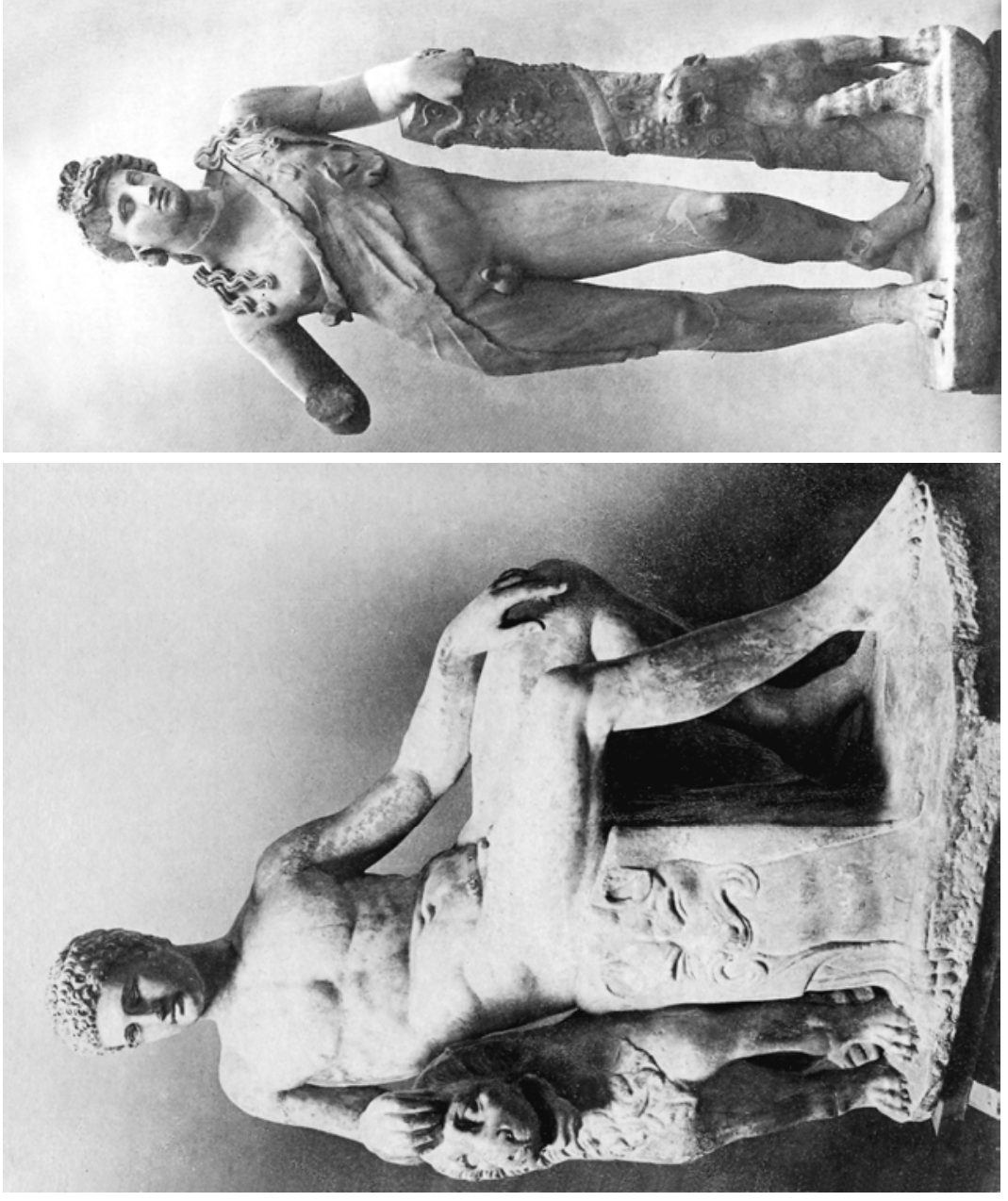

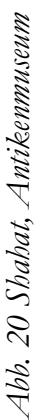

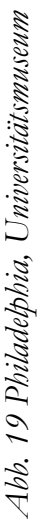




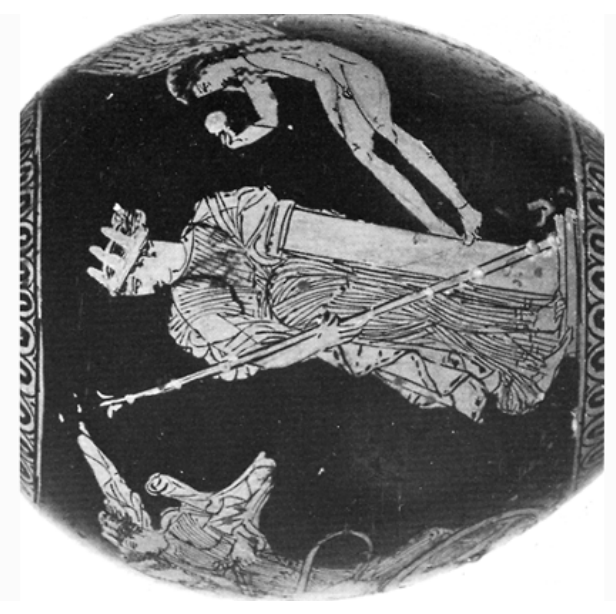

है

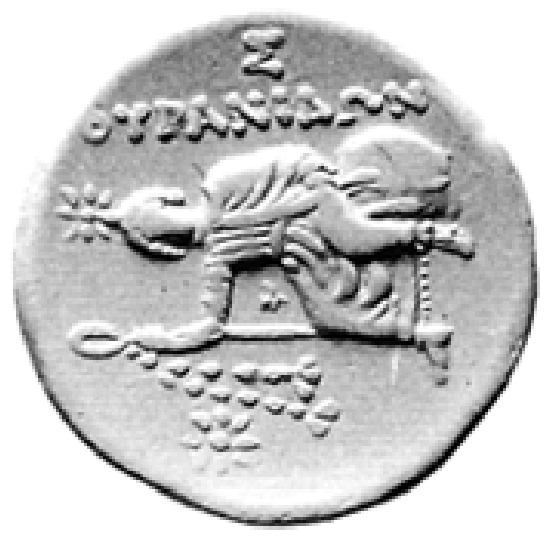

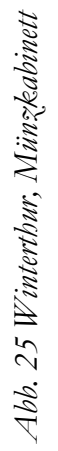
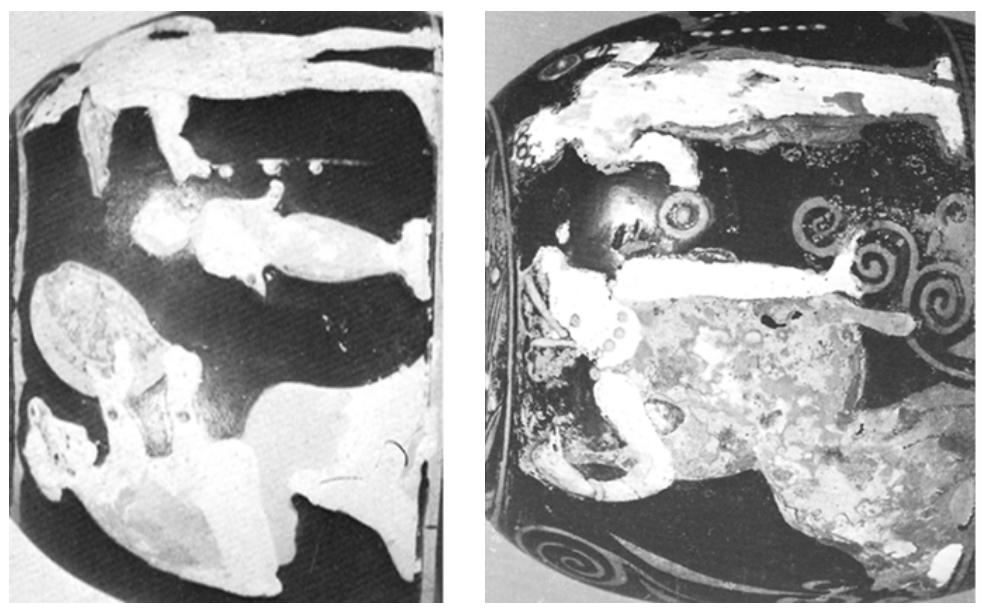

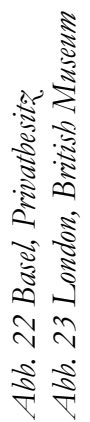




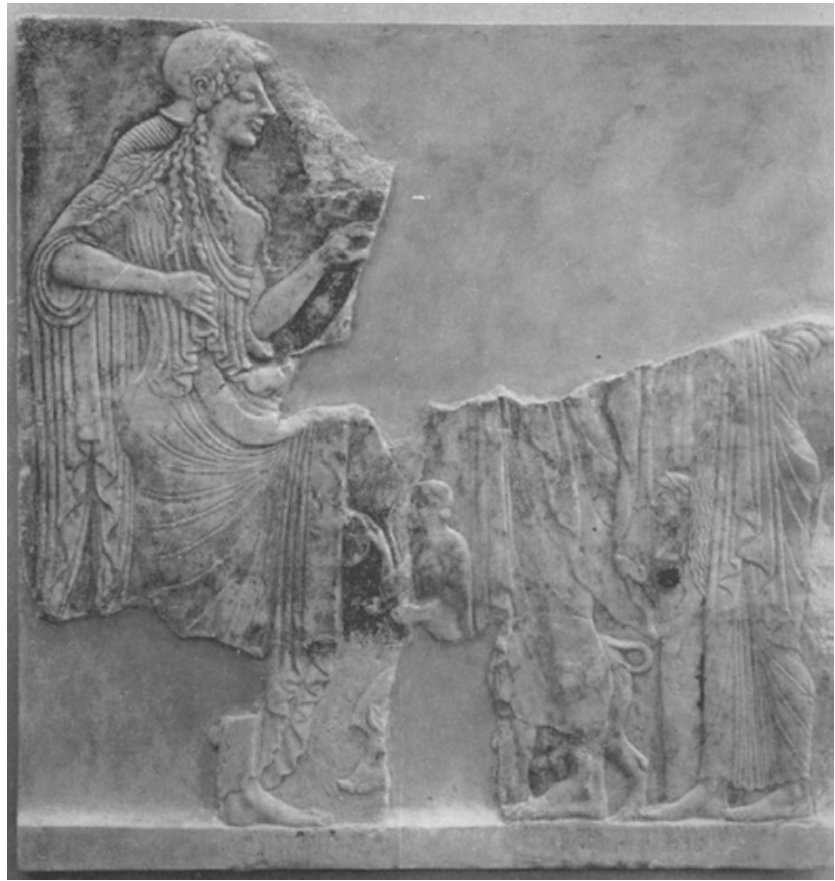

Abb. 24 Athen, Akropolismuseum

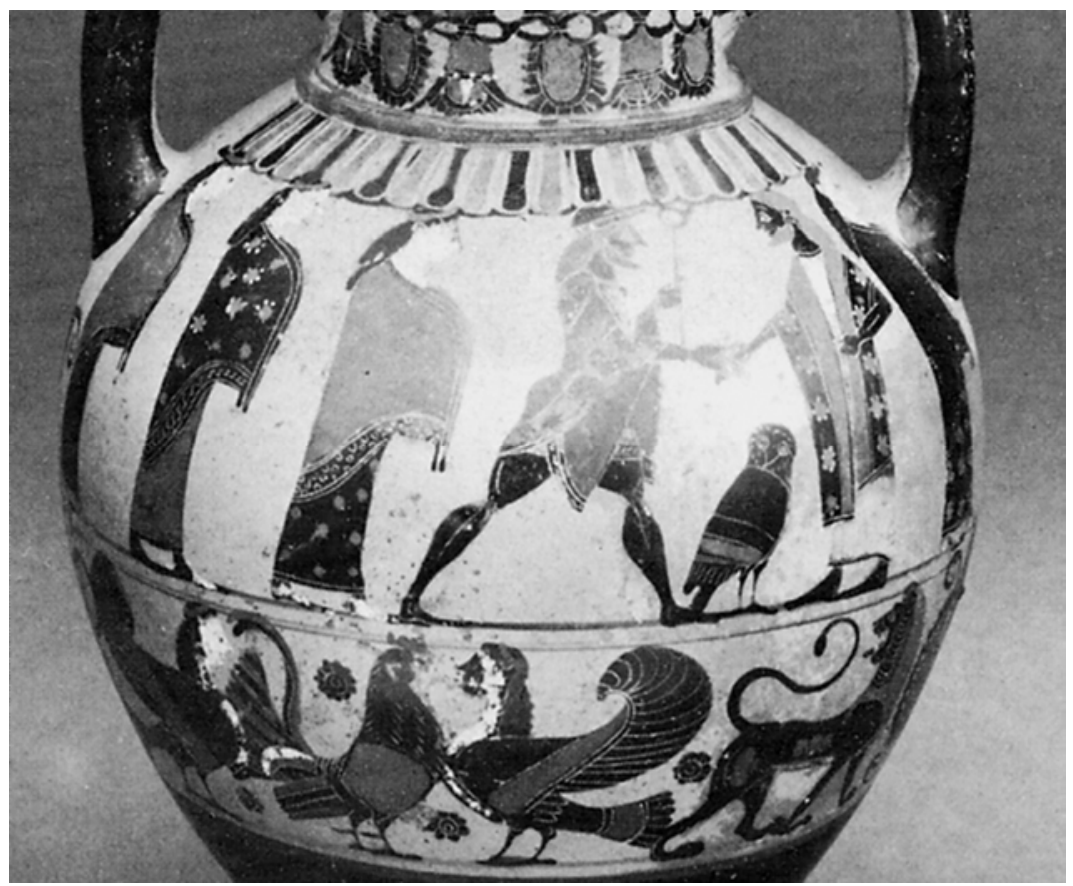

Abb. 27 München, Slg. Bareiss 


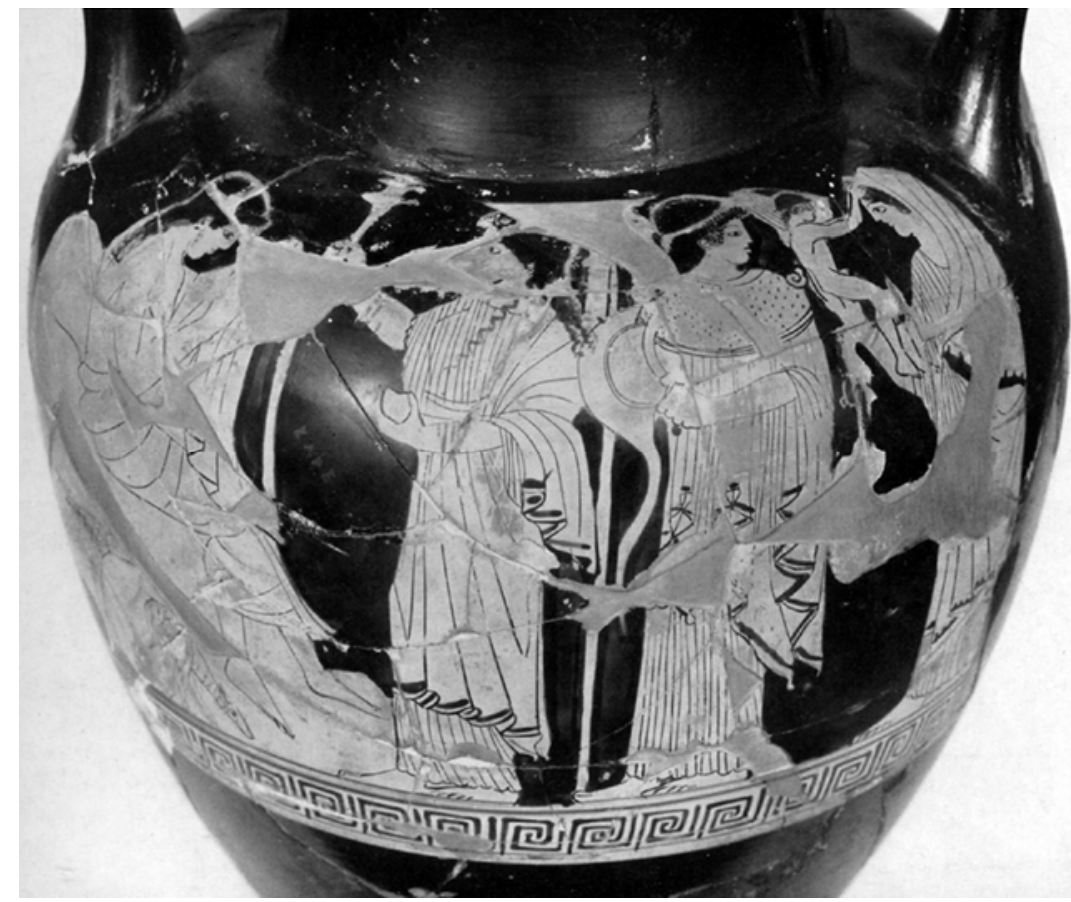

Abb. 28 London, British Museum

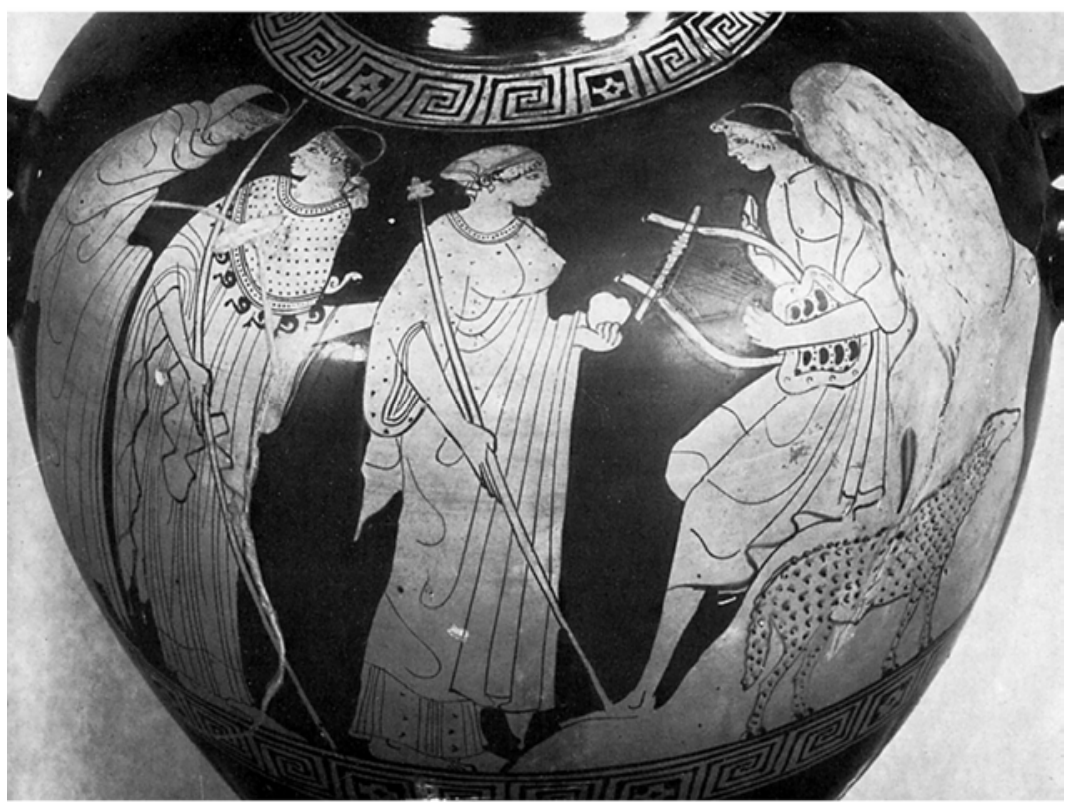

Abb. 29 London, British Museum 


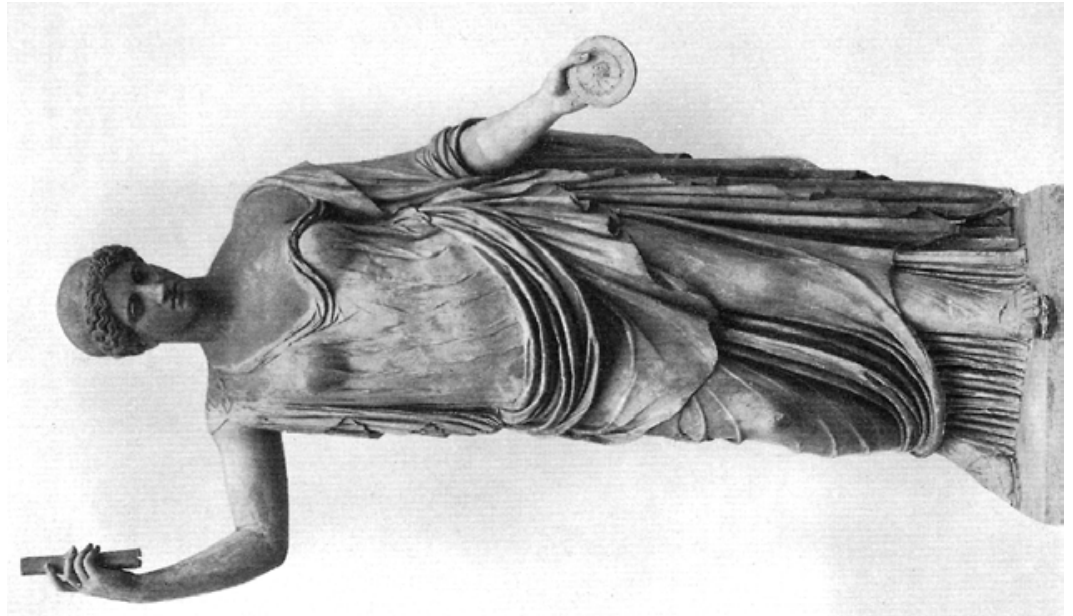

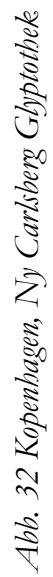

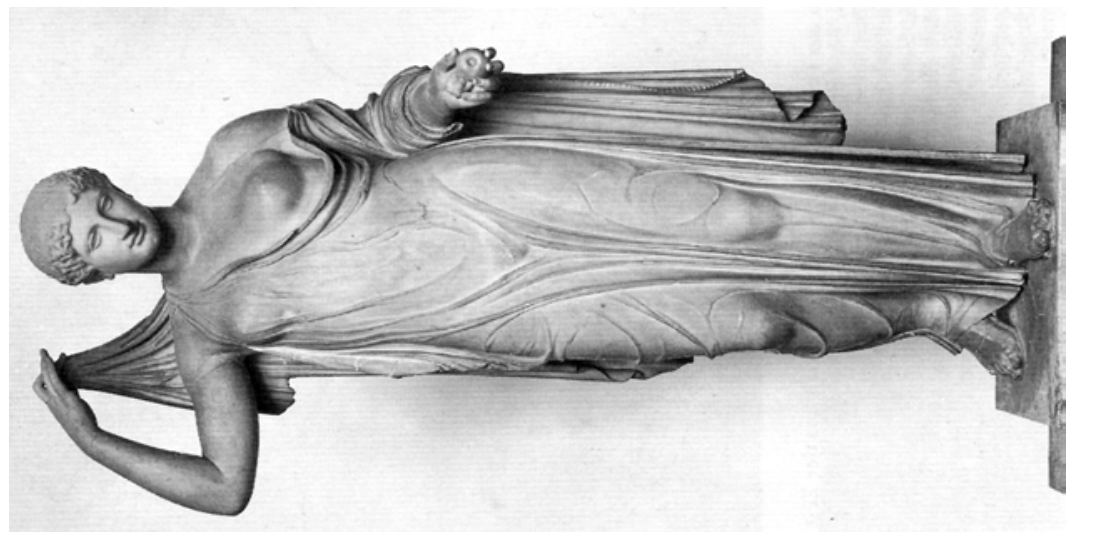

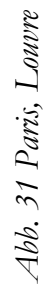

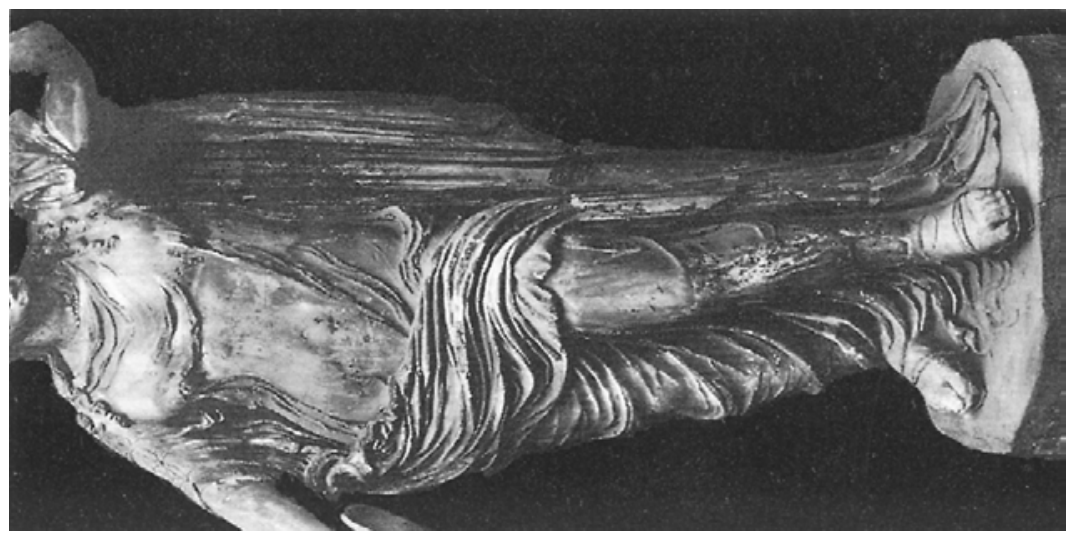

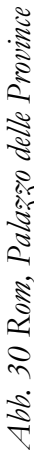




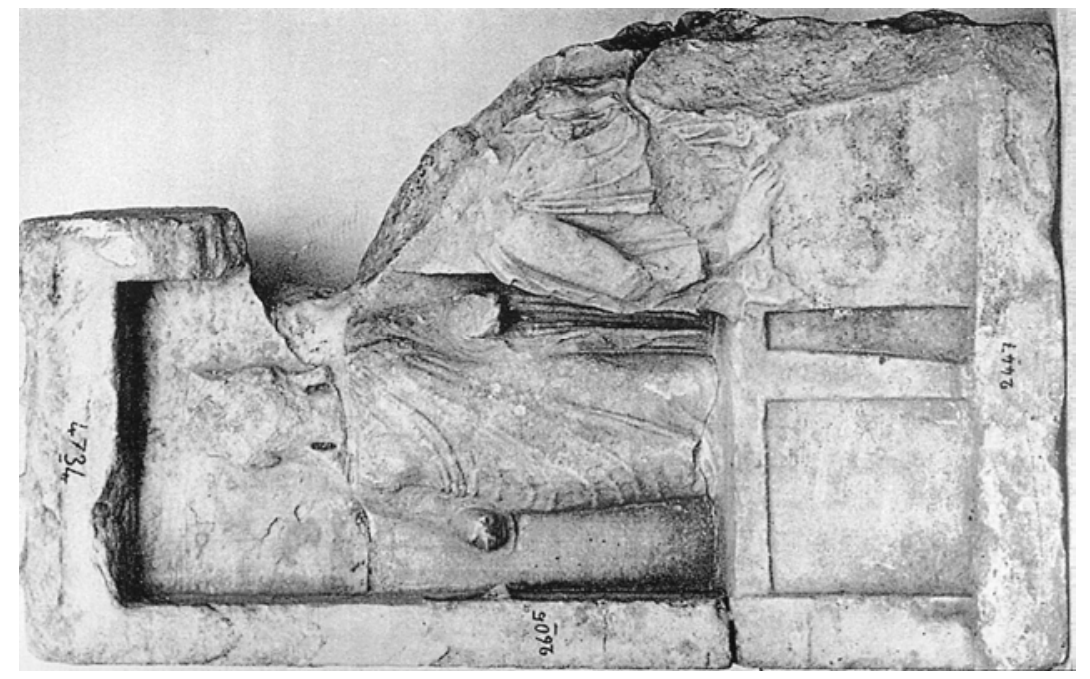

है
है
है
है
है
है
के
चे
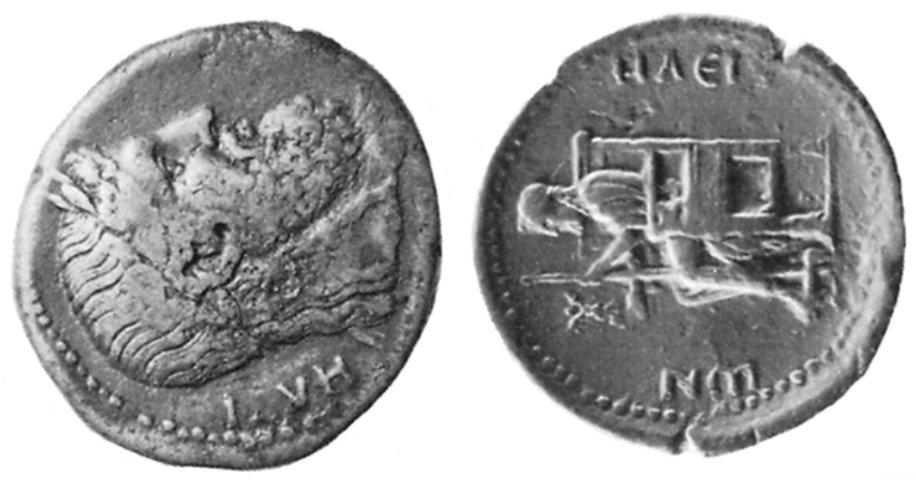

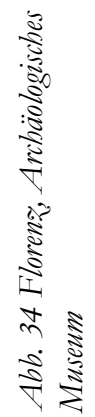

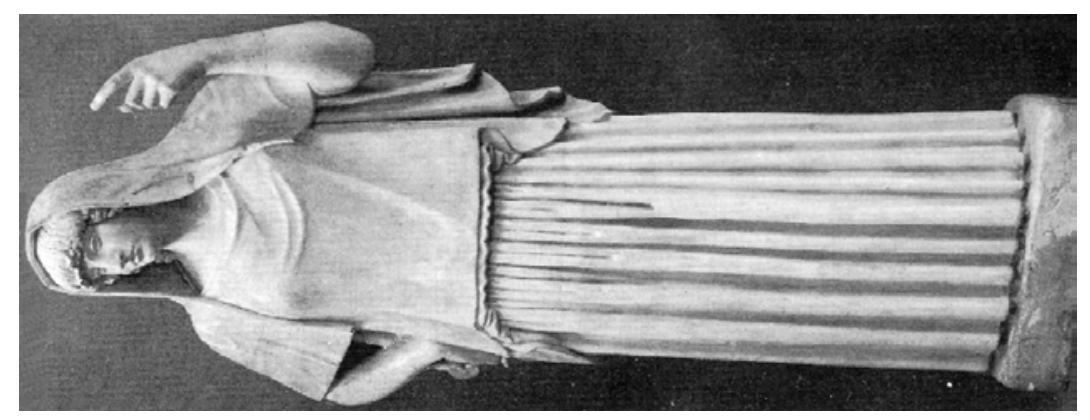

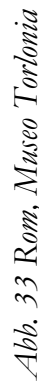




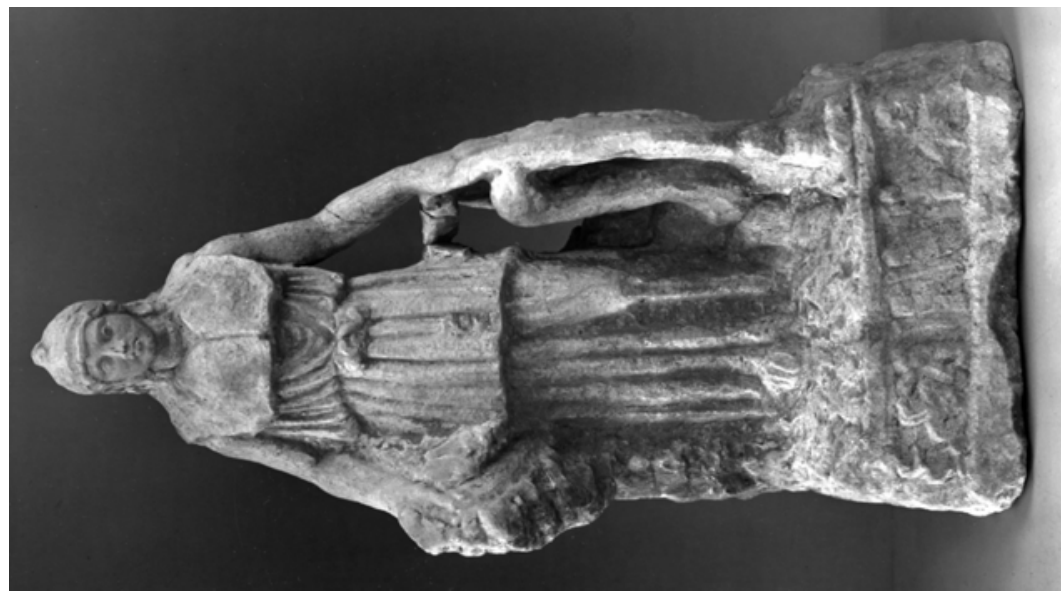

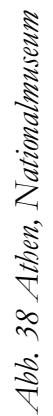

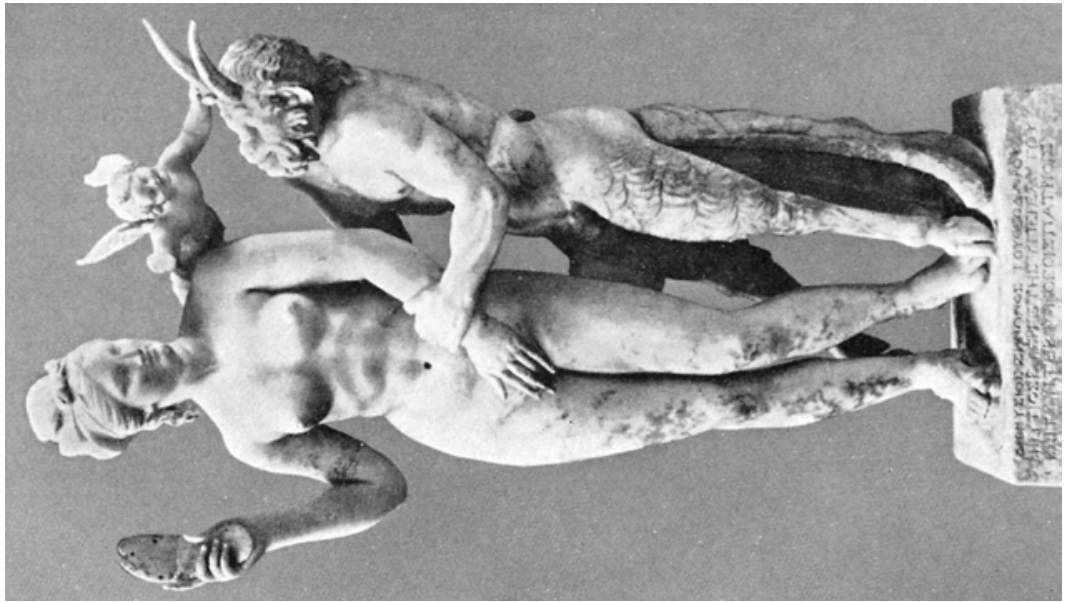

है
है
है
है
ते
ते
ते

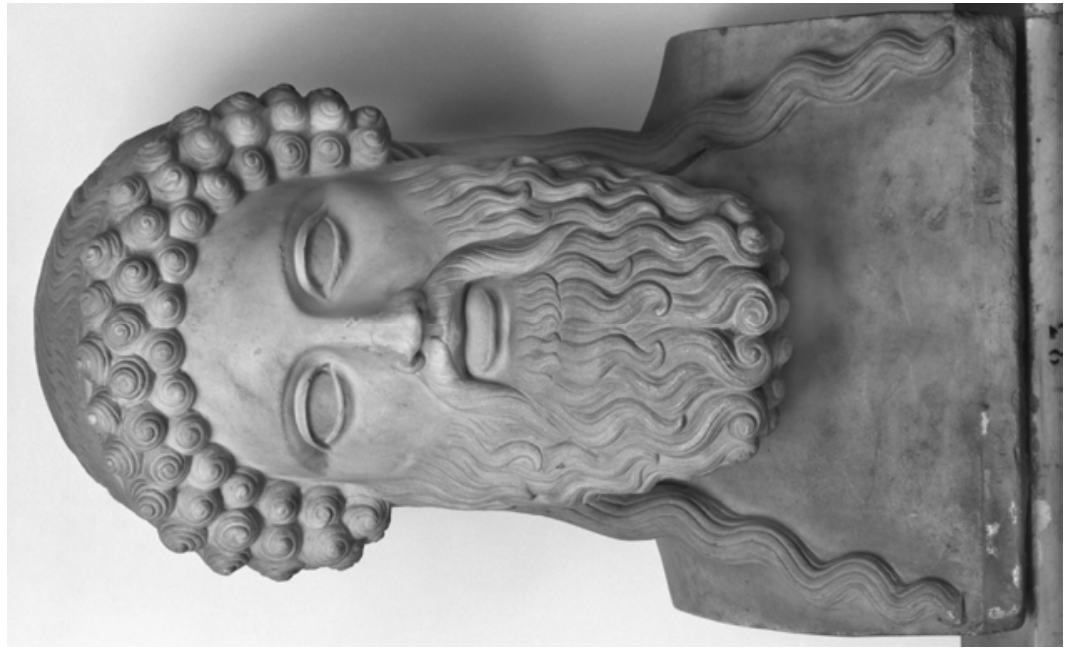

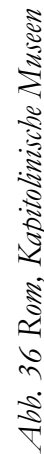




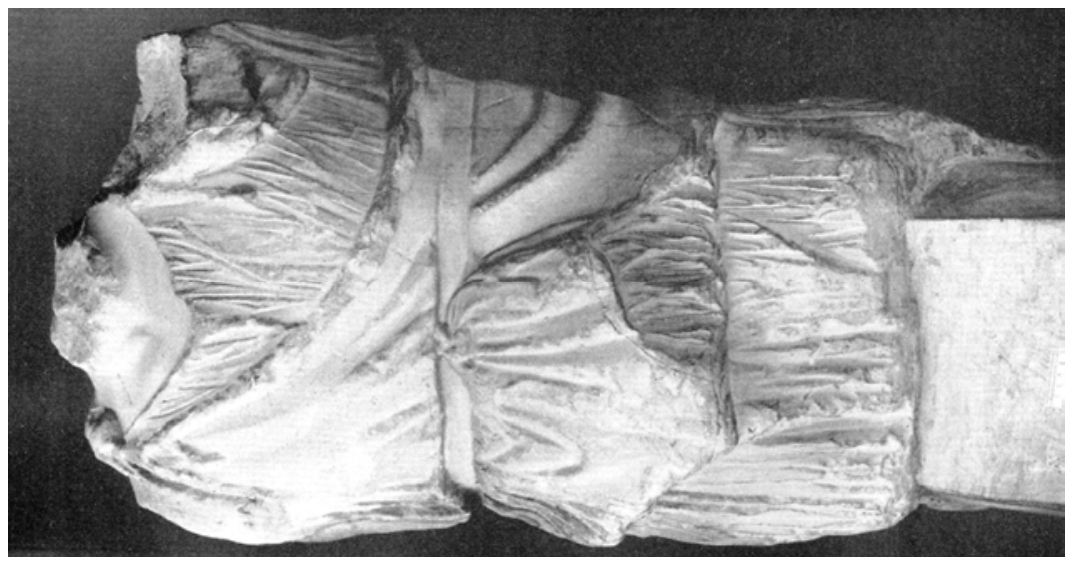

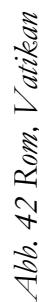
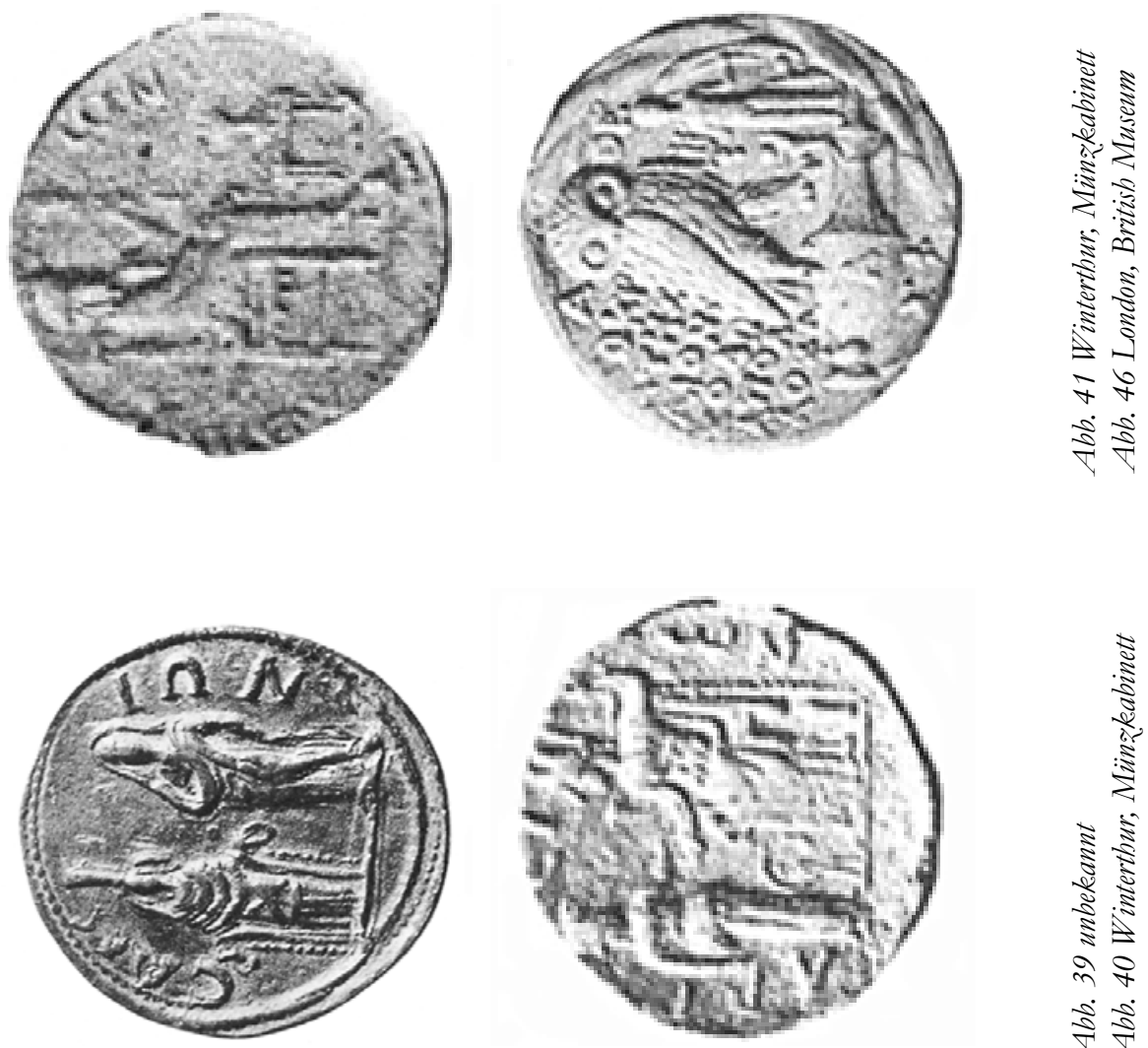

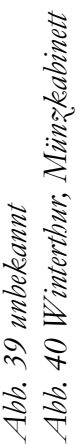




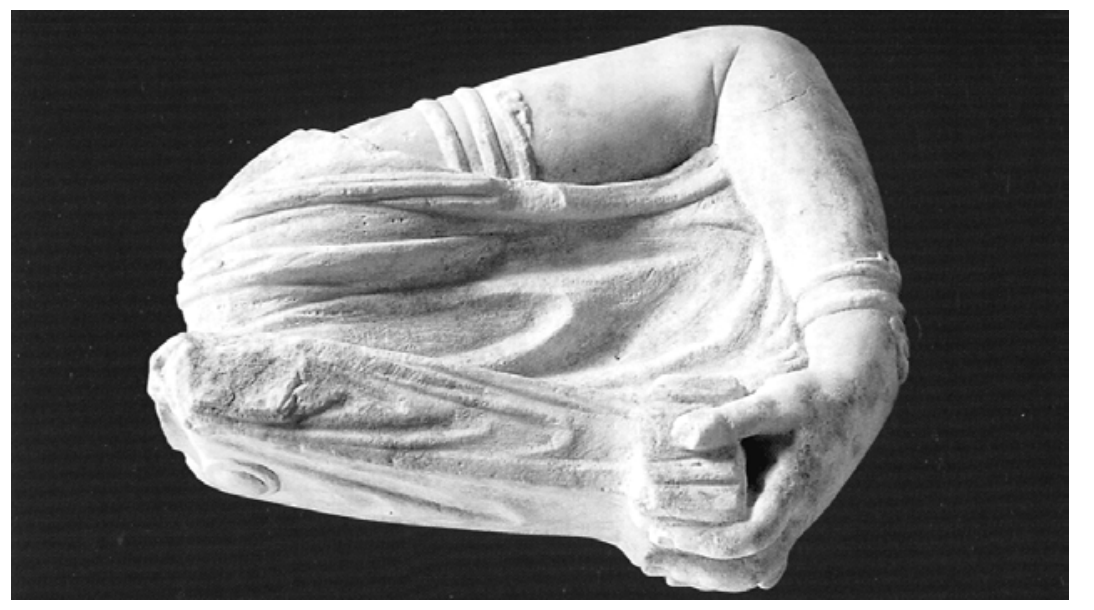

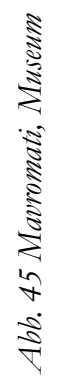
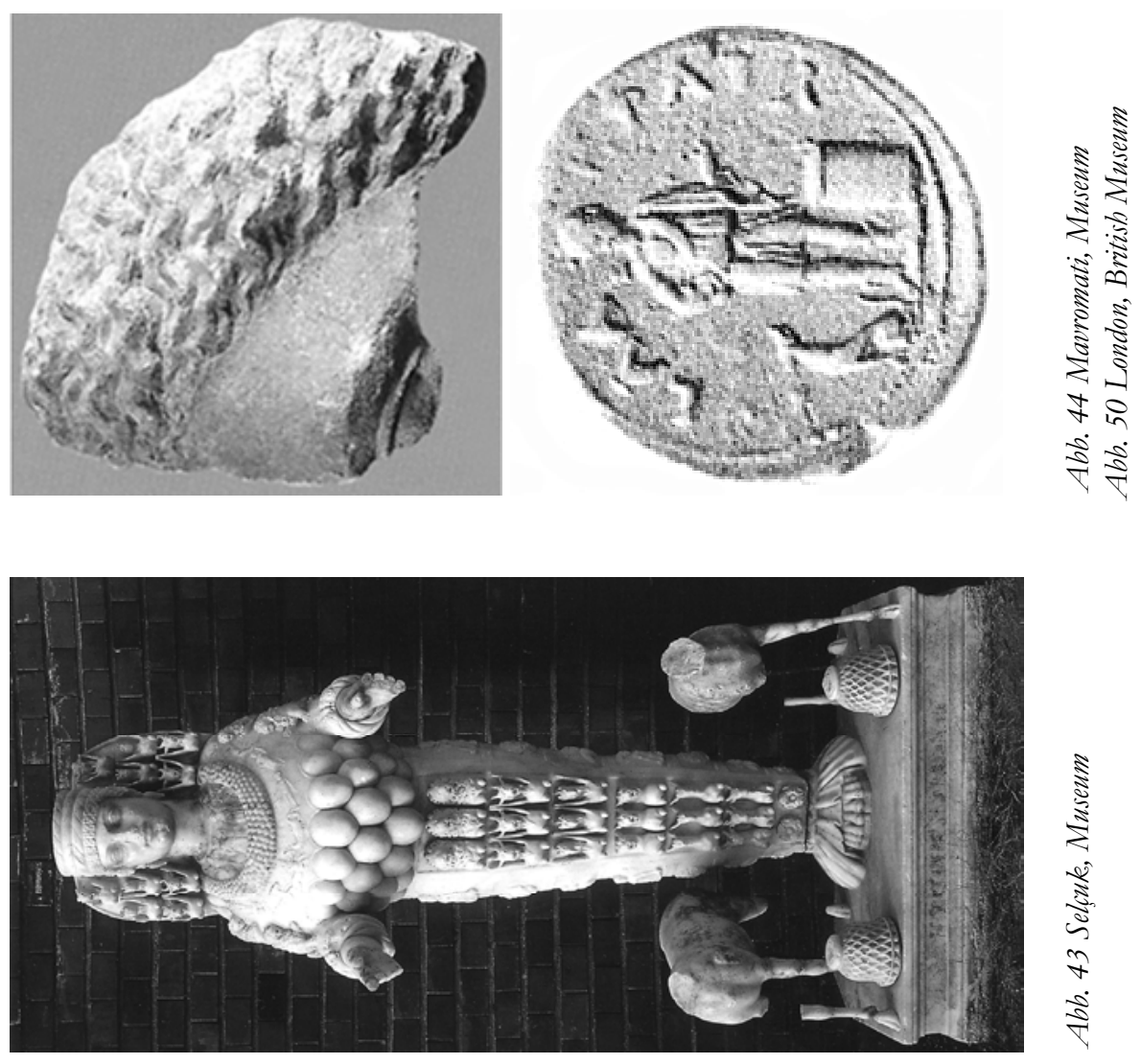

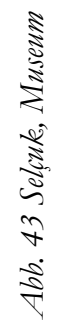



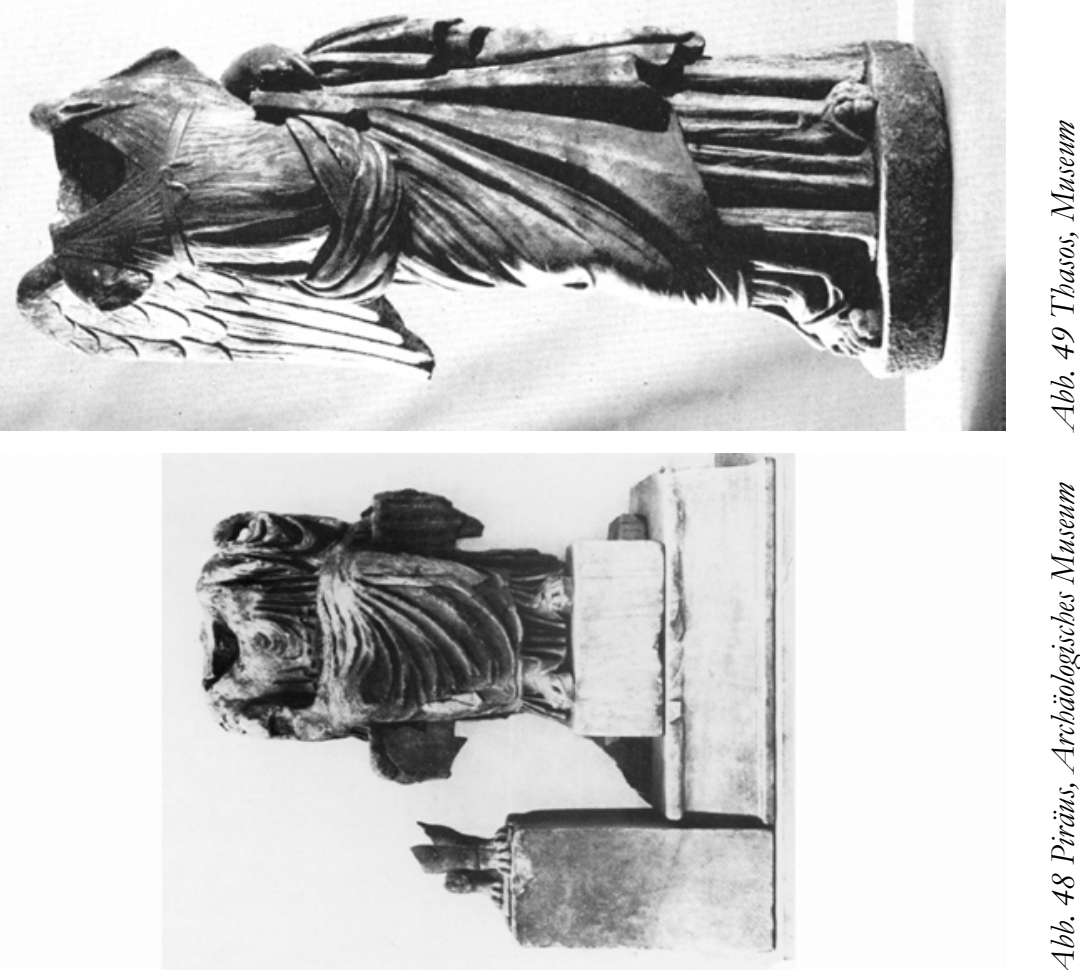

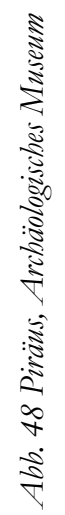

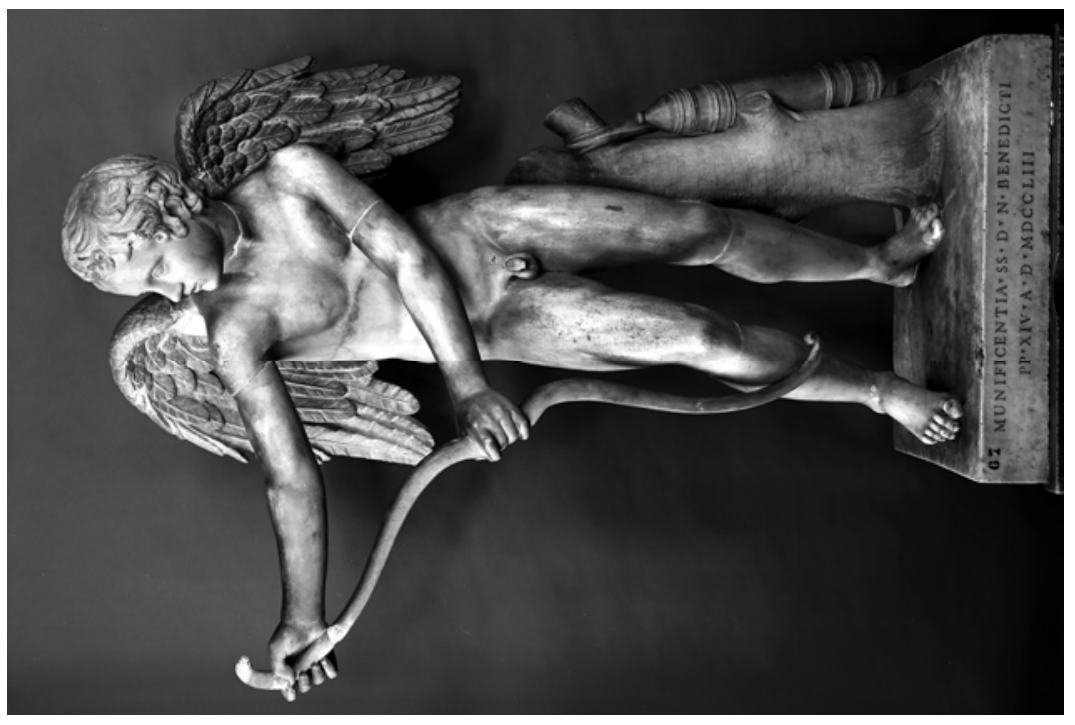

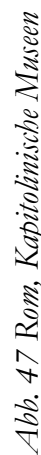


Ein altes Rätsel in den Diskussionen um die Gestaltungsmöglichkeiten klassischer Götterbilder ist die Frage nach dem Sinn der archaistischen Figuren, die seit dem späteren 5. Jahrhundert v. Chr. v. a. Aphrodite und später in geringerer Zahl auch anderen Göttern als Stützen dienten sowie die Deutung dieses Bildmotivs insgesamt. Die Bilder fügen sich in die klassische Darstellungsweise der Götter ein, bei der ihre Wirkungsweise und ihr Charakter durch ihr Körperbild und ihre Körperhaltung zum Ausdruck gebracht wurden. Aphrodite wurde dementsprechend als möglichst lässig und sinnlich mit betont weiblichen Körperformen gezeigt.

Die starke Veränderung des Körperbildes der Göttin in der klassischen Kunst legt die Möglichkeit nahe, in ihren Bildern darauf hinzuweisen, dass sie zugleich auch eine altehrwürdige Göttin mit langer Kulttradition war. Dies wurde symbolisch durch die Verbindung der zeitgenössischen Darstellung mit einem >alten Bildk in Gestalt eines archaistischen Stützidols ausgedrückt. Auch in der Realität lassen sich zahlreiche griechische Heiligtümer nachweisen, für die mehre mögliche `Kultbilder` aus unterschiedlichen Zeiten überliefert sind, die zugleich verschiedenen Bedürfnissen des Kultes gerecht wurden. 